\title{
Fortunes of High-Tech
}

Citation for published version (APA):

van Duijn, J. (2019). Fortunes of High-Tech: A history of innovation at ASM International, 1958-2008.

[Doctoral Thesis, Maastricht University]. Wilco. https://doi.org/10.26481/dis.20191122jv

Document status and date:

Published: 01/01/2019

DOI:

10.26481/dis.20191122jv

Document Version:

Publisher's PDF, also known as Version of record

\section{Please check the document version of this publication:}

- A submitted manuscript is the version of the article upon submission and before peer-review. There can be important differences between the submitted version and the official published version of record.

People interested in the research are advised to contact the author for the final version of the publication, or visit the DOI to the publisher's website.

- The final author version and the galley proof are versions of the publication after peer review.

- The final published version features the final layout of the paper including the volume, issue and page numbers.

Link to publication

\footnotetext{
General rights rights.

- You may freely distribute the URL identifying the publication in the public portal. please follow below link for the End User Agreement:

www.umlib.nl/taverne-license

Take down policy

If you believe that this document breaches copyright please contact us at:

repository@maastrichtuniversity.nl

providing details and we will investigate your claim.
}

Copyright and moral rights for the publications made accessible in the public portal are retained by the authors and/or other copyright owners and it is a condition of accessing publications that users recognise and abide by the legal requirements associated with these

- Users may download and print one copy of any publication from the public portal for the purpose of private study or research.

- You may not further distribute the material or use it for any profit-making activity or commercial gain

If the publication is distributed under the terms of Article $25 \mathrm{fa}$ of the Dutch Copyright Act, indicated by the "Taverne" license above, 


\section{FORTUNES \\ OF HIGH TEQH}
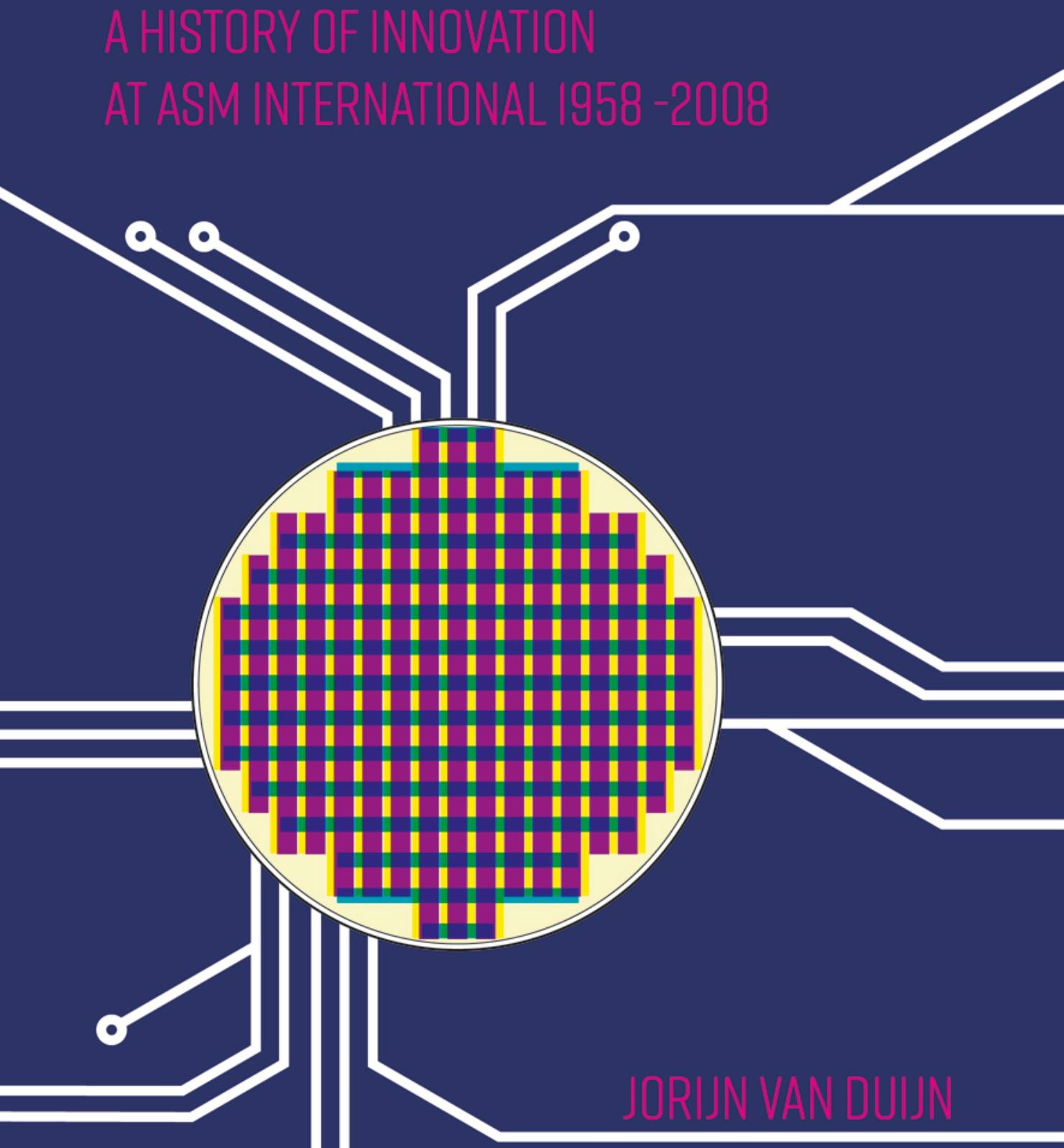

Copyright (C) 2019 Jorijn van Duijn

All rights reserved. No part of this book may be reproduced in any form or by any electronic or mechanical means, including information storage and retrieval systems, without permission in writing from the publisher, except by reviewers, who may quote brief passages in a review.

Typesetting and design: Justin López, Jenna Postma and Jorijn van Duijn Coverdesign: Jenna Postma and Jorijn van Duijn

Editing: Ton Brouwers and Jorijn van Duijn

Printing: Wilco, Amersfoort

ISBN/EAN: 978-90-827074-3-4

www.techwatchbooks.nl 


\title{
FORTUNES OF HIGH TECH
}

\author{
A HISTORY OF INNOVATION \\ AT ASM INTERNATIONAL, 1958-2008
}

PROEFSCHRIFT

ter verkrijging van de graad van doctor aan de Universiteit Maastricht,

op gezag van de Rector Magnificus, Prof dr. Rianne M. Letschert

volgens het besluit van het College van Decanen, in het openbaar te verdedigen

op vrijdag 22 november 2019 om 12 uur

door

JORIJN VAN DUIJN 


\section{Promotores}

Prof. Dr. Ir. Harro van Lente

Prof. Dr. Dirk van Delft (Leiden Universiteit)

\section{Beoordelingscommissie}

Prof. Dr. Cyrus Mody (voorzitter)

Prof. Dr. Ernst Homburg

Prof. Dr. Keetie Sluyterman (Utrecht Universiteit)

Prof. Dr. Erik van Vleuten (Technische Universiteit Eindhoven)

Deze studie is mogelijk gemaakt door een financiële bijdrage van Arthur del Prado en na diens overlijden Stichting ADP. ASM International, Maastricht Universiteit en het WTMC hebben de publicatie financieel ondersteund. Rijkmuseum Boerhaave faciliteerde het onderzoek. 
voor

Opa Frans 



\section{Table of contents}

\section{Acknowledgments}

\section{Introduction}

Exploring innovation processes

A historiography per element

Historical resources

Outline of the book

\section{Business I}

\section{The founding years, 1958-1980}

Chapter 1

Joining a revolutionary development, the 1950s

Industrial context: Carrying along the rising tide of silicon

Corporate course: Arriving during a critical phase in Silicon Valley

Elaboration of affairs

Chapter 2

A man of business, 1958-1964

Industrial context: A diverging appreciation of silicon

Corporate course: Starting from scratch

Elaboration of affairs

Chapter 3

The start of Advanced Semiconductor Materials, 1964-1968

Industrial context: The advent of chip technology

Corporate course: Hedging businesses

Elaboration of affairs

Intermezzo:

Emergence of a standard semiconductor product and

production methods, 1965-1975 
Introduction

Chapter 4:

ASM as original equipment manufacturer, 1969-1974

Industrial context: Merchant semiconductor equipment industry

Corporate course: Emancipation of a sales agent

Elaboration of affairs

Chapter 5:

Globalizing operations, 1975-1977

Industrial context: A limited European market

Corporate course: Seeking growth abroad

Elaboration of affairs

Chapter 6:

Conflicting activities, 1977-1980

Industrial context: Rising competition

Corporate course: Completing the transition toward equipment Manufacturing

Elaboration of affairs

Conclusions

\section{Innovation I}

\section{Manufacturer of chemical vapor deposition equipment, 1969-1985}

Chapter 7:

Atmospheric pressure chemical vapor deposition, 1969-1974

Chapter 8:

Low Pressure Chemical Vapor Deposition, 1974-1978

Chapter 9:

Plasma Enhanced Chemical Vapor Deposition, 1978-1980s

Chapter 10:

Aluminum Chemical Vapor Deposition, 1981-1985

Conclusions 


\section{Business II \\ Golden years of expansion, entrepreneurism and opportunity, 1979-1985}

Chapter 11:

A thriving market for semiconductor technology, 1979-1983 235

Industrial context: A resounding technological and industrial dynamism 235

Corporate course: Scavenging for new inventions to sustain growth 238

$\begin{array}{ll}\text { Elaboration of affairs } & 240\end{array}$

Chapter 12:

A surging American-Japanese rivalry, 1983-1985 264

Industrial context: Escalating competition $\quad 264$

Corporate course: Reaping fruits $\quad 268$

$\begin{array}{ll}\text { Elaboration of affairs } & 269\end{array}$

$\begin{array}{ll}\text { Conclusions } & 288\end{array}$

\section{Innovation II \\ Development of the Epsilon epitaxy reactor, 1982-1988}

Chapter 13:

Toward an epitaxial reactor, 1970s-1983

Chapter 14:

A competition of enactment, 1983-1986

Chapter 15:

Commercialization of the Epsilon reactor, 1986-1990s

Conclusions 


\section{Business III}

\section{The game to sustain leveraged innovation, 1985-1992}

Chapter 17:

Ceasing of the American-Japanese rivalry, 1985-1986 375

Industrial context: Rules of play no longer suffice 375

$\begin{array}{ll}\text { Corporate course: ASM during the downturn } & 378\end{array}$

$\begin{array}{ll}\text { Elaboration of affairs } & 381\end{array}$

Chapter 18:

Changing semiconductor production technologies, 1986-1987 388

Industrial context: A new dynamism 388

Corporate course: Anticipating commercial opportunities and

$\begin{array}{ll}\text { technological developments } & 390\end{array}$

$\begin{array}{ll}\text { Elaboration of affairs } & 391\end{array}$

Chapter 19:

Derailing external and internal events, 1987-1992 402

Industrial context: Balancing on quicksand $\quad 402$

Corporate course: Dealing with Dutch drag 403

$\begin{array}{ll}\text { Elaboration of affairs } & 409\end{array}$

$\begin{array}{ll}\text { Conclusions } & 438\end{array}$

\section{Innovation III}

Innovation strategy, governmental support and defiant realities, 1979-1993

Chapter 20:

Economic policies and governmental support, 1979-1984

Chapter 21:

A new innovation strategy, 1984-1988

Chapter 22:

The (un)fulfilment of a promise, 1988-1993

Conclusions 


\section{Business IV}

Contemplation and core competencies, 1992-1999 517

Chapter 23:

Hitting bottom, 1992-1994

Industrial context: A downward spiral

Corporate course: Draining a poisoned cup

Elaboration of affairs

Chapter 24:

The only way is up, 1994-1996

Industrial context: A most welcome revival

Corporate course: Regained confidence and aligning forces

Elaboration of affairs

Chapter 25:

Prospects put into perspective, 1996-1999

Industrial context: Harmonization and destabilization

Corporate course: When ASM Pacific Technology sneezes,

all of ASM International gets a cold

Elaboration of affairs

\section{Innovation IV \\ Enacting high-k gate dielectrics and atomic layer deposition technology, 1996-2007}

Chapter 26:

Pursuing integrated and rapid thermal processes, 1995-1999

Chapter 27:

Enacting atomic layer deposition for high-k, 1999-2001

Chapter 28:

Integrating high-k into production, 2001-2007

670

Conclusions

694 


\section{Business V}

\section{Finding a balance between sustaining and disrupting technologies, 1999-2008}

Chapter 30:

Surging ahead, 1999-2001

Industrial context: The Dotcom Boom

Corporate course: Ongoing expansion

Elaboration of affairs

Chapter 31:

Redefining foundations, 2001-2004

Industrial context: From Boom to Bust

Corporate course: Biding time

Elaboration of affairs:

Chapter 32:

A shake up, 2004-2008

Industrial Context: Separating the sheep from the goats

Corporate course: A dynamic finale

Elaboration of affairs

\section{Epilogue}


Characterization of ASM's innovation processes $\quad 834$

$\begin{array}{ll}\text { Explanation of ASM's innovation process } & 840\end{array}$

$\begin{array}{ll}\text { Explaining with path } & 840\end{array}$

$\begin{array}{ll}\text { Explaining with fortuna } & 852\end{array}$

$\begin{array}{ll}\text { Explaining with virtù } & 855\end{array}$

Grasping innovation through business and technology 860

$\begin{array}{lr}\text { Afterword } & 863\end{array}$

$\begin{array}{lr}\text { Fortuna } & 866\end{array}$

$\begin{array}{lr}\text { Virtù } & 869\end{array}$

$\begin{array}{ll}\text { Path } & 871\end{array}$

$\begin{array}{ll}\text { Inventing an author } & 876\end{array}$

$\begin{array}{lr}\text { Historical resources } & 879\end{array}$

$\begin{array}{ll}\text { Timeline } & 921\end{array}$

$\begin{array}{ll}\text { Abbreviations } & 925\end{array}$

$\begin{array}{ll}\text { Glossary } & 930\end{array}$

$\begin{array}{ll}\text { Business index } & 940\end{array}$

$\begin{array}{ll}\text { Name Index } & 947\end{array}$ 


\section{Acknowledgments}

Thanks to this research project, I have been able to cross psychological and physical barriers and borders. In the most literal sense, I had the exciting opportunity to travel the world. Interviewing ASM employees and visiting ASM facilities took me from rustic Bilthoven, dynamic Silicon Valley, the heat of the Phoenix valley, the lush surroundings of Newport (Rhode Island), the odd familiarity of Helsinki, and vibrant Flanders to vast and buzzing metropoles like Tokyo, New York, Hong Kong, Seoul, Chengdu and Singapore.

This $\mathrm{PhD}$ project also allowed me to open up new horizons intellectually. If equally mind-blowing, these new experiences happened within the solitary confinement of my mind. Often at home - or I should say homes, as I lived in Amsterdam, Rotterdam, Esch, and Utrecht - and very regularly on the train as well. Here, I want to show my gratitude to those who accompanied me on these journeys. After all, as cheesy as it may sound, without them I would not have been able to travel this path.

And there has been plenty of companionship indeed. Foremost, all the interviewees. Here I am thinking about all my various encounters, such as with the 89-year-old industry veteran John Krickl, the inspiring Patrick Lam - modest in appearance but illustrious in his business and personal achievements - the impressive and acute Ray Friant, and the soft-spoken inventor of atomic layer deposition, Tuomo Suntola. Being all ears, I enjoyed the tales of amazement and adventure told to me by Jaap Bijsterveld in South Korea or Timo Bergman in the Silicon Desert. Or by the few women in ASM's various operations - Gloria Zemla, Suvi Haukka, and the late Mary Jo Dieckhaus - each one firmly holding ground in a man's world, whether in accountancy, technology, or Wall Street. And there have been plenty of other beautiful encounters. Thank you all for your willingness to make time for me, share insights into your unique and intriguing lives, and help me understand.

A few interviewees I wish to single out for their impact on this study and their constant willingness to help me grasp the technological and historical details. This involves the inventive and inquisitive Martin van Beest. For our joyfully digressed conversations about ASM, the application of mass flow controllers in the Apollo space flights, and the mutually highly anticipated conclusion of my study. I want to single out Wiebe de Boer, who explained the technical finesses of silicon technology to me and whose most-welcome critical eye helped me to avoid outright mistakes, poor descriptions, and technical misinterpretations. Chris 
Werkhoven sparked my appreciation for the incredible technological dynamism in the chip industry - from equipment suppliers to leading chip manufacturers. The gracious hosting of Fukumi Tomino allowed me to meet pivotal players in Japan, and his patience helped me to grasp the major lines and slightest details of ASM Japan's history. Ernst Granneman let me pick his incredible expertise of ASM's innovations, and the organizational and business dynamism of the equipment manufacturer. Armand Ferro and MacDonald Robinson showed me the ins and outs of the project that resulted in their beloved Epsilon machine. Yong Min Yoo hosted me in South Korea. And Patrick Lam made time for me amidst his busy schedule of charity, teaching, and hiking.

My contacts with the interviewees and my visits to them could not have been possible without the support from ASM International itself. Foremost, this involved Chuck del Prado, who I like to thank for his trust, benevolence, and his generous contribution to the publication of this study. I thank Han Westendorp for being my prime contact at ASM, for his participation in the advisory board, and for all the effort in reviewing the manuscript. I am grateful in particular for his willingness to deal with my unremitting cries for attention to my questions and requests, in between his flights, urgent business calls, and endless string of meetings. Ivo Raaijmakers, ASM's chief technology officer, who while managing the company's technological treasure trove, found time for interviews with me, and for reviews of my manuscript. Petra van Eijk, thank you for your warm welcome at ASM time and again, helping me with accessing the archive, finding my way within the company, and our pleasant conversations over cups of coffee. I would also like to thank the supporting staff at ASM: Yvette, Jean Paul, Petra \& Jenneke at the reception desk in Almere, thank you for your generous hospitality.

My sincere thanks go out to W.K. Lee for granting me access to the unique dynamics of ASM Pacific Technology and its extraordinary (former) employees. Through the predominant focus on front-end in this study, I hardly do justice to the accomplishments of ASM Pacific Technology. Yet my admiration and appreciation for the life stories of those I interviewed are profound, as is true with respect to the history of the company itself. Next to the interviewees, I want to thank Katherine Ho Win Yin in Hong Kong and Yuan Yang in Chengdu for giving me a warm welcome at ASM Pacific Technology.

Others accompanied me in Maastricht, Ravenstein, Utrecht, Leiden, and Amsterdam. In Maastricht, Cyrus Mody was always willing to lend an ear, sharing a rather rare interest in the history of semiconductor technology. WTMC offered me access to an inspiring range of academics. Bernike Pasveer, together with Govert Valkenburg, stimulated new perspectives during the WTMC Summerschools in Ravenstein. In Utrecht, I learned the tricks for being a business 
historian from Keetie Sluyterman, Bram Bouwens, Joost Dankers, and Gerarda Westerhuis. Moreover, they put me on the path towards a PhD!

In Leiden, the management of Rijksmuseum Boerhaave facilitated my project within the museum, even if I was the odd one out with my study on the latest semiconductor technology in a museum about science and medicine. Here I want to mention Marion \& Pieter Jan explicitly for their heartfelt support and conversations, making me feel part of the Boerhaavianen. Working from Amsterdam - or abroad - Ton Brouwers edited and ironed out my twisted sentences and Dunglish. The city of Amsterdam also accommodated the most exciting and stimulating meetings of my project. At the distinguished office of Baker McKenzie, my advisory board was generously welcomed and taken care of. I want to thank you all.

This brings me to the omnipresent advisory board. Apart from the vibrant and invigorating discussions, its members asserted their influence even when I was writing, through my anticipation of their respective, typical critical reactions. They represented my audiences beautifully. Ernst Homburg as the critical, experienced, and incredibly well-informed professor in the history of technology. Peter Tindemans for his constructive and constant contributions - even when just arriving from a midnight-flight from Buenos Aires. René Raaijmakers for showing how to do justice to all the numerous remarkable actors in a technology history, guiding me into the world of ASML and for publishing the book at Techwatch Books. Again, I want to mention Han Westendorp for bringing the realities of ASM and the semiconductor industry to this rather academic thinktank. Michiel Eijkman for initiating the whole endeavor, for introducing me to Arthur del Prado, and for his amiable support as de-facto godfather of the project. Maarten van der Lande for his help in grasping Arthur del Prado's personality, for his appropriate keenness on language, and for facilitating the advisory board's meetings at Baker McKenzie. Moreover, I want to thank Maarten and Michiel, in their capacity of Stichting ADP director, for their help in generously extending the financial base of the project.

As my project's supervisors, Harro van Lente and Dirk van Delft were also on the advisory board, but obviously their impact extended much further. Harro helped me to explore the terra incognita that was Science and Technology Studies for me, accompanied by leisurely yet insightful conversations about an incredible range of topics, in Utrecht, Maastricht, or at the Korenwolf. Often patiently taking in a torrent of words, as I chattered on about my latest insights, reconstructions of the events, and speculations of the future. Dirk supported me in the optimistic interaction with stakeholders and the subtleties of writing a book, even amidst the joyful chaos ensuing from the Rijksmuseum's renovation. In particular I happily remember our concerted writing days at your university office during 
the final year of the project. Both of us fully absorbed in, respectively, ASM and the Dutch scientist Lorentz.

I am most grateful for the trust and independence that both of you granted me to explore the subject of my study and make it my own, to formulate and verify my perceptions, and to set out a course of my own. As Doktorvaters - or PhDfathers - you witnessed my advancements. The fortunes we shared seemed to me life at its best. Like in a protracted emotional rollercoaster - from excitement, disappointment, frustration and boredom to amazement - I managed to deal with all sorts of intellectual, organizational, and personal challenges, opportunities and obligations. A mere thanks would not cover my gratitude.

Before I turn to my companionship in the personal domain, I turn to the man who in life and death dominated the project: the late Arthur del Prado. His generous support laid the foundation of this study, this book, and also defined the parameters of the past six years of my life. That alone would be reason for my deep thankfulness.

But foremost, I want to thank Arthur for granting me access to his personal life. Initially in the form of the kind hospitality offered to me by him and Joan at their house in Bilthoven, but also through his monthly phone calls, his sharing of contacts, and, in the final year of his life, by granting me access to his vast and insightful personal archive. Most significant was Arthur's trust and his joyful interest in my explorations. Through this, he gave me a unique chance to explore the developments and dynamics of a multinational multidivisional enterprise in high-tech.

I continued to feel his presence also after his passing in 2016. During the most recent years, I enjoyed my conversations with Joan - Arthur's partner immensely, keeping the remembrance of Arthur alive in good and bad. His life and his various dealings with so many people worldwide inspired and taught me more than I am able to comprehend at this very moment.

At a personal level, another old and wise man dominated the project. My grandfather - Opa - Frans Smeltzer, to whom I dedicated this book, was my most trusted advisor and a true inspiration. His advice resonates throughout the book, as he defined the framework of the study in scope and time, but also because he was the one to set me up for studying history (instead of the arts, my other favorite subject). Despite the complexities of my research project, a snippet of information was enough for him to grasp the entire playing field of stakeholders involved - company, family, interviewees, advisory board, supervisors, universities, etc. Opa Frans stimulated my love for the interplay of characters and personalities, each with their own agendas, paths, and lessons. His personal stories about Dutch corporate life and businessmen helped me in my contacts and empathy toward the interviewees and actors in the history of ASM. 
Yet beyond his advisory role it was also his enthusiasm and pride about this project and my capabilities that resonated after his death in 2015. My PhD study offered him some excitement in his final year, made him feel still relevant, and gave him a sense of purpose. If it was not for him, I would not have crossed paths with this project or the exciting business of ASM and Arthur del Prado. I miss his advice, clarity, and quick-wittedness to this day.

The moral support at a personal level has been tremendous over the years. All the friends \& family, from Postma's, amice-kes, Units, Dak-helden to many others in Amsterdam, Utrecht, Rotterdam, Brabant, and Friesland. Thank you for all the pleasant distractions and social meetings at festivals, parties, BBQs, diners, and bars, most often accompanied by the occasional refreshments or powered by Keen Coffee. You all helped me appreciate that the room was much bigger than the proverbial elephant in it - the elephant being my study here. I want to thank Kimmie for supporting me when I engaged this endeavor, and for her patience when I was pondering it endlessly. Of course, I cannot forget Tessa and Marith. With a big smile and a heavy sigh of relief, I am now able to thank you for your companionship - for joining me in the final miles of our PhD projects with numerous coffees and sharing with me your brilliant minds and the groaning \& moaning about our protracted research processes, as well as the beautiful discussions about our respective topics, personal breakthroughs, and life at large. Company in distress makes sorrow less, just as they say!

My family! To start with my brothers David and Beren, and their lovely partners, being my great examples in life, following their own respective paths professionally and as persons. And being my best friends and my supporters. My parents, thank you for your incessant loving support and care. Moreover, thank you for your patience whenever I ventilated my burning frustrations or glowing understandings and new inspirations. Time and again, you formed the perfect litmus test to verify my reconstructions or whether I understood everything sufficiently. Your enthusiastic faces showed that I was onto something. A glazed look indicated the opposite. I could not have wished for a more solid, loving, and warm home base.

Last but most certainly not least, my dear Jenna. Thank you for enduring me in my darkest hours and in times of almost hyperbolic excitement. And thank you for your patience in living through a process totally alien to you, i.e. my PhD study. Unfamiliar as this may have been, you continued to think along and reflect on my challenges, routines, and opportunities in an utterly commonsensical way. Furthermore, you were a source of inspiration through your joyful self as well as your incredible entrepreneurism. Managing your design studio made you - and myself in the process - encounter all highs and lows of running a business, from design and production to sales, service, and marketing. I am very grateful for joining you on this entrepreneurial journey, but I am foremost blessed with you 
Acknowledgments

on my side. With the conclusion of this project, there is finally time to look ahead and to each other, with a big smile on our faces, and a world of opportunities at our feet. There is one question that still needs to be answered: will you ever read this book? 
Introduction 


\section{Introduction}

Arthur del Prado (1931-2016) resigned as chief executive officer of ASM International on March 1, 2008, to be succeeded by his eldest son. The Dutch entrepreneur left behind a company that accounted for net sales of almost one billion euros, employing almost 12,000 individuals at one American operation and various European and Asian operations. ${ }^{1}$ Upon his retirement, Del Prado's career in the chip industry spanned as many as fifty years. In 1958, his career took off in the region now known as Silicon Valley in California, after which, from 1964 onward, he founded and developed Advanced Semiconductor Materials (ASM), a company located in Bilthoven, the Netherlands.

Through equipment manufacturer ASM, Del Prado became involved in virtually all technologies used in the fabrication of computer chips. He contributed to the rise of the chip industry and witnessed the technology's profound impact on our daily life. His perseverance, entrepreneurial instincts, and captivating cosmopolitism enabled major innovations in chip technology. The size and healthy condition of ASM at his resignation in 2008 testify to his achievements.

This study offers a glimpse into the tangled world of the chip industry through the untold history of a visionary entrepreneur and his little-known business. Companies active in competitive, volatile, and pricy high-tech industries depend on their innovative prowess for survival. Here, more than elsewhere, innovation is vital. By tracing and unraveling both innovation and business at ASM, it is possible to draw multiple lessons: about the dynamics of innovations, about the viability of business strategies, and, more in general, about the fate of high-tech firms in modern economies. After all, the realization of innovations depends on numerous influences, which always present themselves in unique ways throughout history.

For all those years, ASM was a major supplier of innovative technologies and this is an achievement that did not come about automatically. The company's long history is one of both failures and successes in innovation and business. Moreover, the wide variety of chip manufacturing technologies in which it engaged makes it a perfect case to study the various meanings and manifestations

$1 \quad$ The exact figure is 955.2 million euros. In 2008 the company had operations in the Netherlands, Belgium, Finland, the United States, Japan, Hong Kong, Singapore, China, South Korea, and Taiwan, with a total staff - in full time equivalents - of 11,832. - ASM International, 2007 Annual Report ASM International (April 2008). 
of innovation processes. The story of ASM allows us to explore and clarify the dynamics of high-tech innovation. Specifically, this study centers on the following research question:

How to characterize and explain the innovation processes at ASM International from 1958 until 2008?

The timeframe covered by this study corresponds with Del Prado's presidency of ASM International, from his establishment of the company in 1964 until his resignation as CEO in 2008.

In this study I explore and reconstruct ASM's organizational and technological developments. I focus on specific innovations, and will also provide a general history of ASM - its struggles, failures, expansions, and successes. As such the study presents both a business history and a study of innovation. Various other aspects of ASM's business adventures will pass in review throughout the main story and its subplots as well. This includes the rather Machiavellian capers cut by Del Prado, detailing the wide-ranging entrepreneurial perils of operating in the chip industry. Also, the wizardry and ingenuity required to fabricate a computer chip will be explored, for ASM engaged in almost all major fabrication techniques. Moreover, because Del Prado's presidency of ASM basically concurred with the powerful rise of the chip industry, this study also offers various insights into the complex realities of the global computer chip industry. Overall, the study maps an industry and enterprise which, so far, hardly has been covered in academic historical analysis.

ASM International is a multidivisional company. ${ }^{2}$ To be precise, the study takes the perspective of ASM International and subsequently its variety of subsidiaries. However, ASM International also encompasses the head office, which oversees and manages the various operations. For clarity sake, I will make the following distinction. Whenever I talk about the head-office, I speak of 'ASM International'. If I speak about ASM as the whole group of operations or 'companies' - including the headquarters - I will speak of 'ASM'. The various

2 The structure of multinational enterprises can be seen in various ways, like the functional, holding or multidivisional structure. Business historians Keetie Sluyterman, Gerarda Westerhuis and Abe de Jong defined the multidivisional structure as '(..) distinct and coherent operating units, a preference for substantial majority ownership of businesses, more or less standardized accounting and control systems, and the active integration of newly acquired operations.' - Abe de Jong, Keetie Sluyterman, and Gerarda Westerhuis, 'Strategic and structural responses to international dynamics in the open Dutch economy, 1963-2003’, Business History 53:1 (2011) pp. 63-84, p. 69. The authors based their definition on: Richard Whittington and Michael Mayer, The European Corporation: Strategy, Structure and Social Science (Oxford University Press, Oxford, 2002). 
subsidiaries are indicated through their respective names, - like ASM Japan, ASM Lithography, ASM Pacific Technology, etc.

From the 1990s onwards, the company itself distinguished its activities in 'front-end' and 'back-end'. Front-end being the businesses involving equipment that processes silicon wafers. Back-end concerned technologies for assembly and packaging of chips.

This study tends to focus upon the wafer processing activities. After an initial public offering of ASM Pacific Technology in 1989, back-end was managed by a distinct management team of this respective company, which merely gave account to its parent company ASM International on a quarterly basis. The head office did not interfere operationally within ASM Pacific Technology. Elaborating upon this distinction between front- and back-end, this study focusses upon the operations that were directly managed and overseen by ASM International. From the 1990s onwards, that is front-end.

\section{The vibrant and innovative world of semiconductor manufacturing}

The industry in which ASM has been operating is one of dazzling numbers. This includes the size of the chip industry, the different manufacturing processes, and the impact of chips on our daily life. Chips are everywhere. Throughout the day, we all rely on this particular technology numerous times, from our alarm clock waking us in the morning, our car driving us to work, and our payments made through our bank card to the seemingly endless possibilities of our smartphone. The list of applications involving computer chips is immense and continues to expand. The ordinary and overwhelming presence of computer chips in our lives overshadows the extraordinary world of innovation required to produce a chip.

In less than a lifetime - from the invention of the first solid state transistor in 1947 onward - the various skills and technologies required to make a chip were modified, improved, and transformed at an unprecedented rate. A basic constitutive element of the computer chip - and thus of the revolutionary development of information technologies - is a material that through minor alterations can either conduct or insulate electrical signals. This so-called semiconductor material is most often silicon. ${ }^{3}$ Semiconductor materials proved to be more resilient and reliable than the preceding information technology of vacuum tubes. The centrality of the material and its properties is reflected in another term for the chip industry: the semiconductor industry. The key capability in the chip industry pertains to yielding and modulating semiconductor materials.

All the different treatments of semiconductor materials are primarily aimed at the large-scale and perfect production of a particular and vital component of

\footnotetext{
3 And other variations like germanium and gallium arsenide are used, though not in the volumes and applications like silicon.
} 
a chip, the so-called transistor. It is an electrical switch, billions of which are packed into a single computer chip. In fact, the transistor as part of a computer chip is the most fabricated man-made object in the history of the world. ${ }^{4}$ To get a sense of their sheer quantity, just imagine the few billion transistors on a chip multiplied by the millions of chips produced annually.

The semiconductor supply chain, from raw materials into application into an electrical device, is one of the most elaborated and globalized in the world. Advanced expertise resides and has been cultivated locally. As stated in The Economist:

'It may start in the Appalachian mountains, where deposits of silicon dioxide are the highest quality. The sand may then be shipped to Japan to be turned into pure ingots of silicon. These are then sliced into standardized wafers, $300 \mathrm{~mm}$ across , and sent to a chip factory, or "fab", perhaps in Taiwan or South Korea. Here the slices will be imprinted with a particular pattern using photolithography equipment made in the Netherlands. That pattern will be determined by the overall design of the chip. This design might come from ARM, a company based in Britain. ... Once finished, it must be assembled into a package, in which the etched silicon is placed inside the familiar ceramic or plastic containers that are dotted across any circuit board, and then comes testing. That might take place in China, Vietnam, or Philippines.'

Once tested, again, the chip is dragged multiple times across continents for integration in printed circuit boards, which are assembled into electrical products which on their turn are shipped to customers across the globe. This whole chain is a delicate balance, or as historian of technology David Brock put it, 'an orchestration of innovation'. ${ }^{6}$

By 2008, the wide presence of computer chips in our world resulted in a global annual revenue of about 250 billion dollars, a figure that grew to 469

4 David Brock and Christophe Lécuyer, 'Digital Foundations: The Making of Silicon-Gate Manufacturing Technology', Technology and Culture 53:2 (2012) pp. 561-597, p. 561. Estimates of data service IC Insights were that in 2018 alone over 1,075 billion semiconductor products will be produced. In 1978 this number was just 32.6 billion. - Paul van Gerven, 'Halfgeleiderverkoop doorbreekt grens van een biljoen', bits-chips.nl (30-1-2018).

5 The Economist, 'The Chips are Down', The Economist (1-12-2018) pp. 20-22, 21.

6 'This in contrast to systems of innovation. 'In semiconductor manufacturing there exists an ecosystem of technologies. Within this ecology lithography exposure tools and photoresist are highly coupled: the performances and characteristics of each help define the fitness and success of the other.' - David C. Brock, 'Patterning the World: The rise of Chemically Amplified Photoresist', Chemical Heritage Foundation, Center for Contemprorary History and Policy: Studies in Materials Innovation (2009), pp. 17. 
billion dollars in 2018. ${ }^{7}$ These revenues were obtained by the sales of various kinds of computer chips. The majority of them are so-called memory chips that store information. In addition, there are chips that translate analog signals into digital ones - called linear chips - and those that process information, called microprocessors and controllers. Furthermore, some chips are designed in a general way, allowing users to program the chip for their own needs. And, finally, there are chips that are specifically designed and manufactured for a single application. Many chip manufacturers are specialized in one or a few of those different kinds of products.

Since the early days of computer chip manufacturing, the machines to produce chips changed rapidly as well. A distinct industry has emerged to design, develop, and sell new semiconductor manufacturing techniques and equipment. Apart from semiconductor equipment manufacturers, like ASM, this industry consists of material suppliers and companies specialized in the construction of chip factories. The semiconductor equipment industry amounted to a value of around 30 billion dollars in 2008, a figure that increased to 65 billion dollars in 2018. ${ }^{8}$ Despite the fairly small size of the manufacturing sector in comparison to the chip industry as a whole, this sector clearly plays a vital role.

There are numerous processes involved in altering the semiconductor material. The production of one computer chip involves tens of chemical and physical treatments, if not up to about one hundred. Three techniques are paramount and employed in different variations: the growth of a thin film through deposition techniques; the projection of a pattern through lithography; and the etching of materials through gasses and liquids. Next to these three predominant manufacturing processes, there are multiple metrology techniques and many steps in the assembly and packaging of chips.

Each step in the manufacturing process depends on highly specialized knowledge, forming a market of its own. For instance, the size of the market for lithography, a technology that involves highly specialized handling of optics, was 5.4 billion dollars in $2008 .{ }^{9}$ The semiconductor production machines themselves

7 Global sales of 2008 and 2017 based upon information of the Semiconductor Industry Association (SIA). - SIA, 'Global Semiconductor Sales Fell by 2.8 Percent in 2008', semiconductors.org (2-2-2009); and SIA, 'Global Semiconductor Sales Increase 13.7 Percent to $\$ 468.8$ Billion’, semiconductors.org (4-2-2019).

8 The number is relatively low in 2008 due to the global financial crisis. In 2007, the worldwide revenue for semiconductor manufacturing technology was 43 billion dollars. The chip industry's total revenue in 2007 was 255.6 billion dollars. Numbers derived from press releases of industry association for semiconductor equipment and materials, SEMI. - SEMI, 'SEMI Reports 2008 Global Semiconductor Equipment Sales', semi.org (25-3-2009); SEMI, '2018 Global Semiconductor Equipment Sales Jump to Record \$64.5 Billion', semi.org (10-42019).

9 Dylan McGrath, 'Gartner sees tough year for litho stepper sales', EETimes.com (22-6-2009). 
are costly, as equipment prices range from one hundred thousand euros up to as much as one hundred million euros. The semiconductor equipment industry, in which ASM is active, covers all these different segments.

The manipulation of semiconductor materials pertains in particular to miniaturization of transistors and other components of a computer chip. The industry's rule of thumb is: the smaller the transistor, the better. Smaller size improves a transistor's performance and decreases its cost. Furthermore, if a transistor is smaller, more transistors will fit on a single computer chip, and more transistors means more capabilities of the chip. For over half a century, the chip industry sought to shrink transistors to the smallest size possible, given the available technologies. As a consequence, innovation throughout the chip industry - and in particular in manufacturing techniques - has concentrated on the shrinkage of transistors.

The pace of the miniaturization by the chip manufacturers has been captured in the notable 'Moore's Law', which states that about every eighteen months the number of transistors on a chip is being doubled. Gordon Moore formulated this 'law' in 1965, and over the decades it turned out to be true. ${ }^{10}$ Students of innovation have explained its veracity by detailing how it operates as a selffulfilling prophecy in a strategic game. ${ }^{11}$ Players in the semiconductor industry use the law as a yardstick to measure their own progress and to calibrate their strategy - in the knowledge that other players will do the same. Indeed, compliance with Moore's Law - regardless of the physical and organizational limits faced - has defined the competitiveness of chip manufacturers.

The endless race toward smaller chips forced suppliers of semiconductor equipment to run a parallel race. After all, the production of the newest chip that obeys Moore's Law requires, in its turn, new manufacturing technologies. In other words, the semiconductor equipment industry, in which ASM has been a player, had to follow the dictate of miniaturization. This task spurred continuous innovation for the equipment manufacturers. Besides miniaturization, the manufacturing techniques had to sustain or increase the production volumes, as well as improve the quality of the production processes. Every new and anticipated investment by chip manufacturers in their fabrication technology formed a new opportunity for equipment companies to distinguish themselves from their competitors.

10 Gordon Moore, 'Cramming More Components onto Integrated Circuits', in: David Brock (ed.), Understanding Moore's Law (Chemical Heritage Press, Philadelphia, 2006) pp.55-61.

11 R.R. Schaller, 'Moore’s Law: Past, Present and Future', IEEE Spectrum 34:6 (1997) pp. 522-59; Harro van Lente, 'Navigating foresight in a sea of expectations: lessons from the sociology of expectations', Technology Analysis \& Strategic Management 24:8 (2012) pp. 769-782. 
The semiconductor equipment industry has a cyclical market. ${ }^{12}$ Commonly, its customer base - the chip manufacturers - will run ahead or stall their investments in new equipment simultaneously. The chip industry's investments are based on projected sales of their products, as well as on economic and industrial forecasts. Overcapacity in the production of memory chips or a financial crisis on the stock market may cause drastic cuts in capital expenditures by chip manufacturers.

Forecasting and anticipating needs and market developments are therefore central in managing and running a business in the semiconductor equipment industry. This involves balancing and assessing numerous aspects continuously, as well as justifying them in the quarterly and annual reports and at conference calls. It is all about securing one's share in potential growth markets. Equipment manufacturers have to navigate through these volatile and unpredictable waters of highs and lows in demand, while maintaining investments for the forthcoming generation of chips with yet again smaller transistors.

\section{Exploring innovation processes}

Navigating innovations in a complex and challenging environment like the semiconductor equipment industry hardly involves a straightforward task. The industry expresses a dialectic of order and capriciousness. On the one hand, markets are volatile and innovations bring major uncertainties. ${ }^{13}$ On the other hand, notoriously strict and detailed procedures and processes guide the production of the tiniest transistors in massive volumes. Moreover, the industry makes a display of ambitious organizational and financial efforts in order to stay reliable and predictable for investors and customers.

Likewise, studying such a dynamic environment is not straightforward either and requires an appropriate conceptual framework. This study follows a rich tradition in social science and economic scholarship on innovation by regarding innovation as an evolutionary process of variation and selection that is shaped by numerous influences, forces, and dynamics. ${ }^{14}$ In the remainder of this introduction I will draw from the evolutionary traditions in the history of technology, economics of innovation, and science and technology studies (STS)

12 Clair Brown and Greg Linden, Chips and Change: How Crisis Reshapes the Semiconductor Industry (MIT Press Paperback Edition, Cambridge, 2011).

13 For instance, uncertainty about the acceptance of the innovation by the market, about the viability of established technologies, or about standards. - Clayton Christensen, The Innovator's Dilemma: When New Technologies Cause Great Firms to Fall, (Harvard Business Review Press, Cambridge, 1997).

14 Richard Nelson and Sidney Winter, An Evolutionary Theory of Economic Change (Harvard University Press, Cambridge, 1982) p. 97; Giovanni Dosi and Richard Nelson, 'An Introduction to evolutionary theories in economics' Journal of Evolutionary Economics 4:3 (1994) pp. 153-172. 
to build a conceptual framework that allows me to trace the dynamics, as well as to explain and characterize the innovation processes at ASM between 1958 and 2008.

\section{Three insights into studying high-tech innovation}

While the historical, social, and economic scholarship on innovation as an evolutionary process is far too broad to summarize its findings in a few pages, I will highlight three basic insights that support the main tenets of these tradition: the discrepancy between contingency and the rule; the plea for symmetry in analysis; and the role of expectations in innovation.

The first insight is that any innovation is interspersed with contingency. While innovation processes definitively show some regularity and predictability, they are also notoriously uncertain and elusive. This contradistinction refers not only to the politics of running an innovative business - by means of procedures and rules versus contingency-bound entrepreneurship - but also to the academic perception of history. As such it relates to the traditional academic chasm between the need to narrate and the need to interpret historical events, or theorizing versus historicizing. Whereas socio-economic scholars tend to generalize technological change through concepts and theories, historians seem to feel most comfortable with presenting the unique events as they evolved. ${ }^{15}$

This in-depth historical study offers the opportunity to nurture new understanding about the dynamics of high-tech innovation, and it very much intends to do so. However, we have to be careful with generalizations and conceptualizations about this complex environment. For instance, the chip industry's ostensibly paramount Moore's Law did not become institutionalized by the whole industry until the late 1980s. ${ }^{16}$ Throughout the history of the industry, none of the central actors managed to look beyond their immediate horizon, say, five or ten years ahead. Periodic premature proclamations about Moore's Law's imminent finality prove this point. ${ }^{17}$ Moreover, this study of only one company should fully account for the case-specific conditions underlying it.

15 John Tosh and Seán Lang, The Pursuit of History: Aims, methods and new directions in the study of modern history (Pearson Longman, Harlow, fourth edition; 2006), pp. 220-221.

16 Implicitly, however, miniaturization defined the course of innovation since the early 1970 s already. - Robert Schaller, Technological Innovation in the Semiconductor Industry: A Case Study of the International Technology Roadmap for Semiconductors (George Mason University, 2004); and E. Mollick, 'Establishing Moore's Law', IEEE Annals of the History of Computing 28:3 (2006) pp. 62-75.

17 For instance in popular outlets about semiconductor engineering: Chris Mack, 'The Multiple Lives of Moore's Law', spectrum.ieee.org (30-3-2015; Or: The Economist, 'Technology Quarterly: After Moore's Law' (12-3-2016). 
Either way, the argument in this dissertation aims to do both with regard to ASM's innovation processes, by uncovering the unique circumstances surrounding and affecting ASM's innovations and by reflecting on these results on the basis of the existing bodies of literature. This is why assessing innovation processes means reconstructing the possibilities, expectations, and assets as they were perceived and realized throughout the history at issue. The preservation or disregard of conventions in the chip industry will be revealed through a frame which seeks the appreciation of contingencies surrounding and defining innovation processes.

The second insight of evolutionary studies of innovation is that materiality matters. This insight concerns the ostensible discrepancy between the social and material domains. Renowned anthropologist Bruno Latour and sociologist Michel Callon attributed objects with social agency. ${ }^{18}$ They convincingly argued that objects define social interactions and relations, and hence we should think more nuanced about the relationship between 'object' and 'subject' in technology studies. Latour and Callon plead for 'symmetry' in analyzing technological change, thus taking into account both human and material agency.

An innovation process involves specific dealing of humans and materials. This dealing is accompanied by power structures, molding humans and materials to their will. It is not a stretch to argue that an innovation process is a political process through which social, economic, and material elements are combined, negotiated, and aligned. ${ }^{19}$ Michel Callon dubs this process 'translation'. ${ }^{20}$ Through their realizations about the unnatural chasm between the social and material domains, Callon and Latour laid important foundations for Science \& Technology Studies. Yet, this apprehension of the material world is hardly self-evident for most economic historians, which is why it requires explication.

The third insight is that all innovation processes are deeply future-oriented. In order to aptly reconstruct the development of ASM's innovation processes, the forward-looking aspect of the technology and the industry has to be recognized explicitly. The so-called 'sociology of expectations' in particular has examined this condition and its implications for the development of novel technologies. As sociologist of technology Harro van Lente has argued, expectations about

18 Bruno Latour, 'How to write "The Prince” for machines as well as for machinations', in: Brian Elliott (ed.), Technology and Social Change (Edinburgh University Press, Edinburgh 1988), pp. 20-43; and Michel Callon, 'Some elements of a sociology of translation: domestication of the scallops and the fishermen of St Brieuc Bay', in: John Law (ed.), Power, action and belief: a new sociology of knowledge? (London, Routledge, 1986), pp. 196-223.

19 Bruno Latour, 'How to write “The Prince” for machines as well as for machinations'.

20 Michel Callon, 'Some elements of a sociology of translation'. 
the future shape and define realities and actions in the present. Or as he put it: 'expectations are performative: they do something. ${ }^{21}$ Expectations legitimize, direct, and coordinate actions. ${ }^{22}$

In particular in the high-tech environment of the chip industry, expectations define the viability and operation of a company like ASM. This becomes unequivocal by looking at its public reporting and that of its competitors. In quarter and annual reports and conference calls, the executives justify their business decisions and primarily explain how they position themselves to reap the benefits of any future potential business effectively. Running the business of ASM is not so much about historical performances; it is about anticipating and effectuating new market developments. It is all about the future and its promises. This makes it relevant to consider the performative function of expectations and history.

\section{Three elements to study innovation processes}

With these three insights in mind I will now introduce three 'elements' that together shape innovation processes: fortuna, virtù, and path. These elements are shorthand for influences, forces, and dynamics studied by scholars in historical, social, and economic approaches of innovation.

The element of 'path' constitutes the strategic technological alternatives available to a firm. ${ }^{23}$ It relates to the central concept of 'routine' put forward by evolutionary economists Richard Nelson and Sidney Winter: '[routines] may refer to a repetitive pattern of activity in an entire organization, to an individual skill, or, as an adjective, to the smooth uneventful effectiveness of such an organizational or individual performance. ${ }^{24}$ The element path helps to comprehend ASM's innovation processes beyond the ostensible random sequence of events, or fortuna. ${ }^{25}$

'Fortuna', then, is a contingency that disrupts order, and propels innovative actions. ${ }^{26}$ It can manifest itself as luck, coincidence, crisis, or happenstance, which serves to delegitimize the beaten track or conventions. 'Virtù' is the creative will

21 Harro van Lente, 'Navigating foresight in a sea of expectations: lessons from the sociology of expectations', Technology Analysis \& Strategic Management 24:8 (2012) pp. 769-782, p. 772.

22 Ibid.

23 David Teece and Gary Pisano, 'The dynamic capabilities of firms: an introduction', Industrial and Corporate Change 3 (1994) pp. 537-556, pp. 541, 546, and 547.

24 Nelson and Winter, An Evolutionary Theory of Economic Change, p. 97.

25 Mark Blyth, 'Coping with the Black Swan: The Unsettling World of Nassim Taleb', Critical Review 21:4 (2009) pp. 447-465.

26 J.G.A. Pocock, The Machiavellian Moment: Florentine Political Thought and the Atlantic Republican Tradition (Princeton University Press, Princeton, 1975); and Teece and Pisano, 'The dynamic capabilities of firms'. 
or improvisation in anticipation of or in response to fortuna. ${ }^{27}$ Innovation does not materialize without this will to adapt conventions to new realities.

By building on these three elements - fortuna, virtù, and path - I will be able to study the innovation processes at ASM as part of an evolving semiconductor equipment industry. Together, these elements provide an adequate heuristic to trace the many actors and factors in the history I seek to reconstruct and understand. Moreover, they do justice to the three basic insights of historical, social, and economic studies of innovation listed above. Aside from acknowledging the importance of path dependence and expectations, these elements allow symmetry in analyzing the social and material domains, while also allowing us to reflect on history beyond its mere apprehension as a sequence of accidents and contingencies.

\section{A historiography per element}

The three elements to sustain this study - path, fortuna, and virtù - relate to and summarize wider bodies of literature about innovation and technological development. In particular, path aligns with a wide range of conceptualizations regarding innovation processes. Correspondingly, the discussion of path is more elaborate compared to those of fortuna and virtù.

\section{Path}

Basically, path is the opposite of fortuna and virtù. The element encompasses the 'rule', regularity and order in technological development. It encompasses the notion of 'routines', a key notion in the seminal work of Nelson \& Winter:

'It is that most of what is regular and predictable about business behavior is plausibly subsumed under the heading "routine", especially if we understand that term to include the relatively constant dispositions and strategic heuristics that share the approach of a firm to the nonroutine problems it faces. ... At any time, a firm's routines define a list of functions that determine (perhaps stochastically) what a firm does as a function of various external variables (principally market conditions) and internal state variables (for example, the firm's prevailing stock of machinery, or the average profit rate it has earned in recent periods)' 28

Various theories and concepts relate to the element of path, such as 'path dependency', 'opportunities', strategizing, and contextual logics affecting

27 Pocock, The Machiavellian Moment.

28 Nelson and Winter, An Evolutionary Theory of Economic Change, p. 15 and 16. 
variation and selections in the innovation process. ${ }^{29}$ Capabilities, capacity, knowledge, and experience accumulated in the past determine the alternatives available; combined with particular expectations about the future, a probable path in pursuit of an opportunity emerges. In this historiography of path, I reflect upon these key attributions of 'path'.

A representation of the future provides a sense of purpose, direction. Expectations about opportunities shape future realities for business, products, innovations, etc. The idea of an opportunity gives technological development a notion of directionality. ${ }^{30}$ Opportunities are constantly present. Though in the literature some disagreement pertains about the level of articulation of the final opportunity at the start of an endeavor. ${ }^{31}$ For instance, in the field of entrepreneurial history, the question is posed: Can an innovator, entrepreneur or company really foresee an opportunity in the way it comes about at the end of an innovation process or business development? Some pursuits of opportunities might be very causal. ${ }^{32}$ Though in most cases, the appreciation of an opportunity

29 Teece and Pisano, 'The dynamic capabilities of firms: an introduction', pp. 546 and 547. Others have made a similar point: 'This pattern of technical opportunity being exploited through a group of technological trajectories is a very robust feature of industrial dynamics. It is a reflection of the path-dependence, or directionality, of technical change, which exercises such a powerful influence on the evolution of the industry itself.' - Rod Coombs, 'Technological opportunities and industrial organization', in: Giovanni Dosi, Christopher Freeman, Richard Nelson, Gerald Silverberg, and Luc Soete, Technical Change and Economic Theory (Pinter Publishers, London, 1988) pp. 295-308, p. 298.

30 Coombs, 'Technological opportunities and industrial organization', p. 298. Two kinds of opportunities are to be distinguished - though this distinctions bears fairly little relevance for this study: "Schumpeterian" opportunities created by disruptive changes in technology, politics, and regulation, society and demography, which alter the value of resources, and "Kirtzerian" opportunities which arise on account of errors and mistakes by prior market participants.' - Colin Mason and Charles Harvery, 'Entrepreneurship: Contexts, opportunities and processes', Business History 55:1 (2013) pp.1-8, p. 2.

31 In an article overviewing the debate about opportunities and posing different understandings, historians Daniel Wadhwani and Christina Lubinski aptly note: 'an uncritical retrospective point of view wipes away the uncertainty faced by entrepreneurs and the judgmental processes involved in opportunity identification because the actors' future has become revealed, the categories of events and developments are known and calculable and imply lie in a future waiting to be discovered.' - Daniel Wadhwani and Christina Lubinski, 'Reinventing Entrepreneurial History’, Business History Review 91:4 (2017) pp. 767-799, p. 781. Another comprehensive overview about the literature of opportunities is John Park, 'Opportunity recognition and product innovation in entrepreneurial hi-tech start-ups: anew perspective and supporting case study', Technovation 25 (2005) pp. 739-752.

32 Mark Casson, Entrepreneurship: Theory, Networks, History (Cheltenham, 2010); The authors distinguish entrepreneurial opportunity (to create something new) from opportunity for optimization. - Scott Shane and Sankaran Venkataraman, 'The Promise of Entrepreneurship as a Field of Research', The Academy of Management Review 25:1 (2000) pp. 217-226; p. 220. 
changes as more information is obtained. ${ }^{33}$ Either way, the opportunity appears as very real for the innovator, entrepreneur or management.

To comprehend a rationalized opportunity for technological development, a concept suggested by historian of technology Thomas Hughes is helpful. In his marvelous discussion of Thomas Edison's systematic development and expansion of the electricity network, he made both the material and the social world part of the systematic analysis. ${ }^{34}$ To conceptualize opportunities and directionality of actions in a system, he introduced the concept of a reverse salient, inspired by the battle lines of the First World War. ${ }^{35}$ A reverse salient is an element that has fallen behind others and threatened the continued development of a technological system. ${ }^{36}$ Thus understood, the reverse salient forms an alternate interpretation of an opportunity in a technological path. The system itself in which these reverse salients emerge is - similar to history itself - not static. It expands. Hughes shows the imperative nature of the innovation network in which ASM operated.

In the chip industry a reverse salient would be any failure to comply with Moore's Law. Such possibility is perceived to bear consequences for the competitiveness of respective chip manufacturers, the applicability of technology, or the state of the chip industry as a whole. Overcoming this imminent matter of obstruction constitutes an opportunity, a way to compete. ${ }^{37}$ As will become

33 Among others, historians Andrew Popp and Robin Holt argued for the consideration of 'structural conditions containing and shaping the possibility for opportunity. Andrew Popp and Robin Holt, 'The presence of entrepreneurial opportunity', Business History 55:1 (2013) pp. 9-28, p.9.; Other authors: Wadhwani and Lubinski, 'Reinventing Entrepreneurial History', p. 780; Saras D. Sarasvathy, 'Causation and Effectuation: Toward a Theoretical Shift from Economic Inevitability to Entrepreneurial Contingency', The Academy of Management Review 26:2 (2001) pp. 243-263; Dimo Dimov, 'Grappling with the Unbearable Elusiveness of Entrepreneurial Opportunities', Entrepreneurship: Theory and Practice (January 2011) pp. 57-81.

34 The literature on innovation systems is very expansive. Various perspectives exist, such as national, regional, sectoral and technological innovation systems: Charles Edquist, 'Systems of Innovation Approaches - Their Emergence and Characteristics', in: Charles Edquist (ed.), Systems of Innovation: Technologies, Institutions and Organisations (London 1997) pp. 1-34, pp.

35 Hughes original explanation: 'The idea of reverse salient suggests the need for concentrated action (invention and development) if expansion is to proceed. A reverse salient appears in an expanding system when a component of the system does not march along harmoniously with other components. ... the reverse salient will not be seen, however, unless inventors, engineers, and others view the technology as a goal-seeking system.'- Thomas Hughes, Networks of Power: Electrification in Western Society, 1880-1930 (John Hopkins University Press, Baltimore, 1983) pp. 79 and 90.

$36 \quad$ See also Brock and Lécuyer, 'Digital Foundations’ p. 564.

37 Reverse salients do not bare the same consequences as fortuna. The reverse salient does not threaten the existence of the system, but only the pace of its expansion. Moreover, it is knowable, whereas fortuna is not. 
apparent throughout the dissertation, reverse salients can be distinguished retrospectively, but they were also purported industry-wide during the innovation process as 'anticipatory reverse salients'. ${ }^{38}$ Moreover, a reverse salient does not have to be commonplace. Its potency might differ for the participants in an industry.

The pursuit and realization of opportunities are influenced by numerous forces. Historians of technology, David Brock and Christophe Lécuyer claimed that technological development is influenced by the challenges posed by user, competitive and material 'logics'. ${ }^{39}$

'These material, [user], and competitive logics are not determinative, in the sense that they do not lead to necessary outcomes. But they are particularly stable over time and provide powerful resources and constraints to innovators and their patrons. When combined, they define chains of potential events that are actualized by the will, passions, and efforts of scientists and technologists - in other words, their emotional and professional commitments. ${ }^{.40}$

The logics point to forces that affected the pursuit of an opportunity - and the coming about of an innovative process.

Arguably, these three logics are not all, though. Depending on the interest of research other logics might be added as well. For instance, the organizational challenges might play a part - an organizational logic. Organizational processes define the ability to proceed into a direction and realize a potential. As such it offers sufficient leads for developing theories and concepts, ranging from study of the $R \& D$ department within an organization to reflection on roles and change

38 Brock and Lécuyer, 'Digital Foundations'.

39 The exact denotations of the logics differ in the respective publications. - Christophe Lécuyer and David Brock, Makers of the Microchip: A Documentary History of Fairchild Semiconductor (MIT Press, Cambridge, 2010) pp. 2-3; Christophe Lécuyer, and Takahiro Ueyama, 'The logics of Materials Innovation: The Case of Gallium Nitride and Blue Light Emitting Diodes', Historical Studies in the Natural Sciences 43:3 (2013) pp. 243-280, p. 246. Brock and Lécuyer's user and material logic resemble a scheme by Bodewitz et al. but stems from Latour; Henk Bodewitz, Gerard de Vries, and Pieter Weeder, 'Towards a cognitive model for technology-oriented R\&D processes', Research Policy 17 (1988) pp. 213-224.; Moreover, the line of thinking is traceable to the philosopher Martin Heidegger, in his essay 'The Question Concerning Technology'. To comprehend his idea, I quote from the article by Popp \& Holt: 'causa materialis, the material from which a thing is formed; ... causa formalis, the form into which a thing enters; ... causa finalis, the end to which it is formed ...; and the causa efficiens, that [the actor] which brings about the effect [having agency]' -Popp and Holt, 'The presence of entrepreneurial opportunity', p. 19.

40 Lécuyer and Ueyama, 'The logics of Materials Innovation', p. 246. 
in organizational processes, as well as on the organization's internal power and social dynamics. This social component hardly gets a place within the logics as formulated by Brock and Lécuyer, while the formulation and understanding of opportunities foremost is a social process.

A specific theory stressing the deeply social character of innovation is provided by Wiebe Bijker and Trevor Pinch. ${ }^{41}$ Their 'social construction of technology' (SCOT) approach identifies, in the first place, the different meanings surrounding the development of a technology. The accompanying concept of 'interpretative flexibility' underscores that an artefact means different things for different social groups and that these interpretations decide the course of innovation. Moreover, an innovator might relate himself to more than one social group. ${ }^{42}$ The SCOT approach follows the subsequent confrontations and negotiations, and the eventual 'closure' in which a particular meaning is stabilized.

While the SCOT approach is reluctant to specify in advance which social groups will be relevant, other approaches are more specific. For this study the concepts of enactor and selector are useful. Management scholars Raghu Garud and David Ahlstrom proposed the terms 'insiders' and 'outsiders', technology philosopher Arie Rip convincingly argued for 'enactors' and 'selectors' as useful terms ${ }^{43}$ to distinguish different roles in the process of innovation.

Enactors present a technology as a solution to various perceived problems and are committed to make this particular technology successful. ${ }^{44}$ Selectors operate just the other way around: they define the problem and consider various solutions. They are indifferent to the success of a particular technology, as they are committed to solve a problem. Garud \& Ahlstrom call the phase during which the enactor and selectors assess each interests and arguments a 'bridging incident'. 45 Throughout an innovation process, moments of 'closure' exist, during

41 Engineers - and especially experts - define their status of competence not only within their own organization, but also through their relative position among their peers. Trumping their competing engineers at other organizations might be one way to do so. - Trevor Pinch and Wiebe E. Bijker. 'The Social Construction of Facts and Artefacts: Or How the Sociology of Science and the Sociology of Technology Might Benefit Each Other'. Social Studies of Science 14 (August 1984) pp. 399-441.

42 Edward Constant II, 'The Social Locus of Technological Practice: Community, System or Organization?', in: Wiebe Bijker and Thomas Hughes (ed.), The Social Construction of Technological Systems: New Directions in the Sociology and History of Technology (MIT Press, Cambridge, 1989) pp. 223-242.

43 . Raghu Garud and David Ahlstrom, 'Technology assessment: a socio-cognitive perspective', Journal of Engineering and Technology Management 14:1 (1997) pp. 25-48; and Arie Rip, 'Folk Theories of Nanotechnologists', Science as Culture 15:4 (2006) pp. 349-365, pp. 360 and 361.

44 A comprehensive definition is given by Sjoerd Bakker in his dissertation: Sjoerd Bakker, Competing Expectations: The case of the hydrogen car (BOXPRess, Oisterwijk, 2011), p. 8.

45 Garud and Ahlstrom, 'Technology assessment: a socio-cognitive perspective’, p. 44. 
which one of the roles persists. ${ }^{46}$ This could be one of multiple enactors, or the viewpoints of one of multiple selectors. Closure can occur through new insights or results, a redefinition of the problem at hand, or rhetorically.

The positions of enactor and selector cut across conventional roles within an organization, such as the role of engineer, marketing manager, CEO, and equipment supplier. Categorizing individuals, groups, and/or organizations into either enactors or selectors highlights their intentions and their posture within the innovation process beyond their formal position. Without dwelling into, for instance, typical CEO-behavior or sales management personalities, the notions of enactor and selector focus on the agencies within the formation of a technological path.

Another important body of literature addressing the direction and speed of a technological path focuses on 'strategy'. A famous definition is to regard strategy as a pattern in a stream of decisions. ${ }^{47}$ This definition holds both for business as for the innovation process. The appreciation for and articulation of strategy for business and innovation differed over time. New understanding of business and innovation strategies succeeded each other. In case of business management, for instance, this involved the introduction of new management theories applicable for multi-divisional firms. ${ }^{48}$ Prominent contributors to this part of strategy involve management gurus like Peter Drucker, P.H. Prahalad, Michael Porter, Gary Hamel and Clayton Christensen. ${ }^{49}$

In case of innovation management, scholarship on 'strategy' relates to innovation as being part of a wider system or ecosystem, or the distinction of 'Research \& Development (R\&D) generations'. ${ }^{50}$ This general conception reflects

46 In their original paper, Pinch and Bijker distinguished closure through rhetoric and closure by redefinition of the problem. The authors emphasize that closure involves foremost that the key social groups see a controversy as being solved. - Pinch and Bijker, 'The Social Construction of Facts and Artefacts'.

${ }_{47}$ Henry Mintzberg and James Waters, 'Of Strategies, Deliberate and Emergent', Strategic Management Journal 6:3 (1985) pp. 257-272, p. 257.

48 Keetie Sluyterman, Dutch Enterprise in the Twentieth Century: Business strategies in a small open economy (Routledge, Abingdon 2005), part of: Geoffrey Jones and Mary Rose (ed.), Routledge international studies in business history, p. 3; and Pankaj Ghemawat, 'Competition and Business Strategy in Historical Perspective', Business History Review 76 (2002) pp. 37-74.

49 Peter Drucker, 'The Effective Decision', Harvard Business Review 45:1 (1967; C.K. Prahalad and Gary Hamel, 'The Core Competence of the Corporation' Harvard Business Review (May 1990) pp. 79-91; Michael Porter, 'From Competitive Advantage to Corporate Strategy', Harvard Business Review (May 1987) pp. 43-59; and Clayton Christensen, The Innovator's Dilemma: When New Technologies Cause Great Firms to Fail (Harvard Business Review Press, Boston, 1997).

50 De Jong, Sluyterman, and Westerhuis, 'Strategic and structural responses'; Johan Schot and 
that the management of R\&D within an organization over time improved, matured and adapted to the changing context and demands for an innovative firm. ${ }^{51}$ So far, at least six generations have been distinguished by various authors. The first generation can be seen as technology-push, where basic research determines the course of technological and subsequently product development of a firm. This generation prevailed until the early 1970s. The second generation, until the mid-1980s, involved market-pull, with business units determining the requirements for $R \& D$. The third generation involved an integrated and parallel approach across divisions, balancing the corporate and business units' R\&D interests; it emerged in the early-1980s and lasted until the mid-1990s. The distinctions between generations are not often that clear, foremost since authors tend to distinguish their 'generation' in order to spotlight their own contribution. Yet, the distinctions and their temporal embedment do indicate changing understanding of how R\&D should be managed and deployed within an organization.

Fitting with our notion of 'path', strategy is both progressive and retrospective, it relates to the future but is situated in the past. ${ }^{52}$ For the actor involved in an innovation process or business development, a strategy can be conscious or it can be revealed after a series of decisions. ${ }^{53}$ Management scholars Henry Mintzberg and James Waters defined strategy as a deliberate or emergent pattern in a stream of decisions. ${ }^{54}$ Deliberate strategy involves a realization of a strategy as originally intended, and the emergent strategy entails the realization of patterns or consistencies regardless of the original intention. Mintzberg and Waters' distinction is pivotal.

At any point of time, an innovator can reassess or reinterpret this pattern of decisions. Through such an exercise, the innovator might turn a hitherto emergent

Edward Steinmueller, 'Three frames of innovation policy: R\&D, systems of innovation and transformative change', Research Policy 47 (2018) pp. 1554-1567, p. 1558; Philip Roussel, Kamal Saad, and Tamara Erickson, Third Generation R\&D (Harvard Business School Press, Cambridge, 1991)

51 Roussel, Saad, and Erickson, Third Generation R\&D; William Miller, and Lagndon Morris, Fourth Generation R\&D: Managing Knowledge, Technology and Innovaiton (John Wiley \& Sons, New York 1999); Roy Rothwell, 'Towards the Fifth-Generation Innovation Process', International Marketing Review 11:1 (1994) pp. 7-31; and Dennis Nobelius, 'Towards the Sixth Generation of R\&D Management', International Journal of Project Management 22:5 (2004) pp. 369-375.

52 Business historian Alfred Chandler famously stated that structure followed strategy. However, the stipulation of a strategy does not always precede action. - Alfred Chandler, Strategy and Structure: Chapters in the History of the American Industrial Enterprise (MIT Press, Cambridge, 1962).

53 Sluyterman, Dutch Enterprise in the Twentieth Century, p. 2 and 3

54 Mintzberg and Waters, 'Of Strategies, Deliberate and Emergent', p. 257. 
strategy into a new deliberate one. If a strategy is reinterpreted, a company's structure is already in place and subsequently defines the maneuverability of the manager. Then, strategy follows structure. The reciprocal relation between strategy and structure makes the corporate (innovation) strategy both constant and variable.

After a while, as time progresses, the strategic pursuit of opportunities - deliberate or emergent - creates a path that, in its turn, constrains and informs further decisions. Based on the sequence of actions, contingencies, and innovations, it is possible to distill a rule through the first interpretation of opportunities present already. This rule serves as a handle on the hurtling pace of history. ${ }^{55}$ These conventions about one's path also define the perception of future possibilities.

Path dependency implies that the innovator is constrained by assets, experience, capabilities, and reputation. As economists Richard Nelson and Sidney Winter argued, technological development in complex industries like the chip industry is cumulative. ${ }^{56}$ It is very hard to innovate from scratch. Chip production relies on experience and the capacity to absorb any new bit of relevant information - or 'absorptive capacity'. ${ }^{57}$ It is not easy to change one's business within the industry, as it depends on very specific skills and knowledge. ${ }^{58}$ The perseverance of the past - the path dependency - defines the anticipation of opportunities ahead.

55 Over time, a strategy gets embedded in the organization. Utterback characterizes the organizational development as 'from entrepreneurial organic firm to hierarchical mechanistic firm with defined tasks and procedures and few rewards for radical innovation.' - James Utterback, Mastering the Dynamics of Innovation (Harvard Business School Press, Boston, 1994), p. 91. Theorizing about entrepreneurship, Joseph Schumpeter distinguished two phases, dubbed Schumpeter Mark I and II. Mark I consists of pioneering entrepreneurs and Unternehmergeist, while Mark II rather involves routinized entrepreneurship embedded in clear procedures. - Roberto Fontana, Franco Malerba, and Astrid Marinoni, 'Knowledge intensive entrepreneurship in different sectoral systems', in: Franco Malerba, Yannis Caloghirou, Marueen McKelvey, and Slavo Radosevic (Ed.), Dynamics of Knowledge Intensive Entrepreneurship: Business strategy and public policy. Part of series: Routledge Studies in Innovation, Organization and technology (Routledge 2015) pp. unknown.

56 Nelson and Winter, An Evolutionary Theory of Economic Change, p. 97.

57 Franco Malerba, The Semiconductor Business: The Economics of Rapid Growth and Decline (University of Wisconsin Press, Madison, 1985); Wesley Cohen and Daniel Levinthal, 'Absorptive Capacity: A New Perspective on Learning and Innovation', Administrative Science Quarterly 35:1 (1990) pp. 128-152.

58 Giovanni Dosi, 'Technological Paradigms and technological trajectories. A suggested interpretation of the determination and directions of technical change', Research Policy 11 (1982) pp. 147-162. 
Efforts have been made to characterize this path, also dubbed 'regime' by economists. ${ }^{59}$ This involves characterizations of the technological path as well as the industrial path. In the case of technology, Keith Pavitt's taxonomy of sectoral patterns is most notable, involving the supplier-dominated, scaleintensive, science-based, information-intensive, and specialized-supplier patterns of technological change. ${ }^{60}$ Pavitt's taxonomy of 'paths' was altered, repealed, complemented, and renewed various times. ${ }^{61}$

Economists James Utterback and William Abernathy offered another characterization of technological and industrial path. ${ }^{62}$ They distinguish two waves of innovation during the development of an industry, which typically takes several decades. The first wave consists of a rise and fall of product innovations, like, say, a diode, the DRAM memory chip, or the CMOS transistor. A second, subsequent wave entails the rise and fall of innovations of techniques to produce the products - to which we might refer as manufacturing technology. The authors label these process innovations. Examples in the semiconductor industry are the invention of a manufacturing procedure, packaging techniques, and the

59 Nelson and Winter, An Evolutionary Theory of Economic Change; Stefano Breschi and Franco Malerba, 'Sectoral Innovation Systems: Technological Regimes, Schumpeterian Dynamics, and Spatial Boundaries', in: Charles Edquist (ed.), Systems of Innovation: Technologies, Institutions and Organisations (London 1997) pp. 130-15, p. 133.

60 The supplier-dominated pattern concerns companies dependent on innovations of their suppliers. The scale-intensive pattern pertains to companies that competed through economies of scale. Innovation occurred at the mass-producing companies themselves. The science-based pattern concerns ventures that innovated through intensive R\&D efforts, whether internal or in cooperation with research institutes. The last one, specializedsupplier pattern, relates to suppliers who concentrate on product innovations intended for other industries. Later, Pavitt added the 'information-intensive' trajectory, which involves firms in the service sectors relying upon complex information processes. - Keith Pavitt, 'Sectoral patterns of technical change: Towards a taxonomy and a theory', Research Policy 13:6 (1984) pp.343-373; Joe Tidd, John Bessant, Keith Pavitt, Managing Innovation: Integrating Technological, Market, and Organizational Change (2nd edition; Wiley, Chichester, 2001), p. 115.

61 A very useful overview of the efforts in this regard is offered by: Fontana, Malerba, and Marinoni, 'Knowledge intensive entrepreneurship in different sectoral systems',. Other examples are the patterns formulated by historians Mila Davids, Harry Lintsen, and Arjen van Rooij as part of the extensive project on Business in the Netherlands during the Twentieth Century (BINT) - Mila Davids, Harry Lintsen, Arjen van Rooij, Innovatie en kennisinfrastructuur: vele wegen naar vernieuwing. Bedrijfsleven in Nederland in de Twintigste Eeuw (Boom Amsterdam, 2013), pp. 213 and 214. Or the alternatives offered by. - Stefano Breschi, Franco Malerba and Luigi Orsenigo, 'Technological Regimes and Schumpeterian Patterns of Innovation', The Economic Journal 110 (2000) pp. 388-410.

62 James M. Utterback and William J. Abernathy, 'A Dynamic Model of Product and Process Innovation', Omega 3:6 (1975), pp. 639-656; Utterback, Mastering the Dynamics of Innovation, p. xviii. 
introduction of new lithography stepper machines. These are in fact the products developed and sold by ASM.

Utterback and Abernathy claim that both waves will always be there throughout the development of an industry. The predominance of one will never imply the annulment of the other. ${ }^{63}$ Typically, product innovations are more prominent in the first phase of an industry, and process innovations at a later stage; when the two waves intersect, a dominant design emerges in the industry. In a later work, Utterback defines a dominant design as a - I would say, rather Platonic - template of how a product is 'supposed to look and operate'. ${ }^{64}$ From that moment on, competitiveness in the industry tends to depend predominantly on the efficient production of the dominant design. Hence, the rise of process innovations.

As we will see in this study, Utterback \& Abernathy's waves of innovation help to explain the demand for ASM's products. The wave of process innovation in the chip industry created a strong demand for new manufacturing technologies, which ASM managed to provide. The waves of innovation appoint to the dynamism in the chip industry, as well as to the subsequent position of ASM's technological development in it. ${ }^{65}$

To conclude, the element 'path' opens the door to theories about opportunities and innovation, but also to characterizations of the technological and industrial patterns. Bearing in mind the contrast between contingency and the rule - as discussed above- the element of path offers a hold on the interminable sequence of contingencies, acts, and innovations constituting and affecting the course of ASM's history. Path constitutes regularity, order.

\section{Fortuna}

The element fortuna challenges the rule and disrupts the element path. In his magnum opus The Machiavellian Moment, Pocock explores Machiavellian thought about political innovators dealing with uncertainty and contingencies, or fortuna. According to Machiavelli, fortuna involves an event that moves beyond

63 This was suggested by Malerba, for instance: 'At a general level, Abernathy and Utterback (1975 and 1978) claimed that product innovations are more frequent in the early stages of an industry, while process innovations characterize the later stages. The early stages of the semiconductor industry, on the other hand, have been characterized by both product and process innovations.' -Malerba, The Semiconductor Business, p.57.

64 Utterback, Mastering the Dynamics of Innovation, p. 25.

65 The rise and fall of innovations touches on Hughes's notion of momentum, during which a system displays velocity. - Thomas Hughes, 'The evolution of large technological systems', in: Wiebe Beijker, Thomas Hughes and Trevor Pinch (ed.), The Social Construction of Technological Systems (MIT Press, Massachusetts, 1987), pp. 51-82, p. 76. 
conventionality and expectations, and this urges a reaction of the political leader. ${ }^{66}$ The significance of unexpected events, fortuna, for our political world was also recognized by philosopher and historian Van Middelaar. In a striking passage, he stresses the significance of events for the unfolding of history:

"The word "contingency" - Ereignis as Heidegger called it - ... refers to the substantial openness of human affairs. This concept leaves room within the unforeseen. It forces an opening in the closed view of history of Hegelians and Marxists, who see humanity progressing towards a defined destination; an opening in the deterministic worldview of scientists who ban chance, will-power, and choice from their causal schemes; an opening in the extrapolations and scenarios of economic planning offices and futurologists, who get a kick out of their jaunty dotted lines leading toward tomorrow. Who knows, contingency tells all of them, things might turn out differently. ${ }^{\text {'7 }}$

In terms of the evolutionary thinking in which this study is situated, fortuna can be seen as mutations - spontaneous or affected by wider developments - that alter the course of technological development, or business.

Pocock also labels some events as 'Machiavellian Moments'. During such event, an entity is confronted with its 'own temporal finitude', while it tries to 'remain morally and politically stable in a stream of irrational events conceived as essentially destructive of all systems of secular stability.' ${ }^{68}$ In response to this contingency and subsequent uncertainty, the entity might move ahead beyond conventions, and thus innovate. Pocock indeed calls the entity or political leader confronted by Machiavellian Moments an 'innovator'. ${ }^{9}$

66 Nassim Nicholas Taleb would call fortuna a Black Swan. After years of getting the apparent truism of 'All swans are white' reconfirmed at every encounter with a white swan, the confrontation with a 'Black Swan' urges one to revise one's point of view or conventions. This notion is drawn from philosopher Karl Popper's famous critique on falsifiability. Nassim Nicholas Taleb, The Black Roman: The Impact of the Highly Improbable (Penguin Books, 2nd edition, London, 2010). In the terminology of former US Secretary of Defense Donald Rumsfeld, fortuna can be seen as the 'unknown-unknown': that which cannot be known and yet be very consequential.

67 Original quote in Dutch. - Luuk van Middelaar, De nieuwe politiek van Europa (Historische Uitgeverij, n.p., 2017), p. 198.

68 Pocock, The Machiavellian Moment, p. viii.

69 For instance: 'Il Principe is a study of the "new prince" - we know this from Machiavelli's correspondence as well as from internal evidence - or rather of that class of political innovators to which he belongs. The newness of his rule means that he has performed an innovation, overthrowing or replacing some form of government which preceded him.' Pocock, The Machiavellian Moment, p. 160. 
Current economic and technological competition quite resembles the political domain - pervaded by uncertainty, strive and also rules - as studied and characterized by Machiavelli and Pocock. ${ }^{70}$ The challenges faced by political leaders during such Machiavellian Moments of blind contingencies bear a striking resemblance with those confronted by techno-industrial innovators such as ASM as a company, or Arthur del Prado as ASM's chief executive officer. This resemblance was propagated by anthropologist Latour, who applied the Machiavellian apprehension of politics to the process of innovation. ${ }^{71}$ Embedded in a socio-technical environment, the innovation process can be seen as a politics - as negotiating, aligning, and dealing with human and non-human agencies. ${ }^{72}$ In other words, the political accounts for both the social and the technological domain. Likewise, fortuna itself manifests in both these domains, for instance as competition between companies or a disappointing result of research. Whether material or social, fortuna provokes innovation beyond conventionality.

In some instances, fortuna will originate in the immediate environment or in broader historical shifts, such as the Cold War, the rise of transnational capitalism, or the cumulative digitalization of society, which propelled further technological development in semiconductor and interrelated industries. ${ }^{73}$ The conceptualization of fortuna allows us to appreciate the contingencies and uncertainties underlying technological and social change. By tracing manifestations of fortuna and its effects throughout the history of ASM, it becomes possible to integrate the unforeseen yet defining contingencies into the analysis.

\section{Virtù}

The disruption of path by fortuna requires an answer. After all, as business historian Keetie Sluyterman stated:

'[C]hanging economic or political circumstances invariably forces [business leaders] to react and reconsider their strategies. This pattern of action and reaction is central to the development of businesses. ${ }^{74}$

70 Latour, 'How to write “The Prince” for machines as well as for machinations'.

71 Ibid.

72 His understanding elaborated upon his and Callon's plea for symmetry in analysis. Latour, 'How to write "The Prince" for machines as well as for machinations'; Callon, 'Some elements of a sociology of translation'.

73 Brock and Lecuyer, 'Digital Foundations', p. 564.

74 Sluyterman, Dutch Enterprise in the Twentieth Century, p. 2. 
And, as we should add, central to innovation as well. The disturbance of regularity poses the innovator - or business leader - in a situation surrounded with uncertainty in which the old order does not offer consolation.

Machiavelli sees virtù as a vital ability for survival in the face of happenstances or fortuna. ${ }^{75}$ Virtù is the art of dealing with uncertainty. ${ }^{76}$ It involves both reactive and anticipative serendipity. Inspired by both Machiavelli and Pocock, Van Middelaar - once again - defines the notion of virtù aptly:

'For him [Machiavelli], it is strictly a political notion: a combination of intelligence, courage, and perseverance, stripped of any moral and theological connotations. It is about taking action, taking initiative, anticipation, and playing along with a given situation. ... All human institutions are susceptible to erosion through time. ... virtù is vital to counter fortuna's disruptive power. ${ }^{\text {77 }}$

In particular in the competitive environment of the chip industry, dealing with contingencies is a matter of life and death. This pertains to both the entrepreneur in pursuit of new business opportunities and the engineer engaging in technological development. Their success in dealing with uncertainty defines their competitiveness. There is always a competitor who will be happy to take over your share of the market or rob you of your customers. A company like ASM constantly has to prove its relevance. Moreover, as claimed by Pocock, innovation is the mere consequence of virtù:

'Since by his own act the innovator inhabits a delegitimized context, where fortuna rules and human behavior is not to be relied on, he is obliged to take the short view and continue to act - and in that sense, to innovate. In a very precise sense, then, action is virtù; when the world is unstabilized and the unexpected a constant threat, to act - to do things not contained within the structures of legitimacy - was to impose form upon fortuna. ${ }^{78}$

75 The notion of virtù as used rather implicitly by Machiavelli has been subjected to intense study. The meaning of virtù can be traced back to Greek, Roman and early Christian uses. - Pocock, The Machiavellian Moment,; and see also: John Geerken, 'Machiavelli Studies since 1969', Journal of the History of Ideas 37:2 (1976) pp. 351-368.

76 Pocock defines virtù also as: '...the skill and courage by which men are enabled to dominate events and fortune." - Pocock, The Machiavellian Moment, p. 92.

77 Original quote in Dutch. - Van Middelaar, De nieuwe politiek van Europa, p. 29.

78 Pocock, The Machiavellian Moment, pp. 177-178. 
In contrast to the deliberate and strategic pursuit of opportunities - as expounded in the element of path - action as virtù is more impromptu. It is an act swaying the innovator into terra incognita, impelling innovation. Without virtù there is no innovation.

Pocock also recognizes that deeds bear consequences:

'On the one hand virtù is that by which we innovate, and so let loose sequences of contingency beyond our prediction or control so that we become prey to fortuna; on the other hand, virtù is that internal to ourselves by which we resist fortuna and impose upon her patterns of order, which may even become patterns of moral order. ${ }^{79}$

To show virtù, and thus to innovate, paves the way for new conventions and rules. As such, innovation is central to human behavior and changes in our world. It changes the course of history and creates new opportunities beyond our expectations. To paraphrase another scholar in Machiavellian thought, John Geerken, virtù is to keep laws and reality into equilibrium, to prevent their excessive separation. ${ }^{80}$

Though, very much like path, virtù is defined by path dependency and expectations about the future. Perceptions about prevailing certainties determine the direction of action in response to fortuna. ${ }^{81}$ Opportunities as defined within path - such as the reverse salients - are evanescent when facing fortuna. The perception of opportunities becomes more intuitive, foremost relying upon experience, trust, or a gut feeling. As stated by management scholar Dimo Dimov:

'[B]ecause the ultimate results of entrepreneurial actions cannot be reliably anticipated, but are revealed only when the uncertainty about the future is resolved, for opportunity (...) to be presented as a rational mean-ends choice, one needs to assume complete foreknowledge of future states and payoffs, thereby standing outside the realm of uncertainty. Without such axiomatic specification, people cannot be deemed to have acted rationally on the expectations that they would

79 Pocock, The Machiavellian Moment, pp. 167 and 169.

80 Geerken, 'Machiavelli Studies since 1969', p. 363.

81 This is what management scholar Saras Sarasvathy dubs effectuation. She defines it as '(..) processes [that] take a set of means as given and focus on selecting between possible effects that can be created with that set of means'. In other words, what can we do with what we have, instead of what do we need to get where we want to be. - Sarasvathy, 'Causation and Effectuation: p. 245. 
gain what cannot yet be fully or reliably defined before the action takes place $^{82}$

In this way, virtù is the temporal adaption of a strategy or a path, and is rooted in a bounded rationality. It is an indispensable attribute for running a business. Without adaptation to unforeseen events - virtù - business flounder. ${ }^{83}$ Rather than emanating from thin air, innovation follows from the human willingness to engage and adjust to an uncertain future packed with contingencies.

\section{Historical resources}

This study relies on three kinds of resources. The first source is the personal archive of Arthur del Prado. This archive consists of roughly one hundred moving boxes containing documentation covering the period from Del Prado's initial start in 1958 to his resignation as chief executive officer of ASM International in 2008. The archive reflects Del Prado's position within the company, which resembled that of a spider in a web. Technical reports came in frequently, and numerous boxes contained drafts or negotiations surrounding stock options, public listings, merger and acquisition negotiations, legal disputes, and changes to the articles of association.

Remarkably, most of the archive contains information sent to Del Prado. Relatively few files contain his own writings, reports, or correspondence. His personal writings are in abundance only during his years as European Marketing Manager for Knapic Electro-Physics from 1958-1964. As president of ASM, Del Prado rarely committed his thoughts and decisions to paper. As such, the archive seldomly offers direct insight into his perspective, yet it helps to chronologize and detail events and streams of information. At the time of writing, the future of this personal archive is yet unknown. Presently it is in the possession of ASM International.

The second source comprises interviews I conducted with various individuals involved with ASM in the past or up to the present. For this study, I interviewed eighty-five individuals at various locations around the globe, including executives, engineers, and management assistants (cf. list of interviewees in the bibliography).

82 Dimov, 'Grappling with the Unbearable Elusiveness of Entrepreneurial Opportunities', p. 61

83 Mind the apt quote of Popp and Holt: 'Creative, inceptive, imaginative decision-making, the conjuring of entrepreneurial opportunity, is firmly located in time as an unending flow in a world where there is action and not merely the illusion of action: a world where history comes into being. The entrepreneurial decision-maker becomes an active rather than a passive figure.' - Popp and Holt, 'The presence of entrepreneurial opportunity', p.9 
The purpose of these interviews was twofold: to gain a better understanding of the technology sold or produced by ASM and to get a better grasp of the history of ASM and its activities beyond the written sources and through the perspectives of the interviewees. In context of the former, some individuals I interviewed multiple times. The interviews were important in particular for re-imagining decisions, emotions, and expectations beyond or in line with those expressed on paper in the archive.

In addition, this study concerns secondary sources, including academic publications, industry reports, and personal recollections. The majority of the academic literature focuses on chip manufacturers, while rarely covering equipment suppliers as well. At a technological level, the period after the early 1970s appears to be a blind spot. Historians David Brock and Christophe Lécuyer covered individually and together some major elements of innovations in the semiconductor industry. ${ }^{84}$ Another particularly relevant study is Franco Malerba's The Semiconductor Business, on the decline of European competitiveness in semiconductor manufacturing until the early 1980s. ${ }^{85}$ As such it is an indispensable resource on the European semiconductor industry's state of affairs from the early 1950s to the 1980s.

The wider context of development in Dutch business and technology is extensively covered by two distinct, multi-volume projects written in Dutch: 'Business in the Netherlands during the Twentieth Century' and 'Technology in the Netherlands in the Twentieth Century' ${ }^{86}$ Although these projects address

84 David Brock, Understanding Moore's Law: Four Decades of Innovation. (Philadelphia: Chemical Heritage Press, 2006); David Brock and David Laws, 'The Early History of Microcircuitry: An Overview', IEEE Annals of the History of Computing (2012) pp 7-19; David Brock, 'From automation to Silicon Valley: the automation movement of the 1950s, Arnold Beckman, and William Shockley', History and Technology 28:4 (2012) pp. 375-401; David Brock and Christophe Lécuyer, 'Digital Foundations'; Brock and Lécuyer, Makers of the Microchip; Christophe Lécuyer, Making Silicon Valley: Innovation and the Growth of High Tech, 1930-1970 (MIT Press, Cambridge, 2005); Christophe Lécuyer, 'Silicon for Industry: Component Design, Mass Production, and the Move to Commercial Markets at Fairchild Semiconductor, 19601967', History and Technology 16:2 (1999) pp. 179-216; Christophe Lécuyer and David C. Brock, "The Materiality of Microelectronics," History and Technology 22:3 (2006) pp. 301-325; Christophe Lécuyer and David C. Brock, "High Tech Manufacturing," History and Technology 25:3 (2009) pp. 165-171; Christophe Lécuyer and David C. Brock, "From Nuclear Physics to Semiconductor Manufacturing: The Making of Ion Implantation," History and Technology 25:3 (2009) pp. 193-217.

85 Malerba, The Semiconductor Business.

86 The project on 'Business in the Netherlands during the Twentieth Century' (Bedrijfsleven in Nederland in the Twintigste Eeuw) consists of seven volumes about the following topics: entrepreneurs, multinationals, competition, governmental policies, innovation, human capital, and corporate governance. The project is led by Joost Dankers, Keetie Sluyterman, and Jan Luiten van Zanden. The project 'Technology in the Netherlands in the Twentieth Century' 
various themes like innovation, entrepreneurship, corporate governance, and several technological domains, they do not specifically deal with ASM or the semiconductor equipment industry.

The industry reports I used for this study were published by industry data service companies like VLSI Research, Dataquest and Gartner. VLSI Research published some of its industry reports at its own chipshistory.org website. The Dataquest reports were made available by Gartner, after the latter acquired the former. The reports are accessible via the online archives of Computer History Museum. The reports involve monthly newsletters and data reports of chips and equipment manufacturers from 1979 until 1998.

Finally, I relied on personal recollections as found in articles on websites, in academic journals, and in biographical works. Three former ASM managers have published a book about their work for the company: Richard Fierkens, Patrick Lam, and Ray Friant. ${ }^{87}$ These books are more akin to management books, however, as the authors try to sum up the origins of success in business. In addition, a few business histories are available, such as one on Applied Materials and one on Kulicke \& Soffa. ${ }^{88}$ In both cases, their writing seems motivated by marketing interests of the company rather than by scholarly objectives.

\section{Outline of the book}

This book tells the story of ASM and its innovations in two types of chapters. The Innovation chapters explain and characterize various innovations and innovation processes at ASM, while the Business chapters discuss the organizational and entrepreneurial developments at ASM. Both storylines, of innovation and of business, are closely interwoven. Furthermore, the first segment of Business chapters is interrupted by an intermezzo, in order to detail an emerging standard outline of a chip and its fabrication process in the late 1960s. This intermezzo also contributes to my analysis by providing a clear and historically correct picture of the complex - and for many readers, unknown - manufacturing process of computer chips and its evolvement.

consists of six volumes, discussing 'public works, the office and information technology', 'minerals, energy and chemicals', 'agriculture and nutrition', 'household technologies and medical technology', 'transport and communication', and 'cities, construction, and industrial production'. The series was edited by Johan Schot, Harry Lintsen, and Arie Rip.

87 Richard Fierkens, Hightech in een boerendorp. De biografie van Fico-ondernemer Richard Fierkens (Herwen 2014); Patrick Lam and Edmund Lam, Soaring like Eagles: ASM's High-Tech Journey in Asia (John Wiley \& Sons, Singapore, 2006); Ray Friant, Beyond Buzzwords: The New Agenda for Directors, CEOs \& Executives (Advanced Management Press, Convent Station, 2006).

88 Eric Nee, Information for Everyone: The Applied Materials Story, 1967-2002 (Applied Materials, Santa Clara, 2003); Jeffrey Rodengen, 50 Years of Innovation: Kulicke \& Soffa, 1951-2001 (Write Stuff Enterprises, Fort Lauderdale, 2002). 
The Innovation chapters deal with a selection of ASM's innovations in semiconductor deposition technologies in order to explain and characterize innovation processes at ASM. After the establishment of ASM's general innovation processes in the first innovation chapter, the successive innovation chapters detail anomalies and their effect to this practice. Moreover, each chapter highlights a theme of innovation, like innovating in a start-up or governmental influence on innovation. In the Innovation chapters only wafer processing equipment and processes are studied, and to be even more precise, only chemical vapor deposition techniques. This fabrication process - in all its varieties - constituted the prime competence of ASM Front-end throughout the company's history.

The innovations covered by the Innovation chapters are told in chronological order. In each case the development of one technology is reconstructed, and the technologies at hand elaborate upon the one discussed in the preceding one. These respective accounts are followed by a reflection through the abovediscussed three elements path, fortuna and virtù. These three scoop nets, so to speak, pass in review, depending on the structure of the story. Together, the innovation chapters offer a unique peek into the heart of the company: there where it innovates semiconductor technology.

Innovation I focuses on the establishment of ASM's innovation pattern as the firm transformed from representative into equipment manufacturer. This is done by following ASM's innovations in chemical vapor deposition (CVD) technology, from 1971 until 1985. Through mapping the change in innovation methods and habits, the reader obtains insight into the dynamics and regime of innovation at a high-tech start-up venture.

Innovation II describes in detail how a new product - the Epsilon single wafer epitaxy reactor - was developed from the first sketches in 1982, until its introduction to the market in 1988. Through the example of the epitaxy reactor, developed by American and Dutch engineers in Tempe, Arizona, I will study social factors affecting the variation and selection process resulting in an innovative product.

Innovation III explores how ASM and the respective European and Dutch authorities collaborated in altering ASM's innovation strategy from 1979 until 1995. In this chapter, the analysis centers on the development of cluster technology at ASM through governmentally supported research projects. I will investigate the changing governmental means and ASM's needs.

Innovation IV discusses the protracted effort to innovate a major anticipated obstacle for the continuation of Moore's Law, from 1996 until 2007. It concerned the introduction of a so-called 'high-k gate dielectric'. Through intense cooperation with customers and research institutes, ASM engaged this challenge, while pioneering the innovative atomic layer deposition technique in semiconductor 
manufacturing. This chapter provides an analysis of the close involvement of envisaged customers throughout the development of the high-k technology.

The Business chapters study the organizational development of ASM as a whole. These chapters investigate where, why, and what happened during Arthur del Prado's presidency. Whereas the innovation chapters zoom in on separate segments of the company, these business chapters investigate the importance of all the other activities of ASM as a whole. As such, they substantiate the organizational context in which ASM's innovation processes occurred. They also explain the entrepreneurial and strategic maneuvers made by Del Prado to steer his company through the industry, adapting to its constantly changing environment.

Each set of Business chapters centers around a successive phase in the company's history. Moreover, as ASM as a multidivisional enterprise evolved, so did its organizational trials. At the start of each segment of Business chapters, these challenges are related to temporal insights from leading management scholars, like Peter Drucker in the 1960s, Michael Porter in the 1980s and Clayton Christensen in the $21^{\text {st }}$ century. The chapters themselves consistently start with a characterization of the industrial developments ('Industrial context'), a short indication of the affairs at hand within ASM ('Corporate course'), followed by a more in-depth discussion of events ('Elaboration of affairs'). I analyze these organizational perils, developments and strategic changes from the angle of the concepts of path, fortuna and virtù.

This set of chapters starts with Del Prado's entrance in the industry in 1958, the establishment of ASM in 1964, and its transformation into a multinational original equipment manufacturer until 1979 (Business I). Accordingly, this chapter describes the maturation of ASM's business strategy, tracing it back to Del Prado's early career as salesman.

Business II zooms in on the early 1980s, ASM's golden years. Through a series of cunning acquisitions of operations and technologies, the company expanded into new markets and engaged new technological opportunities in the period between 1979 and 1985 .

This was followed by a period in which the company struggled for survival, from 1985 until 1993, discussed in Business III. These chapters reveal that ASM's business strategies and operations, which had been a source of impressive growth earlier, were contested. As important innovations and new activities were leveraged with external funds, a deterioration of the market and subsequent anxious investors caused ASM to hit rock bottom.

After the turmoil of the late eighties and early nineties, ASM had to make drastic choices to reach calmer waters in the period between 1993 and 1999. Business IV describes these years as a time when ASM recovered financially and 
refocused its operations. Throughout these years, however, ASM's financial resources remained scarce and some of its internal weaknesses were still very much present.

Business V discusses the years 1999 until 2008, in which the company engaged technological expansions and implemented operational consolidations simultaneously. The account in these chapters show that Del Prado's entrepreneurial spirit was far from extinguished yet, even though temporal expectations with regard to corporate governance and shareholder value limited his ability to engage new opportunities. Eventually, these events culminated in Del Prado's resignation as CEO in 2008.

Together, the nine blocks of Innovation and Business chapters bring a detailed account of the history of ASM and the fortunes of high-tech. Still, the structure of the book allows readers to be selective. Some readers will be happy to read the introduction and conclusion of each block only. This will bring them an overview of the highlights and an indication of finer details of the story. Others might be solely interested in the organizational developments and stick to the Business chapters, which are attuned to each other. The same accounts for the Innovation chapters. Moreover, the distinction of industrial, organizational and in-depth analysis of the Business chapters helps the reader navigate this elaborate history.

The book ends with a discussion about what, in the end, shaped the innovations at ASM and how this allowed the company to navigate the stormy waters of the semiconductor industry. In this final chapter, I will return to the research question posed at the beginning of this introduction. Based on reflection on the findings from the innovation and business chapters, I will offer a general characterization of ASM's history. I will also draw lessons about the dynamics of innovation, about the direction of business strategies, and, in general, about the fate of high-tech firms in modern economies.

Given the prominence of ASM in the semiconductor industry, in particular in the Netherlands, some readers will be curious about what happened after 2008, when Del Prado resigned. In the Epilogue, therefore, I will concisely discuss the current state of affairs at ASM. This concerns the industrial developments, organizational developments and Arthur del Prado's entrepreneurial activities from 2008 until 2018, which I will address merely on the basis of publicly available sources.

In a personal afterword I will account for my adventure of studying these histories. I briefly recall what it meant to meet and interview engineers, business people, scholars, and secretaries, as well as what it was like to travel to Japan, Singapore, and Silicon Valley and to digest dozens of meters of archives. I will consider what guided me through questions and fascinations, through puzzles, 
Introduction

mysteries, and the magical sense of understanding and appreciation. Here I will reflect, as I should, on my own path, fortuna and virtù. 


\section{Business I \\ The founding years, 1958-1980}




\section{An introduction}

It all starts with sand. Or, to be more precise, the primary element composing sand: silicon. The extraction of silicon crystals from sand represents the first step in the manufacturing process of a computer chip. Coincidentally, this step also marks the starting-point of the career of Arthur Hendrik del Prado (1931-2016) in the semiconductor industry - and of the company he founded, ASM International. Just as Rome was not built in one day, the emergence and growth of ASM as a company would follow from an accumulation of specific events and experiences. The maturation of Arthur del Prado's personality and the development of his business principles have been defining factors for ASM. Therefore, telling the story of ASM starts with Del Prado's career, and thus with silicon, sand.

Business I addresses Arthur Del Prado's early career and the initial years of ASM. The unfolding of this story was primarily determined by his personality and some remarkable contingencies - or fortuna. Del Prado was a man who often found himself in the right place at the right time, and, more importantly, he knew how to respond well to his good luck. In the words of Machiavelli, he had virtù.

One of these contingencies involved the advent of the semiconductor equipment industry in the early 1970s, which coincided with the transformation of ASM into an equipment manufacturer. But Del Prado's arrival in the area now known as Silicon Valley in the pivotal year of 1957 was perhaps even more remarkable in this respect. At the time, the 26-year-old Dutchman was traveling in the United States, accompanied by his wife Hanni (Johanna Jonge Poerink, 1934-1986). After their arrival in California, the young Del Prado took a turn that would define the course of his life. By that time, he seemed keenly aware of his capabilities, among which an unbridled entrepreneurial instinct combined with charm and perseverance featured prominently. His character was defined by his childhood and wartime experiences in Indonesia, as well as by his subsequent education in the Netherlands and the United States.

Business I offers a detailed account of Del Prado's maturation as a businessman. Throughout this crucial episode of his career, Del Prado gained experience in dealing with uncertainties and trusting upon longerterm technological and industrial trends. The knowledge he gained about his capabilities, organization, and business environment determined how the entrepreneur would set up ASM and put it onto the pathway of becoming a multinational original equipment manufacturer in the late 1970s. Key ingredients 
were decentral organization, relative autonomy of business groups in the pursuit of opportunities, diversification in products, and his pivotal role in strategizing.

\section{Contemporary appreciation of a multi-divisional enterprise}

The insights that Del Prado obtained from his activities in the early years of his career were in line with leading views about management at the time. Throughout his career he continued to follow advances in management studies, as published in magazines like Businessweek, Harvard Business Review, and Electronics Weekly. ${ }^{1}$ The organizational structure of ASM International as a multi-divisional enterprise, as it emerged in the 1960s and 1970s, was not merely the result of Del Prado's imagination.

Several management concepts that predominated in the 1950s until the 1970s pertained to the pervasiveness of strategizing, decentralization, and diversification. ${ }^{2}$ Prominent management scholars Peter Drucker and Igor Ansoff proclaimed that successful managers will focus on long-term strategies instead of a firm's daily affairs. ${ }^{3}$ Drucker further argued, in the early 1970s, that decentralization would help to empower employees, because small business units make employees feel more relevant. He also argued in favor of management by result instead of management through oversight, something which was achieved by 'decision making that ... is action-oriented, and is carried out at the lowest possible level of management.'

Historians Keetie Sluyterman and Ben Wubs identified decentral management as one of a few common denominators in how Dutch companies managed their international activities from 1945 until 1980..$^{5}$ Such an organizational structure allowed overseas subsidiaries to adjust to local circumstances, as well

1 Arthur del Prado's personal archive contains numerous magazines, articles, newspaper clippings, and snippets. Most of these involve management insights or industry-related news. Electronics Weekly got published from 1960 onward, and found a particular predominant presence in Del Prado's archive as of the mid-1970s.

2 Already in 1956 did prominent business scholar Alfred Chandler distinguish decentralization as the most common organizational structure. - Alfred Chandler, 'Management Decentralization: An Historical Analysis', The Business History Review 30:2 (1956) pp. 111-174.

$3 \quad$ Keetie Sluyterman, Dutch Enterprise in the Twentieth Century: Business strategies in a small open economy (Routledge, Abingdon 2005), part of series: Geoffrey Jones and Mary Rose (ed.), Routledge International studies in Business History, p. 163; and Peter Drucker, 'The Effective Decision', Harvard Business Review 45:1 (1967); Igor Ansoff, Corporate Strategy: An Analytical Approach to Business Policy for Growth and Expansion (McGraw-Hill, 1965).

4 Peter Drucker, 'New Templates for Today's Organizations', Harvard Business Review 52:1 (1974) pp. 45-53.

5 Keetie Sluyterman and Ben Wubs, Over grenzen: Multinationals en de Nederlandse markteconomie (2009) Amsterdam, Boom, pp. 200 and 201. 
as facilitating internationalization rather quickly, due to the limited size of the Dutch national market.

Moreover, Ansoff argued in favor of diversification to harness new products and new markets. ${ }^{6}$ As explained by business historian Keetie Sluyterman, through diversification risks were hedged:

'Conglomerate companies had the task of managing their cash flows in such a way that the money made by cash cows was invested in new, promising products'?

In the 1960s and 1970s, big conglomerates were the norm, and from the start Del Prado seemed to follow the practice of leveraging products, diversification, and decentralization. ${ }^{8}$

\section{Outline Business I}

The story below will first zoom in on Del Prado's early life and his introduction to the semiconductor business, as a way to illustrate the formative influences on his character. The second chapter will describe his first steps in the semiconductor industry as trader in silicon, a period in which he developed his main business principles. The founding and early years of ASM, from 1964 until 1968, are discussed in the third chapter. In this phase, the company shifted its activities toward trading in semiconductor equipment.

Next, in an intermezzo interrupting the chapter, I present and explain the emergence of a standard product, a basic manufacturing process, and the main drivers for innovation in semiconductor manufacturing, as they coincidentally came about in the late 1960s. This description constitutes a template for the understanding of ASM's forthcoming activities as equipment manufacturer.

The fourth chapter addresses the company's transformation from a trade agency into a multinational original equipment manufacturer with subsidiaries in Hong Kong and Phoenix, Arizona. In the final section, I discuss the completion of ASM's transformation from sales agent into equipment vendor.

6 Igor Ansoff, 'Strategies for Diversification', Harvard Business Review 35:5 (1957) pp. 113-124; Sluyterman, Dutch Enterprise in the Twentieth Century, pp. 163-164.

7 Sluyterman, Dutch Enterprise in the Twentieth Century, p. 164.

8 Abe de Jong, Keetie Sluyterman, and Gerarda Westerhuis, 'Strategic and structural responses to international dynamics in the open Dutch economy, 1963-2003', Business History 53:1 (2011) pp. 63-84. 


\section{Chapter 1}

\section{Joining a revolutionary development, the 1950s}

In this first chapter, covering predominantly the 1950s, Arthur del Prado's encounter with a man named Dean Knapic was pivotal. It was Knapic who got Del Prado into the semiconductor business and allowed the young Dutchman to pursue opportunities rather autonomically. As such, Knapic sowed the seed of ASM.

Moreover, in retrospect it can be said that the two men met each other in the right place and at the right moment. Del Prado's 1957 encounter with Knapic took place at a decisive time in the history of the chip industry and Silicon Valley. This showed itself in two ways: through the advent of silicon as the predominantly used semiconductor material, and, second, through the falling apart of a company called Shockley Semiconductor Laboratory in 1957, which marked the start of a new era of startups and entrepreneurship in Silicon Valley. Together, both events were crucial for launching Del Prado's career in the semiconductor industry.

\section{Industrial context:}

\section{Carrying along the rising tide of silicon}

Large integrated electronics companies that earlier had produced electron or vacuum tubes provided the early semiconductor technology a dynamic beginning. ${ }^{9}$ The germinating semiconductor industry managed to capitalize on the existing infrastructure, applications, products, and manufacturing operations of these companies, because the new transistor technology initially elaborated or complemented electron or vacuum tube products. Each Western economy - the American, Japanese, and European ones - had its own oligopoly of firms active in electron tubes. These were companies like the American RCA, General Electric, Western Electric, or the Japanese Hitachi, Toshiba, and Mitsubishi Electric, and the European Siemens, Bosch, Philips, GEC, and Thomson-Houston. ${ }^{10}$ Through

9 Franco Malerba, The Semiconductor Business: The Economics of Rapid Growth and Decline (University of Wisconsin Press, Madison, 1985, p. 4; John Tilton, International Diffusion of Technology: The Case of Semiconductors (Brookings Institution, Washington 1971); Mila Davids and Geert Verbong, 'Absorptive Capacity in Solid-State Technology and International Knowledge Transfer: The Case of Philips', Comparative Technology Transfer and Society 5:1 (2007) pp. 1-31.

10 Franco Malerba, The Semiconductor Business, p. 4. 
these incumbent electronics manufacturers, national semiconductors industries initially had been growing at a fairly equal pace. ${ }^{11}$

Predominantly in the United States, merchant semiconductor manufacturers were established. ${ }^{12}$ These companies solely focused on the development and production of semiconductor products. Examples were Shockley Laboratories, Fairchild Semiconductors or Texas Instruments. Attracted by the governmental procurement, other integrated electronics producers turned toward the development and production of semiconductor devices, like IBM, Motorola, Honewyell, General Motors, and ITT. Based on their concentrated efforts aimed at the innovation of semiconductor technology, these merchant manufacturers would develop into the flag bearers of the silicon revolution. ${ }^{13}$

From the mid-1950s onward, this material, silicon, rose in prominence in the industry. The semiconductor industry was, and is, very much material-driven. ${ }^{14}$ The ability to manipulate semiconductor materials into a transistor defined the course of innovation in the industry. Up to that point, the semiconductor manufacturers produced discrete products - not yet chips - predominantly made from germanium. ${ }^{15}$ In contrast to those made of germanium, silicon proved to be more reliable in high-frequency transistors. Such discretes were initially used in radio and telecommunication and in the aerospace programs.

The rise of silicon as semiconductor material was propelled by the United States governmental procurement of silicon-based discretes. ${ }^{16}$ In October 1957, the Soviet Union heralded the 'Space Race' by launching the first artificial satellite

11 In 1952, AT\&T Bell Labs, the inventor of the transistor, licensed their technology to various American and foreign companies. This propelled the solid-state transistor technology worldwide. Naturally, the American market was much bigger than the market in warshattered Europe and Japan.

12 In Europe, merchant semiconductor manufacturers were established as well, like Semikron in Germany and Soral in France. But their size did not come close to their integrated counterparts. In particular Texas Instruments sold its first silicon transistors as wildfire to the United States Department of Defense. - Franco Malerba, The Semiconductor Business, pp. 5 and 85.

13 Caleb Pirtle III, Engineering the World: Stories from the first 75 Years of Texas Instruments (Southern Methodist University Press, Dallas, 2005).

14 Christophe Lécuyer and David C. Brock, "The Materiality of Microelectronics," History and Technology 22:3 (2006) pp. 301-325.

15 Philip Seidenberg, 'From Germanium to Silicon: A History of Change in the Technology of Semiconductors', in: Andrew Goldstein and William Aspray (ed.), Facets: New Perspectives on the History of Semiconductors (1997) pp. 35-74.

16 See also: Stuart W. Leslie, 'How the West Was Won: The Military and the Making of Silicon Valley', in: William Aspray (ed.), Technological Competitiveness: Contemporary and Historical Perspectives on Electrical, Electronics, and Computer Industries (1993) pp. 75-89. 
into space. The United States Department of Defense responded by establishing an expansive program to secure its stake in space. For its ambitious air and space programs, the Department of Defense's demand for silicon-based discretes increased exponentially. This strong demand caused more semiconductor manufacturers to use silicon as basis for their transistors instead of germanium. ${ }^{17}$ This is why the apparent advent of silicon was a mere deviation of the Cold War, and as such it was driven by the United States authorities.

\section{Corporate course:}

\section{Arriving during a critical phase in Silicon Valley}

The origins of Arthur del Prado's career - and thus ASM International's origins - reside in a burgeoning Silicon Valley. The events that occurred in Silicon Valley in 1957 have been extensively discussed and studied, and these involve some of the most illustrious entrepreneurs of the twentieth century. ${ }^{18}$ Most of the stories center around the co-inventor of the transistor, Dr. William Shockley (1910-1989), and the group of eight engineers that left Shockley's company to found their own semiconductor manufacturer called Fairchild Semiconductors in 1957. Later in their careers, these eight engineers - nicknamed by Shockley as the 'Traitorous Eight' - would be involved in the proliferation of high-tech startups in the Bay Area, such as Intel, Signetics, and National Semiconductor.

The role of the venturous migrant Dr. Dean Dinko Knapic (1921-1993) in the disintegration of Shockley's Laboratories, however, has been discussed much less so far. Shockley alienated Knapic in a similar way as the eight founders of Fairchild. Shockley was notoriously suspicious, unable to trust his engineers. It was not easy to work for this man, to put it mildly. Shockley's winning of the Nobel Prize for the invention of the transistor, in 1956, hardly seemed to temper his behavior. It was actually his management style that motivated his engineers to start their own enterprises in the fall of 1957.

17 Lécuyer and Brock, 'The Materiality of Microelectronics.' p. 311; Marc J. De Vries, 80 Years of Research at the Philips Natuurkundig Laboratorium, 1914-1994 (Pallas Publications, Amsterdam, 2005), p. 176, Davids and Verbong, 'Absorptive Capacity.

18 Joel N. Shurkin, Broken Genius: The Rise and Fall of William Shockley: Creator of the Electronic Age (Palgrave Macmillan 2006); Arnold Thrackray, David C. Brock, and Rachel Jones, Moore's Law: The life of Gordon Moore, Silicon Valley's Quiet Revolutionary (2015 Basic Books); Lesli Berlin, The Man Behind the Microchip: Robert Noyce and the Invention of Silicon (Oxford University Press, Oxford, 2006); Christophe Lecuyer, Making Silicon Valley: Innovation and the Growth of High Tech (MIT Press, Cambridge; 2006) part of series: Inside Technology; Michael S. Malone, The Intel Trinity: How Robert Noyce, Gordon Moore, and Andy Grove Built the World's Most Important Company (2014 Harper Collins); and for a personal reflection upon the invention of the transistor: William Shockley, "The Invention of the Transistor - "An Example of CreativeFailure Methodology", Proceedings of Conference on the Public Need and the Role of the Inventor, June 11-14, 1973, Monterey California, (May 1974) pp. 47-89. 
The relationship between Shockley and Knapic revolved around the crucial technology of creating pure silicon crystal rod through so-called silicon crystal puller technology. ${ }^{19}$ As argued by historians Christophe Lécuyer and David Brock, this technology was essential in the manufacturing of semiconductors during the years before and after the invention of transistors in $1947 .{ }^{20}$ It determined the proper functioning of a semiconductor device. Shockley had in fact been keenly aware of the strategic role of silicon and its manufacturing process. Intimate knowledge of the process was very valuable.

With his company, Shockley diverted from the conventional approach to produce semiconductor devices. Apart from developing innovative product designs, Shockley was convinced of the need to develop his own silicon crystal puller technology. ${ }^{21}$ To this end, he had hired three former Western Electric employees: Dean Knapic, Julius Blank, and Eugene Kleiner (the latter two cofounded Fairchild). ${ }^{22}$ Although they had no experience with semiconductors, Shockley hired them for their experience in high-volume manufacturing. ${ }^{23}$ Being Shockley's third employee, the Yugoslavian-born engineer Knapic became responsible for production, and later also for administration. ${ }^{24}$ At a location separate from Shockley Semiconductor Laboratory's product development, Knapic co-developed the silicon crystal puller technology. ${ }^{25}$

In early 1957, the relationship between Knapic and Shockley deteriorated after the former was called a 'pathological liar' by Shockley, who believed that Knapic had falsified his résumé. ${ }^{26}$ To keep up appearances, Knapic sometimes brushed up his accomplishments. One example was his claim to have sailed as a navy officer

19 For some clarity, in the documentation of Arthur del Prado and Knapic Electro-Physics, reference is made to silicon crystal 'shafts'. A more common deonomination is 'ingot' or 'rod'. Immediately after pulling the crystal, it is called an ingot. Successviely, the ingots are polished in cylindrical shape and named 'rod'. Since, Knapic Electrop-Physics sold the rods and not the ingots, I refer to rods.

20 Lécuyer and C. Brock, 'The Materiality of Microelectronics'.

21 Thrackray, Brock, and Jones, Moore’s Law, p. 147; David Holbrook, 'Diversity, Complementarity and Cooperation: Materials Innovation in The Semiconductor Industry', in: Andrew Goldstein and William Aspray (ed.), Facets: New Perspectives on the History of Semiconductors (1997), pp. 75-131, p. 90.

22 R Victor Jones, 'Interview by David Brock via Telephone' Chemical Heritage Foundation Oral History Transcript \#0336 (18-4-2006).

23 Western Electric was the engineering and manufacturing subsidiary of AT\&T. Bell Labs - the former employer of Shockley - served both Western Electric as AT\&T as research department.

24 Jones, 'Interview by David Brock via Telephone'.

25 Berlin, The man behind the microchip, p. 65 and Jones, 'Interview by David Brock via Telephone'; Bo Lojek, History of Semiconductor Engineering (Springer 2007), p. 75.

26 Berlin, The Man Behind the Microchip, p58; Lojek, History of Semiconductor Engineering, pp. 74, and 92; Shurkin, Broken Genius, p.174. 
during the war, which was regarded to be very respectable in postwar American society. ${ }^{27}$ However, during the Second World War, Knapic sailed as an engineer in the merchant marine, which served the navy in those times. ${ }^{28}$ Although this claim was not far from the truth, it showed his willingness to stretch things a bit to pursue his ambitions. At Shockley's request Knapic was investigated by a psychological testing company, but this did not lead to substantial proof of these suspicions. In their biography of Gordon Moore, historian David Brock et al. quote the conclusion of the investigation. According to the report:

'[Knapic was] a very typical European refugee, surrounding himself with a cloak of magical thinking which tends to give an air of unreality. ${ }^{29}$

Needless to say, the relation between Knapic and Shockley never recovered.

Following the example of the other eight, Dean Knapic left Shockley Semiconductor Laboratory to start his own venture in December 1957. ${ }^{30}$ With his new operation, he intended to capitalize on his newly acquired knowledge of silicon crystal pulling. He succeeded in attracting an investor by the name of Norsworthy Industry, originally from Texas. External funds were indispensable to start the manufacturing of the silicon crystals. The company, named Knapic Electro-Physics, was established in Palo Alto, California.

Through his intimate experience with silicon and relying upon Shockley's insight, Knapic knew that the market would turn toward silicon sooner or later. Shockley had convinced Knapic- and the founders of Fairchild - that silicon was the most beneficial material for creating transistors, if it could be manufactured

27 Born as Dinko Cosmo Knapic, he changed his name to Dean Dinko Knapic. His father was called Dinko Knapic. - Ancestry.com. According to author Lojek, Knapic falsified his résumé by stating that he had served in the Navy and had a PhD. After his departure from Shockley Semiconductor Laboratories, Shockley found out that Knapic had been a fraud. -Berlin, The Man Behind the Microchip, p. 58; Lojek, History of Semiconductor Engineering, pp. 74 and 92.

28 Knapic sailed on board of the Donald W. Bain, Mont Everest, Baalbek, and Dunav, during which he crossed the Atlantic from South Africa, to Hull (UK) and New York. Multiple registers derived from Ancestry.com: Year: 1944; Arrival: New York, New York; Microfilm Serial: T715, 1897-1957; Microfilm Roll: Roll 6846; Line: 15; p. 55. And Year: 1941; Arrival: New York, New York; Microfilm Serial: T715, 1897-1957; Microfilm Roll: Roll 6600; Line: 38; p. 118. Derived from: Ancestry.com, New York, Passenger Lists, 1820-1957 [database on-line]..

29 Thrackray, Brock, and Jones, Moore's Law, p. 153.

30 He did so with some of the shareholders: Gerthard R. Fisher, S. Marshall Kempner, and Benjamin Swing. In March he had started to propagate the sale of in-house produced silicon - Lécuyer and Brock, 'The Materiality of Microelectronics.', p. 313; Lojek, History of Semiconductor Engineering, pp. 89 and 91. 
in the highest quality. ${ }^{31}$ Subsequently, Knapic Electro-Physics, Knapic and a newly assembled team of engineers optimized the creation of monocrystalline silicon.

Knapic Electro-Physics' single crystal was grown by melting polysilicon crystals and pulling monocrystalline rods by means of the Czochralski process out of this molten silicon. This process had been around since 1916, but was applied in semiconductor manufacturing for the first time around 1948 at Bell Labs. ${ }^{32}$ The Czochralski process reminds one somewhat of the way cotton candy is made: spinning a seed in a tank of molten polysilicon. In this process, it was key to reduce dislocations and contaminations, and to control the dopants in the crystal. Adding certain dopants defined to what extent the semiconductor material would conduct or insulate. The Czochralski process also allowed the manufacturer to orient the crystal direction in the rod, which influenced the applicability of the silicon. The crystal rods were cut into wafers and used as basis for transistors.

In the early semiconductor industry, Knapic Electro-Physics stood out by offering monocrystalline silicon. ${ }^{33}$ It was something new, as most of the semiconductor manufacturing operations created their semiconductor crystals - foremost germanium - in-house. Being the first merchant manufacturer of silicon crystal rods, Knapic Electro-Physics tried to convince semiconductor manufacturers of the benefits of the material. His arguments were supported by the growing governmental procurement for the Cold War and the Space Race. ${ }^{34}$ Indeed, the favorable tide for silicon ensured a healthy start for Knapic ElectroPhysics. By buying from Knapic, semiconductor manufacturers could access stateof-the-art silicon, without having to invest in a new operation and familiarize the manufacturing process of the crystals. This pioneering merchant semiconductor material manufacturer Knapic Electro-Physics prepared the ground for ASM International.

The way the 27-year-old Arthur del Prado stumbled upon Dean Knapic, after the latter had just founded his company, remains hidden in a veil of mystery. The two men, however, got along well immediately. One can only guess about their mutual appeal. Maybe it was the fact that both men were not easily daunted, or maybe it was their shared interest in nautical matters. After his sailing career during the war, Knapic officially became an American citizen at age 25, got married, and

31 Thackray, Brock, and Jones, Moore's Law (Introduction).

32 The difference between polycrystalline and monocrystalline silicon is easy to see. The former has clearly visible grain boundaries, while the latter is homogeneous and forms an unbroken crystal structure. -Holbrook, 'Diversity, Complementarity, and Cooperation', p. 89.

33 Worden and Risberg, 'Evaluation Silicon Monocrystal Market: Knapic Electro-Physics, Inc' (1959) Archive Arthur del Prado - Knapic Electro-Physics Archive, p. 1.

34 Lécuyer and Brock, 'The Materiality of Microelectronics.', pp. 310 and 311. 
started a career as an engineer ashore. He embodied the American Dream: a selfmade man from abroad who made it in the United States. Meeting Del Prado, it might very well be that Knapic recognized something of himself in this fearless, recently married young Dutchman. Perhaps this spark of recognition convinced him to take the tall, slightly tinted bright and energetic man under his wing.

\section{Elaboration of affairs Prelude to a sensational career}

To understand the character and the entrepreneurial style of Arthur del Prado - which eventually resulted in the establishment of ASM International - his early life is telling. His youth spanned continents and a period of great historical significance, from the Dutch East Indies, the Japanese occupation, and the postwar years of recovery in the Netherlands to the late 1950s' nascent Bay Area in California. Moreover, he was exposed to a vivid spectrum of human conditions, ranging from innocent youthful adventures and atrocious detainment to unfettered love and hopes of a new future. As such, Del Prado wnet through major formative experiences at a young age already, and these would define his character for the rest of his life.

In 1931, Arthur del Prado was born as a son of Arthur Eugène del Prado (19011986) and Hedwig ('Hetty') del Prado-van den Berg (1906-2002) in Batavia, now known as Jakarta. ${ }^{35}$ His father, a far descendant of Portuguese Jews finding refuge in Suriname, sailed as captain - one of the few colored - on the ships of the Royal Packet Navigation Company (Koninklijke Pakketvaart Maatschappij), which served to interconnect the many islands of the Dutch East Indies' archipelago. ${ }^{36}$ Years later, Del Prado junior characterized himself as a katjong, a Dutch Indies nickname for a scamp. ${ }^{37}$ At home or when he joined his father on his travels, young Arthur would explore his surroundings in an inquiring and undaunted manner, experiencing the world as one big playground.

This playful period came to a early end in March 1942, when Japanese troops defeated the Dutch army in the Dutch East Indies, marking the beginning of the

35 Arthur del Prado was named after his own father, Arthur Eugene del Prado, and the father of his mother, Hendrik van den Berg [family message], 'Obituary Arthur Eugene del Prado' NRC Handelsblad (23-12-1986) p. 16.

36 In the 17th Century, Portuguese Jews found refuge in Suriname, after the Dutch were chased away from Brazil. In Suriname, the Jews were tolerated by the English authorities and, later on, by the Dutch as well. Over the years, their descendants mingled with members from other groups. Arthur del Prado's family on his father's side - including his father - had a dark skin color. Arthur del Prado's parents married by proxy on November 24, 1927, his father being in the Dutch Indies and his mother in Watergraafsmeer, Amsterdam. - Noord-Hollands Archief, Amsterdam Huwelijksbijlagen 1927, Watergraafsmeer Reg.W2 fol 22v (24-11-1927).

37 Arthur del Prado, Conversation with author (23-9-2014). 
Japanese occupation of the archipelago. One month later, on the island of Java, the Japanese authorities decided to confine all Dutch citizens present. Being just a small boy, Arthur was detained together with his mother and his older sister in Camp Tjideng in Batavia. ${ }^{38}$ While life in this camp was tough, to say the least, the worst was still to come for young Del Prado.

In July 1944, all boys over age 10 were separated from their mothers. ${ }^{39}$ While most of his peers were sent to a boys' camp, Arthur ended up in a mixed camp for prisoners of war and internments, Camp Tjimahi 4. At the age of 12, he was separated from his father, mother, and sister, and he had to save his own skin under the degrading circumstances of those camps. ${ }^{40}$ Even then, apparently, he continued to be a katjong. Decades later, Del Prado recalled that he used a slingshot to hunt chickens and harass Japanese guards occasionally. ${ }^{41}$ That he returned from internment physically unharmed is perhaps an early indication of his ability to maneuver between compliance with authority and pushing boundaries for his own benefit.

The capitulation of Japan in the summer of 1945 did not automatically make life easier for the young Del Prado. The Japanese capitulation gave rise to a power vacuum in the Dutch East Indies. While at first the Dutch authorities failed to regain control of their colony, the Indonesian people declared their country's independence. Crowds rioted the streets. As a consequence, the Europeans had to stay inside the camps for their own safety, a challenging situation for a young and adventurous boy like Arthur.

38 In April 1944, Arthur was still interned, together with his mother and sister in Camp Tjideng in Batavia. The camp's register lists the ages of those interned there. H. Del Prado (Arthur's mother) listed their ages as 37, 14, and 11. At his original internment in 1942, Del Prado was 11. In the camp, Del Prado's mother was responsible for the soup kitchen, which allowed them some relief. - Author unknown, 'Tjideng Register: Register of Families in Tjideng in April 1944'; Arthur del Prado, 'Conversation with author (23-9-2014).

39 Author unknown, 'Soorten kampen', indischekamparchieven.nl (19-5-2010).

40 In conversation with the author, his partner mentioned camp Ambarawa as the camp where Del Prado was detained by himself, but nothing can be found about this in the registers. The register of Camp Tjimahi 4 lists A.H. del Prado (b. 17-11-1931), together with Edgar Del Prado (b. 9-4-1928), Arthur's cousin. Del Prado's detention number was 41649. Through people close to Arthur de Prado, the author learned that Del Prado managed to survive the camps partially by running a bike shop of some kind. - Author unknown, 'Tjimahi kampen West-Java: Naamlijst (Augustus 1945)', japanseburgerkampen.nl (26-11-1945. For a story about these camps and the journey from Tjideng to Tjimahi, see: Gerard Samson, 'Pinda's en Poepchinezen' and 'Verwonderd over een wrede wereld' (4-12-2011). For a book on Camp Tjimahi,, based on diaries, see M. Heijmans (ed.), Kamp Tjimahi 4 - De Japanse bezetting in dagboeken (Bakker 2002); Ray Friant, 'Interview with author'.

41 Arthur del Prado, conversation with author. 
In this tumultuous period, Arthur traveled on top of a train to his parents, who had already been reunited in the Tjideng camp. ${ }^{42}$ To ensure his safety, his father decided to send him to the Netherlands (by signing him up as a ship boy on S.S. Oranje), where later on the family - father, mother, and sister - was to be reunited with him. ${ }^{43}$ During the long journey, many passengers passed away, weakened by their experiences in the camps. ${ }^{44}$ Working as a ship boy, one of Arthur's tasks was to help the crew with the burial at sea of those unfortunates. At the ship's arrival in wintry Amsterdam, Arthur managed to catch a ride to his grandmother, whom he saw for the first time. ${ }^{45}$ Born and raised in the tropics, his sudden exposure to the Dutch winter will have contributed to his contracting pneumonia right away (whereby his ride in Amsterdam in an open car may have been a factor as well).

Upon his arrival in the Dutch capital in January 1946, Arthur del Prado was just fourteen years old. The divergent and partly trying circumstances of his young life - ranging from the tropical pleasures of his early childhood to the miseries of war - stimulated him to seize every opportunity with both hands and to get the most out of his remaining life. As a young, slightly colored boy of Jewish descent and a son of a dark-skinned captain (still quite unusual in the

42 Del Prado's mother is mentioned as H. Del Prado van der Berg, her number being 3690. She was in charge of the soup kitchen, according to Arthur del Prado. Author Unknown, 'Tjideng West-Java Naamlijst (augustus 1945)', japanseburgerkampen.nl (5-2-2016). For more literature about this camp, see: Jeroen Kemperman (ed.), Tjideng: De Japanse bezetting in dagboeken (Bakker 2002) and Elise Lengkeek, De hel van Tjideng (Mitral 2010).

43 The Oranje was one of the first ships repatriating Dutch people from the Dutch East Indies to the Netherlands in the fall of 1945. The ship's first journey started December 15, 1945 from Semarang to Southampton, where it arrived January 5, 1946. This journey was still under the command of the Royal Australian Navy, yet with a Dutch crew. The Oranje was still painted in white with a red cross, indicating its function as a hospital ship in the war. Due to the presence of sea mines in the North Sea, the passengers were transferred from the Oranje to the HMS Almanzora and HMS Atlantis for their final journey from Southampton to Amsterdam. Also on this short journey, a few passengers passed away because of the cold and a measles epidemic. The 14-year-old Arthur del Prado was on board of the first journey of the Oranje (0100) and registred with number OR0106. The woman who would be his partner from 1993 onward, Joan de Vos-Steenwijk, was also on board of this vessel, together with her family (ref: OR121). - Indische Genealogische Vereniging, 'De schepen van de Stoomvaart Maatschappij Nederland, Oranje’, Passagierslijsten repatriering (1946-1968) (June 2014).

44 From the 1245 persons on board of the Oranje, 1187 made it through. For a description of the circumstances on board of these repatriation ships, see Tijmen Koh, 'Terug naar waar je niet vandaan kwam - Repatriering met MS Oranje', Historiek.net (datum onbekend); Or the following documentary (in Dutch): Hannah Dogger and Merlijn Schneiders, 'Mazelen op de Nieuw Amsterdam', anderetijden.nl (29-9-2013).

45 His grandmother was called Kätchen Wetzler, born January 13, 1885 in Kronach, Germany. She was of Jewish descent. Little is known about her experiences in the war. 
Netherlands), just returned from the Dutch East Indies, Del Prado had to prove himself in his new home.

After being reunited with his parents and sister, the Del Prado family moved to Naarden, a small town to the southeast of Amsterdam. ${ }^{46}$ During his bachelor studies in chemistry at the Hogere Textiel School in Enschede (near the German border), Arthur became a fanatic player of field hockey and mingled among members of the locally renowned and rather sizable Scholten family, who owned a major textiles factory. ${ }^{47}$ During this period and in his tenancy as chairman of a local student society - guaranteeing him esteem among his peers - Arthur made eyes to the town's prettiest girl named Hanni Jonge Poerink. Whether it was Arthur who charmed Hanni or the other way around remains unsure. What is known, though, is that love prevailed. Hanni would become Arthur's wife, the mother of his children, and an indispensable support, after his successful career in business began to unfold.

When Del Prado was living in Enschede, however, his future was still up in the air. After his graduation, many of his friends started their career in the local textile industry, but he decided to move away. Initially, he studied economics in Amsterdam for a while. ${ }^{48}$ After this failed to motivate him, he decided to engage in a new challenge across the Atlantic.

\section{A critical phase in the history of Silicon Valley}

While Europe was still recovering from the Second World War, the United States were setting the pace in economic and technological development. It seemed to be the place to be! Like many other Dutch citizens emigrating to the United States, Canada, Australia, and New Zealand since the late 1940s, Del Prado sought his fortunes in the New World.

The bright young man intended to join the prestigious Harvard Business School. ${ }^{49}$ While he tried to get admitted, Hanni joined him in April 1956. On the

46 The other members of Arthur's family were repatriated in the summer of 1946. Their ship, S.S. Johan de Witt, departed May 23 from Singapore and arrived in Amsterdam on June 19.

47 One of his best friends was the junior member of this family, Harm Scholten. J.F. Scholten \& Zonen was one of the biggest textile factories in Twente, a region where most of the Dutch textile industry was concentrated. The Scholten family was rather successful and famous. A couple of family businesses in textile joined forces to establish the Koninklijke Nederlandse Textiel Unie (Royal Dutch Textile Union) in 1962. In 1973 the firm was closed during a period of sustained decline. A biography of this family is written by the son of Harm Scholten: Jaap Scholten, Horizon City (2014 Samenwerkende Uitgevers VOF).

48 Whether this was only to get a membership of the Amsterdam rowing club for male students remains unknown.

49 Harvard Business School, 'Yearbook 1957’ (1957), pp. 157. Derived from: Ancestry.com, U.S. School Yearbooks, 1880-2012 [database on-line]. 
last day of that same year, the couple got married in Morris Plains, New Jersey. ${ }^{50}$ Del Prado succeeded to enter the university, but he did not earn a degree. 'It was too scholastic' for his taste, as he recalled years later. ${ }^{51}$ Joined by his beloved Hanni, he was eager to make his fortune in the United States, and if Harvard did not prove to be his way to move ahead, there would be another way.

After arriving in Northern California, on the other side of the American continent, Del Prado was soon struck by the hustle and bustle of the various startups active there in the late 1950s. This triggered his entrepreneurial spirit. Although the startup scene would mature in Silicon Valley only gradually, over the following decades, the innovative, optimistic, and enthusiastic mentality could be felt already. On his way to San Francisco, while hanging out in the Bay Area, Del Prado crossed paths with an individual named Dr. Dean Knapic in the fall of 1957. This encounter was surely an unexpected but defining moment in the life of Del Prado and, subsequently, in the history of ASM.

\section{The rising tide of silicon in the industry}

His association with Dean Knapic resulted in Del Prado's dispatch to the Netherlands. In the capacity of 'European Marketing Manager' for Knapic Electro-Physics, it was up to him to explore the Dutch and Western European market for monocrystalline silicon. ${ }^{52}$ In the spring of 1958, Del Prado wrote to a family member:

'I will try to do some business in a selection of Western European countries. The product is a quite new invention, and the company is the only one in the USA capable of producing it in an efficient and qualitative way. ... If the European market is open for this product and if we succeed in selling a reasonable volume, I will be responsible for the international representations. ${ }^{53}$

50 Year: 1956; Arrival: New York, New York; Microfilm Serial: T715, 1897-1957; Microfilm Roll: Roll 8713; Line: 19; p. 53. Derived from: Ancestry.com, New York, Passenger Lists, 18201957 [database on-line]; CBG Centrum voor Familiegeschiedenis, 'Familieadvertenties Jonge Poerink [periode tot 1970]', Gescande Familieadvertenties tot 1970, p. 3.

51 Arthur del Prado, 'Conversation with author' (23-9-2014).

52 Arthur del Prado, 'Memo from Art del Prado: Material Inventory In Europe' (November 1960) Arthur del Prado Archive - Topsoe file; Arondisements-Rechtbank Utrecht, 'Conceptversie Memorie van Antwoord inzake Arthur Hendrik del Prado contra Haldor Topsøe' (25-3-1970) Arthur del Prado Archive - Topsøe file.

53 Original quote in Del Prado's imperfect Dutch. - Arthur del Prado, 'Letter to Herman Jonge Poerink' (undated, probably Spring 1958) Archive Arthur del Prado - Knapic ElectroPhysics. 
While his stay in the United States was nearing its end, Del Prado was eager to bring his belief and confidence in this new innovative environment to the Netherlands. He realized his lack of proper education in semiconductor technology. As he humbly wrote in the same letter about his - in retrospect rather remarkable - apprehension of his chances in the industry:

\begin{abstract}
'Although, I am not very sure whether I will continue in this electronic industry, it is certain that these semiconductor developments are about to replace the vacuum tubes in many ways. This makes the industry a very promising one to work in. The know-how required cannot be mastered very easily, which is a disadvantage obviously, if you did not study the technology. ${ }^{54}$
\end{abstract}

On June 28, 1958, Del Prado returned to the Netherlands. Silicon crystals or the substrates used in production were still very small and easy to bring along on an airplane. As he recalled: 'I returned to the Netherlands with silicon in one hand, and 500 dollars in the other.' 55 With the presence of companies like Philips, there had to be some interest in these technological developments in his home country. After the contingency of stumbling into Dean Knapic and his promising silicon business, Del Prado joined a burgeoning but auspicious industry. It was the start of an illustrious career in semiconductor technology.

54 Original quote in Del Prado's imperfect Dutch: 'Alhoewel ik nog geenszins weet of ik in deze electron industry zal blijven voorlopig, het is wel zo dat deze semiconductor ontwikkelingen op de drempel staat de vacuum-tubes in vele velden te vervangen. Op zichzelf maakt dit deze industrie dus een veel belovende om in te werken. Alhoewel de know-how die er bij te pas komt nu niet bepaald overnacht geleerd kan worden en dat is natuurlijk een nadeel als je er niet in gestudeerd heb.' - Arthur del Prado, 'Letter to Herman Jonge Poerink' (undated, probably Spring 1958) Archive Arthur del Prado - Knapic Electro-Physics.

55 Friso Endt, 'Silicon Valley in de Jan Steenstraat', NRC Handelsblad (3-10-1981) p. 13. 


\section{Chapter 2}

\section{A man of business, 1958-1964}

Del Prado's initial career at Knapic Electro-Physics determined his forthcoming leadership at ASM. Far away from the Palo Alto headquarters of Knapic ElectroPhysics, he enjoyed great autonomy in his pursuit of opportunities in the European market. Through his modus operandi and activities, he matured his business principles. These basics would determine his management at ASM.

This chapter tells how Del Prado became a man of business by exemplifying critical events and developments that resonated in ASM. This includes his explorations of the Western European market, which made him aware of the world beyond 'Big Philips' - the dominating electronics giant of his home country, the Netherlands. His growing confidence in his abilities paved the way for an important ambition: starting a local manufacturing operation on behalf of Knapic Electro-Physics. At the start of 1960s, Del Prado got himself well established as trader in silicon and personally. After a few years, however, changes in the market posed new challenges, which eventually resulted in his decision to establish ASM. The chapter concludes with an assessment of Del Prado as a man of business.

\section{Industrial context:}

\section{A diverging appreciation of silicon}

In the late 1950s, the European semiconductor industry largely consisted of many smaller operations. Yet this industry also showed substantial growth. ${ }^{56}$ Each European economy had its own ecosystem of electronics and semiconductor companies. Philips Gloeilampenfabriek - the Dutch multinational and vertically integrated manufacturer of electronics (light bulbs, vacuum tubes, radio and so on) - was a major party in the European semiconductor industry, having factories in the Netherlands, Germany, France, the United Kingdom, and Switserland. Apart from Philips, few European semiconductor manufacturers succeeded in selling their products beyond their national market.

In the late 1950s, semiconductor manufacturers in Western Europe were closely watching the rapid technological developments in the United States. They were fully aware of the increasing applicability of silicon. Across the ocean, the American merchant manufacturers actively pursued the development not only

56 Japan accounted for a production of 78 million dollars, the UK for 35, France for 32 and West Germany 30 million dollars - Malerba, The Semiconductor Business, p. 101. 
of transistors made of silicon, but also rectifiers, diodes, infrared applications, and solar cells. ${ }^{57}$ The new material accelerated the replacement of the vacuum tube and comparable technologies, such as the ceramic tube and the cold cathode tube. At the Philips Research Laboratory in Eindhoven (popularly called 'Natlab'), several preliminary initiatives into the development of a silicon transistor had been started. ${ }^{58}$ But such initiatives did not yet imply that silicon was going to be utilized in high-volume manufacturing very shortly.

The rise of silicon caused a divergence in the budding worldwide semiconductor industry between the United States and the rest of the world. ${ }^{59}$ The Western European and Japanese semiconductor industries were clearly lagging behind technologically. This followed from the dominance of the unwieldy incumbent former vacuum tube companies, with their huge organizations and expansive commitments, as well as from the fact that governments in Western Europe and Japan did not participate in the Space Race. It was a matter of time, however, before these semiconductor manufacturers would follow their American competitors in using silicon.

As a consequence, the European and Japanese markets constituted a major opportunity for specialized manufacturers of silicon like Knapic Electro-Physics. The Californian startup provided better quality than most of the vertically integrated semiconductor manufacturers could realize by producing it themselves. The materials supplied by Knapic were ideal for researching the applicability of silicon. In particular the smaller manufacturers needed substantial amounts of externally supplied silicon, as they lacked production capabilities.

\section{Corporate course: Starting from scratch}

The international silicon business of Knapic Electro-Physics hedged upon this initial divergence in the worldwide semiconductor industry. The responsibility to capitalize on the tardy silicon developments in Europe fell upon the young Arthur del Prado.

The European Knapic Electro-Physics activities were initially very much a oneman show. From a small office near his apartment in Naarden, Del Prado traveled all over the Western European continent to cultivate his business relations and obtain orders. He felt comfortable moving around in foreign countries and he had a natural talent for sales. Del Prado enjoyed a small salary, having to obtain

57 Worden and Risberg, 'Evaluation Silicon Monocrystal Market: Knapic Electro-Physics, Inc' (1959) Archive Arthur del Prado - Knapic Electro-Physics Archive, p. 6.

58 De Vries, 80 Years of Research at the Philips Natuurkundig Laboratorium, p. 176.

59 Malerba, The Semiconductor Business. 
most of his earnings from his sales. ${ }^{60} \mathrm{He}$ and his wife did not have a nickel to spare, and sometimes he had to request an advanced payment on his earnings from Knapic to continue his business travels. Del Prado traveled across Western Europe most economically, while keeping up appearances. He had to earn every dollar of his income. To ensure the right proceedings of his business, he tried to keep full control.

Del Prado acted quite independently in handling his operations, which was remarkable given his young age and lack of experience. The Palo Alto headquarters was far away, and communications were slow at the time. Calling was too expensive. A steady stream of reports, quotations, and letters through the mail from Naarden to Palo Alto constituted the main channel of communication, also to justify his various activities to his supervisor. Such independent attitude was crucial, however, as control was hard to maintain for a small startup company. One of the consequences was that Del Prado determined his own schedule, and that he could offer discounts to disappointed customers on his own merits ${ }^{61} \mathrm{He}$ never gave his customers no for an answer, in order to keep all the options viable.

Del Prado developed a tactful sales procedure indeed. After securing an appointment, he overwhelmed his recipients with the benefits and characteristics of Knapic Electro-Physics' silicon crystals. To substantiate his claims about the quality of the silicon shafts, he would suggest them to order a sample. At this stage, he had to sustain the customer's interest, while ensuring adequate service from the head office. By being open to customer requests and jumping to their complaints and demands, Del Prado was capable of quickly cultivating good relations with most of his customers. If the samples complied with the customer's needs, he tried to sell as much volume as possible. At this stage, he merely forwarded follow-up orders and made sure he obtained his share of the sale. Periodically, he would visit his customers to make sure that everything was still in order and to inquire after new demands they might have. ${ }^{62}$

\section{Elaboration of affairs}

Del Prado easily sold his first silicon in the rapacious European market after his return to the Netherlands in June 1958. His assignment was to search the

60 Archive Arthur del Prado - Knapic files.

61 Knapic Electro-Physics, Arthur del Prado, 'Letter to George M. Macleod, Vice President of Sales' (9-6-1960) Archive Arthur del Prado - Knapic 1960+1961, div. 1958-1960.

62 Even if a customer had its own silicon operation, a shortage might occur during an unexpected rise of demand. In such case, Del Prado would be the candidate to supply new materials. This happened at an operation of Texas Instruments in Belford, the United Kingdom, for example - KEP, Vernon Rowlands, 'Customer Report CR/7: Texas Instruments Ltd., Bedford' (1-7-1960) Archive Arthur del Prado - Knapic Electro-Physics: Knapic Customer Reports 1960-1962. 
European market for customers, while he also needed to gain knowledge of Europe's silicon developments. Initially he worked from his parents' home in Naarden.

The first potential customer he approached was the Dutch giant in electronics, Philips Gloeilampenfabrieken NV.6 ${ }^{63}$ Del Prado managed to get an appointment with the general manager of the company's semiconductor production department, as well as the silicon engineer. He showed them the state-of-theart silicon crystals developed in the United States. He repeated this at Philips Transistor Fabrieken in Nijmegen. In both cases did Del Prado receive a cordial welcome. Yet during both meetings, Philips' integrated manufacturing strategy was expounded, which did not allow external procurement of silicon materials, beyond some of his samples for further comparative research.

While the visits to Philips marked the start of Del Prado's career as salesman for Knapic Electro-Physics, they also forced him to look beyond 'Big Philips' in pursuit of sales. Del Prado had to become familiar with the various European economies if he was to sell more of his silicon crystals. In the first month after his return, he visited potential customers in the United Kingdom and Germany. ${ }^{64}$

\section{Ensuring a pivotal position}

Although Knapic appointed Del Prado as his European Marketing Manager, the Dutchman certainly had to earn this title. This was true in particular for one of the biggest potential markets in Europe: West Germany. In this market, Del Prado had to cooperate with a local agent, called Frank \& Schulte M.B.H. This company had been in operation for some years, and was more experienced in the business - if not specifically for silicon crystals, but for related products. Initially their cooperation with Del Prado could be characterized as patronizing. They would take care of the young entrepreneur.

However, Frank \& Schulte seemed to have underestimated the perseverance and Machiavellian tactics employed by Del Prado to secure his own position in the European market, thereby helped by his natural charm and ostensible fairness. Del Prado's first step was to ensure that Frank \& Schulte would report to him. In a letter to Dean Knapic, Del Prado explains his proposition strategically:

'To prevent a mix-up in price quotations for sample orders, in this particular case of Frank \& Schulte and Bowring and Co, I suggest that

63 KEP, Arthur del Prado, 'Report N.V. Philips Transistor Fabrieken' (July 1958) Archive Arthur del Prado - Knapic Electro-Physics: Philips 1965.

64 Knapic Electro-Physics, Arthur del Prado, 'Letter to Dean Knapic' (23-7-1958) Archive Arthur del Prado - Dean Knapic Correspondence 1958. 
you have quotations go over [sic] me. The reason herefore [sic] is that F\&S very likely is visiting the same people I contact.'.65

Del Prado insisted on being included in all communications. He would not let this agent undermine his position as European Marketing Manager. As soon as he found out that not all the correspondence was passing his office, he proved mistakes made by Frank \& Schulte. ${ }^{66}$ In Palo Alto they sided with their European sales and marketing manager. He was loyal, after all, and had a good track record in expanding the European sales. Del Prado felt sufficiently empowered to correct Frank \& Schulte:

'In light of these facts, I am unpleasantly surprised about the remark in your letter dated March 2, quote: "We believe that the delay in the settlement is due to the fact that we have been making our orders to you through the mediation of Mr. del Prado." On top of this I must inform you that many times a delay is caused by your own inaccuracy in giving specifications. ${ }^{67}$

By playfully referring to their refusal to work with letters of credit, Del Prado gained sufficient arguments to finish his dealings with this difficult business partner. Within a year after the start of his operation, Del Prado took over the business from Frank \& Schulte. Never again would he allow others, who interfered with his interests, to exclude him from their communications. He had to be the pivot in an operation.

After being half a year in business, in the spring of 1959, Dean Knapic came over to visit Del Prado. Accompanied by Knapic's family and Del Prado's wife Hanni, both men traveled to major customers. Del Prado used this visit to increase the credibility of the company with his customers, and to show his achievements and capabilities to Knapic. The visit allowed him to verify Del Prado's reports, and on the road, there was plenty of time to discuss business. With tremendous effort and charm, Del Prado wanted to convince Knapic of entrusting the European market to him.

Del Prado passed the test. His reports to Knapic proved to be accurate, while the sales volume he achieved was high enough for Knapic to justify his trust in

65 Knapic Electro-Physics, Arthur del Prado, 'Letter to Dean D. Knapic' (30-8-1958) Archive Arthur del Prado - Dean Knapic Correspondence 1958.

66 Knapic Electro-Physics, Arthur del Prado, 'Letter to Judy, KEP Palo Alto office' (5-2-1959) Archive Arthur del Prado - Knapic Correspondentie 1959.

67 Knapic Electro-Physics, Arthur del Prado, 'Letter to Frank \& Schulte Handelsgesellschaft MbH - Ref: K/sc' (3-4-1959) Archive Arthur del Prado - Knapic Correspondentie 1959. 
his Dutch representative. Knapic Electro-Physics prospered and its European Marketing Manager proved to be effective. In terms of their communication, it was decided that Del Prado no longer had to write directly to Knapic, but would communicate to the responsible sales manager in Palo Alto.

That Del Prado felt himself to be responsible for his own earnings stimulated him to be bold, enterprising, and creative. The independence he experienced as Knapic's European representative would become a cornerstone of his own business philosophy. Decades later, Del Prado would allow his managers high degrees of liberty in order to stir and unleash their entrepreneurial spirit. But they should never dare to undermine his position, for this he could not tolerate, as Frank \& Schulte had experienced.

\section{Importance of proximity and local manufacturing}

Being responsible for European sales was not enough. During his time in Silicon Valley, Del Prado already got the idea to start a European manufacturing operation for Knapic Electro-Physics, of which he would become the general manager. ${ }^{68} \mathrm{~A}$ few months after his move back to Europe, Del Prado wrote to Dean Knapic:

'Also, I would like to hear your opinion of [sic] setting up your own subsidiary company in one of the European countries and how much capital, if at all possible, you could make available for this purpose. I hope you understand that I am working on this problem and on the alternative of licensing together at one time, in order to get a better overall picture of the exciting opportunity.' ${ }^{\prime}$

It did make sense. As Del Prado began to establish his potential customer base in 1958, one of the first things he learned was the importance of proximity. Palo Alto was too far away. His European client base would benefit from short supply routes and quick tuning of needs and specifications. Also, the predominant use of Knapic Electro-Physics silicon crystals for development purposes demanded short supply lines. In the start-up of new semiconductor materials in production, it took too long to wait for samples from California.

Already in the first year of operation, Del Prado reached out to the Dutch, Belgian, and Swiss governments to discuss the possibilities of starting a local operation. Each one of them responded positively to the establishment of such a high-tech venture in their country. However, the Knapic Electro-Physics

68 Arthur del Prado, 'Letter to Herman Jonge Poerink' (undated, probably Spring 1958) Archive Arthur del Prado - Knapic Electro-Physics.

69 Knapic Electro-Physics, Arthur del Prado, 'Letter to Dean D. Knapic' (29-9-1958) Archive Arthur del Prado - Dean Knapic Correspondence 1958, p. 2. 
management board kept delaying the discussion as demand for their crystals did not stabilize.

Imperturbably, Del Prado continued to look for opportunities to establish a European manufacturing operation. One route was the installation of a Knapic crystal puller at another company's factory in the Netherlands. This company, called Van der Heem NV, would buy one of the advanced crystal pullers of Knapic, of which Knapic would then take a certain amount of the produced silicon. ${ }^{70}$ The proposal was rejected by Dean Knapic, partly because he did not favor a transfer of the property technology to another company. Moreover, a crystal puller was all but readily available as a standard product.

Del Prado was not one to throw in the towel after a failed attempt. Every time he ran into a potential set-up for a manufacturing operation, he prepared it extensively before informing the headquarters in Palo Alto. He studied locations, the required local permits, the cooperation of national and local governments, and the financial consequences - most of all in terms of currency exchange rates. In Germany, he proceeded by trying to recruit two PhDs who were interested in working for him. ${ }^{71}$ Simultaneously, he contacted suppliers of gasses and other materials required for the production of silicon. But, for the time being, it was all to no avail.

The American manufacturing operation had sufficient capacity to supply the European market. Starting another production line would generate a surplus. Furthermore, in 1960 and 1961, the American semiconductor industry suffered one of its many recurring downturns. ${ }^{72}$ Del Prado had to halt his plans and rein in his ambition. In his view, at the headquarters in Palo Alto, they failed to appreciate his apprehension of the market. Because of their distance from the markets in Western Europe, they neglected the opportunities he perceived. It was a frustration that would linger on throughout his employment with Knapic Electro-Physics and beyond.

\section{Establishing a footing in Europe}

Del Prado managed to establish himself as the major supplier of silicon in the Western European market, due to the growing applicability of silicon as well as his own salesmanship. Within a few years, he gained control of 40 percent of the Western European market for silicon on behalf of Knapic Electro-Physics. ${ }^{73}$

70 Knapic Electro-Physics, Arthur del Prado, 'Letter to Ir. P.G. Zaaijer, Van der Heem NV - Ref. Dir.46:2000’ (28-1-1959) Archive Arthur del Prado - Knapic Correspondentie 1959.

71 Knapic Electro-Physics, Arthur del Prado, 'Letter to Dr. G. Greger' (24-6-1960) Archive Arthur del Prado - Knapic 1960+1961, div. 1958-1960

72 Malerba, The Semiconductor Business, p. 57.

73 Arthur del Prado, 'Memo from Art del Prado: Material Inventory In Europe' (November 
In Germany his major customers were Semikron, Telefunken R\&D, AEG, and Siemens \& Halske. In the United Kingdom, he regularly struck deals with Westinghouse Brake \& Signal Co (Chippenham, Wilts), International Rectifier Co (Oxted, Surrey), Standard Telephones \& Cable (Footscray, Sidcup, Kent), Joseph Lucas (Mere Green, Sutton Colfields, Warwicks), Ferranti (Gem Mill, Oldam, Lancs), and Plessey Co (Towcester). His third major market was Italy with SGS Italy, ATES (a RCA subsidiary in Catania), Pirelly Applicazioni Electroniche (licensing General Instruments technology), and Raytheon-ELSI. In the Low Countries, sales never got very substantial, as Philips and its various European subsidiaries produced their own silicon materials.

It became clear that Del Prado needed support to cover all these accounts. Support became undispensable after he managed to add the German market to his portfolio, also because the applicability of silicon increased significantly. From the start the French market was covered by Claude J. Varnier, president of Société Française du Diamant, a French trading and distribution company. While Del Prado's relationship with his German counterpart deteriorated quickly, his ties with Varnier remained healthy for years. Possibly because the Frenchman was willing to include Del Prado in his correspondence with Palo Alto.

After two years of cultivation by Del Prado, the British market began to see substantial growth. In the spring of 1959, Knapic, during his visit to Europe, suggested to Del Prado to look for support for this market. This led to the hiring of Vernon Rowlands. While Varnier ran his own operation, Rowlands was an employee of Knapic Electro-Physics and reported to Del Prado.

Around the turn of the decade, then, Arthur del Prado, Vernon Rowlands, and Claude Varnier spent many weeks annually traveling across their respective European territories in pursuit of sales. They sought to learn about customers' needs, their feedback on samples, industry gossip, commercial forecasts, benchmark information, and/or shipments. Del Prado and his cohorts embraced the role of the traditional American salesman, being on the road for days and relying on a swift and optimistic sales pitch to win over potential customers. As freebooters always scanning the horizon for new opportunities and trying to pocket new successes, they sometimes bluffed their way in while pretending either innocence or expertise.

After the first four years of being a salesman in semiconductor technology, things were running smoothly for Arthur del Prado. Based on his instincts, he developed the main characteristics of his entrepreneurship, which would resonate throughout his life. These included the importance of proximity for a

1960) Arthur del Prado Archive - Topsoe file; Arondisements-Rechtbank Utrecht, 'Conceptversie Memorie van Antwoord inzake Arthur Hendrik del Prado contra Haldor Topsøe' (25-3-1970) Arthur del Prado Archive - Topsøe file. 
successful operation, his insistence on being part of all communication related to his operations, the significance of earning autonomy in pursuing and realizing local opportunities, as well as his specific style of economic management. Aside from these business principles, several of his character traits were crucial for his success, most notably his charm, cosmopolitism, and intrepidness.

Since the Del Prado family emigrated to the Netherlands after the Second World War, they had been living in Naarden. After his return from the United States, Del Prado junior worked at Baarnscheweg 18 achter, Huis ter Heide, close to his parents' home. ${ }^{74}$ Until 1961, he worked from and lived at Prins Frederik Hendriklaan 2 in Naarden. He hired a secretary, while his wife Hanni took care of finances. In 1961, after being three years in business, it was clear that Del Prado had survived the first years of uncertainty, and he was even making some decent money. In 1960, his salary of 10,000 dollars and his official half percent commission amounted to an income of 11,558 dollars (figure 1 ) ${ }^{75}$ Revalued to the current dollar value, this would constitute some 93,000 dollars.

\section{Figure 1}

Table of sales of Arthur del Prado on behalf of Knapic Electro-Physics, June 1958-October 1960.

\begin{tabular}{|l|r|r|}
\hline Year & \multicolumn{1}{|c|}{ Total Sales } & \multicolumn{1}{l|}{ Monthly Average } \\
\hline 1958 & $\$ 9.000,-$ & $(6$ months) $\$ 1.330,-$ \\
\hline 1959 & $\$ 148.800,-$ & $\$ 12.400,-$ \\
\hline 1960 & $\$ 249.300,-$ & (9 months) $\$ 27.700,-$ \\
\hline
\end{tabular}

This more secure financial base allowed Del Prado and his wife to plan for the future. In fact, the couple was expecting their first child. In April 1961, Del Prado announced his intention to move to the nearby town of Bilthoven, and just prior to their moving their son Charles (Chuck) Dean del Prado was born, on May 22, 1961. He was named, obviously, after Dean Knapic, the man who was instrumental in launching Del Prado's career in semiconductor technology. One month after the birth of their first child, the young family moved to Obrechtlaan 47 in Bilthoven. Until Del Prado's death in 2016, this small affluent town in the center of the Netherlands would remain his home base.

74 De Twentsche Bank N.V., 'Letter to A.H. Del Prado: ref. EB/WA' (22-6-1959) Archive Arthur del Prado - Knapic Electro-Physics.

75 Unfortunately, no other accounts or balances of Arthur del Prado's salary and commissions can be traced back. - Knapic Electro-Physics, Arthur del Prado, 'Letter to Jim Cameron: Commission 1960’ (11-3-1961) Archive Arthur del Prado - Knapic 1960+1961, div. 1958-1960. 


\section{Turmoil at Knapic Electro-Physics' headquarters}

Despite the promising results during the first four years, dark clouds were gathering around his business activities. It may have been a matter of beginner's luck starting to fade out, but after a couple of years in business it became more challenging to grow. Many uncertainties surrounded the young semiconductor industry, and Knapic Electro-Physics got its share as well.

Three developments marked the demise of the silicon manufacturer: radical price reductions for silicon, the advent of new semiconductor materials, and the limited grasp of the company's future by its original investors. Having to deal with these new realities, Del Prado succeeded to keep his European business viable. Since he could hardly rely on the Palo Alto headquarters, he had to depend on his own entrepreneurial instincts.

The first challenge posed to Del Prado formed the significant price reductions from $\$ 4$ per gram to $\$ 1,89$ in $1959 .^{76}$ This resulted from the growing acceptance of silicon by the major semiconductor manufacturers. By 1959, most European semiconductor manufacturers initiated their own operations to produce monocrystalline silicon. ${ }^{77}$ Instead of relying on external supplies, they grew the silicon materials themselves. If initially Del Prado may have succeeded in obtaining some sales or orders for samples, in the long run little was gained from this part of the customer base.

Moreover, other competing merchant silicon suppliers entered the market. The competitive edge of Knapic Electro-Physics was still its advanced production facility, but proximity of other semiconductor material suppliers increasingly began to haunt the operation. This included Wacker in Germany, Monsanto in the United Kingdom, and some beginning operations in Belgium. Demand further shrank due to a downturn in the American semiconductor market 1960 and $1961 .^{78}$ This caused a decline in the consumption of silicon for Knapic ElectroPhysics' home-market.

In addition, the demand for silicon crystals was not limited to those manufactured by means of the Czochralski method, but also through float-zone. This new method to grow semiconductor crystals was developed at Bell Labs in 1955. In particular for the smaller diameters of silicon shafts of 1 to 2 inches, which were the industry standard in those days, the float-zone technique could be more competitive. While Knapic Electro-Physics was convinced of the more

76 Worden and Risberg, 'Evaluation Silicon Monocrystal Market: Knapic Electro-Physics, Inc' (1959) Archive Arthur del Prado - Knapic Electro-Physics Archive, p. 1.

77 Ibid.

78 Malerba, The Semiconductor Business, p. 57. 
proven and solid Czochralski materials, its competitors offered the new floatzone material in increasingly better qualities and against competitive prices. ${ }^{79}$

More and more customers asked Del Prado about other semiconductor materials, like float-zone silicon, germanium, polysilicon, and the newest kid on the block: epitaxy wafers. Semiconductor manufacturers experimented with new materials to improve properties, and more suppliers joined the competition. The niche competence of Knapic Electro-Physics in Czochralski crystals limited Del Prado's capability to serve his customers.

In this context, epitaxy was a prime example. In 1962, semiconductor manufacturers started to use epitaxial films on top of their wafers to improve the speed of the transistor's switching. It was Del Prado's first acquaintance with epitaxy, a technology that would provide a major base upon which he would build his future business (cf. Innovation II). However, in 1962, it posed a problem. As Del Prado's representative in the United Kingdom, Rowlands, reported to him:

'nearly every firm of standing has now installed a small silicon evaporation unit in order to make epitaxial layers. It seems that the companies, as they did for pulled crystals initially, have set up the epitaxial facilities themselves, because they cannot yet trust any manufacturers of epitaxial layers. ... all transistor and small-diode manufacturers will be obliged to use epitaxial material, or else their devices will not be competitive. ${ }^{80}$

For Del Prado, being a distributor of silicon rods, the growing interest in wafers with an additional epitaxial film was a threat to his business. So far, the Palo Alto operation had been very reluctant to diversify from its core business, limiting Del Prado's ability to meet the demand for this new product. ${ }^{81}$

If these changing characteristics of the European silicon market posed a challenge, more worrisome were the troubles at the Knapic Electro-Physics headquarters. In the summer of 1961 the investors of Knapic Electro-Physics

79 Knapic Electro-Physics, Vernon Rowlands, 'Information Report No IR/12: Prices of Czochralski and Float-zone Material’ (14-2-1961) Archive Arthur del Prado - Knapic ElectroPhysics: Knapic Customer Reports 1960-1962.

80 Knapic Electro-Physics, Vernon Rowlands, 'Customer Report NCR/196: Royal Radar Establishment’ (6-6-1962) Archive Arthur del Prado - Knapic Electro-Physics: Knapic Customer Reports 1960-1962.

81 One major competitor offering epitaxial wafers was medical company Merck. It opened an epitaxial wafer operation in the United Kingdom in the early 1960s. One of the inventors involved in the development of this technology at Merck was Dr. Walter Benzing, one of the co-founders of Applied Materials and future competitor of ASM. 
sidetracked the company's founder Dean Knapic..$^{82}$ They were not convinced anymore of Knapic's strategy and, for that matter, the business itself. Having its origins in the Texas oil industry, the investors failed to apprehend the new and promising semiconductor industry. By 1960, the American semiconductor industry generated a value of 607 million dollars, which would increase to 635 million dollars by 1964. Despite an industry downturn in 1960 and 1961, the industry enjoyed good prospects and growth. Nevertheless, the investors moved forward to safeguard their investments, and took control of the company. In January 1962 Knapic was ousted.

This turn of events taught Del Prado a final but cynical lesson about trusting financial backers. He intended not to make such a mistake himself. Eager and intelligent young engineers and entrepreneurs, like Del Prado and of course Knapic, were convinced of the potential of the emerging semiconductor technologies. But this was not the consensus among the majority of the American investors in technological developments.

Del Prado had to deal with the new situation. The ousting of Dean Knapic and the appointment of new management did not alter interactions with the headquarters for Del Prado. But the strings were loosened to some extent. Rejecting the realities of the market where silicon was in abundance, the new management did not allow further price reductions of its products and was now willing to look for alternative sources of income. To maintain his levels of sales and his income, Del Prado had to diversify his product portfolio.

Next to the pulled silicon crystals, he started to offer float-zone grown silicon crystals, germanium, and some epitaxial wafer materials. He often quoted these products before he was sure how to realize his promise to deliver. In those cases, he had to look for external suppliers, while ensuring that both the subcontractor and Knapic Electro-Physics got their share of the sale. It proved to be fruitless, however, for often the resulting rates were too high to be competitive. In practical terms it meant that he would buy products from lesser known or beginning competitors to maintain his reputation and sales.

One of these suppliers was an 46-year-old prominent Danish industrialist named Haldor Topsøe. Del Prado first met him in 1959. ${ }^{83}$ Topsøe had been

82 Knapic Electro-Physics, Vernon Rowlands, 'Customer Report No. CR/191: Ferranti Limited' (25-5-1962) Archive Arthur del Prado - Knapic Electro-Physics: Knapic Customer Reports 19601962.

83 Del Prado stated: "I am in contact with a company named "Haldor Topsoe" in Denmark. Although they are not in the market yet with silicon, they seem to have engineered a new and relative inexpensive form of purifying silicon. Within a short time they will send some samples." - Knapic Electro-Physics, Arthur del Prado, 'Letter to Dean Knapic' (11-5-1959) Archive Arthur del Prado - Knapic Correspondentie 1959. 
running a company in catalysts since the 1940s, and, in the late 1950s he started a small operation in float-zone silicon crystals called Topsil - which exists to this day. Back then, Del Prado tried to get a grasp of the competitive field, and looked for ways to open up a local manufacturing operation for Knapic Electro-Physics. This effort came too early, as Topsøe did not have anything substantial to offer yet. However, when the float-zone demand increased in the early 1960s, Del Prado reached out to Topsøe again.

Initially, Del Prado's plan was to secure some part of Topsøe's manufacturing operation to alleviate the demand of Knapic Electro-Physics, perhaps facilitated by some kind of joint-venture between Knapic Electro-Physics and Topsøe. ${ }^{84}$ However, the Danish entrepreneur only offered float-zone silicon, and his manufacturing capacity was not yet sufficient to supply products to meet the needs of both Knapic Electro-Physics' and his own business. ${ }^{85}$ It proved to be very difficult to align the interests and capabilities of both parties, and their discussions failed to result in anything substantial.

Del Prado's efforts at diversification continued beyond the immediate market for semiconductor materials. In 1963, when still working for Knapic Electro-Physics as European Marketing Manager, Del Prado was hired as agent for US Dynamics, a company active in gas drying and purification technology. This new non-silicon client formed the writing on the wall of the imminent end of Knapic ElectroPhysics. After the silicon manufacturer's founder was sidelined, its management was replaced, its interests had changed, and its sales force engaged in selling products made by others.

Aware of the company's approaching collapse, Del Prado was keen on ensuring the continuation of his activities. By having developed the European market for silicon on behalf of Knapic Electro-Physics, he had an extensive network among semiconductor manufacturers in Western Europe. ${ }^{86}$ He was resolved to cash in on this knowledge and experience. In 1964 the curtain fell for Knapic ElectroPhysics, as the investors withdrew their support due to their lack of confidence in the semiconductor business.

Rather than taking a wait-and-see approach, Del Prado immediately started his own sales and marketing agency in February 1964. In order to decrease

84 Knapic Electro-Physics, Arthur del Prado, 'Daily Call Report: Haldor Topsoe, Copenhagen' (26/27-11-1962) Archive Arthur del Prado - Knapic Electro-Physics Customer Reports European division 1961-1964.

85 Knapic Electro-Physics, Arthur del Prado, 'Report European Division: S.G.S., Italy'(18-101962) Archive Arthur del Prado - Knapic Electro-Physics Customer Reports European division 1961 1964.

86 Ray Sawyer, 'Letter to Mrs. Rita Thomson, Basic Products Corporation' (9-2-1965) Arthur del Prado Archive - Sola Basic file. 
his exposure to the silicon market and to join new markets in semiconductor technology, his plan was to represent American manufacturers of semiconductor materials and equipment. ${ }^{87}$ Del Prado named his agency 'Advanced Semiconductor Materials' (ASM) and registered it as a one-man business on May 14, 1964. Shortly after the start of his agency, Knapic Electro-Physics was liquidated.

\section{Defining an entrepreneur}

In the years following his time in Silicon Valley, Arthur del Prado discovered and developed his talent to sell and market new semiconductor technologies. In this process, he mapped all the possible customers in Western Europe. Being a representative for the most basic material in semiconductor production, he dealt with almost every European semiconductor operation, resulting in an extensive network of customers, technologists, entrepreneurs, engineers, subcontractors, and bankers. In this way, he gained an intimate and complete understanding of the market early in his career. Later in life, this knowledge would give rise to his visionary capability to recognize new promising technologies and trends for the industry very early in their development.

During his years as marketing manager for Knapic Electro-Physics, several characteristics of the man surfaced that would define his leadership of ASM. First, and above all, Del Prado was intrepid and committed to his commercial ambitions. If the distant future was unpredictable, in particular after the liquidation of Knapic Electro-Physics, he was clear on what he wanted in the years ahead. To achieve that, he would deploy all his talents to mangle everyone and everything that separated him from his goals. He pulled out all stops: his natural charm, his negotiation skills, as well as Machiavellian tactics.

Second, Del Prado was a first-class salesman. To secure maximum margins, he had a wide range of sales tactics. Charismatic, energetic, and courteous, he convinced others of his products and vision. But his style also resembled the audacity and single-mindedness more commonly associated with Wild West outlaws than with sophisticated twentieth-century entrepreneurs. As a salesman, Del Prado would always remain the katjong - scamp - he was in his youth in the Far East.

Third, his playing field was not limited to the Netherlands or the United States. Born in Batavia in the Dutch East Indies (now Jakarta, Indonesia), detained in a Japanese camp for civilian prisoners during World War Two, raised and grown up in the Netherlands, and partially educated in the United States, Del Prado was able to move around and get things his way in different business 
cultures very easily. Although he strongly identified with the Netherlands as his home country - and with Bilthoven as his home base - he was a man of the world.

The fourth and final aspect of Del Prado's characteristics as a businessman pertains to his solid business principles that emerged in this early period of his career. These included the importance of proximity, staying on top of all flows of business communication, and granting and earning autonomy to pursue envisaged opportunities. Forced by the demise of Knapic Electro-Physics, Del Prado established himself as an agent in semiconductor equipment and materials, allowing him to develop his talents. His vision, perseverance, sales tactics, and cosmopolitanism would also determine his role as founder and president of ASM in the years to come. 


\section{Chapter 3}

\section{The start of Advanced Semiconductor Materials, 1964-1968}

During the first few years of ASM, Del Prado, acting as an independent tradesman, pivoted his activities from semiconductor materials toward the business of semiconductor equipment. But at the start of ASM early in 1964, the eventual focus of the company was far from certain. As the name 'Advanced Semiconductor Materials' suggests, it was Del Prado's intention to sustain his business network by continuing to provide silicon. His ensuing preoccupation with semiconductor equipment, which constituted ASM's life and bread in the forthcoming decades, was rather the consequence of several specific contingencies.

\section{Industrial context:}

\section{The advent of chip technology}

Two innovations - another display of the unforeseen - were defining for the growth of ASM in the 1960s. These innovations were a new manufacturing process called the 'planar process', and the rise of 'integrated circuits' as common product. Both elaborated upon the advent of silicon as semiconductor material. Both groundbreaking innovations, the planar process and the integrated circuit, date from the late 1950s. The willingness and ability to adopt these innovations proved in fact to be decisive for the competitiveness of semiconductor manufacturers during the 1960 s. $^{88}$

The planar process refers to a manufacturing process of silicon discretes, allowing them to be produced in two dimensions rather than three (figure 2). This increased the reliability of the product by offering a more robust manufacturing method. This process - only applicable for silicon products - developed into the standard procedure in semiconductor manufacturing, which is true to this day.

The other innovation - the integrated circuit - configured and integrated electrical components such as transistors, diodes, rectifiers, and the like in one piece of silicon or germanium. Original circuitry design traditionally combined these components by soldered wires on a print board. In particular for airborne electronics this posed a problem. As noted by the United States Airforce in 1966: 
'The few simple groups of individual components previously associated with electronic equipment, such as transmitters and receivers, were rapidly being supplemented by additional, more complex circuits. The result was a tremendous increase in the number of individual components and interconnections between them - each of which was a possible point of failure. This, coupled with lack of highly reliable parts, compounded the failure rate problem. ${ }^{89}$

Through the planar process - in the case of silicon-based integrated circuits the components, wires, and partition between the parts could be integrated in a planar product..$^{90}$ It enabled solid state technology to perform better under more demanding circumstances. ${ }^{91}$ In other words, the chip was born.

\section{Figure 2}

Difference between mesa transistor and planar transistor technology

The planar process embeds the vulnerable parts of a bipolar transistor in silicon oxide, planarizing the surface.

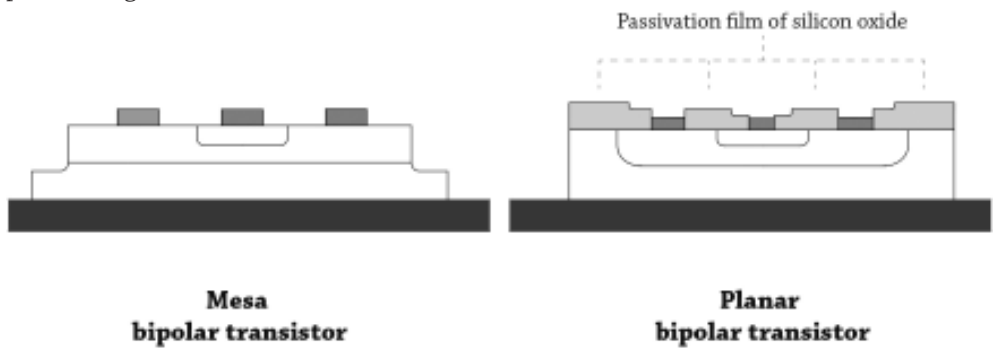

The integrated circuit or chip enabled semiconductor manufacturers to concentrate on new applications for their circuits, instead of merely developing new kinds of transistors, diodes, etc. Through both inventions, the configuration of electrical

89 United States Air Force, Air Force Systems Command, Integrated Circuits Come of Age (Washington D.C. 1966), p.5. Derived from: Computer History Museum (Catalog Nr. 102740473).

90 In the case of Fairchild. The original germanium-based integrated circuit was not manufactured according to the planar process. This only accounted for the Fairchild invention made shortly afterward.

91 There are numerous publications about the benefits of integrated circuit technology and its meaning. Some of these are quite insightful, including Brock and Lécuyer, Makers of the Microchip; Lojek, History of Semiconductor Engineering; Charles Phipps, 'The Early History of ICs at Texas Instruments: A Personal View', IEEE Annals of the History of Computing 34:1 (2012) pp. 37-47; David Brock and David A. Law, 'The Early History of Microcircuitry: An Overview', IEEE Annals of the History of Computing 34:1 (2012) pp. 7-19; David Brock and Christophe Lécuyer, 'Digital Foundations: The Making of Silicon-Gate Manufacturing Technology', Technology and Culture 53:3 (2012) pp. 561-597. 
components on a chip became part of the semiconductor manufacturer's job. New semiconductor products now contained new types of transistors as well as new circuitry design.

Fabricating the new chips required partially new methods and different application of existing techniques. The planar process caused changes in the field of epitaxy, the evaporation of metals, the growth of glass through vapor deposition, ion implantation, the bonding of wires, and encapsulation of devices. ${ }^{92}$ The control over all these modified techniques became more difficult to comprehend at once. Like in haute cuisine, the best results depended on extensive experience and craftsmanship in handling ingredients and recipes, as much as it did rely on written formulas and processes.

The proliferation of new applications and manufacturing processes of chips propelled the American semiconductor industry to new heights, supported by the unremitting procurement efforts of the American government for its Cold War and Space Race. According to economist Franco Malerba, in his The Semiconductor Business, the European semiconductor manufacturers were once again a bit late to recognize the advances made by the Americans. ${ }^{93}$ From the start, the Europeans were behind a few months, if not a few years, when it came to major chip development and process innovations.

The actions of Philips well illustrated the slow response to the rise of chips and the planar process by European semiconductor manufacturers. Moreover, the laxity of Philips would also be a major factor in ASM's success in semiconductor equipment. Only in 1962 did Europe's biggest semiconductor manufacturer lay its hands on a chip manufactured through a planar process. ${ }^{94}$ Its hesitancy to switch to silicon-based chips and transistors was caused by three aspects. The first factor was its successful germanium transistor, which impeded the switch to silicon. Secondly, the dominance of the silicon planar process and chips was not yet a foregone conclusion. Prestigious semiconductor manufacturers like IBM, RCA, and others studied a new type of transistor made of cadmium sulphide on glass instead of the silicon-based chip. ${ }^{95}$ And thirdly, Philips and its Natlab research laboratory tended to rely on external technology initially. ${ }^{96}$ Only when the advent of silicon was inevitable, and the licensing strategy faltered, by 1963, did Philips Natlab turn all research toward silicon-based chip technology.

\footnotetext{
92 Malerba, The Semiconductor Business, p. 99.

93 Ibid., p. 105.

94 René Raaijmakers and Paul van Gerven, Natlab: Kraamkamer van ASML, NXP en de CD (Techwatch, Nijmegen 2016), p. 184.

95 Davids and Verbong, 'Absorptive Capacity', pp. 15 and 19.

$96 \quad$ Ibid, p. 17.
} 
The late acceptance of the silicon chip thus caused a technological disparity between the European and American semiconductor industries. ${ }^{97}$ As Malerba explains:

'Late entry during the transistor period did not greatly disadvantage the entrant; entrants that were endowed with certain technological capabilities could imitate or "catch up" with existing producers. Late entrants during the integrated circuit period, on the other hand, were at a great disadvantage relative to existing producers; as technological change became cumulative, complex and appropriable, it became harder for firms to "imitate" or "catch up" with their competitors who had gained technological advantages in a product or process range. ${ }^{.98}$

This was experienced by Philips. After its decision to develop silicon-based semiconductor technology in 1963, it took a couple of years before it was able to put a reliable product onto the market. If a resourceful company like Philips initially missed the boat, the same applied to universities, research centers, and small semiconductor manufacturers, all of which lacked the means to develop both the chips and the required manufacturing processes simultaneously. One way to limit any further falling behind with the American chip industry was to acquire American technology from the open market.

\section{Corporate course: Hedging businesses}

The demise of Knapic Electro-Physics and the successive start of ASM International marked a new phase in the crystallization of Del Prado as businessman. Had he discovered and matured his personal talents in the previous years, in this next part, he defined and developed his essential organizational strategy. This involved his strategy to commercialize others' inventions, diversification in product offerings, a decentralized organization structure, and the significance of having a production facility in the proximity of his customers. All these strategic values were rooted in his experience as European Marketing Manager of Knapic ElectroPhysics, and were reinforced by the contemporary ideas of management scholars like Peter Drucker and Igor Ansoff. Over the course of his career, he would not deviate from these principles.

In early 1964, Del Prado was hardly discouraged by the demise of Knapic ElectroPhysics, an impending manifestation of fortuna. The American company had not

97 Malerba, The Semiconductor Business, p. 100.

$98 \quad$ Ibid, p. 106. 
been resilient enough in the face of the new realities of the semiconductor market, and Del Prado felt that he could adapt his newly established sales agency more adequately to arising opportunities. In contrast to Knapic Electro-Physics, he did not have the responsibility to sustain a silicon manufacturing operation. His investment in his new business basically involved a little money for his car, an American Rambler, and some office equipment, amounting to some 13,500 Dutch guilders. ${ }^{99}$ His main capital was his network among European semiconductor manufacturers.

To spread the risks of his business, Del Prado engaged three opportunities at his disposal. The first was the continuation of his trade in silicon. The second opportunity formed a minor deviation of his earlier semiconductor business: trade in technologies related to printed circuit boards on which transistors and other semiconductor discretes were mounted. The third option available to him was to focus on semiconductor manufacturing equipment, which was in line with the US Dynamics agency he obtained in the final months of Knapic ElectroPhysics. By choosing to concentrate on selling equipment, Del Prado committed himself to a defining technological development that was going to change the semiconductor industry and that would determine the course of his activities.

\section{Elaboration of Affairs}

\section{Laying the foundations of future business}

In the first months of 1964, Del Prado looked for other suppliers of silicon to fulfill the demand of his clientele. Knapic Electro-Physics' market share had become obsolete and the other suppliers of silicon were eager to fill the vacuum. However, Del Prado knew his customers well, and they would stay with him if he could offer them an alternative. ${ }^{100}$ This meant he had to act quickly, causing him to contact the Danish entrepreneur Haldor Topsøe again. Earlier, Topsøe's silicon operation failed to deliver the quality and quantity needed by Del Prado. However, times had changed, and he was in desperate need for a new silicon supplier. At a 1964 meeting at Frankfurt Airport, the two men agreed to cooperate. ${ }^{101}$ Topsøe would supply Del Prado with silicon, while also hiring the Dutchman to develop the Benelux, German, Swiss, and Italian market on his behalf. ${ }^{102}$ Del Prado's

99 Accountants en Administratiekantoor, G.J. Huls, 'Advanced Semiconductor Materials: Fiscaal rapport 1965+1964' (March 1967) Archive Arthur del Prado - ASM Jaarverslagen file

100 Arondisements-Rechtbank Utrecht, 'Conceptversie Memorie van Antwoord inzake Arthur Hendrik del Prado contra Haldor Topsøe’ (25-3-1970) Arthur del Prado Archive - Topsøe file.

101 Arondisements-Rechtbank Utrecht, 'Conceptversie Memorie van Antwoord inzake Arthur Hendrik del Prado contra Haldor Topsøe’ (25-3-1970) Arthur del Prado Archive - Topsøe file; Paul van den Hoek, 'Interview with author'. 
former associates, Claude Varnier of Société Française du Diamant and Vernon Rowlands of the Knapic Electro-Physics United Kingdom office, would join the effort for the French market and British market, respectively.

Del Prado served Topsøe a market on a golden plate. Almost overnight, the Danish entrepreneur became the dominant player in the European market, while his production of silicon and silicon equipment was not yet remotely meeting the demand. Conversely, the deal allowed Del Prado to sustain his primary source of income as well as his network of customers. The Dutchman presented his new one-man business ASM as a de-facto continuation of his former activities, which was accentuated by the resemblance between his ASM stationary and that of Knapic Electro-Physics.

Del Prado felt he had to diversify his sources of income. Being dependent for his income on Topsøe's silicon business was too much of a risk, also because the competition was fierce. One solution presenting itself was to join forces with a family member. In anticipation of the collapse of Knapic Electro-Physics, Del Prado had convinced his 35-year-old brother-in-law Herman Jonge Poerink to team up. In May 1964, their collaboration resulted in the establishment of an agency called Eurolectron that would focus on technologies related to semiconductor materials, such as, eventually, printed circuit boards. ${ }^{103}$ They each owned fifty percent of the agency, for which they rented a space in a mansion converted into an office building at Laurilliardlaan 27 in Bilthoven. A secretary provided office support. ${ }^{104}$ The responsibility for Eurolectron fell upon Jonge Poerink, however, as ASM demanded all of Del Prado's attention. Over the years, Jonge Poerink would expand this business without any interference by Del Prado. For him, Eurolectron seemed primarily to serve as a safeguard in the event his insecure semiconductor business would fail.

Soon, Del Prado saw another solution for limiting his dependence on the silicon business. This involved the trade in semiconductor manufacturing technologies. Commonly, materials and equipment were procured through the same channels.

Prado - Topsøe file.

103 Del Prado and Jonge Poerink founded Eurolectron as a general partnership (in Dutch: 'Venootschap onder firma, VOF') on 25 November 1963 under a 'Provisional Understanding of Agreement', which was officially registered on May 14, 1964, as Eurolectron. This took place simultaneously with the registration of ASM as a one-man business. Through an acquintance of Jonge Poerink, Euroelectron specialized in the trade of printed circuit boards. Del Prado remained 50\% owner of Eurolectron until 1976. His withdrawal from Eurolectron was caused by a conflict between the two men about overlap between ASM and Eurolectron. - Arthur del Prado and H. Jonge Poerink, 'Short review of facts' (1-9-1976) Arthur del Prado archive - Eurolectron 1976 file.

104 Her name was Ris van der Horst. - Martin van Beest, 'Interview with author'. 
This made it possible for him to utilize his existing network for other products. Through the trade in semiconductor manufacturing technologies, he tapped into an emerging market, which, propelled by the advent of the planar process and integrated circuits, soon overtook Del Prado's silicon business.

\section{Capitalizing on technological disparity between the United States and Europe}

By the time Del Prado decided to use ASM for trade in semiconductor equipment alongside silicon, a healthy demand had emerged for American technologies in Europe, in particular because often the quality offered by American merchant equipment suppliers proved not to be inferior to the in-house developed systems. Instead of developing their own manufacturing tools, European manufacturers could procure innovative fabrication techniques off the counter. These pieces of equipment entailed components - gas equipment, molds, and materials - and complete fabrication systems, such as furnaces or assembly equipment. The more advanced American semiconductor technology began to enter the European market, and European customers were happy to pay amply for the innovations. Just like with his original silicon business, Del Prado found himself in the right business at the right time.

One particular principal proved to be decisive in Del Prado's efforts at selling American semiconductor equipment. It was the merchant supplier of diffusion furnaces, called Lindberg Heavy Duty from Milwaukee, Wisconsin. ${ }^{105}$ Lindberg Heavy Duty was a manufacturer of heat treatment equipment, and through its diffusion furnaces it became one of the first to offer dedicated semiconductor manufacturing technology on the open market. ${ }^{106}$ Since 1963 this company had been part of a conglomerate called Sola Basic Industries, which participated in various sectors next to the semiconductor industry. ${ }^{107}$

105 Lindberg Heavy Duty originated from Chicago. However, by the time Del Prado obtained the agency of this company, Sola Basic Industries had acquired Lindberg Heavy Duty. Hence its new headquarters was Milwaukee, Wisconsin, the home base of Sola Basic. Another early vendor of semiconductor equipment was Kulicke \& Soffa, a manufacturer of die- and wire bonders. - VLSI Research - 'Diffusion \& Oxidation', Chipshistory.org, (1988) pp. 4.4.1.3 and Jeffrey L. Rodengen, 50 years of Innovation - Kulicke and Soffa, 1951-2001 (2002 Fort Lauderdale) p. 19.

VLSI Research - 'Diffusion \& Oxidation', p. 4.4.1.3.

In addition to the Lindberg diffusion furnaces, Sola Basic offered die- and wire bonders as well. Die- and wire bonding equipment separates dies from the wafer and connects it to a lead frame. Through this, Sola Basic was a major competitor of Kulicke and Soffa, the first merchant die- and wire bonder supplier. Since ASM represented Sola Basic, it could not represent Kulicke \& Soffa. In the 1980s, ASM became a direct competitor of K\&S through its Hong Kong activities. - Author unknown, 'Sola Basic industries, Inc: List of Deals', Harvard Business School Baker Library, Historical Collections: Lehman Brothers Collection - Contemporary Business Archive. 
Diffusion furnaces played a vital part in the semiconductor manufacturing process during the 1960s. The diffusion process was used to introduce impurities - called dopants - into the semiconductor wafer. ${ }^{108}$ By means of these impurities, the electronic properties of the silicon were altered. This was done by heating the substrate shortly, while gasses containing the dopants flowed over the substrate. Through the heat, the impurities penetrated the substrate and changed its electronic properties.

Furthermore, the diffusion furnaces were also used to oxidize the silicon, creating an insulating film of silicon dioxide. Oxidation occurred by exposing the substrate to oxide or water vapor at higher temperatures, which resulted in a thin film of silicon oxide on top of the substrate. Silicon oxide was determinative for the partition and protection of various electrical components on an integrated circuit, as well as for the proper working of transistors.

Through his hiring as agent by Sola Basic Industries to sell the Lindberg diffusion furnaces, Del Prado obtained a trump card. The technology was indispensable in the latest semiconductor manufacturing. But more importantly, the American technology offered its users unprecedented temperature uniformity across the chamber. ${ }^{109}$ The first diffusion furnace of Lindberg Heavy Duty, introduced in 1961, already contained the first electronic temperature controller. From then on, the American company became the dominant merchant supplier of diffusion furnaces in the early sixties. Del Prado offered this latest piece of American innovation in semiconductor manufacturing technologies to his network of European manufacturers.

The start of Del Prado as the Sola Basic representative and distributor coincided with Philips' efforts to catch up in chip technology. Philips wanted to integrate the American diffusion furnaces in its forthcoming chip manufacturing lines. The Dutch giant in electronics had semiconductor operations at its European subsidiaries Valvo in Hamburg, Mullard in Southampton, MBLE in Brussel, La Radiotechnique in Caen, and Faselec in Zürich. These factories all needed the same semiconductor equipment, which the company purchased and tested centrally at its headquarters in Eindhoven, the Netherlands. Once Del Prado succeeded in convincing the Dutch Philips engineers of Sola Basic's products by 1964, he sold furnaces to all these subsidiaries. ${ }^{110}$

108 The diffusion process meant for transistors was invented by Bell Labs chemist Calvin Fuller, engineer Daryl Chapin, and physicist Gerald Pearson from 1952 until 1954. - Computer History Museum, '1954 - Diffusion Process Developed for Transistors' computerhistory.org (date unknown); VLSI Research - Diffusion \& Oxidation 4.4.01.

109 VLSI Research - Diffusion \& Oxidation, p. 4.4.1.3.

110 Martin van Beest, 'Interview with author', and Craig Addision, 'SEMI Oral History Interview: Karl Lang', semi.org (17-8-2006). 
The Lindberg agency was the first step of ASM in the market for semiconductor deposition equipment, and it finally opened the doors of Philips to Arthur del Prado. Since his return from Silicon Valley as marketing manager on behalf of Knapic Electro-Physics in 1958, Del Prado had not been able to sell anything substantial to Europe's biggest semiconductor manufacturer. He got the Sola Basic agency right on time. From 1965 onward, Philips opened more production lines for its chips using the Lindberg furnaces. Because Del Prado secured a share of the deal for every sale he made, the rather sizeable and expensive machines proved to be very lucrative for him.

The Sola Basic agency provided Del Prado and ASM enough room to breathe and even to expand. More agent agreements followed (figure 3). From 1965 on, his portfolio reflected the rising diversity in available technologies of merchant semiconductor equipment manufacturers. These principals allowed him to sustain his network among European semiconductor manufacturers. Furthermore, having gained access to Philips, Del Prado also saw opportunities to extend his dealings with Philips. These included gas dryers and purification equipment from the US Dynamics agencies, for example. ASM became a first contact for American companies in semiconductor equipment and materials that intended to engage the European market.

Although the European market was relatively small compared to North America, it consisted of quite a diverse number of semiconductor manufacturers. The major European manufacturers were Philips and its subsidiaries, Siemens in Munich, AEG-Telefunken in Heilbronn. Smaller ones included Ferranti in Manchester, Standard Telephones and Cables in London, Plessey in Ilford, UK, and Pirelli in Milan. By the late 1960s, American chip manufacturers opened factories in Europe as well: ITT Intermetall in Freiburg, IBM Germany in Sindelfingen, Motorola in Toulouse, National Semiconductors in Greenock, Scotland, and Texas Instruments in Freising, Germany. These American subsidiaries would dominate the European market for integrated circuits, and they purchased some Americanmade components of their manufacturing line via ASM.

On top of the abovementioned commercial customers, Del Prado sold and distributed his principals' products among research institutes and universities. 


\section{Figure 3}

Table of agencies of ASM, 1964-1981

Not all agencies pertained to the same territory. This often depended on obligations of the principal with other representatives or the principal's own representatives in the area. These numbers are not known to the author or untraceable in the available documentation. The agencies are listed in chronological order. This table does not reflect the relative weight of each agency with respect to ASM's sales. Some years are marked with the following sign: *. This symbol indicates the earliest mention in documentation available to the author. Gaps in information are indicated: [unknown].

\begin{tabular}{|c|c|c|}
\hline Year & Agency & Product \\
\hline $1964-1967$ & Haldor Topsee Chemical Engineers & Silicon \\
\hline $1964-1972$ & $\begin{array}{l}\text { Lindberg Heavy Duty Furnaces (v.a. } 1966 \\
\text { Sola Basic Industries) }\end{array}$ & Diffusion furnaces \\
\hline $1965-1970$ & US Dynamics & Gas Drying and Purification equipment \\
\hline 1965 & General Microelectronics & [unknown] \\
\hline 1965 & Qualitron Corporation & Photo masks \\
\hline $1965-1968$ & GTI Corporation (UK, Benelux) & Glass-Tite Industries, Saegertwon, ADVAC, etc \\
\hline $1966-1972$ & $\begin{array}{l}\text { Lindberg Heavy Duty Bonder (as of 1966: } \\
\text { Sola Basic Industries) }\end{array}$ & Wire and Die Bonders \\
\hline $1966-1968$ & Chassis Trak Incorporated & [unknown] \\
\hline 1967 & Siliconix Inc. & Contact printer, wafer probes, FET test modules \\
\hline $1968^{*}$ & Dumas (Navan) & Probe Heads \\
\hline 1968-1969 & Lorlin Ind. Inc. & Transistor and diode testers \\
\hline $1968-1973$ & Tizon Chemical Corporation & Silicon Polish \\
\hline $1968^{*}$ & Watson \& Sons & Lithographic camera systems \\
\hline $1968^{*}$ & Phoenix Materials Corporation & Epitaxy reactors, chemical and accessories \\
\hline $1968^{*}$ & Micro Abrasives Corporation & Lapping and Polishing Compounds \\
\hline $1968^{*}$ & Dexon lnc. & Gas flow Boxes and Cabinets \\
\hline $1968-1969$ & Numerical Control Corp & Semiconductor dice probing and sorting machines \\
\hline $1968^{*}$ & Kasper Inc. & Mask Aligner \\
\hline 1969-1971 & Applied Materials & CVD reactors \\
\hline $1969-1974$ & $\begin{array}{l}\text { South London Electrical Equipment } \\
\text { Company }\end{array}$ & Air filtration machines, clean rooms, etc. \\
\hline $1970-1980$ & Siltec & Silicon \\
\hline $1970^{*}$ & Gaiser & Bonding wedges, Capillaries \\
\hline $1971^{*}$ & O. Glaessner \& Company Ltd & Envair product line \\
\hline 1971-1975 & Metallurgie Hoboken-Overpelt & [unknown] \\
\hline $1972-1974$ & Gereedschappenfabriek FICO & Encapsulation and molds \\
\hline 1972 & Computervision (Cobilt) & CAD/CAM computer and mask alignment systems \\
\hline $1972-1979$ & Tylan & Mass Flow Equipment \\
\hline $1972^{*}$ & Silsco & Filters \\
\hline $1972-1974$ & PLAT General & Photo Resist Spinner \\
\hline 1973-1981 & Morton Chemical Company & Polyset Epoxy molding compounds \\
\hline $1973-1974$ & Ultek (Perkin Elmer division) & [unknown] \\
\hline $1973-1975$ & High Voltage Engineering Europa & Ion Implantation systems \\
\hline 1974-1975 & Trio-Tech Inc & Electronics, Dynamics, Hydraulics \\
\hline $1976-1979$ & $\begin{array}{l}\text { International Plasma Corporation (later } \\
\text { Dionex Corporation) }\end{array}$ & Plasma products (mostly etching) \\
\hline $1979-1981$ & Cominco American Inc. & Gold bonding wire \\
\hline
\end{tabular}


In particular this segment of the market would help to accelerate the breakthrough and acceptance of merchant equipment suppliers. Due to limited financial resources, these customers depended on these suppliers. Apart from the more voluminous occasional deals with semiconductor manufacturers, like Philips, these research institutes actually constituted the first stable market for equipment manufacturers. Moreover, at these organizations, the equipment makers were able to tap into early developments in semiconductor technology. Developing and building technologies at the request of these research institutes enabled the machine producers to participate in activities at the cutting edge of technological development. This solidified their capabilities and reputation for the more substantial and profitable high-volume orders of the industrial semiconductor manufacturers.

With the growing number of principals and his increased range of customers, Del Prado needed more support. For one thing, all the diffusion furnaces had to be installed and maintained - something Del Prado was not able nor willing to do. He needed a service engineer. In 1965 he hired several staff. ${ }^{111}$ A prominent member on his team was a 23-year-old electronics engineer by the name of Martin van Beest. ${ }^{12}$ For the next several years, ASM would basically be operated by Del Prado, his field engineer, and two supporting staff members at the office. From his home base in Bilthoven, Del Prado and Van Beest traveled across Western Europe in order to visit customers. ${ }^{113}$ Del Prado would sell the materials and equipment of the companies he represented. Trained by the respective principals in the United States in controlling their products, Van Beest installed and serviced the ordered equipment. A commercial engineer and the secretary took care of the clerical tasks afterward. In January 1966, the small company moved into a former mansion at Soestdijkseweg 328 in Bilthoven. ${ }^{114}$ This location would be ASM's home base for the next decade.

111 Del Prado hired one commercial engineer, a technical engineer, and a part-time secretary. Only the technical engineer and the secretary would stay on. - Van Beest, 'Interview with author'.

112 The commercial engineer, Pieter Engwirda (date of birth unknown to the author), was soon replaced. His work consisted of keeping track of all the requests and quotations made by customers and Del Prado. He largely worked from the office in Bilthoven. The secretary also worked for Del Prado's brother-in-law, Herman Jonge Poerink, who ran Eurolectron.

113 Van Beest, 'Interview with author'.

114 ASM acquired the building for about 161,000 guilders. Originally a couple continued to rent a small apartment on the first floor. As renters, they were protected by law and could stay. But this situation ended when a fire broke out in the apartment in 1969, after which Del Prado was able to add the space to his office. - Accountants en Administratiekantoor, G.J. Huls, 'Advanced Semiconductor Materials: Commercieel rapport 1965' (17-3-1967). 
For Del Prado and Van Beest it became increasingly difficult to cover all the accounts by themselves. As Del Prado had experienced as agent for Knapic Electro-Physics, a local presence was indispensable. Proximity to the customers was and is very important in the semiconductor equipment industry, a notion of which Del Prado frequently reminded his principals. To this end, he hired Marc Brousinne to be his sales and service manager in ASM's UK office in Wokingham, Berkshire, in 1966. ${ }^{115}$ And in 1968, Peter Haussmann became general manager of the sales office in Munich, Germany. In just a few years, Del Prado transformed ASM into a small multinational enterprise, capable of servicing and installing semiconductor equipment in the major Western European economies.

Del Prado's decision to become a representative in semiconductor equipment and materials involved a leap of faith, of course, but it turned out well. ASM's sales grew from 81,000 guilders in 1964 to 848,000 guilders in 1968, with profits of, respectively, 1,560 and 94,200 guilders (figure 4). To penetrate the European market, a growing number of principals chose to rely on Del Prado's experience and skills. He continued the modus operandi he developed on behalf of Knapic Electro-Physics, the big difference being that he was his own boss now. Responsible for his own success, he had to work hard and serve his principals adequately.

\section{Figure 4}

Graph of annual revenues Advanced Semiconductor Materials, 1964-1968

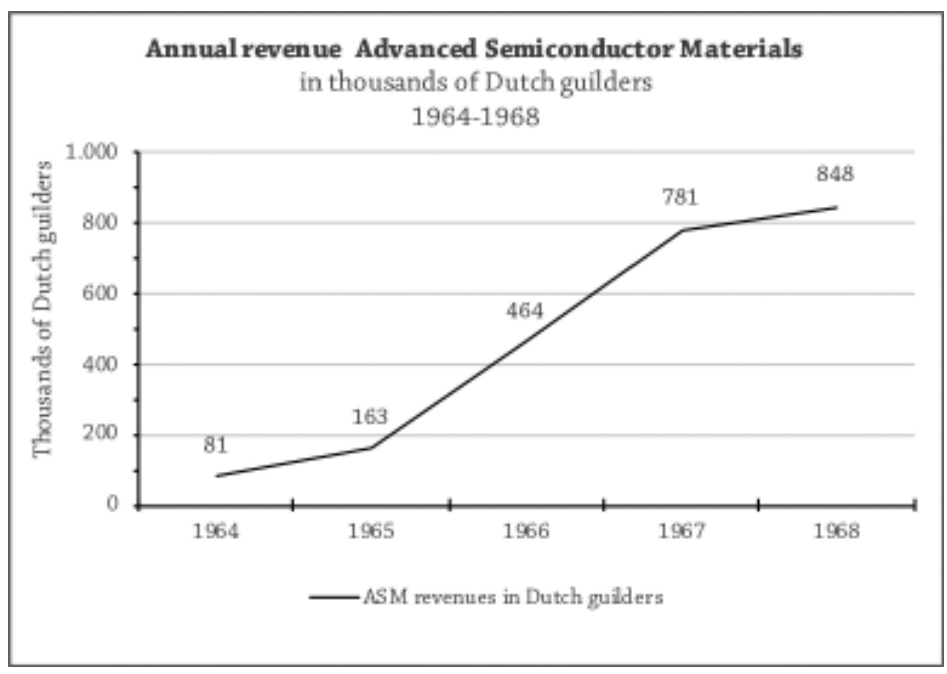

115 Arthur del Prado, 'Letter to Mr. Brian Power' (27-6-1968) Arthur del Prado Archive - UK Office. 
The sky was the limit - a statement regularly verified by the young entrepreneur. As of 1966 at the age of 35, Del Prado would fly to his European meetings in his own light aircraft. ${ }^{116}$ Despite this luxury, he ran his business extremely economically. Every bit of value in ASM was his, and by being quite scrupulous about money, he had managed to grow his company, as also reflected in the modest start of his operations on behalf of Knapic Electro-Physics. Van Beest later recalled that when you asked Del Prado for a quarter, you most often received a dime. ${ }^{117}$ ASM's money was Del Prado's, and also when it was needed for the benefit of the company, he granted it most soberly.

Del Prado's work ethic and his business principles defined the reputation of his trading agency. These principles complemented his personal characteristics as katjong - displayed through his impudent pursuit of sales - and his irrepressible entrepreneurial instincts. As his company grew and hired new staff members, he expected the same unrelenting commitment from them. From the start, then, ASM was an impetuous company scrounging and pursuing opportunities in the flourishing and dynamic semiconductor industry.

\section{Shift toward semiconductor equipment}

After the initial years passed, Del Prado shifted ASM's main business toward semiconductor equipment. His safeguards - the silicon business and his participation in Eurolectron - were no longer necessary. His role in Eurolectron remained negligible. Del Prado solidified his focus on semiconductor equipment in response to two events: by having to part with the silicon business and by establishing a local assembly facility for one of his equipment principals.

The two events directly followed from disadvantages inherently associated with the role of being an independent representative, which ASM was. As a market matures and stabilizes, the agent often becomes redundant. For the principal, it becomes more attractive to organize sales internally, instead of relying on an agent who eats into one's profit by means of his commission. ${ }^{118}$ The first event

116 In 1966, Del Prado bought his first aircraft, a Piper PA 28-180 Cherokee C, registered as PHASM. In 1968 it was replaced by a Beechcraft, which used to belong to the former president of Philips Gloeilampenfabrieken, Frits Philips (hence the name: PH-ILE, an acronym of Philips). To pay for it, Philips NV granted Del Prado a loan of 220,000 guilders, which he redeemed by 55,000 guilders annually. The airplane symbolized Del Prado's wheedling to secure Philips' favor. From time to time, he rented his aircraft to the Dutch Broadcast Foundation NOS, which used it to transport tapes of Dutch Premier League soccer matches from match to studio. On one such occasion, the aircraft - with Del Prado on board - had to make an emergency landing. After extensive repairing, he would fly it until 1978.- Arthur del Prado Archive-Annual accounts; Martin van Beest 'Interview with author'. Martin van Beest, 'Interview with author'. internationalize. - John Dunning, 'Toward an Eclectic Theory of International Production: 
showed this inevitability to Del Prado, while the other one was meant to secure a new base of earnings. Both successive events put Del Prado and ASM onto the path of becoming a semiconductor equipment manufacturer, instead of merely trading in semiconductor materials, as the company's name suggested.

The first event was in fact triggered by Topsøe's unilateral ending of the agency to sell silicon in Western Europe in 1967. A few years after Del Prado had granted Topsøe access to the former customer base of Knapic Electro-Physics, the Danish industrialist no longer had any need for the Dutch salesman. Yet, much in the same way as the German sales agent Frank \& Schulte in 1959, the older and more experienced Topsøe underestimated Del Prado's persistence and Machiavellianism. Del Prado felt cheated. He argued that Topsøe breached their agreement and that he owed him an appropriate redress for the early cancelation of the contract. ${ }^{119}$ Naturally, Topsøe disagreed.

Del Prado's response can be seen as a vivid display of his rampant and ruthless commercial intrepidness. He was not willing to let Topsøe get away with his painstakingly cultivated customer base in silicon without putting up a fight. But Del Prado needed a sharp hand to secure his right in the argument. Looking for the best legal support he could find, he had reached out to the prestigious Dutch corporate law firm Stibbe, which assigned a talented 29-year-old lawyer by the name of Paul van den Hoek to the case. It proved to be a match made in heaven.

Since Topsøe did not want to compensate Del Prado, Stibbe, and Van den Hoek adviced to take control by withholding payments made by their customers, which normally had to be forwarded to Topsøe after deducting his commission as agent. By 1968 these accumulated payments amounted to 181,000 guilders, a significant sum compared to the company's annual turnover of 848,000 guilders. ${ }^{120}$ It was a provocation to Topsøe, as Del Prado was well aware that through such an action he would not preserve his silicon business.

Topsøe answered the incitement by disputing the legal grounds upon which Del Prado had appropriated the payments and challenged him. It was a decision heralding years of legal battles in the Netherlands and in Denmark. ${ }^{121}$ In the ensuing fight, the argumentation centered around the question of whether Del

Some Empirical Tests', Journal of International Business Studies 11 (1979) pp. 9-31.

119 Arondisements-Rechtbank Utrecht, 'Conceptversie Memorie van Antwoord inzake Arthur Hendrik del Prado contra Haldor Topsøe' (25-3-1970) Arthur del Prado Archive - Topsøe file.

120 Accountant en Administratiekantoor G.J. Huls, 'Advanced Semiconductor Materials: Rapport Fiscaal boekjaar 1968, Commercieel 1/11-1966 t/m 31/12-1968' (31-12-1968) Archive Arthur del Prado - Annual reports 1964-1981, 'Vervolgblad' p. 3.

121 After winning the legal dispute in the Netherlands, Stibbe, Van den Hoek, and Del Prado wanted to havethe decision of the Dutch judges apply in Denmark as well. However, Topsoe did not want to give in yet, and he disputed the authoritization of Del Prado. 
Prado was within his right to withhold the payments, and whether Dutch or Danish law applied. ${ }^{122}$ While Topsøe argued that he never signed a contract, Del Prado claimed he had a valid commitment on paper. ${ }^{123}$ In the mid-1970s, the shrewd Dutch businessman and his cunning young lawyer won their case against Topsøe. ${ }^{124}$ The Danish entrepreneur had breached contract, and Dutch law applied.

The legal affairs following the collapse of ASM's trade in semiconductor materials forged an enduring professional companionship between Del Prado and Van den Hoek. Together they had challenged and prevailed over the establishment, impersonated in the Danish industrialist Topsøe and his legal staff. The young attorney would become Del Prado's counsel, and first and only chairman of ASM's Supervisory Board from the initial public offering in 1981 until Del Prado's retirement in 2008. Although Del Prado finally won his case, the affair meant the end of ASM's silicon business. Moreover, it convinced him of the vulnerability implied in being purely a representative.

The second event that sealed ASM's shift toward semiconductor equipment happened shortly after the relationship with Topsøe deteriorated. In the same year, 1967, ASM and its biggest principal Sola Basic Industries prepared for the start of a local manufacturing operation in the Netherlands. ${ }^{125}$ The decision followed Del Prado's unflagging efforts to construct a local manufacturing operation to serve his customers more adequately, as well as to protect himself in this way against the vulnerabilities inherently related to being a representative.

122 The dispute centered around the 'concept of characteristic performance.' Topsoe and Del Prado disputed which country's law applied, the Danish law of the principal or the Dutch law of the agent. In the end, Del Prado won. The Dutch High Court decided that in an agencyagreement, the agent renders the characteristic performance of the contract - selling the principal's products - and that thus the nationality of the agent prevailed. However, at that point, in order to execute this decision, Stibbe, Van den Hoek, and Del Prado had to make their case in Denmark as well. This resulted in another round of legal disputes. - Hoge Raad, 'ECLI:NL:HR:AB3926, Uitspraak m.nt HE. Bröring, Hoge Raad inzake Topsoe-Del Prado' (6-4-1973).

123 Del Prado's proof was a dodgy note written down during the meeting of Topsøe and Del Prado at the Frankfurt Airport in 1964, when they agreed to cooperate. It mentioned the duration of their cooperation as lasting ten years, which meant that Topsøe had breached this contract by ending the agency in 1967. - Paul van den Hoek, 'Interview with author'.

124 Hoge Raad, 'ECLI:NL:HR:AB3926, Uitspraak m.nt HE. Bröring, Hoge Raad inzake TopsoeDel Prado' (6-4-1973).

125 Sola Basic Industries, F.H. Roby, 'Letter from president Roby to Mr. Claude J. Varnier President Societe Francaise du Diamant' (31-3-1967) Arthur del Prado Archive - Sola Basic File.; Nationaal Archief, Ministerie van Economische Zaken Directoraat Generaal Industrie en Handel (1939) 1965-1973 (1975) Archiefbloknr E10. Inv.Nr. 254. 
The participation in this local factory constituted a substantial commitment to the semiconductor equipment activities of ASM.

The local factory was called Sola Basic Netherlands, and ASM participated as shareholder and investor. The preference for a location in the Netherlands corresponded with the presence of Sola Basic's biggest European customer: Philips and its European subsidiaries. In a letter to Sola Basic Industries' headquarters in Milwaukee, Wisconsin, Del Prado explained:

'During a recent discussion with the top management of Philips, we have been informed that very likely it will become a Philips policy to purchase diffusion furnaces, and possibly bonders, from a European source by the end of the year.' ${ }^{126}$

He emphasized the urgency of this development by alluding to competitors' strategies and recent moves regarding European manufacturing. Del Prado concluded his plea by offering to take care of all organizational aspects of starting an European operation.

In order to manufacture the Lindberg Heavy Duty products locally, ASM, Sola Basic Industries, and the representative for France - Del Prado's old acquaintance Varnier of Société Française du Diamant - set up a joint-venture called Sola Basic Netherlands in November 1967. Del Prado invested 135,000 Dutch guilders (or 37,500 dollars). ${ }^{127}$ Initially, the factory was located in Mijdrecht near Amsterdam, but soon - following attractive government incentives - it was moved to Hoogeveen in the north-east of the Netherlands. ${ }^{128}$ Sola Basic Netherlands focused on the manufacturing of Sola Basic diffusion furnaces, while ASM and Société Française du Diamant continued their sale in Western Europe.

Through its participation in Sola Basic Netherlands, ASM extended its activities as agency beyond simply selling and distributing someone else's goods. Servicing became more important, while the Dutch Sola Basic operation also marked the first step into manufacturing operations. Del Prado and Van Beest coordinated the start-up of this factory: hiring employees, setting up the supply chain, and renting a building. During the late sixties, Del Prado consolidated ASM as an independent representative in semiconductor technologies, and finally achieved what he had been pursuing ever since his return from Silicon Valley: setting up a local manufacturing operation.

126 ASM, Arthur del Prado, 'Letter to Sola Basic Industries, Mrs. Rita L. Thomson' (18-7-1966) Arthur del Prado Personal Archive - Sola Basic file.

127 Accountant en Administratiekantoor G.J. Huls, 'Advanced Semiconductor Materials: Rapport Fiscaal boekjaar 1968, Commercieel 1/11-1966 t/m 31/12-1968' (31-12-1968) Archive Arthur del Prado - Annual reports 1964-1981, 'Vervolgblad' p. 4. 
The crowning glory of Del Prado's efforts since his return to the Netherlands in 1958 was the formal incorporation of ASM. Together with his lawyer Paul van den Hoek and accountant Nico Nobel (1933-2016), he looked into the most suitable format. ${ }^{129}$ The way he considered every legal listing is exemplary of his strategic approach. Since the establishment of ASM by name in 1964, he operated it as a one-man business. Eventually, on March 4, 1968, the agency was formally listed as a private limited company called 'Advanced Semiconductor Materials BV'. ${ }^{130}$ This date counts as the official founding date of ASM.

129 Like Van den Hoek, Nobel worked at a renowned fiscal legal office and was assigned to Del Prado. Nobel joined Van den Hoek as board member of the ASM Supervisory Board in 1981. He resigned in 1992.

130 Statuten ASM BV. This establishment was accompanied by a fiscal statement on the last several years. For fiscal purposes it was originally listed as NV - a public limited company, but this was changed into a 'Besloten vennootschap, BV'. 


\section{Intermezzo}

\section{Emergence of a standard semiconductor product and production method, 1965-1975}

From the late 1960s onward, the semiconductor equipment industry experienced tremendous growth. This intermezzo describes why the growth and maturation of the equipment industry accelerated in the wake of a defining moment in the course of the semiconductor industry's history. This moment involved the emergence of a basic configuration for computer chips and their standard manufacturing process. The waves of innovation model designed by James Utterback \& William Abernathy is useful for understanding this manifestation of fortuna.

With the benefit of hindsight, it is possible to reconstruct the semiconductor industry's basic product as a metal-oxide-silicon-field-effect-transistor (MOSFET, or simply MOS-transistor) as part of an integrated circuit. It served as the common design in all the various types of chips that would follow in the decades to come. ${ }^{131}$ The years between 1965 and 1975 proved to be a defining period, as various chip manufacturers introduced a polysilicon gate MOS-transistor (or in short, polygate transistor) to the market. This particular variation marked the breakthrough of the MOS-transistor chip at the expense of its competing alternatives. Moreover, it would remain the predominant manufactured chip configuration for several decades.

In their article 'Digital Foundations', historians Christophe Lécuyer and David Brock detail the industry-wide contingent, nonlinear, and painstaking efforts leading to the creation of this polygate transistor. ${ }^{132}$ They distinguish three benefits of the design that beat the competing alternative transistors, causing the breakthrough of the MOS-transistor chip in the chip industry. ${ }^{133}$

131 It has been argued that the 'polygate transistor' is even the most man-made object in the world - Brock and Lécuyer, 'Digital Foundations'.

132 Brock and Lécuyer, 'Digital Foundations'.

133 The first MOS-transistor was invented in 1959 already, at Bell Labs. It consisted of an aluminum as metal gate. The use of this material for the gate limited its success when compared to bipolar transistors. The polygate transistor changed that. According to the authors, the three benefits complied with chip user demands for speed, yield, and compatibility. Brock and Lécuyer, 'Digital Foundations', pp. 570 and 580. 
The first pertains to the issue of 'self-alignment'. This fabrication process is meant to ensure that the gate dielectric, gate electrode, and the channels are efficiently aligned. ${ }^{134}$ Self-alignment enabled efficient shrinkage of the transistor, enhanced its speed, and even improved the quality of the production process.

The second advantage is the 'low threshold voltage'. The threshold voltage is the current applied to the gate electrode to make the transistor 'switch', i.e. enable a current from source to drain. The lower the threshold voltage, the better, for this will limit power consumption and increase switching speed.

The third benefit of the polygate Transistor chip concerns the 'compatibility of materials'. In this case, every component consisted of silicon and silicon compounds with different electrical properties. The conductivity of the parts depended on the addition of respective positive or negative charged impurities, called dopants. The predomination of silicon secured a perfect chemical adhesion of the transistor's parts, in contrast to earlier variations of the MOS-transistor that partially consisted of aluminum. Under most circumstances, silicon tends to adhere to silicon best. This chemical compatibility of the polygate Transistor's components made this design very robust.

Through its three beneficial characteristics, the polygate transistor and its subsequent manufacturing process remained the standard for forty years. Figure 5 shows the manufacturing process of a polygate transistor as part of a computer chip. The manufacturing process consisted of two parts. In the first part, the wafer processing stage or 'front-end', the chip was manufactured on a thin silicon wafer. Through various deposition techniques the transistor was constructed. Thin layers of materials are patterned through the exposure of photoresist material by means of optical lithography, and successive etch processes of the exposed areas. In this process, lithography and the photoresist material define the dimensions of the electrical components integrated on a chip. In the second stage of the fabrication process, called 'back-end', the chips were separated from the wafer, and assembled and packaged to fit in a printed circuit board.

Of course, production processes of the polygate transistor chip were not immune to change. The product and its relatively robust manufacturing process enabled major innovations in chip applications. The prime examples of innovative chip designs are the 'dynamic random-access memory' (DRAM) chip and the first microcontroller, first introduced in, respectively, 1969 and 1971. It was also applied in another type of MOS-transistor, the 'complimentary metal-oxidesemiconductor' (CMOS) transistor, which became the industry's predominantly fabricated transistor in computer chips through the silicon gate innovation.

134 This in contrast to earlier methods, where 'engineers used wide tolerances in their microchip designs to ensure that the channels and gates of the transistors would align properly.' - Brock and Lécuyer, 'Digital Foundations', p. 573. 


\section{Figure 5}

Simplified outline of a production process for a polygate-MOS transistor by the 1970 s and early 1980s.

The fabrication process is depicted from the silicon ingot until the mounting of a finished computer chip on a printed circuit board. In particular the deposition fabrication processes are highlighted, due to their relevancy for this study. By contrast, the complex sequence for patterning - involving resist spinning, drying, exposure, and development - are discussed in a rather stepmotherly way.

\section{Description of fabrication process}

1. Wafering

\section{Acid strip}

3. Clean

4. Initial oxidation

5. Silicon nitride deposition

6. Photolithography processing

7. CD measurement

8. Visual inspection

9. Silicon nitride etch

10.Etch Inspection

11. Photoresist strip

12. CD measurement

13. Silicon oxide etch

14. Silicon etch

15. Final inspection

\section{Cross-sectional depiction on a silicon wafer}

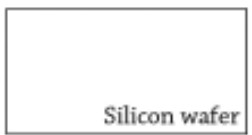

Silicon nitride
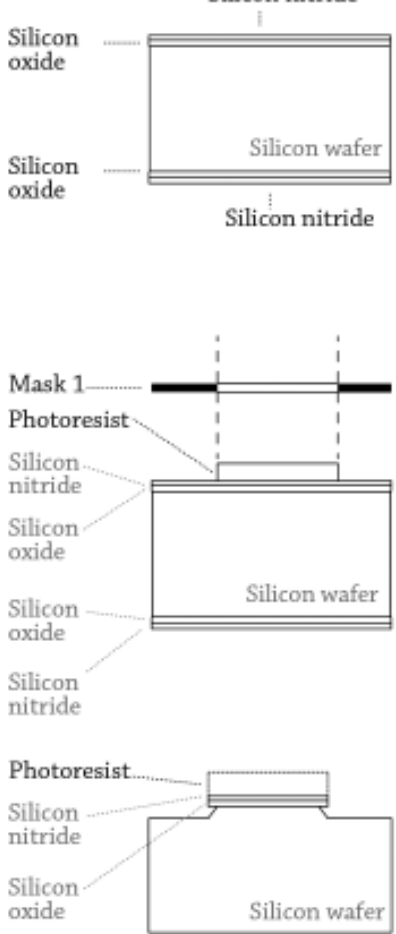

\section{Fabrication technology}
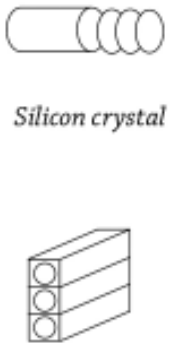

Oxidation/LPCVD furnace Oxidation and deposition of silicon nitride

(41-present

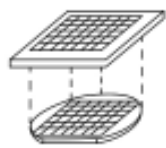

Wafer stepper (lithography) Mask 1

(28) '84-'88

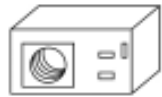

Plasma etch Removal of silicon nitride, photoresist, and silicon oxide 


\section{Description of fabrication process}

16. Field oxidation

17. Oxide etch on upper side wafer

18. Silicon nitride etch

19. Oxide etch

20. Growth of gate oxide

21. Photolithography process

22. Virtual inspection

23. Hardbake photoresist

24. Boron implant

25. Gate oxide etch on backside

26. Photoresist strip

27. Clean

28. Polysilicon deposition

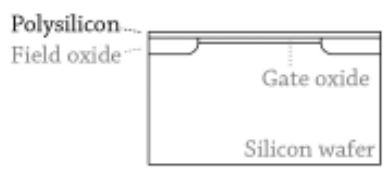

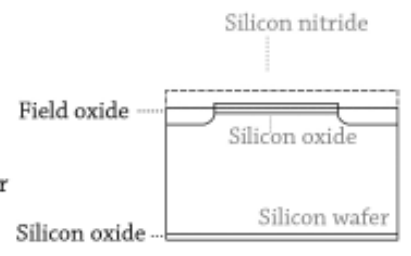

\section{Cross-sectional depiction on a silicon wafer}

\section{Fabrication technology}

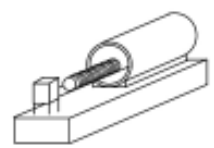

High temperature oxidation

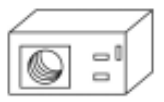

Etcher

Oxidation etch

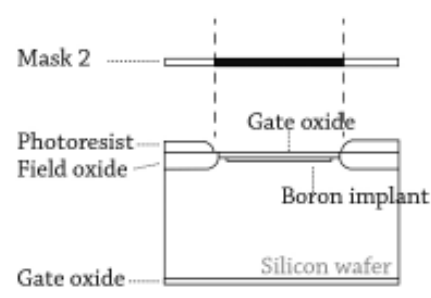
Photolithography
Mask 2

(6) '84-' 88

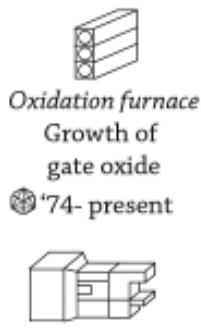

Ion Implantation Boron implant (4. '85-'88

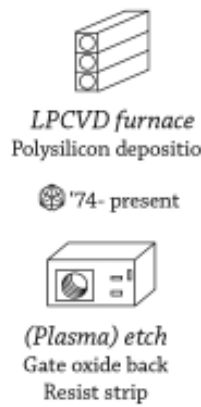

29. Photolithography process

30. CD measurement

31. Visual inspection

32. Hardbake photoresist

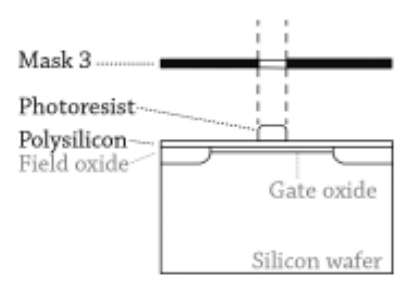

Photolithography Mask 3: Gate stack (28)' 88 


\section{Description of}

fabrication process

33. Polysilicon etch

34. Etch inspection

35. Photoresist gate strip

36. CD Measurement

37. Final inspection

38. Photolithography process

39. Visual inspection

40. Hardbake photoresist

41. Etch gate oxide

42. Etch inspection

43. Final visual inspection

44. Bake

45. Ion implantation source and draint

46. Photoresist strip

47. Final inspection

48. Chemical clean

49. Diffusion

50. Clean

51. Deposition phosphosilicate (PVX) glass

52. Clean/Densify

53. Reflow PVX glass

54. Chemical clean

55. Photolithography process

56. Visual inspection

57. Hardbake photoresist

\section{Cross-sectional depiction on a silicon wafer}
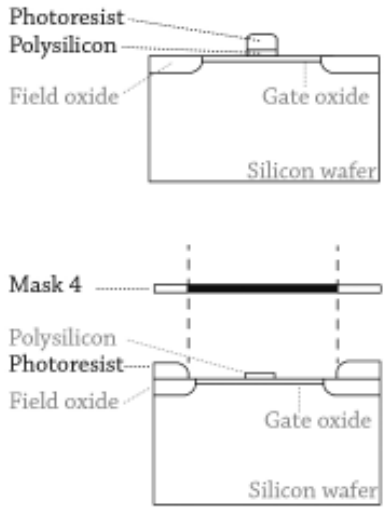

Polysilicon

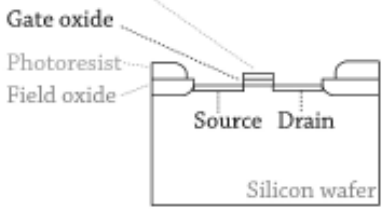

Transistor gate

Polysilicon electrode

oxide

Field oxide
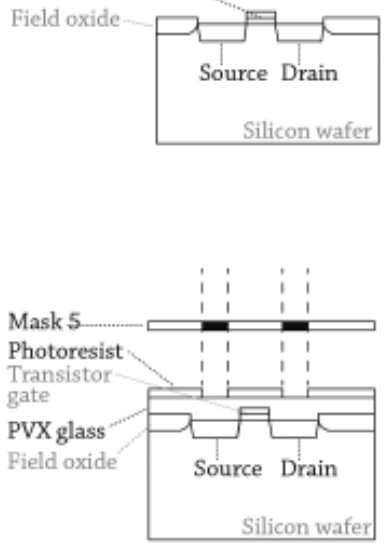

Fabrication technology

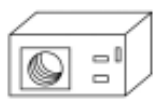

Plasma etch Removal polysilicon and photoresist gate

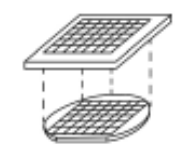

Photolithography

Mask 4

48. '84-'88

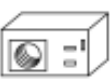

Etch Removal gate oxide

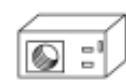

Etch Resist strip

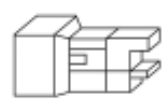

Ion Implantation Source and drain

(4) '85-'88

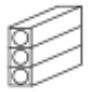

Diffusion furnace Source and drain diffusion

76-present

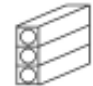

LPCVD furnace low temperature phosphosilicate

(PVX) glass

4. 76- present

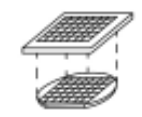

Photolithography Mask 5

(7) '84-' 88 


\section{Description of fabrication process}

58. Etch glass

59. Etch inspection

60. Photoresist strip

61. Final inspection

62. Clean

63. Metal deposition

64. Photolithography process

65. Develop

66. Visual inspection

67. Hardbake photoresist

\section{Cross-sectional depiction on a silicon wafer}

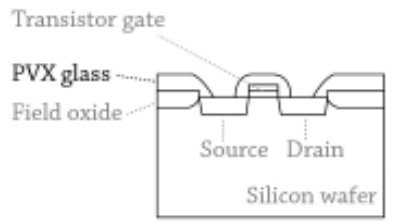

Transistor gate
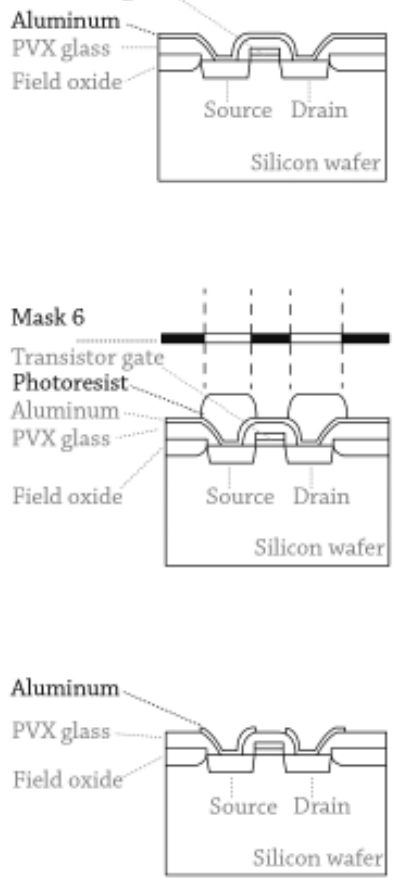

\section{Fabrication technology}

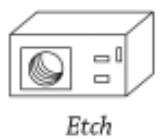

Remove glass Resist strip

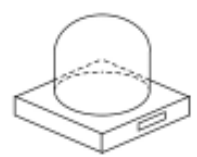

Metal deposition system Aluminum '81-'92

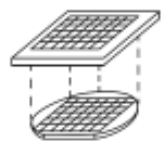

Photolithography Mask 6

82 '84-'88

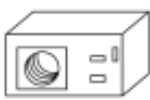

(Plasma) etch Removal of aluminum Resist strip

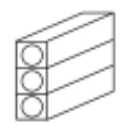

PECVD furnace Deposition of passivation film

84. 79-present 


\section{One CMOS devices}

(consisting of two polygate transistors, one NMOS and one PMOS)

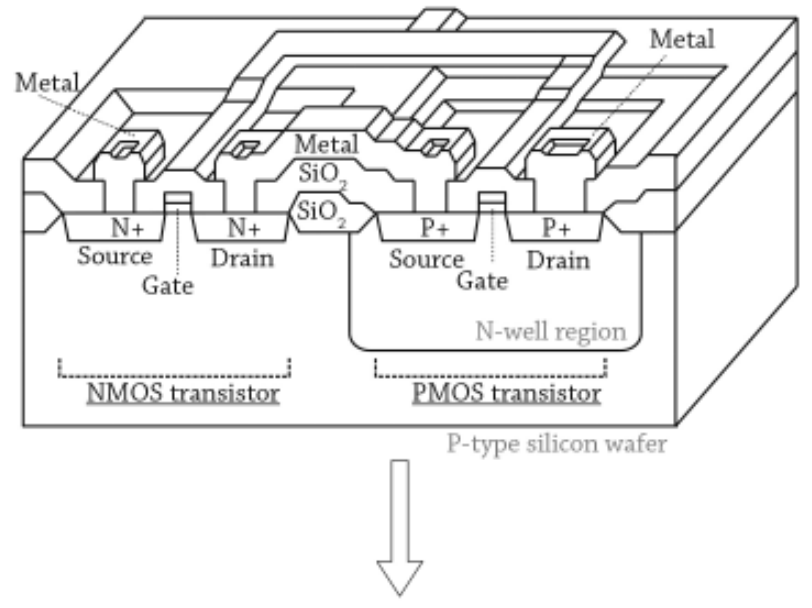

One computer chip (a die)

(consisting of a few hundred up to a few billion CMOS devices)

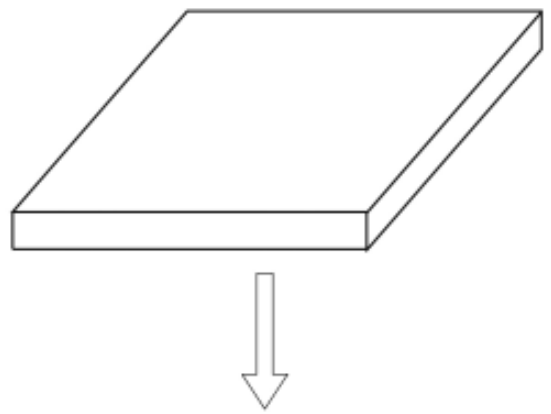

One silicon wafer

(containing hundred to thousands of dies)

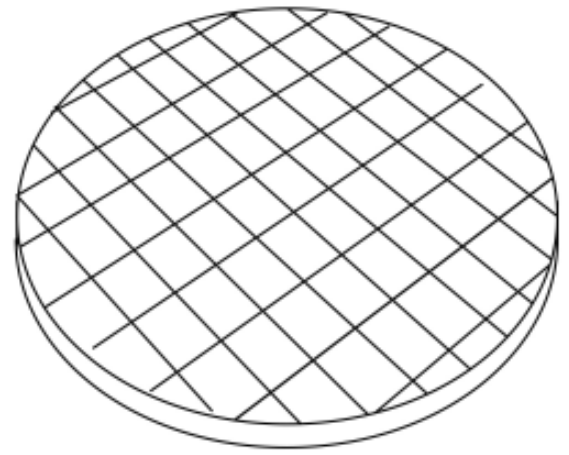




\section{Description of fabrication process}

\section{Simplified depiction of fabrication process}

Die Inspection

Electrical inspection of each die on a wafer.

Leadframe stamping

Leadframes are stamped from copper or iron-nickel, on which later the chips will be mounted. \&4. '78-present

Leadframe Plating

The leadframes are plated with silver or gold for electrical contact. \& '80-present

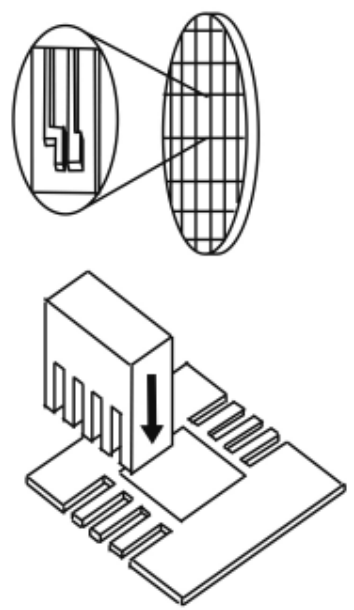

Die Seperation The dies are separated by diamond wafer saws.

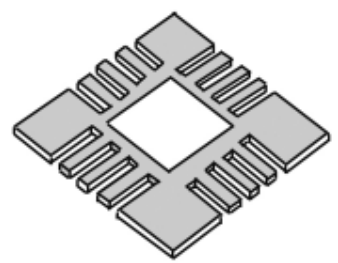

Die Bonding

The good dies are bonded on leadframes.

84 '81-present

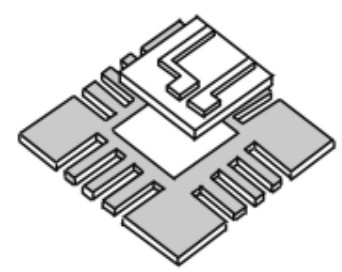




\section{Description of fabrication process}

Wire Bonding

Thin aluminum or gold wires are bonded between the die and the leadframe for electrical connection. 282 -present

\section{Encapsulation}

The chip is encapsulated in an epoxy cover by means of molds.

The package protects the chip and the wiring,

(4. '74-present

Trim \& Form

The chips are cut out from the leadframe, and the leads are bent in the desired form.

88 '78-present

\section{Mounting}

The chip is mounted on a printed circuit board.

48. '10-present

\section{Simplified depiction of fabrication process}
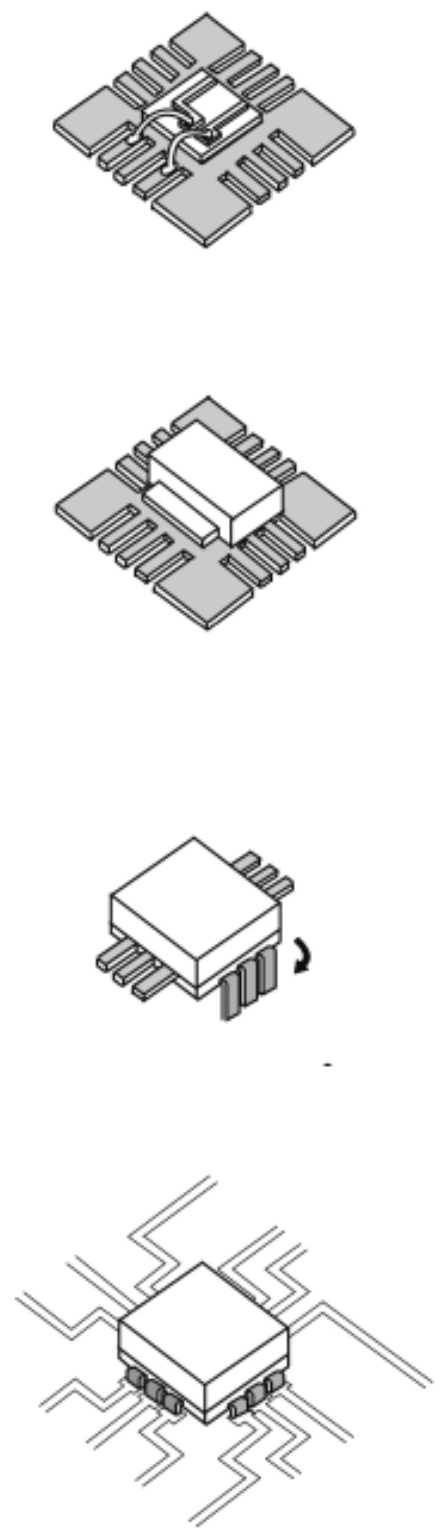
Many more variations of transistors and chips were manufactured before and after the introduction of the polygate MOS transistor chip, such as the bipolar transistor in a chip and germanium based discretes. However, these other designs have been manufactured in lower volumes than the polygate transistor as part of a computer chip.

\section{Moore's Law}

Simultaneously with the industry's development of the polygate MOS transistor chip, the issue of scaling surfaced. This would be the most profound characteristic of the semiconductor industry, one that also had distinct ramifications for society at large. The size of the components on a chip, such as a transistor, was constantly shrinking in order to increase performance and decrease cost. In 1965, this trend was captured in the famous Moore's Law. This - for clarity's sake, non-physical - law states that the number of transistors on a computer chip doubles every 18 months (figure 6). Consumers of electronics will have become familiar with its consequences: the rapid obsolescence of smart phones or computers due to their lagging computer power for satisfying the users' present needs.

\section{Figure 6}

Graph of Moore's Law: the original 1965 projection and its future course, 1960-2020

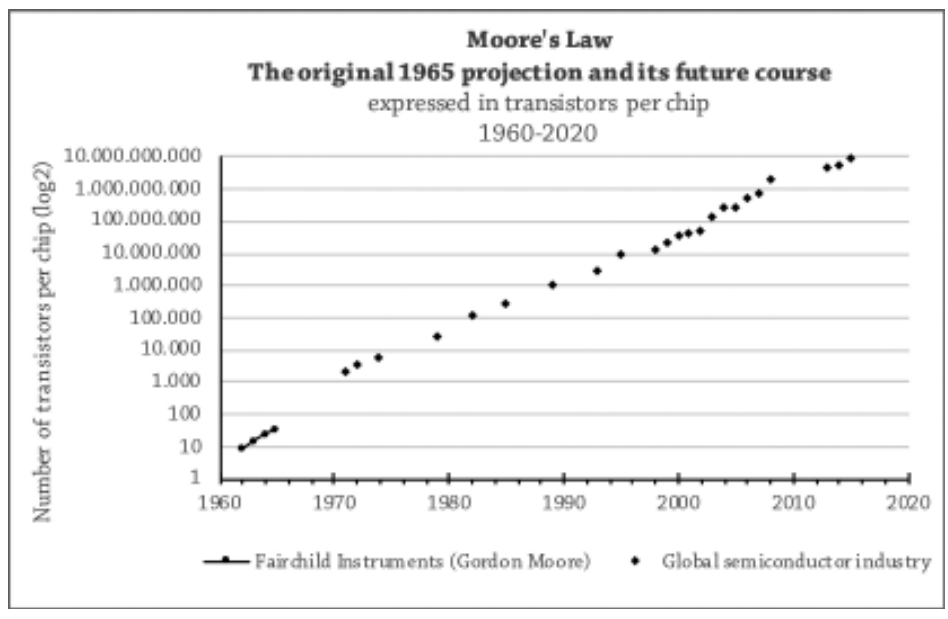

Numerous articles, analyses, alternatives, dismissals, predictions, and other statements have been written about Moore's Law. Most of them concentrate on the observation that it is a self-fulfilling prophecy, and that as an exponential development it cannot last forever. Without going into the details of these claims, I merely elaborate the relevant aspects of Moore's Law for this study. These 
aspects result from the understanding that the prediction was an inherent part of an industrial surge of innovation in semiconductor manufacturing techniques.

Moore's Law was pronounced in a context where multiple industrial and technological leaders contemplated an intellectual exercise to assess future technological and economic realities. ${ }^{135}$ These predictions were made in anticipation of emerging characteristics of chips. One of the particularities involved cost and performance of these transistors when miniaturized. ${ }^{136}$ In 1965, Gordon Moore, co-founder of Fairchild Semiconductors and Intel, also presented his expectation. So, what did he say, and why was it relevant for the semiconductor industry?

Moore was invited to formulate his expectations for the microelectronics industry in the industry trade journal Electronics in a feature dubbed 'The Experts Look at the Future.' ${ }^{137}$ The basic economic premise underlying his prediction was, as he wrote:

'Reduced cost is one of the big attractions of integrated electronics, and the cost advantage continues to increase as the technology evolves towards the production of larger and larger circuit functions on a single semiconductor substrate. ${ }^{\text {138 }}$

Moore counted the number of transistors on an integrated circuit since the invention in 1959 until 1965, recognized a trend and extrapolated it. The trend: every one or two years the number of transistors on an integrated circuit - a computer chip - doubles.

Although this observation had major technological ramifications, it was foremost a statement about economics. ${ }^{139}$ The trend identified by Moore was basically that miniaturization of transistors resulted in a lower cost of producing them. It was a rule of thumb for semiconductor manufacturing effectiveness.

135 David Brock, 'A Clear Voice: The Origins of Gordon Moore’s 1965 Paper', in: David Brock (ed.), Understanding Moore’s Law (Chemical Heritage Press, Philadelphia, 2006) pp. 25-36, pp. 26 and 27.

136 Initially this concerned bipolar transistors integrated on a computer chip, and only later the polygate MOS transistor.

137 Brock, 'A Clear Voice', p. 35.

138 This is taken from a reissue of the original paper Moore published in Electronics 38: 8 (194-1965) pp. 114-117, printed for the occasion of the fortieth birthday of his prediction. Gordon Moore, 'Cramming More Components Onto Integrated Circuits', in: David Brock (ed.), Understanding Moore's Law: Four Decades of Innovation (Chemical Heritage Press, Philadelphia, 2006), pp.55-61, p. 57.

139 Gordon Moore, 'Chapter 7: Moore’s Law at 40', in: David Brock (ed.), Understanding Moore’s Law: Four Decades of Innovation (Chemical Heritage Foundation, Philadelphia, 2006), pp. 67-84, p. 72. 
It took a while before the truism of Moore's prediction became apparent or even determinative in the industry. In the early 1970s, computer scientist Carver Mead found out that shrinkage not only reduced cost per transistor, but also increased performance of the integrated circuit. ${ }^{140}$ For this reason, miniaturization opened new applications for computer chips. While Moore originally based his prediction on bipolar transistors on a chip, the MOS-transistors would sustain miniaturization from the early seventies onward. In 1974, IBM engineer Robert H. Dennard, the inventor of DRAM memory, calculated how scaling of MOStransistors in an integrated circuit could be achieved. Ten years after his original statement, Moore himself evaluated and adjusted his original prediction slightly.

In time, the initial rather phenomenological assessment of computer chip shrinkage grew more applicable to the industry's needs. The discoveries that led to this awareness started with Moore's original prediction in 1965 and ended with Moore's evaluation by 1975 . This process of assessing the competitive significance of miniaturization for economics and performance coincided with the emergence of the polygate MOS transistor chip as the most common design. One might say, in other words, that his statement about miniaturization anticipated the course of technological development. Indeed, the polygate transistor in particular made Moore's Law come true.

From the mid-1970s on, Moore's own company Intel - established together with Robert Noyce in 1968 - became the major protagonist of Moore's Law. Meanwhile the rest of the industry came to the same conclusion about the economic need and technological benefits of the Law, resulting in its official institutionalization in the early 1990s. ${ }^{141}$ Enabling the shrinkage of MOStransistors became the major focal point of innovation in the semiconductor industry (figure 7). ${ }^{142}$

140 David Brock, 'Chapter 8: Reflections on Moore's Law', in: David Brock (ed.), Understanding Moore's Law: Four Decades of Innovation (Chemical Heritage Foundation, Philadelphia, 2006), pp. 87-108, p. 99.

141 For a well-researched study about the emergence of Moore's Law in the industry and its institutionalization in technology roadmaps, see Robert Schaller's dissertation. This author reports that the first references to Moore's prediction as Moore's Law originated in 1977 among Fairchild or Intel personnel. - Robert Schaller, Technological Innovation in the Semiconductor Industry: A Case Study of the International Technology Roadmap for Semiconductors (George Mason University, 2004).

142 A list of milestones enabling Moore's Law shows a clear predominance of process innovation, proving the point made. - David Lammers, 'Moore's Law Milestones', ieeespectrum.com (304-2015). 


\section{Figure 7}

Depiction of transformation of semiconductor chips over time according to Moore's Law The size of the transistor shrinks, and the number of interconnection layers increases over time. Smaller transistors enable faster processing of information. Moreover, if transistors are smaller, more fit on a chip, resulting in the ability to process more information. As transistors shrink and their numbers increase (Moore's Law), an increasingly complex web of interconnections is required to direct current to the transistors.

Not to scale.

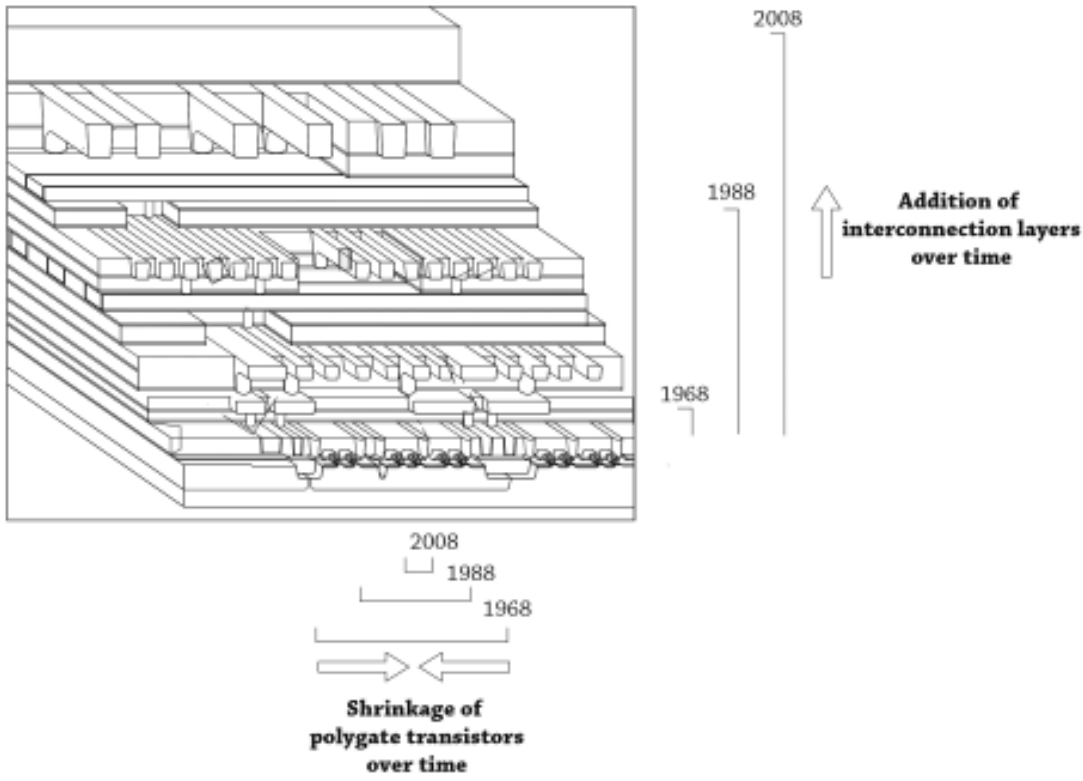

\section{Waves of innovation and the emergence of a dominant design}

The emergence of the basic configuration of a chip, its standard manufacturing recipe, and Moore's Law coincided with Arthur del Prado's decision to focus ASM primarily on semiconductor equipment. It also concurred with the advent of the merchant semiconductor equipment industry. Apparently, ASM - led by Del Prado - engaged the business of equipment manufacturing at exactly the right moment. It proved to be a contingency that would define the course of ASM's history and Del Prado's life

The impact of this contingency, or fortuna, may be explained by means of the concept of 'dominant design', introduced by James Utterback and William Abernathy as part of their framework for understanding waves of innovation. ${ }^{143}$ In his later monography entitled Mastering the Dynamics of Innovation, Utterback

143 James Utterback and William Abernathy, 'A Dynamic Model of Product and Process Innovation', Omega 3:6 (1975) pp. 638-656. 
defines a dominant design as a - rather Platonistic - template of how a product is 'supposed to look and operate'. ${ }^{144}$ His more concrete definition is:

'A dominant design in a product class is, by definition, the one that wins the allegiance of the marketplace, the one that competitors and innovators must adhere to if they hope to command significant market following. The dominant design usually takes the form of a new product (or set of features) synthesized from individual technological innovations introduced independently in prior product variants. ${ }^{145}$

Furthermore, the dominant design inherently involves a dominant production method, which constitutes the common processes required for the fabrication of the dominant design.

According to this idea, a new phase in industrial development is marked by the revelation of the dominant design. Before the surfacing of this design, competition largely depends on unique or innovative product designs. This leads to a higher rate of 'product innovations' compared to innovations in production, i.e. 'process innovations'. The rules of competition change through the emergence of the dominant design. In the subsequent new phase, competitiveness of firms depends increasingly on their capability to produce the design in a most efficient way. This results in a wave of process innovations.

It is difficult in most cases to identify a single moment at which a dominant design surfaces, because there is no unanimous ceremonial proclamation by members of the industry involved. The dominant design is the result of an uncoordinated gradual process of variation and selection among various product designs circulating among firms and throughout the industry. This is why commonly a dominant design can be determined more adequately in retrospect.

Projecting this model onto the chip industry, one may argue that the MOS transistor chip is a dominant design (figure 8). Its emergence in the late 1960s and early 1970s heralded a new phase in the industry's development. In this new phase, competitiveness depended on the manufacturing efficiency. In correspondence with Utterback and Abernathy's framework, this resulted in more inventions in the production process - process innovations - in comparison to the number of product innovations.

144 James Utterback, Mastering the Dynamics of Innovation (Harvard Business School Press, Boston, 1994), p. 25. 


\section{Figure 8}

Graph of waves of product \& process innovation, 1940-2020

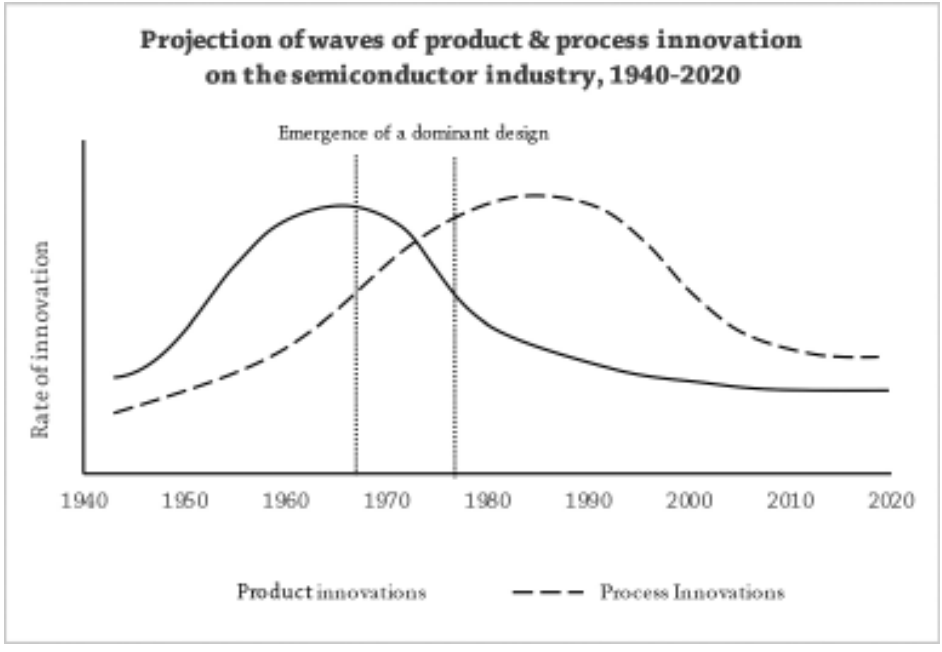

Semiconductor manufacturers, equipment manufacturers, and research institutes were the source of these developments. In particular, the semiconductor equipment manufacturers applied themselves to the innovation of manufacturing technologies. From the late sixties onward, then, the growth of the semiconductor equipment industry was propelled by the need to produce the dominant design most effectively.

\section{Quantity, quality and scaling}

Continuing the projection of the wave of process innovation onto the chip industry's history, we can assess how manufacturing efficiency was and would be achieved. This was done by complying to three requirements, of which the first two are rather common: the innovations had to increase the quantity of production per system or over the whole process and, second, the quality of the manufacturing process or individual techniques had to improve to secure a maximum number of working chips at the end of the production line. Thirdly, and this is where Moore's Law comes into play, the process innovations had to enable further scaling of the dominant design. This miniaturization of components constituting a computer chip - such as the dominant design - defines competitiveness for both the semiconductor manufacturers and the subsequent equipment industry. In the wave of process innovation, scaling in particular enjoyed specific attention from the industry.

In the semiconductor industry, there were multiple ways to increase the quantity producible. The more chips could be manufactured in one cycle, the 
lower the cost of owning the manufacturing plant. In this sense, throughput of one's manufacturing systems, or the output of chips, was defining. The quantity producible largely depended on the number of wafers processed per hour, the size of the wafer, and the number of chips resulting at the end of the production cycle. Increasing quantity would require innovations in various areas like automation, design, mechanics, and chemical processes.

Apart from improving capacity and process speed, another way to increase the quantity of production was by enlarging the wafers themselves. Bigger wafers could contain more computer chips. ${ }^{146}$ During the emergence of the dominant design in semiconductor technology, the years 1967-1973, the diameter of silicon wafers increased from 25 millimeters to 75 millimeters.

Each enlargement of wafers in the industry required and propelled tremendous process innovations and alterations to manufacturing technologies, from increasing the size of reactor chambers and modifying chemical reactions to new automation and controlling systems. The enlargements during the late 1960s were still quite straightforward, but future bigger wafers required increasingly more coordination among chip manufacturers, equipment suppliers, and wafer producers.

For the back-end of the chip manufacturing process, throughput was defined by the number of individual chips. In this phase, the chips were cut loose from the wafer. The more chips were bonded, wired, or encapsulated in one hour, the better it was. This was basically a matter of speeding up mechanics.

The issue of quality in manufacturing processes was evidently of importance. Apart from the production of high volumes, the number of deficient chips had to be as low as possible. Many things could go wrong in the long and complex manufacturing process of computer chips. In the semiconductor industry, this was managed through the parameter called yield. This variable indicated the number of working chips after the complete manufacturing cycle or individual processes thereof. Yield had to be as high as possible.

To achieve this maximum yield, the industry innovated numerous aspects of the semiconductor manufacturing process. ${ }^{147}$ Production processes had to be reproducible and of consistent quality. This resulted in automating the laborer out, computer-controlled processes, and constructing more clean environments like vacuum reactors or clean rooms. Also, the quality of the techniques had to

146 This enlargement of wafers was also required to compensate for the growing surface area of the chips.

147 In the case of the back-end manufacturing processes, quality primarily pertained to the quality of the encapsulation and assembly processes. The focus was predominantly on the quality of mechanics, rather than on the quality of chemical processes. 
be maximized to secure a maximum uptime of the system. The lesser servicing or fewer repairs a system required, the better for the user.

Returning to the issue of scaling to semiconductor manufacturing as part of the wave of process innovation, Moore's Law constitutes a guideline for innovating manufacturing technology. As expounded above, this law was originally an economic statement, and as such it would fit into the wave of process innovation. The ability to produce the cheapest transistors - and thus cramming as many as possible into a chip - determined competitiveness of chip manufacturers. A bit down the semiconductor manufacturing supply chain, the technological development at semiconductor equipment manufacturers was geared to achieving this parameter: how to enable further shrinkage of transistors as far as possible? With regard to process innovation, this was the major consideration, along with quantity and quality. ${ }^{148}$

Thus, according to the concept of Utterback and Abernathy, the emergence of the MOS-transistor chip dominant design defined the basic characteristics of a chip, its fabrication process, and the rules of competition during the wave of innovation. The particular matter of scaling - Moore's Law - can be understood in line with the surfacing of the dominant design and subsequent wave of process innovation. Shrinkage was a way to decrease cost per transistor, which later proved to improve and enhance the functionality of chips as well. Miniaturization of chip's components would become the most remarkable and determinative aspect of innovation and competition in the industry. This and the other basic premises of innovation in semiconductor manufacturing - quality and quantity - would define the dynamics in the chip industry.

The model as such helps to explain the relation between the emergence of a basic configuration of a computer chip, Moore's Law, and the forthcoming growth of ASM. It also sheds light on the technological dynamics faced by ASM later in its history. A basic product had been established through competition, and from now on it was the challenge to produce it most effectively.

148 One could sensibly argue that Moore's Law is also about quantity, for it is about integrating a maximum number of transistors in one chip. As indicated, however, quantity, quality, and scaling involve interrelated lines. 


\title{
Chapter 4
}

\section{ASM as original equipment manufacturer, 1969-1974}

\begin{abstract}
ASM's turn toward semiconductor equipment - and away from semiconductor materials - coincided with the emergence of something like a 'dominant design' in the chip industry. It was unforeseen, but unescapable for those active in the industry. Guided by his ambition to expand his role as representative - and thus his appropriable remuneration - Del Prado steered ASM down the path of semiconductor equipment manufacturing. Selling advanced innovations offered high returns. Moreover, he diversified his product offerings to increase the sales at his customers. On this route, ASM enjoyed fair weather, since it pursued new business opportunities that elaborated on the emerging 'dominant design' and manufacturing procedures.
\end{abstract}

\section{Industrial context:}

\section{Merchant semiconductor equipment industry}

With every new wafer size and the emergence of a dominant design, semiconductor manufacturing technologies became more harmonized across the industry. Semiconductor manufacturers still adapted the chemical and mechanical production processes to their respective needs. Yet more general patterns were found from one factory to the next. This applied to diffusion furnaces, as offered by Sola Basic, but also packaging materials. Encapsulation of transistors, microprocessors, and diodes involved a technique innovated by Fairchild Semiconductors in the mid-1960s. ${ }^{149}$ Instead of using previously common metals, the products were enclosed by ceramic or epoxy. The design, called a 'dual inline package', was adopted by all the other semiconductor manufacturers. The invention of this new standard in encapsulation became part of the dominant design's manufacturing process.

The harmonization paved the way for merchant semiconductor equipment suppliers. Fabrication technology no longer had to be developed or produced internally. External subcontractors could supply such technologies as well. Engineers and entrepreneurs, often formerly employed by semiconductor

149 Christophe Lécuyer, 'Silicon for industry: Component design, mass production, and the move to commercial markets at Fairchild semiconductor, 1960-1967', History and Technology 16:2 (1999) pp. 179-216. 
manufacturers, capitalized on their knowledge and experience by designing, producing, and selling semiconductor equipment.

New startups in the semiconductor industry often lacked the means to develop the manufacturing technologies by themselves, like the incumbent semiconductor manufacturers had done. For those enterprises, it was more lucrative to procure these techniques from the shelve. A early merchant equipment industry happily fulfilled this demand.

As technological developments moved fastest in the United States, with regard to new integrated circuits and production methods, this emerging merchant semiconductor equipment industry initially was an American affair. But Western Europe and Japan soon became actively involved as well. Semiconductor manfuacturers in those countries were eager to get their hands on the latest American manufacturing technologies.

\section{Corporate course:}

\section{Emancipation of a sales agent}

From the late 1960s onwards, Del Prado's interpretation of ASM's role changed. ASM increasingly had to overcome objections inherent to its expanded role of sales agent. On the one hand, the principals wanted their representative to focus solely on the task for which they hired it: increasing their sales and market share. On the other hand, ASM was fully aware of the risk of being exposed to the will of its principals. This chiefly entailed the risk of being excluded from lucrative markets - as in the Topsøe affair. As the market matured, the added-value of an agent diminished gradually. Del Prado wanted to prevent this risk of obsolescence by expanding his activities. Revenues from his sales were leveraged to the benefit of his ambitions. In the late 1960s, this ambition involved the familiarization and realization of local production and assembly. Soon this strategy of leveraged innovation became central to the entrepreneur's modus operandi.

The startup of Sola Basic Netherlands proved ASM's capabilities beyond its traditional job description. This development continued through an intensification of ASM's interactions with US Dynamic. In 1969, at the request of US Dynamic's major European customer Philips, ASM started the local assembly of the US Dynamic's gas dryers and purifiers. Gas control was crucial in the fabrication of semiconductors, and the local assembly of purifiers and dryers allowed Philips to shorten the supply chain for this vital technology. Moreover, it was more efficient to deal with the differences in the American and European metric systems and electrical standards. Based on the drawings of its principal, Van Beest assembled and procured the parts at ASM's office in Bilthoven. The assembly of US Dynamics products enhanced the accumulation of technological expertise at ASM over time.

Del Prado was keen on cultivating interest among his contacts among the European semiconductor manufacturers for the latest available semiconductor 
manufacturing technologies. He had been able to do so with Knapic's silicon, US Dynamic's gas handling equipment, and Sola Basic's diffusion furnaces. Through these successes, Del Prado developed the understanding that his principals bought access to his customers, or his market even. He had a market, and they could supply their products via him to this customer base. The geographical distance between the American and European continent fed this illusion. Starting companies in semiconductor manufacturing technologies had to rely on their experienced representative overseas. They lacked the resources and communication means to effectively control Del Prado's reputation. His substantial sales proved his competence. Non-compliance with his view would unleash his wrath, as Topsøe had experienced.

\section{Elaboration of affairs}

\section{ASM and the market for chemical vapor deposition}

Like Topsøe, another principal would learn the truth with respect to Del Prado's assumed proprietary market. Around 1969, ASM was hired as an agent to develop the market for chemical vapor deposition (CVD) furnaces on behalf of a new semiconductor equipment manufacturer, called Applied Materials Technology (further referred to as Applied Materials). Founded in the fall of 1967 by Michael McNeilly (1939-2005), this company was one of the first merchant manufacturers of CVD technology. Rather quickly, the demand for its chemical vapor deposition tools increased.

In line with his ambitions and earlier proposals to Knapic Electro-Physics and Sola Basic, Del Prado convinced McNeilly to start a local assembly and service operation in the Netherlands. ${ }^{150}$ After all, ASM had the right experience and it already procured certain parts locally when these had to be replaced. ${ }^{151}$ Moreover, the diffusion technology of Sola Basic and the CVD of Applied Materials were to some extent comparable, while ASM had a proven track record in setting up local assembly and service operations. McNeilly dispatched an employee by the name of Max Perez to explore together with ASM the local opportunities for such an operation.

History, however, seemed to repeat itself. Applied Materials withheld its support. McNeilly went back on the plans due to a slump in the American market in the years 1970 to 1971. Like Knapic earlier in Del Prado's career, McNeilly argued that such European assembly operation would create an overcapacity in manufacturing and deteroriate profits. After this unpleasant surprise for Del Prado, the relationship between the two companies deteriorated rapidly.

Martin van Beest, 'Interview with author'.

151 This involved for example, quartz chambers. - Martin van Beest, 'Interview with author'. 
At the same time, Applied Materials added peripheral features and modules to its furnaces that conflicted with products of ASM's other principal, Sola Basic Netherlands. ${ }^{152}$ These were parts pertaining to the system's controllability. Selling the additional features of Applied Materials was not an option for ASM. Del Prado got squeezed between his principals, while Applied Materials did not engage his proposal. By 1971, the Applied Materials-ASM agreement was dead, implying that ASM lost its primary supply of CVD equipment.

Del Prado turned to Sola Basic Netherlands to assess whether they were willing to seize this opportunity in the European market. Due to their experience in the partially comparable diffusion technology and existing manufacturing capabilities, this operation was well suited to supply CVD systems for European customers. Moreover, at the start of Sola Basic Netherlands, Del Prado already had bigger plans with this operation. As shareholder, he regarded Sola Basic Netherlands as the perfect vehicle for responding more adequately to local market opportunities, without having to rely on the slow response by the headquarters in Milwaukee. ${ }^{153}$

Due to Applied Materials' withdrawal, the European CVD market was up for grabs, at least temporarily. It seemed a perfect opportunity for Sola Basic Netherlands to substantiate the plans Del Prado had in mind all along. Until Applied Materials would hire a new agent or start its own sales office, there would be a vacuum in the supply of CVD technology. Unfortunately for ASM, Sola Basic Netherlands' parent company refused to cooperate. Sola Basic Industries was quickly developing into a conglomerate, in line with the popular business philosophy of the 1960s and 1970s. Semiconductor equipment was just one of the operations, and the management of Sola Basic Industries was not interested in the newly arising possibilities in this segment. It had more urgent fish to fry.

Del Prado was furious and felt betrayed. A major opportunity evaporated right on his watch due to unenterprising short-sighted management. Meanwhile, he was expected to continue his work as a simple agent. This offended him deeply. He was not just an agent like the ones in the United States. Del Prado had developed the Western European market for Knapic Electro-Physics, Sola Basic Industries, and the likes of Applied Materials years before these companies were even ready or willing to enter the European market. No one had the experience, network, and capabilities that he had. On top of that, ASM had proven its manufacturing capabilities during the start-up of Sola Basic Netherlands in a situation where few

152 Arthur del Prado, 'Letter to F.H. Roby, president Sola Basic International: Reply to letter' (10-5-1972) Arthur del Prado Archive - Sola Basic File, p. 1.

153 Ibid, p. 2. 
had the capability or the knowledge of the burgeoning semiconductor equipment market and technologies.

Fortunately for Del Prado, he had winning cards. The first was a special - or one-issue - order from IBM Sindelfingen for a silicon oxide CVD furnace. ${ }^{154}$ In the light of the recent events, he was not willing to forward this to Applied Materials, while Sola Basic was not interested to pick it up. Del Prado's second asset was Martin van Beest. Van Beest had proven himself to be a creative, energetic, and hands-on engineer, capable of rapidly absorbing new technological information and developments. While Del Prado formed the heart and brain of the small venture, Van Beest had become its technical conscience. As Del Prado approached Van Beest:

'Those lousy Yanks! They promise you something and then fail to deliver! We are going to do it ourselves! ... You know what these things look like. You know their strengths and weaknesses. We will manufacture them ourselves!'155

With some external support, Van Beest developed a piece of equipment that complied with the IBM order. In the attic space of their office mansion, Van Beest built a first silicon oxide reactor (for more on the development of this system, see Chapter 7). The resulting so-called SOX 10-2 marked the transition of ASM from representative to original equipment manufacturer. Luckily, IBM Sindelfingen accepted the order.

Del Prado had cast the die. The decision to move ahead and manufacture his own chemical vapor deposition systems was bold and risky. The dismissal by McNeilly and Sola Basic's headquarters of his envisaged role as representative backfired on them, just as in Topsøe's case. In his thirteen-year career, Del Prado made similar moves that appeared to the outside world as rather audacious and hazardous. From his point of view, he surely took a risk, yet it was a calculated one. He was able to make these moves because he was on top of his Machiavellian game - technology-wise and business-wise.

\section{Engaging the market for semiconductor packaging technologies}

Some of the new technological opportunities emerged right under Del Prado's nose. Around 1971, traveling in the United States, the entrepreneur learned about a Dutch company active in semiconductor manufacturing technology. ${ }^{156}$ Apparently, he had not been alone under the Dutch skies after all. The company

Martin van Beest, 'Interview with author'. 
in question was Fico Toolings, a family business located in the village of Herwen, near the German border. After the establishment of Fico Toolings in 1956, its cofounder and manager, Richard Fierkens, decided to specialize in fine-mechanics. To be more precisely, Fico designed and manufactured molds and stamps used in a big variety of products: from plastic cloth hangers and milk crates to transistor packages.

Fico Toolings, including its employees, had a solid base in its local rural environment and agricultural life. Farmer's wisdom, craftsmanship, and an entrepreneurial spirit had driven the company into the semiconductor industry. In 1966, the company started to design and manufacture stamps and molds for the semiconductor factory of Philips in Nijmegen. ${ }^{157}$ These molds were used to enclose and protect the transistor in the final stage of the fabrication cycle. The molds designed and manufactured by Fico Toolings elaborated on one aspect of the emerging dominant design for semiconductors: the dual inline package.

Fierkens and his team at Fico Toolings improved the reliability and accuracy of the molds. This involved short and intense heating of the chromized mold to kill further shrinking and expansion. Eventually, Fico Toolings also got involved in other aspects of semiconductor packaging and assembly beyond producing molds and stamping lead frames. For example, it developed and built hydraulic or manual presses used for trimming and forming the chip after encapsulation. Gradually its customer base among semiconductor manufacturers expanded. By the time Del Prado learned about Fierkens' company, Fico Toolings sold its products to Philips Semiconductors Nijmegen, Texas Instruments Almelo, Robert Bosch Reutlingen, and Motorola Toulouse. ${ }^{158}$

After initial contact, the 41-year-old Del Prado and the 37-year-old Fierkens decided to join forces. ${ }^{159}$ ASM was hired as an agent to develop the Western European market beyond the Netherlands in 1972. At that time, Fierkens employed about sixty-five employees, while ASM just a couple. The Dutch market would be covered by Fierkens himself. A specialized sales and marketing manager of ASM, Wim Petterson, traveled across Europe in order to sell Fico's products. ${ }^{160}$ Del Prado and Fierkens hoped that utilizing the sales and marketing network of ASM would improve both companies' exposure to the semiconductor industry.

157 Richard Fierkens, Hightech in een boerendorp. De biografie van Fico-ondernemer Richard Fierkens (Herwen 2014), p. 71.

158 Ibid. p. 90.

159 Ibid. p.94,

160 Later, after the establishment of ASM Asia in 1975, he traveled to various parts of Asia. Furthermore, parts of Eastern Europe were visited by Petterson as well. 


\section{Becoming an original equipment manufacturer}

In the years 1973 and 1974, ASM consolidated as an equipment manufacturer. This started with the deterioration of the relationship between ASM and Sola Basic Industries. The new activities of ASM into CVD technologies overlapped with some of the products offered by Sola Basic Netherlands. ASM could not adequately represent its principal while selling its own technology at the same time. Also, Sola Basic Industries' refusal to have its Dutch operation pursue local opportunities caused Del Prado to question whether Sola Basic and ASM were on the same page. Why participate in a joint-venture if this operation was not allowed to be entrepreneurial to Del Prado's standards? Furthermore, competition had increased with the advent of Thermco as one of the leading manufacturers of diffusion technology. Perhaps, ASM could develop its own furnaces over time as well.

The rising frictions between Sola Basic Industries and ASM resulted in the latter's leaving the Sola Basic Netherlands joint-venture in 1973. The other participant, Claude Varnier, the agent for Sola Basic in France, remained. As a consequence, the old division of labor between Varnier and Del Prado originating from their Knapic Electro-Physics days - was ended. In July 1973, Del Prado established a third foreign sales office: ASM France, located in Montpellier.

Del Prado's divestment from Eurolectron in 1974 was another step in the firming as equipment supplier. After establishing the business together with his brother-in-law Herman Jonge-Poerink, Del Prado never committed himself to this company, in which at the start he invested a mere 1,000 Dutch guilders. Eurolectron had grown under the management of Jonge Poerink as venture in printed circuit boards, while Del Prado officially remained co-owner.

But his participation made little sense anymore, and he was requested to end his involvement in Eurolectron. Although ASM was doing well and he did not need his participation in this other company as a safeguard anymore, the divestment was accompanied by a severe struggle. Once again, Del Prado seemed not to be willing to give up any activities without a fight, even when his involvement had been marginal at best.

A final step in the consolidation of ASM as equipment manufacturer was the take-over of Fico Toolings on February 22, 1974. Fierkens' original shareholders indicated that they wanted to relieve themselves from their involvement in the company, as they were predominantly old of age. Not willing to become major shareholder himself, Fierkens asked Del Prado to acquire the shares. Henceforth ASM acquired a controlling interest of 65 percent in Fico Toolings. A few years later, Fico Toolings was formally incorporated into ASM under the name of 
ASM Fico. ${ }^{161}$ Through its controlling interest in Fico Toolings, ASM became a de facto manufacturer of semiconductor backend materials. The new Fico earnings supplemented the development of the wafer processing activities. In just a few years, coping with these developments, Del Prado transformed his agency into a representative with its own products and manufacturing operation.

Through several developments - each with their own logic and rationale ASM traveled further along the path of semiconductor equipment technologies. This started with the annulment of Del Prado's silicon business in the wake of the Topsøe affair. A variety of subsequent steps - he participation in Sola Basic Netherlands, the US Dynamics local assembly, the termination of the Applied Materials and Sola Basic agencies, Del Prado's quitting Eurolectron, and the cooperation with Fico Toolings - would complete ASM's transformation.

After the industry settled on a basic chip design, added value was to be gained by innovating semiconductor manufacturing technologies. As equipment manufacturer, ASM was capable of addressing this new opportunity more effectively, instead of merely selling others' products. This called for innovation, however (see Innovation I). The necessity to innovate created new challenges and required other capabilities and resources than the ones developed by ASM as a simple representative. To overcome this, Del Prado leveraged the profits from his agencies - Fico Toolings and others - in support of the starting manufacturing operation in Bilthoven.

ASM attracted young engineers who wanted to engage the fascinating chip industry. In the Netherlands, there were not so many options beyond Philips. Moreover, working at ASM proved to be adventurous and exciting. Its engineers, including Van Beest, Petterson, and Wiebe de Boer, witnessed the immediate impact of their work on the success of ASM. They were allowed to be inventive and bold in developing technologies or securing sales. The presence of these enterprising engineers enabled the company to be lean and adaptive.

Del Prado himself ran the company still most economically. Through his keen sales and marketing capabilities, he presented ASM as a supplier of innovative and advanced technologies. The commercial brochures mentioned the latest

161 March 1, 1973, Del Prado became member of the Supervisory Board of Fico. In 1976 Fico divested a factory called Nobuwin, which specialized in molds used in the plastics industry and which in 1969 it had acquired from an acquaintance of Fierkens. After the divestment, the founder and former seller of Nobuwin, Jaap van Noort, became owner again. In addition, Fico acquired another molding manufacturer called Muroon on March 7, 1975, and renamed it Fico Limburg. It was located in Brunssum, the Netherlands. At that moment, Fierkens would exchange his shares in Fico for shares of ASM whenever the latter would be publicly listed. In 1980, in preparation of the initial public offering of ASM on the Nasdaq Stock Exchange, ASM acquired all the shares of ASM Fico. - Fierkens, Hightech in een boerendorp, pp. 96-97. 
features for its technologies, just like the ones offered by competitors. In most cases, these attributes were developed and integrated in a product only after a customer ordered it. Only by means of an order were the young engineers allowed to innovate and improve the products in line with their advertisements. Luckily, they were highly creative and inventive, which is why ASM succeeded in expanding its product portfolio in a salutary and most economical fashion. 


\section{Chapter 5 \\ Globalizing operations, 1975-1977}

Notwithstanding the fact that ASM had just began to manufacture its own products, Del Prado globalized the company's presence. As a natural salesman, he knew that in order to sell his products, he had to be where the customers were. In the 1970s, his customers were not so much in Europe anymore. To appropriate future growth, Del Prado established subsidiaries in Hong Kong and the United States.

\section{Industrial context:}

\section{A limited European market}

In the early 1970s, ASM was confronted with several limitations of the European chip market. Four factors in particular complicated ASM's ability to compete as European semiconductor equipment manufacturer in the European market: the European disadvantage in chip technology, notably as regards anticipation of the emerging dominant design; increased competition among European chip manufacturers, as American companies started European operations; sharp price reductions of chips, which brought European manufacturers to bay; and impediments of Cold War politics. These four factors made internationalization indispensable for ASM's survival.

First, the European semiconductor industry increasingly lagged behind its American counterpart. As argued by Malerba, in the early 1960s the European industry missed the boat technologically due to its sluggish anticipation on integrated circuits and the planar process. ${ }^{162}$ Only after five years, European manufacturers like Philips succeeded in innovating and introducing their own chips. But these consisted predominantly of bipolar transistors, rather than MOS-transistors - which would become the dominant design for the industry - prolonging the technological disadvantage of European semiconductor manufacturers.

This disparity proved beneficial for Del Prado as a trader. But this situation was hardly favorable for a beginning European equipment manufacturer. Chip manufacturers had to be convinced to procure from an unexperienced, and

162 Malerba, The Semiconductor Business. 
unknown equipment manufacturer, instead of relying on the readily available American suppliers with more proven products.

Secondly, the establishment of European subsidiaries by American chip producers made it more difficult for the European equipment suppliers to compete. ${ }^{163}$ Through these subsidiaries, the advanced and more attractive American chips became more readily available on the European market. At a time when geographical distance strongly determined competitiveness, this move deteriorated the position of the traditional European semiconductor manufacturers. Their home advantage evaporated.

For ASM, this new group of customers did not necessarily increase the potential market for its own equipment. The American chip manufacturers often developed their manufacturing technologies in-house or procured their equipment from the same sources as in the United States. In some instances, ASM merely succeeded to sell one-issue machines for research and development purposes. ${ }^{164}$ Apart from the ongoing agencies of American products, it remained difficult for ASM to sell its own equipment.

Thirdly, this was even aggravated further by severe price reductions. In the late sixties, Fairchild had taken its competitors by surprise by drastically cutting the price of its computer chips. It had done this in order to gain market share, and to make chips attractive for commercial - instead of military - applications. It was a revolution. The European semiconductor industry had barely managed to develop competitive chips, or they were forced drastically to optimize their costly production operations.

The American companies managed to cope with price reduction by innovating the manufacturing processes and offshoring some segments of their laborintensive production. In his article 'Silicon for industry', historian Christophe Lécuyer describes the actions taken by Fairchild in this effort. ${ }^{165}$ He lists four modes of cost reduction: adjusting the chip package design, improving quality and quantities of production, more automation and mechanization, and offshoring assembly plants to the Far East. As Lécuyer describes:

'Rather than "automating the labor out" in transistor and integrated circuit assembly, Fairchild's mass production-oriented engineers sought to increase the productivity and reduce the cost of manual labor to each device. ${ }^{.166}$

Malerba, The Semiconductor Business.

Gerard Smink, 'Qoutations Book ASM' (1971) - Personal collection Gerard Smink 
In other words, offshoring assembly operations was Fairchild's solution to bring down labor costs - initially to Maine in 1962, and next to Hong Kong in 1963. Lécuyer mentions the huge difference in hourly rates for an assembler in the Bay Area and in Hong Kong: $\$ 2.80$ versus 25 cents, respectively. ${ }^{167}$ Furthermore, there was an abundance of engineers in Hong Kong eager to find a job. It took several years before other semiconductor manufacturers would follow Fairchild's example. RCA opened a semiconductor operation in Taiwan in 1970, Motorola in Hong Kong in 1968, and Philips in Hong Kong by $1969 .{ }^{168}$ Offshoring assembly operations had become a standard recipe to cope with the reduced prices of chips. The decision to offshore implied definite separation of wafer processing operations from the assembly and packaging production steps. Never again would these production processes be housed together.

The price reductions bore consequences in particular for Fico Toolings. The other developments - Europe's technological disadvantage and increased competition - mainly affected the products made in Bilthoven, rather than those of Fico Toolings. The advent of the new dual inline package design caused by the price reductions propelled Fico's penetration of the chip industry. Its molds for this package found ready buyers. However, these price reductions created a problem as well. The offshoring of assembly plants limited the sales of Fico's molds in Europe, as more assembly and packaging operations moved to the East.

The fourth and final factor complicating ASM's ability to compete in Europe was caused by the Cold War. The political strife between the capitalist Western countries and the socialist Eastern European countries led to specific economic restrictions. The American allies - almost all united in the North Atlantic Treaty Organization (NATO), except France - had agreed to restrict their trade in strategic goods with communist countries. High-tech products like chips or semiconductor equipment and materials were regarded as strategic in particular. It was evident that the communist economic and technological progression should not be stimulated by a transfer in know-how via trade links. This meant that the geographical European market was limited to Western Europe.

Whereas ASM's in-house manufactured CVD systems were not distinctive enough for the more advanced Western European market, it enjoyed the particular interest of the Eastern European semiconductor manufacturers. These customers were eager to lay their hands on any advanced piece of semiconductor technology, just as Western European manufacturers wanted to buy the American technology. Selling in Eastern Europe would guarantee ASM healthy margins and substantial sales. Being an entrepreneur pur sang, Del Prado had already

167 Lécuyer, 'Silicon for industry', p. 202.

168 In Hong Kong, Philips established an assembly operation for discrete products, called EDL. Philips owned 90 percent of the shares, while the rest was owned by Tommy Zau. 
scrounged the shielded but eager Eastern European market for his own products. Selling the equipment below the radar, via Switzerland, into a market that was willing to pay a very substantial price had offered some financial consolation for ASM's CVD and gas equipment activities. The American competitors were much more bound by their national export rules. ${ }^{169}$ By selling this equipment in Eastern European companies, Del Prado capitalized on his intrepidness and his proximity to this market. Be that as it may, the required efforts and prudence seriously limited prospects on the Eastern side of the European continent; ASM was geographically and politically bound to the Western European market. ${ }^{170}$

It became more challenging for ASM to compete with its in-house developed and manufactured products in the early 1970s. This situation was aggravated by its decreasing activities linked to selling the products of other companies, the Fico Toolings molds excepted. American equipment vendors did not have to use an agent like ASM anymore, as the viability of the market was more certain. ASM had to compete with its own products against American and some European equipment and material suppliers. In this European context, expanding the company became increasingly problematic.

\section{Corporate course: \\ Seeking growth abroad}

In a fairly quick succession of moves, Del Prado expanded ASM's presence in two new playing fields: South-East Asia and North America. The sustainable

169 During the Cold War, the European allies of the United States in the strife against Communism were not as straight-lined as the Americans. Western export restrictions toward Communist countries were codified in the so-called CoCom (Coordinated Committee for Multilateral export Controls). By the mid-seventies, the Western European countries relaxed the CoCom agreements, while the United States still maintained its strict export limitations. The European reality was not the American one, separated as it was from the direct communist threat by the Atlantic Ocean while there was no division among its own people, as in the case of the Germans. However, by the late 1970s, the US Congress considered adjustment of export restrictions for older semiconductor technology, as it was harming its own competitive position. This was something very closely watched by Del Prado, as proven by the numerous American news articles discussing this matter he saved in his archive. Relaxation of export restrictions would allow him to export ASM America's technology to the East. He tried this already by exporting an LTO system via ASM Europe, dispatched to India and transported in a van across the Himalaya into China, a scheme that eventually was detected by the American authorities in the late 1970s. - Jorijn van Duijn, BA Thesis: [In Dutch] (Utrecht University, 2011); Del Prado's news articles about export restrictions Arthur del Prado Archive - Newsarticles '70s-'80s; Don Jackson, 'Interview with author'.

Still, Del Prado would continuously try to export to communist countries, even including China. In this, he was not alone. All major competitors tried to sell their tools to these countries. Often this happened via distributors in India, Korea, Hong Kong, etc., which would ship the tools to China. 
and accurate molds of ASM Fico enjoyed interest in Asia and the United States, forming the stepping stone for ASM's new global activities. ASM's own gas and CVD systems were not yet distinctive enough in the European market to win attention elsewhere. But these technologies required an international base to mature, while also urging expansion of the new manufacturing operation in Bilthoven.

ASM lacked a reputation supporting its claim of relevance and competence in CVD technologies. It competed with the more proven products of its former principals, but most European chip producers were not yet eager to buy ASM's own products. Starting operations in the United States, enabled access to the American market and technology, which would strengthen ASM's reputation and capabilities. Beyond the pursuit of commercial opportunities, then, establishing a footing in the major markets for semiconductor technology was vital for ASM if it was to become an established semiconductor equipment manufacturer.

The new American and Asian operations were managed decentrally. Each of the new operations started from scratch, just like Del Prado had done at the start of his career while working for Dean Knapic. Elaborating upon his own experience in cultivating customer relations, Del Prado granted his new subsidiaries significant autonomy. The new additions obtained valuable information about local opportunities and determined a course of actions in pursuit of them. In this effort, Del Prado remained closely involved, ensuring his role as pivot and defining the strategy.

\section{Elaboration of affairs}

\section{Establishing ASM Asia in Hong Kong}

By 1974, ASM's best-selling products were Fico Tooling's packaging technologies. But the company also had an agency for epoxy from an American chemical company called Morton Chemical. ${ }^{171}$ Epoxy was the material that filled the trenches of Fico's molds and encapsulated the transistors. Both agencies complemented each other perfectly. ASM could offer to customers both the molds and the material to fill the molds. This attractive combination became a stepping stone for elevating ASM beyond Europe.

The offshoring of assembly and packaging operations by semiconductor manufacturers offered new opportunities for Fico and Morton Chemical. In the slipstream of the chip manufacturers, the merchant equipment vendors followed

171 Initially, a representative of Morton Chemical located in the Netherlands approached Fico to sell its epoxy together with the Fico molds, as these products were complimentary. Fierkens suggested to sell Morton's epoxy via ASM. This prevented estrangement among other suppliers of epoxy, which might be used in Fico's molds elsewhere. Fierkens, Hightech in een boerendorp. p. 102. 
suit. Suppliers in assembly technology like Kulicke \& Soffa and Tempress formerly known as Sola Basic - opened offices in Hong Kong in, respectively, 1970 and 1972. ${ }^{172}$ Fico's American competitor in molds, Kras, followed in 1973. As the Fico and Morton combination proved to be very lucrative, it was simply a matter of time before ASM would join this development.

In 1975, Del Prado traveled to Hong Kong to start a sales office mainly meant to represent Fico and Morton products. ${ }^{173}$ By means of an advertisement, Del Prado announced his interest in hiring a sales representative. Three people were invited for the position. One particular individual was notable, the 27-year-old See Pong - Patrick - Lam. Del Prado hired Lam as his local sales representative, told him his job description, handed over some starting capital, and returned to the Netherlands shortly afterward. From Hong Kong, Lam had to cover the whole South-East Asian region for sales. It was the start of ASM's operations in Hong Kong, named ASM Asia.

For a small company like ASM, establishing and managing such a distant operation was all but a riskless venture. At the time, flying to Hong Kong from the Netherlands entailed several stop-overs and was quite an undertaking. Del Prado managed ASM Asia from a distance, primarily by means of telex communication. The venture's success, then, would largely depend on Lam's entrepreneurial activities in pursuit of local opportunities. As long as he kept Del Prado wellinformed about his actions, opportunities, and decisions, Del Prado trusted Lam, leaving him significant autonomy. It resembled the autonomy Del Prado had enjoyed himself when he represented Knapic Electro-Physics at the beginning of his career. From time to time, Del Prado and the designated sales officer Petterson traveled to Hong Kong to support and manage Lam's office.

Due to the complimentary business mix of molds and epoxy, and in particular owing to his entrepreneurialism and management skills, Lam succeeded in making his sales office very profitable. The decision to sell the Fico products in South-East Asia would in fact be defining for the subsequent history of ASM. The semiconductor assembly and packaging operations in the region would not leave. Even more, they would prosper and propel new innovations.

\section{Establishing ASM America in Phoenix, Arizona}

While the Hong Kong business got established, Del Prado began to look more toward the American market as well. In May 1974, ASM introduced its and Fico's

172 Patrick Lam and Edmund Lam, Soaring like Eagles: ASM's High-Tech Journey in Asia (John Wiley \& Sons, Singapore, 2006, p. 30.

173 Naturally, ASM Asia was expected to sell the other products as well. But in those days, the wafer processing industry was almost absent in South-East Asia. The business concentrated around the encapsulation and assembly areas in semiconductor manufacturing. 
products at the Semicon West Conference in San Mateo, California. ${ }^{174}$ The newly established branch organization for semiconductor equipment and materials, called SEMI, organized this event for the third year in a row in order to showcase semiconductor equipment and materials in the United States. Customers and suppliers met at this event to discuss business and upcoming technological developments. At Semicon West, Del Prado and Fierkens got in touch with Ed Foley. Foley sold equipment and materials in Phoenix, where since 1948 Motorola ran its semiconductor operations.

Foley enjoyed substantial business in the Arizona dessert. In the 1960s and 1970s, Motorola was the alternate number one or two in the worldwide semiconductor industry. The Phoenix area might well be dubbed Silicon Desert, due to the huge impact of Motorola's semiconductor operations on the local economy. Owing to his expansive network at this chip producer, Foley managed to introduce ASM and Fico to Motorola in 1974. Expectations were modest, as Motorola developed and manufactured almost all its equipment and materials internally.

One year later, however, a distinct opportunity presented itself. In the fall of 1975, Motorola reorganized its manufacturing operations. To reduce costs, in-house developments were stopped. This initially concerned the mold-making, but was also contemplated for other equipment and material departments. The annulment of the internal mold-making capability constituted a clear opportunity for Fico to get its products under the attention of this semiconductor powerhouse. Finally, the Motorola bastion seemed to provide an opening for merchant equipment and materials manufacturers, like ASM.

Surprisingly, the newly established Hong Kong sales office acted as a catalyst. In November 1975, Patrick Lam and Wim Petterson visited a Motorola assembly operation in Kuala Lumpur, Malaysia. ${ }^{175}$ To sell the Fico Molds and Morton Polyset epoxy, they met the person responsible for the mold operations. Coincidentally, this same man had been involved in the first contacts between Fico and Motorola earlier in Phoenix, and was familiar with the Fico products.

Through a contingency - or fortuna - the right Motorola manager was exposed to the Fico products at the right time. In those years, procurement of molds in the Asian assembly operations still required approval of the headquarters in Phoenix. ${ }^{176}$ The familiarity of the Motorola manager with the Fico products eased the sale of Lam and Petterson. ASM's quotation was well received by the

174 Stand 417 (Hall of Flowers) - Fierkens, Hightech in een boerendorp. p. 116.

175 E.J. Foley and Associates, 'Letter from Ed Foley to Art del Prado' (15-12-1975), Arthur del Prado archive - Ed Foley File; and Fierkens, Hightech in een boerendorp., p. 116.

176 Patrick Lam, 'Interview with author'; and Lam and Lam, Soaring like Eagles. 
manager. This was of particular importance, since the Motorola manager reported his satisfaction to the Motorola headquarters in Phoenix.

As it happened, the American Motorola operations needed new molds. In alignment with the emerging dominant design, Motorola opened new manufacturing lines for the production of MOS-transistor chips. In this context, Motorola moved its MOS operations to Austin, Texas, in 1975. Through this effort, the company was about to change the package of its chips, and a new package meant a few new molds. Because the Motorola management contemplated the procurement of these materials externally for the first time, as part of its reorganization, this constituted a major opportunity for ASM to do some American business. After Foley informed Del Prado that the quotation made by Lam and Petterson in Kuala Lumpur was received positively in Austin as well. For the first time, ASM sold its products in the United States.

Apart from creating the need for Fico's molds, the Motorola reorganization paved the way for the establishment of an American operation for ASM. The reorganization uncertainties had stirred its employees beyond the mold-making operations. Ed Foley had many contacts within the Motorola organization in Phoenix, and one of them was the 41-year-old Dr. Don Jackson. ${ }^{177}$ Jackson managed the epitaxial operation. In late 1975 it was not clear whether the epitaxial operation was part of the written-off materials operations. ${ }^{178}$ For this reason, Jackson was uncertain about his future at Motorola.

The world had been developing rapidly outside the safe walls of this vertical integrated semiconductor manufacturer. After the rise of the merchant equipment industry, the new opportunities kept pace with the rapidly advancing technological innovations in it. Furthermore, Motorola was no longer the only semiconductor manufacturer in the Phoenix area. In the 1970s, more companies opened factories or started new activities in the Phoenix area; Siemens, for example, did so in 1976. ${ }^{179}$ Many engineers, like Jackson and his colleagues, were anxious to join or to contribute to these new opportunities.

Jackson and Del Prado got in touch with each other through Foley. Fierkens and Del Prado had been contemplating an American operation for some time. To expand sales in the United States, ASM required its own stronghold in the area. Del Prado highly valued such strategic presence in the proximity of a major client,

177 E.J. Foley and Associates, 'Letter from Ed Foley to Art del Prado' (15-12-1975) Arthur del Prado archive - Ed Foley File.

178

179 Motorola engineer called Donald Dickson in 1960. Intel started operations in Arizona in 1979. - Author unknown, 'A Series of 1976 reviews of Don Hoefler's Microelectornics News', Integrated Circuit Engineering Collection - Project File 10085 (2-4-1976). 
if only, in this case, to deal with the different metric systems and standards. The timing seemed right, and Foley convinced the experienced and knowledgeable Jackson to explain his situation to Del Prado. ${ }^{180}$ Hoping to get his friends - ASM/ Fico and his Motorola contacts - to join forces, Foley proposed to launch an American subsidiary of ASM.

The men agreed upon their cooperation and this resulted in the founding of ASM America in May 1976. From the start, the American operation was not meant to be merely a sales office for the European activities of ASM. Jackson wanted to take advantage of his knowledge and experience in semiconductor manufacturing. Moreover, it should be ASM America's mission to access and exploit the local expertise in semiconductor manufacturing. ${ }^{181}$

Its Phoenix location provided ASM America the opportunity to tap into a stable engineering workforce, which was no longer available in the major hub for semiconductor technology, Silicon Valley in California. By the mid-1970s, Silicon Valley was already notorious for its being a Grand Central Station, where people constantly moved in and out. Such a business climate did not exist yet in Arizona, where ASM could attract and retain a stable, experienced, and loyal group of employees. On top of that, the presence of Motorola Semiconductors offered prospects for sales, a well-developed economic infrastructure, and a source of engineering talents.

For the start of ASM America, Don Jackson convinced some ambitious engineers, who had been working with him at Motorola, to join the ASM subsidiary. This included Dean Terry for the development of new measurement technology, and Ron Colvin for setting up a manufacturing operation. A controller and a marketing manager, as well as several other supporting staff such as secretaries, were hired, totaling about ten employees initially.

The American subsidiary operated under the umbrella of ASM - read Arthur del Prado's control - as a startup operation. It started from scratch, and it enjoyed a relatively high degree of autonomy in its pursuit of opportunities in the semiconductor equipment industry. With this freedom came the responsibility to secure its own success.

The future was uncertain, for ASM America still lacked a real product portfolio. Most of ASM's European products were not yet competitive, while intellectual property rights complicated the potential of some other products in the United States. But Del Prado offered Jackson and his employees the opportunity to commercialize their knowledge in a new semiconductor manufacturing startup.

180 E.J. Foley and Associates, 'Letter from Ed Foley to Art del Prado' (16-01-1976) Arthur del Prado archive - Ed Foley File.

181 ASM America, 'ASM America: A Pattern for Growth', Diamond Lattice - A publication of ASM America 1 (Sept/Oct 1980). 
The potential prospect of finding immediate relevance and results through their actions attracted the enterprising engineers.

Competing in the American market promised to be far from an easy ride. In particular in the United States, the developments in chip technology succeeded each other rapidly. The shrinkage of components on a chip and the growing applicability of these devices had increased the complexity significantly. By the mid-1970s, developing new generations of chips required more advanced manufacturing techniques in design (computer-aided design systems), metrology, automation, and deposition tools. Design and manufacturing of such complex chips required a total new level of competence, which initially was only available in the United States. ${ }^{182}$

Having an American subsidiary enabled ASM to be a more closely involved player in the industry. The engineers originating from Motorola were a major asset in this sense. Yet it would take time before it was possible to cash in on this knowledge. The first year, ASM America only offered the European products of its parent company: epitaxial furnaces, CVD furnaces, and gas purification equipment. At the same time, ASM America represented ASM Fico in the United States. It sold Fico's molding, stamping, cutting, and bending tools to American customers.

Ambitious as he was, Jackson had a couple of ideas of his own. He wanted to develop measurement and test systems. Del Prado had agreed to transfer the newest epitaxial furnace, called Epi 21-3 to ASM America. It was developed in the Netherlands, but as an expert in epitaxy, Jackson and his team got the assignment to modify it to their wishes and sell it. Initially this entailed the transfer of the sizes from the metric toward the imperial system. Unfortunately, the American-made Epi 21-3 only sold in Europe. ${ }^{183}$ Still, ASM was not capable of selling its CVD products in the most prestigious American market.

The real growth of ASM America originated from its own products. Jackson and his team expanded their product portfolio with a controller called Micon, a Low Temperature Oxide process in 1977, and a plasma enhanced CVD furnace in 1979 (see Chapters 8 and 9 for a detailed discussion). In combination with the CVD products and designs from Bilthoven, these products established ASM as a wafer processing equipment manufacturer in the worldwide semiconductor industry.

Malerba, The Semiconductor Business.

183 ASM America, Don Jackson, 'Telex to Arthur del Prado, ref: t1137.76' (9-11-1976) Archive Arthur del Prado-ASM America 1970s file. 
The globalization of ASM beyond Europe was propelled by ASM's transformation into original equipment manufacturer. The advantages of the European market were limited, as it lagged behind technology-wise and was highly competitive due to the presence of American chip and equipment manufacturers. The ASM products were not distinctive enough to secure healthy sales in this market. The Fico Toolings molds enabled access to the growing South-East Asian and prestigious American markets. And in the case of the latter, this justified the establishment of an American operation. ASM America granted access to the knowledge, capital, and entrepreneurialism of the American chip industry.

By 1978, the 47-year-old Del Prado had turned his initial solitary trading business into a multinational operation. ASM employed 243 employees, of which 160 in Europe, 59 in the United States, and 24 in Asia. The responsibility for sales shifted toward his new sales managers at ASM Asia, ASM America, in Bilthoven, and at ASM Fico. The total company accounted for sales of 31.1 million Dutch guilders, of which about 69 percent originated from ASM's own manufactured goods (figure 9). ${ }^{184}$ These consisted of the Fico molds, the various CVD furnaces from Bilthoven and Phoenix, and the gas flow equipment. ASM and its owner seemed to have found the right business in the form of developing, manufacturing, and selling semiconductor manufacturing equipment.

\section{Figure 9}

Graph of revenues Advanced Semiconductor Materials, 1968-1979

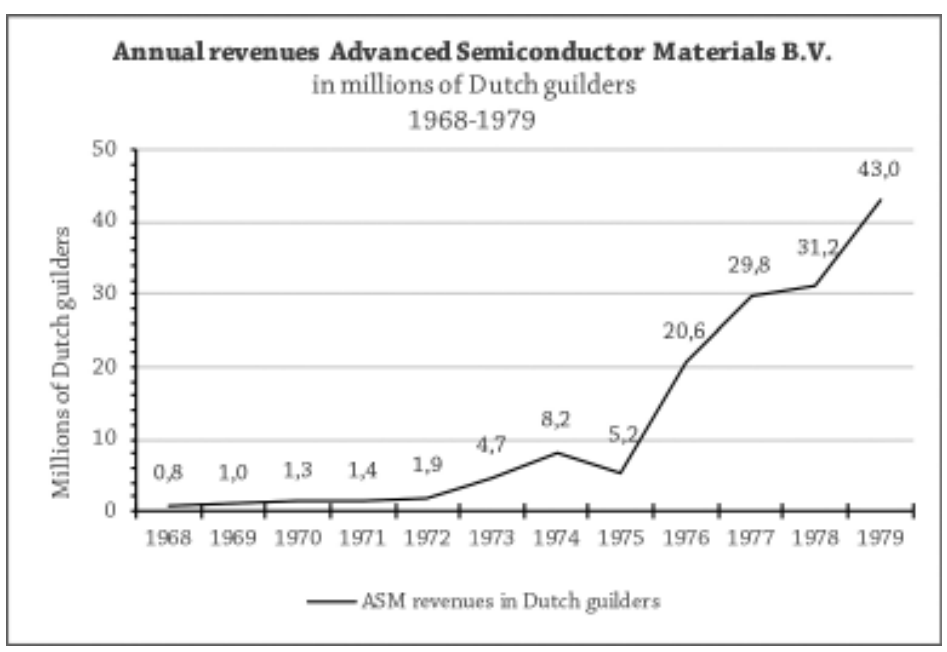

184 Nederlandse Accounts Maatschap, 'Rapport to the management of Advanced Semiconductor Materials Holding B.V., re: financial statements for the year 1978' (15-8-1979) Archive Arthur del Prado - Annual reports 1964-1980. 


\section{Chapter 6}

\section{Conflicting activities, 1977-1980}

At the end of the 1970s, ASM completed the transformation from sales representation into semiconductor equipment manufacturer. The disengagement with principals continued to happen with the corresponding clashes. Moreover, ASM, in its new role as equipment manufacturer, itself had to hire sales representatives. Against this backdrop, the Japanese semiconductor industry embarked on an ambitious plan to overcome its technological gap with the United States. The nascent American subsidiary of ASM capitalized on an insatiable Japanese demand for American technology. ASM entered the Japanese market.

\section{Industrial context: Rising competition}

The late 1970s were defined by the advent of the Japanese computer and semiconductor industry, at a time when Western economies stagnated. In a concerted effort, Japanese authorities, semiconductor manufacturers, and financial institutes tried to overcome the national lag in semiconductor and computer technology. ${ }^{185}$ The Ministry of International Trade and Industry, better known as MITI, coordinated and enabled industrial collaboration between competing semiconductor manufacturers. Since computer technology was dubbed of vital importance for the country's economy, all stops were pulled to overcome the technology gap.

By the mid-1970s, MITI's public officials were alarmed by a rumour that the worldwide leader in computer and semiconductor technology, IBM, worked on a first megabit memory chip. Such a device was dubbed Very Large Scale Integration (VLSI) - chips comprising more than 100,000 transistors - and would undo previous MITI efforts in support of the Japanese computer industry. Shielding the national industry through tariffs and regulatory demands would not suffice.

185 Malerba, The Semiconductor Business; Martin Fransman, The Market and Beyond: Information Technology in Japan (Cambridge University Press, 1990); and Kiyonori Sakakibara, 'From imitation to innovation: The Very Large Scale Integrated (VLSI) Semiconductor Project in Japan', MIT Alfred P. Sloan School of Management Workingpaper, WP \#1490-83 (1983); Kiyonori Sakakibara, 'R\&D cooperation among competitors: A case study of the VLSI Semiconductor Research Project in Japan', Journal of Engineering and Technology Management 10 (1993) pp. 393-407; Jon B. Thornberry, 'Competition and Cooperation: A Comparative Analysis of SEMATECH and the VLSI Research Project', Enterprise \& Society 3 (2002) pp. 657-686. 
In response, a very expansive program was initiated. Called 'VLSI Technology Research Project', it lasted from 1976 until 1980.

Within this ambitous project, MITI forced Japanese semiconductor manufacturers to harmonize research and collaborate. In order to increase the country's technological and industrial clout, duplication or even negation of efforts had to be prevented. Companies whose efforts used to be connected were grouped into two consortias: Hitachi \& Fujitsu started a joint laboratory with Mitsubishi named Computer Development Labs (CDL), while NEC teamed up with Toshiba, forming NEC-Toshiba Information Systems Labs (NTIS). Moreover, a cooperative laboratory was created in support of all the research and development in the program.

The highly competitive firms were joined for the duration of the project through carrots and sticks. Generous innovation subsidies and interest-free loans from the government did the trick. About 70 billion yen, or 288 million dollars, was spent on the program, of which 30 billion yen originated from the government. ${ }^{186}$

The VLSI project sparked the innovation in Japanese semiconductor fabrication equipment technologies, by the likes of Hitachi Kokusai and Tokyo Electron. But lithography technology by the three renowned producers of optics - Canon, Nikon, and Olympus Optical - benefited as well. If Japanese equipment suppliers could not match the technological demand, American merchant suppliers might. As a consequence, American technology was in high demand. Equipment suppliers flocked to profit from this rapacious yet still secluded feast.

Only a few years later, in the early 1980s, the American semiconductor industry would be aroused from its dream. Japanese companies had used the American naivity and desire for sales to their own benefit and propelled their national industry to the same level, if not beyond that of the American industry. At the same time, MITI prevented foreign companies to compete in Japan. In a period of economic stagnation, Western European countries and the United States set up similar efforts, such as the VLSI project, to prevent further advance of Japanese manufacturing power (cf. Innovation III).

\section{Corporate course:}

\section{Completing the transition toward equipment manufacturing}

By the end of the 1970s, ASM was about to bid farewell to its trading activities. Through its transformation into equipment maker and its internationalization strategy, Del Prado ensured that ASM could benefit from the growing need for semiconductor manufacturing technologies. The company was rather small. The

186 Fransman, The Market and Beyond; Sakakibara, 'From imitation to innovation'; and Sakakibara, 'R\&D cooperation among competitors'. 
Bilthoven, Hong Kong, and Phoenix operations still operated in the margins of the chip industry. Furthermore, in addition to its own developed and manufactured products, ASM functioned as a representative, selling the products of other companies. In some cases, ASM's internal manufacturing operation was used to assemble and manufacture the principals' products locally.

The dual strategy of being a representative and an original equipment manufacturer could not be sustained, however. ASM's new products aligned or conflicted with those of its principals. Del Prado managed to sail very close to the wind for a long period of time - continuing both the agencies and his equipment operation. Ending an agency would deprive Del Prado of a market, which often he himself had developed and which he regarded as his own. Abandoning business was not part of Del Prado's character. He still was a katjong. Instead, he would try to supply the market with his own variation of the products, thus competing with former principals.

\section{Elaboration of affairs}

\section{A troubled relationship}

At some point in time, ASM's stance as equipment supplier was bound to clash with the interests of ASM's principals. In 1978, this is in fact what happened with the Tylan agency. Tylan was a manufacturer of mass flow equipment, gas panels, and several basic CVD tools. Tylan was the first supplier to offer commercial electronic mass flow controllers. The technology was developed during the Apollo space program to measure the supply of oxygen, and was - other than conventional rotameters - not pressure or temperature sensitive. These pieces of equipment were and are essential for the adequate processing of gasses in diffusion and (low pressure) CVD furnaces according to the recipes of the chip manufacturers. ASM's own CVD machines were equipped with Tylan's parts as well. In 1973, Tylan hired ASM as agent for their mass flow equipment and gas panels.

ASM also assembled Tylan's products. All gas equipment customers had their own specifications and demands for adequate processing of gasses, and they did not accept a general product. The different metric systems between the United States and Europe proved a complicating factor in particular. Therefore, it was more profitable to assemble the mass flow meters and controllers locally, which meant at ASM in Bilthoven. If in the past Del Prado could only dream of setting up a European manufacturing operation - just think of Knapic Electro-Physics, Sola Basic Industries, and Applied Materials - this was no longer necessary. At ASM, the infrastructure was in place, and Tylan might as well profit from it.

It was a prosperous relationship indeed, and Tylan even expanded its activities into designing, manufacturing, and selling CVD furnaces. This expansion, 
however, increasingly coincided with the new activities ASM adopted in those areas, which implied that in the course of the 1970s Tylan's activities and those of ASM became more and more complimentary, if not conflicting. The original agreement between the companies concerning the sale of mass flow equipment - not the other products - was no longer sufficient and accurate.

Because ASM still relied on Tylan's proven mass flow equipment for its won CVD furnaces, while the latter flourished through the sales generated by ASM on its behalf, Del Prado and Don Jackson - ASM America's general manager - explored various options to continue the relation with Tylan. They proposed even a gradual merger between the companies. ${ }^{187}$ After all, their activities were very much complimentary. But when the discussions about a merger became more serious and substantial, Tylan withdrew its support. ${ }^{188}$ On account of their respective ambitions and activities, the interests of the two companies meanwhile continued to diverge.

By 1978, Tylan's president, Charles Drexel (1924-2015), concluded that a fullyowned European subsidiary would be more suitable to sell its products. ${ }^{189}$ One of his reasons was that ASM had a distorted relationship with various customers of Tylan, including Sola Basic Netherlands, Applied Materials, and even Philips. As agent of Tylan's mass flow equipment, ASM had to serve these competitors as well. According to Drexel, ASM failed to do so. On the other hand, ASM had trouble obtaining parts of Tylan products from Tylan itself. ASM's designated mass flow equipment engineer Gerrit Hartemink suspected that Tylan intentionally delivered inadequately in preparation of terminating its contract with ASM. ${ }^{190}$

In May 1978, due to the conflicting activities of the companies, Drexel terminated the agreement with ASM as of the end of the year. Del Prado saw the storm coming and had already informed Drexel of his plan to have ASM develop its own mass flow controllers. After all, ASM needed a reliable source of mass flow equipment for its own products. ${ }^{191}$ The unilateral termination of the agency and the consequences for their relationship could endanger this supply,

187 Tylan, 'Preliminary Proposal ASM/Tylan Joint Effort' (October 1976), Arthur del Prado Archive - Tylan USA feb 1978-june 1981 file.

188 Tylan, Charles F. Drexel, 'Letter from Tylan president Charles Drexel to Arthur del Prado' (10-2-1978) Arthur del Prado Archive - Tylan USA feb 1978-june 1981 file.

189 Tylan, Charles F. Drexel, 'Letter from Tylan president Charles Drexel to Arthur del Prado' (22-12-1978) Arthur del Prado Archive - Tylan USA feb 1978-june 1981 file.

190 ASM, Gerrit Hartemink, 'Letter to Attorney Harry M. Weiss: Tylan Patents, you letter of December 19, 1980; Answers to Complainant Interrogatories, No. 337-TA-91' (4-2-1981) Arthur del Prado Archive - Tylan USA feb 1978-june 1981 file.

191 Stibbe \& Blaise, Mr. T de Waard, 'Pleitnotitie Mr. T. de Waard inzake ASM BV tegen Tylan Corporation, Arrondissements-Rechtbank Utrecht', (1-5-1980), Arthur del Prado Archive Tylan USA feb 1978-june 1981 file. 
and would deprive Del Prado of the lucrative market for gas flow equipment. As has become apparent throughout this chapter, he was not easily daunted.

In July 1978, Del Prado acquired patents and manufacturing rights for gas flow control components and gas panel technology from the French industrial conglomerate Alstrom-Atlantique SA. For the amount of 1 million French francs, he managed to secure proprietary gas handling technology, crucial for his own CVD technology. ${ }^{192}$ The move allowed ASM to distance itself from Tylan's proprietary technology. The acquisition gave birth to ASM Southern Europe later dubbed ASM Qualiflow - which became an expert center for gas handling systems for ASM's internal use over the years. After the acquisition, Del Prado asked Hartemink to design and produce ASM mass flow equipment.

Tylan suspected use of transferred proprietary technology, which previously was explicitly not allowed in the ambit of the agreement between both companies. ${ }^{193}$ In the Netherlands, Tylan sued ASM for breach of contract. The resulting trial, held in Utrecht between May 1 and May 9 1980, was won by ASM. Tylan's products were not protected by European patents, and ASM's comparable products differed sufficiently from those of Tylan. In vain, the company appealed to a higher Dutch court, after which it filed a complaint against ASM at the United States International Trade Commission for unfair trade practices. ${ }^{194}$ In response, ASM filed a complaint that disputed Tylan's patents in question. ${ }^{195}$

While legal actions escalated, both companies stayed in touch to settle the disputes outside the courts. ${ }^{196}$ ASM still needed a small supply of Tylan's mass flow equipment. ASM could provide most of the mass flow equipment in its products, but sometimes customers specified configurations including Tylan's equipment. This resulted in a settlement in June 1981. ${ }^{197}$

192 This included about 905,735 French francs in inventories. Depending on the success of ASM in selling the flow control equipment in the first three years, Alstrom Altantique could receive some royalties up to 200,000 French francs. - Nederlands Accounts Maatschap, 'Rapport to the management of Advanced Semiconductor Materials Sales B.V., re: financial statements for the year 1978' (15-8-1979) Archive Arthur del Prado - Annual reports 1964-1980.

Arthur del Prado, 'Telex from Arthur del Prado to Mr. T. de Waard - visiting ASM America' (date unknown) Arthur del Prado Archive - Tylan USA feb 1978-june 1981 file.

194 United States International Trade Commission, 'Complaint of Tylan Corporation: In the Matter of Certain Mass Flow Devices and Components Thereof, Inv. No. 337-TA-91' (14-101980) Arthur del Prado Archive - Tylan USA feb 1978-june 1981 file.

195 United States District Court for the District of Arizona, 'ASM adv. Tylan, No. Civ. 80-869 PHX-VAC' (22-10-1980) Arthur del Prado Archive - Tylan USA feb 1978-june 1981 file.

196 Redacteur, 'Oktrooi-conflict bedreigt export van Nederlands bedrijf in chips-branche', Financieel Dagblad (24-11-1980) p1, Arthur del Prado Archive - Tylan USA feb 1978-june 1981 file.

197 Brown \& Bain, Philip P. Berelson, 'Letter to Attorney John C. Hussey of Sheppard, Mullin, Richter \& Hampton: ASM adv. Tylan’ (2-6-1981) Arthur del Prado Archive - Tylan USA feb 1978-june 1981 file. 
By the time the disputes were settled, ASM had conducted an initial public offering at the NASDAQ (cf. Business Chapter II). It marked the consolidation of the company as original equipment manufacturer. The conflict between ASM and Tylan was no longer about their relationship as principal and agent. It had evolved into a dispute about the stable supply of indispensable parts between competitors. The tensions and eventual conflict with one of the last major agencies of ASM underscored the irreconcilability of being a full-grown original equipment manufacturer and a representative at the same time.

\section{Reputation of original equipment manufacturer opens Japanese market}

Exemplary for the transformation of ASM from representative into equipment manufacturer was the deployment of external sales representatives by ASM America. In the 1970s, it was common to contract local sales agents near a potential chip factory. For example, ASM would hire a local agent to get in touch with and sell equipment to an IBM factory in Burlington, Vermont. Or think about the role Ed Foley initially had in establishing contact between ASM and Motorola.

These representatives - often a former affiliate of the factory - knew their ways to the factory's management and, motivated by their commission, they were eager to successfully close a deal between their principal and client. Local sale agents served as a lubricant between ASM and its potential customer, just as Del Prado himself at the start of ASM and on behalf of Knapic Electro-Physics. The strategy of ASM America to hire local agents was very common in the United States, but in the case of ASM it showed how much the tide had turned for the company and its president.

ASM America's president Don Jackson and newly hired marketing manager Dale Stoddard did not limit this sales strategy to the United States. Due to a large governmental support program, the Japanese semiconductor market was rapidly growing, creating a huge demand for American semiconductor technology. In the 1970s, the Japanese authorities' awareness of the strategic importance of joining the development of VLSI chips resulted in an extensive governmentally funded development effort called the VLSI project.

To support their catch-up effort, the Japanese semiconductor manufacturers were eager to get their hands on any American technology available. To facilitate this huge demand for American technology, a first Semicon Conference was organized in Tokyo in 1977. For the merchant equipment industry, it constituted a wonderful opportunity to sell products in a rapacious market. This was also true for ASM America, which still had difficulties to penetrate the American market. Maybe the Japanese eagerness for American technology would offer some consolation for ASM America. 
During Semicon Japan 1977, Del Prado and Jackson got in touch with Marubeni Electronics, a subsidiary of a major trading house in Japan. ${ }^{198}$ Marubeni Electronics already represented several Western semiconductor equipment manufacturers, like Extrion, Cambridge Instruments, and High Voltage Engineering. To improve its earnings in the semiconductor industry even further, the trading company looked for new principals, and in this process it came into contact with ASM America. Late 1977, it contracted Marubeni to sell and service ASM America's products in Japan (the deal did not apply to the other ASM subsidiaries' products). In particular, the American technology was favored in Japan.

Thanks to the efforts of the enthusiastic and motivated young Japanese engineers and managers at Marubeni, ASM America's products sold like hot cakes in Japan. This initially pertained to the Low Temperature Oxide furnace, and as of 1979 the plasma enhanced CVD furnaces in particular (cf. Chapters 8 and 9). At a technological level, the United States resembled the promised land for the young and recently graduated Marubeni engineers and managers, who handled the ASM account. This impression was confirmed upon their arrival in Phoenix for their training in servicing ASM America's products.

During their stay, the first dispatched service engineers, including the 28-year-old Fukumi Tomino, paid a visit to a big cinema in order to sniff up some American culture. ${ }^{199}$ They happened to watch the first Star Wars movie: A New Hope. This confirmed their suspicions and ideas of the United States as a technologically advanced society where the future was apparent - even in cinema and in the auspicious motion picture's title. In the case of Tomino it marked the start of a life-long career at ASM.

After their return to Japan, Marubeni Electronics succeeded to sell the first ASM system to one of the consortia of the government funded VLSI program. The NTIS consortium - consisting of NEC and Toshiba - bought a LTO furnace. In the next years, the sales of ASM America's equipment would gradually increase in Japan. The introduction of the plasma deposition furnace in 1979 proved to be a major success in particular.

The Marubeni representative opened the doors of the Japanese market for ASM. However, as ASM had experienced first-hand, the use of agents becomes rather gratuitous once sales in a market begin to stabilize. Respecting the efforts and enthusiasm of the Marubeni staff, and in order to service the demands of

Fukumi Tomino, 'Interview with author'.

The other engineer was Masafumi Kabaya. - ASMA, Dale Stoddard, 'Memo: Training of Marubeni Electronics Corporation, LTD. Personnel - Our New Japanese Representatives' (28-11-1977) Archive Arthur del Prado - ASMA 1970s file; Fukumi Tomino, 'Interview with author'. 
the Japanese market more adequately, ASM started preparations to enhance its agreement with Marubeni and bring it to a new level - as will be discussed in the next Business Chapter. 


\section{Conclusions}

In almost twenty years, Arthur del Prado transformed his Dutch agency in silicon and silicon pullers into a multinational original semiconductor equipment manufacturer offering gas, deposition, and packaging equipment. Del Prado was keenly aware that the world was a big place, and he knew how to find his way in it. In these first years, the Dutch entrepreneur obtained valuable skills, experiences, and knowledge about entrepreneurism, sales, and the semiconductor industry. These assets underpinned his serendipity - his ability to intelligently exploit unexpected but benevolent occurrences - or virtù. As he succeeded in growing his businesses, he grew more confident about his abilities.

In Business I, but in particular later on in his career, Del Prado learned to rely upon these skills and experiences whenever faced with uncertainty. In this conclusion, I sum up these skills and insights, such as the benefits of decentral management and diversification, and his strategy to innovate and commercialize inventions with external origins. But I also typify his personality - character and his experiences - and how this shaped ASM. This is done through the conceptual elements fortuna, path and virtù.

\section{Fortuna}

As we have seen in Business I, Del Prado's career and ASM's early years were shaped by a range of contingencies, events, incidents, and meetings - or, in other words, fortuna. Most often, fortuna was in his favor. He was often the right man in the right place at the right moment. Or he managed to deal with, overcome, or anticipate the wide array of variations of fortuna. Every time, fortuna opened new pathways, offering new opportunities for the relentless entrepreneur.

Basically, the various manifestations of fortuna of Business I can be grouped into four categories. The first is industrial. Within this catagorie, fortuna manifested itself in the benevolent advent of silicon, the invention of the planar process and integrated circuit, and the advent of merchant equipment industry. Also the emergence of a dominant design and subsequent wave of process innovation, as discussed in the intermezzo, fit in this category. The second category involves the semiconductor market. A striking example was the positive evaluation of Fico's molds by Motorola in Asia, which paved the way for the establishment of ASM America. The third category pertains to manifestations of fortuna at an individual level. One example is the personal encounter of young Arthur del Prado with Dean Knapic. But his meeting and hiring Patrick Lam, who would become a defining figure for ASM, is a case in point as well. 
The fourth and final category stands out from the other three. It pertains to what is called a Machiavellian Moment, a situation during which an innovator realizes his temporal finitude. In Business I, the dissolvement of the Applied Materials agency was such an event. Del Prado realized more than ever that his days as sole representative were less prospective. To sustain his footing, he moved ahead and began the manufacturing of his own semiconductor equipment. Through this bold decision, ASM was further exposed to benevolent dynamics (cf. Conclusions Innovation I). All in all, fortuna paved the way for ASM and Arthur del Prado, forging sweeping decisions.

\section{Path}

In these early years, ASM's path very much concurred with that of Del Prado. From scratch, he developed into a shrewd businessman. After his early exposure to the semiconductor industry as a 27-year-old graduate, he discovered, trained, and consolidated his talents. Over the years, he grew in his role of cosmopolitan entrepreneur in semiconductor equipment. Sometimes freebooting, sometimes strategically planning, and predominantly ensuring his position as pivot in a market or within ASM, Del Prado shaped his activities and venture. His strategies were carefully prepared and well considered. Supported by young and very talented advisors, like Paul van den Hoek and Nico Nobel, he was able to make bold moves and leaps of faith. Here, I observe the basic elements in Del Prado's - and thus ASM's - path, which consisted of three elements: close alignment, diversification, and decentralization.

Close alignment with customers and supplying them with critical innovations in semiconductor fabricaton technology proved vital for ASM. This started with the continuation of the obsolete market for silicon of Knapic Electro-Physics via Topsøe. The local Sola Basic operation adressed Philips' requisite for an equipment supplier in the vicinity of its Dutch operations. Del Prado's conviction that a local CVD supplier was indispensable resulted in the end of the Applied Materials agency and the start of ASM's own equipment manufacturing operation.

The close alignment determined also the internationalization of ASM. In this case, the Fico Toolings' agency and later subsidiary formed the steppingstone for operations in Asia and the United States. Moreover, the newly established American operation - ASM America - would be crucial for joining the latest American chip developments through the low temperature oxide and plasma enhanced CVD processes. Every time, in pursuit of sales Del Prado yoked others' inventiveness to his ASM cart, and every time it resulted in enhanced capabilities of the small Bilthoven-based company. 
The second element of ASM's strategy entailed diversification of the company's product portfolio. The demise of Knapic Electro-Physics taught Del Prado that betting on one horse provided little protection against industrial changes. As propagated by contemporary management guru Igor Ansoff, diversification served as a hedge against unforeseen disappointments. Success of one product could be leveraged against the limited achievements of another. Accordingly, ASM became an active player in silicon, diffusion furnaces, and a range of complementary products. Even as the company developed into an original equipment manufacturer, the strategy of diversification was maintained: from several variations of chemical vapor deposition products to packaging technologies, and gas handling equipment.

The third basis in ASM's strategy was decentral management. Slowly, and sometimes salutary, the company changed as more staff was employed and activities abroad were expanded. In 1965, ASM consisted of three employees and a director: Arthur del Prado, Martin van Beest, a secretary, and a commercial employee. Compare this with the situation in December 1980, when ASM employed about 580 employees across the world (figure 10).

\section{Figure 10}

Number of employees employed by ASM December 31, 1980

\begin{tabular}{|l|r|}
\hline Operation & Employees \\
\hline ASM Bilthoven & 70 \\
\hline ASM Fico (Herwen \& Brunssum, NL) & 120 \\
\hline European sales offices & 30 \\
\hline ASM America & 200 \\
\hline ASM Asia & 160 \\
\hline
\end{tabular}

Fresh staff created a new dynamic and culture. Most of the engineers were attracted to work in the impetuous equipment manufacturer. The chip industry was an exciting and fascinating environment, where personal wealth and innovation were salient features. ASM's engineers were able to contribute to the success of the relatively small company as well as experience the relevance of their work directly. Their inventiveness and entrepreneurialism bore immediate results. This motivated the engineers and managers to often work in overtime. ASM, in other words, was a typical startup.

Little leveling occurred between the European, American, and Asian operations (figure 11). Each was still discovering its strengths and weaknesses. It was Del Prado who guaranteed them this independence and trust. The local entities knew the local opportunities best. Therefore, it was better to have them exploit these by themselves instead of centrally managing or unifying the 
operations. It was this independence and trust in local talents, in combination with favorable developments of the industry, that boosted ASM's growth.

\section{Figure 11}

Organigram of ASM by 1979.

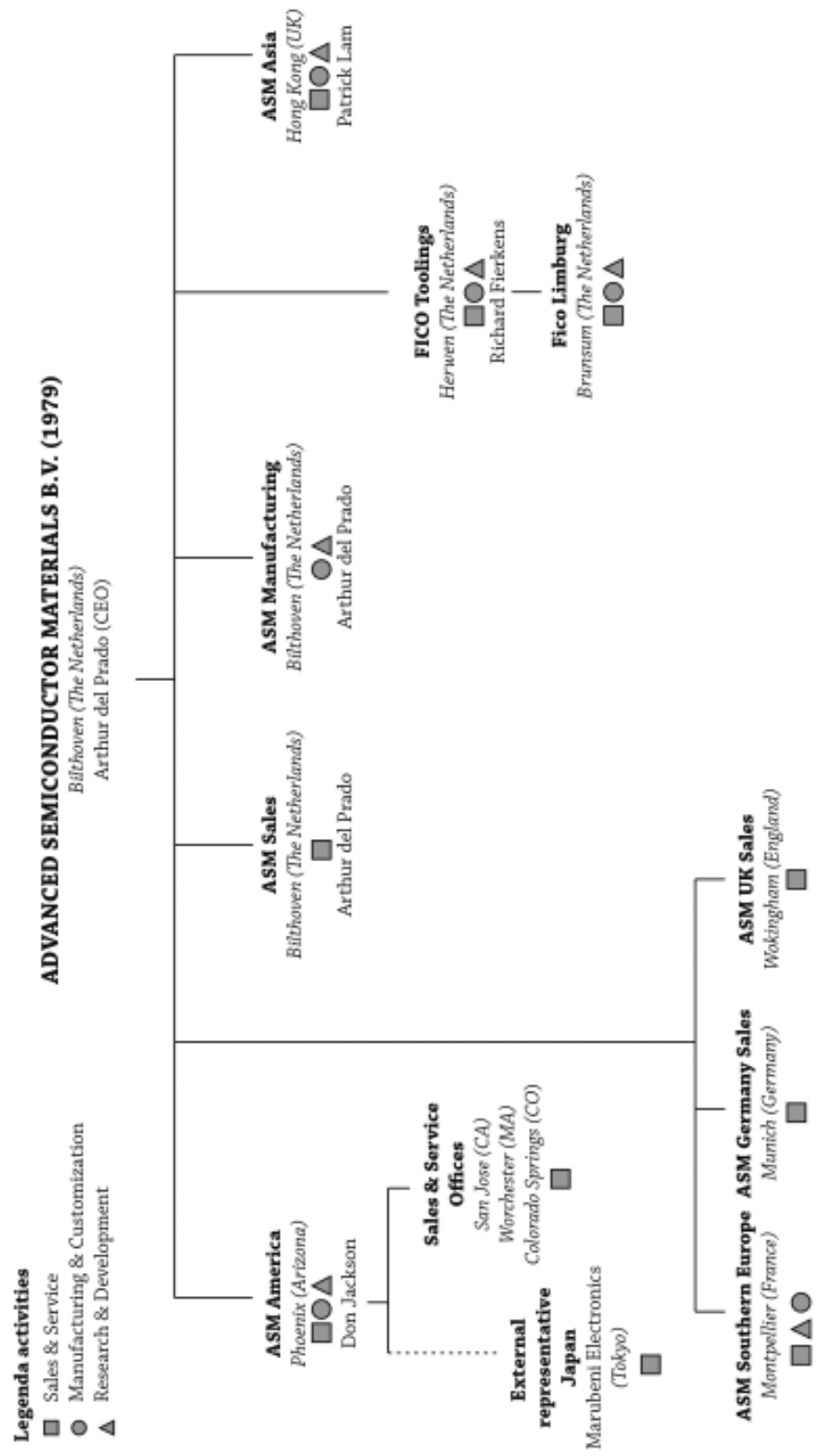


There was virtually no central operation staffed with controllers, managers, and secretaries. Principally, Del Prado traveled to and communicated with the different operations. Thus, he was intensively and closely involved in the activities and processes taking place at its subsidiaries. He was managing his consortium of startups in semiconductor technology virtually alone. He was Mr. ASM. He ensured that his money was well spent and that the company grew into the direction he wanted.

In the words of management scholar Peter Drucker, Del Prado managed by result. Del Prado had structured the company this way deliberately. During his tenure as European Marketing Manager on behalf of Knapic Electro-Physics, he had experienced that the granted autonomy motivated himself to be intrepid, creative and entrepreneurial. At ASM, he imitated the template of his relation with Knapic Electro-Physics.

ASM's business strategy very much fitted the times. While Drucker was a distinct protagonist for decentral management, trust in business units' capabilities, and merely strategy oversight, Ansoff argued in favor of diversification. These various insights, which widely circulated in the early 1960s and 1970s, confirmed and aligned with Del Prado's own experience.

\section{Virtù}

Virtu, or the art of improvisation in the face of fortuna, defined the materialization of ASM into a multinational semiconductor equipment manufacturer. Not only were the starting company and its founder exposed to fortuna; they acted upon it. Until the mid-1970s, it was the combination of a talented, charismatic, and convincing entrepreneur and a positive business environment created by the increasing demand for microelectronics that pushed ASM forward. All these alignments or agreements originated from Del Prado's personal network. No industry-wide platform in this sector existed as of yet. The first Semicon Conferences - that were vital for networking and operating in semiconductor business - started just in 1971, and were strictly an American affair.

The growth of ASM was not always smooth. Disentanglement of business relations was often accompanied by - intended or unintended - mutual grievances. These were in part caused by the business-to-business environment in which ASM operated. As business-to-business relations involve small or complex organizations, most often the rational pursuit of self-interests largely determines courses of action. Relations are only viable as long as the self-interest of both parties coincide. As a consequence, relationships will deteriorate or collapse once the interests begin to diverge or clash.

In the case of ASM, Del Prado's Machiavellian tendencies colored the disentanglement of those relationships excessively. In particular when the 
ended relation involved markets Del Prado had developed on behalf of his principals' requests, he made his mark. He regarded those markets to be at his own disposal, and he would provocatively and daringly fill in demand with his in-house manufactured products. Engaging him to pursue new opportunities was one thing, but unraveling a business relationship was another. This is exemplified by the affairs with Frank \& Schulte, Topsøe, Herman Jonge Poerink, Applied Materials, and Tylan (and the many others to follow). Del Prado's ruthless response to disentanglement was a reflection of his understanding of industry as power politics.

Del Prado was a katjong: undaunted, entrepreneurial, and charming when necessary. Those characteristics would certainly help him further to transform ASM. From the start of the 1980s, ASM no longer supplied someone else's products, but developed and produced innovations on its own. Facilitating technological solutions to semiconductor manufacturers was and remained the core business of ASM. Under Del Prado's management and leadership since the early 1960s, the company developed its own identity after a series of crises through ingenuity and persistence. The next decade ASM would elaborate upon this base. 


\section{Innovation |}

\section{Manufacturer of chemical vapor deposition equipment, 1969-1985}




\section{An introduction}

From 1969 to 1985 ASM transformed from a European sales agent into a multinational 'original equipment manufacturer.' This meant that ASM increasingly began to focus on designing and manufacturing its own equipment. Revenues grew from 1.3 million Dutch guilders in 1971 to 353 million in 1985, while in this same period the company's staff expanded from a handful to 1868 employees. Innovating and selling its own original equipment propelled ASM's growth and globalized its operations. Initially, however, the company did not pursue innovation as a goal in its own right. The company evolved into an equipment supplier for the chip industry in the wake of an accumulation of opportunities, new experiences, and business strategies. Throughout this transformation, ASM would also retain some of the more idiosyncratic characteristics from its past as a sales agent.

ASM made strides into semiconductor equipment manufacturing and became a global equipment vendor by developing four innovations in chemical vapor deposition (CVD): atmospheric pressure CVD systems in 1971, low-pressure CVD (LPCVD) systems in 1975-1977, plasma enhanced CVD (PECVD) technology in 1980, and an aluminum CVD machine in 1982. Each innovation represented a new stage of development for the company.

My focus in Innovation I is on ASM's development of chemical vapor deposition technologies. Specifically I address the following question: how did ASM's innovation processes evolve during the company's initial years as original equipment manufacturer, from 1971 until 1985? Aside from designing, making, and selling CVD equipment, ASM engaged in two other main activities during this period. The first consisted of its traditional business of representing foreign companies in semiconductor materials and equipment across Europe and, from 1975 onward, in South-East Asia. The other activity pertained to selling semiconductor packaging techniques and materials, a service formally provided by Fico Toolings, which would later be renamed ASM Fico.

The development of deposition technologies would gradually replace ASM's original business of representing and distributing products made by others. This new endeavor would define the front-end activities of ASM for the future, significantly transforming the modus operandi of the small Bilthoven sales agency led by Arthur del Prado. 


\section{Prolific market of deposition technologies}

Deposition technologies emerged in semiconductor manufacturing in the late 1960s, after the advent of 'integrated circuits' - or computer chips (figure 12). Due to their more complex construction compared to semiconductor discretes, chips required multiple films of semiconductor materials and metals stacked on top of each other. Each material used for these layers required application of specific techniques and tools. This caused deposition techniques to become more prominent in chip fabrication, propelling the advent of an entire new market of manufacturing equipment. ${ }^{1}$

\section{Figure 12}

Graph of share of integrated circuits of total semiconductor shipments in the United States, Japan and Europe, 1969-1980

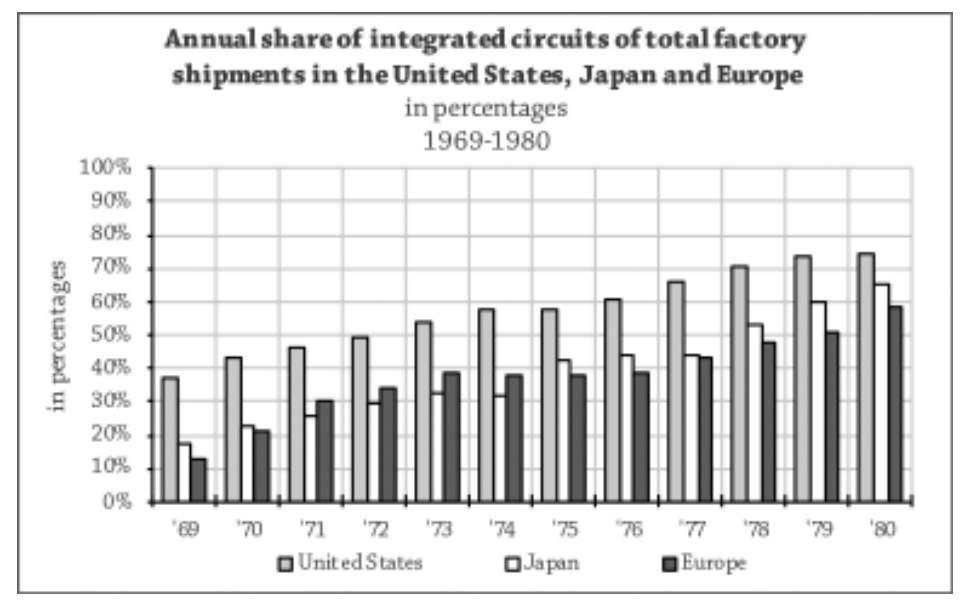

The growing need for deposition techniques in chip production coincided with the emergence of start-up chip producers. ${ }^{2}$ Engineers and managers employed by the incumbent chip industry and separate producers began to pursue their own opportunities in chip technology. From the late 1960s, this resulted in a rise of computer chip startups, predominantly located in the urbanized region south of San Francisco, now known as Silicon Valley. Up to that point, chip producers designed and developed their manufacturing techniques in-house. However, the new startups lacked the resources to follow this convention, and, instead, they turned to the few merchant suppliers of equipment manufacturing, thus boosting this slumbering industry.

1 The growth of the semiconductor equipment industry during the 1960s and 1970s in VLSI Research, '2.0 Equipment Suppliers' (1990) p. 2.0.8.

2 Dataquest, A Decade of Semiconductor Companies (June 1988). 
Due to the increased need for deposition techniques and an expanding number of chip producers, merchant manufacturers of deposition equipment saw their business grow strongly. Moreover, in the 1970s, merchant semiconductor equipment manufacturers offered access to the latest American production techniques for European and Japanese chip producers. Taken together, the newly emerging applicability of chips, the growing number of chip producers, and the rise of merchant equipment suppliers redefined the dynamics of the semiconductor industry. The transformation of ASM, then, is also a story of the emergence of the merchant equipment industry as an indispensable segment of the global chip industry worldwide.

\section{Outline of Innovation I}

The four chapters of Innovation I detail the transformation of ASM into an original equipment manufacturer. Chapter 7 describes the first steps, showing how from 1969 to 1974 ASM familiarized chemical vapor deposition and built its first machine. Chapter 8 provides a reconstruction of the company's innovation of low pressure chemical vapor deposition, which took place from 1975 until 1977. Next, Chapter 9 narrates how ASM obtained and innovated the technology of plasma enhanced chemical vapor deposition in 1979. Finally, Chapter 10 discusses how ASM tried to extend the applicability of chemical vapor deposition to the growth of metals by means of aluminum chemical vapor deposition. These successive chapters thus reveal the process of ASM's maturation into a global innovator of chemical vapor deposition technology. Innovation I concludes with a reflection on ASM's transformation in terms of fortuna, virtù, and path 


\section{Chapter 7}

\section{Atmospheric pressure chemical vapor deposition, 1969-1974}

In the early 1970s, ASM took a leap of faith and produced its first piece of semiconductor production equipment: an atmospheric pressure chemical vapor deposition machine. It was a bold move away from its conventional mode of operation, as a representative of predominantly American equipment and materials used in semiconductor manufacturing (cf. Business I). Selling someone else's products proved to be a lucrative business, because in that same year ASM enjoyed healthy sales of around 1.3 million Dutch guilders. Since the establishment as Del Prado's one-man-business in 1964, ASM had been growing beautifully indeed.

To support the expanding activities of the small Dutch enterprise, it employed several employees in the Netherlands and at its regional sales offices in Germany and the United Kingdom. All of their activities were tightly led and managed by Del Prado, who was in charge of sales, general management, most acquisition of new customers, and communications with principals. Technical engineer Martin van Beest took care of the technical aspects of the business, such as installing and servicing equipment. A handful of commercial engineers and secretaries handled interactions with customers, as well as the correct finalization of transactions in Bilthoven and at the regional sales offices. By 1971, ASM was a leading European representative for American merchant equipment and materials producers.

By selling American semiconductor innovations in Europe, ASM sought to benefit from a discrepancy in technological competence on the two continents. In The Semiconductor Business, Franco Malerba, a scholar in economic development and innovation, recognized a technological lag as the root cause for the European semiconductor industry's decreased competitiveness. ${ }^{3}$ One of the causes he identified was the relatively late recognition of the potential of 'integrated circuits' (or: chips) by the major European semiconductor producers. By the late 1960s, the American chips were more and more exported to Europe, and their

\footnotetext{
3 Franco Malerba, The Semiconductor Business: The Economics of Rapid Growth and Decline (University of Wisconsin, Madison, 1985).
} 
makers founded local subsidiaries to serve the European markets adequately. This caused a decline of the competitiveness of European chip manufacturers.

To make up for their lost edge, European chip manufacturers were eager to get their hands on the latest American chip manufacturing technologies, in particular after chip technology found greater acceptance beyond the governmentally funded aerospace programs. During the 1960s, as described by historian Christophe Lécuyer in 'Silicon for industry,' Fairchild Semiconductors was the first to reorient its activities toward consumer markets, to be followed by the other players in the American chip industry. ${ }^{4}$ In contrast to military procurement, where strategic considerations prevail, price is a decisive factor for application in consumer goods.

Efficient manufacturing operations were crucial for achieving cost reductions. These first chips were applied in the first handheld calculators, such as the Busicom Junior, and in fairly big computers, such as the IBM 370. Traditionally, the European semiconductor industry had been competitive in commercial applications, and it was eager to win its share of the potentially lucrative market for chips.

Through his contacts in the young and slumbering American merchant semiconductor equipment and materials industry, Del Prado helped the European producers in obtaining the latest manufacturing techniques. Furthermore, he also acted as supplier for the European subsidiaries of American producers, who required the same tools as they used in the United States. By the late sixties, as more European semiconductor manufacturers turned to American equipment and materials, ASM began to do better all the time.

\section{Selling chemical vapor deposition technology}

In 1969, ASM obtained a rather lucrative agency in deposition technologies from a company called Applied Materials Technology (further referred to as Applied Materials). This company, founded by Michael McNeilly in the fall of 1967, relied on a process developed by Dr. Walter Benzing from Santa Clara, California. ${ }^{5}$ Applied Materials offered deposition technologies, such as machines, gas systems, and other components, and was one of the first merchant suppliers of these techniques. Through its chemical vapor deposition (CVD) technologies, it rapidly made a name for itself in the Silicon Valley area.

4 Christophe Lécuyer, 'Silicon for industry: Component design, mass production, and the move to commercial markets at Fairchild semiconductor, 1960-1967', History and Technology 16:2 (1999) pp. 179-216, p. 184.

5 McNeilly hired Benzing and his patents from Merck. James Morgan and Joan Hamilton, Applied Wisdom: Bad News is Good News And Other Insights That Can Help Anyone Be a Better Manager (Chandler Jordan Publishing, Los Altos, 2016) p. 83. 
Applied Materials' products involved epitaxial processes. Basically, the epitaxial process involved growing a crystal film of lightly doped silicon on top of the highly-doped substrate to form the functional components of a bipolar transistor. But the company also offered equipment used for growing dielectric materials. Through the advent of the planar process in semiconductor manufacturing (see intermezzo in Business I), silicon dioxide became indispensable as a dielectric material in the production of chips. ${ }^{6}$ This process requires more detailed discussion here.

Silicon dioxide $-\mathrm{SiO}_{2}$, or often simply referred to as 'oxide' - performed two functions in a chip. One was to form a protective and insulating barrier layer over previously diffused areas and metallic interconnections. The dioxide separated the various electrical components on a chip. Second, a final layer of the material protected the circuits of the chip against external particles by covering the complete chip in a final layer of oxide. It passivated the external environment, so to say, and hence the name 'passivation film' for this final layer. From the late 1960s, due to the increased complexity of computer chips, comprising a few layers and integrating more components, the application of silicon oxide films increased in chip production.

Previously, silicon oxide was grown in diffusion furnaces. By exposing the silicon substrate to oxygen and water vapor, a thin film of native oxide was created. This method worked fine on silicon substrates, but it did not work when a film of silicon oxide had to be grown on top of other materials, such as aluminum interconnections. Here, the CVD method complemented the traditional process of growing films of silicon oxide.

Utilizing the chemical precursor silane $\left(\mathrm{SiH}_{4}\right)$, a film of silicon oxide could be deposited on top of silicon alloys and aluminum (figure 13). By exposing silane to oxide $\left(\mathrm{O}_{2}\right)$, a film of silicon dioxide is produced. ${ }^{7}$ Silane was a rather common material in semiconductor production for growing silicon-based components, and as such it had been used for epitaxial processes for some time. ${ }^{8}$

6 Christophe Lécuyer and David Brock, Makers of the Microchip: A Documentary History of Fairchild Semiconductor (MIT Press, Cambridge, 2010) p. 256.

$7 \quad$ Silicon tends to oxidize naturally, as metals tend to do. This film of native oxide was too thin to function as a proper dielectric. Hence the need to use silane for obtaining a thicker film than the native oxide.

$8 \quad$ Christophe Lécuyer and David Brock, 'The Materiality of Microelectronics', History and Technology 22:3 (2006) pp. 301-325. For example, the Dutch device manufacturer Philips used this material; see F. Everstijn, and H. Peek, 'US 3750620: Vapor Deposition Reactor' (priority: 11-3-1970; published: 7-8-1973). But Motorola used this material as well; see Bernard Boland, Don Jackson, and James Williams, 'US: Deposition of Silicon Nitride' (priority: 30-10-1967; published: 23-2-1971) and Don Jackson and James Norling, 'US 3496037: Semiconductor growth on dielectric substrates' (filed: 17-2-1970; published: 29- 
That silane was common did not mean it was not risky. On the contrary, silane is pyrophoric; it reacts quickly with the smallest amounts of oxygen. This made it very hazardous to process. By diluting the reactants - silane and oxide - with a so-called carrier gas, like nitrogen, the chemical reaction could be controlled. Handling silane was critical for the rise of CVD in chip manufacturing.

This capability was also decisive for the rise of Applied Materials in its early years. As McNeilly recalled in the same interview with SEMI in 2004:

'one of the first things I needed to do was demonstrate that I could produce and handle silane ... And everyone - the people in the industry I was talking to - certainly saw the benefits that silane brought in lower temperature depositions ... But everyone was terrified of how to handle it in production.' ${ }^{9}$

McNeilly and Benzing had obtained intrinsic experience in producing and handling silane safely at their former employer Union Carbide Electronics. ${ }^{10}$ Through the combination of Benzing's know-how in handling gas and McNeilly's entrepreneurial spirit, the two men managed to open a new market for CVD tools.

3-1976). Intel was a player, too; see W. Baerg, 'US385443: Reactor for Depositing Thin Films' (filed 19-12-1973; publication: 17-12-1974). For more on the historical usage of this material other sources are relevant. For Raytheon, see Ray Ellis and Walter Leverton, 'US2916359: Preparation of substantially pure silicon' (filed: 14-12-1956; published: 8-12-1959). For Texas Instruments, see James Biard, 'US 3463975: Unitary semiconductor high speed switching device utilizing a barrier diode' (filed: 31-12-1964; published: 26-8-1969). For RCA, see Alfred Mayer and Jospeph Lesky, 'US3177100: Depositing epitaxial layer of silicon from a vapor mixture of SiH4 and H3' (filed: 9-9-1963; published: 6-4-1965). And for ASM America, see Don Jackson, 'White Paper: Motorola Epitaxial Processing History and Technology, 1960 through 1976' (25-10-1976) Archive Arthur del Prado - ASM America 1970s file.

9 SEMI, Craig Addison, 'SEMI Oral History Interview: Michael A. McNeilly' (20-7-2004).

10 There was a strong linkage between Applied Materials and Union Carbide Electronics. The founder of this Union Carbide subsidiary was the inventor of the planar process, Jean Hoerni. He would later serve on the board of Applied Materials. McNeilly and Walter Benzing both worked for Union Carbide Electronics. Benzing worked earlier at Merck, the pharmaceutical giant, where he became involved in their epitaxy development department. Hoerni would later found Intersil, to which Applied sold its first whole CVD system. Initially, it sold only an automated gas panel to Fairchild. Later this would be the case as well with General Electric, which was a major investor in Applied Materials and supplier of the critical lamps used in the epi reactors. As was the case with ASM-Philips later on, the availability of high-energy lamps from General Electric defined the success of the Applied Materials reactors. - SEMI and Addison, 'Oral History Interview: McNeilly'; and Union Carbide, Walter Benzing, 'US 3484311: Silicon Deposition Process' (filed: 21-6-1966; published: 16-12-1969); Eric Nee, Information for Everyone: The Applied Materials Story, 1967-2002 (Applied Materials, Santa Clara, 2003). 


\section{Figure 13}

Simplified depiction of a chemical vapor deposition process

A deposition process of silicon oxide is depicted: $\mathrm{SiH}_{4(\mathrm{~g})}+\mathrm{O}_{2(\mathrm{~g})} \rightarrow \mathrm{SiO}_{2(\mathrm{~s})}+2 \mathrm{H}_{2(\mathrm{~g})}$

Process temperature is around $400^{\circ}$ Celsius.

Step 1: Silane ( $\left.\mathrm{SiH}_{4}\right)$ and oxygen $\left(\mathrm{O}_{2}\right)$ molecules enter the reactor chamber via the gas inlet. To prevent a reaction between precursors in the gas phase and to concentrate the reaction upon the heated silicon wafers, gasses are diluted with a non-reactant carrier gas nitride $\left(\mathrm{N}_{2}\right)$.

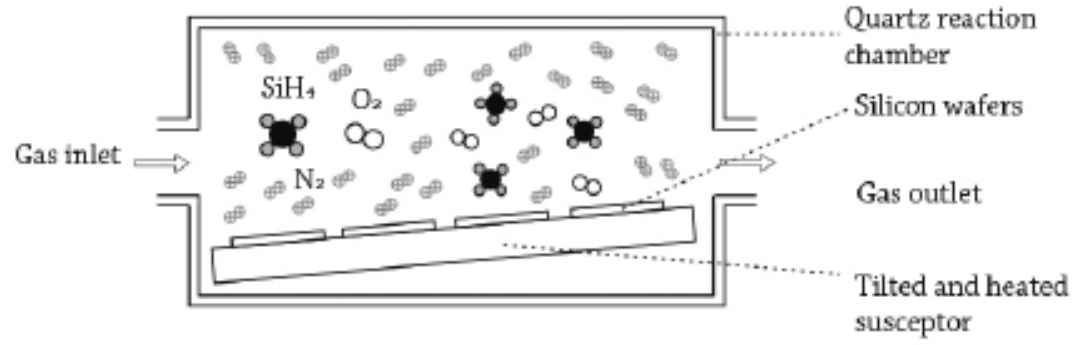

Step 2: Silicon and oxide atoms bond with each other and form silicon dioxide $\left(\mathrm{SiO}_{2}\right)$. Hydrogen $\left(\mathrm{H}_{2}\right)$ and nitride $\left(\mathrm{N}_{2}\right)$ atoms leave the reactor chamber via the gas outlet.

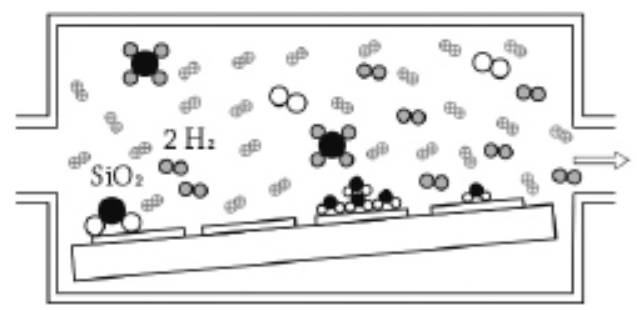

Step 3: On each wafer a thin film of silicon dioxide is formed. Hydrogen $\left(\mathrm{H}_{2}\right)$ and nitride $\left(\mathrm{N}_{2}\right)$ atoms leave the reactor chamber via the gas outlet.

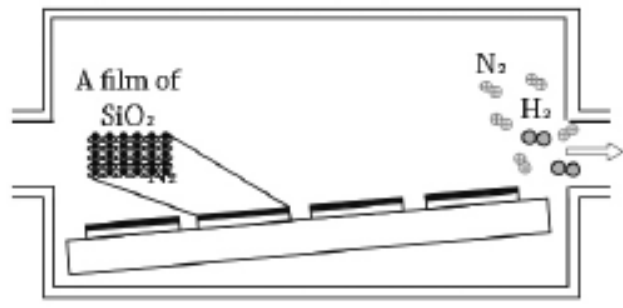


This started with the production of a specified gas panel and, later on, complete machines for research purposes. The external procurement of these one-issue tools saved time and resources for companies' research groups, while McNeilly and Benzing were able to substantialize their claims of competence. These orders in fact pushed Applied Materials toward the design and production of complete deposition systems.

McNeilly and Benzing familiarized the process technology of CVD systems, being an orchestration of elements - heating, gas flow, shape of the process chamber and so on - enabling the growth of a thin film. Once Applied Materials was able to build epitaxial furnaces that utilized silane, they built other CVD systems for the growth of silicon dioxide and silicon nitride films as well. ${ }^{11}$ The nitride process was meant to grow a passivation film, the properties of which slightly differed from the silicon dioxide insulator. These were called, respectively, Silox systems and Nitrox systems.

\section{Expanding ASM's role beyond representative}

Around the time of the establishment of Applied Materials, a few other companies started to develop and produce CVD technology. One was Hugle Industries. ${ }^{12}$ Another competitor was Pacific Western Systems, which started with wafer probe technology and later on, by the early 1970s, got into the business of CVD. ${ }^{13}$ With regard to merchant $C V D$ technology, the European market was a terra incognita initially. There were no competitors or other American suppliers yet. In order to crack this market, Applied Materials hired ASM as its European agent in 1969 (cf. Chapter 4).

Without serious competition in Europe, ASM easily achieved substantial sales on behalf of Applied Materials. ASM sold diffusion furnaces on behalf of

11 And a system capable of handling gallium arsenide. - SEMI and Addison, 'Oral History Interview: McNeilly'; Furthermore, they built some of Motorola's in-house developed epitaxial systems by order of the Arizonan device manufacturer, as recalled by Dr. Don Jackson, former head of the Motorola epitaxial department and later co-founder of ASM America - Don Jackson, 'Interview with author'.

12 Little is known about the company and its technologies. Some references are available, and some patents (US $3645230 \mathrm{~A}$, and US $3549232 \mathrm{~A}$ ). Most information about Hugle Industries is related to William Hugle's involvement in the establishment of SEMI, and the Semicon West Conference. Hugle was frustrated about the position of the equipment vendors at the big American electronics conference IEEE. For this reason, he and others decided to start their own industry association and, more importantly, their own conference. This was Semicon. Interestingly, as a direct competitor to Hugle Industries, Applied Materials opposed the initiative initially. Later, Applied Materials became a prominent member of the organization. - William B. Hugle, SEMI - The Early Years (Date unknown).

13 McNeilly mentions another one: Echo Labs originating from New Jersey. However, I could not find anything either to confirm or to negate this statement. - SEMI and Addison, 'Oral History Interview: McNeilly'. 
Sola Basic International and, later, on behalf of its Dutch subsidiary, Sola Basic Netherlands. It was possible for Del Prado to use the same contacts through which he sold the diffusion furnaces. He next managed to sell substantial quantities of Applied Materials' deposition equipment. As recalled by McNeilly in an interview with the industry association for semiconductor equipment SEMI in 2004:

'As a matter of fact, the European business and Japanese businesses grew very quickly to about equal size and combined, represented more than 30 percent of [our] revenues. I'm talking maybe $\$ 5$ to $\$ 50$ million a year for each segment by the mid '70s. Europe was a very independent market. ${ }^{14}$

Customers were Philips and some subsidiaries of American semiconductor manufacturers, as well as several universities. ${ }^{15}$

Relying on his business instinct, Arthur del Prado realized that this Applied Materials agency provided promising and usable equipment. It was already apparent that the market for CVD would complement the market for diffusion furnaces. After all, as the complexity of chips increased, multiple CVD steps might be required. Meanwhile around 1970, Applied Materials succeeded in selling its equipment to the major American semiconductor manufacturers. ${ }^{16}$

By that time, Del Prado had hired an experienced process engineer by the name of Sean Hurley to serve the European market. ${ }^{17}$ Together with ASM's service engineer Martin van Beest, Hurley installed and serviced Applied Materials' products sold by Del Prado. ${ }^{18}$ In order to shorten the delivery time, some spare parts of Applied Materials' equipment - like the quartz chamber - were procured locally. Finally, the merchant CVD technology obtained a firm footing in the industry. This motivated Del Prado to move ahead.

Based on his experience from his other representations, Del Prado knew the value of proximity in the supply chain of semiconductor materials and equipment. To serve the European markets, he championed the idea of founding European subsidiaries for his clients once their sales stabilized Naturally, he would claim a major interest in such an operation. Such European assembly operation decreased

14 Ibid.

15 Gerard Smink, 'ASM Quotations.' (1971) - Personal collection Gerard Smink

16 SEMI and Addison, 'Oral History Interview: McNeilly'

17 Sean Hurley had previously worked at one of the National Semiconductor fabs, and together with Martin van Beest he attended training session at Applied Materials. - Martin van Beest, 'Interview with the author'.

18 Martin van Beest, 'Interview with author'; Gerard Smink, 'Interview with author'. 
the efforts and costs of converting the equipment in line with the European main voltage and safety regulations. It helped the European customers to tune their requirements with their supplier and increase sales, and, consequently, increase Del Prado's commissions.

Furthermore, in the case of Del Prado, participating in local manufacturing operations constituted a hedge for a probable decline of ASM's role as sole sales agent. Its involvement in local subsidiaries boosted ASM's reputation as representative, while it gave Del Prado and his engineers experience in manufacturing equipment. With regard to the Sola Basic diffusion furnaces, this resulted in the establishment of Sola Basic Netherlands in 1968. In line with this earlier move, he proposed the establishment of a European assembly operation for Applied Material's products.

Del Prado's proposal was taken into consideration by the management of Applied Materials in Santa Clara, California, early in 1971. This company dispatched an engineer, Max Perez, to investigate whether a European subsidiary was opportune. However, due to a temporarily depressed market in the United States in 1970 and 1971, further action was delayed and later rejected by the American principal.

\section{A pivotal moment}

The withdrawal of Applied Materials from Del Prado's endeavor deteriorated their agent-principal relation. This was further aggravated due to increasing conflicting interests of Applied Materials and Sola Basic Netherlands. Both principals of ASM offered complementary features for their respective CVD and diffusion systems. ASM got squeezed between their conflicting products and interests, forcing Del Prado to make up his mind. As he was a shareholder of the Sola Basic Netherlands operation, the conclusion was inevitable: the agreement between ASM and Applied Materials became superfluous and was terminated in the fall of 1971.

This was a frustrating experience for the ambitious Del Prado. Earlier, he failed to expand sales by means of a local presence for Knapic Electro-Physics (cf. Chapter 3). When this company was liquidated in 1964, Del Prado regarded the European market - or, more precisely, his contacts among the semiconductor manufacturers - as his own and therefore at his disposal. This logic, combined with his impressive track record as sales agent, strengthened his own perceived position in relation to his principals and customers. For this reason, he also interpreted his role as a salesman in a quite flexible manner.

While the relation with Applied Materials was finalized and the Americans had not yet established a new footing in Europe, Del Prado had a window of 
opportunity and could look for an alternate supplier of CVD. ${ }^{19}$ His first choice was to have Sola Basic Netherlands fill in the gap left by Applied Materials. ${ }^{20}$ After all, Del Prado was a participant in this joint-venture. He tried to convince Sola Basic Netherlands to adapt their diffusion technology for CVD processes. He even had a pending order for a silicon oxide CVD system. Although Sola Basic's diffusion furnaces were complimentary to the CVD systems at that time, the management of the parent company, located in Wisconsin, refused to diversify its semiconductor equipment portfolio of diffusion furnaces.

Del Prado had to act in order to avoid being a mere plaything of fortune or, to be more precise, of his principals. In this context, he experienced, in the words of political historian John Pocock, a 'Machiavellian Moment. ${ }^{21}$ In response to events occurring beyond one's control - a crisis - a leader may experience his own 'temporal finitude.' In such a moment, specific conventions cease to be adequate. In this case, ASM's modus operandi as representative of others' products prevented Del Prado from continuing the profitable business of selling CVD technology. Either he yielded to this apparent reality, which made him dependent on the whims of his principals and which hardly agreed with his audacious character and instincts, or he would move beyond conventionality, retain the initiative, and continue to be, to some extent at least, the master of his own destiny.

\section{Building ASM's first CVD machine}

Del Prado picked up the glove himself. After all, he had an order for a tool in his portfolio, and in Martin van Beest he employed an experienced service-engineer who was more than familiar with Applied Materials' CVD processes. Del Prado was not left empty-handed. But a few things had to be done to prepare the manufacturing of the first CVD tool. While Del Prado was a master in plotting strategic lines, Van Beest was ingenious in getting things to work. Whether these were systems, parts, or operations, based on his inquisitive mindset he would find a way to fix them. His presence allowed ASM to build its first machine.

After being hired by ASM in 1965, Van Beest had gotten first-hand experience and training in the installation and servicing of various semiconductor technologies, from gas dryers and diffusion furnaces to die bonders. Through Van Beest, ASM internalized all these inventions. If this was a valuable asset, the company still lacked the operational capabilities to get the ordered silicon

19 A few months later, Applied Materials decided to set up its own sales office in Munich.

20 ASM, Arthur del Prado, 'Letter to Frank Roby, President of Sola Basic International' (10-51972) Archive Arthur del Prado - Sola Basic file. - Intermezzo.

21 John Pocock, The Machiavellian Moment: Florentine Political Thought and the Atlantic Republican Tradition (Princeton University Press, Princeton, 1975), p. viii. 
oxide CVD system adequately designed and assembled. The first step, then, was to articulate Van Beest's intimate knowledge of the technology in a design on paper. This guaranteed reproducibility of the manufacturing and technical process, while it was also required for the procurement of parts and necessary to substantiate the knowledge of the chemical and physical processes involved.

Since most equipment was directly imported from the United States, Van Beest was used to work with equipment manufactured in the Imperial System, while the design of ASM's equipment had to agree with the European Metric System. Working for ASM's principals and installing their American tools in Europe, Van Beest knew local suppliers for sub-assemblies that could supply parts manufactured in the Metric System. Moreover, some alterations were needed due to the different mains voltage, such as a double heating element. Two temporarily hired designers, supported by Van Beest's knowledge of the technology, put the ideas and technology on paper. ${ }^{22}$

After the system was designed, ASM ordered materials from local subcontractors. The Yellow Pages and the Dutch Chamber of Commerce provided help in locating suppliers of the various parts. Quartz was needed, the system needed to be built in a frame, thermocouples had to be acquired, as well as controllers and electrical and gas components. As Van Beest would recall:

\begin{abstract}
'We knew - among other things - that Quartz Silice in France could produce the chambers. We knew we needed Eurotherm controllers. In Rotterdam was a supplier of graphite, capable of producing big plates and drilling holes in it. In these holes, the heating elements would be put. Frejo in Soest was a sheet metal work company, which produced neat profiles that you could use to make the cabinets by putting in doors and attach them with screws. That's how we devised and built the first system. ${ }^{23}$
\end{abstract}

Indeed, the production of the first machine rather seemed to reflect an episode from a boy's book, instead of representing a major step in the history of a hightech enterprise. Assembly of the CVD system took place on Martin van Beest's desk, located in the attic space of ASM's office mansion. The machine was light enough to be carried downstairs. With his experience of servicing and installing the various systems of ASM's principals, he was able to manufacture the first piece of equipment all by himself.

22 During manufacturing, Van Beest was supported by Frans Verrijken. - Martin van Beest, ' Interview with author'.

23 Original quote in Dutch. - Martin van Beest, 'Interview with author'. 
In order to chemically deposit thin films, the machine processed silane $\left(\mathrm{SiH}_{4)}\right.$, oxide $\left(\mathrm{O}_{2}\right)$, one dopant gas, and the carrier gas nitrogen $\left(\mathrm{N}_{2}\right)$ at atmospheric pressure. The process chamber consisted of quartz in which the wafers rested on a quartz or carbon boat. Temperature measurement by means of thermocouples was needed to control the process. Automated timers permitted the gas flow and pre- and post-deposit purges. The chamber was heated by means of a resistanceheated heater block. Other components were electrically interlocked doors, a reset button, and rotameters.

This first piece of CVD technology built by ASM was called a SOX 10-2. The name referred to silicon oxide, and the figures denoted the number and the size of the wafers that the system could process - ten two-inch wafers at a time. ${ }^{24}$ The system resembled Applied Material's Silox 2600 reactor, but differed slightly in appearance. After testing the airtightness of the gas panel, Van Beest delivered the system in person to the customer in the spring of 1972.

The customer was IBM Laboratories, located in Sindelfingen, Germany. ${ }^{25}$ At the time, IBM developed the latest MOS chips in Burlington, Vermont, and in Sindelfingen, or, to be more precise, the Böblingen facility. ${ }^{26}$ The state of chip technology in those days, to which ASM indirectly contributed through its first in-house built piece of equipment, is well-illustrated by the so-called 'Riesling memory chip.' This was a 2048-bit chip consisting of about 15,000 transistors, developed and manufactured by the German IBM operation. ${ }^{27}$ Its development starting in 1971, the chip was introduced in the fall of 1972. In the years afterward, it became the major memory chip in IBM computers, replacing the previous magnetic recording data storage..$^{28}$

24 Advanced Semiconductor Materials, 'Flyer: Silicon Oxide Vapour Deposition Systems. Models SOX 10-2, SOX 20-2, SOX 40-2, SOX 60-2' Archive Author.

25 Installed in the spring of 1972 - Martin van Beest, 'Interview with author'.

26 Ross Knox Bassett, To the Digital Age: Research Labs, Start-Up Companies, and the Rise of MOS Technology (Baltimore 2007) p. 244.

27 To benchmark this, consider that Intel's competing chips had 2000 transistors at that time. Information obtained from a website of the German R\&D department of IBM: IBM, 'IBM Deutschland Forschung und Entwicklung, IBM Geschichte im Jahr 1970’ http://www-05. ibm.com/de/entwicklung/1970.html (viewed 3-8-2017); more information to be found in: Horst E. Barsuhn and Karl Ganzhorn, The IBM Laboratories Böblingen: Semiconductor and Chip Development: Research and Development in IBM Germany (Sindelfingen 2000).

28 Whether this was achieved through the technology supplied by ASM seems doubtful, as it did not supply the equipment for high-volume manufacturing in those days. 


\section{Becoming an original equipment manufacturer of CVD equipment}

ASM had cast the die, taking the first steps as a supplier of CVD by filling in the omission created by the temporal withdrawal of Applied Materials. For a while, ASM's new role remained limited to the European continent. By the time Applied Materials set up its own European sales office in Munich in 1972, ASM had transformed into its first European competitor. By building the SOX 10-2, ASM broke the ice as a supplier of CVD. However, to be taken seriously, it had to deliver more.

Del Prado and Van Beest turned ASM's first machine into a real product. The SOX 10-2 was offered as a bench model for laboratory and pilot production use to other potential customers. Later, ASM added a bigger version, dubbed SOX 20-2, and a three-stack cabinet called SOX 40-2 or SOX 60-2 to its portfolio. To boost ASM's profile as supplier of CVD technologies, Van Beest and Del Prado basically imitated Applied Materials' products, adding peripheral features to distinguish them from the original ones. The rotameter was replaced by a more advanced mass flow controller from Tylan, a company represented by ASM and for which it assembled products locally (cf. Chapter 6). In addition, ASM offered gas driers and purifiers designed to improve the quality of the gasses and the process.

Van Beest's ability to handle precursors (e.g. silane) safely was a key factor of the first ASM product. This knowledge of process technology was fundamental to expand business in the field of CVD. Even as equipment manufacturer, ASM relied on external innovations, in this case processes developed by Applied Materials. ASM did not have the human, financial, or technological resources to develop these processes on its own. But it did have the competence to add peripheral features.

Apart from silicon dioxide, ASM followed Applied Materials' example by designing nitride and epitaxial machines. The first of these was a system capable of depositing films of silicon nitride. Both the epitaxy and the nitride systems processed at a higher temperature - a few hundred degrees Celsius - and contained different gasses than the SOX. To handle these higher temperatures, the wafer susceptor was changed from aluminum to a graphite plate coated with silicon carbide. Furthermore, the system was heated through lamps. ASM named the system NOX. ${ }^{29}$

Soon after having delivered the SOX 10-2 to IBM Sindelfingen, Van Beest built an extended version of the SOX for AEG Telefunken. In the absence of a real production room, and being much weightier than the first table-sized SOX 10-2, this machine was assembled in the hallway on the ground floor of the ASM mansion. It proved hard, however, to move it through the front door of the 
mansion into a van. Imagine the rollout of a heavy machine on a gravel path. This was yet another illustration of the boy's book character of ASM's beginnings as an equipment manufacturer.

After building and selling these two SOX machines, demand seemed to stagnate. Although ASM still managed to sell several SOX systems, the NOX and epitaxial systems - referred to as Epi's - gained little attention from customers. The IBM and AEG Telefunken tools were so-called 'special products,' of which only one or just a couple of versions were manufactured. They were not used in high-volume manufacturing of semiconductor chips yet, which implied they had to be ordered prior to their design and assembly.

The modest launch of ASM's first product underscored that a future as equipment manufacturer seemed far-fetched. Yet a start was made, and it was still too early to assess its promise for tomorrow. As noted in the 1972 annual report of ASM:

'In 1972, in-house production was developed further. In this segment, sales increased from 70,000 Dutch guilders in 1971 to 575,000 in 1972. This increase was not yet sufficient to compensate the decrease in commissions and the rise of labor costs and depreciations. With an expected continued growth, the contribution of this segment of sales and the interrelated earnings will take up an increasingly important place in the firm's operating results. ${ }^{30}$

In the first half of the 1970s, ASM strengthened its production operation by attracting new employees and adding an annex to its office mansion, where production would take place. One of the new employees, Wiebe de Boer, was a graduate in physics and chemistry, who specialized in semiconductor technology. He was ASM's first engineer educated in solid state physics. Although his work covered a variety of tasks, from troubleshooting to designing new equipment, he became the technician in charge of the development of epitaxial technology. ${ }^{31}$

While Van Beest focused on the SOX and NOX systems, De Boer worked on the epitaxial reactors. He would raise the level of production practices and reasoning a bit beyond that of the informal beginnings. He insisted, for example, on testing the equipment before delivery. Order by order, Van Beest and De Boer managed to improve ASM's technological capabilities. These improvements of the original process techniques were based on the available information as well

30 Original quote in Dutch. - Nederlands Accounts Maatschap, 'Rapport uitgebracht aan de directie van Advanced Semiconductor Materials N.V. te Bilthoven inzake jaarrekening 1972 (25-4-1973) Archive Arthur del Prado - Jaarrekeningen '64-'80, p. 4.

31 Wiebe de Boer, 'Interview with author'; and Martin van Beest, 'Interview with author'. 
as trial and error, marking the start of research and development at ASM. While the SOX and NOX hardly deviated from the trail blazed by Applied Materials, the epitaxial systems soon got their own specifications.

Del Prado, who spent much of his time hunting for new principals and orders, now had a more solid support organization in place in Bilthoven. The production operation started to grow. But ASM was not yet penetrating the major league of the semiconductor industry, as was perhaps well reflected by its running its operations from a mansion in a small town. The company was still very much a sales agent, selling externally supplied innovations. The significance of the first CVD tools was not so much in their innovative properties or their success in the market, but in the sheer fact of their representing ASM's first strides as equipment manufacturer in the semiconductor market. If this reflected a modest beginning, it was also one with potential. 


\section{Chapter 8}

\section{Low Pressure Chemical Vapor Deposition, 1974-1978}

By the mid-1970s, ASM engaged a new kind of CVD process. It was dubbed 'low pressure chemical vapor deposition,' or LPCVD. The applicability of the technique was propelled by the use of polysilicon in the latest MOS-based chips (cf. intermezzo in Business I). In the case of ASM, this new CVD technique proved to be a stepping stone. Through ASM's experiences in familiarizing and innovating LPCVD, the company established its capabilities and expertise as equipment manufacturer. Moreover, the innovation relied on decentral management.

\section{Origins of low pressure chemical vapor deposition}

During the early 1970s, the rise of metal oxide silicon (MOS) transistors and computer chips pushed the application of polysilicon in semiconductor fabrication. As historians David Brock and Christophe Lécuyer explain, by the end of the sixties, semiconductor manufacturers started to apply polysilicon in parts that transmitted the electrical signal, replacing former metal electrodes. ${ }^{32}$

Instead of being one single crystal, like the silicon substrate, polysilicon consists of multiple crystals. As in the case of monocrystalline silicon, one could add dopants to alter the electrical properties and make it suitable for conductive applications. Since this type of silicon did not need to be a monocrystalline to function as an electrode, it could be deposited by means of CVD on top of an insulator like oxide or nitride. The increased applicability of polysilicon - and thus its deposition method CVD - stimulated the market for merchant deposition equipment.

From a design point of view, the polysilicon films were obviously essential, but from a manufacturing point of view this implied one had to take several steps. By the mid-seventies, the industry required new deposition techniques. Initially, these polysilicon films were deposited in a regular atmospheric pressure CVD furnace - being a variation of the ones discussed in the previous chapter. However, throughput and uniformity of these processes were inferior. ${ }^{33}$

32 David Brock and Christophe Lécuyer, 'Digital Foundations: The Making of Silicon-Gate Manufacturing Technology', Technology and Culture 53:3 (2012) pp. 561-597.

33 VLSI Research, 'Deposition', chipshistory.org, p. 4.6.1.5; LAM Research Corp, Martin L. Hammond, 'Poly-Si: A Most Important Material', in: Theordore Kamins, Brhua Raicy, and 
Furthermore, the size of the wafers increased from 50 millimeter in 1969 to 100 millimeter in 1976. This scaling was necessary to accommodate bigger chips and to increase output of manufacturing systems. The doubling of the wafer's diameter meant that the capacity of the equipment had to increase as well, otherwise throughput would decrease. In the case of deposition techniques, sizing up the reactor chamber had consequences for the gas dynamics and thus the deposition process. This implied a need for new methods of growing polysilicon.

Chip manufacturers still took the lead in new manufacturing techniques, having the resources to fund advanced research into this field. Subsequently, they were the first to look into reduced pressure CVD processes. In the fall of 1973, two Motorola engineers by the name of Jerry Chruma and Paul Hilton filed the first patent for 'System and process for deposition of polycrystalline silicon with silane in vacuum. ${ }^{34}$ This invention offered many benefits, in particular the processing of more wafers in one run. The vacuumed deposition process was soon known as 'low pressure CVD.'

The lower pressure improved step coverage and uniformity across the wafer. ${ }^{35}$ It reduced gas consumption significantly. The different gas dynamics under low pressure allowed the wafers to be stacked like discs, instead of lying flat on the susceptor as in atmospheric pressure furnaces (figure 14). The LPCVD configuration offered to process a hundred wafers in one run, an enormous improvement compared to the common furnaces. Furthermore, LPCVD batch furnaces were more flexible. The tube could be expanded to fit bigger wafers without being confronted by new technological challenges, such as changed depletion effects or gas dynamics.

Just like with the diffusion systems and the early atmospheric pressure CVD tools, temperature defined the quality and the speed of the process. A LPCVD batch tube could be hot-walled, which meant that the tube itself was heated. As a consequence, both the walls and the wafers were coated during the deposition process. However, due to this configuration, the heating - and depositing - of the wafers happened more uniform.

Carl Thomspon, MRS Symposium Proceedings 182 (November 1990).

${ }_{34}$ This was US patent US 3900597. - Motorola Inc, Jerry L. Chruma, and Paul G. Hilton, 'US 3900597A: System and process for deposition of polycrystalline silicon with silane in vacuum' (filed: 19-12-1973; published: 19-8-1975) and also as DE2460211 and CA1047850; R.J. Gieske, 'Low Pressure Chemical Vapor Deposition of Polysilicon', Proceedings of 6th International Conference on Chemical Vapor Deposition, October 10-13, 1977.

35 But not necessarily the uniformity across the tube. 


\section{Figure 14}

Vertical cross-section of a horizontal hot-wall low pressure chemical vapor deposition (LPCVD) reactor

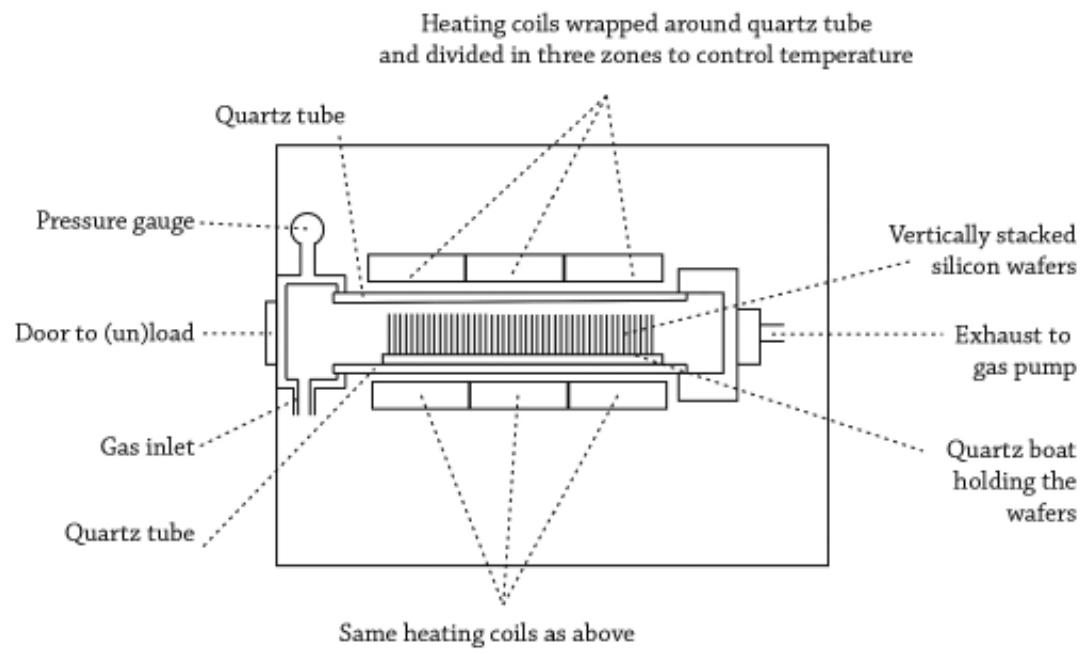

Including a vacuum pump in a CVD tool to lower the pressure was a breakthrough technology, which improved yield and uniformity and proved to be very suitable for increasing wafer sizes. The need for polysilicon in semiconductor manufacturing formed the provocation for this development. Eventually, almost all atmospheric CVD processes were turned into low pressure ones, such as oxides, nitrides, etcetera.

The first LPCVD furnaces were easy to familiarize and commercialize by the burgeoning merchant equipment manufacturers. The LPCVD machines were merely modified diffusion furnaces; only a vacuum pump was added at the rear of the tube. Merchant suppliers of CVD and diffusion technologies distinguished themselves by controlling the growth of various materials. Depending on the material to be processed, the reduced pressure diffusion furnaces were modified accordingly. Gas handling needed to be adjusted, as did the pumping mechanics, gas inlet, chamber design, and wafer boat design. For every new process - and almost every customer - the LPCVD tool needed to be tweaked and tuned until the desirable results were obtained.

The marketing of merchant LPCVD processes was not limited to one or a couple of companies or institutes. It was widespread. Especially in the United States, the number of equipment vendors offering CVD furnaces increased rapidly during the 1970s. The entrance barrier for the LPCVD market was pretty low, while the applicability increased swiftly. Suppliers of diffusion furnaces, CVD 
tools, and gas handling systems jumped at the opportunity, such as Thermco, Applied Materials, Unicorp, General Signal Tempress (formerly known as Sola Basic Industries), Hugle Industries, and Tylan. ${ }^{36}$ As ASM engineer Wiebe de Boer recalled about LPCVD: 'Suddenly, it was everywhere. ${ }^{37}$

LPCVD was just an umbrella term; it did not cover the market dynamics adequately. Competitiveness of the merchant suppliers depended on the control over a particular LPCVD process and the reproducibility of it. Few suppliers mastered all the different processes perfectly, although all of them claimed the opposite of course. With their can-do mentality, the suppliers were able to get their tools process any of the available reactions. However, the required amount of time and money for engineering a new distinctive system limited and distinguished the suppliers. After a few years in the market, the equipment suppliers would focus on the films they mastered most successfully. They continued to expand or tried to expand - their portfolio with other processes.

\section{Entering the market for LPCVD systems}

When the first commercially available LPCVD furnace was introduced by Unicorp in 1974 - based on Motorola's technology - ASM was just making its first strides into the CVD technology and semiconductor equipment manufacturing. ${ }^{38}$ The company was still foremost a sales and marketing organization; the recent acquisition of encapsulation company Fico Toolings remained an independent part of the company (see Business I). Most of ASM's income was still obtained on behalf of its principals, among which Fico. For the time being, then, the company still catered to the European demand for American production technologies. Until the mid-1970s, ASM largely operated from its base in Bilthoven and its British, French, and German sales offices.

However, ASM continued its efforts to increase in-house development and manufacturing activities in Bilthoven. It would occasionally sell one of its CVD systems - SOX, NOX, Epi - and this was just enough to support the growth of its development and manufacturing capabilities. When a machine got assembled for the first time, a lot of tweaking and tuning was required before it worked sufficiently. ASM also supplied semiconductor manufacturers with gas handling systems, assembled in line with the individual customer's guidelines or designs. Through this lucrative activity, ASM became more experienced in handling gasses.

36 Tylan supplied LTO and HTO gas panels for LPCVD processes before they actually supplied a LPCVD furnace. They also offered quartz chambers. However, they lacked the know-how to integrate them all into a proper working LPCVD furnace, in particular after the rise of dedicated LPCVD furnaces.

37 Wiebe de Boer, 'Interview with author'.

38 VLSI Research, 'Deposition', p. 4.6.1.5. 
ASM's deposition equipment and gas panels were mostly sold to R\&D departments, either at semiconductor manufacturers or research institutes, and usually involving just a single tool. The research institutes had little experience with the acquired CVD technology, and many needed quite intensive support from their supplier. Consequently, proximity was a major selling point. The fact that ASM was a European manufacturer guaranteed some of its business in the European market.

So far, the engineers from Bilthoven lacked formal ties with either customers through joint development programs or research institutes. They had to base their understanding of CVD technology on informal sources, such as through what they read in articles or heard at meetings with customers and colleagues. Developing new deposition technologies was done by a small team of engineers in Bilthoven, sale by sale. Being a small organization, knowledge derived from engineering and from customer's feedback quickly diffused among the engineering team. This enabled rapid accumulation of knowledge about CVD processes.

ASM was ambitiously adding processes to its product portfolio in order to improve its appeal to potential customers. As explained above, it started with oxides, followed by nitrides and epitaxial processes. Sometimes processes were added, when the company hardly had a clue how to materialize these premature claims of competence. The same applied to the new kid on the block: LPCVD processes.

The available experience in constructing CVD tools and innovating the early epitaxial reactors, in combination with their common sense, proved to be indispensable during the fabrication of the first LPCVD system at ASM. Van Beest and the other ASM engineers elaborated on the knowledge that they had accumulated so far. They obtained their information from magazines like Solid State Technology, and from discussions with colleagues and customers. As Wiebe de Boer recalled:

'In the first years, the basics of all CVD was similar. A horizontal furnace - whether you grew nitride, oxide, polysilicon or epi. ... When somebody discovered and proved that it could be done in a diffusion furnace at low pressure - very simple, you built it as well. And it ran just smoothly. A little understanding of the workings was required, but it was easily built. ${ }^{39}$

Van Beest started to assemble and configure his first LPCVD 'tinker tool,' as he would call it, in early 1975:

39 Original quote in Dutch - Wiebe de Boer, 'Interview with author'. 
'I did the first experiments at the annex at Soestdijkseweg. You heard and read about LPCVD. That time, I bought a heating element with infrared lights, put it into a quartz tube, and added a vacuum pump from Leybold - a German firm. I built a gas panel and started tinkering with my set-up. It was a miracle that nothing went wrong. But, well, nor did it produce any good results. ${ }^{40}$

The tinker tool was capable of growing a film, which more resembled mildew than a thin film. It was a modest first effort. ASM's capability in LPCVD was still far from being suitable for high-volume manufacturing.

Initial development of the first LPCVD furnace had to be done most economically. ASM was still Del Prado's sole property, and he kept a close watch on the company's expenditures. Engaging ambitious research and development projects was out of the question. Commercial considerations defined the framework within which Van Beest and De Boer could tinker with new CVD processes. As such, the development of the LPCVD tool was led by their practical reasoning, craftsmanship, and hands-on attitude in dealing with the limited financial and technological resources available.

\section{Accessing the American market and knowledge}

The American competition adapted to and familiarized itself with LPCVD technology more swiftly. As competition became increasingly tight in the United States, these companies were eager to look for opportunities overseas, in Europe. Their competitive advantage, generally, was their established base, which dispelled fears among potential clients of being someone's first customer. In addition, the United States was perceived as a leader in semiconductor technologies, which bolstered their reputation in Europe.

Being a European newbie in semiconductor production technologies, ASM's chances shrank with the arrival of unflinching and more experienced American competitors in Europe. There were too many vendors of CVD equipment, and ASM did not offer competitive products. After all, it had merely followed the trail blazed by Applied Materials. ASM's LPCVD technology was still in its infancy. Furthermore, due to the Cold War, it was difficult - if not completely illegal - to sell the advanced CVD products behind the Iron Curtain. The European market was geographically and competitively limited for ASM.

However, the future was certainly not all-out grim. Del Prado used the Dutch Fico encapsulation products as leverage to internationalize. It enabled him to look beyond the European market and open foreign markets for ASM. The establishment of the Hong Kong office, ASM Asia, in 1975 was step one. But 
the Fico molds formed a catalyst to establish ASM America in Phoenix, Arizona in 1976 (cf. Business I). ASM, as equipment supplier, had plenty of opportunity worldwide, notably in situations where proximity was vital.

While ASM Asia merely focused on the encapsulation business, Del Prado and his American companions, Dr. Don Jackson and Ed Foley, envisaged a broader range of activities for ASM America. The new subsidiary would also market and sell ASM's wafer processing technologies, from deposition tools and gas handling systems to test equipment. Furthermore, ASM America would develop and produce its own products. The American market offered ASM knowledge and sales incomparable to other parts of the world for the whole semiconductor manufacturing line. Through the American subsidiary, ASM gained access to American innovation knowledge and practices, and the American market.

Del Prado was keen on having the American operation pursue local opportunities by itself. Therefore, he organized his new foreign subsidiaries in a decentralized manner, which was typical for conglomerates and Dutch multinational enterprises in those days (cf. Business I). Through this trust, Del Prado stimulated local management to take initiative, just as he had enjoyed early in his career working for Knapic Electro-Physics. Although he kept a close eye on the various dealings and activities at the operations, he freed himself from the duty to substantiate the new subsidiary's earnings. Of course, Del Prado would initially support the operations with several preliminary activities. ${ }^{41}$ In the case of ASM America, the latest epitaxial furnace 21-3", developed in Bilthoven, was transferred to Phoenix, as it resembled the epitaxy tool co-developed by Jackson at Motorola. Eventually, ASM America was envisaged to develop its own technological and manufacturing capabilities in line with its local competitive strengths.

As it turned out, the staff of ASM America faced difficulties selling the Dutch CVD products. American customers were reluctant to buy European technology, mainly because of concerns about service, the ordering of parts, and European metric standards. Moreover, the European semiconductor industry was lagging behind in the development of chips and the interrelated manufacturing techniques. In Europe, by contrast, ASM had always been able to rely on Del Prado's extensive network and long track record. In its home-market, the company did have an established reputation.

It was exactly this European reputation that hindered ASM America. Most of the European tools were not sellable in the United States. This concerned the epitaxial furnaces in particular, as they bore too many similarities with those of

41 ASM America, Ron Colvin, 'Summary of Meetings Held 9/30/76 and 10/1/76 - 1977 Sales, etc.' (4-10-1976) Archive Arthur del Prado - ASM America 1970s file. 
the conventional suppliers. The other or later developed diffusion and LPCVD furnaces were not distinctive enough either, as Van Beest still found himself in the stage of tinkering with the technology.

Furthermore, the ASM 21-3" epitaxial system had to compete with the popular barrel reactor of the antagonized former principal Applied Materials. Obviously, the latter was eager to point out to its customers from whence ASM's CVD competences originated. ${ }^{42}$ On top of that deterrent, Applied Materials benefited from the proximity factor, as it was located just around the corner from the majority of the merchant semiconductor manufacturers in Silicon Valley. While Applied Materials enjoyed a home advantage, ASM America still needed to find its own innovative technology to create a local competitive advantage.

\section{Profiting from a giant in the industry}

Luckily, the American ASM subsidiary had strong informal ties with one of the biggest American semiconductor producers, and innovator of CVD processes, Motorola, located just around the corner in Phoenix. Many on ASM America's staff, including Jackson, were previously employed by Motorola. The first ASM America products - a four-point probe, the modified 21-3" epitaxial reactor, and a controller - were inspired by the experiences obtained at Motorola. Of course, technology transfer to ASM America was restricted by Motorola patents and non-disclosure agreements of the (former) employees, but the Motorola career of most of the engineers proved to be a promising starting-point.

Because of the depressed atmosphere and lack of opportunity at Motorola by 1976, its engineers involved in materials and equipment were eager to pursue their aspirations elsewhere, which is why some of them decided to join the ASM America startup. Several of them were highly educated and experienced in solid state technology. In 1976, Jackson was the first to join ASM. Others like Dean Terry and Ron Colvin followed suit. After ASM America was in operation for one year, a Motorola process engineer also joined ASM America: Dr. Jon Goldman. ${ }^{43}$

As suggested by the Chruma \& Hilton polysilicon LPCVD patent, Motorola was at the forefront of LPCVD technologies, and one of its experienced engineers

42 Applied Materials, Ted Rafalovich, 'Interoffice Correspondence: Inputs regards ASM' (September 1977) Archive Arthur del Prado - ASMA 1970s.; ASM America, Don Jackson, 'Telex to Arthur del Prado, ref: t1137.76' (9-11-1976) Archive Arthur del Prado - ASM America 1970s file.

43 Goldman got a PhD from MIT, Cambridge. At Motorola he worked at the Advanced Products Research and Development Laboratory in Phoenix, Arizona. From 1973 until 1976, he was involved in the development of LPCVD nitride processes and poly processes. He joined ASM in Summer 1977. - Jon Charles Goldman, 'Résumé' (January 1977) Archive Arthur del Prado - ASM America file 1970s.; ASMA, Don Jackson, 'Handwritten letter to Jon Goldman' (1-61977) Archive Arthur del Prado - ASMA 1987s file. 
was Goldman. ${ }^{44}$ At Motorola Semiconductors, he co-developed a low temperature oxide (LTO) process and a silicon nitride process for LPCVD furnaces, as many semiconductor manufacturers and equipment suppliers tried at the time. ${ }^{45} \mathrm{Next}$ to the polysilicon, the LTO process formed a very attractive process for LPCVD tools. Most atmospheric CVD processes could be easily transferred into a lowpressure variation, which improved yield and throughput; except for the LTO, for this transfer did not seem possible.

This was a problem because the low temperature oxide processes were indispensable for the growth of dielectric films on top of aluminum interconnecting structures. Dielectrics were, and still are, used to separate the different interconnecting films and components from each other. They insulate. The deposition of the passivation film made of silicon oxide covered the whole integrated circuit, and protected the chips components against the external environment. In this respect, the use for oxidation processes did not deviate from the SOX 10-2, ASM's first CVD product in 1971.

However, by 1976, the oxidation processes' temperature had proven to be useful in production at Motorola. Since the invention of the integrated circuit and the planar process, the number of components - transistors, capacitors and the like - had been increasing (cf. Moore's Law, in Intermezzo, Business 1). The high temperatures at which silicon oxide originally was deposited threatened this increasingly complex web of components, interlayer dielectrics, and interconnections. At higher temperatures of 700-900 degrees Celsius, the interconnecting films of aluminum alloyed with the silicon structures below and on top of it, destructing the chip's structure.

The final passivation film had to be deposited at lower temperatures of 300 to 500 degrees Celsius to prevent this from happening. This explains why low temperature oxide processes had been in demand for some time. But the development of an appropriate process met with some tough material difficulties. The common LPCVD method did not suffice. As ASM engineer De Boer recalled about the LTO low-pressure: 'the] gas phase reaction causes a bull's eye effect on the wafer, a layer very thick at the edge and thin in the center of the wafer. ${ }^{46}$

44 Another sign that Motorola was at the forefront of LPCVD processes was its early patent in growing silicon oxide films through tetraethylorthosilicate (TEOS) - Motorola, Dan Burt, Richard Taraci, and John Zavion, 'US 3934060: Method for forming a deposited silicon dioxide layer on top of a semiconductor wafer' (filed: 19-12-1973; published: 20-1-1976).

45 Others also worked with cages to deposit silicon dioxide, including Dr. Richard Rosler, future R\&D manager at ASM America: Applied Materials, Richard Rosler and Robert East, 'US 4232063: Chemical vapor deposition reactor and process' (filed: 14-11-1978; published 4-11-1980); General Signal, James McMullen and James Vokac, 'US patent, US 4203387A: Cage for low pressure silicon dioxide deposition reactors' (filing: 28-12-1978; publication: 20-5-1980).

46 Wiebe de Boer, 'Thin Layers in Semiconductor Industry' - Comments shared with author; 
To this end, Goldman proved to be a promising asset for ASM. At Motorola, Goldman and his colleagues had succeeded in growing acceptable oxide films at lower temperatures and - most strikingly - at lower pressure! They overcame the challenge posed by the bull's eye - which decreased yield. ${ }^{47}$ Their major innovation entailed the use of a perforated metal cage within the quartz chamber. The cage distributed the gasses more evenly across the tube and over the stacked wafers. It slowed down the chemical reaction. Consequently, silicon oxide could be deposited at relatively low temperatures ranging from 400 to 500 degrees Celsius, while maintaining throughput with the vertically stacked wafers.

Chip manufacturers - like Motorola - desperately needed these processes. As the applicability of Goldman's process became apparent, Motorola filed patents in, respectively, 1976 and $1979 . .^{48}$ The semiconductor Moloch applied the process in their semiconductor manufacturing operation. By the time the patents were filed, Goldman had already left Motorola in order to capitalize on his experience and knowledge of LPCVD processes - and the very attractive LTO in particular.

When the two former Motorola employees Jackson and Goldman met in May 1977, Jackson quickly realized the additional value of Goldman's knowledge about the LTO process. After more than one year in operation - ASM America had not sold any technology in the United States yet. ${ }^{49}$ So far, the European LPCVD tools of ASM had not attracted a lot of attention in the American and European markets. It was not distinctive enough, and it was hoped that Goldman could contribute to ASM's LPCVD technology, thus carving out some market share for ASM.

The reliability of his knowledge of LPCVD and LTO processes was proven by its use in Motorola's operation. In Bilthoven, Van Beest had performed some preliminary work on LTO processes. But he was not the only one. The whole industry tried to decrease the temperatures of the low-pressure oxide processes. ${ }^{50}$

to the bull's eye was also referred to in the Goldman patent: Motorola Inc, Robert Stanley Alberti, Jon Charles Goldman, 'US Patent 4,098,923: Pyrolytic Deposition of Silicon Dioxide on Semiconductors Using a Shrouded Boat' (Filed: 7-6-1976, Accepted 4-7-1978), p. 3.

47 Motorola Inc, Robert Stanley Alberti, Jon Charles Goldman, 'US Patent 4,098,923: Pyrolytic Deposition of Silicon Dioxide on Semiconductors Using a Shrouded Boat' (Filed: 7-6-1976, Accepted 4-7-1978), p. 3.

48 Motorola Inc, Robert Stanley Alberti, Jon Charles Goldman, 'US Patent 4,098,923: Pyrolytic Deposition of Silicon Dioxide on Semiconductors Using a Shrouded Boat' (Filed: 7-6-1976, Accepted 4-7-1978); and Motorola, Jon Goldman, Larry McMillan, and James Price, 'US 4279947: Deposition of silicon nitride' (Priority: 25-11-1975; published: 21-7-1981).

49 ASM America, Don Jackson, 'Memo to E.J. Foley: Continuing program for EJ Foley and Associates' (21-9-1977) - Archive Arthur del Prado-ASM America Diversen 1977, 1978 - 1980, ASM America aug-dec 1977.

50 ASM America, Don Jackson, 'Telex to Martin: Trade Secret Situation with Motorola' (28-71978) - Archive Arthur del Prado - ASM America Sales '76-'78, ASMA Telexen 1978. 
It was what everybody wanted. Yet the coincidental availability of Goldman's and his knowledge of the LTO process, combined with ASM's technology - the hardware, gas handling, and controllers - might tilt the balance in ASM America's favor. And it did.

\section{Familiarizing Goldman's LTO process}

The first thing Goldman had to do, after formally being hired, was to support Van Beest with his LPCVD processes. Instead of losing too much time on tweaking and tuning LPCVD processes, Del Prado expected Goldman to accelerate the Bilthoven engineers' work. For instance, he was asked to assist in the installation and startup of a polysilicon LPCVD furnace at IBM France. Van Beest, having moved beyond his initial tinker tool, had already installed a Special Product LPCVD furnace at IBM. ${ }^{51}$ Goldman also joined the effort to design another LPCVD furnace in Bilthoven.

In the ASM office mansion, development practices and safety procedures were less fixed and rigidly observed compared to those of Goldman's former employer, Motorola. For instance, in Bilthoven, the reactor outlet provisionally emitted its gasses through a hole in the wall into the garden. In those days, no local regulation on exhaust of gasses was in place, also due to the lack of industrial activity in Bilthoven. Moreover, the impetuous and inventive engineers of ASM - Van Beest, De Boer, Cees Polkamp, and this time also Goldman - focused their efforts on getting their systems and processes to work, while any further consideration of the side-effects of those activities got lost in the excitement.

During the first run performed by Goldman in Bilthoven, silane was emitted undiluted by accident, which caused it to catch fire as it reacted with the oxygen in the outside air. Flames flickered into the garden. Normally, silane was processed and emitted in a diluted fashion, with nitrogen to prevent spontaneous and possible disastrous fire. Polkamp and Goldman had forgotten to dilute exhausted gasses with nitrogen. Although no harm was done, the event well illustrated the fiddling and fixing still going on in the Bilthoven mansion.

After Goldman's return to the United States, he assembled a furnace which allowed him to run demos for customers. Most of these parts were supplied by ASM Bilthoven. By October 1977, this three-stack tinker tool was used to tweak and tune the LTO process to perfection - in combination with ASM's LPCVD design and hardware - and to convince customers of the quality of the process. It consisted of three tubes, the lowest for LTO, and the other two for other CVD

51 ASM, Martin van Beest, 'Memorandum: LPCVD Trials' (24-11-1976) Archive Arthur del Prado - ASMA 1970s file. 
processes, and was controlled by an ASM America Micon controller. ${ }^{52}$ It offered ASM America a modest capacity to innovate CVD processes.

Although his Motorola experience directed his system outline, Goldman had to refine and improve the ASM system through his own research and development efforts, in particular if he wanted the system to be applicable for other materials as well. As his Dutch trainee Heico Frima recalled:

'A lof of runs had to be done. Every time it was a matter of loading wafers and processing these under different circumstances, in order to figure out how to perfect the homogeneity, the growth rate, and the kind of film grown. ... You tried it with a higher temperature, lower temperatures.... We had the shroud [the metal cage] and experimented with it. That worked out fine. But we had to deal with the question of the number and the size of the holes in the shroud. And we added a gradient to control the temperatures across the chamber. ${ }^{53}$

Goldman and his temporary trainee Frima continuously ran dummy and used wafers to verify the performance of the process, as new silicon wafers were too expensive. Occasionally, blank silicon wafers were positioned throughout the boat to evaluate the deposition rate across the tube. After each run, these wafers had to be cleaned by etch baths before they were used again for another demo-run. The men tweaked and tuned on various parameters to optimize the process across the tube. This also involved overcoming clogging of gas valves and meters, as well as meticulous leakage tests. ${ }^{54}$

Goldman and his assistant worked often in overtime to get the process ready and reproducible. Goldman's involvement provided ASM America a stronger case when it came to convincing customers. After all, the process had been applied at one of the biggest semiconductor manufacturers, and the company could support its claims through demonstrations ('demos').

As a further push to persuade customers, ASM America offered a retrofit package. Customers with older or redundant diffusion furnaces, originally supplied by competitors like Thermco, could buy a retrofit kit for the LTO process. It entailed a gas handling system, a small controller, and a new tube. The latter was changed for a stainless-steel version instead of the more traditional quartz tube..$^{55}$ These parts were removed from the Thermco tool and replaced by ASM

52 Heico Frima, 'Notes to author' (25-1-2017).

53 Original quote in Dutch - Heico Frima, 'Interview with author'.

54 Heico Frima, 'Notes to author' (25-1-2017).

55 The process temperatures were much lower. Therefore, the tube could be changed for a stainless steel version. This was much cheaper. - Wiebe de Boer, 'Interview with author'. 
parts. Through offering this product, ASM America's managed to compensate for its lack of an established base in the United States.

Through their respective demo tools, ASM America and Bilthoven cooperated to optimize their processes. Most innovation involved the incorporation of peripheral features, improving the process technology to grow thin films. After acquiring the Alsthom gas component operation in 1978, ASM France delivered heating elements and valves. Bilthoven and Phoenix were involved in the processes and control. Bilthoven and Phoenix developed a controller containing Motorola's renowned 'Motorola 6800' and its successor, the '68000' microprocessors. ${ }^{56}$ A recipe was loaded into the European controller - or later in the American version dubbed Micon - which determined the process steps. ${ }^{57}$ Over time, ASM America procured the European parts locally. Each new process required tweaking and tuning by the local engineers. Especially, the LTO required a lot of tinkering before it was settled.

Goldman's demos and experiments entailed various processes, and he proceeded in expanding the number of processes ASM could deliver. This included high-temperature oxide (HTO), TEOS, arsenic and polysilicon processes. His and Van Beest's persistence in expanding the processes on behalf of ASM allowed the company blusterously to advertise the following in the autumn 1977 issue of Solid State Technology:

'Show us your spec's, and we'll build you a low-pressure chemical vapor deposition system guaranteed to meet or exceed them [sic.]. ${ }^{58}$

Early 1978 ASM America succeeded in selling a LPCVD furnace capable of processing LTO to National Semiconductor. ${ }^{59}$ Although competition was fierce, ASM America managed to sell a number of LPCVD tools in the next years. ASM's competitiveness foremost concerned its ability to offer LTO processes for LPCVD furnaces, despite the fact that it was not an easily reproducible recipe. None of

56 This microprocessor was also used in the first Apple products, along with other initial Personal Computers introduced in the market.

57 The Micon was standardly programmed by the engineers of ASM America. If ASM Europe ordered one for their customers, they had to reprogram it. They removed the settings of ASM America and loaded their own recipe. This was a rather irritating task for the European engineers, which made them less willing to opt for the American controller system.

58 While most of the industry referred to low pressure CVD as LPCVD, ASM tried to differentiate itself by calling it Micro Pressure CVD a bit later. Although ASM was persistent in this marketing ploy until the mid-1980s, the industry did not adopt it. - Solid State Technology, 'Advertorial ASM America: Guaranteed Process Performance' (September 1977) - Archive Arthur del Prado - ASM America Diversen 1977, 1978 - 1980, ASM America aug-dec 1977.

59 ASM America, Don Jackson, 'Memo: National Semiconductor LTO order' (24-1-1978) Archive Arthur del Prado-ASM America Diversen 1977, 1978 - 1980, ASM America aug-dec 1977. 
its competitors could do this effectively. In 1979, the American operation got 65 percent of its sales out of LPCVD processes, one year later this was 50 percent. ${ }^{60}$ ASM as a whole had finally carved out its share of the prestigious American market.

\section{LTO substantiates ASM's claim to fame}

But it did not end there, as the LPCVD opened the doors for ASM to another very promising market: Japan. ASM America had to fight for every sale in the United States. Similar to the Bilthoven operation, it ran up against the limitations of its home market. Its response was the same: looking for opportunities abroad.

In the fall of 1977, Semicon, the industry's conference and exhibition, was organized in Tokyo. This first edition of Semicon Japan capitalized on the high demand for American chip technology in Japan. After the first decade of integrated circuits and the subsequent progressing miniaturization, functionality, and complexity of the chips, the industry prepared for the advent of the next generation of chips. This was called 'very large scale integration' (VLSI).

As argued by economist Franco Malerba, the Japanese and European indigenous semiconductor manufacturers were outperformed by their American counterparts. ${ }^{61}$ Competing in the latest generation of chips defined the competitiveness of firms, and thus the survival of national semiconductor industries. The Japanese industry and authorities were well aware of this notion, and tried to make up for their disadvantage by means of an expansive program, launched in the first half of the 1970s. ${ }^{62}$ In this context, they tried to get their hands on any American technology.

Being an American operation in combination with this strong demand for American products constituted a window of opportunity for ASM America. In the Japanese market, there were no scruples to the young company with its barely established reputation. With American bravado and bluff, ASM America's marketing manager Dale Stoddard presented the LPCVD capabilities as being topnotch. During Semicon Tokyo, he, Jackson, and Del Prado succeeded in attracting a well-established trading-house as distributor for its American products (cf. Chapter 6).

Through this cooperation, ASM America succeeded in selling an LPCVD furnace for LTO processes to one of the consortia of the VLSI program early

60 ASM America, Don Jackson, 'Memo: [title unknown]' (February 1980), Archive Arthur del Prado - ASM America America Diversen 1977, 1978-1980.

61 Malerba, The Semiconductor Business.

62 Martin Fransman, The Market and Beyond: Information Technology in Japan (Cambridge University Press, 1990); and Kiyonori Sakakibara, 'From imitation to innovation: The Very Large Scale Integrated (VLSI) Semiconductor Project in Japan', MIT Alfred P. Sloan School of Management Workingpaper, WP \#1490-83 (1983). 
in 1978. The consortium was called NTIS, which consisted of the Japanese semiconductor manufacturers NEC and Toshiba. ${ }^{63}$ Although the LTO sale constituted a small portion of the available capital expenditures within the VLSI Program, it was ASM's first step into the promising and very lucrative Japanese market. ASM America's LTO-LPCVD process cracked the Japanese market, indirectly providing ASM access to Japanese manufacturing practices and demands. For the time being, however, the interaction with this market remained limited.

By 1979, ASM had become a multinational original equipment manufacturer. In Bilthoven, the company finally outgrew its mansion, and moved to a more suitable office at the Jan Steenlaan. Its CVD activities got more established in Europe. Also, the American operation had expanded, now employing nearly 70 staff. The Japanese demand would stimulate this growth, if modestly at first. ASM's sales grew from about 31 million Dutch guilders in 1978 to 42 million one year later, with profits of, respectively, 14.4 and 21.4 million Dutch guilders. The total American market for ASM's products - both molds and wafer processing equipment - amounted to 5 million Dutch guilders in 1978 going up to 15 million one year later. The LPCVD business paved the way for this success.

Although the LTO process proved critical in getting ASM established globally as CVD supplier, its viability was limited. In contrast, the other LPCVD processes offered by ASM - such as polysilicon - remained healthy for years to come in Europe. The sales of the LTO business in particular started to flounder in the early 1980s.

This process was accompanied by increasing conflicts between ASM and Goldman. This friction was triggered by Goldman's ambition to cash in on his intimate knowledge of LPCVD processes and ASM's mounting distrust of his honesty. After the introduction of the LTO process, Motorola suspected that ASM and Goldman had copied Motorola's proprietary and patented LTO process. At his hiring, Goldman repeatedly reassured Jackson that he did not violate non-disclosure agreements and intellectual property of the semiconductor manufacturer. However, Motorola suspected otherwise.

After painstaking efforts, Jackson convinced Motorola's management not to go after the young American operation by supplying Van Beest's predating notes on LTO and through his own excellent personal reputation and contacts at his former employer. ASM America's management and Goldman grew frustrated with each other, which resulted in the latter's resignation. After being hired by ASM's competitor Thermco, Del Prado responded by suing Goldman for violating non-

63 Matsushita - later known as Panasonic - placed an order for an LTO order a bit later. Fukumi Tomino, 'Interview with author'. 
disclosure agreements. The once constructive and enabling relationship between Goldman and ASM ended in mutual resentment.

Yet there were two more reasons for the withering LTO business after the break with Goldman. First, the LTO process had a limited viability. By the late 1970s, the semiconductor industry predominantly used polysilicon gate MOS transistors in chips. The polysilicon gate was vulnerable to contamination by metals, something which was recognized first by a Japanese customer NEC and only later by American chip manufacturers. ${ }^{64}$ The issue rendered the ASM LTO process - with its perforated stainless-steel cage - no longer applicable. As ASM failed to develop a solution, its competitor Anicon carried off the prize through its full quartz chamber by $1984 .{ }^{65}$

Secondly, a new deposition process came along that allowed the growth of passivation and dielectric films at even lower temperatures than the LTO process. This concerned the growth of silicon nitride dielectrics through a plasma CVD process. ASM was eager to pursue this novel technology, as will become apparent below. Moreover, it solved the problem of the metal contamination of polysilicon gates. ASM's success with this new process also explained the company's tardy efforts in overcoming the stainless-steel cage troubles in the floundering LTO process.

${ }^{64}$ Japanese chip manufacturers in general had been aware earlier of the impact of particles on chip yield, compared to their American competitors. This awareness contributed to their rapid rise in memory chips.

65 In Bilthoven, the ASM engineers did some preliminary work on a quartz cage for LTO processes afterward. Also ASM Japan developed a quartz cage. 


\section{Chapter 9}

\section{Plasma Enhanced Chemical Vapor Deposition, 1978-1980s}

In the late 1970s, ASM gradually warmed to its role as supplier of CVD technology. With every machine sold, the company received customer feedback, gained more experience with the previous generations of tools, and learned about new technologies buzzing around throughout the rapidly developing industry. This accumulation did not occur evenly across the ASM subsidiaries located on the different continents. Gaps in expertise arose as a consequence of the physical separation, the limited communication technologies spanning this distance, and the still very distinct local requirements.

The CVD processes that ASM developed simultaneously in Europe and the United States slightly differed. Its operations in the two regions would often have their own preferences for components. ASM Bilthoven, for instance, also offered diffusion furnaces by the late seventies, a move that was motivated by local preferences and availability of suppliers. Diffusion furnaces were vital for the manufacturing of bipolar computer chips, and European chip manufacturers excelled in these products, but they were less competitive in MOS-based chips. ${ }^{66}$ As such, the Bilthoven and Phoenix operations experienced different demands in this segment, causing them to employ different efforts.

The decentral management of the ASM group stimulated this divergence even further. The strategy of having the local entities scout for the best opportunities had a centrifugal effect on the operations. In some sense, they became islands within the wider ASM ocean. Each of these islands developed its own ecosystem of products, marketing, suppliers, customers, etc. Fair winds falling to the industry accelerated this development of specialization and localization, with Arthur del Prado serving as guiding force.

In 1979 ASM introduced a CVD process that would aggravate local diversification. It was called 'plasma enhanced chemical vapor deposition' (PECVD). This new CVD process was imperative for the company's staggering growth at the start of the 1980s.

66 Malerba, The Semiconductor Business. 


\section{Origins of plasma enhanced chemical vapor deposition}

The need for low temperature processes addressed by the LTO process also accounted for the development of plasma CVD. The number of electrical components, and the subsequent production steps to create them, increased through the advent of VLSI chips. More thin films of various materials had to be stacked together, while compatibility of the layers became critical. Because semiconductor manufacturing is a commercial business, production should result in a maximum number of working chips. The deposition process of one material ought not to annul the previous production steps.

To sustain compatibility among the growing number of layers compromising a chip, decreasing temperature was imperative. In regular CVD furnaces, thermal energy and the gas flow determined the deposition rate. This meant: the higher the temperature, the quicker the reaction occurred. However, high temperature processes were not always an option. In particular, the deposition of dielectric or passivation films on top of the metal interconnections proved to be challenging.

These dielectric and passivation layers consisted of either silicon oxide or silicon nitride. High deposition temperatures of these materials affected the underlying aluminum interconnections. When the final films were deposited on top of the chip - in particular the passivation layer - the temperature during the deposition process should not be too high.

To this end, the above-discussed LTO process had resulted in a significant reduction of the temperature needed to deposit silicon oxide. But the quest for CVD processes with lower temperatures was not yet over, in particular regarding other dielectric materials used in semiconductor manufacturing. Silicon nitride was still deposited at high temperatures.

By the mid-seventies, it became apparent that plasma-based CVD was highly useful for growing materials at relatively low temperatures. The plasma activated the gasses instead of the common thermal energy. When igniting a plasma to ionize the reactants, temperature was no longer critical. It could be decreased from relatively low temperatures of 400 degrees Celsius for silicon nitride to room temperatures, depending on the specifications of the user.

Standard Telecommunication Laboratories - a British research laboratory of International Telephone and Telegraph Corporation (ITT), located in Harlow, UK - was initially responsible for discovering the plasma processes and the advantageous application of silicon nitride passivation films. ${ }^{67}$ Two British engineers, Richard Swann and Henley Sterling, studied and explored the possibilities of this process at different laboratories of ITT, and patented it in

${ }_{67}$ Richard Swann, 'First-Hand: The Birth of Glow Discharge Chemistry (aka PECVD)', ethw.org (Date unknown, perhaps 2014). 
1964. They called it the 'Glow Discharge Process.' Other chip producers, such as IBM, Texas Instruments, Fairchild, and Sprague, would also begin to explore plasma-based processes. The most promising results in plasma CVD concerned the growth of silicon nitride and variations of this material.

In 1976, the inventive plasma process of Swann and Sterling was picked up by the equipment industry. That year Dr. Richard Rosler, Dr. Walter Benzing, and James Baldo of Applied Materials presented a production reactor capable of processing silicon nitride at low temperatures using plasma CVD (figure 15). ${ }^{68}$ It was based on a patent of Texas Instruments engineer Alan R. Reinberg, called 'Planar radial flow reactor for PECVD processes. ${ }^{69}$ Benzing and his team basically reversed the direction of the gas flow, while maintaining the basic configurations of the Reinberg reactor. This way, they steered clear from Texas Instruments' intellectual property, and could commercialize plasma CVD rather economically. The Applied Materials system was called Plasma I.

\section{Figure 15}

Vertical cross-section of the Applied Materials plasma enhanced chemical vapor deposition (PECVD) reactor, early 1970 s

Applied Materials elaborated upon a design from Texas Instruments, a similar configuration, merely reversing the direction of the gas flow.

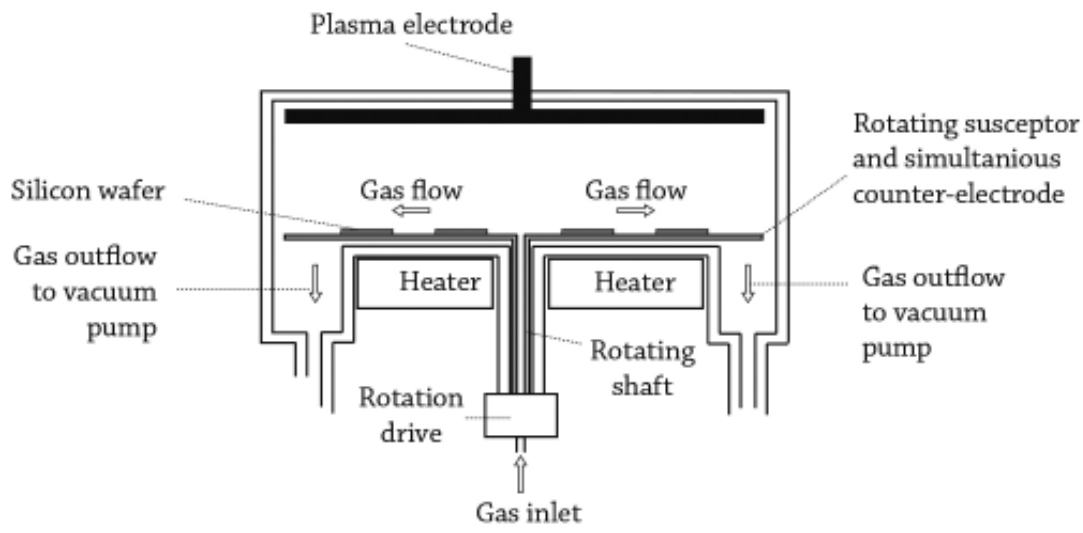

More merchant equipment suppliers followed. A company named LFE offered a plasma system. Next, there was a company called Pacific Western, which made its strides into CVD equipment only recently. It introduced its tool in 1978 and succeeded in getting the system into Intel. And lastly there was ASM America in

68 Rosler S, Benzing W C, Baldo J, Applied Materials Inc., 'A Production Reactor for Low Temperature Plasma-Enhanced Silicon Nitride Deposition', Solid State Technology (June 1976).

69 Alan Reinberg, 'US 3757733: Radial flow reactor' (filed: 27-10-1971; published: 11-9-1973). 
1979, which became market leader with its PECVD system. To gain a better idea of the dispersion of knowledge among these three suppliers of plasma technology, and its arrival at ASM, it is instructive to look at the career of two engineers.

\section{Enter George Engle and his plasma system}

The first engineer to have a major impact on the development of PECVD was George Engle. ${ }^{70}$ Having no educational background in semiconductor technology, he succeeded in innovating the plasma CVD processes drastically. His career started at Applied Materials as mechanical engineer responsible for the wiring of the deposition systems, while later he also became involved in supply chain management. Working for customer service, and thus being exposed to customer complaints about Applied Materials' first plasma tool, he developed an alternative method for PECVD processes.

Hindered by his lack of expertise - and the consequent troubles of expressing his ideas properly - he got nowhere with his suggestions at Applied Materials. Confident about the feasibility of his PECVD system, he started to construct a prototype in this garage in California, creating an experimental laboratory at home. Similar to ASM's production practices in Bilthoven at the same time, safety and environmental concerns did not restrain the engineer from working on his chemical processing system in a residential area. But even after making his idea work in his garage, his employer was still not convinced.

Due to the working tinker tool in his garage, Engle became more determined than ever about the applicability of his innovation in semiconductor manufacturing. Looking for other prospective buyers, he got in touch with a CVD company called Pacific Western Systems. This company founded and managed by Dan Worsham originally and predominantly focused on probers and testers, but it became involved in CVD via Charles Ellenburger. ${ }^{71}$ Engle's plasma tool extended this company's activities in this market.

Engle and Pacific Western decided to cooperate in mid-1977. Part of the deal was that Pacific Western granted Engle the manufacturing rights of the system after they had commercialized it together. ${ }^{72}$ Supported by the more resourceful company, Engle turned the system into a chip-production-worthy piece of equipment. Even more, Pacific Western succeeded in selling the first product to the young but already leading chip manufacturer Intel by 1978. The technology

70 George Engle, 'Interview with author'.

71 SEMI, Craig Addison, 'Oral History Interview: Dan Worsham', semi.org (date unknown); George Engle, 'Interview with author'.

72 This concerned the following patent: Pacific Western Systems, George M. Engle Jr., 'US4223048A: Plasma Enhanced Chemical Vapor Processing of Semiconductor Wafers' (file: 7-8-1978; publication: 16-9-1980); George Engle, 'Interview with author'. 
was part of Intel's latest product line: the soon-to-be-famous Intel 8088 computer chip. ${ }^{73}$

A bright future lay ahead for Engle and his plasma process. He was resolved to cash in on his promising innovation. However, his request for a raise was refused by Pacific Western's management. Confronted by their frugality and lacking ambitions, he decided and was stimulated by his manager Ellenburger to go out and look for a more appreciative partner for his ideas. Although Engle had the manufacturing rights of a patented tool, there was also the fact that Intel was using it. Perhaps somebody else appreciated his innovation at its true value.

Engle returned to Applied Materials to see whether they were interested. By that time, its founder, Michael McNeilly, had left Applied Materials. Jim Morgan in the capacity of CEO and Bob Graham as marketing manager ran the show. Graham dismissed Engle again, as he still did not believe Engle would have the technical capabilities to substantialize his idea. As Engle later recalled: 'They thought they knew the reasons why his system would not work. ${ }^{74}$ The fact that Morgan and Graham were struggling to keep Applied Materials viable may have played a role as well. Again, Engle was not able to get a deal and had to pursue his ambitions elsewhere.

\section{Enter Dick Rosler}

During the turbulent mid-1970s at Applied Materials, the second individual relevant for our story sought salvation elsewhere as well. This was Dr. Richard ('Dick') Rosler, who co-developed Applied Materials' first PECVD reactor, Plasma I. After a career at Shell America and teaching at Gonzaga University in Spokane, Washington, Rosler was convinced by Applied Materials' founder McNeilly to join the equipment manufacturer, where he quickly familiarized himself with the semiconductor technology. ${ }^{75}$ In the next years, Rosler closely cooperated with the company's technical conscience, Dr. Walter Benzing, on the various CVD processes.

Until the mid-seventies, Applied Materials had expanded its activities beyond CVD in barely related areas. This diversification in fact threatened the company's survival. Jim Morgan took control over the management of the company and shacked things up.

73 The Intel 8088 would be integrated in IBM's first PC 5150, which defined the PC boom in 1981.

74 George Engle, 'Interview with author'.

75 Rosler and McNeilly knew each other from Gonzaga University, where McNeilly used to play basketball. -Morgan and Hamilton, Applied Wisdom, pp. 81. 
In these turbulent times, Rosler looked for more quiet grounds, ending up at Motorola Research and Development Labs in Phoenix. It was quieter indeed. The contrast could not have been bigger:

'It was an eight to five company and at five PM everybody is gone. Except me, I'm used to work in longer hours at Applied Materials and all these small companies like Applied Materials at that time. ${ }^{76}$

After two years at Motorola, Rosler was eager to return to more familiar waters of entrepreneurial engineering. Like Engle, he wanted to see results from his contributions - whether personally through financial rewards or commercially in a company's success. As a consequence, two engineers with special capabilities in plasma CVD, Engle and Rosler, were available simultaneously.

\section{ASM America enters the market for plasma CVD}

ASM America's engagement of plasma CVD technology was all but anticipated. Moreover, it did not require any investment in research and development. On the contrary, it resulted from the remarkable availability of both Engle and Rosler, and the crossing of their paths by a newly hired sales representative at ASM America. In 1978 ASM America hired a new sales representative to cover the country's Western states. This was Ing-Marie Helmer, who earlier worked at Applied Materials and proved most effective in selling ASM technology. She ran into her former colleague George Engle, and took notice of his ambitions.

Helmer recognized the opportunity after listening to Engle's complaints regarding his current employer Pacific Western. More important, he co-owned the manufacturing rights of a system, already in use by Intel. Engle was not just a fortune hunter, being the co-owner of a proven innovation. Helmer contacted her sales and marketing manager Dale Stoddard to convince him of contracting Engle.

On October 4, 1978, Stoddard and manufacturing manager Ron Colvin met with Engle to hear him out about his wishes and his technology. It appeared auspicious. A day after the meeting, in a telex to Arthur del Prado, ASM America's general manager Don Jackson summed up the opportunity embodied by Engle:

'Has plasma enhanced LPCVD in hotwall. Very high growth rates and perfect uniformity. Oxide nitride poly and perhaps low temp epi. Has put machine into Intel. Has contract with Pac. West. Has license which is personal and non-transferable ... Discussed possible employment here. He would work for us short time to prove or not whether he has 
something. If so, we keep him in some capacity and pay him royalties on each machine. If not, we part friends. ${ }^{77}$

Stoddard, Colvin, and Helmer were convinced of the technology and trusted Engle's claims. Trusting their judgement, Jackson continued:

'He has created quite a stir in the industry.... If what he has does what he says, he really has something and we should not pass it up. ... He is not a smooth-talking promotor with silver tongue, which makes his story credible. ${ }^{178}$

What did Engle have up its sleeve that attracted ASM's attention? Instead of working with the Texas Instruments design as Applied Materials had done, he returned to a more familiar configuration. In his garage and at Pacific Western Systems, Engle innovated the PECVD process by using a diffusion furnace as basis. However, in his design the wafers did not lie flat on a susceptor, nor did it involve a disc boat. The wafers were held by a couple of vertically stacked plates lengthwise in the tube (figures 16 \& 17). Between the plates a plasma was ignited. Engle's PECVD system proved to produce better quality silicon nitride films due to their vertical placement. It made them less vulnerable for particles falling on the substrate. The system's throughput was comparable to the other common CVD processes, like ASM's LTO.

Engle's system fitted perfectly within ASM's portfolio of CVD processes. The gas dynamics of the horizontal hot-walled PECVD system did not deviate too much from the CVD furnaces of ASM itself. Most of the process development was already done at Pacific Western and in Engle's garage. His tweaking and tuning had involved the creation of a homogenous plasma and temperature across the whole tube, from front to rear. By the time, he met ASM's representatives, Engle experimented with different chemical processes. ASM was so lucky to get an innovative CVD process served on a golden plate.

ASM America seized this opportunity to expand its capabilities in CVD processes, and hired Engle. In the fall of 1978, he moved to the Phoenix area and started at ASM America. The required components for his machine were listed and a tool was assembled, in order to have Engle experiment and ASM's engineers improve his design as quickly as possible. The work was rather straightforward. Engle had to build the same system as the one of Pacific Western. Wherever possible, ASM's own in-house developed or commonly procured components

77 ASM America, Don Jackson, 'Telex to Ah del Prado: [No ref.]' (5-10-1978) - Archive Arthur del Prado-ASM America Sales' '76-'78, ASMA Telexen 1978. 
were used, such as mass flow meters and the control equipment. Afterward, ASM would improve the tool in order to compete with Pacific Western, as having the exact same tool would not do it.

\section{Figure 16}

Vertical cross-section of George Engle's horizontal hot-wall plasma enhanced chemical vapor deposition (PECVD) reactor, late 1970s

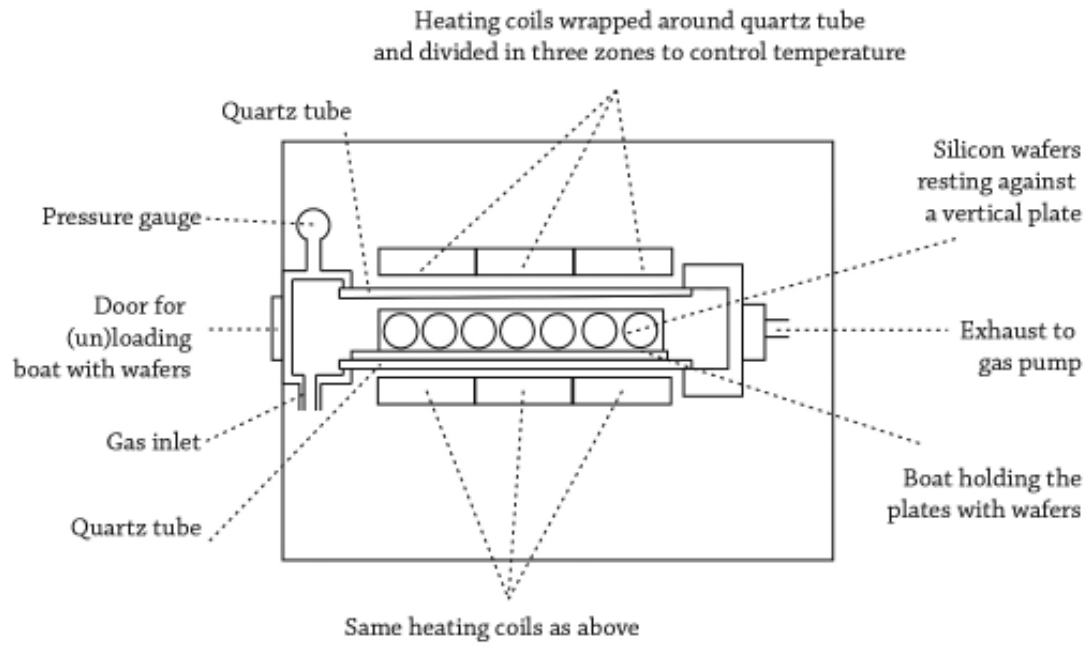

\section{Figure 17}

Horizontal cross-section of George Engle's horizontal hot-wall plasma enhanced chemical vapor deposition (PECVD) reactor, late 1970s

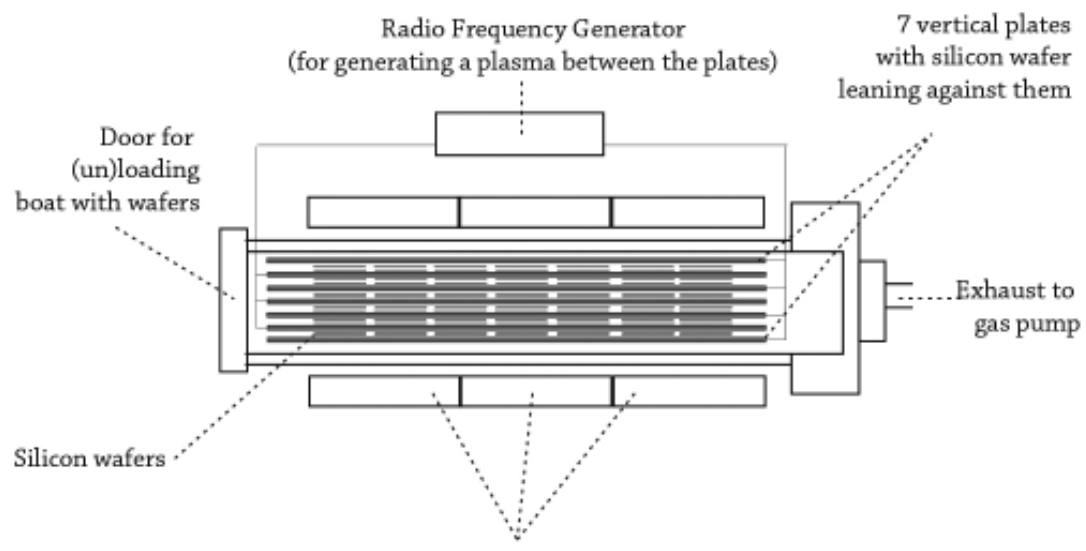

Heating coils wrapped around quartz tube and divided in three zones to control temperature 
Having a sellable product was one thing, selling it was another. Customers demanded hard facts and scientific explanations before they would integrate a new technology in their costly production line. The engineers of ASM America were not familiar with the plasma technology, and lacked an expert in CVD processes. Their CVD expert, Jon Goldman, had resigned. Solely relying on his intuitive understanding of his plasma process, Engle himself was not the most suitable person to go out and convince customers of the technology either. ASM needed somebody who was familiar with plasma technology and could 'talk technology.'

Rosler was just the right man. Through their contacts at Motorola and in the Phoenix area, ASM America's management learned about Rosler's availability. In the late 1970s, he was seen as one of the most renowned experts in CVD processes owing to his publications together with Dr. Benzing at Applied Materials. ASM's marketing manager Stoddard approached Engle: 'Would you mind if we talk to Dick [Richard Rosler] to talk him aboard?'79 Engle had known Rosler from Applied Materials, and was aware of his reputation. He supported this idea, and in 1979, Rosler was hired as ASM America's R\&D manager.

Rosler and Engle teamed up to launch ASM America into the market for PECVD tools. As a pair, both men perfected ASM's plasma tool. Engle acted as the mad scientist, testing his inimitable and sometimes outrageous ideas for improving the system. ${ }^{80}$ Lacking the education to translate his intimidate knowledge of the tool and process into words, Engle experimented continuously. This way the tool and results spoke for themselves. It was Rosler who picked up the role of interpreting and explaining the outcomes of Engle's test runs to the customers, and of course restrained Engle whenever necessary, thus ensuring a proper focus.

Moreover, Rosler operated as the interface between ASM and its customers in case technical questions could not be answered by ASM's sales and marketing department. Customers often wanted to talk to the technical person directly. And when they did, they delved into the most intrinsic details of processes and tools to verify the supplier's capabilities and knowledge. Rosler acted as a spokesperson in this regard, as an intermediary between Engle and the market.

79 George Engle, 'Interview with author'.

80 Bob Haro, 'Interview with author'. See also the following patents: Advanced Semiconductor Materials America, Richard S. Rosler, and George M. Engle, 'US4401687A: Plasma deposition of silicon' (filed: 12-11-1981; publication:30-8-1983), and Advanced Semiconductor Materials Of America, Inc, George M. Engle, and Richard S. Rosler, 'US4610748A: Apparatus for processing semiconductor wafers or the like' (filed: 10-12-1984; published: 9-6-1986). 


\section{ASM introduced its PECVD technology}

The sales of the LTO process had allowed the company some slack in its finances, through which the development of the first PECVD tool - dubbed Plasma I - could be funded. Engle's and Rosler's work was translated and codified into designs and adjusted according to the ASM standards by engineer Bob Haro. Ron Colvin prepared the manufacturing operation. The first assembly and preparation of the Plasma I was expected to take almost four months. ${ }^{81}$

In this timeframe, all the parts had to be purchased: generators, gas panels, vacuums, control panels, graphite, quartz, seals, materials, cabinets, gases, etc. Engle knew all the suppliers of Pacific Western, and initially they could support him in the development of the prototype. One example was a supplier of heating elements for diffusion furnaces called Thermcraft. For the carbon plates on which the wafers were placed, Engle used Pacific Western's supplier Ultra Carbon. ${ }^{82}$ Most components, such as the electronic and gas controls, loading parts, and others were designed and manufactured by ASM America. Basically, after all, Engle's PECVD machine, apart from the internal tube, was a common horizontal CVD system as made by ASM for some time already.

For this reason, ASM's experience with the LTO was often helpful. It could rather easily improve the process by adding peripheral features. For example, its generic electronic controller dubbed Micon III could be used in both tools. This was also true for the boat handler, which was originally designed for the LTOLPCVD system.

After final assembly of the Plasma I, it took one month to get the system fully operational. This entailed bringing the processing nitride and undoped oxide into line with the industry requirements. Because the process technology had already been developed by Engle, ASM's PECVD process was ready rather quickly for introduction to the chip industry. It was yet another very economical innovation process for the rising equipment manufacturer.

While assembling the first tool for demos, ASM America's sales and marketing staff reached out to some customers. Engle, Rosler, and all the other engineers

81 ASM America, George Engle, '1st Draft of PERT-Chart for Plasma System' (date unknown January 1979) Archive Arthur del Prado - ASM America Plasma/A.

82 'And I'd already establish relationships with people like I didn't have to pay an arm and a leg. We worked so well with Ultra Carbon that for a long time I would order the plates and sell them back to ASM, I didn't really make any money. It was easier that way because we were worried about Pacific Western. And so was Ultra Carbon. So that worked really well. Our delivery on plates on both assemblies was like two weeks. I mean, I could call, they would be in the middle of doing something and we - Oh we got more orders for this or that, I could call them and tell them and they would switch it. While purchasing, someday one guy there got pissed for whatever reason, I don't know why. He said I was on the tape for Ultra Carbon.' - George Engle, 'Interview with author'. 
needed feedback from customers about the machine to perfect the tool for highvolume production - thus being in use constantly - and enhance the process accuracy. As Intel already used the Pacific Western variation, ASM did not have to start modestly. The more prestigious an attracted customer was, the better.

In the fall of 1979, ASM got in touch with IBM. ${ }^{83}$ IBM was the biggest and most influential semiconductor manufacturer, and 'Big Blue' showed interest in the plasma technology to passivate its latest Very Large Silicon Integrated (VLSI) chips. This time, ASM's engagement with IBM surpassed the modest level of supplying one-issue-research tools, as it had done in Europe previously. Now, ASM America enjoyed the prospect of supplying multiple tools to the industry leader.

However, IBM was a very demanding customer. ${ }^{84}$ This pertained, for instance, to the handling of gasses, like the pyrophoric silane, but this was even stretched to the use of wafer sizes different from the rest of the industry. IBM demanded more severe leakage check procedures of the gas lines, more robust switchers, etc. In the process of selling the plasma machine, ASM received requests about the system's capability, and, after reaching a sales agreement, it was partially introduced to IBM's manufacturing practices (not the use of IBM's equipment in chips production). As a consequence, ASM became more exposed to the most advanced standards and procedures in chips manufacturing.

It took some patience and readjustments, but working in line with IBM's procedures was very beneficial for the reputation of ASM. As Bob Haro, head of design at that time, recalled:

'their IBM standard became an industry standard. But if you wanted to sell to IBM, you had to do it. Of course, IBM was the biggest customer, everybody wanted to sell to them, so everybody had to start converting their tools if they wanted to get in the IBM door. And it was a big milestone for us, it really was.'

Regardless of whether ASM America had to re-engineer and design the envisaged tool, it jumped to IBM's command. The demands of IBM pushed the ASM engineers to improve the quality of their product and their engineering practices - or, in one word, to professionalize. Although the company was not allowed explicitly to advertise their sale to IBM, the fact that the system was verified and endorsed by a big customer had major benefits for marketing.

83 George Engle, 'Interview with author'.

84 Bob Haro, 'Interview with author'. 
Initially, ASM sold its first system to Delco, from which IBM procured some of its computer chips, and to which IBM had propagated the use of ASM's plasma tool. ${ }^{85}$ The second tool was shown at the annual Semicon West Exhibition and Conference, in San Mateo, California, in May 1980. ${ }^{86}$ Every year, the most significant new technologies were introduced at this event, as had been the case with ASM's LTO and PECVD innovations. The event made it possible for customers and competitors to peek and speculate about the achievements and capabilities presented by the various equipment suppliers. Throughout the year, other Semicon Conferences were organized globally, such as in Tokyo, Zürich, and on the East Coast of the United States. However, Semicon West was the biggest and most prestigious - due to the proximity of Silicon Valley.

After introducing the machine at Semicon West to a wider audience, ASM successfully obtained orders from all major semiconductor manufacturers in the United States. The example set by Intel, Delco, and IBM urged the rest of the industry to follow, in particular in the wake of the growing demand for chips applicable in personal computers. As industry analyst company Dataquest describes in its 1977 report:

'To remain competitive, a semiconductor manufacturer must buy new capital equipment when the product output (or yield) from a given amount of a silicon material improves. If he is one of the first to install the equipment, he will be able to amortize if before the product prices fall in the marketplace. If he is late in installing it, he will soon become non-competitive. Most semiconductor manufacturers do not seek to build excess capacity; instead, the excess capacity that plagues the industry is often the result of a race to improve the yields and thus lower the product costs. Semiconductor manufacturing equipment does not usually wear out; it merely becomes obsolete in the face of more efficient equipment. Sometimes the rate at which obsolescence occurs can be surprising. ${ }^{87}$

Engle's technology proved to be the most advanced and most economical in the market, and quickly earned the allegiance of the industry. Customers included

85 IBM started to procure some of its chips externally. Most notably, the Intel 8088 chip for its first PC from fall 1979, spring 1980 onward. - Dataquest, James Riley, Daniel Klesken and Frederick Zieber, 'IBM Enters the Commercial Memory Marketplace as a Customer', Dataquest Research Newsletter (14-7-1978).

86 This was, at least, most likely the case. - George Engle, 'Interview with author'; and Bob Haro, 'Interview with author'.

87 Dataquest, 'Dataquest Semiconductor Manufacturing Model', Dataquest Semiconductor Industry Service' (22-7-1977), p. 3.0.2. 
National Semiconductor, Motorola, Hewlett-Packard, and IBM, and shortly thereafter ASM took over Intel as customer from Pacific Western.

The ASM tool beat the comparable Pacific Western system in throughput, as more plates were used to hold the wafers, and through the merits of an ambitious sales force. Process-wise the Engle configuration was superior to the Texas Instruments/Applied Materials model. In contrast to their horizontal placement of wafers, the ASM tool processed wafers vertically, which prevented particles to fall on the substrate. The plasma process was predominantly used for the silicon nitride, the passivation film in the latest VLSI chips. Every chip had to be passivated by means of this film. For this application, the ASM tool was the most competitive in the market.

The Plasma I was applied in the production lines for the latest chips, used in the first personal computers. As noted, this involved the Intel 8088 chip, but also DRAM chips contained a passivation film deposited by Engle's plasma process. In particular the use of the Plasma I for passivating memory chips propelled demand for the machine. IBM's first PC, the IBM 5150, contained the Intel 8088 chip but also numerous DRAM chips. In the period 1980-1983, with a severe but short recession in 1981, all chip manufacturers invested in new production lines in order to take advantage of the growing demand for computer chips applied in PCs. It resulted in the first 'PC Boom' in 1981. PCs, and thus computer chips, sold like hot cakes. Time magazine's proclamation of the computer as 'Person of the Year' in 1982 playfully illustrates the prominence of the technology. The application of Engle's plasma process in the 8088, and its many copies thereafter, paved the way for ASM's advent as CVD supplier.

\section{The innovation process never stopped}

While his innovation obtained acceptance by the market, Engle did not take a breather. To increase the applicability of the plasma furnace - and thus the addressable market - other processes were developed for it, such as plasma-based deposition of nitrides, oxides, titanium silicates, and even polysilicon. ${ }^{88}$ However, silicon nitride continued to be the major seller, and Engle would also pursue this process further as well.

Each sale was preluded by processing demo-wafers, as well as adapting the tool and process to the customer's specifications. Compliance with customer specifications continuously required tweaking and tuning of the system and the silicon nitride process. Through customer feedback, the limitations and strengths of the process became visible, and this was subsequently addressed by Engle and Rosler.

88 George Engle, 'Interview with author'. 
It proved problematic to ensure uniformity at the tube's end. To achieve maximum throughput, the tube's length was stretched as much as possible. However, the gasses were inserted in the front-end of the tube, which meant that the reaction did not occur evenly across the tube. At the back-end of the tube, the gas ratio of silane and ammonia would be much lower, and most reactants were used already. A major innovation added to the subsequent generations of plasma deposition tools was called a 'limited depletion mode.'

In his trial-and-error experiments, George Engle started to switch the plasma generator:

'I said: "What the hell, I'm going to turn it on and off." So, I turned it off, and - low and behold - it got better!'89

Later, he and Rosler figured out why this improved the process. By turning the plasma off, the reaction stopped for a while, allowing the gasses to flow to the end of the tube. It facilitated more even distribution of reactant gasses within the tube. By turning the plasma on, the reaction continued again. As Engle explains:

'You don't add the gasses if its ionized. So, you'd have a chance to replenish the gas. So, then we got real fancy; we made a circuit board and all this shit, so we could bounce it. And then we got the uniformity better. It wasn't really perfect yet, but it was better.'90

This feature - dubbed 'limited depletion mode' by the marketing department - was solely applied for the silicon nitride processes, as it appeared not to be working with oxides. ${ }^{91}$ This ongoing effort underlines that Engle's process was a work-in-progress, resulting in new innovation, even after introduction of the first version to the market.

\section{Customization and demand in Europe and Japan}

The PECVD system was a global success, catapulting ASM to the forefront of the market for plasma CVD (figure 18) Apart from the United States, it was sold in Western Europe and Japan. Sales in South-East Asia remained modest, since most of the regional industry still concentrated on assembly and packaging. The success of the PECVD nitride process largely derived from its use in the production of the latest memory chips.

89 Ibid.

90 Ibid.

91 Engle and Rosler succeeded in making it work with oxides as well, but these processes were sold little. - George Engle, 'Interview with author'. 
Each geographical market had its own preferences and standards for manufacturing technologies. Whether this involved compliance with safety regulations or the Metric System, the plasma furnace had to be adapted. Furthermore, any local customer base would have its own traditions and manufacturing specifications. Customization to local demand was critical, and required constant tweaking and finetuning of the process. This small-scale innovation took place locally, implying that it was not solely performed by Engle and Rosler in the United States.

\section{Figure 18}

Graph of revenues ASM International in worldwide market for horizontal PECVD furnaces, 1982-1987

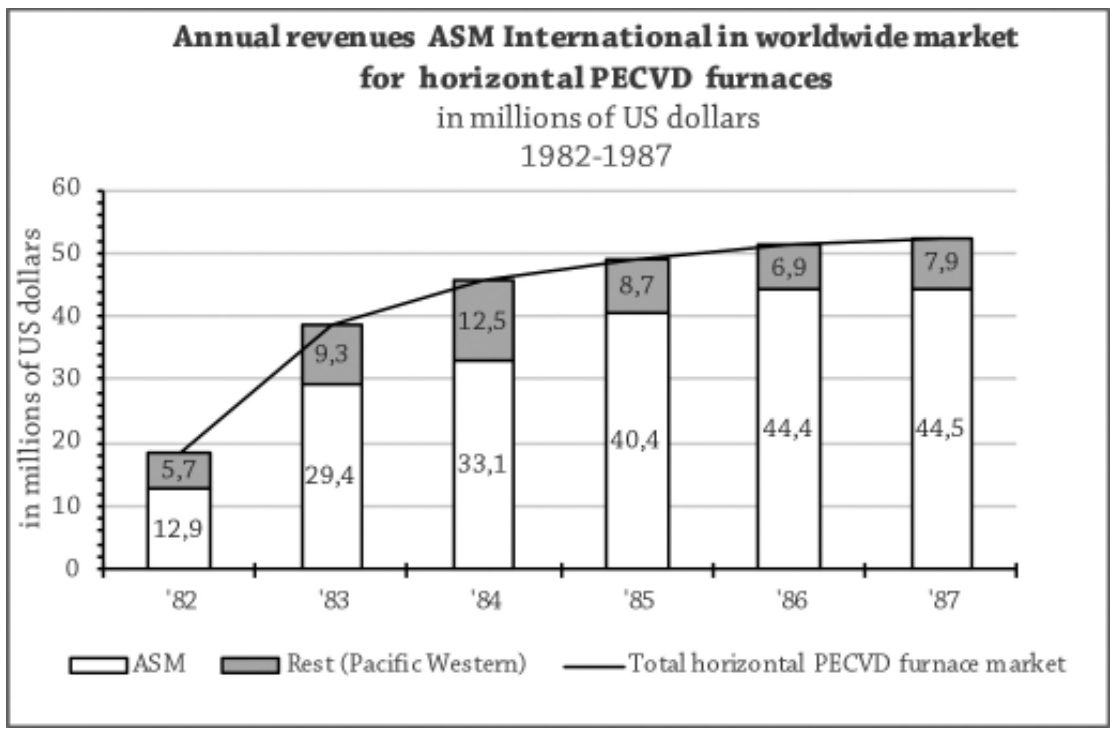

Shortly after its introduction in 1980, the PECVD technology was transferred to the Netherlands. This was in line with Del Prado's business philosophy, in which proximity of manufacturing was key to satisfy local demand. Being responsible for the European market, and complementing local production of LPCVD and diffusion furnaces, it did make sense to have the PECVD system simultaneously built in Bilthoven.

This was equally true for the Japanese market, even though initially ASM still lacked an assembly or manufacturing operation there. In 1978, the LTO process had cracked the Japanese market, with support from distributor Marubeni 
Electronics. ${ }^{92}$ The Plasma I enjoyed even more interest from the Japanese memory manufacturers. In the late seventies and early 1980s, a Japanese-American rivalry in memory manufacturers increased investments in new production equipment in both countries. ASM America played a double game. The American operation manufactured the systems and shipped them to the Japanese customers, where local agent and distributor Marubeni Electronics' engineers would install the tools

As sales volumes increased, so did the need for apt customization. To really profit from the Japanese market's interest in ASM's products, Del Prado founded a local operation, dubbed ASM Japan in the summer of 1982 (cf. Business II). Japanese chip producers increasingly required customization of the equipment, which ASM America was not capable of delivering or unwilling to perform. In response, the sales engineers of Marubeni started fiddling with the PECVD tools to satisfy the demand. Next, a local ASM operation would internalize this customization, and through it, the Japanese market could be addressed and served more adequately. Guided by the local demand, the Japanese plasma system slowly deviated more and more from the original American one.

\section{The PECVD success disrupts ASM America}

From the introduction of the Plasma I in 1980, ASM America's production group had to satisfy both the Japanese and American demand for its plasma CVD nitride process. Due to the huge demand, the company had trouble keeping up with production and supply. The company existed just four years and had hardly made any money in the first two years. As it successfully penetrated the major chip manufacturers with its plasma technology, it suddenly had to comply with the highest standards in the industry.

The ordered volumes of Plasma I furnaces prompted the operation to expand rapidly and rather unrestrained. Everything had to be done to satisfy the demand and to achieve maximum sales. Manufacturing capacity had to be expanded exponentially. Transferring the technology to Bilthoven relieved the American operation slightly. But still, the American management had to pull out all the stops, soon experiencing riotous growing pains.

92 Former Applied Materials CEO Jim Morgan published a book entitled Cracking the Japanese Market, in which he explains how he managed to get a footing in the protective Japanese market at the time. Another interesting note is that LFE - a competitor in PECVD technology through its SYSTEM 8000 - had struck a deal with Marubeni for the distribution of their reactors as well. In January 1980, Fukumi Tomino, Yaduo Yamada, and Yukikazu Ueno visited both ASM America and LFE to select the best tool. The men opted for ASM's PECVD tool, since it proved to be more reliable, a choice tremendously affecting their lives. Two years later, all three were among the founders of ASM Japan. - Fukumi Tomino, 'Interview with author'. 
Investment in the plasma process itself - innovating the PECVD process was lagging. Throughout ASM, expenditures for research and development would not exceed 5 percent of the total sales until the early 1980s. This well illustrates ASM's preoccupation with selling equipment instead of innovation at the time.

Because of the unexpected success of the American startup, it was thrown off balance. The technological applicability of its plasma reactor had opened many doors, more than the organization seemed able to cope with. Moreover, the ongoing innovation of the plasma furnace was predominantly carried by an immature organization. This undermined the innovation process of ASM's PECVD technology in the longer term. ASM America and the plasma innovation process got derailed by a severe downturn of the American memory chip market in 1984 and the start of local manufacturing in Japan by 1985 (cf. Business III). Consequently, ASM America missed the boat in PECVD technology during the second half of the 1980s. 


\section{Chapter 10}

\section{Aluminum Chemical Vapor Deposition, 1981-1985}

By 1981, the chip industry witnessed the first PC revolution. Personal computers - made by IBM, Apple, and Commodore - gained access to offices and households on a large scale. In combination with the increasing rivalry among Japanese and American memory chip producers, the early eighties saw a huge demand in production technologies. To secure market share and decrease production costs, chip manufacturers invested heavily in new production infrastructure. New production lines meant opportunities for ASM to sell its equipment. Simultaneously, after years of economic stagnation, major diversified electronics manufacturers, like ITT, Philips, AT\&T, and General Electrics, divested research activities. Advanced inventions were up for sale, and within reach for the Dutch equipment supplier. The early eighties were golden years for ASM (see Business II).

More importantly, due to the success of the PECVD, ASM managed to expand its contacts and reputation among semiconductor manufacturers. The LPCVD systems of ASM Europe and ASM America were selling fine. As the plasma systems proved to be sound, the major semiconductor manufacturers were more willing to listen when ASM introduced new technologies. The company had proven its capabilities in gas handling, system design, and horizontal CVD machines. Characteristically for Del Prado, he was already looking for new opportunities for his young company. What was next? Were there any other applications for CVD?

ASM still lacked the capability to invent entirely new CVD processes. Research institutes of universities, electronics conglomerates, and semiconductor manufacturers and, to some extent, equipment suppliers had been exploring the limits and capabilities of CVD technology. The manufacturing technique formed a highly economical way of adding films to the chip. By converting the process to lower pressure and plasma, new applications were discovered. In the early 1980s, other variations were considered as well, such as laser-activated CVD. ${ }^{93}$ Multiple

93 In 1983, in response to rumors that competitor Thermco was pursuing this path, ASM America started a futile project for laser activated CVD - ASM America, Dale Stoddard, 'Monthly Status/January 1983' (17-1-1983) Archive Arthur del Prado - ASM America 1983 - R\&D; ASM America, Dick Rosler, 'Memo: R\&D Projects' (28-9-1983) Archive Arthur del 
materials with multiple functions could be deposited by means of CVD, but their applicability for semiconductor manufacturing had to be proved.

These institutes and corporate laboratories had been the main source of inventive CVD processes in the 1970s. In the economic recession of the early eighties, some of them were forced to divest their ongoing developments. Del Prado was preying on those, and a first opportunity emerged in the summer of 1981.Via his contacts, he had the chance to acquire a new process, dubbed aluminum CVD. The technology originated from Standard Telecommunication Laboratories (STL), an ITT research laboratory, located in Harlow, United Kingdom. STL was an organization with a sound reputation of technological ingenuity. In the 1960s, as sketched above, the laboratory was the birthplace of the first plasma CVD process. ${ }^{94}$ A decade after the invention of plasma CVD, ASM crossed paths with a new technological development.

\section{Origins of aluminum CVD}

The aluminum CVD process followed from research funded by the British government. ${ }^{95}$ Amidst wider governmental interest in semiconductor industry during the late 1970s, the British Ministry of Defense had been supporting industrial projects in microelectronics. ${ }^{96}$ Many of these initiatives were funded and coordinated by the Directorate of Components, Valves, and Devices (DCVD). It was this department that started off the research project resulting in aluminum CVD.

At STL, a group of engineers led by scientist Dr. Rudolph Heinecke had developed an alternate way of metallization, from 1976 on. This research project concentrated on aluminum and titanium CVD processes, which were developed to metallize interconnecting parts of a computer chip.

Prado - ASM America $1983-R \& D$.

94 Swann, 'First-Hand'.

95 Standard Telecommunication Laboratories, 'CVD Project RP7-96: Advanced Semiconductor Process Technology Annual Report 1978’ (February 1979) Arthur del Prado Archives Aluminum CVD, p. 1.

96 In 1974/'75, one of the UK's biggest semiconductor manufacturers Ferranti was saved by the National Enterprise Board (NEB) from going bankrupt. Prime Minister Callaghan initiated a national semiconductor manufacturer INMOS - a subsidiary of the NEB. Its operations were in Bristol and Colorado Springs. During the Thatcher government, in 1983, it was sold to Thorn-EMI, just after it had become profitable (see Morris, PhD Dissertation (1994) pp. 107, 108 127). An example was the Microelectronics Support Scheme from 1974 until 1979, saving a major semiconductor manufacturer Ferranti Electronics from bankruptcy in 1974. Another example was the establishment of a government-owned and controlled semiconductor manufacturer called INMOS in 1978, meant to halt the demise of the British microelectronic industry. 
Until the late 1990s, aluminum formed the metal used for structures that conducted the electrical current throughout the device to the appropriate transistor. As explained by industry data company Dataquest:

'Aluminum has several characteristics that have made it a widely-used material for interconnection at the device level. These characteristics include ease of deposition and patterning, good bondability, low resistivity, good adhesion to silicon and oxide, and low cost. ${ }^{.97}$

For the deposition of the aluminum interconnecting films, a process called 'sputtering' was used. Sputtering entailed the vaporization and deposition of metals. After vaporization of an aluminum source, the metals are guided through the reactor and deposited on top of the wafer. This contrasted with CVD, in which films are deposited by means of chemical reactions on top of the substrate. Sputtering aluminum had some intrinsic drawbacks, which Heinecke and his team had tried to overcome.

Sputtering involved a tricky process. The forthcoming so-called very large silicon integration (VLSI) chips consisted of 100,000 transistors or more, involving increasingly complex and dense circuitries. Sputtering proved to be problematic. The step coverage of sputtering was inferior compared to CVD processes. This caused problems in particular for the VLSI chips.

The stronger and faster VLSI chips required more power to be processed through smaller aluminum interconnections. This led to the phenomenon of 'electromigration,' which entailed the local displacement of aluminum. Through this, voids and so-called 'hillocks' prevented the correct functioning of the interconnecting structures. Especially at the more narrow interconnecting lines - just above the transistors and other electrical components - the relatively deplorable step coverage of sputtering proved to be problematic.

Earlier, the step coverage issue of sputtering was overcome by heating the wafer shortly at higher temperatures after the deposition of aluminum. This process step, labeled 'annealing,' was required to stabilize and improve the results. However, as a consequence of the annealing, underlying silicon tended to dissolve into the aluminum, and vice versa. ${ }^{98}$ The higher the temperature of the annealing process, the more silicon and aluminum got diffused. It created spikes of aluminum, which punched through the junctions below and made the whole chip circuitry leaky.

97 Dataquest, 'Markets and Technology: Chemical vapor deposition' Semiconductor Equipment and Materials Service (26-9-1985), p. 57.

98 Standard Telecommunication Laboratories, 'CVD Project RP7-96: Advanced Semiconductor Process Technology Annual Report 1978’ (February 1979) Arthur del Prado Archives Aluminum CVD, p. 1. 
One issue led to the next. The industry tried to overcome this problem by adding a nominal amount of silicon during the deposition step. This ensured that the aluminum was saturated with silicon, and that no silicon dissolved from the earlier constructed junctions. Furthermore, it limited the occurrence of electromigration. But as Heinecke noted in his annual report on the project: 'Difficulties in composition control, however, produces problems in manufacturing. ${ }^{99}$ The silicon alloying was not ideal for the most narrow interconnections just above the transistor, as the added silicon increasing resistivity. Heinecke and his team - like others in the industry - worked on a solution for this phenomenon.

Heinecke and his team settled onto two courses of action to overcome the metallization challenge. One solution was to add an additional film of titanium silicates. ${ }^{100}$ This film was much thinner than the aluminum one, and functioned as a barrier layer - preventing the dissolution of silicon into the aluminum. It involved a titanium fence, so to speak, keeping the elements on both sides apart. Theoretically, this solution was preferable, as it promised a better composition control, as well as benefits with regard to corrosion prevention, hillock growth, and precipitation phenomena (flaking off materials). ${ }^{101}$

For manufacturing, the titanium barrier meant that prior to the deposition of the interconnecting parts through sputtering a thin film of titanium would be deposited. This implied an extra manufacturing step. The main problem was rather technical, related to the materials needed for deposition - the so-called titanium compounds. These could hardly be procured commercially, if at all.

The other potential solution was aluminum CVD. This entailed a theoretically simple, single procedure comprising both annealing and deposition steps. If the aluminum interconnections could be deposited by means of an CVD process, it would be possible to add the required fraction of silicon at the same time. An aluminum precursor called tri-isobutyl aluminum - or simply: TIBA - and the above-discussed silicon precursors silane ought to be processed in a low-pressure environment. ${ }^{102}$ The process initially started with a hydrogen plasma step to

99 Ibid.

100 Heinecke refers to the titanium barrier film as an 'underlayer.' However, this will later be known as a 'barrier layer' in the industry. For clarity's sake, I use the latter term. - Standard Telecommunication Laboratories, 'CVD Project RP7-96: Advanced Semiconductor Process Technology Annual Report 1978' (February 1979) Arthur del Prado Archives - Aluminum CVD, p. 3.

101 Ibid

102 Experiments were done in which a sandwich structure was created, such as: silicon, aluminum, silicon. However, this did not lead to satisfying results, as the adhesion of the various films was not sufficient. For the relevance this, see Chapter Five about the atomic 
promote film adhesion. ${ }^{103}$ This was later replaced by another vapor compound..$^{104}$ In contrast to sputtering, annealing would not be required.

Both solutions - titanium barrier and aluminum CVD - were possible from a merely theoretical point of view, but they were accompanied by quite a lot of practical challenges that had to be overcome first. The initial experiments showed good results, and Heinecke's team decided to dedicate more resources to the aluminum CVD solution than the titanium barrier one. Research into the latter was continued as back-up approach, until the Directorate of Components, Valves and Devices urged Heinecke and his team to commercialize the aluminum CVD process. ${ }^{105}$ It was envisaged that the aluminum CVD solution would comply to an urgent challenge in the industry, involving the issue of hillock growth.

During the economic recession of the late 1970s, the Directorate urged STL to attract support from a third party for commercial exploitation of the aluminum CVD process. ${ }^{106}$ In his PhD dissertation The Growth and Decline of the Semiconductor Industry within the U.K., 1950-1985, historian of technology Peter Robin Morris explains that, by 1980, the UK government requested companies to commercialize technology developed under contract of the Ministry of Defense. Moreover, electronics conglomerates like ITT had been struggling for years and had to cut costs. One of the major British semiconductor manufacturers, Ferranti Electronics, had been involved in the aluminum CVD project as potential enduser of the technology. ${ }^{107}$ This cooperation entailed the use of Ferranti's process wafers, which were returned to the semiconductor manufacturer for evaluation and further processing. This feedback was essential for improving the process, as well as for indicating the requirements of a real industrial machine.

The research group moved into the realm of equipment manufacturers. So far, their aluminum CVD experimentations were conducted in a tinker tool, and thus way removed from usage in industrial production of computer chips. Its inadequacy for production, for one, entailed the size of the wafers it could process.

layer deposition process, which does exactly this at an atomic level! - Ibid., p. 12.

103 The report refers to the plasma step as a 'glow discharge process.' This is in line with the inventors of the plasma process, Dr. Swann and Dr. Henley, who also worked at STL. However, this technique was later known as PECVD. In the case of the hydrogen glow discharge, it referred to a plasma etch step. - Standard Telecommunication Laboratories, 'CVD Project RP7-96: Advanced Semiconductor Process Technology Annual Report 1979' (February 1980) Arthur del Prado Archives - Aluminum CVD, p. 4.

This was $\mathrm{TiCl}_{4}$. - Ibid, p. 2.

Progression in titanium barriers depended on the availability of precursors. The Inorganic Chemistry Laboratories of Oxford University showed some progress in that regard. - Ibid, p. iii. 
This experimental set-up had to scale up to three inch wafers in order to appeal to the interest of semiconductor manufacturers. To save the project's results - and the government's investments - from rescission, the maturation of the tinker tool had to be accelerated, perhaps with support from external (non-British) parties. Maturing the tinker tool and initial process, the STL project team faced new challenges.

\section{An opportunity for an eager ASM}

Enter ASM, or to be more precise, enter Arthur del Prado. Probably through his contacts at the British semiconductor manufacturer Ferranti, Del Prado was approached with the question of whether ASM had any interest in the aluminum CVD process. Naturally, the entrepreneur yielded to this opportunity, and seized it with both hands.

In the summer of 1981, he summoned his Dutch engineers to his office. ${ }^{108}$ In this case, this was his head of R\&D, Martin van Beest, and several others, including Wiebe de Boer and Johan Maes. For them, this new process came out of the blue, as new technological developments often did at ASM. The engineers responded positively, but further details were required. After all, Del Prado was not an engineer himself. They planned a fact-finding mission. A few months later, in November 1981, a couple of ASM engineers - among which ASM America's general manager Don Jackson and ASM Bilthoven engineer Johan Maes - visited the STL laboratory to inspect the aluminum CVD tool over the course of nine days. ${ }^{109}$

By the time the ASM engineers saw the tool, Heinecke's redesigned machine very much looked like a working low pressure CVD furnace. More importantly, the process results shown by Heinecke were very promising. During their visit, the ASM staff was trained in the use of the tool, discussed the design and inadequacies, and listed what needed to be done by ASM. Both parties took up some of the issues addressed. STL would conduct research into ultra-high vacuum processing and some parts, while ASM would develop a new gas panel and automation process. The engineers returned enthusiastically.

The promise of aluminum CVD was very attractive. For the semiconductor manufacturers, this would create a more economical way of production. In general, CVD processes had better step coverage, which was key in decreasing the interconnection's dimensions. Sputtering might be replaced, which meant

Martin van Beest, 'Interview with author'.

109 Participants from ASM were Johan Maes, Huub Corsius, Don Jackson, and Jaap Harryvan, while the representatives from STL were Michael Cooke, Rudolph Heinecke, and T. Jackson. - STL, Michael Cooke, 'Visit of ASM Staff to STL (10-19th November 1981). Ref: R449/MJC/ IM' (20-11-1981) - Archive Arthur del Prado - AlCVD '79-'82. 
that most of the components of a semiconductor product could be deposited by means of CVD. Such an innovation was expected to be disruptive.

For suppliers of CVD technologies, like ASM, this would mean a significant expansion of their addressable market. After acquiring the innovation rather cheaply, the reward of offering a metallization CVD process first would be tremendous. A whole new market would be created, while another - the sputtering market - could be marginalized. After the success of the PECVD and LTO, ASM might well have run into something spectacularly innovative again. Aluminum CVD might prove to be ASM's definitive consolidation as innovative equipment supplier.

\section{Familiarizing aluminum CVD}

As soon as ASM and STL entered into an agreement with each other, a new tool was built in Bilthoven, while STL continued some development at theirs. In Bilthoven, the engineers started to reproduce the results of Heinecke with their tool, trying to turn it into a sellable product, suitable for semiconductor manufacturing. ASM contributed by replacing some of the parts it worked with itself. Moreover, it displayed its proclaimed competence as CVD supplier by automating the gas handling system.

Except achieving reliability and reproducibility of the process, ASM applied its knowledge and experience in building horizontal CVD furnaces for industrial use, thus complying with the highest safety and quality standards. Especially the waste treatment of the very polluted rest products was important. It was not responsible to burden the customer with that. Being innovative was not sufficient for the process; the machine and its supplier had to be dependable.

It proved to be a challenge to handle the precursor of the aluminum CVD process, TIBA. Being a very hazardous material, it required solid safety measurements. The engineers of ASM America were especially interested in how the Dutch engineers would tackle the matter. The American counterparts became involved with regard to the controller - their Micon III - and the marketing of the system. After all, the major market was still the United States.

Don Jackson reached out to some of his acquaintances at his former employer Motorola to verify their position with regard to TIBA. The concerns of ASM America were confirmed. As Jackson reported:

'First response was: no way! ... Their concern is that TIBA causes terrible burns and is an extreme personnel hazard. They want to know what will happen if TIBA is accidentally spilled. ${ }^{110}$

110 ASM America, Don Jackson, 'Telex t0212.82: alcvd' (11-2-1982) - Archive Arthur del Prado - AlCVD '79-'82. 
Johan Maes, the engineer most involved in the development of aluminum CVD, was on top of it already. In January, he and his colleague Huub Corsius visited a German supplier of TIBA, Schering A.G. ${ }^{111}$ With these experts, they discussed specifications, application, handling, and disposal of TIBA. The properties of TIBA, the abilities of the suppliers, and the concerns of the customers had to be addressed.

In this effort, ASM expanded its involvement beyond the design of the equipment by including the supply and disposal of the material as well. ${ }^{12}$ When 100 wafers per run were processed, the customer had to remove 130 liters of diluted waste every day. ${ }^{113}$ This entailed a major logistic and operational effort. It remained a major area of concern and required much of ASM's engineers' ingenuity.

\section{Securing ASM's lead in aluminum CVD}

The promise of aluminum CVD fitted perfectly in the ambitions of Arthur del Prado. Throughout his career, he had not been able to address the market for metallization technologies yet, not even as a representative. This might very well be the first real opportunity, and a possible success would imply a disruption of the industry. In addition, ASM was enjoying fair weather. It recently performed an initial public offering (IPO) at the NASDAQ Stock Exchange in New York, by May 1981. The IPO drew attention from customers, competitors, and authorities alike. The announcement of the potential breakthrough technology of aluminum CVD might boost the company's reputation. Being a sales and marketing manager of origin, Del Prado quickly put his pen to paper, and formulated his marketing strategy.

The tool would be introduced at the biggest stage available for semiconductor technologies: the Semicon West Conference in San Mateo, near San Francisco. The annual exhibition and meeting was the most prominent way to present new innovations and attract the attention of potential customers for the whole worldwide semiconductor industry. The first opportunity for ASM to introduce aluminum CVD to the public at Semicon West was May 1982.

Prior to that, the American marketing manager Dale Stoddard and Del Prado decided to have an advertisement published in the Solid State Technology magazine. ${ }^{114}$ This announced the product to the public of semiconductor industry

11 ASM Bilthoven, Johan Maes, 'AlCVD - Handwritten visit report of meeting at Schering A.G, 15-01-1981.' (probably January 1982) - Archive Arthur del Prado - AlCVD '79-'82.

112 ASM America, Don Jackson, 'Memorandum: Summary of Design Review - ALCVD System, Bilthoven, January 25-29, 1982.' (3-2-1982) - Archive Arthur del Prado - AlCVD '79-'82, p. 6.

113 Ibid., p. 4.

114 ASM America, Dale Stoddard, ‘Telex t0133.82: Aluminum CVD system’ (29-1-1982)-Archive 
managers and engineers, ensuring sufficient attention during the event. Van Beest and Heinecke would present the technology, also by amplifying its promise. The product was expected to be groundbreaking.

This marketing scheme resulted in a very strict timetable for the engineers developing the technology. At the Bilthoven operation, renamed ASM Europe after the IPO, newly appointed general manager Erik Kamerbeek reached out to Philips to evaluate some aluminum CVD test wafers from STL. ${ }^{115}$ While confirming the excellent step coverage, Philips was not content with the thickness and the hardness of the aluminum layer. This feedback was critical for the engineers and the marketing team. The positive part of the information could be used in the advertisements.

All the marketing efforts aside, the engineering team in Bilthoven worked in overtime to finish the prototype for the Semicon Conference, working on a frame, parts, and mechanical and electrical drawings, in order to be able to assemble the system in a 'show-ready' version. ${ }^{116}$ The demonstration tool was just that, and probably it did not even contain the core technology yet.

After returning the showcase machine to Bilthoven, the system's assembly was finished; it was be installed in the demo lab, and the first evaluation processes would be run. The whole exercise involved a strange order of things. Without having run once, the tool was to be dragged across the Atlantic Ocean, presented with much bravura, and shipped back again. ASM relied on the solid reputation of prestigious STL, so this strange order of things seemed justified.

Enthusiastic by the prospect of the introduction, Del Prado tossed off some slogans:

'Thank you sputtering for covering our metallization steps in the seventies. Welcome Aluminum LPCVD, your step coverage is what we need during the eighties.' 117

Arthur del Prado-AlCVD '79-'82.

115 ASM Bilthoven, 'Memorandum: Al-CVD test wafers, evaluated by Philips Nijmegen.' (3-21982) - Archive Arthur del Prado - AlCVD '79-'82; and STL, Michael Cooke, 'Handwritten letter to Huub [Corsius]' (10-12-1981) - Archive Arthur del Prado - AlCVD '79-'82.

116 ASM Bilthoven, Johan Maes, 'Report: Al-CVD Design Meeting, 25-27 January 1982' (262-1982) - Archive Arthur del Prado - AlCVD '79-'82, p. 3; and ASM America, Don Jackson, 'Memorandum: Summary of Design Review - ALCVD System, Bilthoven, January 25-29, 1982.' (3-2-1982) - Archive Arthur del Prado - AlCVD '79-'82, p. 8.

117 ASM International, Arthur del Prado, 'Note on backside of paper' (late February 1982) Archive Arthur del Prado - AlCVD '79-'82. 
Although the system was not yet proven or even ready for running demos for interested customers, ASM introduced the aluminum CVD tool during Semicon West 1982. Del Prado's slogans had set the bar.

Not only was the conference the place to reach out to customers. It also formed the perfect occasion to gather all the engineers and managers involved in the product as well. Prior to it, these ASM employees pulled together to tune the marketing pitch, which they would present to the visitors of ASM's stand. This meeting, and more importantly the comments and questions from customers during the conference led to a new planning for after the conference. Semicon West allowed engineers, customers, and competitors from all over the world to discuss technology in person in a highly informative, elucidating, and, above all, efficient way.

At the conference, the promise of aluminum CVD, was received very positively. As ASM America engineer Jerry Tong reported - rather impartially of course - in a memorandum:

'The [aluminum CVD] system was the most innovative product at the show this year, as far as I can see. I also feel it is premature to place on the market at this time. We need at least another six months in development in BV in my opinion. ... The [aluminum CVD] definitely has a future for high density circuits including multilayer metal structures. Another advantage I see with [aluminum CVD] is the elimination of the reflow process. The only purpose of reflow is to assure good conformal step coverage of metal over oxide layers. [Aluminum CVD] solves this problem.' 118

After the introduction at the conference, the tool was shipped back to Bilthoven, where assembly was finished. Meanwhile, the managers drafted a new marketing plan, based on the input received in San Mateo.

The technology was introduced to a global audience as the replacement for the existing sputtering technology. But to realize this promise, the chip manufacturers had to bite the bait. A list was made with potential customers who had shown interest. ${ }^{119}$ In contrast to its earlier CVD innovations, ASM intended to forge formal relations for the introduction of its novel technology. Candidates

118 Within ASM, aluminum CVD was referred to as ALCVD or even APCVD (Aluminum Pressure CVD). By 1999, ASM acquired atomic layer deposition, which it rather confusingly branded as 'atomic layer chemical vapor deposition'(ALCVD). For clarity's sake, I have chosen the notion of 'aluminum CVD.' - ASM America, Jerry Tong, 'Memo: Semicon Report' (22-6-1982) Archive Arthur del Prado-ASM America $1983-R \& D$.

119 ASM America, Dale Stoddard, 'Memo to Arthur del Prado: APCVD Preproduction System Plan’ (25-6-1982) Archive Arthur del Prado-ALCVD - ALCVD 1981-1983. 
were Bell Labs, Motorola, IBM, Hitachi, and many others - not limited to one of the respective territories where ASM was active. The sales and marketing team set out to assess the willingness of these customers to commit themselves to this new and yet unproven technology.

\section{Living up to expectations}

The inspiring commitment from customers motivated ASM to arrange a joint development program. In such a program, ASM would supply a tool to a customer, while keeping one for its own evaluation. For a period of time, both parties - the user and supplier - would evaluate and improve the process. The participation of a customer was crucial in order to obtain valuable information about the applicability.

In particular, the customer's ability to evaluate wafers and to supply partiallyprocessed-wafers was important. ASM only had blank wafers, but the aluminum CVD deposition step was not the first step in wafer processing. Rather, it was meant for deposition on processed wafers, and the suitability of the process depended on its coverage across these. For this reason, STL had cooperated with Ferranti. ASM needed a similar cooperation for evaluation as well, but preferably with a more prestigious chip manufacturer.

In January 1983, six months after the highfalutin introduction, the demo tool was finished in Bilthoven. Secrecy clouded the performance and derived results. ${ }^{120}$ Much focus was still on the technology's sales and marketing, rather than on overcoming the process and production challenges. The technology was expected to be so disruptive, that ASM kept all its cards close to its chest - and probably too close.

In the fall of 1982, in succession of ASM's announcement and in hopeful anticipation of the promises made, a number of customers had sent ASM demo wafers, on which ASM had to deposit a film of aluminum. ${ }^{121}$ But since the tool was not yet finished, their evaluation had to wait. ASM Europe had difficulties processing the wafers, as the tool was not yet capable of consistently growing films in line with the presented requirements. It was important that the processed demo wafers would give results in line with the earlier stated parameters. ASM's aluminum CVD process, proclaimed so loudly at Semicon West, caused skepticism among customers.

120 ASM Europe, Peter Schumbera, 'Memorandum: APCVD' (8-8-1983) Archive Arthur del Prado - ALCVD - ALCVD 1981-1983.

121 ASM Europe, Pieter Greveling, 'Telex 0022/mc: APCVD demo wafers' (4-1-1983) Archive Arthur del Prado-ALCVD - ALCVD 1981-1983. 
Nevertheless, one customer remained interested. This was the Japanese semiconductor manufacturer Hitachi Semiconductors. ${ }^{122}$ Aluminum CVD fitted into the plans of Takeo Yoshimi. In February 1983, this professor and a couple of engineers from Hitachi visited Bilthoven to view and discuss the aluminum process. Their pro-active attitude - compared to other candidates - resulted in a joint-development agreement. ASM would supply a tool to Hitachi by April 1983, which they would use to evaluate the process for at least one year. ${ }^{123}$ Now, the engineers of ASM Japan had to be involved in the development more intensively as well. ASM Japan's Mitsutoshi Shutoh was asked to take care of this. He had to maintain the machine and discuss some of the results before these were forwarded to Bilthoven.

The project was off to a bad start: the installation of the Hitachi tool took place three months later than expected. Despite this delay, the fact that Hitachi studied the technology constituted a first positive step in the envisaged marketing plan. One year after the introduction of the tool at Semicon West '82, expectations were still running high, but there were no results yet. ASM Europe's sales manager, Pieter Greveling, summarized the situation after Semicon West of ' 83 by saying that the company made a lot of promises and announcements but that 'no real proof could be given. ${ }^{124}$ While customers were still waiting for their demo wafers, ASM claimed to be facing a new problem, which was surface roughness. Before processing the demo wafers, this problem had to be solved. Be that as it may, most of the customers replied, show us the demos, and we will draw conclusions by ourselves. They insisted on returning the demo wafers to move the discussion beyond the level of promises and unverifiable claims. ${ }^{125}$ Even after these clear remarks, ASM kept on delaying. The engineers had placed their hopes in part on the results at Hitachi.

As was true for ASM America and the PECVD technology, by 1984, ASM Europe had too much on its plate. It had to deal with its ongoing products LPCVD, diffusion, and several epitaxy systems - as well. Furthermore, the

122 Even at the time that ASM was still represented by Marubeni Hytech, ASM was already approached by Yoshio Homma of Hitachi Central Research Labs to discuss the aluminum CVD process. This was just shortly after Del Prado concluded the license agreement with STL about the technology. Del Prado asked Yo Miyazaki to find out whether Homma was part of the 'famous "Hitachi Copying Team"' - ASMI, Arthur del Prado, 'Telex: [subject unknown], ref: 158/jm' (10-11-1981) Archive Arthur de Prado - Marubeni file.

123 ASM Japan, 'Memorandum of Understanding between Hitachi and ASM Japan for loan of one set of Aluminum CVD' (Date unknown, 1983) Arthur del Prado Archive-ASM Japan 80's; memo's.

124 ASM Europe, Pieter Greveling, 'Memorandum: APCVD demo wafers' (14-6-1983) Archive Arthur del Prado-ALCVD - ALCVD 1981-1983.

Ibid. 
original managers of the Bilthoven operation stepped down by 1984. Van Beest and Kamerbeek focused on the forthcoming ASM Microelectronic Technology Center (AMTC). The new manager Jan Heetebreij failed to establish a footing in the firm. Del Prado continued to thwart the Bilthoven management whenever he rushed in and out. Though inspiring and decisive, his interventions did not result in ownership of the aluminum CVD process by the engineers in Bilthoven.

Since ASM Europe lacked the resources to internalize the process development substantially, Dr. Heinecke and STL were still involved to some extent. From time to time, Del Prado asked Heinecke to participate in presentations. After all, he was the inventor, and had accumulated an intimate knowledge of the process over the years. Furthermore, STL was a prestigious laboratory, and their involvement, through Heinecke's presentations, would remove anxiety among customers.

After ASM acquired the technology, STL engineers continued their experimentation as well. However, the course of both ASM and STL diverted soon enough. One of the key engineers left STL, after which their aluminum CVD tool soon broke down. ASM decided not to repair it. Results were still not convincing, and no system was ready to be sold. The project dragged on.

After one year of experimentation, Hitachi returned their system to Bilthoven in July $1984 .{ }^{126}$ After installation in the fall of 1983, ASM had to wait until December, before it was allowed to operate the Hitachi tool overnight and conduct the first deposition processes. ${ }^{127}$ Working at night was required to prevent interruption of Hitachi's development schedule during the day. The tool suffered from vacuum leakages, and the boat puller appeared to work imperfectly as well. The old issue of alloying aluminum interconnections with silicon was still not really solved by means of Heinecke's process, and ASM was not yet able to solve the issue. ${ }^{128}$

After the Hitachi engineers had been running it for a while, they concluded that ASM needed to limit its ambitions. In theory, the process was better than sputtering. But ASM tried to be competitive by processing almost 100 wafers in one run. According to Hitachi, that was way too much. They advised ASM to develop a smaller tool initially, and scale it up after they controlled the process. Yet Hitachi's message fell on deaf ears. For the original marketing plan, the required throughput to have it compete with traditional sputtering was calculated, and

126 Mr. Shutoh tours Mr. Takamatu along ASM’s operations. - ASM Japan, M. Shutoh, 'Monthly report June/July 1984 (4-9-1984) Arthur del Prado Archive - ASM Japan 80's; Weekly Activity Reports ASM Japan.

127 ASM Japan, M. Shutoh, 'Weekly Report Week 51 and 52' (December 1983) Arthur del Prado Archive - ASM Japan 80's; Weekly Activity Reports ASM Japan..

128 ASM Europe, Pieter Greveling, 'Telex 1393/ob: Status APCVD’ (3-3-1983) Archive Arthur del Prado - ALCVD - ALCVD 1981-1983. 
decreasing the number of wafers processed in a run was deemed not possible. Moreover, apart from Hitachi's feedback, the process never got a solid screening by other customers. ASM very much held on to the course as set out by Heinecke for the horizontal configuration, and the initial market strategy of ASM itself. By May 1984, in the absence of constructive cooperation with ASM, Hitachi gave up and decided to return the tool to Bilthoven. ${ }^{129}$

\section{Monopolizing the development of aluminum CVD}

ASM had underestimated the state of aluminum CVD. It was not ready for commercialization yet. Overcoming the shortcomings of the process required more financial, technological, and human resources than ASM Europe was willing to invest. Just like ASM America and ASM Japan, the company relied on external inventions to commercialize, and was preoccupied with selling these techniques instead of innovating the underlying process technology.

In addition, eager to reap all the technology's profits after a breakthrough, ASM tried to monopolize the new technology. The development was shrouded in secrecy, as ASM Bilthoven was anxious that its knowledge would be copied. This counted in particular for the Japanese market. In the United States, but also in Europe, the semiconductor industry accused their Japanese counterparts of imitating and copying their technology. These accusations did not materialize out of thin air, of course. Furthermore, ASM Bilthoven tried to monopolize the aluminum CVD internally within ASM. Its management and engineers did not want the other subsidiaries, being ASM America and ASM Japan, to go their own way with the highly prospective technology.

The convulsive efforts of ASM Bilthoven to keep the development and status of aluminum CVD process proprietary illustrated the maturation of ASM as equipment manufacturer. In slightly more than a decade, it had carved out its own market share by imitating technology developed by others. One could argue that the company knew the consequences of imitating as a first-hand experience.

Given the advent of VLSI technology, however, it did not make a lot of sense to keep the technology too close to one's chest. By the middle of the 1980s, semiconductor technology and manufacturing had become too complex to be tackled by one company. After all, innovation of manufacturing techniques was performed only in part by the equipment vendors. Most work was done by the chip manufacturers, which integrated the available technology into their production lines. They had to find the right recipe to make their newest chips work. This further intensified with the arrival of VLSI chips.

129 ASM Japan, M. Shutoh, 'Monthly report May/1984' (14-06-1984) Arthur del Prado ArchiveASM Japan 80's; Weekly Activity Reports ASM Japan; Fukumi Tomino, 'Interview with author'. 
Any process became part of a whole chain of processes, and the effectiveness of some final result - a computer chip - depended on the integration. This demanded cooperation across the traditional competitive barriers. The advent of the VLSI chips cracked open the traditional walls companies erected around their technologies. An open conversation between equipment supplier and chip manufacturers was needed, while intellectual property protected the owner and innovator (for more on this, see Innovation III).

So far, ASM lacked a consistent policy on intellectual property. Del Prado was quite skeptical about its benefits. It was expensive, as most of the patents had to be filed in Western Europe, various Asian countries, and in the United States. Some of these regions had a reputation of copying technology, and lacked compliance and control of existing legislation. In addition, according to Del Prado, patents educated the competition about ASM's innovations. Whereas this position made some sense in the sixties and seventies, it became less tenable in the decades thereafter. Innovators had to protect their technologies and innovations to open the conversation with customers, as well as to deter competition.

ASM did not file any patents on aluminum CVD initially. It relied on the publications and patents of Heinecke and his colleagues, which it had licensed. ${ }^{130}$ Yet it did publish some articles about its technology and process. ${ }^{131}$ One possible reason for delaying or deprioritizing the filing of patents pertained to the expansion of other activities at ASM.

By 1984, ASM's activities proliferated across all semiconductor manufacturing techniques. Del Prado, who kept the Bilthoven operation responsible for aluminum CVD under close control, had more on his plate than the patents. Also in Bilthoven, most of the engineers had been busy with fulfilling orders for their other products, such as LPCVD and PECVD. Moreover, by the fall of 1983, the beneficious winds that for several years had befallen upon ASM ceased.

130 Examples are: ITT Industries Inc., Rudolf A.H. Heinecke, Ronald C. Stern, 'US4328261A: Metallizing semiconductor devices' (priority date: 9-11-1978; published: 4-5-1982); : ITT Industries Inc., Rudolf A.H. Heinecke, Ronald C. Stern, 'US4460618A: Aluminum deposition on semiconductor bodies' (priority date: 25-5-1978; published 17-7-1984); : ITT Industries Inc., Rudolf A.H. Heinecke, Ronald C. Stern, 'US4433012A: Process for the pyrolytic deposition of aluminum from TIBA' (Priority date: 10-7-1980; published 21-2-1984); and finally: ITT Industries Inc., Rudolf A.H. Heinecke, Ronald C. Stern, and Michael Joseph Cooke 'EP0068738A1: Metalllisation Plant' (priority date: 17-6-1982; published: 5-1-1983).

For example: Cooke, M. J., and R. Heinecke. "LPCVD of Aluminum and Al-Si Alloys for Semiconductor Metallization.” Solid State Technology 25.12 (1982), pp. 62-65; Rudolph Heinecke et al., "Low-pressure Aluminum CVD", Proceedings of the Fourth European Conference on Chemical Vapor Deposition, (1983) pp. 119-121; H.J. Cooke, R.A. Heinecke, R.C. Stern, and J. W.C. Maes, Solid State Technol. 25 (1982) p. 62. 
Deprived of a genuine opportunity to verify ASM's aluminum CVD process, the industry moved forward. They were not going to wait for ASM. More competitors overcame the metallization problems in the meantime. Suppliers of sputtering processes had tried to overcome the main disadvantages of their products. But more importantly for ASM, there were rivals with alternate processes in the field.

By 1983, an American startup by the name of Genus introduced a new innovative reactor dedicated to tungsten CVD processes. This introduction was preceded by announcements of computer and captive chip producer HewlettPackard (HP). HP was one of the earliest to adopt two-level tungsten metallization in its 32-bit microprocessor family containing 450,000 transistors. For this step, Hewlett-Packard used its in-house developed tungsten CVD reactor, since no other was yet available on the market. ${ }^{132}$ At the smallest dimensions, tungsten proved to be more reliable than aluminum interconnections.

Whereas ASM failed to adequately address the ongoing concerns of chip producers about the aluminum CVD process, one after another turned toward the new tungsten CVD process. The interconnections above the transistors - those with the smallest linewidths - could be constructed by tungsten, while for the bigger aluminum structures the existing sputtering techniques would still suffice. Tungsten had a higher melting temperature compared to aluminum, which prevented electromigration. Halfheartedly, ASM tried to develop a tungsten CVD within the framework of a European support scheme, but it did not lead to anything. ASM had missed the boat. ${ }^{133}$

\section{Epilogue}

The aluminum CVD process, as developed by Heinecke, did no longer fit the needs of the chip producers. The batch configuration was anachronistic. The industry had moved to a single wafer tungsten CVD system in order to secure the highest

132 By the mid-eighties, the smallest interconnections of computer chips could no longer be made of polysilicon or aluminum. Tungsten was the solution. While the European project got approved, Hewlett Packard announced its first chip containing tungsten interconnecting films, grown in an in-house developed piece of equipment. In the same year, 1983, a startup equipment vendor called Genus introduced a dedicated tungsten LPCVD system dubbed the Genus 8301. - Dataquest, 'Markets and Technology: Chemical vapor deposition' Semiconductor Equipment and Materials Service (26-9-1985), p.22, Nielsen Dataquest, 'Research Newsletter: chemical vapor deposition' Dataquest (12-8-1985) p. 9.

133 It was called 'Project MR-11-ASM: Development of a refractory metal deposition process and related equipment', and commenced December 1983 lasting until May 1987 - ASM Europa, Hans Hanekamp, 'Minutes of Meeting: Tungsten LPCVD-1' (22-2-1984) Archive Arthur del Prado - ESPRIT/JESSI file; and EU Cordis, "Project MR-11-ASM: Development of a refractory metal deposition process and related equipment'; ASM Europe, Peter Schumbera, 'Interim Report Tungsten LPCVD' (27-12-1983) Archive Arthur del Prado - ESPRIT/JESSI file. 
quality at the interconnections' smallest dimensions. ${ }^{134} \mathrm{~A}$ severe downturn in the fall of 1984, resulting from the Japanese and American rivalry in chip production, and a successive shake-up among manufacturers, temporarily evaporated demand for equipment (cf. Business III). This downturn threw ASM off balance, taking the wind out of the sails of the horizontal aluminum CVD technology.

If aluminum CVD was to become successful, it had to be redesigned and reconfigured. As the miniaturization of computer chips continued, future generations might require the conformity of aluminum CVD. The process became one of the flagship projects of a newly established central research laboratory called the ASM Microelectronic Technology Center (AMTC) in Bilthoven. This center, founded with support from the Dutch government (see Innovation III), would enable ASM to start development processes a bit removed from the market.

At the AMTC, the R\&D manager, Ernst Granneman contemplated a new configuration for the aluminum CVD process. Instead of a horizontal furnace, he configured it to a batch clustered system dubbed the A600. Through this new design, ASM Europe succeeded for a final time in securing interest in the market by the end of the 1980s.

At the beginning of the 1990s, IBM and AT\&T Bell Labs showed renewed interest in the aluminum CVD technology of ASM. AT\&T Bell Labs had itself looked into aluminum CVD throughout the eighties. Both ASM and AT\&T agreed upon a joint development program for the development of a cluster configuration for aluminum CVD. The project lasted from 1989 until 1992. IBM became interested as well at the turn of the new decade. It was already contemplating new interconnecting materials, and through this it looked into copper or copper alloyed materials. It regarded aluminum CVD as possible backup process.

These events are beyond the scope of this chapter, and for now it is sufficient to mention that the interest of both companies led to nothing. By 1992, AT\&T Bell Labs was no longer convinced of the applicability of aluminum CVD. ASM's renewed aluminum CVD process succeeded in overcoming the problem of electromigration and continued to offer perfect deposition conformality. However, during cool-down to room temperatures, pin-holes were formed in the aluminum film, disrupting the materials. The pin-holes proved to be too difficult to solve within the joint-development program. This conclusion, drawn by AT\&T and IBM, was the final blow to aluminum CVD.

After more than a decade of research and development this meant the end of ASM's aluminum CVD ambitions. Although hard to quantify, ASM will have lost a few millions in developing the process as of 1981. Regardless of these investments, the biggest loss was the chance of participating in the market for metallization processes.

134 Kees van der Jeugd, 'Interview with author'. 
The persistence in this process was typical for Del Prado's entrepreneurship. While he had to fight for the survival of the company in the early 1980s, he allowed the aluminum process to continue. The promise of disruptive innovation remained until the end. Aluminum CVD, in other words, continued to be a solution for an elusive, if not illusive, problem to be solved. 


\section{Conclusions}

The state in which ASM found itself by 1985 contrasted strongly with its condition roughly a decade earlier. The company developed from a Dutch representative into a multinational original equipment manufacturer with a presence in Europe, the United States, Japan, and South-East Asia. The company owed this change and expansion to the CVD and - not discussed in Innovation I - its packaging and assembly activities.

Basically, the four processes discussed - atmospheric pressure chemical vapor deposition (APCVD), LPCVD/low temperature oxide (LTO), plasma enhanced chemical vapor deposition (PECVD), and aluminum CVD - deviated little from each other. Each of them required similar heating, pressure control, gas components, and had comparable configurations. All used hot-walled horizontal tubes. The holding of the wafers differed in the case of the PECVD, and it contained a plasma, but the gas dynamics and control mechanism corresponded with each other. The four processes merely increased the applicability of the horizontal CVD furnace, which ASM had familiarized and tried to sell.

The company grew by opportunistically commercializing semiconductor fabrication technologies with external origins; the company earned its money by running only the few last miles to the finish of the proverbial marathon representing an entire innovation process. Elaborating upon its past as sales company, ASM did not rely upon a costly research department. ${ }^{135}$ Initially most innovation occurred during fabrication of the machines, as illustrated by the development of the first low pressure chemical vapor deposition (LPCVD) furnaces. The R\&D groups lacked the financial, technological, and human resources to engage technological developments from scratch. Even until 1982 $R \& D$ expenditures remained below five percent of the total sales. ${ }^{136}$ Expenditures into research and development (R\&D) increased from 26.3 thousand Dutch guilders in 1976 to 39.9 million by 1985 , or respectively 0.1 and 10.5 percent of total revenues (figure 19). ${ }^{137}$ To sustain and expand its market share, then, ASM required an external supply of inventions to be commercialized.

135 Keetie Sluyterman, Dutch Enterprise in the Twentieth Century: Business strategies in a small open economy (Routledge, Abingdon 2005) pp. 196-205, p. 200; David C. Mowery, 'Plus ca change: Industrial R\&D in the "third industrial revolution", Industrial and Corporate Change 18:1 (2009) pp. 1-50.

ASM Annual reports.

Ibid. 


\section{Figure 19}

Graph of ASM R\&D expenditures and as percentage of total sales, 1976-1986

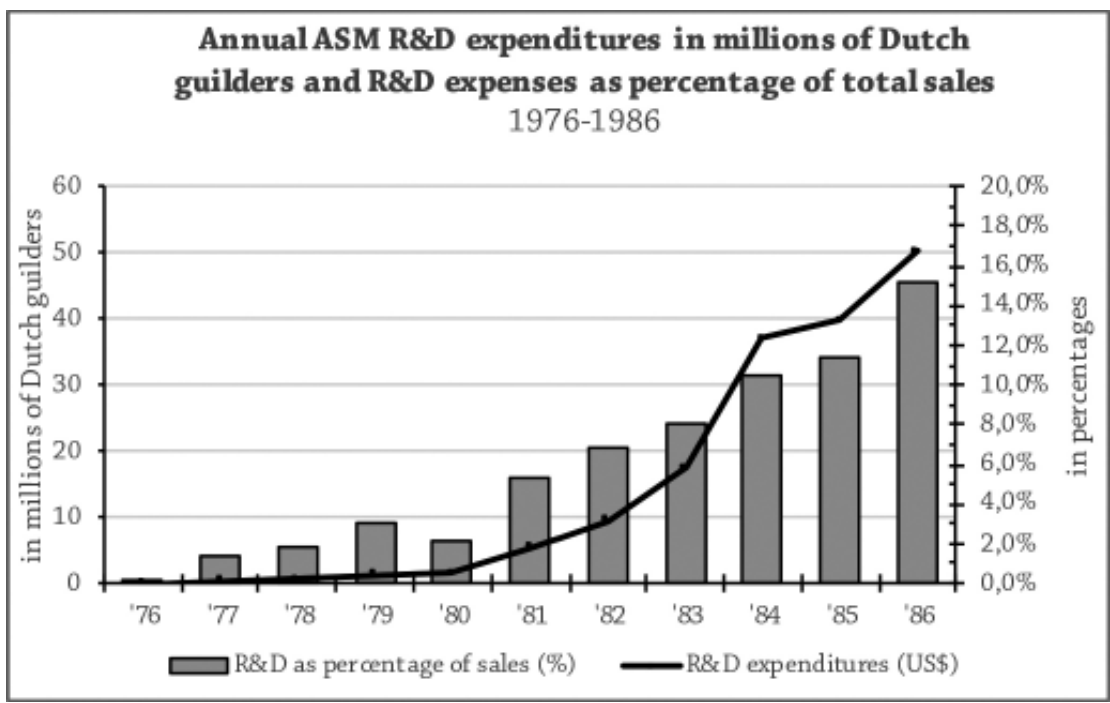

The question formulated at the beginning of Innovation I was: how did ASM's innovation processes evolve during the company's initial years as original equipment manufacturer, from 1971 until 1985? In this conclusion I reflect on ASM's early innovations and its transformation into a manufacturer with the triad virtù, path, and fortuna.

Virtù

Virtù, or the will to cope with uncertainty, created and appropriated opportunities, and in this process shaped the organization, its business, and its innovation effort. Who showed virtù and how was it shown? What was its effect on the transformation of ASM's innovation process?

Obviously, virtù was primarily in the hands of Del Prado. He urged and inspired his employees to innovate, as this was indispensable for the commercial viability of the firm. The most striking example was his order to Van Beest to build the first machine in 1971. Faced with the finality of being a representative, Del Prado took a leap of faith, starting upon the path of developing CVD. This decision prompted a sequence of events through which Del Prado continuously had to enable his engineers to develop new technologies and techniques. One thing led to the next. Or, to be more precise, one CVD machine had to be succeeded by another.

Over the years, the entrepreneurial managers of the various subsidiaries displayed virtù as well, such as reflected by Don Jackson and the hiring of 
Goldman, or Dale Stoddard's lead in exploring the Japanese market. Virtù was also shown by the engineers in their open-minded tinkering to address material problems, as exemplified by George Engle's efforts to overcome depletion effects across the furnace tube by turning the plasma on and off, resulting in the limited depletion mode. The displacement of virtù to others within ASM corresponded with the growing size of the company.

In these early years covered in these Innovation chapters, virtù mostly took the form of sheer opportunism, rather than flowing from deliberate exploration of technology and science. After all, each one of the various innovations discussed above had external origins. The company was keen on seizing the opportunities when they emerged.

This opportunism was rooted in the relative freedom enjoyed by the managers of new business units to run a business, stemming from ASM's decentral organization. This structure allocated responsibility for success to the local managers, and motivated employees to be entrepreneurial and innovative (cf. Business I).

The relative freedom of the business units allowed them to diversify the product portfolio. For the young company, diversification was a key strategy to appropriate new opportunities, markets, and prospects (cf. Business I). Foremost, the company diversified its offerings in deposition techniques. Although ASM was not deliberately designed as a supplier of chemical vapor deposition technology, it increasingly became attentive to further opportunities in this segment. Only gradually did ASM embrace the identity of a deposition equipment supplier.

This brings us to the influence of virtù on ASM's innovation process. By opportunistically elaborating on ASM's intellectual assets, instead of following a premeditated and well-planned trajectory, the entrepreneurial managers transformed the equipment supplier into a specialized innovator of horizontal CVD processes. In this respect, in the words of John Pocock, virtù became 'a pattern of moral order. ${ }^{138}$

This development of how opportunities get defined is in line with business historian Alfred Chandler's notes about how 'first-movers' define paths of learning and establish integrated learning bases. ${ }^{139}$ ASM as a company was 'a creator and repository of product-related embedded organizational knowledge.' ${ }^{140}$ As Chandler explains:

138 Pocock, The Machiavellian Moment, pp. 167 and 169.

Alfred Chandler, Inventing the Electronic Century: The Epic Story of the Consumer Electronics and Computer Industries (Harvard University Press, Cambridge, paperback version 2005) p. 5. 
'Once the new enterprise's competitive power has been demonstrated, its sets of integrated organizational capabilities become learning bases for improving existing products and processes and for developing new ones in response to changes in technical knowledge and markets, and in reaction to macroeconomic developments, including wars and depressions. ${ }^{141}$

For instance, the gradual expansion from Bilthoven to Phoenix, and eventually to Machida, enabled an adequate absorptive capacity for any new development of CVD. ${ }^{142}$ The exposure to different national industries and subsequent technological needs and opportunities propelled local customization and diversification of ASM's products. By appropriating opportunities and elaborating upon an expanding repository of knowledge, virtù shaped ASM's new path as innovator of chemical vapor deposition technology.

\section{Path}

Although ASM's progress was very much driven by opportunities that happened to present themselves, the company's past and Del Prado's anticipation of future developments also played a role.

Structural elements in ASM's path from 1971 to 1985 pertained to the company's past as sales agent and its mode of conduct as innovator of semiconductor fabrication technologies. As a sales agent, the company's core activity basically involved the effort of convincing customers to buy its products. It thereby supplied innovations of external origins - from its principals. The company's own resources merely involved staff and accumulated commissions on sales.

As an innovator, ASM continued to operate very closely to its customers, the semiconductor manufacturers, as it had done as a sales agent. To recover its investments in technological development, accreditation by a customer was indispensable. For this reason, ASM did not engage advanced, costly, and indefinite innovation trajectories to develop its own CVD processes. In this, the Dutch enterprise did not differ much from its competitors. Yet as a starting equipment supplier, its competences not necessarily matched the continuously advancing demands of the semiconductor manufacturers. To overcome this disadvantage, claims of competence preceded the actual familiarization and

Modern Chemical and Pharmaceutical Industries (Harvard University Press, Cambridge, 2005), p. 6.

141 Ibid., p. 8.

142 Wesley Cohen and Daniel Levinthal, 'Absorptive Capacity: A New Perspective on Learning and Innovation', Administrative Science Quarterly 35:1 (1990) pp. 128-152. 
innovation of semiconductor fabrication technologies. The acquisition of proven techniques also helped to overcome ASM's junior status within the semiconductor industry.

With respect to the atmospheric CVD, the LTO and the PECVD technologies, the applicability of the tools had been proven. This was not the case yet for the aluminum CVD process, which therefore constituted a major risk. Del Prado's confidence in ASM's ability to commercialize the unproven aluminum CVD, even neglecting the help of Hitachi, was misguided. Some customer allegiance was indispensable; ASM was not able to innovate all by itself.

Conceptualizations in academic literature help to put this dynamic in context. For instance, the concepts of enactor and selector point to different roles in the variation and selection process. ${ }^{143}$ 'Enactors' present a technology as a solution to various perceived problems. ${ }^{144}$ They create variations. 'Selectors' operate just the other way around; they define the problem and consider various solutions. This role selects from the variations. Clearly, ASM operated as an enactor in its offerings of semiconductor equipment, while its customers performed the role of selector.

Originally as sales agent and later as equipment supplier, it was ASM's sole objective to sell its products. How the technologies were used mattered less than that they were sold. Therefore, the innovation of CVD processes was very much bound to the commercial operation of the company. After 1976, the Bilthoven and Phoenix demo-labs became imperative in the effort to expand and realize the applicability of ASM's CVD technology.

ASM's customers - the semiconductor producers - operated as selectors. Regardless of the dazzling sales efforts and technological argumentations of ASM, they considered various available technologies from competing CVD suppliers to complete other techniques as a solution to their problem. This explains why - despite the ostensible applicability - ASM's first CVD machines and the aluminum CVD gained little attention from customers. But the PECVD and LTO processes did appeal to their interests more accurately, resulting in substantial sales for ASM. The customers were the final selector of technology.

Furthermore, this interaction between ASM and the semiconductor producer fits Keith Pavitt's taxonomy of sectoral patterns of change, which is widely

143 Raghu Garud and David Ahlstrom, 'Technology assessment: a socio-cognitive perspective', Journal of Engineering and Technology Management 14:1 (1997) pp. 25-48; and Arie Rip, 'Folk Theories of Nanotechnologists', Science as Culture 15:4 (2006) pp. 349-365, pp. 360 and 361.

144 A comprehensive definition is given by Sjoerd Bakker in his dissertation Competing Expectations: The case of the hydrogen car (BOXPRess, Oisterwijk, 2011), p. 8. 
used to characterize innovation patterns. ${ }^{145}$ In the case of ASM, the company's technological pattern belonged to a 'specialized supplier firm':

'Specialized supplier firms are small and high-performing inputs into a complex system of production and product development in the form of machinery, components, instruments and software. Specialized supplier firms benefit from the operating experience of advanced users, in the form of information, skills and the identification of possible modifications and improvements. Specialized supplier firms accumulate the skills to match advances in technology with user requirements, which given the costs, complexity and interdependence of production processes - put a premium on reliability and performance, rather than on price. The mains tasks of innovation strategy are keeping up with users' needs, learning from advanced users and matching new technologies users' needs. $\underline{146}$ -

This characterization almost completely applies to ASM, as detailed in the chapters of Innovation I. The company specialized in one particular element CVD - 'in a complex system of production,' benefitting most certainly from its contacts among 'advanced users.'

In contrast to Pavitt's definition, however, ASM still tried to sail rather independently of its customers. This was still possible due to the diverse customer base, requiring very different technologies and a struggle with very diverse problems. ASM's internal technological path was not yet truly focused on its customers' demands, and, in this significant aspect, its path deviated from that of a 'specialized supplier.' By the mid-eighties, this independency started to decrease; increasingly ASM operated as a 'specialized supplier.'

\section{Fortuna}

ASM's transformation was carried by fortuna. Contingencies and coincidental meetings beyond the norm, or that which was not to be expected, instigated new innovation processes.

Fortuna manifested itself at an individual level. This involved the encounters with Goldman and his LTO process, Engle and his PECVD machine, and Heinecke and the aluminum CVD process. And fortuna showed itself in the material realities encountered by ASM's engineers. Consider the result of Van Beest's first LPCVD

145 Keith Pavitt, 'Sectoral patterns of technical change: Towards a taxonomy and a theory', Research Policy 13:6 (1984) pp. 343-373.

146 Joe Tidd, John Bessant, Keith Pavitt, Managing Innovation: Integrating Technological, Market, and Organizational Change (2nd edition; Wiley, Chichester, 2001), p. 113. 
run resulting in a film resembling mildew, or the troubles in making aluminum CVD work in the mid-1980s. But fortuna manifested itself also as the benevolent technological and industrial dynamics, as exemplified by the advent of very large silicon integration (VLSI), the PC revolution, and the American-Japanese rivalry. These resulted in a huge demand for ASM's PECVD systems and the subsequent rise of ASM as an established equipment manufacturer.

One particular manifestation of fortuna stood apart from the others: the sequence of events threatening the participation of ASM in the CVD business in 1971 (cf. Chapter 7). The annulment of the Applied Materials operation in Europe, the subsequently cancelled Applied Materials contract, and Sola Basic's refusal to fill in demand for CVD tools made ASM the plaything of its principals. In response, Del Prado realized his finality as representative, which caused him to take a leap of faith by ordering Van Beest to manufacture a CVD tool himself.

The deterioration of the Applied Materials' relation and Del Prado's subsequent actions constituted a true Machiavellian Moment. ${ }^{147}$ Faced with ASM's temporal finitude, Del Prado took the initiative and moved beyond conventional procedures. He filled the order for Applied Materials with his own creation. Through this calculated decision - virtù - Del Prado exposed his small firm to new sequences of fortuna by embarking on a new trajectory: developing, building, and selling CVD equipment made by ASM. As such, the provocation for the SOX 10-2 formed an extraordinary manifestation of fortuna, more defining for the company's existence and future than any other.

Fortuna instigated ASM's transformation into a semiconductor equipment manufacturer. The 1971 decision to manufacture its own semiconductor equipment exposed ASM, unexpectedly, to a wider contingent development of disintegrating conglomerates. As explained by economist David Mowery:

\begin{abstract}
'Beginning in the late 1970s ... Large corporations reduced or eliminated their central R\&D laboratories, increasing their reliance on external sources of $R \& D$ and knowledge, such as universities, interfirm alliances, licensing transactions, and acquisitions of other firms. ... Entry by new firms also benefitted from and accelerated the evolution of "vertical specialization" in industries ... in which specialist firms performed activities ... that formerly were included within the boundaries of large corporations. ${ }^{148}$
\end{abstract}

And as he elucidates elsewhere:

Pocock, The Machiavellian Moment, p. viii. 
'The large basic research establishments in universities, government, and a number of private firms served as "incubators" for the development of innovations that "walked out the door" with individuals who established firms to commercialize them. ${ }^{149}$

This development gave ASM unexpected further opportunities along the path of chemical vapor deposition.

Later, in the early 1990s, such changes in how firms organized innovation processes were understood as 'Generations of R\&D. ${ }^{150}$ The first generation refer to basic research groups determining the products and course of a company, also known as technology-push. In contrast, the second generation of R\&D, emerging in the early 1970s, is characterized as market-pull. The third generation, from the 1980s on, involves an integrated approach. Within this template, ASM's application-driven innovation process arguably belongs to ' $2{ }^{\text {nd }}$ generation R\&D.' Also here, then, ASM fitted the times.

In the following decades, ASM continued on the new path chosen. Del Prado's virtù and the defining contingencies mentioned above enabled the company to proceed. Del Prado's gamble paid off. He proved to be a Machiavellian Prince in his dealing with fortuna. By scrounging for new inventions externally, he sustained the company's relevance toward its customer base without having to amass a costly development department.

Without fortuna - Applied Materials, Goldman, Engle, and Heinecke - ASM would not have been able to expand its identity as supplier of CVD furnaces. Due to its original tenancy as sales agent and the subsequent prioritization of sales, ASM remained reliant upon externally supplied inventions. As such, ASM's innovation process did not succeed in wrenching itself from fortuna's spell.

149 Ibid.

150 Abe de Jong, Keetie Sluyterman, and Gerarda Westerhuis, 'Strategic and structural responses to international dynamics in the open Dutch economy, 1963-2003', Business History 53:1 (2011) pp. 63-84; Johan Schot and Edward Steinmueller, 'Three frames of innovation policy: R\&D, systems of innovation and transformative change', Research Policy 47 (2018) pp. 1554 1567, p. 1558; Philip Roussel, Kamal Saad, and Tamara Erickson, Third Generation R\&D (Harvard Business School Press, Cambridge, 1991). 


\title{
Business II
}

Golden years of expansion, entrepreneurism,

\author{
and opportunity, \\ 1979-1985
}




\section{An introduction}

At the doorstep of a new decade, ASM's future looked bright. The geographical areas and technological domains covered by the company, including its new role as equipment manufacturer, constituted a promising starting-point. With Arthur del Prado at the helm, ASM was well-positioned to reap the benefits of a prospering and dynamic semiconductor industry. And so it did. The company explored a wide pool of inventions, which could be developed and commercialized into real semiconductor production technologies. Business II details the resulting phenomenal technological, geographical, and financial expansion of ASM from 1979 until 1985.

As of the late 1970s, the semiconductor industry was experiencing a period of drastic change. This involved three overlapping developments. The first concerned the spectacular growth of the semiconductor industry, propelled by the 'PC revolution' and in striking contrast to the general economic recession. Personal computers (PCs) entered the daily lives of consumers and businesses, creating increasing demand for new computer chips - microprocessors and memory chips - and, subsequently, semiconductor fabrication equipment.

The second development involved the disintegration of big manufacturing conglomerates, in semiconductor technology and beyond..$^{1}$ Due to the recession tormenting the Western economies since the 1970s, conglomerates in electronics were forced to divest activities deemed not relevant to their core-business. ASM snatched up these new technologies from advanced industrial research laboratories, as well as further developed and commercialized them.

The third development involved the booming market for memory chips, accompanied by a politicized rivalry between Japanese, American, and European chip industries. Of all the various semiconductor products, memory chips in particular were produced in bulk, and therefore regarded as the most valuable and competitive products of the semiconductor industry. Commanding this technology and market offered companies and countries a stake in the promising and strategic microelectronics industry. The strive for market share in the memory business boosted investments in new semiconductor production technologies.

Each of the developments - the disintegration of conglomerates, the PC revolution, and the memory rivalry - formed a contingency to which Del Prado

1 David C. Mowery, 'Plus ca change: Industrial R\&D in the "third industrial revolution", Industrial and Corporate Change 18:1 (2009) pp. 1-50, p. 13. 
and his firm had to respond. As such, ASM's expansions of the early eighties are related to and contextualized in terms of these developments. They constituted the wind, which filled ASM's sails and defined the course of the company.

\section{Contemporary appreciation of a multi-divisional enterprise}

Years of economic stagnation in Western economies gave rise to reflection on new approaches. Foremost, the Japanese successes in various manufacturing industries struck the eye. Following the Japanese example, scholars reconsidered presumptions about technological development and innovation. They began to pay more attention to evolutionary economics. Closely related to this field, the contextual embedment and interdependency of innovations within an industry or economy gained notice, resulting in the study of innovation systems. ${ }^{2}$

In response to Japanese successes, policymakers in the West pursued ways of addressing the decline of their national economies and 'national champions' (big corporations firmly embedded in a national economy). This triggered a new look at economic policies. Defensive policy instruments had not been successful in altering economic stagnation or preventing the faltering of large corporations. Within Europe, innovation policies aimed at advancing national competencies for the future were developed at both European and national levels. Such policies aimed in particular at technological domains like microelectronics and biochemistry.

As highly structured big corporations with professionalized managers faltered, entrepreneurship regained the interest of management scholars and business managers. As noted by business historian Keetie Sluyterman:

'It had become evident that continuity in business was not a matter of course; even large and well-known companies could still go under. Thus entrepreneurship was an achievement, and consequently the person behind the office and individual style of leadership merited closer attention.'

Sluyterman highlights one particular example of management literature as illustrative for this wider appreciation of business management: In Search of Excellence, an international bestseller by two McKinsey consultants, Tom Peters and Robert Waterman, published in 1982. ${ }^{4}$ The authors argue for the importance

2 Johan Schot and Edward Steinmueller, 'Three frames of innovation policy: R\&D, systems of innovation and transformative change', Research Policy 47 (2018) pp. 1554-1567, p. 1558.

3 Keetie Sluyterman, Dutch Enterprise in the Twentieth Century: Business strategies in a small open economy (Routledge, Abingdon 2005), part of series: Geoffrey Jones and Mary Rose (ed.), Routledge International studies in Business History, pp. 196-205, p. 200.

4 Tom Peters and Robert Waterman, In Search of Excellence: Lessons from America's Best-Run 
of 'unleashing' the entrepreneur. ${ }^{5}$ Recipes for success, in their view, include a 'bias for action,' 'customer-focus,' 'autonomy and entrepreneurship,' 'hands-on management,' and 'simple form and lean staff.'

Amidst this period of structural transformation of economics and business, Del Prado and ASM seemed to be a textbook example of entrepreneurship, organizational structure, and innovation. After all, ASM was active in the industry of the future: microelectronics. The company was led by an entrepreneur pur sang, guiding the company into the rarely appreciated growth market of microelectronics fabrication technology. Also, the company did not rely upon costly and ineffective basic research laboratories, but closely operated near the market. ASM was agile and entrepreneurial, and at that point in time it seemed to be an almost perfect embodiment of the business principles set forth in The Search of Excellence. Moreover, ASM realized record revenues and growth. In this period, then, everything - ASM's achievements, new opportunities, and public recognition - seemed to converge, driving the equipment manufacturer to new heights.

\section{Outline of Business II}

Major episodes in the history of ASM addressed in Business II include the initial public offering, the start of ASM Lithography, the development ASM Japan, and the focus on new technological endeavors, such as automated assembly technology. The story covering this period is divided into two chapters. Chapter 11 tells the story of ASM from 1979 until 1983. In these years, the company benefitted from the disintegration of conglomerates and the $\mathrm{PC}$ revolution. Both wider developments resulted in a full war chest and plenty of opportunities to foster the company's ambitions and capabilities in semiconductor manufacturing. Chapter 12 covers the years 1983 to 1985, when memory-chip sales and production boomed. The American, European, and Japanese rivalry for dominance in memory chips boosted sales of equipment. Amidst these benevolent times, ASM deliberately established relations within the industry and with authorities. However, this chapter will also deal with some inherent deficiencies of ASM's business and innovation strategy. Business II will be concluded with a discussion of the company's transformation during the first half of the 1980s and the changed mode of business conduct by 1985 .

Companies (Harpers \& Row, New York, 1982).

5 Ibid. 


\section{Chapter 11 \\ A thriving market for semiconductor technology, 1979-1983}

Having established ASM as a multinational equipment manufacturer, Arthur del Prado rapidly capitalized on the benevolent tidings driving the semiconductor industry. Together with the entrepreneurial management of his subsidiaries, local opportunities were swiftly exploited. Although money seemed to be a limiting factor, growing revenues in horizontal deposition machines helped to overcome skepticism regarding the company's innovative capacity and managed to attract the interest of investors, customers, and the authorities.

\section{Industrial context:}

\section{A resounding technological and industrial dynamism}

From the mid-seventies until the early 1980s, most Western economies struggled with a recession. During this period, there was hardly any economic growth. Unemployment increased, as did inflation and interest rates. Economic policies based on the work of economist John Keynes became defunct (see Innovation III). In the early 1980s, the economic slump propelled a change in economic thought and policies toward what is now known as 'neo-liberalism'. This transformation was embodied by political leaders such as Ronald Reagan, Margaret Thatcher, and, in the Netherlands, Ruud Lubbers.

As argued by business historian Keetie Sluyterman, the state of the economy, in the early 1980s, urged manufacturing conglomerates to hive off so-called 'noncore' activities. ${ }^{6}$ This involved electronics companies like Philips, General Signals, ITT, and Western Electric. Most often, projects slumbering in basic research laboratories for years, without a short-term prospect of commercialization were

6 In the early 1980s, a number of Dutch conglomerates fell apart. Among them, a firm called OGEM, which had been a prime example of successful diversification strategies. The downfall of these big and diversified companies was accompanied with the rise of the "leveraged buyout'. By means of this strategy, viable parts of a company were separated from the non-viable activities in order to safe as much as possible. Also the notion of 'core' and 'non-core' activities emerged in management literature., propelled by: Michael Porter, Competitive Advantage: Creating and Sustaining Superior Performance (Free Press, New York) - Keetie Sluyterman, Kerende Kansen. Het Nederlandse bedrijfsleven in de twintigste eeuw (Boom 2003) pp. 252 and 262; or the English version Keetie Sluyterman, Dutch Enterprise in the Twentieth Century, pp. 196-205. 
divested first. This applied in particular to semiconductor production equipment. The economic recession and the maturation of the merchant equipment industry made such divestments necessary.

\section{The $P C$ revolution}

Although there was a generally depressed economic climate, the semiconductor industry showed strong growth. The global market for semiconductors grew from 6.85 billion dollars in 1979 to 20 billion dollars and 30 billion dollars in,

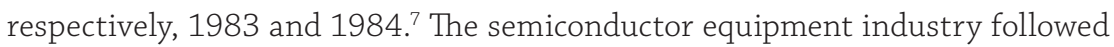
in its slipstream, with global sales of, respectively, 645 million, 2.12 billion, and 3.53 billion dollars. ${ }^{8}$ Even though growth was rather volatile on a quarterly base, the semiconductor industry clearly outperformed the general economy in the United States, Japan, as well as Western Europe.

Propelling this growth was a new application of computer chips: the personal computer (PC). Earlier, consumers got in touch with computer chips by buying pocket calculators, digital watches, or by playing videogames in Arcade Halls. Other than that, computing was merely done at the big mainframe computers of the likes of IBM at corporations and institutions. From the late 1970s until the mid-eighties, electronics manufacturers and start-ups - such as Hewlett Packard, Apple, Texas Instruments, NEC, Atari, and Compaq - readily joined the new, promising market of personal computing.

In this respect, the introduction of IBM's first PC, the IBM 5150 Personal Computer, in September 1981, was a milestone. Equipped with Intel's 8088 computer chip, it ran on generally applicable software called PC-DOS, developed by an upcoming company named Microsoft. The entrance of 'Big Blue' in the market for PCs was a crucial development. IBM's machine was not the first, the best, or the last PC on the market, but it commanded the allegiance of the market. ${ }^{9}$ Through its specifications and IBM's supreme sales force, its PC soon became the standard in the burgeoning PC industry.

By means of PCs, the latest and most advanced computer chips found ready buyers in ordinary offices and households. Initially, the price of IBM's PC ranged between 1600 and 4500 dollars. The PC soon contributed to the emergence of a large audience interested in the latest chips; after all, a better PC came with the best and latest chips, and consumers were willing to pay for that. TIME

Dataquest market statistics, computerhistory.org

$8 \quad$ Ibid.

9 The economist James Utterback would use the term 'dominant design': that which defines the standard of a product. See intermezzo in Business I. - James M. Utterback and William J. Abernathy, 'A Dynamic Model of Product and Process Innovation', Omega 3:6 (1975), pp. 639-656; James Utterback, Mastering the Dynamics of Innovation (Harvard Business School Press, Boston, 1994), p. 25. 
magazine's selection of 'The Computer' as 'Machine of the Year' in 1982, which represented an exceptional deviation of its annual 'Person of the Year' feature, was telling in this regard.

This PC revolution of the early 1980s drove many other related - or even indirectly related - sectors. It led to the establishment of an array of software, computer, and semiconductor companies that managed to attract the interest of investors. While the economic recession caused ebbs and flows of stock prices, companies involved in electronics, generally speaking, enjoyed a strong and rising interest at the American stock exchanges. This occurred in highly cyclical economic circumstances. Investments in production lines for the latest chips, strong demand for PC technology, and the concurrent economic recession all contributed to major market volatility. This capriciousness in demand applied in particular to semiconductor equipment.

The PC revolution itself was enabled by the continuous technological innovation of new computer chips and production technologies. The best PCs on the market available for consumers were equipped with the fastest microprocessors and most powerful memory chips. The chip manufacturer capable of supplying the best performing computer chip or introducing the latest chip technology first could therefore reckon on strong market penetration. The first was often the one to make off with the lucrative PC loot.

\section{Illustrious VLSI chips}

In the chip and the equipment industry, competitiveness was defined by command over the latest technologies. In the late 1970s and early 1980s, integrating electrical components on a silicon chip reached a new level of complexity (figure 20). Chip manufacturers, chip designers, and equipment builders prepared themselves for this new generation of chips, dubbed very-large-scale-integration (VLSI).

\section{Figure 20}

Table of changes in manufacturing development in 1965, 1975 and 1985

\begin{tabular}{|l|r|r|r|}
\hline & $\mathbf{1 9 6 5}$ & $\mathbf{1 9 7 5}$ & $\mathbf{1 9 8 5}$ \\
\hline Cost of a fab & $\$ 1 \mathrm{M}$ & $\$ 9 \mathrm{M}$ & $\$ 100 \mathrm{M}$ \\
\hline Automation & Manual & Semi-Autoload & Cassette to cassette \\
\hline Wafer size & $28-50 \mathrm{~mm}$ & $100 \mathrm{~mm}$ & $125 \mathrm{~mm}$ \\
\hline Linewidth & $20-30 \mu$ & $5-3 \mu$ & $2-1 \mu$ \\
\hline Clean room class & 10.000 & 1.000 & 10 \\
\hline Chip Generation & $\mathrm{SSI}$ & $\mathrm{LSI}$ & VLSI \\
\hline \# components & 10 & 1.000 & 1.000 .000 \\
\hline Workers garment & Lab coats & Smocks & Bunny suits \\
\hline
\end{tabular}


These chips contained more than 100,000 transistors, with a critical dimension, dubbed line-widths, of less than 2 micron. The previous generation of large-scale-integration (LSI), the first microprocessors and memory chips comprising 100 to a 100,000 transistors, had already opened new applications, integrated new functionalities, miniaturized the size of the components, and steadily increased the complexity of computer chips. ${ }^{10}$ VLSI posed the industry with new technological challenges. ${ }^{11}$ The VLSI chips elaborated on the development of previous generations of semiconductor technology, but also required new levels of preparation, cooperation, and development.

At the start of the 1980s, it was assumed that in particular manufacturing equipment and technology would be critical in the realization of VLSI. ${ }^{12}$ The chips required new cleaner production rooms (clean rooms), more automation to get reproducible manufacturing processes, and computer-aided design software to cope with the complex chip designs. In this context, historian David Brock referred to an 'orchestration of innovation,' which seems to cover the scope of the challenges faced by the chip industry as a whole. ${ }^{13}$ The cost of a chip factory - a fab - increased from 2 million dollars in 1970 to 50 million dollars in 1979, and this cost would continue to grow. ${ }^{14}$

Both developments - the advent of the VLSI chips and the PC revolution reinforced each other. On the one hand, the improved performance of computer chips enabled PCs and their new applications. On the other hand, the rise of PCs stimulated the innovation of chip technology. Customers were willing to pay for more memory and computer power. Innovation paid off.

\section{Corporate course:}

\section{Scavenging for new inventions to sustain growth}

At the start of the new decade - the 1980s - ASM's roots as a sales company still resonated. Del Prado continued to scavenge for new innovations in Europe and

Franco Malerba, The Semiconductor Business: The Economics of Rapid Growth and Decline (University of Wisconsin Press, Madison, 1985, pp. 148-149.

11 Nathan Rosenberg, and W. Edward Steinmueller, 'The Economic Implications of the VLSI Revolution', Futures 12:5 (October 1980) pp. 358-369.

12 Chih-Tang Sah, 'Evolution of the MOS Transistor - From Conception to VLSI', Proceedings of the IEEE 76-10 (1988) pp.1280-1326, p. 1310.

13 'This in contrast to systems of innovation. 'In semiconductor manufacturing there exists an ecosystem of technologies. Within this ecology lithography exposure tools and photoresist are highly coupled: the performances and characteristics of each help define the fitness and success of the other.' - David C. Brock, 'Patterning the World: The rise of Chemically Amplified Photoresist', Chemical Heritage Foundation, Center for Contemporary History and Policy: Studies in Materials Innovation (2009), p. 17.

14 Rosenberg, and Steinmueller, 'The Economic Implications of the VLSI Revolution', p. 359. 
America. But in contrast to the earlier decade, ASM now had an international presence and an in-house development and production capability. The new innovations could be appropriated and integrated into ASM's portfolio, as well as built and sold through the company's own channels.

To join the rampant growth of the chips industry, ASM had to offer innovative technologies. Put differently, ASM had to sell technology relevant for the latest developments in VLSI, or the company's added value and viability would be limited. At the same time, ASM was still a small and very much commercially driven enterprise. The company lacked the financial, technological, and human resources to commence on precarious and expensive research and development (R\&D). For this reason, ASM predominantly relied on the external supply of inventions to meet the latest VLSI demands.

Since the early seventies, ASM improved its technological capabilities by maturing, developing, and slightly innovating innovations developed by others, such as the low temperature oxide process developed by Jon Goldman or George Engle's plasma deposition process. Elaborating upon these experiences, the company mastered semiconductor production technology with fairly low investments in R\&D. ASM foremost industrialized existing processes by added inventive hardware, such as computer control, gas handling, electrical engineering, and wafer handling, while the heart of the innovation - the novel chemical processes - originated elsewhere.

With the increasing disintegration of manufacturing conglomerates, Del Prado was confronted with new innovative technologies on a regular basis. As long as the economic recession continued, central research laboratories had to hive off non-core activities. Whenever this involved semiconductor equipment, the entrepreneur did not hesitate. To sustain the growth of this company, these inventions were vital. Throughout the early 1980s, Del Prado deployed his entrepreneurial and commercial instincts to scavenge for these pearls, relying upon his extensive network in the chip industry.

These acquisitions or purchases were funded through the company's cash flow and profits. At this stage, no external loans or investments came into play. The commercialization of inventions happened through ASM's own cash. However, as the available external technologies and the company's own technological developments increased, the reliance upon internal funds became a problem. The internal financial means were insufficient to finance all available opportunities and investments. In order to realize the company's potential, cash was indispensable. 


\section{Elaboration of affairs}

\section{ASM enters the market for wire bonding technology}

The immediate example of ASM's tactic of incorporating external inventions and the limitations of the internal funding formed an acquisition in Hong Kong, 1979. By acquiring a local operation, ASM entered a new market segment: semiconductor assembly equipment. Yet this market was subjected to intense automation. Although ASM had to invest in the automation of the newly acquired technologies to sustain the new business, the company - in particular its Hong Kong operation - lacked the necessary technological and financial resources.

By the late seventies, two ASM operations were active in the development and production of packaging technologies and materials. In the Netherlands, ASM Fico - led by its founder, Richard Fierkens - produced sophisticated molds for the packaging of chips, stamped lead-frames, and fabricated trim \& form machines. ${ }^{15}$ The other operation was ASM Asia, which was principally established as a sales office for the Fico packaging products in South-East Asia, in 1975, and managed by Patrick Lam. To supply the regional market - in delivery time and in price - ASM Asia in part localized the production of lead-frames and some molds, previously fabricated by Fico. ${ }^{16}$ The operation's access to a vast labor force, and the interrelated low wages, gave it a competitive edge.

So far, both operations only operated in the segment of encapsulation products, which foremost relied on fine precision tooling - on craftsmanship on a turning lathe. However, there was a major segment between encapsulation and wafer processing that was not yet addressed by ASM (figure 5). This was the assembly of computer chips: after separating the chips - called a 'die' at this stage - from each other on a wafer, each 'die' had to be attached on a lead-frame (die bonding); next, the die was electrically connected with wires to the lead-frame (wire bonding), after which the die was encapsulated (packaging). In particular ASM Asia served a market consisting of customers who assembled and packaged chips, to which the subsidiary was able to sell encapsulation products only. As such, adding assembly technologies would improve the competitive position of the Hong Kong operation toward its customers. By 1979, Patrick Lam and Del Prado got a chance of adding assembly equipment to their product portfolio. But they were also confronted to the more fundamental challenges posed by automation and VLSI in this segment.

15 Richard Fierkens, Hightech in een boerendorp. De biografie van Fico-ondernemer Richard Fierkens (Herwen 2014).

16 Patrick Lam, 'Interview with the author', and Patrick Lam and Edmund Lam, Soaring like Eagles: ASM's High-Tech Journey in Asia (John Wiley \& Sons, Singapore, 2006), p. 35. 
During the chip industry's transition toward VLSI technology, manual assembly methods became obsolete. The assembly technology of wire bonding faced miniaturization. Due to the increasing complexity of VLSI chips, more wires had to bonded at smaller contacts in the same or less amount of time (figure 21)

\section{Figure 21}

Depiction of a wire bonding process.

Over time the number of wires increased, and the surface of the bonding pad shrank. New wire bonding equipment had to bond wires faster and more precise.

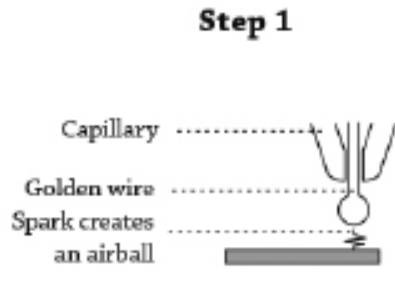

Step 3

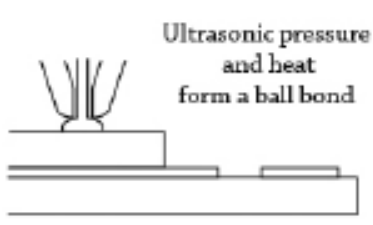

Step 5

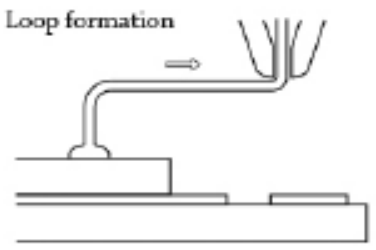

\section{Step 7}

The capillary rises.

Wire clamps are applied and the wire breaks away from the stitch

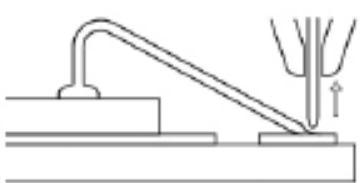

Step 2

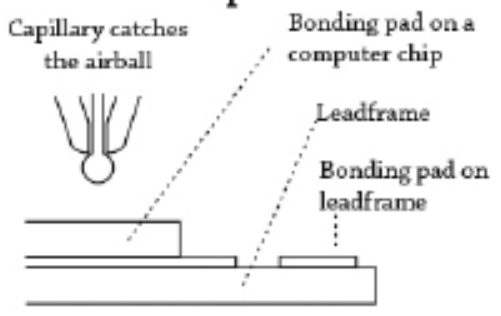

Step 4

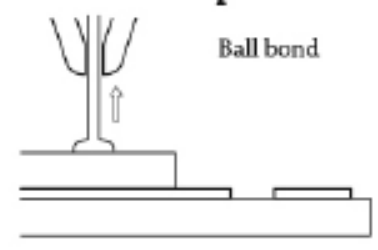

Step 6

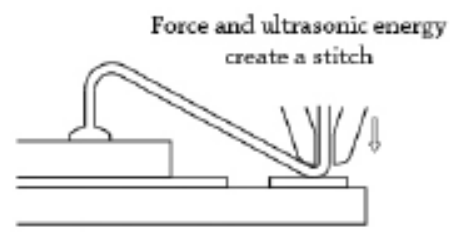


The refinements made automation of chip assembly process indispensable. So far, bonding the gold and aluminum wires between chips to the lead-frame had been done manually. Japanese assembly equipment manufacturer Shinkawa had introduced the first automated wire bonder already in 1972, followed by G.C.A. in 1976 and Kulicke \& Soffa in 1977. ${ }^{17}$ After manual alignment, the wires got bonded automatically at the designated spots. By the late seventies, automation urged suppliers of manual bonding equipment to reconsider their future.

One of the companies facing this challenge was ComputerVision. This company was a conglomerate active in multiple segments of semiconductor equipment, software and computer technologies. It had a small operation involved in the development and production of manual bonders located in Hong Kong. ${ }^{18}$ Facing the advent of automated bonders, the prospects of this operation diminished rapidly, and resulted in the decision to divest this Hong Kong Assembly Products Division early in 1979.

This was of potential interest to ASM. The well organized and talented manager of the Hong Kong operation, Patrick Lam, knew his customers, his competition, and thus his commercial opportunities. Moreover, Del Prado was familiar with ComputerVision. The Bilthoven operation had represented a ComputerVision subsidiary in mask alignment technology in the European market during the first half of the seventies. ${ }^{19}$ By mere occurrence of fortuna, the paths of ComputerVision Hong Kong and ASM were bound to intersect. The sale of the Hong Kong operation offered ASM an unique chance to enter a new market.

In autumn 1979, ASM and ComputerVision Hong Kong opened negotiations. ${ }^{20}$ Among the assets offered for sale were manual wire bonders, and a not-yet introduced conversion kit, which enabled owners of manual bonding equipment to automate their tools retroactively. It was this particular kit which convinced

17 VLSI Research, '5.4. Bonding and Inspection', chipshistory.org, p. 5.4.1.8; Jeffrey L. Rodengen, 50 Years of Innovation: Kulicke \& Soffa, 1951-2001 (Write Stuff, Fort Lauderdale, 2002) pp. 85 and 86 .

18 To be more accurate, ComputerVision had a subsidiary active in mask alignment technology called Cobilt. The Hong Kong operation, confusingly dubbed ComputerVision Hong Kong, was in fact a subsidiary of Cobilt. Mask alignment required precise motion control, and in this aspect there were similarities with manual bonding technology. Moreover, ComputerVision Hong Kong was a joint-venture together with a Philippine company called Deltron. - SEMI, Craig Addison, 'SEMI Oral History Interview: Peter Wolken', semi.org (16-6-2007); This company was founded as Westar Limited on May 5, 1972, and changed into ComputerVision in April 1974.

19 This was the company called Cobilt. Del Prado was an acquaintance of its founder and president Peter Wolken - SEMI, Addison, 'SEMI Oral History Interview: Peter Wolken'.

20 ASM Asia, Patrick Lam, 'Letter to Stephen Lee, Computervision HK' (8-10-1979) Archive Arthur del Prado-ASM Asia files. 
ASM to continue the negotiations. The conversion kit extended the product lifetime of ComputerVision's manual bonders beyond its imminent obsolescence.

December 1979, ASM acquired ComputerVision Hong Kong for 1,5 million Dutch guilders. ${ }^{21}$ Part of the deal involved the transfer of staff, the regional sales network, and a manufacturing operation in the so-called Watson Center in Kwai Chung, Hong Kong (where it is still located today). The newly acquired operation was renamed ASM Assembly Automation.

The integration and commercialization of the new group and technology proved to be an uphill battle. In the first months of 1980, Patrick Lam took over the management of ASM Assembly Automation, and tried to integrate the acquired assets and employees. A first disappointment concerned an exodus of engineering staff and their intimate technological knowledge. ${ }^{22}$ New staff was hired, among which Peter Lo and Wai Kwong ('W.K.') Lee, who would constitute the company's management in the decades to come. ${ }^{23}$ The technological knowledge of bonding technology had to be rebuilt by Lam and his new team.

The second setback concerned the poor commercial state of the wire bonders. Sales and customer support had been neglected. In the first year, ASM Assembly Automation succeeded in selling some manual bonding machines to pre-existing customers, such as Standard Microelectronics in the Philippines, Fairchild in Indonesia, and Sanyo Electric in Hong Kong. ${ }^{24}$ Disappointingly, only a few research institutes and laboratories were interested in the conversion kit.

If ASM was to succeed in the assembly business, it had to come up with a bonder tool which more adequately complied with the demands of the market: automated bonder products. Early in 1981, Lam and his management team started to plot a development effort for an automated bonder. Simply adding peripheral automation features to the bonders did not suffice. To develop an automated wire bonder machine, a complete new machine had to be developed.

21 The acquisition experienced some drag, as one of the stakeholders, Art Tyler, decided to stay with Deltron, initiating a back-and-forth legal dispute about commissions, breach of contract, and theft of intellectual property. - ComputerVisionHK, Roger Emerick, 'Telex to Art del Prado, telexnr. 6744' (7-12-1979) Archive Arthur del Prado - ASM Asia file; ASM, Arthur del Prado, 'Telex to Roger Emerich, telexnr. 6032/ab' (10-12-1979) Archive Arthur del Prado - ASM Asia file.

22 These engineers left ASM Assembly Automation and teamed up with the joint-venture partner in ComputerVision HongKong, Deltron. Naturally this resulted in legal disputes.

23 Peter Lo would become Vice President of the Hong Kong operation, and responsible for the aluminum wire bonder products. W.K. Lee became the Vice President of the Singaporean subsidiary from 1991 onward, and would succeed Patrick Lam in 2006 (cf. Business V).

24 Lam \& Lam, Soaring like Eagles; Patrick Lam, 'Interview with author', Peter Lo, 'Interview with author'. 
However, ASM Assembly Automation simply lacked the required financial, human, and technological resources to that end. Either ASM would have to find cash to ramp up the research and development efforts in Hong Kong, or ASM Assembly Automation would somehow have to secure access to externally nurtured inventions to speed up the automation project. Otherwise ASM's efforts to penetrate the market for assembly equipment would be futile. Either way, both options required cash.

\section{Securing cash for growth and an extraordinary initial public offering}

The Hong Kong situation exposed the financial constraints to which ASM was subjected. If ASM wanted to compete with the latest technologies - whether in wire bonding or deposition technologies - it required more money than the company could harness internally. While each operation grew on their own merits, pursuing commercial opportunities within their allocated markets, it was up to the CEO Del Prado to sustain their growth. Being the sole owner of a relatively small and unknown company, Del Prado faced difficulties in funding his commercial ambitions.

ASM was not bankable. The local operations - ASM Asia, ASM Assembly Automation and also ASM America - were too small to be eligible for substantial funding schemes. Bankers and other financial institutions - even governmentally supported ones - were not familiar with the semiconductor industry, nor with its equipment suppliers. Moreover, in the Netherlands, the country where the company was incorporated, nobody appreciated ASM's business or, for that matter, was able to appreciate its business. ${ }^{25}$

The financial limitations stretched beyond Hong Kong. Next to ASM Assembly Automation, ASM America desperately needed cash to pep up the operation. By 1980, a surge in demand for the American plasma enhanced CVD (PECVD) furnace - propelled by its applicability in VLSI production - required investments in the manufacturing operation of the Phoenix subsidiary. While ASM America was having trouble securing funding for its growth, comparable technological companies successfully obtained external funding by listing on the on the New York Stock Exchange.

ASM America's general manager Don Jackson, and Del Prado turned to the option of floating the American operation on the stock exchange, which quickly was expanded to include ASM as a whole. Amidst the PC revolution, American investors were more familiar with ASM's business. Enjoying healthy prospects,

25 Arthur del Prado and his lawyer Paul van den Hoek visited the 'Nederlandse Participatiemaatschappij', the only available venture capital organization in the Netherlands, and were politely dismissed. - Paul van den Hoek, 'Interview with author'. 
Del Prado and his strategic advisors in the United States, and the Netherlands, started to prepare for a public offering in the summer of 1980.

Those involved - in particular the Dutch counsels - were quite overwhelmed by the proceedings of 'going public'. ${ }^{26}$ Never before was a Dutch company directly listed on the American stock exchange. ${ }^{27}$ All was scrutinized to pave the way for a successful listing, and this happened below the radar for most of the company's employees. Aside from Jackson, a select few, who were granted options in ASM's stock, were aware of the approaching listing. ${ }^{28}$ Because Del Prado owned a large majority of the stock, he was in charge of the whole procedure.

On May 12, 1981, ASM International was listed on the NASDAQ, the American stock exchange for technological stocks. Around 1 million common shares changed owners for 15 dollars per share, valuing the total company at a stunning 85 million dollars. ${ }^{29}$ Capitalizing on the momentum for PC related stock in the United States, ASM got launched into the spotlight of customers, competitors, investors, and authorities. ${ }^{30}$

The initial public offering changed ASM's reality profoundly. Things got real. The wild and impetuous days were over. The listing required the company to comply with American regulations for corporate governance in order to safeguard the shareholders' and other investors' investments in the company. Although

26 Bob Moya, 'Interview with author', Richard Bowers, 'Interview with author', Don Jackson, 'Interview with author', Paul van den Hoek, 'Interview with author', and Nico Nobel, 'Interview with author'.

27 Companies like Philips enjoyed an additional listing on the New York Stock Exchange, next to their initial listing in Amsterdam.

28 This involved Martin van Beest, Richard Fierkens, Patrick Lam, Don Jackson, and some options for ASM America managers. - ; E.F. Hutton \& Company Inc, and Dean Witter Reynolds Inc, 'Preliminary Prospectus; Advanced Semiconductor Materials International N.V.' (17-3-1981) Archive Arthur del Prado - IPO file.

29 Of those, 750,000 were new shares sold by the company for cash. The others were sold by Del Prado and Richard Fierkens (founder and manager of ASM Fico). Total outstanding common shares after the IPO was 5,65 million. - Richard W. Bower, Advanced Semiconductor Materials N.V.: Forms S-1 registration Statement Effective May 12, 1981, closing date May 19, 1981 (19-5-1981) Archive Arthur del Prado - IPO file; E.F. Hutton \& Company Inc, and Dean Witter Reynolds Inc, 'Preliminary Prospectus; Advanced Semiconductor Materials International N.V.' (17-3-1981) Archive Arthur del Prado - IPO file.

30 The coincidence of the IPO with the annual Semicon West Exhibition in San Mateo stimulated the stir even more. At home, in the Netherlands, Del Prado and his firm in Bilthoven suddenly received more appreciation; it was the first Dutch firm listed on the NASDAQ. - Robertson, Colman \& Stephens, Shearson/American Express Inc., and Dean Witter Reynolds Inc, 'Prospectus; Advanced Semiconductor Materials International N.V.' (15-9-1983) Archive Arthur del Prado - IPO file, p. 5. 
these regulations were not yet as strict as today, they affected the company tremendously.

The company got renamed Advanced Semiconductor Materials International (ASMI); the 'international' denoting the holding company, located in Bilthoven, overseeing and controlling the range of global ASM operations. The manufacturing, development and sales activities in Bilthoven became a new business unit called ASM Europe. ASM Europe oversaw all the European activities for wafer processing equipment, thus also the sales offices in France, the United Kingdom, and Germany.

The IPO made ASM International a public limited company, which required - according to the American corporate federal law - the establishment of a non-executive board. Such a board corresponded to a Supervisory Board in the Netherlands, in which non-executive board members had to protect the interests of the shareholders. Taken by surprise by the requirement of a Supervisory Board, Del Prado asked his two most trusted advisors in corporate legal affairs. Paul van den Hoek, his legal trustee since the Topsøe dispute in 1967 and an experienced Supervisory Board member, became chairman of the Supervisory Board. Nico Nobel, Del Prado's tax counselor since the conversion of ASM from a one-manbusiness into a company in 1968, became the second board member (cf. Business I).

Unlike the role of today's Supervisory Board, the supervision provided by this Board was rather modest. Del Prado, Nobel, and Van den Hoek were professionally well acquainted, while Del Prado performed several roles at the same time, being ASM's founder, CEO, and majority shareholder. Moreover, the two Board members were not familiar with the products and technology ASM was involved in, or about to engage. Foremost, they ensured compliance with corporate regulations with regard to reporting and procedures in an amicable atmosphere. As the company was flourishing, no concerns prevailed with regard to performance and structure.

Del Prado released his Machiavellian talent in scavenging for funds, without losing control over the company's affairs. In the early 1980s, this involved the offering of shares on the stock exchange, attracting investors for limited partnerships, securing bank loans, and accessing subsidies in the Netherlands. In this process, ASM got entangled in a new web of stakeholders: investors who expected returns, guarantees, and justifications. This concerned the public accounts of business decisions through press releases, quarterly reports, the annual report, and the annual general meeting.

At this point, Del Prado still owned around 69 percent of the outstanding shares of ASM. Although he was courteous and aware of his obligations vis-àvis the other share- and stakeholders, it was his clear objective to hold the reins tightly. ASM continued to be his company. 


\section{Harnessing cash for growth}

In the months after the listing, Del Prado's bravura and virtù ensured that the company got most out of these fortunate times indeed. Some opportunities had been burning in Del Prado's pocket, others' reached him after the media attention surrounding the public offering. Del Prado and ASM now represented money and success, and suddenly many people knew where to find the entrepreneur. With the proceeds of the listing, Del Prado was able to strengthen his subsidiaries and acquire other inventions offered by struggling conglomerates. ${ }^{31}$

Specifically, ASM engaged three new technological endeavors. In June 1981 alone - one month after the listing - Del Prado proceeded with the acquisition of aluminum CVD, the acquisition of an American operation in die bonding technology, and he considered the procurement of advanced plasma etching technology. Through these new innovations, ASM might be able to address a bigger portion of the growing market for semiconductor equipment.

Additionally, the replenished cash reserves were employed in support of existing operations. This involved the strengthening of the Hong Kong and American activities. In June, ASM Asia acquired a local plating company. One month later, ASM Assembly Automation started a project for the development of ASM's first fully automated wire bonder.

On the other side of the Pacific Ocean, the proceeds of the listing alleviated growing pains of ASM America. The success of the plasma CVD technology, in the United States and also abroad in Japan, was almost too much for the Phoenix operation. The financial and technological momentum enjoyed by ASM allowed Del Prado to establish a subsidiary in Japan. This new operation relieved ASM America and offered ASM a presence in the rapidly growing Japanese market. In merely a year, all the funds of the public offering were leveraged into new opportunities, most technological and some operational.

\section{Exploring new markets: Aluminum CVD}

The first market which ASM engaged immediately after the public offering was the market for metallization deposition techniques. This was aluminum CVD, acquired from Standard Telephone Laboratories, a subsidiary of ITT in the United Kingdom (discussed in detail in Chapter 10). The process was intended to be used for the growth of thin films of aluminum, creating the electrical interconnections between a chip's components (e.g. transistors, diodes, resistors).

Aluminum CVD bore the promise of replacing existing metallization techniques, such as sputtering. This market for metallization equipment totaled

31 One part of the IPO's proceedings was used to redeem loans at the local American bank and for the settlement with Tylan. - E.F. Hutton \& Company Inc, and Dean Witter Reynolds Inc, 'Preliminary Prospectus; Advanced Semiconductor Materials International N.V.' (17-3-1981) Archive Arthur del Prado - IPO file. 
165 million dollars worldwide in 1980, compared to the 70 million dollars of CVD. ${ }^{32}$ By commercializing this already well-developed invention, ASM would be able to penetrate the vast market for metallization processes, in which it had not been present at all yet. It could be a game-changer for ASM and the industry.

The acquired technology fitted well with ASM's existing portfolio of horizontal CVD furnaces. The engineers of ASM Europe familiarized and commercialized the aluminum CVD process. This process would take much longer and cost a lot more than originally expected. But at the time of the acquisition hopes were high that ASM got something for merely nothing.

\section{Exploring new markets: Die bonding}

In June 1981, just one month after the IPO, ASM engaged a second new market and technology by acquiring Elmont International located in Chandler, Arizona (near Phoenix). ${ }^{33}$ It was a start-up venture and a subsidiary of a Swiss company. Elmont International employed 19 employees. ${ }^{34}$ In its 1,5 year of existence, the Arizonan operation had not sold anything yet. Through the acquisition, ASM could speed things up in Hong Kong. ASM acquired the company by offering 50.000 additional shares of its stock, after which it was renamed ASM Die Bonding. ${ }^{35}$

Elmont International had developed automatic die bonding and die attach equipment, which complemented the ambitions of ASM Assembly Automation. Die bonding and attach tools take a chip - dubbed a 'die' - from a wafer and attaches it to a lead-frame. In successive steps, wires were bonded between the die and the lead-frame, after which it was be encapsulated. To automatically pick up and place the die upon the lead-frame, die bonding equipment relied upon the same capabilities, which ASM Assembly Automation yet lacked for its wire bonding tools. Hence the acquisition of Elmont International offered ASM access to this technology, while it also expanded ASM's presence in the market of die bonding equipment.

The newly acquired operation had a major asset in the technology called a 'pattern recognition system'. ${ }^{36}$ In order to automatically pick-up a die and bond

32 Dataquest, 'Dataquest worldwide equipment history', Dataquest SEMS Markets and Technology (November 1986), p. 2.

33 Almost similar to the acquisition of ComputerVision, this acquisition was accompanied with legal disputes among the former owners of Elmont International, into which ASM got dragged. - Elmont, 'Letter to ASM N.V., Mr. Del Prado' (15-6-1981) Archive Arthur del Prado - Elmont file.

34 Primarily, Elmont International relied on the knowledge of a Suisse engineer working at the parent company, Dieter Enderlein.

35 In addition to those offered during the IPO.

36 Elmont International, Business Plan 1981 (April 1981) Archive Arthur del Prado - Elmont file. 
it on the lead-frame, the machine had to recognize the relative positions of the die, the lead-frame and the pick-up tool. Software had to interpret video images from a camera mounted above the chip, and successively coordinate and control the bonding motions in accordance to this information. In our current world with digital photography permeating every aspect of our daily life, it is hard to appreciate the complexity and challenges posed by digital imaging technology in 1981. But this technology was the key for competing in assembly technologies. In an industry magazine, Semiconductor International, this was elucidated:

'Pattern recognition is bringing complete automation to semiconductor assembly operations. Most so called automatic assembly equipment still requires operator alignment. For example, an automatic wire bonder uses a program of bonding pad locations to complete the bonding sequence, but this program is valid only if the precise location of the die is known, a function that is performance by manual alignment. Patter recognition, on the other hand, performs the alignment step without operator aid ... Thus pattern recognition achieves operator-free bonding from one device to the next. ${ }^{37}$

The technology increased productivity, and reduced human interference. Automatic alignment decreased alignment time from the 2-5 seconds range to a mere 0.5 seconds. A massive gain, for which chip assemblers would be ready to pay.

Del Prado was eager to get his hands on this commercially viable technology. As Del Prado explained in an article in Electronic News:

'We think it will be a synergistic fit. We were considering developing our own pattern recognition system. Now we will be able to round out our back-end equipment and automate all of these systems, from die bonding to final encapsulation by 1983. ${ }^{38}$

Immediately after formalizing the acquisition of ASM Die Bonding, Del Prado send a telex to Patrick Lam:

'This is to inform you that we formally signed up Elmont yesterday ... We still have to keep the info confidential until a public announcement will be made early July. You can start planning to integrate the Elmont

37 Pieter S. Burggraaf, 'Pattern Recognition on Bonders and Probers', Semiconductor International (February 1981) Archive Arthur del Prado - Elmont file.

38 Electronic News, author unknown, 'Advanced Semicon Set To Purchase Elmont Int'l', Electronic News (13-7-1981) Archive Arthur del Prado - Elmont file. 
P.R. system in the bonder a.s.a.p. At same time, we can start planning to sell the units after early July.' ${ }^{39}$

If transferred to ASM Assembly Automation, the American pattern recognition system formed an important asset for Patrick Lam's ambition to penetrate the matured market for automated wire bonding tools. It would have saved ASM from investing time and money in the development of this technology, and as such accelerate the commercialization of its automated wire bonder.

Yet, the acquired technology from ASM Die Bonding soon fell into oblivion. Apart from selling a few tools in South-East Asia and the United States, the technology did not succeed in securing allegiance of the market. Moreover, the pattern recognition system proved not transferable to the wire bonding machines developed by ASM Assembly Automation. If any, the Elmont International acquisition proved that some of Del Prado's ventures did not meet expectations. Failure was also part of the game. ASM Die Bonding would die a silent death by the mid-1980s.

\section{Exploring new markets: Plasma etching}

Almost simultaneously occurring with the previous expansions, the third opportunity concerned a chance to license a plasma etch process from the prestigious Bell Telephone Laboratories of Western Electric, commonly known as Bell Labs. ${ }^{40}$ At Semicon West in May 1981, Del Prado was approached on whether he would be interested in licensing an innovative plasma etch process. Although it would not result in anything substantial, ASM's flirtations with this opportunity foremost illustrate that the Dutch equipment vendor competed in its search for innovations developed by prestigious research laboratories.

The Bell Labs process was the first process capable of etching below 4 micron at an industrial scale. About 24 four inch wafers could be loaded on a hexodeshaped column. Through the ionized etch gasses, it was known as a dry etch process. ${ }^{41}$ The process offered unprecedented conformity and throughput. The

39 Arthur del Prado, 'Telex to Patrick Lam, tlxno. 2294/jp' (17-6-1981) Archive Arthur del Prado - ASM Asia file.

40 Western Electric, 'Technical Information Agreement between Western Electric Company, Incorporated and Advanced Semiconductor Materials International, NV., effective as of June 1, 1981' (1-6-1981) Archive Arthur del Prado - Ion Implant box; Reactive ion etcher file; Western Electric, 'Patent License Agreement between Western Electric Company Incorporated and Advanced Semiconductor Materials International, N.V., effective as of June 1, 1981' (1-61981) Archive Arthur del Prado - Ion Implant box; Reactive ion etcher file.

${ }_{41}$ By the early eighties, multiple etch processes could no longer adequately etch the thinnest materials. Due to miniaturization and increased complexity, the existing wet etch processes did not remove all ruminative materials, a concern that applied in particular to the etching of 
technology was a winner and thoroughly developed by Bell Labs. Moreover, it would offer ASM access to the global market for etch equipment of 96 million dollars in $1980 .{ }^{42}$

Bell Labs offered this valuable technology to ASM not out of charity, but out of resentment. ${ }^{43}$ ASM's major competitor, Applied Materials, had outwitted the prestigious laboratory. ${ }^{44}$ After years of experimenting and developing the process, Bell Labs' engineers reached out to experienced equipment manufacturers to build on demand a single fully functional system. ${ }^{45}$ To this purpose, Applied Materials had been approached. ${ }^{46}$

Applied Materials' bold marketing manager, Bob Graham, seized the window of opportunity. Before the license agreement got concluded, he convinced the Bell Labs engineers to capitalize on their process knowledge. ${ }^{47}$ In contrast to the big and anonymous Western Electric Bell Labs, the engineers could gain personal

aluminum structures - Dataquest, 'SEMS Markets and Technology: Dry etching' (November 1986) p. 11.

42 Dataquest, 'Dataquest world wide equipment history', Dataquest SEMS Markets and Technology (November 1986), p. 2.

43 ASM America, Dick Rosler, 'Confidential Memo: Visit to Dr. A.C. (Curt) Adams at BTL (Murray Hill) on September 29th to investigate their plasma etcher' (1-10-1981) Archive Arthur del Prado - Ion Implant box; Reactive ion etcher file.

$44 \quad$ As Rosler reported to ASM's management: 'While negotiating a license agreement with AMT [Applied Materials Technology] they [Bell Labs] bought and received two systems from them. Since breakoff of discussions with AMT, they plan no further etcher purchases and probably no other equipment from them, with a lawsuit likely.'- ASM America, Dick Rosler, 'Confidential Memo: Visit to Dr. A.C. (Curt) Adams at BTL (Murray Hill) on September 29th to investgate their plasma etcher' (1-10-1981) Archive Arthur del Prado - Ion Implant box; Reactive ion etcher file.

45 Bell Telephone Laboratories, Dan Maydan, 'US 4,298,443 High Capacity Etching Apparatus and Method' (filed 20-12-1979; published 3-11-1981) Archive Arthur del Prado - Ion Implant box; Reactive ion etcher file.

46 These first tools enabled the Bell Lab engineers Dr. Dan Maydan, David Wang, (and Sansi Somekh), to publicly announce their achievements in the spring of 1981 - Dan Maydan, David Wang, 'Reactive Sputter Etching and its Applications', Solid State Technology (May 1981) pp. 121-125; and David Wang, Dan Maydan, H.J. Levinstein, 'Reactive Sputtering Etching and Its Applications', Solid State Technology (August 1980) p. 122.

47 'Bob Graham, then VP of Marketing at Applied, once told me of his epiphany while visiting Bell Labs. Dan Maydan showed off his new etcher to Bob, who mistook it as a modified version of the AME 7600. Bob returned to Applied convinced that batch etching was the way to go and that they must bring Maydan and his team out to Applied. Dan brought along David Wang and Sass Somekh. David had tremendous trouble with oxide etching, always winding up with too much detritus and grass a kind of growth that looked like grass. He eventually invented a new process that included an organic covering which eliminated most of these problems.' - VLSI Research, Dan Hutchison, 'Hall of Fame: Applied Materials AME-8100 Batch Etcher'. Chipshistory.org (Date unknown). 
recognition - in stature and financially - by joining the smaller and commercial Applied Materials.

Bell Labs lost its critical process engineers for the plasma etch process, the technology itself got transferred to an equipment supplier, and the company's internal development effort interrupted. So far only an aluminum etch process was fully developed. Others etch processes, such as polysilicon and in particular silicon oxide, had not been perfected. The plasma etch engineers took their knowledge of these immature but very valuable processes with them. Needless to say, Bell Labs was infuriated. Hence its determination to retaliate.

Bell Labs management decided to license the hexagon batch plasma etch technology to other equipment vendors. First, by securing their supply of equipment, this allowed them to continue development on other etch processes. Second, by licensing the technology to other parties, Applied Materials would get severe competition. Bell Labs would not make it easy on Applied Materials.

By the time ASM conducted due diligence of the technology, Bell Labs already licensed the technology to others. ${ }^{48}$ ASM considered extensively whether it wanted to persevere in this commercial opportunity. In a very limited period of time, ASM would have to harness the licensed technology to compete with the likes of Applied Materials, IPC and Plasmatherm. ASM would have to invest in a dedicated R\&D team of experts in etch processes, engineering, and marketing. Furthermore, it was expected that the competition would present their tools by Semicon West in May 1982. Time was running out.

Regarding the circumstances, and in particular with regard to the terms of the licensing, Del Prado had his doubts about the opportunity of acquiring plasma etching. He urged his American management:

'We told [them] that we wanted to deal with w.e. [Western Electric] direct on techn. but that he should not penalize us for it by putting this heavy techn. fine on it ... I don't buy the eternal argument about the government ${ }^{49}$, neither the fact that others pay up so we should. If parties are creative, we can find constructions of contract ... I wonder whether you left enough room to negotiate this point sensibly. ... If you follow yr

48 ASM America, Dick Rosler, 'Confidential Memo: Visit to Dr. A.C. (Curt) Adams at BTL (Murray Hill) on September 29th to investigate their plasma etcher' (1-10-1981) Archive Arthur del Prado - Ion Implant box; Reactive ion etcher file.

49 Western Electric in the late seventies and early eighties was forced to divest activities and technologies by the American authorities, due to the monopolization by subsidiary AT\&T. The licensing of the plasma etching was done under the pretext of this governmentally forced anti-monopolization divestments. 
reasoning ... you may decide to run for the hills before the water rises too high. ... Make sure we have competitive info available next week. ${ }^{50}$

The option offered by Bell Labs was not to Del Prado's liking. The costs were too high, and the context of the deal was not attractive. ${ }^{51}$

ASM refrained from entering the etching business. The race was run. Applied Materials had a head-start already. ${ }^{52}$ Some other equipment vendors could not withstand the temptation and took the offer of Bell Labs, such as LFE and Technics. Nevertheless, Applied Materials became market leader in plasma etch technology. The market would grow immensely over the next years, constituting 300 million dollars of the total 502 million dollars of etch equipment in 1985, propelling Applied Materials to new heights.

The story about the plasma etcher also exposed similar opportunistic methods of ASM's competitors. They too acquired innovations without having to internalize an accompanying inventive capacity. The whole affair illustrated that Del Prado was not willing to procure all available inventions, no matter how commercially viable. The invention should offer ASM some competitive lead over the competition. Given the circumstances in the fall of 1981 and early 1982, commercializing plasma etch technology would have diluted the resources for his other ongoing developments.

\section{Consolidating existing operations}

The various other operations of ASM also clamored for more money. Apart from the acquisition of new technologies, Del Prado deployed the proceeds of the

50 Arthur del Prado, 'Telex to Don Jackson/Max Wieringa, telexnr: 128/jm' (15-10-1981) Archive Arthur del Prado - Ion Implant box; Reactive ion etcher file.

51 He rather looked into alternative ways of accessing plasma etch technology An alternative was offered by another chip manufacturer called Synertek, a Honeywell subsidiary, which resembled the Bell Labs tool, but could only etch aluminum. Though on much more favorable terms, this deal was rejected. - ASM America, Don Jackson, 'Memo to Arthur del Prado: BBTL RIE compared to Synertek' (November 1981) Archive Arthur del Prado - Ion Implant box; Reactive ion etcher file.; Synertek, 'Proposal to ASM' (date unknown) Archive Arthur del Prado - Ion Implant box; Reactive ion etcher file. Later, Del Prado tried - in vain - to interest Philips for a collaboration into plasma etching within the scope of new research efforts of the European Economic Community, the so-called Microelectronics Program (mind Innovation III).

52 This realization was inescapable by another article of Maydan and Wang in Solid State Technology in December 1981, this time on behalf of their new employer Applied Materials. In the article, the authors announced that they had mastered the difficult process of etching silicon oxides, completing their ability to etch all major semiconductor materials. - David Benzing, David Wang, Dan Maydan, 'Ion-Assisted Plasma Etching of Silicon-Oxides in a Multifacet System', Solid State Technology (December 1981), pp. 71-75. 
listing in support of his existing operations. Immediately after the listing, this involved the Hong Kong operation. In June 1981, ASM Asia acquired a local plating company, which supported the ASM operation in the production of leadframes. It was renamed ASM Assembly Materials. By means of the involved tools and engineers, the operation ran by Patrick Lam enhanced its capabilities in stamping the lead-frames, enabling it to further localize this activity instead of relying upon the ASM Fico products from the Netherlands.

But, Del Prado and Lam wanted to do more in Hong Kong. As explained above, ASM just had acquired a wire bonder company, renamed ASM Assembly Automation. To compete, it had to develop an automated wire bonder, which required advanced motion control, robust software, and video pattern recognition. To make up for its lack of knowledge regarding these technical capabilities, ASM Assembly Automation needed cash and technology.

In July 1981, ASM Assembly Automation started a project to develop its first fully automatic wire bonder, temporarily code-named AB-1000. If successful, the AB1000 would get ASM into the market for wire bonding technologies, a market dominated by American, Japanese, and Swiss companies. Patrick Lam put L.K. Chan in charge of the endeavor.

Initially, the project elaborated on extensive market analysis and sourcing of components and suppliers. Crucial parts were required to get the machine working, such as wire bond heads, servo-drivers, sensors, electronics and computer systems, and software. Most importantly, a pattern recognition system was needed, after the one from ASM Die Bonding did not suffice. ${ }^{53}$ By the start of 1982, the Hong Kong engineers began to design and develop the hardware in conjunction with the pattern recognition system. ${ }^{54}$ Working overtime, the engineering team was determined to make the system successful. ${ }^{55}$

53 'Several different methods for pattern recognition in wire bonders were considered and in general we felt that it is possible to develop an algorithm utilizing primarily the P.R. system used in the Elmont die bonder. We believe it would be the quickest way to turn out a P.R. system for wire bonders. However, it still requires two full time engineers (one software and one hardware) to work for six to eight months on this project.'- ASM Assembly Automation, L.K. Chan, and Heico Frima, 'Meeting between Elmont \& ASM A.A.' (10, 13,14-9-1981) Archive Arthur del Prado - Elmont file.

54 The whole AB1000 was developed rather from the start by the Hong Kong engineers. Beyond the PRS, they tended to do everything by themselves, not willing to rely upon the work done by ASM Die Bonding. This involved designing the electronics hardware, for instance. The Dutch engineer in the development team in Hong Kong - ASM Assembly Automation, Heico Frima, 'Letter to Arthur del Prado' (14-1-1982) Archive Arthur del Prado - ASM Assembly Automation file.

55 The sole Dutchman, Heico Frima (see Chapter 8), was rather struck by their working attitude, business culture, and probably the level of expertise present. As he complained to Del Prado: 'at my suggestion to make a thorough planning, I learned that planning is strictly taboo at A.S.M. A.A. because management favors the "pressure cooker" management technique. 
The automated wire bonding business enabled ASM to effectively participate in the whole range of back-end technologies: from die bonding and wire bonding to encapsulation. Having the Hong Kong operation take care of a majority of those activities created a competitive advantage. The operation led by Patrick Lam enjoyed proximity to a wide customer-base of light-emitting-diode (LED) assembly and packaging factories in the region. Bonders for LEDs merely had to bond two aluminum wires instead of tens of golden ones for computer chips, a requirement with which ASM Assembly Automation's products could comply. Moreover, Lam's operations could offer their equipment much cheaper compared to the incumbent suppliers of bonding equipment, due to the low wages in Hong Kong and the region.

As ASM rapidly expanded, it was rather easy to forget about the company's existing operations, in this respect the one in the United States. During the listing on the stock exchange, ASM America played a pivotal role. The American operation had contacts among the most renowned American and Japanese chip manufacturers through its successful plasma CVD technology. The international presence of ASM, and its strong product portfolio, largely defined the appreciation by investors. The American operation constituted the immediate reference for the American investors, exemplified by its touring president Don Jackson. The scintillating listing of ASM blinded growing pains of the Phoenix operation (figure 22).

The most salient symptom of these growing pains was the operation's depleted cash reserve. In particular for the production and development of ASM's complex machines, a cash reserve was vital. It covered the procurement of materials during the manufacturing of products, the payment of salaries, and the funding for ongoing R\&D efforts. If managed well, and in the case of organic growth, payments of previous orders funded present orders. Bank loans merely helped to remedy immediate shortages.

This management technique sets final dates for projects that in the opinion of management cannot be met. People are then pressed to work very hard in order to still finish in time. I noticed that the people I had to work with got very nervous from this and made many many over hours. They could not be talked with at any reasonable level of intelligence during this period ... I did not want to enter into the pressure cooker heated by Pat myself and so also $t$ become a victim of nervous breakdowns.... We concluded that A.S.M. A.A. engineers do good work and know what they are talking about in most cases. However, management should take care not to want to make small profits.' - Ibid. 


\section{Figure 22}

Graph of revenues ASM America, 1976-1983

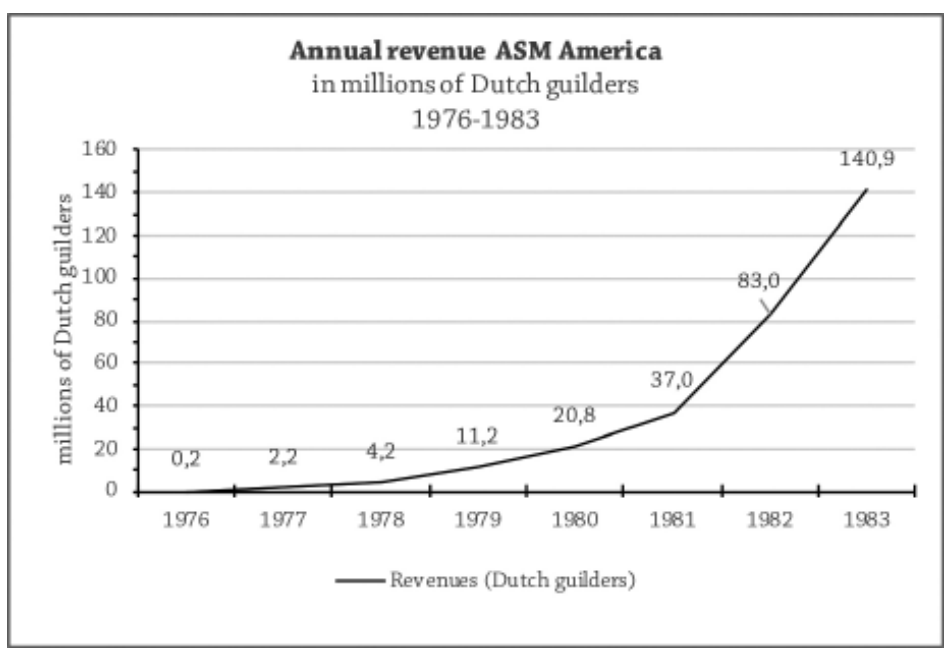

But in the case of ASM America, the high demand for the plasma deposition tools, and the subsequent high inventory, had exhausted these lines of credit already. As ASM America's management reported to Del Prado:

'Continuing losses and bad payment terms from customers and principals, while not able to reduce inventories rapidly, have caused very severe cash flow problems in 1982. The impossibility to find additional finance capacity at U.S. banks resulted in heavy cash inputs from ASMI. In November the most dramatic cash injection took place in order to save ASMA's capability to ship because suppliers have started cutting off their deliveries due to nonpayment by ASMA. ${ }^{56}$

The cash situation at ASM America in fact threatened the functioning of the whole organization. Del Prado warned the American management:

'the general state of ASM America is still a matter of grave concern. This is particularly true since the results of both 1981 and 1982 have serious compounding negative effects on the overall cash flow situation of ASMI,

56 ASM America, Max Wieringa, 'Memorandum: overview 1982' (Spring 1983) Archive Arthur del Prado-ASM America memo's '77-'83. 
which, if not corrected soon, will put forward heavy constraints on our ability for growth in many of our product areas elsewhere. ${ }^{57}$

The enormous demand for plasma deposition equipment caused ASM International to pledge its precious cash reserves to ASM America, instead of leveraging them through investment in new innovations.

ASM America had not been able to cope with the huge demand due to an absent and overburdened management, and internal strife after the introduction of the plasma deposition machine in 1980. The original pioneers of ASM America - the managers who had been involved from the beginning - had trouble finding their way in the company they had co-founded. ${ }^{58}$ Being a group of highly ambitious, hard-working but also strong-willed engineers, the lack of leadership had a centrifugal effect on the management of ASM America. All the American managers got too much on their plate to effectively coordinate and align their activities.

The manager in charge of the American operation, Don Jackson, was completely taken up by other pressing issues. One of these was the Tylan litigation, a supplier of mass flow controllers, gas systems, and CVD systems (cf. Chapter 6). Another issue was the preparation of ASM's public offering. Jackson was distracted from the daily management, which the American operation desperately needed.

To re-establish governance, Del Prado hired a 36-year-old Dutchman, Max Wieringa. In the capacity of vice-president of ASM America, this fellow countryman was expected to inform Del Prado more adequately, and, as an outsider, to thwart the management turmoil. Unfortunately, Wieringa got stuck in the internal American affairs. His American colleagues regarded him as a foreign intruder, keeping him from making his mark.

Next to Wieringa, marketing manager Dale Stoddard tried to fill in the ongoing void left by Jackson, and he became the operational focal point for the rollout of the plasma deposition business. However, lacking clear authority within the organization, he also failed to improve the situation. Without proper management, ASM America's internal operation got clogged by a dysfunctional

57 ASM, Arthur del Prado, 'Memorandum to Max Wieringa, ref: 49/83 DP/jm' (8-3-1983) Archive Arthur del Prado-ASM America Memo’s 1977-1983.

58 These disagreements concerned Dean Terry, Ron Colvin, Don Jackson, and Dale Stoddard. The latter was responsible for the sales force and the operation, while Ron Colvin tried to manage the manufacturing and engineering expansion. Engle and Rosler stayed out of the turmoil, as they were fully occupied with processing demo wafers, and answering customer's requests with regard to the plasma processes. The big leader, Del Prado could not help either. He had to divide his time and attention among all his operations. 
engineering department, accumulation of inventory, and understaffing of the manufacturing group. ${ }^{59}$

Profit margins on ASM America's activities were far too low. High variation of components for relatively few machines caused excessive inventories. Inventory piled up, which diminished the company's clout. ${ }^{60}$ The inventory problem was partially the result of a dysfunctional engineering department ${ }^{61}$ This group served as lubricate between all the company's activities. The department effectuated new orders, customer service, manufacturing, and new technologies offered by the $R \& D$ department. The engineering group had to design and utilize as many as possible common components in the PECVD reactors to prevent undue procurement of inventory and, subsequently, a deterioration of profits. Its dysfunctionality hampered ASM America's ability to serve its customers effectively, and prevented a more economical usage of components.

Furthermore, the bad cash situation caused an understaffing of the manufacturing department. ${ }^{62}$ By the fall of 1982, ASM America employed 300 employees, of which 146 in manufacturing, 50 in engineering, about 85 in sales and marketing, 20 in $R \& D$, and the rest in supporting roles. There was too much work for too few employees. The company tried to overcome the shortage by making manufacturing more effective with new tools, manufacturing methods, and better coordination with the engineering department. ${ }^{63}$

Since ASM America played a pivotal role in the company, Del Prado had to inject cash reserves from time to time. If the operation could no longer accommodate the demands from its customers in the United States, and in Japan, ASM's reputation would be ruined. Wieringa, Jackson, and Stoddard were put to the task to address the deficiencies of the operation. To remedy the situation in the short term, Del Prado replenished ASM America's cash reserves; burning his precious proceedings of the IPO, instead of investing them.

\section{The establishment of ASM Japan}

ASM America's stable sales in Japan, and the organizational problems it faced in Phoenix, paved the way for the next move: starting a Japanese operation. In the early eighties, the Japanese market grew rapidly and brought water to the mouth of many Western equipment manufacturers (figure 23). However, access to the Japanese market was restricted. It was very hard to enter this market as a foreign

\footnotetext{
59 ASM America, Max Wieringa, 'Overview 1982' (Spring 1983) Archive Arthur del Prado - ASM America Memo's 1977-1983.

60 Ibid.

61 Ibid.

62 Ibid.

63 Ibid.
} 
company. Via Marubeni Hytech, ASM America sold plasma and Low Temperature Oxide deposition systems in Japan (cf. Chapter 6 and 8). ${ }^{64}$

\section{Figure 23}

Graph of revenues semiconductor industry Japan, 1975-1984

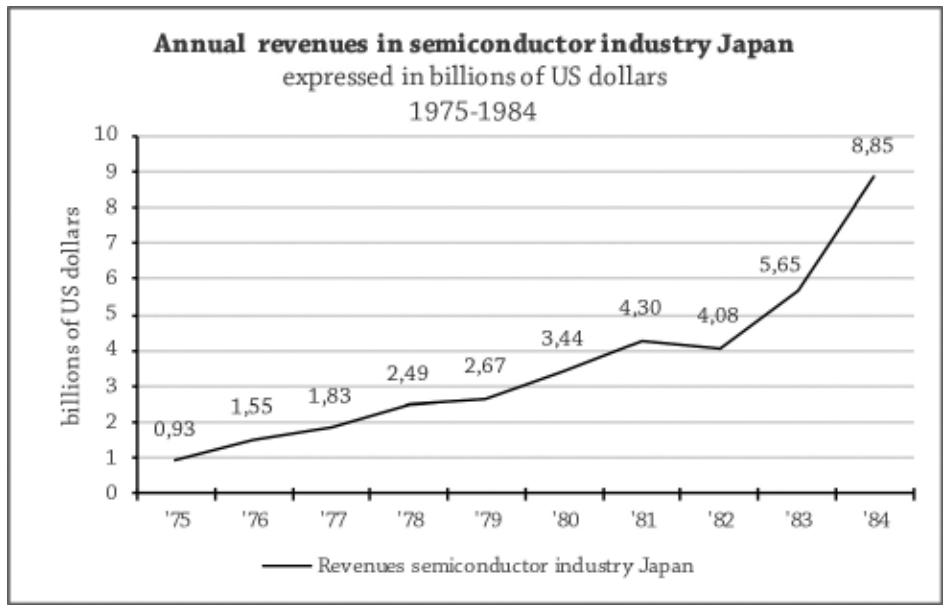

To sustain its foothold, ASM America had to improve its service to the Japanese customers. Months earlier, by April 1981, Dale Stoddard - being responsible for the Marubeni relation - had reported about the Japanese customers:

'The Japanese customers are more demanding than U.S. customers with regard to deposited film characteristics and film cosmetics. Companies like Matsushita and NEC are identifying difficulties we have not been made aware of before. Oki and TIJ are demanding much lower particle densities than the bulk of other companies. ... There is definitely a desire on the part of the Japanese customers to buy equipment locally to control the technology, obtain custom equipment more readily and stabilize and reduce costs. ${ }^{65}$

64 By August 17, 1981 Marubeni Corporation established a new wholly owned operation called Marubeni Hytech, it consisted of the Semiconductor Product Equipment Division, the Industrial Systems Division, and a part of Computer Automation Division, formerly all part of Marubeni Electronics. The specialization was meant to more adequately address these rising markets. - Marubeni Hytech, I. Kimura, 'Letter to Arthur del Prado' (25-9-1981) Archive Arthur del Prado - Marubeni file.

65 ASMA, Dale Stoddard, 'Memo to Max Wieringa: Far East Trip 3/7 - 3/27/81' (9-4-1981) Archive Arthur del Prado - ASMA 1980s file. 
A Japanese subsidiary would be a solution. Such an operation would relieve ASM America partially. It would also be in line with one of Del Prado's key business principles: establishing a presence in the proximity of the targeted market. And an Japanese business unit would also create the opportunity to offer other ASM products in Japan, beyond the ones of ASM America. ${ }^{66}$

Del Prado intended to establish a wholly-owned subsidiary first, and to invite Marubeni Hytech to participate for 30 percent afterwards, making it a jointventure. ${ }^{67}$ He already sounded out the key individuals responsible for ASM's account at Marubeni, and knew they were enthusiastic about the prospect of starting a new venture. This order of things kept Del Prado in charge of ASM's own fate.

By securing his footing in Japan first, in combination with the essential support of the critical engineers, Del Prado confronted Marubeni with a fait accompli. Whether or not, Marubeni would participate, ASM localized its supply of plasma deposition furnaces, relying upon the enthusiastic Marubeni sales force. Del Prado argued that Marubeni's participation would be most welcome to further ASM's reputation in Japan, and for removing any hesitance of the engineers responsible for the ASM account. But the Dutch entrepreneur would not let his local distributor call the shots, and play out his unfamiliarity with the Japanese market. ASM's local distributor could join the effort, or had to step aside. Del Prado entered the negotiations about the joint-venture from a position of strength.

ASM's chief executive officer announced his intent of the visit in a letter to the Marubeni manager responsible for the ASM account, Yo Miyazaki:

'During that week, I intend to take further steps towards the establishment of an ASM venture in Japan. This venture is now definitely planned for ASM to be implemented during the early part of 1982. We have decided to establish a wholly owned daughter of ASM International N.V. in Japan ... This company then will undertake a joint

66 ASM America renewed the distributor agreement with Marubeni Electronics by August 1981. Though this was never returned to ASM. - ASM America, 'Distributor Agreement between Advanced Semiconductor Materials America, Inc. and Marubeni Electronics Co. Ltd.' (1-8-1981) Archive Arthur del Prado - Marubeni file.

67 Stibbe Blaisse \& De Jong, P.C. van den Hoek, 'letter to Marubeni Hytech, Mr. Marubeni, ref: vdH/h1' (2-4-1982) Archive Arthur del Prado - Marubeni file; ASM International, 'Joint Venture Agreement Marubeni Hytech Company Limited and Advanced Semiconductor Materials International N.V., Draft 1.4.1982' (1-4-1982) Archive Arthur del Prado-Marubeni file. 
venture with a third party, presumably Marubeni Hytech to establish a microelectronics manufacturing company.' 68

In the letter, Del Prado specified the initial outlines of this operation and the employees he was looking for. Most importantly, he invited Miyazaki and his colleagues to join the deliberation about the set-up. He knew he stirred their interest to capitalize on their strong sales in plasma deposition machines. On January 18, 1982, Del Prado flew to Japan.

During his visit, Del Prado successfully convinced the core engineers and managers, who represented ASM America at Marubeni Hytech, to join his new cooperation. A small team was formed, consisting of the account manager Yo Miyazaki, marketing manager Fukumi Tomino, and financial account manager Hitoshi Miura.

A few weeks after Del Prado's visit, Tomino and Miura quit their jobs at Marubeni, and set up a very small office to prepare for the start of ASM Japan. From this temporal office, they arranged a location for the Japanese start-up. A former warehouse called tenko-Soko was converted into an assembly and customization operation in Machida on the outskirts of Tokyo. While Tomino and Miura prepared the start of the Japanese operation, Miyazaki remained working at Marubeni-Hytech in Toshima-Ku, Tokyo until the joint-venture proposal with Marubeni got finalized. ${ }^{69}$

Not surprisingly, the Marubeni Hytech management refused to play along with Del Prado's scheme. They were blindsided by his bold tactics. Instead of engaging the local manufacturing of semiconductor equipment, Marubeni Hytech's management decided to stick to their trade, literally.

On June 14, 1982, ASM Japan was officially established. It was the first subsidiary 100 percent owned by a Dutch company in Japan. Miyazaki joined as its general manager, accompanied by a few other engineers. ${ }^{70}$ Starting capital was about 20 million yen, or 210 thousand Dutch guilders. ${ }^{71}$ Responsibilities for sales, service, spare parts and stocks shifted from Marubeni to the newly established

68 ASMI, Arthur del Prado, 'Letter to Marubeni Hytech, attn. Mr. Miyazaki' (18-12-1981) Archive Arthur del Prado - Marubeni file. By that time, Applied Materials had been through a similar process as well. - Morgan, James; and Joan Hamilton, Applied Wisdom: Bad News is Good News And Other Insights That Can Help Anyone Be a Better Manager (Chandler Jordan Publishing, Los Altos, 2016) p. 110.

69 Del Prado proposed the name for the joint-venture to be ASMI-Marubeni K.K. K.K. means Kabushiki Kaisha.

70 ASMI, Arthur del Prado, 'Letter to Yo Miyazaki' (5-5-1982) Archive Arthur del Prado Marubeni file.

71 Hitoshi Miura, 'Interview with author'. 
ASM Japan. Marubeni Hytech and ASM International informed all the Japanese customers of the founding of ASM Japan and the mechanics of the transfer of responsibility from Marubeni to ASM Japan. ${ }^{72}$ Since ASM owned the technology, and had hired all the critical staff, Marubeni could only comply.

In the next months, the warehouse was prepared. On September 1, 1982, after completing the renovation, ASM Japan sent its first telex to the headquarters in Bilthoven:

'Hello, this ASM Japan, Just borne [sic].'73

As of September, as mentioned in the telex, the organizational structure of ASM Japan comprised 14 employees. Miyazaki was managing director, Tomino was assistant to the general manager and responsible for marketing. Miura was in charge of accounting. ${ }^{74}$

ASM Japan commercialized innovations supplied by the other ASM operations. Initially, the operation continued primarily to sell the American CVD products: plasma CVD and low temperature oxide. Standard tools were shipped to Machida, where they were adjusted and modified according to the Japanese customers' demands. Furthermore, plasma deposition and low temperature oxide demo tools were installed for experimentation and evaluation. ASM Japan completed ASM's presence globally.

\section{Innovation and new funding instruments: the Epsilon limited partnership}

To further ASM's growth, money was most welcome; especially if it was venture capital. In the spring of 1982, Del Prado and Jackson came across a new American funding vehicle: the 'R\&D limited partnership', which allowed private investors to exempt taxes by investing in risky $\mathrm{R} \& \mathrm{D}$ projects. The limited partnership allowed ASM to create an internal and dedicated R\&D capacity. The financial instrument formed a perfect way to foster innovation and expand ASM's business; risk resided entirely with the private investors.

Through the funding vehicle ASM was able to pay for the development of a new epitaxial reactor. Epitaxy was critical for the construction of bipolar discretes

72 ASMI, Arthur del Prado, 'Letter to Marubeni Hytech, attn. Mr. I Kimura' (30-7-1982) Archive Arthur del Prado - Marubeni file.

73 ASM Japan, Yo Miyazaki, 'Telex to Arthur del Prado' (1-9-1982) Archive Arthur del Prado ASMJ 80's; Founding and early years.

74 Other managers were Taiji Fujimori for engineering and service, and Yasuo Yamada \& Yukikazu Ueno as sales managers. - Taiji Fujimori, 'Interview with author'; Hitoshi Miura, 'Interview with author'; Yasuo Yamada, 'Interview with author'; Fukumi Tomino, 'Interview with author'. 
and integrated circuits, and thus constituted an attractive market of 19 million dollars in the United States, and 46 million dollars worldwide by 1982. Applied Materials dominated the market with its barrel reactor. ASM's epitaxy machines were not sufficiently competitive in performance and reputation compared to the Applied Materials reactor. ASM America lacked the funds to develop an innovative epitaxial furnace that deviated from Applied Materials' and ASM's own variations. The America operation absorbed all the available cash to sustain demand for its PECVD furnaces.

This proved a bitter pill in particular for ASM America's president, Don Jackson. Prior to his affiliation with ASM, he had been in charge of the advanced epitaxial production and development line at Motorola. It had been his ambition to capitalize on his intimate knowledge of epitaxial of epitaxial processes and equipment ever since. Due to the rampant need for cash of ASM America in support of the plasma CVD business, Jackson lacked the financial resources and had to postpone his ambitions.

Through the 'Epsilon Limited Partnership', ASM secured investments for the development of a new epitaxial reactor in the fall of 1982 (for extensive discussion of this funding vehicle, see Innovation II). Earlier, the set-up of the limited partnership required extensive preparations by lawyers and ASM America's management, almost matching the initial public offering in scrupulousness. ${ }^{75}$ This effort distracted Jackson once again from the daily management of ASM America. By January 1983, the project to develop a new epitaxial reactor was on its way.

The epitaxy project added to the list of new technological endeavors pursued by ASM in the first half of the 1980s. Through the R\&D Limited Partnership, ASM, once again, elaborated on the public interest for investments in electronics to realize its ambitions.

75 This involved writing a prospectus, but also a road trip organized by underwriters to convince private investors to pledge their money. - Richard Bowers, 'Interview with the author', Bob Moya, 'Interview with the author', Don Jackson, 'Interview with the author'; Dean Witter Reynolds, 'Confidential Private Placement Memorandum: Epsilon Limited Partnership, \$ 10,500,000 Limited partnership Interests' (26-10-1982) Archive Arthur del Prado - Epsilon Limited Partnership file. 


\section{Chapter 12}

\section{A surging American-Japanese rivalry, 1983-1985}

After picking fruits abroad, Del Prado revitalized his position in the Netherlands, helped by an escalating American-Japanese rivalry. The Japanese advent in manufacturing - from semiconductors to cars - formed a wake-up call for the capitalist economies (figure 24). To halt further economic stagnation, authorities and industries joined forces in the United States and Western Europe. Opportunistically yet skillfully, Del Prado anticipated and took advantage of this changing sentiment. The entrepreneur expanded ASM as much as he could, accepting the risk of overloading the company's foundations.

\section{Figure 24}

Graph of overproduction of semiconductors in Japan and United States, 1975-1984

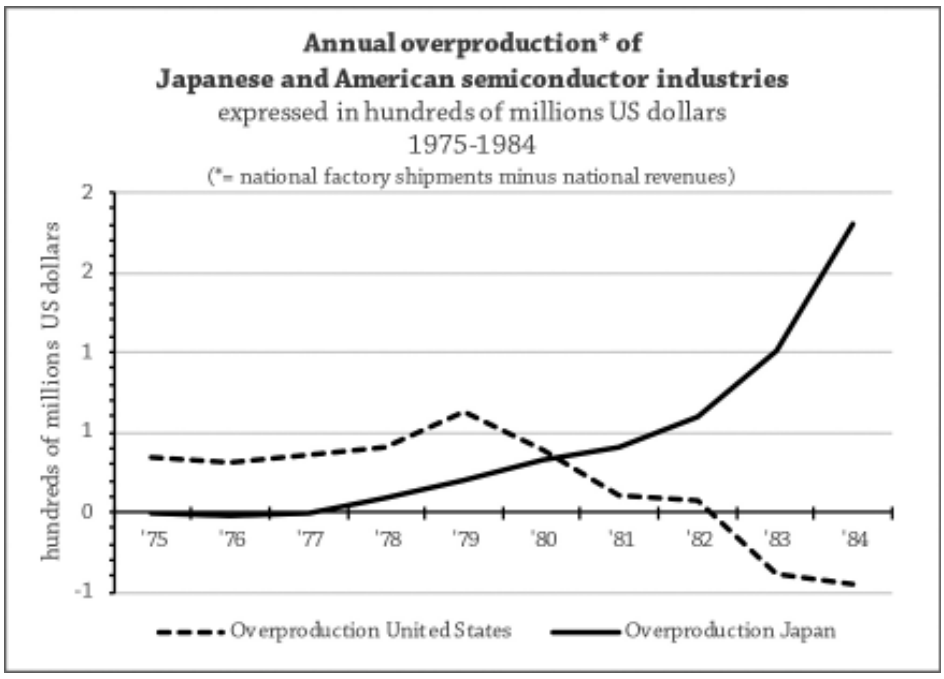

\section{Industrial context:}

\section{Escalating competition}

Throughout the early 1980s, the stagnation of economic recession resulted in new appreciations of competition and management. Interventionist, mitigating, 
and defensive policies were exchanged for neoliberalism and innovation policies. Economic policies had to support competitiveness, and leave matters to the market. This new understanding of competitiveness also changed perceptions of management.

In particular, the difficulties faced by manufacturing conglomerates enjoyed attention. Business historian Keetie Sluyterman describes how the demise of conglomerates was attributed to management principles of the sixties and seventies. ${ }^{76}$ American management thinkers criticized the ability of 'professional managers' to manage an 'unfamiliar company and run it successfully though strict application of financial controls, portfolio concepts, and market driven strategy. ${ }^{77}$ Instead, according to Sluyterman, there was a plea propagating a different management:

'To achieve long-term success, the companies needed not just controllers, market analysts, and portfolio managers, but leaders. How the new leader was going to look, the authors did not state, but they probably were thinking of a Schumpeterian entrepreneur who brings innovation by accepting risks.

... the creation of economic growth and employment depended on enterprising businessmen. Moreover, it had become evident that continuity in business was not a matter of course; even large and wellknown companies could still go under. Thus entrepreneurship was an achievement, and consequently the person behind the office and the individual style of leadership merited closer attention. ${ }^{.78}$

The first half of the 1980s was a period of economic transformation - a fluid period without clear certainties and truisms. In this confusing time, business and economic theorists found refuge in the imagination and conceptualization of an almost Messianic leader. An entrepreneur showing the way through perseverance and a keen eye on the horizon. The disintegration of conglomerates was accompanied by a reappraisal of entrepreneurs, leadership, and market oriented innovation.

76 Sluyterman, Dutch Enterprise in the Twentieth Century, p. 199.

77 R.H. Hayes and W.J. Abernathy, 'Managing our way to economic decline', Harvard Business Review (1980) pp. 67-77; quote derived from: Sluyterman, Dutch Enterprise in the Twentieth Century, p. 199.

78 Sluyterman, Dutch Enterprise in the Twentieth Century, pp. 199 and 200. 


\section{The prominence of memory chips}

During this period of economic transformation, the semiconductor industry continued to be a shining example of growth in the years of economic recession. Especially, the market for memory chips became pivotal toward the mid-1980s. The ability to store information paved the way for the PC revolution, and vice versa. In a PC more memory chips were installed compared to microprocessors, which contributed to the fact that the market for memory chips was bigger than any other semiconductor market. The global production of memory chips grew from 1,709 billion dollars in 1979 to 2,615 in 1982, and further to a staggering 6,225 billion dollars in 1984, representing, respectively, 15, 17 and 21 percent of the global semiconductor output. ${ }^{79}$

Moreover, memory chips led the semiconductor industry technology-wise. Due to the architecture, components integrated on dynamic random access memory (DRAM) chips and static random access memory (SRAM) chips could be miniaturized and produced in high volumes more easily compared to other chips. Smaller components on a computer chip meant more capacity, more storage of data. Customers were willing to pay for this. The high volume production offered economies of scale.

Consequently, memory chips served as a most prominent driver of VLSI chips. Mastering the orchestration of innovation belonging to these advanced chips, manufacturers of memory chips pioneered the shrinkage of CMOS transistors (see Intermezzo in Business I). This involved cleaner and efficient manufacturing technologies, capable of creating the smallest constructs. The ability to drive shrinkage of CMOS transistors on a chip was critical. Being able to compete in the memory market increased chances of competing in all the other markets. Memory chips were the banner-bearers of semiconductor technology and as such they would soon enjoy the particular attention of public officials.

\section{A technological race}

Throughout the eighties, advancing memory chip technology became a race among chip manufacturers, design-houses, equipment suppliers, authorities, and research institutes. ${ }^{80}$ The appreciation of the memory-chips centrality to this cause dawned gradually among policy makers and industrial leaders in the major markets. The competition in memory chips caused the European, American, and Japanese semiconductor industries to diverge from each other.

The Japanese had been the first to foster memory chips manufacturing in support of the country's ambitions in microelectronics. From the 1976 VLSI

Dataquest Industry Statistics, computershistory.org

80 Annemieke Roobeek, Een race zonder finish: de rol van de overheid in de technologiewedloop (VU Uitgeverij, Amsterdam, 1988). 
program of the Japanese Ministry of International Trade and Industry (MITI) onward, Japan invested in overcoming its lag in chip manufacturing. This was at the expense of the American and European industries. In a time of general economic recession since the fall of 1981, the Japanese rise was watched increasingly with more suspicion by the West.

By 1983, it became clear that Japan not only imitated American chip technology, but improved the production techniques and operations. American chip manufacturers had underestimated the Japanese determination, and their purported innocent curiousness in the latest American technologies. Led by the Semiconductor Industry Association (SIA), the American chip industry tried to put a check on the Japanese advent in two ways. ${ }^{81}$

The first response was increasing productivity. In order to sustain market share, American companies - and their Japanese counterparts - ramped up production volumes of memory chips. To counteract the influx of cheaper Japanese chips, American factories increased their output. This involved in particular improving yield, the percentage of working chips at the end of a fabrication process. Chip producers improved their operations by means of adding more automation, cleaner manufacturing methods, and thus new equipment. This required additional product lines and thus new investments in equipment.

Secondly, SIA secured political support from the American Congress. ${ }^{82}$ It mobilized the American authorities to counter the purported unfair competition practices of Japan. By 1982, Japan produced more than it consumed, and - while safeguarding its internal market against foreign chips - exported these to the United States. SIA dubbed it dumping, while so far, it had been the American chip industry which flooded the Japanese and European markets. The table got turned. Moreover, SIA tried to secure political support to strengthen the American industrial versatility, in imitation the Japanese cohesion among financial, governmental, and industrial organizations. ${ }^{83}$

By politicizing the rivalry, the debate became more nationalistic. Chip companies' embedment in national industries became virtually more prominent in the public debate about the future of national chip industries. Western European chip manufacturers and their respective national authorities followed suit, as is detailed in Innovation III.

81 Douglas Irwin, 'Trade Politics and the Semiconductor Industry', in: Anne Krueger (ed.), The Political Economy of American Trade Politics (University of Chicago Press, Chicago, 1996) pp. 11-72, pp. 30-35;

82 Yoichiro Sato, 'The Industrial Policy Debate Minus Public Relations: Depoliticizing the History of Semiconductor Industry Development in Japan', Japan Studies Review 5 (2001), pp. 61-80.

83 Jon B. Thornberry, 'Competition and Cooperation: A Comparative Analysis of SEMATECH and the VLSI Research Project', Enterprise \& Society 3 (December 2002) pp. 657-686. 
The new political and industrial awareness of the role of memory chips, in combination with new perceptions about competitiveness and industrial leadership, resulted in a surge in memory technology. This drove revenues in semiconductor equipment to new heights. And it created new sources of money in support of innovation.

\section{Corporate course: Reaping fruits}

The escalating rivalry in memory chips between the Japanese and American chip industries blew more wind into ASM's sails. The company's plasma deposition furnaces were in demand on both sides - in Japan and in the West. However, ASM had to be careful that growth became not too riotous, threatening the ability to maneuver and manage. It was up to Del Prado to navigate his company through these treacherous seas.

One route was to influence the industry's dynamics, together with the authorities. ASM's ability to influence the American-Japanese rivalry was limited. The operations in Japan and the United States were too small. But ASM did carry weight with the Dutch authorities. To that purpose, Del Prado presented ASM as the sole credible representative for semiconductor equipment industry in the Netherlands and even in Western Europe, as is described more extensively in Innovation III. From 1982, Del Prado managed to obtain a position at the heart of the Dutch and European semiconductor industry.

Through the extraordinary listing on the American NASDAQ and the successive media attention in national media, Del Prado secured a hearing at the Dutch Ministry of Economic Affairs. The equipment vendor and its entrepreneurial leader seemed to fit perfectly in the new plans of the public officials. ASM was a successful example of new innovation management and entrepreneurial leadership. Moreover, the company had been active in the promising and potentially strategic microelectronics industry. ASM offered the public officials the chance to assess technological and industrial developments without having to rely on the dominant information of 'Big Philips.' The Ministry was eager to hear Del Prado's perceptive with regard to the national microelectronics industry, and how to strengthen it.

To participate in the rising interest in the Dutch microelectronics industry, a good relationship with the Dutch government was not sufficient. If Del Prado wanted to have an impact, he had to cooperate with Europe's biggest semiconductor manufacturer and compatriot Philips. However, that was easier said than done.

The Bilthoven operation still had an audacious reputation, as it used to have in the seventies. Especially its sales force and R\&D engineers tested and defied 
conventions in the European semiconductor industry - read Philips' particular ideas. It was very much sales driven. Following the example of Del Prado, the operation propagated an international view of how to commercially operate in the dynamic chip industry. It made ASM Europe a whippersnapper kind of an enterprise. This attitude and reputation repulsed Philips.

\section{Elaboration of affairs}

\section{Positioning at the heart of the European microelectronics industry}

By the fall of 1982, the intrepid venture was still growing, but it also faced the limitations of the Dutch and European market more regularly. ASM was a rather small company, located in a rather rustic non-industrial village, valiantly repelling, engaging, and exploring the European semiconductor industry, dominated by Philips and the German Siemens. So far, most of ASM's expansions happened abroad, rather than at home, in the Netherlands.

In contrast to the foreign acquisitions and expansions, most of the growth of the Dutch operations occurred organically. ASM Fico, under the management of its founder, Richard Fierkens, steadily expanded the molding, trim \& form, and lead-frame business. The Bilthoven operation had increased its own technological capabilities. It was most experienced in horizontal LPCVD processes, offered some radiant heated epitaxial processes, integrated computer controlled diffusion furnaces, and customer-specified gas systems.

Total sales of the European operations - ASM Bilthoven and Fico - amounted to 34,5 million Dutch guilders in 1981 and would steadily grow to 78,9 million Dutch guilders by $1984 .^{84}$ Employment in Bilthoven increased from a staff of 70 in December 1980 to 140 in mid-1983. Having outgrown the mansion it had occupied during the seventies, the Bilthoven operation was moved to a facility at the Jan Steenlaan 9 in Bilthoven. Since Del Prado moved around globally to manage the other operations, local management was hired. In August 1980, the 35-year-old Erik Kamerbeek was hired as general manager. Meanwhile, old hand Martin van Beest was still present as head of the local R\&D operation.

With the involvement of the Ministry of Economic Affairs, Del Prado continued to make advances to Philips in 1981 and much of 1982. After all, the three parties - ASM, Philips, and the Ministry - shared a strategic interest in improving the European and Dutch microelectronics industry. Philips remained hesitant, raising arguments such as: 'ASM was too small, did not offer added value, etcetera, etcetera.' But the born sales-man Del Prado persisted. The public officials had

\footnotetext{
$84 \quad$ Various ASM annual reports.
} 
the means - subsidies foremost - to gather the parties, and have Philips listen to Del Prado's proposals for collaboration.

Through these meetings, Del Prado learned about Philips' intention to commercialize an in-house developed lithography stepper machine. ${ }^{85}$ Since the sixties, Philips Research Laboratories had pursued the development of a wafer stepper, called the 'Silicon Repeater' ${ }^{86}$ In line with the shrinkage of development activities conducted by the vast manufacturing conglomerates, Philips wanted to commercialize the stepper machine, named Philips Automated Stepper (PAS) 2000 .

This technology involved a very lucrative market. In 1982, the market for stepper machines amounted to 297 million dollars worldwide, compared to the 92 million-dollar market for CVD processes. ${ }^{87}$ Since the late 1970s, stepper lithographic machines were the convention in semiconductor manufacturing, and their demand had grown rapidly.

Lithography was, and still is, critical in the production of computer chips and the ongoing miniaturization of transistor dimensions (see Intermezzo in Business I). In the wafer stepper, a beam of light projected the pattern of one or more chips from a mask, reduced by a sophisticated lens, on a photosensitive film on top of the wafer (figure 25). By projecting the tiniest lines in this way, the outlines of the integrated circuit were defined. Hence lithography was a returning step in the fabrication process of chips. Such machines had to be able to precisely position the patterns on the wafers, with a margin of less than a few microns, and project images with lines of a few microns' width. Moreover, the technology had to be orchestrated with the innovation of successive photoresist and etch processes, enabling a step-and-repeat sequence. ${ }^{88}$

Basically, three ways existed for lithography: x-ray, e-beam, and optical. Only e-beam and optical lithography had been applied at an industrial scale. Philips had developed e-beam, lithography by means of electrons, and the optical version.

85 This initial discussion followed the initial discussion about the European Microelectronics Program, where amongst others Philips intended to secure subsidies for 'stepper and repeat' and e-beam lithographic technologies. - ASMI, Arthur del Prado, 'Letter to Philips Gloeilampenfabrieken, Director of Science \& Industry, attn.: ir. A.G. de Boer’ (19-10-1982) Archive Arthur del Prado - ASML 1983-1984 file.

86 Rene Raaijmakers and Paul van Gerven, Natlab: Kraamkamer van ASML, NXP en de cd (Techwatch Books, Nijmegen, 2016); Raaijmakers, De architecten van ASML (Techwatch, Nijmegen, 2017).

87 Dataquest database.

88 David Brock, 'Reflections on Moore’s Law', in: David Brock (ed.), Understanding Moore’s Law (Chemical Heritage Press, Philadelphia, 2006) pp. 87-108; David C. Brock, 'Patterning the World: The rise of Chemically Amplified Photoresist', Chemical Heritage Foundation, Center for Contemporary History and Policy: Studies in Materials Innovation (2009), p. 17. 
The PAS-2000 was an optical lithography machine, dubbed a wafer stepper. It enabled the accurate positioning of a wafer up to a micron. The stepper mechanics of the Philips machine promised to be far more accurate than everything on the market, and thus could gain wide acceptance in the industry.

\section{Figure 25}

A simplified overview of an optical lithography machine

The first steppers of ASML had an innovative and unique through-the-lens-alignment system, necessary to precisely align the reticle and wafer.

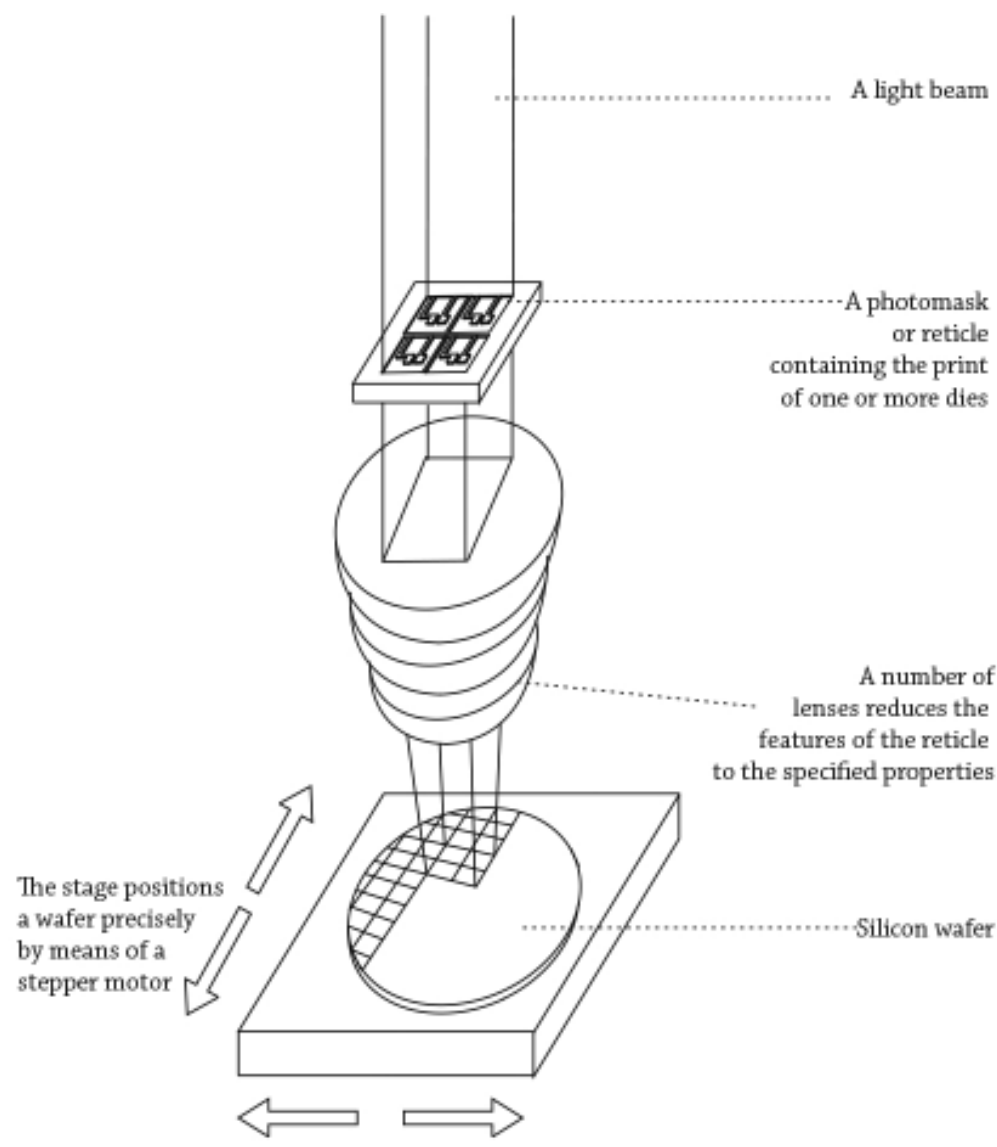

By October 1982, Philips looked for a partner to commercialize its lithographic machine. Philips by itself would never be able to sell the equipment to other semiconductor manufacturers, its competitors. Customers would mistrust their Philips equipment and serviceman with this strategic and critical technology. Because significant investments, estimated at 100 million Dutch guilders, were 
required, the electronics giant looked into equipment manufacturers of more substance than ASM, like the American lithography vendor Perkin Elmer or the mask-alignment manufacturer Cobilt. ${ }^{89}$

Nevertheless, Del Prado seized the opportunity and indicated his availability. Since lithography constituted the biggest market in the chip equipment industry, he had been eager to enter the lucrative market for lithography systems for some time. But he was also aware of the entry barriers he had to incur. ASM lacked the resources to develop a lithographic machine itself from scratch. A few months earlier, in February 1982, Del Prado observed in a letter to a staff-member:

'As you know, I am very sceptic to make serious efforts to engage the competitors in lithography, this late, with the big boys in this area (Perkin Elmer, G.C.A., Hitachi, Canon, etc.). Unless this happens together with one of the big companies like Philips or others, or if we could make a big leap forward in a new direction; X Ray or something else.' ${ }^{90}$

Since Philips seemed to look for a partner in lithography, one of Del Prado's preconditions for engaging the lithography market was fulfilled. It would take another year before Philips responded to the entrepreneur's overtures. By that time, the search for a partner had not resulted in anything, while the need to commercialize the machine had increased. By September 1983, ASM and Philips agreed to start a joint-venture for the development and commercialization of the stepper machine. The new company was named ASM Lithography.

The new joint-venture was the result of growing awareness among public officials and industrial leaders of the need for strategic industrial competitiveness and collaboration. ASM Lithography was a prestigious endeavor, which would position ASM at the heart of the European microelectronics industry. It was the symbol of the shared interest and willingness to contribute to a more competitive European microelectronics industry.

89 Raaijmakers, De architecten van ASML, p. 194

90 The letter was written to Mr. Heico Frima, a nephew of Nico Nobel (member of the newly established supervisory board from 1981 until 1991). Frima worked on the LTO process together with Jon Goldman at ASM America during an interruption of his study (mind Chapter 8). In 1982 and 1983, he worked in the engineering team for the automatic wire bonder, Hong Kong. After his return to the Netherlands, he started as liaison at the newly established lithography joint venture ASM Lithography. At the time Del Prado wrote the quoted letter, Frima ran ahead of the events by accident. Del Prado suggests a leap into a new direction, something which he would pursue in 2001 as he invested in a new Dutch start-up in e-beam lithography called Mapper. Original quote in Dutch. - ASMI, Arthur del Prado, 'Letter to Heico Frima' (11-2-1982) Archive Arthur del Prado-ASM Assembly Automation file. 
ASM Lithography would turn out to be the world's biggest equipment vendor decades later. However, ASM would never reap the benefits. Its overconfidence and courage was never rewarded, as will become apparent in Business III. The commercialization of the lithographic machine proved to be too costly.

\section{A rising star}

Del Prado utilized the momentum of the surging market and public interest into semiconductors. During the negotiations with Philips about the establishment of ASM Lithography, he pulled off another tour de force. On September 15, 1983, ASM offered an additional pledge of shares upon the NASDAQ, generating millions in cash. ${ }^{91}$

This second listing capitalized once again on a peak in demand for computerrelated stocks throughout 1983. During this year, several new start-ups in personal computing technology, such as Compaq, conducted an initial public offering. ASM had expanded its operations rapidly since its own initial listing in 1981. These investments in commercially viable innovations paid off, and in combination with rapidly grown sales, the additional offering of shares reflected this.

During the 1983 offering, 1 million shares of the company were issued, in addition to 350,000 of Del Prado himself. After reduction of the underwriters' share, ASM got 27,6 million dollar in cash. Each share was sold for 29 dollars, valuing the whole company at 197,24 million dollars. This was a staggering increase since the initial public offering, when shares were sold for 15 dollars, and the company's worth totaled 85 million dollars. In two and a half years, ASM's estimated value had more than doubled!

Man of the match, naturally, was the company's founder, CEO and major shareholder: Arthur del Prado. Even after the second offering, he retained 53 percent of the shares. In the short period of time, since the listing, he had prolonged the company's exponential growth. The new expansions - ASM Assembly Automation, ASM Japan, aluminum CVD, die bonding, and Epsilon Technology - bore the promise of fast growth.

The company was seen as a treasure trove of semiconductor production technologies. The latest addition, ASM Lithography with its technology from the prestigious Philips Research Laboratories, formed the jewel in the crown. Through his entrepreneurship, perseverance, and commercial intrepidness, while exploiting the momentum on the capital markets for electronics-related stock, Del Prado had expanded his company into a semiconductor equipment powerhouse.

91 Robertson, Colman \& Stephens; Sheason/American Express Inc; and Dean Witter Reynolds Inc, 'Prospectus of Advanced Semiconductor Materials International N.V. for the issuance of 1,350,000 Common Shares' (15-9-1982) Archive Arthur del Prado - IPO file. 
ASM turned into a multinational multidivisional enterprise in semiconductor equipment at a time when manufacturing conglomerates disintegrated and had to divest or annul activities. ${ }^{92}$ But where many multidivisional firms faltered, ASM's star rose. Del Prado's strategy of decentralized product-driven business units and research and development seemed to be the crux to success. In line with the changed public perceptions about management strategies, and through the second offering of shares by ASM in the fall of 1983, Del Prado found himself in the limelight.

His achievements were recognized by his Dutch peers. In November 1983, Del Prado was named 'Director of the Year 1983'. This was a biannual award from the Dutch Association of Board and Supervisory Board Members. ${ }^{93}$ Del Prado was praised for his entrepreneurism and competence with regard to new technologies within the Netherlands and beyond, and his accompanying staffing policies, such as internal trainings and decentralization of responsibilities. ${ }^{94}$

In times of economic stagnation, Del Prado was the example of entrepreneurism upon which the Dutch executives pinned their hopes. The award was presented to Del Prado by the Dutch Prime Minister, Ruud Lubbers. ${ }^{95}$ It exemplified Del Prado's and ASM's new standing in the Netherlands and marked the astonishing growth of the company. The accompanying sculpture was entitled 'In Pursuit of Excellence', a clear reference to the popular management book, In Search of Excellence. The views on running a successful modern company as promoted by this book seemed to be perfectly reflected by ASM and Del Prado.

The 1983 public offering replenished the cash reserves. But this time these funds were not yet used for new acquisitions. Foremost, they were spent in support of existing activities. This involved in particular ASM America, ASM Japan, and forthcoming ASM Lithography.

The surge of the memory market and the subsequent American-Japanese strive propelled the growth of the American and Japanese operations. Their plasma furnaces were applied in the production of the latest memory chips on both sides of the rivalry. However, the growing pains of the American operation persisted. The company still faced organizational problems and relied on additional cash flow. ASM Japan, in contrast to ASM America, was flourishing. Moreover, investments to further the Japanese success were attracted locally.

92 Sluyterman, Dutch Enterprise in the Twentieth Century, p.199.

93 Nederlandse Vereniging voor Commissarissen en Directeuren, NCD.

94 ANP, "Visie PvdA op economie komt 13 jaar te laat”, Nederlands Dagblad (2-12-1983), p. 9.

95 Nederlands Centrum van Directeuren en Commissarissen, 'Persbericht: NCD Prijs 1983 Toegekend aan de heer A.H. del Prado’ (Oktober 1983) Archive Arthur del Prado - RvC 1980s file. 


\section{Strengthening ASM America}

After intense years of trying to cope with the growing organization, ASM America's general manager Jackson resigned. In June 1984, a new general manager of ASM America was appointed: Franc DeWeeger. Just like Del Prado, he was born in the Dutch East Indies in 1931, and had taken up the chances of making it in the United States, enjoying a beautiful career in the chip industry. ${ }^{96}$ Having a shared background in the tropics and the industry, Del Prado hoped that DeWeeger could turn the tide at ASM America, while also allowing Del Prado to monitor the internal dealings of the company more closely.

Meanwhile, the plasma furnaces still were very much in demand; ASM America's sales continued to grow. Plasma deposition tools accounted for 14,7 million of the 23,5 million dollars in sales in 1983 (62\%), and 25,7 million of the operation's total sales of 39,9 million dollars in 1984 (64\%). ${ }^{97}$ To meet growth, the total staff more than doubled, going from 310 in 1983 to 630 in 1984. In particular manufacturing staff increased strongly, from 146 to 350, whereas R\&D remained the same at 20 . The organization's focus evidently was on fulfilling the commercial potential - meeting the surging interest for its plasma deposition technology.

The new demand for the plasma deposition tools caused a renewal of the inventory problem. The introduction of a new generation of plasma CVD equipment capable of processing bigger wafers of six inches and the new peripheral features, increased the variety among the available plasma furnaces. Volumes of sold plasma furnace configurations varied strongly. As a consequence, inventory clogged further, burning the much-needed cash reserves.

Meanwhile DeWeeger took over control. On top of the business challenges, the management change caused further unrest among the ranks, as others had aspired his position. The internal troubles, such as the inventory problem, manufacturing efficiency, and engineering, ate into the agility of the company.

\section{Expanding ASM Japan}

This also affected ASM Japan, which relied on the American operation for its supply of plasma CVD generics. In the former warehouses in Machida, the Japanese engineers customized the American machines, and shipped them to their Japanese customers. The small Japanese company focused on the reliability

96 DeWeeger was born in Sumatra. In the United States, he was hired by Motorola in Arizona, after which he was dispatched as general manager of the Motorola assembly operation to Kuala Lumpur. Here, in the late seventies, he got in touch with ASM and Del Prado for the first time with regard to the ASM Fico molds. After Motorola, DeWeeger worked for microprocessor manufacturer Zilog. DeWeeger passed away in 2010. - [Family message],'Franc R.J. deWeeger obituary’ Arizonar Republic (11-7-2010)

97 ASM America, Max Wieringa, '1984 overview' (March 1985). 
of their tools initially. Being advanced and innovative was of later concern. As marketing manager, and co-founder, Fukumi Tomino recalled:

'When we started ASMJ, I put in the company goals that we would develop production equipment - no R\&D - but production equipment! Those machines would adopt the most advanced technology, but we focussed on the production of machines. They had to be very reliable. From my experience, it had to be user-friendly on top of high reliability and advanced technology. So, we wanted to develop those production machines in order to compete better. ${ }^{98}$

This was a very tactical decision, since the Japanese industry competed with the Americans foremost on their productivity of memory chips. Therefore, the Japanese market offered a bonus for equipment vendors appealing to that competitive edge.

The Japanese engineers ensured a consistent growth of their business, as they secured the same customers they once had on behalf of Marubeni. ${ }^{99}$ Slowly, ASM Japan's local engineering activities increased in order to commercialize the PECVD technology. ASM Japan's R\&D capabilities were modest, even according to the other ASM operations. The sales of the company and the present manufacturing workload made investment in engineering and R\&D not yet worth it. By December 1983, ASM Japan expanded the original facility by procuring the warehouse next door, and kept its eyes on another neighboring warehouse by the fall of 1984 .

For engineering and minor R\&D efforts, ASM Japan relied partially on an subcontractor called Adtec Engineering. ${ }^{100}$ Initially, Adtec manufactured various subassemblies, such as boat loaders and controllers. To accelerate domestic production and manufacturing, ASM wanted to intensify cooperate with this company. Therefore, ASM acquired land to open a neighboring factory to Adtec

98 Fukumi Tomino, 'Interview with author'.

99 After the founding of ASM Japan, ASM could no longer rely on the Marubeni reputation. An adequate response to a major incident at a customer site - Oki - secured the reputation of the start-up company. In a moment of crisis, the start-up venture showed its adequacy and dedication towards his customers. This was critical for the Japanese chip manufacturers, and the story spread around. The Oki-fire constituted the starting shot for ASM Japan's success as equipment supplier.- ASM Japan, Yo Miyazaki, 'Telex: [subject unknown], ref:kk-50’ (710-1982) Archive Arthur del Prado-ASMJ 80's; Founding and early years.

100 This was a company, established October 26th, 1983 by former engineers of Kenseisha - a parts manufacturer for Sony, Nikon, and Canon. lead by Mr. Mitzutani - ASMJ, Hitoshi Miura, 'memo: Adtec Engineering' (15-6-1985) Archive Arthur del Prado-ASMJ 80's; Founding and early years. 
in Nagaoka, the Niigata prefecture, in the fall of $1984 .{ }^{101}$ The location allowed ASM to rely upon Adtec's experience, and - as the Adtec management assured Yo Miyazaki - the region was full of engineers and technological suppliers. Moreover, the building was situated in an area, where the local authorities intended to stimulate industrial activities.

The new factory would lay down the foundation of ASM Japan's growth, and secure its ability to serve the Japanese customers in its competition with Western chip producers. As ASM Japan thrived, the company was less affected by the troubles in Phoenix.

\section{Starting ASM Lithography}

Amidst the American-Japanese rivalry, the Dutch semiconductor equipment industry improved its global stance by the newly established Philips-ASM jointventure. As René Raaijmakers details in his thoroughly researched history of ASML, the new lithographic operation had been perceived by ASM as an easy way into the business of selling lithographic equipment. ${ }^{102}$ In his optimism, and naivety perhaps, Del Prado overlooked signs that contradicted this perception. It looked promising on the paper, but required benevolence to make the best of it in reality.

Already one month after the announcement of the joint-venture in September 1983, ASM's technical liaison in the Philips joint-venture, Heico Frima, summarized the problems. He reported in a handwritten note:

'It is clear that the big hydraulic system, causing noise and vibrations in the building, has to be replaced by an electrical system, as quickly as possible. Moreover, customers are afraid that the used oil might leak here and there, contaminating the system ... A proto-type of the electrical motor, which is intended to replace the hydraulic system, is already demonstrated at the Nat. Lab. [Research Laboratory]. On this, people speak mysteriously. ${ }^{103}$

Frima noted additional weak points of the stepper machine, such as the quality of the critical Cerco lenses, the supply of subassemblies by Philips Machinefabrieken, the supply of PC boards, lacking compliance with six-inch

101 ASMJ, Yo Miyazaki, 'Memo: Plan for ASM/J Nagaoka Factory, ref: AJ4-0096' (16-5-1985) Archive Arthur del Prado - ASMJ 80's; Founding and early years.

102 Raaijmakers, De architecten van ASML; and the English version: René Raaijmakers, ASML's Architects (Techwatch, Nijmegen, 2018).

103 Original quote in Dutch. - ASM International, Heico Frima, 'Rapport bezoek aan Philips Lithografie’ (5-10-1983) Archive Arthur del Prado - ASML 1983 file. 
wafer handling capability, and the reticle system. ${ }^{104}$ In other words, the product was not yet as ready for commercialization as originally indicated.

Nevertheless, and perhaps blinded by the opportunity, Del Prado and his designated managers pushed for a quick commercialization of the system. ASM would show the unwieldy giant in electronics how things were done in the merchant semiconductor equipment industry. It was a confrontation between the agile and commercial ASM culture and the inventive but cumbrous Philips culture.

By April 1984, the provisional announcement about the Philips-ASM jointventure was translated into a real venture with the registration of the company as ASM Lithography BV. ${ }^{105}$ Both ASM and Philips pledged about 7 million each, of which Philips deducted its contribution in materials, inventory, and other aspects. ${ }^{106}$ The joint-venture started temporarily at a Philips location in Eindhoven. Initially, 47 employees were transferred from Philips to ASML, most against their wishes, and several new staff members were added, including Heico Frima, Martin van den Brink, and Frits van Hout (the latter two are still in charge of ASML today).

In the Spring of 1984, a manager was attracted: Gjalt Smit, who had a PhD in plasma physics a career in airplane construction, and had worked for Philips, Holec, and ITT. Beyond a healthy mind, Smit was strong in sales. He had no previous experience with lithography, but the charming and optimistic Del Prado inspired him to engage this new opportunity anyway.

In the first month after his start, Smit learned that lithography involved a product that completely differed from the other wafer processing equipment of ASM. It would require an entirely different innovation strategy capacity than ASM had now. Furthermore, the competitive field was already fully occupied: GCA and Ultratech in the United States, Censor in Liechtenstein, and Nikon and Canon in Japan. It seemed obvious that selling a lithographic tool would not be a piece of cake.

104 ASM International, Heico Frima, 'Rapport bezoek aan Hr. G.A. Jansen, Philips' (13-10-1983) Archive Arthur del Prado - ASML 1983 file.

105 For a while, the participation of governmentally supported venture capitalist, MIP, was considered, but it did not materialize The fairest option was a de facto banking relationship, unless MIP was willing to pay up for its lack of material contributions. - ASM International, Arthur del Prado, 'Telex to MIP and Board and Supervisory Board: Deelname mip in de lithografie joint-venture tussen Philips en ASMI, ref: 1662/jn' (4-11-1983) Archive Arthur del Prado-ASML 1983 file.

106 ASM Lithographic Systems, 'Overeenkomst hoogte van inbreng door Nederl. Philips Bedr. B.V. in A.L.S. B.V.' (17-5-1984) Archive Arthur del Prado - ASML 1983 file. 
An opportunity existed in the forthcoming VLSI chips with 0,7 micron dimensions. ASM Lithography had a superior through-the-lens-alignment system plus the forthcoming electrical position table. Smit decided to ensure ASML's competitiveness by introducing the 0,7 micron capable tool in a timely fashion. Not the PAS2000, but its successor, the PAS2500 with an electrical table would be leading ASML into the market for lithographic technologies. ${ }^{107}$ He remodeled the business plans of ASML accordingly.

To succeed, ASML required far higher investments from its owners ASM and Philips. Smit pursued both new technological development and commercialization at the same time. The company had to be innovative and commercially agile. By the fall of 1984 the number of employees increased from the original 47 to 111 , and even further 211 in 1985. The new staff changed the business culture from Phillips into, what we now would call, an informal start-up culture. As a crowning touch, by November 1984, the construction of a futuristic looking new building started in the village of Veldhoven, near Eindhoven. ASML was burning money at an unprecedented pace, without making any sales.

By the fall of 1984, ASML and its owners, in particular Del Prado, had already been through a range of perceptions about the feasibility of their endeavor. After each new insight, Smit adapted the plans and mobilized his employees with concrete deadlines, and his board members by projecting a golden future of sales. Although often too ambitious, these promises caused ASML to persevere.

A frank overview of the situation at the start in 1983, and even in 1984, would have any wise entrepreneur throw in the towel. In this sense, the perseverance of Smit, but also of his CEO Del Prado, made up for their ingenuousness toward lithographic techniques.

\section{Disadvantages of a decentralized structure}

By means of each new added invention, the Dutch equipment manufacturer gained a new operation, independently operating from the others, and only subjected to the control of the holding company ASM International (figure 26). The basic principles of Del Prado's management enabled the operations to diverge and pursue their commercial opportunities by themselves. Each business unit was responsible for its own success, which stimulated entrepreneurism and intrepidness. It had been a formula for success and ASM's explosive growth.

107 However, in the meantime, in order to secure any sales and comfort the growing anxious owners, ASML directed its attention on another variation of the stepper machine, the PAS2400 G-line. -Raaijmakers, De architecten van ASML. 


\section{Figure 26}

Organigram of ASM by 1984

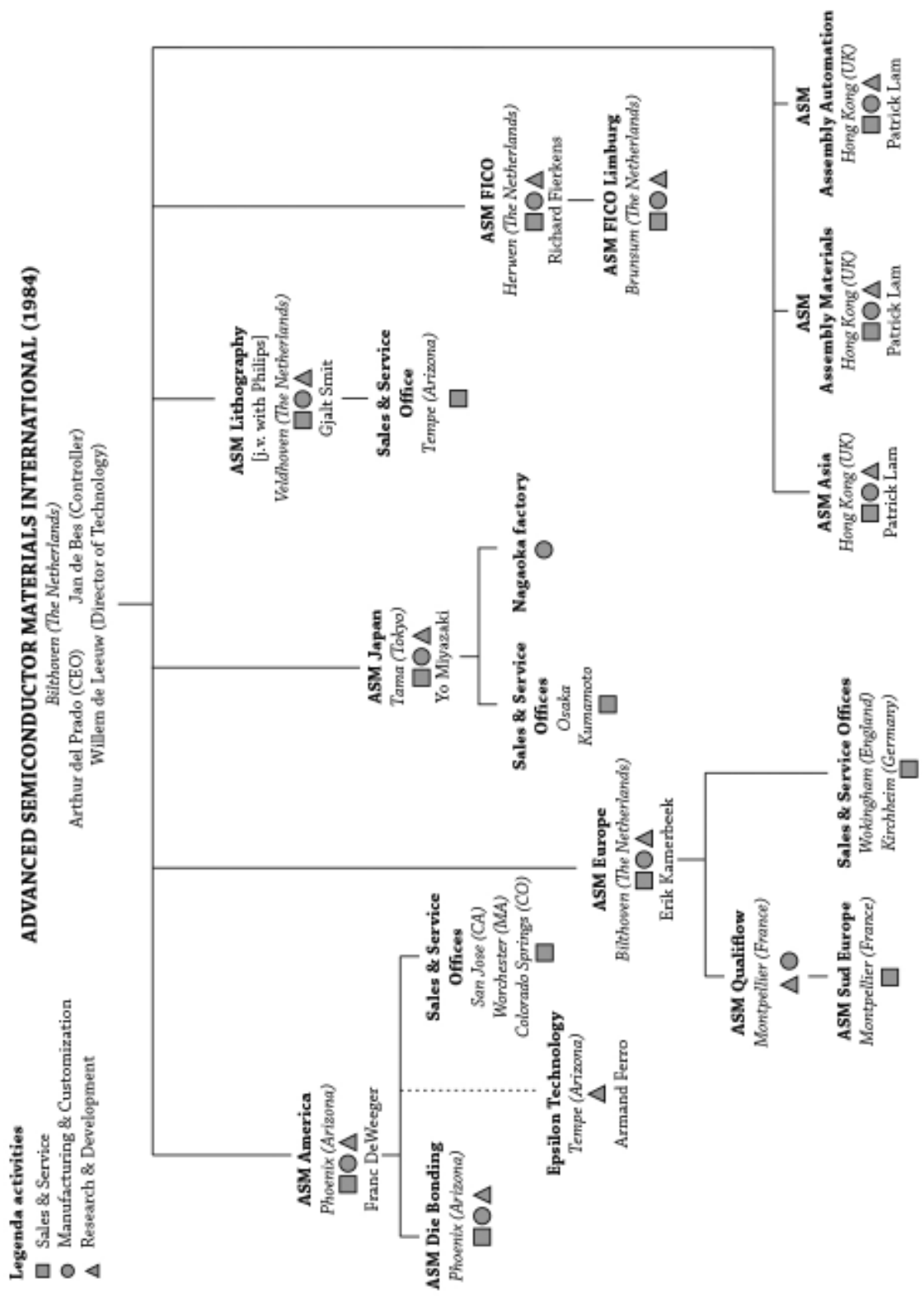


The localization of products enabled ASM to balance between the rivalry among European, American, and Japanese chip industries. Each local operation was a national operation, with a national reputation. The willingness to customize their products to the demands of the customers strengthened this approach. But in some areas, it started to go beyond the pale.

The decentralized organization and the successive expansion of ASM failed to enhance the cohesion among the operations, resulting in inefficiencies and doubling. Since the company's growth and well-being was defined by an ability to commercialize innovative technologies, it was in this particular area that some sort of tuning of activities was required first.

\section{Figure 27}

Table of ASM's presence in distinct semiconductor fabrication processes, 1980-1985

PROCRSSES

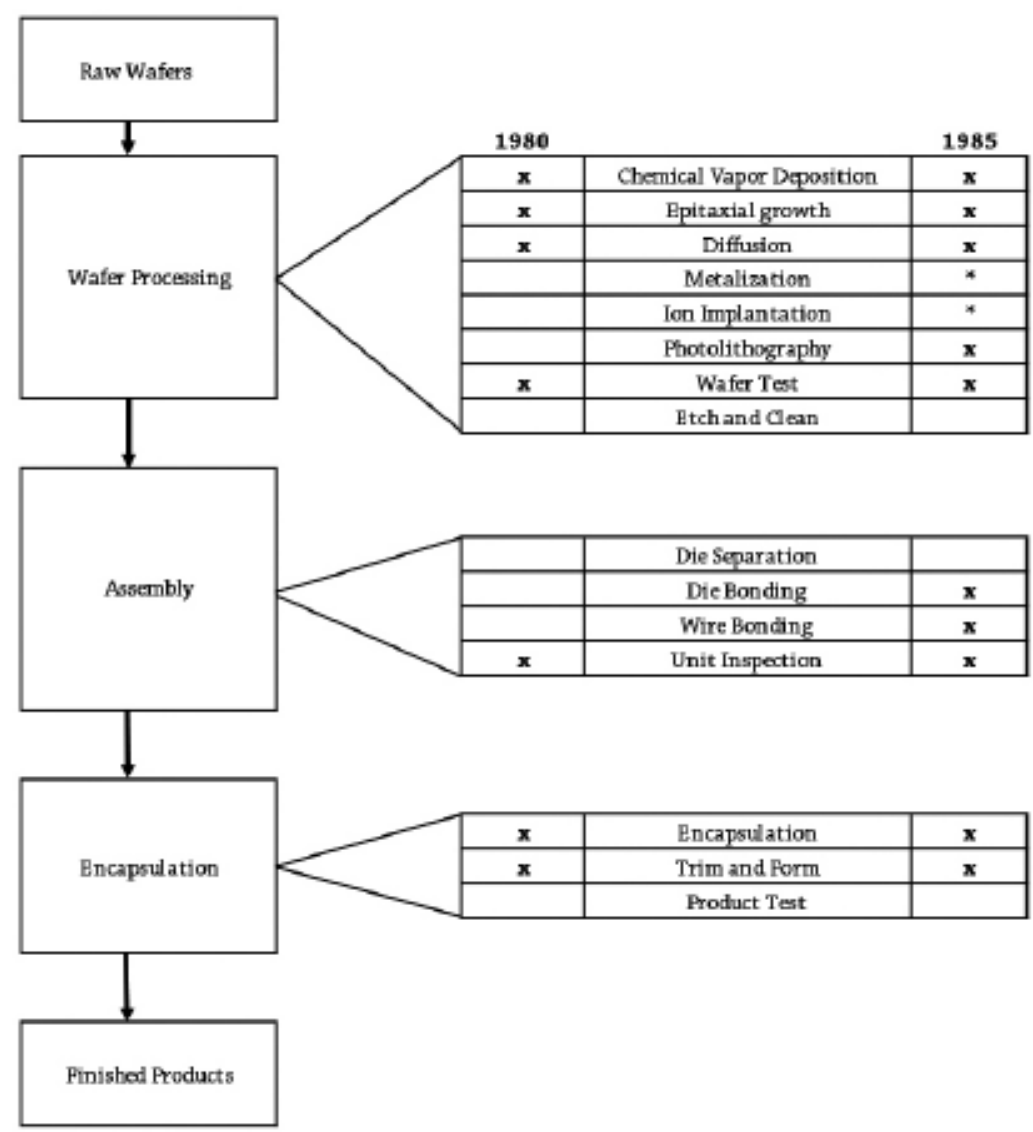


It was up to the newly hired Director of Technology, Willem de Leeuw, to manage and coordinate the rapidly proliferating technological activities of ASM (figure 27). Del Prado simply lacked the time to keep track of all the advances in technological development in Hong Kong, Japan, Phoenix, Bilthoven, Montpellier, and Herwen. On advice of the Supervisory Board, Del Prado hired the former technological director of the Dutch airplane manufacturer Fokker to support him in the management of the technological developments. From May 1983 onward, De Leeuw had to coordinate technological customization and developments, and, where possible, create more coherence among the operations, without nipping local commercial potential in the bud.

The first step in this regard had been the development of a standardized computer controller for ASM's various CVD furnaces. It was called the StandAlone Tube Controller (SATC), and was developed by ASM Europe even before De Leeuw joined ASM. The SATC was a programmable computer, capable of controlling low pressure CVD and diffusion systems. Moreover, it could be turned into a system that could oversee and control up to 24 furnace tube processes. De Leeuw envisaged the SATC as a replacement for the different controller systems used in the American, Japanese, and European diffusion, plasma CVD, and LPCVD processes. It was deemed easiest to introduce in software and computer design common peripheral features among the various products.

Another step was the founding of a central research laboratory, dubbed ASM Microelectronics Technology Center (see Innovation III). This prestigious center was meant to supply the front-end operations with the latest technologies and coordinating technological developments among them. It was meant as a central knowledge center for the whole company, and another effort to create coherence among the technological activities of ASM. Throughout 1984, Del Prado and De Leeuw worked intensively with the Dutch authorities to secure their support for this initiative. Since the Dutch authorities were committed to stimulate their national industry in the race among national chip industries, ASM had sensed a clean opportunity to secure financial support.

Management of the business units involved in wafer processing equipment remained wary about De Leeuw's initiatives. They worried about their own independence and their ability to serve their market base. In a memo to Del Prado, general manager of ASM Japan, Yo Miyazaki confirmed this:

'I certainly can feel that ASM is now big and solid. But simultaneously I cannot stop being concerned about the tendency that too many things are decided only by the top-down method under the name of company policy. Indeed I appreciate the necessity of the top-down decision, but if you should think a little bit more time and make effort to create a general atmosphere of consensus among all of them, I think. ... I order 
to execute the management decision at once or within a possible shortest time frame, what we need is the positive participation of our people in the execution of it but not a relocation and remote consent. ${ }^{108}$

Miyazaki tried to ensure his autonomy by appealing to consensus among the operations. However, with regard to technological choices, this consensus was virtually absent. The technological domain was strongly linked to the commercial performance of each operation, and this prevented alignment among the operations.

In the early 1980s, most multi-divisional firms had decentralized profit responsibilities to overcome inherent weaknesses of their diversified activities. ${ }^{109}$ This strategy also propelled ASM's growth (figure 28). Each operation managed its own local profit and loss statement, and made its decisions upon these numbers. Del Prado dealt with each operation based on these statements, as they together defined ASM International's success. As such, ASM was a coalition of ASM's, all bounded by their founder, name, their technological ambitions, and common pursuit of profitable business opportunities.

\section{Figure 28}

Graph of revenues ASM International, 1979-1985

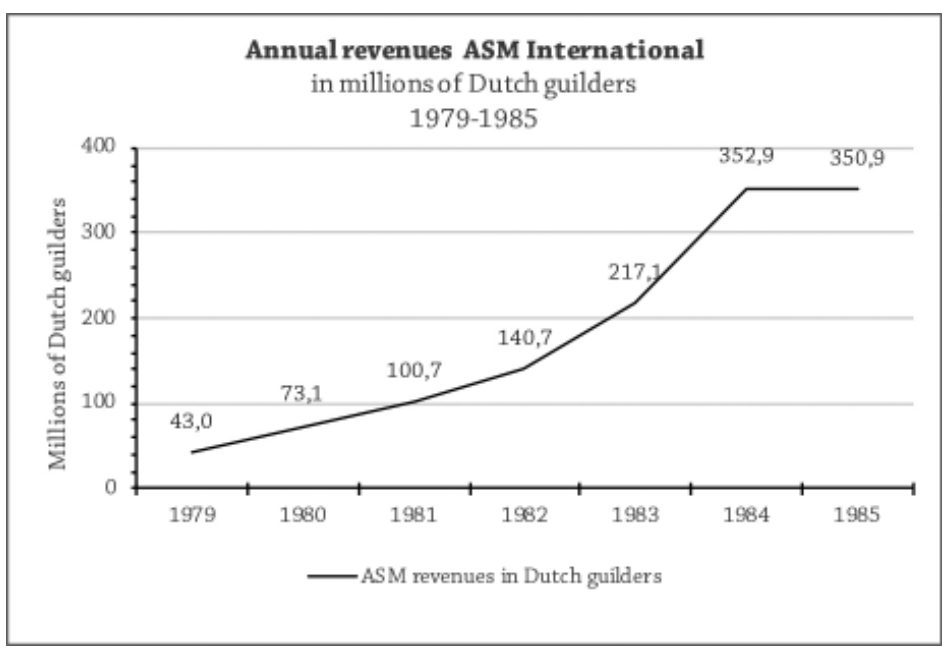

108 ASM Japan, Yo Miyazaki, 'Memo: [no title]' (8-11-1984) Archive Arthur del Prado-ASM Japan 80s file.

109 Sluyterman, Dutch Enterprise in the Twentieth Century, p. 199. 
All of this went fine as long each operation stayed within the geographical boundaries assigned to them, while serving their customers. It grew more difficult whenever the ASM operations had to transfer products to each other. The sales on behalf of, and from, principal suppliers within ASM were treated like 'internal sales', and required specific internal pricing mechanisms.

At a commercial level, internal sales were problematic, however. Since each operation was keen on their own profit and loss statements, internal transfer pricing caused much discontent on each side. For instance, if ASM Japan sold an PECVD furnace made by ASM America, both companies tried to ensure their respective margins on the sale. The impact of internal sales on the operations' performance was significant. Of ASM America's total bookings of 40 million dollars in 1984, around 16 million was obtained from ASM Europe and primarily ASM Japan. ${ }^{110}$ This amounted to some 40 percent!

The strive among the subsidiaries was due to inadequate sales representation, bad payment terms, bad deliverance, or completion of the proceedings. These were typical administrative matters, which Del Prado tended to look down upon. Since no one else had the authority to make and enforce a decision, the internal interaction among subsidiaries remained rather laissez fair. Yet, normal realities of competition in the chip industry - among competitors and towards customers - did not apply, since each ASM operation actually was part of the same team. But this was not reflected in the arguments and disagreements surrounding internal pricing.

The zeal and competitive behavior instilled in the operations to serve their regional markets caused frictions among the subsidiaries themselves. Most often these disagreements were solved bilaterally. Only in escalations did Del Prado interfere. Being a katjong himself, he did expect from each operation to be assertive and daring. There was little incentive to take good care of the products made by one of the other ASM operations due to the problems associated with margins, shipping, and pricing.

\section{Outline of a rapidly approaching challenge}

Lifted by the energy of ASM Lithography's promise, its undaunted manager Gjalt Smit did not hesitate to warn Del Prado in a letter about the centrifugal effect of the current business organization. ${ }^{111}$ He plainly explained his perception about the matter in a handwritten letter to Del Prado, in January 1985:

110 ASM America, Max Wieringa, '1984 overview' (March 1985) Archive Arthur del Prado - ASM America 1980s file.

111 Moreover, Gjalt Smit not only had to deal with Del Prado, but also with Philips. Due to the joint-venture structure, Smit had extraordinary freedom towards Del Prado personally. 
'In the forthcoming year, it is to be expected that ASM exceeds a sales of half a billion. Without believing in the magic of numbers, it is obvious that it won't be merely a proud milestone, but also heralds a new critical phase. The next years will tell whether ASM continues to grow into an independent, durable and an international market leader ... or into a ponderous progressing average, or even worse, just good enough for an acquisition.

What accounts for ASM-L, does so for ASM in general: it is a classic business case. It involves the question whether the enterprise, after the Sturm und Drang of the pioneering years, will be able to mobilize the professionality and discipline (military-like precision) required by the best of the world. After the 'robbing knighthood', with all its undeniable charms, noblesse oblige, which offers more nuanced rewards to differentiated players.

That professionality concerns all sectors of the company, so not only commerce or research, but in particular operations, such as personnel and organization (due to the crucial motivation of the executive basis of the company). Here and there, the approach to this end will have farreaching consequences, and has to be supported by a well-considered organizational strategy. One, which not only stimulates the creative entrepreneurism, on which ASM is soundly based. But also offers the coherence of an enterprise operating globally instead of respectively local and national markets. ${ }^{112}$

Smit touched exactly where it hurt with regard to ASM's organizational structure and strategies. But this is perhaps easy to point out in retrospect.

His perception, at any rate, was not shared by Del Prado at the time of writing. Like no one else, the founder of ASM knew what impetuous pioneering behavior had brought him. Operating very opportunistically with regard to commercialization of inventions in a decentral organizational structure had enabled ASM to fight itself up to the position where it was today. There was still a world to be gained in the chip industry, and organizational formalities merely prevented the rapid fulfillment of ASM's potential. Del Prado did not intend to stop here.

Moreover, the coalition of ASM operations was not easily reined in. Each had their own path, their own momentum, and it was up to Del Prado to balance all

112 Original quote in Dutch, mingled with English, French and German phrases. - ASMLithography, Gjalt Smit, 'Letter to Arthur del Prado' (14-1-1985) Archive Arthur del Prado - ASML 1985 file. 
these forces. It was his prime goal to allow each of the operations to flourish. This was done by means of stimulating local entrepreneurism, aligning expectations, pulling strings, and comforting concerns across various cultures and economies. Rummaging through this complex web of promises, activities, and relations to iron out the inherent deficiencies and flaws, might unravel the seed-bed of ASM's rooting.

Hence Del Prado, following his commercial talent, focused upon stimulating the company's entrepreneurism and pursuit of opportunities. He led by example, one could say. Fusing his coalition enjoyed less priority. Smit recognized at least the latter part, as he wrote in the same letter:

'Honesty compels me to admit, that I am concerned about the timing, thoroughness, expertise, and standards through which the process of professionalization will occur at ASM. My own, rather extensive, exposure to varied organizational issues, respectively crises, at a wide spectrum of equipment industries, raised my awareness for acting slow, neglecting of key-issues, and taking refuge in sub-problems.

Also at ASM, I scent the risk of an ad-hoc approach. This could, for instance, occur by means of centralizing sub-functions, here and there, or, here and there, appointing a strong professional manager: "and then, let's see how it all turns out."' 113

Smit continued by pleading for more cohesion among subsidiaries of ASM, thus more meetings beyond the annual Semicon West gatherings. He was critical of the national perspectives. It caused the operations to pass the bucket to each other with no one taking responsibility.

In his letter, Smit was blunt, honest, and perhaps accurate, but he missed his goal. Most of the general managers of ASM's subsidiaries knew better, and had their own ways to persuade Del Prado to adopt their ideas. To find Del Prado's hearing, Smit had to play the game according to Del Prado's rules, implicitly respecting his position of leadership. Del Prado appreciated ingenuity, perseverance, and commercial success. But no one should try to compromise his position as CEO of the company. Smit's letter came close to doing so through his pedant warning to the tried and tested Del Prado.

Although Smit honestly, and perhaps rightly, criticized the current organizational structure and procedures of ASM as a whole, it was the structure that got Del Prado where he was. Since Smit had not yet achieved any sales with

113 Original quote in Dutch, mingled with English phrases. - ASM-Lithography, Gjalt Smit, 'Letter to Arthur del Prado' (14-1-1985) Archive Arthur del Prado - ASML 1985 file. 
ASM Lithography, and - even worse, in Del Prado's eyes - displayed a prodigal management style, Smit was in no position to lecture Del Prado. His message fell on deaf ears. But Del Prado's ignoring the message would prove to be ominous in the forthcoming years. 


\section{Conclusions}

The appearance of ASM changed profoundly during the first half of the 1980s. The company greatly expanded, in terms of revenues and number of employees, but also geographically and technologically. Sales increased from 43 million Dutch guilders in 1979 to 353 million Dutch guilders in 1984, while profits went up from 409 thousand to 23 million Dutch guilders (figure 28). In the same years, the number of employees increased from 337 to 2129. The company's product portfolio expanded to cover a wide range of chip production technologies. The company was bursting at the seams. How to explain this growth? In conclusion I will reflect on this question by considering the role of fortuna, path, and virtù.

\section{Fortuna}

ASM, during the early eighties, continued to be propelled by favorable yet unexpected events - or fortuna. ASM seemed very much the master of its own fate. Most growth followed from deliberate actions of ASM's employees and hardly from unexpected encounters or opportunities. The timing of the initial public offering was well managed, and the availability of new technologies lithography from Philips and plasma etching from Bell Labs - did not appear out of the blue. No manifestation of fortuna affected the company's path negatively. Fortuna was foremost a force of opportunity.

Here in these conclusions, I distinguish four versions of fortuna. Ostensibly, fortuna affected the course of ASM through single events. Such as, the availability of aluminum CVD (cf. conclusions Innovation I), the availability of the Epsilon Limited Partnership (cf. Innovation II), Elmont International, or Del Prado's nomination as Director of the Year. Yet, those followed mostly from wider developments.

First, fortuna involved the ever continuing miniaturization of chip components. In these Business chapters, this revolved around VLSI chips - in particular memory - and the accompanying technological difficulties. Equipment vendors who offered products that overcame these challenges could count on a premium on their sales. The advent of VLSI technology made innovating production technology worthwhile.

Secondly, the PC revolution and the competition in memory chips improved public awareness of the applicability and profitability of the electronics industry. ASM's business gained a better appreciation, which improved access to capital. 
By issuing shares to the stock exchange, perfectly timed in periods of boom, the company replenished its cash reserves.

Thirdly, the rivalry between the American and Japanese chip manufacturers, and the accompanied surge in production and production technologies, increased demand for ASM's production. The volumes in which ASM was able to sell its production technologies increased.

And, lastly, the general economic recession in the West raging against the background of these contingencies urged electronic conglomerates with an internal basic research capability to hive off development projects. Del Prado preyed on these opportunities. It gave him the chance to get his hands on viable technologies, without having to invest time and money in these technologies or accompanying research capabilities from scratch. Bluntly put, he managed to steal away the loot. The rise in the estimated value of the company in 1983, compared to the IPO in 1981, reflected the profitability of this strategy. ASM proved that industrialization of externally acquired inventions paid off. Moreover, amidst the economic recession, this strategy and entrepreneurship received praise (figure 29).

\section{Figure 29}

Graph of annual growth semiconductor industry, semiconductor equipment industry and ASM International worldwide, 1978-1984

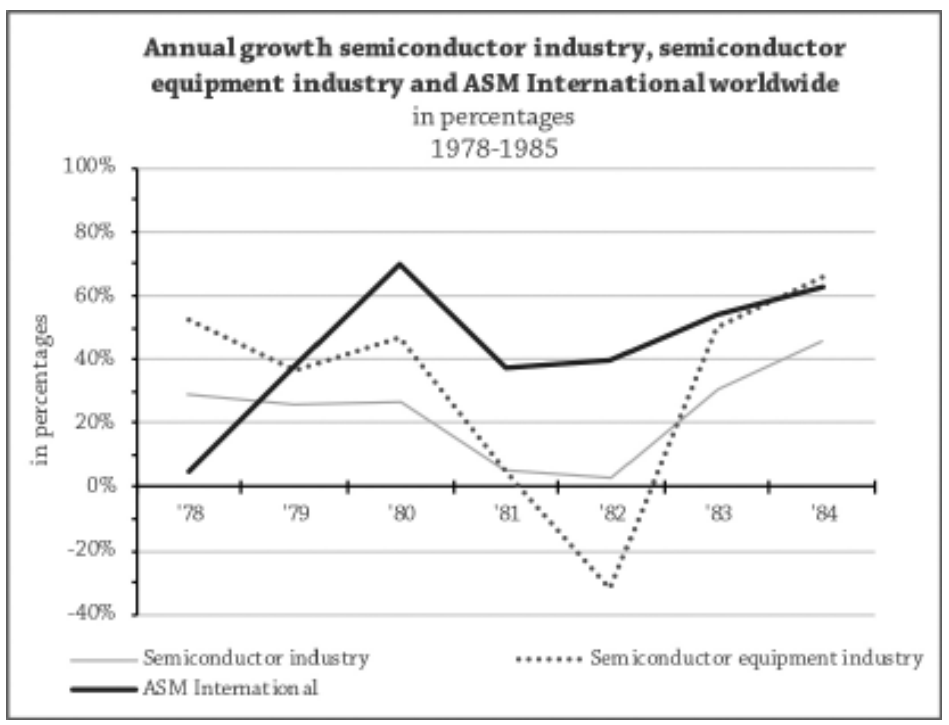




\section{Path}

In the appropriation of opportunities and contingencies, ASM foremost relied on experiences from the 1970s. Del Prado intended to continue his path as he used to do. This involved the decentralized multi-divisional structure, accompanied with a diversified business strategy. Other basic ingredients of ASM were the allocation of entrepreneurial and technological responsibilities to the business units. It innovated technologies that were most certain of being applied in the market. The company's resources - technological, financial, human - did not allow for indefinite development projects.

Instead of one organization integrating and familiarizing the externally supplied inventions, Del Prado simply added separate operations, making ASM a conglomerate of semiconductor equipment technologies. Given appropriate responsibility for their own commercial success, and start capital, entrepreneurial managers of these operations would commercialize their products in their geographical markets most effectively. ASM's growth was an accumulation of their entrepreneurship.

Yet, this course was not exclusively salutary. Through the rapid addition of new operations, the whole enterprise developed into a coalition of ASM's. Little aligning occurred among the operations, as each was vigorously pursuing their own commercial success. Managing by means of the local profit and loss statements aggravated this. The decentral structure allowed rapid growth and efficient pursuit of commercial opportunities. But, accumulatively, minor local deficiencies caused major issues.

In the prosperous semiconductor market of the early eighties, and with very much diverged geographical markets, these defects of decentral management remained manageable. The benefits of decentral management outweighed the drawbacks, as the organizational structure allowed ASM to capitalize on the rivalry among chip industries in Japan, the United States, and Europe. Del Prado's main task was to continue to secure funds to pay for ASM's growth, and to sustain the external supply of inventions. ASM was a small operation, and it had to make money. Ironing out organizational or procedural deficiencies did simply not yield commercially, according to him.

However, ASM's path had changed, and within the organization, there was no one to influence Del Prado's - and thus ASM's - mode of conduct. Even after the issuing of shares, his dilution of ownership, and the involvement of external stakeholders such as banks and authorities, Del Prado remained fully in charge. In a Machiavellian fashion, he ensured that he still called the shots.

The Supervisory Board was not capable of altering the company's course. The Board represented a minority of shareholders vis-à-vis founder, CEO, and majority 
shareholder Del Prado. The shareholders did not have much to complain about anyway, since their investments were secured by the excellent performance of the company. Moreover, despite the Supervisory Board members' merits as experts in corporate law, their understanding of the technologies and market was limited. As long as everything was going well, their job as supervisors was to make sure ASM complied with the corporate standards of a public listed company. It was Del Prado who steered, managed, and pushed the company forward. Becoming a public company provided no reason whatsoever to alter this firmly established balance of power.

Actually, Del Prado's - and thus ASM's - practices seemed to fit the times. In the bestseller In Search of Excellence, management gurus Tom Peters and Robert Waterman propagated business principles that perfectly agreed with the ASM approach. ASM relied on little oversight and on local operations that enjoyed autonomy in pursuit of their opportunities, while entrepreneurship was valued over process management and the company innovated generally applicable technologies. ASM was an exemplary multi-divisional enterprise according to the parameters set by Peters \& Waterman. In fact, the authors seemed to advocate more management by virtù. In light of these viewpoints, ASM's changed appearance and dynamics did not require any alterations.

\section{Virtù}

Del Prado and the entrepreneurial managers of the subsidiaries appropriated new opportunities. Their impromptu reactions to sudden events enabled the phenomenal growth of ASM in revenues. Since all manifestations of fortuna were benevolent, the manager's virtù foremost involved clear opportunism.

The company's ability to continue this trend would be more defining. Through the growth in size and the subsequent accumulation of new responsibilities, ASM got exposed to new external and internal dynamics. Sustaining growth was a matter of organization and preparation. As such, the advice and warning of ASM Lithography's general manager Gjalt Smit bore some undeniable truths. The new appearance of the company affected the robustness of ASM's structure and strategy whenever, and in whichever form, fortuna might recur.

The viability of the assessments made by Peters and Waterman in their book In Search of Excellence, which aligned and underscored Del Prado's and ASM's mode of conduct, seemed doubtful. Two years after publication of their book, by 1984, a number of the 'successful' companies on which the book was based faltered. ${ }^{114}$ Reality overtook their enthusiastic plea for emancipation of entrepreneurism. It was abundantly clear that there were many drawbacks to overly reliance on

114 This hardly affected the sales of the book, however. -Sluyterman, Dutch Enterprise in the Twentieth Century, p. 200. 
unleashed entrepreneurs. In the case of ASM, Del Prado's keenness on his control - the ability to call the shots - prevented the professionalization of management.

The second half of the 1980s proved to be the ultimate test for Del Prado and his firm on both a personal and a business level. Would ASM follow the example of the firms depicted in In Search of Excellence? By the fall of 1984 and throughout 1985, an escalation of the American-Japanese competition disrupted the industry, overproduction of chips caused chip producers to annul their investments in new production lines or even stop their involvement in chip production entirely. ASM's sales dropped sharply across the globe. In the recovery, the chip industry changed profoundly. Under these new circumstances, it was a big question whether ASM's mode of conduct remained applicable, and whether the company could prolong its advance. 
Innovation ||

The development of the Epsilon epitaxy reactor,

1982-1988 


\section{An introduction}

In a period of financial, geographical, and technological expansion, ASM started an unique development project for a new epitaxial reactor in 1982. The result of this development, the Epsilon reactor, redefined traditional epitaxial production technology used in semiconductor manufacturing. The Epsilon reactor changed the epitaxy technology by processing one wafer at a time - a single wafer process - instead of multiple ones simultaneously in a batch. The innovative machine was a success, conquering 45 percent of the market after its introduction, enabling new innovative processes, and being produced to this day. ${ }^{1}$ Moreover, unique for ASM, this reactor was developed from scratch. Rather than commercializing an external invention, as ASM was used to do, this process also comprised the invention of the machine's chemical and mechanical processes.

This case therefore offers us a unique opportunity to trace a complete innovation process of semiconductor equipment technology, from the very first concepts on the drawing table to the product's market introduction. As will become clear, a profound clash of routines and interests among the developing engineers defined this particular development phase, marked by a highly interesting social and technological dynamics. To study this initial development stage in conjunction with ASM's more common innovation practice, I will specifically explore the following question: how did the development phase of the Epsilon single wafer epitaxy reactor influence the commercialization of this product?

\section{The advent of CMOS: an opportunity or a threat for epitaxy?}

The development of the Epsilon epitaxial reactor took place against the backdrop of the technological and industrial transformation of the chip industry. This transformation involved the replacement of bipolar transistors by complementary metal oxide silicon (CMOS) transistors on a chip (see Intermezzo in Business I). The architecture of the two types of transistors completely differed, involving quite distinct production techniques. In the 1980s, the advent of CMOS transistors affected the viability of the epitaxy technique - and the future of equipment manufacturers supplying it.

The rapid rise of $C M O S$ was propelled by three interrelated developments. The first development was the ongoing shrinkage of transistors as part of so-called

1 In 1992, four years after the Epsilon's introduction, ASM's sales of this product amounted to 31 million US dollars, the total market for silicon epitaxy being 84.5 million dollars Dataquest files. 
very large silicon integrated (VLSI) chips. Such devices consisted of 100,000 transistors and more. The continuous miniaturization of transistors and other components created new possibilities and gave rise to new applications. The second development involved the rapid increase of the memory market, of which CMOS transistors and capacitors were a vital part. The more CMOS transistors and capacitors fitted on a memory chip, the more information could be stored. Consumers wanted to store as much as possible, and were willing to pay for that capability. And the third development was the PC revolution. In the early 1980s, the personal computer opened new possibilities for consumers. CMOS transistors enabled good performance against lower energy consumption. ${ }^{2}$ Relying on the latest chip technology, the PC drove sales of memory chips in particular because a PC contained a bigger number of memory chips compared to microprocessors or logic chips.

CMOS transistors were pivotal to these three developments. It was relatively easy to shrink CMOS transistors, and this was indispensable for VLSI and memory. More PC sales meant more memory chip sales, which in turn implied more CMOS-based chips (see Business II).

While an epitaxial film was not indispensable for MOS-based computer chips, the opposite was - and is - true for bipolar transistors. ${ }^{3}$ In 1960, at the renowned Bell Telephone Laboratories of AT\&T, engineers discovered that an epitaxial film improved the performance of silicon bipolar transistors. In combination with diffusion furnaces, epitaxy became the most critical aspect of the production of bipolar transistor discretes and computer chips. Until the early 1980s, bipolar computer chips constituted the majority of chips produced worldwide, placing epitaxy at the heart of the chip industry.

The epitaxial process makes it possible for a semiconductor manufacturer to grow a pure film of silicon exactly according to the wishes of the producer. Epitaxy is a continuation of the crystal structure of the silicon wafer. But epitaxy is more than just another film of silicon with the same crystalline structure and properties. An epitaxial film offers one very important benefit: control of the electrical properties of the active layer comprising the transistor. An epitaxial film also exceeds the purity of the already highly 'pure' silicon wafer. This is important

2 CMOS transistors are fabricated in pairs, wherein an npn and a pnp transistor are connected in series. When one of the transistors is biased to turn on, the neighboring transistor is automatically biased to turn off. The result is that the transistor pair is turned off at all times except for the brief moment when the polarity of the device is changed. This allows CMOS devices to use a fraction of the power required for bipolar devices. - MacDonald Robinson, 'Correspondence with author'.

3 Computer History Museum, '1960 - Epitaxial Deposition Process Enhances Transistor Performance', computerhistory.org. 
for MOS transistors because the smallest concentration of unwanted impurities in the silicon wafer, originating from the crystal pulling process, may influence the functioning of a transistor. By means of epitaxy, semiconductor engineers and producers limit the chance that undesired impurities affect the functioning of a transistor. ${ }^{4}$

Moreover, and perhaps surprisingly, epitaxy enables chip producers to add impurities in a very controlled fashion, in order to influence the electrical characteristics according to their wishes. Such elements are called 'dopants.' Examples are atoms of phosphorus or boron with, respectively, surplus electrons and deficit electrons if incorporated in a silicon crystal. By adding more of either one of these dopants to the silicon epitaxial film, the deficit or excess of electrons increases, and, consequently, so does the conductivity of the silicon material. As such, the manufacturer is capable of tweaking the semiconductor silicon according to its wishes, while the crystal structure remains intact. If the benefits of epitaxy were evident for bipolar transistors, this was not the case for CMOSbased computer chips.

The advent of CMOS computer chips constituted an opportunity for suppliers of epitaxial equipment. Due to the miniaturization of transistors and components on a computer chip - Moore's Law - and the lagging quality of the silicon pullers, CMOS chips became vulnerable to the impurities in the silicon wafers. By 1981, those in the chip industry and equipment manufacturing began to contemplate the use of an epitaxial film to stabilize the MOS transistor.

In the industrial production of CMOS-based chips, a lightly doped silicon substrate created in some occasions unintentionally thyristor - another kind of semiconductor switch than a transistor. ${ }^{5}$ This parasitic switch could not be turned off, and disturbed the proper function of CMOS transistors and thus the chip. The phenomenon was dubbed 'latch-up.' Turning to heavily doped wafers covered by a thin lightly-doped epitaxial film - instead of the previous lightly-doped wafers provided an adequate answer to this problem. The highly-doped wafer had better conductivity, removing potential resistance caused by an undesirably asserting thyristor. The chance that a CMOS transistor latched decreased significantly. Since a CMOS transistor required a lightly-doped substrate, such a film was grown on top of the highly-doped wafer by means of epitaxy (figure 29). Thus, to solve an emergent anomaly in the high-volume production of CMOS-based chip, chip manufacturers could replace the lightly-doped wafers for highly-doped ones and add an additional manufacturing step of epitaxy.

$4 \quad$ Wiebe de Boer, Interview with author; VLSI Research. '4.6 Deposition', Chipshistory.org, p. 4.6.123.

5 L.C. Parrillo, 'VLSI Process Integration', in: Bell Laboratories, S.M. Sze (ed.), VLSI Technology (McGraw-Hill Book Company, New York, 1983), pp. 478-490. 


\section{Figure 29}

A bipolar (upper) and CMOS (lower) transistor cell containing epitaxial films The epitaxial film is depicted in grey.
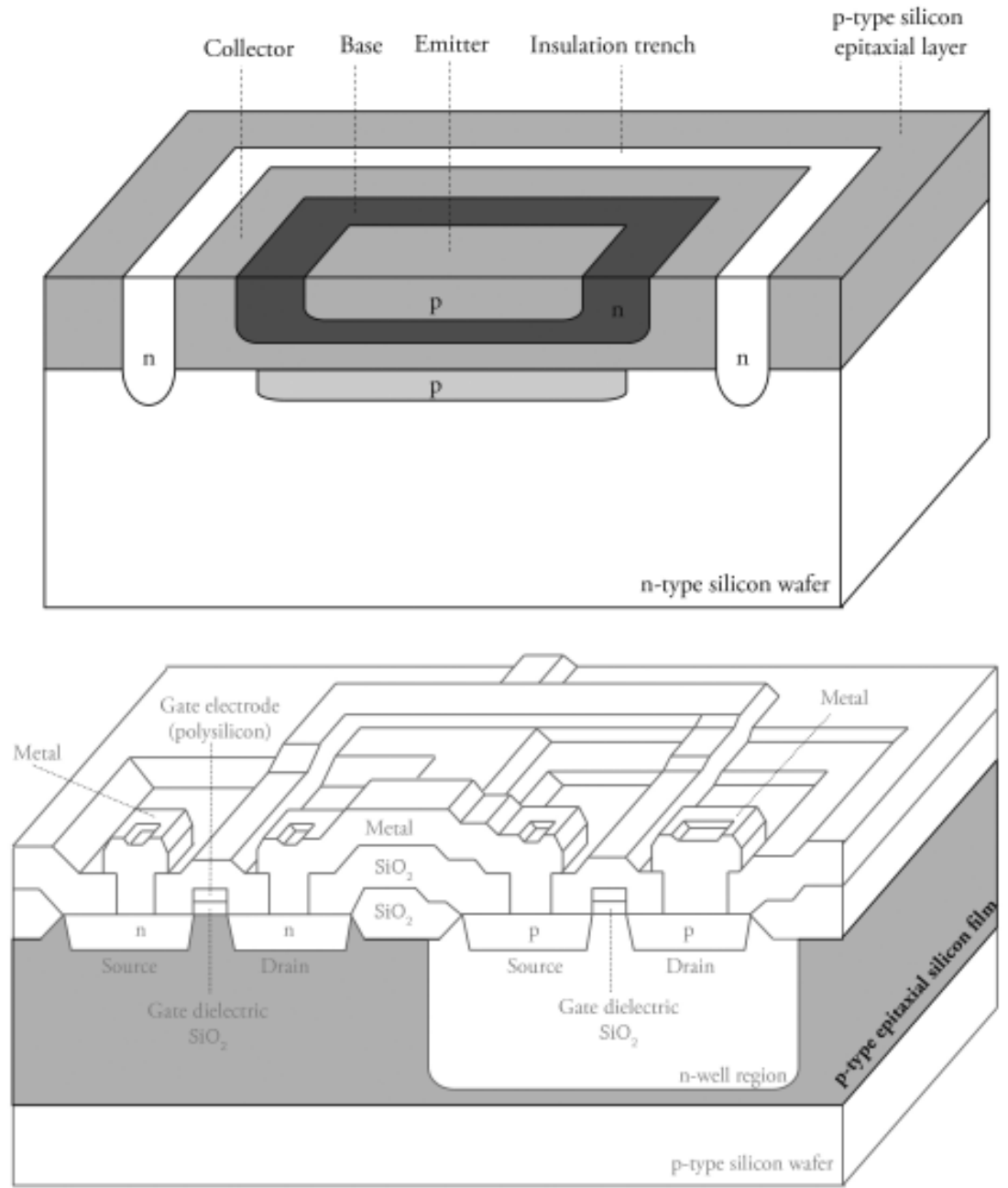

The promise of integrating epitaxy in the production of MOS computer chips increased the potential of epitaxy equipment. It was expected that the industry would need machines capable of growing extra uniform and high-quality epitaxial films due to the increased wafer sizes and dependence of MOS on high-quality silicon. This was confirmed in a 1983 issue of semiconductor equipment magazine Semiconductor International: 
'Using epitaxial silicon for MOS applications means adding an unconventional (and expensive) process step, a step engineers were glad to get rid of when they were first able to switch from bipolar to MOS processing. ... To the equipment vendors the use of epitaxial deposition in CMOS applications is most important for its market potential. ... The bottom line is that CMOS, with epitaxial silicon, is forcing future epitaxial-silicon trends - a potential for increased reactor sales, a need for lower hardware and processing costs.' ${ }^{6}$

Growing a thin film uniformly across a bigger wafer was more difficult based on the existing technologies. If suppliers of epitaxy equipment could develop such more advanced process technology, this might turn epitaxy into an inherent part of MOS chip production. ${ }^{7}$ Because the market for CMOS chips was expected to increase rapidly, epitaxy might well prove to be a highly effective technology.

If the epitaxial film offered specific benefits, however, it was not indispensable. Manufacturers of epitaxial furnaces had to come up with an economical solution in order to keep the technique relevant. The major disadvantage of epitaxy was the additional cost of such a film in the manufacturing of a chip, expressed in the so-called cost-per-wafer. The investment of purchasing and utilizing an epitaxial furnace was high compared to the advantages of the technology for MOS chips. Chips producers could design the epitaxial layer out or use alternative technologies, like annealing or ion implantation.

At the same time, across the industry, proponents of the application of epitaxy for CMOS manufacturing grew more excited in the early 1980s. Manufacturers of silicon wafers saw potential if they could offer their wafers with an additional epitaxial film. ${ }^{8}$ Chip manufacturers started weighing the costs of the additional epitaxial film against the benefits. Each of these potential customers defined different specifications and demands for the application of epitaxy in CMOS fabrication. From the early 1980s, suppliers of epitaxy equipment enacted their technology as a solution for CMOS production. Equipment suppliers pushed for the application of epitaxy in CMOS because it offered them an opportunity to sell tools (figure 30). All wanted to benefit from the surging sales of CMOSbased computer chips. The new application of epitaxy was likely to create new possibilities and future growth. ASM picked up the gauntlet as well.

$6 \quad$ Pieter Burggraaf, 'The Forces Behind Epitaxial-Silicon Trends', Semiconductor International (October 1983) Archive Arthur del Prado - Epsilon file Jan '82 - Oct '83.

7 Dean Witter Reynolds, 'Epsilon Limited Partnership', p. 28; VLSI Research. '4.6 Deposition'.

8 This possibility existed next to the wafer manufacturers' efforts to improve the quality of their production process, aimed at rendering an epitaxial process for CMOS superfluous. 


\section{Figure 30}

Graph of market forecasts for epitaxial equipment in 1982, 1985 and 1987

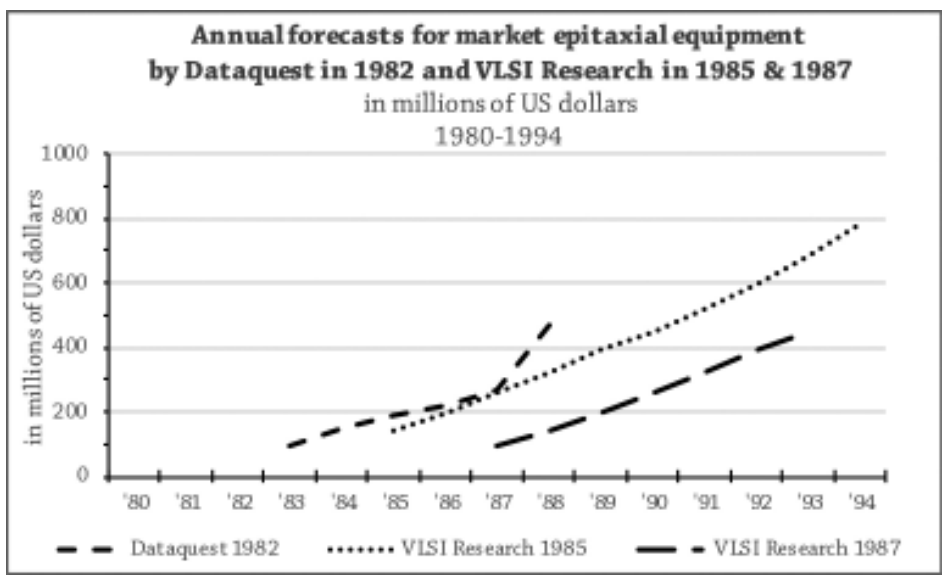

\section{Outline of Innovation II}

To address this part's central research question, Innovation II is divided into three chapters. Chapter 13 first provides a discussion of the previous activities of ASM into epitaxial production equipment, after which I detail the run-up and start of the project, involving the discovery and utilization of a quite specific funding scheme. In Chapter 14, I consider the process of invention and the development phase resulting in the design of the new machine. Finally, Chapter 15 covers how ASM commercialized this new concept through its common innovation practice, including the machine's market introduction and its reception by the market. Just like in the previous Innovation chapters, I reflect on the story in a conclusion, where I dwell on the abovementioned question by linking it to the three central conceptual elements of my study: fortuna, virtù, and path. 


\section{Chapter 13}

\section{Toward an epitaxial reactor, 1970s-1982}

Opportunities are everywhere but not for everyone's taking. Fertile ground is needed in order for them to be identified and taken serious. Epitaxy was a technique not unfamiliar to ASM. Early in his career, in the capacity of sales manager on behalf of Knapic Electro-Physics, Arthur del Prado first learned about the prominence of epitaxy in semiconductor manufacturing. Only after the establishment of ASM in 1964 he began to address the lucrative market for epitaxy himself. He did so by selling Applied Materials' epitaxial gas systems and reactors from 1969 (cf. Chapter 7). After the annulment of this sales agency and ASM's transformation into an original equipment manufacturer in 1971, Del Prado took the decision to manufacture epitaxial machines.

ASM's first epitaxial reactors were built by Martin van Beest. The first machine was capable of processing two two-inch wafers, while its successor processed six two-inch wafers. Water cooling caused insurmountable problems with leaking flanges, however. The newly employed engineer Wiebe de Boer began to work on developing and improving ASM's ramshackle epitaxial technology. From 1974, De Boer became the pivotal engineer in ASM's epitaxial product line.

The first serious epitaxy machine made by ASM was the Epilogic 15-2, a machine capable of processing fifteen two-inch wafers at a time. In the successive Epilogic 21-3, the throughput was increased and its process capability improved by some early computer controllers, capable of processing 21 three-inch wafers at a time. In all the systems, the wafers lay down flat upon a silicon carbide coated susceptor, were heated radiantly, and exposed to a horizontal flow of gasses from the front to the backside of a quartz process chamber.

Although the two models were sold to various customers in Europe, the market remained small. Likewise, ASM America, led by Don Jackson, failed to generate much interest in the company's epitaxy equipment. This was in particular unfortunate for Jackson. In the late 1960s and early 1970s, when he was manager of the epitaxial group of the world's biggest bipolar chip manufacturer Motorola, he automated complete epitaxial production processes, from epitaxy to electrical metrology by means of four-point probes. ${ }^{9}$ ASM America's sales in epitaxy lagged due to inadequate familiarization of the European Epilogic 21-3 reactor. Despite

9 Jackson's PhD project was in fact on automating epitaxial production. - Don Merrill Jackson, The Computer Control of an Epitaxial Silicon Production Facility (Arizona State University, April 1974) Private collection author. 
some resemblance, the Bilthoven tools differed from those used by Motorola. This contributed to ASM's limited access to the lucrative market for epitaxy (figure 31).

\section{Figure 31}

Graph of number of epitaxial machines sold by ASM Europe, 1975-1988

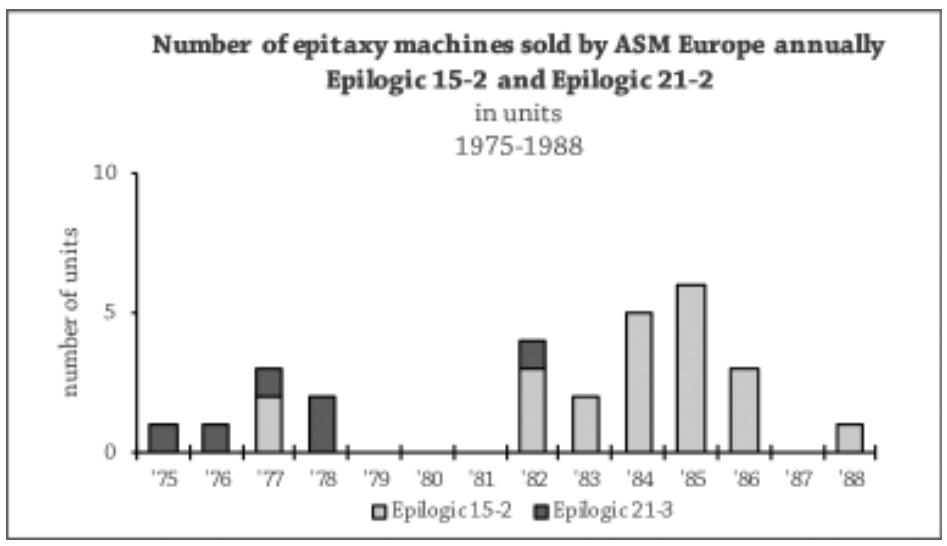

\section{Applied Materials' leadership in epitaxy}

The major cause for the modest success of ASM in epitaxy, however, was the dominance of Applied Materials. ASM's competitor offered a defining barrelshaped batch reactor since 1974, which beat all competition in uniformity and throughput of three-inch (or 75 millimeters) wafers. Applied Materials relied on the extensive process knowledge of its co-founder Dr. Walter Benzing, who had familiarized epitaxy during his time at Merck and Union Carbide Electronics. ${ }^{10}$ His knowledge of epitaxy was the main reason for Applied Materials' success as deposition equipment supplier.

Applied Materials was determined to maintain its dominance as supplier of epitaxy equipment, in particular after by the mid-seventies chip producers turned to the merchant equipment suppliers for their latest production technologies. Because epitaxy was critical for bipolar chips, which were still predominant, and Applied Materials dominated the market for merchant epitaxy technology, the equipment supplier grew extensively, epitaxy serving as the company's foundation.

Applied Materials tried hard to prevent ASM from selling its epitaxy technology in the United States. This included sharing their controversial experiences with ASM as a representative. Another tactic was sending 'cease and

10 James Morgan and Joan Hamilton, Applied Wisdom: Bad News is Good News And Other Insights That Can Help Anyone Be a Better Manager (Chandler Jordan Publishing, Los Altos, 2016) p. 83. 
desist' letters to ASM America, threatening with litigation if ASM continued the sale of epitaxial techniques presumably based on Applied Materials' proprietary technology. ${ }^{11}$

By 1981, as wafer sizes increased and more customers grew concerned about the epitaxy monopoly of Applied Materials, the situation began to change. The Applied Materials barrel reactor had trouble dealing with bigger wafer sizes, of four inches (or 100 millimeters), in terms of the uniformity of the epitaxial film across the wafer. Moreover, as a result of its monopolization of the market, the service to customers deteriorated, in particular to the smaller ones. As ASM still tried to sell its epitaxy equipment in Europe, it learned about the complaints and desires of customers. Although ASM's tools were still not competitive, the market seemed to be not as locked as before.

Overcoming or circumventing Applied Materials' patent for radiant heating was a hurdle for the Dutch company. ASM needed more robust financial resources to develop an alternative reactor. For ASM America's president Jackson it was a bitter pill to swallow. He had left Motorola to create a merchant semiconductor equipment manufacturer, and now he was not able to work with the technology he was most familiar with. He decided to pursue other ambitions within ASM America until new opportunities would arise in the field of epitaxy.

\section{Turning of tide and start of the Epsilon development program}

On October 14, 1981 the tide turned for ASM. An old acquaintance of Arthur del Prado revitalized his aspiration to compete in the market for epitaxial furnaces. An executive from wafer manufacturer Siltec contacted Don Jackson with the proposition for a joint-development program for an epitaxy machine capable of processing epitaxial layers for MOS products. ${ }^{12}$ Both companies were familiar with each other. ASM had served as a representative for Siltec in Western Europe until 1980. ${ }^{13}$ In a successive meeting, five days later, Jackson and Max Wieringa,

11 According to Applied Materials, ASM was violating one of its United States patents in radiant heating epitaxy. The new Chief Executive Officer of Applied Materials was James (Jim) C. Morgan. Inspired by the aggressive strategies of his former employer, General Electric, Morgan had no intention to let the competition freely use Applied Materials' innovations. The same aggressive tactics were leveled against another supplier of epitaxy, called Epitaxy Inc. - Drummond, Nelson \& Ptak, William H. Drummond, 'Letter to Milton W. Schlemmer, Esq: Applied Materials, ref.: I-32524/MWS’ (5-1-1978) Archive Arthur del Prado-Applied Materials; Armand Ferro, John Krickl, and Gloria Zemla, 'Interview with the author'.

12 ASM America, Don Jackson, 'Memorandum to Arthur del Prado and Max Wieringa: Joint Development Program of Epi with Siltec' (15-10-1981) Archive Arthur del Prado - Siltec File; ASM America, Don Jackson, 'Memorandum to Arthur del Prado: Recap of the Possible Siltec Program' (29-10-1981) Archive Arthur del Prado - Siltec File..

13 The companies differed little in size. In 1980 and 1981, respectively, Siltec's sales amounted 
together with Siltec's representatives, elaborated on the idea of co-developing an epitaxial machine. ${ }^{14}$

Siltec's approach formed a preliminary and yet indefinite starting signal for the development resulting in the Epsilon machine. From the fall of 1981 until the summer of 1982, Siltec would steer ASM into the right direction, both technologically and financially. Although in the end the wafer manufacturer's role remained limited to this input, it very much defined the outcomes and further progression of the development effort.

Siltec gave ASM a solid marketing pitch. As a potential user of epitaxy machines, Siltec expounded the specifications for an ideal epitaxy machine. The wafer manufacturer indicated the additional benefits for applying epitaxy in the production of CMOS chips. The company, which itself envisaged troubles in supplying ultra-pure silicon wafers for future CMOS chips, characterized the specifications of the epitaxial wafer applicable in CMOS production. This information gave ASM a clear understanding of the minimum capabilities of an epitaxy machine applicable in the production of MOS chips.

Apart from the application of epitaxy in bipolar discretes and chips, the promise of CMOS made the technology commercially prospective. The CMOS market was growing considerably. Moreover, the specifications for CMOS were more stringent compared to bipolar chips. If the machine complied with the standards for this market, it would most certainly beat the existing competition and enable impressive growth.

Even more important was Siltec's suggestion for funding. After all, ASM had ample marketing information at its disposal about new opportunities in the various markets in which it operated. But the Dutch company lacked the financial resources to pursue them. Developing a competitive machine required substantial funds, and thus financial risk. At the first meetings, Siltec pointed ASM's attention to the innovative financial instrument called an 'R\&D Limited Partnership.'

In the United States, legal and fiscal experts had developed the R\&D Limited Partnership to combine the interests of private investors and innovative companies looking for funding. By investing in a limited partnership - with the purpose of funding research and development - private investors were able to exempt their money from taxes. The whole scheme was a financial innovation

to 50 million and 39.5 million US dollars, compared to ASM's 36.7 million and 40.2 million dollars. Kidder, Peabody \& Co, and Hambrecht \& Quist, 'Preliminary Prospectus Siltec; 600,000 shares of common stock with warrants to purchase 600,000 shares of common stock' (8-12-1982) Archive Arthur del Prado - Siltec File; ASM International, 'Annual Report 1981'.

14 ASM America, Don Jackson, 'Memorandum: Siltec/ASM Joint Venture on Advanced Epi, review of meeting on 10/19/81' (20-10-1981) Archive Arthur del Prado - Siltec File. 
itself, using loopholes and undefined situations in American federal law, and would not be around much longer.

It was a legal construction to assemble private investments to fund technological development. Such an investment was very risky because the outcome of the R\&D project would not automatically result in a commercially viable product. Moreover, the investment in a Partnership was non-tradable; once on board, the investor had to sit through the development period. But if the $\mathrm{R} \& \mathrm{D}$ program succeeded, the investors could expect royalties, or, in other words, a return on their investment, beyond the tax exemption.

By suggesting the investment vehicle and its workings, Siltec cleared the way for ASM to engage an advanced development project into epitaxy. Siltec's president Robert Lorenzini had been involved in one as a board member. ${ }^{15}$ By means of the R\&D Limited Partnership, ASM would be able to pursue epitaxy without encumbering the existing operations, shifting the financial risks predominantly to the private investors.

While Siltec revitalized ASM's ambitions in epitaxy, its role remained rather limited. From the fall of 1981 until the summer of 1982, ASM relied on Siltec's know-how to learn more about and verify the wafer manufacturer's knowledge about CMOS epitaxy and the R\&D Limited Partnership. By June 1982, however, Del Prado decided to discontinue the collaboration. ${ }^{16}$ As Siltec demanded a year's advance in utilizing the machine compared to other potential customers of ASM, i.e. the wafer manufacturers' competitors, ${ }^{17}$ Del Prado, being a Machiavellian strategist, concluded that cooperating with Siltec did not offer any commercial benefits. ${ }^{18}$ Commercial success depended on applicability and availability of the machine to various customers for evaluation and sales. In the end, then, Siltec merely provided the idea for the program, leading ASM onto the path of developing a new epitaxial machine.

15 Siltec Silicon Division, Larry Jo, 'Memorandum to Don Jackson: Siltec/ASM Joint Venture on Advanced Epi' (2-11-1981) Archive Arthur del Prado - Siltec File.

16 ASMI, Arthur del Prado, 'Telex to Don Jackson: epsilon and r-d partnership, ref: 458/jm' (14-6-1982) Archive Arthur del Prado - Siltec File.; Later, Del Prado considered the Limited Partnership also for other purposes: Nobel \& Van Wierst BV, Nico Nobel, 'Letter to Donald Goldman - Touche Ross: A.S.M./R\&D partnership' (25-6-1982) Archive Arthur del PradoEpsilon file Jan '82 - Oct' 83.

17 ASM America, Don Jackson, 'Memorandum: Siltec/ASM Joint Venture on Advanced Epi, review of Meeting on 10/19/81' (20-10-1981) Archive Arthur del Prado - Siltec file.

18 Up to that point, only Del Prado, Jackson, and Wieringa were involved. De Boer was also consulted by Del Prado to assess the epitaxial technique. - ASM America, Don Jackson, 'Memorandum to Arthur del Prado and Max Wieringa: Joint Development Program of Epi with Siltec' (15-10-1981) Archive Arthur del Prado - Siltec File. 


\section{Cementing requirements and securing funding}

The development project was named 'Epsilon,' the letter E in Greek as a reference to Epitaxy. ${ }^{19}$ Accordingly, the R\&D Limited Partnership was named Epsilon Limited Partnership. The organization executing the development program was named Epsilon Technology, while the envisioned epitaxial reactor was called Epsilon-1000.

Elaborating upon the information obtained from Siltec, Jackson set out to get the development program started. This involved, successively, detailing the technological requirements and purpose of the program, securing the funding through the Epsilon Limited Partnership, and laying down the foundations of an organization.

In this process, the funding instrument was pivotal. To attract and protect private investors, the Epsilon Limited Partnership required extensive enunciation of risks and warranties, which involved almost the same amount of scrutiny as ASM's initial public offering, a year earlier. A prospectus was written. ${ }^{20}$ Preparing the Epsilon Limited Partnership required ASM America's lawyers, Bob Moya and Richard Bowers of the Phoenix law firm Lewis \& Rocca, to work out the legal details of the investment vehicle. ${ }^{21}$ This entailed, among other things, definitions of risk and liabilities, conditions for closing the Limited Partnership, and commercialization of the machine.

Investors could buy half a unit or more of the total of 70 available units. Each unit costed 150,000 US dollars, and at least 54 had to be sold to get the program started. ${ }^{22}$ Maximum funds in the Epsilon Limited Partnership totaled 10.5 million dollars, of which 9,005 million would be available for the project after deduction of the underwriters' fee.

Next to stipulating legal procedures and financial aspects, the prospectus described the technological requirements of the machine:

19 ASM America and Siltec, 'Epsilon Board Meeting' (7-5-1982) Archive Arthur del Prado - Siltec File.

20 Dean Witter Reynolds, 'Confidential Private Placement: Epsilon Limited Partnership (An Arizona Limited Partnership): \$10,500,00 Limited partnership interests' (26-10-1982) Archive Arthur del Prado - Epsilon file.

21 Richard Bowers, 'Interview with author', and Bob Moya, 'Interview with author'.

22 The investors pledged their money in three steps. Upon subscription this was 60,000 dollars, by June 301983 another 60,000 dollars, and one year later, June 30 1984, a final pledge of 30,000 dollars. - Dean Witter Reynolds, 'Confidential Private Placement: Epsilon Limited Partnership (An Arizona Limited Partnership): \$10,500,00 Limited partnership interests' (26-10-1982) Archive Arthur del Prado - Epsilon file, p. 2. 
'The EPSILON-1000 Reactor will be a silicon epitaxial reactor designed specifically for the manufacturing of ultra-high quality silicon epitaxial wafers for MOS applications. The reactor is expected to supply low-cost material to the semiconductor industry for very high density integrated circuits. Several independent technical approaches to the system will be explored initially and the best on or combination will be further developed until a model is produced. The selected system should enable the semiconductor manufacturer to develop and market very high density MOS integrated circuits during the late 1980's and early 1990's. ASM America estimates the selling prices of each EPSILON-1000 Reactor system will be approximately $\$ 1.5$ million. ${ }^{23}$

The prospectus stipulated a variation and selection process for the new epitaxial reactor. Based on literature and available industry data, two or three likely variations of the new epitaxial reactor would be selected. The next step was to construct experimental reactors and test the concurring processes, after which a prototype of one system was going to be developed. In the last phase, all details of this prototype had to be designed - put on paper - and tested. Initial expectations were, quite naively, that all of this would be done by Fall $1984 .{ }^{24}$

Finally, the prospectus for the Epsilon Limited Partnership laid down the organizational outlines of the endeavor (figure 32). The project consisted of four prime organizational bodies: the Epsilon Limited Partnership, consisting of the funds of private investors; Epsilon Technology, the organization responsible for the development of the technology; a Technical Advisory Board; and ASM America. The Technical Advisory Board oversaw the process and progress of developments, and reported to ASM America. This Board consisted of persons related to ASM and a number of independent experts in epitaxy and engineering. The Board evaluated the technical progress and took the final decisions in the variation and selection process. In such a way it decided which variations needed to be pursued or needed more attention, based on its technological and economic merits. The role of ASM America was to be 'general partner.' This meant that as advisory board member it would keep an eye on the progress and quality of the work performed.

Funding the research by means of an R\&D Limited Partnership placed ASM at arm's length of the project. ASM would not invest anything, and this limited

23 Ibid.

24 ASM America and Siltec, 'Epsilon Board Meeting' (7-5-1982) Archive Arthur del Prado - Siltec File. 
its financial risks. ${ }^{25}$ If the development program was completed successfully, the general partner would have the option to license and purchase the technology developed by the program. In other words, the organization funded by the Limited Partnership developed a new kind of epitaxial reactor, which ASM America would commercialize for the semiconductor industry. The R\&D Limited Partnership funded the development phase, and ASM America would walk the last miles toward market introduction. Considering the innovation practices of ASM set forth in Innovation I, the role of ASM America basically did not deviate from its normal one in the innovation process: commercializing externally supplied inventions.

\section{Figure 32}

Organogram Epsilon Technology and stakeholders

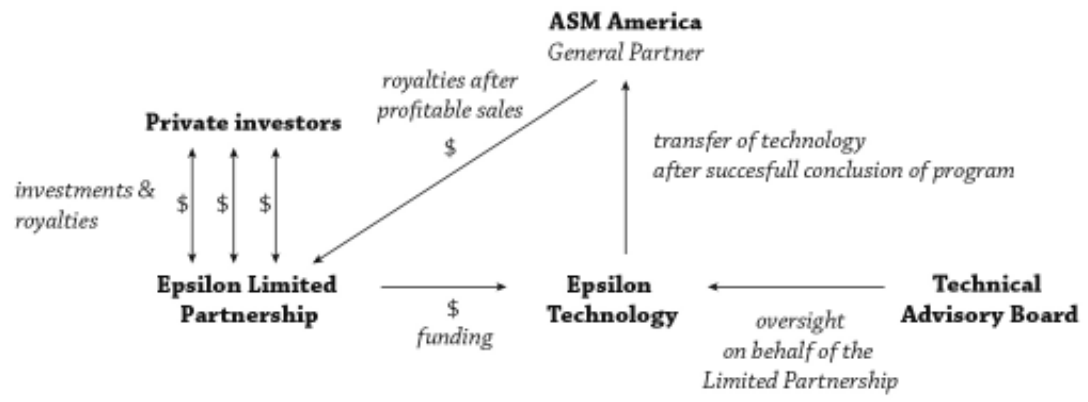

\section{A start in staccato}

The start of the research and development program was slow. Throughout the fall of 1982, the selling of units for the Epsilon Limited Partnership and the hiring of a general manager took more time than needed. Despite a road trip across the United States by Jackson and the program's underwriters in order to attract private investors, almost no units were sold until November 30. ${ }^{26}$ Moreover, in September, Del Prado and Jackson interviewed the projected general manager at

25 Beyond an initial pledge of 350 thousand dollars meant as warrant for an initial bank loan. The bank loan was required to fund for initial expenditures. - Dean Witter Reynolds, 'Confidential Private Placement: Epsilon Limited Partnership (An Arizona Limited Partnership): \$10,500,00 Limited partnership interests' (26-10-1982) Archive Arthur del Prado-Epsilon file.

26 This was also the underwriter of ASM International's public offering a year earlier. - E.F. Hutton \& Company Inc, and Dean Witter Reynolds Inc, 'Preliminary Prospectus; Advanced Semiconductor Materials International N.V.' (17-3-1981) Archive Arthur del Prado - IPO file. 
the Chicago Airport. ${ }^{27}$ Their candidate was Armand Ferro, who previously worked at the research laboratory of General Electric and as Director of Electrical and Electronic Engineering at International Harvester, a manufacturer of farming equipment. Due to the involvement of Bilthoven and the common delays and misinterpretations tied to Trans-Atlantic negotiations, Ferro was formally appointed only by December 28, 1982. Six days later the program officially commenced.

At his first day in the office, a week after his appointment, Ferro flew to Amsterdam to participate in the first Technical Advisory Board meeting at ASM in Bilthoven ${ }^{28}$ Present at the meeting were Arthur del Prado, Don Jackson, ASM America's R\&D Director Dick Rosler, ASM Europe's epitaxy expert Wiebe de Boer, and two external experts: Professor Jan Bloem and Dr. Frans Saris. From May onward, this group would be complemented by ASM's newly hired Director of Technology, Dr. Willem de Leeuw, and a yet to be hired Technical Director of Epsilon Technology. Ferro would have to report to this group of people throughout the program. During the Technical Advisory Board meeting, it became clear that three aspects needed attention right away: to get the operation up and running; to close the Epsilon Limited Partnership by selling all the remaining units; to jumpstart process development. In the first year, all these three activities were pursued simultaneously.

Upon his return from Bilthoven, Ferro and the supporting administrative staff - a total of three - started in temporary facilities at 3220 S. Fair Lane, Eaton Industrial Park, Tempe (near Phoenix). In the first months, Ferro's task was to get the infrastructure ready: bookshelves, desks, drawing tables, office equipment, and, last but not least, a development facility. An engineering room had to be designed, including power needs, communication equipment, etcetera. It would take several months before Epsilon Technology moved into a definite building at 2308 West Huntington Road, Tempe. Uncertainty about the financial resources restricted Ferro's options regarding investments in infrastructure and other resources.

After the initial road trip in November 1982, no more units were purchased by investors. Not even the minimum number of units - 54 out of 70 - was sold. The delay of the closure beyond January 1 caused an untenable situation to the investors already involved, among whom Jackson himself. ${ }^{29}$ If ASM failed to

27 Don Jackson, 'Telex to Arthur del Prado: Epsilon' (23-9-1982) Archive Arthur del Prado Epsilon file Jan '82 - Oct' '83.

28 Armand Ferro, 'Interview with the author' (11-5-2015).

29 Dick Bowers, 'Interview with the author' (6-5-2015); Bob Moya, 'Interview with the author' (12-5-2015); Don Jackson, 'Interview with the author' (5-5-2015), Armand Ferro, 'Interview with the author' (11-5-2015). 
obtain sufficient investments to close the Limited Partnership, it had to pay back these investors, who in their turn had to pay taxes over their cancelled investment after all. To still the unrest, ASM guaranteed not only all investments in the Limited Partnership, but also the actual closing of the Limited Partnership. If the underwriters and ASM failed to attract enough investors, ASM would buy the remaining units.

In May 1983, Del Prado and Jackson deployed the carrot and stick approach to mobilize the underwriters. Del Prado complained to the underwriter's chief executive officer, while Jackson stirred their interest for an additional public offering ASM was planning in Spring 1983 (see Business II). Another road show commenced, which eventually succeeded in closing the Epsilon Limited Partnership at a total of 9,425 million dollars for $625 / 6$ units on July 7 . This was 1.3 million dollars short of the amount planned. ${ }^{30}$ Despite the fact that the program started in January, the green light for the project was given not until after the closure in July 1983 - six months too late.

30 Epsilon Technology, Armand Ferro, 'E.T. July 1983 Monthly Report' (9-8-1984) Archive Arthur del Prado - Epsilon file Jan '82 - Oct'83. 


\section{Chapter 14}

\section{A competition of innovations, protagonists and routines, 1983-1986}

The completion of the infrastructure and the closing of the Epsilon Limited Partnership freed the way for the most fundamental task: getting the process development started. Hardly any development was done in the first half year of the program. Following the discussion by the Technical Advisory Board and having heard the rumors circulating in the industry, the team of Epsilon Technology was fully aware of the ambitious task ahead.

To penetrate the market for epitaxy successfully, and to appeal to CMOS manufacturers, Ferro and his team had to come up with something radically innovative. This was confirmed by an article about epitaxy and the challenges ahead, published in a 1983 issue of Semiconductor International:

'A significant reduction in epitaxial-silicon deposition costs [for MOS technology] is possible. In the past, this cost reduction has been accomplished for other films. ... However, this transition was a major change in process technology, as well as equipment design. A similar change in technology is required to bring down the cost of MOS epitaxy film deposition. Simply making traditional reactor configurations bigger is not enough.

We must focus first on the film requirements which are dictated by device requirements. Then we must decide what process chemistry we want. Finally, the process chemistry must be implemented in hardware. It is a materials science and chemistry problem, rather than simply an equipment construction project. Traditional equipment development focuses on the machine itself. To achieve the break-through technology required for high quality economical MOS epitaxy, focus must be on film chemistry. ${ }^{31}$ 
This challenge for materials science and chemistry was also recognized by the Technological Advisory Board, as well as verified by initial experimentations done in the summer of 1983. If ASM wanted to develop a new epitaxial machine, it had to do more than it normally did. Epsilon Technology had to invent process technology. The accompanying variation and selection of alternatives and propositions required high-skilled and inventive engineers.

From the summer of 1983, development commenced by a technological team that balanced between the applied and pragmatic engineering routine of ASM and a more scientific and fundamental research approach, rooted in industrial research laboratories. Throughout this phase of the program, these two modes of engineering would clash and compete.

Only by the fall of 1986, almost two years later than projected in the original prospectus, the Epsilon reactor was ready for commercialization. It basically involved a variation of the machine proposed at the beginning of the program. The clash between pragmatic and theoretical engineering resulted in a machine that addressed the tangled puzzle of materials science, chemistry, and equipment engineering posed by CMOS-epitaxy.

\section{No easy road ahead}

The process of variation and development was begun with an as of yet incomplete technical team. ASM America engineers with extensive hands-on experience in developing and manufacturing epitaxy equipment, like Earl Fleck, performed the first steps. An engineer named Dave Klem started to work on advanced wafer handling and automation, and he also equipped the machine shop. But most notably, early work was done by ASM Europe's epitaxy expert Wiebe de Boer, who moved to Tempe to join the Epsilon program.

These engineers set up the research effort along the lines initially indicated by the Technical Advisory Board. ${ }^{32}$ The first experiments were done fairly inexpensively and quickly by relying on familiar configurations, known and available components from ASM's inventory, and ASM's epitaxy experts. ${ }^{33}$ Being the most experienced epitaxy expert, De Boer supervised the work on each variation.

32 Epsilon Technology, Armand Ferro, 'Memo: Report for Technical Activities' (August 1983) Archive Arthur del Prado - Epsilon file Jan '82 - Oct'83.

33 In addition, De Boer and consultant Barbara Fronczak researched several databases for earlier work done on cold wall reactors. Nowadays this is done digitally and instantly, but at the time this kind of work could take weeks before a clear picture presented itself. The same goes for the delivery of the requested parts. - Epsilon Technology, Armand Ferro, 'Telex to Arthur del Prado: Epsilon Report for Week Ending 2-27-83' (28-2-1983) Archive Arthur del Prado - Epsilon file Jan'82 - Oct'83. 
Because of the experimental nature of the project, the Technical Advisory Board assessed initial results in terms of their pros and cons for each variation by September 1983 already. The Epsilon team pursued four variations: a horizontal, vertical, continuous, and single wafer process. Initial calculations and experimentations with regard to the other models revealed that these were impractical if not impossible. Based on the initial results and assessments, only the single wafer processes proved to be a viable variation.

Due to the familiarity of the ASM engineers with the concept, the horizontal variation (named Model 1A, see figure 33) and vertical variation (Model 1B) could be tested first. ${ }^{34}$ Both were hot-walled, meaning the whole chamber was heated; they offered a high throughput and were based on known parts and processes. The first runs with the hot-walled configurations showed a discrepancy between growth rate and uniformity, which proved to be insurmountable, even after the experimenting with innovative solutions like plasma enhancements of the process. ${ }^{35}$ The quick start of these experiments enabled a fairly quick killing of these variations in the fall of 1983.

The other variation deselected by September 1983 was a continuous reactor, named Model 2A, proposed during the initial Siltec-ASM deliberations inspired by an announcement of chip manufacturer Texas Instruments (figure 34). ${ }^{36}$ In this configuration the wafer would be transported on a belt or a rail, passing through different environments during the process. ${ }^{37}$ Although some preliminary

34 Epsilon Technology, Armand Ferro, 'E.T. Monthly Reporting - June' (11-7-1983) Archive Arthur del Prado - Epsilon file Jan '82 - Oct'83; Epsilon Technology, Armand Ferro, 'E.T. July 1983 Monthly Report' (9-8-1983) Archive Arthur del Prado - Epsilon file Jan '82 - Oct '83.

35 ASM America engineer Earl Fleck had done some experiments using plasma since the start of the program. Although the growth rate increased, the plasma caused entrapment of undesired impurities in the epitaxial film. The results prompted the decision to stop work on the horizontal plasma variation - James Plummer, 'Advanced Semiconductor Materials Inc. Visit Report 8/6/82' (date unknown), Epsilon file Jan '82 - Oct'83 - Private Archive Arthur del Prado; Epsilon Technology, Armand Ferro, 'Telex to Arthur del Prado and Don Jackson: Epsilon report for week ending March 4, 1983' (7-3-1983) Archive Arthur del Prado - Epsilon file Jan '82 - Oct '83. ASMA, Earl Fleck, 'Memo to Richard Rosler: Plasma Epi - January 1982 Status Report' (15-2-1982) Archive Arthur del Prado - Epsilon file Jan '82 - Oct '83.

36 Robert Bernhard, 'Rethinking the 256-kb RAM', IEEE Spectrum (May 1982) pp. 46-52, p. 52. Archive Arthur del Prado - Epsilon file Jan '82 - Oct'83.

37 An example of this process involves transport of the wafer through a heating and cleaning chamber, followed by a process chamber where the film was deposed, after which it would enter a chamber to cool down. Gas curtains would separate the different process chambers from each other. Another alternative would be to use load locks to separate the reactor. It was suggested to have the susceptor and wafer transported on a rail of gas cushions. - Epsilon Technology, 'Epsilon Board Meeting Minutes, May 3, 1983' 2-3, Epsilon file Jan '82 - Oct '83 - Private Archive Arthur del Prado. 
work was done, there were too many technical challenges - notably shielding the process from external conditions and the engineering required to make it work compared to the expected benefits of the configuration and the other variations. ${ }^{38}$ The continuous reactor (model 2A) was canceled during the September Technical Advisory Board meeting.

After the other variations were abandoned, the single wafer approach was the only remaining option. ${ }^{39}$ This variation (Model 2B) was the brainchild of ASM engineer Wiebe de Boer, who proposed the idea earlier (figure 35). ${ }^{40}$ In Bilthoven, he had developed several ideas about his ideal and innovative epitaxial furnace that could be realized in a relatively short period of time. As he recalled:

'It always annoyed me that the deposition in the horizontal systems, in terms of uniformity, couldn't be made better by more than, say, plus and minus ten percent. And you could easily see that it would become a problem. So I knew exactly what I wanted to build. Something that would excel in this field. ${ }^{21}$

It was a single wafer configuration. Model 2B did not process multiple wafers in one run; it processed them one by one in an atmospheric pressure cold-wall chamber. Due to the cold-walled chamber, the chemical reaction concentrated on the heated wafer due to the temperature differences between the wafer and the walls of the reactor chamber. ${ }^{42}$ Moreover, his concept included a horizontal gas flow, wafer rotation, and even load-locks. ${ }^{43}$ With this proposition, aspects associated with, for instance, controllability, quality, and costs were dealt with in equal terms. Model 2B was the most radical solution so far in the program.

38 Epsilon Technology, Inc, 'Technical Advisory Board Meeting, Presentations' (11-10-1983) Archive Arthur del Prado - Epsilon file Jan '82 - Oct' 83.

39 Epsilon Technology, Armand Ferro, 'Minutes of April 1984 Meeting' (24-4-1984) Archive author-McDonald Documentation (1984-1985).

40 ASM Europe, Wiebe de Boer, 'Remarks concerning section VIII of Epsilon Board Meeting' (30-6-1982) Archive Arthur del Prado -Epsilon file Jan'82 - Oct' '83; and Wiebe de Boer, 'Note to author: De ontwikkelingen van de Epsilon reactor vanuit mijn perspectief' (18-1-2019).

${ }^{41}$ Quote translated from Dutch - Wiebe de Boer, 'Interview with author'.

42 In order to limit the thermal mass to enable quick cycle times, De Boer did some experiments without a susceptor: susceptorless epitaxy. The wafer would rest on three small quartz pins instead of a susceptor. This had the additional benefit that the susceptor did not have to be cleaned after several runs.

${ }_{43}$ Wiebe de Boer, 'Note to author: De ontwikkelingen van de Epsilon reactor vanuit mijn perspectief' (18-1-2019). 


\section{Figure 33}

Artist impression of Model 1A - a horizontal hot-wall batch configuration for epitaxy This initial concept was suggested by ASM America's general manager Don Jackson in the early phases of the project. Model 1A elaborated upon ASM's expertise in horizontal hot-walled deposition furnaces.

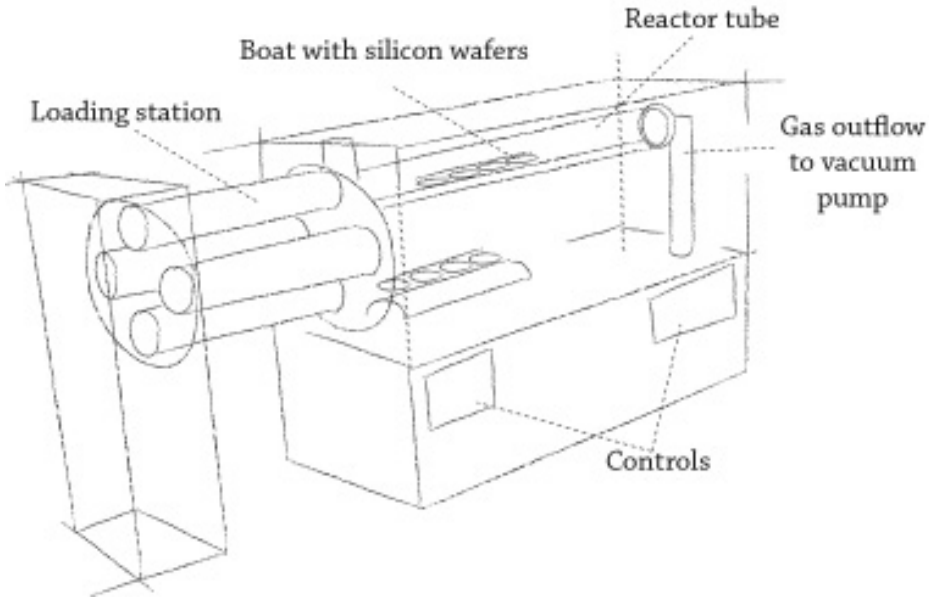

\section{Figure 34}

Artist impression of Model 2A - A continuous cold-wall reactor In the early phases of the project, a continuous reactor was considered, since Texas Instruments proclaimed its engineers had designed such a configuration successfully. In this type of machine, the wafer would move from reactor chamber to reactor chamber on a wafer track.

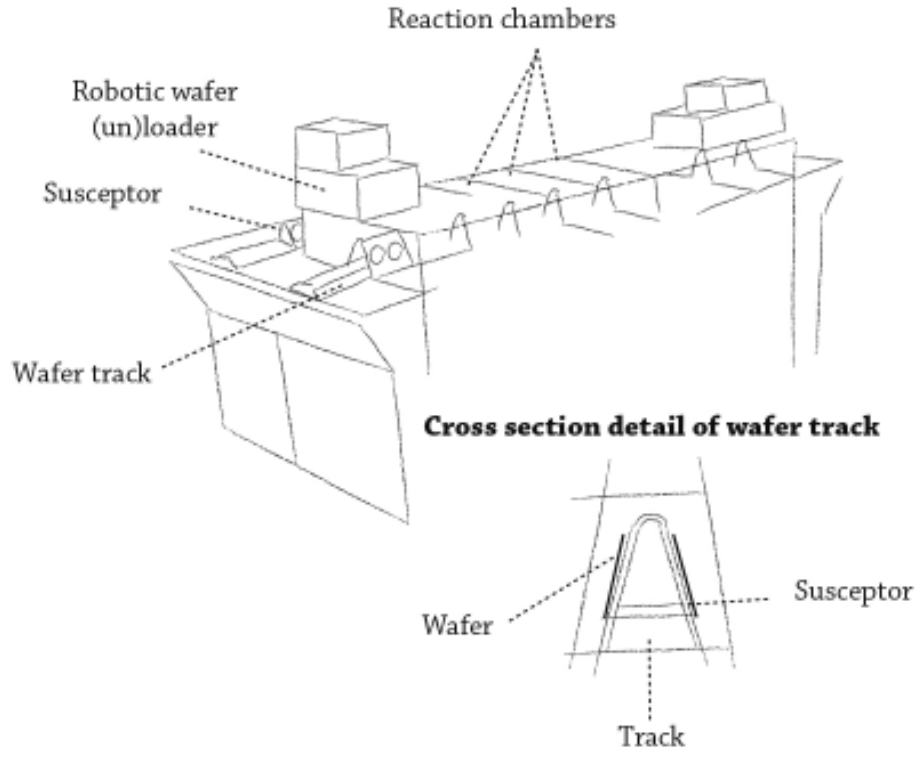




\section{Figure 35}

Vertical cross-section of Model 2B - A cold-wall single wafer reactor with horizontal gas flow This configuration was developed and championed by Wiebe de Boer at the start of the project, elaborating upon his own experiences and ideas into epitaxy. Model 2B contained most of the elements that defined the final design of the Epsilon reactor.

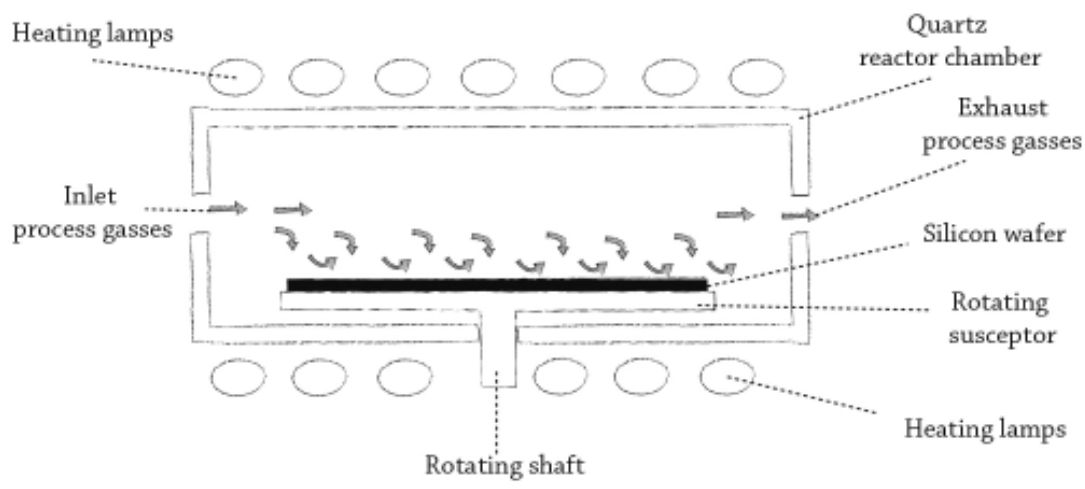

Similar to the other variations, Model 2B came with several difficulties. One was the heating. Applied Materials had a patent for radiant heating, which was common in cold-wall epitaxial reactors. As explained in the prelude of Innovation II, one of the objectives of the program was to develop an innovative epitaxial reactor that circumvented existing intellectual property. To that extent, engineers proposed to solve this through microwave or induction heating. ${ }^{44}$

But there were more uncertainties. ${ }^{45}$ It was doubtful to what extent Model 2B anticipated the industry's need for low cost-of-ownership and high throughput. Was it desirable to emphasize quality instead of the other aspects? It was a concern that De Boer overcame by suggesting a cluster of smaller single wafer reactors. ${ }^{46}$ By combining multiple single wafer reactors, the desired throughput per square feet in a clean room remained the same.

Despite initial skepticism regarding the economic feasibility of Model $2 \mathrm{~B}$, and in striking contrast to the cancelled variations, De Boer secured just enough support to continue this line of research. Since he had proven his intimate knowledge of

44 Epsilon Technology, Inc, 'Technical Advisory Board Meeting, Presentations' (11-10-1983) Archive Arthur del Prado - Epsilon file Jan '82 - Oct '83; Epsilon Technology, 'Epsilon Advisory Board Meeting, April 9 \& 10, 1984 (Day 1)' (9-4-1984) Archive Arthur del Prado - Epsilon file '84 - '85.

45 Epsilon Technology, Inc, 'Technical Advisory Board Meeting, Presentations' (11-10-1983) Archive Arthur del Prado - Epsilon file Jan '82 - Oct'83.

46 Epsilon Technology, Inc, 'Technical Advisory Board Meeting, Presentations' (11-10-1983) Archive Arthur del Prado - Epsilon file Jan '82 - Oct '83; and Epsilon Technology, Wiebe de Boer, 'Memo: EPSI Epi, status and future' (11-2-1986) Archive Arthur del Prado - Epsilon file 1985. 
epitaxy extensively at ASM, the Dutch engineer enjoyed the particular trust of the ASM representatives on the Technical Advisory Board. Elaborating on this reputation, and increasingly supported by the results of his experiments, De Boer became the protagonist of Model 2B throughout the program.

However, the unconventional nature prevented definitive endorsement of De Boer's proposition. On the one hand, more experimentation and study was required. Model 2B would form a test bed for these alternative ideas. On the other hand, the technical team's staffing was not yet finished, which is why alternative designs had not been fully explored yet.

\section{Attracting and deploying a promising technical team}

Considering the challenge posed by CMOS-applicable epitaxy, the management of Epsilon Technology and ASM International intended to hire highly qualified and trained staff for technical management positions. This had to be done regardless of the outcomes of the preliminary efforts performed by De Boer, Fleck, and others. Moreover, Armand Ferro insisted on a heavyweight for the position of Technical Director. As he explained:

'My own involvement with financing, recruiting, facilities, administration, and outside relationships with potential customers leaves insufficient time to track each contributor and push where each needs it on a daily basis. This alone has contributed to numerous delays where decisions should have been made by the staff or for them on a continuous basis instead of when I happened to have spotted the problem or potential problems.' ${ }^{47}$

From the summer onward, Armand Ferro and Willem de Leeuw, ASM's newly appointed Director of Technology and subsequent chairman of the Epsilon Technology Advisory Board, approached various engineers from renowned and prestigious industrial laboratories..$^{48}$ In this process, Ferro got in touch with Dr. Wayne Johnson, who was employed by an American bastion of scientific inventiveness, the federal Lawrence Livermore National Laboratory. Johnson impressed Ferro, especially as he presented himself as a man aware of the social interactions during development. As Ferro wrote in a report to Del Prado:

47 Epsilon Technology, Armand Ferro, 'Memo: Wayne Johnson and ET' (14-7-1983) Archive Arthur del Prado - Epsilon file Jan '82 - Oct'83.

48 This concerned, among other things, a notoriously wayward but brilliant scientist named Dr. Dan Flamm, who had been involved in Bell Labs' radically innovative plasma etch process (see Business II). In addition, several other process engineers from Bell Labs, like Ronald Levi and McDonald Robinson, were considered for other technical management positions. 
'Johnson stated that an important role he saw himself playing ... was to keep the time schedule of the nuts and bolts on track and to act as an interpreter ... of the real world epi experience he saw in Rosler, De Boer and Fleck.' ${ }^{49}$

After approval by ASM America's managers Max Wieringa and Richard Rosler, and Epsilon Technology managing staff Wiebe de Boer, Gloria Zemla (financial director), and Dave Klem (robotics) by August 1983, Ferro hired Johnson as Technical Director. ${ }^{50}$

In the succeeding months after the September Technical Advisory Board meeting, Wayne Johnson took over the technical management of Epsilon Technology, and aligned the activities to his ideas. He acknowledged that the production of semiconductor electronics required intrinsic craftsmanship, which contradicted the scientific methodology underlying its technological development. As he stated:

'Making semiconductors is an art. Making the art reproducible or controllable requires codification of inventions through modelling. ${ }^{.51}$

In this perception, he was supported by another newly hired manager, Dr. McDonald Robinson, a kind-hearted and experienced process engineer from Bell Labs. Robinson would take care of the process development and characterization, which was crucial for rendering epitaxy compatible with the stringent demands of CMOS manufacturers.

Ferro, Johnson, and Robinson pioneered computer aided engineering (CAE) tools for modeling the process development. While using computer models in process development is common sense in today's research and development practice, it was revolutionary and very innovative in the mid-1980s, in particular for the hands-on innovation practices at ASM. Setting up experiments costed more money by far than computer modeling, and money was scarce at Epsilon Technology. Of course, experimentation by means of trial and error remained the basic tool to verify ideas on their feasibility.

49 Epsilon Technology, Armand Ferro, 'Memo: Wayne Johnson and ET' (14-7-1983) Archive Arthur del Prado - Epsilon file Jan '82 - Oct'83.

50 ASM would remain in touch with Flamm for other roles for the time being - Epsilon Technology, Armand Ferro, 'Memo: Wayne Johnson and ET' (14-7-1983) Archive Arthur del Prado - Epsilon file Jan '82 - Oct'83.

51 Wayne Johnson, 'Conversation with author'. 
Already in August, Ferro consulted Professor Sorab Ghandhi of Rensselaer Polytechnic Institute, an expert in metalorganic vapor phase epitaxy. ${ }^{52}$ Professor Ghandhi advocated the use of the latest computer software to improve process development, as reported by Ferro:

'Prof. Ghandhi has delivered a computer model on disc of a single wafer in a horizontal reactor which calculates the thermally induced stresses and the resulting onset of slip. ... The simple model which is a combination of wafer and reactor characteristics indicates that flow conditions in the reactor can have a very strong influence on slip. Our 3D computer simulations using CAE tools should be able to extend this concept and more accurately predict results. ${ }^{.53}$

In November 1983 Robinson took charge of the team responsible for modeling the ideas, and elaborated on the initiative provided by Ghandhi. ${ }^{54}$

By means of computers and software, he and his designated computer engineer Ron Behee translated the newest ideas and insights into a computer model, after which they tried to predict the consequences for the process. ${ }^{55}$ The improvement of provisional computer models required inventiveness and creativity. Consequently, the perfecting of the software would pass through a learning curve. The first models would be inferior to the final ones, yet all of them increased the chances of success before the experiments were executed.

Up to this point, the research at Epsilon Technology was characterized by pragmatism. Johnson and Robinson brought their scientific experience in advanced and complex research programs with them, and redirected attention of research toward more theoretical considerations. This involved not so much getting experimental set-ups to work, but to understand how things worked and what else might be a solution; it would be a waste if they overlooked a technological opportunity to be used.

52 One of Ghandhi's major contributions was to confirm that De Boer's Model 2B was in the right direction. Ghandhi emphasized the importance of high-quality epitaxy: 'Cost is only slightly less important than crystalline perfection.' - Epsilon Technology, Sorab Ghandhi, 'ET Proprietary Information: Program Overview' (27-3-1983) 1, Archive Arthur del Prado - Epsilon file Jan' 82 - Oct'83..

53 Epsilon Technology, Armand Ferro, 'Memo: Report for Technical Activities' (August 1983) Archive Arthur del Prado - Epsilon file Jan '82 - Oct '83.

54 McDonald Robinson, 'Interview with the author'..

55 The engineers of Epsilon Technology first worked at terminals connected to a mainframe computer, and later they had the first personal computers at their disposal. - Armand Ferro, 'Interview with the author' and Wiebe de Boer, 'Interview with author'. 
By hiring experienced, research-minded engineers for process development, Epsilon Technology deviated from the common innovation practice of ASM. The employment of Johnson - and subsequent engineers - constituted an investment in the inventive capacity of the program. It indicated an ambition to be more thorough in the development of the machine, while also considering the commercial purpose of the endeavor.

\section{Enactors make their mark}

With their experience at Livermore Laboratories and Bell Labs, Johnson and Robinson encouraged non-conformist and creative thinking with regard to alternate technical solutions. The computer models verified feasibility before allocating resources to real experiments. As such, the computer models lowered the barrier for inventiveness and out-of-the-box solutions. Throughout most of the program, this atmosphere of creativity prevailed.

The new vitality and creativity was accompanied by assertiveness and ambition. Solutions and alternatives were proposed for the susceptor of the single wafer reactor, Model 2B. Moreover, Robinson and Johnson also propagated their own variations and enacted these throughout the program. From the fall of 1983 until the spring of 1984, the development program expanded and got up steam.

Initially, the engineers concentrated on Model 2B by defining all factors relevant to the process technology, such as temperature measurement, gas flow, and the growth of epitaxy on wafers. One topic in this regard was the wafer's susceptor, on which the wafer rested during processing. It was vital that the wafer and the susceptor were heated uniformly, with minimal warming of other parts like flanges or the fused quartz reactor chamber. Also the pace of heating up was of relevancy for the quality of the process, in addition to its impact on the process time and thus overall throughput of the machine.

Robinson and De Boer turned to a remarkable innovation. ${ }^{56}$ At a previous Semicon West, De Boer saw a demonstration on how to levitate wafers by means of gas. The wafer could float on a cushion of gas during the process (figure 36 ). The pressure of the gasses, originating from gas jets in the bottom of the chamber, compensated gravity, enabling it to float. Gas levitation was the first example of out-of-the-box thinking in the process of proposing variations and alternatives for the process technology.

During the research into gas levitation, the team was confronted almost immediately with the problem of 'slip.' ${ }^{57}$ This phenomenon entailed a fault in

56 Epsilon Technology, Mac Robinson, 'Memo to Armand Ferro: Gas Jet Levitation' (29-3-1985) Archive Arthur del Prado - Epsilon Jan '85 t/m Juli '86.

57 Epsilon Technology, Ann Foster, 'Memo to Wayne Johnson: Model 2 Meeting (August 16, 1984)' (17-8-1984) Archive Author - McDonald Robinson Documentation (1984-1985). 
the crystalline structure of the wafer after growing an epitaxial film, caused by dislocations moving through the crystal. In this case, the gas jets underneath the wafer cooled parts of the wafer. Due to these temperature differences across the wafer, the wafer slipped. To fix this problem, thorough engineering and experimentation were called for.

\section{Figure 36}

Vertical cross-section of Model 2B incorporating the novel concept of gas levitation Through the concept of gas levitation the wafer floated on a cushion of gas during process. More than a decade later, the idea was applied in the Levitor, developed by ASM Europe.

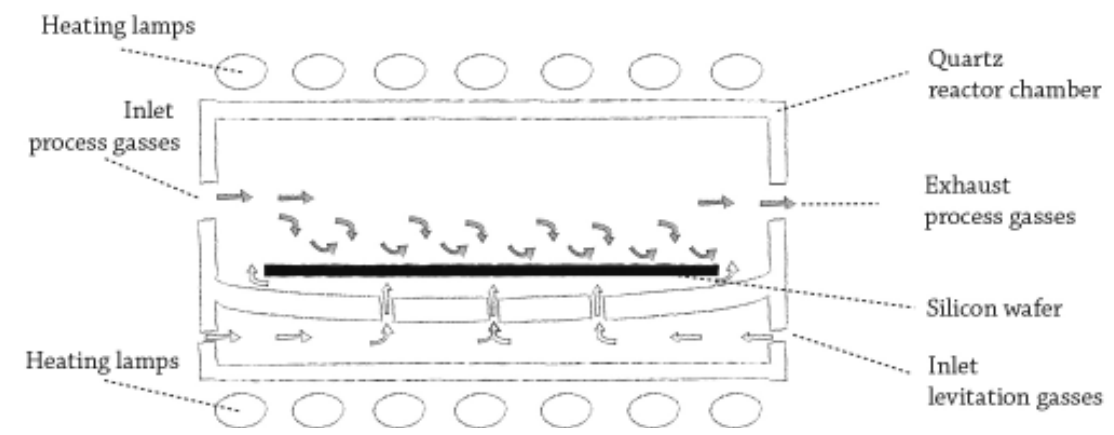

In line with the culture that stimulated the exploration of creative solutions, Robinson wanted to experiment with another variation of the single wafer configuration. The horizontal gas flow in Model 2B resulted in an uneven growth of epitaxy across the wafer surface. For example, it might grow faster near the gas inlet than on the other side. It was not insurmountable, yet Robinson proposed a so-called stagnation point flow as alternative.

The gas flow resembled that of a shower. The gasses were injected above the wafer. Robinson was inspired to think along this line by a paper of Klavs Jensen, a professor at the University of Minnesota. ${ }^{58}$ In theory, the stagnation point flow injection offered perfect uniformity across the wafer. But more analysis had to be done of the gas dynamics, the ideal chamber configuration, heating, and gas injection. Such a puzzle was right up Robinson's alley. In the spring of 1984, he drew out a computer model and some experimental set-up and named it Model 2C (figure 37).

58 Already in September 1983, while applying for his position at Epsilon Technology, Robinson suggested this alternative approach to Model 2B.- Klavs F. Jensen, 'Modelling and Analysis of Chemical Vapor Deposition Processes', Technical Engineering Seminar (2-9-1983) Archive author - Epsilon documentation Robinson; McDonald Robinson, 'Interview with author', and Epsilon Technology, McDonald Robinson, 'Letter to Prof. Klavs F Jensen' (16-2-1984) Archive author - Documentation McDonald Robsinon (1984-1985). 
Also, Johnson put his mind to the task of developing an alternative reactor. Although the horizontal and vertical hot-walled batch configurations had been annulled, he was unwilling to rule out the line of research into Model 1 batch reactors. Most importantly, these variations offered a huge throughput of wafers per run, which potentially decreased the costs of ownership. The single wafer approach was too risky, especially with wafer sizes below six inch. Between the fall of 1983 and the spring of 1984, Johnson therefore continued to contemplate alternate batch configurations. ${ }^{59}$

\section{Figure 37}

Vertical cross-section of Model 2C - A cold-wall single wafer reactor with stagnation point flow This configuration elaborated upon Model 2B, yet differed in its gas flow. Instead of horizontal, the gas were introduced above the silicon wafer. MacDonald Robinson proposed this variation, yet the construction of the quartz reaction chamber proved problematic.

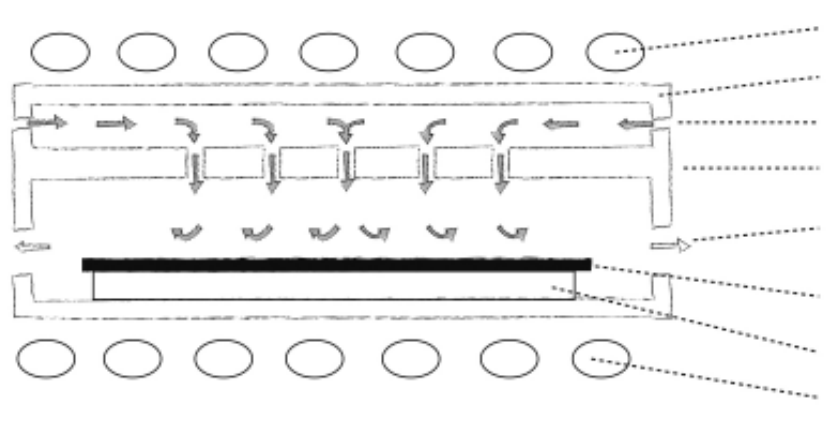

\section{Heating lamps Flat plate quartz Inlet process gasses Showerhead Exhaust process gasses}

\section{Silicon wafer} Susceptor

\section{Heating lamps}

The most prominent variation, called Model 1D, was a carrousel configuration (figure 38). It consisted of a round graphite cylinder in which slots were milled to hold the wafers. The idea was that the cylinder would rotate while the wafers in their slots were subjected to a gas flow. The benefit of this configuration was throughput. Depending on the slot width and angle, the number of wafers processed at one time was quite high. De Boer's proposition - Model 2B - was still regarded as nonconformist, and this was even more true of Model 1D, it being a creative, radical, and bold proposition.

On April 9 and 10, 1984, the Technical Advisory Board convened to discuss the development program's progress and to make up a running score. During this meeting, the technical staff presented the new lines of research into machine

59 This new variation constituted a hedge against the single wafer approach. One was a twozone batch reactor, a follow-up of Models $1 \mathrm{~A}$ and $\mathrm{B}$, which was soon abandoned. - Epsilon Technology, 'Epsilon Advisory Board Meeting, April 9 \& 10, 1984 (Day 1)' (9-4-1984) Archive Arthur del Prado -Epsilon file '84 - '85; Epsilon Technology, Armand Ferro, 'Minutes of April 1984 Meeting' (24-4-1984) Archive author - McDonald Documentation (1984-1985). 
configurations and sub-fields like heating methods, susceptor design, wafer handling, gas dynamics, and the economics of each proposition. ${ }^{60}$ The Technical Advisory Board was pleased. Hiring the experienced and inventive engineers seemed to pay off. The creative propositions underscored the program's potential for good results.

\section{Figure 38}

Artist impression of Model 1D - A hot-wall batch carousel reactor for epitaxy This configuration was proposed and championed by Wayne Johnson, early in 1984

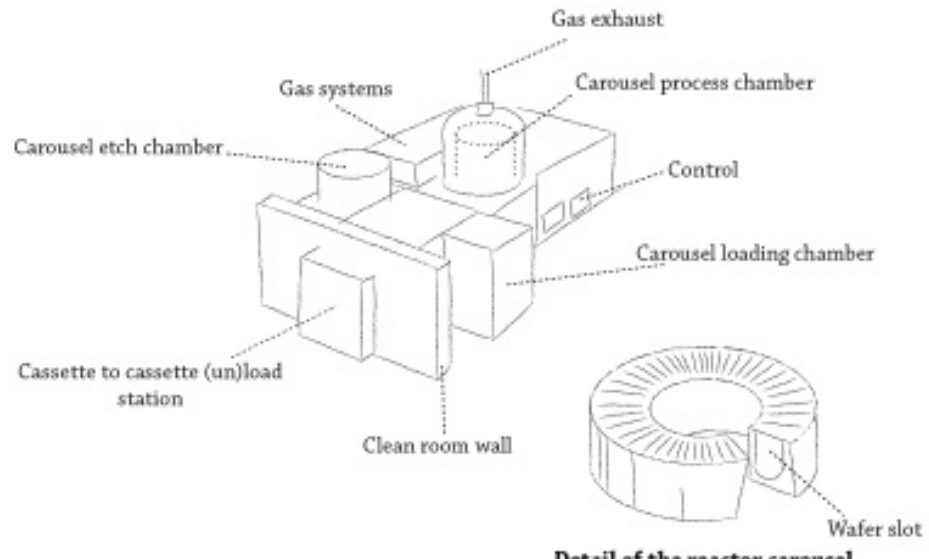

The Model 2 variations were reason for optimism in particular. Professor Jan Bloem recognized the cleanliness of these variations, compared to the hot-wall approaches, and in his view the single wafer configuration was easy to scale for bigger wafer sizes. As Bloem stated:

'Model 2 is a born winner for reasons of its potential high degree of cleanliness; it can also be adapted to other CVD applications; the approach is relatively independent of wafer size; ... this type of reactor deserves a large amount of attention. ${ }^{61}$

60 During the periodic Board meetings Ferro would briefly present the overall progress and program status - including financial expenditures, personnel, and market information and this was followed by feedback from the technical staff. Johnson's two-phased batch reactor, Model 2C, was briefly discussed as well. Robinson developed another variation, a radiant heated small batch reactor, named 1E. - Epsilon Technology, 'Epsilon Advisory Board Meeting, April 9 \& 10, 1984 (Day 1)' (9-4-1984) Archive Arthur del Prado - Epsilon file '84 - '85; Epsilon Technology, Armand Ferro, 'Minutes of April 1984 Meeting' (24-4-1984) Archive author - McDonald Documentation (1984-1985).

61 Epsilon Technology, Armand Ferro, 'Minutes of April 1984 Meeting' (24-4-1984) Archive author-McDonald Documentation (1984-1985). 
Some doubts remained, however. In particular the ASM America board members questioned the economics of the configuration. ${ }^{62}$ Being very commercial engineers, they focused on the economic connection to the market. Production equipment had to make money for the equipment manufacturer and the chip manufacturer. Del Prado nuanced their concern:

'the cost of the machine is not of major impact; the Model 2 has an advantage in its ability to scale up to larger wafers; there is also less risk with invested dollars in the batch; ... Model 2 seemed to merit throttles forward.' 63

Despite this optimism for Model 2, it was seen as too risky to put all the Limited Partnership's money on the single wafer model, also because too many sub-fields still had to be defined. For instance, the gas levitation did not work well yet, nor was it possible to choose between variation B (single wafer horizontal flow) and $C$ (single wafer with stagnation point flow). To lower the risk involved, the Board supported Johnson's plea further to explore the possibilities of a batch reactor. Given the promising results of Model 2B, more attention was given to the alternative Model $1 \mathrm{D}$ and $2 \mathrm{C}$ in order to see what these approaches might generate, thus also evening up the competition between the variations.

Moreover, the Board approved the exploration of sub-fields. This involved alternate heating of the chamber other than through lamps, such as through induction or microwaves. Also, the Board requested to exclude alternate or uncommon temperature measurements, like video, laser, and optical thermography. For each of the machine configurations - Model 1D, 2B, and 2Cthese sub-fields of research were taken into consideration over the course of 1984.

Johnson's and Robinson's creativity in developing alternate innovations for these areas virtually knew no bounds. Supported by their ability to express and substantialize their ideas in clear language and calculations, they were capable of looking beyond the norm in semiconductor equipment development. Epsilon Technology's mission was to develop an innovative epitaxial machine, and both men were resolved and highly stimulated to realize this. All technical options had to be put on the table for consideration, modeling, and experimentation, and after obtaining clear results, specific options had to be either rejected or integrated

62 ASM America was represented at this meeting by its general manager Don Jackson, R\&D manager Dick Rosler, and marketing manager Dale Stoddard.

63 Epsilon Technology, Armand Ferro, 'Minutes of April 1984 Meeting' (24-4-1984) Archive author-McDonald Documentation (1984-1985). 
into the final design. Elaborating upon their experiences at advanced laboratories, Robinson, Johnson, and Ferro advocated a thorough research process. ${ }^{64}$

\section{A terror of PhDs?}

De Boer regarded the efforts put into the new variations as leading them astray from the obviously successful Model 2B. Based on his extensive experience in epitaxy, he suggested the single wafer variations at the program's early beginning already. His single wafer with horizontal gas flow had proven to be simple and robust. It seemed like his colleagues wanted to make their mark by championing inventive solutions. According to De Boer, the management of Epsilon Technology suffered from talent manqué.

His frustration was directed in particular toward Model 1D. De Boer regarded this proposition unfeasible, since the uncertainties and subsequent required experiments outpaced the scope of the development program. 'A carbon monster,' he dubbed it. ${ }^{65}$ It did not make any sense to the experienced semiconductor equipment builder. But during the technical discussions he found no hearing. Ferro recalled that Johnson would argue the following during the technical meetings:

'We got to do this. It is batch, we need it for CMOS and the batch will have a high throughput. So, it makes sense to make this work. You guys are doing one wafer at a time, and you're gonna be killed on the cost per wafer basis. ${ }^{66}$

During the summer, an experimental set-up was made to assess the gas flow and depositions of Model 1D. ${ }^{67}$ Instead of committing all resources to his variation, a lot of energy and time was lost in singling out ostensibly far-fetched

64 Epsilon Technology, Ann Foster, 'Memo to Wayne Johnson: Model 2 Meeting (August 16, 1984)' (17-8-1984) Archive Author - McDonald Robinson Documentation (1984-1985).

65 The cost of the graphite susceptor with the slots containing the wafers would be very high to the customer, while also involving a huge thermal mass to be heated up during process time. - Wiebe de Boer, 'Interview with author'.

66 Armand Ferro, 'Interview with author'.

67 For the time being, this only involved a single slot, positioned in the horizontal tube of Model 1A. Also, they did models of and experiments into inductive heating of Model 1D. In addition, calculations and designs were made for automated loading systems. An external supplier of coatings was approached to develop a special coating that had to cover the slots and withstand very high temperatures without flaking off. Epsilon Technology, Armand Ferro, 'Technical report: June 1984' (10-7-1984) Archive Arthur del Prado - Epsilon 1984 files. 
alternatives, like pyrometers, double or single lamp arrays, and even laser and video thermography optics for measuring temperatures. ${ }^{68}$

Model 2C also competed for attention and resources. This variation required parallel plates of quartz to be joined. Earlier in his career at ASM in Bilthoven, De Boer experimented regularly with quartz joints and flanges, obtaining intimate knowledge about the possibilities in this regard. The Dutch engineer regarded the stagnation point flow as interesting from a theoretical point of view, but also as impractical - or even impossible - to manufacture. Meanwhile, by June 1984, Model 2B with a stationary susceptor resulted in slip-free epitaxy!

De Boer's frustration increased by the day. Being a blunt Dutchman among Americans, he plainly stated his objections, calling a spade a spade. During heated discussions, the technologically eloquent Johnson and Robinson, tried and tested in technical debates at respectively Livermore and Bell Labs, overpowered De Boer with their argumentation. But De Boer was not daunted by their display of intellect, and he relied on his own hands-on experience and dug in his heels. As a result of his stubbornness, he entrenched himself. In his disinclination to pursue excessive lines of research - Model 1D, microwave heating, laser-thermography, etc. - he became a unequivocal dissonant in the team. Aside from cultural differences, it involved a clash between routines: pragmatic craftsmanship versus scientific engineering.

De Boer's resentment toward the technical management erupted after he discovered a discrepancy in salary. In the run-up to the upcoming Technical Advisory Board meeting of September 1984, De Boer felt that his Model 2B would be neglected. He complained to the Dutch Vice-President of ASM America, Max Wieringa, who reported back to Arthur del Prado:

'Unfortunately, I have to conclude that there is no evidence at all of there being a team at Epsilon Technology, and I sense that the impression of progress is primarily based on unchecked claims and presentations during Board-meetings, rather than on actual facts.

A few months ago Wiebe de Boer accidentally saw a list of all salaries of ET employees. Aside from the fact that Wiebe does not appreciate the contributions of people like Wayne or Mac to the project, it was a downright shock to Wiebe to see the salaries of these gentlemen....

68 Epsilon Technology, Armand Ferro, 'Technical report: June 1984' (10-7-1984) Archive Arthur del Prado - Epsilon 1984 files; Epsilon Technology, Armand Ferro, 'Technical report: July 1984’ (13-8-1984) Archive Arthur del Prado - Epsilon 1984 files. 
I describe it as terror of the PhDs. Probably, Dave Klem [engineer for automation on Model 1] already discussed with Willem [de Leeuw] a letter in which he was forbidden, under penalty of discharge, to raise certain matters during the Board-meeting. Is this another example of terror of the PhDs? I'm growing increasingly convinced of it! I'm also convinced of the paranoid nature of the companionship.

Throughout the last weeks and up to this day, Sunday 1984/09/09, they have been practicing their Board-meeting presentations. I'm sure that not all facts will be put on the table. I'm also sure that the Board-members will be manipulated by half-truths. I'm convinced the intention is to gain full support for the further development of the Model 1D reactor. ${ }^{169}$

Wieringa's memo may have over-emphasized De Boer's viewpoint on the matter. It perhaps contained slander as well. Or perhaps it well reflected the state of affairs at the operation. Either way, the memo and Wieringa's underlying irresistible need to report about Epsilon Technology illustrated the deteriorated atmosphere among the technical managers.

Through De Boer's anxiety about his Model 2B, the process of variation and selecting the right configurations became politicized, in particular because his good reputation still colored the view of his fellow-Dutch members on the Technical Advisory Board, including Del Prado, De Leeuw, Bloem, and Saris. Moreover, the ASM members on the Board shared De Boer's background in commercializing semiconductor equipment without dwelling into exhaustive research. The upcoming board meeting should reveal the extent to which his dissenting attitude struck a chord.

\section{Full steam ahead}

Irrespective of De Boer's criticism of the technical management of Epsilon Technology, the Technical Advisory Board was eager to see results. Even if progress and work were promising, the original Fall 1984 deadline, as stated in the Epsilon Limited Partnership prospectus, would not be met. During the presentations on September 10 and 11, progress on Model 1 and 2 was presented, including market estimates and updated customers' requirements for CMOS epitaxy.

The Board selected Model 2 as its favorite approach, despite the proposal of the technical team to continue work on both Model 1D and Model 2 into prototype

69 Original quote in Dutch. Probably Wierenga wrote intentionally to Del Prado in his native language. ASM America, Max Wieringa, 'Memo: Epsilon Technology' (9-9-1984) Archive Arthur del Prado - Epsilon 1984 files. 
status. ${ }^{70}$ Model 1D was deemed too complex, big, experimental, and expensive to be attractive for the industry. ${ }^{71}$ The Board members suggested to focus all the work on Model 2 and turn it into a prototype machine, ${ }^{72}$ without expressing a preference for Model 2B or $2 \mathrm{C}^{73}$ Although the various sub-line options still had to be explored, selecting Model 2 as prototype surely represented a milestone. ${ }^{74}$

Time and money were running out, however. To address these concerns, Ferro and Johnson set an ambitious new deadline combined with an incentive program to motivate the employees of Epsilon Technology. Everything was now put in place to deliver a prototype by May 1985, which coincided with the annual Semicon West Conference in San Mateo, the industry's annual conference on the latest developments in semiconductor technologies. As Johnson suggested, it would be a great opportunity to show the first version of the reactor to the outside world. ${ }^{75}$

Despite the annulment of the batch variation, the workload hardly decreased, as creative propositions continued to be considered. After the Board meeting, it was decided to work on two new variations of Model 2B and 2C. These variations, $2 \mathrm{D}$ and $2 \mathrm{H}$, elaborated on the best aspects of the original concepts. They comprised a mechanically supported susceptor but differed from each other in gas flow: stagnant point flow in $2 \mathrm{D}$ and horizontal in $2 \mathrm{H} .{ }^{76}$

The reinvigorated effort resulted in several timely features, in particular in the area of wafer handling. Manager of engineering Jack Wengert proposed the use of transfer boxes. These cassettes were used to transport wafers from machine to machine in the clean room, and were a novelty back then. The Epsilon machine

70 Epsilon Technology, W.H. de Leeuw, 'Conclusions of the Board Meeting d.d. September 10 and 11, 1984' (4-10-1984) Archive Arthur del Prado - Epsilon Technology Jan '85 t/m Juli '86.

71 Even a quartz variation (model 1F) would not overcome these concerns. - McDonald Robinson, 'Personal Note - File 0402' (2-4-1985) Archive Author - McDonald Robinson Documentation (1984-1985)

72 The work on Model 1D would be discontinued only gradually, however. This pertained in particular to work on alternative coatings performed by Battelle Inc. The findings on this coating would later be used for Model 2B, which initially would be equipped with a stationary susceptor. Experiments with Model 1D itself never resulted in any suitable epitaxial films.

73 Epsilon Technology, Armand Ferro, 'September 1984 Epsilon Technical Report' (9-10-1984) Archive Author - Notes from Armand Ferro Documentation (1984-1985).

74 Epsilon Technology, Armand Ferro, 'Sept 1984 Draft Board Minutes' (6-2-1985) Archive Arthur del Prado - Epsilon Technology Jan' 85 t/m Juli '86 p. 7.

75 Epsilon Technology, Armand Ferro, 'Epsilon memo: September 1984 Report' (9-9-1984) Arthur del Prado - Epsilon 1984 files.

76 In addition to an already extensive list for each sub-line, Johnson continued to add new solutions. He himself suggested a variation of the stagnant point flow, a rotating showerhead, temporarily dubbed Model 2J. Also, several inventive suggestions were made regarding the different sub-lines. 
made it possible for wafers to be loaded automatically. The new phenomenon was immediately incorporated in the design of the reactor.

De Boer had another complementary idea for wafer handling. In February 1985 he started to work again on wafer handling by means of a so-called 'Bernoulli wand', as it relied on the Bernoulli effect. An arm mounted above the wafer blew gas, which caused the wafer to be sucked to the wand - nearly touching it. This way, the Bernoulli wand picked up the wafer from a cassette, turned around, and placed it in the hot reactor on the susceptor. After processing, it picked up the wafer again - of course without damaging the surface - and placed it into another transfer box containing the processed wafers.

All the ongoing developments - and the new insights and suggestions, relevant to the process technology - were modeled first in computers before further exploration. Robinson constantly tried to get access to better software by consulting experts in modeling for vapor deposition, while keeping a keen eye on his budget. To get the most out of the computer aided engineering software, inventiveness and perseverance were required. Just like the experimenting with the real chambers, this relied on intimate craftsmanship.

In the run-up to the ambitious deadline of May 1985, all sails were set. Staff worked over-hours. Working days from 7 AM until 10 PM grew more common, as was true of working in weekends. Discussion occurred in standing meetings, to sustain a high pace and avoid the risk of slackening attention. ${ }^{77}$ As Ferro reported:

'The present mode of operation requires all project leaders to attend a standing meeting at 1:00 PM each day, to discuss the status as developed in the last 24 hours. Each Project Leader is required to see that efforts are applied 16 hours a day 7 days a week on any of their critical path items.'78

Staff remained motivated due to the major breakthroughs achieved in the six months after the September Board-meeting. ${ }^{79}$ A sense of progress prevailed. ${ }^{80}$ Moreover, Ferro secured some sort of bonus in the event the prototype was ready on time.

77 McDonald Robinson, 'Interview with author'; Wayne Johnson, 'Conversation with author'; Epsilon Technology, Armand Ferro, 'Memo: Epsilon December 1984 Technical Report' (211-19845 Archive Arthur del Prado - Epsilon 1984 files.

78 Epsilon Technology, Armand Ferro, 'Memo: Epsilon December 1984 Technical Report' (211-1985) Archive Arthur del Prado - Epsilon 1984 files.

79 Epsilon Technology, Wayne Johnson, 'April Technical Report' (8-5-1985) Archive Arthur del Prado - Epsilon file Jan '85 - Juli '86, p. 3. 
In December 1984, another effort to speed up the process involved the purchase of a quartz shop by ASM. ${ }^{81}$ This in-house quartz shop significantly accelerated experimental projects. Even for minor modifications of the models, the technical team did not have to wait for supplies anymore (it was not uncommon for quartz to break during transport).

In March 1985 the technical team settled on the minimum requirements of the reactor chamber configuration of the prototype. Initially, this configuration was called $2 \mathrm{~B} / 2 \mathrm{H}$, after the basic variation and the name of the prototype. As Ferro reported:

'The minimum reactor chamber configuration would consist of: the 2B/2H chamber design; parabolic reflectors, crossed lamp arrays top and bottom, horizontal gas flow; and a rotating susceptor. ${ }^{82}$

New alternatives were still contemplated, however. In the computer model of Model $2 \mathrm{H}$, a mechanical rotating susceptor was integrated. ${ }^{83}$ If highly promising, this variation also required some experimentation into the effects of rotation speed on the epitaxial film.

In the rush toward the May deadline, steps were missed. Too much work had to be done in too little time, while initially for every crossed-off solution another problem was added - if not more than one. Tensions among staff members erupted. Questioning the feasibility of the deadline or the allocation of time and resources was discouraged. Depending on the staff members' temper, emotions ran up and clashes escalated. The pressure-cooker was on the verge of exploding.

As the minimum features of the machine became apparent, Armand Ferro started to draw up a statement of the developed intellectual property. ${ }^{84}$ Patents

81 This was an operation called California Quartz. McDonald Robinson, 'Personal notes - File 1221' (21-12-1984) Archive author - McDonald Robinson Documentation.

82 Epsilon Technology, Armand Ferro, 'Epsilon March 1985 Report' (12-4-1985) Archive Arthur del Prado - Epsilon file Jan '85- Juli'86.

83 Engineer Albert Beers suggested to add a rotating susceptor to the horizontal flow variation (Model 2B/2H) in April 1985. At that point, only the Model 2C/2D with stagnant point flow gas inlet had been designed with a rotating susceptor. - Epsilon Technology, Wayne Johnson, 'Strategy for the final development of Epsilon's reactor' (30-5-1985) Personal files Armand Ferro; - Epsilon Technology, Mac Robinson, 'Weekly report (April 5-12, 1985)' (15-4-1985) Personal documentation Armand Ferro.

84 Epsilon Technology, Wayne Johnson, 'Memo to all project leaders: Patent Involvement Identification Process' (13-3-1985) Archive Author - McDonald Robinson Documentation (19841985). 
were prepared for the reactor, heating, gas flow, and even wafer levitation. ${ }^{85}$ But who contributed what, exactly, to each patent? A consultant named Jacky Awerman was hired by Johnson to assess and establish the individual contribution of all engineers. ${ }^{86}$ This seemed to aggravate tensions among the staff, however. For the technical leaders, this was the moment to ensure that their brilliance and ingenuity were formally recognized. Having your name on a patent gave a clear signal to the rest of the company, the industry, and even the world. Getting your name on the patent was a prestigious issue, and soon a discussion erupted about everyone's contribution. ${ }^{87}$ Not surprisingly, this had a centrifugal effect on the team at this stage.

As the deadline was near and the financial reserves supplied by the Epsilon Limited Partnership were almost depleted, it was time for tough decisions. Model 2B had troubles with slip. Model 2C/2D did not live up to its theoretical promises; its quartz structure remained too vulnerable and unfit for loading of wafers. Johnson summarized the state of the machine as follows:

'upon comparison of the two reactors, we find that the $2 \mathrm{H}$ reactor is significantly simpler in its present embodiment than 2D. This simplicity is projected to allow easier maintenance of this system. Some people believe that one further iteration of 2D could provide similar simplicity and maintainability, but we won't know until that exercise is concluded.' 88

Although Ferro wanted to select either Model 2H or Model 2D, it was apparent that this was not yet possible and that more research was needed. The desire to make a selection did not square with the state of development yet. As Robinson logged:

'At this morning's 8:00 meeting, Armand reviewed the 2D/2H evaluation ... He showed that the "manufacturability" indicators suggest that $2 \mathrm{H}$ should be the first reaction chamber ... but that the "technology" indicators show that $2 \mathrm{D}$ may ultimately be the better machine for

85 Epsilon Technology, Armand Ferro, 'Memo to W. Johnson: Patent Authorship' (14-5-1985) Archive Author - McDonald Robinson Documentation (1984-1985).

86 Jackie Awerman Associates, Inc, Jackie Awerman, 'Summary and analysis of the postprocess discussion and written comments' (4-4-1985) Archive Author - McDonald Robinson Documentation (1984-1985).

87 Epsilon Technology, Wiebe de Boer, 'Memo to A. Ferro: Your memo 5/14/'85, patent auth.' (15-5-1985) Archive Author - McDonald Robinson Documentation (1984-1985).

88 Epsilon Technology, Wayne Johnson, 'Strategy for the final development of Epsilon's reactor' (30-5-1985) Personal files Armand Ferro. 
uniformity, rate, and autodoping. We will therefore, according to Armand, continue with both reactors until the board meeting.' ${ }^{89}$

By the end of May 1985, no prototype was finished; the deadline was missed. Nevertheless, the management was happy with having articulated the ambitious deadline because for the first time substantial progress had been made. ${ }^{90}$

\section{The 'terror' continues through the summer of 1985}

De Boer was furious about the whole situation. His frustration about the terror of the PhDs' had not diminished since the fall of 1984. Although ultimately all effort was put into Model 2, this had done little to bring a final product within reach. His basic design managed to withstand all experiments, also after testing various new alternative ideas, most of which he saw merely as idle attempts of the technical management to distinguish themselves. The process surrounding the listing of patents only made things worse.

In the run-up to Ferro's selection on May 31, De Boer responded to Del Prado's inquiries. ASM's chief executive officer regularly contacted his fellow-Dutchman to assess the progress beyond the officially supplied monthly reports of Ferro and Johnson. De Boer's growing frustrations worried Del Prado, and the chief executive officer requested a meeting with Epsilon Technology's management. During this informal session, De Boer did not mince matters. As Robinson wrote in a personal log:

'he expressed frankly his negative views on a) reactor 2D, and b) Wayne's management style. I expressed to Wiebe my dissatisfaction with the nature of Friday's meeting, in that a) 2D's mechanical problems were stressed to the exclusion of the process principles that the machine is supposed to demonstrate, and b) the result of the meeting may be to undercut Wayne's ability to lead the organization. ${ }^{.91}$

The recriminations and the deteriorated atmosphere were not to the gentle Robinson's liking. He considered the criticism leveled at his idea of stagnation point flow - integrated in Model 2D - to have no merit, despite the production difficulties. Moreover, Robinson did not appreciate De Boer's frustration about Wayne Johnson's management. As Robinson noted in his log about the meeting:

89 Epsilon Technology, McDonald Robinson, 'Personal Log: 2D/2H' (31-5-1985) Personal files McDonald Robinson.

90 Armand Ferro, 'May 1985 report' (17-6-1985) p. 2 Archive Arthur del Prado -Epsilon file Jan '85 - Juli' 86.

91 Epsilon Technology, McDonald Robinson, 'Personal Log: Organizational issues, file: 0530' (30-5-1985) Personal files McDonald Robinson. 
'I further gave Wiebe the feedback that, in my experience, Wayne listens to any viewpoint that is backed up by sound reasoning, and that I have frequently observed Wiebe's views not being accepted by Wayne because Wiebe "goes rigid" in the discussion, resorting to generalities and "because I said so" arguments. ${ }^{92}$

The deadline's pressure and internal disagreements hardly helped to boost morale. And still much had to be done. To make the case for continuation until completion during the upcoming Technical Advisory Board meeting in July, some soul-searching was required. Consultant Jacky Awerman, who accompanied the patenting process, was asked to write a report about the distorted relations within the team. ${ }^{93}$

Her report was straightforward, concluding that the team operated as an informal organization with many overlapping responsibilities. According to Awerman, the main problem was leadership - or a lack thereof. The leaders of the program were regarded as brilliant, even though their strong personalities had a negative impact on the organization as well. For example, the technical director Wayne Johnson had poor manners and he took 'shoot from the hip' decisions. Armand Ferro and Wayne Johnson often contradicted each other, creating confusion on the work floor. In the run-up to the deadline, the team members were more often threatened with firing or ostracizing than stimulated by means of compliments. More and more people felt that the promised bonus was unattainable and that it had not been realistic from the start.

The missed deadline put the team under a tremendous amount of pressure, while it deteriorated the working relations and the ability of the leaders to manage the program. The clashing routines - the pragmatic engineer versus the scientific engineer - were not acknowledged. Their different backgrounds and experience in debating technological matters resonated in their interactions.

\section{Replenishing funds and re-evaluation of progress}

From the summer until the fall of 1985, the management of Epsilon Technology and ASM International tried to fix things. Since the project missed its deadline, the financial reserves had to be replenished. ${ }^{94}$ Throughout the program, Ferro and his financial officer Gloria Zemla keenly managed the expenditures. All

92 Ibid.

93 Jackie Awerman Associates Inc, 'Epsilon Technology Inc, Organizational Survey. May 24 June 3, 1985’, Archive Arthur del Prado - Epsilon File 1984-1985.

94 Epsilon Technology, Armand Ferro, 'Epsilon April 1985 Report' (15-5-1985) Archive Arthur del Prado - Epsilon file Jan '85 - Juli '86; ASM International, Arthur del Prado, 'Letter to Raad van Commissarissen: Epsilon' (22-8-1985) Archive Arthur del Prado - Epsilon file Jan '85 - Juli '86. 
the money was most soberly spent. No reproach could be made in that regard. The depletion of funds was solely caused by the delay of the program. Either additional funding was found or the program would peter out without resulting in a working epitaxial reactor. Zemla estimated that an additional 3.5 million dollars was needed for completion of the program by mid-1986. ${ }^{95}$ To substantiate this claim, Ferro developed a plan to speed up development.

Since Del Prado faced the consequences of a deepening downturn in the market (see Business III), it was all but an obvious decision to provide additional funding for Epsilon. ASM's chief executive officer replenished the funds in exchange for a proportional share in the Epsilon Limited Partnership - and in the eventual royalties. To facilitate and justify the refinancing of the program and the accompanying overhaul of the Epsilon Limited Partnership, the whole program was re-evaluated. This was done by the management of ASM America, Epsilon Technology, and lawyers Dick Bowers and Bob Moya, who had written the prospectus of ASM and the Limited Partnership. ${ }^{96}$ They arranged that on behalf of the private investors a running score was made. The exercise was convincing. All the investors in the Epsilon Limited Partnership approved. Better fewer royalties than nothing.

As a consequence of these rearrangements and the program's financial stakes, ASM become more directly involved. Moreover, one of the external experts, Jan Bloem, fell seriously ill and could no longer serve on the Board. ${ }^{97}$ The dominance of ASM in the Technical Advisory Board - Del Prado, ASM America's new general manager Franc DeWeeger, Dick Rosler, and Willem de Leeuw - caused a shift toward commercial considerations.

Ferro was requested to list assets that might be sold in order to improve the financial situation of Epsilon Technology.$^{98} \mathrm{~A}$ major effort was put into selling the ideas that failed to work in the context pursued, such as model 1D to Mitsubishi. ${ }^{99}$

95 Richard W. Bowers, 'Telex from Richard W. Bowers to Arthur del Prado: untitled' (20-8-1985) Archive Arthur del Prado - Epsilon file Jan '85- Juli '86.

96 Moya, Bailey, Bowers, Jones P.C., Richard W. Bowers, 'Telex to Arthur del Prado: The project needs...' (20-8-1985) Archive Arthur del Prado - Epsilon file Jan '85 - Juli' 86; Epsilon Technology, Armand Ferro, 'Telex to ASM International [Art del Prado, Willem de Leeuw, Jan de Bes]: Limited Partner Voting' (7-12-1985) Archive Arthur del Prado - Epsilon file Jan '85- Juli '86.

97 Jan Bloem eventually died of cancer in 1986.

98 Armand Ferro, 'ET Plan' (19-7-1985) Archive Arthur del Prado - Epsilon file Jan '85 - Juli '86; Epsilon Technology, Armand Ferro, 'ET Schedule' (10-9-1985) Archive Arthur del PradoEpsilon file Jan '85 - Juli '86.

99 Armand Ferro, 'Letter to Yo Miyazaki, president of ASM Japan' (5-2-1986) Archive Arthur del Prado - Epsilon Technology Jan' 85 - April' 86. 
Another measure was to decrease labor costs. Only the indispensable staff members were allowed to stay on. Ferro had to lay off 19 of the 46 employees. ${ }^{100}$ The new plan assumed that model 2H, De Boer's brainchild, would be the only chamber considered. The depletion of financial resources was the final blow to the stagnation point flow variation, Model 2C/2D. All the efforts into stagnation point flow resulted in robust computer models but not in a machine. Whether the former alternatives had been more perfect or not was now irrelevant. Time and the depleted financial resources decided the argument.

\title{
Final push of the development phase
}

The program entered the final phase of development. The team was hopeful about the potential of the machine. As De Boer stated:

\begin{abstract}
'The growth rate will not be beaten by any batch reactor. ... Uniformity is another strong point to which batch reactors cannot even come close.... There is not any reason to believe [resistivity uniformity] would act any different than the thickness uniformity, as is confirmed by the experiments so far. ... The surface quality maybe is the best part of all this. We of course were glad to finally see the Bernoulli pick-up perform. ${ }^{101}$
\end{abstract}

From the summer of 1985, final details of Model 2H had to be solved (figure 39). ${ }^{102}$ Modeling concentrated on gas flow across the chamber, the interface with the clean room, deposition and etching processes on reactor walls and gas outlets. ${ }^{103}$ Furthermore, designs were prepared for translation into the first prototype, named P1.

100 In the run-up to the May deadline, Ferro had increased staff. - Epsilon Technology, Armand Ferro, 'July Executive Summary' (20-8-1985) Archive Arthur del Prado - Epsilon file Jan '85 - Juli '86.

101 Epsilon Technology, Wiebe de Boer, 'Memo:EPSI EPI, status and future' (11-2-1986) Archive Arthur del Prado - Epsilon file Jan '85 - Juli '86

102 Epsilon Technology, 'Wayne Johnson, Memorandum: December Technical Status Report (7-1-1986) Archive Arthur del Prado - Epsilon file Jan '85 - Juli '86.

103 Armand Ferro, 'July Report' (16-8-1985) Archive Arthur del Prado - Epsilon file Jan '85 - Juli '86 p. 2. 


\section{Figure 39}

Schematic drawing of the Epsilon One single wafer reactor configuration, 1988

This image was depicted in the original customer flyer of ASM Epitaxy, to introduce the novel concept of single wafer processing.

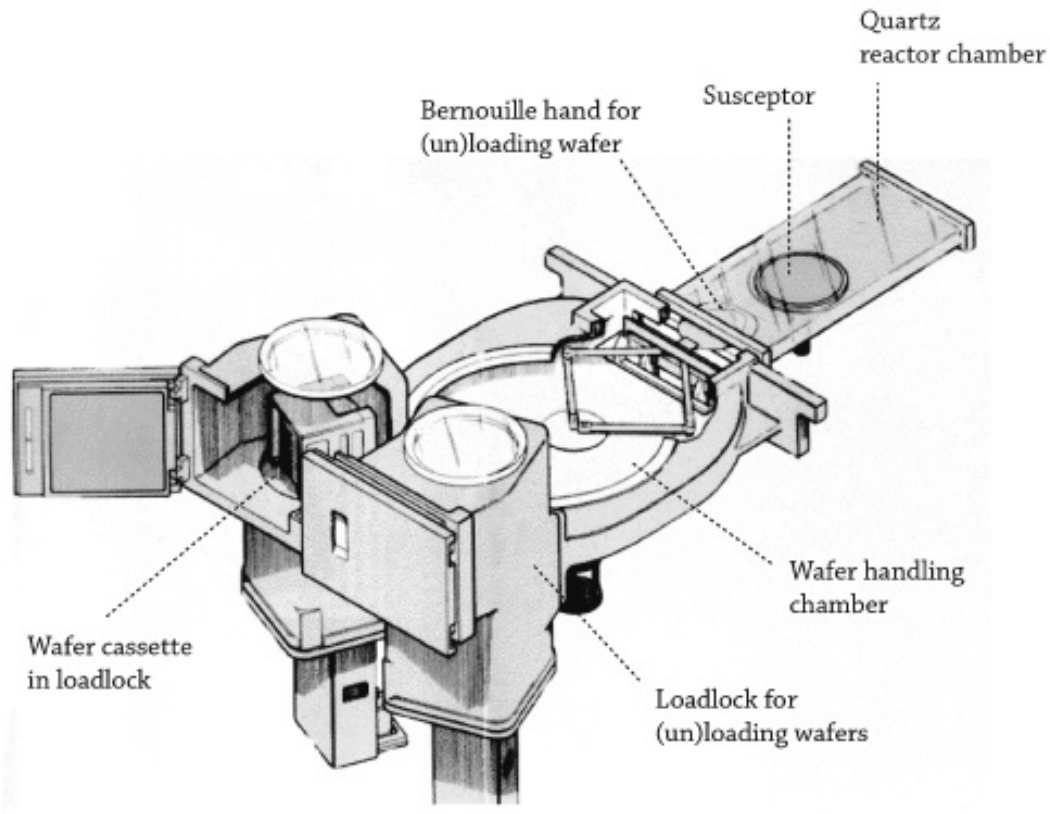

With regard to heating, several critical solutions were put on the table. One was the automated tuning profile of light arrays, which enabled manipulation of the deposition process by tuning the radiation of the heating lamps. Another solution, proposed by Robinson in March 1986, was to direct spot reflectors on the susceptor in addition to the crossed overlay rays of lamps. ${ }^{104}$

The heating profile of the lamps could be adapted based on the information supplied by the temperature measurement components. One of these was a pyrometer, which measured through the rotator shaft the heating of the center of the wafer. ${ }^{105}$ However, the heating at the edges of the wafer also had to be

104 MacDonald Robinson, 'Interview with author'; see also: Epsilon Technology, McDonald Robinson and Albert Ozias, 'United States Patent 4,836,138: Heating System for Reaction Chamber of Chemical Vapor Deposition Equipment' (filed: 18-6-1987; published: 6-6-1989).

105 Wiebe de Boer, 'Interview with author', Armand Ferro, 'Interview with author', McDonald Robinson, 'Interview with author', and Wayne Johnson, 'Interview with author'; see also: Epsilon Technology, Wiebe de Boer, Albert Ozias, 'United States Patent 4,821,674: Rotatable Substrate Supporting Mechanism with Temperature Sensing Device for Use in Chemical Vapor Deposition Equipment' (filed: 31-3-1987; published: 18-4-1989). 
monitored constantly in order to guarantee perfect uniformity across the wafer. Since the susceptor itself rotated, it was difficult to integrate thermocouples. In March, Ferro decided to add a stationary ring surrounding the susceptor - dubbed a Saturn ring - containing the thermocouples. ${ }^{106}$

In combination, these inventions offered absolute control over the heating in the chamber in the critical area, the susceptor, and they were key to the machine's performance. With these latest additions to its design in place, the final production of the P1-machine could be started in the spring of 1986 . The P1 was used to verify the capabilities of the system developed by Epsilon Technology.

Work with the P1 entailed fine-tuning the susceptor, temperature measurement, heating, and wafer handling. This also involved air flow, tube deposits, tube design, temperature control by means of the pyrometer and thermocouples (and proposal of Saturn ring), seals, quartz, and wafer automation. In computer models, process variables were tweaked and tuned, and the complete machine was designed and tested throughout the summer of 1986. ${ }^{107}$

Technological issues became more and more comprehensible. In September 1986 the first slip-free wafers as defined by the industry's standards were achieved in the first prototype, $\mathrm{P} 1{ }^{108}$ Most of the remaining shortcomings were overcome and improved in the designs of P2 and P3. ${ }^{109}$ Although some minor technical issues remained, it was time to start work on the final process of commercializing the product.

\section{A new phase and a need for new staff}

Throughout 1986, the new phase of the program was reflected by the need for new staff, with commercial rather than technical talents. From Spring 1986, the leading members of the technical team left the program in search of new

106 The idea of the Saturn ring was suggested by Al Ozias. - Armand Ferro, 'Interview with author'; Epsilon Technology, Armand Ferro, 'May 1986 Monthly Report' (6-6-1986) Archive Arthur del Prado - Epsilon file Jan '85 - Juli '86; Also mind: Epsilon Technology, McDonald Robinson and Albert Ozias, 'United States Patent 4,836,138: Heating System for Reaction Chamber of Chemical Vapor Deposition Equipment' (filed: 18-6-1987; published: 6-6-1989).

107 ASM, Inc, B. Haro, 'Interoffice Memorandum to A. Ferro: Epi Documentation' (19-5-1986) Archive Arthur del Prado - Epsilon file Jan '85 - Juli '86.

108 Epsilon Technology, Armand Ferro, 'September Epsilon Report' (8-10-1986) Archive Arthur del Prado - Epsilon Epitaxy Juli 1986 - Juni 1990; Epsilon Technology, Al Ozias, 'Interoffice memorandum: Monthly Prototype Status Report - September 1986' (4-10-1986) Archive Arthur del Prado - Epsilon Epitaxy Juli 1986 - Juni 1990.

109 The team designed a simplified version of the machine front-end. Eventually, designers from Gregory Fossella Associates would partially redo this initial effort in order to get the best visual effect. - Epsilon Technology Inc, Jack Wengert, 'Interoffice Memorandum: Monthly Report - May' (2-6-1986) Archive Arthur del Prado - Epsilon file Jan '85- Juli '86. 
challenges. ${ }^{110}$ After the completion of the Epsilon Technology program, all knowledge and experience would be transferred to ASM, or staff members would have to try their luck elsewhere.

One by one, the original technological leaders resigned. In February 1986, Wiebe de Boer was the first to leave the program for Philips. ${ }^{111} \mathrm{He}$ had become too embittered in the program's last one year and a half. More importantly, the variation he championed had made it to the finish line, meaning that he could now withdraw without fearing the annulment or manipulation of his machine.

In the summer of 1986, Wayne Johnson's role as Technical Director became irrelevant. The development phase was almost over, and engineers from ASM America would help in the machine's commercialization. Facing the end of the development phase, Johnson tried to recreate Epsilon Technology in a projects-based R\&D center for ASM America. In this, he - together with Mac Robinson and Dick Rosler - would elaborate on the computer models developed throughout the program. ${ }^{112}$ Because Del Prado was already committed to the ASM Microelectronic Technology Center - with support from the Dutch authorities - and had no more funds available, Johnson's proposal was rejected. A man of his capabilities was of no use anymore in the program and Johnson was urged to resign in July.

At ASM America, things had changed as well, and not merely for the better. ${ }^{113}$ Epsilon Technology staff started to work simultaneously at ASM America. This already involved controller Gloria Zemla. A process engineer, Aage Olsen, became responsible for service at ASM America, and in 1986 Armand Ferro became head of R\&D at ASM America, while also staying on as general manager. In order to save costs, Epsilon Technology and ASM America were more integrated.

110 Epsilon Technology, Armand Ferro, 'Reorganization' (18-2-1986) Archive Arthur del Prado - Epsilon file Jan '85 - Juli '86; Wiebe de Boer, 'Letter of Resignation to Armand Ferro' (28-11986) Archive Arthur del Prado - Epsilon file Jan '85 - Juli '86.

111 As ASM could not yet offer him a job in a comparable development program, De Boer applied at Philips. At the prestigious Nat.Lab. he would continue to work with epitaxy and other deposition techniques, and transform himself into an external protagonist of the Epsilon machine. De Boer was replaced by Albert (Al) Ozias. Al Ozias was an old acquaintance of the program, having been involved in its start-up while working at Siltec. By the fall of 1986, after completion of the development phase, Ozias moved on as well.

112 On a napkin, Johnson rather prophetically proposed the development of a single wafer plasma reactor, elaborating upon the Epsilon. Also, Wiebe de Boer anticipated other applications of the reactor like polysilicon, etc. - Epsilon Technology, Wiebe de Boer, 'Memo: EPSI EPI, status and future' (11-2-1986) Archive Arthur del Prado - Epsilon file Jan '85 - Juli '8; Gloria Zemla, 'Interview with author', Mac Robinson, 'Interview with author', and Wayne Johnson, 'Conversation with author'.

113 Gloria Zemla, 'Interview with author'; Armand Ferro, 'Interview with author', Bob Haro, 'Interview with author'; John Krickl, 'Interview with author'; ASM International, Annual Reports 1984-1988. 
Illustrative for the new phase of the innovation process was the arrival of Bob Haro at Epsilon Technology in July 1986. The experienced ASM America engineer had to get the reactor ready for production. He was assigned to 'reduce footprint, reduce cost of parts and assembly, and to introduce product reliability, maintenance and appearance features without compromising performance. ${ }^{114}$ In this effort, Haro was translating the rudimentary designs into documentation fit for ASM America's manufacturing operations.

The new developmental phase was also heralded by the hiring of an experienced epitaxial marketing consultant: in June 1986, Steve Corlett arrived to develop a marketing plan. ${ }^{115}$ His hiring and that of designer Bob Haro marked the start of the commercialization process. From the initial technical leaders, only McDonald Robinson, Armand Ferro, and Jack Wengert were still around. Robinson remained indispensable to analyze minor modifications to the machine's design in his computer models. Wengert ran the machine and quartz shop. And Armand Ferro remained general manager and - supported by his controller Gloria Zemla - steered the program into its final round: getting the machine ready for introduction to the market.

114 Epsilon Technology, Armand Ferro, and Jack Wengert, 'Interoffice Memorandum: June Monthly Report' (1-7-1986) Archive Arthur del Prado - Epsilon file Jan '85 - Juli '86.

115 Ibid. 
Portrait of the Del Prado family, prior to the Second World War.

From left to right, Arthur Eugène del Prado, Arthur Hendrik del Prado, Hetty del Prado, and Hedwig ('Hetty') del Prado-van den Berg. After the Second World War, the family was enlarged with another daughter.
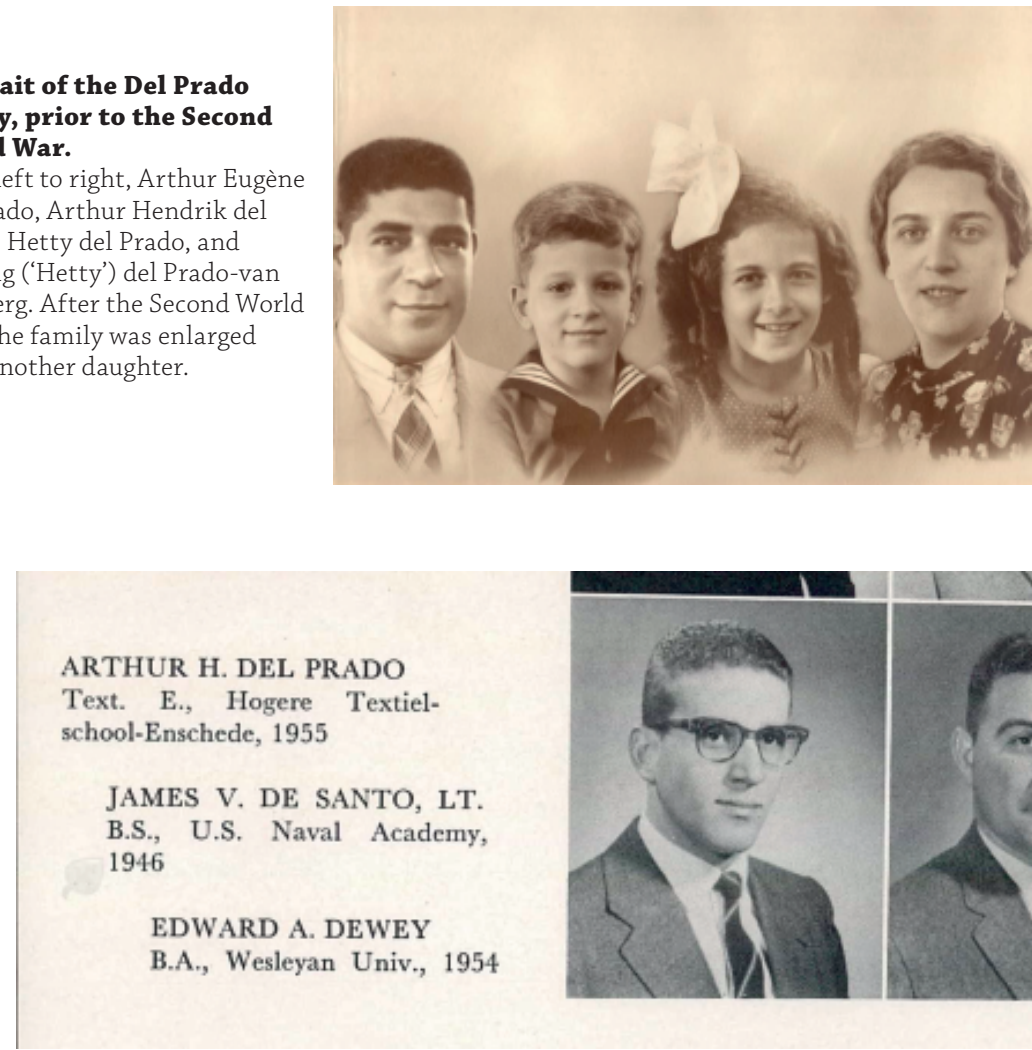

Portrait of Arthur del Prado in the Harvard yearbook, 1957

From left to right William Shockley, Smoot Horsley and Dean Knapic at Shockley Semiconductor Laboratory, late 1950s

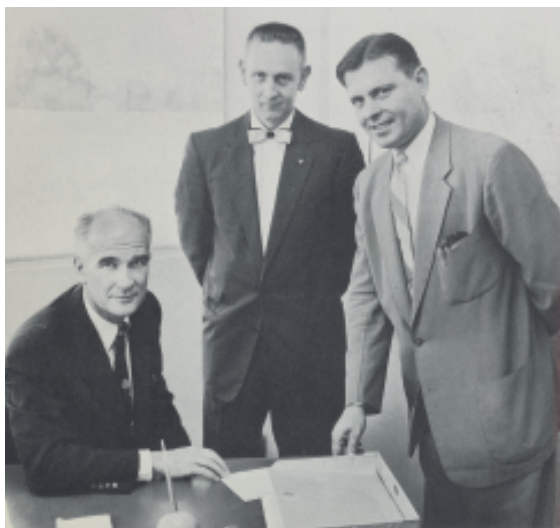



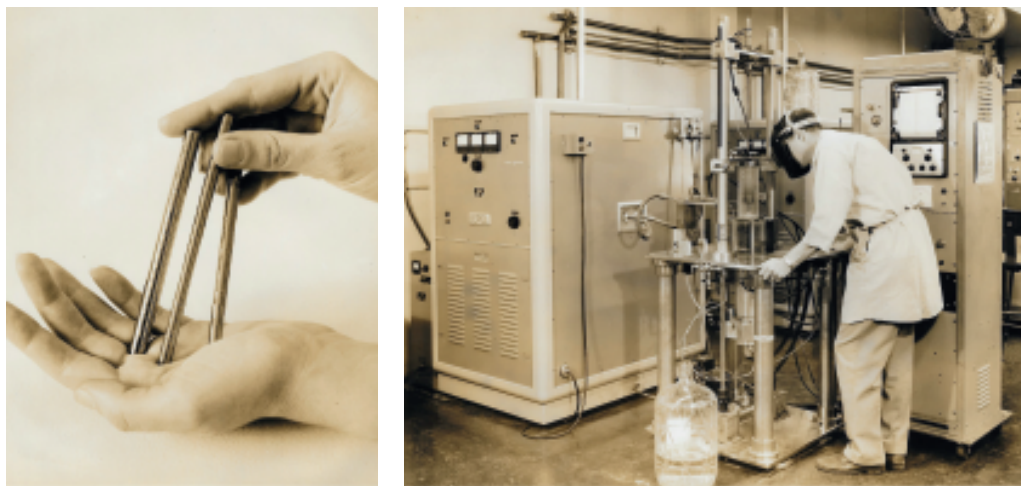

Knapic Electro-Physics silicon ingots (left) and silicon puller (right), 1959
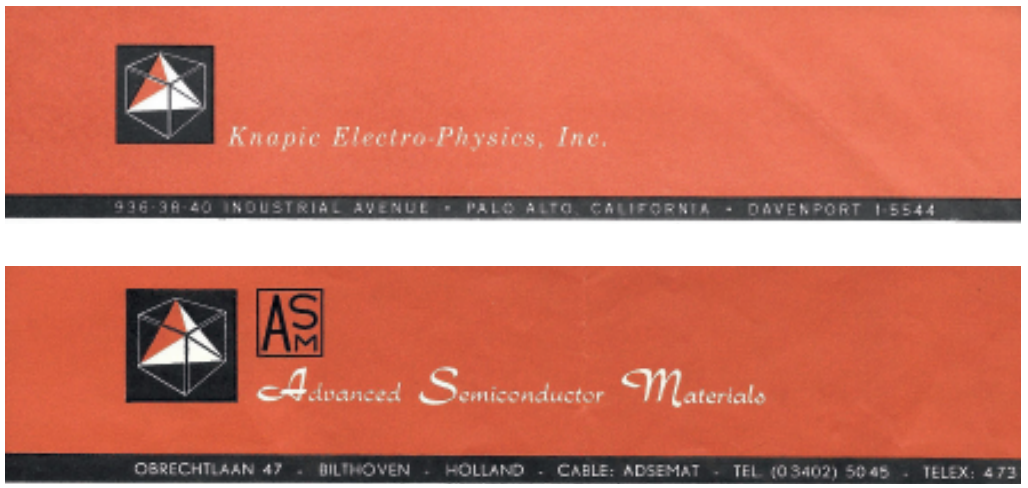

Stationary of Knapic Electro-Physics and Advanced Semiconductor Materials, 1960s

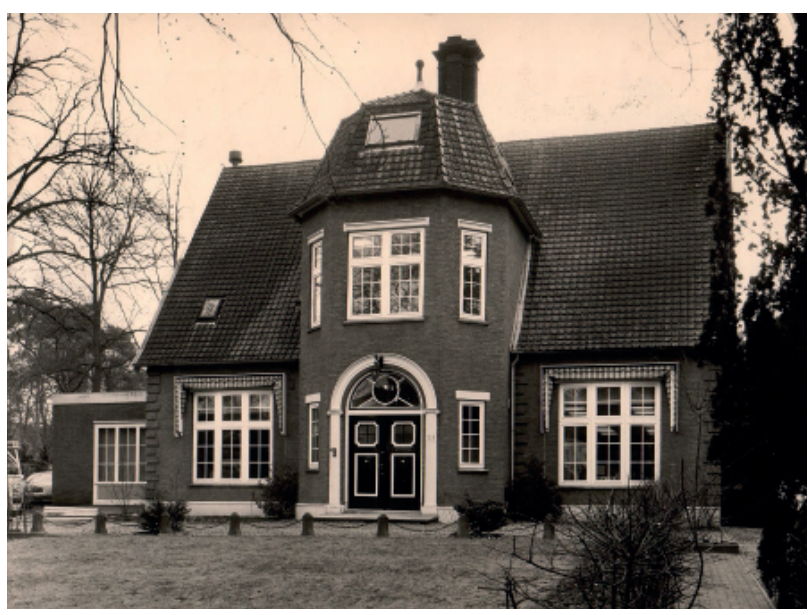

ASM office on

Soestdijksweg Noord, Bilthoven, 1960s

The first machine was built in the attic of the house. Later an extension was added behind the building. During one of the experiments, flumes would blast into the garden. 
Arthur del Prado and his airplane, mid-1970s

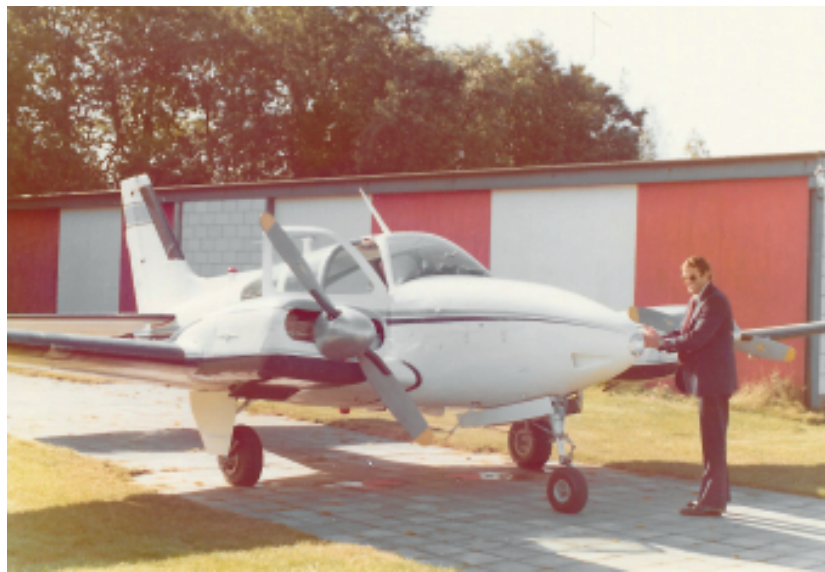

Photograph of chips representing the increase of bipolar IC complexity, 1960s

Copyright Computer History Museum

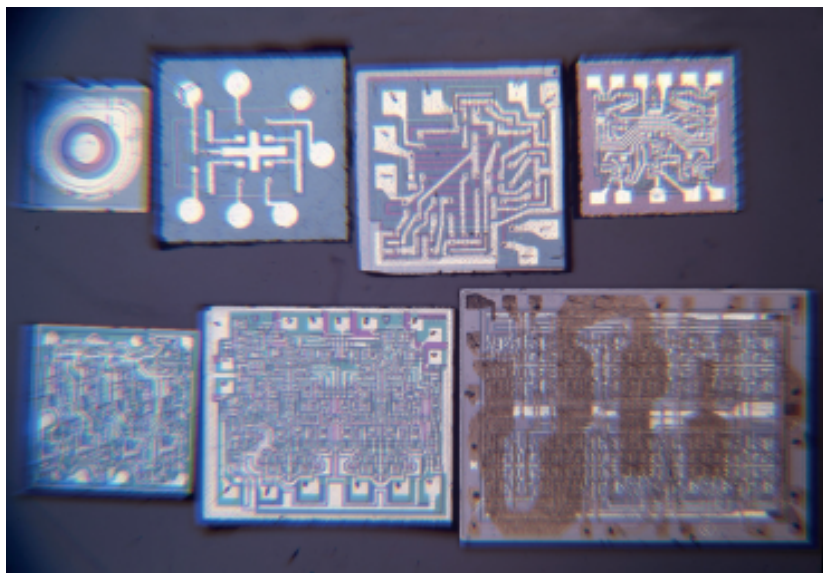

Martin van Beest (left) and Gerard Hartemink (right), Bilthoven, 1970s

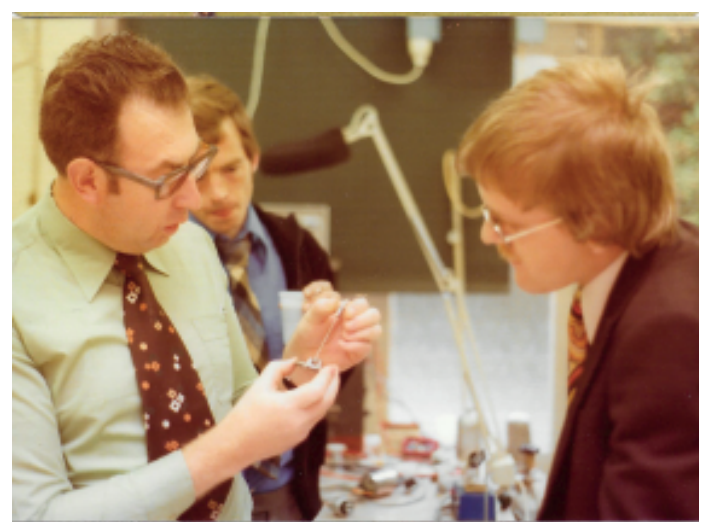




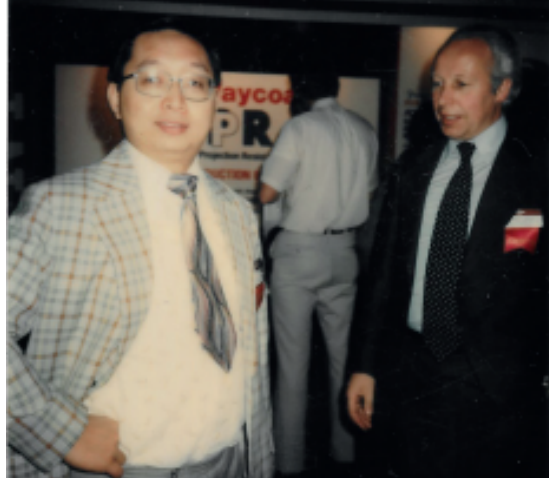

Co-founder and general manager of ASM Asia Patrick Lam (left), and founder and general manager of ASM Fico Richard Fierkens (right) at Semicon West, 1970s

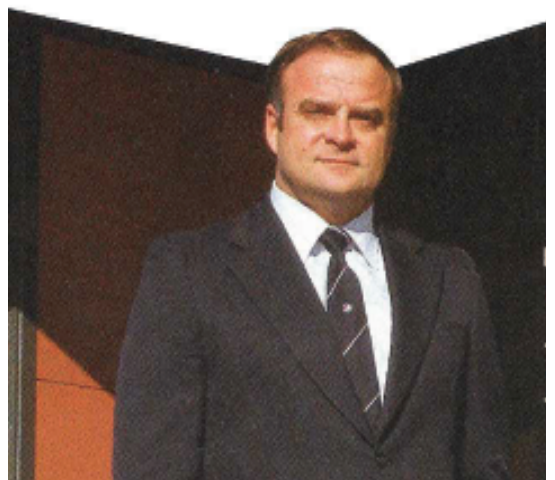

Don Jackson, ASM America's co-founder and first general manager, late 1970s

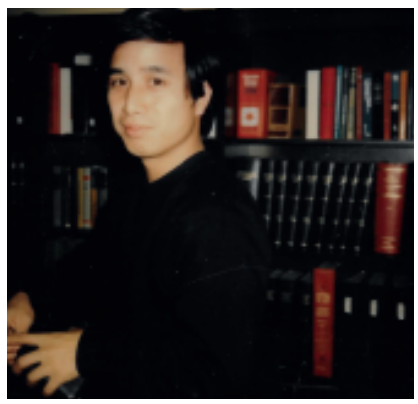

A young Fukumi Tomino during his first training course at ASM America in 1977, still on behalf of Marubeni Electronics

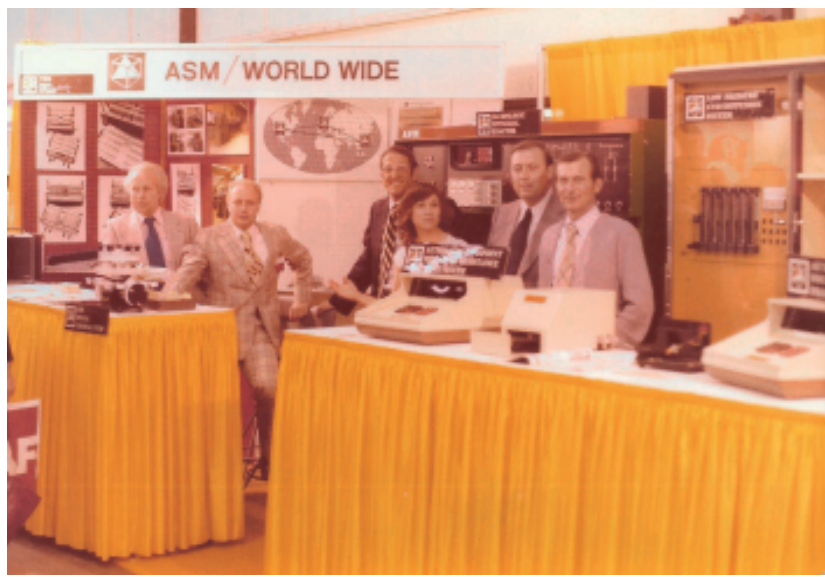

ASM exhibition during Semicon West [probably 1977]

First left is Richard Fierkens, third from left Arthur del Prado. Products at display on tables are fourpoint-probes of ASM America, and CVD equipment in the background. 
The SOX 10-2, 1972;

ASM's first chemical

vapor deposition machine

for the deposition of

silicon oxide.

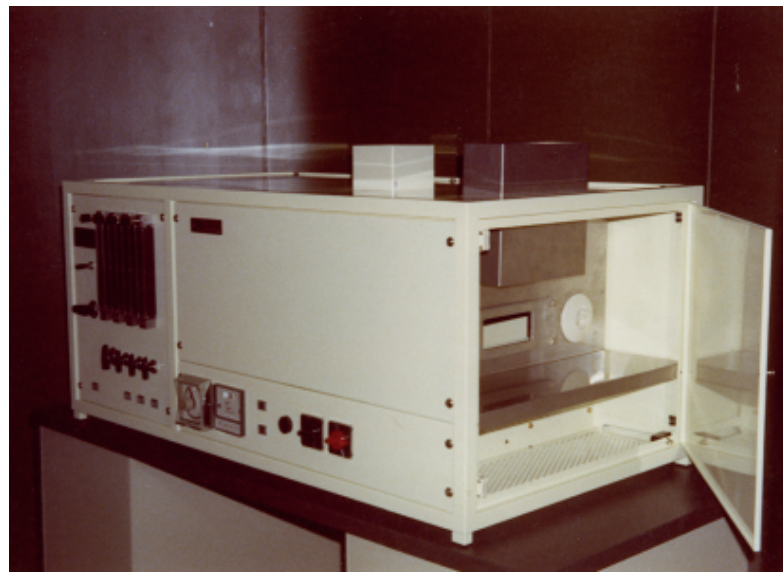

On the right, ASM's initial horizontal hot-walled

low-pressured chemical vapor deposition machine, approximately 1976.

On the left, an 'Etch-o-matic 500' wafer cleaning machine. Mind the 'industrial' colors of the machines.

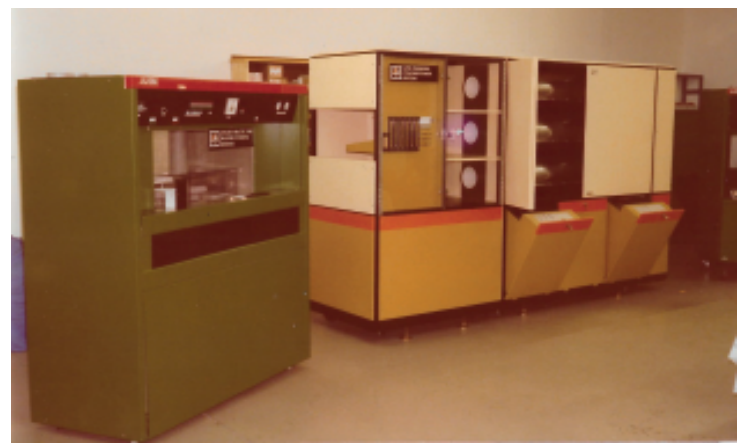

Plasma I, 1979.

ASM America's first plasma enhanced chemical vapor deposition machine,

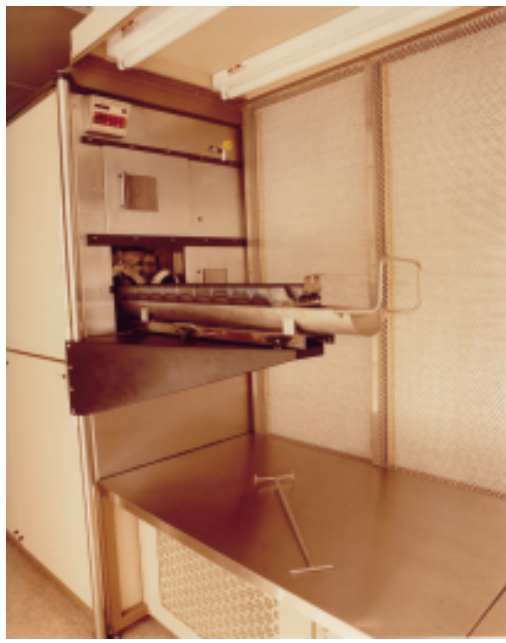



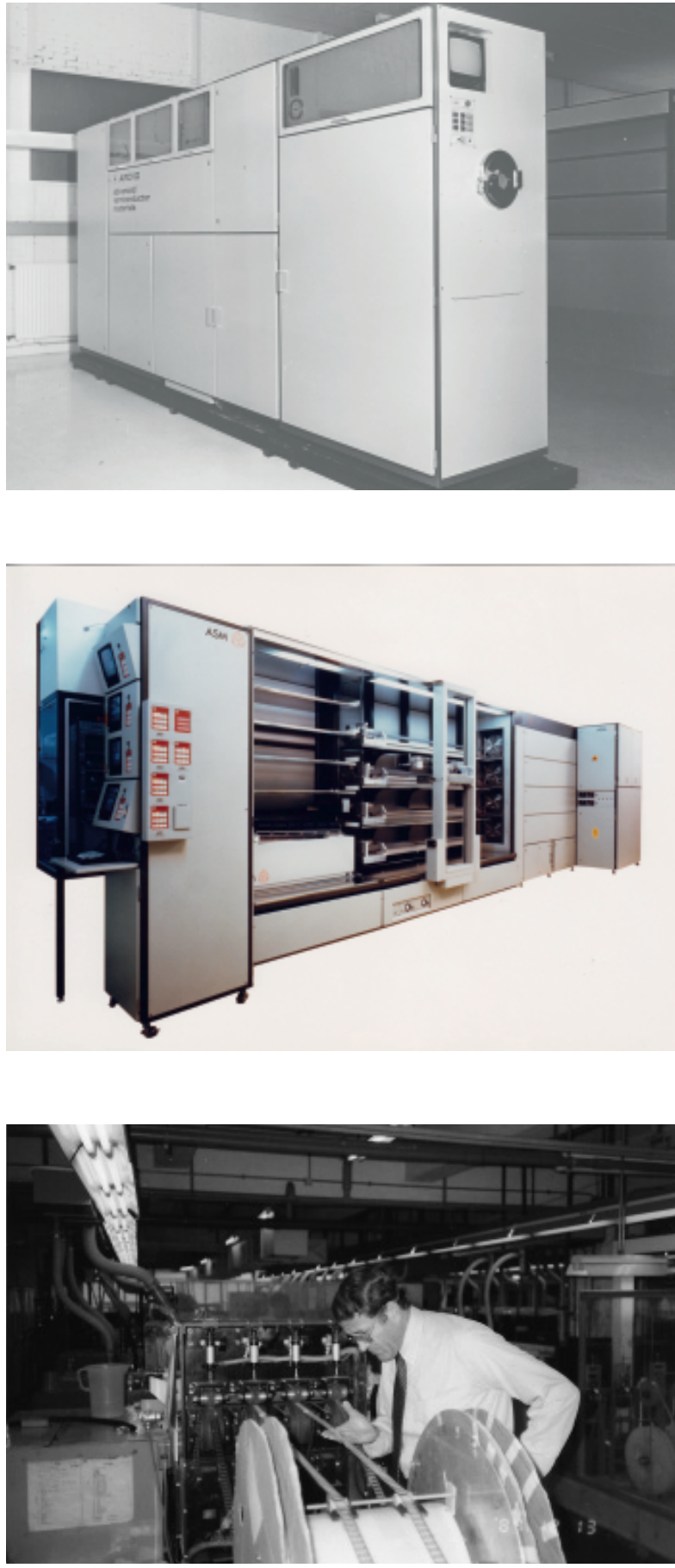

ASM Europe's aluminum chemical vapor deposition machine, 1982.

\section{A horizontal furnace,} 1980s.

This bulky machine was developed and fabricated by ASM Europe.

On the left side are the comprol panels. In the middle is the loading section. On the right side are the actual reactor tubes.
Arthur del Prado at a role of lead frames at ASM Assembly Materials, Hong Kong, 1980 
Close up of the AB1000 automatic aluminum wedge wire bonder, early 1980s.

Wires were bonded between the

leadframe and bonding pads on the die.

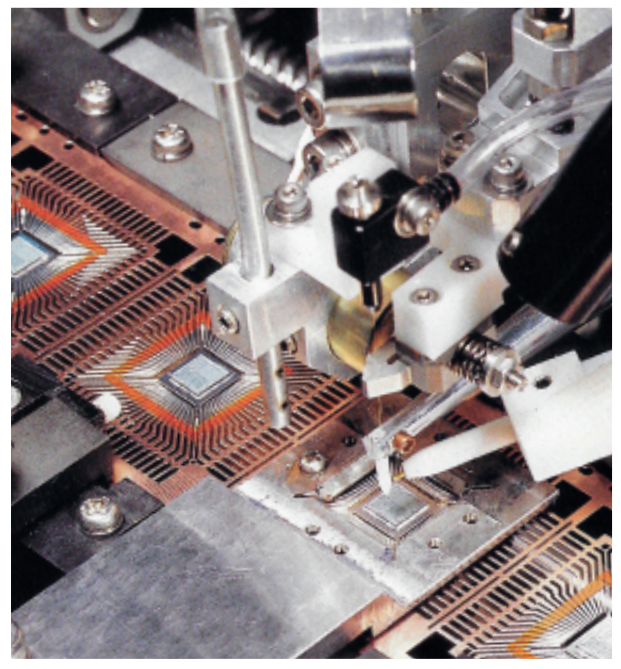

The first Supervisory Board of ASM

International, 1981

From left to right: Nico

Nobel, Arthur del Prado and Paul van den Hoek (chairman).

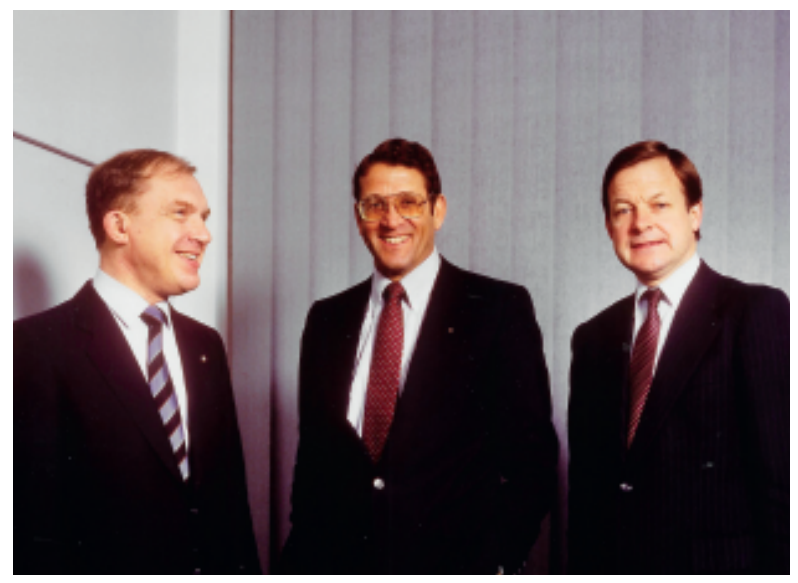

Arthur del Prado (right) receives the award 'Pursuit of Excellence' from Dutch prime minister Ruud Lubbers (left), November 30th, 1983.

Del Prado was awarded as Director of the Year.

Copyright ANP

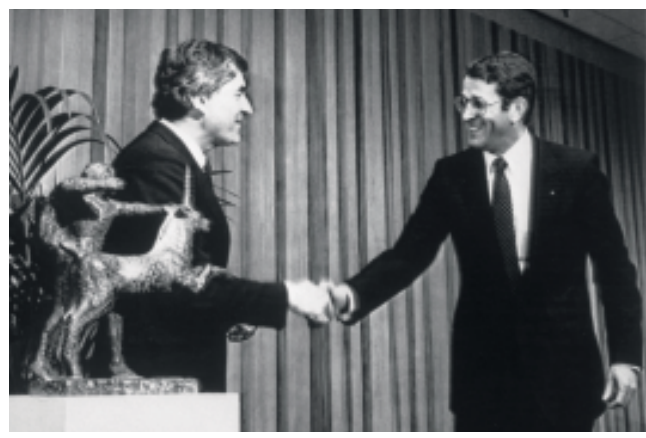




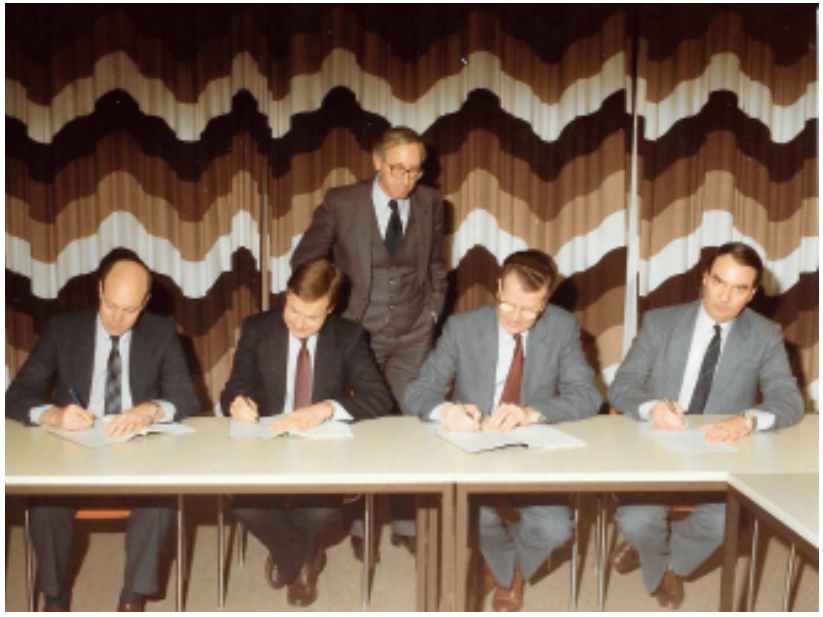

Signing ceremony for the founding of ASM Lithography, 1984

From left to right: Willem de Leeuw (Director of Technology, ASM), Paul van den Hoek (Chairman Supervisory Board, ASM), A.G. Asselman (legal affairs Philips), George de Kruiff (Director Philips S\&I) and Wim Troost (Director Philips S\&I).

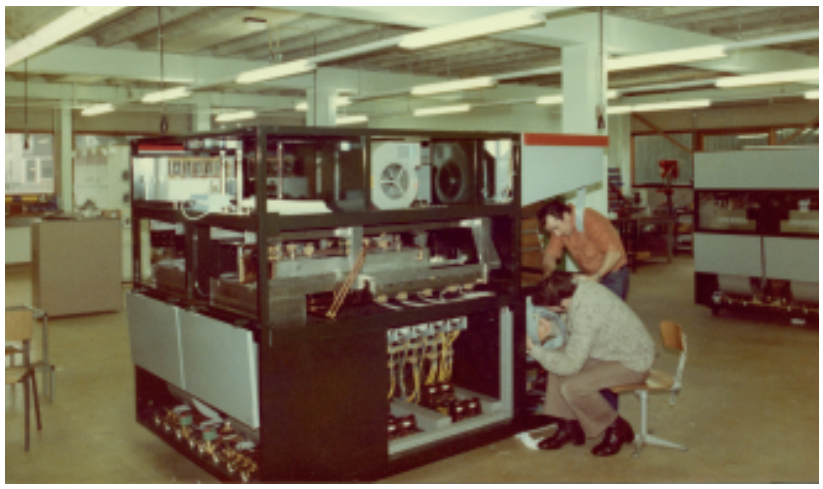

\section{Engineers of ASM assembling an Epilogic 21-3 epitaxial reactor in Bilthoven, late 1970s}

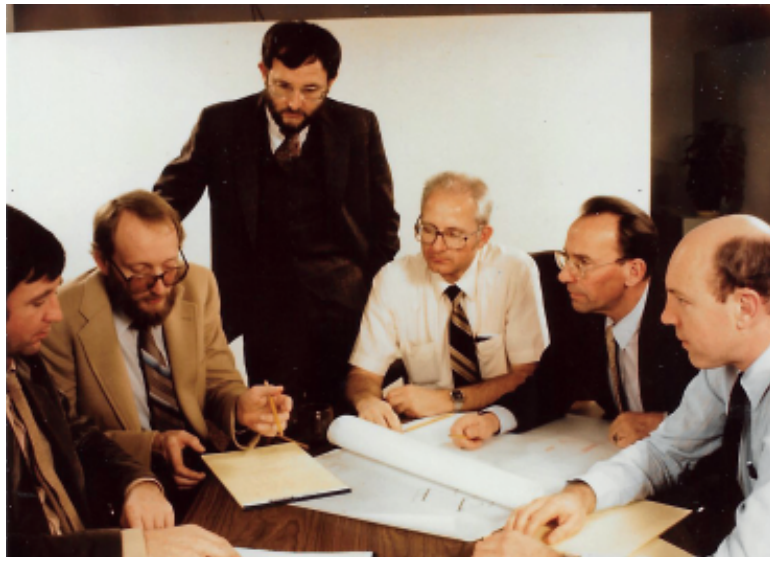

A meeting of some members of the Technology Advisory Board of Epsilon Technology, 1985

From left to right:

Professor Frans Saris (Amolf Institute), Wayne Johnson (Epsilon), MacDonald Robinson (Epsilon), Dick Rosler (ASM America), Professor Jan Bloem (Philips), and Willem de Leeuw (ASM International). 
View from above into a hot reactor chamber of the Epsilon, 1989

A wafer is loaded upon the susceptor. The typical process temperature for epitaxy is above 1150 degrees Celsius.

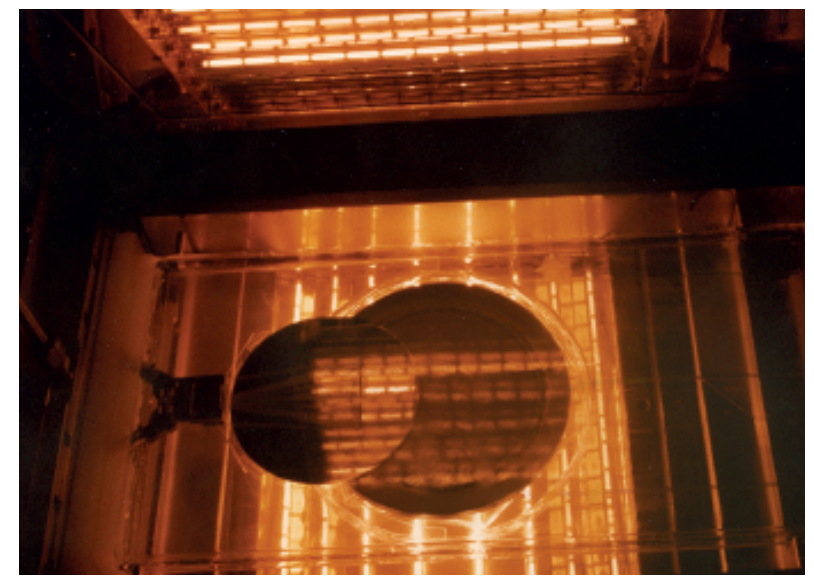

An engineer of ASM Epitaxy fabricating a quartz reactor chamber, 1989
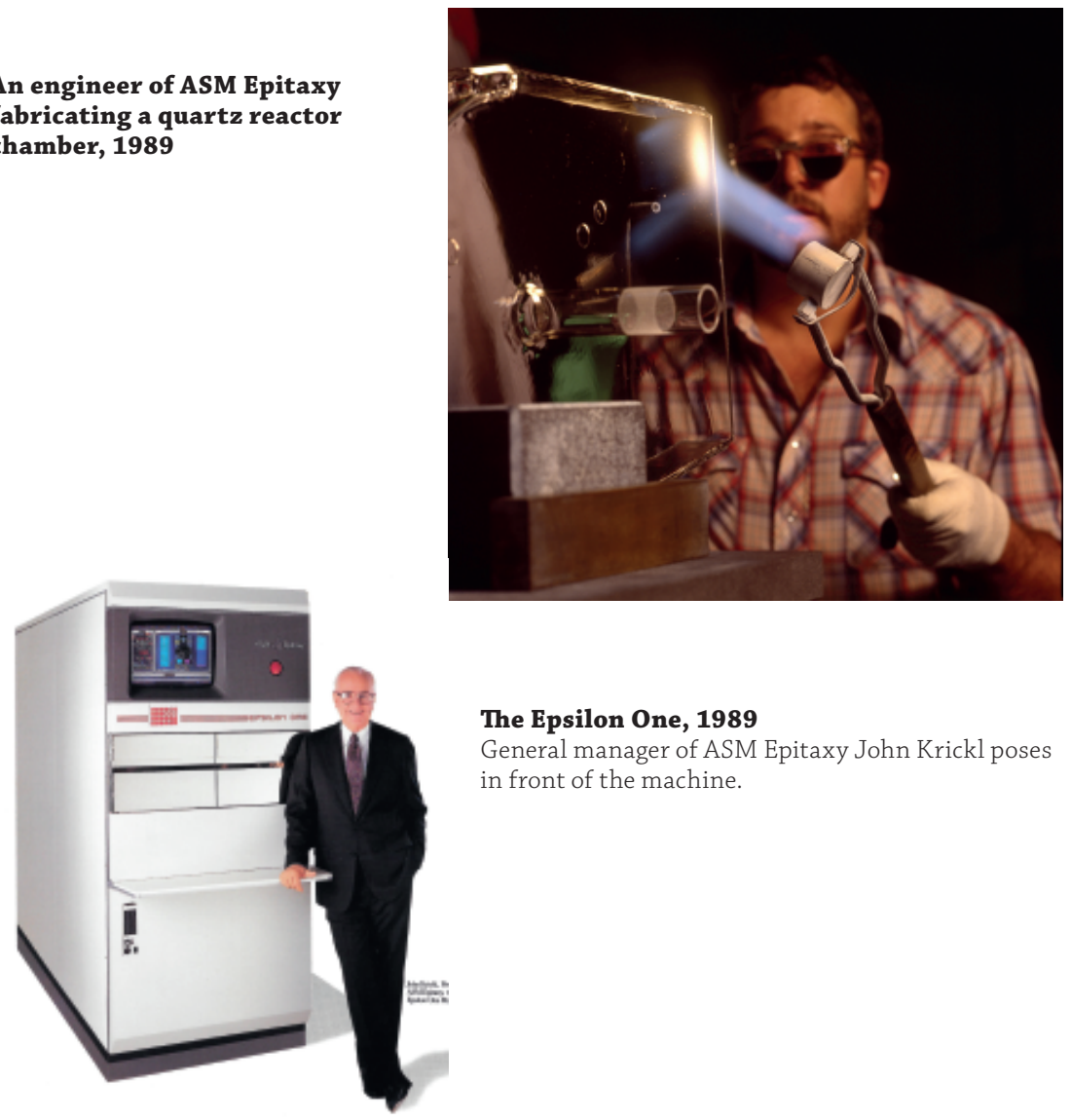

The Epsilon One, 1989

General manager of ASM Epitaxy John Krickl poses in front of the machine. 

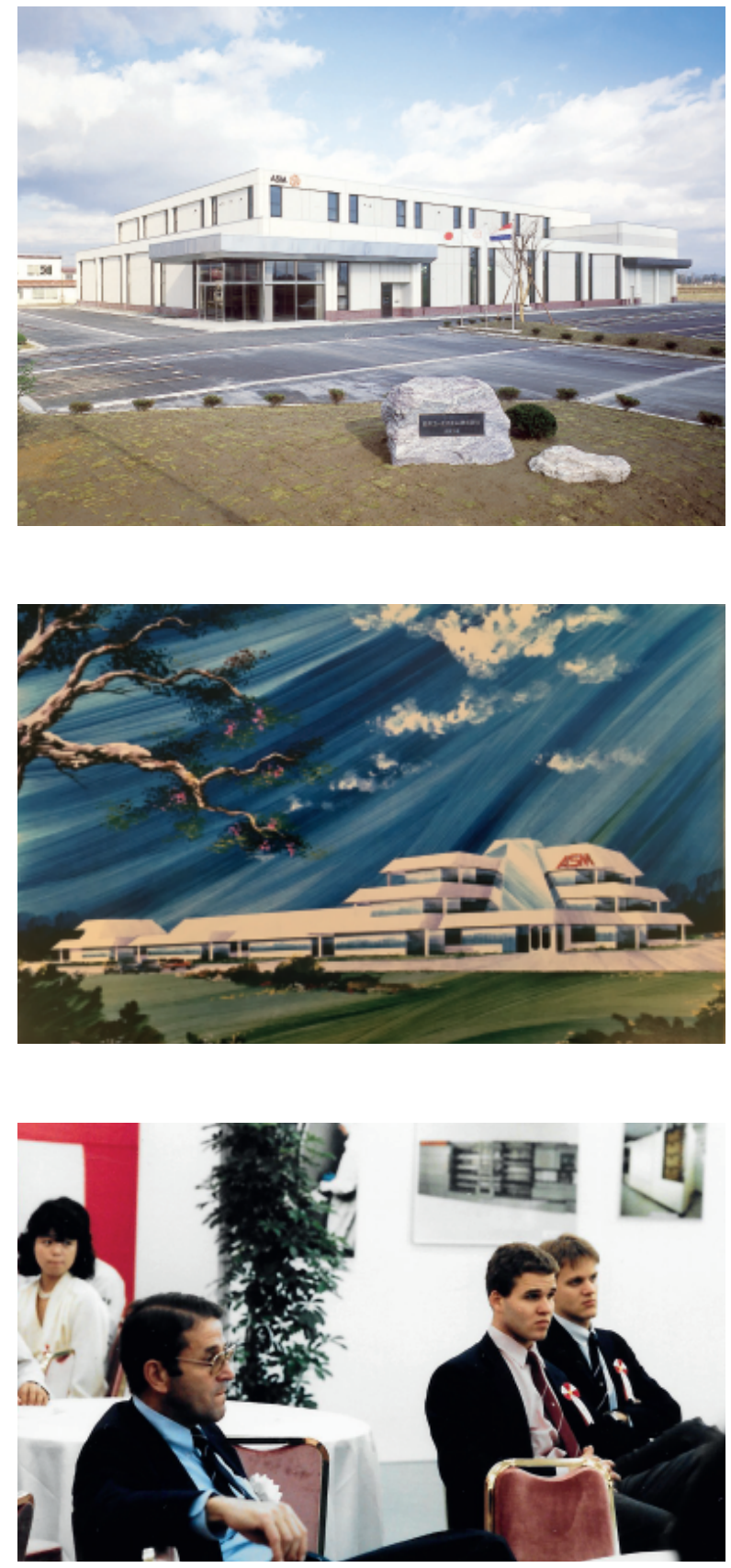

Arthur del Prado and his sons Mike (left) and Chuck (right) during the opening ceremony of the Nagaoka factory in 1985
ASM Japan

manufacturing facility in Nagaoka, Niigate

prefecture, 1986

Artist rendering of the new facility for ASM Lithography in

Veldhoven, 1985 


\section{Chapter 15 \\ Commercialization of the Epsilon reactor, 1986-1990s}

The end of a technological path is demarcated, ideally, by the introduction of a new product. Formally, Epsilon Technology was still an independent entity, funded through the Limited Partnership. After ASM's interference by replenishing the program's financial resources, Epsilon Technology moved closer toward the realm of ASM America. This foremost concerned the activities involved in commercializing the resulting product, as another external invention.

For the commercialization of the machine, it was imperative for ASM America to establish the strengths and deficiencies of the machine. In other words, the known-knowns and known-unknowns had to be mapped. Based on this information, a well informed and strategic marketing scheme could be developed. After all, after the many investments and man-years put into the project, the success of the machine could not be left to chance - or fortuna, so to speak.

From the fall of 1986 until the spring of 1988, the commercialization of the Epsilon reactor occurred along two lines. The first was the technological evaluation and perfecting of the machine. This involved conducting marathonruns in the prototype machines, carefully reaching out to potential customers for evaluation of the processed wafers, and cooperating with a befriended epitaxial service company. Through these actions, all final faults were mapped and addressed. Halfway through this line of work, the project was formally concluded, as outlined in the prospectus of the Epsilon Limited Partnership. ASM America exercised its option and Epsilon Technology became an integral part of ASM.

The second line of work occurred simultaneously and involved the marketing of the machine. Based on the technical evaluation, information marketing manager Steve Corlett benchmarked the machine and set out a strategy for selling the first machine. The marketing plan was gradually to introduce the machine into the market in order to keep control of the machine's burgeoning reputation. The introduction of the reactor to the general public during Semicon West in 1988 was a major step. A successive announcement of the availability of the version capable of processing the new 200-millimeter wafers contributed to a viable and sustainable reputation of the machine. 
In this final stage of the innovation process, the machine moved from the protective environment of Epsilon Technology into the light of day. In these new surroundings, numerous forces could affect and determine the fate of the machine. A great deal of those were beyond ASM's immediate control, such as the performance of competing machines worldwide, counter-strategies of the competition, and the purchasing processes of customers. ASM therefore deployed its full virtù to cope with all the uncertainties and probabilities during the commercialization of the machine.

\section{Mapping strengths and weaknesses}

From the summer of 1986, the machine was tweaked and tuned to improve reliability, increase throughput, and decrease cost. This involved changes in wafer handling and automation, as well as reconfiguration of several process steps, like hot wafer pick-up, hydrogen purges, and short and intense etch procedures for the susceptor and chamber. ${ }^{116}$ Some work was also done for the processing of bigger, yet to be developed eight-inch (or 200-millimeter) wafers. These adjustments largely concerned the software and programming of the system, as well as a few changes in the hardware. Continuously, two prototype machines processed as many wafers as possible wafers in order to map their behavior in the longer term. ${ }^{117}$ The long-term viability of the machine had to be determined.

Furthermore, the first demo wafers were processed on behalf of selected customers. Wafer and chip manufacturers had advanced metrology tools capable of verifying the characteristics of the grown epitaxial layers. To access this evaluation capacity, customers were invited to run their wafers in the machines at Epsilon Technology. ${ }^{118}$ This information was most welcome in the final development stage of the system.

For this purpose, the location of ASM America in Phoenix and the network of its employees made it logical to approach Motorola first. In October 1986, Corlett, Ferro, and Robinson presented the reactor to Bob Cassaro, director of

116 For example, this involved the development of an alternative for the innovative Bernouilli wand. The wand had two prominent advantages: clean pick-up without accessing the rear side and automatic alignment of the wafer in the cassette or susceptor. An alternative had to comply with the existing susceptor design, as this design was part of the process development. To this end, three pins, coming through the susceptor, would lift the wafer during pick up by a clamp. - Epsilon Technology, Nils Enderberg, 'Memo: Considerations concerning the design of the epitaxial prototype machine' (25-10-1985) Archive Arthur del Prado - Epsilon Epitaxy Juli 1986 - Juni 1990.

117 Throughout November, 200 four-inch wafers were processed in P2. After the change to sixinch wafers, 300 wafers were processed in January 1987.

118 ASM America, Steve Corlett, 'Interoffice Memorandum to Yo Miyazaki, ASM Japan: Silicon Epitaxy Reactor Program’ (15-10-1986) Archive Arthur del Prado - ASM Epitaxy juli 1986 - Jan 1990. 
operations at Motorola Semiconductors. Cassaro was an acquaintance of ASM America's president Franc DeWeeger, who had worked at Motorola earlier in his career. As it turned out, Cassaro was 'pleasantly surprised, and had not expected to see what they saw. ${ }^{\prime 19}$ Other customers invited for demo wafers included wafer manufacturers Osaka Titanium Corporation, Monsanto, and Shin-Etsu Handotai (SEH), as well as three chip manufacturers: AT\&T, IBM, and Motorola. This was done without notifying other players within the industry.

In late 1986, P1 had been running epitaxy for some time and Epsilon Technology was able to benchmark its product (figure 40). The system had some clear technological advantages. One was the operational flexibility arising from the single wafer format. This format made it easy to scale up as well, if the industry moved to larger wafer sizes than six inches (or 150 millimeters). Other advantages concerned the uniformity, low particulate contamination due to the automation, slip-free heating, and low thermal budget. The latter concerns the time required to process at the highest temperature - in this case 1200 degrees Celsius. In particular the uniformity of the tool was unprecedented in the industry: a consistent three percent or lower, whereas competitors scored five to ten percent at best. ${ }^{120}$

Disadvantages of the system were the cost-of-ownership (due to its low throughput), lack of low pressure operations required for the production of bipolar chips, and lack of experience with other precursors. Of course the latter would change over time, as the team would become more experienced with the reactor. By running demos the technical team would gain more knowledge about the wafer to wafer performance. This was important to be able not only to characterize the reactor for sales purposes, but also to fine-tune and increase its functioning to desired levels.

Throughout 1987, the technical work at Epsilon Technology shifted toward solely processing demo wafers according to specifications of a growing group of interested customers. However, the need for mapping weaknesses in the reactor remained as important as ever. This required intense utilization of the machine and evaluation of the wafers, which was not possible within the budget of ASM. Moreover, it could not ask this from customers once they acquired the machine. Customer feedback was most often sporadic and incident-driven.

To chart the hidden deficiencies of the Epsilon reactor, a collaboration was started with market consultant Monte Lawrence. In the summer of 1987, he

119 ASM America, Franc DeWeeger, 'Memo to Arthur del Prado: EPI' (1-10-1986) Archive Arthur del Prado - Epsilon Epitaxy Juli 1986 - Juni 1990.

120 Epsilon Technology, Armand Ferro, 'Memorandum to Herbert Lakens: 'Fax 12/18/86, EPI Business Plan’ (25-12-1986) Archive Arthur del Prado - ASM Epitaxy juli 1986 - Jan 1990. 
entered into an agreement with ASM to explore the process capabilities of the P2 reactor and to establish selected customer contacts. ${ }^{121}$ Lawrence was about to start an epitaxial wafer service company. ${ }^{122}$

\section{Figure 40}

Table of process flow Epsilon One, 1988

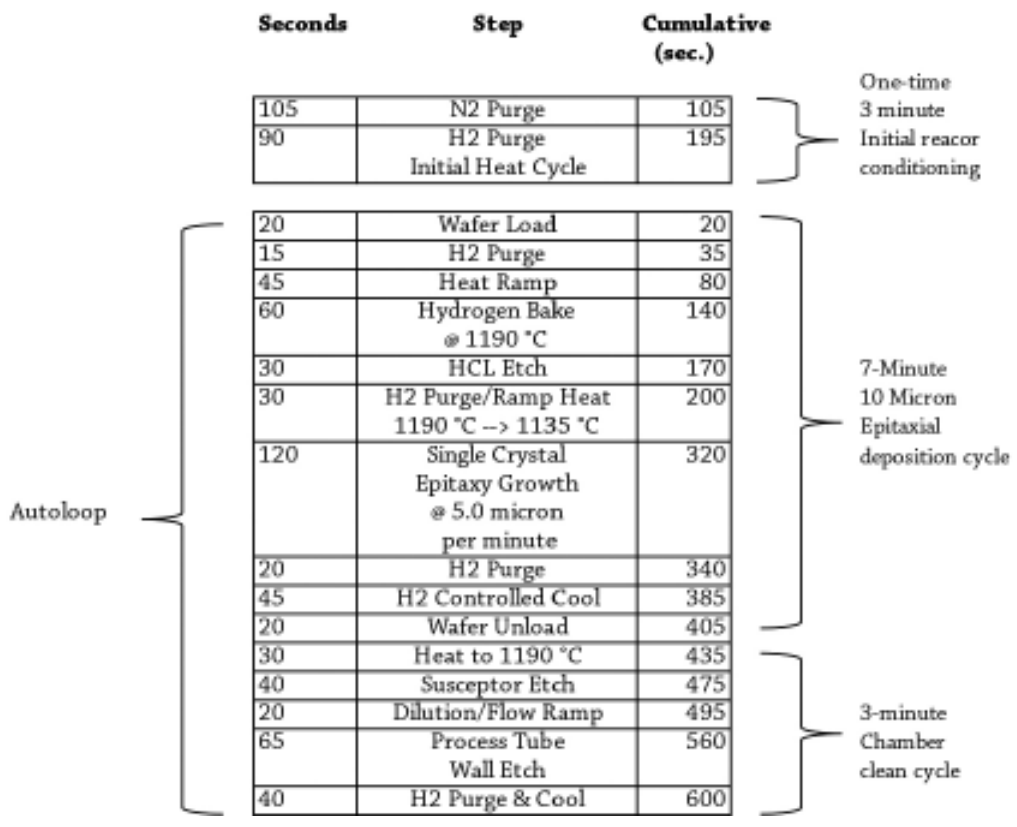

His new firm, Lawrence Semiconductor Laboratories, processed varying silicon epitaxy films for power semiconductor applications on behalf of customers who did not want to buy reactors and only needed epi-wafers with certain characteristics. His new business depended on the right performance of the Epsilon machines: the faster and better they processed wafers, the more money he could make. This intense utilization of the machine offered ASM invaluable information about the machine's performance before it would be used for highvolume manufacturing by other customers.

For his new company he bought - with a discount - two Epsilon reactors, in exchange for co-evaluating the machines with ASM. It was a win-win situation

121 ASM Epitaxy, Armand Ferro, 'May-June 1987 Report' (14-7-1987) Archive Arthur del Prado - ASM Epitaxyjuli 1986 - Jan 1990.

122 The company called Lawrence Semiconductor Laboratories eventually started as of May 1988 - Lawrence Semiconductor Laboratories, Inc.,' Compiled Financial Statements Two Months Ended July 31,1988' (31-7-1988) Archive Arthur del Prado - ASM Epitaxy juli 1986 - Jan 1990. 
for both companies. In particular throughout the first years of commercialization, the technical problems encountered by Lawrence were valuable. ${ }^{123}$ This involved the loading temperatures and replacing broken thermocouples in the susceptor. The deal underscored the importance of a close relationship with customers during the development and final phase of a new product.

As the development phase at Epsilon Technology was close to finished, the technical details of the machines were captured and published. To that end, Armand Ferro reignited the process of filing patents. ${ }^{124}$ Almost ten major patent applications were identified, of which almost four were actually granted. As a conclusion to the major technological research and demo runs, McDonald Robinson and Monte Lawrence published a paper at the Fifth International Symposium on Semiconductor Processing in Santa Clara, California, in February 1988. ${ }^{125}$

\section{Finalizing the Epsilon development program}

With the technological development process drawing to a close, ASM America could exercise its option to obtain the technology from the Epsilon Limited Partnership. Before this could be done, a final procedural hurdle had to be taken concerning the certification of the system. An independent consultant had to evaluate and sign off on behalf of the Epsilon Limited Partnership that the system developed concurred with the specifications of the program. This independent consultant was James D. Plummer, a professor from Stanford University. He evaluated the program and the technical plans of Epsilon Technology at the program's start and halfway. Plummer concluded that P2 concurred with the specifications:

'The new P2 reactor is a very impressive machine. It is well engineered and solves the problems that existed with earlier designs. The machine has not fully met all of the certification specifications, particularly those involving defect density and throughput. However, in my opinion, the

123 Lawrence Semiconductor Laboratories Inc., Lamonte H. Lawrence, 'Letter to John E. Krickl, president ASM America’ (22-12-1988) Archive Arthur del Prado - ASM Epitaxy juli 1986 - Jan 1990.

124 Epsilon Technology, Armand Ferro, 'Feb. 1987 Epsilon Report' (23-3-1987) Archive Arthur del Prado - ASM Epitaxy juli 1986 - Jan 1990.

125 McDonald Robinson, and Lamonte Lawrence, 'Characterization of High Growth Rate Epitaxial Silicon From a New Single Wafer Reactor', American Society for Testing and Materials, Dinesh C. Gupta (ed) Semiconductor Fabrication: Technology and Metrology (Philadelphia 1989) pp. 30-42. 
new machine is in substantial compliance with the specifications from an overall perspective. ${ }^{\text {'126 }}$

ASM America could now exercise its option to incorporate the program and its system. Its new president, John Krickl, did so on June 12, 1987.127 The Technical Advisory Board was dissolved and the program came to an end. ${ }^{128}$ Epsilon Technology was incorporated as an ASM America subsidiary named ASM Epitaxy. The name was consistent with the new ASM market identity and product lines, such as ASM Ion Implant and ASM Lithography.

All the remaining investments required for commercialization of the machine were on the account of ASM. Armand Ferro expected these to be around 3 million dollars - on top of the 3.5 million ASM already invested in 1985/1986. ${ }^{129}$ These costs entailed getting the manufacturing, sales, and service operations ready on a global scale. By January 1987, the project's total cost amounted to 12.1 million dollars: 7.6 million dollars from the Epsilon Limited Partnership, a 1 million-dollar loan from ASM International, and an additional 3.5 million-dollar contribution to the Partnership by ASM International. ${ }^{130}$

\section{Marketing the Epsilon reactor}

As the technological and commercial outlines of the machine became more distinct, Ferro was able to report:

'The Epsilon reactor is a 6 inch, automated single wafer reactor. It has a wafer throughput rate of approximately 6 wafers/hr using trichlorosilane process for CMOS. It is expected to sell for about $\$ 540 \mathrm{~K}$ or more. ${ }^{131}$

From the summer of 1986, it was up to the newly hired marketing consultant Steve Corlett to transform the idea into a sellable product. Based on the evaluation efforts of Epsilon Technology and the initial demo wafers for customers, Corlett

126 James D. Plummer, 'Epsilon Technology Inc. Visit Report 3/6/87’ (6-3-1987) Archive Arthur del Prado - ASM Epitaxy juli 1986 - Jan 1990, p. 5.

127 Epsilon Limited Partnership, John Krickl, 'Letter to investors in Limited Partnership: Several significant events...' (7-7-1987) Archive Arthur del Prado - ASM Epitaxy juli 1986 - Jan 1990.

128 ASM International, Willem de Leeuw, 'Letter to John E. Krickl - Ref.: BRI.110.87 WdL/jm' (10-6-1987) Archive Arthur del Prado - ASM Epitaxy juli 1986 - Jan 1990.

129 Epsilon Technology, Armand Ferro, 'Memo to Franc DeWeeger: Topics for ASMI Mgt Meeting' (18-11-1986) Archive Arthur del Prado - ASM Epitaxy July 1986 - Jan 1990.

130 Epsilon Technology, Armand Ferro, '1986 Epsilon Accomplishment Summary for Performance Review’ (28-1-1987) Archive Arthur del Prado - ASM Epitaxy July 1986 - Jan 1990.

131 Epsilon Technology, Armand Ferro, 'Functional Narrative - 1987 Business Plan' (20-101986) Archive Arthur del Prado - ASM Epitaxy juli 1986 - Jan 1990. 
defined a marketing strategy. One key aspect in this was to prevent installation of the first reactors at customer sites until all major deficiencies were addressed. ${ }^{132}$ Although ASM missed much desired revenue, it offered total control on the performance and evaluation of the machine. It prevented a potential negative impact of these first systems on the reputation of ASM and Epsilon caused by teething troubles.

The Epsilon program and reactor remained concealed in clouds. Its capabilities had to be verified first, after which ASM should try to sell some systems without burdening its limited marketing budget. The Epsilon machine, applicable for CMOS/epitaxy, would be introduced in a market dominated by bipolar discretes and chips. Trying to comply with the demands of the bipolar market could easily damage its immature reputation. ASM had to conquer the market slowly - first with CMOS and maybe later on with additional bipolar processes, such as a combined bipolar-CMOS chip dubbed BiCMOS (figure 41).

\section{Figure 41}

Graph of forecasts and actual annual market for epitaxial equipment, 1980-1994

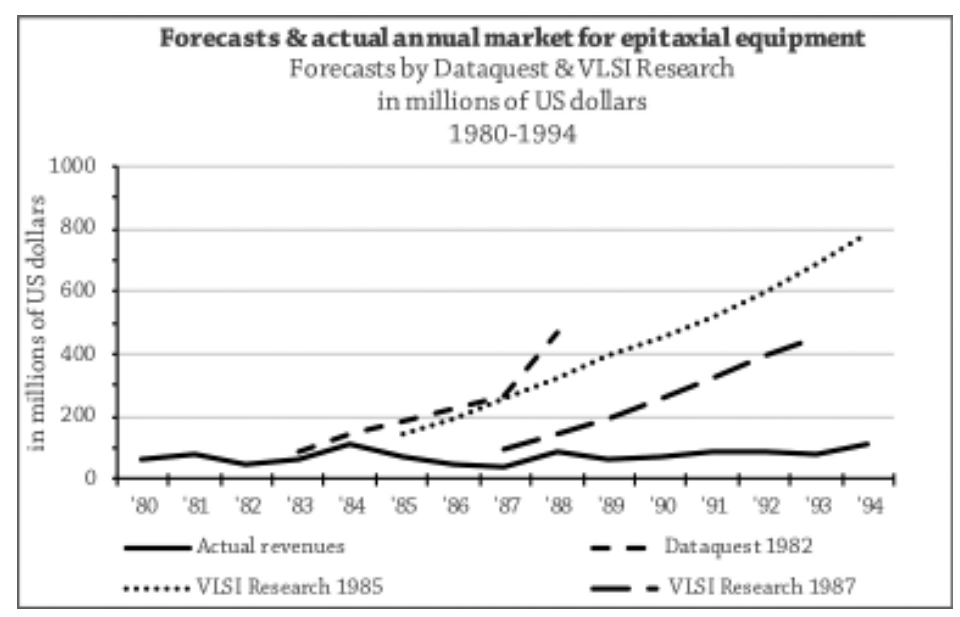

Based on his contacts in the industry and in discussions with customers, such as Motorola, Corlett gained a better understanding of the market. The market for epitaxy furnaces could be divided into three parts: bipolar discretes, bipolar chips, and CMOS chips. ${ }^{133}$

132 John Krickl, 'Interview with author'; Epsilon Technology, Armand Ferro, 'August Epsilon Report' (10-9-1986) Archive Arthur del Prado - Epsilon Epitaxy Juli 1986 - Juni 1990.

133 Epsilon Technology, Armand Ferro, 'Functional Narrative - 1987 Business Plan' (20-101986) Archive Arthur del Prado - ASM Epitaxy juli 1986 - Jan 1990. 
The market for bipolar discretes concerned single function chips, which were produced in high volumes and did not require the uniformity of epi-films offered by the Epsilon. Neither could this reactor meet the demands for throughput, as rather thick layers of epitaxy were required. The market for bipolar chips was defined by layer thickness and resistivity, a market which would become more addressable at bigger wafer sizes. Also for this market, ASM's growth rate was not yet competitive enough.

As described at the start of these Innovation chapters, Epsilon Technology aimed at the rapidly growing CMOS market. So far, semiconductor manufacturers designed their chips in such a way, that no epitaxial film was required. As a consequence, the market for epitaxial systems fell short of expectations. CMOS epitaxy required a low cost per wafer to be relevant at all. At the same time, the fact was that for CMOS wafers no clear products were available, and Epsilon Technology seemed to be the first to fill that gap.

Corlett learned more about the performance and specifications of Epsilon competitors as well. Applied Materials still dominated the existing epitaxy market with its semi-automatic AMT 7800 furnaces, together with Gemini's 2 pancake reactor, applied in the production of bipolar chips and discretes. Both competitors also announced new epitaxial furnaces applicable for CMOS-epitaxy, the AMT 7010 and the Tetron One, respectively. Furthermore, another competitor, Anicon, melded a new CMOS epitaxial reactor with a particular chemical process, only addressing a niche application.

The American semiconductor industry's turn toward applications-specific integrated circuits (ASIC's) - chips varying in design and produced in low volumes - stimulated the advent of single wafer processes across the industry (see Business III). Processing a single wafer at a time offered better control and flexibility of the deposition process. Moreover, it allowed easier adaption to bigger wafer sizes compared to batch systems.

This was all in line with the assumptions underlying the Epsilon reactor. While Applied Materials solely offered barrel reactors for epitaxial processes, it also developed single wafer processes for sputtering - metallization - and several chemical vapor deposition processes. These machines were dubbed, respectively, Precision 5000, announced in 1987, and Endura 5500, announced simultaneously with ASM's Epsilon reactor. Moreover, a startup named Novellus started to compete with ASM's horizontal batch processes with a single wafer plasma chemical vapor deposition. Luckily for ASM, by 1987, it was the only one offering single wafer process for epitaxy. 


\section{Selling the first machine}

By the end of 1986, the marketing team of Epsilon Technology and ASM America identified Japanese wafer manufacturers as the most probable customers of the first Epsilon reactors. ${ }^{134}$ As Ferro reported to ASM International:

'We have chosen to initially deal only with SEH and OTC, both of which are very aggressive and have U.S. operations. ... Further, the center of gravity of the MOS market is continually shifting towards the aggressive Japanese with U.S. customers putting plants on hold, e.g. AT\&T.'135

In this effort, Japanese silicon manufacturers acquired American operations to gain access to the American market and technology. ${ }^{136}$ These Japanese companies were very interested in the single wafer tool of Epsilon Technology, despite the fact that they had just invested in the competitor's batch systems.

The first company that obtained details from the epitaxial furnace and ordered a machine was a new American subsidiary of Osaka Titanium Corporation (OTC) ${ }^{137}$ In June 1987, the new entity ASM Epitaxy received its first verbal order for the Epsilon reactor from OTC. ${ }^{138}$ The personal reassurance of total support and commitment by Arthur del Prado, in his capacity of chief executive officer of ASM, had removed any remaining doubts about procuring an unproven production machine. ${ }^{139}$ Two ASM engineers were dispatched to OTC to install the Epsilon reactor and get this first system sold to work properly.

Meanwhile, ASM's sales staff reached out to more potential customers. These included General Electrics, Intel, Stanford University, Philips, and many others. ${ }^{140}$

134 Epsilon Technology, Armand Ferro, 'Memorandum to Herbert Lakens: ‘Fax 12/18/86, EPI Business Plan' (25-12-1986) Archive Arthur del Prado - ASM Epitaxy juli 1986 - Jan 1990.

135 Epsilon Technology, Armand Ferro, 'Memo: Fax 12/18/86, EPI Business Plan' (25-12-1986) Archive Arthur del Prado - ASM Epitaxy July 1986 - Jan 1990.

136 In 1986, Mitsubishi Metal took over Siltec, ASM's former partner in the Epsilon project. In the same year, Osaka Titanium Corporation acquired US Semiconductors, an epitaxial wafer company from Fremont, California. - Dataquest, "And there were less than none..." OTC to acquire epi wafer division of Cincinnati Milacron' Dataquest SEMS Research Bulletin (December 1988).

137 Epsilon Technology, Armand Ferro, 'September Epsilon Report' (8-10-1986) Archive Arthur del Prado - ASM Epitaxy juli 1986 - Jan 1990; Steve Corlett, 'Review of Marketing Plan for Epsilon' (13-5-1987) Archive Arthur del Prado - ASM Epitaxy juli 1986 - Jan 1990.

138 ASM Epitaxy, Armand Ferro, 'May-June 1987 Report' (14-7-1987) Archive Arthur del Prado - SM Epitaxy juli 1986 - Jan 1990.

139 John Krickl, 'Interview with author'.

140 Steve Corlett, 'Review of Marketing Plan for Epsilon' (13-5-1987) Archive Arthur del Prado - ASM Epitaxy juli 1986 - Jan 1990; ASM Epitaxy, Armand Ferro, 'May-June 1987 Report' (14-7-1987) Archive Arthur del Prado - ASM Epitaxy juli 1986 - Jan 1990. 
The second customer was the German wafer manufacturer Wacker, by the fall of $1988 .{ }^{141}$ IBM and SEH America were next in line. The system was ready for industry-wide introduction.

In May 1988, ASM Epitaxy introduced the Epsilon One, as it was eventually called, to the general audience of professionals in semiconductor production technologies at the Semicon West Exhibition in San Mateo, California.

Initially, the machine met with limited enthusiasm. Wafer size appeared to be one of the causes. ${ }^{142}$ The Epsilon One processed six-inch wafers. The technical team of Epsilon Technology had assumed that single wafer tools would become more economical with a wafer size of six inches. But the industry had already scaled its wafer processing equipment up to six-inch wafers by the time the Epsilon One was introduced in 1988, implying that ASM was quite late with its six-inch wafer tool.

ASM was not taken aback, however. As Ferro already reported months before the introduction:

'we have been told by AT\&T and our Japanese customers that eight-inch will be a major factor in the 1990 time frame. ... Our machine improves on cost at eight inch.' ${ }^{143}$

Anticipating the machine's improved competitiveness at bigger wafer sizes, Ferro already quietly prepared a scaled-up version of the reactor. It merely required some adjustments to the reactor chamber and a bit of tweaking and tuning of the process technology. ASM was right on time.

Prior to the rest of the industry, epitaxial equipment capable of processing eight-inch wafers was required. Wafer manufacturers had to be able to supply these new wafer sizes with an epitaxial film before the chip producers started their developments into eight-inch. In May 1989, ASM Epitaxy announced the eight-inch version of the Epsilon reactor. ${ }^{144}$ The eight-inch capability guaranteed the sales ASM and the Epsilon Limited Partnership had been hoping for. ${ }^{145} \mathrm{~A}$ few

141 ASM Epitaxy, 'Memo to Andre van Rhee: Headcount \& Min. Business Plan Meeting in July 1988’ (3-1-1989) Archive Arthur del Prado - ASM Epitaxy juli 1986 - Jan 1990.

142 Armand Ferro, 'Interview with author'.

143 Epsilon Technology, Armand Ferro, 'Memo: Fax 12/18/86, EPI Business Plan' (25-12-1986) Archive Arthur del Prado - ASM Epitaxy juli 1986 - Jan 1990.

144 ASM Epitaxy, 'News release: ASM Epitaxy Announces 200MM Capability for Epsilon One Epitaxial Reactor’ (23-5-1989) Archive Arthur del Prado - ASM Epitaxy juli 1986 - Jan 1990. 
years after the introduction of the variation capable of processing bigger wafers, sales took off.

Surrounding the introduction, many of those involved in the process development phase resigned or got a new position. Steve Corlett departed, as his job as marketing consultant was done. In the spring of 1988, McDonald Robinson moved from ASM Epitaxy to Superconductor Technologies, a startup in Santa Barbara, California before returning to Arizona in order to start a research arm of Lawrence Semiconductor Laboratories in 1992. The rest of his career, he would continue to experiment with and improve the process of the machine he had co-developed.

In February 1989, David Sikes, former manager of ASM Lithography America, replaced Armand Ferro as general manager of ASM Epitaxy. ${ }^{146}$ Del Prado wanted someone else to accompany the commercialization of the Epsilon. It was a major disappointment for Ferro. He had been in charge of the Epsilon program since the start of the endeavor in 1983, and now on the verge of introducing the machine to the market, he was not allowed to lead it into the final phase.

Ferro became head of sales and marketing - later dubbed product manager - and this was a downgrade according to him. Be that as it may, it was a very beneficial decision for the company. Nobody at ASM knew and cared for the Epsilon reactor as Ferro did. His wholehearted commitment to the machine won over many a customer with reservations regarding this wholly new reactor design. It was key to the market acceptance of the Epsilon reactor.

\section{Epilogue: a bittersweet success}

In the early 1990s, ASM Epitaxy succeeded in penetrating the market for epitaxy. By August 1991, ASM Epitaxy already shipped 46 tools to wafer suppliers and chip manufacturers in the United States, Asia, and Europe (figure 42). The majority of the shipments were in the United States. Of the total shipments, most were 200 -millimeter machines. ${ }^{147}$ The machine's applicability for this new wafer size proved to be critical for its success. Moreover, the machine won the industry magazine Semiconductor International's 1994 Editor's Choice Best Product Award. $^{148}$

146 ASM Epitaxy, Armand Ferro, 'Interoffice memorandum: management changes' (31-1-1989) Archive Arthur del Prado - ASM Epitaxy juli 1986 - Jan 1990.

147 ASM Epitaxy, Bob Haro and Steve McGrady, 'ASM Epitaxy' (7-8-1991) Archive Arthur del Prado - ASM Epitaxy juli 1986 - Jan 1990.

148 ASM America, Ken Davidson, 'ASM Epitaxy Receives Semiconductor International's 1994 Editor's Choice Best Product Award', ASM News (February/March 1995). Archive author. 


\section{Figure 42}

Graph of units sold of ASM's Epilogic and Epsilon reactors, 1975-2000

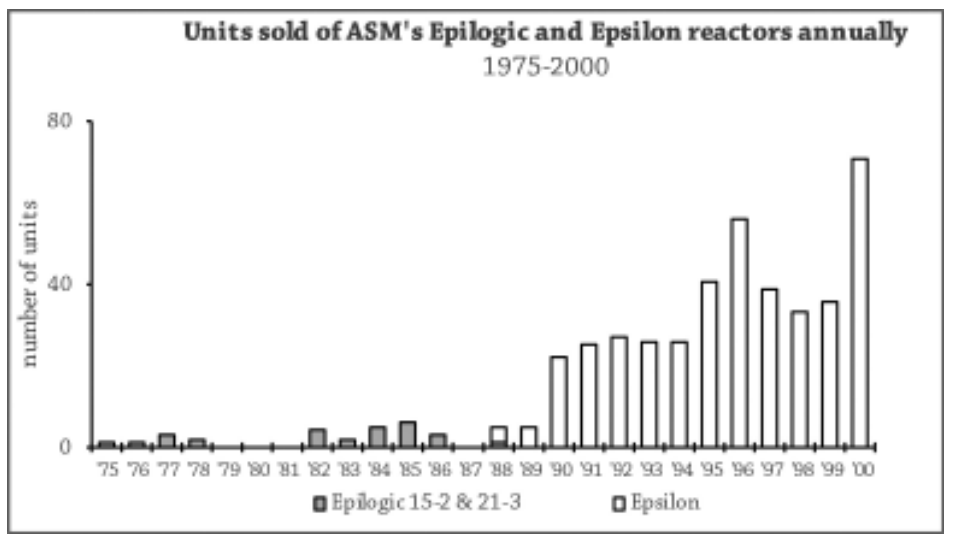

Through this success, ASM Epitaxy saved ASM America, as the American operation was confronted with faltering sales of its horizontal plasma furnaces. Staff and facilities were changed for the new epitaxy technology, and this would define the future of ASM America. Moreover, the machine lived up to its promises. By May 31, 1990 the private investors of the Epsilon Limited Partnership received their first cash distribution of approximately 1,300 dollar per unit. ${ }^{149}$ Until 1999, they would regularly receive their royalties, achieving maximum return on their investment.

However, the success of the Epsilon machine was marred by something that would haunt ASM until 1998: Applied Materials was determined to enforce its intellectual property. From 1991 until 1997, ASM was involved in an escalating litigation surrounding the Epsilon machine. The settlement of this litigation would put ASM into a scrape.

During the Epsilon program, several kinds of heating were tried before the Technological Advisory Board settled on the radiant heating concept. Applied Materials had a patent on the concept of radiant heating, so it was most certain would come after ASM on this subject. ${ }^{150}$ Even though restricted by budgetary constraints, Ferro had initiated several activities in the sphere of intellectual property. This involved the costly process of filing patents for key inventions.

149 Epsilon Limited Partnership, John Krickl, 'Letter to Limited Partners: We are pleased...' (15-3-1990) Archive Arthur del Prado - ASM Epitaxy juli 1986 - Jan 1990.

150 Epsilon Technology, Armand Ferro, 'Sept 1984 Draft Board Minutes' (6-2-1985) Archive Arthur del Prado - Epsilon Jan '85 t/m Juli '86; Don Jackson, 'Letter to Franc de Weeger, President ASM America' (30-8-1985) Epsilon files Jan '85 - Juli '86. 
Ferro also tried to reassess Applied Materials' intellectual property concerning radiant heating. ${ }^{151}$ Moreover, Ferro also closely watched the proceeding of a legal battle between Applied Materials and another supplier of epitaxy, called Gemini. ${ }^{152}$

Ferro and his team concluded that the radiant heating patent was not something Applied Materials could claim as its invention. A Russian scientist had written about it years before Applied Materials filed for a patent. Also, the big conglomerates in electronics like Philips had done work on epitaxy with radiant heating prior to Applied Materials' patents. In the fall of 1988, Armand Ferro reassessed ASM Epitaxy's exposure to Applied Materials' radiant heating patents 4.081.313 and 4.496.609. ${ }^{153} \mathrm{After}$ a close reading of the claims in these patents, he and ASM's America's patent lawyer concluded that ASM was not violating them with the Epsilon reactor. It was concluded that Applied Materials' claims had no merit. On the issue of the Applied Materials' intellectual property, then, Epsilon Technology and ASM failed to take into account Murphy's Law: 'Anything that can go wrong, will go wrong.'

On November 23, 1988, Epsilon Technology received a first letter stating that the company infringed patents of Applied Materials. ${ }^{154}$ In 1990, ASM America received a 'cease-and-desist' letter from Applied Materials concerning violation of its intellectual property with the Epsilon epitaxial furnace. ASM denied its wrongdoing and did not recognize the ground on which Applied Materials claimed their right. ASM badly underestimated the stubbornness and aggressiveness of its competitor in this matter.

ASM had not been paying attention to a fundamental change in American federal law. Through a change of legislation in 1988, Applied Materials was able to threaten any customer of ASM for using the technology under question. ${ }^{155}$

151 In 1984, Armand Ferro located a copy of a 1967 Russian paper entitled 'The Possibility of Utilization of Radiant Heating to Grow Films' by A.A. Uglov, which could serve in ASM's defense when it would be sued for utilizing radiant heating of a susceptor. Several other American patents were found as well. Epsilon Technology, Armand Ferro, 'Letter to Mr. William Holloway, attorney of Weiss and Holloway P.C.' (15-9-1985) Epsilon files Jan '85 - Juli '86.

152 Epsilon Technology, Armand Ferro, 'Telex to Arthur del Prado: Our lawyer Paul Padgett...' (10-09-1986) Archive Arthur del Prado - Epsilon Epitaxy Juli 1986 - Juni 1990.

153 ASM Epitaxy, Armand Ferro, 'Memo to Art del Prado: AMT Patents' (19-21-1988) Archive Arthur del Prado - ASM Epitaxy juli 1986 - Jan 1990.

154 Cahill, Sutton \& Thomas, Robert von Hellens, 'Letter to Paul L. Hickman, patent counsel of Applied Materials' (23-3-1989) Archive Arthur del Prado - ASM Epitaxy juli 1986 - Jan 1990.

155 Definition of infringement amended to include import into the United States of products made abroad by a process covered by a US patent and to reverse the burden of proof in certain cases of alleged infringement of a process patent. (Process Patent Amendments Act) 35 U.S.C. 
This meant that if a wafer or a chip was produced using the Epsilon reactor, even outside the United States such as by the Japanese OTC or the German Wacker, the manufacturer would be violating Applied Materials' intellectual property. This legislation helped Applied Materials to deter ASM's customers from purchasing the Epsilon.

Furthermore, in preparation of the litigation, ASM's competitor made sure that it hyped up its intellectual property portfolio, in particular with regard to its own single wafer techniques. And, finally, Applied Materials was keen on delivering the first blow, by filing the litigation in the nearby court district. Because the American legal system relied on a jury consisting of citizens, having the litigation take place in California offered a home advantage. Moreover, Applied Materials' legal team was well informed on the judges in the California legal district after their earlier litigations; they knew the system's players.

By February 1991, Applied Materials filed the first suit against ASM in the Northern District of California. In the years until 1997, ASM and Applied Materials battled each other in court. The whole documentation of Epsilon Technology was turned upside down. All employees of Epsilon Technology and ASM who had anything to do with the program were interrogated. For most of them this was a horrible experience.

Litigation did involve not only the old Applied Materials' barrel epitaxy machine patents but also their latest single wafer patents, as well as those of ASM. Every stick that could be used was used by both parties, raising the stakes on each side. Applied Materials had prepared their lawsuit very well. ASM, on the other hand, was forced to fight a rearguard action all the time - often surprised as it was by its opponent's legal assertiveness.

Six years later, ASM agreed to a settlement of 80 million dollars and additional royalties over every sold Epsilon furnace after introduction. ASM was wrung out completely and had to look for external sources of cash to pay for the settlement (see Chapter 25). One should conclude that ASM successfully got itself into the epitaxial market, but that it disregarded the protection of its innovation. The price for this naivety was high, evaporating much of the profits created by the machine. With the conflict out of the way, the Epsilon would yield a profit unrestrainedly for the next decades.

$\S \S 271(\mathrm{~g}), 287,295$ - Ladas \& Parry, 'A Brief History of the Patent Law of the United States', Ladas \& Parry Education Center. From the 1980s onwards, broad patents became valid. - David C. Mowery, 'Plus ca change: Industrial R\&D in the "third industrial revolution"', Industrial and Corporate Change 18:1 (2009) pp. 1-50, p. 32; Bonwyn Hall and Rosemarie Ham Ziedonis, "The patent paradox revisited: an empiral study of patenting in the U.S. semiconductor industry, 1979-1995', The RAND Journal of Economics 32:1 (2001) pp. 101-128. 


\section{Conclusions}

The development of the Epsilon epitaxial reactor costed about 13 million dollars over the course of almost five years. As such the program took two years and about 4 million dollars more than originally envisaged. Throughout the program, a modest number of 20 to 45 employees were employed by Epsilon Technology. After the transfer to ASM Epitaxy, due to the preparations needed for the manufacturing of the machine, this number would increase significantly.

The entire effort, which lasted nearly seven years, was instigated by dissatisfaction with ASM's competitive position in the epitaxial market - and an unexpected backing by Siltec. The effort was successful, as by 2000, twelve years after its official introduction, ASM had sold over 400 units of the machine worldwide, creating sales of over 590 million dollars, including spares, service, etc. (figure 42) ${ }^{156}$ Obviously, the 1981 decision of engaging the market for epitaxy had been prolific.

\section{Figure 43}

Graph of growth in revenues from Epsilon epitaxial reactors , 1988-2008 Absolute percentages are proprietary information to ASM International.

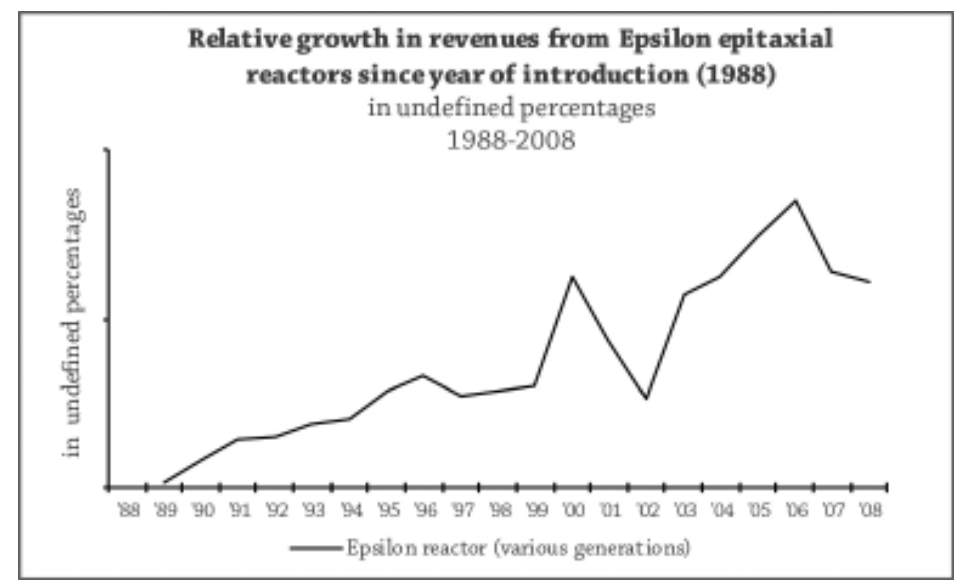

This success primarily followed from the versatility of the Epsilon's design. The creative and heavily contested development phase compelled the final product's

156 ASM America, 'Overview sales per product segment of ASM America, ASM Epitaxy and ASM VT, 1984-2000’ (day unknown, 2001) Archive Arthur del Prado-ASM America 1998-2002 file. 
robustness. Experimentation, inventive computer models, and the depleted financial resources settled selection of the variations. Although this was not immediately clear after the completion of the development phase, given all the individual disappointments and frustrations, the thorough innovation process ensured ASM's success in epitaxy.

The development of the Epsilon epitaxial reactor offers unique insights into the comprehensive process of innovating semiconductor production technology. In the context of the 1980s and ASM's mode of innovation in that period, the Epsilon case stood out. As such, it offers the opportunity to study the development of the process technology from scratch. How, then, as I formulated my central question at the beginning of Innovation II, did the development phase of the Epsilon single wafer epitaxy reactor influence the commercialization of this product? Here I reflect on this issue by again considering the role of fortuna, virtù, and path.

\section{Fortuna}

Throughout the development of Epsilon, fortuna - an event that disrupts a perceived regularity - manifested itself in four ways. The first concerned Siltec's uninvited, welcome, and unexpected suggestion of utilizing the R\&D Limited Partnership. This funding method enabled the development process, serving as its catalyst. Without Siltec's suggestion and experience with this innovative funding scheme, ASM would not have started the program. The sudden availability of the Epsilon Limited Partnership defined the program's initiation but also the course of its development. The funding through private investors positioned ASM at arm's length of the development effort. This scheme allowed Epsilon Technology to establish its own organizational practices independently of ASM, enabling a thorough innovation process. The Epsilon Limited Partnership, in other words, was a profound manifestation of fortuna, resonating throughout the program and defining the outcome of the innovation process.

A second fortuna related to materiality. For instance, the breakage of quartz in Model 2c dashed hopes - sparked by computer models - that the stagnation point flow might actually work. Or consider the regular observance of slip during experiments.

The third manifestation of fortuna involved the depletion of funds in the summer of 1985. Although this was not utterly dramatic, as Ferro and his staff saw it coming, it proved to be a pivotal moment. In fact, it was a Machiavellian Moment, as it threatened the project's continuation. It was not self-evident that Del Prado would carry the project forward; there was no legal obligation regarding the Epsilon Limited Partnership that forced ASM to do so. ${ }^{157}$ Moreover, 
Del Prado's decision to persevere came with consequences: ASM did not accept another delay. Theoretical variations had to be tuned down in favor of pragmatic solutions. Johnson's thorough approach was found wanting. ASM's more commercial innovation practices began to weigh more heavily, finally causing Model 2B to gain momentum.

The fourth and final occurrence of fortuna pertained to the timing of the Epsilon's introduction to the market, or in other words, the moment when the selectors - the wafer and chip producers - could actually start applying the machine in the industrial production of chips. Due to the delayed introduction of the Epsilon, ASM missed the introduction of six-inch wafers and started in a market dominated by bipolar-epitaxy. Moreover, eight-inch wafers were about to be introduced, for which single wafer processing became more competitive. The timing of the introduction and the subsequent reception of the industry defined the machine's commercial viability and success.

In Innovation II, then, fortuna both instigated and defined the development of the Epsilon. Just like in Innovation I, fortuna, in the guise of the availability of the Limited Partnership, enabled ASM to join benevolent contingencies, which in this case was the expected application of epitaxy in CMOS chip production. But fortuna also had another impact on the innovation process: it forced a selection, constricting variations in the development after the funds were depleted in 1985. Fortuna directly interfered in the innovation process by bringing the endless debate among the engineers to a halt.

\section{Virtù}

Actors demonstrated virtù, or the art of coping with fortuna, four times in the innovation project discussed. Like in Innovation I, virtù first of all served as a force of creation. Being entrepreneurial managers, Jackson and Del Prado appropriated the sudden opportunity posed by the Limited Partnership. They set up the development program, made sure that a prospectus was formulated as to the outlines of the program, they assessed risks and uncertainties, and they worked on convincing the private investors. Once the program started, ASM was not so much exposed to fortuna anymore because the financial risk resided entirely with private investors, while the Epsilon Technology team became responsible for the completion of the program.

The second instance involved the engineers' dealings with unexpected material realities. Throughout the program, the engineers mapped 'unknowns' as much as possible by means of experimentation and modeling. Experiments were deployed as controlled procedures for mapping uncertainties. Responses to

'Interview with author', and Armand Ferro, 'Interview with author'. 
outcomes of experiments were very reactive, resembling virtù. Through tweaking and tuning, new solutions were envisaged and concocted.

The third instance of virtù again involved the managers, in this case Del Prado and Armand Ferro. Del Prado showed virtù by investing money. Ferro did so by making choices to appease concerned investors, restore confidence, and boost the program. This time however, their virtù did not merely initiate the innovation process but also influenced it.

Finally, the introduction of the Epsilon to the market involved virtù. Normally, an innovation will be introduced and exposed to the unruly market in a very controlled fashion, limiting the impact of fortuna. However, in this case, ASM faced the imminent transfer to a new wafer size for which it had not prepared the Epsilon. Moreover, Del Prado explicitly forbid Ferro to work on an eight-inch compatibility. His defiance irritated Del Prado, but Ferro's effort aimed at rendering the design compatible without needing much change was a sheer form of virtù. After all, without the eight-inch capability, ASM would have missed the allegiance of the market. Ferro's foresight ensured that the Epsilon was capable of joining the contingent introduction of eight-inch wafers. Like the second instance, this kind virtù is basically a matter of pragmatic adaptability.

\section{Path}

Path is determined by the past and deliberate strategies to appropriate envisaged opportunities in the future. In Innovation I, I characterized ASM's distinctive technological path as application-driven and dependent upon allegiance of chip manufacturers. Here I will reflect upon path during the development phase and its impact on the overall innovation process by characterizing structural elements in the innovation process resulting in the Epsilon and by invoking relevant literature. Finally I reassess ASM's innovation process by elaborating on the findings of my analysis.

As regards to the structural features of the path taken in the Epsilon program, the competition among variations in design and the subsequent debates and strives stand out. Throughout the development process, confusion, friction, and debates occurred about the feasibility of variations, the need for further experimentation, and requirements of the machine. In this, pragmatic engineers like Wiebe de Boer were pitted against theoretical-scientific engineers like Wayne Johnson and McDonald Robinson. Both groups originated from different backgrounds, yet all aspired appreciation by their colleagues within the wider semiconductor industry.

At the beginning, most of the proposed variations - batch configurations and De Boer's horizontal flow single wafer reactor - were rooted in ASM's experience, knowledge, and mode of innovation. From the fall of 1983 onward, coming from a different setting, Johnson and Robinson continued and stimulated 
extensive exploration and rationalization of alternatives to the reactor design and components. For them, it was also imperative to know how and why technical solutions did (not) work. De Boer and the Technical Advisory Board members from ASM normally operated much closer to the market, and as such they represented a pragmatic commercial innovation practice. But the program's management consisting of Johnson, Robinson, and Ferro came from a more scientific direction, having an industrial laboratory background (with, respectively, Livermore, Bell Labs, and General Electric). They embodied the 'terror of PhDs,' a phrase put forward during the process to capture the underlying tensions.

Another salient structural ingredient was the role of the customer - the chip manufacturer - throughout the Epsilon program. As established in Innovation I, accreditation of customers was vital for a semiconductor equipment manufacturer like ASM. Yet, throughout the development phase of the Epsilon program, customers were not involved in the selection of variations. Only indirectly did customers indicate their demands, such as Siltec at the beginning of the program and the wafer and chip manufacturers that were contacted for benchmark information.

In the process of variation and selection, it was the Technical Advisory Board that imposed specific courses of action, based on their interpretation of the objectives formulated in the Epsilon Limited Partnership prospectus. Responding to the information presented by the Epsilon Technology staff, such as experimental results, calculations, and marketing information, the Board decided which line of research had to be abandoned or which required further exploration, and as such it preselected among the variations.

Moreover, the results of experiments with particular materials also influenced selection of variations. The fate of Model 2C/2D was a clear example of this role of the material reality as a force of selection. Despite the theoretical adaptability of the stagnation point flow, it was not possible to get it to work properly. Quartz continued to break or flanges would leak. Although the computer models indicated the feasibility of the stagnation point flow, the actual construction was more unruly. In this context, the process of trial and error - experimentation - was indispensable.

These observations resonate with concepts derived from academic literature. The debates among engineers during the Epsilon project can be seen as a 'clash of routines.' In the view of the prominent scholars in evolutionary economics Richard Nelson and Sidney Winter:

'[routines] may refer to a repetitive pattern of activity in an entire organization, to an individual skill, or, as an adjective, to the smooth 
uneventful effectiveness of such an organizational or individual performance. ${ }^{158}$

The apparent clash of routines indicates different appreciations of what an innovation process entails.

These differences may be traced back to different generations of R\&D. ${ }^{159}$ The scientific routine rooted in what was known as the first generation of $R \& D$, involving basic research departments of vast vertically integrated manufacturing conglomerates that defined innovation and product development. As noted in Innovation I, ASM was a textbook example of a company involved in $2^{\text {nd }}$ generation $R \& D$, in which the market defined the course and outcomes of innovation. Within the Epsilon program - in particular after ASM supplemented the depleted funds of the Epsilon Limited Partnership in 1985 - this type of R\&D sufficed and prevailed.

In the previous Innovation chapters, the concepts of enactor and selector helped to enunciate the interaction between ASM and its customers throughout an innovation process. ${ }^{160}$ Elaboration upon these same concepts helps to illuminate the interaction within the development program and the role of ASM/Epsilon Technology toward its customers.

ASM/Epsilon Technology was the enactor, in line with the analysis of Innovation I. Within the development phase all the engineers were 'enactors' propagating the applicability of a solution for one or various problems. Moreover, the engineers were involved in a 'competition of enactment,' arguing for the selection of their respective propositions. This rivalry was not insignificant. Innovation scholar Edward Constant II pointed out that innovators relate themselves not only to their own organization, but also to wider communities of similar technological practices. ${ }^{161}$ Apart from the individual careers, success in the competition of enactment might result in peer recognition across the industry.

158 Richard Nelson and Sidney Winter, An Evolutionary Theory of Economic Change (Harvard University Press, Cambridge, 1982) p. 97.

159 Abe de Jong, Keetie Sluyterman, and Gerarda Westerhuis, 'Strategic and structural responses to international dynamics in the open Dutch economy, 1963-2003', Business History 53:1 (2011) pp. 63-84; Johan Schot and Edward Steinmueller, 'Three frames of innovation policy: R\&D, systems of innovation and transformative change', Research Policy 47 (2018) pp. 15541567, p. 1558; Philip Roussel, Kamal Saad, and Tamara Erickson, Third Generation R\&D (Harvard Business School Press, Cambridge, 1991).

160 Raghu Garud and David Ahlstrom, 'Technology assessment: a socio-cognitive perspective', Journal of Engineering and Technology Management 14:1 (1997) pp. 25-48; and Arie Rip, 'Folk Theories of Nanotechnologists', Science as Culture 15:4 (2006) pp. 349-365, pp. 360 and 361.

161 Edward Constant II, 'The Social Locus of Technological Practice: Community, System or Organization?', in: Wiebe Bijker and Thomas Hughes (ed.), The Social Construction of Technological Systems: New Directions in the Sociology and History of Technology (MIT Press, 
A corresponding concept to enactor, called the 'enactment cycle' helps to understand this competition during the development phase. ${ }^{162}$ This sequence involves a self-referential system, during which enactors anticipate an end-state by means of scenario-thinking, after which subsequent steps are identified to realize this goal. During the enactment cycle, the enactors empathized with the yet absent selector. ${ }^{163}$ Within the Epsilon development program and its profound competition of enactment, each of the enactors for a variation - whether Robinson's Model 2C, De Boer's Model 2B and the propositions for components - lived through enactment cycles until a selector decided.

To disrupt these competing cycles of enactment, selections had to be made within a 'selection cycle. ${ }^{164}$ This cycle involved the articulation of criteria and subsequent comparison of the available propositions. With regard to the Epsilon development program - and ASM's general innovation process - this selection cycle took place at its customers, the chip and wafer manufacturers. Both the 'cycle of enactment' and the 'selection cycle' happen at the same time. A 'bridging incident' occurs when the enactors and the selectors 'probe each other's realities. ${ }^{165}$

However, as observed above, such a bridging incident did not occur until the machine got introduced and customers were allowed to evaluate the machine. Until that time, the competition of enactment cycles was affected by materiality and decisions from the Technical Advisory Board. Materiality, thus, functioned as selector. The Technical Advisory Board operated as a pre-selector, anticipating the needs of envisaged customers by projecting a selection cycle based on input from Siltec at the beginning of the program. At the end of the bridging incident, when the wafer or chip manufacturer decided to procure the Epsilon, 'closure' occurred. ${ }^{166}$ The competition of enactment came to an end.

The development of the Epsilon reactor constituted the first exercise of ASM into developing a new piece of semiconductor equipment from scratch. The clashing routines underlying this process and the competition of enactment may have contributed to the resulting, highly robust and innovative design.

Cambridge, 1989) pp. 223-242.

162 Garud and Ahlstrom, 'Technology assessment', p. 42.

163 Sjoerd Bakker, Competing Expectations: The case of the hydrogen car (BOXPRess, Oisterwijk, 2011), p. 8.

164 Garud and Ahlstrom, 'Technology assessment',p. 42.

165 Ibid., p. 44.

166 Trevor Pinch and Wiebe Bijker, 'The Social Construction of Facts and Artefacts: Or How the Sociology of Science and the Sociology of Technology Might Benefit Each Other' Social Studies of Science 14:3 (1984) pp. 339-441. 
The overall development of the Epsilon reactor overlapped with ASM's usual mode of conduct. This involved the prevailing routine in the competition of enactment cycles: that of the pragmatic, customer-oriented practice. Moreover during the commercialization of the machine the innovation process adhered to the common innovation practices of ASM: commercializing an external invented semiconductor fabrication technology, Epsilon Technology's P2 reactor. This commercialization process was characterized by the quick implication of potential customers, instigating a bridging incident. For ASM, as 'specialized supplier,' it was imperative to bring such a bridging incident to the fore. Early accreditation of 'selectors' increased the chance of commercial success.

After procurement of the Epsilon reactor, the competition of enactment continued in other forms. As becomes apparent in Innovation IV, engineers within ASM propagated the application of the Epsilon reactor configuration to other processes than epitaxy. In the early 1990s, this involved the growth of polysilicon and silicon nitride. ${ }^{167}$ Also, some argued for the reconfiguration of the machine from a standalone into multi-chamber cluster set-up. ${ }^{168}$ The closure of one competition of enactment might result in the start of another. But much of this happened beyond the scope of Innovation II, just like ASM's engagement in similar expansive research endeavors like the Epsilon program. All in all, the Epsilon, and its thorough innovation process, raised the bar quite high.

ASM America, Steve Reiutz, 'Paragon Business Plan' (3-2-1994) Archive Arthur del Prado - RvC 1994-1996.

168 Chris Werkhoven further mentions that the Epsilon cannot be integrated with the A600. - ASMI, Chris Werkhoven, 'Facsimile Message: Epsilon Technology: future applications, ref:90.135/CW/jdk' (28-8-1990) Archive Arthur del Prado - Chris Werkhoven file.ASM Epitaxy, Bob Haro, 'ASM Epitaxy R\&D Programs' (7-3-1991) Archive Arthur del Prado - ASM Epitaxy files. 
Business III

\section{The game to sustain leveraged innovation, 1985 - 1992}




\section{An introduction}

In the second half of the 1980s, ASM found out the true meaning of the saying: 'When it rains, it pours.' After years of continuous growth, ASM was confronted by internal and external challenges. Relying upon his entrepreneurial virtù, Del Prado continued to stick to his game principles. However, this time the issues on his plate were bigger and more complex, exposing ASM's organizational shortcomings. How and why ASM experienced a downfall is discussed in the chapters of Business III.

By 1985 ASM was no longer the small entrepreneurial and audacious enterprise, but a multimillion dollar, multi-divisional manufacturer of semiconductor equipment technology. The company was well on its way to become a 'one-stop-shop' for semiconductor equipment. However, the company was also confronted by the inherent deficiencies of a diversified company.

The rampant entrepreneurism displayed by the various operations bore centrifugal effects: their vigorous pursuit of their respective opportunities spiraled out of control. Apart from Arthur del Prado and some managers and staff of the holding company, ASM's operations knew little oversight. Just like ASM Lithography's general manager Gjalt Smit frankly indicated in his handwritten letter mentioned at the end of Business II, ASM yearned and deserved professional management structures and procedures in order to secure its potential. A central plan was needed.

\section{Contemporary appreciation of a multi-divisional enterprise}

Throughout the decade, the matter of 'strategy' formed a central theme in the answers formulated by business scholars to problems encountered by multidivisional enterprises. Illustrative was Michael Porter's article entitled 'From Competitive Advantage to Corporate Strategy.' ${ }^{1}$ In it, Porter distinguished two levels of strategy within a diversified company. One level of strategy involved the business units, to which he allocated the notion of 'competitive strategy.' The other level was companywide, named 'corporate strategy.' As he explained:

'Competitive strategy concerns how to create competitive advantage in each of the businesses in which a company competes. Corporate strategy concerns two different questions: what businesses the corporation

1 Michael Porter, 'From Competitive Advantage to Corporate Strategy', Harvard Business Review (May 1987) pp. 43-59. 
should be in and how the corporate office should manage the array of business units.' ${ }^{2}$

Porter distinguished three reasons for diversification. The first was the 'attractiveness-test', in which the attractiveness of the new market had to be assessed. The second reason for diversification formed 'the cost-of-entry test', which entailed that cost of entry should not be too high. And finally, 'the betteroff test', which implied that the new division should benefit from its acquaintance within the enterprise.

As Porter recognized, however, the competitive strategies among the subsidiaries of diversified firms might not necessarily align; they might even conflict. To secure the interests of the company as a whole, a corporate strategy was deemed indispensable:

'Those who have restructured must decide what to do next to avoid repeating the past; those who have done nothing must awake to their vulnerability. To survive, companies must understand what good corporate strategy is.' ${ }^{3}$

Porter assessed that for a successful corporate strategy might consist of a plan to transfer skills or to share activities among the divisions. ${ }^{4}$ At the same time, this corporate strategy should not affect the competitiveness of the business units themselves. As he explained:

'Diversified companies do not compete; only their business units do.'

Porter's assessment about strategy seemed to apply to the realities of ASM in the mid- and late-1980s.

The question that came to the fore most prominently throughout the late 1980s was: what is ASM International's corporate strategy? Del Prado, the general managers, his Supervisory Board, and external stakeholders wondered about this, and tried to find an answer. On the one hand, Del Prado and his management

\footnotetext{
2 Ibid.

3 Ibid.

4 Porter distinguished two types of solutions, one for a multi-divisional firm with divisions lacking any coherence or connection, and another where some connection or coherence existed. ASM belonged to the latter. After all, ASM Japan, Europe, and America were all involved in horizontal deposition systems. Also the Hong Kong and ASM Fico operations were active in similar segments. Thus, for the sake of clarity, I only focus on Porter's solutions for ASM's category.

5 Porter, 'From Competitive Advantage to Corporate Strategy'.
} 
recognized the need for a corporate strategy. On the other hand, this strategy should not eliminate the subsidiaries' competitiveness, i.e. their ability to make money. As will become apparent throughout Business III, there was no easy answer.

The analysis in Business III relies on the distinction between competitive and corporate strategy as suggested by Michael Porter. His discernment illuminates the dynamics between ASM's subsidiaries and ASM International, as the company plunged into one of its deepest crises. As such it illustrated the rather time-based understanding of diversified enterprises and their challenges.

\section{Outline of Business III}

Business III revolves around three essential developments that defined ASM's efforts to balance its competitive and corporate strategies, which are elaborated in three chapters. Amidst these events, the formulation and implementation of a corporate strategy - though recognized as the most viable solution to ASM's problems - proved to be easier said than done.

The first event, discussed in Chapter 17, was the overheating and subsequent conciliation of the American-Japanese economic rivalry from the fall of 1984 until early 1986. While demand for new equipment evaporated, Japanese chip manufacturers triumphed in the memory market. Chapter 18 revolves around the second development, involving a technological transformation of geographical markets, from 1985 until 1988. The direction of technological development in the Japanese, American, and European markets diverged. Moreover, in anticipation of the first sub-micron chips and 200-millimeter wafer process, innovative production techniques challenged and replaced common equipment and manufacturing practices. In contrast to the others, the third and final development was defined by ASM's internal circumstances, covered in Chapter 19. From 1987 until the fall of 1992, ASM struggled with an escalating equity crisis. The company's debt and liabilities constantly threatened to become higher than its assets.

Throughout these Business chapters critical passages in the history of the company are discussed, such as the divestment of ASM Lithography, ASM Ion Implant, the initial public offering of ASM Pacific Technology, and the introduction of defining new products like the Epsilon and the Eagle reactor. 


\section{Chapter 17}

\section{Ceasing of the American-Japanese rivalry, 1985-1986}

The ceasing of the memory rivalry between the United States and Japan informs the events addressed in this chapter. As the storm abated, the damage for ASM seemed limited. Soon, however, as the industrial dynamics shifted, things began to fall apart and structural deficiencies of ASM's organization came to the fore.

\section{Industrial context:}

\section{Rules of play no longer suffice}

Throughout the early 1980s, the Japanese and American semiconductor industries vied with each other for dominance in the market of memory chips. This competition fitted in a wider effort by the United States and Western European economies to halt the advent of Japanese manufacturing industries. The memory market was determined by high-volume production and the ability to increase the memory capacity of chips. Historically, the American memory manufacturers - IBM, Intel, and many others - had led the industry through the introduction of innovative and bigger memory chips. ${ }^{6}$ From the late seventies on, however, Japanese chip manufacturers gained the initiative with introduction of $64 \mathrm{~K}$ and bigger memory chips, and higher manufacturing output.

In order to sustain market shares and competitiveness, Japanese and American memory chip manufacturers accelerated production and product introductions. ${ }^{7}$ Both in Japan and the United States, this created healthy prospects for the equipment industry during the mid-eighties (see Chapter 12). However, by the fall of 1984, this feast had come to an end.

The rivalry resulted in severe over-production of memory chips. Supply was much higher than demand, and prices of memory chips dropped. Chip

6 The European chip industry hardly had a stake in memory chips. Philips, Siemens, and their respective national governments set up an ambitious program to get the European chip industry back in the game of memory chips through the MEGA-project. This started in 1984. More about this in Innovation III.

7 Richard Langlois and Edward Steinmueller, 'Strategy and Circumstance: The Response of American Firms to Japanese Competition in Semiconductors, 1980-1995', Strategic Management Journal 21:10 (2000) pp. 1163-1173; Michael Hobday, 'Corporate strategies in the international semiconductor industry', Research Policy 18 (1989) pp. 225-238. 
manufacturers faced excessive stock of memory chips. Each side of the rivalry - the Japanese and the Americans - raised their stakes. But by the fall of 1984, the industry on both sides had to fold or reveal their hand.

All of a sudden, the roaring global memory industry came to a standstill (figure 44). First American and later the Japanese semiconductor factories - fabs - were closed, planned new production lines got cancelled, products were stopped, and output of remnant fabs decreased. Orders for semiconductor equipment got delayed or annulled in the final quarter of 1984. From 1984 until 1986, semiconductor manufacturers decreased their capital expenditures from 8.3 billion dollars to 5.1 billion dollars worldwide - or about 29 and 15 percent of global sales in semiconductors. The semiconductor industry - and in particular the equipment industry - witnessed its most severe downturn from the fall of 1984 until 1986.

\section{Figure 44}

Graph of worldwide revenues in MOS memory chips, 1981-1988

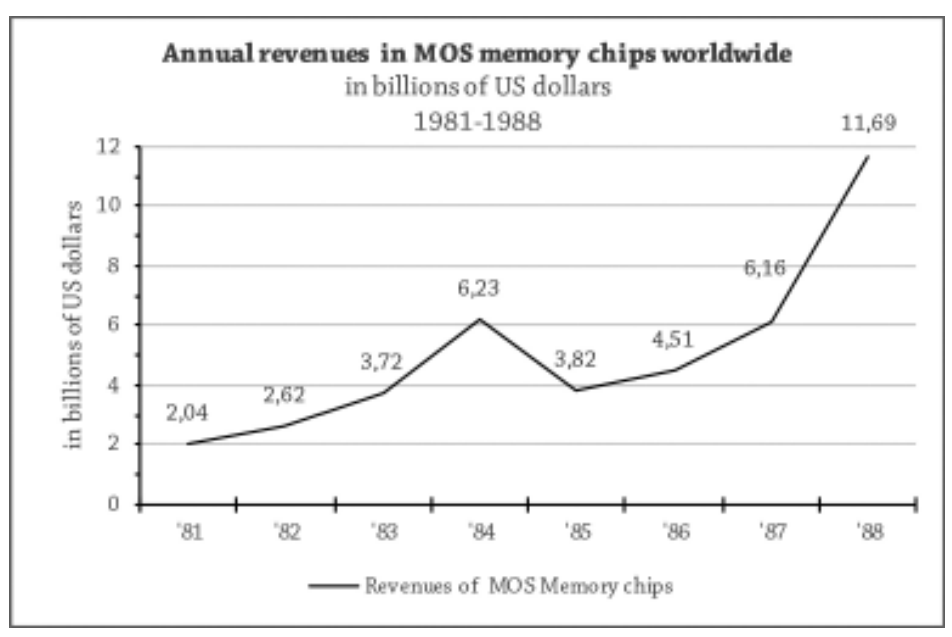

In particular the American semiconductor industry suffered severely from the overheated memory market, and many players left this market. The most notable one was Intel, a pioneer of 'dynamic random-access-memory' (DRAM) chips. ${ }^{8}$ Facing the far more productive Japanese competition, Intel had to make choices. One route was to lead an industry-wide response under its illustrious chairman Robert Noyce and through the Semiconductor Industry Association

8 Intel had introduced the first microprocessor in 1971 - Arnold Thrackray, David C. Brock, and Rachel Jones, Moore's Law: The life of Gordon Moore, Silicon Valley's Quiet Revolutionary (2015 Basic Books), pp. 297, 413, and 434. 
(SIA). Another was to reconsider its position in DRAM chips, despite the fact that it just introduced a 256K DRAM and created a first Megabit memory chip in its R\&D laboratory. As Gordon Moore, chief executive officer of Intel, recalls in a biography written by historians Arnold Thackray, David Brock, and Rachel Jones:

'To become a significant player again, we would have had to build two new fabs at a cost of about $\$ 400$ million. [Yet] nobody was making money in DRAMs. We had the funds to make the investment, but chances of getting a return on it seemed awfully small, because of the way DRAM prices had collapsed.'

After endlessly contemplating his company's position in the memory business, Moore cut the knot. ${ }^{10}$ In 1985, Intel stopped its DRAM business and put all its cards on microprocessor chips, which would prove to be a far-reaching decision, in line with that of the majority of the American memory manufacturers.

In 1985, the American memory industry shrank tremendously, focusing upon microprocessors and other computer chips instead, while increasing political pressure on the Japanese economy and semiconductor industry in particular. Individually and through SIA, American chip manufacturers accused their Japanese counterparts of dumping memory chips on the American markets for too low prices and the restricted access of the Japanese market. ${ }^{11}$ The significant losses of memory activities in the United States even caused the discussion to become political.

The American semiconductor industry led and urged the American government in its effort to curb the Japanese advent. From 1985 to 1986, the American authorities and industry pulled strings to limit the damage of Japanese competition. This involved a depreciation of the dollar versus the Japanese yen and Western European currencies, dropping the value of a dollar of 3,6 to 2,1

$9 \quad$ Thackray et al., Moore's Law, p. 434.

10 Intel wanted to cover the whole range of chip products. As Thackray et al. write: 'Intel's marketing leaders felt it was essential to offer customers a full suite of microchips, from memory to microprocessors, and Intel was unique in having the latest CMOS DRAMs. Gordon [Moore] still could not make the numbers work. There seemed no way to make the numbers work. ... [An executive, Andy Grove, posed the question to Moore] "If you were coming in through the door from the outside to run the company, would you stay in DRAMs?" ... Then Gordon replied: "No". In this revolving door moment, the answer emerged with clarity. It was time for Intel to get out of the DRAM market.' - Thackray et al., Moore's Law, p. 343. The quotes in the passage are different in Michael S. Malone, The Intel Trinity: How Robert Noyce, Gordon Moore, and Andy Grove Built the World's Most Important Company (2014 Harper Collins), p. 390.

11 Douglas Irwin, 'The US-Japan Semiconductor Trade Conflict', in: Anne Krueger (ed.), The Political Economy of Trade Protection (University of Chicago, Chicago, 1996) pp. 5-14. 
Dutch guilders in respectively 1985 and $1987 .{ }^{12}$ The political negotiations resulted eventually in the controversial 1986 Semiconductor Trade Agreement between the United States and Japan, settling pricing and sales between national industries. ${ }^{13}$ To overcome the national entrenchment, Japanese chip manufacturers opened factories in the United States. This gradually ended the rivalry between the two countries in this area.

\section{Corporate course: ASM during the downturn}

The smoothing of the American, European, and Japanese competition in the fall of 1984, and onwards, came as a surprise for ASM. The company had hedged and tuned its whole organization to benefit from the rivalry. This involved predominantly ASM Japan and ASM America selling plasma enhanced chemical vapor deposition (PECVD) equipment to memory manufacturers in both economies. Their success had been the foundation of ASM's rise. The downturn of 1984-1986 took the wind out of ASM America's sails.

Next to a steep decline in sales, the downturn caused ASM to change its competitive positioning in Japan, the United States, and Europe. Each geographical market had its own specialty in computer chips, and thus its own demands for equipment. The ceasing of the rivalry shifted the production of memory chips to Japan, concentrating the demand for PECVD tubes in Japan. Meanwhile the American chip manufacturers moved away from memory chips and turned to microprocessors. The American subsidiary experienced a severe hick-up in demand for plasma deposition furnaces. In Europe changes were not yet dramatic. The downturn caused a divergence in sales, product development, and marketing at ASM Europe, ASM Japan, and ASM America.

At the holding company - ASM International - a recently hired international marketing manager, Herbert Lakens, assessed the consequences of the downturn. Lakens was the second manager to support Arthur del Prado in his oversight of the expansive and growing activities of ASM, next to Director of Technology Willem de Leeuw. After his first visit to ASM America, Lakens reported:

'The U.S. semiconductor industry is still in deep trouble with bad news coming till the last day of my visit. Most notably reporting of heavy losses at AMD and INTEL and regular reports of additional lay-off.

12 Historical data taken of January 1st 1985 and January 1st 1987 from poundesterlinglive. com (viewed 12-4-2018).

13 Douglas Irwin, 'The US-Japan Semiconductor Trade Conflict'; and among others: Richard Baldwin, 'The Impact of the 1986 US-Japan Semiconductor Agreement' Japan and the World Economy 6 (1994) pp. 129-152; Langlois and Steinmueller, 'Strategy and Circumstance'. 
There is a consensus of which parts of the industry are hurt most: the high-volume memory plants. The custom- and military segments of the business are still doing well. No consensus exists regarding the end of the slump ... The equipment industry has some tough times as a result of this economic situation.' ${ }^{14}$

Initially during the downturn - as it started in the fall of 1984 - ASM was well equipped to sit through the depressed market situation.

Initially, only the American operation was severely hit by the downturn. Orders for its bulky plasma enhanced CVD (PECVD) furnaces by American memory manufacturers evaporated. Such systems had been applicable in particular in the high-volume production of memory chips. But as this market almost completely moved to Japan, ASM America suffered from the evaporated demand from this segment of its customer base. Sales declined from 39.5 million to 30.2 million and 15.7 million dollar in, respectively, 1984, 1985, and 1986. ASM Die Bonding - never fulfilled its promise beyond its initial contribution to ASM Assembly Automation - shut down.

ASM Japan on the other hand continued to enjoy healthy sales. Japanese memory manufacturers still bought the PECVD furnaces. From the summer of 1985 onward, ASM Japan prepared the localization of production in a new factory in Nagaoka, in the Niigata prefecture. This enabled the Japanese engineers to further customize the plasma deposition machines. For instance by adding a new soft contact loader, and an advanced robot-arm in addition to the already localized procurement of quartz tubes and pump systems. While the localized production helped ASM Japan's ability to serve its customers, and improve its margins, it worsened the situation at ASM America. The operation in Phoenix was already deprived of its sales to American memory manufacturers, and now it also lost access to Japanese customers.

Meanwhile ASM Europe outperformed its sister-operations. While the memory chip market in the United States evaporated, the European chip manufacturers were just ramping up developments to compete in memory by the end of the decade (see Innovation III). This was well reflected by the 1984 MEGA-bit program of Siemens, Philips and their respective German and Dutch governments. Through their concerted efforts, Siemens and Philips - Europe's biggest chip manufacturers - worked on an innovative product line of CMOS-based 1 Megabit or more memory chips. They impregnated the Western European microelectronics

14 ASMI, Herbert Lakens, 'Memorandum to Arthur del Prado: Report Visit HL to ASMA' (1810-1985) Archive Arthur del Prado - Herbert O Lakens files. 
industry with an optimistic appreciation about the future, and continued to invest in new production lines and products.

This trust propelled ASM Europe's growth. The Bilthoven company enjoyed healthy sales of its horizontal CVD furnaces. In particular its diffusion and low pressure CVD (LPCVD) furnaces sold well - indispensable for the production lines of predominant bipolar chips and discretes in Europe. The lack of a European memory industry worked out well for ASM Europe, its sales hardly being affected by the downturn.

The other European operation, ASM Fico, also profited from the ongoing European sales. Although it experienced a temporal slack in its American sales (through ASM America's sales offices), the Fico moulds, lead-frames, and stamping tools still got sold in Europe as well as, to a lesser degree, in South-East Asia.

Since the majority of the assembly and packaging operations of European, American, Japanese, and regional semiconductor manufacturers were located in South-East Asia, the Hong Kong based operation of ASM continued to prosper. This partially followed from its new presence in the market for light emitting diodes (LED) and Chip-on-Board assembly through its new wire bonders. The LED market formed a beneficial hedge against any of the regular downturns in the chip industry. In combination with its general manager's consistent focus on operational profitability, the Hong Kong operations succeeded in neglecting the overhaul in the chip industry.

Del Prado was not too worried by the downturn of the market. During its first year - from the fall of 1984 until 1985 - Del Prado saw proof that his business strategy worked. As he reported in the 1985 annual report of ASM International:

'Fundamentally, the downturn which is depressing most segments of the worldwide semiconductor equipment markets has not altered our basic philosophy and strategy. We believe that long-term success and profitability will depend on the ability to address the industry's challenges from broad perspectives both in terms of products and markets. ... Our broad product base and geographical diversification again mitigated the effects of the industry down cycle. ${ }^{15}$

Del Prado still trusted in the competitive strategies of his business units. Their ability to compete would guide ASM as a whole through the depressed market. At the general account of ASM International, the losses of ASM America were offset against the profits of the European, Japanese, and Hong Kong operations. 
Throughout 1985, Del Prado settled upon his tactic to sit through the downturn. On the one hand, the general managers of the subsidiaries had to stay keen on the operational performance of their ongoing operations. On the other hand, Del Prado would make sure that ASM as a whole would stay on course and in alignment with the general opportunities arising in the global semiconductor industry. To that extent, he was determined to keep up the pace of ASM's advent into the industry.

\section{Elaboration of affairs}

\section{Strengthening ASM}

Del Prado's confidence in the ability of the business units to drag ASM out of the recession enabled him to strengthen and expand the business units. During the downturn, he invested in new infrastructure to facilitate the expected future growth of operations, and he established new operations in pursuit of new opportunities and in support of the rest of the firm. Through the investments ASM would be ready to cope with the growth as soon as the market would recover.

Throughout 1985, ASM started the construction of a new building of ASM Lithography in Veldhoven, near Eindhoven, opened ASM Japan's new manufacturing facility in Nagaoka, and procured a new building at the Rembrandtlaan in Bilthoven to facilitate ASM Europe's growth. Predominantly these new facilities were funded by means of local banking loans, secured against the value of the real estate.

ASM also invested in new technologies. This involved a supplement to the Epsilon Limited Partnership - the fund paying for the development of the epitaxial reactor in the United States. Development had overrun its original schedule, and required an additional pledge of about 2 million dollars to see the whole endeavor through. Since the cash reserves rapidly decreased in the downturn, also this pledge was funded by a short-term bank loan.

The latest technological developments at ASM Lithography required new funds as well. The new envisaged stepper machine - the PAS2500 - was partially funded by a venture capital scheme of the Dutch Ministry of Economic Affairs. This so-called Technisch Ontwikkelingskrediet of 25 million Dutch guilders enabled ASM Lithography to pay half of its development, which completely had to be redeemed with interest a few years later, or after its introduction on the market. ${ }^{16}$ It was the perfect funding vehicle for the costly lithography technology, elevating both Philips' and ASM's cash injections. Obviously, the new building and the ambitious output targets equally required substantial financial resources.

16 ASM International, Annual Report 1985 (March 1986) p. 10. 
While most of the new investments were dispersed among the business unit, one of them struck the eye. Leveraging Dutch and European governmental support, Del Prado and his Director of Technology Willem de Leeuw worked out the plan of a technology center (see Chapter 21). This new operation - named the ASM Microelectronic Technology Center (AMTC) - would function as a central knowledge and development base in support of the various subsidiaries. In its intent, the AMTC constituted a first concrete effort to strengthen cohesion within the diversified equipment manufacturer, implementing a corporate technological strategy.

Moreover, the AMTC would strengthen the Dutch knowledge and expertise in semiconductor equipment. By September 1985, the Dutch Ministry of Economic Affairs approved ASM International's plan, and pledged 40 million Dutch guilders in its support. This sum matched ASM International's proposed investment in the AMTC. To pay for the AMTC and for ASM Lithography, Del Prado negotiated a subordinated loan of 30 million Dutch guilders. This long-term credit line was obtained through the state-owned National Investment Bank [in Dutch: Nationale Investeringsbank, NIB]. ${ }^{17}$ The money was available for ASM by January 1, 1986.

A new facility on the Rembrandtlaan in Bilthoven was remodeled to contain the latest cleanroom and a pilot line of all ASM's wafer processing technologies, offering customers all the benefits of the company's comprehensive product portfolio. Initially only the products of ASM Europe were installed.

The establishment of the AMTC did not mean that Del Prado focused all his attention on strengthening the coordination and oversight of his operations. In contrast, he continued to add new activities to ASM. In 1985, the modest activities in sales and the manufacturing of gas flow technology of ASM France were expanded through the incorporation of a bankrupt manufacturer of diffusion furnaces called SEMY. ${ }^{18}$ This French manufacturer, located in Montpellier in the south of France, applied its systems foremost for optical fiber instead of semiconductor production. The rather economical acquisition of SEMY foremost increased ASM's presence within the industry in France.

17 However, just a few months later, the National Investment Bank was privatized by the Dutch authorities.

18 SEMY had been established by a former ASM sales manager, Ivon Pellegrin, who had been forced to resign. The acquisition of SEMY merely involved the purchase of some stock. SEMY had ongoing commitments with IBM France, Motorola Toulouse, and Alcatel. Hence it made sense for ASM to acquire this competing business of diffusion furnaces. Until the mid-1990s, ASM France continued the development of these diffusion furnaces, next to those developed in Bilthoven. 


\section{Entering the market for ion implantation}

While ASM prepped up its existing operations, Del Prado engaged in one final technological and organizational expansion: ion implantation. This technology constituted a critical market in the production of MOS chips (mind Intermezzo). By bombarding a silicon wafer with ions, the electrical properties of the substrate could be changed. ${ }^{19}$ In this functionality ion implantation competed with the traditional diffusion furnaces. It provided the benefits of low temperatures and deep penetration of the substrate, allowing the alteration of the substrate electrical characteristics later in the production process. Since the early seventies, the source and drain of a MOS transistor were created by means of ion implantation.

By the mid-eighties, the global market for ion implant machines totaled 286 million dollars - compared to the 199 million dollars for diffusion furnaces. ${ }^{20}$ The technology was much more advanced and complex, which was reflected in the cost per machine. Within the market for ion implant machines, three kinds could be distinguished. These were high, medium, and low current implanters. The difference entailed the flux with which the substrate got bombarded.

Already in the fall of 1984, ASM America's manager Franc DeWeeger had been approached by a group called Eclipse. ${ }^{21}$ This organization consisted of four highly experienced engineers: Jack Vanderpot, Donald Berrian, Robert Kiam, and Eli Young. This gang of four worked or had worked at all major American suppliers of ion implantation technology in the capacity of engineer, manager, or consultant. Through these experiences, they had developed a new machine, and looked for a partner to commercialize it. ${ }^{22}$ Throughout 1985, ASM and the members of Eclipse discussed, negotiated, and evaluated their proposal. As DeWeeger reported to Del Prado:

'Ion implantation has been brought to the market place by people like Eli Young, Peter Rose, Andy Wittkower, who worked HVEC and then moved from company to company, introducing new implanters more or less successfully until they got trapped by Eaton recently. ... If $\mathrm{U}$ start with Eli Young, etc. it is rather likely that a number of people now working for Eaton will jump over. If $U$ start this effort in the Boston Area, you would

19 An elaborate history of ion implant's entry into semiconductor manufacturing is: Christophe Lécuyer and David Brock, 'From nuclear physics to semiconductor manufacturing: the making of ion implantation', History and Technology 25:3 (2009), pp. 193-217.

20 Dataquest newsletters.

21 Eli M. Young, 'Letter to Franc DeWeeger' (7-11-1984) Archive Arthur del Prado -ASM Ion Implant/Eclipse files.

22 ASM America, Franc DeWeeger, 'Memo to Arthur del Prado: Ion Implantation' (December 1984) Archive Arthur del Prado -ASM Ion Implant/ Eclipse files. 
make a very fast start also because people don't have to move, know vendors, have consultants, friends, etc. So, U don't start from scratch. ${ }^{23}$

The Eclipse engineers had developed a medium current implanter (figure 45). They projected a market of 148 million dollars in 1984, which they expected to grow to 328 million by $1988 .{ }^{24}$ And they had also formulated a ready-made ion implant development program, which nearly covered everything: a building, most of the required staff, planning, the machine and components, and areas requiring further research.

\section{Figure 45}

Simplified view from above of an ion implanter

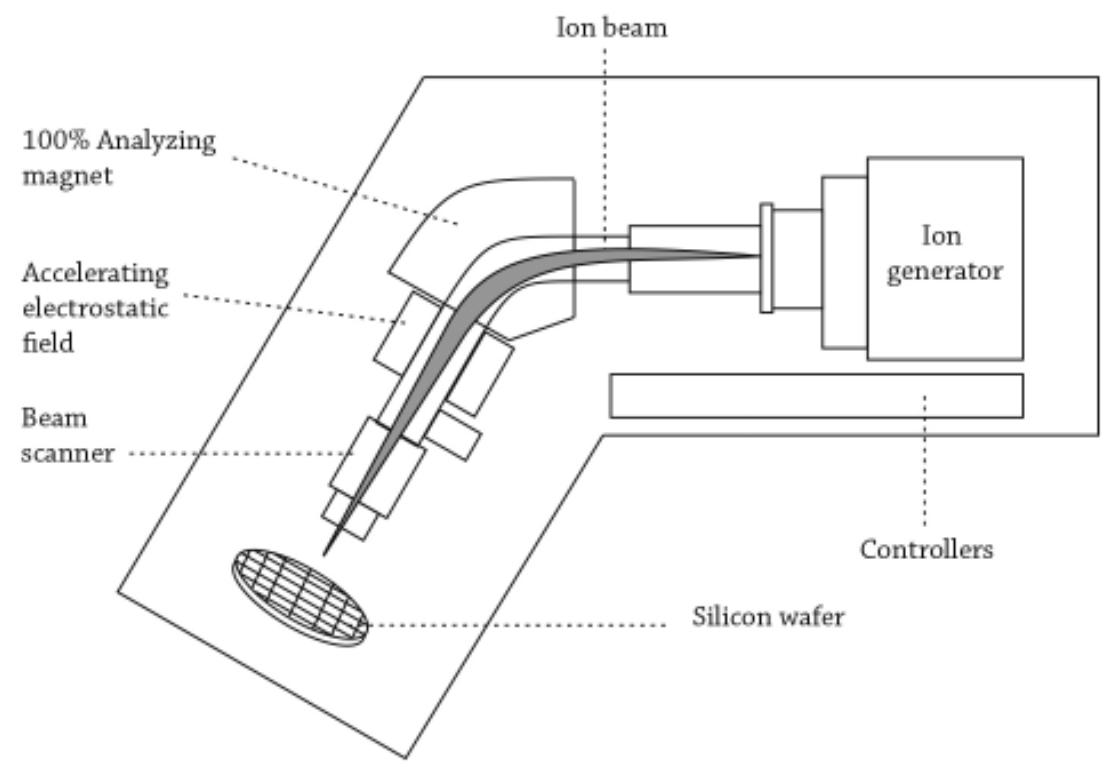

Eclipse proposed to ASM a joint-venture in which ASM would have 55 percent of the shares and Eclipse the remaining 45 percent. ${ }^{25} \mathrm{ASM}$ would invest money, while Eclipse would bring in the knowledge, the plan, etc. The required funds

23 ASM America, Franc DeWeeger, 'Memo to Arthur del Prado: Ion Implantation' (December 1984) Archive Arthur del Prado-ASM Ion Implant/ Eclipse files.

24 Naturally, this was exaggerating the real market. In 1984, the worldwide market for medium current implanter totaled just 118 million dollars. - Eli M. Young, 'Letter to Franc DeWeeger' (7-11-1984) Archive Arthur del Prado-ASM Ion Implant/ Eclipse files; Dataquest newsletters.

25 Eclipse, Eli Young, 'Letter to Arthur del Prado' (20-5-1985) Archive Arthur del Prado-ASM Ion Implant/Eclipse files. 
were estimated at 4 million dollars. In three years, the group would be able to introduce a working ion implanter.

By September 1985, ASM and Eclipse met in Bilthoven to discuss and evaluate the plan. ${ }^{26}$ Del Prado, De Leeuw, and the new head of the AMTC center, Dr. Ernst Granneman, represented ASM, while Eclipse was represented by Jack Vanderpot, Norman Turner, Kaim and Berian (Eli Young dropped out of the project). Also present were engineers from Philips - who had experience in using ion implant technology - and Frans Saris, director of an Amsterdam-based research institute with significant expertise in ion implantation and member of the technological advisory board of Epsilon Technology. During the meeting, the outlines of the machine and its viability became more apparent.

A market opportunity for medium current implanter was envisaged due to the downturn. Existing American ion implanter manufacturers like Eaton, Varian, Nova, and Applied Materials had canceled this market segment or they no longer pursued it any further. The machine involved would be single wafer with a magnetic/electrostatic scanning concept. For many critical parts, like the ion sources, the engineers opted for known and proven configurations, rather than gambling on the latest of the latest.

All critical questions posed by ASM, Saris, and the Philips engineers were convincingly answered. It was up to ASM to consider its ambitions. There was little risk for ASM in the short term. The whole project seemed well considered and worked out, and the investments were relatively modest. The main risks for ASM pertained to the introduction of the machine to the market and the possible decision of the Eclipse engineers to pursue their chances elsewhere. ${ }^{27}$

This consideration was deemed of rather minor importance. Del Prado did not evade this opportunity to complete ASM's product portfolio of semiconductor technologies. It would be most counterintuitive to the entrepreneur if he did not follow through. The opportunity had just fallen into his lap. By December 1985, he and Jack Vanderpot of Eclipse worked out all the details to enable a flying start of ASM Ion Implant by January 1986.

\section{Business as usual?}

These investments in facilities, ongoing operations, and prestigious developments like the AMTC and ASM Ion Implant underscore Del Prado's great confidence during his period. He knew the volatility of the industry very well, and was

26 ASMI, Ernst Granneman, 'Meeting report Ion implant, 30-9-1985, ref: R\&D/85 - 48/I.F.' (10-10-1985) Archive Arthur del Prado-ASM Ion Implant/ Eclipse files.

27 AMOLF, Frans Saris, 'Letter to Arthur del Prado, Willem de Leeuw, and Ernst Granneman' (16-9-1985) Archive Arthur del Prado-ASM Ion Implant/ Eclipse files. 
not too worried about the current slump. So far in his career, he had used these moments to prepare for new upswings.

However, in 1985, there were several signs that things were not going to be quite the same. The first matter concerned the size of ASM International. The company was no longer as easily manageable as in the past. Many things happened at many places simultaneously. New staff - De Leeuw and Lakens took over some of Del Prado's tasks. But they lacked the clout of the company's founder, as well as experience in semiconductor technology. This implied that they had to earn the respect of the headstrong subsidiaries before they could implement a corporate strategy. Only time would tell whether the new central management was able to make their mark on the diversified company.

The second matter entailed the new involvement of external stakeholders. To pay for the investments, Del Prado utilized lines of credit from banks throughout 1985. For the first time in its history, the company incurred debts, in anticipation of the downturn's recovery. The benefit of the bank loans for Del Prado was that he would not have to dilute his ownership much further. ${ }^{28}$

The chief executive officer and founder was keen on keeping a 50 percent ownership of the firm indeed. He wanted to stay the master of his and ASM's fate. Rather than securing investments through offering new shares or convertible notes, Del Prado leveraged his company's innovation by means of external funds. As would become apparent later on, this proved to be a fatal mistake. The stakeholders required adequate justification and measures for their involvement.

The third matter was that Del Prado's sole authority was no longer obvious, despite his clinging to his 50 percent ownership. This stemmed from a heart attack Del Prado suffered in the summer of 1985. Although he recovered quickly, the incident caused concern with the chairman of the ASM Supervisory Board, Paul van den Hoek. ${ }^{29}$ What if Del Prado passed away or was no longer capable of managing the whole enterprise? Nobody in the company had the overview of the operations and actions like Del Prado had. His drop-out would be fatal for the company as a whole.

Van den Hoek urged Del Prado to strengthen the supervisory board and the management of ASM International. In his plea, Van den Hoek was supported by the National Investment Bank, which required strengthening of the supervisory board as one of its terms for the 30 million subordinated loan. ${ }^{30}$ The bankers

28 Richard Blickman, 'Interview with author', André van Rhee, 'Interview with author', Paul van den Hoek, 'Interview with author', and Nico Nobel, 'Interview with author'.

29 Paul van den Hoek, 'Interview with author'.

30 ASMI, Arthur del Prado, 'Letter to Nationale Investeringsbank N.V., ref: 213.86 AdP/jm' (91-1986) Archive Arthur del Prado - Banks - NIB file; and NIB, P.C. Van Gool, 'Letter to Arthur del Prado' (15-1-1986) Archive Arthur del Prado - Banks - NIB file. 
recognized that Del Prado's central position in the firm constituted a risk for the firm and thus for their loan.

Nevertheless, throughout 1985 and 1986, Del Prado disregarded these demands and requests, even after Han, his wife and personal anchor, unexpectedly passed away in April 1986, leaving their three children motherless. Evidently, also during these disruptive circumstances, Del Prado remained a Machiavellian pur sang, not willing to lose control over his company. He pulled the strings. However, as the crisis in the industry continued, accelerating technological change across the equipment industry, ASM and Del Prado proved to have misjudged the times. 


\section{Chapter 18}

\section{Changing semiconductor production technologies, 1986-1987}

During the mid-1980s, the memory downturn caused a deviation in technological development in the respective American, Japanese and European markets. ${ }^{31}$ This divergence exposed ASM's organizational deficiencies. The respective business units failed to formulate a cohesive answer to the technological challenges posed. Competitive strategies did not align. The lack of a corporate strategy became apparent.

\section{Industrial context:}

\section{A new dynamism}

From 1986, the chip industry faced new technological challenges for its production technologies, based on innovation in the semiconductor equipment industry (see Intermezzo in Business I). Structural drivers were the need to improve quantity and quality of production methods, and the enabling of further scaling of transistors. Following these dynamics, the industry moved into the production of submicron-dimensions - transistors the size of the smallest bacteria - on wafers with a diameter of 200 millimeters (or about 8 inch). Both the submicron size and the upscaling of the wafers required tremendous changes to production technologies in automation, processes, and cleanness.

In addition to the ceasing of the memory rivalry, the progression of miniaturization and wafer scaling caused a divergence in technological development between Japan, the United States, and Europe. This deviation followed from the specialization of the regional semiconductor industries. The majority of the memory manufacturers resided in Japan, while most producers of microcontrollers and customized chips, also known as ASICs (application specific integrated circuits), were based in the United States. A bit of both sectors was found in Western Europe. The characteristics of these markets - memory in Japan and ASICs and microprocessors in the United States - steered technological development and demand for new production equipment.

Initially, the requirements for mega-bit submicron memory chips came to the fore in Japan. The production of memory chips was characterized by relative 
low variety and high volumes. Moreover, memory chips led the whole chip industry into the submicron-era. Production equipment had to be clean, high in throughput, and automated. Equipment manufacturers serving the Japanese market - like ASM Japan - were confronted with new demands stemming from the memory market.

In the deposition segment, this created a new demand for vertically configured deposition and diffusion batch furnaces - instead of the horizontal ones. Vertical systems required less floor space in the latest cleanrooms. The construction and utilization of the latest cleanroom was highly expensive; every square inch of cleanroom adds to the price tag. Moreover, automation of the wafer loading in vertical furnaces was easier - in particular with bigger wafer sizes. Additionally, vertical systems offered some process benefits due to an improved heat transfer across the tube. From 1985 onward, initially starting in Japan, the demand shifted from horizontal to vertical systems; a major change for equipment suppliers. ${ }^{32}$

In the United States, the advent of ASICs posed new requirements for production equipment. ASICs were advanced computer chips dedicated for specific tasks, like controlling video displays, and other electronics. Each of these ASICs needed adaptation of the circuitry design - the maze of transistors, resistors and the electrical interconnections - and dedicated software in order to fulfil this task. The production process might have to be adapted from one ASIC to the other. Hence these chips were made in relative low volumes and in bigger variety compared to memory chips.

In addition to the processing of bigger wafers and miniaturization, ASICs created a demand for wafer processing machines that processed fewer wafers simultaneously. The production of ASICs required smaller batch - or even single wafer - machines. The big batch reactors were too costly and inflexible. Processing a single or just a few wafers at a time offered chip manufacturers more flexibility and control. Properties of the deposition and etch processes could be adjusted and controlled more easily according to the highly varying ASICs production recipes. Initially, single wafer processes were required for the deposition and etching of new materials in the interconnecting area of a chip, like tungsten. Whereas the Japanese chip industry led the way in vertical systems, the United States did so in single wafer machines.

32 The first supplier of vertical reactors was a Swiss equipment manufacturer Helmut Seier (later Disco-Seier), followed by the Japanese equipment vendor Denko. The third one to introduce a vertical system, Model 2000, was Tempress. Later in the history of ASM, Tempress and ASM would collaborate in the development of vertical furnaces, a critical phase for the survival of ASM. In 1985, the parent company of Tempress, General Signal, also introduced a vertical system in Japan through a joint-venture called Koyo-Lindberg. - Dataquest, 'Chemical Vapor Deposition: Vertical Tube Reactor', Dataquest SEMS Markets and Technology (26-9-1985) p. 24. 
The downturn in the industry, as well as the forthcoming changes in it, accelerated development. Most of the equipment vendors used the pause in the market to prepare for an imminent surge by addressing these changes. As such, the downturn and the subsequent advanced technological change benefited newcomers. Incumbent diversified equipment makers with major manufacturing operations in place - like ASM - had difficulties adapting to these new changes.

The divergence in technological demand exposed ASM's difficulties in formulating and implementing a corporate strategy. Competitive strategies of the different business units and product groups conflicted with the course set out in Bilthoven, but they also did so among each other. Each of the operations - including the holding company - rigorously followed their own interests. An ongoing recession and disappointing sales aggravated the difference in strategies.

\section{Corporate course:}

\section{Anticipating commercial opportunities and technological developments}

Having a dispersed presence across geographical and technological markets, ASM was keenly aware of the technological challenges looming ahead for the front-end operations. Del Prado's management team at ASM International tried to align interests into a corporate strategy, while preserving the business units' ability to compete. This task devolved upon Controller Jan de Bes, new marketing manager Herbert Lakens, and Director of Technology Willem de Leeuw. Furthermore, a new R\&D manager, Ernst Granneman, was hired as technical leader of the forthcoming ASM Microelectronic Technology Center (AMTC). Managing and aligning the technological developments at the operations constituted the heart of the integration efforts set forth by these men.

This applied in particular to the plasma deposition systems, in which ASM was the worldwide market leader. ASM was an incumbent with regard to horizontal CVD machines. So far, ASM's geographical operations - in Japan, America, and Europe - had relied upon the same technology: horizontal deposition furnaces. A single innovation had been sold in multiple geographical markets with just minor adaptation of the machine. It was imperative to continue this advantage in whatever direction future deposition technology would develop.

The new product groups - ASM Lithography, ASM Ion Implant, and Epsilon Technology - had a rather different point of departure. All of them were still developing their products, preparing manufacturing operations and establishing a sales \& marketing network. Having a focused goal - the commercialization of a product, instead of exploring a geographical market - and lacking the organizational burdens of an established company, these operations were more capable of adequately addressing the technological and competitive changes in the industry. 
The newly established AMTC, led by Erik Kamerbeek and Ernst Granneman, was intended to become the pinnacle in coordinating the diverging competitive strategies of the geographical and product operations. In this effort, its engineers and management studied new technological developments. The AMTC was also meant to be the central node for enacting general technological solutions among the operations. The AMTC's relation to the subsidiaries could be characterized as 'technology-push', or a top-down approach. ${ }^{33}$

To achieve economies of scale, the director of technology, Willem de Leeuw, propagated general hard- and software controllers among all the operations. This involved a computer - the Stand-Alone Thermal Controller (SATC) - and an expansive automation effort for wafer handling and loading, dubbed ASM Computer Automated Manufacturing System (ACAMS). Innovations like ACAMS were enforced by ASM International - through the AMTC - upon the operations, whether it aligned with their interest in the market or not.

This enforcement of coordinated development by the AMTC conflicted with the dispersed needs of the operations. Each of the geographical business units had to deal with its regional customers, marketing particularities and time schedules. Moreover, the product groups - Epsilon, Ion Implant, and Lithography - constituted rather independent packages of technology. They had done their work, elaborating and analyzing every possible part of their machines. Adapting their products to the general interest of ASM would only cost money and deteriorate their distinctive technology.

Traditionally, ASM's innovations had been market-driven rather than technology-driven (see the Innovation chapters). The coordination of technological development through the AMTC constituted a deviation from this practice. And as will become apparent, the execution of this innovation strategy did not occur without a hitch. The internal rationality for a cohesive reply conflicted with the market-driven mode of conduct of the business units.

\section{Elaboration of affairs}

\section{Differing appreciations about the future of CVD machines}

In the fall of 1985 and throughout the spring of 1986, ASM's geographical operations - ASM Japan, ASM America, and ASM Europe - disagreed about the course of the market with regard to CVD processes. ASM Japan was confronted

33 Only in relation with ASM Europe did AMTC work in a more 'technology-pull' manner. As a cost saving measure and in order to accelerate the start of the AMTC, the R\&D efforts of ASM Europe had been transferred to the AMTC. Consequently, ASM Europe relied upon the AMTC's expertise and innovations. In response to the ASM Europe marketing team, the AMTC successfully developed an innovative 'cascade controller', and worked on tungsten CVD. 
with a demand for vertical batch machines by its customer base, predominantly existing of memory manufacturers. ASM America distinguished a trend for systems with smaller volumes to even single wafer processes. ASM Europe still succeeded in selling its horizontal systems as the European industry tried to overcome its lag in memory chips. ASM International and AMTC lacked a clear apprehension of the developments. This was illustrated by the assessment of ASM International's marketing manager Herbert Lakens about the emergence of vertical furnaces in the market place:

'Apparently, there is a lot of interest in the market since vertical furnaces were introduced some years ago ... Information of large quantities ordered so far, could not be confirmed or were denied by customer. Buying plans are somewhat vague, maybe influenced by the downturn. It looks like customers have many questions about vertical furnaces as well. Maybe the current vertical furnaces are ahead of their times and need the 8" [wafers] gaining ground before they break through.' ${ }^{34}$

Since ASM enjoyed a strong position in plasma CVD, discussion among the operations centered around the need to develop a vertical plasma CVD machine. ${ }^{35}$ However, the marketing information provided in the three geographical markets did not create a coherent view on the necessity and benefits of this approach.

ASM Japan, ASM America, and the AMTC recognized a different sense of urgency and direction with regard to the incumbent horizontal CVD business. After the Japanese operation received queries from its customers on whether it would supply a vertical plasma machine, it passed on this urgency to the company's other units. ASM America, meanwhile, was hesitant about the idea of a vertical plasma CVD machine, and propagated a smaller horizontal variation. They had to address the forthcoming American market for ASIC's. The debate about vertical machines bore the risk of creating an American response and a Japanese one, which decreased economies of scale. Henceforth the engineers of AMTC tried to come up with a general solution applicable for both ASM Japan and ASM America.

Director of Technology De Leeuw was in the lead to balance the interests. To spread risk, he tried to pursue multiple options for the time being, steering a middle course. ${ }^{36}$ This involved the development of a vertical low pressure CVD

34 ASMI, Herbert Lakens, 'Memorandum: Vertical furnaces/ALCVD' (29-11-1985) Archive Arthur del Prado - Vertical furnaces file.

35 ASM America, Dick Rosler, 'Memo: Your request for comparison of George's small footprint system for LPCVD/Diffusion versus a vertical system approach' (30-12-1985) Archive Arthur del Prado - Vertical furnaces file.

36 ASMI, Willem de Leeuw, 'Memorandum: Vertical Reactor Development' (3-7-1986) Archive 
(LPCVD) process by ASM Japan and a vertical aluminum CVD process by ASM Europe. The AMTC would supply a central load system on which both systems could be connected (figure 46). Each of the operations could fulfil its competitive strategy. Only the question about vertical plasma processes remained open.

\section{Figure 46}

Simplified side-view (left) and view-from-above (right) of the A600-2, late 1980s

This early outline depicts the concept of the A600, with its central loading system and multiple reactors. Initially this configuration was dubbed Vertex and later renamed A600. The second variation - A600-2 - was meant for low-pressure CVD and oxidation.

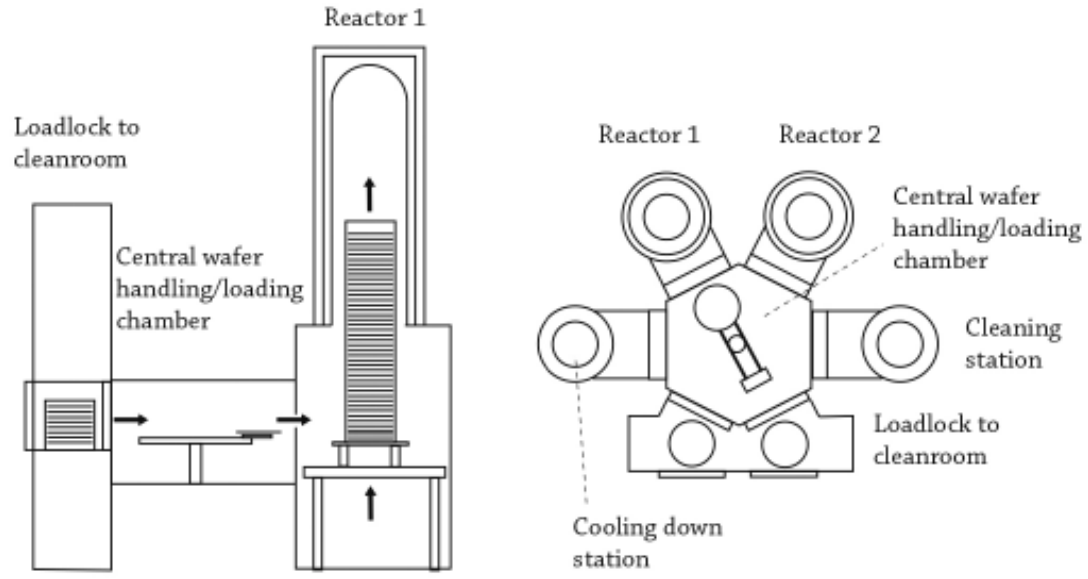

Within ASM America - the company's experts in plasma processes - there were heavy debates about whether vertical plasma furnaces should be pursued. ASM America's general manager Franc DeWeeger stated:

'As you may or may not know, we have been struggling with the issue of vertical plasma and low pressure versus horizontal. George Engle, who I am sure you all know, and I have been agonizing as to how we can improve our market share without impacting our current product portfolio.' ${ }^{37}$

ASM International and ASM America were not on the same page. ASM America's consultant for plasma processes George Engle recognized practical disadvantages for vertical plasma furnaces. Moreover, Franc DeWeeger and his experienced

Arthur del Prado - Vertical furnaces file.

37 ASM America, Franc DeWeeger, 'Memorandum' (31-12-1985) Archive Arthur del PradoVertical furnaces file. 
R\&D manager Dick Rosler were not happy with the central directed R\&D efforts. Rosler complained:

'From a market standpoint, a vertical technology introduction in the US will adversely affect several introductions of new PECVD products. We are just embarking on the ACAMS version of our PECVD Horizontal Reactor. If we were to also announce a vertical reactor, the semiconductor manufacturers will be confused as to which technology ASM is supporting for the future (horizontal or vertical?) ... The Vertical approach is in direct competition with it and would probably curtail its life cycles; thus, ASM would not be able to recover its investment on this product.

... It is foreseen that, by $1990,50 \%$ of the semiconductor market in the US will be producing ASIC devices. This market will require small flexible systems of either small batch type reactors or single wafer reactors. The currently defined Vertical approach does not seem to address this market. ... However, if the [Central Load System] Program was applied toward the single wafer approach, then ASM America could have a significant advantage in the ASIC markets. ... Our plate is full in 1987; so we do not foresee the resources available within ASM to properly address a new technology like the Vertical Program, nor a growing economic place in $1987 .^{38}$

The issue lingered on without a decision being made. Throughout the fall of 1986, ASM International and its subsidiaries continued to ponder the pros and cons of each approach: vertical furnaces, a central load-system, small horizontal batch machines, or single wafer. Each of the operations lacked the resources to set up a comprehensive answer to the challenges posed in the CVD market. However, time was running out.

Facing exclusion of the market in the near future, the operations moved ahead by themselves. It was a particular example of ASM's excessive virtù. The urgency to engage the unknown future, in the face of each operations' temporal finitude, outlasted a more deliberate approach. ASM's dynamism and impetuosity created a dispersed answer to the forthcoming technological changes.

ASM America continued to develop the mini batch horizontal furnace for plasma CVD, dubbed SF-50. The machine elaborated upon the common horizontal

38 ASM America, Richard Rosler, Jeff Clifford, and Juergen Achterfeldt, 'Memorandum: Vertical Reactor Position from ASM America, Inc.' (30-9-1986) Archive Arthur del Prado - Vertical furnaces file. 
machines and required less investments in development and engineering. It complied with ASM International's strategy to increase coherence among the operations, since the SF-50 incorporated the ACAMS controller and automation technology. ${ }^{39}$ Furthermore, the need for more flexibility and smaller volumes of ASICs manufacturers was addressed.

Meanwhile, ASM Japan's management decided to stay in control of its own fate. Vertical furnaces of the competition made significant inroads in the Japanese market, and the ASM engineers were still empty-handed. By November 1986, with Del Prado's approval, ASM Japan's general manager Yo Miyazaki decided to move ahead. ${ }^{40}$ He teamed up with a subcontractor named Tokyo Hitec. ${ }^{41}$

This firm was a spin-off of Denko, one of the pioneers of vertical systems, and employed a group of experienced Fujitsu engineers. Tokyo Hitec developed the automation and hardware of a vertical LPCVD furnace, and it approached ASM Japan for cooperation, specifically regarding the development of LPCVD processes, the design of the wafer handling system, and the marketing of the machine. The deal allowed ASM Japan to make up for its lag in vertical furnaces.

This new approach deviated from the corporate technological strategy outlined by De Leeuw. Instead, the cooperation with Tokyo Hitec constituted a relapse into ASM's old innovation strategy: decentral commercialization of external inventions (see Innovation I). The idea that ASM Japan would develop a vertical process reactor attachable to the AMTC central load system became an instant anachronism. To serve the Tokyo Hitech vertical furnace ASM Japan had designed a dedicated loading system and internal mechanics. In this new reality, ASM Japan just got a completely new machine and no longer required the central load system.

More remarkably, Del Prado sided with ASM Japan, even as this annulled the centralization efforts of De Leeuw. Due to the enduring crisis in the market, ASM could not afford to pass by any chance of sales. The Tokyo Hitec and ASM Japan cooperation offered the company a short-cut to sales in vertical furnaces. Hence

39 ASM America had to incorporate ASM Europe's ACAMS software and loading software in its machines. This was done with much internal protest. Centralizing software development was far from logical, as software constantly required updates an adjustments. Quick tweaking and tuning was indispensable. A central system would slow down ASM America's ability to serve its customers and address any shortcomings. Moreover, both the horizontal furnaces and the ACAMS system could not comply with the demand of customers for cassette-tocassette loading of wafers. This feature was requested by almost all customers in order to improve clean transport and handling of wafers from process to process. - ASM America, Franc DeWeeger, 'Fax to Willem de Leeuw: Vertical Reactor Development' (7-7-1986) Archive Arthur del Prado - Vertical furnaces file

40 Ibid.

41 ASM Japan, Yo Miyazaki, ‘Telex to Franc DeWeeger, ref: KK-86-1708’ (13-11-1986) Archive Arthur del Prado-ASM japan 1985-1988 file. 
Miyazaki and his team were allowed to continue along their path. ASM Japan and Tokyo Hitec developed a low pressure variation (VMP-100) and a diffusion version (VDF-100) of the machine. After introduction to the Japanese customers in the spring of 1987, the machines would also be presented in Europe and the United States. In the meantime, the AMTC continued the development of the central load system.

The divergence in technological development in the respective geographical markets formed a challenge for ASM. The company hardly recovered from the jumping start of the early 1980s and was not yet capable of formulating an answer. A corporate strategy in which Del Prado and his management tried to increase coordination and cooperation within the diversified company failed to achieve its goals.

Even worse, the competitive strategies of the operations hardly got any closer. While ASM Japan went its own way in the old decentralized business fashion, ASM America tried to comply. Meanwhile the AMTC stood up to its envisaged role as embodiment of the new innovation strategy. It resulted in a stalemate within ASM, while the industry's other players were swiftly moving on.

\section{ASM's product groups: epitaxy, lithography, and ion implant}

Meanwhile the product groups followed their own competitive strategy, hardly complying with the intentions of the ASM International or the other geographical operations. Epsilon Technology, ASM Ion Implant, and ASM Lithography were lined up for the approaching submicron CMOS technologies, in particular for the American market. Their organizational focus on a single product seemed to work well with regard to the new technological challenges faced by the chip industry.

The team of Epsilon Technology had reached the final development phase, after ASM supplemented its depleted resources in the summer of 1985 (see Chapter 14). Their epitaxial reactor took the form of a standalone single wafer system. This configuration would guarantee unprecedented uniformity and control for the growth of silicon epitaxy films. From the fall of 1985, the team developed the final components before it would be prepared for marketing and market introduction under the name of ASM Epitaxy by 1987.

The latest addition to the family of ASM operations, ASM Ion Implant, knew a flying start. Under management of its general manager Jack Vanderpot, the Boston operation hurtled along the path stipulated by Vanderpot and the other members of Eclipse. The intended president of ASM Ion Implant, also a veteran in ion implant technology, Andrew Wittkower still had to begin. By the time Wittkower started in the summer of 1986, he was confronted with a well-oiled enterprise. As he reported to Del Prado: 
'Upon my arrival here, I found a well-structured machine based on an interesting combination of proven concepts together with new ideas.... At this point, the only brake on our progress is the expansion capital needed ... You must be aware of that the group of people gathered here under the ASM banner is really quite exceptional. Apart from their impressive individual skills, the group effort is producing output which is much greater than the sum of the separate parts. We are ahead of our goals because of this factor alone. Under no circumstance must we disturb this delicate spirit and group enthusiasm. ${ }^{42}$

Wittkower had not much to manage. Vanderpot and his team ensured a rapid progression of the development program: process development, engineering, preparation for manufacturing - everything went according to plan. ${ }^{43}$ The machine took shape. It had a parallel scanning beam, in-situ dose monitoring and correction, advanced automation, graphic display features, as well as high reliability and low maintenance as a priority. ASM Ion Implant was at the top of the class.

In the case of ASM Lithography, its general manager Gjalt Smit and his technical team had set new objectives after the original stepper machine had proven to be practically unsellable. This new machine, dubbed PAS2500, was - rather naively - expected to be ready by May 1986. ${ }^{44}$ The machine with a minimum linewidth of 0.7 micron and an overlay accuracy of a 0.125 micron had many of the basic features of future lithographic machines. To realize ASM Lithography's connection to the most advanced market, ASM and Philips had to increase their investments with tens of millions annually. Securing a stake in the submicron lithography market would come at a high price.

ASM Lithography's chances improved due to the downturn and subsequent technological changes. The depressed market caused a shake-out among the competition, as well reflected by the struggling market leader GCA. This company enjoyed the biggest installed base, but lost the allegiance of the market place. Its technology was no match for the latest stepper machines of the Japanese Nikon and Canon. Also ASM Lithography's stepper machines aligned better with the forthcoming demands. By the fall of 1985, the American stepper manufacturer

42 ASM Ion Implant, Andrew Wittkower, 'Letter to Arthur del Prado' (4-12-1986) Archive Arthur del Prado-ASM Ion Implant/ Eclipse files.

43 ASM Ion Implant, Jack Vanderpot, 'Letter to Arthur del Prado' (1-8-1986) Archive Arthur del Prado-ASM Ion Implant/ Eclipse files.

44 Raaijmakers, De architecten van ASML, pp. 318 and 326. 
was up to its neck in financial difficulties. An investment banker was set to the task of contemplating a new future for the incumbent stepper maker.

In June 1986, via a French GCA joint-venture called Matra GCA, Del Prado learned about the problems at the American lithography manufacturer and its search for a partner. ${ }^{45}$ ASM was certainly interested in obtaining a firm footing in the industry through a merger or acquisition with GCA. If it would make ASM Lithography immediately an established supplier of lithography, it also came with the risk of inheriting GCA's structural flaws. ${ }^{46}$

While Del Prado optimistically explored possibilities for the acquisition, a group of investment bankers stole his march. ${ }^{47}$ They succeeded to recapitalize GCA, thus preventing its immediate faltering. It was a blessing in disguise for the already overburdened Dutch stepper manufacturer. ASM would have bought a declining company. ASM Lithography's commercial chances for success were better served with the drop-out of GCA as competitor, something which would happen either way.

The product groups deliberately wanted to keep control of their own sales. Cooperation with the geographical business units - ASM Japan, Europe and America - remained problematic. ASM Lithography's general manager statement to De Leeuw was illustrative:

'I meant the, whatever the reason, raised bad reputation of ASM on the American market, enhanced by its rapidly declining market share and company results. At various potential customers of ASM Lithography, it appeared that the association with ASM America acts as a check on us. Furthermore, the sales crew of ASMA tries to sell the stepper in its own way. In this process it mentions specs, prices and other preconditions without knowing what is what, nor with any tuning or approval of ASML. ... The lithography market is too complex and strategic to be served by a representative. ... I don't know why ASMA does this. ... Some

45 ASM Europe, Jan Heetebrij, 'Memorandum: Matra GCA, ref: 172 jhe/ejo' (11-6-1986) Archive Arthur del Prado-ASML; GCA file.

46 ASM International, Arthur del Prado, 'Memorandum: Overname GCA, ref: MEM.255.86 AdP/jm' (9-9-1986) Archive Arthur del Prado-ASML; GCA file; ASM Lithography, 'GCA-ASM-L' (1-9-1986) Archive Arthur del Prado-ASML; GCA file.

47 Prudential-Bache, Stephen Balog, 'GCA Company Update: Recapitalization Plan Approved By Lenders - GCA Lives!' (5-11-1986) Archive Arthur del Prado - ASML; GCA file; ASML, Arthur del Prado, 'Memo to board members: GCA' (18-11-1986) Archive Arthur del Prado - ASML; GCA file. 
internal political aspirations might be underlying the motivation for all this. ${ }^{148}$

Alignment of competitive strategies with geographical business units did not happen. It was more efficient and successful if the product groups took care of that themselves. The plurality of competitive strategies within ASM persisted.

\section{Eruption of internal competition}

The conflicting competitive strategies between product groups and geographical business units was not limited to the wafer processing activities of ASM. Also, in ASM's activities in the assembly and packaging segments, these management issues prevailed. Moreover, in this case, it became apparent that there was no easy solution. Changing geographical groups into product groups proved to be problematic, as illustrated by the troubles between ASM Fico and the Hong Kong operations.

ASM Fico developed encapsulation technology - molds, stamps, trim \& form, and lead-frames - which were sold by the geographical business units. However, the most successful subsidiary of ASM in encapsulation technology, ASM Asia managed by Patrick Lam, no longer sold these products but had also localized some of the production (cf. Business II). This was done under the name of ASM Assembly Materials. In order to compete on price, lead-frame production was entirely transferred to Hong Kong.

To level the various ASM operations, Del Prado ordered a study for a name change of ASM Fico in the summer of $1986 .{ }^{49}$ He explained to ASM Fico's general manager, Richard Fierkens:

"It is intended that after "ASM" an extension follows indicating the business of ASM Fico, emphasizing on the functional. ${ }^{50}$

Such a name change would bring ASM Fico in line with the other subsidiaries like ASM Lithography, ASM Ion Implant, etc. However, the study concluded it was better not to hurry through the name change. Just changing the name would not result in a better integrated business unit. It might cause confusion among customers and employees, while the Fico name enjoyed a good reputation. Apart from this conclusion, the effort alienated ASM Fico's founder and general

48 Original quote in Dutch. - ASML, Gjalt Smit, 'Interne mededeling: De ASMA-ASML relatie' (7-5-1986) Archive Arthur del Prado-ASM Lithography 1986 box.

49 Hill and Knowlton, 'Onderzoeksrapport inzake naamswijziging ASM Fico' (September 1986) Archive Arthur del Prado-ASM Fico files.

50 Original quote in Dutch. - ASMI, Richard Fierkens en Herbert Lakens, 'Memorandum: Naam ASM Fico' (14-8-1986) Archive Arthur del Prado - Fico files. 
manager Richard Fierkens. Removing 'Fico' - denotating Fierkens Company was a personal issue. ${ }^{51}$

It came on top of disagreements between Lam and Fierkens about the pricing of molds and stamping equipment and Fierkens' requests for a compensation for the transferred knowledge. Due to the lower labor costs, ASM Asia was able to offer similar molds against lower prices than ASM Fico. This confused customers, and put Fierkens in a difficult position. He was not able to lower prices and manifested himself as a vocal opponent of Del Prado's integration efforts. According to Fierkens, ASM Fico was treated unfairly.

The position of ASM Fico - and its founder - within ASM became unworkable in the summer of 1986. To compete in the biggest market for semiconductor assembly and packaging technologies - the South-East Asian market - Del Prado deemed it imperative to allow Lam's price reductions. In an effort to overcome the management dispute, and to raise cash for supplementation for ASM's rapidly draining cash reserves, he decided to explore an initial public offering or divestment of a portion or the whole ASM Fico operation. ${ }^{52}$ Fierkens seized the moment to draw up a proposal for a management buy-out throughout the fall of 1986.

The whole situation exposed the forces derailing ASM International's integration forces. The autonomy of the business units - if not coordinated well - might result in internal competition, as revealed by the disagreements about price between ASM Asia and Fico. As the downturn lasted longer than expected - throughout 1985 and into the first half of 1986 - each operation vied for sales. Even if they had to compete with each other (figure 47).

51 Richard Fierkens, Hightech in een boerendorp: de biografie van Fico-ondernemer Richard Fierkens, pp. 185; Richard Fierkens, 'Interview with author'.

52 ASM Fico, Richard Fierkens, 'Brief Directie ASMI-Bilthoven: Aanbod arbeidsvoorwaarden uw brief van 26 Januari 1989' (31-1-1989) Archive Arthur del Prado - ASM Fico Jan '88-Mei '99 file. 


\section{Figure 47}

Organigram of ASM International by 1987

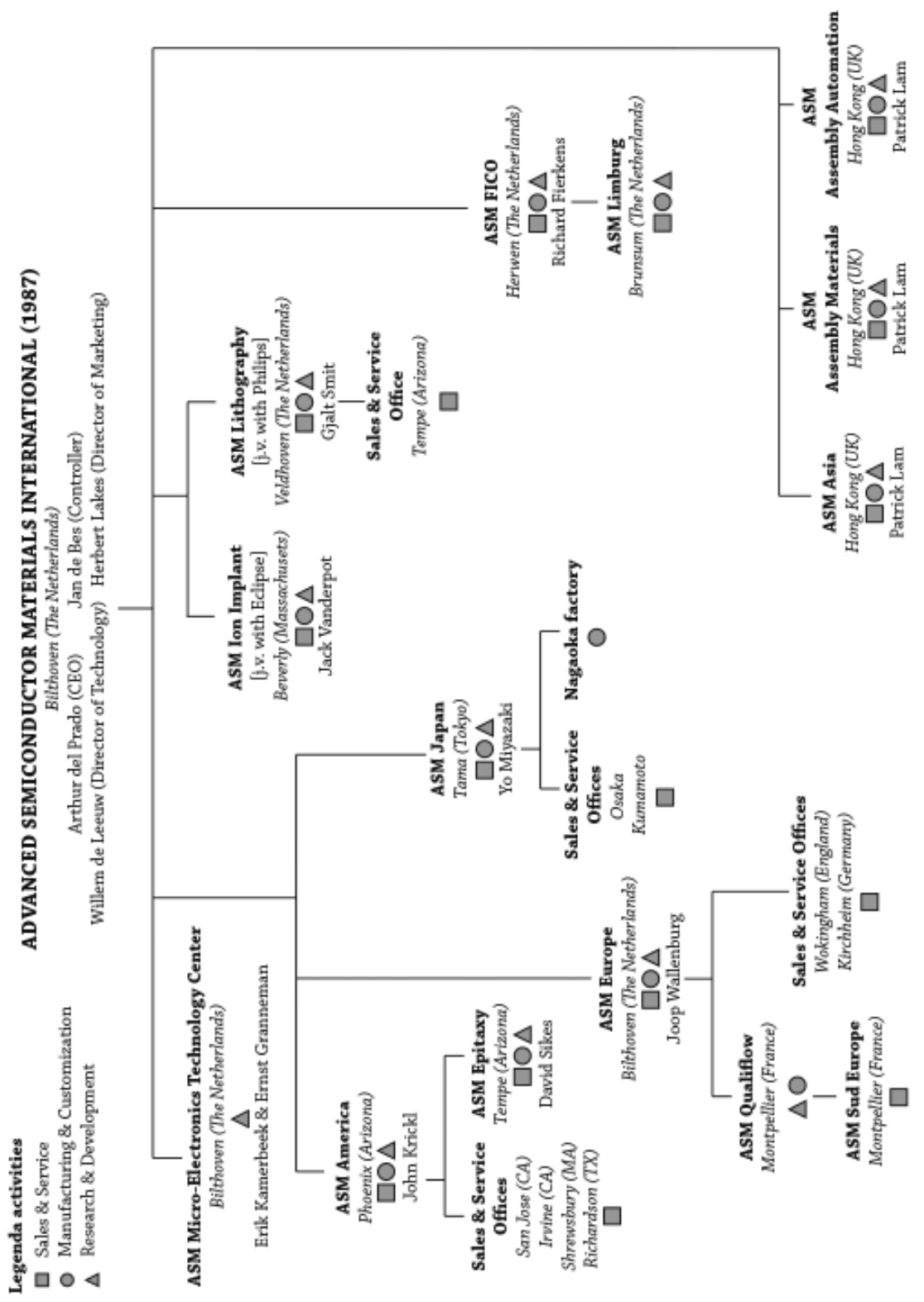




\section{Chapter 19}

\section{Derailing external and internal events, 1987-1992}

By the end of the 1980s, it was clear that ASM failed in aligning the competitive strategies by addressing the technological challenges. This eroded its ability to benefit from the resurgence of the market. The heavy investments in new technology - in particular in ASM Lithography - drained the cash reserves and were hardly covered by other sources of revenue.

There was no reason to expect a swift resolution, as the incumbent product lines faltered and new developments were not yet ready for market introduction. The industry's appetite for horizontal CVD furnaces rapidly evaporated, adding the weight of ASM America's and ASM Europe's losses to the financial deficits. Every day ASM International was losing money indeed. Bankers seeking instalment of their loans exposed the company's flawed strategy of leveraged innovation.

\section{Industrial context:}

\section{Balancing on quicksand}

A series of three unexpected global events undermined economic recovery and subsequent healthy demand for semiconductor equipment. The downfall of Del Prado's semiconductor equipment emporium seemed impossible to avoid. There was no single blow. Strains faltered one after another. A long and incessant stream of internal events, aggravated by global events, undermined the company. The company's prospects for survival diminished in fits and starts over the period of 1987 until 1992.

The first event causing ASM to miss its hold on economic recovery was the sudden crash of the New York Stock Exchange in October 19, 1987. The event, dubbed 'Black Monday', entailed an evaporation of about 20 percent of the stock value in a single day. The event caused significant anxiety on the financial markets, as the crash seemed like a thunderbolt from the blue. Only indirectly did this event affect ASM. It made the company's relations with bankers more stringent, while Del Prado was already struggling to fulfil its financial obligations.

The second event concerned political and economic uncertainties surrounding the end of the Cold War, involving the competition between communist and capitalist economies. Optimism and anxiety alternated. A process of détente 
originated from bilateral talks between Ronald Reagan and Michael Gorbachev on the one hand, and China's pragmatic adoption of capitalist principles on the other. In 1989 this was disturbed by the ruthless suppression of student protests at Tiananmen Square in Beijing on June 4, and the fall of the Berlin Wall in November. The Chinese events dashed glimmering hopes of democratic reform, and created waves of concern - in particular in Hong Kong. The small city-state's future looked grim, as it would be returned by the British to China in 1997.

The fall of the Berlin Wall heralded the end of the Cold War. From 1989 until 1991, Eastern European states one after the other rejected the communist economic principles and sought to establish contacts with the West. After military interventions in earlier forms of resistance, such as the Hungarian Uprising in 1956, the Prague Spring in 1968, and the recent Tiananmen Square suppression, the period after the fall of the Berlin Wall was perceived with intense anxiety. However, the opening up of markets in Eastern European also came with the promise of expansion of the market for semiconductors and equipment.

The third event undermining the recovery of ASM was the escalation of the Japanese asset bubble in 1990. Japanese asset prices had been declining for some years. In 1990, however, this process dragged along the stock exchange as well, causing a financial crisis which lasted until 1992. After more than a decade of unprecedented growth, the foundations of the Japanese financial system collapsed. The burst of the asset bubble plunged Japan into an economic recession, carrying the semiconductor industry along with it.

\section{Corporate course: \\ Dealing with Dutch drag}

ASM's internal deficiencies - foremost its depleted financial reserves - overly exposed the company to the three developments described above. While sales in general continued to grow, the company increasingly relied on Dutch banks to fulfil its immediate financial obligations, such as paying salaries, suppliers, rent, etc. This dependence raised the anxiety of bankers and investors, in particular given the more instable political and economic conditions. Moreover, excessive leverage of external funds deprived the firm from financial clout to iron out the conflicting competitive strategies of the business units.

Throughout the first half of 1987, the Dutch operations contributed to a worsening of ASM's situation. The Bilthoven operation followed the example of its sister-operations ASM America and ASM Japan, its horizontal furnaces losing allegiance of the market place as well (figure 48). ASM Lithography continued to burn cash, as it tried to fight its way into the market. And ASM Fico struggled. The uncertainty surrounding its future within ASM, the internal competition with ASM Asia, and disappointing sales caused a loss. All these operations had a 
negative impact on ASM's cash flow. ASM was dragged down further by several affairs at its Dutch operations and by its Dutch bankers.

\section{Figure 48}

Graph of annual growth revenues ASM Europe and European market for LPCVD equipment, 1982-1992

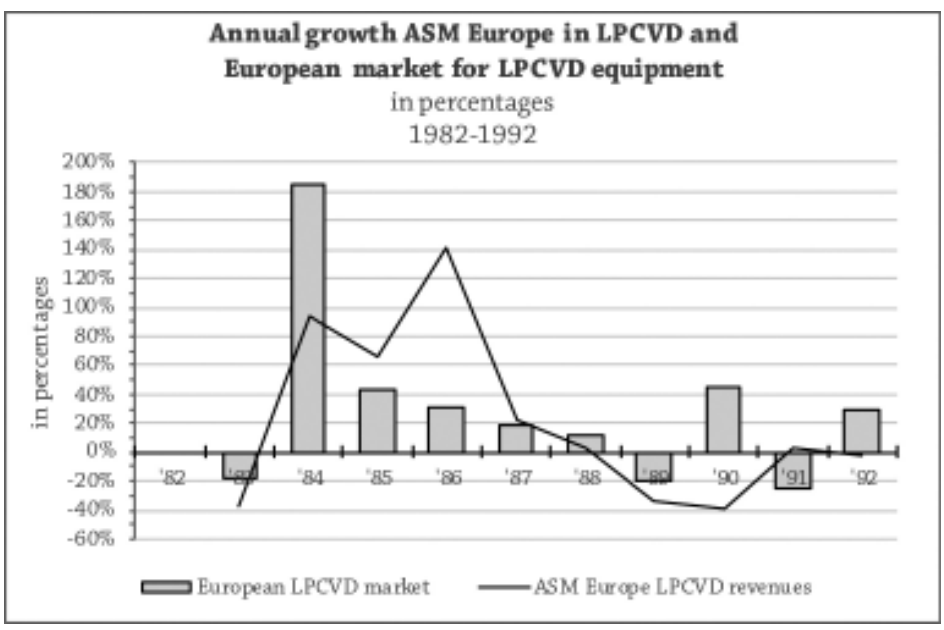

The distress began in the spring of 1987, when ASM Europe's sales deteriorated rapidly. Due to the deprecation of the dollar compared to European currencies, American competitors flooded the European market. The home-advantage of ASM Europe evaporated. Moreover, the Bilthoven operation had focused its resources too much on advanced development programs, losing alignment with the current market demands. Its management tried to limit damage by laying off 85 employees as of February 1987.

ASM Fico struggled to stay profitable as well. Its sales declined. Anxiety surrounding the divestment caused anxiety on the working floor. Its general manager Richard Fierkens increasingly became agitated. His efforts to conduct a management buy-out had been rejected by Del Prado, as the ASM chief executive officer deemed the proposition insufficient. Furthermore, ASM Asia's competitive strategies clashed with the interests of ASM Fico.

Meanwhile, the financial needs of ASM Lithography surpassed ASM International's resources. On a regular base, ASM Lithography's controller Gerard Verdonschot faced an empty cash book when he was expected to pay the salaries of the staff. ${ }^{53}$ The Veldhoven operation burned money at an unprecedented rate in 
order to secure a position in the prestigious lithographic market. ${ }^{54}$ In the summer of 1987, Del Prado was no longer capable of supplementing new cash to ASM Lithography. For the first time, Philips advanced 13.5 million Dutch guilders on behalf of ASM and in addition to its own pledge, preventing an immediate closure of ASM Lithography.

Initially, ASM International tried to prevent further deterioration through cutting costs and replenishing financial reserves. In January 1987, the Supervisory Board expected a negative cash flow of 48 million Dutch guilders by the end of the year. ${ }^{55}$ It became obvious that the situation was no longer tenable. For immediate salvation, ASM had to dilute its stake in the lithography joint-venture, limiting the drain on its financial resources. Throughout 1987, Del Prado approached several Japanese industrial groups like Sumitomo and Mitsui \& Co to participate in the ASM Lithography joint-venture. ${ }^{56}$ The effort was a bitter pill, even though there was still a chance of fulfilling ASM's ambitions in lithography.

Additionally, Del Prado approached several new investment bankers, supported with a positive evaluation report of an industry veteran, Robert Heikes. ${ }^{57}$ As of May, investment banker Drexel Burnham Lambert, on behalf of ASM, explored the divestment of ASM Fico. ${ }^{58}$ Hiving off ASM Fico would

Archive Arthur del Prado - ASM Lithography 1986 box; ASML, Gerard Verdonschot, 'Interne mededeling: Financiering ASM-L' (9-9-1986) Archive Arthur del Prado - ASM Lithography 1986 box.

${ }^{54}$ By that time ASM lithography started to make inroads into AMD. More details in René Raaijmakers, ASML's Architects.

55 Stibbe Blaisse de Jong, M.J.J. de Bontridder, 'Minutes of the Supervisory Board Meeting of Advanced Semiconductor Materials International N.V. (ASMI) held on February 10, 1987 in Bilthoven.' (date unknown) Archive Arthur del Prado - RvC '80's file.

56 Inviting such Japanese industrial partners - hardly or not at all active in the semiconductor industry - offered limited interference with the technological and competitive affairs of ASM Lithography,. Moreover, they could be essential in penetrating the lucrative Japanese market for steppers, dominated by Nikon and Canon.

57 An industry veteran and acquaintance of Del Prado, Robert Heikes wrote an evaluation report about the company, evaluating prospects, competitive position, and organizational outline. Such reports were indispensable for attracting new external funds, for, unlike annual reports, they in particular explored future opportunities based on ASM's current state. ICEurope, Robert Heikes, 'ASM Business Evaluation' (24-3-1987) Archive Arthur del Prado - RvC 80's file.

58 And temporarily the European Investment Bank, even though this did not produce anything. Drexel et al. was approached via a family member of ASM Europe's sales manager of ASM Fico products in Europe, Richard Blickman. Drexel et al. had co-managed an emission of 20 million shares of Philips N.V. in 1987. - Stibbe, Blaisse \& De Jong, Paul van den Hoek, 'Contacten met P.Treumann (EIB) d.d. 16/17.4.1987, Kempen \& Co d.d. 16.4.1987 (28-41987) Archive Arthur del Prado - Banks; Kempen \& Co file; Drexel Burnham Lambert, Edmond 
halt internal competition, improve ASM's financial position, and remove the temporarily faltering operation from the 1987 books. Drexel Burnham Lambert set up to the task of finding either a partner for a management buy-out or a third party willing to acquire the subsidiary. ${ }^{59}$

In July 1987, Del Prado succeeded in offering a convertible and partially subordinated debenture note with investment banker Kempen \& Co of 35 million Dutch guilders. This risk-baring note was an ideal way of cranking up ASM's cash reserves. It provided ASM with immediate cash, while repayment and interest would be installed through conversion of the loan into shares in 1993. Assuming a steadily rising share price, this could be very lucrative for Kempen \& Co. ${ }^{60}$ Most of the proceeds were used to repay Philips' advance in ASM Lithography and for relief of the desperate financial needs of the other subsidiaries. ${ }^{61}$

Next to the financial interventions, resolution was sought in shaking up the company's management. Due to operational reasons, urgent calls by his Supervisory Board directors Van den Hoek and Nobel, and in compliance with the demands of the National Investment Bank, Del Prado made three changes to the management of his enterprise. This involved setting up an international advisory board, an extension of the Supervisory Board, and replacing general managers throughout 1987.

The first change was rather superficial: the establishment of the international advisory board. To this board, Del Prado invited several high-level and experienced captains of industry or governmental officials. ${ }^{62}$ This board had no

D. Franco 'Letter to Arthur del Prado' (5-5-1987) Archive Arthur del Prado - Banks; Drexel Burnham Lambert.

59 Drexel Burnham Lambert, Edmond D. Franco 'Letter to Arthur del Prado' (14-5-1987) Archive Arthur del Prado - Banks; Drexel Burnham Lambert; Drexel Burnham Lambert, Edmond D. Franco 'Letter to Arthur del Prado' (26-5-1987) Archive Arthur del Prado - Banks; Drexel Burnham Lambert.

60 ASM and Kempen \& Co agreed upon a share price of 9 dollar per share by 1993. However, as will become apparent, ASM's share price deteriorated below this share price. Its convertible note was under water.

61 Of the 35 million Dutch guilders, 18.5 million went straight to Philips to repay the advance made earlier Another 5 million was required as bank guarantee for a loan for ASM Japan - or about 350 Million yen. The remaining 9.75 million Dutch guilders were available for the rest of the firm. - ASMI, Jan de Bes, 'Memorandum: Opbrengst Converteerbare Obligatielening F 35 Miljoen via Kempen \& Co' (9-7-1987) Archive Arthur del Prado - Banks; Kempen \& Co file.

62 This involved a former executive of Motorola, Stephen Levy, a former deputy--minister of the Japanese Ministry of International Trade and Industry, Naohiro Amayo, a prominent French scientist in semiconductor technology, Pierre Aigrain, and a former United States ambassador to the Organization for Economic Cooperation and Development (OECD), William Turner. The latter was a strong proponent of such international advisory boards, and convinced Del Prado of creating this board. Turner lived in the Phoenix area, where the two men first met 
real influence, being hardly more than a prestigious debating society. For Del Prado it was a way to meet demands with regard to establishing better oversight, increasing ASM's prestige, and these well-connected board members might access new opportunities financially, technologically, or business-wise.

More significant was the expansion of the Supervisory Board with two members. Frans Saris, director of an Amsterdam-based research institute and through advisory roles already acquainted with ASM, improved the technological expertise of the Supervisory Board. Lex Helfrich, former president of Royal Dutch Shell Netherlands, contributed expertise through his contacts in Dutch corporate and governmental circles and his experience in running complex and multinational organizations. The expansion of the Supervisory Board was just in time. As the crisis at ASM deepened, the Supervisory Board had to convene on a monthly base.

At an operational level, the company experienced various management changes. Most often this followed from their incapability to redirect the course of their organization according to their or Del Prado's will. In Bilthoven, Jan Heetebrij was replaced by Joop Wallenburg,. Treasurer Paul Krebs resigned, because Del Prado failed to stop interfering in his dealings. Franc DeWeeger grew tired of running the American operation, resigned, and was replaced by John Krickl in the Summer of $1987 .{ }^{63}$ At ASM Ion Implant, the newly appointed president Andrew Wittkower left the company with slamming doors in May 1987. The operation did not require another leader next to Vanderpot, who knew exactly what he was doing. ${ }^{64}$ Also Gjalt Smit of ASM Lithography resigned mid-1987. Smit and Del Prado had fierce debates and quarrels, predominantly about Smit's big spending. ${ }^{65}$ Wim Troost, the godfather of Philips lithographic activities prior and during the formation of ASM Lithography returned.

Despite significant efforts to supplement ASM's cash flow, halt the rising of debt, and limit drainage of cash, it all was just a drop in the ocean. In 1988, ASM was expected to install loans of $A B N$ and Banque Paribas. However, seeing the current state of ASM set off alarm bells at these banks (figure 49). ${ }^{66}$ ASM got into the department of 'special credits,' or in other words, lenders not capable of

each other. Turner had created similar positions in other companies as well.

63 Krickl was an industry veteran with earlier positions at Lindbergh Diffusion furnaces in the 1960s and, more recently, as president of ASM's major competitor in furnaces, Thermco.

64 ASM Ion Implant, Donald Strand, 'Notes on Andrew Wittkower' (12-5-1987) Archive Arthur del Prado - ASM Ion Implant, '87-'88.

65 ASML, Gjalt Smit, 'Conclusions Board Meeting 27/8/1986' (27-8-1986) Archive Arthur del Prado - ASM Lithography 1986 box; and Raaijmakers, The Architecten van ASML, p. 463; Gjalt Smit, 'Letter of resignation' (27-2-1987) Archive Arthur del Prado - ASM Lithography 1987 box.

66 ASM International, Annual report 1986 (March 1987). 
guaranteeing the banks return of investments. In an effort to secure their shortterm loans, ABN and Banque Paribas demanded an immediate and thorough response. The anxious bankers had found ASM's reorganization efforts wanting.

\section{Figure 49}

Graph of ASM International revenues, profits and shareholder equity, 1983-1993

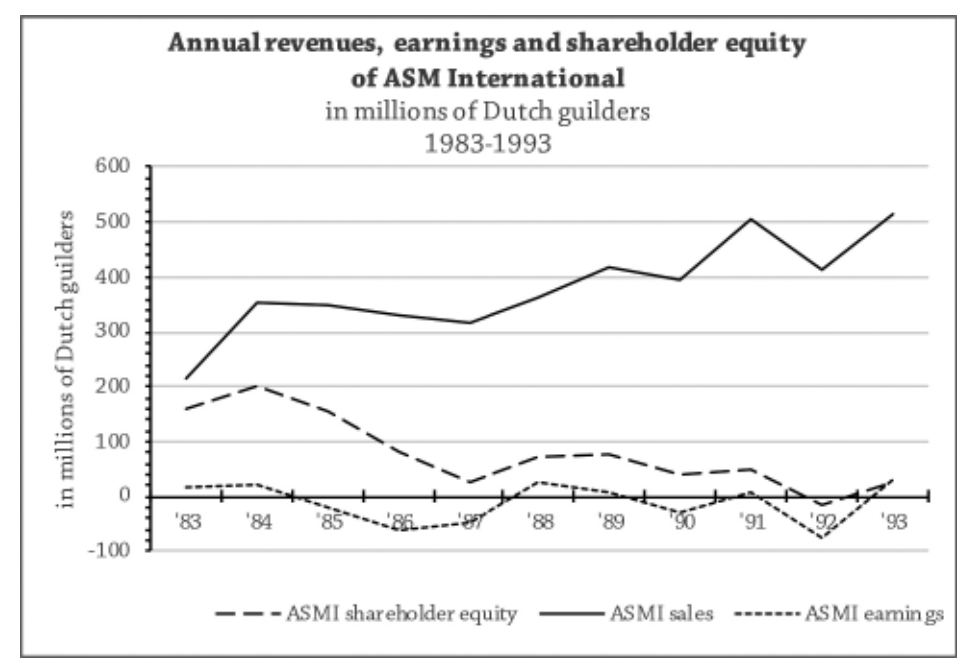

This infuriated Del Prado. He regarded it as a signal of distrust and total lack of appreciation of ASM's potential. Ever since the founding of ASM, he had proven the viability of his business. In some handwritten notes prior to meeting with bankers of $\mathrm{ABN}$, he wrote:

'Until 1984/85, growth funded out of own cash flow and by attracting venture cap. 1981/83. ... 85/86 heavy losses. Main causes: external circumstances; internal: a) planning budget of several project were wrong; b) management mistakes; c) vast $R \& D$ efforts.

Equity shrank. Of importance: is the company viable on the long term/ good strategy/good products/good industry? Answer: Yes, see Heikes report.... Funding of investment out of cash flow and attracting venture capital. ASM has always worked that way, only temporarily not now. Reversion ASAP. Will do everything to achieve this. ${ }^{67}$ and ASM financial position' (Date unknown, 1987) Archive Arthur del Prado - Banks; ABN. 
Del Prado found it difficult to accept that the bankers wielded influence in his company. The securitization of their short-term interest did not exceed the longterm interest of ASM as a company. ${ }^{68}$ In his vision, the bankers nipped ASM's growth and expansion in the bud.

His chairman of the Supervisory Board, Paul van den Hoek, unremittingly acted as intermediary between Del Prado and the banks. ${ }^{69}$ Van den Hoek and the banks urged Del Prado to hire a chief financial officer (CFO), who would operate alongside Del Prado (rather than under his authority). Somebody had to take action with regard to the actual financial realities faced by ASM.

Reluctantly Del Prado yielded. He realized that somebody had to clean things up. Moreover, he would make sure that he stayed in control anyway. By the end of 1987, he reached out to André van Rhee, CFO of Oldelft. Del Prado was a member of this company's Supervisory Board. By April 1988, Van Rhee would start, which was just in time, as will become apparent.

\section{Elaboration of affairs}

\section{Black Monday disrupts any hope of short-term redemption}

Of all Del Prado's efforts to improve ASM's debt ratio and operational performance, and appease the anxious bankers, the divesture of ASM Fico seemed most promising. In September 1987, investment banker Drexel Burnham Lambert introduced ASM to a banker specialized in management buy-outs called Oppenheimer. ${ }^{70}$ This contender offered 46 million Dutch guilders including a subordinated note of 3 million Dutch guilders to be retained by ASM. ${ }^{71}$ Although it was the highest bid so far, it also meant that ASM would continue to be a shareholder in ASM Fico after divestment. The offer served as a good startingpoint for negotiations. Del Prado did not want to retain a stake in Fico after divestment, while Oppenheimer feared competition with ASM Asia and was skeptical about Fico's access to the South-East Asian market.

68 Banque Paribas, F.H. Sundermeyer and R.H.M.G. van der Mast, 'Letter to ASMI, ref: 1584/ FS/AM’ (15-10-1987) Archive Arthur del Prado-Banks; Banque Paribas.

69 ASM Japan, Yo Miyazaki, 'Fax to ASMI HQ', (4-6-1987) Archive Arthur del Prado - ASM japan 1985-1988 file.

70 The first company was called Schick, Inc., and it initially offered 40 million Dutch guilders, including debt and proof of profitability. A Dutch investment banker was interested as well, but probably more for the role of Drexel Burnham Lambert as broker. - Schick Incorporated, Steven Hart, 'Letter to Arthur del Prado and Edmond D. Franco, re: ASM FICO Tooling B.V.' (7-7-1987) Archive Arthur del Prado - Banks; Drexel Burnham Lambert; Mees \& Hope Participaties, G.F. van der Linden, 'Letter to Arthur del Prado' (4-9-1987) Archive Arthur del Prado-Banks; Drexel Burnham Lambert.

71 Oppenheimer \& Co, Inc, Alain Dubois, 'Letter to Edmond Franco of Drexel Burnham Lambert' (4-9-1987) Archive Arthur del Prado - Banks; Drexel Burnham Lambert. 
On Monday October 19, 1987 fortuna manifested itself in a profound and disruptive manner. In a single day, out of the blue, the Dow Jones index of the New York Stock Exchange dropped more than 20 percent. This crash caused immediate panic across financial markets worldwide. Market capitalization of listed companies plunged. The crash, later dubbed Black Monday, was fatal for the approaching divestment of ASM Fico - and subsequent alleviation of ASM's financial problems.

In the fall of 1987, the prospects of reaching an agreement about the sale of ASM Fico seemed unfeasible. Chairman Paul van den Hoek reported to the rest of the Supervisory Board of ASM:

'The dramatic drop in stock prices on Wall Street - especially for overthe-counter-stock and of these in particular the technology funds have resulted in a significant decline of the current acceptable ratings. ... Oppenheimer announced its withdrawal unless we can agree upon a lower purchase price. ... The most important consideration for Del Prado and I to agree with these unattractive conditions, is that our banker ABN and Paribas again show signs of some disquietedness. The substantial loss over 1987 is responsible for this, just like the general atmosphere of anxiety in financial circles after the recent events on the stock market. ${ }^{72}$

Del Prado continued to pay lip service to this deal in order to appease the bankers, although it lost its attraction for him. Black Monday had queered the pitch. Del Prado and his staff explored alternative routes to divest ASM Fico - and the more overarching issue: restoring ASM's solvency.

\section{Inherent weaknesses persist}

The best way to improve ASM's situation was by achieving more sales. However, the competitive strategies of the business units to that purpose continued to diverge. ASM International could interfere only reactively. By the time Del Prado, De Leeuw, or Lakens convinced one business unit of the significance of the company's overall interests, another hurtled on in pursuit of its own, more particular interests, causing all the hard-earned cash reserves to spiral down the drain unremittingly.

Almost every subsidiary had breakthrough technology on the verge of introduction, just needing a final push. By the start of 1988, this involved ASML's PAS2500 stepper, ASM Ion Implant's ASM-220, ASM Epitaxy's Epsilon epitaxial reactor, ASM Japan's VMP and VDF vertical furnaces, the AMTC's vertical cluster

72 Stibbe, Blaisse \& De Jong, Paul van den Hoek, 'Lettter to Supervisory Board Members ASMI' (11-12-1987) Archive Arthur del Prado - RvC f until feb 1992. 
machine, ASM America's SF-50 small batch PECVD furnace, and ASM Europe's ACAMS project. Every group called for additional funds to sustain their efforts in penetrating their respective markets in 1987 and 1988.

The different product groups and geographical operations engaged in a struggle with each other with regard to mutual responsibilities, expectations, and interests, and ASM International's management did not succeed in interfering in it effectively. As ASM Epitaxy, ASM Lithography, and ASM Ion Implant were about to introduce their respective products, their general managers were keen on maintaining control over their product and its introduction.

In particular, ASM Ion Implant's search for integrating itself into the ASM family was illustrative for the organizational inefficiencies of early 1988. The Boston organization was a distinct product group. During the introduction of the ion implanter machine, ASM Ion Implant's determined and experienced manager Jack Vanderpot faced the particularities of ASM when disagreeing with ASM Japan's general manager Yo Miyazaki on the need for local customization. Miyazaki argued that this was necessary, in succession of the transfer of the plasma CVD technology of ASM America to Japan in the early eighties. But as Vanderpot claimed:

'In the event the Japanese customer had a preference for other types of pumps, we would not be able to guarantee the performance of the machine.... We wish to be as fully cooperative as possible, but want very much to avoid losing all economies of scale in production and the loss of control of service and documentation that will result from uncontrolled customer demands for machine modifications. ${ }^{73}$

The times of localizing products had come to pass, according to him. The arguments underpinning the decision to localize the American PECVD technology years earlier no longer applied.

Apart from refusing to indulge in the centrifugal forces, Vanderpot also remained critical about centralization efforts. Herbert Lakens propagated an stringent approach with regard to marketing expenditures at the various operations. Vanderpot contested the "we know what is best for you" approach of Herbert Lakens. ${ }^{.74}$ Also efforts by De Leeuw to lower the investment and suggested budget cuts did not go well with Vanderpot. ${ }^{75}$ While the Boston

73 ASM Ion Implant, Jack Vanderpot, 'Letter to Yo Miyazaki: Japanese Market' (9-3-1988) Archive Arthur del Prado-ASM Ion Implant 87-88 files.

74 ASM Ion Implant, Letter to Arthur del Prado: Our Conversation of Thursday, March 31, 1998' (4-4-1988) Archive Arthur del Prado -ASM Ion Implant 87-88 files.

75 Although de Leeuw was responsible as Technical Director for this project. However, by the spring of 1988, ASM Ion Implant had turned into a real product group and was no longer 
operation enjoyed healthy prospects among Texas Instruments, AMD, IBM, Motorola, and Adam Russels, only four machines were sold in 1988, and for this reason Vanderpot wanted an additional investment of 3.5 million dollars. The money was indisputably needed, but its announcement came at a most inconvenient moment.

The central management lacked the means to join the forces and address the organizational inadequacies. Technology director De Leeuw tried to fill the void left by a fully preoccupied Del Prado and Van den Hoek by assessing budget plans of all operations, and suggesting budget cuts. In this he moved beyond his expertise. Aligning and judging budgetary plans belonged to the job description of financial officers. But the controller of ASM International, Jan de Bes, was ill and not capable of taking this job upon him, while the new financial officer had not yet started.

The decentral organization of ASM remained unruly. Time and again, ostensibly simple and obvious ways of straightening out deficiencies failed to take into account specific logics of products and markets. As a result, competitive strategies within the different ASM groups and units continued to prevail over any form of corporate strategy.

In an effort to save its own skin, ASM Europe crossed a red line. One day in April 1988, all staff members present at the Jan Steenlaan in Bilthoven were summoned to their building's cafeteria. The Economic Control Service (Economische Controle Dienst, ECD) of the Dutch Ministry of Economic Affairs paid a formal visit to the facility. The ECD monitored compliance with rules on the export of restricted goods to other countries, in particular Communist ones. ASM Europe was suspected of exporting its furnaces to the Soviet Union, and the ECD turned the whole building inside out to find proof of ASM Europe's actions.

To limit the damage of the disappointing Western European market, ASM Europe looked for options behind the Iron Curtain. Such sales offered particular beneficial terms, as the communist countries were eager to get their hands on Western technology. The Eastern European customers paid well. However, this trade was illegal, and getting caught bore severe consequences. The ECD deprived ASM Europe of its last profitable businesses, numbing the organization and aggravating its misery.

Despite the intimidating raid and interrogations, the ECD investigation fizzled out, as facts on the ground moved faster. The Cold War was about to come to an end. As discussed below, the United States took the lead in softening trade

a technological development operation. Its new function required different considerations with regard to planning and budget. 
restrictions vis-à-vis the Soviet Union, in an effort to stimulate further détente. ${ }^{76}$ The export restrictions became an anachronism by the end of 1988, and so did the charge against ASM's illegal export.

\section{Attracting new stakeholders}

In April 1988, the ongoing drain of cash, an imminent instalment of short-term bank loans, and the unsuccessful divestment of ASM Fico confronted Del Prado with the need to make some tough decisions. In this, he gained support from his chief financial officer André van Rhee, who just took office. Van Rhee was a talented and vigorous finance director, and he had to set all sails from the very first day. After he secured his position as undisputed executive alongside Del Prado, he plunged himself into the big task ahead. ${ }^{77}$ His fresh view on things provoked breakthroughs on various issues.

The most urgent issue involved ASM Fico. Del Prado and his Supervisory Board just decided to cancel the negotiations with Oppenheimer. Instead, ASM would prepare a future floating on the Amsterdam stock exchange. Until that time, ASM strengthened the organization and made the operation more independent from the Hong Kong infrastructure. Moreover, ASM opened negotiations with the Nederlandse Middenstandsbank (NMB) and the governmental capital venture organization MIP for a partial stake of 30 percent in Fico. This course of action would alleviate the weight of the restructuring operation of ASM Fico.

The second line of action resembled the one involving ASM Fico: Van Rhee set himself to the task of finding a third partner for ASM Lithography. Del Prado's courtship of potential Japanese partners had come to a standstill. The CFO reached out to the MIP, to the Dutch Ministry of Economic Affairs, and even to DSM, a large chemical company owned by the Dutch state. As ASM's liquidity deteriorated, and ASM Lithography required new investments, ambitions had to be lowered. Van Rhee decreased ASM's proposed future stake to a maximum of 35 percent, while maintaining hope on future restoration of the old ratios. ${ }^{78}$

76 Ed Scannel, Soviets Seek Ventures with PC Firms: U.S.S.R. Signs Deal with Dataease International' InfoWorld (8-8-1988) p. 8.

77 Van Rhee had been convinced by Del Prado and Van den Hoek to join ASM after the promise that he would become the co-executive of ASM International. As a member of the executive board, Van Rhee would be present at the meetings of the Supervisory Board. This authority was indispensable for his ability to turn the company around. Initially, however, Del Prado still kept him not entirely in the loop. Only after complaining and threatening with his resignation to Van den Hoek did Van Rhee gain the full authority promised to him. This course of affairs was illustrative for the stubborn Machiavellianism hindering and characterizing Del Prado. - André van Rhee, 'Interview with author'.

78 ASMI, André van Rhee, 'Memorandum: Samenvatting gesprek d.d. 14 april 1988 inzake financiering ASM-Lithography, ref: 88.001/AvR/jdk' (18-4-1988) Archive Arthur del PradoASML ontvlechting files. 
Simultaneously, a worst-case-scenario was worked out, in which ASM would completely abandon its stake in ASM Lithography. ${ }^{79}$

The third course of action pursued by Del Prado, Patrick Lam, and Van Rhee was to consider an initial public offering of the Hong Kong activities. ${ }^{80}$ The various companies led by Patrick Lam were the most profitable ASM operations. Selling shares to new shareholders would give ASM immediate cash and future dividends to replenish its reserves. As of May, several preliminary actions were taken to this end. The number of shares to be floated depended on the progress of the other resolutions.

\section{Stop the bleeding}

The cash shortages troubling ASM caused one of its operations to seize control of its own fate. In the spring of 1988, ASM America withheld funds it had collected on behalf of ASM Fico in the United States. ASM America desperately needed cash to pay its employees and suppliers and could no longer wait. This disrupted the turn-around process of ASM Fico. As Van Rhee reported:

'Upon closer examination of the cash forecast of America (ASM-A +Epi), in comparison to the adjusted result forecast of Bilthoven, a significant inconsistency seems to exist. ... Without too much knowledge, I can predict that it will lead into a cash forecast deterioration of Fl. 5-8 million. This case is easily supported by the fact, ASMA removed clandestine a rather Fl. 4-5 million guilders from Fico in three months' time, while cash-wise pretend nothing has happened. (This phenomenon of non-transferred so-called courtesy-collections should be entirely abandoned. It does not only spoil the relation with Fico, but results in a depreciation of credit lines with NMB, and a lack of trust in ASMI. With these practices in the company, I'll better cease my funding efforts). ${ }^{\text {'1 }}$

ASM America's desperate act bore grave consequences for ASM as a whole. ASM Fico's bank, NMB, called its bank loan of approximately 2 million guilders immediately. Moreover, the so-called 'courtesy-collection' by ASM America interfered in the precarious negotiations surrounding ASM Lithography and

79 ASMI, André van Rhee, 'Fax: Voorstel herstrukturering ASM-Lithography, ref: 88.025/AvR/ jdk’ (11-5-1988) Archive Arthur del Prado - André van Rhee files, 1987-1991.

80 ASMI, André van Rhee, 'Memorandum: Minutes staffmeeting May 9, 1988; ref: 88.024/ AvR/jdk' (10-5-1988) Archive Arthur del Prado - André van Rhee files, 1987-1991.

81 Original quote written in Dutch. - ASMI, André van Rhee, 'Memorandum to Arthur del Prado: Cashontwikkeling; ref: 88.044/AvR/jdk’ (6-7-1988) Archive Arthur del Prado - André van Rhee files, 1987-1991. 
ASM Fico. It undid any prospect of having the NMB participate in ASM. ${ }^{82}$ The situation put Van Rhee up for some hard decisions:

'The conclusion on my part is that we - next to the Fico and Hong Kong actions - have to sell Ion Implant, have to sell Qualiflow, and have to sell our Litho-stake for cash at the most immediate notice. Furthermore, ... substantial reorganization programs should be written for Europe and ASM-A.' ${ }^{\prime 3}$

In June, 1988 Del Prado informed his Supervisory Board about an expected cash shortfall of eight to nine million Dutch guilders by July. ${ }^{84}$ Some cash support from Hong Kong and a small intercompany loan from ASM Japan hardly provided a way out of ASM's equity problem. The summer of 1988 would prove to be an extra hot summer for Del Prado and his cohorts. Everything was up for sale.

The Supervisory Board requested an assessment of Del Prado about all the options available to improve the equity of the firm, including mergers. Del Prado tried to convince the Supervisory Board to support him and Van Rhee in their efforts to keep ASM independent. Mergers or inviting venture capitalists - who also required a say in the operation - were out of the question. Del Prado had not been, and was still not, willing to dilute his ownership below 50 percent. ${ }^{85}$ By issuing new shares, Del Prado might have been able to attract more risk-bearing funds, while decreasing his dependency on short-term bank loans. A study of these options was merely lip service by Del Prado. ${ }^{86}$

On July 31, 1988, there was some alleviation as ASM withdrew from the ASM Lithography joint-venture. Philips took over ASM's stake of 50 percent for a mere 8.6 million Dutch guilders - a trifle compared to the investment of approximately 70 million Dutch guilders made by ASM up that point. ${ }^{87}$ Yet the divestment

82 ASMI, André van Rhee, 'Fax: Courtesy affiliate collections on behalf of ASM-Fico, ref:88.034/ AvR/jdk' (25-5-1988) Archive Arthur del Prado - André van Rhee files, 1987-1991.

83 Original quote in Dutch. - ASMI, André van Rhee, 'Memorandum to Arthur del Prado: Cashontwikkeling; ref: 88.044/AvR/jdk' (6-7-1988) Archive Arthur del Prado-André van Rhee files, 1987-1991.

84 ASMI, Arthur del Prado, 'Letter to Raad van Commissarissen' (22-6-1988) Archive Arthur del Prado - outward correspondence files 1988-1993.

85 André van Rhee, 'Interview with author', Paul van den Hoek, 'Interview with author', Richard Blickman, 'Interview with author'.

86 ASMI, Arthur del Prado, 'Letter to Raad van Commissarissen' (22-6-1988) Archive Arthur del Prado-outward correspondence files 1988-1993.

87 Philips itself made an agreement with its house banker NMB to take up ASM's fifty percent. This was required to continue the 100 million governmental support contract of Philips. If ASML with its own portfolio of support lines was added to Philips, this would be deducted 
was the absolute saver of ASM's liquidity crisis. The company's results improved by 19 million guilders, in addition to a balance sheet reduction of 64 million guilders. ${ }^{88}$ Moreover, it relieved ASM from future obligations and risk. But it also meant a painful reality-check with regard to Del Prado's ambition and belief in lithography, as well as a contraction of ASM's product portfolio.

Next, ASM Ion Implant was divested as well. In July 1988, Vanderpot reached out to Varian Associates, one of the three major manufacturers of ion implant machines and currently lacking a medium-current implanter. In a few months, the matter was settled. For a sum of around 15 million dollars, ASM Ion Implant as a whole was transferred to Varian. ASM would receive future royalties over every sold piece of equipment, accumulating to a maximum of 25 million dollars.

The deal also released ASM from the 3.5 million extra investments required by Vanderpot, and helped to overcome incertitude of customers regarding ASM's reputation as newcomer in ion implantation. It also constituted a balance sheet reduction of 8 million Dutch guilders. At the same time, ASM had to bade farewell to another ambition with a huge potential for the future. But as Van Rhee concluded:

'In my view, this is a unique chance to significantly improve the financial structure of ASMI - without loss to the core-business, and in a time in which other paths are impassable. Moreover, the whole investment + interest + return can be recovered.' ${ }^{89}$

Given the excellent state of the technology, Van Rhee was absolutely right. Over the course of years, ASM would retain all royalties of the machine, making the original investment in ASM Ion Implant a profitable investment after all.

Furthermore, the floatation of the Hong Kong activities on the Hong Kong Stock Exchange was given the green light by the end of the year. A quarter of the stock was offered for sale, expecting to result in 20 million Dutch guilders. Of that part, 10 million could be used to decrease ASM International's debt. Additionally, it would improve profits by 16 million Dutch guilders. ${ }^{90}$ But Van

from the Philips subsidies. Hence Philips negotiated terms with NMB to pick up ASM's share, merely in name. All risks and investments still lay with Philips. - Raaijmakers, Architecten van ASML

88 ASMI, André van Rhee, 'Memorandum to Supervisory Board: persoonlijke beoordeling bij enkele te overwegen transactie's, ref:88.140/AvR/jdk' (23-8-1988) Archive Arthur del Prado - André van Rhee files, 1987-1991.

89 Original quote in Dutch. - ASMI, André van Rhee, 'Memorandum to Supervisory Board: persoonlijke beoordeling bij enkele te overwegen transactie's, ref:88.140/AvR/jdk' (23-81988) Archive Arthur del Prado - André van Rhee files, 1987-1991.

90 ASMI, André van Rhee, 'Memorandum to Supervisory Board: persoonlijke beoordeling bij 
Rhee and Del Prado also acknowledged several immediate drawbacks of this transaction, such as a loss of control in Hong Kong, loss of access to a stable source of profits, a rise of ASM International's general risk profile, and the relative high costs of raising money through the public offering. However, like in the other cases, Van Rhee saw no other option. ${ }^{91}$

A final action was to have investment banker Kempen \& Co already convert some of its 35 million guilders on convertible notes immediately instead of waiting until 1993. ${ }^{92}$ This and the installment of the banks' short-term loans decreased ASM's liabilities and thus improved its equity significantly. Meanwhile negotiations about diluting ownership in ASM Fico by an investment of MIP continued as well.

In general, all the above actions were very drastic. They dashed most of Del Prado's ambitions of the early 1980s. But as Van Rhee concluded:

'Given my conclusions per transaction and the alarming state of equity of ASMI, I take the view that all four mentioned transactions have to be realized as soon as possible (preferably in 1988). This offers an optimum point of departure for normalization of our bank relations and regaining access to the capital markets. ... Moreover, we are back in our core businesses, CVD (incl. Epitaxy), backend and materials, which all three demand heavy investments, but also offer substantial growth opportunities. ${ }^{93}$

It had to be done. The bleeding had to stop. ${ }^{94}$

\section{Creating a cash cow: the initial public offering of ASM Pacific Technology}

On December 16, 1988, a quarter of the shares of ASM's Hong Kong operations were floated on the Hong Kong Stock Exchange. ${ }^{95}$ This accounted for 90 million shares for 1.61 Hong Kong dollars each, valuing the whole group at 579 million

enkele te overwegen transactie's, ref:88.140/AvR/jdk' (23-8-1988) Archive Arthur del Prado - André van Rhee files, 1987-1991.

91 Ibid.

92 Kempen \& Co, H.H. van der Kwast, 'Letter to Andre van Rhee, ref: HvdK/1vd' (30-8-1988) Archive Arthur del Prado - Banks; Kempen \& Co file.

93 Original quote in Dutch. - ASMI, André van Rhee, 'Memorandum to Supervisory Board: persoonlijke beoordeling bij enkele te overwegen transactie's, ref:88.140/AvR/jdk' (23-81988) Archive Arthur del Prado - André van Rhee files, 1987-1991.

94 The statement of 'the bleeding had to stop' became a mantra in the weeks before and in the years after the turn-around of 1988. - Willem de Leeuw, 'Interview with author'.

95 CEF Capital Limited, Prospectus ASM Pacific Technology Limited (13-12-1988) Archive Arthur del Prado-ASM PT file. 
Hong Kong dollars, or about 139 million Dutch guilders. ${ }^{96}$ ASM International retained 75 percent of the shares. The three combined operations under management of Patrick Lam - ASM Asia, ASM Assembly Automation, and ASM Assembly Materials - were listed under the name of ASM Pacific Technology.

In 1988, ASM Pacific Technology had a total sales of 390 million Hong Kong dollars (39 million Dutch guilders) and profits before tax of 63.3 million Hong Kong dollars (15 million Dutch guilders) ${ }^{97}$ It employed a total of 936 employees. A small core staff of five constituted the holding company ASM Pacific Technology. The firm was located at various floors of the Watson Center in Kai Chung, Hong Kong (which remained the case up until 2019). ${ }^{98}$

The company sold and manufactured predominantly back-end materials. In this it was commercially intrepid and technologically skilled. ASM Asia (169 employees) sold and produced molds, trim \& form machines, and represented ASM International's wafer processing equipment. ASM Assembly Materials (367 employees) designed, stamped, plated, and etched lead-frames for light emitting diodes and chips. About 70 million lead-frames a month were produced by this operation. ${ }^{99}$ ASM Assembly Automation (393 employees) developed, manufactured and sold assembly equipment, like aluminum and gold wire bonders.

To give a better sense of these fine-mechanical machines' capabilities: ASM's die bonders bonded dies - chips - to a lead-frame 'at a typical speed of 6000 dice per hour,' while the wire bonders positioned and welded 'fine wires between the bonded die and specific pins on a [printed circuit board] or lead-frame at a rate of six wires per second within a positional accuracy of 25 microns. ${ }^{100}$ These dazzling numbers illustrate the precise mechanical capabilities - motion control, positioning, materials, etc. - of the Hong Kong company.

The company was a challenger in a field packed with experienced and highlyskilled incumbents originating from Europe, the United States, and Japan. Since ASM Pacific Technology had to accumulate the knowledge, skills, and experience before it could compete in the prestigious computer chip market, it had focused on disregarded assembly and packaging markets for LED and chip-on-board applications. These technologically less advanced markets allowed ASM Pacific Technology to learn and set up a proper presence in the region.

\footnotetext{
96 Based on the exchange rate in the ASM International annual report of 1988.

97 ASM Pacific Technology, Annual Report 1988 (March 1989).

98 The lead-frame production was located at the Wo Kee Hong building in Kwai Chung, Hong Kong.

99 CEF Capital Limited, Prospectus ASM Pacific Technology Limited (13-12-1988) Archive Arthur del Prado-ASM PT file, p. 12.

100 Ibid., p. 13.
} 
The proceeds of ASM Pacific Technology's public offering were immediately invested in the company's expansion. First, preliminary negotiations for the acquisition of a Hong Kong lead-frame operation dubbed QPL were opened in February 1989. While these discussions resulted in nothing substantial, Patrick Lam and his management had to attend to more urgent matters.

In June 1989, ASM Pacific Technology established a machine tool shop in Shenzhen, just across the border of Hong Kong in the People's Republic of China, implying a significant change of its corporate strategy . As Patrick Lam explained:

'As our business grows, we need more precision metal parts for our stamping dies, tools, and molds and our bonders. Besides in-house supply, we have difficulties in the subcontractors supply of precision parts. The labor shortage problem also prevent us from expanding our base for producing more precision parts.' 101

The new facility offered ASM access to an immense supply of cheap labor and enabled the company to set up an integrated manufacturing strategy; all the parts and materials of ASM Pacific Technology's products were produced and supplied by this factory. The Hong Kong company created a low-cost and reliable integrated supply chain. It became a key element in its corporate strategy, enabling significant lower prices.

However, many Hong Kong citizens - and thus ASM employees - were anxious about their giant neighbor China. After the end of a 99 -year lease by the United Kingdom in 1997, the small city state would become part of China. Due to the political and economic differences between the United Kingdom and mainland China, most citizens worried about this forthcoming transfer of sovereignty. This was aggravated by the violent suppression of protests at Tiananmen Square in Beijing on June 4, 1989. ${ }^{102}$ The apparent relaxation of communist dogma's suddenly came to a halt, and this rang alarm bells in Hong Kong and London. ${ }^{103}$

In the case of ASM Pacific Technology, the event did not terminate the Shenzhen plant, but it did accelerate flirtations with the Singapore Economic Development Board. ${ }^{104}$ After the June 4 events, many Hong Kong citizens moved

101 ASM Pacific Technology, Patrick Lam, 'Memorandum: China Factory for Metal Parts Fabrication, ref: IM025-89/PL' (20-3-1989) Archive Arthur del Prado - ASM Pacific Technology files.

102 Kenneth Ko, 'Upheavals hit ASM plant in Shenzhen' South China Morning Post (16-6-1989); Peggy Sito, 'ASM Shenzhen plan is on' Hong Kong Standard (19-6-1989) Archive Arthur del Prado-ASM Pacific Technology 1988-1991 file.

103 After 'Munich, 1939' appeasement was a curse. The United Kingdom sought securities for its citizens after the 1997 transfer.

104 Bosworth Dewey, 'ASM expansion plan strictly a business decision' South China Morning 
or intended to move to Singapore, a city state with comparable political and economic standards. A brain drain was imminent. ${ }^{105}$ This situation was decisive for Patrick Lam, and prompted him to set through his slumbering ambition to establish a footing in Singapore. ${ }^{106}$ A presence in the nearby city-state would form a hedge against the political uncertainties and was accompanied with very attractive terms, such as, for instance, a ten-year pioneer status: a tax holiday for all products. ${ }^{107}$

In the fall of 1989, Patrick Lam - in concordance with Arthur del Prado approved expansion plans in Singapore. The facility would:

'Take future growth to Singapore. ... Reduce country risk. ... Keep talents within ASM in case they want to emigrate. ... Stabilize people in Hong Kong. ... The stronger presence in Singapore/Malaysia region enhances business development. ... [and allow ASM to] build up [a] future asset base in Singapore.' 108

Initially, ASM would be housed in a temporal building, while preparing the construction of a complete new facility and developing local sourcing of staff and materials. Product development and final assembly of bonders would be in both Hong Kong and Singapore. The Singapore operation was named ASM Technology Singapore. ${ }^{109}$

The initial public offering of ASM Pacific Technology and the subsequent Hong Kong, Shenzhen, and Singapore expansions laid down the foundations of a sustainable and profitable company. The listing offered ASM International

Post (24-7-1989); ASM Pacific Technology, Patrick Lam, 'Fax: Trip Planning Singapore, re: T290-89/PL' (2-8-1989) Archive Arthur del Prado-ASM Pacific Technology 1988-1991 file.

105 Peggy Sito, 'Migration bug' Hong Kong Standard (1-7-1989); Jimmy Leung, 'Singapore lures HK medical staff' South China Morning Post (21-7-1989) Archive Arthur del Prado-ASM Pacific Technology 1988-1991 file.

106 ASM Pacific Technology, Patrick Lam, 'Memorandum: Long Term Strategic Planning Expansion in Singapore' (18-9-1989) Archive Arthur del Prado-ASM Pacific Technology 19881991 file.

107 ASM Pacific Technology, Patrick Lam, 'Fax: Singapore, re: T352-89/PL' (19-9-1989) Archive Arthur del Prado -ASM Pacific Technology 1988-1991 file; Singapore Economic Development Board, Chow Tat Kong, 'Letter to Patrick Lam' (21-9-1989) Archive Arthur del Prado -ASM Pacific Technology 1988-1991 file.

108 ASM Pacific Technology, Patrick Lam, 'Memorandum: Long Term Strategic Planning Expansion in Singapore' (18-9-1989) Archive Arthur del Prado-ASM Pacific Technology 19881991 file.

109 ASM Pacific Technology, Patrick Lam, 'Fax: Company name in Singapore, re: T457-89/PL' (22-11-1989). 
some immediate cash, while its stake in ASM Pacific Technology was used as a securitization for future bank loans. Moreover, in times of needs, shares could be sold for cash. ASM Pacific Technology became a cash cow for its parent company.

Patrick Lam had gained control over his operations' own fate. From December 1988, future transactions from Hong Kong to Bilthoven were limited to dividends. ${ }^{110}$ His economic, steady, and strategic management enabled a resolute and organic growth of his enterprise, and contrasted strongly with the cyclical and over-leveraged developments of its parent company ASM International. This had been the case throughout the 1980s and would be even more so in the future. Over the years, ASM Pacific Technology would stay a vital base to rely upon during contingencies - most often involving acute financial distress.

\section{Reconsolidation of foundations?}

The relief about ASM's survival was short-lived. After immediate bankruptcy had been prevented, ASM International's management had to deal with operational problems. The organizational deficiencies of the diversified enterprise had not been solved and continued to destabilize the company throughout 1989, 1990, and 1991. The foundations upon which Del Prado had built his organization were not in line with the new realities of ASM and the industry.

Fortunately, there were positive developments as well. The most promising one was the introduction of the Epsilon single wafer reactor. After a modestly successful introduction during Semicon West, in May 1988, the machine very slowly gained appreciation. By the fall of 1989, the advanced development project finally succeeded in making inroads into the market. Epsilon's entrance into the limelight constituted a welcome boost, and it reaffirmed ASM's technological prowess.

Meanwhile, the company's technological development hurtled forward, even during the financial crisis, in particular in Bilthoven, where governmental support stimulated advanced research and development projects. The ability to pursue new technological opportunities and make an impact upon the company and potentially the industry excited ASM's engineers. Ernst Granneman, in his capacity of technical director at the AMTC and part-time professor at Delft University stimulated this even further. It was this thrilling potential of creating new opportunities through the deployments of brains, skills, and experience, which constituted the raison d'etre for the company. For Del Prado it made all the financial and operational squirms worthwhile.

At the same time, the direction of innovation very much depended on the technological and commercial interest of the respective business units. Tensions

110 Though initially, ASM Pacific Technology paid also a 'consultancy fee' of a few millions annually. - CEF Capital Limited, Prospectus ASM Pacific Technology Limited (13-12-1988) Archive Arthur del Prado-ASM PT file. 
between competitive and corporate strategies persisted. The unsatisfying 1986 compromise surrounding the development of a vertical furnace in Japan, a central load system by the AMTC, and the American small batch plasma system continued to have its effect, as will be apparent below.

\section{ASM Japan comes to the fore}

The atmosphere of technological innovation, entrepreneurism, and the conflicting competitive strategies of the business units came most strikingly to the fore at ASM Japan. All the remaining operations had to adjust their competitive strategies to new circumstances. This was a process which occurred by fits and starts, clashes and strife. ASM Japan's story illustrates the internal and external - industrial, commercial and technological - challenges faced by the subsidiaries in the years 1988 until 1991.

After the reorganizations in 1988, ASM Japan had become the sole profitable front-end operation. The operation had grown from a mere sales and customization operation into an equipment manufacturer capable of developing, manufacturing, and selling its own product lines. Moreover, it was very well embedded in the Japanese semiconductor industry. Its sales totaled 5.8 billion yen (89.7 million Dutch guilders) and 7.2 billion yen (111.9 million Dutch guilders) in, respectively, 1988 and 1989. It employed around 120 employees.

Its general manager Yo Miyazaki made sure that ASM Japan got what he thought it deserved A celebratory opening of a new headquarters - located in Tama, on the outskirts of Tokyo - marked the conclusion of the startup years in the summer of 1989. The presence of the famous Dutch judoka and member of the International Olympic Committee Anton Geesink did not make up for the underestimation for ASM Japan's achievements. As Miyazaki complained to Del Prado:

\footnotetext{
'Since we started here in October 1982, there must have been enormous amount[s] of money ... spent for development of new products or other purposes in Europe and America. (I have no concrete idea how much, where, how). ${ }^{111}$
}

Miyazaki's frustration about the lack of support for his operation was tied to three developments. The first was the globalization of Japanese semiconductor manufacturers. The second involved the development of successive plasma deposition technology. And the third was ASM's fumbling with vertical furnaces.

111 ASM Japan, Yo Miyazaki, 'Memo: Ion Implantation' (8-11-1988) Archive Arthur del PradoASM Japan 1985-1988 file. 
In each of the developments, Miyazaki saw a conflict with the strategies of the other ASM operations.

The internationalization of Japanese semiconductor manufacturers exposed ASM's defunct corporate strategy of having the geographical business units serve merely their own districts. After the US-Japanese semiconductor trade agreement of 1986, Japanese chip manufacturers set up factories in the United States and Europe. By internationalizing, companies like Hitachi, Toshiba, Mitsubishi, NEC and Fujitsu hoped to avert the trade issues from the years before.

To this end they transferred existing product lines. This way, the latest knowledge remained in Japan, while it also allowed a smooth and quick start-up of the new American and European operations. However, this also meant that the Japanese manufacturers wanted exactly the same production technologies from Japan abroad. None of the production techniques could be changed or removed from this orchestration of innovation, as this might risk the productivity, quality and economics of a production line.

This proved to be a problem for ASM's global strategy. But now, the customers of ASM Japan moved their operations abroad and demanded their common machines: the PXJ furnaces of ASM Japan. ASM Japan's manager Miyazaki warned Del Prado about this problematic situation:

'Smooth transfer of process technology currently used from Japan to abroad is the top priority, which can only be achieved easily by introduction of equipment they use now. ... In this context, our customers believe ASM is the ideal equipment supplier. To look at the issue and understand it only as competition between ASMA and AMSJ is not appropriate. They automatically expect that there will be an identical PECVD with our PXJ-200 locally available in USA and therefore quality of service as well. ${ }^{\prime 12}$

However, ASM America and ASM Europe refused to support the sales and service of ASM Japan's plasma equipment in their apportioned geographical markets. Both the Phoenix and Bilthoven operations faced substantial difficulties in selling their own horizontal CVD machines. ${ }^{113}$ They wanted to secure these new Japanese customers for themselves. Moreover, support of the ASM Japan machines in Europe required investments in spare parts and training, while their own tools and stock remained defunct.

112 ASM Japan, Yo Miyazaki, 'Fax to Arthur del Prado: Overseas Operation by Japanese Device Manufacturer, ref: KK-88-0845' (2-6-1988) Archive Arthur del Prado-ASM Japan '85-'88 file.

113 ASM Europe, Richard Blickman, 'Memorandum: Action plan outstanding quotation ASM Front-End production' (21-3-1989) Archive Arthur del Prado - ASM Europe reorganization file. 
The second development occupying Miyazaki concerned the development of new plasma deposition technology. Due to the divergence in technological development in Japan and the United States and through the equity crisis, ASM's horizontal plasma furnaces steadily lost allegiance of the market (figure 50). Still some furnaces were sold by ASM America to Intel and by ASM Japan to its Japanese customers, but this faded compared to the growth of the global plasma deposition market. American competitors Applied Materials and Novellus had entered the market for plasma deposition with a single wafer process, initially applied for the growth of new interlayer dielectrics. By 1988, ASM's bulky horizontal furnaces were pushed out of the market by these single wafer tools. Something had to be done.

\section{Figure 50}

Graph of revenues ASM International in worldwide market for PECVD technology, 1983-1993

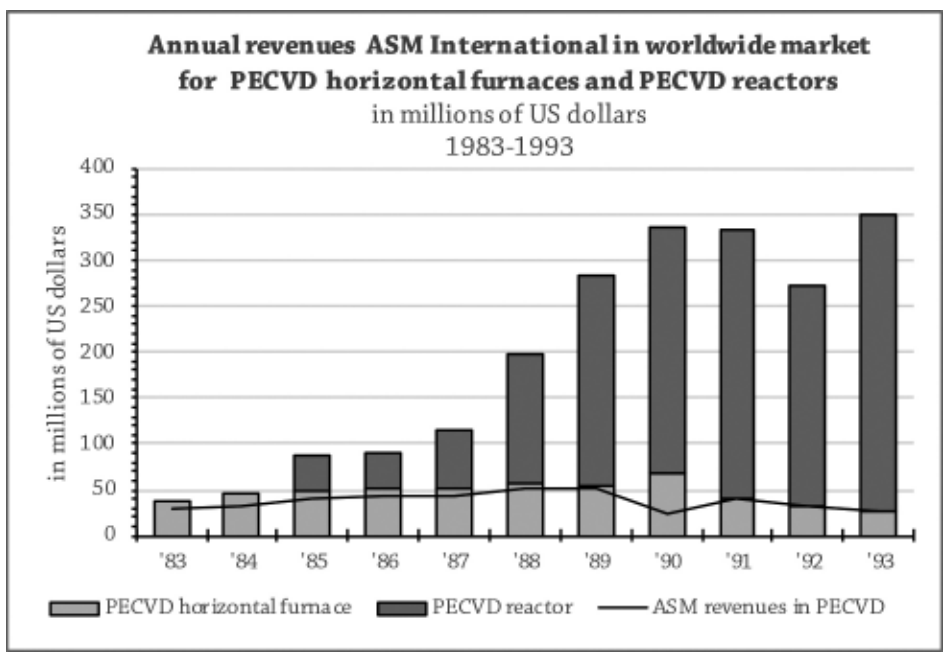

Having the biggest installed base of plasma furnaces, ASM Japan picked up the gauntlet. Its customers asked it to supply a single wafer plasma CVD reactor of its own. To this end, ASM Japan cooperated with the same junior partner in vertical furnaces, Tokyo Hitec. This company supplied ASM Japan with a single wafer handler module and basic configuration. From October 1988 onward, the R\&D department led by Fukumi Tomino had to turn these basics into a working machine. The project was dubbed K-1.114

114 The R\&D department was managed by Kouji Izumi. The collaboration with Tokyo Hitec was managed by Tetsuji Kawakami. - Fukumi Tomino, 'Interview with author', ASM Japan, Willem Enzing, 'Memorandum: Report Single Wafer PECVD in Japan, ref: KK-88 1548' (18-10-1988) Archive Arthur del Prado - ASM Japan R\&D. 
The single wafer approach was also very new for the Japanese engineers. ASM Japan had to accumulate an entirely new body of knowledge. The machine had to run the standard passivation processes for the horizontal furnaces, and for various interlayer dielectrics such as tetraethylorthosilicate, or simply TEOS. The configuration of the plasma, gas dynamics, and the whole sequence of wafer handling had to be developed and perfected.

While ASM Japan took the matter in its own hand, ASM International set out on an effort of its own. It still pursued a cohesive approach with the central load system, which ought to be integratable with various process modules developed by the subsidiaries (see Innovation III). Three variations were pursued under the product name 'Advance 600' (A600). ${ }^{115}$ One was the new plasma reactor dubbed A600-1 of ASM America. The second was an integrated LPCVD and diffusion vertical reactor, dubbed A600-2. The third variation was called A600-3 and entailed vertical process modules for aluminum CVD. The AMTC had been established as a binding organization among the subsidiaries, and through the A600 it would realize this goal.

The plasma variation of the A600, the A600-1, formed an alternative to ASM Japan's K-1 single wafer plasma reactor. It consisted of a wheel with cold wall plasma CVD single wafer chambers and was connected to the A600 wafer handler platform. ${ }^{116}$ It resembled the plasma technology of Novellus. However, it was short-lived and stopped by the fall of 1989. Preliminary calculations indicated that the machine would not be economical, nor would it offer quick consolation to ASM's demise in the plasma business. ASM Japan's competitive strategy for plasma products prevailed.

The pinnacle of conflicting competitive strategies of the geographical business units formed ASM's response with regard to the industry's transition towards vertical furnaces. By the end of the 1980s, it was a matter of time before ASM would no longer be able to compete in its core market of horizontal batch LPCVD and diffusion systems. ASM Japan tried to convince ASM America and ASM Europe to market its vertical VMP-100 LPCVD furnace and a VDF-100 diffusion

115 ASMI, Arthur del Prado, 'Memorandum: AURA Organization (New name for all our Vertex activities), ref: 89.016/HL/AdP/tv' (5-2-1989) Archive Arthur del Prado - Vertical furnaces file.

116 ASM America hired an engineer named Peter Hey in the spring of 1988. The A600-1 consisted of a circular arrangement of a number of single wafer deposition stations ('wheel') where wafers were stepped through until the right layer thickness was obtained. Two of those wheels were connected to the wafer handler. - ASM America, Paul Brown, 'Fax: New PECVD Project Objectives' (15-6-1988) Archive Arthur del Prado - CVD 1987-1991 files. 
furnace. From 1987 to 1990, about thirty of these machines had been sold in Japan. ${ }^{117}$

However, the Phoenix and Bilthoven operations identified shortcomings to the Japanese furnace. ${ }^{118}$ One was that it was not yet capable of processing 200-millimeter wafers, which were about to be introduced industry-wide. Second, European and American customers wanted a single platform for LPCVD, be it oxidation or diffusion. Serving and acquiring different systems for diffusion and LPCVD was just not economical. ${ }^{119}$ Moreover, the AMTC developed integrated vertical LPCVD, oxidation, and diffusion processes for its central load system, the A600-2 (cf. Chapter 22). This variation addressed concerns of chip manufacturers, fearing unwanted oxidation prior to the deposition of polysilicon electrodes. However, this machine, too, was not yet capable of processing 200-millimeter wafers, unproven, as well as more expensive (due to its complexity).

By 1990, despite the Japanese and European variations, ASM still failed to make inroads into the market for vertical furnaces. Competitors such as Hitachi Kokusai and Tokyo Electron, or the American Silicon Valley Group, enjoyed a bigger installed base and thus were more attractive compared to the rather inexperienced ASM Japan. To halt ASM's declining market share in low pressure deposition processes, Del Prado and his staff jumped to the opportunity to acquire the technology of a vertical furnace of General Signal in September 1990.

General Signal was a conglomerate in semiconductor equipment, consisting of GCA (lithography steppers), Electroglass (wafer probes), Drytek (etchers), AMI (die bonders), Micro Automation (saws), GSI (track systems), and Ultratech (steppers). Just like ASM it struggled with the alignment of the diversified competitive strategies, and to that end hived off operations. ${ }^{120}$ One of those was the deposition operation, General Signal Thin Film Company, headquartered in Fremont, California. ${ }^{121}$ Among the assets was a vertical furnace dubbed the 'Enhanced Vertical Thermal Reactor' (EVTR).

117 Some of those were VMP-510 and applied in the production of LCD displays by NEC. As indicated by Fukumi Tomino, this involved 1 tube in 1987, 7 tubes in 1988, 22 in 1989, 33 in 1990, and 33 in 1991. - Fukumi Tomino, 'Correspondence with author'.

118 ASM America, Ken Davids, 'Memo: Comments about Itagaki's GSTC Report' (28-9-1990) Archive Arthur del Prado - vertical furnace file; ASM Japan, Yo Miyazaki, 'Memorandum: GSTC' (27-9-1990) Archive Arthur del Prado - vertical furnace file.

119 ASM Japan, Willy Enzing, 'Fax: Visit Report Semicon Europe/AMTC, ref: KK-88-0469' (17-3-1988) Archive Arthur del Prado - ASM Japan R\&D.

120 ASMI, André van Rhee, 'Memorandum: GSTC, ref: 90.230/AvR/evdh' (1-10-1990) Archive Arthur del Prado-André van Rhee files, 1987-1991.

121 This operation consisted of three segments: a group in Hoogeeven, the Netherlands, called Tempress BV, a group called Acorn, and the EVTR group. Del Prado co-founded the Tempress BV operation in 1968 (see Business Chapter I), but was now negotiating the acquisition of the EVTR group. The Tempress group was conducting a management buy-out. As will become 
The machine had been sold to IBM. The American electronics giant encouraged ASM to acquire the EVTR. This would ensure IBM of continuing technical support, while it offered ASM the opportunity to sell furnaces to this prestigious customer. Moreover, the machine overcame the shortcomings of the A600-2 and VMP/VDF machines. Engineers of the AMTC and ASM America recognized the opportunity:

'This system is available NOW. It has been sold to some customers in the USA ... and was even sold to a customer in Europe .... It offers advanced automation, including [Work in Progress] station, ..., 200 mm capability, and is available for both LPCVD and Diffusion. ${ }^{122}$

ASM decided to persevere in the negotiations and purchased the EVTR technology in the fall of 1990. It was renamed A300. The decision to pursue the EVTR opportunity formed a definitive condemnation of the Japanese vertical furnace plans.

However, the decision aggravated the lack of clout in vertical technology. Now, the company had three vertical furnaces: the Japanese VMP/VDF, the American A300, and the European A600-2 for high-end applications. Each competed for allegiance of the ASM sales and service forces and the globalized customers. In the aftermath of the equity crisis of 1988, ASM failed to reconsolidate its foundations. Technological development at the subsidiaries spiraled out of control.

\section{A plan for recovery for ASM Fico}

Following the failed divestment to Oppenheimer and in anticipation of a future public listening, ASM Fico struggled to position itself within ASM and in its market. Its global position was too intertwined with the Hong Kong operations. If ASM Fico was to be sold in the near-future, it required its own foothold in the vast and essential South-East Asian market, and a competitive strategy different from ASM Pacific Technology.

After the hectic summer of 1988, Van Rhee continued his negotiations for a venture capitalist to take an interest in ASM Fico. ${ }^{123}$ Before parties could

apparent, however, two years later it would cross paths with ASM again.

122 AMTC, P. Eppenga and E. ten Have, 'Memo: Possible GSTC EVTR division acquisition' (110-1990) Archive Arthur del Prado - Vertical furnaces file.

123 Discussions with ASM Fico's house banker NMB halted after the 'courtesy-collection' made by ASM America on behalf of ASM Fico. The NMB was replaced by another Dutch investment banker called Amro. The governmental venture capital organization MIP stayed on as a participant. - ASMI, André van Rhee, 'Memorandum to Supervisory Board: persoonlijke beoordeling bij enkele te overwegen transactie's, ref:88.140/AvR/jdk' (23-8-1988) Archive 
officially sign the agreement, ASM Fico's restructuring had to be in place. This involved setting up its own sales offices in South-East Asia, next to those of ASM Asia. To prevent ASM Fico and ASM Asia competing for the same orders, a noncompetition agreement was signed between both subsidiaries.

In addition, investments were needed to reboot ASM Fico's product portfolio. Being a Dutch company, it could not compete on price, as did the Hong Kong operations. The Herwen operation could not rely on cheap labor, nor did it have a vertically integrated manufacturing strategy. But it could compete in automation. Already in the mid-eighties, ASM Fico had developed an automatic molding machine for Texas Instruments. ASM Fico enjoyed a healthy position in the United States, and other leading American chip manufactures like IBM and Intel had shown interest in the automatic molding technology. Elaborations of these automated products would secure allegiance of the American market place, as well as increase market opportunities in South-East Asia.

ASM Fico prospects significantly improved by one major lucrative deal. The company was about to receive a Soviet order worth 115 million Dutch guilders as part of an American rapprochement scheme. In 1988, American companies were allowed to support Soviet industrial state-owned companies in computer and manufacturing technology. In response, IBM set up a factory line, including transfer of knowledge. To enable this technology transfer, some suppliers took part as well. Within this context, ASM Fico was asked whether it could train and supply Russian engineers in the production of molds.

This forthcoming order annulled the negotiations between Van Rhee and MIP and Amro by November 1988. ${ }^{124}$ ASM Fico earned enough to pay for its new technologies and the establishment of an Asian sales network. Now, ASM International could turn ASM Fico into a profitable and viable operation while reaping all earnings of a future public offering alone.

Before ASM Fico's recovery materialized, however, the operation went through a management change. In long handwritten letters to Arthur del Prado, the founder of ASM Fico, Richard Fierkens, had expressed his displeasure and frustrations. ${ }^{125}$ His misgivings consisted of a mix of hurt personal pride, an inability to comply with the wider ASM interests, and intense engagement with his operation. Other factors were the internal competition with ASM Pacific Technology, the failed management buy-out, the divestment, and the 'courtesy-

Arthur del Prado - André van Rhee files, 1987-1991; ASMI, André van Rhee, 'Memorandum: Fico, ref: 88.238/AvR/evdh' (9-11-1988) Archive Arthur del Prado - André van Rhee files, 1987-1991. 
collection' by ASM America. Remarkably, Del Prado seemed not able or willing to decisively intervene in the protracted deteriorating dealings with Fierkens.

In April 1989 Fierkens resigned as general manager of ASM Fico, ending an eighteen-year involvement in ASM. ${ }^{126}$ His leaving was accompanied by legal disputes, ${ }^{127}$ and it took another year before legal matters were solved in favor of ASM. ${ }^{128}$

After Fierkens' resignation, two former sales managers of ASM Europe, Jan Willem Baud and Richard Blickman were appointed to ASM Fico's management. ${ }^{129}$ Both men devoted themselves to the preparation of the operation for future divestment or a public offering. This involved offshoring production of subassemblies to Portugal and creating a presence in Malaysia. ${ }^{130}$ Moreover, new investments were made into automatic molding and improving penetration of the American market. The confirmation of the Soviet Union contract improved the company's finances significantly by the spring of $1990 .{ }^{131}$

The distorted relationship between ASM Fico and ASM Pacific Technology remained an issue. In particular when pursuing sales in South-East Asia, both companies interfered with each other. In September 1990, Baud addressed Patrick Lam about the matter:

126 ASM Fico, Richard Fierkens, 'Brief aan Arthur del Prado' (29-4-1989) Archive Arthur del Prado-ASM Fico Jan'88-Mei '99 file.

127 Initially some disagreements existed about Fierkens' redundancy scheme. Things escalated in the fall of 1989. ASM suspected Fierkens of transferring the latest technologies to a new firm called Smart Technologies, located just around the corner of the Herwen operation. This firm was located in Zevenaar. Among the executives of this firm was Richard Fierkens' son, Richard Junior. Things got moving after ASM Fico's prestigious customer Intel received a quotation from this new firm for highly comparable products. Soon the resignation spiraled into a suspension for bad conduct and legal tit-for-tats between ASM, Fierkens, and Smart Technologies. - Smart Technologies, 'Letter to Intel, Mr. R. Kar' (27-7-1989) Archive Arthur del Prado - ASM Fico Jan '88-Mei' '99 file; Richard H.J. Fierkens, 'Brief aan Arthur del Prado' (4-10-1989) Archive Arthur del Prado - ASM Fico Jan '88-Mei '99 file; Fierkens, Hightech in een boerendorp, pp. 202 and 203.

128 Fierkens, Hightech in een boerendorp, pp. 202 and 203.

129 Richard Blickman, 'Interview with author'. ASM Fico, Theo Vaessen, 'Letter to Del Prado' (18-6-1990) Archive Arthur del Prado - Fico files.

ASM announced the Soviet contract of 115 million Dutch guilders as follows: 'the contract covers technology licensing agreements to produce various types of equipment for the semiconductor industry, the supply of all manufacturing equipment and tooling needed for the envisaged product, and an extensive training and support program. The contract will be executed over a seven-year period by ASM Fico Tooling.' - ASM International, 'Press release: ASM International announces Major U.S.S.R. Contract', PR Newswire (29-3-1990). 
'Yesterday, I was confronted with the fact that the order ... was given to you. Although I am very happy that this order remains within ASM, I am surprised by the way this order was handled.' ${ }^{132}$

The issue of the two competing firms was not resolved. ASM Fico had to establish its own competitive position due to the envisaged divestment, while ASM Pacific Technology as an independent listed company no longer looked the other way in support of its former sister-company. ${ }^{133}$ Although there were opportunities for a resolution in back-end competition, in the case of the front-end operations things only seemed to go from bad to worse. ASM America and ASM Europe suffered from declining business. The conflicting competitive strategies numbed the company.

\section{Fettered in the dock}

The financial situation of ASM Europe rapidly deteriorated. Willem de Leeuw retired from his position as Director of Technology to replace Joop Wallenburg as general manager of ASM Europe. Over 1990, De Leeuw expected a loss of 24 million guilders on total sales of 42 million guilders. Another 50 employees were laid off. ${ }^{134}$ Moreover, De Leeuw initiated thorough operational changes to turn around the working atmosphere and efficiency.

The European market shrank tremendously, and the high hopes of the mid1980s proved to be mirages. Investments in equipment by chip manufacturers decreased, and the American competitors benefited from a weak dollar. ${ }^{135}$ Moreover, prospects about an expansion of the European market by the end of the Cold War failed to materialize.

In addition, the AMTC proved to be too much of a burden for Bilthoven. ${ }^{136}$ Despite the subsidies from the Dutch Ministry of Economic Affairs and from the European research programs the operation made losses. The center came on top of the dispersed R\&D expenses made by each of the operations. Moreover, the

132 ASM Fico, Jan Willem Baud, 'Memo” STM Trim and Form for 8-20 lds, Muar Malaysia' (79-1990) Archive Arthur del Prado - ASM Fico Jan '88-Mei '99 file.

133 ASM Fico, Jan Willem Baud and Richard Blickman, 'Letter to Arthur del Prado and Patrick Lam: Basic Outline for further cooperation ASM-Fico/Asia' (29-3-1990) - ASM Fico Jan '88Mei'99 file.

134 ASMI, Willem de Leeuw, 'Memorandum: General Manager ASM Europe, ref: 90.087/WdL/ jdk' (2-8-1990) Archive Arthur del Prado - ASM Europe reorganization file.

135 ASME, Willem de Leeuw, 'Reorganisatienota ASM Europe BV' (31-8-1990) Archive Arthur del Prado - ASM Europe reorganization file; Hobday, 'Corporate strategies'.

136 ASM Europe, Willem de Leeuw, 'Reorganisatienota ASM' (maart 1991) Archive Arthur del Prado - ASM Europe reorganization file. 
AMTC seemed not to be succeeding to function as a bridge between the various subsidiaries.

The A600 failed to make inroads into the market. After the failure of the plasma-wheel variation - A600-1 - the aluminum CVD lost its viability. Through this news, ASM Europe lost the chance of addressing a new market of metallization processes. ${ }^{137}$ After investing almost a decade into this technology, the failure of A600-3 deepened ASM Europe's distress. ${ }^{138}$ The prospects in Europe were limited, as was the future for ASM Europe. The Dutch operation continued to drag ASM International.

\section{Figure 51}

Graph of ASM high, low, and average annual market capitalization on the Nasdaq stock exchange from 1984 to 1992

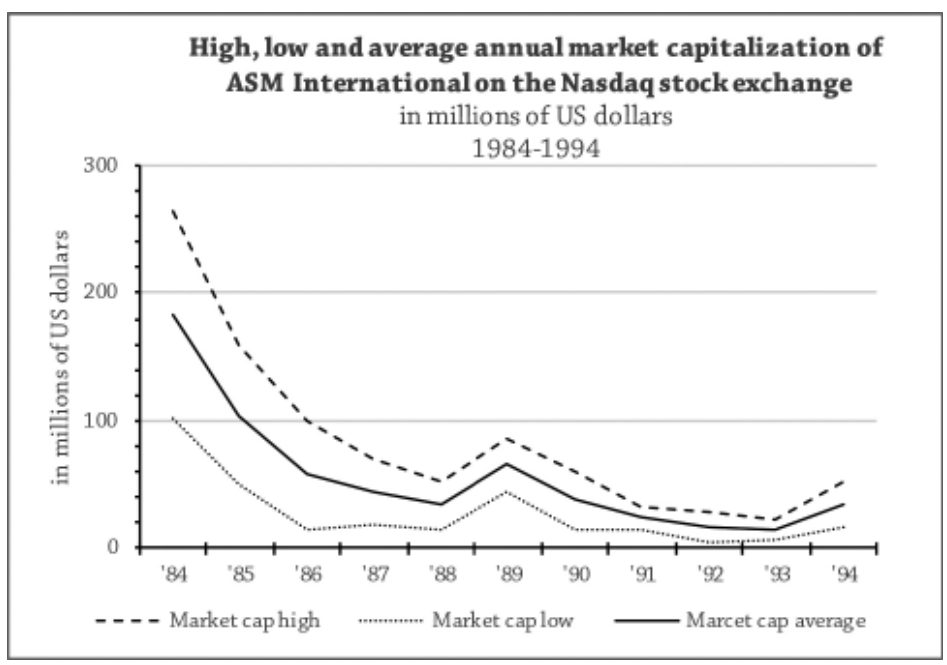

Due to the faltering of ASM Europe, Van Rhee never got out of firefightingmode (figure 51). By 1990, he had to consider the available credit lines all over again. ${ }^{139}$ This involved expanding the loans from ABN and Banque Paribas, and applying for an additional investment of the National Investment Bank (NIB)

137 ASMI, Arthur del Prado, 'Facsimile message to AT\&T, ref:90.115 AdP/tv' (13-11-1990) Archive Arthur del Prado - outward correspondence files 1988-1993; ASMI, Arthur del Prado, 'Letter to IBM General Technology Center, Dr. Fleming, ref: 91.020 AdP/tv' (27-2-1991) Archive Arthur del Prado-outward correspondence files 1988-1993.

138 ASM Europe, Willem de Leeuw, 'Reorganisatienota ASM' (maart 1991) Archive Arthur del Prado-ASM Europe reorganization file.

139 ASM International, André van Rhee, 'Memorandum: 89.291/AvR/evdh' (10-10-1989) Archive Arthur del Prado - André van Rhee files, 1987-1991. 
totaling around 20 million Dutch guilders. ${ }^{140}$ The internal competition and the rapid obsolescence of horizontal furnaces hardly helped. Moreover, the NIB expected installment of its 1985 subordinated loan of 30 million by the second half of 1991, a date approaching rapidly. ${ }^{141}$ Van Rhee had to glean the cash from everywhere.

One solution involved the flotation of ASM Japan. Amidst all misery, this operation continued to maintain profitable. Van Rhee and the Japanese controller Hitoshi Miura worked out the details. ${ }^{142}$ Bankers Daiwa Securities, Kokusai Securities, Yamaichi Securities, and Sanyo Securities were approached for a flotation by 1993. In the meantime, ASM sold another ten percent of its stock in ASM Pacific Technology, creating around 9.4 million Dutch guilders in cash. ${ }^{143}$ Furthermore, each of the operations had to arrange their own bank loans. ${ }^{144}$

Van Rhee got even more on his plate. The 35 million convertible note placed by Kempen \& Co in 1987, of which 15 million was converted in 1988 already, stood under water. Originally, the convertible note had been secured by ASM International's shares against a value of nine dollar per share. However, by the summer of 1991, when ASM International's stock price had plumped, it was merely penny stock. An investment banker named Grantham, Mayo Van Otterloo \& Co took over the remaining convertible debentures, and used it to

140 Even that was not enough. Forlorn, Van Rhee in vain even approached Patrick Lam to remedy an escalating cash crisis. Other solutions at hand were selling a stake in ASM Pacific Technology, transferring bank loans of ASM Japan to ASM International, selling the facilities of ASM France. - ASMI, André van Rhee, 'Facsimile Message to Patrick Lam: Cash Situation, ref: 90.119/AvR/evdh'(8-5-1990) Archive Arthur del Prado - André van Rhee files, 1987-1991; ASMI, André van Rhee, 'Memorandum to Supervisory Board: Notitie inzake liquiditeitsaanvulling, ref: 90.180/AvR/evdh' (31-7-1990) Archive Arthur del Prado-Andrévan Rhee files, 1987-1991.

141 ASMI, André van Rhee, 'Memorandum to Supervisory Board: Notitie inzake liquiditeitsaanvulling, ref: 90.180/AvR/evdh' (31-7-1990) Archive Arthur del Prado - André van Rhee files, 1987-1991;ASMI, Andreé van Rhee, 'Memorandum: front-end business, refL 90.183/AvR/evdh' (1-8-1990) Archive Arthur del Prado - André van Rhee files, 1987-1991.

142 ASMI, André van Rhee, 'Memorandum: IPO proposal for ASM Japan, ref: 90.257/AvR/evdh' (5-11-1990) Archive Arthur del Prado - André van Rhee files, 1987-1991.

143 ASM sold 10 percent stake in ASM Pacific Technology. This amounted to 36 million shares at a share price of 2.025 Hong Kong dollars on March 27, 1991. ASM retained 64.7 percent. On March 27, 1991, 1.927 Dutch guilders or 7.792 Hong Kong dollars equalled 1 U.S. dollar. The value of the transaction was 72.9 million Hong Kong dollars or 9.36 million Dutch guilders; the value of ASM Pacific Technology was 729 million Hong Kong dollars, or 93.56 million Dutch guilders. - ASM International, 'Press release: ASM International sells 10 percent interest in ASM Pacific technology', PR Newswire (4-4-1991).

144 ASM International had secured all its assets against bank loans. Due to the aggregated deplorable situation of the whole firm, conditions underlying these loans were highly unfavorable. Perhaps the operations themselves could attract credit more adequately. ASM International, Annual Report 1990 (March 1991). 
negotiate a new transaction. ${ }^{145}$ Until 1994, ASM International would discuss the restructuring and supplementation of this deal.

To get more control over the operations, Del Prado hired a new manager by the name of Bob Howells. ${ }^{146}$ He created a new business unit out of ASM America and ASM Europe - dubbed the Atlantic Business Unit - hoping that this would improve coherence. ${ }^{147}$ Through this, Howells stipulated the creation of product management for CVD, Epitaxy, and Vertical Furnaces. He released De Leeuw from his position as general manager, who got a position as Director of Corporate Development. These were some promising steps with regard to addressing ASM International's structural deficiencies.

\section{Epilogue}

Despite all the financial and operational hardship, Del Prado did not temper his entrepreneurial instincts. He still stood by the strategy of pursuing opportunities by acquiring new technology, i.e., by diversifying the firm. Earlier he had been forced to let probable acquisitions pass by, including the lithography manufacturer GCA and competitor for horizontal furnaces Thermco. But by 1990, when the troubles were far from over, Del Prado felt that new expansions or acquisitions might be a resolution for the company's problems. His appreciation of ASM's situation had something delusional. Despite all of ASM's obvious problems, Del Prado deemed the diversified approach as key to future success; it allowed the company to spread risk.

He continued to play his own game. This involved a pondering quest to get back into the ASM Lithography joint-venture, whenever possible, in order to strengthen ASM's position in the industry and in the Netherlands in particular. It also concerned the acquisition of the EVTR vertical furnace, which aggravated the internal strife in the short-term, but might prove to be a vital asset in the longer run. The culmination of his undaunted entrepreneurism formed the negotiations with a manufacturer of metallization processes Balzers, located in Liechtenstein by May $1991 .{ }^{148}$

145 De Mol van Otterloo was an acquaintance of Paul van den Hoek during their study in Amsterdam. - ASMI, Andre van Rhee, 'Facsimile Message to Mr. E. de Mol Otterloo, ref: 91.245/AvR/evdh' (8-10-1991) Archive Arthur del Prado - Banks; Grantham, Mayo, Van Otterloo \& Co file.

146 He was an acquaintance of Robert Heikes, a consultant Del Prado hired in 1988.

147 ASM Europe, Bob Howells, 'Memorandum: Organization Announcement' (9-9-1991) Archive Arthur del Prado - ASM Europe reorganization file.

148 Balzers AG was a broad-based company in the field of deposition equipment, high vacuum components and thin films with worldwide activities. It developed the Clusterline CLC 9000 multichamber system for wafer metallization. It also owned Spectrum CVD Inc., based in Phoenix, Ariz. and specialized in metal CVD equipment for TiN, selective tungsten and 
Del Prado's action alienated Van Rhee. ${ }^{149}$ The financial officer had constantly worked in over-time to prevent ASM from immediate shutdown. He had enforced his position next to Del Prado in 1988, but was now blindsided again by his chief executive officer. Even more worrisome, the company's founder seemed not to share the sense of crisis as he pursued new adventures. For Van Rhee, the Balzers proposition was the final straw, and he announced his resignation in the fall of 1991.

Del Prado also alienated his trusted fiscal advisor and Supervisory Board member since the beginnings, Nico Nobel. For the renowned Dutch tax lawyer, the complexity of ASM's organization and the challenges ahead moved beyond his capacity. In a critical letter to Del Prado and the rest of the Supervisory Board, Nobel summarized the difficult situation of ASM and pointed where it hurt:

'The past few years, tensions increased between my loyalty towards Arthur, the interest of ASMI (whatever that may be), and my job as (joint) supervisor on behalf of all the shareholders, including the minority shareholders....

The first real significant frictions emerged in relation towards ASM Lithography. The fact that ASMI was "managing partner" over there was for me of overriding importance, even though Arthur consistently considered this a matter of minor importance. Repeatedly, I urged Arthur verbally and in writing ... to get more personally involved with Litho. Arthur did not do this. He left everything to the discretion of Willem de Leeuw, and limited himself to what he called "remote control" ... Arthur constantly blamed everybody and everything about the debacle (the dollar, Philips, the engineers, Smit), but he was the initiator and in the end, he (and nobody else) was responsible.

The next and even bigger source of friction were the unexpected catastrophic development of ASM Europe, with COCOM, ASM France,

tungsten silicide. Both companies had approached each other within the European research program called JESSI in an effort to develop a cluster machine (see Innovation III). By means of a merger with Balzers metallization group, Del Prado would save ASM's investments in aluminum CVD, get ASM into the lucrative market for metallization processes, and strengthened ASM's and Balzers position within and toward the European chip industry and authorities. The plan was doomed to fail, as ASM hardly had any financial reserves left and because the negotiations required more time than was granted to both Balzers and ASM. - ASM International, 'Press release: ASM International N.V. and Balzers AG investigate merger of metallization activities', PR Newswire (8-5-1991). 
fictitious supplies (with the incorrect annual report of 1989) and stifled bribes. $^{150}$

While Del Prado foremost kept his eyes on the longer term and the company's ability to achieve long-term strategic goals, Nobel no longer oversaw the current troubles. Not everyone has the ability to remain positive in all circumstances.

An unexpected collapse of the Japanese semiconductor market in the fall of 1991 dashed Del Prado's ability to continue his entrepreneurism. With its loss of 40.5 million yen in 1991 on total sales of respectively 7.828 billion yen, ASM Japan joined the group of loss-making operations. ${ }^{151}$ The situation annulled hopes of a Japanese public offering. Only ASM Epitaxy seemed to make any money in the wafer processing business. ASM International was about to collapse.

At the lowest point of the crisis, the new manager of the Atlantic Business Unit, Bob Howells, analyzed the firm and wrote a report. ${ }^{152}$ Over 1991, ASM managed to record a profit of 8 million Dutch guilders over a total sales of 506.8 million Dutch guilders, while employing about 2.600 employees including ASM Pacific Technology. Shares were traded for 1.5 to a maximum of 4.5 dollars, valuing the company between 11.1 million and 33 million dollars. This was just a fraction of the company's esteemed value compared to the 197 million dollars at the 1983 public offering. ASM was back to square one.

Having taxed the deplorable state, Howells assessed the remaining assets. He recognized each of the subsidiaries remaining distinct technological strengths. ASM Japan had its horizontal and forthcoming single wafer plasma technologies, ASM America had the epitaxy business, ASM Europe had the LPCVD process knowledge and the A600, and ASM France had its gas components. Howells also recognized the conflicting competitive strategies:

'There is no question to my mind that one of the historic strengths of our company has been the highly "entrepreneurial" drive that has been inherent in the individual subsidiary strategy that was followed in the earlier years of our corporate development. I believe this has become a

150 Original quote in Dutch. - Nico Nobel, 'Letter to Supervisory Board' (17-6-1991) Archive Arthur del Prado - André van Rhee files.

151 On December 31, 1990, 1 yen had a value of 0.0125 Dutch guilder and 0.00737 US dollar. ASM Japan's 1990 sales, then, amounted to 94.78 million Dutch guilders (or 55.89 million US dollars); its 1990 profits amounted to 3.04 million Dutch guilders (or 1.79 million US dollars). On December 31, 1991, 1 yen had a value of 0.0136 Dutch guilder and 0.008 US dollar. Thus ASM Japan's 1991 sales amounted to 106.46 million Dutch guilders (or 62.62 million US dollars); its losses amounted to 550.8 thousand guilders ( or 324 thousand US dollars).

152 ASM International, Bob Howells, 'Front-end Corporation: A Conceptual View' (13-5-1992) Archive Arthur del Prado - Bob Howells file. 
significant corporate weakness during the later part of the 80's as the market polarized around global companies and Japanese companies. I believe that the current downturn in Japan is to some extent a direct reflection of their "insular" views.' ${ }^{153}$

It has been impossible to align the strategies of each of the business units. Any viable corporate strategy had to take into account the independence and expertise of the business units, take their competitive strategies serious. Accordingly, Howells proposed a matrix organization, relying upon product instead of geographical management:

'To accomplish this, I propose a structure that removes responsibility for all product management and development from the geographic management and that the geographic units become "service" operations providing centralized distribution and administration for the activities in that region. In addition, they will provide local manufacturing or integration capability under "contract" to the central product management organizations.' ${ }^{154}$

This was just a prelude, however, of his real message, one which Del Prado was not going to like.

Howells sketched the ideal solution for ASM's problems, leaving aside the actual financial slack for such an operation. Baring the financial problems, he only saw three real solutions to ASM's immediate problems. The first was a dissolution of all unprofitable sections of ASM International. The second was to transfer a minority or majority interest in the front-end business to a third party. And the third was divesture of either some business units, or, most realistically, the entire ASM front-end operations. As Howells concluded his report:

'It is my opinion that we should seriously consider acquisition of the company in total. If that is not an option, then we should proceed immediately to open negotiations with one or more of our competitor's or customers.' ${ }^{155}$

153 Ibid., p. 10

154 ASM International, Bob Howells, 'Front-end Corporation: A Conceptual View' (13-5-1992) Archive Arthur del Prado - Bob Howells file, p. 11.

155 Ibid., p. 19. 
This was not a conclusion to Del Prado's liking. After an intense discussion of the report, Del Prado exploded: 'What are you even doing here?'156 It was time for Howells to clear his desk.

Throwing in the sponge by selling his company was not an option for Del Prado. It was his undisputed talent to motivate and inspire his staff to pursue distant opportunities, to embark on an uncertain future. He did not want to have anything to do with anyone who no longer believed in ASM's potential. Losing heart was no option. However, after the catastrophic past seven years, Del Prado was standing with his back against the wall. Which openings or opportunities, if any, were still available to him. 


\section{Conclusions}

From the second half of the 1980s to the early 1990s, Del Prado's business strategy for ASM was contested. The foundations of his firm - decentralization, diversification, market-driven innovation, and his own position as undisputed owner and leader of the company - had been the recipe for the company's growth and success from the late sixties until the early eighties. Through an accumulation of unforeseen events, ASM deficiencies got exposed and contributed to the stumbling decline of the enterprise.

Despite this malaise, revenues grew from 350.6 million Dutch guilders in 1985 to 412 million in 1992. Yet, net losses aggravated from 19.1 million Dutch guilders to 73.6 million over the same period of time. The deplorable state of the company was best reflected in its market capitalization (figure 51). The company's estimated value by investors decreased drastically from an average of 104.4 million dollars in 1985 to 17.1 million by 1992 (this last amount merely being an average). Despite the drastic measures taken in 1988, the company's decline had continued (figure 52).

\section{Figure 52}

Graph of annual growth semiconductor industry, semiconductor equipment industry and ASM International worldwide, 1982-1992

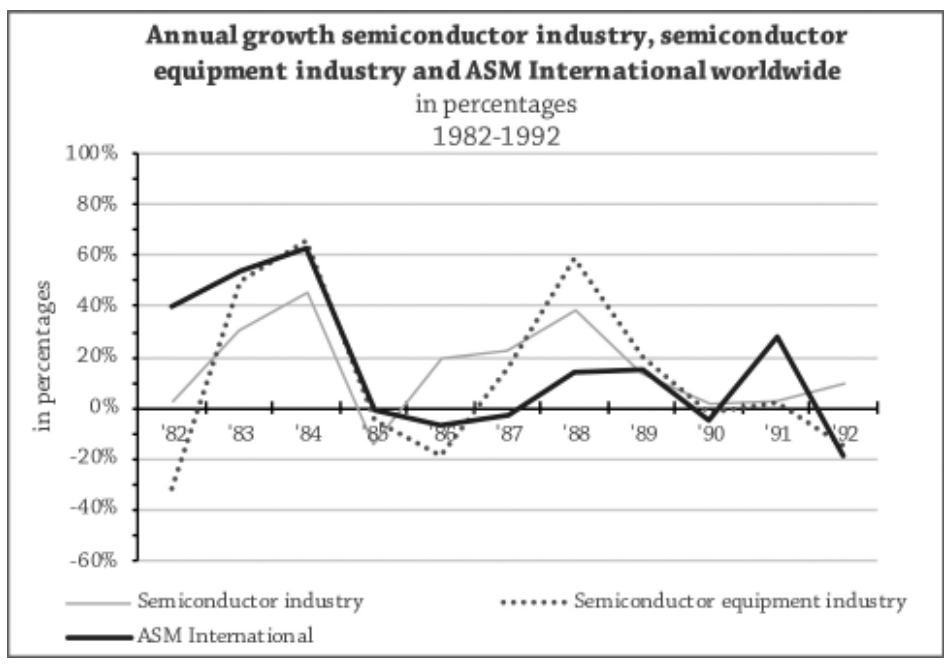




\section{Fortuna}

Unlike in the previous years, unforeseen contingencies - fortuna - no longer bore benevolent effects for ASM International. Instead, each of them further destabilized the company. In the previous booming years, a strategy of leveraged innovation had driven the growth of the firm. But this strategy dragged the company down at an equal pace in the face of more challenging events. In Business III, fortuna manifested itself in four ways.

The first was the sudden overheating of the memory chips market in 1984 and 1985. This initiated a series of events - anti-dumping litigation, depreciation of the dollar, trade agreements, etc. - causing chip manufacturers to reconsider their national competitive entrenchment, and to internationalize and to specialize. Japanese chip manufacturers opened fabs in the West and gained dominance over the memory market. American chip producers focused on ASICS ever since. The specialization resulted in a divergence of technological development.

The second manifestation of fortuna that disrupted the course of the company involved Arthur del Prado's heart-attack in 1985, and to a lesser extent the personal drama in his family a year later (his wife's death). Through these events, the obviousness of Del Prado's management could no longer be taken for granted. The chairman of the supervisory board Paul van den Hoek became aware of the risk of the organization's all-out dependence on Del Prado. If necessary, there was no one available to fill his shoes. Management therefore had to be professionalized and strengthened.

The third manifestation of fortuna was triggered by an unfortunate combination of events disrupting the European activities of ASM. This involved Black Monday interfering in the divestment of ASM Fico, and the raid by the ECD for illegal exports. Sales of the horizontal furnaces declined - due to their misalignment with forthcoming submicron and 200-millimeter production demands. Moreover, the introduction of new products - an ion implanter, the epitaxy reactor, a stepper, a new vertical furnace, and so on - took longer than expected.

This third fortuna instigated the fourth, and most dramatic, fortuna. Through the European troubles, ASM's cash reserves got drained, ringing alarm bells at the head office's Dutch banks. The financial institutes had grown anxious due to a sudden market crash in 1987 and the end of the Cold War. The bankers' requirements for managerial oversight fitted in a wider development. As claimed by economic and business historians Gerarda Westerhuis, Ailsa Roell and Abe de Jong about the changing attitude of Dutch bankers in the late 1980s: 
'Especially after the bankruptcies that occurred during the crisis of the early 1980s, they started to question the competence of companies' managements.' 157

Dutch bankers demanded more security for their loans. With its over-leveraged innovations, ASM was forced to comply, in particular as loans had to be installed from 1988 onward. This pushed Del Prado and his team to improve their solvency.

This demand and the doggedness of the bankers came as a total surprise for Del Prado. Moreover, it forced ASM International's management to take drastic measures. Without support of the banks, everything would be lost. As such, this fourth manifestation of fortuna truly marked a Machiavellian Moment. Tough choices had to be made. For the first time the company had to cope with a sustained series of unfavorable developments. At the same time, it was still the master of its own fate. The instalments to the bankers could be fulfilled by painfully divesting ASM Lithography, ASM Ion Implant, and floating ASM Pacific Technology.

\section{Virtù}

An abundance of virtù - the art of unpremeditated responding to sudden events - lay at the heart of ASM's troubles in the late 1980s. Management at the subsidiaries showed it and the complete management of ASM International showed it. In the wake of fortuna, each of the groups tried to dictate the situation by acting first. As a consequence, ASM International was not capable of responding adequately to the structural and sudden industrial changes.

In particular, the virtù shown by the geographical business units proved to be destabilizing. ASM Japan pushed for vertical furnaces, and ASM America for small horizontal plasma batch furnaces. Meanwhile, an effort to stimulate coherence among the subsidiaries through technology center AMTC failed to make an impact. Instead of a coherent technological answer to the divergent Japanese and American demands, ASM pursued several solutions. Meanwhile, the product groups - ASM Epitaxy, ASM Lithography and ASM Ion Implant pursued and effectuated their own opportunities irrespective of the rest of the company. Virtù was everywhere.

At the same time, management at ASM's headquarters - Arthur del Prado, the Supervisory Board, and corporate managers like Willem de Leeuw - tried to leverage the industrial changes toward a more coordinated strategy. Yet, virtù

157 Abe de Jong, Ailsa Roëll, and Gerarda Westerhuis, 'Changing National Business Systems: Corporate Governance and Financing in the Netherlands, 1945-2005', Business History Review 84:4 (2010) pp. 773-798, p. 789. 
at the headquarters initially hardly transcended that of the business units. The momentum of fortuna foremost disturbed the execution of the new more centralized business strategy. The balance tipped in favor of the business units.

Only in the wake of the second manifestation of fortuna, did the head office gain some traction. Only amidst further depressing circumstances, did ASM International gain the lead over its subsidiaries.

The first instance involved Chairman of the Supervisory Board, Paul van den Hoek. He leveraged Del Prado's personal health issues for further professionalization of corporate management. In this, the Chairman gained support from the National Investment Bank, who demanded expansion of management as a requirement for its loan. At least the Supervisory Board and financial management had to be strengthened. As it turned out, such professionalization seemed to have started just in time - if not too late already.

A second example of the head office taking the lead through its virtù came in response to the third and fourth manifestations of fortuna, in particular the Machiavellian Moment. This time, virtù was shown by the Supervisory Board and the newly appointed chief financial officer André van Rhee. Van Rhee energetically mapped opportunities and burdens for the revitalization of the cash flow and the reassurance of bankers. In a few hectic months, Del Prado, Van Rhee and the Supervisory Board took drastic measures to clean the house. ASM Lithography and ASM Ion Implant were hived off and sold. The Hong Kong operations went public as ASM Pacific Technology. Also, ASM Fico was prepared for future divestment. With the proceeds, debt was installed. Although these measures temporarily appeased the banks, they did not address the organizational deficiencies of ASM International.

After tackling the Machiavellian Moment, virtù continued to prevail at the business units. The prevalence of virtù at the subsidiaries followed from Del Prado's role as sole manager of the whole coalition of ASM groups and units. The entrepreneur allowed both the decentral operations and the head office to show virtù. He allowed this disparity in the company's process to fetter. He tended to leave unpleasant decisions involving personal relations - the managers of the subsidiaries and those of ASM International - to others. It was a sheer contrast compared to his inspiring and vigorous leadership shown when he and his managers pursued opportunities or asserted the company's competitive interests.

Virtù is bound by rationality. In the face of fortuna, an innovator responds to the most urgent obstacles only though his action. The structural and relevant premises in the mind of the innovator become apparent only though his acts. In the aftermath of the Machiavellian Moment when things returned to the old ways at ASM, Del Prado unveiled his cards. 
According to the entrepreneur, acquiescence and introspection would not help to recover ASM International. The company's existence and growth had been defined by violent proliferation, rampant pursuit of opportunities, and selfsufficient entrepreneurship. Growth was secured not through contemplation or restructuring, but through the rush forward. It would be possible to save the company's coalitions through expansion and innovation. Since the business units were the organizational bodies commanding such virtù, Del Prado tacitly gave them free rein. The subsequent revival of misery by 1992 exposed the anachronistic value of Del Prado's perception.

\section{Path}

Following the discussion of contingencies and impromptu actions, I turn to the structural dynamics in ASM - or path. Central to this was the challenge to coordinate and control the diversified and decentralized activities of ASM. In this regard, management scholar Michael Porter's appreciation of structural problems prevailing at multi-divisional enterprises seemed to be spot-on.

The business units were the bodies in the organization through which ASM competed. The diversified firm continued to struggle with competing strategies of its business units. Lacking a clear corporate strategy, their rampant pursuit of their own interests tore ASM International apart.

Porter's three tests for diversification - 'attractiveness-test' 'cost-of-entry test', and 'better-off test' - were no longer applicable for all the divisions. The costs of entry for lithography outweighed all the profits of ASM International. And in the case of ASM Ion Implant and ASM Pacific Technology, the divisions were betteroff apart than as part of the enterprise. Amidst these centrifugal dynamics, the original rationalization of the diversified activities subsided.

Moreover, the effectuation of a corporate strategy failed. Porter regarded the transfer of skills and/or the sharing of activities as ways to shape a corporate strategy. However, the first way - transfer of skills - was hampered in the cases of ASM Fico and the Hong Kong divisions, between the AMTC and the geographical divisions, and between the product groups and the rest of the company. True and portrayed differences in technology prevented the transfer of skills.

The second method for establishing a corporate strategy, by sharing activities, proved to be problematic as well. In the case of ASM, the company's sales network was a collective asset. However, ASM Asia and ASM Fico competed in Asia, and ASM America seemed incapable to operate as sales agent on behalf of the Dutch operations (ASM Fico and ASM Lithography). The insistence of ASM Japan on customization of ASM Ion Implant's product did not help either in this respect.

In the early 1990s, the company plunged again into a deep crisis. The decline of ASM's equity overtook any chance of recovery. Del Prado could no longer set out 
the strategic lines alone or in deliberate consultation with his advisors, as many stakeholders badgered him to secure their interests. It had become unequivocal that the company required a new corporate strategy, which would knit together the conflicting competitive strategies of the remaining business units. That was the task which lay ahead for Del Prado. But time was running out. 


\section{Innovation III}

\section{Innovation strategy, governmental support, and defiant realities, 1979-1993}




\section{An introduction}

In the summer of 1992, ASM International averted an inglorious end by changing its business strategy. The ensuing reorganization would define ASM for years to come. The company's various operations - ASM Japan, ASM America, and ASM Europe - were turned into product groups, each taking care of innovation, sales, and production of their respective designated product (see Business IV). The company basically began to concentrate on four products, while production of all the other ones was discontinued.

This overhaul terminated an almost herculean effort to transform ASM's innovation processes. The company did so by strongly downsizing and partly discontinuing two embodiments of this ambition. The first was the ASM Microelectronics Technology Center (AMTC), which was located in Bilthoven and set up to centralize and coordinate $R \& D$. The second was an advanced multi-chamber deposition machine, the A600, which was envisaged as a general platform for the company's newest chemical vapor deposition processes. Initially, the A600 and the AMTC were conceived as ways to solve the increasing incoherence and divergence among the company's business units. The 1992 reorganization undid both efforts again, causing ASM to return to its common innovation practices: decentralized and very much customer-driven research and development, performed individually by the various business units.

This drastic return to the company's old innovation strategy was rather conspicuous, however. Together with ASM, the Dutch government and the European Economic Community had invested millions of guilders in support of the company's new, integrated focus on innovation. Subsidies had been used to pay for half of the cost of the AMTC's establishment and the development of the A600. During the 1992 reorganization, and in the rush to save the company, Del Prado and his management had to write off these investments. The governmental involvement in the envisioned new mode of innovation had been to no avail.

Innovation III explores the influence of the Dutch government - and the European authorities - on ASM's innovation strategy. Four questions are central to my argument: why did ASM want to change its innovation process? Why did the Dutch European authorities support ASM in this ambition? How did they do so? And, finally, what was the impact of the governmental support on ASM's new innovation process? By exploring these questions, I will be able to shed light on the context and often temporary nature of governmental policies, ASM's 
specific dialogue with the authorities at various levels, and the effectiveness of governmental support for innovation in this industrial sector.

\section{Emergence of a new appreciation for innovation}

ASM's considerations for developing a new strategy for its innovation process agreed well with a reinvigorated attention for innovation emerging in the $1980 \mathrm{~s}^{1}$ In this decade, the question of how to enable innovation preoccupied the minds of scholars, public officials, entrepreneurs, industrial leaders, engineers, and civil society alike. In the capitalist economies of Japan, the United States, and Western Europe, enabling innovation evolved into a central concern, resulting in new and sometimes passionately pursued ways of managing, stimulating, and understanding innovation.

This obsession had a threefold origin. ${ }^{2}$ The first one related to the prolonged economic stagnation numbing the West throughout the 1970s. The second pertained to the declining competitiveness of Europe vis-à-vis the United States and Japan. And the third involved the seemingly successful policies underlying Japan's economic rise. These three problems called the earlier, Keynesian, economic policies and theoretical models into question.

From the late 1970s until the late 1980s, debates spiraled around the optimum interpretation and realization of the economy and the interrelated policies. New economic theories and concepts accompanied an emerging comprehension of these three developments. These new theories and concepts were most prominently articulated within the framework of neoliberalism, ${ }^{3}$ evolutionary

1 Johan Schot and Edward Steinmueller, 'Three frames of innovation policy: R\&D, systems of innovation and transformative change', Research Policy 47 (2018) pp. 1554-1567; Abe de Jong, Keetie Sluyterman, and Gerarda Westerhuis, 'Strategic and structural responses to international dynamics in the open Dutch economy, 1963-2003', Business History 53:1 (2011) pp. 63-84.

2 Wayne Sandholtz, High-Tech Europe: The Politics of International Cooperation (University of California Press, 1992); Evert Jan Velzing, Innovatiepolitiek: Een reconstructie van het innovatiebeleid van het ministerie van Economische Zaken van 1976 tot en met 2010 (Eburon, Delft, 2013); Jan Peet and Erik Nijhoff, Een voortdurend experiment: overheidsbeleid en het Nederlandse bedrijfsleven (Boom, Amsterdam, 2015); Keetie Sluyterman, Dutch Enterprise in the Twentieth Century: Business Strategies in a Small Open Economy (Routledge, Abingdon, 2005); and Annemieke Roobeek, Een race zonder finish: de rol van de overheid in de technologiewedloop (VU Uitgeverij, Amsterdam, 1988).

3 From the late seventies until the mid-eighties, theories and policies inspired by the works of John Keynes were replaced by those of Friedrich Hayek, Milton Friedman, and Joseph Stiglitz. Keynesian economics made way for neoliberalism. 
Innovation III - Innovation strategy, governmental support, and defiant realities, 1979-1993

economics, ${ }^{4}$ and national innovation systems. ${ }^{5}$ Many felt that the solution to the various economic problems was to be sought for in stimulation of innovation, in particular in the microelectronics sector. ${ }^{6}$

Political scientist Annemieke Roobeek summarizes the general perceptions as these emerged in the United States and various Western European countries throughout the 1980s:

'While there is a growing body of opinions arguing for a need to reduce the role of authorities in society and leave matters to the market,at the same time widespread consensus prevails with regard to the expansion of governmental responsibilities in technology policies. After the dismissal of defensive industrial policies of the seventies, it was up to an assertive technology policy to revitalize a bogged down economy by means of innovations. The development and application of new technologies has become key, and for some even a magical charm, to avert the economic crisis. Without exception, all industrialized countries recognize the same technologies as pivotal. These are microelectronics and information technologies, biotechnologies, and new materials. It is expected that around these technologies new innovation systems will emerge, which might boost the economy, resulting in a new period of economic growth.'

4 Economists like Richard Nelson and Sidney Winter elaborated on the work of Joseph Schumpeter, introducing evolutionary notions of variation and selection in their studies about the role of firms and technological development for economic growth. In particular technological development took center-stage in their analysis of the rise, fall, and survival of firms. - Richard Nelson and Sidney Winter, An Evolutionary Theory of Economic Change (Harvard University Press, Cambridge, 1982); Giovanni Dosi, Technical Change and Survival: Europe's Semiconductor Industry (Sussex European Research Center, Sussex, 1981); Giovanni Dosi, Technical Change and Industrial Transformation (St. Martin's Press, New York, 1984); and Franco Malerba, The Semiconductor Business: The Economics of Rapid Growth and Decline (University of Wisconsin Press, Madison, 1985).

5 Coinciding with the Japanese example of concerted - or systematic - economic policies, studies emerged about 'system theory.' These system analyses involved technological systems, or, as they were later known, 'innovation systems.' A good example is the work of Thomas P. Hughes, such as his Networks of Power: Electrification in Western Society, 1880-1930 (Baltimore, John Hopkins University Press, 1983). From the late eighties, system theory explicitly focused on national innovation systems: Richard Nelson, 'National Innovation Systems: A Retrospective on a Study', Industrial and Corporate Change 1:2 (1992) pp. 347-374.

$6 \quad$ For instance: Nathan Rosenberg and Edward Steinmueller, "The Economic Implications of the VLSI Revolution' Futures (1980) pp. 358-369.

7 Original quote in Dutch - Annemieke Roobeek, Een race zonder finish, p. 1. 
Throughout the 1980s, and in line with the abovementioned considerations, Western economies witnessed some general developments. First of all, this involved the development of new governmental support instruments to boost information and microelectronic technologies. ${ }^{8}$ In Western Europe, a most relevant region for ASM, defensive economic policies were replaced by more assertive ones, focusing on the stimulation of competitiveness and innovative capabilities. Instead of supporting weak operations and companies, subsidies became solely available for technological development, or, in one word, innovation.

Secondly, centralized and fundamental industrial research declined and was replaced by application or market-oriented development at the various business groups. ${ }^{9}$ Companies like Philips, IBM, and AT\&T downscaled their central laboratories and shifted the weight of innovation to their business groups. This was motivated by the view that too much money was lost in futile experimentation and research at central research operations of big industrial technology firms. Due to economic stagnation and, in some instances, anti-trust considerations, such a money draining operation could no longer be sustained.

Finally, institutions were established in support of the national or geographical innovation climate and local technological competitiveness. ${ }^{10}$

8 A selection of literature: Jan van den Ende, Nachoem Wijnberg, and Albert Meijer, 'Public Policy and Innovative Capabilities: The Case of Philips' IT Activities', Technology Analysis \& Strategic Management 13:3 (2001), pp. 389-405; Douglas Irwin, 'Trade Politics in the Semiconductor Industry', in: Anne Krueger (ed.), The Political Economy of American Trade Policy (University of Chicago Press, Chicago, 1996) pp. 11-72; Daniel Holbrook, 'Government Support of the Semiconductor Industry: Diverse Approaches and Information Flows', Business and Economic History 24:2 (1995) pp. 133-165; Sandholtz, High-Tech Europe; Thomas C. Lawton, Technology and the New Diplomacy: The creation and control of EC industrial policy for semiconductors (Ashgate Publishing, 1997) p. 66; Velzing, Innovatiepolitiek; Peet and Nijhoff, Een voortdurend experiment.

9 A selection of literature: Cyrus Mody, The Long Arm of Moore's Law: Microelectronics and American Science (MIT Press, Cambridge, 2017), p. 152; David Mowery, 'Plus ca change: Industrial R\&D in the "third industrial revolution"', Industrial and Corporate Change 18:1 (2009) pp. 1-50; Alan Stone, Wrong Number: The Break-Up of AT\&T (Basic Books, New York, 1989); René Raaijmakers and Paul van Gerven, Natlab: Kraamkamer van ASML, NXP en de CD (Techwatch, Nijmegen, 2016); Marc J. de Vries, 80 Years of Research at the Philips Natuurkundig Laboratorium, 1914-1994 (Pallas Publications, Amsterdam, 2005); Kees Boersma and Marc de Vries, 'Transitions in industrial research: the case of the Philips Natuurkundig Laboratorium (1914-1994)', Business History 50:4 (2008) pp. 509-529; Michael Noll, 'Bell system R\&D activities: The impact of divesture' Telecommunications Policy 11:2 (1987) pp. 161-178; Philip Roussel, Kamal Saadn, and Tamara Erickson, 'The Evolution of Third Generation R\&D', Planning Review 19:2 (1991) pp. 18-26; Jorge Niosia, 'Fourth-Generation R\&D: From Linear Models to Flexible Innovation', Journal of Business Research 45:2 (1999) pp. 111-117.

10 A selection of literature: Mody, The Long Arm of Moore's Law, pp.149-161; Christophe Lécuyer, 'What do Universities Really owe Industry? The Case of Solid State Electronics at Stanford', Minerva 43:1 (2005) pp. 51-71; Larry Browning, Janice Beyer, and Judy Shetler, 'SEMATECH 
Innovation III - Innovation strategy, governmental support, and defiant realities, 1979-1993

These were governmentally supported industrial or academic research centers performing as a platform for industrial and academic-industrial collaborations. These institutions in part compensated the loss of central research laboratories. ${ }^{11}$ Examples of industrial research consortia were Sematech in the United States, Eureka/JESSI in Europe, and IMEC in Belgium.

The main argument in Innovation III addresses the developments characterized above by zooming in on ASM. This company had long profited from the divestment of research by central laboratories, as it acquired innovative technologies at bargain prices (see Business II). At the same time, ASM would become the textbook example of the new innovation approach. Innovation at ASM used to take place in a decentralized fashion, at the subsidiaries, entailing applied research only. It was very market-oriented (cf. Innovation I). But, as will be argued here, ASM managed to make clever use of the new governmental support instruments by adopting a quite active stance vis-à-vis the new research consortia and centers. The company even became a central player in them. ASM's innovation strategies, then, were tightly linked to the historical moment of the 1980s and the new opportunities it offered.

\section{Outline of Innovation III}

Innovation III is divided into three chapters. The first chapter, Chapter 20, describes the alignment of interests between the Dutch and European public authorities and ASM from 1979 until 1984. Philips played a vital role in this arrangement as well. The common concern of these actors was the improvement of the Dutch and European economic climate, in particular for microelectronics. In Chapter 21, I discuss how from 1984 to 1988 ASM yoked governmental support to its cart. Facing increasing discrepancy among the directions and concerns of $\mathrm{R} \& \mathrm{D}$ at its subsidiaries, Del Prado and his management tried to restructure the

and the Semiconductor Industry', The Academic of Management Journal 38:1 1995) pp. 113151; Peter Grindley, David Mowery, and Brian Silverman, 'SEMATECH and Collaborative Research: Lessons in the Design of High-Technology Consortia' Journal of Policy Analysis and Management 13:4 (1994) pp. 723-758; Stephen Martin, 'Protection, Promotion and Cooperation in the European Semiconductor Industry', Review of Industrial Organization 11 (1996) pp. 721-735; Caroline Mothe, Bertrand Quélin, 'Creating Competencies Through Collaboration: The Case of Eureka R\&D Consortia', European Management Journal 18:6 (2000) pp. 590-604; Kiyonori Sakakibara, 'R\&D Cooperation among competitors: A case study of the VLSI Semiconductor Research Project in Japan, Journal of Engineering and technology Management 10 (1993) pp. 393-407; Jon B. Thornberry, 'Competition and Cooperation: A Comparative Analysis of SEMATECH and the VLSI Research Project', Enterprise \& Society 3 (2002) pp. 657-686; Johan Schot and Edward Steinmueller, 'Three frames of innovation policy: R\&D, systems of innovation and transformative change', Research Policy 47 (2018) pp. 1554-1567.

11 Mody, The Long Arm of Moore's Law, p. 152. 
company's overall innovation process. Governmental funds were deployed to implement a new innovation strategy, resulting in the AMTC. Chapter 22 details the actual realization of the new, integrated approach to innovation between 1988 and 1992 through the development of the multi-chamber A600 machine. ASM had the AMTC develop this advanced machine to meet the diverging needs of its subsidiaries by utilizing various support instruments and participating in industrial research consortia. Finally, in the Conclusions, I reflect on the influence of the Dutch government on ASM's innovation process in the 1980s. 


\title{
Chapter 20
}

\section{Economic policies and governmental support, 1979-1984}

During the period from 1979 until 1984, economic policies of the Dutch government and the European Economic Community (EEC) swung toward supporting innovation. This transformation occurred gradually, without a predetermined outcome, and was very much guided by events in and interactions with the Dutch industry. Historians Jan Peet and Erik Nijhof characterize the $20^{\text {th }}$-century Dutch economic policies as an ongoing experiment. The authors comprehend this Dutch socio-economic reality as follows:

\begin{abstract}
'Socio-economic policies have an experimental character. ... This does not mean that the government and policymakers, through a process of sheer trial-and-error, more or less hope for the best with regard to socio-economic policies. Policymakers learn, or should learn, from their mistakes and the success of policies pursued in the past. Economic scholars study and evaluate socio-economic developments. ... Economic and societal developments continuously challenge the socio-economic order and policies, for which new, not yet tested solutions have to be explored. Under these conditions, and in a tentative and searching manner, the Dutch government develops its social and economic policies. ${ }^{.12}$
\end{abstract}

To a major degree, this assessment also accounted for the policies of the European Economic Community at the beginning of the 1980s. In this period, policies turned toward the microelectronics industry in particular. Microelectronics were at the forefront of innovation, new businesses, and economic growth.

The centrality of microelectronics in the new economic policies played into ASM's hands from the early 1980s onward. During these years of 'economic experimentation,' ASM and the Dutch government found each other in their common interest to improve the competitiveness of the European semiconductor industry. Arthur del Prado positioned ASM as the pivotal representative for the European semiconductor equipment industry. As such, ASM actively contributed 
and participated in the transformation of economic policies. After discussing the transformation of the Dutch economic policies and the new policies of the EEC, I address how Del Prado managed to find and secure a sympathetic hearing among government officials.

\section{Changing tides in the Netherlands}

By fits and starts, the Dutch government changed its perspective on economic policies. This change was accompanied by one governmental white paper on innovation and two commissioned reports in the years around 1980. These reports all propagated a shift toward innovation policies, drew attention to the opportunities and risks of microelectronics, and urged for a liberalization of the economy. ${ }^{13}$ Successive new economic policies under consecutive governments led by Prime-minister Dries van Agt and his successor Ruud Lubbers - corrected deficiencies presented in these reports. More than in the past, the new policies focused on the financial support of innovation, as well as improving the marketorientation of support instruments and knowledge institutes. ${ }^{14}$

In the spring of 1983, the sudden bankruptcy of the major shipbuilder and machine manufacturer Rijn-Schelde-Verolme (RSV) sealed the fate of traditional interventionist economic policies. ${ }^{15}$ Intense involvement of the Dutch Ministry of Economic Affairs had not prevented this company 's demise and with it the loss of 18,000 jobs. In the subsequent formal parliamentary inquiry, lasting from March 1983 until October 1984, the inadequacy of the ministry's interventions was exposed most painfully.

The 1983 RSV Affair acted as a reflux valve, or, in semiconductor terms, as a diode, preventing a reflow of current. This implied in this case a blocking of a return to interventionist policies and the securing of a continuation of innovation policies. After the public indignation about their interventionist support of the shipbuilder, public officials at the Ministry of Economic Affairs were traumatized.

13 The first report was the so-called 'Innovation Note.' In October 1979, the respective Dutch ministries of Science Policy, Economic Affairs, and Education \& Science propagated an assertive attitude toward employment and economic growth through innovation. The second report was written in 1980, by the so-called 'Advisory Committee for Societal Consequences of Microelectronics' ('Adviesgroep voor de maatschappelijke gevolgen van de Micro-Electronica') or, in short, the Rathenau Committee report. This committee's findings raised awareness among the Dutch government and actors in society of the opportunities of microelectronics. The third report centered on industrial policies; it was entitled 'A new industrial élan' and was written by the Wagner Committee, consisting of captains of industry. In the summer of 1981, this committee concluded that the government should liberalize the economy. -Velzing, Innovatiepolitiek, p. 47; Interview Peter Tindemans (December 2013); Peet and Nijhoff, Een voortdurend experiment, p. 213.

14 Velzing, Innovatiepolitiek, p. 47.

15 Ibid., pp. 45 and 46. 
Innovation III - Innovation strategy, governmental support, and defiant realities, 1979-1993

Ever since, companies and industries in distress could reckon on governmental support in favor of innovation or technological development only.

\section{A European approach and the notion of precompetitive research}

Simultaneously with the Dutch transformation of economic policies, a determined Commissioner for Industrial Affairs and Energy named Étienne Davignon set out to improve the competitiveness of the microelectronics industry within the EEC. ${ }^{16}$ Davignon argued that the EEC member states should take more advantage of the common market in dealing with the rapidly changing world. ${ }^{17}$ It was no longer sufficient to rely on national champions and national markets. ${ }^{18}$

\section{Figure 53}

Graph of European, Japanese and American semiconductor market, 1980-1993

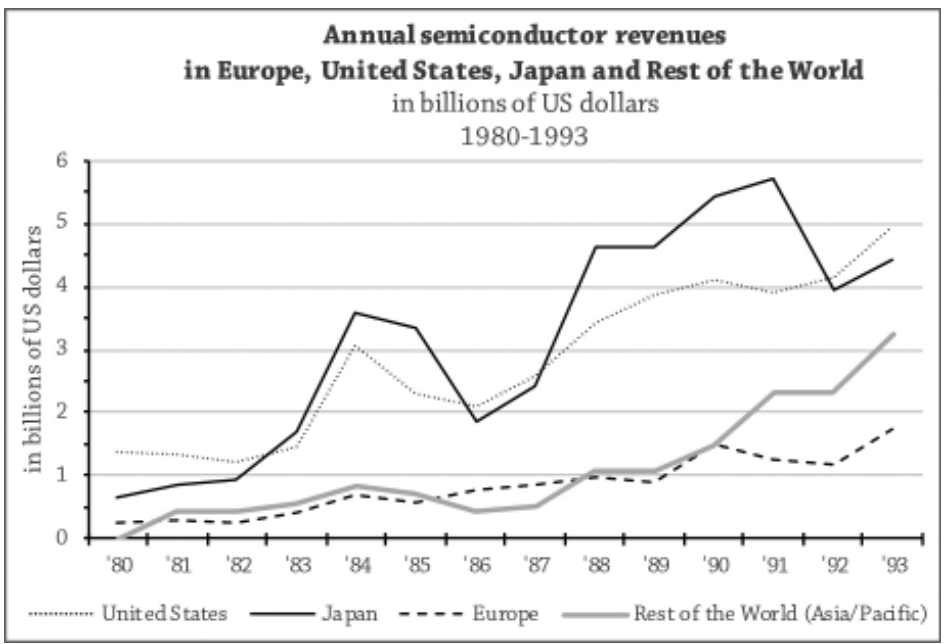

16 Davignon was the first European Commissioner for Internal Market, Customs Union, and Industrial Affairs from 1977 until 1981. Next, he was Commissioner for Industrial Affairs and Energy from 1981 until 1985.

17 Stichting Toekomstbeeld der Techniek, Etienne Davignon, 'Micro-Elektronica voor onze toekomst. Een kritische beschouwing: opening' Toekomstbeeld der Techniek 32 (1982) pp. 1-8.

18 Having experienced the demise of the European steel industry, Davignon was keen to prevent a reoccurrence of this fate for the microelectronics industry. The demise of the European steel industry under the Japanese challenge was caused by its reactive instead of proactive response to the new market realities. - Pablo Díaz-Morlán and Miguel SáezGarcía, 'The European response to the challenge of the Japanese steel industry (1950-1980), Business History 58:2 (2015) pp. 244-263. By 1978, Davignon became aware of the need for collaboration in the chip industry, through the reports of a working group called 'Forecasting and Assessment in the Field of Science and Technology', and a research group called the 'Long Lead-Time R\&D in Information Technology'. - Wayne Sandholtz, High-Tech Europe, p. 160. 
In the wake of fierce American and Japanese competition, Davignon propagated a cohesive support scheme for the microelectronics industry of the EEC countries (figure 53). Yet, structural subsidies by the EEC constituted a striking novelty, and harmonization of national differences in economic policies had to be achieved first. Through a 'Round Table' of Europe's twelve biggest corporations in electronics, the Commissioner had national champions discuss the basic premises for collaboration, encouraging them to gain backing from their national governments for a first European microelectronics policy. ${ }^{19}$ Davignon and his Round Table tried to establish a basis for cooperation and governmental support, while complying with antitrust regulations and diverging national standards with regard to governmental interventions. ${ }^{20}$

The result was the rather euphemistic notion of 'precompetitive research.' This deliberately ambiguous definition related to $R \& D$ projects quite removed from market introduction yet involving research that was applied rather than basic. ${ }^{21}$ Davignon proposed an expansive European program, which would back precompetitive research of the European microelectronics industry. Through the concept of precompetitive research, the EEC was able to grant subsidies in R\&D and, through those, stimulate industrial collaboration.

The first time the EEC put support for precompetitive research into action was the 'Microelectronic Program.' Approved in November 1981, the program was a rather modest testing ground for European collaboration. ${ }^{22}$ The program totaled 40 million ECU, or approximately 104 million Dutch guilders, which amounted at most to half of the total estimated project cost. The other half had to be paid by the companies participating in the projects. The Microelectronic Program intended to stimulate collaboration among semiconductor producers, equipment manufacturers, and universities. The program focused on design and manufacturing equipment. ${ }^{23}$ It was a first, but rather modest step in line with

19 Lawton, Technology and the New Diplomacy, p. 95.

20 Thorsten Käseberg and Arthe van Laer, 'Competition Law and Industrial Policy: Conflict, Adaptation and Complementarity', in: Kiran Klaus Patel and Heike Schweitzer (ed.), The Historical Foundations of EU Competition Law (Oxford University Press, Oxford, 2013) pp. 162-191.

21 Luca Guzzetti, 'A Brief History of European Union Research Policy', European Commission Science Research Development Studies 5 (October 1995), p. 78.

22 European Commission, CORDIS, 'PRE-MELREG C - Community Actions (EEC) in the field of microelectronic technology, 1982-1985' cordis.europa.eu (viewed 19-7-2017); Sandholtz, High-Tech Europe, p. 163.

23 It entailed the following areas: computer aided design (CAD), lithographic step-and-repeat equipment, e-beam lithography, plasma etching \& deposition, and test technologies. 
Davignon's propagated requirements, and the first example of new innovative policy design within the EEC.

After the European Council approved the Microelectronics Program, European Commissioner Davignon's plea for more substantial European initiative in support of its microelectronics industry did not subside. The Microelectronics Program was the first step toward a more comprehensive program within the EEC. Six months later, in May 1982, the Commissioner presented his next move to the European Council: the 'European Strategic Program for Research and Development in Information Technology' (ESPRIT). ${ }^{24}$ The focus of ESPRIT was much wider than the Microelectronics Program. Target areas were advanced microelectronics, advanced computing, software technologies, and office automation; but there was no mention of semiconductor production technologies. The total investment into ESPRIT - both corporate and by the EEC - amounted to 1.5 billion ECU, or 3.9 billion Dutch guilders, for the duration of five years. It was a major breakthrough for the EEC to have the European industry collaborate on such a large scale. In February 1984, the European Council approved the start of ESPRIT, completing the turnaround of economic policy design at a European level. ${ }^{25}$

\section{Del Prado takes the stage}

While the Dutch governmental reports looked promising for innovative companies like Philips and ASM, their management was not at all convinced about their outcomes. As a member of Davignon's Round Table, Philips felt that the Dutch government was not moving quickly enough. Despite all the public attention, it seemed like the Netherlands were missing the boat. Publicly and in dialogue with public officials, Philips and ASM intervened in the transformation of the Dutch economic policies.

The involvement of ASM's founder and chief executive officer Arthur del Prado with the Dutch economic climate initially began with an overture to Dutch electronics giant Philips. The immediate provocation for this move was an interview with the director of the prestigious Philips Research Laboratory, Eduard Pannenborg, in a Dutch newspaper. ${ }^{26}$ In the article, the Philips executive complained about the lack of entrepreneurship and initiative with regard to microelectronics in the Netherlands. Philips was alone, according to him.

24 Sandholtz, High-Tech Europe, pp. 167-169.

25 Ferry Mingelen, 'Informatica brengt vreugde binnen EG', Nieuwsblad van het Noorden (29-21984) p. 21; Commission of the European Communities, 'Community Actions in the Field of MicroElectronics' Technology Council Regulation (EEC) No 3744/81' (23-10-1984), p. 22.

26 H.F. van Loon, 'Wie gaat de meeste en dus de beste chips maken?' Telegraaf (31-1-1981) p. 18. 
ASM's chief executive officer and founder complemented and challenged Pannenborg's analysis. So far, Del Prado had been trying in vain to get public support for his growing company. This pertained to the Dutch government as well as Philips. Neither of them had been willing to take up Del Prado's overtures. Two weeks after Pannenborg's interview in the newspaper, Del Prado sent a letter to the Philips executive. The letter stipulated clearly the entrepreneur's position vis-à-vis the changing economic policies of the Dutch and European authorities:

'I completely agree with many of your comments, in particular your observations concerning the absence of a European industrial policy, the unremitting prevalence of national interests in Europe, the consensus in Japan about capturing a leading position in the global market for electronics, the role played by the United States, and, finally, your comments with regard to the Dutch industrial climate in relation to the lack of entrepreneurial spirit in this country. The latter is tragic in particular because various studies show that employment has to be stimulated through the development of new industries. ${ }^{27}$

Del Prado continues to applaud Pannenborg's statements about the Dutch entrepreneurial spirit, even though he politely confronted the Philips executive with the fact that he did not practice what he preached. As a national champion in electronics, Philips itself had to lead by example:

'Although we did many proposals for collaboration to Philips, time and again it was the American industry where we did find intensive support for launching almost all of our current and latest products. If you argue that the Dutch young people lack entrepreneurial spirit, I would counter that in my view Philips lacks the pioneering spirit that might co-determine the development of a Dutch 'Silicon Valley' in miniature.

Even though, as argued earlier, I fully agree with your assessment about the shortcomings at the European and national level, caused by the discord and lack of vision among politicians, I do hold the opinion that the European industrial world would gain a bigger share in microelectronics if cooperative efforts would be strengthened at the level that we can influence. This involves in particular mutual connections

27 Original quote in Dutch. - ASMI, Arthur del Prado, 'Letter to Philips, attn: Dr. Ir. A.E. Pannenborg' (16-2-1981) Archive Arthur del Prado - ASM Lithography 1983-1984. 
among European corporations, and inasmuch young or new companies are involved, companies like yours should stimulate them. ${ }^{28}$

Although the letter was politely acknowledged by Pannenborg's office, Philips did not respond. It seems that big Philips still disregarded the small Dutch company in semiconductor equipment for its size and its impetuous reputation as equipment supplier. But Del Prado had something up his sleeve, which would turn the tide and put him and his company in the spotlight.

On May 19, 1981, ASM International conducted its initial public offering (IPO) at the United States capital market for technology enterprises, the NASDAQ. ${ }^{29}$ The listing was a novelty for the Netherlands, ASM being the first Dutch company to be listed on the NASDAQ. This tour de force launched ASM into the major league, and this could not be ignored by either Philips or the Dutch authorities (see Business II).

Enjoying the new attention and admiration, Del Prado seized the opportunity to express his assessment of the Dutch climate for microelectronics publicly. In October 1981, in a page-long article in a leading Dutch national newspaper, NRC Handelsblad, Del Prado showed off his achievements and vented his frustrations about the Dutch business environment. In 'Silicon Valley at the Jan Steenlaan,' Del Prado publicly restated the argument of his letter to Pannenborg earlier that year. Deliberately, if not articulated directly, Del Prado took a sideswipe at Philips. Also, the Dutch capital market had to catch it. Still, at the end of the article, he emphasized his pride of being a Dutchman, articulating the hope that the industrial climate in the Netherlands would improve. This public announcement was a clear gesture toward the authorities and Philips of his intention to contribute to the Dutch innovation infrastructure and to help the government with its ambitions in microelectronics. ${ }^{30}$

28 Original quote in Dutch. - ASMI, Arthur del Prado, 'Letter to Philips, attn: Dr. Ir. A.E. Pannenborg' (16-2-1981) Archive Arthur del Prado - ASM Lithography 1983-1984.

29 Dean Witter Reynolds and E.F. Hutton \& Company, 'Advanced Semiconductor Manufacturing International N.V Prelimenary prospectus dated March 17, 1981' (April 1981) Archive Arthur del Prado-IPO files.

30 Two months later, in another article in a regional newspaper, Del Prado repeated his message in slightly different wordings, underlining the role of the government in support of microelectronics. - Ad van Liempt, 'ASM, Industriële vernieuwing in Bilthoven: "Deze tak bruist van dynamiek, je staat continu in de vechthouding"', Utrechts Nieuwsblad/NZC (24-12-1981) Archive Arthur del Prado - Press clippings file, p. 27. 


\section{Start of a dialogue}

Del Prado's rising star and his advances toward collaboration were not missed by the public officials of the Dutch Ministry of Economic Affairs and the Ministry of Education \& Sciences. In the aftermath of the Rathenau Committee report, and in order to formulate new policies, various working groups and reports focused on the microelectronics sector in the Netherlands. ${ }^{31}$ The government officials were interested to learn about Del Prado's opinion on the matter and included him in some of their deliberations.

In these contacts with the Dutch Ministry, Del Prado presented himself as the only legitimate conversation partner on the subject of semiconductor production equipment. ${ }^{32}$ The entrepreneur succeeded in communicating a proper understanding of his business and industry to the authorities. By September 1982, he was personally invited as a board member of the Foundation for Centers of Microelectronics (Stichting Centra voor Micro-Electronica, SCME) for a period of three years. ${ }^{33}$ The SCME was set up in response to one of the governmental advisory commissions and reports in 1980. The foundation's task was to enlighten the Dutch public about microelectronics beyond the overshadowing predominance of Philips.

For Del Prado, being a member of the SCME board offered him two benefits. First, it granted access to actual and elaborate information about the Dutch and worldwide microelectronics industry. ${ }^{34}$ And, secondly, Del Prado's membership

31 Examples of these reports are: Ministerie van Economische Zaken, H.J. Bosch, De Toekomst van IC-Productie-Apparatuur en Materialen (December 1981) Archive Arthur del Prado - EZ file; Ministerie van Wetenschapsbeleid, A.A. Th. M. van Trier, 'Regeringsstandpunt over het Rapport-Rathenau: Maatschappelijke gevolgen van de micro-elektronica,' Tweede Kamer der Staten-Generaal, zitting 1980-1981, 16407 (16-9-1980) Archive Arthur del Prado-SCME file; and Ministerie van Wetenschapsbeleid, 'Rapport van de werkgroep micro-elektronica' (March 1982) Archive Arthur del Prado - SCME file.

32 ASM, Arthur del Prado, 'Notes on letter paper', in: Ministerie van Economische Zaken, H.J. Bosch, De Toekomst van IC-Productie-Apparatuur en Materialen: Een onderzoek naar de mogelijkheden en potentiele positiebepaling van de Nederlandse industrie in de Europese markt van IC-produktie-apparatuur en materialen (December 1981) Archive Arthur del Prado - EZ file.

33 The other members were A.C. Schaik (NRM office for information supply services ), P. van Tilburg (owner engineering company), Prof. Dr. Ir. Veltman (rector Delft Technical University),Mr. van Giesen (Ministry of Economic Affairs), and Dr. Tindemans (Ministry of Education and Sciences). The board was chaired by Dr. Wolhoff (formerly of Akzo). Secretary was Nico Bel, and Director was Harrie Bosch. - Ministerie van Onderwijs en Wetenschappen, Voorlichtingsdienst Wetenschapsbeleid, 'Persbericht: Voorzitter en directeuren Microelektronica centra benoemd' (September 1982) Archive Arthur del Prado-SCME file.

34 Following the advice of the Rathenau Committee, the executive part of the Foundation focused on the generation and propagation of information about and for the Dutch microelectronics industry. The executive part of the Foundation focused on providing SME with technical support. In this effort, facilities, institutions, and companies were visited worldwide to learn about their expectations and understanding of the industry. Doors were 
Innovation III - Innovation strategy, governmental support, and defiant realities, 1979-1993

of the foundation guaranteed him access to the government, without the interference of Philips (not a member of the SCME). Through his new interactions with government officials, ASM became an active player in the transformation of Dutch economic policies.

\section{Forging a triangular relationship}

In contrast to his contacts with the government officials and despite the purported shared interest in a healthy Dutch microelectronics industry, Del Prado had to forge a relationship with Philips. This occurred by fits and starts. After the media attention, the entrepreneur came into contact with several engineers of the prestigious Philips Research Laboratories. ${ }^{35}$ While this resulted in some visits, real cooperation failed to materialize. Moreover, for the European Microelectronics Program, Philips and ASM did not cooperate. To the dissatisfaction of Del Prado and the public officials, both companies submitted proposals independently of each other. ${ }^{36}$ The ongoing animosity between ASM and Philips was counterproductive to the interests of both the government and the companies themselves.

Del Prado leveraged his new relationship with the Dutch Ministry of Economic Affairs in his flirtations with the Dutch giant in electronics. Since Philips enjoyed substantial financial support from the Dutch government, while the company had argued for more European collaboration, the Ministry had the means to urge Philips to hear ASM out. And Del Prado was persistent, countering every

opened for the semi-public officials, which remained closed for Del Prado, being a (potential) competitor. These reports were shared with the Board and supported the public reports of the Foundation.

35 So far, Del Prado had tried to get into touch with the product group for semiconductors at Philips named Elcoma, located in Nijmegen. A lot of mistrust from ASM's past as representative distorted the relation with Philips Elcoma. - ASM, Arthur del Prado, 'Letter to Philips Gloeilampenfabrieken N.V., Technical Director Elcoma, attn. Ir. A.J. Huart' (1111-1976) Archive Arthur del Prado - ASML 1983-1984 file; N.V. Philips Gloeilanmpenfabriek, A.E.T. Kuiper, 'Letter to A. del Prado, ref: AETK/pv' (23-10-1981) Archive Arthur del Prado - ASML 1983-1984 file; and Chris Werkhoven, 'Interview with author'.

36 ASM Europe's general manager Erik Kamerbeek proposed two kinds of epitaxial reactors. One was based on its horizontal plasma furnace, while another one was based on its horizontal LPCVD furnace. Total costs of the project - for bothASM and the EEC - were estimated at 1.3 million Dutch guilders. - ASM Europe, Erik Kamerbeek, 'Letter to European Commission - Director-General Internal Market and Industry Mr. Grata' (26-7-1982) Archive Arthur del Prado - ESPRIT/JESSI file;.ASM Europe, Erik Kamerbeek, 'Note to contact Mr. Grata about requesting doc. 559' (November 1981) Archive Arthur del Prado - ESRPIT/JESSI file. Philips proposed a plasma etching technology together with a Swiss equipment vendor ETEC. ASM had just rejected a deal with Western Electric's Bell Labs (see Business Chapter 2). - ASM, Erik Kamerbeek, 'Letter to Elcoma, attn.: Dr. W. Edlinger' (17-2-1982) Archive Arthur del Prado-ASML 1983-1984 file. 
argument of Philips managers against cooperation. It became more and more difficult for Philips to neglect or deny the advances of the small Dutch enterprise.

On October 7, 1982, during a meeting at the Ministry of Economic Affairs in The Hague, Del Prado finally detected an opportunity. In this meeting with the interim director-general of industry at the Ministry of Economic Affairs, Jan Hillige, and Ab de Boer, director of the Philips Science and Industry (S\&I) department, the intentions of Philips to commercialize an in-house developed lithography stepper machine were discussed. ${ }^{37}$ Philips S\&I was looking for a resourceful manufacturing partner to introduce the system to the market. Del Prado set himself up as a ministering angel.

The wafer stepper constituted the first real opportunity to have Philips and ASM collaborate, next to a procurement contract in which the semiconductor business group of Philips, named Elcoma, would purchase ASM's horizontal furnaces. After the meeting, Del Prado wrote a letter to De Boer:

'After ample consultation, I intend to confirm the position of ASM to reassure you that if Philips decides to introduce its wafer stepper into the American and Japanese markets, it could consider ASM as partner for this project after all. ... Assuming that the wafer stepper is a fairly complete engineered product, ASM will be willing to take up the "final assembly" and marketing of the stepper in America.'38

To remove any objections, he detailed how he envisaged the cooperation, from manufacturing and marketing to development. With regard to the funding of the endeavor, Del Prado suggested:

'The eventual need to attract venture capital seems no insurmountable problem to us. Perhaps the Ministry of Economic Affairs might play a role in this regard, in particular if it proves possible to substantiate the spillover effects to the Netherlands. ${ }^{39}$

37 This initial discussion followed naturally the initial discussion about the Microelectronics Program, where, among others, Philips intended to secure subsidies for 'step and repeat' and e-beam lithographic technologies. - ASMI, Arthur del Prado, 'Letter to Philips Gloeilampenfabrieken, Director of Science \& Industry, attn.: ir. A.G. de Boer’ (19-10-1982) Archive Arthur del Prado-ASML 1983-1984 file.

38 Original quote in Dutch. - ASMI, Arthur del Prado, 'Letter to Philips Gloeilampenfabrieken, Director of Science \& Industry, attn.: ir. A.G. de Boer' (19-10-1982) Archive Arthur del Prado - ASML 1983-1984 file.

39 Ibid. 
He finished his argument by ensuring that ASM did not engage speculative projects, which might result in unnecessary risk, but he also pointed to Philips' responsibilities for the Dutch microelectronics industry:

'Many speak about the leading role of Philips for Dutch microelectronics, and European collaboration is considered of paramount importance by Philips; it would be [a] pity, then, if an American partner were to be preferred, without giving the opportunity to a young but successful Dutch company with a solid American subsidiary of its own. ${ }^{40}$

Although it would take another several months to convince Philips seriously to consider ASM's proposal, a beginning was made. Del Prado knew which chords he had to play to ensure the attention and backing of the Dutch government. He emphasized that the cultivation of Dutch capabilities and knowledge in microelectronics was of strategic interest and that a collaboration between ASM and Philips constituted a most promising approach.

The receptivity for his charm offensive was confirmed in a successive letter by Hillige. The public official was content with the intended purchase by Philips Elcoma of ASM equipment, as well as in particular the considered collaboration in lithography:

'I'm positive about the intended follow-up appointment between ASM and Elcoma, for further deliberation about opportunities for collaboration. ... In the case that at a later stage matters require consultation with [the Ministry] about the possibilities for support, I will be happy to study these. ... As attentive observer of the conversation, I cannot evade the impression that an in-depth analysis of the opportunities for collaboration between ASM and S\&I might be fruitful ... To conclude, I hope that also through ASM and Philips the Dutch industry of IC-production equipment and materials may capture and retain an international position of strength. ${ }^{41}$

In his thorough study of the history of ASML, René Raaijmakers has indicated that it would take another six months before Philips would return on Del Prado's proposal. ${ }^{42}$ By September 1983, following a second public offering of ASM

40 Ibid.

41 Original quote in Dutch. - Ministerie van Economische Zaken, Director-Generaal ir. J.W. Hillige, 'Letter to ASM B.V., attn.: A. Del Prado, ref: I/MV/MEM 282/VIII/1753 79(7556)' (5-11-1982) Archive Arthur del Prado - ASML 1983-1984 file.

42 René Raaijmakers, ASML’s Architects (Techwatch, Nijmegen, 2018). 
International's stock and Del Prado's nomination of Dutch Director of the Year, both parties agreed to create a joint-venture in order to market Philips' wafer stepper technology. ${ }^{43}$ The joint-venture was named ASM Lithography. ${ }^{44}$

Finally, then, the two Dutch players in the global microelectronics market joined forces in order to propel the Dutch industry forward. The Ministry of Economic Affairs was content. Through Del Prado's persistence and the ministry's intermediation, ASM had managed to convince Philips and create a new Dutch semiconductor equipment company in the prestigious market for optical lithography. In the following years, the Dutch government continued and expanded its support for ASM Lithography. The joint-venture proved that cooperation within the Dutch economy could result in promising and highly innovative initiatives.

\section{ASM participates in the European Microelectronics Program}

In the fall of 1983, EEC officials and the Dutch Ministry of Economic Affairs tried to hook up ASM with other participants in the Microelectronics Program. ASM's original proposal had been rejected. Because the Dutch government sought to make this initial program for European collaboration a success, it combined several comparable propositions into a single viable proposal.

Three semiconductor manufacturers submitted project proposals for the development of new refractory materials. These were Plessey Research from the United Kingdom, the French-American Matris Harris Semiconductors and the French Institut National des Sciences Appliquées de Lyon (INSA). The new proposal, negotiated by the companies and authorities, centered on the development of a production method for a new material: tungsten. ${ }^{45}$ ASM was invited to develop and build the equipment for this new process.

43 ASMI and Philips, 'Fourth Draft of Ontwerp Letter of Intent voor samenwerking tussen ASM en Philips, ref: DB2-4-776 WT/TB' (5-9-1983) ) Archive Arthur del Prado - ASML 1983-1984 file.

44 Initially, the joint-venture was named ASM Lithographic Systems (ALS). As this abbreviation also referred to a horrible chronic disease, the name was changed to ASM-L.

45 By the mid-eighties, the smallest interconnections of computer chips just above the transistor gate could no longer be made of polysilicon or aluminum. Electrical resistance of these materials limited transistor speed. Tungsten was the solution, also because of its favorable adhesion, chemical resistance, and etch properties. While the European project was approved, Hewlett Packard announced its first chip containing tungsten interconnecting films, grown in an in-house developed piece of equipment. In the same year, 1983, a start-up equipment vendor called Genus introduced a dedicated tungsten LPCVD system dubbed the Genus 8301. - Dataquest, 'Markets and Technology: Chemical vapor deposition' Semiconductor Equipment and Materials Service (26-9-1985) p. 22, Nielsen Dataquest, 'Research Newsletter: chemical vapor deposition' Dataquest (12-8-1985) p. 9. 
In the fall of 1983, the EEC approved the project. ${ }^{46}$ It was granted 1,169,000 ECU, or about 2.97 million Dutch guilders, which was matched by investments of the participating companies. ${ }^{47}$ The grant covered the construction of an LPCVD and plasma CVD furnace for tungsten processes for Plessey and INSA. ${ }^{48}$

Despite the historical importance of the first governmentally supported European research project, the tungsten CVD development did not enjoy the particular interest of ASM. The manufacturer of furnaces placed its bets on its own unique compatible aluminum CVD process (see Chapter 10). Above all, ASM tried to present itself as a constructive partner toward the authorities.

46 It was called 'Project MR-11-ASM: Development of a refractory metal deposition process and related equipment', and commenced December 1983 lasting until May 1987 - ASM Europa, Hans Hanekamp, 'Minutes of Meeting: Tungsten LPCVD-1' (22-2-1984) Archive Arthur del Prado-ESPRIT/JESSI file; and EU Cordis, "Project MR-11-ASM: Development of a refractory metal deposition process and related equipment'.

47 Commission of the European Communities, 'Community Actions in the Field of Microelectronic Technology Council Regulation EEC No.3744/81’ (2-2-1987), p. 34.

48 Initially, hot-walled LPCVD batch reactors were investigated for the growth of metal interconnections at the smallest dimensions - just slightly larger than the MOS transistor. For ASM, being an established manufacturer for horizontal LPCVD furnaces, this technology also represented the most obvious route. The semiconductor manufacturers in the project would develop the integration of the process and material. ASM merely had to build the equipment and enable the process according to the specifications of the partners INSA and Plessey. - ASM Europe, Peter Schumbera, 'Interim Report Tungsten LPCVD' (27-12-1983) Archive Arthur del Prado - ESPRIT/JESSI file. 


\section{Chapter 21}

\section{A new innovation strategy, 1984-1988}

Through the intense interactions with Philips and ASM, the Dutch authorities gained a better appreciation of the role of the equipment industry. This recognition resulted in substantial support schemes, in the Netherlands as well as in context of the EEC. The increase in governmental support for microelectronics coincided with that of the competing American and Japanese authorities and, as such, it was a deliberate effort to halt the decline of European competitiveness. ${ }^{49}$ This involved the so-called 'Mega-project' of Philips and Siemens, set up with support from the Dutch and West-German governments in $1984 .{ }^{50}$ Furthermore, several generic support instruments became available. ${ }^{51}$ By the mid-1980s, the Dutch government was undisputedly committed to its ambitions in microelectronics.

Del Prado deployed this governmental commitment - and his new relation with Philips - in support of a new corporate innovation strategy. ASM grew

49 According to Dataquest, the share of European companies in the worldwide semiconductor market decreased from 27 to 19 percent in the period from 1979 to 1985. - Dataquest, 'Semiconductor Equipment and Material Systems Industry Econometrics: European Semiconductor Manufacturing' (July 1986), p. 1.

50 Theintention was todevelop and produce, in small volumes, 1M SRAM chips using the latest wafer size, i.e. 150 millimeter. In addition, Philips built a production fab in Nijmegen, Fab 87. Both fabs were supposed to use the newest available process technologies, in-line controls, and wafer handling automation. The total investments for the program amounted to 1.5 billion guilders, of which the Dutch government contributed about 190 million guilders. The German Federal government supported Siemens through 300 million DM. The program included the construction of a complete new pilot line, using state-of-the-art technologies on the premises of Philips Research Laboratories in Waalre (WAX building), near Eindhoven. In its scope and resources, the Mega-project was ambitious and bold. - Tweede Kamer der Staten-Generaal, Minister van Economische Zaken G.M.V. van Aardenne, 'Brief van de Minister van Economische Zaken, ref: 18600, nr.15.' Vergaderjaar 1984-1985: Rijksbegroting voor het jaar 1985 (11-10-1984).

51 For instance, Innovation Incentive Regulation (INSTIR, or 'Innovationstimuleringsregeling'), Innovation Centered Research Programs (IOP, or 'Innovatiegerichte Onderzoeksprogramma'), and Research of Focus Areas (ROAG, or 'Research op Aandachtsgebieden'). Through the INSTIR-instrument, introduced in 1984, the Ministry of Economic Affairs subsidized part of the salaries of R\&D employees after the project's conclusion. Originally, the ROAG was called 'Advancement of High-Quality Industry and Services' (Bevordering van hoogwaardige industrie en dienstverlening). The ROAG directly funded development in certain strategic areas from 1985 onward. Furthermore, a subsidy tool from the 1950s, the Technology Development Credit (TOK), was strengthened. 
rapidly throughout the early 1980s, offering all major semiconductor production technologies. The company was on its way to become a semiconductor powerhouse. The entrepreneur rightly assessed that such a status, in an industry driven by technological development, had to be substantialized by a genuine and solid innovative capability. After all, noblesse oblige. ${ }^{52}$

Despite all their commercial benefits, ASM's decentralized, market-driven, and opportunistic innovation processes were not efficient or reliable. ASM's operations were often unaware of the developments at other subsidiaries. A phenomenon called the 'not-invented-here-syndrome' prevented quick dispersion of knowledge and technology among the company's different operations. Moreover, their interests, and thus their activities and developments, increasingly diverged. For these reasons, Del Prado contemplated the establishment of a corporate center that would support the decentralized research and development activities at the subsidiaries. ${ }^{53}$ He intended to leverage governmental funds for this purpose. ${ }^{54}$

\section{ASM Micro-Electronics Technology Center}

Throughout the spring and summer of 1984, Del Prado, together with his Director of Technology, Willem de Leeuw, and ASM Europe's general manager Erik Kamerbeek, developed an ambitious plan for a technology center in Bilthoven. ${ }^{55}$ As noted in the proposal:

'In this Center, which we intend to name ASM Micro-Electronics Technology Center (AMTC), various technological disciplines will

52 Cf. the assessment made by ASM Lithography's general manager, discussed in Business II - ASM-Lithography, Gjalt Smit, 'Letter to Arthur del Prado' (14-1-1985) Archive Arthur del Prado-ASML 1985 file.

53 Del Prado and De Leeuw envisaged two ways originally. One was to establish a corporate $R \& D$ center in Phoenix. The other was to strengthen the local $R \& D$ centers at each of the subsidiaries. The availability of Dutch government funds flipped the coin to a corporate R\&D center, to be located in the Netherlands. - ASMI, Willem de Leeuw, 'Memorandum: R\&D Centers' (4-7-1983) Archive Arthur del Prado - Willem de Leeuw file.

54 During a first meeting, ASM's proposal for such a center was discussed in concordance with an ostensibly similar idea developed by Technical University of Delft. Both plans elaborated upon the advice in the Rathenau Committee report for an application laboratory in the Netherlands. - Directorate Research and Development of Ministry of Economic Affairs, Dr. L.S.J.M. Henkens, 'Letter: Overleg ASM-THD-EZ, ref: I/RO/ARB/248/IV/736 7975524' (114-1984) Archive Arthur del Prado - AMTC files; ASMI, Arthur del Prado, 'Letter to Ministry of Economic Affairs, Drs. B.J.M. Giesen’ (16-5-1984) Archive Arthur del Prado - AMTC files; Delft University of Technology, S. Middelhoek, 'Delfts Atelier voor Schakelingen en Sensoren (DASS): Korte samenvatting’ (date unknown) Archive Arthur del Prado-SCME file, p. 2.

55 ASMI, 'Voorstel voor de vestiging van een Technology Center t.b.v. de micro-elektronica.' (30-3-1984) Archive Arthur del Prado - AMTC files. 
be combined at a state-of-the-art level, such as solid source physics, chemical technology, metallurgy, electronics, optics, robotics, etc. In this context, it will be essential to use the knowledge and skills presently available in the Netherlands, and this, in turn, can have major positive effects on the surrounding environment. ${ }^{56}$

The purpose of the AMTC was as follows:

'For multiple reasons, it is desirable to join our forces in the realm of $R \& D$. First, the required efforts for the development of more advanced and complex equipment are beyond the independent capabilities of the respective subsidiaries, while such separate developments result in fragmentation and inefficiencies as well. The AMTC will offer the opportunity to coordinate the research and development activities of ASM strategically and substantially, while enhancing and expanding the synergy of knowledge and experience at our American, East-Asian, and European operations. ${ }^{57}$

In addition, the AMTC was meant to have a 'pilot line' to align its equipment and material innovations with the development laboratories of customers and also to be able to evaluate these innovations. ASM intended closely to cooperate with Dutch universities and academies as well.

ASM estimated the cost of such a center to be about 75 million guilders for a two-year period, to which operational expenses had to be added. ${ }^{58} \mathrm{ASM}$ mentioned operational costs of about 20-40 million guilders annually, in the case of a total staff of about fifty. The investment cost comprised all the semiconductor equipment, from lithography and CVD to metallization and encapsulation. Furthermore, it included 20-25 million guilders for the construction and facilities of a building.

The report mentioned that these investments went beyond the available budget of ASM. This is why the company intended to invest $1 \%$ of its sales in the AMTC annually, which was estimated to be about 5 million guilders. The rest had to be paid by the government, taking into account the significant returns on the investment for Dutch society following from this support.

56 Original quote in Dutch. Ibid.

57 Original quote in Dutch. - ASMI, '2nd version - Voorstel voor de vestiging van een Technology Center t.b.v. de micro-elektronica.' (30-3-1984) Archive Arthur del Prado - AMTC files

58 The original plan even amounted to 90 million guilders, as well as proposinga staff of about 100 to 200 people. In this new version, these numbers were tuned down significantly. 
Innovation III - Innovation strategy, governmental support, and defiant realities, 1979-1993

The government official in charge, Ben Giesen, did not respond unfavorably to the AMTC proposal. ${ }^{59}$ But he indicated that the governmental support be temporary, lasting only five years or so. Moreover, before the ministry could pledge support, an external advisory institute had to evaluate the plan. ${ }^{60}$

In the fall of 1984, ASM's proposal was evaluated and rewritten a first time. ${ }^{61}$ The evaluation report acknowledged the dispersed state of ASM's R\&D, an undervalued reputation of the Dutch equipment manufacturer with its customers, and a lag in starting joint-development programs for the state-ofthe-art manufacturing techniques with customers. There were doubts about the equivocal purpose of the AMTC as R\&D laboratory and 'showroom.' Likewise, ASM's level of ambition was questioned:

'The broad product portfolio of ASMI requires an extensive effort to consolidate its current position. After all, the competitors of ASMI some with similar sales - spend similar percentages of their sales on $\mathrm{R} \& \mathrm{D}$ for one or at maximum two product groups.' ${ }^{6}$

Other criticism involved the distinction between $R \& D$ and application lab, the hiring of $\mathrm{PhD}$ candidates for $\mathrm{R} \& \mathrm{D}$ work, and alternative funding schemes of the AMTC beyond the use of subsidies. ${ }^{63}$

59 Van Giesen was also a member of the SCME, as was Arthur del Prado. - AMSI, Willem de Leeuw, 'Telex to Arthur del Prado: AMTC' (4-7-1984) Archive Arthur del Prado - AMTC files; Directorate-General Industry of Ministry of Economic Affairs, ir. J.W. Hillege, 'Letter to Arthur del Prado: Technologie-centrum van ASM, ref: I/LE/EIE/284/VI/10015/79-1681’ (24-7-1984) Archive Arthur del Prado - AMTC files

60 This was the Central Institute for Industrial Development (Centraal Instituut voor Industrieontwikkeling, CIVI). Simultaneous with the AMTC proposal, CIVI studied the support project proposals for ASM Lithography and ASM Fico. ASM-Lithography secured both TOK and INSTIR support for its operations. Earlier in the seventies, Fico obtained a TOK for one of its products. In the eighties, for the development of its first automated molding system, called AMS-480, ASM Fico used the TOK instrument again. - Richard Fierkens, Hightech in een boerendorp: de biografie van Fico-ondernemer Richard Fierkens (Uitgeverij Fagus, Aalten, 2014) pp.159-160; and Richard Fierkens, 'Interview with author'.

61 CIVI, Drs. A van der Schuyt, 'Letter to Willem de Leeuw, ref: sch/dv/899' (7-11-1984) Archive Arthur del Prado-AMTC files.

62 CIVI, Drs. A van der Schuyt, 'Letter to Directorate Research and Development of Ministry of Economic Affairs, Ir. JAPM Smeekens: ASMI/AMTC, ref: b1/dv/1031' (14-12-1984) Archive Arthur del Prado-AMTC files.

63 Del Prado was all but pleased with the evaluation report. It sketched a too negative image of ASM, which antagonized the founder with his solid marketing instincts. The strengths of ASM were hardly mentioned. In their reply to Del Prado, CIVI acknowledged their critical assessment.- CIVI, Drs. A van der Schuyt, 'Letter to Willem de Leeuw, ref: sch/dv/899' (711-1984) Archive Arthur del Prado - AMTC files, p. 25. 
In response to the concerns, Del Prado hired the executive director of the Foundation Center for Microelectronics (SCME), of which he was himself a board member, to prepare the official application of ASM for support of the AMTC. ${ }^{64}$ These preparations involved an extensive benchmark study about comparable microelectronics research laboratories in the United States and Western Europe. It was expected that the final application for support would take a few months. The intentions underlying the AMTC gained new appreciation due to a sudden manifestation of fortuna.

\section{A whole new ballgame}

The global surge of the chip industry came to an abrupt halt in the fourth quarter of 1984. The American and Japanese competition in the market for memory chips resulted in overcapacity. The supply of memory chips outpaced the demand. In the fall of 1984, this situation caused most memory producers to cease production and halt investments in new production lines. The consecutive downturn in the market for semiconductor equipment proved to be a watershed for the technological and industrial dynamics.

The 1984 downturn gave rise to two effects, which became gradually apparent in the following years, up until 1987 (see Business III). The first effect was a geographical divergence in chip technologies. Japan continued with memory, while the United States - and Europe to a lesser extent - decreased their ambitions in this market, if not quitting it altogether. The second effect was an acceleration of innovation of production technologies. Almost the whole industry used the intercession to prepare for the next surge in the market. Traditional production techniques were replaced or altered rapidly.

The crisis pressured ASM's decentralized innovation process and increased the need for central coordination. Due to the divergence in technology across the geographical markets, the interests of ASM's subsidiaries hardly aligned anymore. This deviation hindered ASM's innovative clout. Making use of the pause in the industry, and in anticipation of the diverging interests of his subsidiaries, Del Prado pushed through the plans for a development center. While ASM was already fully engaged in multiple advanced technological developments, in particular the new lithography joint-venture, governmental support became indispensable. This dependency aggravated as the industry crisis deepened, and this in turn caused the subsidies to become the driving force of ASM's new innovation strategy.

64 Stichting Centra voor Micro-Elektronica, J.A. Wolhoff, 'Letter to Del Prado: Werkzaamheden Ir. H.J. Bosch in kader AMTC plan' (11-12-1984) Archive Arthur del Prado - AMTC files. 
Innovation III - Innovation strategy, governmental support, and defiant realities, 1979-1993

\section{The embodiment of a new course}

While the downturn in the market deepened during the fall of 1984 and the first six months of 1985, ASM and its consultant worked out the AMTC plan in close harmony with the authorities. ${ }^{65}$ By visiting various new centers in the United States, ASM was able to list the requirements for the AMTC and future chip technology. ${ }^{6}$

The Dutch government and ASM were not alone in their ambition to support the local microelectronics industry. Across the globe, industrial and academic technology centers had been established. This happened in the United States, but also in the Netherlands, where universities espoused similar ambitions. Even in Belgium, which hardly had a microelectronics industry, the Flemish authorities started a center named IMEC, setup near the University of Leuven in $1984 .^{67}$ By the early 1990s, IMEC rapidly developed into a prestigious institution for the industry and ASM. The AMTC was very much in line with this general development of emerging technology centers.

In the spring of 1985, the new, much more detailed, proposal was finished. The proposed budget for the establishment of the AMTC amounted to 80 million Dutch guilders, with annually 11 million for operational expenses. This sum

65 ASMI, Ernst Granneman, H.J. Bosch, Willem Enzing, 'Various Visit Reports' (JanuaryFebruary 1985) Archive Arthur del Prado - AMTC file.

66 ASM visited multiple centers, such as the Center for Submicron Technology at Cornell University, the Rochester Institute of Technology, the Center for Integrated Systems of Stanford University in California, the Microelectronic Center of North Carolina, and International Microelectronics Products (IMP) in San Jose, California. Moreover, the consultant visited competitors such as the Applied Materials Technology Center and Eaton. - ASMI, Ernst Granneman, H.J. Bosch, Willem Enzing, 'Various Visit Reports' (JanuaryFebruary 1985) Archive Arthur del Prado - AMTC file.

67 After lobbying by professors at Technische Hogescholen (now Universities of Technology), the Ministry of Education and Science (O\&W) signaled that perhaps around 100 million guilders might be available for chip manufacturing facilities for applied research. The chair of the SCME and Peter Tindemans (Ministry of Education and Science) decided to explore the option of turning IMEC, whose development had just begun, into a joint Flemish-Dutch application center. Professor Rogier van Overstraeten, who had been charged by the Flemish government to establish and lead the new institute IMEC, would be in favor, but for political reasons this proposal was rejected by the Dutch Minister of Education and Science, Wim Deetman. It would be a tough sale to invest this money abroad, while the pressure was huge to invest it in the Netherlands. - Peter Tindemans, 'Interview with author'; The Flemish authorities - not the Belgian - decided to invest in microelectronics as part of their strategy toward the Third Industrial Revolution in Flanders (the DIRV White Paper) and were willing to support it generously for the longer term. IMEC was granted around 125 million guilders in support and hired around 100 scientists. - Flemish Government, author unknown, 'Proposal: Ontwikkeling van de Micro-Elektronica in Vlaanderen, sent to members of SCME' (3-121982) Archive Arthur del Prado - SCME file. IMEC would cooperate with Philips and most major foreign chip manufacturers by the late eighties. 
included the construction of a cleanroom, estimated at a total of 30 million guilders. ASM would gradually increase its contribution to the total cost from inception in 1985 until 1992.

The new proposal also described the projected technological research to be performed by the new facility, covering all of ASM's products and more. This entailed work on lithography and mask making for ASM Lithography, improving diffusion systems, preliminary work on plasma etching, gas handling, and test equipment. Initial research would focus on an advanced automation project, new metallization CVD techniques, and new configurations of plasma and low pressure CVD furnaces.

After another round of evaluations and endorsements, the new proposal met with approval. In September 1985, the Dutch Minister of Economic Affairs, Gijs van Aardenne, informed the Dutch Parliament about his decision to support ASM's AMTC with a total of 38.6 million guilders, paid out of the 'Advanced Industry' and 'Research of Focus Areas' funds.$^{68}$ The remaining operational cost of AMTC would be paid for by the various ASM subsidiaries, in particular ASM Europe, and a new bank loan. ${ }^{69}$

With the support granted, ASMI immediately moved forward by approaching real estate developers..$^{70} \mathrm{ASM}$ Europe's original and former R\&D manager Martin van Beest began to plan construction of the AMTC building. His successor, Dr. Ernst Granneman, became R\&D manager, while former ASM Europe general manager Erik Kamerbeek took care of the administrative management of the AMTC. The center as a whole became a subsidiary of ASM International, the holding office, and as such a responsibility of Willem de Leeuw, ASM's Director of Technology.

Furthermore, Granneman increased the center's prestige through an ASMsponsored chair in vacuum processes at Delft Technical University. Moreover, the center established close relations with the AMOLF institute, located in

68 The Dutch names of the funds were 'Hoogwaardige Industrie' and 'Research op Aandachtsgebieden' (ROAG) - Ministry of Economic Affairs, Gijs van Aardenne, 'Letter to Voorzitter van de Tweede Kamer der Staten-Generaal; ref: I/RO/OPC/285/IV/1277 797036’ (6-9-1985) Archive Arthur del Prado - AMTC files.

69 ASM obtained a 30 million-dollar subordinated loan from the National Investment Bank (Nationale Investeringsbank, NIB), secured by the Dutch government, for a period of fifteen years, on December 24, 1985. This loan was meant for the funding of ASM-L and the AMTC. Another potential source of credit, the government's venture capital MIP, was out, as ASM was considered too big to be eligible for venture capital. - Nationale Investeringsbank N.V., 'Letter to Advanced Semiconductor Materials N.V., ref: 117-F7, Dossier 36879' (24-12-1985) - Archive Arthur del Prado - NIB file.

70 These were Van Boxtel \& Touber, the same team that took care of the ASM Lithography building ASM Europe, Ernst Granneman, 'Memorandum: Bezoek bouwteam van Van Boxtel \& Touber, 5 sept 1985' (5-9-1985) Archive Arthur del Prado - AMTC files. 
Amsterdam and led by an acquaintance of Del Prado, Frans Saris. After one year of preparation, work on the key structure of ASM's new innovation strategy was underway.

\section{Appropriating the envisaged role of pivot}

The establishment of the AMTC was right on time. In the fall of 1985, it became apparent that the traditional horizontal CVD machines might not be needed in the production of the next generation of computer chips (see Business III). These machines had fostered the growth of the Japanese, American, and European ASM subsidiaries. This is why their imminent obsolescence would possibly rock the foundations of ASM. A cohesive and decisive answer had to be formulated, which was right up the AMTC's alley.

However, the new innovation strategy of ASM was not a foregone conclusion. Any answer formulated by the AMTC - and, consequently, its role as pivot was all but easily accepted by the various other actors within the company. The technological demands of the operations diverged to such an extent that any solution would be a compromise. But such a dilution in response to local customer demands was impossible in the highly competitive and technologically advanced chip industry. If the AMTC was to succeed in coordinating and strengthening ASM's innovative clout, it had to meet all the diverging interests without compromising - a challenge impossible to overcome without innovation.

Immediately after its establishment, the AMTC engineers had to take care of a range of tasks. Specifically this work concerned the revitalization of the aluminum CVD process of ASM Europe, the tungsten CVD project of the Microelectronics Program, new reactor development, studies into fiber optics, mass flow controller development, and a comprehensive computer aided manufacturing system, called ACAMS ${ }^{71}$ However, the real opportunity to improve mutual cohesion among the operations would be tied to the development of a new plasma CVD machine.

After the downturn of the memory market in the fall of 1984, customers expected different replacements of the traditional horizontal furnaces in Japan, Europe, and the United States (see Chapter 18 for more details). Initially, ASM Japan was asked by its customers to develop a vertical batch machine, while ASM America wanted to develop a smaller batch or even a single wafer CVD machine. At the same time, ASM still enjoyed healthy prospects for the existing machines. Developing and maintaining three different plasma CVD machines was out of the question.

71 ASMI, Willem de Leeuw, 'Memorandum: New Projects and ASM role as a company' (10-31986) Archive Arthur del Prado - Willem de Leeuw file. 
In the fall of 1985 and throughout 1986, De Leeuw and the AMTC staff intermediated and tried to come up with a comprehensive solution. ${ }^{72}$ Time was limited, as ASM Japan had been losing terrain and was missing out on the rapidly growing market for vertical CVD furnaces. If ASM was to compete with a vertical furnace, it had to devise a new plan rather quickly. After all, developing, manufacturing, and introducing a completely new vertical machine took time - much more time at any rate than a rather easy scale-down of a horizontal machine, as envisaged by ASM America.

De Leeuw cut the knot. ${ }^{73}$ In order to have ASM Japan serve its customers unimpededly, a coherent and sustainable solution was pursued. The AMTC would develop a central loading system, while simultaneously developing a new vertical aluminum CVD process module. ASM Japan was going to work on a vertical CVD module as well, either for plasma or low pressure CVD. Each of the modules would be integrable with the central loading system of the AMTC. In other words, ASM would pursue a single platform on which the subsidiaries could integrate and develop their own processes.

The job ahead for the AMTC engineers was clear. It was up to them to develop the comprehensive central loading system and the compatible vertical aluminum CVD process. If they succeeded in doing this in an acceptable way for all the operations, the AMTC would prove its practicability. Moreover, it would prove the viability of the new innovation strategy of ASM, set out by the management of the holding company in Bilthoven.

\section{Earning AMTC's keep}

Aside from the technology, the funding of the AMTC continued to be source of concern. By the time the technology center was approved and established, in the fall of 1985, the operational units began to suffer huge losses. ASM America had to lay off hundreds of employees to cope with the decline in demand for its horizontal plasma furnaces. By 1986, ASM Europe followed as well. ${ }^{74}$ To relieve the Bilthoven operation and to enable a swift start of the AMTC, ASM Europe's R\&D operation was transferred to the AMTC. Yet the severe cutbacks

72 ASM America, Dick Rosler, 'Memo: Your request for comparison of George's small footprint system for LPCVD/Diffusion versus a vertical system approach' (30-12-1985) Archive Arthur del Prado - Vertical furnaces file.

73 ASMI, Willem de Leeuw, 'Memorandum: Vertical Reactor Development' (3-7-1986) Archive Arthur del Prado - Vertical furnaces file.

74 In total 350 employees were laid off. This initially entailed about 200 employees in the United States and around 100 of ASM Europe. - Author unknown, 'ASM verdrievoudigt verlies tot f 61,7 mln, omzet dealt met 7pct', NRC Handelsblad (31-3-1987) p. 13. 
and reorganizations at the business units and the heavy expenditures for the technology center gave rise to envy among the various subsidiaries.

Moreover, ASM's cash flow from the subsidiaries toward the AMTC ran dry. The operations did not have a nickel or dime to spare. Del Prado increasingly had difficulties in matching the investments made by the Dutch government. Having already taken up a bank loan to fund the new center, ,more governmental support was hardly available. ${ }^{75}$ The AMTC was temporally moved to a building of ASM Europe at the Rembrandtlaan in Bilthoven. The development and construction of a new building was paused, as was the construction of a pilot line. Ambitions were lowered indefinitely.

In the summer of 1986, ASM failed to join a recovery of the market. Yet, even though the pressure mounted, the need for the company's central laboratory was still there. Del Prado and his managers even deemed the new center indispensable for the company's technological future. He urged De Leeuw to tap into other sources of funding, wondering whether there were any opportunities with the European authorities in Brussels:

'In view of earlier discussions about our ineffectiveness to develop subsidies with various authorities, keep track of them, also because these outside sources exist to provide support in this effort. ${ }^{76}$

Del Prado's note marked the start of ASM's active campaign for European support. ${ }^{77}$ Through European subsidies, ASM was able to continue the AMTC and realize the overhaul of its innovation process.

\section{AMTC and ESPRIT II}

As a participant of the European Microelectronics Program, ASM was in touch with the public officials of the European Economic Community. While the Bilthoven company did not participate in the more comprehensive ESPRIT program, it was invited to join workshops. ${ }^{78}$ In 1986, some of those workshops

75 ASM-L and ASM Fico made use of a governmental venture capital scheme, but the support instrument used for the AMTC could not be extended or expanded. The MIP, a governmental venture capital facility, was not applicable. - J. Bakker, 'ASM zoekt tevergeefs naar Nederlands geld voor ambitieuze groeiplannen', Economisch Dagblad (23-2-1987) - Archive Arthur del Prado - News articles.

76 Original quote in Dutch. - ASMI, Arthur del Prado, 'Memorandum: subsidies' (29-9-1986) Archive Arthur del Prado - Willem de Leeuw file.

77 AMTC, Erik Kamerbeek, 'Memorandum: Bezoek Drs v/d Harst en dr. Hartmann, Ministerie van Economische Zaken' (7-3-1988) Archive Arthur del Prado-AMTC files.

78 In September, 26 1985, Granneman participated in an ESPRIT Technical Workshop called 'New Trends in VLSI Patterning' in Brussels. It was foremost organized and chaired by British 
explored the interests of the European microelectronics industry in the successive ESPRIT II program, which was expected to commence by 1987 or $1988 .{ }^{79}$

As the scope of ESPRIT II became clear, it also became evident that it would not automatically involve the semiconductor equipment industry. ${ }^{80}$ Throughout 1986 and 1987, the management of the AMTC (De Leeuw, Granneman, and Kamerbeek), together with staff from ASM Lithography, argued and lobbied for the inclusion of the equipment industry in the forthcoming program. ${ }^{81}$ This was done through efforts by Dutch officials and by Siemens and Philips. These ASM customers supported its EEC lobby through their position at the Round Table, because they depended on ASM's technology and had stakes in securing ASM's technological competence.

From 1986 until 1988, the AMTC operated as a mouthpiece for the European semiconductor equipment industry. By writing position papers, proposals, lobbying, and participating in workshops, the AMTC managers made sure that the European authorities did not neglect the equipment industry. After all, it was in ASM's interest to enlarge the addressable source of subsidies. In pursuit of funding, and to prove its viability, the AMTC became the flag-bearer of the European semiconductor equipment industry.

Slowly, ASM succeeded in expanding support for semiconductor equipment and materials within the forthcoming ESPRIT II program. The European bureaucracy at the EEC, which seemed to give priority to complex political considerations, determined the scope of the ESPRIT program. ${ }^{82}$ In ESPRIT II,

universities. Three equipment vendors were present: ASM, Electrotech, and Cambridge Instruments. During the event, the position of the European semiconductor equipment industry was discussed. - ASM Europe, Ernst Granneman, 'Memorandum: ESPRIT Technical Workshop "New trends in VLSI Patterning"' (6-10-1985) Archive Arthur del Prado - ESPRIT/ JESSI file.

79 ASM Europe, Ernst Granneman, 'Memorandum: ESPRIT II workshops on February 5 and February 20,21 1986' (28-2-1986) Archive Arthur del Prado - ESPRIT/JESSI file; ASM Europe, Ernst Granneman, 'Memorandum: ESPRIT II workshops on October 2 and 3, 1986' (7-101986) Archive Arthur del Prado - ESPRIT/JESSI file;. Although the first ESPRIT program was meant to last until 1989, discussions about its successor started earlier than expected. The European Commission had already allocated all the ESPRIT funds by the end of 1985. As commented by Wayne Sandholtz in this context: 'to preserve the momentum achieved under the first phase, the second should begin in 1987, two years earlier than originally planned.' - Sandholtz, High-Tech Europe, p. 192.

80 ASM Europe, Ernst Granneman, 'Memorandum: ESPRIT II workshops on October 2 and 3, 1986' (7-10-1986) Archive Arthur del Prado - ESPRIT/JESSI file.

81 This were Mr. Cadiou and Mr. Tsalas. - ASMI, Willem de Leeuw, 'Memorandum: Visit report HQ, Brussels, ref: 88.188/WdL/jdk' (5-5-1988) Archive Arthur del Prado - Willem de Leeuw file.

82 Organizing ESPRIT II involved extensive tug-of-war among the member states, as it had to be fitted in the new Single European Act and the first Framework Program. Getting it approved in a timely matter was challenging enough already. 
ASM and a few other equipment manufacturers were allowed to participate. This ensured some ongoing EEC support for the semiconductor equipment industry, as the Microelectronics Program was about to be finished by 1987.

By April 1988, with a slight delay, ESPRIT II was approved as part of the European Framework Program. The EEC received over 1000 proposals after an official request for proposals in the fall of $1987 .{ }^{83}$ In the end, 156 proposals were selected, involving 585 organizations, with 58 Dutch projects winning approval within the ESPRIT II program. Around 1.6 billion ECU had to be allocated for the first round. ${ }^{84}$

\section{AMTC and JESSI}

This new role of ASM as representative of the European semiconductor equipment manufacturers was not limited to the negotiations involving ESPRIT II. Another effort was a new European intergovernmental research consortium, named 'Joint European Submicron Silicon Initiative' (JESSI). This program succeeded the original bilateral 'Mega-project' of Philips and Siemens and their respective national governments, aimed at narrowing the European lag in memory chip technology. ${ }^{85}$ ASM's participation in JESSI constituted an enormous boost for the company's position and efforts in Europe toward its customers, competitors, and the authorities.

While Siemens and Philips envisaged Mega II in 1986, political pressure mounted to widen the effort beyond the Dutch-German scope. One of these considerations was to bolster the economic competitiveness of European countries through a new form of European cooperation beyond the EEC framework. Since the Megaproject involved substantial governmental support (300 million DM and about 200 million guilders), the wishes and demands of the officials involved were decisive. Urged by their governments, Siemens and Philips decided to integrate Mega II into a new multilateral research initiative, called European Research Coordination Agency or EUREKA. ${ }^{86}$

83 Sandholtz, High-Tech Europe, p. 199.

84 Ibid., p. 200.

85 For more on the politics preceding JESSI, see the excellent and insightful history by Wayne Sandholtz. France and Italy forged their participation in the Mega II project by merging their national semiconductor champions SGS and Thomson into SGS-Thomson, now known as ST; Sandholtz, High-Tech Europe, p. 293. See also Jeffrey A. Hart, Rival Capitalists: International Competitiveness in the United States, Japan and Europe (Cornell University Press, 1992) p. 216.

86 EUREKA was started as a response to the Strategic Defence Initiative (commonly known as Star Wars), launched by the American president Ronald Reagan in the 1980s. The Western European companies and governments were afraid that the accumulated knowledge of this program - partially through European contributions - would not be allowed to leave the 
Cooperation within the EUREKA framework entailed precompetitive research, using the same template as the ESPRIT program. As an intergovernmental initiative, projects organized within Eureka programs were funded by the governments involved. The initiative was strongly industry-driven, implying that the companies themselves determined the technological requirements and focus areas, while ensuring support of their respective national governments. The European Economic Community was not leading, and in some cases not even involved. In contrast to ESPRIT, EUREKA did not entail a central bureaucracy or top-down entering of items on the agenda; instead, its subsidy schemes were organized in a bottom-up manner.

There were three main drivers of JESSI: the Dutch Philips, the German Siemens, and the French-Italo SGS-Thomson, each with support from their government. These parties negotiated the scope of the program. In 1987, after intervention of the Dutch government and Philips, the program was expanded to include the equipment and materials industry. Being Europe's biggest equipment vendor, ASM was invited to join the JESSI negotiations.

The reasoning for this was twofold: it was indispensable for a serious program in chip technology to include the semiconductor equipment and materials industry, and, secondly, this allowed Philips to invite Europe's most prominent equipment supplier, ASM International, to the table. The two companies cooperated in their joint-venture ASM Lithography, while they also joined forces with the Dutch government in support of the Dutch microelectronic industry. The participation of ASM as fourth company strengthened the Dutch position in the JESSI negotiations. ${ }^{87}$

On behalf of ASM, AMTC manager Erik Kamerbeek participated in the negotiations of JESSI, and he became one of the key players in the program. ${ }^{88}$ For Kamerbeek, this started in May 1987, as he visited the EUREKA office in the

United States. In response to this initiative and the growing secrecy of American technological developments, partially caused by its trade war with Japan, the French president François Mitterrand proposed the European R\&D initiative.

87 Ad Burgmans, 'Interview with author', Erik Kamerbeek, 'Interview with author', Cees le Pair, 'Interview with author', Margriet Jansz, 'Interview with author', and Jan van den Biesen, 'Interview with author'.

88 Over the years, by being an honest deal broker for the entire European equipment industry and in relation to the European authorities, Kamerbeek gained a prominent position in the European subsidy programs. Naturally, this positively affected ASM and Del Prado as well. In 1989, Kamerbeek became responsible for communications with the public authorities at the AMTC, and he was allowed to spend half his time on behalf of JESSI. In 1996, years later, his contribution was recognized through a Special Service Award from the industry organization SEMI Europe. At the start of the JESSI negotiations, however, such a central role for Kamerbeek and ASM could not have been foreseen. 
Netherlands and met with the local managers. ${ }^{89}$ For the financially struggling company, the program might be an additional source of European funds. The Dutch ministry reserved some of its available subsidies for this program. Therefore, if ASM wanted additional subsidies, it might get them by participating in JESSI.

Early in 1988, through existing contacts with Philips, ASM learned about a new round of negotiations taking place in Itzehoe, Germany. ${ }^{90}$ Kamerbeek joined the meetings. As he recalled it was a rather impetuous action, as he lacked a formal invitation for participating in the meeting:

'So without thinking much, I went to Itzehoe. I simply joined the folks gathered together there - ST [SGS Thomson], Siemens, and Philips - and they did not dismiss me. ${ }^{91}$

After this initial meeting, ASM returned to the Dutch Ministry of Economic Affairs to make sure that it would support its position to include the equipment industry explicitly. The Director-General for Industry at the Ministry of Economic Affairs, Mich van der Harst, gave his full support indeed at a meeting in March 1988:

'With respect to JESSI or the MEGA II project, EZ [Economic Affairs] shall set as condition for its financial contribution that ASM will actually be involved in the project.' ${ }^{92}$

With the backing of the Ministry and Philips, Kamerbeek could present himself as a protagonist of the European equipment industry in the JESSI negotiations.

89 This concerned Mr. De Jong and Mr. Luppus. In the report of this meeting by Kamerbeek, JESSI is not yet mentioned explicitly. However, it seems that these contacts may have made Kamerbeek aware of the forthcoming negotiations for JESSI in Itzehoe. - AMTC, Erik Kamerbeek, 'Memorandum: Bezoek Eureka Secretariaat Nederland' (27-5-1987) Archive Arthur del Prado-AMTC files.

90 These meetings took place at a new location of the Fraunhofer Institut run by Professor Heuberger, who hoped to establish a new JESSI research institute in Itzehoe. If it was up to him, the project would be called the Joint Silicon Submicron Institute instead of Initiative. However, nobody else saw the benefits of that. After all, JESSI would guarantee public funds for the MEGA-operations in Eindhoven. Furthermore, the negotiators felt that Itzehoe was too small a town ('It's a hole'), lacking any form of entertainment or diversion. - Ad Burgmans, 'Interview with author', and Erik Kamerbeek, 'Interview with author'.

91 Original quote in Dutch. - Erik Kamerbeek, 'Interview with author'.

92 Original quote in Dutch. - AMTC, Erik Kamerbeek, 'Memorandum: Bezoek Drs v/d Harst en dr. Hartmann, Ministerie van Economische Zaken' (7-3-1988) Archive Arthur del PradoAMTC files; Erik Kamerbeek, 'Interview with author'. 
He became official chair of the Equipment \& Materials group during the initial negotiations. JESSI consisted of four subprograms: 'Technology,' 'Applications,' 'Equipment \& Materials,' and 'Basic Research' (figure 54). Each branch had its own budget and had to specify and define the scope of its activities.

In the capacity of chairman, Kamerbeek invited other equipment and materials suppliers - like Electro-Tech, Air Liquide, Wacker Siltronic, and ASM-L - to substantialize the scope of activity they intended to pursue within JESSI. Later, Del Prado joined the executive board of JESSI. ${ }^{93}$ Through Kamerbeek's central position in the JESSI negotiations and Del Prado's membership of the board, ASM enjoyed a prominent position.

Since the JESSI program was driven by the companies, ASM's position yielded substantial influence. ${ }^{94}$ The European industry had to stick their heads together, create an alliance, and come up with a plan, acceptable for their respective governments. Through its position at the negotiation table, ASM tried to prevent too much political interference in the definition of the program's goals. ${ }^{95}$ After evaluation and approval by the JESSI organization - consisting of managers like Erik Kamerbeek and public officials - a maximum of fifty percent of their total project costs was funded by the respective national governments. ${ }^{96}$

After the public authorities confirmed their commitment to the procedures and operational guidelines set up by the companies in the fall of 1988, the program was open to receive proposals. JESSI represented 21,400 man-years and 3.8 billion ECU in total. ${ }^{97}$ The Dutch government pledged 30 million guilders annually, a major portion of which went to Philips. ${ }^{98}$

93 ASM initially did not represent the equipment industry. For political considerations, this position was given to the chief executive officer of the British ElectroTech in the first one and a half years, after which Del Prado took over his position within the JESSI board.

94 This was in contrast to the ESPRIT program, where the big semiconductor companies and the European Commission determined the terms and conditions.

95 ASMI, Willem de Leeuw, 'Concept letter to Ministry of Economic Affairs, Mr. M.C. van der Harst, ref: 90.045/WdL/jdk' (5-4-1990) Archive Arthur del Prado - EZ file.

96 In some cases, securing national support took longer than in other cases, depending on the decisiveness of the national governments. This was known as the problem of synchronization. - Jan van den Biesen, 'Interview with author'.

97 Elisabeth Feder, 'The JESSI Program Adopts a Japanese-Style Strategy' Electronique International Hebdo (9-4-1992), published in JPRS Report Science \& Technology: Eureka, p. 2.

98 In those days, Philips enjoyed a separate deal with the Dutch Ministry of Economic Affairs. This deal entailed that Philips was eligible for a maximum of 100 million guilders of subsidies annually, in order to prevent Philips from emptying all the available government support instruments. The subsidies Philips obtained within the MEGA and JESSI projects were deducted from this 100 million guilders. - Jan van den Biesen, 'Interview with author'. 


\section{Figure 54}

Organigram of JESSI, highlighting ASM International's presence.

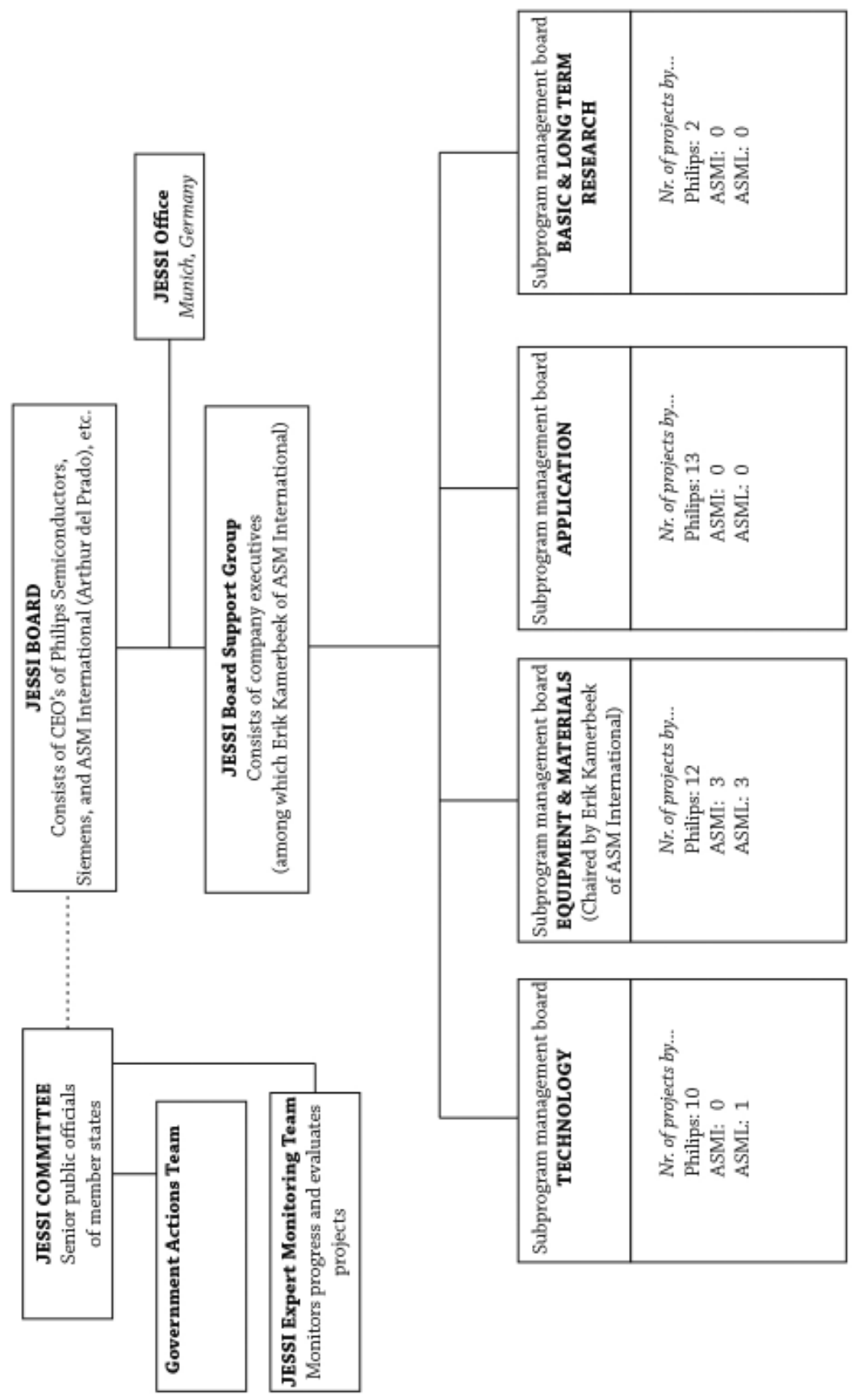


The AMTC efforts in lobbying European support programs ESPRIT II and JESSI paid off. This was illustrated in the 1989 Annual Report of the ESPRIT program, in which the European Commission acknowledged its changed perspective:

'From the 1988 ESPRIT call for proposals, it became evident that the Semiconductor Fabrication Equipment (SFE) sector had become the object of particular attention, in recognition of its strategic importance. The equipment market is currently about $10 \%$ of that for ICs, but its importance is amplified by its enabling characteristics. The rapidity with which IC generations (and associated packing densities) succeed each other gives advantage to IC manufacturers having early access to the most up-to-date processing equipment. Hence, the urgently felt need to assure a European sourcing base for such types of equipment. ${ }^{99}$

ASM successfully brought its industry's - and thus its own - interests to the fore. As a result, its activities qualified for a bigger pool of subsidies. ASM investments into its relation with the Dutch government and Philips proved to be rewarding. Governmental support was deployed to sustain the embodiment of ASM's new corporate innovation strategy, the AMTC.

99 Commission of the European Communities, ESPRIT European Strategic Programme for Research and Development in Information Technology 1989 Annual Report (Luxemburg, 1990), p. 18. 


\section{Chapter 22}

\section{The (un)fulfilment of a promise, 1988-1993}

Within ASM, the AMTC had to take the initiative in formulating a coherent answer to the changing technological and industrial dynamics. The AMTC's R\&D manager, Ernst Granneman, adopted a leading role. He proposed a technological solution for the diverging technological interests of the subsidiaries: a central loading system on which multiple process chambers could be integrated, forming a cluster of process chambers. The success of this machine became the litmus test for the new innovation strategy.

However, some of the innovation projects performed and pursued by the business units were still ongoing. In fact, in the late 1980s, ASM engaged in two paths of research toward the changing CVD market. One was linked to marketoriented and rather opportunistic and decentralized solutions developed at the subsidiaries. The other one involved the centralized, advanced, and more precompetitive machines developed by the AMTC in alliance with customers and research institutes.

The stakes on both sides of the bet were raised. In the fall of 1986, ASM Japan - seeking short-term relief and with Del Prado's explicit support - decided to procure vertical furnace technology from a local subcontractor and to turn this into a new product. The result was the VMP-100, which was not compatible with the central loading system of the AMTC. Meanwhile, the AMTC, also with Del Prado's support, continued its development of the cluster machine. As discussed below, the AMTC would manage to leverage European and Dutch subsidies - and ASM's own funds - in support of the envisaged multi-chamber innovation.

\section{Advent of multi-chamber systems}

By 1988, it had become apparent that the AMTC central loading system fitted in a wider development. Multi-chamber systems emerged across the industry. ${ }^{100}$ The advent of these machines was propelled by the introduction of single wafer machines in the United States. These machines had to meet the demands on process quality and flexibility as formulated by the surging customized chips manufacturers (these chips were also known as 'application specific integrated 
circuits, or ASIC). To overcome the economic disadvantage of processing only one wafer at a time, multiple single wafer chambers had been clustered, forming multi-chamber machines.

Multi-chamber processes ran wafers either parallel or sequential. In the parallel version, a central wafer handler platform served multiple process modules that ran exactly the same process. In the sequential variation, the wafer handler transferred the wafer from one process chamber to the next, for a different treatment in each module. By 1988, the sequential process in a multi-chamber system opened the door to new possibilities.

One such possibility was to open multi-chamber systems for the integration of technology developed by other suppliers. For example, process chambers of a competitor - say, Novellus - could be connected and integrated to a wafer handling system module of ASM. In particular, IBM welcomed and propagated open cluster systems in the United States and in Europe, which combined multiple processes from multiple vendors. ${ }^{101}$ This company called it 'Integrated Vacuum Processing Systems' (IVPS). Through its prominent position, IBM's wishes loudly and clearly resonated throughout the chip industry. ${ }^{102}$

The demands of IBM and the ambitions of the equipment manufacturers propelled standardization of cluster technology in the semiconductor equipment industry. ${ }^{103}$ To be able to integrate the various modules, coordination and harmonization was required. This foremost concerned the standardization of the interface - hardware and software - of the various chambers and wafer handling platforms. The effort, named 'Modular Equipment Standards Committee' (MESC), started in March 1989 by a small group of US based equipment manufacturers

101 IBM engineers, like those of Intel, tended to tweak and tune the procured manufacturing equipment to their own desired needs. If not vertically integrated, as in developing and building their own manufacturing techniques, they modified externally procured technologies to their own demands. An ASM tool at IBM was rather an ASM/IBM tool. But the equipment vendor was not always involved in this alteration of its product. The modularity demand posed by IBM with regard to integrated processing aligned with this business practice. It allowed the chip manufacturer to combine and optimize manufacturing techniques to their own wishes.

102 ASM was also approached by IBM - AMTC, Chris Werkhoven, 'Visit Report: IBM Sept. 26 1989, ref: R\&D/91002/ljvg-eg' (3-10-1989) Archive Arthur del Prado-AMTC files.

103 Economist Richard Langlois and market analyst VLSI Research projected two trajectories with regard to standardization of clusters. One was the closed architecture of Applied Materials, and the other one was the open architecture of MESC. This overemphasizes the 'Applied Materials contra the rest of the industry' version of history, in my opinion. Also ASM wanted to develop its own closed architecture, next to an open one. - Richard Langlois, 'Competition through institutional form: the case of cluster tool standards', in: Shane Greenstein and Vicotr Stango (ed.) Standards and Public Policy (Cambridge University Press 2006) pp. 60-86; VLSI Research, Julie Jackson, 'Executive Advisory: MESA' (31-101989) Archive Arthur del Prado - Herbert Lakens file. 
Innovation III - Innovation strategy, governmental support, and defiant realities, 1979-1993

and involved incorporation of the industry's SEMI Standards Organization. ${ }^{104}$ Through ASM America in the United States and the AMTC in Europe, ASM joined the negotiations about an industry standard by mid-1989.

The standardization effort was meant to form partnerships among equipment vendors. It is important to note that MESC was by no means meant for customers to cherry-pick their multi-chamber system. ${ }^{105}$ Not all equipment manufacturers offered all processes. A company like ASM could integrate external technology with its own cluster system, allowing ASM to compete in markets it previously could not serve. As indicated by an AMTC engineer:

'The user community ultimately benefits as the open architecture should lead to a broader choice of clustered tools and where indeed "best of breed" subsystems and modules will evolve to be the cluster tool market.' 106

The advent of multi-chamber processes meant that integration of several manufacturing steps could be done with one central wafer handling system, instead of with a series of standalone systems of the same equipment producer. Observing these tendencies, Granneman rightfully summarized the huge transformation for equipment manufacturers:

'In this case of clustered processes the customer not only requires the individual films to meet specific requirements, but also the complete stack of films, i.e. the equipment maker is expected to guarantee the

104 Originally it was named the 'Modular Equipment Standards Architecture' (MESA). MESA was founded by General Signal Thin Film Company, Genus, Lam Research, Novellus, AG Associates, Drytek, Matrix, Peak Systems, Silicon Valley Group/Thermco, and Semiconductor Systems. Before it became part of SEMI, it established the M1-Single Wafer Mechanical transfer Interface. At SEMI, standardization processes slowed down severely.. - AMTC, Ian Birnie, 'Memorandum: MESA Update' (22-12-1989) Archive Arthur del Prado-AMTC files.

Despite IBM's insistence on that direction. Equipment vendors wanted to stay in control. As explicitly stated by an AMTC engineer, Ian Birnie: 'To begin with, the MESC Mission can be briefly described as an effort to standardize interfaces such that the best choice of interchangeable equipment modules can be offered by equipment suppliers for clustered wafer processing tools, i.e. the definition and standardization of the mechanical and automation interfaces that facilitate module clustering. MESC is not directed to the standardization of stand-alone modules that are completely "plug-compatible" with "standard clusters" nor directed to the idea that end-users should be able to purchase "off-line qualified" off-the-shelf modules (process, transport, I/O) and simply assemble their won cluster tool in a LEGO-like manner' [italics in original].- AMTC, Ian Birnie, 'Memorandum: MESA Update' (22-12-1989) Archive Arthur del Prado - AMTC files.

106 AMTC, I. Birnie, 'Memorandum: MESA Update' (22-12-1989) Archive Arthur del Prado-AMTC files. 
electrical performance of the structure coming out of his tool. In fact, the responsibility of a large part of the vertical process development is shifting from the IC producer to the equipment manufacturer.'107

Through the cluster technology, the equipment industry assumed responsibility for process integration, which used to be done by the chip producers themselves. To enable this new role, then, the technology required close cooperation between equipment and chip manufacturers.

In the late 1980s and early 1990s, the multi-chamber systems offered many opportunities for the semiconductor industry. Naturally, these systems improved the production of chips by cleaner processes and the ability to process bigger wafers. The cluster machines also required an improvement in technical integration of processes and modules. This stimulated standardization and cooperation among equipment and chip manufacturers, while also allowing the equipment vendors to expand their role in innovation of new chip production technologies. The multi-chamber systems represented a promising development, and, what's more, the AMTC had been working in the right direction already.

\section{The AMTC deploys European support}

The roots of the AMTC's approach to multi-chamber systems differed from those of the majority of the industry. The original central loading system, proposed in 1985, primarily resulted from internal debate among the ASM operations about new CVD deposition technology. Based on this incentive, the AMTC pursued a clustered batch reactor, not single wafer like its American competitors. Through it, ASM anticipated both the development of vertical furnace and the integrated process systems.

By 1988, the AMTC's idea transformed into a bold innovation. The original central loading system was now dubbed the Vertex, whose development was partially funded by a Dutch governmental venture capitalist instrument. ${ }^{108}$ It was a sequential process system and consisted of multiple batch reactors. The Vertex was meant to handle multiple processes, and had a 'closed' architecture, i.e., it was not meant to accommodate or integrate process modules from other suppliers.

107 AMTC, Ernst Granneman, 'Proposal for process development on ASM equipment placed at IMEC' (6-8-1992) Archive Arthur del Prado - IMEC file.

108 AMTC, Erik Kamerbeek, 'Letter to Ministry of Economic Affairs, Dr. M.C.G. Hartmann, ref: BA/EK/016” (19-4-2016) Archive Arthur del Prado - AMTC files; AMTC, Erik Kamerbeek, 'Memorandum: PBTS' (6-5-1988) Archive Arthur del Prado - AMTC files; AMTC, Ernst Granneman, 'Memorandum: Inleiding bij aanvraag Technisch Ontwikkelingskrediet EZ, ref: R\&D/8809/mm-eg' (3-8-1988) Archive Arthur del Prado - Vertical Furnaces file. 
The Vertex was intended as ASM's future standard platform for handling all deposition processes. Various process modules - like diffusion, oxidation, aluminum CVD, plasma CVD, and low pressure CVD processes - could be developed by one of the ASM subsidiaries, depending on their expertise and capabilities. The possibilities of the Vertex were impressive. The Vertex concept was precisely the kind of advanced technological development for which the AMTC was established, as the product was innovative and served to improve the cohesion of ASM as a whole.

Much had to be done, however, to ensure the realization of such an ambitious plan. The various process chambers had to be developed, built, and evaluated. To achieve all these goals against the lowest cost, ASM exploited various options. One was to develop a plasma CVD module with help of an external consultant - buying it off the shelf, so to speak. Another way was to set up a comprehensive joint-development program with a customer. This was done with regard to the new vertical aluminum CVD process, together with AT\&T. And, finally, governmental support would help as well.

The advent of the multi-chamber technology aligned perfectly with the instruments and intentions of the European governmental support programs. As described at the beginning of Innovation III, the European Economic Community envisaged cooperation among the European microelectronics industry through 'precompetitive research.' These support schemes were intended to unite the fragmented national efforts and improve the competitiveness of the European industry versus their American and Japanese counterparts.

To that extent, vertical and horizontal cooperation in the supply chain of microelectronics was deemed of utmost importance. The notion of 'precompetitive research' ensured compliance with anti-trust legislation and risks of unwanted knowledge transfers. Both European programs - ESPRIT II, backed by the EEC, and the intergovernmental JESSI effort - required projects to cooperate internationally and industrially in precompetitive research.

Developing the multi-chamber systems via these support schemes seemed to tick all boxes. It was an ambitious and complex technology, which required substantial research before it could be commercialized. It was also clearly in demand, as the majority of the industry contemplated this new configuration. Moreover, the development of cluster machines required cooperation among research institutes, suppliers, competitors, and customers to evaluate and improve the process integration.

Next to the multi-chamber systems, the accompanying MESC standardization effort aligned with governmental interests. The air was full with references to other industry standards, such as, in the case of electrical components, video 
players and compact discs. ${ }^{109}$ On both sides of the Atlantic Ocean, the MESC efforts took place within governmentally backed industry consortia. In the United States, there was a coordinated research effort called Sematech, established by the Semiconductor Industry Association (or SIA) in 1987 and located in Austin, Texas. In Europe, the JESSI program facilitated such effort. The involvement of the public authorities stimulated the bridging of competitive suspicions among the equipment makers during the negotiations on MESC.

The AMTC's deployment of European support for the development of its multichamber system was obvious. After all, the AMTC established itself at the heart of the European support programs, relied on the governmental support to continue its operations, and had to pursue the multi-chamber approach to prove the center's viability within ASM. From 1988 until 1993, the AMTC utilized European programs - ESPRIT II and JESSI - for the development of multi-chamber systems. ${ }^{110}$

In ESPRIT II the Bilthoven engineers developed the batch cluster from 1988 onward. This was a closed architecture system, only consisting of ASM technology, and thus merely involving vertical cooperation, with research institutes and customers. In JESSI, a single wafer approach was pursued from 1990 onward, with an open architecture, and therefore involving vertical and horizontal collaboration. The different lines of research in ESPRIT II and JESSI resulted from a growing understanding of the processes involved, new demands of the industry, and the commercialization of the batch cluster machine.

\section{ESPRIT II and MCBRIDE}

Within the ESPRIT II program, Granneman and his colleagues at the AMTC had various options to work on the Vertex. To get a project approved within ESPRIT II, they visited multiple customers to verify their interest, align their and ASM's technological roadmaps, and create alliances for enacting the cluster technology. ${ }^{111}$ Options involved multi-chamber processes for the growth of CMOS gate transistors, poly emitters, interconnections, and 'selective processes.'

109 It should be added that the resulting MESC standard never amounted to anything substantial. In the end, suppliers of equipment offered their own distinct standards for tools and processes by the 21st century.

110 Apart from the AMTC, ASM-Lithography submitted its own project proposal for Deep Ultra Violet lithography. But by the time ESPRIT II commenced, Philips and ASM reached agreement about ASM's leaving the lithography joint-venture.

111 AMTC, M. Hendriks and Granneman, 'Visit report Siemens Perlach, 28-1-1988' (1-2-1988) Archive Arthur del Prado - AMTC files; ASMI, H. Piekaar, 'Visit Report LETI, CNET, JIPELEC, AET: Discuss possible ESPRIT Collaboration' (25-1-1988) Archive Arthur del Prado - AMTC files; STC Technology, P.J. Rosser, 'Letter to E.Granneman, ESPRIT Proposals' (12-1-1988) Archive Arthur del Prado - ESPRIT/JESSI file; ASMI-AMTC, 'ESPRIT Proposal on "Selective 
Granneman put forward a proposal on an advanced multi-chamber batch system for the production of 'multi-layer interpoly dielectrics.' These were insulating films grown by a sequential process consisting of dry oxidation, silicon nitride low pressure CVD and wet oxidation. The result was a oxide-nitrideoxide dielectric stack of films, which would be positioned between two films of polysilicon - hence the name 'interpoly dielectrics.' These stacks of materials were used in the production of memory chips, the so-called EPROM in particular. The project would rely on an Italian operation of SGS-Thomson and the French research institute CEA-LETI as partners. The proposal was submitted in March 1988.

Experts from the EEC's member states - primarily staff from universities and research institutes - evaluated the proposal in terms of its quality, importance for the European chip industry, coherence with participants' interests, realism, management, and competitiveness. Also a political and strategic evaluation took place by the Round Table and the ESPRIT advisory Board. ${ }^{112}$

After this evaluation, the AMTC was allowed to proceed with this proposal. ${ }^{113}$ The project's formal name was 'Multichamber Batch Reactor for the Production of Multilayer Interpoly Dielectrics' or, in short: MCBRIDE. The project was estimated to cost 13.5 million Dutch guilders, of which ASM would pay 9.5 million, allotting around 5.4 million guilders of subsidy to the participants of the project. The project started in November 1988. Through the MCBRIDE project, ASM was able to continue its development of the Vertex system, despite the financial difficulties facing the company.

\section{Consolidation of ASM's multi-chamber platform: the A600}

As the MCBRIDE project was well underway by 1989, ASM International decided it was time to start initial commercialization of the Vertex machine. The clustered batch system was transformed into a product. The Vertex was renamed into A600 (Advanced 600). ${ }^{114}$ Three variations were offered: the PECVD version A600/1, the

Deposition of Silicides”' (31-3-1988) Archive Arthur del Prado - ESPRIT/JESSI file.

112 AMTC, Erik Kamerbeek, 'Memorandum: ESPRIT' (28-6-1988) Archive Arthur del Prado ESPRIT/JESSI file; AMTC, Erik Kamerbeek, 'Memorandum: ESPRIT/JESSI/TOK, ref: BA/ EK/063’ (15-8-1988) Archive Arthur del Prado-ESPRIT/JESSI file.

113 Another proposal for the development of selective-silicides could not proceed initially. AMTC, Erik Kamerbeek, 'Memorandum: ESPRIT/JESSI/TOK' (15-8-1988) Archive Arthur del Prado - AMTC files; ASMI-AMTC, 'ESPRIT Proposal on "Selective Deposition of Silicides"' (31-3-1988) Archive Arthur del Prado - ESPRIT/JESSI file.

114 ASMI, Herbert Lakens, 'Facsimile message: Name New CVD System, ref: 89.374/HL/jdk' (16-1-1989) Archive Arthur del Prado - CVD files; ASMI, Herbert Lakens, 'Facsimile Message: Name Advance 600; ref: 89.587/HL/jdk' (6-7-1989) Archive Arthur del Prado - ASM Europe, A600 file. 
thermal A600/2, and the aluminum CVD A600/3. Within these denominations, the MCBRIDE project aligned with the A600/2 version (figure 46 in Chapter 18).

But other multi-chamber systems were considered as well. A new engineer propagated a single wafer cluster machine, in addition to the batch version of Ernst Granneman. From 1989, Chris Werkhoven joined ASM as 'Executive Scientist' after a long career at Philips Research Laboratories in the Netherlands and in Silicon Valley. Having extensive experience in state-of-the-art chip production at Philips during the Mega-project and being a man with outspoken convictions about technological development, Werkhoven championed foremost the reconfiguration of the recently introduced Epsilon single wafer epitaxial reactor:

'It is also clear that, in spite of all attractive properties of a standalone SW [Single Wafer] tool, the market will ask for multi-chamber equipment. It seems not very difficult and costly to develop such a multichamber version out of the existing Epsilon system. ${ }^{115}$

Unfortunately, for Werkhoven, the Epsilon single wafer cluster did not enjoy priority. The company had made significant investments already into the A600 batch cluster and was committed to it through several ESPRIT II projects. The single wafer cluster was given a final chance, late in the JESSI program, three years later.

\section{JESSI and IVPS}

In 1989, as the possibilities of multi-chamber systems became more distinct, chip manufacturers embraced the configuration and pushed for open systems. Placing this technological development on the agenda perfectly coincided with the forthcoming platform for industrial cooperation in JESSI. In the fall of 1989, the framework, procedures, and scope for governmental support and industrial collaboration had been negotiated.

Within the JESSI program, ASM tried to create alliances in support of its ambitions. The Dutch company secured funds for three projects with regard to multi-chamber processing. ${ }^{116}$ The first JESSI multi-chamber project was called the E-61 CMOS project. It concentrated on the reliability of the A600/2 system for the manufacturing of CMOS gates. Funds concerned 15 man-years and about 1

115 Chris Werkhoven further mentions that the Epsilon cannot be integrated with the A600. - ASMI, Chris Werkhoven, 'Facsimile Message: Epsilon Technology: future applications, ref:90.135/CW/jdk' (28-8-1990) Archive Arthur del Prado - Chris Werkhoven file.

116 In additional, ASM was a partner in a project that defined new wafer characteristics with German silicon wafer manufacturer Wacker (Siltronics). 
million ECU from 1991 to mid-1993. ${ }^{117}$ The second multi-chamber project, called ADICT and also started in 1990, concerned an epitaxial process with a cleaning module. The third, however, was the most prominent, prestigious, and elaborate. It was a so-called 'Flagship Project' for the Equipment \& Materials branch of JESSI and for ASM. ${ }^{118}$ The project was named 'Integrated Vacuum Processing System' (IVPS), after IBM's denomination for integrated processes, and it elaborated on the MESC standardization efforts. ${ }^{119}$ Through the IVPS project, the AMTC would be able to pursue Werkhoven's brainchild: multi-chamber single wafer processes.

The aim of the IVPS was to harmonize and integrate process modules of other European equipment suppliers with a wafer handling platform of ASM. Within the IVPS program, ASM cooperated with European equipment suppliers and customers - in a format of horizontal and vertical cooperation. By being an open architecture system, the project opened doors to processes that ASM did not command, like sputtering and etching. It would bolster ASM's position as process integrator.

The start of the IVPS project took much longer than anticipated, however. From the fall of 1990, Kamerbeek, on behalf of the JESSI Equipment \& Materials subprogram, arranged several meetings with a few European equipment vendors to define their position with regard to the MESC standards. ${ }^{120}$ Later, also customers were invited, like Philips, Siemens, SGS-Thomson, and IBM Germany. In the negotiations, the participating companies had to settle on an application for their cluster system. All the parties had to be able to integrate their contribution to the process, and the resulting system had to be attractive and versatile for the industry.

ASM was the system integrator, and thus leader of the project. ElectroTech (United Kingdom) supplied sputtering, plasma CVD, metal etch, and pre-clean technologies. Balzers (Liechtenstein) offered sputtering, metallization CVD and pre-clean. Leybold (Germany) added an etch for aluminum, silicon, plus resist.

117 AMTC, Chris Werkhoven, 'Memorandum: A600/2 Reliability Program' (15-1-1991) Archive Arthur del Prado - Willem de Leeuw file.

118 Even though it would receive this designation only in 1991, in an effort to add prestige to the JESSI program.

119 ASM Europe, Boudewijn Sluijk, 'Memorandum: IBM Sindelfingen visit, March 13, '91' (193-1991) Archive Arthur del Prado-AMTC 1988-1992 files.

120 During the meeting, representatives of ASM, a Liechtenstein sputtering supplier Balzers, British plasma CVD and sputtering manufacturer ElectroTech, and German subcontractor for semiconductor gas equipment Leybold were present. - ASM Europe, H. Hanekamp, 'Minutes of Meeting: IVPS Meeting, ref: HH/91.020-ivb’ (8-3-1991) Archive Arthur del Prado - AMTC 1988-1992 files; AMTC H. Hanekamp and Ernst Granneman, 'Memorandum: IVPS meeting, ref: amtc/910407/mm-hh’ (12-4-1991) Archive Arthur del Prado-AMTC files. 
And ASM provided low pressure CVD batch, oxidation batch, a cleaning module, single wafer epi, and plasma CVD. The total cost was estimated at 28 million ECU for three years.

However, the organizational challenges of one of the participants affected the progress of the project. In the middle of 1991, Balzers withdrew from the market for sputtering processes. ${ }^{121}$ Initially it approached Del Prado to see whether ASM was interested in acquiring the technology. ${ }^{122}$ However, ASM was in no position to pursue this opportunity - attractive as it was. ${ }^{123}$ Within the IVPS project, Balzers was replaced by AST Electronik. ${ }^{124}$

The participation of this supplier of single wafer deposition processes instigated a renewed negotiation of technological details and space. The technology and market of AST differed from those of Balzers, and the German company also had interests and preferences that differed from those of the Liechtenstein company. The involvement of AST pushed the program toward a single wafer cluster, just like ASM's Chris Werkhoven had wanted. By February 27, 1992, the IVPS project formally received the JESSI label, opening the door

121 Balzers was confronted with declining business prospects in the United States for its sputtering technology. In this market - in both a geographical and a technological sense Applied Materials made spectacular inroads through its cluster PVD system.

122 ASM also contemplated the acquisition of another part of Balzers. Earlier, Balzers acquired a company located in Arizona - a subsidiary of Motorola - which developed a single wafer CVD system. The company was called Spectrum, and ASM America's former R\&D manager was one of its managers. The Spectrum CVD technology was in part the reason to engage Balzers for the development in the IVPS program. It had a selective tungsten CVD technology. Technological and competitive reasons made ASM opt out of an acquisition - ASMI, Chris Werkhoven, 'Memorandum: Conversation with J. Visser about Balzers and other equipment makers, ref: 91.248/CW/mk' (23-4-1991) Archive Arthur del Prado - Chris Werkhoven file; ASM Cluster Technology, Ernst Granneman, 'Memorandum: Discussion with Christopher Case (AT\&T) on Balzers and Applied Materials, ref: CT/910606/mm-eg' (11-6-1991) Archive Arthur del Prado - AMTC 1988-1992 files.

123 In the fall of 1991, Balzers sputtering Cluster Line was acquired by a dedicated metallization company, the Japanese MRC-Sony. Like Balzers intended with their sputtering cluster technology and the IVPS project, MRC-Sony used the cluster system for an open architecture like MESC. - Dataquest, 'Deposition market trends: Multilevel Metal Mania: 1991 Sputter Equipment Market in Review' (20-7-1992) Dataquest Semiconductor Equipment Manufacturing and Materials, pp. 5-10.

124 AST was a German company founded by two former ASM Germany sales managers. Initially, it had introduced CVD technology similar to ASM's PECVD process, giving rise to suspicions of theft of ASM's intellectual property. By the early nineties, however, AST developed single wafer cleaning and rapid thermal processes (RTP) chambers. Siemens in particular was interested in the technology. Through the JESSI framework, AST was invited to fill in the spot left empty by Balzers, notwithstanding the anxieties and ambivalences between ASM and AST. 
for new funds in support of ASM's innovation strategy. ${ }^{125}$ The commencement of the project met with further delay, however.

\section{All for nothing?}

In the meantime, from 1990 until 1993, ASM's new innovation strategy collapsed by fits and starts, dragging down the AMTC and the A600. ASM's traditional money-makers - the horizontal low pressure and plasma furnaces - became obsolete in Europe, the United States, and Japan, while overinvestment in new innovations - lithography, ion implantation, epitaxy, and aluminum CVD - had exhausted the financial reserves of ASM International (see Business III). As the financial malaise aggravated, all business units were thrown upon their own resources. Each struggled for survival. The lack of financial means at the holding company - ASM International - undid the centralization efforts and undermined the new innovation strategy.

The problems faced by the Bilthoven operation in the European market gave rise to the reoccurrence of decentralized innovation within the company. The demise of ASM Europe was set against the backdrop of general malaise in the European chip industry and the answers formulated to it. The opening of the Eastern European market after the end of the Cold War in 1990 failed to live up to its promises. Moreover, in 1990 and 1991 it became evident that the original ambitions of Western European countries with regard to competing in the memory chip industry could not be realized. Growth of the European semiconductor market decreased. This was true in particular for Philips and Siemens, Europe's biggest electronics and semiconductor manufacturer.

During a dramatic but vital reorganization, codenamed Operation Centurion and initiated in the fall of 1990, Philips changed its plans for the semiconductor industry. The electronics manufacturer halted the development of the $4 \mathrm{MB}$ SRAM and the production of a 1MB SRAM, as it was too farfetched. Instead, Philips turned to applied specific integrated circuits (ASICs), just like its American competitors had done half a decade before. This decision had negative implications for ASM.

The new strategy of Philips decreased the prospects for the European chip industry. The existing production techniques at Philips were sufficient for the production of ASICs. No new machines had to be bought, and if this was still necessary, the company purchased low volume and flexible single wafer processes, offered by American equipment suppliers. For the production of ASICs, it had no need for ASM Europe's new horizontal batch furnaces.

125 ASMI, Willem de Leeuw, 'Interoffice Memorandum: Cluster Product Meeting (Thursday, February 27, 1992)’ (5-3-1992) Archive Arthur del Prado - Willem de Leeuw file. 
In contrast to Philips' strategy to opt out of the memory market, Siemens decided to license technology of Toshiba and IBM. Following the recipe of these memory manufacturers, Siemens required vertical batch deposition furnaces, preferably of Japanese and American origins. These needed less space in the cleanroom compared to the bulky horizontal systems and had been proven in manufacturing at Toshiba and IBM. However, ASM had fallen behind in the rapidly growing market for vertical systems.

\section{Figure 55}

Graph of revenues ASM Europe in horizontal and vertical LPCVD/Diffusion furnaces, 1984-1994

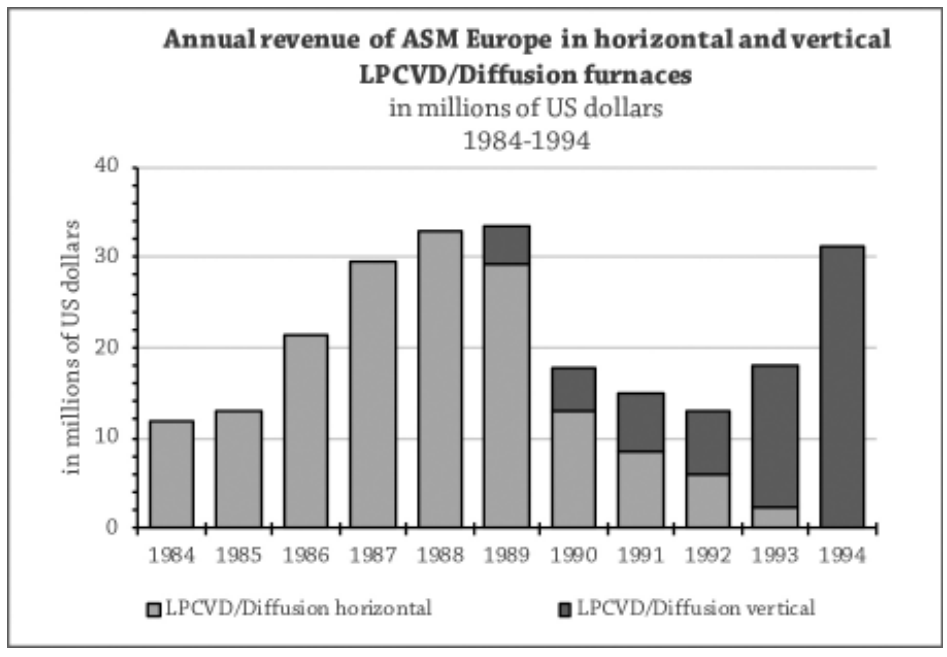

This situation, and the subsequent forecasts, constituted a reality check for the Bilthoven activities, encapsulated by ASM Europe. The size of the European market for semiconductor equipment dwindled compared to Japan, the United States, and the rapidly rising South-Korean and Taiwanese markets. Moreover, ASM Europe's horizontal furnaces constituted a dead-end, and the company lacked a vertical furnace (figure 55). Neither the vertical furnace of ASM Japan nor a newly acquired American A300 vertical reactor offered relief. ${ }^{126}$ Willem de

126 ASM Japan had two vertical systems: the VMP-100 offered LPCVD processes, while the VDF-100 was applicable for diffusion processes. These were two different machines, requiring different servicing and training. European customers preferred a vertical furnace, which could be used either for diffusion or LPCVD processes, rather than a completely different machine for each process. Hence ASM Japan's machine failed to make inroads in Europe. The American A300 - originally named EVTR and acquired from General Signal - came rather late into play: in the middle of 1991. Its acquisition represented a move out of desperation. It was not the most economical machine. Furthermore, by the time ASM was able to offer the A300 in Europe, it competed with the A600/2 and the forthcoming CVTR. 
Leeuw, operating as interim general manager of ASM Europe summarized the problem in the 1991 reorganization note for ASM Europe:

'For some time, vertical furnaces have been introduced in the production of integrated circuits. In this respect, ASM Europe has taken insufficient action. While being confronted with a clear demand in the market, it also faced fierce competition from the United States as well as from Japan. This competition is highly menacing, as vertical systems constitute a gap in ASM's product portfolio. ASM threatens to get the image of having an antiquated product portfolio.' ${ }^{\text {127 }}$

In order to survive, ASM Europe continuously laid off staff. This involved 85 employees in 1987, 50 employees in 1990, and 20 in 1991. Lacking a viable product and operating in a less prospective market, ASM Europe's remaining asset was its marketing and technological expertise of LPCVD processes.

The exhausted financial reserves of ASM International and the dramatic situation of ASM Europe affected the AMTC as well. The technology center did not make any money. As noted by De Leeuw in his 1991 reorganization note:

'Despite the received subsidies, and in addition to the anticipated R\&D efforts of the subsidiaries, the AMTC constitutes a considerable burden to ASM. According to the original budget of 1991, this amounted to 8 million Dutch guilders. ... Although the technological capabilities of the AMTC are regarded as high-quality, its ability to transfer technology is considered as too slow and ineffective. The accommodation of innovations among business units is deemed imperative. ... It is still seen as necessary to hold on to the AMTC as a separate unit for advanced research and general technology, albeit in a strongly downsized fashion.' ${ }^{28}$

Through this assessment, De Leeuw recognized the difficult situation of the AMTC. Envisaged as the flag-bearer of a new corporate innovation strategy, the center could not keep up with the pace and direction of the competitive realities faced by the business units. Moreover, the market-driven innovation strategies of the business units did not align with the corporate-driven innovation strategy of the AMTC (cf. Business III).

Original quote in Dutch. - ASM Europe, Willem de Leeuw, 'Reorganisatienota ASM' (maart 1991) Archive Arthur del Prado - ASM Europe reorganization file. 
The A600 constituted Bilthoven's only tangible asset in the face of the rapidly changing European market. Del Prado and his management betted the future of ASM Europe on a rapid commercialization of the A600/2- the clustered vertical LPCVD, diffusion, and oxidation processes. The $\mathrm{A} 600$ no longer would bridge the technological capabilities of the business units. Instead, it became a last resort for the survival of the Bilthoven operation.

In 1991, ASM established a Cluster Technology Group, which would be responsible for marketing and production of the A600 technology. ${ }^{129}$ By formally structuring the cluster activities as part of the Cluster Technology Group, the A600 left the precompetitive phase of European programs ESPRIT and JESSI. ${ }^{130}$

But even as a product, the A600 offered no immediate consolation for ASM Europe. Over the course of five years, ASM invested as much as 24 million dollars in the A600, and more was needed. ${ }^{131}$ The road ahead for the A600 remained uncertain and fragmentary at best on account of the many applications and processes. Furthermore, due to the long evaluation time for batch processes (many wafers that had to be characterized), development remained expensive and slow. ASM Europe could not carry these investments.

The accommodation of the A600 in one product group - de facto ASM Europe - determined its future. As part of ASM Europe, the machine competed with the other business units for funds, yet it failed to secure allegiance beyond its own business unit. Only technologies and operations capable of securing sufficient sales or customer interest prevailed within ASM. Both the AMTC and ASM Europe lacked clout to propel the A600 as a general platform for ASM's deposition processes.

Moreover, the $\mathrm{A} 600$ failed to become a general platform for wafer processes. By 1992, ASM had various wafer handling platforms: the one of the A600, a newly developed single wafer plasma reactor of ASM Japan, and the Epsilon single wafer reactor of ASM America. In the capacity of Director of Technology and interim-manager of ASM Europe, De Leeuw summarized the arguments in February 1992:

129 The A600 was part of the ASM Cluster Technology product group, managed by Hein Onkenhout. This product group was intended to span ASM Europe, America, and Japan. However, in reality it remained predominantly a European affair. The other operations had their hands full with their own products. The establishment of ASM Cluster Technology was also done in preparation for future joint-ventures, like with Balzers, etc. Bearing in mind the IVPS initiative and ASM's financial troubles, the cluster technology might need an external partner. In anticipation of this, the technology was housed in a separate business unit.

130 ASMI, Willem de Leeuw, 'Interoffice Memorandum: Cluster Product Meeting (Thursday, February 27, 1992)’ (5-3-1992) Archive Arthur del Prado - Willem de Leeuw file.

131 ASM Europe, Willem de Leeuw, 'Memorandum: ASM Cluster Platform Strategy, ref: 033\ WdL \LO' (27-3-1992) Archive Arthur del Prado - Willem de Leeuw file. 
'Can we afford to develop both single wafer and batch poly clusters simultaneously? ... Our company may not be able to afford multiple handling platforms for its cluster products. ... Related to the issue of multiple platforms, it appears we possess an even larger variety of control architectures (including non-clustered products). ${ }^{132}$

The A600, and subsequently the AMTC, clearly failed to improve the mutual cohesion among the subsidiaries. ${ }^{133}$ The envisaged innovation strategy yielded to the unruly and unavoidable decentral realities of ASM.

In the summer of 1992, ASM Europe and the AMTC continued to perform poorly, as was true of ASM Japan. A fresh new perspective was required to take drastic measures and save the Dutch operations. Moreover, ASM International's bankers threatened to call their loans, which would jeopardize the survival of the whole firm (cf. Chapter 23).

Such fresh new perspective presented itself in the person of Ray Friant, who, in the capacity of chief operations officer, initiated the turnaround of the entire front-end operation of ASM International. It encompassed a change from geography-based management toward product management. From 1992 until 1994, each operation and product was stripped to its core capabilities. The new product groups would take care of their own respective R\&D. And, importantly, Friant canceled the new innovation strategy.

\section{Accepting the primacy of decentralized innovation processes}

The decentral innovation structure of ASM prevailed after all. The A600 exclusively became a product of ASM Europe. Of all the variations - the plasma, LPCVD, and aluminum - only the LPCVD version remained, the A600/2. ${ }^{134}$ The fate of the A600 was linked to that of ASM Europe. But the Bilthoven operation's future was in jeopardy. There was no market and no sellable product. A growing body of opinions among ASM's front-end management and on the Supervisory Board argued for the closure of the European operation. ASM Europe should merge with ASM America, and only focus on sales and service for the European market, while manufacturing and R\&D were discontinued.

132 ASMI, Willem de Leeuw, 'Memorandum: Cluster Product(s) meeting, ref: 008.92/Wdl/MV' (13-2-1992) Archive Arthur del Prado - Willem de Leeuw file.

133 ASM Europe, Willem de Leeuw, 'Memorandum: ASM Cluster Platform Strategy, ref: 033\ WdL\LO' (27-3-1992) Archive Arthur del Prado - Willem de Leeuw file.

134 AT\&T had ended the joint-development program of the A600/3 (the aluminum CVD variation). The A600/1 plasma wheel variation could not compete with Novellus. Moreover, ASM Japan developed a single wafer plasma reactor that had better prospects. 
Moreover, the AMTC had become a mere shadow of its former self. It only functioned as a demonstration laboratory, where ASM processed wafers on request. By 1992, the industry introduced a bigger wafer scale (200 millimeter), and this required new equipment for the AMTC demonstration lab. In the absence of money for such investment, the closure of ASM's ambitious technology center seemed a matter of time. $R \& D$ once again predominantly took place at the business units.

It was impossible for ASM, however, to write off the investments in its new innovation strategy, embodied by the AMTC and the A600. The Dutch and European authorities had invested significant sums in both projects. If ASM wanted to remain a trustworthy and viable player in the European semiconductor industry, it had to secure the public investments and its future in Europe. ${ }^{135}$

In the first half of 1992, ASM International was also bogged down by its creditors (cf. Chapter 23). After several disappointing results in a row, bankers insisted on the installment and consistent underwriting of their loans. These demands pushed the company toward imminent bankruptcy. ASM's carefully cultivated relation with the Dutch authorities constituted a last resource. For its survival, ASM depended upon the government's support. As Del Prado explained in a position paper for his Supervisory Board and officials of the Dutch Ministry of Economic Affairs:

'A prerequisite is that the Dutch government does not abandon its support to ASMI to sail through this period by calling its outstanding loans at this point in time. ASMI needs a few more years to enact a return of these funds. ... Lack of support would mean a waste of all combined investments in our product programs made by the Dutch government, ESPRIT, JESSI (Eureka) as well as ASM. ... With an ASMI holding its ground, a Philips which is re-considering a new start in this industry, Holland has yet an excellent opportunity to be a leading country in Europe in this industry, and not only recover its investments made but reap long term educational, scientific and economic benefits. ${ }^{136}$

Luckily, the Dutch government had an interest in securing the expertise in semiconductor equipment - or, to be more precise, safeguarding jobs in this strategic industry. For some time now, ASM and the Dutch authorities had collaborated in an effort to secure jobs and the investments made in new

135 ASMI, Arthur del Prado, 'Memorandum: enclosed, ref: 93.013 AdP/tv' (23-2-1993) Archive Arthur del Prado-RvC 1992-1993.

136 ASMI, Arthur del Prado, 'A position paper on the status of ASM International in the MicroElectronics World Market 1992' (27-4-1992) Archive Arthur del Prado - RvC 1992-1993. 
technology. A bankruptcy of ASM International, or the closure of ASM Europe, would negate all these efforts and imply a waste of public money. To secure the capabilities and knowledge in semiconductor equipment manufacturing, the Ministry of Economic Affairs answered ASM's call for support. However, the ambition for a new corporate innovation strategy had to be abandoned. Saving the industrial capabilities and knowledge - even at the expense of the jobs, mind the RSV affair -of ASM was imperative.

From 1992 until 1994, the Dutch government supported ASM within the decentral organizational structure and strategy that had proven so difficult to change. This collaboration occurred along two routes. One was to enable ASM Europe's survival as a manufacturing and R\&D operation by elaborating upon its LPCVD expertise and the A600. The second route involved reinterpreting the role of AMTC in the organization. In close cooperation, the Dutch Ministry of Economic Affairs and ASM managed to secure their investments and commitment to strengthening ASM's, the Dutch, and the European innovation capabilities.

The first route involved another Dutch equipment manufacturer named Tempress BV, located in Hoogeveen in the northeast of the Netherlands. This company was originally co-founded by Arthur del Prado as Sola Basic Netherlands in 1968. After he withdrew his involvement in 1974, Tempress had been competing with ASM in horizontal furnaces. In 1989, the management of Tempress conducted a management buy-out, and became independent of its original parent General Signal. Just like ASM Europe, Tempress suffered from the declining European market. And just like ASM Europe struggled with the A600, this company tried to commercialize a promising vertical furnace. In 1992, both Tempress and ASM Europe were in the same boat, which offered the Ministry of Economic Affairs the opportunity to kill two birds with one stone.

From May until November 1992, under pressure of the Dutch Ministry of Economic Affairs, Tempress and ASM Europe negotiated a collaboration. ${ }^{137}$ Each of the parties had a strategic interest to cooperate. Tempress could not survive alone, being a much smaller company than ASM. ASM Europe struggled in commercializing the A600 while facing a growing need for a more viable and competitive vertical furnace. And the Dutch authorities wanted to secure jobs, expertise, and its investments in the Netherlands. A fourth party, the NOM, a regional development company for the northern provinces of the Netherlands, also got involved, since it had supported Tempress financially as well.

137 On behalf of the Dutch Ministry of Economic Affairs, this involved the agency Stipt, which was responsible for the allocation of subsidy schemes on behalf of the Ministry. Also officials of the Ministry were kept in the loop. - ASMI and Tempress, 'Intentieverklaring' (27-11-1992) Archive Arthur del Prado-RvC 1992-1993. 
The cooperation centered around a vertical furnace developed by Tempress. This was named the clustered vertical thermal reactor (CVTR). The machine intermediated between ASM's A600, A300, and VMP-100 vertical furnaces. ${ }^{138} \mathrm{It}$ offered more capabilities and was more economical than the A300 and VMP-100; it could process 200-millimeter wafers, while being less complex and advanced than the A600. ${ }^{139}$ The CVTR consisted of various standard modules (figure 56). These generic modules made it relative simple to adapt the design to specific and diverging customer demands without losing economies of scale. Moreover, the fabrication of the modules could be easily outsourced to subcontractors. Overall, the design was much more versatile to the volatile semiconductor market. However, still some major development had to be done by Tempress.

\section{Figure 56}

Schematic view from above of A400

This configuration was developed by Tempress as the Clustered Vertical Thermal Reactor (CVTR), after which ASM added its chemical process knowledge. After Tempress bankruptcy, the product was acquired by ASM Europe.

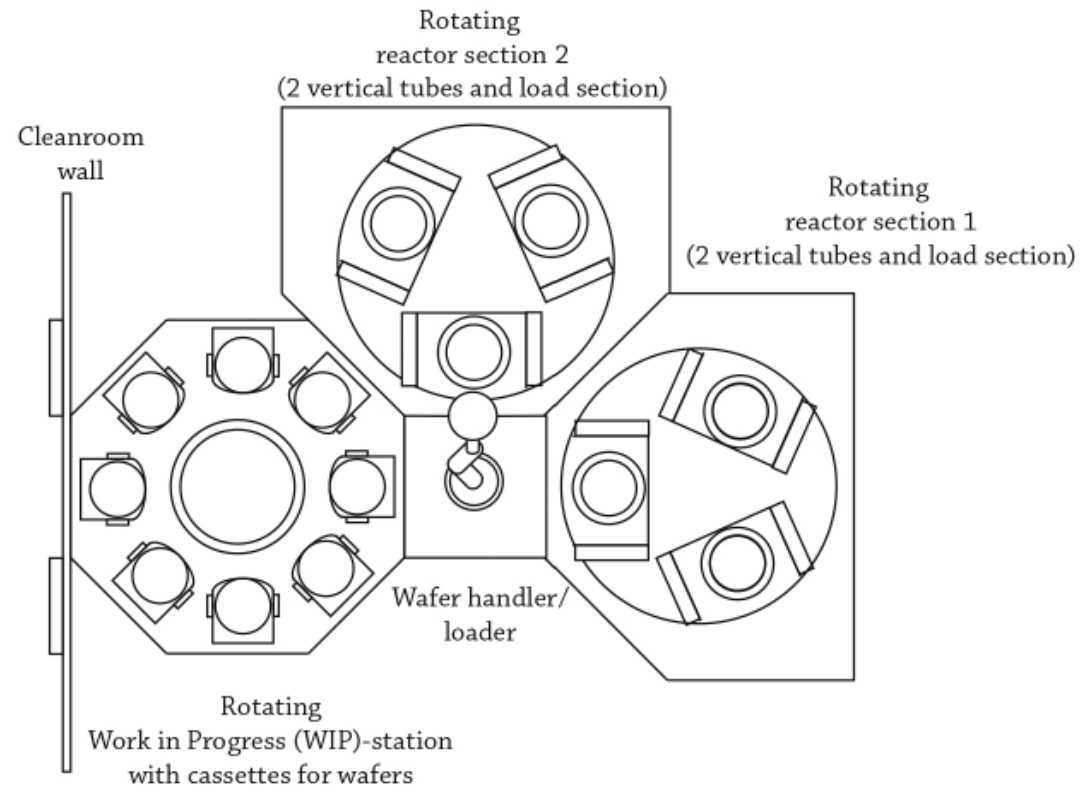

138 ASM America, Greg Jones, 'Memorandum: Benefits of Product Collaboration with Tempress' (4-5-1992) Archive Arthur del Prado - CVTR file.

139 This foremost followed from the fact that the CVTR was an atmospheric clustered vertical furnace. The $\mathrm{A} 600$ operated in vacuum, which made it more complex. In additional, the A300 was not clustered and thus offered fewer possibilities. 


\section{Figure 57}

Schematic overview of technology transfers for vertical furnace process and hardware innovations within ASM International, 1987-1994

The image details the transfers and initiatives at ASM International with regard to the novel vertical furnace technology, starting with ASM Japan's VMP (upper left corner, 1987) and resulting in ASM Europe's A400 (lower-right corner, 1994).

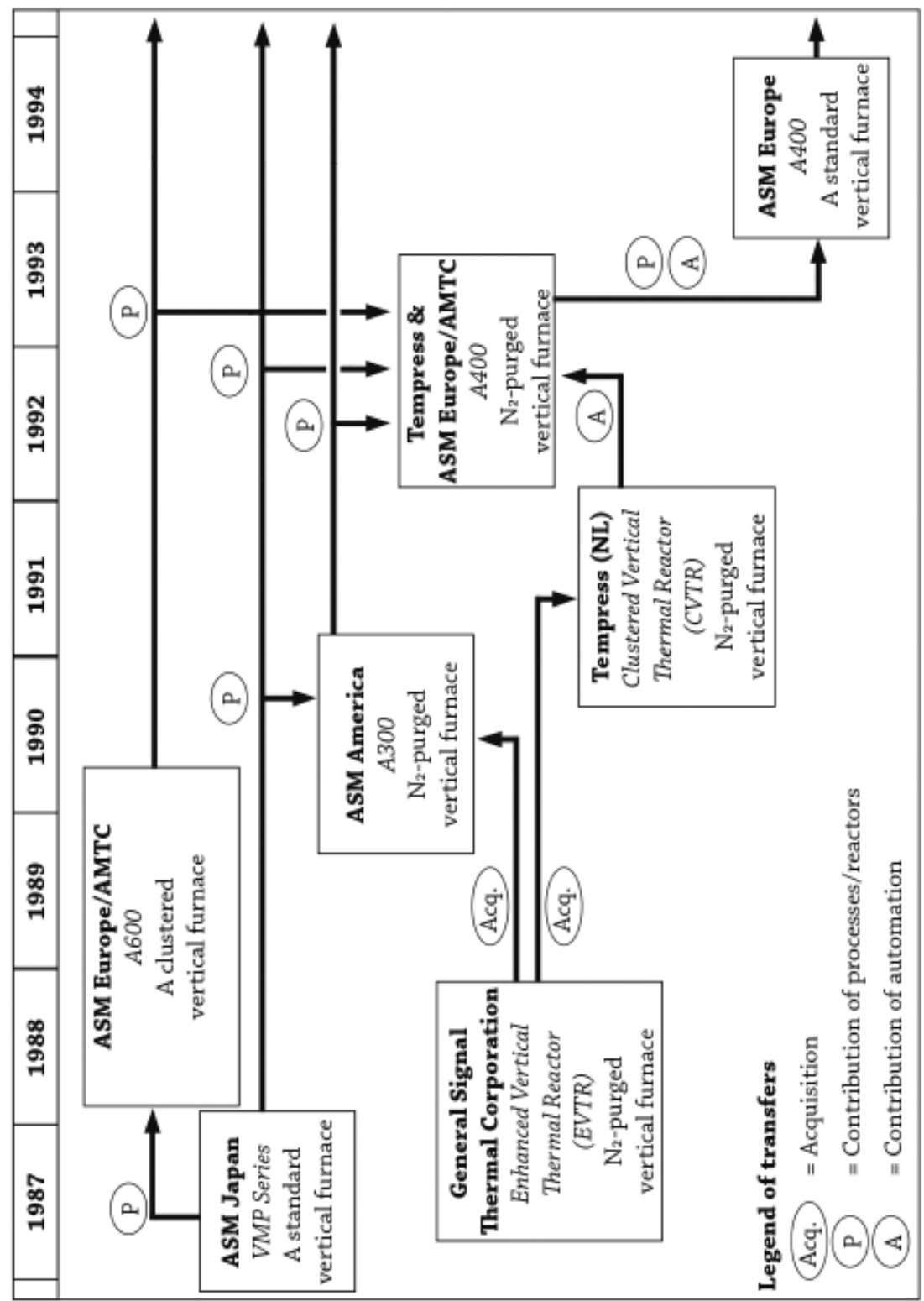


The four parties agreed to the following scheme. ${ }^{140}$ ASM and Tempress would commercialize the CVTR. This machine would be transferred to a joint-venture named CVTR BV. ${ }^{141}$ ASM, the NOM, and Tempress each owned a third of the joint-venture. The Ministry of Economic Affairs supported the commercialization financially through its venture capital scheme, the TOK, and the NOM would provide funding as well.

Tempress contributed the software and hardware designs, while ASM transferred its process knowledge of clustered vertical furnaces - the A600/2, the VMP-100 and the EVTR (figure 57). Moreover, ASM would market the machine worldwide through its global sales network. Tempress would be responsible for the manufacturing. ${ }^{142}$ After one year, if expedient, ASM could exercise an option and acquire all the shares of the CVTR joint-venture.

The CVTR collaboration formed a solution for ASM Europe's troubles with the A600. Due to its relative simplicity, compared to the A600, the commercial prospects of the CVTR were much better. ASM could transfer the processes developed in the A600 - through the ESPRIT and JESSI projects - to the CVTR. ${ }^{143}$ Moreover, the governmental support of the NOM and the Ministry limited the risk and the cost. ASM planned to market the CVTR as the A400.

The second route outlined by ASM, in close collaboration with the Dutch authorities, involved a reinterpretation of the role of the AMTC. After ASM International's financial support for the technology center evaporated, R\&D solely took place at the various business units. ASM was in a hurry to divest the center, as costing too much money. However, since the authorities had invested significant funds in the AMTC, ASM was not able to simply abandon it.

140 Aside from the following part, the collaboration involved the transfer of ASM's horizontal furnace technology to Tempress. - ASMI, Arthur del Prado, 'Tempress. ref: 92.035 AdP/tv' (31-8-1992) Archive Arthur del Prado - RvC 1992-1993; ASMI and Tempress, 'Intentieverklaring' (27-11-1992) Archive Arthur del Prado - RvC 1992-1993.

141 If ASM was no longer eligible for subsidies, Tempress was. Through the joint-venture, ASM could work on process development of the CVTR with subsidies of the Dutch government nonetheless. - ASM International, Arthur del Prado, 'Tempress, ref. 92.035 AdP/tv' (3108-1992) Arthur del Prado Archive - Raad van Commissarissen '92-'93, RvC ASMI Maart 1992 - februari 1993; ASM International, Erik Kamerbeek, 'Cooperation on Horizontal and Vertical Reactor Development and Manufacturing between ASMI and Tempress' (5-10-1992) Arthur del Prado Archive - Raad van Commissarissen '92-'93, RvC ASMI Maart 1992 - februari 1993.

142 ASM International, Supervisory Board, 'Minutes of the ASMI Boardmeeting held on September 22, 1992' (28-09-1992) Arthur del Prado Archive - Raad van Commissarissen '92'93, RvC ASMI Maart 1992 - februari 1993.

143 ASM Europe, Ernst Granneman, 'Memo: Placement CVTR system at AMTC, ref: PTG-92/ m491/EG-pk' (24-11-1992) Archive Arthur del Prado - RvC 1992-1993; ASM Europe, Boudewijn Sluijk, 'Memorandum: Update Status Marketing Advance 400 CVTR' (3-2-1994) Archive Arthur del Prado - RvC 1994-1996. 
Apart from its role as a central technology center for ASM, the AMTC had been envisaged as a pilot line for the integration of ASM's latest machines. Through a pilot line, results of the governmentally supported precompetitive research projects could be tested and verified on their commercial and industrial viability. In a series of meetings at and letters to the Ministry of Economic Affairs, including the Minister himself, Del Prado explained that also this role of the AMTC had been superseded:

'As already discussed, the AMTC concept - that is, the need for a manufacturer to have a complete semiconductor production line - is outdated. Many of our customers prefer to integrate a product into their own production line. ... Usually, a manufacturer will put such a product at their disposal free of charge. After testing and approval, this will then lead to the purchase of this product and multiple machines. ${ }^{144}$

Customers did not need the integration capability from their equipment supplier. Such orchestration of innovation was highly proprietary, competitive, and specific to the chip manufacturer. ${ }^{145}$ However for the enactment of semiconductor equipment, verification of the applicability of the products was indispensable for the equipment supplier. Offering multiple machines to multiple customers free of charge - including maintenance, engineering, and service - was simply too costly. Some sort of pilot line was still required for ASM.

An alternative for a demonstration laboratory was found in the Flemish research institute IMEC, located in Leuven. ASM's executive scientist, Chris Werkhoven, familiar with the capabilities of IMEC from his time at Philips, championed the idea of transferring the remaining technologies and functionality of the AMTC to the Flemish research institute. This was done through a mutual terms settlement, whereby ASM installed its latest equipment at IMEC for a percentage of the available equipment time. ASM could use the IMEC facilities and technologies to demonstrate and evaluate the integration of ASM's new processes. In contrast to the AMTC, the Belgian institute already had all equipment needed to make test structures or even fully functional chips, like lithography, etching processes, metallization, and advanced metrology.

144 Original quote in Dutch. - ASM International, Arthur del Prado, 'Letter to Ministry of Economic Affairs, ref: 92.064 AdP/tv' (5-8-1992) Arthur del Prado Archive - Raad van Commissarissen '92-'93, RvCASMI Maart 1992 - februari 1993; Reference to the presence of the Minister was made in: ASM International, Arthur del Prado, 'Letter to Ministry of Economic Affairs, ref: 92.061 AdP/tv' (29-7-1992) Archive Arthur del Prado - Raad van Commissarissen '92-'93, RvC ASMI Maart 1992 - februari 1993.

145 The term 'orchestration of innovation' originated from David C. Brock, 'Patterning the World: The rise of Chemically Amplified Photoresist', Chemical Heritage Foundation, Center for Contemporary History and Policy: Studies in Materials Innovation (2009) p. 17. 
The decision to move the remnants of the AMTC abroad - to Belgium - was uncomfortable, taking into consideration the original ambitions of ASM and the Ministry with regard to the Dutch microelectronics industry. ${ }^{146}$ However, no other Dutch institute had these capabilities. ${ }^{147}$ At IMEC, ASM was better equipped to evaluate, integrate, and demonstrate its new processes, instead of relying on sporadic feedback from customers. ${ }^{148}$ In this sense, IMEC offered even more opportunities than the AMTC. The Ministry realized the benefits and the necessity. In October 1993, IMEC and ASM officially entered into an agreement. ${ }^{149}$ Werkhoven subsequently moved to Belgium to oversee the move and develop the technology development with the center.

In the turmoil surrounding the restructuring of ASM's front-end activities, Werkhoven saved the cluster technology from being thrown out with the bath water. The A600 program continued in the CVTR, and in an additional NEC joint-development program in Japan. The only project remaining for ASM's multichamber ambitions was the IVPS project as part of the ongoing JESSI program.

Werkhoven championed the IVPS as a hedge for future multi-chamber developments at ASM. In February 1993, he argued to Friant that the project was still worth pursuing further:

'There is a substantial budget for ASM available to pay $50 \%$ of any cost we make within IVPS; this is a general JESSI rule. IVPS leads to a definition and manufacturing of a MESC compatible platform to be used in cluster tools aiming at almost all kind of applications thinkable, including epi and A600/2 type ones. ... Hence IVPS will not only give us the exposure as a driver of standardization and international cooperation, but reduces the cost of projects we had to encounter anyway, by several millions [of

146 AMTC, Erik Kamerbeek, 'Memorandum: IMEC-ASM, m-A921101/EK/ivi' (6-11-1992) Archive Arthur del Prado - IMEC file.

147 The microelectronics center of Delft Technical University, named DIMES, could not compete with IMEC. Yet ASM evaluated this option carefully, also in collaboration with the Ministry, Tempress, and ASM Lithography. - ASM International, Hans Peter Hukshorn, 'Memorandum: Minutes of the ASMI Supervisory Board Meeting on Wednesday June 24, 1992’ (3-7-1992) Archive Arthur del Prado - RvC 1992-1993. P. 4; Delft Institute of Microelectronics and Submicrontechnology, CIM Beenakker, 'Fax: Samenwerking DIMES/ Nederlandse microelectronica equipment industrie. Verslag bijeenkomst d.d. 7 januari 1993 te Delft' (8-1-1993) Archive Arthur del Prado - CVTR.

148 ASMI, Erik Kamerbeek, 'Concept letter to Ministry of Economic Affairs, Mr. W.R.J.L. van 't Hof, ref: b-A/9211.EK/if' (6-11-1992) Archive Arthur del Prado-IMEC file.

149 ASMI, IMEC, 'Overeenkomst IMEC vzw - ASM International' (18-10-1993) Archive Arthur del Prado-IMEC file. 
Innovation III - Innovation strategy, governmental support, and defiant realities, 1979-1993

guilders]. As said before, these projects cover epi, A600/2 and Eagle10. ${ }^{150}$

At that point, the project was not yet developed beyond the level of literature studies and deliberations among the participants. Some of those joined and left in the meantime. ${ }^{151}$ By November 1994, four years after the first meetings, the IVPS program began at the Fraunhofer Institute in Erlangen, Germany. All major players in the European chip industry joined: chip producers SGS-Thomson, Siemens, Philips, Mietec, and IBM Germany, as well as all major equipment manufacturers: the German AST, Leybold, and Plasmos; the British Electro-Tech; the French Cybernetix and LETI; and the Dutch RPI and ASM.

Apart from an ASM wafer handler installed at the Fraunhofer institute, Werkhoven, as the default manager for the IVPS project, dispatched one software engineer, Timo Bergman, to work on the integration of the various modules. ${ }^{152}$ The actual execution of the IVPS project seemed modest compared to its initial intentions, and to ASM's other technological developments for its own product lines. But it did secure ASM's capability in cluster technology for the future, a rather pyrrhic victory compared to the original ambitions.

\section{Epilogue}

The change of course in the European microelectronics industry in the early 1990s, after a decade of optimistic investments, was accompanied by critical media attention. ${ }^{153}$ In particular the governmental support was denounced. The

150 AMTC, Chris Werkhoven, 'Fax to Ray Friant: The importance of IVPS for ASM, ref: 1-A/930201/CW/if’ (3-2-1993) Archive Arthur del Prado - Chris Werkhoven file.

151 ASMI, Chris Werkhoven, 'Memorandum: IVPS and ASM: A Status Review, ref: PTG/m976/ CW-pk' (10-8-1993) Archive Arthur del Prado - Chris Werkhoven file; Within the JESSI program, and even the American counterpart Sematech, the cooperation was presented as a major success and example for international cooperation in the development of MESC standards. - ASMI, Chris Werkhoven, 'Visit report: Sematech, Austin' (23-11-1993) Archive Arthur del Prado - Chris Werkhoven file; ASM Europe, Chris Werkhoven, 'Memorandum: Semicon West, 1994 information on Forums/Meetings, ref: m-A/940801/CW/if' (5-8-1994) Archive Arthur del Prado - Chris Werkhoven file.

152 ASM Europe, Chris Werkhoven, 'Fax: Minutes IVPS/ADICT meeting and on 22 November, 1994 and IVPS Workshop on 23 November at FhG-IIS in Erlangen, ref: f-A/941121/CW/if' (29-11-1994) Archive Arthur del Prado - Chris Werkhoven file.

153 Author unknown, 'Europese samenwerking geen liefde op eerste gezicht' Leeuwarder Courant (1-9-1990) p. 21; Author unknown, 'Chipproject JESSI gaat EZ extra geld kosten' NRC Handelsblad (1-6-1990) p. 9; Dick Wittenberg, 'Mega-project commerciele flop voor Philips' NRC Handelsblad (31-8-1990) p. 11; Cees Banning and Ben van der Velden, 'Andriessen wijst verwijten over subsidie aan Philips af; "Chip-project normaal risico"', NRC Handelsblad (59-1990) p. 11; Dick Wittenberg, "Debacle Philips zet Europa verder op achterstand; Chips cruciaal in strijd om industriele wereldhegemonie' NRC Handelsblad (5-9-1990) p. 1; Author 
Dutch Ministry of Economic Affairs did not seem to have learned from the 1984 RSV affair. However, as it turned out, the negative reporting in the dramatic early 1990s was shortsighted and misinformed.

To start with the biggest recipient of Dutch governmental support, Philips. Although it failed to succeed in competing in the memory market, in the long term the investments made in the Mega-project paid out. In return for a significant stake in the company, the SRAM technology developed during the Mega-project had been licensed to an existing contract chip manufacturer in Taiwan, named TSMC, in 1987. Based on this technology, TSMC grew to be one of the biggest chip manufacturers in the first decades of the twenty-first century. After two decades of significant dividends and dilutions of shares 2007 and 2008, Philips sold its final stake in TSMC - 16.2 percent - for almost 6.5 billion Euro. ${ }^{154}$ That final dilution alone repaid the original investments into the memory technology multiple times. Moreover, due to the governmental support, Philips continued its industrial presence with regard to semiconductors in the Netherlands. Currently named NXP, Philips Semiconductors commands unique capabilities in computer chips applied in telecommunication and automotive.

The same was true for ASM Lithography. After the extensive investments of ASM, Philips, and the Dutch government, the incumbent manufacturer of stepper machines conducted an initial public offering in 1995. The company itself received around 90 million guilders, valuing it at approximately 990 million guilders. ${ }^{155}$ In 1995 and during subsequent years, Philips reaped the gains - almost 200 million guilders - as it diluted its stake. ${ }^{156}$ The investments made by the Dutch government were also reimbursed, as ASML developed into a national high-tech powerhouse in the next decades. In its industrial footprint in the southern region of the Netherlands, the lithography manufacturer even vied with Philips. At the time of writing, the embedment of ASML within the Dutch and European semiconductor ecosystem still constitutes a prime competitive asset, for which governmental support had been indispensable. Yet ASM International did not share in this success; it was not rewarded for its courage and contribution. In 1988, it was forced to divest its stake in ASM Lithography.

The use of governmental support for the AMTC was less a success. On account of the dissolution of the AMTC and the mothballing of the A600 in 1993, most of the investments in the new innovation strategy had to be written off as

unknown, 'JESSI schiet tekort op gebied chipproduktie' NRC Handelsblad (26-4-1991) p. 15; Michel Kerres, 'Alleen fusie kan Europese chips redden' NRC Handelsblad (15-5-1991) p. 25.

154 Unknown author, 'Philips to sell its 16.2\% stake in Taiwan's TSMC', The New York Times (93-2007).

155 ASML, Annual Report 1995 (March 1996); René Raaijmakers, De Architecten van ASML, p. 636.

156 René Raaijmakers, De Architecten van ASML (Techwatch, Nijmegen, 2016) p. 636. 
depreciation. ${ }^{157}$ From 1994 to 2002, only one variation of the A600, the A600UHV, was sold to NEC and Samsung, accumulating a fairly modest 103 million dollars in revenues over the following decade. ${ }^{158}$ The competing vertical furnaces propagated by the business units of ASM - Japan's VMP and America's A300 proved to be unsellable in the longer term as well.

The tour de force surrounding the CVTR/A400 in conjunction with the Ministry of Economic Affairs, Tempress, and NOM did pay off, however. In February 1994, ASM decided to buy the CVTR joint-venture. This was just in time, as a few months later Tempress went bankrupt. ${ }^{159}$ ASM hired ten key engineers and bought the software source codes of the CVTR from Tempress. The manufacturing of modules was done not by Tempress but by Philips Machine Fabrieken in Almelo. This soothed the interests of the NOM to create and protect manufacturing jobs in the northern Dutch provinces. Although the acquisition and final investments totaled 4.2 million Dutch guilders, the deal would eventually help to save ASM Europe.

In June 1994, ASM Europe received its first orders for dozens of A400 furnaces from the American memory manufacturer Micron, located in Boise, Idaho, followed by orders from the R\&D institute Fraunhofer Gesellschaft in Itzehoe, Germany, and some from Philips. ${ }^{160}$ By the year 2000, the A400 furnaces sold worldwide by ASM generated earnings of over 250 million dollars, a sum that continued to go up to approximately 1.5 billion dollars by 2007. ${ }^{161}$ Apart from being a staggering success, the innovation of the A400 was typical for ASM's traditional business strategy: commercializing external inventions. Subsequently, the success of the $\mathrm{A} 400$ was the result of a combination between the advanced centralized research - done within the AMTC into the A600 - and the versatile and market-driven development of the business units.

157 ASMI, Ray Friant, 'Memo: Summary and Conclusions from 8,9 September Board Meeting' (23-9-1994) Archive Arthur del Prado- RvC 1994-1996.

158 Of this sum, operational costs and the successive investments to develop the UHV variation had to be paid as well. - Total sum derived from various numbers in the archive of Arthur del Prado.

159 Tempress was acquired by a Phoenix firm called Amtech and continues to operate to this day. Currently it is located in Vaassen.- Author unknown, 'NOM steekt weer geld in Tempress Hoogeveen', Dagblad van het Noorden (25-1-1995); ASMI, Willem de Leeuw, 'Facimile Messsage: Tempress, ref: 95.018WdL/dz' (27-1-1995) Archive Arthur del Prado - Willem de Leeuw.

160 ASM Europe, Boudewijn Sluijk, 'Memorandum: Update Advance 400 marketing status' (17-6-1994) Archive Arthur del Prado - RvC 1994-1996; ASM America, Art Launder, 'Facsimile Transmission: Micron Visit - August 8, 1994' (9-8-1994) Archive Arthur del Prado - RvC 19941996.

161 Numbers compiled from various documents in archive Arthur del Prado. 
Moreover, where the AMTC failed, IMEC - and ASM's cooperation with the Flemish institute - succeeded. Throughout the 1990s, IMEC developed into a key player in the industry. Not long after ASM moved in, ASML negotiated its place at IMEC as well, followed by all major worldwide equipment manufactures. To this day, ASM has a substantial process engineering staff at IMEC to execute a wide variety of programs, in many cases in co-operation with IMEC and chip manufacturers. The increased understanding about the relationship between process and chip eventually gave ASM the reputation of a process innovator.

Above all, ASM's involvement with the Dutch government resulted in other, less quantifiable results, such as a sustainable and cohesive knowledge and industrial infrastructure. The JESSI and ESPRIT programs have been extended to the present day - and have been successful. By the turn of the century, the company's governmental, and industrial knowledge infrastructure, established in the late 1980s, would be to ASM's benefit again. As argued in Innovation IV, the results of the IVPS project and the institutionalized governmental support would play an important role in the revolutionary developments in atomic layer deposition and high-k dielectrics. 


\section{Conclusions}

By the late 1970s, ASM's applied, decentralized, and opportunistic approach to innovation proved to be too unruly. In the 1980s, its new and ambitious innovation strategy differed too much from the realities and capabilities of the globally and technologically dispersed ASM operations, while subsidies provided an insufficient basis to ward off financial problems. Yet, governmental involvement in the new strategy stimulated institutionalization of technological development and collaboration with the European chip industry. In this conclusion, I assess the effect of the political support by returning to the four questions posed at the beginning of Innovation III, after which I reflect on the findings by considering the role of path, fortuna, and virtù again.

The first question pertained to ASM's reasons for wanting to change its innovation processes. By the mid-1980s, ASM had turned into a global conglomerate in semiconductor production technology. Up to that point, its management structure was still highly decentralized. R\&D, production, sales, and marketing were all done by its business units on the various continents. For instance, the development of deposition technology materialized differently at its subsidiaries in Europe, Japan, and the United States. Moreover, as the company's size was growing, it increasingly became apparent that it lacked clout. More coordination and cooperation among the subsidiaries was deemed necessary. A new innovation strategy - though, never explicitly articulated as such - was conceived to overcome the inadequacies of decentralized management and R\&D. A central technology center, the AMTC, would operate as a liaison among the R\&D operations of the subsidiaries. The AMTC's major innovation, the A600, was meant to be a vehicle for this purpose.

The answer to the second question, as to why the Dutch European public authorities supported ASM in this ambition, goes back to the late seventies and early eighties, when the Dutch government gained a new appreciation of the role of high-tech innovation and the microelectronics industry in particular. In order to secure the competitiveness of the Netherlands and the European Economic Community (EEC) member states, a healthy microelectronics industry was deemed vital. Successive cabinets in the Netherlands hardly altered this appreciation. Elaborating on this growing awareness, ASM forged a triangular relationship with Philips and the Dutch Ministry of Economic Affairs. Through this close collaboration, Del Prado and his managers succeeded in obtaining financial support for setting up the AMTC and subsequently developing the 
A600. Through ASM's healthy relationship with the authorities, the company was able to influence the European programs as well.

As to the character of the support to ASM, my third question, the AMTC and the A600 feature prominently as well. From 1981 until 1992, ASM received about 159 million Dutch guilders in governmental support for all its Dutch operations, including ASM Fico and ASM Lithography (figure 58). ${ }^{162}$ Of this sum, approximately 55 million was used for the new innovation strategy, or 14 percent of all R\&D expenditures of ASM International in this period. The AMTC was partially funded through these contributions (a total of 40 million), while the remaining millions were invested in the development of the $\mathrm{A} 600$ multi-chamber machine via Dutch and European funding channels. This funding was solely for development, not for commercialization.

\section{Figure 58}

Graph ASM International R\&D expenses and governmental grants \& credits, 1980-1994

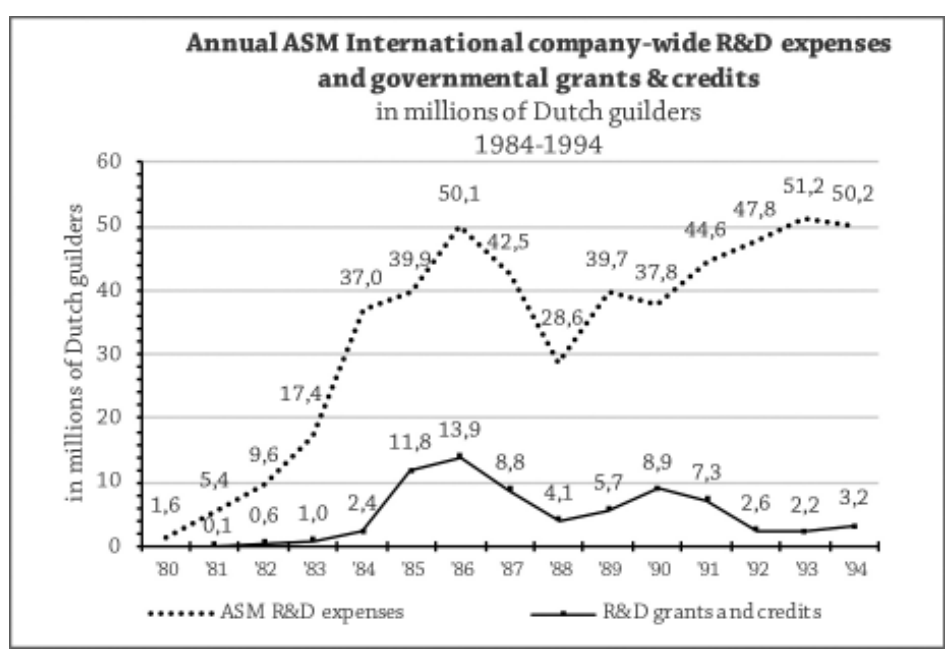

Moreover, the European authorities offered support for 'precompetitive research' in pursuit of improving industrial cohesion within the EEC. These subsidies were limited to a maximum of 50 percent of the total development cost. ASM had to contribute the other half. The contribution of European programs ESPRIT and

162 This includes 23 million (ASML) and 28 million (rest of ASM) on governmental development credit (TOK), which had to be repaid. It also includes a single grant for the AMTC of 40 million Dutch guilders. Without ASML (TOK and subsidies), the total received support was 55 million guilders (excl. TOK for ASM Fico and the AMTC). The total R\&D expenditures of ASM International amounted to some 400 million Dutch guilders. No governmental support was received for the other operations. - ASM International, Annual Reports 1989-1992. 
JESSI came with another precondition: collaboration with other European players in the semiconductor industry - whether customers, research institutes, or other equipment vendors. ASM was left in charge of the execution of the R\&D involved as long as it periodically informed the public funding agencies.

The impact of the governmental support on ASM's new innovation process, which was my fourth and final question, is more difficult to assess. The immediate results of governmental support for ASM were disappointing (as was true for Philips in relation to its ambitions in memory chips). It proved hard to bypass ASM's decentral management structure. Both the AMTC and the A600 did not live up to their expectations. In the longer term, however, the support did pay off. The success of the A400 was rooted in the A600, and ASM's experiences with the AMTC contributed to its cooperation with IMEC. Moreover, through its interactions with the Dutch authorities, ASM secured a position at the heart of the European semiconductor industry, allowing it to influence policies like JESSI, ESPRIT, and successive programs. As discussed below, the failure of the AMTC and the A600 revealed some key elements of ASM's innovation process.

\section{Fortuna}

Unexpected events, contingencies and crises - or, in other words, fortuna defined the transformation of ASM's innovation process and the role of the authorities. Regarding the period covered here it is possible to identify as many as six manifestations of fortuna, some involving a force for good, and some for bad. Here I will briefly mention them in chronological order, followed by a short reflection as to their impact on governmental interaction and ASM's innovation process.

The first manifestation of fortuna involved the fair winds befalling the microelectronics industry in the early 1980s. New economic policies, developed in the wake of the economic recession of the 1970s, were marked by a new appreciation of the economic benefits of a healthy microelectronics industry and the Japanese competition. By playing these chords, Del Prado managed to gain the attention from both the government and the industry. The momentum enjoyed by the microelectronics industry in the 1980s enabled the pursuit of ASM's ambitious new innovation strategy.

The RSV affair formed a second fortuna. After the bankruptcy of this major shipbuilder and machine manufacturer in the Netherlands, public and political outcry about the role of the Dutch Ministry of Economic Affairs in it ensured that interventionist support or policies would never happen again. This was unfortunate for ASM, as it was desperate for money by the late 1980s and early 1990s, and it only could apply for funds in support of technological development. 
A third instance of fortuna was the sudden, devastating downturn of the memory market (see also Business III). The crisis drastically changed the industrial and technological dynamics involved. The memory market tilted toward Japan, while the United States and, later on, Europe turned toward application of customized chips (ASICs). The subsequent geographical divergence in technological development aggravated the inadequacy of ASM's former innovation strategy. Moreover, as the downturn lasted, it accelerated technological development across the industry. Investments and technological projects absorbed all the cash and profits of ASM. New external funds became vital, and this would have to include governmental support. The memory downturn did not only expose the risks of the former innovation strategy; it also increased ASM's dependency on governmental support.

The fourth fortuna was linked - once again - to materiality. Like in the previous Innovation chapters, ASM's engineers encountered unexpected material realities, which defined the innovation processes they engaged in. In this case, the complexity of the A600 originated from this materiality. Although ASM's engineers managed to build a working machine, their efforts resulted in a rather expensive and subsequently uncompetitive machine. This contributed to the failure of the A600.

The fifth occurrence of fortuna involved the dramatic transformation of the European semiconductor market. This followed from the Operation Centurion at Philips, launched in 1990, in which ASM's major Dutch industrial partner changed its ambitions in the chip industry. Philips decided to stop investment in memory, causing a change in its demand for fabrication technologies. Philips - and also Siemens - no longer had a need for ASM Europe's horizontal furnaces, turning to more versatile American and Japanese equipment suppliers instead. Quite suddenly, then, ASM Europe got stuck with several obsolete products, but its Dutch competitor in horizontal deposition technologies, Tempress, suffered the consequences as well. This fourth manifestation of fortuna resulted in the end of ASM's new innovation strategy, which aggravated ASM's financial troubles. But it also bore the fruit for the company's salvation through the equally lifethreating situation of its competitor Tempress (see below).

The sixth and final manifestation of fortuna was also its most defining. In fact, it was a Machiavellian Moment - a situation causing a reappreciation of one's temporal finitude. In 1992 and 1993, ASM International's bankers threatened to call their loans, which - if effectuated - would make ASM insolvent and herald immediate bankruptcy. This situation is elaborated upon in more detail in Business IV (Chapter 23). With ASM's survival - and thus the governmental investments - at stake, only dramatic actions might save the day. Public officials pulled their strings at both Tempress, ASM, and Philips in order to save jobs and 
the Dutch semiconductor equipment industry. ASM had to ditch its ambitious innovation strategy.

In Innovation III, fortuna accelerated, delayed, and changed the course of events profoundly. In contrast to the previous Innovation chapters, manifestations of fortuna at the technological, industrial, and economic level not only created opportunities; they also turned pursued opportunities into mirages. Most prominently, this involved the transformation of the European market at the end of the 1980s. Moreover, ASM's innovation process was affected by fortuna in the guise of external stakeholders - the Economic Affairs ministry's negative role in the RSV affair and the anxious bankers calling ASM's loans. In this way, fortuna tested ASM's new innovation strategy, the company's relation with the government, and the robustness of the government's new economic policies. The equipment manufacturer's new innovation strategy proved to be the weakest link.

\section{Virtù}

Within Innovation III, virtù features primarily in ASM's dialogue with the government. The relationship with the Dutch Ministry of Economic Affairs offered ASM access to a stable and durable source of support. Through the synchronization of interests, ASM was able to re-channel this support to a new innovation strategy.

Just like in the previous Innovation Chapters, virtù was shown by ASM's entrepreneurial managers: by Arthur del Prado in his efforts to establish a dialogue with the Dutch government, but also by Willem de Leeuw, Erik Kamerbeek, and Ernst Granneman, in their consistent efforts to attract or influence governmental support schemes in the Netherlands and within a European context.

Consistently, these men tried opportunistically and constructively to strengthen and preserve the relation with the authorities and subsequently appropriate its support. Good examples are Granneman's argument for including the equipment industry in ESPRIT II, Kamerbeek's bold attendance of the first JESSI board meetings, and De Leeuw and Del Prado's engagement with the Dutch Ministry of Economic Affairs surrounding the dismissal of the new innovation strategy in the early 1990s. They explored even the slightest opportunity carefully. Del Prado and his staff remained dedicated to the Dutch microelectronics industry, verbally and in practice, and the ensuing trustworthiness as partner was pivotal in winning governmental support for the company's activities.

Likewise, ASM's engineers showed virtù in overcoming unexpected technological challenges of the A600. Making the machine work in vacuum proved to be more difficult than originally envisaged, and its work-arounds affected the machine's applicability and success. 
Yet not only ASM's management and engineers displayed vigor and entrepreneurship. Some of the public officials exhibited virtù in a way as well, such as the European Commissioner Davignon with his initiative to create European support schemes to beef up industrial cohesion. An even more striking case, in the context of ASM's interactions with the authorities, was the action of the Dutch Ministry of Economic Affairs that resulted in the collaboration between Tempress and ASM in the early 1990s.

The Ministry leveraged these two companies' dependence on governmental support. With their backs against the wall, Tempress and ASM had to cooperate. Through this course of action, the public officials safeguarded their investments in the various innovation projects and still complied to the standards of governmental support. It involved, using the words of political historian Luuk van Middelaar, 'a combination of intelligence, courage, and perseverance'; it was a matter of 'taking action, taking initiative, anticipation, and playing along with a given situation. ${ }^{163}$

Throughout Innovation III, virtù was a force of creation, elaboration and preservation in the relation between ASM and the European and Dutch authorities. Through virtù, interests were synchronized amidst benevolent and disruptive circumstances. Moreover, just like in the previous Innovation chapters, in the face of a Machiavellian Moment the consequences of virtù were pivotal - pertaining in this particular case to the affirmation of ASM's decentral and customer-oriented innovation and business strategy. This seemed to be a return to square one, and not so much an example of renewal or innovation as one might expect to ensue from virtù. Yet, as expounded in Business IV (Chapter 23), the outcome that followed in the wake of the Machiavellian Moment redefined the routines of innovation at ASM, as reflected in its shift from geographical management toward product management.

\section{Path}

A consideration of the element of path allows us to see how ASM's innovation process was structurally affected by governmental interaction. In the early 1980s, Del Prado deliberately pursued recognition for ASM's role in and potential for the Dutch and European microelectronics industry. Such acknowledgment by the government and the industry - most significantly Philips - would contribute to the company's reputation and might result in beneficiary collaborations. This was true in particular because at a European and national level a consensus

163 Original quote in Dutch. - Luuk van Middelaar, De nieuwe politiek van Europa (Historische Uitgeverij, n.p., 2017) p. 29. 
emerged about the benefits of industrial collaboration for economic growth. The government was even willing to grant subsidies in support of that goal.

To appropriate governmental support, ASM had to adhere to a different routine of innovation. This involved precompetitive research and industrial collaboration. The template of precompetitive research stimulated ASM to move towards more fundamental research and development. Simultaneously, the demand for industrial collaboration encouraged ASM to ally other European companies in technological development. The AMTC and the A600 addressed these requisites effectively, while also tackling the growing disparity among interests of ASM's business units. The opportunity of governmental support actuated a dramatic overhaul of the company's innovation strategy.

The effectuation of this new strategy was defined by technological and market dynamics worldwide. One example is the cooldown of the memory rivalry between Japan and the United States from 1984 to 1985, or the transformation of the European semiconductor industry in the early 1990s. In these dynamics, research projects supported by European and/or national governments were a mere plaything of the vicissitudes involved, just like the companies themselves in fact.

The effects of the governmentally supported projects were in a way defined by the chip manufacturers. Any joint-development project required the involvement of the European semiconductor producers. Their consent was indispensable. The joint-development programs, set up in European programs like ESPRIT and JESSI, competed on a global stage with efforts of American and Japanese semiconductor producers. A change in priorities by the European chip manufacturers - like during Operation Centurion - bore major consequences for these projects and subsequently for the equipment manufacturers involved. Even with governmental support, the industrial embedment of ASM in the service of chip manufacturers prevailed.

Finally, when turning to a more conceptual approach of the observations above, it is clear that both the template of precompetitive research and industrial collaboration fitted the newly emerging appreciation of innovation. Innovation scholars Johan Schot and Edward Steinmueller referred to this as the move to national systems of innovation. ${ }^{164}$ The different appreciation of innovation by business managers also resonated in the template of 'Third Generation R\&D' as presented by consultants from consulting firm Arthur D. Little. ${ }^{165}$ In this concept, the corporate and business innovation strategies were more closely aligned, in

Schot and Steinmueller, 'Three frames of innovation policy', p. 1558.

165 Roussel, Saad, and Erickson, Third Generation R\&D; and Kesler, Kolstad and Clarke, 'Third Generation R\&D'. 
contrast to the first and second generations of $\mathrm{R} \& \mathrm{D}$ discussed in the Conclusions of Innovation I and II. If the new generation $R \& D$ seemed to be right from a pragmatic angle, actual alignment of corporate and business innovation strategies was not so easy. The failure of the AMTC proved this much. Even afterward, when the old innovation process at ASM prevailed, corporate interests continued to divert from those pursued by the business units (cf. Business IV).

Another conceptualization used in the previous Innovation chapters to reflect upon the role of ASM clarifies some of the dynamics here: the notions of enactor and selector. The participants in governmentally supported joint development projects within the ESPRIT and JESSI programs researched and enacted technological solutions. Consider for example, the IVPS project in the early 1990s. The projects could therefore be seen as 'alliances of enactment.' Through their financial contribution, the European and Dutch authorities de facto became an enactor of such technological endeavors as well. After all, it was in their interest that such innovations were applied in the industry.

Through the alliances of enactment, the moment of 'closure' in a process of variation and selection was advanced. Or, in the terminology used in Innovation II, a 'bridging incident' was brought to the fore. ${ }^{166}$ Suppliers and their customers - enactors and selectors - aligned each other's interests at an earlier stage in development of new fabrication technologies. Through the alliance of enactment, commercialization - application of equipment in industrial production of semiconductors - was antedated in the hope of increasing the chance of are turn of investment by participants and authorities.

In some instances, the alliances of enactment spanned even beyond Europe, like the effort of standardization, harmonization, and increasing modularity in semiconductor equipment in the American-European program MESC. This program anticipated an emerging reality in which increasing variety of semiconductor products and fabrication processes resulted in demand for fewer of the same type of manufacturing equipment. Equipment manufacturers like ASM had to adopt their equipment almost per order. Standardization and modularity were seen as ways to increase economies of scale. This appreciation aligns with that of economist Richard Langlois, who regarded the modularization and standardization of multi-chamber semiconductor equipment as a way to achieve economies of scale for the equipment or chip manufacturer. ${ }^{167}$

166 Raghu Garud and David Ahlstrom, 'Technology assessment: a socio-cognitive perspective', Journal of Engineering and Technology Management 14:1 (1997) pp. 25-48, p. 44.

167 Richard Langlois, 'Competition through Institutional Form: the Case of Cluster Tool Standards', Economics Working Papers, University of Connecticut (2004); Richard Langlois, 'Competition through institutional form: the case of cluster tool standards', in: Shane Greenstein and Victor Stango (ed.) Standards and Public Policy (Cambridge University Press 2006) pp. 60-86. 
The governmental programs of the European Community, JESSI in particular, formalized ASM's role as 'specialized supplier.' ASM experienced institutionalized collaboration with customers and competitors for the first time. Its activities were at the service of the chip manufacturers, and to guarantee an effective development, intense contact was indispensable. Through ESPRIT II and JESSI, ASM exposed and adapted itself more to its customers' wishes, an attitude that sharply contrasted with the company's wild years during the 1970s. The involvement of the authorities pertained to that of a proverbial catalysator, accelerating technological development. Yet, they hardy had any effect upon the result or initiation of the innovation process. Chip manufacturers remained the driving force of innovation in relation to ASM.

The new innovation strategy - embodied by the AMTC and A600 - was an anomaly to ASM's general innovation process up until the mid-1980s, as is true of the Epsilon development program discussed in the previous Innovation chapters. ASM's effort to alter its innovation practices by means of the AMTC and the A600 took merely seven years, which, in retrospect, is not all that much, given the meanwhile fifty-year history of the company. After the faltering of the AMTC and the mothballing of the A600, ASM returned to its decentralized R\&D practices permanently. Yet, the overhaul of the company's innovation process resulted in its solid embedding in the European microelectronics industry. Moreover, industrial collaboration remained a vital part of ASM's innovation process.

The investments in a new innovation strategy in the late 1980s sowed the seeds of the company's future capabilities. At the turn of the century, the experiences in building an alliance of enactors would be employed again. ASM's two champions of multi-chamber processes, Ernst Granneman pursuing batch type modules and Chris Werkhoven's single wafer modules, played a pivotal role in this respect. By that time, however, and in marked contrast with the efforts of the 1980s, the new innovation strategy would deviate little from the more traditional operational mode of conduct at the various ASM operations. 


\section{Business IV}

\section{Contemplation and core competencies, 1992-1999}




\section{An introduction}

Throughout the 1990s, ASM engaged in a struggle for survival as a company. Facing immediate disintegration, ASM International's management tried hard to find its way to safer grounds. New paths toward the company's rescue and reconsolidation were considered constantly. All options were on the table, from selling all back-end activities and the closure of front-end to partnering up, divesting subsidiaries, and closing specific operations. Financial turbulence, mainly rooted in an inadequate cash flow and total leverage of assets in favor of innovation, forced the company to slip back into fire-fighting mode all the time. Recovery seemed impossible. Only by the end of the decade, after a sequence of throwbacks and recoveries, did the equipment manufacturer find itself onto a new, more promising path.

This chapter deals with the valiant effort of ASM International to halt immediate disintegration and work toward reconsolidation. As such this account is about ASM International management's facing its own Machiavellian moment. According to historian John Pocock, this kind of moment involves an entity's encounter with its 'own temporal finitude,' while trying to steer a straight course amidst a stream of ostensibly irrational and apparent destructive events. ${ }^{1}$ The only route toward survival, in other words, is in the cold comfort of immediate action, beyond common practices, or, in other words, virtù. But even in this act of virtù, the innovator - ASM International's management in this case - anxiously has to search for a footing, for some basic principles toward the best course of action to be taken.

\section{Contemporary appreciation of a multi-divisional enterprise}

ASM's business strategy was found wanting. In the late 1980s and early 1990s, various Dutch multidivisional firms reconsidered their strategy of diversification. Business historians Keetie Sluyterman, Gerarda Westerhuis, and Abe de Jong suggested that this development was driven by pressure from financial markets to focus on profitable businesses; by new innovations in information \& communication technologies enabling more intense communication between geographically dispersed business units; or by the difficulties of coping with the increasing globalization of industries. ${ }^{2}$ By the early 1990s, this advice evolved

1 John Pocock, The Machiavellian Moment: Florentine Political Thought and the Atlantic Republican Tradition (Princeton University Press, Princeton, 1975), p. viii.

2 Abe de Jong, Keetie Sluyterman, and Gerarda Westerhuis, 'Strategic and structural responses to international dynamics in the open Dutch economy, 1963-2003', Business History 53:1 
into the mantra 'fix, close, or sell,' commonly attributed to General Electric's chief executive officer Jack Welch. ${ }^{3}$

Multi-divisional enterprises found their way out of their respective dire situations by adopting new insights on business management. Most prominent among them were those of management scholars C.K Prahalad and Gary Hamel. These authors elaborated on Michael Porter's notions of corporate and competitive strategies (cf. Business III). The authors warned for the 'tyranny of the strategic business units' that underpinned struggling multi-divisional enterprises at the end of the 1980s. ${ }^{4}$ This tyranny resulted in underinvestment in developing core competencies, imprisoned resources, and bounded innovation (i.e., pursuing only innovation available on relative short notice). The strategic business unit, which had been an 'organizational dogma for a generation,' had become an anachronism. ${ }^{5}$

In their defining articles 'Strategic Intent' and 'The Core Competence of the Corporation,' Prahalad and Hamel argue that businesses should pursue the achievable, not the incredible. ${ }^{6}$ Moreover, they introduce the fairly vague notion of 'strategic intent':

'Companies that have risen to global leadership over the past 20 years invariably began with ambitions that were out of all proportion to their resources and capabilities. But they created an obsession with winning at all levels of the organization and then sustained that obsession over the 10- to 20-year quest for global leadership. We term this obsession "strategic intent."

The authors define strategic intent as the goal and the terms to chart progress, as well as - more importantly - involving an active management process that

(2011) pp. 63-84, p. 77.

3 Keetie Sluyterman, Dutch Enterprise in the Twentieth Century: Business Strategies in a Small Open Economy (Routledge, Abingdon, 2005) p. 206.

4 C.K. Prahalad and Gary Hamel, 'The Core Competence of the Corporation' Harvard Business Review (May 1990) pp. 79-91.

5 Ibid.

$6 \quad$ Although these ideas were developed by C.K. Prahalad and Gary Hamel, only Prahalad was actually involved as a consultant here (providing advice to the Philips management board) and therefore I will refer to him alone in my account below. - C.K. Prahalad and Gary Hamel, 'Strategic Intent', Harvard Business Review (May 1989) pp. 65-76; Prahalad and Hamel, 'The Core Competence of the Corporation'.

$7 \quad$ C.K. Prahalad and Gary Hamel, 'Strategic Intent',. 
'includes focusing the organization's attention on the essence of winning, motivating people by communicating the value of the target, leaving room for individual and team contributions, sustaining enthusiasm by providing new operational definitions as circumstances change, and using intent consistently to guide resource allocations. ${ }^{8}$

Prahalad and Hamel argue for a return to core competencies in order to galvanize these for the creation of new markets. ${ }^{9}$ To exemplify their definition of core competencies, the authors compared a diversified corporation with a tree:

'The trunk and major limbs are core products, the smaller branches are business units, the leaves flowers, and fruit are end products. The root system that provides nourishment, sustenance, and stability is the core competence.' ${ }^{10}$

In the view of Prahalad and Hamel, collective learning in the organization, harmonization of technology, and internal communication are key ingredients of core competences. Moreover, core competencies should provide access to a wide variety of markets, comply to perceived customer needs, and should be difficult to imitate.

When ASM faced the finiteness of its existence in 1992, its leadership seemed to find the solution to the company's agony along these lines. Throughout the 1990s, and by fits and starts, the company reconsidered the structure of its business units and competencies, complying with the popular convictions of Prahalad and Hamel. Did the company excel in semiconductor assembly and packaging equipment? Was there still a future in front-end - the wafer processing equipment? Were there any commonalities among the products? Misalignment with customer interests, a depressed market, and pressure from bankers urged the company to formulate answers to these questions. Disruptions in the cash flow repeatedly plunged the company into yet another crisis, closing off easy ways out, forging drastic decisions, and demanding a change of course. Only through action, clarity was obtained.

\section{Outline of Business IV}

Business IV is divided into three chapters, each one of them describing a new phase in the company's history based on fortuna as defining force. The first

8 Ibid.

9 Prahalad and Hamel, 'The Core Competence of the Corporation'.

$10 \quad$ Ibid., p. 83. 
chapter, Chapter 23, describes how ASM found itself in a true Machiavellian moment - when its survival was most uncertain - from early 1992 until the start of 1994. Many of its products were obsolete and the market was depressed. Chapter 24 describes how the company slowly but steadily regained its footing on account of a sudden surge in demand, from 1994 until 1997. And the third part, Chapter 25, covering the period 1997 until 1999, discusses how ASM's recovery was put in jeopardy through a costly settlement with Applied Materials and through the economic crisis in Asia. Finally, in the Conclusions, I will reflect on the company's course of action and the impact of fortuna. 


\section{Chapter 23 \\ Hitting bottom, 1992-1994}

In the years covered by this chapter, ASM was fully occupied with itself. External developments such as the advent of Asian semiconductor industries passed by without much responses from the equipment manufacturer. If the company was to survive, there was only one option: dealing with its inner demons.

\section{Industrial context:}

\section{A downward spiral}

From 1992 until 1994, ASM was confronted with two major transformations in its environment The first was economic and geographical: a downturn in the market and the subsequent emergence of a new equilibrium among national semiconductor industries. ${ }^{11}$ The second involved the industry-wide introduction of fabs that processed 200-millimeter wafers. Both transformations weakened the competitive position of ASM. Because the equipment manufacturer lacked the resources to anticipate and respond to them, the company's already painful situation grew worse.

\section{The rise and fall of national industries}

In the early 1990s, the Japanese semiconductor industry received a blow. After the bursting of an asset price bubble, the Japanese economy plunged into a recession. ${ }^{12}$ The country's growth stagnated, resulting in a dramatic shrinkage of the Japanese market for semiconductor equipment by 30 percent, from 3 billion dollars in 1991 to 2.1 billion in $1992 .{ }^{13}$ In 1993, this market slightly recovered, to 2.5 billion dollars, as American demand for personal computers somewhat alleviated the misery of the Japanese manufacturers of memory chips. ${ }^{14}$ As Japan was the global center of DRAM chips manufacturing, the country's recession

11 Dataquest, 'Chapter 3: Overview of the 1992 Wafer Fab Equipment Market', Dataquest Wafer Fabrication Equipment: 1992 Market in Review (14-6-1993), pp. 3.1 - 3.14, p. 3.3.

12 Ibid.

13 Dataquest, 'Chapter 3: Wafer Fab Spending Forecast', Dataquest Semiconductor Equipment Manufacturing and Materials: Midyear 1995 Forecast: Capital Spending, Wafer Fab Equipment, and Silicon (31-7-1995), p. 19.

14 Dataquest, 'Capital Spending Growth Snaps Back in 1993', Dataquest Semiconductor Equipment Manufacturing and Materials: Dataquest Perspective (23-8-1993) pp. 2-10, p. 6. 
resulted in deferment of investments in new, bigger DRAM chips and also, after a while, in scarcity.

In this period, the European chip industry began to stagnate as well, if not as dramatically as its Japanese counterpart. Two of the three predominant European chip manufacturers - Siemens and Philips - radically altered their technological and competitive strategies. Siemens decided to rely on Japanese technology for the realization of its ambitions in the memory market. Philips completely annulled its plans for SRAM and returned to its core competencies across the electronics conglomerate. ${ }^{15}$ Those two companies had been prime investors in new semiconductor equipment in Europe. Only the French-Italian chip manufacturer SGS-Thomson in fact invested in new equipment. ${ }^{16}$

All other European factories - foremost subsidiaries of American and Japanese chip producers - fabricated second generation computer chips, and did not rely on the latest equipment. ${ }^{17}$ These chips basically were copies of the native product lines from the likes of Motorola, NEC, Texas Instruments, and IBM. This implied that these European chip factories were filled with equipment from Japanese or American suppliers - depending on the origin of the parent company. While primarily in Europe these foreign subsidiaries invested in new equipment, European-based equipment manufacturers - like ASM Europe - had a hard time selling their products. The equipment vendors had to convince their customers to replace a proven - American or Japanese - machine with their own. This was an uphill battle.

The turnaround of Siemens' and Philips' strategies, then, resulted in an evaporation of the addressable European equipment industry. The equipment market shrank 16 percent in 1991 and another 1 percent in 1992 (totaling 641 million and 634 million dollars) before it recovered again in 1993 to 978 million dollars. ${ }^{18}$ The prospects for ASM Europe were extremely grim at the start of the decade.

Wherever there are losers, there are also winners (figure 59). In this case, the American semiconductor industry clearly prevailed. American chip manufacturers gained ground compared to all their European and Japanese competitors. The American market for semiconductor equipment grew three

15 During the dramatic reorganization scheme of 1990, dubbed Operation Centurion, C.K. Prahalad offered specific advice to Philips Chief Executive Officer Jan Timmer.

16 Dataquest, 'Chapter 3: Overview of the 1992 Wafer Fab Equipment Market', pp. 3.1 - 3.14, p. 3.5.

17 Dataquest, 'Capital Spending Growth Snaps Back in 1993', pp. 2-10, p. 7.

18 Dataquest, 'Chapter 3: Wafer Fab Spending Forecast', (31-7-1995), p. 19. 
percent to 1.6 billion dollars in 1992, and to 2.1 billion in $1993 .{ }^{19}$ Moreover, new initiatives were deployed to strengthen the cohesion of the national industry. This involved the Sematech Institute from the late 1980s onward, and related to that, a National Technological Roadmap for Semiconductors (NTRS) in 1992.. ASM America, being a subsidiary of a European company, fell apart and could not participate, except for the initiatives instigated by the global semiconductor equipment industry association SEMI.

\section{Figure 59}

Graph of worldwide capital expenditures by semiconductor producers in Europa, US, Japan and the rest of the world 1988-1999

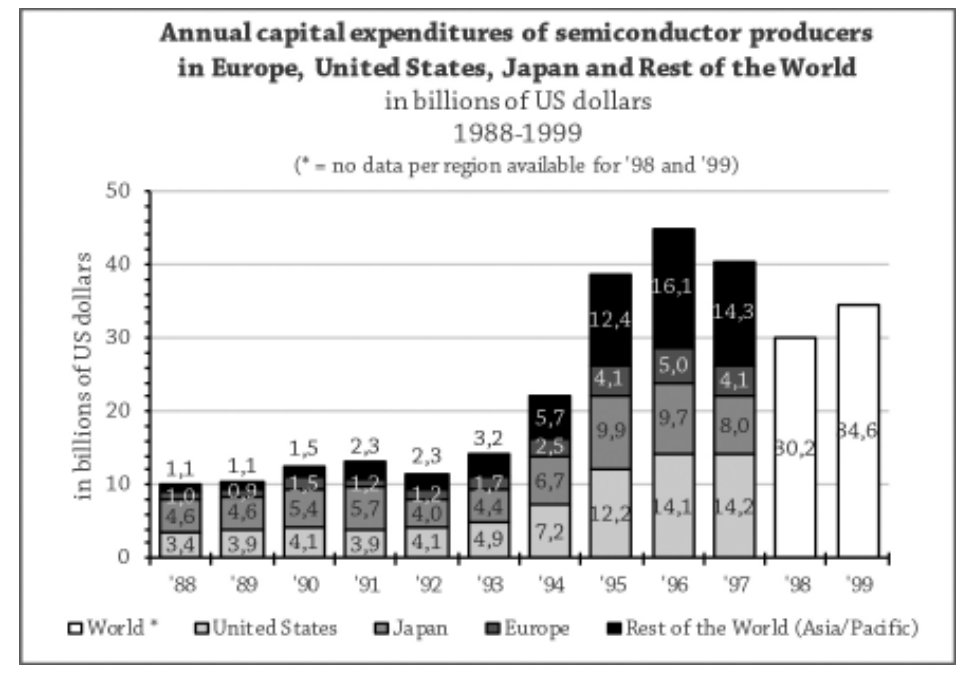

19 Ibid

20 Robert Schaller, Technological Innovation in the Semiconductor Industry: A Case Study of the International Technology Roadmap for Semiconductors (George Mason University, 2004); Richard Langlois and Edward Steinmueller, 'Strategy and Circumstance: The Response of American Firms to Japanese Competition in Semiconductors, 1980-1995', Strategic Management Journal 21:10 (2000) pp. 1163-1173; Rose Marie Ham, Greg Linden, and Melissa Appleyard, 'The Evolving Role of Semiconductor Consortia in the United States and Japan', California Management Review 41:1 (1998) pp. 137-163; Peter Grindley, David Mowery, and Brian Silverman, 'SEMATECH and Collaborative Research: Lessons in the Design of HighTechnology Consortia', Journal of Policy Analysis and Management 13:4 (1994) pp. 723-758; and Larry Browing,, Janice Beyer, and Judy Shetler, 'Building Cooperation in a Competitive Industry: SEMATECH and the Semiconductor Industry', The Academy of Management Journal 38:1 (1995) pp. 113-151. 
While Europe and Japan were struggling, two other national economies set their heads to the semiconductor industry: South Korea and Taiwan. ${ }^{21}$ Since the late 1980s, each developed a coherent strategy to foster their national chip industry. Ever since, their chip manufacturers steadily gained terrain, familiarizing themselves with the latest technology. In this effort, both countries closely observed the progression of the American-Japanese rivalry. Through a concerted effort of financial institutions, government, universities, chip manufacturers, and subcontractors, Taiwan and South Korea were determined to make their mark. From 1993, Samsung was market leader in the memory segment, taking benefit from Japan's economic stagnation. ${ }^{22}$

Central to their ambition was a new business model: the contract manufacturer, or in industry jargon, the 'foundry.' ${ }^{23}$ Such manufacturers - sometimes dubbed 'pure-play foundries' - did not design their own computer chips, but produced designs developed by other companies by contract. The foundry business that emerged in South Korea and Taiwan elaborated upon the assembly and packaging contract manufacturing industries that had been established in these countries since the late 1960s. From the late 1980s, this contract manufacturing started to offer wafer processes as well - completing the whole production line of a computer chip. Initially, foundries competed on manufacturing price, making up for their inadequacy in chip design (the US was way ahead in software development and chip design), while making complex production processes their own. Local Asian circumstances enabled competitiveness on cost, ranging from land and facilities

21 Unfortunately, Dataquest did not publish separate data for these national industries. Their growth was included in 'Rest of the World' or 'Asia/Pacific', thus including semiconductor industry activities in Hong Kong, Singapore, and Malaysia. Only from 1995 onward did Dataquest start to distinguish the two countries in its reports. By 1994, the Korean market for wafer fab equipment (1.7 billion dollars) had already outgrown Europe (1.4 billion dollars). In 1996, Taiwan constituted a market of 2.5 billion dollars compared to the South Korean market of 3 billion dollars and the European one of 2.8 billion dollars. In 1997, Taiwan also outpaced Europe (3.3 billion to 2.4 billion). - Dataquest, 'The 1995 Worldwide Wafer Fab Equipment Market: A Record Year - Competitive Analysis of Regional Dynamics, Industry Segments and Company Market Shares', Dataquest Semiconductor Equipment Manufacturing and Materials Worldwide Market Analysis (28-10-1996) p. 19; Dataquest, 'Wafer Fab Equipment: Market Summary', Dataquest 1997 Wafer Fab Equipment Market Share Estimates: Process Control and manufacturing Automation (1-6-1998), pp. 13-14.

22 Samsung's advent was based on DRAM chips, which were produced in the highest volumes. Only in flash memory - totaling 2.87 billion dollars in 1996 - did American chip manufacturers like Intel and AMD lead. The South-Korean chip manufacturer was followed by the Japanese Hitachi, NEC, and Toshiba. - Dataquest, 'Will the Memory Market Ever Recover?’ Dataquest Memories Worldwide Market Analysis (30-11-1998) pp. 11 and 12.

23 Initially, the foundry business was referred to as semiconductor contract manufacturing. The foundry business was not new. Chip manufacturers produced externally designed computer chips in the 1970s already. However, with development and fab costs escalating, the foundry business gained traction as of the early 1990s. 
to loans and labor. Moreover, foundries served and facilitated a growing American market of fabless chip companies, which lacked the resources to invest in a costly fab but commanded intrinsic knowledge about chip design. Over the years, the Taiwanese industry specialized in pure-play foundries, while South-Korean manufacturers would do a bit of both: develop their own designs and adopt the foundry model.

Regarding the equipment markets of South Korea and Taiwan, proven technologies set the tone. In the early 1990s, the Korean and Taiwanese chip manufacturers were not yet able to lead the industry technologically. First they had to catch up with the rest of the global industry. As latecomers, most of the foundries had an interest in equipment that allowed them to grow, to increase their capabilities, and to decrease risk. Moreover, the South-Korean memory chip industry in particular - in close conjunction with the authorities - pushed for the localization of development and manufacturing by equipment vendors. The Korean demands did not keep pace with the size of their markets, however.

These circumstances made the Korean and Taiwanese markets a mere fill-in job for many equipment manufacturers, including ASM. Through the Japanese or other Asian markets, the equipment vendors served their growing clientele in South Korea and Taiwan. In the case of ASM, these new markets were addressed by ASM Japan, ASM Pacific Technology, and ASM America. Each of these operations had other priorities, resulting in an inadequate response to the geographical market shifts.

\section{A new wafer size}

The second external development constituted the industry-wide introduction of silicon wafers with a diameter of 200 millimeters. This new wafer size required a complete redefinition of chip manufacturing plants (figure 60). Equipment had to be adjusted, as was true of factory facilities. The bigger wafer size constituted a coupe de grâce for the horizontal batch systems of ASM. At this size, it was more economical to process wafers either vertically or in single wafer systems. While less floorspace was required, higher process control was achieved. The introduction of the new wafers offered a new opportunity for all the equipment vendors. Results from the past did not guarantee selection for these new 200-millimeter fabs. Success in penetrating the new factories ensured sales for years to come. Once a tool was selected, chip manufacturers were reluctant to change.

Because of the crisis that numbed ASM in the late 1980s and the pervasive disunity among its business units, the company did not adequately address this new wafer size. Whereas ASM failed to make inroads, its competition did not hesitate and eagerly hurtled forward. Revenues among some of its major competitors - Applied Materials, Novellus, Tokyo Electron - in fact soared. Their 
success in selling 200-millimeter grew stronger over time, as extra production lines were opened. ${ }^{24}$ That ASM missed the boat regarding this development would come at a great cost to the company.

\section{Figure 60}

Table of changes in semiconductor manufacturing technology in 1985 and 1995

\begin{tabular}{|l|r|r|}
\hline & $\mathbf{1 9 8 5}$ & $\mathbf{1 9 9 5}$ \\
\hline Cost of a fab & $\$ 100 \mathrm{M}$ & $\$ 500 \mathrm{M}$ \\
\hline Automation & Cassette to cassette & SMIF \\
\hline Wafer size & $125 \mathrm{~mm}$ & $200 \mathrm{~mm}$ \\
\hline Linewidth & $2-1 \mu$ & $0.5-0.35 \mu$ \\
\hline Clean room class & 10 & 10 \\
\hline Chip Generation & VLSI & VLSI \\
\hline \# components & 1.000 .000 & 4.000 .000 \\
\hline Workers garment & Bunny suits & Bunny Suits \\
\hline
\end{tabular}

\section{Corporate course:}

\section{Draining a poisoned cup}

In each successive quarter of 1992, Arthur del Prado and his management team faced a deterioration of business, prospects, and their relationship with stakeholders. All major ASM front-end operations recorded losses, and their prospects for 1992 were all but favorable. The European market had evaporated in 1991, leaving ASM Europe frantically searching for orders to sustain its operation. ASM America continued to make losses. Furthermore, ASM Japan joined the pitiful as well, being confronted with a disappointing and rapidly worsening order book for 1992.

Within a depressed global semiconductor market, ASM failed to provide products that fulfilled the needs of its customers. Forecasts were negatively adjusted, backlogs disappointing, and profitability evasive. Three major issues prevented a recovery: obsolete products, immature innovations, and managerial turbulence.

The obsolete horizontal batch furnaces played a central role in this malaise. These products - whether for plasma, low pressure, or diffusion processes - had propelled ASM's growth since the late 1970s. The advent of customized chips in the United States and global progression to cleaner cleanrooms made the bulky horizontal furnaces obsolete. New deposition equipment was either single wafer

24 Dataquest, 'Chapter 5: Etch and Deposition Market Trends, Dataquest Wafer Fabrication Equipment: 1992 Market in Review (14-6-1993) obtained from computerhistory.org, p. 5.4-5.7. 
or a vertical batch (cf. Chapter 18). ASM's business units - ASM Europe, ASM Japan, and ASM America - faced different demands and commanded different expertise, and they failed to formulate coherent answers. They were being overtaken by the competition at a disquieting pace.

ASM's geographical business units sought to stop their decline through new products. In 1992, however, not a single one of these machines was yet in a state to substitute the regressing earnings. ASM Europe had placed its bets on the advanced cluster machine A600, of which three variations - low pressure chemical vapor deposition (LPCVD), aluminum, and plasma enhanced chemical vapor deposition (PECVD) - had been envisaged (see Chapter 22). ${ }^{25}$ At the instigation of IBM, ASM America had acquired a new vertical furnace from General Signal. This system, originally named EVTR and rebranded as A300, was meant to secure a stake in the rapidly growing market for vertical machines and to boost the competitive position of the Phoenix operation. However, originally projected purchases by IBM and affiliated chip manufacturers failed to materialize. ${ }^{26}$ In Japan, the local engineers developed a single wafer plasma CVD reactor in reaction to the increased competition from Applied Materials and Novellus and the subsequent decline of horizontal batch plasma deposition systems. By 1992, this new tool - originally dubbed K-1, but renamed Eagle-10 - was adopted by one Japanese customer only. ASM Japan's other group of products, its vertical furnaces, failed to make inroads beyond Japan, and even in Japan these did not succeed in obtaining any substantial market share. All of ASM's geographical business units were in the midst of transforming their business, in a desperate attempt to turn the tide.

To make things worse, the management team responsible for steering the American and European operations out of the mess disintegrated. The highly valued general manager of ASM Epitaxy, Dave Sikes, left the sinking ship in pursuit of another position. Bob Howells, the manager of a newly established Atlantic Business Unit covering ASM Europe and ASM America, clashed with Del Prado on the former's effectiveness, which resulted in the resignation of Howells (cf. epilogue Chapter 19). Meanwhile, Willem de Leeuw as Director of Corporate Development intervened again at ASM Europe, repairing the damage, restructuring activities, and steering the operation to safer grounds. Despite his best efforts, it was a job that hardly suited the original Director

25 Only Motorola remained interested in a LPCVD variation, named A600/2. In October 1992, both parties signed a joint development agreement. - ASM International, Arthur del Prado, 'Memorandum to Supervisory Board: Motorola A600/2, ref: 92.044 AdP/tv' (15-10-1992) Archive Arthur del Prado - RvC 1992-1993.

26 To cope with the company's financial troubles, ASM would cut back servicing. This negatively affected the relationship with IBM for years. - ASMI, Ray Friant, 'Memo: ASM Front-End status' (20-3-1993) Archive Arthur del Prado - RvC 1992-1993. 
of Technology. Operational management was quite different from managing technological development. All in all, the management turbulence aggravated ASM International's outlook for 1992. Del Prado had to hire new managers to curb further decline and to implement much needed reorganizations.

\section{A reviving equity crisis and a yearning for cash}

From the spring of 1992, things began to escalate (figure 49 in Chapter 19). ${ }^{27}$ The limited availability of cash was in fact the key problem. The financial forecast of ASM Europe fell short by 1.5 million Dutch guilders. Moreover, as ASM Japan could not attract bank loans, the head office had to jump in to provide a few basic guarantees. Also, the parent company - ASM International - did not have much left to pledge as collateral for the loans. Existing bank loans were fully utilized already and some had to be repaid. ${ }^{28}$ Cash was needed to alleviate the immediate needs while the organization adjusted to the new deplorable forecasts and assessment of assets.

Because the semiconductor industry as a whole was going through a period of relative stagnation, stocks did not attract investors. In the case of ASM International this low appreciation of its shares added to the deplorable performance of the company (figure 51 in Chapter 19). As a result, its quotation was depreciated to mere penny stock, evaporating the company's market capitalization. The share price declined from a maximum of 3.75 dollars per share at the start of 1992 to 0.75 dollar by the end of the year, or a market capitalization decline from 27.7 million dollars to a deplorable 5.55 million dollars. ${ }^{29}$ This depreciation was caused by declining sales - an 18.6 percent drop in 1992 - and losses of 41.1 million Dutch guilders, and these data even included ample interest in the flourishing ASM Pacific Technology stock. Taking into account all of these matters, ASM's exhausted loans were no longer adequately covered by collateral. The equity crisis revived.

Understandably, perhaps, the company's bankers grew more anxious. Both ABN Amro and the National Investment Bank [in Dutch: Nationale Investeringsbank, NIB] moved to secure their loans, as well as to limit their risks. Apart from ASM Pacific Technology and ASM Epitaxy, the company no longer seemed to represent any value at all. It was deemed unable to guarantee its loans or even the rent to be paid. In April 1992, the National Investment Bank issued a warning, referring

27 ASMI, Hans Peter Hukshorn, 'Memorandum: Financing opportunities, ref: 92.030/HPH/ evdh' (5-3-1992) Archive Arthur del Prado - RvC 1992-1993.

28 ASMI, Hans Peter Hukshorn, 'Memorandum: Minutes of the ASMI Supervisory Board Meeting on Tuesday March 17, 1992' (15-4-1992) Archive Arthur del Prado - RvC 1992-1993.

29 ASM International, Annual Report 1992 (March 1993). 
to a forthcoming instalment due by June 30, 1992. This amounted to 9.5 million Dutch guilders, with another 5.5 million by the year's end. An appointee of the banks orchestrated the contacts between ASM and the consortium of banks. ASM had to bend or break.

The bankers' decision to secure their loans instigated panic at ASM's headquarters. ${ }^{30}$ Del Prado assessed that in response to the bankers' verdict the company's auditors would add a qualification of concern to the annual report. ${ }^{31}$ Such a classification would destroy the public perception of ASM's solvency. Suppliers would insist on cash payments. New lenders would be deterred. And even more daunting, customers would challenge ASM's ability to serve them after procurement of its machines.

The ASM International Supervisory Board frenetically listed options to solve the immediate liquidity crisis and tried to determine a course of action that would regain the trust of the banks. ${ }^{32}$ Throughout the summer of 1992, the Supervisory Board met on a monthly - and sometimes even weekly - basis to assess progression and new options. The future of ASM was on the hinge.

The Supervisory Board played a pivotal role in 1992. Its members belonged to the highest echelons of the Dutch corporate world: Alexander ('Lex') Helfrich was former president of Royal Dutch Shell Netherlands and Ferdinand Rauwenhoff was former president of the semiconductor division of Philips and Philips Netherlands. Moreover, chairman Paul van den Hoek was one of the country's notable corporate lawyers. Finally, there was professor Frans Saris, director of the AMOLF research institute who operated as the board's technological conscience. All were accomplished professionals who did not have to prove themselves anymore.

The influence of the non-executives was ambiguous, however. On the one hand, their role as supervisory board member gave Del Prado and ASM International credibility toward the bankers and public officials involved. On the other hand, their actual input was fairly small. Most of them knew little about the dynamics of the chip industry and the interrelated technological developments. For these particularities they depended on Del Prado and the team of executives. The Supervisory Board supervised a chief executive officer who also happened to

30 ASMI, Hans Peter Hukshorn, 'Memorandum: Extraordinary Supervisory Board meeting Thursday April 23, 1992, ref: 92.117/HPH/gsf' (27-4-1992) Archive Arthur del Prado - RvC 1992-1993.

31 ASMI, Arthur del Prado, 'A position paper on the status of ASM International in the MicroElectronics World Market 1992' (27-4-1992) Archive Arthur del Prado - RvC 1992-1993.

32 ASMI, Hans Peter Hukshorn, 'Memorandum: Extraordinary Supervisory Board meeting Thursday April 23, 1992, ref: 92.117/HPH/gsf' (27-4-1992) Archive Arthur del Prado - RvC 1992-1993. 
be the company's majority shareholder and founder. Moreover, despite the board members' professionalism and stature, they were all friendly acquainted with Del Prado, as reflected in their mutual addressing each other as amice, or, in the plural, amici. As long as Del Prado did not smooth over the directives and concerns of the non-executive board members, he had been able to pursue his interest rather unperturbed. But in 1992 this was no longer an option.

\section{All for sale}

The reoccurrence of the financial distress and the drastic response of the banks reflected structural deficiencies in ASM International. Because the company was unable to safeguard the interests of its share- and stakeholders, the Supervisory Board had to intervene and Del Prado had to comply with its demands. The board concluded that the viability of the front-end operations as a whole was found wanting. ${ }^{33}$ The members discussed the continuation of ASM as sole supplier of assembly \& packaging equipment, attracting a partner for front-end, terminating front-end, and effects of decisions on governmental relations. This gave rise to the formulation of a new course of action. Del Prado defined the company's ambition and the parameters that had to be achieved to realize it:

'[We] decided on a course of action to implement an earlier decision by the board not to continue [front-end] on our own strength but to do so by finding a partner. This decision was made at previous board meetings and subsequently presented to our banks and the complete [business facilitator] commission. Both banks and commission wholeheartedly supported our views and encouraged us to handle the proceedings in an expeditious manner. ${ }^{34}$

In other words, all front-end operations - ASM Europe, ASM Japan, ASM America, and ASM Epitaxy - would be divested. A shrewd American investment banker by the name of Samuel ('Sam') Seidman was hired to search for probable partners. The Supervisory Board intended ASM to continue as a manufacturer of semiconductor assembly and packaging equipment.

This intention to divest front-end was just one half of the bargain; what was also needed was a distinct definition of how progress toward that goal was achieved. For this plan, the goal's operationalization was clear: to be able to sell the subsidiaries, the house had to be put in order at each of the front-end

33 Lex Helfrich, 'ASMI Strategie, organisatie en liquiditeit' (8-10-1990) Archive Arthur del Prado - RvC 1992-1993.

34 ASMI, Arthur del Prado, 'Memorandum to Raad van Commissarissen: ASM Front-End' (19-6-1992) Archive Arthur del Prado - RvC 1992-1993. 
subsidiaries. Their products had to represent at least some prospect, and their financial balance had to be improved.

Realizing this part of the strategic intent required intense process management, deliberate interference, and restructuring of activities, a task which was beyond Del Prado's capabilities - despite his unimpeded and audacious habits as entrepreneur. Del Prado typically avoided direct confrontation and had a hard time in acting vigorously in the operations he himself had so enthusiastically established and fostered. Making front-end ready for divestment required him to return on promises and sidelining loyal, trusted, and befriended managers. His inability to do so had put the company in its dreadful position in the first place. Someone else had to do the dirty work. The Supervisory Board proposed to hire a chief operating officer (COO) for front-end operations (including ASM Japan) in order 'to make front-end profitable in 1993 at 1992 sales levels.' ${ }^{35}$

Facing the company's temporal finitude, the new $\mathrm{COO}$ had to prevent the ship from sinking. All the subsidiaries had to comply with the strategic intent set out by the Supervisory Board and enforced by the COO. Their own survival was at stake. The Supervisory Board and Del Prado authorized the $\mathrm{COO}$ to do whatever was needed to make the front-end operations sellable. Facing their inability to clean up their own act, the subsidiaries had no other option but to comply.

\section{Elaboration of affairs}

\section{Friant takes up stock}

Del Prado had already selected his man: Ray Friant. Friant was an experienced, hands-on, and energetic manager with a proven record of restructuring faltering companies - including IT\&T and Gulf \& Western - who did not lose himself in grand strategies and organizational concepts. Moreover, he was a partner in the firm of investment banker Sam Seidman, hired to attract a buyer for ASM's entire set of front-end operations or parts thereof. Friant did not dodge the issues at hand and put his finger where it hurt.

Friant identified several strengths and shortcomings of the organization. ${ }^{36}$ This also included the role of Del Prado within the company. Friant foremost evaluated all challenges and opportunities for the company as to their chances of making money. After all, restoring the cash flow and profitability was ASM's shortest way out of its mess. One of the things he soon identified was the company's inadequate central authority. Friant was aware of Del Prado's strategy

35 ASM International, Hans Peter Hukshorn, 'Memorandum: Minutes of the ASMI Supervisory Board Meeting on Wednesday June 24, 1992' (3-7-1992) Archive Arthur del Prado - RvC 19921993, p. 4.

36 Seidman, Friant, Levine, Ltd., Ray Friant, 'Report to ASM International' (24-7-1992) Archive Arthur del Prado - Raad van Commissarissen '92-'93, RvC ASMI Maart 1992 - februari 1993. 
to grant the business units high levels of independence, in order to have them pursue their opportunities optimally. But, as the company expanded, Del Prado had lost control. According to Friant, this lack of central management caused 'confusion, duplication, non-cooperation, and ultimately significantly increased costs. ${ }^{37}$ ASM Japan was not aware of ASM America's or ASM Europe's activities and vice versa. As Friant stated: 'A common experience was for customers to tell ASM employees about what was happening within ASM. ${ }^{38}$ The lack of central authority was painfully visible in the product portfolio of ASM, which became kind of an anomaly in a globalizing industry. As argued by Friant:

'Much Money is wasted in Unwise Uncoordinated Projects ...; noncooperation between units has resulted in massive duplication wherein each geography has been allowed to develop their own version of almost any tool. Thus, ASM had paid to develop three vertical furnaces, two A600's (with a third cluster tool in the planning stages) and new versions of commercially available components. And all these actions have been justified in part by the "unique requirements of the local marketplace." 39

To decrease costs, this duplication had to end. Moreover, he propagated that the business units would take their financial responsibilities and that the holding company structured the cash flow:

"personnel have lived with the attitude that ASMI had "deep pockets", so that if things did not go well, the company would eventually send more money.' 40

In order to keep all the new projects and innovations viable, Del Prado had shared his financial resources among the operations to even their balances. Unpleasant surprises of the business units were absorbed by the head office and had put ASM in its current position.

Furthermore, across the company, forecasts and expectations had been structurally too optimistic. Friant characterized it as unwarranted optimism, since the company had been 'betting on the come' too long. Often, the supporting arguments did not really clear the objections for investment; economic pipedreams did. Friant was clear on this subject:

$\begin{array}{ll}37 & \text { Ibid., p. } 1 . \\ 38 & \text { Ibid., p. 2. } \\ 39 & \text { Ibid. } \\ 40 & \text { Ibid. }\end{array}$


'One of the least available talents is the individual who can look at the inertias of business, visualize the future, and chart a proper direction with the bold selections necessary for success. There is no question in my mind that Arthur del Prado has that talent. Perhaps he is too strong in capability. Because the counterbalance to the visionary is the restraint provided by practical business personnel who are focused on making money each month ... and that talent has not exerted itself within ASM's frontend business. ${ }^{41}$

Other concerns identified by Friant pertained to ASM France, which had to be sold because 'it was not central to the company's future. ${ }^{\prime 2}$ Moreover, ASM's management suffered from the frequent hiring of consultants and new executives, who often had little to add. And he advised to concentrate manufacturing at one location (or two locations at most). All of the above aspects, in the view of Friant, contributed to dragging ASM down, draining its cash flow, and undermining its versatility in the case of unexpected disappointments. ${ }^{43}$

Despite - or maybe due to - the bluntness of Friant's report, Del Prado was convinced by its analysis. So far, he had seen many consultants and executives come and go without making any impact on the company's organization. Being fairly small and highly decentralized, ASM required clear directives from the top, and these had to be accompanied by a round of process management to ensure that the directives were executed at all its operations across the globe. It was exactly this understanding that distinguished Friant from the earlier consultants. What is more, he respected the company's particularities and Del Prado's role as owner, founder, and chief executive officer.

On July 31, 1992, Del Prado announced the hiring of Ray Friant as chief operating officer, adding that all ASM front-end business operations would have to report to him. ${ }^{44}$ Initially this would apply for a year, a period that was to be extended if warranted by the results. All the operations had to report to Friant - including ASM Japan, which had been exempted so far - and he would report to Del Prado. Only in this way Friant would be able to manage the turnaround.

$41 \quad$ Ibid., p. 4.

$42 \quad$ Ibid.

43 Ray Friant, Beyond Buzzwords: The New Agenda for Directors, CEOs \& Executives (Advanced Management Press, Convent Station, 2006).

44 ASM International, Arthur del Prado, 'Letter to Miyazaki, Krickl, Granneman, and Hukshorn: Reorganization of the Front-End Business' (31-7-1992) Archive Arthur del PradoRay Friant files. 
He would not allow managers to shortcut to Del Prado, as had been common practice in the past.

In the successive months, Del Prado laid down his basic presumptions and objectives about the company's strategic intent, stipulating what he expected from the newly appointed chief operating officer. ${ }^{45}$ Primarily this involved the survival of ASMI with preferably the integral continuation of front-end with or without a partner. Next, he invited Friant to redefine the cooperation between ASM Europe, ASM America, and ASM Japan. Del Prado especially drew attention to ASM Europe, where the situation was most dramatic, with an expected loss of 20 million Dutch guilders in 1992. The chief executive officer warned his newly appointed chief operating officer not to rush to conclusions. The European operation was critical to sustain backing - not only financially - from the Dutch government, the National Investment Bank, and Philips.

Having laid down his priorities, Del Prado left everything else up to Friant to sort out. Friant became responsible for the execution and operational management of all the company's divisions and operations, from development to sales and manufacturing. Del Prado explained his own modus operandi, which he intended to continue:

'I would like to repeat again that I have no intention to participate in daily operations, yet I have a strong desire and intent to be involved in critical decisions dealing with product choices, where, when, how, etc. ... To follow the heartbeat of the group closely during the first few months is very important to me and I intent [sic] to listen to a number of telethons and join some of the management meetings. In none do I plan to take a role of any significance other than when called upon. ${ }^{46}$

The arrival of Friant enabled Del Prado to do what he did best. Put in nautical terms, Del Prado remained the skipper, determining the course and destination, exploring the horizon, and ensuring his position as leader, whereas Friant did the rest: removing ballast that dragged down the ship, establishing order among the crew and having them man the pumps, repair the sails, and clean the deck.

\section{Easy pickings}

Right from the start, Friant had to implement lingering reorganizations that were meant to cut costs. These actions were primarily aimed at decreasing the drainage of cash on a monthly basis. Up to that point, ASM International's chief financial

45 ASM International, 'Facsimile Message to Ray Friant, ref: 92.068 AdP/tv' (21-8-1992) Archive Arthur del Prado - Ray Friant files.

46 Ibid. 
officer (CFO) Hans Peter Hukshorn had managed to maintain a cash flow by the skin of his teeth, and to ensure just sufficient to cover immediate expenses like salaries. One of these solutions - which would prove to be a rather bitter one in the long term - was to liquidate ASM's receivables from its participation in the ASM Lithography joint-venture, effectively annulling any prospect of returns in that company or sharing in its future fortunes. With Friant on board, the operations could be shrunk in conjunction with their diminished order books.

From August onward, all operations had to lay off employees. ${ }^{47}$ This accumulated to ten percent of the total 2,500 staff members worldwide. ASM America laid off 45 staff members, and ASM France 30. At ASM Europe in Bilthoven, 100 staff members were forced to leave the company, reducing the staff to 540. For the first time in ASM Japan's history, Friant convinced the Japanese management to lay off 75 employees as well..$^{48}$ Simultaneously, Friant opened discussions with Del Prado to launch an incentive program for the remaining key employees. ${ }^{49}$

Having curbed costs, Friant moved on to reorganize ASM International. The organizational structure and the ensuing appropriated tasks had to contribute to the defined strategy of making front-end profitable again. Friant instigated a major change from geographically oriented management to product management..$^{50}$ Geographical management - embodied in ASM Japan, ASM America, and ASM Europe - had reinforced the proliferation and diversification of products. Local demands had been adduced as rationalizations for localization of products, which had deteriorated economies of scale. The geographical viewpoint obstructed a clear apprehension of the true cost of the products. By turning to product management, all products could be evaluated on their merits. This made it possible to discontinue an activity swiftly if some problem presented itself. Friant's reorganization toward product management improved the flow

47 ASM International, Arthur del Prado, 'Memorandum to Supervisory Board' (16-09-1992) Archive Arthur del Prado - Raad van Commissarissen '92-'93, RvC ASMI Maart 1992 - februari 1993.

48 Though this was easier said than done. Reducing staff was difficult due to Japanese standards of 'life-long employment'. However, Friant convinced ASM Japan's managers Yo Miyazaki and Fukumi Tomino that it was either this or bankruptcy. A neighboring company that shut down, leaving all its employees jobless, helped to make Friant's plea more convincing. -Friant, Beyond Buzzwords; Ray Friant, 'Interview with author', Fukumi Tomino, 'Interview with author'.

49 ASM International, Supervisory Board, 'Minutes of the ASMI Boardmeeting held on September 22, 1992' (28-09-1992) Archive Arthur del Prado - Raad van Commissarissen '92'93, RvC ASMI Maart 1992 - februari 1993.

50 ASM International, Arthur del Prado, 'Memorandum: Reorganization ASM front-end organization' (24-8-1992) Archive Arthur del Prado - Ray Friant file. 
of information, affording him and the Supervisory Board a better apprehension of a given situation.

Friant appointed designated product managers. He picked Armand Ferro for epitaxy and Greg Jones for clustered furnaces, the EVTR. Hein Onkenhout stayed on as product manager for the A600 in Europe and the United States, while Nobuyoshi Takahashi was put in charge of the A600 in Japan. Yasuo Yamada was made responsible for the single wafer plasma reactor Eagle-10, and Yukikazu Ueno for the remaining horizontal plasma business in Japan. No product manager was appointed to the horizontal LPCVD and diffusion furnaces, as this business had virtually come to a halt. Furthermore, Friant assigned distinct sales managers to pivotal customers, such as the experienced John Krickl to Intel.

The technical director of the AMTC, Ernst Granneman, was appointed as chief technology officer, tasked to coordinate technological development at and among the various product groups. In this capacity, he replaced Willem de Leeuw, who temporarily devoted all his energy to ASM Europe. More importantly, Granneman had to curtail the proliferation of technological developments. Like Friant, he visited all the subsidiaries on a monthly basis to enforce the corporate strategy, realize the strategic intent, and control their competitive strategies. This was done by spending one week at ASM Japan, one week in the United States, one week at ASM Europe in Bilthoven, and another week at the Bilthoven headquarters.

In this comprehensive effort to turn around the company, ASM Europe proved to be a real tour de force. Ever since the late 1980s, its operation had been troublesome, from the accusations for illegal export behind the Iron Curtain in 1987 and the evaporation of the European market in 1991 to the obsolete horizontal furnaces and constantly declining sales. Basically it had no products and no market anymore. What was left was its profound expertise in diffusion and low pressure chemical vapor deposition processes.

However, the Dutch government and the European authorities had invested heavily in ASM's Bilthoven activities. This involved an ambitious technology center, the AMTC, and technological development embodied by the A600 (cf. Innovation III). The National Investment Bank debenture had been guaranteed by the authorities as well. Simply depreciating these investments was not possible. Had it not been for its embedment in the strategic European governmental and industrial infrastructure, ASM Europe would have been scrapped years earlier.

The Dutch Ministry of Economic Affairs was a powerful ally in the effort to salvage the Bilthoven operation, making it sellable. ${ }^{51}$ Del Prado unleashed all

51 ASMI, Hans Peter Hukshorn, 'Memorandum: Extraordinary Supervisory Board meeting Thursday April 23, 1992, ref: 92.117/HPH/gsf' (27-4-1992) Archive Arthur del Prado - RvC 1992-1993; ASMI, Hans Peter Hukshorn, 'Memorandum: Minutes of the ASMI Supervisory Board Meeting on Tuesday March 17, 1992' (15-4-1992) Archive Arthur del Prado - RvC 
his charm in his interaction with the Ministry, appealing to the strategic role of the microelectronics industry and ASM's position in it. ${ }^{52}$ From June onward, the Dutch government and ASM engaged in protracted deliberations about the redefinition of ambitions for the Bilthoven operation and creating new prospects - which might attract buyers.

The first step was to confront the reality of the AMTC's poor functioning. This technology center had not lived up to the original expectations of improving coherence among the operations and harnessing technological development (cf. Innovation III). But its continued operation would come at a high price, and therefore it was decided - in close consultation with the public officials - to shut down the technology center. ${ }^{53}$

One AMTC activity, the internal evaluation of new technologies, was transferred to a rapidly growing research institute called the 'Inter-universitair Micro-Elektronisch Centrum' (IMEC) in Leuven, Belgium - fairly close to the Dutch border. ${ }^{54}$ At IMEC a complete new 200-millimeter production line for CMOS computer chips was present, including ASM's tools and also lithography, etching, etc. ASM installed its latest products in the IMEC cleanroom for free, while in return it would get to evaluate and integrate its processes in the IMEC CMOS-production line. IMEC would be allowed to use ASM's machines for a designated amount of time, while also having access to the latest semiconductor manufacturing equipment. It was a win-win deal. ${ }^{55}$ Although the papers and agreements were prepared in the fall of 1992, the collaboration would officially commence in October 1993 (and it in fact lasts to this day). ${ }^{56}$

Simultaneous with the termination of the AMTC, ASM's managers - Del Prado, Director of Corporate Development Willem de Leeuw, and the designated manager for governmental affairs, Erik Kamerbeek - discussed with the public

1992-1993; ASMI, Hans Peter Hukshorn, 'Memorandum: Extraordinary Supervisory Board meeting Thursday April 23, 1992, ref: 92.117/HPH/gsf' (27-4-1992) Archive Arthur del Prado - RvC 1992-1993.

52 ASMI, Arthur del Prado, 'A position paper on the status of ASM International in the MicroElectronics World Market 1992' (27-4-1992) Archive Arthur del Prado - RvC 1992-1993.

53 ASM International, Arthur del Prado, 'Letter to Ministry of Economic Affairs, ref: 92.061 AdP/tv' (29-7-1992) Archive Arthur del Prado - Raad van Commissarissen '92-'93, RvC ASMI Maart 1992 - februari 1993, ASM International, Arthur del Prado, 'Letter to Ministry of Economic Affairs, ref: 92.064 AdP/tv' (5-8-1992) Archive Arthur del Prado - Raad van Commissarissen '92-'93, RvC ASMI Maart 1992 - februari 1993.

54 AMTC, Erik Kamerbeek, 'Memorandum: IMEC-ASM, m-A921101/EK/ivi' (6-11-1992) Archive Arthur del Prado-IMEC file.

55 ASMI, Erik Kamerbeek, 'Concept letter to Ministry of Economic Affairs, Mr. W.R.J.L. van 't Hof, ref: b-A/9211.EK/if' (6-11-1992) Archive Arthur del Prado - IMEC file.

56 ASMI, IMEC, 'Overeenkomst IMEC vzw - ASM International' (18-10-1993) Archive Arthur del Prado - IMEC file. 
officials of the Ministry of Economic Affairs how competencies in semiconductor equipment development and manufacturing could be saved. Another Dutch semiconductor equipment manufacturer, Tempress (see Innovation Chapter III), also engaged in these talks. This company was a subsidiary of the American electronics conglomerate General Signal, until it became independent through a management buy-out in the late $1980 \mathrm{~s} .{ }^{57}$ Afterward, Tempress had obtained technology development credit - a subsidy scheme resembling venture capital - from the Dutch government to develop a vertical furnace. This new furnace, named the clustered vertical thermal reactor (CVTR), elaborated upon a furnace developed by General Signal, named EVTR, which earlier in 1990 was acquired by ASM America from General Signals (figure 56 in Chapter 22). By 1992, Tempress faced the same problems as ASM Europe. It could not sell its incumbent products, the horizontal deposition and diffusion furnaces, while the CVTR was not yet ready for introduction.

Thus, by 1992, the Dutch Ministry of Economic Affairs faced two faltering businesses in semiconductor equipment, which it had both supported by means of innovation subsidies. To safeguard its investments and local employment, as well as the Dutch role in semiconductor manufacturing technology, the Ministry's agency responsible for technological development, named Stipt, brought together Del Prado and the president of Tempress, John Benoist. As reported by Erik Kamerbeek:

'Stipt claimed ... that it has analysed both ASM and Tempress and that it came to the conclusion that both companies are technically very advanced and are having problems due to market conditions beyond their influence. In order to overcome this difficult period, the companies have to be financially supported, [but] ... Tempress will only be given [support] on the basis of a close cooperation with ASM. ${ }^{58}$

Throughout the summer of 1992, the outlines of the plan emerged, attracting severe criticism of the cynical ASM Supervisory Board..$^{59}$ The CVTR seemed to

57 Del Prado had been co-founder of Tempress in 1968, which at that time was known as Sola Basic Netherlands. After General Signal and Sola Basic Industries merged in the mid-1970s, the Dutch operation was renamed. By that time, Del Prado no longer had a stake in the operation. See Business I.

58 ASMI, Erik Kamerbeek, 'Memorandum: Cooperation on Horizontal and Vertical reactor development and manufacturing between ASMI and tempress, ref: m-A/921001/EK/pk' (5-10-1992) Archive Arthur del Prado - RvC 1992-1993.

59 ASM International, Supervisory Board, 'Minutes of the ASMI Boardmeeting held on September 22, 1992' (28-09-1992) Archive Arthur del Prado - Raad van Commissarissen '92'93, RvC ASMI Maart 1992 - februari 1993. 
overcome the shortcomings of ASM America's EVTR, ASM Japan's VMP, and ASM Europe's A600 vertical systems. ${ }^{60}$ The collaboration with Tempress constituted ASM's last straw for staying in the market for low pressure CVD, and saving ASM Europe from obsolescence. Moreover, the governmental involvement ensured a very low risk for commercialization of the CVTR. This is why ASM's Supervisory Board yielded and gave its consent.

Under close supervision of public officials, a deal was concocted in which ASM would transfer its knowledge for integrated low pressure CVD and oxidation and diffusion processes to a joint-venture named CVTR B.V. ${ }^{61}$ Tempress would transfer the hard- and software of the CVTR and the interrelated public funds. ASM Europe, Tempress, Stipt, and NOM - a public fund in support of employment in the northern Dutch provinces - would have a stake in the joint venture. After one year, ASM could acquire the complete CVTR. In exchange, manufacturing of the CVTR would be done by Tempress, in Hoogeveen, and ASM Europe would transfer its remaining knowledge, inventory, and business for horizontal furnaces to Tempress. For commercialization, the CVTR would be renamed A400. In December 1992 all parties signed an agreement, formalizing ASM Europe's and Tempress' - last resort while also appeasing an anxious government. ${ }^{62}$

\section{Buying time}

Amidst all operational turmoil, the bankers' anxiety had not yet been removed. After years of crisis, bankers had grown tired of Del Prado's audaciousness. In the fall of 1992, members of the Supervisory Board capitalized on their esteem in the Dutch corporate world in order to nudge the bankers. ${ }^{63}$ The efforts to improve

60 ASM Europe, Greg Jones, 'Memorandum: Benefits of Product Collaboration with Tempress' (4-5-1992) Archive Arthur del Prado - Raad van Commissarissen '92-'93, RvC ASMI Maart 1992 - februari 1993.

61 ASM International, Arthur del Prado, 'Tempress, ref. 92.035 AdP/tv' (31-08-1992) Arthur del Prado Archive - Raad van Commissarissen '92-'93, RvC ASMI Maart 1992 - februari 1993; ASM International, Erik Kamerbeek, 'Cooperation on Horizontal and Vertical Reactor Development and Manufacturing between ASMI and Tempress' (5-10-1992) Archive Arthur del Prado - Raad van Commissarissen '92-'93, RvC ASMI Maart 1992 - februari 1993.

62 ASMI and Tempress, 'Intentieverklaring' (27-11-1992) Archive Arthur del Prado - RvC 19921993; ASMI, Arthur del Prado, 'Letter to Minister of Economic Affairs, dr. J.A. Andriessen, ref: 92.084 AdP/tv’ (21-12-1992) Archive Arthur del Prado - RvC 1992-1993.

63 Stibbe \& Stimont, Paul van den Hoek, 'Letter to Nationale Investeringsbank, Prof. Dr. M.J.L. Jonkhart; ref. PCH/1h-105308.B10’ (11-9-1992) Archive Arthur del Prado - Raad van Commissarissen '92-'93, RvC ASMI Maart 1992 - februari 1993; Van den Hoek managed renegotiations of a convertible loan of 21.1 million guilders with American bankers Grantham, Mayo Van Otterloo \& Co By pledging ASM Epitaxy as security, he succeeded in extending the installment by six years, from 1993 to 1999. - ASM International, Hans Peter Hukshorn, 'Financieringsvoorstel GMO; ref. 92.039 AdP/tv' (4-09-1992) Archive Arthur del Prado - Raad van Commissarissen '92-'93, RvC ASMI Maart 1992 - februari 1993. 
ASM's front-end profitability had stretched the bankers' patience and bought the company some time. In December 1992 and January 1993, the bankers urged the Supervisory Board to act: either sell front-end or improve the company's equity in another way.

But the search for a partner for front-end had not resulted in anything substantial yet. Seidman, the investment banker acting on the company's behalf, approached competitors Novellus and Varian, the German Ministry of Education and Technology (BMFT) and Daimler, the Japanese Sumitomo Bank and NEC subsidiary Anelva, and he established initial contacts with General Electric and also Alcatel. ${ }^{64}$ The board members grew outright pessimistic about the prospects of recovery. The lack of equity, the huge debt, and the constantly regressing results and forecasts offered little consolation.

Finding a partner for ASM's front-end operations as a whole seemed not feasible. ${ }^{65}$ Nobody was interested. Canaan Partners negotiated for a stake in ASM America, but remained hesitant as the American operation continued to dwindle. For ASM Japan, there were talks with a variety of candidates, including Tokyo Electron, Anelva, and Mitsui \& Co. With respect to ASM Europe, the collaboration with Tempress continued to evolve, while the possibility of developing new initiatives together with the wider Dutch industry and/or the Dutch authorities was contemplated as well. ${ }^{66}$ ASM Epitaxy was still performing beautifully, and therefore an initial public offering of this operation was considered. This option could not be pursued, however, because of an unremitting and escalating litigation about intellectual property infringement with Applied Materials. Moreover, as Del Prado concluded:

'After extensive discussions with Ray Friant, Ernst Granneman, John Krickl and others we all have come to the conclusion that if Epi were to be sold $100 \%$ there is no future left for the other front-end operations.' ${ }^{67}$

64 ASMI, Arthur del Prado, 'Memorandum to Raad van Commissarissen: ASM Front-End' (19-6-1992) Archive Arthur del Prado - RvC 1992-1993.

65 ASM International, Supervisory Board, 'Minutes of the ASMI Boardmeeting held on December 8, 1992' (21-12-1992) Archive Arthur del Prado - Raad van Commissarissen '92-'93, RvC ASMI Maart 1992 - februari 1993.

66 Delft Institute of Microelectronics and Submicrontechnology, CIM Beenakker, 'Fax: Samenwerking DIMES/Nederlandse microelectronica equipment industrie. Verslag bijeenkomst d.d. 7 januari 1993 te Delft' (8-1-1993) Archive Arthur del Prado - CVTR.

67 ASMI, Arthur del Prado, 'Memo: Financing operations, ref: 93.023 AdP/tv' (21-3-1993) Archive Arthur del Prado - RvC 1992-1993. 
An initial public offering and an equity investment of 35 million dollars for ASM Epitaxy was annulled. ${ }^{68}$

This conclusion and the state of affairs put the original strategic intent in jeopardy. It meant that either it would take longer to improve results of the frontend operations or they could not be sold at all. At the same time, however, the company still had to deal with immense financial liabilities. Pledged securities were slightly higher than the approximate 115 million Dutch guilders indebted to ABN Amro, Paribas, and the National Investment Bank.

There were different perceptions of the gravity of the situation, however. In particular Del Prado dismissed the anxiety of the banks. ${ }^{69}$ The entrepreneur estimated the value of the securities - this concerned ASM Fico and ASM Pacific Technology - much higher. He was most certain that in the case of a divesture, he would get a better price for these two operations than assumed by the banks. Not 40 but 50 million dollars for ASM Fico, and 110 million instead of 80 million for ASM Pacific Technology, plus he also pointed out that the Dutch government secured a significant portion of the loans. ${ }^{70}$ Consequently, he calculated a positive margin in securities of approximately 51 million dollars. Del Prado's assessment illustrated his defiant attitude toward his financiers.

Supervisory Board member Lex Helfrich - capitalizing on his reputation as former president of Shell Netherlands - took it upon him to find a compromise between Del Prado and the agitated bankers. ${ }^{71}$ In their meetings, the bankers threatened annulment of all credits by the summer of 1993, but Helfrich persuaded them slightly to improve the valuation of the securitizations. At the same time, he urged Del Prado to consider the sale of ASM Pacific Technology and ASM Fico. His expectations for an immediate resolution were grim:

'The front-end companies have continuously suffered heavy losses and cash inputs; the only bright exception being Epi. ... The 5-year FE [front-

68 Bear, Stearns \& Co, Michael H. Lowry, 'Letter to Arthur del Prado, confirmation of management IPO ASM Epitaxy’ (13-4-1993) Archive Arthur del Prado - ASM Epitaxy files; ASM Epitaxy, 'ASM Epitaxy, Inc: $\$ 35,000,000$ equity investment. Executive Summary’ (April 1993) Archive Arthur del Prado - ASM Epitaxy files.

69 In the margins of this note, Del Prado wrote down his estimation of the securities. In a later note to Supervisory Board member Lex Helfrich, Del Prado even adjusted his valuation of the securities from 174 million to 203 million. -ASM International, Hans Peter Hukshorn, 'Memorandum: Banks Perception about their security, ref: 93.006/HPH/evdh' (5-1-1993) Archive Arthur del Prado - RvC 1992-1993; ASMI, Arthur del Prado, 'Facsimile Message to Lex Helfrich, ref: 93.016 AdP/tv' (25-1-1993) Archive Arthur del Prado-RvC 1992-1993.

70 ASMI, Arthur del Prado, 'Facsimile Message to Lex Helfrich, ref: 93.016 AdP/tv' (25-1-1993) Archive Arthur del Prado-RvC 1992-1993.

71 ASM International, Alexander Helfrich, 'Note 93.006 AdP/tv' (1-2-1993) Archive Arthur del Prado-RvC 1992-1993. 
end] plan is very optimistic, even in case of strong economic growth in the USA. It is already revised downwards. As RF [Ray Friant] says: the base is so small, that every product must technically and economically (out-)perform against bigger and good competitors. To continue with it, is appealing for say another two years, but it is no doubt a high risk road which requires luck and financial backing and reserves of substance. ${ }^{72}$ [emphasis in original]

After it became clear that the ASM front-end could not be capitalized, loans had to be redeemed by the back-end operations of ASM Fico and ASM Pacific Technology. This involved a divestment of five percent of shares held by ASM International in ASM Pacific Technology, creating about 10.4 million Dutch guilders in cash. An installation of 2.8 million Dutch guilders of the convertible debenture held by Grantham, Mayo, and Van Otterloo was fulfilled by pledging 1.3 million shares of ASM International, preventing a drainage of the exhausted cash reserves. ${ }^{73}$

More importantly, the Supervisory Board ordered the immediate divestment of ASM Fico. ${ }^{74}$ The Dutch operation, active in packaging technologies, had been prepared for divestment since the late 1980s (see Business III). After a first effort at divestment failed in 1987, ASM Fico's managers Jan Willem Baud and Richard Blickman were tasked to make the operation sellable. This primarily involved unraveling the various activities at ASM Pacific Technology. Both operations had been fishing in the same pond. Blickman and Baud set up an independent sales infrastructure in South-East Asia, developed a competitive product portfolio, and reduced the manufacturing costs of its products.

By 1993, ASM Fico had a new advanced product portfolio of automated encapsulation machines, including an attractive clientele of major American chip manufacturers. Trim \& Form machines were built and designed in Zevenaar, molds in Brunssum, and automated molding equipment in 's-Heerenberg and Herwen, all locations near the Dutch-German border. In addition, operations for the production of parts were established in Portugal and Malaysia, to lower the costs of production and in imitation of the integrated manufacturing strategy pursued by ASM Pacific Technology. ${ }^{75}$ A very lucrative deal with the former Soviet

72 Alexander Helfrich, 'Handwritten Note for Discussion' (4-2-1993) Archive Arthur del Prado - RvC 1992-1993.

73 ASM would have the right to call these shares once they reached a certain value within one and two years. - ASM International, 1993 Annual Report.

74 ASMI, Arthur del Prado, 'Memorandum: Present strategies and progress, ref: $93.003 \mathrm{AdP} /$ tv' (28-1-1993) Archive Arthur del Prado - RvC 1992-1993.

75 ASMI, Hans Peter Hukshorn, 'Memorandum: Minutes of the ASMI Supervisory Board Meeting on Tuesday March 17, 1992' (15-4-1992) Archive Arthur del Prado - RvC 1992-1993. 
Union involving transfer of knowledge in succession to a Soviet-IBM deal had improved the balance sheet even more. In 1992, ASM Fico (employing a staff of 495) managed to secure 110 million Dutch guilders in revenues. The operation was ready for divesture. Throughout 1993, Del Prado, Willem de Leeuw, and the managers of ASM Fico approached various potential buyers.

These actions - selling a stake in Pacific Technology, the discharge in stock, and the preparations for divesting ASM Fico - bought again some time. Through these actions, Del Prado's assessment about the value of his back-end operations was tested. In the meantime, ASM front-end proceeded further along the 'high risk road' of commercializing its remaining products, while tempting yet disinclining candidates as partner. Damocles' sword had been hanging over ASM for some time already. Just as Helfrich had foreseen, ASM still required a helping hand from fortuna to succeed on this journey.

\section{Distinguishing glimmers of hope}

In the spring of 1993, skepticism about the viability of front-end prevailed within the Supervisory Board. Among others, Van den Hoek and Helfrich urged for deliberate action: divest back-end or sell/close front-end. Relying on the results of Ray Friant, Del Prado regained hope about a continuation of his firm, however. The minutes of one of the meetings illustrated the disparity in confidence within the Supervisory Board:

'The choice between back-end and front-end as per RF is one taking of risks and depends on one's passion for front-end. At this point $\mathrm{PvdH}$ made clear that this passion clearly exists with AdP and not with the Supervisory Board. AdP commented that his "passion" only relates to this responsibilities in view of the opportunities that exist in FE as defined earlier on .... AdP believes that a "halfway alternative" is possible as he believes in front-end due to the many recent changes. ${ }^{76}$

Del Prado had to balance between sustaining his reputation of being rational toward the Supervisory Board and the bankers, while ensuring he persevered in saving as much as possible of the company he founded and nurtured. To that end, he deployed the strategic interest taken by the Dutch ministry in ASM, and the role of ASM within a bigger game than the daily financial mores of ASM International. It was an argument to which the Supervisory Board members minding their position in Dutch society and their friendly relationship with Del

76 ASMI, Hans Peter Hukshorn, 'Memorandum: Minutes of the ASMI Boardmeeting held on February 5, 1993’ (3-3-1993) Archive Arthur del Prado - RvC 1992-1993. 
Prado - were susceptible. The minutes of the same Supervisory Board meeting summarized Del Prado's plea:

'the Dutch ministry of Economic Affairs had provided significant amounts of research funding to ASM. He [AdP] considered it the boards responsibility and certainly his responsibility that everything is being done to preserve the potential, positive industrial product capabilities in the Netherlands. Only when both, the banks, the government, after considering the contemplated drastic restructuring and refinance actions and in spite of the securities they possess refuse to maintain to support these efforts, should ASM consider closing its front-end operations in this country.' ${ }^{\text {77 }}$

Del Prado's argument was supported by glimmers of hope.

Meanwhile, Friant had been making some impact. In the first half of 1993, Friant still kept all product groups intact. Although faltering products such as horizontal furnaces were not deducted yet, their viability was limited and their continuation ate into the overall research and development funds. All attention was directed to stopping the drainage of cash. ASM Epitaxy and its Epsilon epitaxial reactor served as the backbone of ASM front-end's future (see Innovation II). This product constituted the sole profitable and prospective product of the whole organization.

Through the frantic efforts of the subsidiaries, however, Friant managed to identify two new products that could help the recovery of ASM. The first was the Paragon, developed by ASM Epitaxy. It was a de facto Epsilon reactor, but adjusted to deposit polysilicon. The machine addressed a projected need for cleaner and more uniform polysilicon processes in the American market, where the advent of customized chips had put a premium upon flexibility and quality of production techniques. The marketing team of ASM Epitaxy expected that the Paragon might replace traditional batch furnace-based polysilicon processes. Moreover, the Paragon constituted the first test of the versatility of the Epsilon reactor, because for a long time it had been argued that the machine would be applicable to many other single wafer deposition processes. ${ }^{78}$

The second product that might increase ASM's viability in the future was the CVTR. Friant was confronted with the fact that ASM might have to leave the market for low pressure CVD and diffusion processes, as the Japanese and American machines were not competitive. Only the CVTR - a product not yet

77 Ibid.

78 This involved Chris Werkhoven since 1989, but also Wiebe de Boer in 1986. The latter moved from Epsilon Technology to the group of Chris Werkhoven at Philips Research in 1986. 
fully developed - seemed to constitute a last resort. As Friant reported to Del Prado:

'The belief ... is that CVTR can be produced more cheaply, and will ultimately have greater flexibility than the A300. This argument has a lot of merit. And the arrangement which now exists to have the development done at the AMTC with a joint ASM-Tempress team, paid for by the Dutch Government is brilliant. ... Right now, we are gambling that the CVTR will prove to be the best solution.' ${ }^{79}$

As development of the CVTR continued and results of its potential were achieved, Friant and Del Prado included the machine as an integral part in ASM's future product portfolio.

By June 1993, after serving almost one year as COO, Friant distinguished some minor glimmers of hope for ASM. As he stated in a letter to Del Prado:

'My enthusiasm for the Front-End is based on ASM continuing Epi, developing Paragon, and acquiring and developing CVTR.' ${ }^{\text {'8 }}$

However, betting the company's future on two unfinished products was hardly desirable, given the company's narrow base. As Friant continued:

'there is no way Epi will generate enough cash to fund 1) Paragon development, 2) CVTR acquisition and development, and 3) losses from other Front-End product lines. Thus the idea expressed in your memorandum of "letting F/E carry its own flag... (during 1994, 1995 and 1996)" is unrealistic.... I also have the perspective that if ASM tries to develop CVTR on a shoe-string budget, the project will fail, and ASM Front-End will fail along with it. It takes money to make money. And while I am mindful of the Supervisory Board's skepticism because they have received so many unrealistic forecasts in the past, I also believe that we have spent enough time with CVTR to make the risk worthwhile. ${ }^{81}$

79 ASM Front-End Business, Ray Friant, 'Memo to Del Prado, Hukshorn and Seidman: Operating with an Arm's Length America' (14-1-1993) Archive Arthur del Prado - RvC 19921993.

80 ASM International, Ray Friant, 'Memo: Front-End Priorities; Response to your June 17 Letter' (20-6-1993) Arthur del Prado Archive - Ray Friant file.

81 Ibid. 
After the summer of 1993, ASM prepared the acquisition of the CVTR technology and commercialize it as A400. ${ }^{82}$ This process was accompanied by careful maneuvering between the interests of the Dutch Ministry of Economic Affairs, the NOM, and the agreements made with Tempress. Moreover, ASM lacked the cash to pay for the technology up front. To realize a viable front-end - required to attract a buyer and including the CVTR machine - more cash was needed. None of that would come from the banks, as Friant wrote to Del Prado:

'Arthur, while you and I understand the intrinsic value of each of ASMI's elements, I'm skeptical that neither the banking nor the investment communities will give ASM credit for intrinsic values. ... banks don't lend money to those who need it; banks lend money to companies whose deeply discounted, readily salable hard assets secure their loans, and to companies whose cash flow covers interest and debt service with a comfortable cushion. Investors have a similar mentality. ${ }^{\text {'8 }}$

Yet, some salvation was achieved by the liquidation of back-end activities.

\section{Selling ASM Fico}

Throughout 1993, Del Prado, Willem de Leeuw, Jan Willem Baud, Richard Blickman, and investment banker Sam Seidman searched for potential buyers. A prominent and experienced manufacturer of semiconductor assembly and packaging equipment, Kulicke \& Soffa, was picked as the most probable candidate. ${ }^{84}$ A stand-still agreement was concluded, stopping all negotiations but the one with Kulicke \& Soffa. However, the negotiations did not evolve well. The Americans were not willing to pay more than 45 million guilders for the Fico activities, which was at least five million short of Del Prado's assessment of the operation's value. Moreover, Baud and Blickman expressed their dissatisfaction about their dealings with the American equipment manufacturer. ${ }^{85}$

82 Tempress, C. Pannevis, 'CVTR BV: Hoofdlijnen aandeelhoudersovereenkomst ASM, CVTR, Tempress, NOM’, (19-8-1993) Archive Arthur del Prado - RvC 1992-1993.

83 ASM International, Ray Friant, 'Memo: Front-End Priorities; Response to your June 17 Letter' (20-6-1993) Arthur del Prado Archive - Ray Friant file.

84 Kulicke \& Soffa was selected through intervention of Intel and Motorola, ASM Fico's biggest customers. - Richard Blickman, 'Interview with authors', ASMI, Hans Peter Hukshorn, 'Memorandum: Minutes of the ASMI Boardmeeting held on February 5, 1993' (3-3-1993) Archive Arthur del Prado - RvC 1992-1993; Kulicke and Soffa Industries, Inc, C. Scott Kulicke, 'Letter to Arthur del Prado' ((19-5-1993) Archive Arthur del Prado - RvC 1992-1993.

85 ASMI, Hans Peter Hukshorn, 'Minutes of the ASMI boardmeeting held on June 2, 1993' (7-6-1993) Archive Arthur del Prado - RvC 1992-1993. 
As soon as the standstill-agreement expired, the Fico managers initiated negotiations with a German entrepreneur, Dr. Manfred Bernau. Through his holding firm Berliner Elektro, Bernau acquired firms and cashed in on the investment through public offerings or selling. Blickman and Baud pulled all stops to convince Bernau to acquire ASM Fico. Severe doubts prevailed, though, about ostensibly insurmountable differences in culture between the German holding company and the Dutch ASM Fico operations. A Swiss competitor, ESEC, which feared the prospect of a merger between Kulicke \& Soffa and ASM Fico, urged the German entrepreneur to accept Blickman and Baud's offer. ${ }^{86}$ Moreover, time was running out. ASM's bankers wanted to see results. ${ }^{87}$

By October 1993, ASM Fico was sold to Berliner Elektro Holding for a sum of 60 million guilders The major protagonists of the deal, Blickman and Baud, remained with the operation. The former Fico activities - supplemented with some complementing activities - would be organized as Berliner Elektro-Holding Semiconductor Industries, or BESI.

ASM Fico proceeds were used to refund banking loans. Additionally, nine percent of ASM's shares in ASM Pacific Technology were sold to cover expenses in front-end, accumulating to 30.6 million Dutch guilders and decreasing ASM's interest in ASM Pacific Technology to 51 percent.

In total, the liquidation of ASM's activities in semiconductor assembly and packaging technologies generated approximately 90 million Dutch guilders, which was sufficient to remove the anxiety of the bankers. ${ }^{88}$ But the divestments also evaporated prevailing ideas within the Supervisory Board about ASM as solely a back-end company. ASM International now consisted of a set of front-end operations that were hardly profitable and ASM Pacific Technology, of which it just owned 51 percent.

This new situation had a clear implication for the front-end activities: it was kill or cure. Front-end had to become profitable, be it to attract buyers or to continue the operations. The alternative was immediate liquidation to secure the bankers' remaining loans, heralding the end of ASM International. As it would turn out, however, the front-end operations slowly regained confidence.

86 Richard Fierkens, 'Interview with author'.

87 Ibid.

88 ASMI, Hans Peter Hukshoorn, 'Financieringsplan ASM Front-End' (12-1-1994) Arthur del Prado-RvC 1994-1996 files. 


\section{Chapter 24}

\section{The only way is up, 1994-1996}

Still trembling on its feet from the previous turbulence, ASM was lifted up by a reviving market. At the start of 1994, the company hardly managed to realize the conditions for its subsistence. Just before it would perform below par, however, the newest pending products dragged the equipment manufacturer out of its mess.

\section{Industrial context: A most welcome revival}

After the tough early 1990s, the market and economic circumstances improved for ASM (figure 59 in Chapter 23). From 1993 to 1996, the global semiconductor market grew by 60 percent to nearly 137 billion dollars. In its wake, demand for semiconductor equipment increased by 77 percent, from 6.87 billion dollars in 1993 to 19.05 billion dollars in 1996. The healthy prospects of the electronics industry at large raised the confidence of investors, in the Netherlands as well as abroad. Moreover, the semiconductor industry established collaborative efforts for the development of a new wafer size, which indicated the trust of the chip manufacturers in their equipment suppliers and the future.

The market for personal computers propelled the recovery of the chip industry. By 1995, approximately 59.7 million personal computers were shipped worldwide, an increase of more than about 20 percent over $1994 .{ }^{89}$ New software like Microsoft Windows 95, introduced in August 1995, made personal computing more accessible for consumers. To run the software, new memory chips with more capacity were needed. As such, the introduction and success of Windows 95 stimulated demand for the latest 8 and 16 Megabit DRAM chips. ${ }^{90}$ Furthermore, mobile telephony opened new markets for wireless computer chips. In 1993 about 18.7 million cellular phones were produced, which increased to 108.9 million in 1997, and was expected to grow to 240 million units by $2000 .{ }^{91}$

89 Dataquest, Jim Handy, 'The 1995-1996 DRAM Fab Outlook - Can PCs Absorb That Much DRAM Capacity?', Dataquest Memories Worldwide: Telebriefing Summary (19-6-1995), p. 6; ‘Dataquest, 'Worldwide PC Market Grew 24 Percent in 1995', tech-insider.org (29-1-1996).

90 Dataquest, Jim Handy, 'How Windows 95 Will Impact Today's Dram Shortage', Dataquest Memories Worldwide Focus Analysis (14-8-1995).

91 Dataquest, Bruce Bonner and Dale Ford, 'Flash Talks in Digital Cellular Phones', Dataquest Communications Semiconductors and Applications Worldwide: Technology Analysis (9-3-1998). 
Since a single personal computer contained numerous memory chips and merely a few microprocessors, the memory segment of the semiconductor industry experienced most growth. The combined market for DRAM, SRAM, and flash memory peaked in 1995 at 55.3 billion dollars in 1995, or 36.5 percent of all semiconductor sales in that year. ${ }^{92}$ In an effort to meet demand, memory chip manufacturers heavily invested in new equipment during this boom. A shortage in the latest memory chip had been caused due to deferment of investments by Japanese chip manufacturers during the Japanese crisis of the early 1990 s. $^{93}$ The new investments in production lines caused a peak in demand for semiconductor equipment.

The boom in semiconductor equipment had positive effects on related stocks. Investors in semiconductor companies - both chip and equipment manufacturers - were eager to join the bonanza. During this period, in the Netherlands, ASM Lithography and BESI (formerly known as ASM Fico) conducted an initial public offering on both the Nasdaq and the Amsterdam Stock Exchange. Anxiety about the viability and prospects of the chip industry seemed to vanish in thin air.

\section{Another new wafer size}

Confidence in the future was further illustrated in the preparations for a new wafer size. From 1995 onward, industry-wide, the semiconductor industry discussed, negotiated, and defined the introduction of 300-millimeter - or 12-inch - wafers. Just like the 200-millimeter wafer size, such a transition constituted a clear opportunity for equipment vendors. For this new wafer size, all equipment had to be re-evaluated. Suppliers of 200-millimeter equipment were not certain of supplying 300-millimeter wafer tools.

For the first time in the history of the semiconductor industry, the introduction of the new wafer size was prepared by industrial consortia. Earlier, single companies had driven the transition, like Intel with 150-millmeter wafers in 1980, and IBM with 200-millimeter wafers in 1990. The development cost for 300-millimeter equipment was too high to be carried by a single company. Moreover, due to the 1980s' rivalry between the United States, Japan, and Europe, a matured and comprehensive infrastructure existed for industrial collaboration in each of these regions. The global industry association for equipment and materials, SEMI, coordinated standardization efforts. This involved the definition of standards for equipment interfaces, cleanroom facilities, ergonomics, safety, and cost.

93 Dataquest, 'Will the Memory Market Ever Recover?' Dataquest Memories Worldwide Market Analysis (30-11-1998) pp. 11 and 12. 
The new wafer size carried along new logistic challenges. A full transfer box, containing twenty-five 300-millimeter wafers was almost impossible to carry, nor was it desirable. A 200-millimeter wafer weighed approximately 53 grams, while a 300-millimeter wafer weighed between 128 grams and up to as much as 750 grams, depending on the specifications. Imagine the loss of value when dropping a box full of 300-millimeter wafers! Thus, the new wafer size commanded advanced automation of wafer handling in the factory. Standard Mechanical Interface (SMIF) boxes were replaced for Front-Opening Unified Pod (FOUP) boxes to transfer wafers from one production step to the next. Moreover, these FOUPs were transported by overhead conveyors attached to the ceiling of the cleanroom.

The first semiconductor equipment and material segment to be confronted with the new wafer size involved the producers of silicon crystal shafts and the wafer fabricators. The relative thickness of 300-millimeter wafers increased from 725 micron to 775 micron, while the area increased from 314 to 707 square centimeters. ${ }^{94}$ This was an increase of 225 percent. The quality of the silicon wafer had to be the same as that of the previous generation.

Traditionally, silicon epitaxy had been a way to overcome minor deficiencies in silicon wafer quality during the production of chips containing CMOS transistors (cf. introduction of Innovation II). By growing an epitaxial film, electrical properties of the substrate could be controlled, while continuing the crystalline structure of a wafer. To offer the best quality of silicon wafers, most wafer manufacturers offered their wafers with an epitaxial film on top of it. This meant that apart from the wafer fabricators, also the suppliers of epitaxy equipment had to be ready for the new wafer size at an early stage. This was relevant in particular for ASM and Applied Materials. Only after new 300-millimeter silicon wafers with an epitaxial film - became available, the other 300-millimeter production technologies could be evaluated. Thus, epitaxy led the equipment industry in the transition towards 300-millimeter wafers.

The new wafer size bore consequences for all semiconductor equipment. One example involved the equipment that sequentially or linearly scanned the wafer surface, such as lithography and metrology equipment. The movements involved had to cover a larger surface in the same amount of time, or otherwise the throughput would decrease and the cost of ownership would deteriorate. For plasma CVD, the increase in wafer size affected the coverage of the plasma field and new gas flow patterns. Another concern pertained to the implications for vertical furnaces, the tool type expected to be significantly impacted by the

94 On the International 300-millimeter Initiative, see Randal K Goodall, 'The Impact of the 300 mm Scale-Up on IC Fab Process, Metrology, and Automation Equipment', Silicon Materials Science and Technology: Proceedings of the Eight International Symposium on Silicon Materials Science and Technology (1998) pp. 1302-1324. 
new wafer size. ${ }^{95}$ Matters that had to be considered for these machines were the ramp rates, wafer spacing, quartz ware, gas flow, and gravitational effects. While the surface of the wafer almost doubled, this could not be allowed for the footprint of the machines themselves. Within SEMI and in conjunction with the chip manufacturers it was decided that the size of the machines had to remain the same. After all, every square centimeter of a cleanroom was extremely expensive. Furthermore, SEMI restricted price increases to a maximum of 30 percent to control the cost of future chips factories and to make the new wafer size economically more attractive.

From 1996 onward, the evaluation of new 300-millimeter equipment occurred within an American-European research consortium and a Japanese one, in conjunction with preparations for forthcoming 250 and 180 nanometer technology nodes. In the West, a consortium was established called International 300-millimeter Initiative, or I300i, which eventually merged with Sematech, the American research consortium for semiconductor manufacturing technology. ${ }^{96}$ In Japan, the new wafer size was prepared by Japan300 (J300) and Semiconductor Leading Edge Technologies (Selete). ${ }^{97}$ SEMI organized some harmonization among Selete, I300i, and J300.

After all production steps of a chip factory had been evaluated by the consortia, chip manufacturers had to decide for themselves when to build their first fab for 300-millimeter wafers, which was expected to be around late 1998 to 2000. The commitment of the whole chip industry to the new wafer size strengthened confidence in future investments in semiconductor equipment. Until the first tools got sold, however, equipment manufacturers had to carry the full weight of the development cost and thus the financial risk. If, in other words, the opportunity was beautiful, the burden was rather unilateral initially.

\section{Corporate course: Regained confidence and aligning forces}

From 1994 onward, ASM regained its footing. The deliberations about the company's future in either back-end or front-end had gotten beyond a point of closure. The divestments of ASM Pacific Technology stock and the whole of ASM Fico had been necessary to remove the anxiety of the bankers. But this resolution had come at a cost. All the remaining operations - ASM Europe, ASM

95 Ibid.

96 Chip manufacturers Intel, Motorola, Lucent, Texas Instruments, IBM, AMD, Siemens, SGS-Thomson, Philips, Samsung, Hyundai, LG, and TSMC got access to the results of wafer evaluations.

97 In it, Fujitsu, Hitachi, Matsushita, Mitsubishi, NEC, Oki, Rohm, Sanyo, Sharp, Sony, and Toshiba evaluated the new equipment. Samsung and Seiko Epson shared in the results as well. 
America, and ASM Japan - had to work with a very narrow base (figure 61). These front-end operations relied on the product portfolio of a startup venture, while carrying the organizational burden of a matured firm. The technologies they produced were either phasing out or merely beginning to make inroads into their respective markets. Their products, in other words, could hardly carry the costs of the organization.

\section{Addressing persistent cash shortages}

Cash remained scarce, which ensured that the pursuit of core competencies remained a pressing concern within front-end. ${ }^{98}$ Cash reserves were derived from banks. ASM Pacific Technology's stock secured the bank loans of frontend. Since it was not viable for divestment, the remaining ownership of ASM Pacific Technology was required as leverage to sustain the front-end activities. There seemed to be only one option: slogging on.

In addition to operational costs, there were significant instalments and legal charges that drained the cash flow. In 1994, ASM got entangled in a number of litigations. This involved an accusation by Kulicke \& Sofa with regard to the procedures surrounding the divestment of ASM Fico. But there was also a claim by General Signal for compensation for technology used in the A400, which was settled for 1.4 million dollars. Moreover, the litigation against Applied Materials surrounding the Epsilon continued to escalate, swallowing large amounts in legal fees. ${ }^{99}$ On top of these exceptional costs, there was the periodical installment of the convertible loan held by investment bankers Grantham, Mayo Van Otterloo \& Co. This was too much. The company simply did not have the cash, while turning the installment into stock would give the bankers an undesired hold on the company. Del Prado intervened by providing a personal non-interest bearing loan of 3 million Dutch guilders to ASM, which made it possible to meet the installment. 100

98 ASM International, Willem de Leeuw, 'Position Paper on ASM Front-End Funding' (July 1994) Archive Arthur del Prado - RvC 1994-1996.

99 Knobbe, Martens, Olson \& Bear, Don Martens, 'Facsimile: ASM America Inc, v. Applied Materials, Inc, ref: ASMEX.023L' (15-2-1994) Archive Arthur del Prado - RvC 1994-1996.

100 Earlier installments of 2.8 million Dutch guilders in March 1993 were paid for by 1.3 million shares, 1 million of which were called by ASM International for a value of 1.56 million Dutch guilders in March 1994. The calling of stock prevented further increase of ownership by the investment bankers. - Stibbe Simont Monahan Duhot, Maurits van den Wall Bake, 'Letter to Arthur del Prado, ref: vdWB/ek-91968.B53' (1-2-1994) Archive Arthur del Prado - RvC 1994-1996; ASMI, Arthur del Prado, 'GMO Conversion in March, ref: 94.009 AdP/tv' (2-21993) Archive Arthur del Prado - RvC 1994-1996; Del Prado defended the move as follows: 'A continuation of such dilution will seriously jeopardize our ability to lift our stockprice to the levels whereby equity can be attracted.' Thus he was also interested, of course, in maintaining his personal hold on the company. - ASMI, Arthur del Prado, 'GMO Conversion in March, 


\section{Figure 61}

Organigram of ASM International by 1995

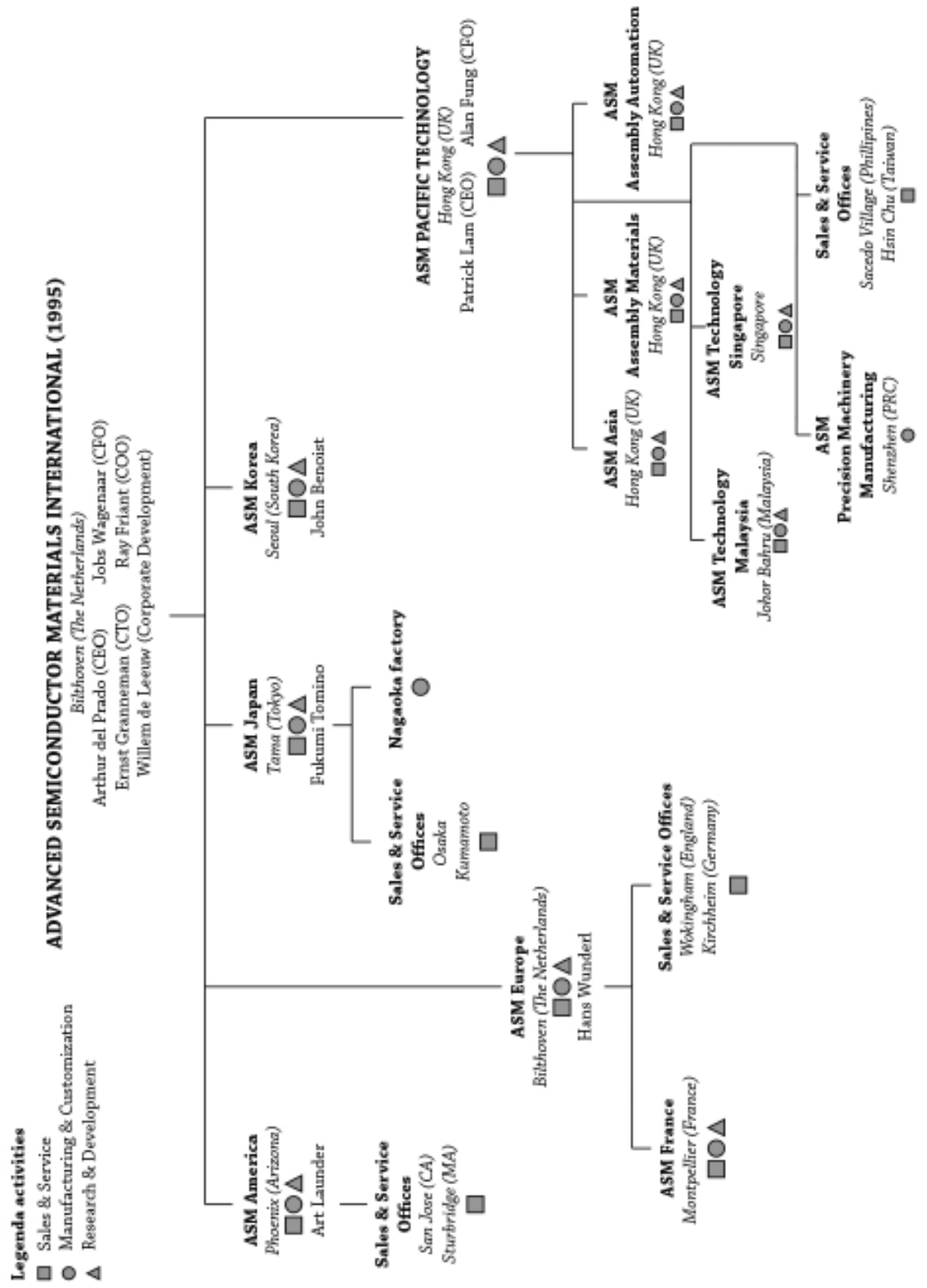

ref: 94.009 AdP/tv' (2-2-1993) Archive Arthur del Prado - RvC 1994-1996. 
Apart from the financial intervention by Del Prado, the company's financial distress was relieved further by approximately 3.5 million Dutch guilders through the divestment of ASM facilities in Bilthoven. This involved three locations (Rembrandtlaan 4 and 2a and Jan Steenlaan 9), whereas the company headquarters was moved to another location (Jan van Eijcklaan 10). Furthermore, Del Prado, Willem de Leeuw - who in his role as Director of Corporate Development acted as a de facto treasury officer - and members of the Supervisory Board re-engaged their financial supporters for new loans. This also involved the Dutch government. ASM's application for a governmentally backed venture capital scheme, called 'industry fund' (industriefaciliteit) and involving an amount of 50 million Dutch guilders, was rejected because of ASM's poor solvency status. ${ }^{101}$ For another scheme, called Technolease, ASM just missed the boat. ${ }^{102}$ Technolease was a 'sale and lease back' construction through which immaterial technological assets - knowledge and intellectual properties - were sold to a bank, the Rabobank, and subsequently rented by the previous owner. ${ }^{103}$ This construction provided the seller of the assets with cash to redeem financial distress, while it allowed the bank to decrease taxes on its profits. The scheme was withdrawn, however, before ASM could make use of it. ${ }^{104}$

\section{Restructuring management}

By the mid-1990s, Friant had managed to cultivate some shared belief in a corporate strategy for ASM's front-end operations. He continued to redefine the flow of information and relations within and among the front-end subsidiaries.

101 Del Prado and De Leeuw suggested to pledge the remaining value of ASM Pacific Technology, amounting to 185 million Dutch guilders, as collateral for an 'industry fund' of 50 million Dutch guilders. The scheme was funded by, among others, the National Investment Bank. In preparation of the decision, De Leeuw traveled to all major ASM operations together with representatives from the National Investment Bank. - ASMI, Arthur del Prado, 'Visit to E.Z., The Hague, ref: 94.001 WdL/tv' (14-1-1994) Archive Arthur del Prado - RvC 1994-1996; Evert-Jan Velzing, Innovatiepolitiek: Een reconstructie van het innovatiebeleid van het ministerie van Economische Zaken van 1976 tot en met 2010 (Eburon, Delft, 2013), p. 129.

In a first assessment, ASM listed the investments in its European R\&D portfolio since 1982. This amounted to 146 million Dutch guilders. - ASMI, Erik Kamerbeek, 'Memorandum: Background Re Technolease, ref: m-A/940801/EK/if' (11-8-1994) Archive Arthur del PradoRvC 1994-1996; ASMI, Arthur del Prado, 'Progress report august' (July 1994) Archive Arthur del Prado - RvC 1994-1996; ASMI, Willem de Leeuw, 'Facsimile message: Letter to W.A. Vermeend, Ministerie van Financiën' (28-3-1995) Archive Arthur del Prado - Willem de Leeuw; ASMI, Arthur del Prado, 'Progress report august' (July 1994) Archive Arthur del Prado - RvC 1994-1996.

Velzing, Innovatiepolitiek, p. 135.

Both Philips and Dutch aircraft builder Fokker used the Technolease construction in, respectively, 1992 and 1994, despite disputes about its legality among officials of the Ministry of Economic Affairs, the Ministry of Finance, and the European Commission. 
He established adequate management directives with regard to cash flow, forecasts, and product management. The chief operating officer (COO) stipulated what he expected from the full front-end board - consisting of Del Prado, the chief financial officer (CFO), the chief technology officer (CTO), the general managers, and the product managers - in terms of reporting, availability, and meetings. ${ }^{105}$ Having grown organically, rapidly, and in a diversified manner, ASM had always lacked such a coherent structure.

New general managers were appointed, replacing company veterans, filling in interim positions, and revitalizing the operations with their energetic and fresh views on the matters at hand. The five years of crisis had taken its toll on the older executives, most of whom got promoted to a non-executive position within the firm or their subsidiary. At ASM Europe, the bold Hans Wunderl filled in the vacancy of general manager. At ASM Japan, the inquisitive Fukumi Tomino replaced Yo Miyazaki, and at ASM America, Art Launder took over the helm from John Krickl. Ernst Granneman grew in his role of CTO, while Jobs Wagenaar succeeded Hans Peter Hukshoorn as CFO. The new executives offered Friant the chance to renew company procedures, disrupt entrenched habits, and reconcile strategies and interests with each other anew. ${ }^{106}$

\section{New core products}

ASM's recovery was stimulated by a sudden surge in demand for semiconductor equipment in 1994 and 1995. Four of the company's newest products succeeded in joining the heave. Through the concerted efforts of Friant and Granneman, more certainty emerged about the viability of the various products. The base and methodology for forecasts was harmonized, tested, and adjusted. The improved flows of information boosted performance and prospects. Technological development, after all, had to be market-driven, while commitment of customers was indispensable. ${ }^{107}$ Equipment that merely served local demands was deprioritized. Products only could be continued on a cash-neutral base, and across the subsidiaries so-called 'make-or-buy' analyses were performed to distinguish activities that might be divested or outsourced.

Gradually, a sense of ASM's core competencies for the future emerged. The production of four technologies was sustained, which were innovated and sold

105 ASMI, Ray Friant, 'Memo: Front-End Management Structures' (6-8-1994) Archive Arthur del Prado-RvC 1994-1996.

106 Ray Friant, 'Memo: Front-End Organization and Staffing' (20-4-1994) Archive Arthur del Prado-Ray Friant files.

107 ASMI, Willem de Leeuw, 'Facsimile message: Front-end management structure, ref: 94.0042 WdL/tv' (23-8-1994) Archive Arthur del Prado - Willem de Leeuw files. 
by the three geographical operations. ${ }^{108}$ ASM America, through its subsidiary ASM Epitaxy, concentrated on the Epsilon single wafer epitaxial reactor. ASM Japan focused on the single wafer plasma enhanced CVD reactor Eagle-10. ASM Europe took care of the A400 vertical reactor. And a new version of the A600 for ultra-high vacuum processes, the A600-UHV, was developed by all front-end operations. It was also clear that the glory days of the horizontal furnaces were over. Most of the intellectual property was sold and products were discontinued. The other vertical furnaces - ASM Japan's VMP and VDF, plus ASM America's A300/EVTR - were de-prioritized. ${ }^{109}$ The success of the four products - the Epsilon, Eagle-10, A400 and A600-UHV - helped to restore confidence in the viability of the company.

Each of the front-end subsidiaries, except ASM Epitaxy/America whose Epsilon continued to sell well, had to redefine its core competencies. This directly pertained to the selection of products and also production. Moreover, operating in the advanced, volatile, and complex chip industry called for a long-term strategy. This involved preparing for the forthcoming new 300-millimeter wafer size, but also new applications and processes. Such technological milestones offered unique opportunities to strengthen the focus on organizational and technological competencies and improve the company's cash flow for the future. Economies of scale could be achieved through standardization and harmonization of the 300-millimeter wafer-handling technology across the operations. At the previous conversion to 200-millimeter wafers, ASM had almost entirely missed the boat, and Granneman was determined to prevent this from happening again. However, centralization and harmonization of integral technological components of each of the products seemed impossible. Once again, the competitive strategies of the operations did not align with the corporate strategy of ASM International.

As results improved over 1995, the window of opportunity for further operational alignment and restructuring declined. The original strategic intent of making front-end sellable was no longer relevant. Without this sword of Damocles hanging over their heads, and boosted by the recent success of several products, the decentral realities and stubbornness that had aggravated ASM International's crisis since the late 1980s surfaced once again. Elaborating on

108 In the 1993 Annual Report, published in April 1994, the new organization was announced. At the time of writing the annual report, the Paragon was still part of ASM America's product portfolio. However, a few months later, this product was mothballed. - ASM International, '1993 Annual Report' (26-4-1994).

109 A few tools were still sold in 1994. This involved some VMP furnaces for LCD production to Korean customers, and a few A300 furnaces for IBM Burlington and Sindelfingen. - ASM International, Arthur del Prado, 'August Progress Report' (July 1994) Archive Arthur del Prado - RvC 1994-1996 files. 
the newly established core competencies, the subsidiaries seemed more eager to pursue the imminent opportunities on their own distinct terms.

\section{Elaboration of affairs}

\section{Selecting four core competencies}

At the same time, though, some of the hopeful developments identified the year before by Friant, Del Prado, and Granneman slowly began to materialize. ${ }^{110}$ ASM's brightest star continued to be the Epsilon reactor. In 1993, under the guidance of its original and long-time product manager, Armand Ferro, sales went up to 39 million dollars (in a global market of 83 million dollars). Moreover, a newly appointed general manager by the name of Art Launder expected sales to grow to 73 million dollars by 1997.111 ASM America was market leader. Every year, the applicability of the reactor got extended to new materials and fabrication processes, such as silicon germanium and power chips. Even, America's biggest chip manufacturers chose the reactor to grow selective epitaxial films, and pushed their wafer suppliers to follow their example. Moreover, industry magazine Semiconductor International celebrated the Epsilon with its '1994 Editor's Choice Product of the Year Award'.112

\section{Figure 62}

Schematic view-from-above of the Eagle-10 single wafer PECVD reactor, developed, manufactured and sold by ASM Japan from the early-1990s onwards.

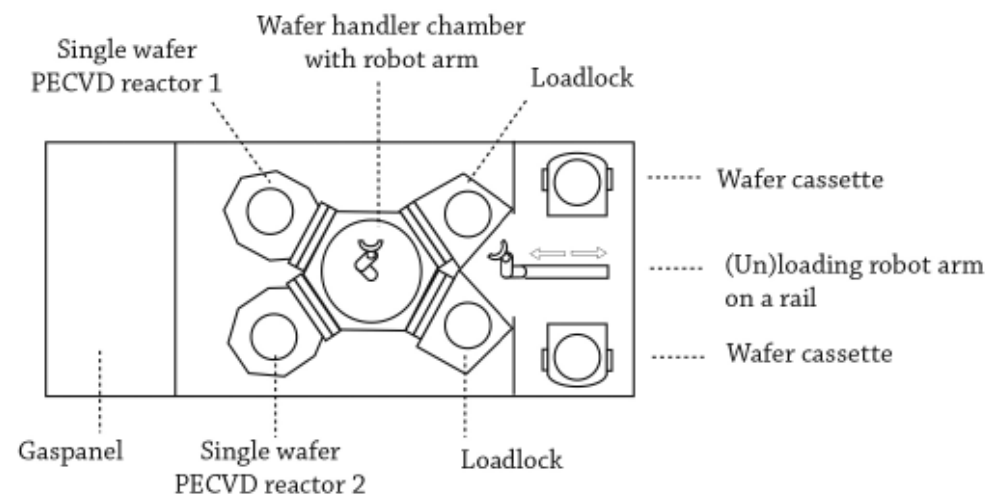

110 ASMI, Hans Peter Hukshoorn, 'Financieringsplan ASM Front-End' (12-1-1994) Archive Arthur del Prado-RvC 1994-1996 files.

111 ASM Epitaxy, 'ASM Epitaxy, Inc: $\$ 35,000,000$ equity investment. Executive Summary' (April 1993) Archive Arthur del Prado - ASM Epitaxy files.

112 ASM America, Ken Davidson, 'ASM Epitaxy Receives Semiconductor International's 1994 Editor's Choice Best Product Award', ASM News (February/March 1995). Archive author. 
In Japan, the engineers and sales officers succeeded in carving out some market share for its single wafer plasma deposition tool, the Eagle-10, which had been developed since 1989 (figure 62). The tool clustered two single wafer plasma deposition reactors with a shower-head gas inlet (figure 63). The machine was not a trail-blazer in its business segment, as it followed basic outlines set by single wafer plasma CVD reactors of Applied Materials and Novellus. ${ }^{113}$

\section{Figure 63}

A simplified side-view of a single wafer plasma enhanced CVD reactor chamber with direct plasma (upper) and remote plasma (lower).

ASM Japan's Eagle-10 used the direct plasma variation. Innovation IV discusses an Epsilon silicon nitride reactor equipped with a remote plasma source, which resembled the remote plasma variation depicted here. For 'plasma enhanced ALD' the same variations are possible as well (cf. Business V). In case of plasma ALD, ASM Japan and ASM Genitech developed a direct plasma variation.
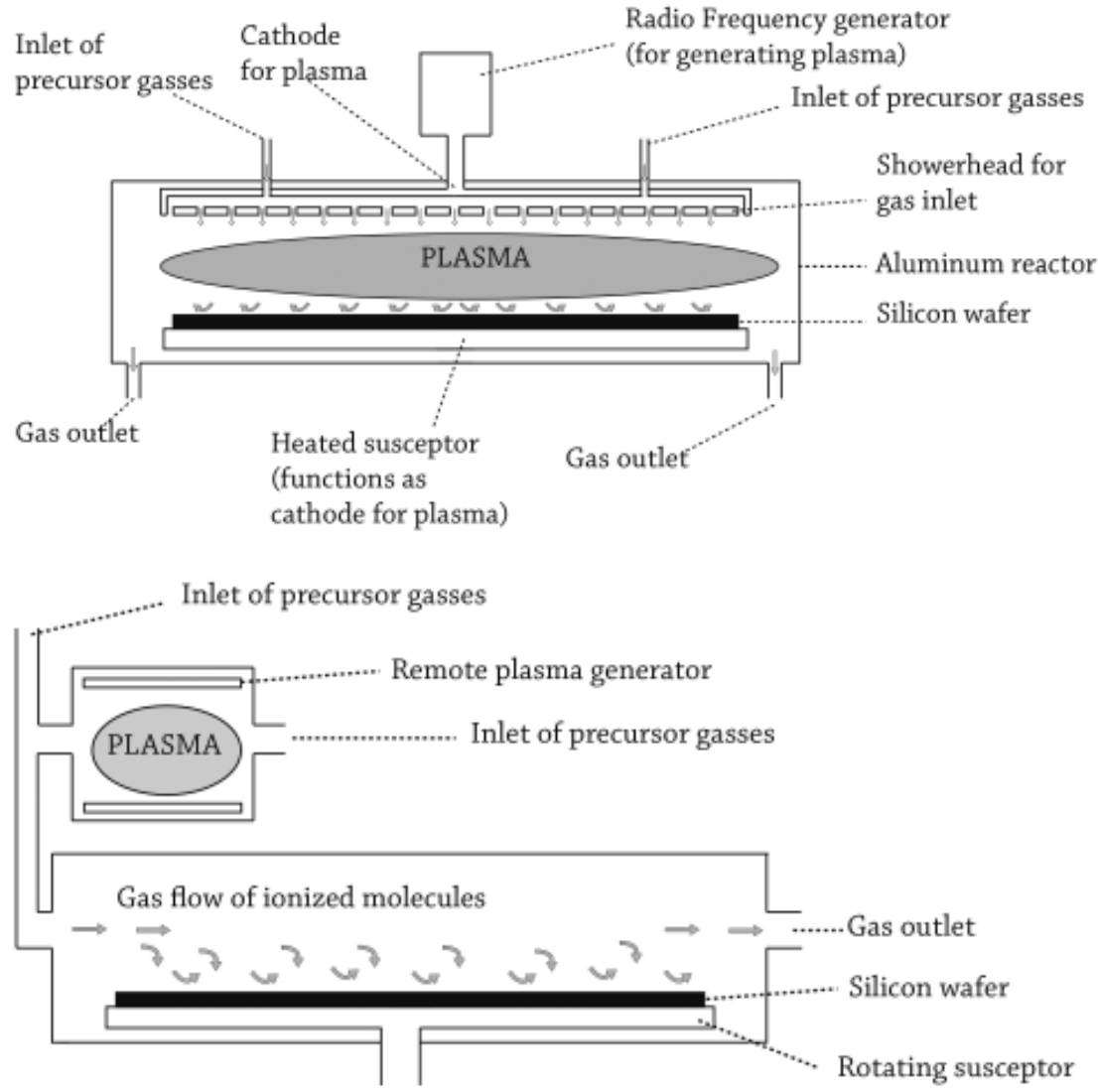

113 Kano, 'Interview with author'. 
But the Eagle-10 proved to be a robust design, and, accompanied by ASM Japan's impeccable reputation for servicing its Japanese customers, it succeeded in attracting the attention of Japan's prominent chip manufacturers. Toyota had qualified a first machine, while it and the likes of NEC, Hitachi, Oki, and Mitsubishi considered the procurement of more. ${ }^{114}$ For the 1994 book year about twenty tools were expected to be sold. ${ }^{115}$ The Eagle-10 saved ASM's future in plasma deposition technology right when its horizontal furnaces became obsolete.

By 1994, the CVTR/A400 finally gained some traction in the market under the new general manager of ASM Europe, Hans Wunderl. The machine seemed to offer the best of both worlds. Its cluster configuration offered high throughput and its modularity of design allowed for better maintenance and thus cost of ownership (figure 57 in Chapter 22). Moreover, it was capable of growing the full range of probable low pressure CVD, oxidation and diffusion processes. ${ }^{116}$ In the spring of 1994, as Tempress filed for bankruptcy, ASM became full owner of the CVTR technology by acquiring the shares of Tempress and NOM in the CVTR joint-venture. Ten key engineers of Tempress were employed by ASM Europe even though temporarily they stayed on in Hoogeveen. ASM Europe sold the A400 to a small research institute named Fraunhofer Gesellschaft in Itzehoe, Germany. Some tools were sold to European chip manufacturers SGS Thomson Micro-electronics (STM) and Philips. Also, the American chip manufacturer Motorola contemplated procurement.

But the real breakthrough came in June 1994. Micron, practically the only remaining memory manufacturer in the United States, completed an extensive evaluation of vertical furnaces for its forthcoming product lines, the A400 emerging as the system of choice. ${ }^{117}$ Micron considered the purchase of approximately 100 systems. Before committing to such a huge order, the memory manufacturer, located in Boise, Idaho, wanted to get several guarantees from ASM Europe. As was reported:

114 ASMI, Rray Friant, 'Memo: ASM Front-End status' (20-3-1993) Archive Arthur del Prado - RvC 1992-1993; ASM International, Ray Friant, 'Memo: Front-End Status' (20-4-1994) Archive Arthur del Prado Archive - Ray Friant file.

115 ASMI, Arthur del Prado, 'Progress report august' (July 1994) Archive Arthur del Prado - RvC 1994-1996; Fukumi Tomino mentioned an installed base of 1 machine in 1992, 3 in 1993, 14 in 1994, and 32 in 1995. - Fukumi Tomino, 'Correspondence with author'.

116 Even more, all the processes developed for the A600 had been transferred to the A400. As such, it was more advanced than ASM Japan's VMP and VDF vertical furnaces, but not as complex as the A600 - ASM Europe, Boudewijn Sluijk, 'Memorandum: Update Status Marketing Advance 400 CVTR' (3-2-1994) Archive Arthur del Prado - RvC 1994-1996.

117 Among the whole range of competitors, ASM had offered the A600-2 but also the A400. - ASM Europe, Boudewijn Sluijk, 'Memorandum: Update Advance 400 marketing status' (17-6-1994) Archive Arthur del Prado - RvC 1994-1996. 
'Steve Appleton, Micron's 33-year-old President, took us to lunch, which I believe was a positive sign of things to come if we perform. He compared ASM America/ASM Europe to ASM Lithography five years ago when they needed help. Steve indicated Micron was prepared to do the same for us, because his people believe in the A400 and we are demonstrating a proactive attitude. ${ }^{118}$

In the year's remaining months, ASM and Micron negotiated technology, conditions of delivery, and purchase orders. ${ }^{119}$ The order proved to amount to nearly 50 systems, containing almost a hundred tubes, in 1995, and about 30 systems, holding 60 tubes, in 1996. From one day to the next, this order turned ASM Europe from a faltering company into an overburdened one.

To fulfill this order, ASM Europe had to outsource production of generic modules. Originally, ASM, Tempress, the Ministry of Economic Affairs, and the NOM - a public investment company in support of employment in the northern Dutch provinces - decided that Tempress would take care of manufacturing. However, its bankruptcy had annulled this arrangement. Since preservation of jobs in the country's northern part had been a prerequisite for the NOM's financial support, ASM contracted Philips Machinefabrieken. This engineering subsidiary of Philips, located in Almelo in the North-East of the Netherlands, had experience with servicing the semiconductor equipment industry. A major part of ASM Lithography's hardware was built by the subcontractor as well. From 1995 onward, Philips Machinefabrieken manufactured the various A400 modules, which were assembled, customized, and tested by ASM Europe in Bilthoven.

The outsource strategy fitted in the company's ambition to focus on its core competences. ASM Europe's competitiveness did not depend on constructing basic modules of metal, painting sheets, and electrical wiring. Such tasks could be done more effectively elsewhere. The Bilthoven operation added value to its product through its ability to facilitate delicate chemical processes with ingenious gas supply systems, control software, and process management. Moreover, the outsourcing scheme offered this operation more flexibility and control of its expenses.

118 ASM America, Art Launder, 'Facsimile Transmission: Micron Visit - August 8, 1994' (9-81994) Archive Arthur del Prado - RvC 1994-1996.

119 Micron was in particular wary of knowledge transfers to ASM Japan - and subsequently to Japanese memory manufacturers. The American memory manufacturer was practically the sole survivor of the American-Japanese rivalry of the 1980s, which resulted in Japanese dominance in this segment. Additionally, Micron wanted ASM Europe not to rely solely on Philips Machinefabrieken. ASML collaborated with Philips Machinefabrieken as well, and this implied that Micron would be exposed too much to a supplier with whom it had no direct relations. ASM America, Art Launder, 'Facsimile Transmission: Micron Visit - August 8, 1994’ (9-8-1994) Archive Arthur del Prado - RvC 1994-1996. 
The breakthrough of the A400 almost pulled the curtains for the A600. This complex machine, which had consumed tremendous investments in research \& development since the late 1980s, was saved from mothballing by NEC. This chip manufacturer - the world's largest - identified a particular application for which it could use the A600's remarkable capabilities in vacuum processes. NEC wanted to use a modified version of the $\mathrm{A} 600$ for the growth selective "hemispherical grained silicon' (HSG) for its forthcoming 256 Megabit and 1 Gigabit memory chips. HSG required an ultra-high vacuum. In close cooperation between ASM Japan, ASM Europe, ASM America and NEC, a new variation of the A600 was developed: the A600-UHV. For ASM Japan, the collaboration with NEC was highly prestigious, involving state-of-the-art technology for memory manufacturing. For the A600, it was the final effort to prove its commercial viability, after the failure of the A600 plasma, aluminum, and LPCVD variations.

Among these various hopeful signs, one of the prospective developments failed to live up to its promises: the Paragon, the Epsilon based polysilicon reactor. ${ }^{120}$ Batch furnaces - like ASM's A400, for instance - proved to be capable of addressing customers' needs for higher uniformities better. Stand-alone single wafer machines like the Paragon could not compete against the high throughput - and thus low cost of ownership - of the batch furnaces. Moreover, in the few niche applications left, it had to compete with established suppliers of single wafer polysilicon reactors, like American AG Associates and Applied Materials. ${ }^{121}$ The seven projected Paragon systems for 1994, as well as sixteen machines for 1995, proved elusive, resulting in an annulment of approximate 12 million dollars in revenues. ${ }^{122}$ The Paragon was mothballed in the summer of $1994 .{ }^{123}$

By the first half of 1994, ASM had limited its front-end operations to four products, after the gradual abandonment of all others. The company's geographical subsidiaries now functioned as product groups, bearing responsibility for the global success of their respective products. No longer would there be geographical localization of products, as happened in the early 1980s. In reality, however, this global outreach was not yet feasible. The Eagle-10 was sold solely in Japan, the

120 ASM America, Art Launder, 'Facsimile Transmission: Paragon Red Flag' (26-8-1994) Archive Arthur del Prado - Ray Friant file.

121 Applied Materials and AG Associates offered single wafer polysilicon cluster tools respectively named Precision 5000 and Integra. Through clustering multiple single wafer tools, costof-ownership decreased, while superior control and quality of ultra-thin layer stacks was achieved. - Ibid.

122 ASM America, Steve Reiutz, 'Paragon Business Plan' (3-2-1994) Archive Arthur del Prado - RvC 1994-1996.

123 The technology was transferred to the governmentally supported IVPS project (cf. Chapter 22 and Chapter 26). 
Epsilon primarily in the United States and modestly in Europe and Japan, and the A400 largely in Europe and the United States.

The four products on which front-end activities relied - Epsilon \& ASM America, Eagle-10 \& ASM Japan, A400 \& ASM Europe, and the A600-UHV compartmentalized technological development. The new organization ensured that each of the subsidiaries focused on the technology in which it excelled. This also provided focus to technological development within the overall company and reduced the chance of easy excuses from subsidiaries, to dodge responsibility, and of overlap in development efforts - problems that plagued the company in the years around 1990 .

\section{A rising sun in the East}

Throughout 1994 and into 1995, the Asian market for semiconductor technologies contributed significantly to ASM's recovery. The Japanese market finally recuperated, carrying not only ASM Japan along with it, but also ASM Pacific Technology, which elaborated on its operational foundations in Shenzhen, Hong Kong, and Singapore and sustained its profitability every consecutive year. Moreover, the Korean market rapidly developed into a factor of significance for wafer processing equipment. During the mid-1990s, the Asian ASM companies repositioned themselves to benefit from the hopeful developments in the East, driving ASM's recovery.

The Japanese operation had suffered from the country's economic stagnation and an obsolete product portfolio. Having experienced incredible heights, depressing lows, and witnessing the bewildering series of restructurings at the headquarters, the company's general manager Yo Miyazaki had trouble adjusting to the new course set out by Friant and Del Prado. Old sores and frustrations hindered his ability to focus on the present needs. If he wanted the leadership to take the particular circumstances of the Japanese market into account, this was out of the question due to the perilous financial situation of ASM and the globalizing market. After Friant and Miyazaki clashed, Del Prado sought to mitigate the conflict between his old-time Japanese companion and the interests of the overall company. ${ }^{124}$ Yet the failure of ASM Japan to have a cash neutral balance over 1992, 1993, and 1994 gave Friant sufficient ammunition to force the Japanese subsidiary into compliance. ${ }^{125}$

124 Friant, 'Interview with author'; ASM Japan, Yo Miyazaki, 'Letter to Arthur el Prado, ref: KK-92.0093' (7-2-1992) Archive Arthur del Prado - ASM Japan 90's files; ASM International, Ray Friant, 'Memo: ASMJ Situation' (4-11-1993) Archive Arthur del Prado - Ray Friant file.

125 ASMI, Ray Friant, 'Memo: ASM Japan Restructuring' (26-1-1994) Archive Arthur del Prado - RvC 1994-1996. 
In the spring of 1994, ASM Japan was restructured, involving lay-offs of almost a hundred employees that had been pending for some time already. The manufacturing of some components was moved temporarily to ASM America to utilize currency advantages, and a small facility in Kumamoto was closed. More importantly, the management changed. Miyazaki got a new role, removing him from the daily management. The 45-year-old Fukumi Tomino - together with Del Prado, Miyazaki, and controller Hitoshi Miura one of the co-founders of ASM Japan - was appointed general manager. Tomino's long tenure in various positions and his younger age (compared to his 58-year-old predecessor) made him perfectly suited to work on the commercialization of the Eagle-10. ${ }^{126}$ Although the transfer of power from Miyazaki to Tomino was rather painful for the staff members, it set the Japanese subsidiary on course for recovery. ${ }^{127}$ The joining of the Eagle-10 with a recuperating Japanese semiconductor market did the rest.

ASM Pacific Technology continued to grow steadily. Sales increased from 62.8 million dollars in 1989 (and a profit of 11.8 million) to 133.3 million in 1993 (and a profit 19.9 million). ${ }^{128}$ As such, the market capitalization of the assembly and packaging equipment manufacturer and its constant dividends constituted a lifeline for parent company ASM International.

ASM Pacific Technology was distinctly a Chinese company. Management was hierarchical, economical, and strongly embedded in the South-East Asian region. Its products were manufactured and sold in high volumes with a low variety among the systems. Typically, dozens of wire- or die-bonders were installed at a customer, with fairly minor differences in specifications. This was in contrast to the front-end deposition systems, which were ordered in much lower volumes and had to deposit a wide range of different chemical processes, implying low volumes and high variety. This characterization of ASM Pacific Technology's products helped the Asian firm to compete on a price-performance ratio. Pivotal was its Shenzhen facility which enabled an integrated production strategy: all parts were made internally, from screws to more complex components. Tapping into the vast

126 Ray Friant, 'Interview with author'; ASM International, Ray Friant, 'Memo: Front-End Organization and Staffing' (20-4-1994) Archive Arthur del Prado - Ray Friant file.

127 Fukumi Tomino, 'Interview with author'; Hitoshi Miura, 'Interview with author'; and Ray Friant, 'Interview with author'.

128 Or, as it was noted originally, in Hong Kong dollars: 1989 sales of 490 million HKD, 1989 profits of 92 million HKD, 1993 sales of 1.03 billion HKD and 1993 profits of 146 million HKD. Exchange rate on December 31, 1989, was 7.809 HKD to 1 USD, and 7.7265 HKD to 1 USD on December 31, 1993. Exchange rate derived from www. Poundsterlinglive.com (viewed: 12-9-2018). Sales ASM Pacific Technology derived from ASM Pacific Technology annual reports. 
market for cheap labor in mainland China, the Hong Kong operation was able to control the cost of its equipment, even up to its components.

In contrast to ASM front-end, research and development centered around technology, not products. R\&D groups targeted specific technological competencies - like vision \& pattern recognition, motion control, etc. - and served the various product groups, such as gold wire bonders, aluminum wire bonders, die bonders, etc. This new structure helped to overcome structural deficiencies that hampered its parent company, ASM International, such as double work in development, the dichotomy between competitive strategies and corporate interests, and a tenacious manifestation of a 'not-invented-here' attitude among product groups.

Outperforming its competitors in pricing, ASM Pacific Technology served numerous smaller semiconductor assembly \& packaging companies. This applied in particular to those active in light emitting diodes (LED), which required relative small volumes: about thirty machines per customer. Being a latecomer to the market and having lucrative exposure to numerous small-scale LED assembly firms in the South-East Asian region, this strategy enabled the ASM operation to familiarize and control the complex wire bonding technique.

By the mid-1990s, ASM Pacific Technology had made inroads with a new product, which symbolized its newly established confidence. ${ }^{129}$ It was a wire bonder, named AB309, which was meant to bond golden wires between a CMOS die and its package. Bonding wires between die and package of LED involved just two aluminum wires, whereas equipment applicable for CMOS chips needed tens of delicate golden wires. As such it required much more control of speed and motion. Critical technology comprised a pattern recognition system, a stepper driven assembly table, a flexible indexer, and loop control. Competitors like Kulicke \& Soffa, and Shinkawa had much more experience in this area. But through the AB309, of which about 1100 were shipped by 1995, ASM Pacific Technology set itself on course to become a major player in the market for semiconductor assembly equipment.

With regard to its position within the wider ASM family, the Chinese saying 'the mountains are high, and the emperor is far away' seemed fitting. ASM Pacific Technology's location, its focus on niche semiconductor segments, and its stable profits did not warrant too much involvement or actions from the ASM International Supervisory Board. Patrick Lam merely involved Del Prado, being the firm's president, in his business decisions. The autonomy of ASM Pacific Technology even increased after the divesture of ASM Fico. Only one subsidiary in semiconductor assembly and packaging remained, negating the need for

129 Y.M. Wong, 'Interview with author'; W.K. Lee, 'Interview with author'; Patrick Lam, 'Interview with author'; and Peter Lo, 'Interview with author'. 
formulating corporate strategy and respective competitive strategies for this market. As long as Lam's output continued to be profitable, quarterly presentation to the ASM Supervisory Board sufficed. Lam in fact never took the trouble of traveling to Bilthoven. Instead, during a tour with Del Prado in February 1995, the Supervisory Board visited all the Asian facilities of ASM Pacific Technology and ASM Japan. It was the first of its kind. Since the mountain did not come to Mohammed, Mohammed had to go to the mountain.

Meanwhile, in order to join the rapid growth of the Korean market - led by Samsung - Del Prado contemplated the establishment of a Korean operation. The characteristics of the Korean market resembled those of Japan in the early 1980s. The involvement of a local party and a clear commitment to localize production were central to obtain a footing in this promising market. Earlier, ASM had served Korean chip manufacturers via ASM Asia - a business unit of ASM Pacific Technology - and later via a local distributor called Won Ik. ${ }^{130}$ This resulted in a few sales, such as two A300's, one Plasma III furnace, and an Epsilon One to Samsung, and a VMP-100 to Hyundai. ${ }^{131}$ However, by 1995, Samsung indicated that ASM had to consider another way of serving the Korean market. ${ }^{132}$

From June 1995, John Benoist and Jaap Beijersbergen worked to prepare the joint-venture. Benoist had been president of Tempress until this firm's bankruptcy a year earlier, and being experienced and undaunted, he was entrusted by Del Prado with this responsibility. ${ }^{133}$ The Dutchman oversaw negotiations with probable partners for a joint-venture and with governmental agencies. ${ }^{134}$ In

130 This firm engaged in three activities: distribution, quartz manufacturing, and LED. It had 190 employees, and totaled 53 million dollars in sales for 1992. - ASM Wafer Process Equipment Limited, Steve Reiutz 'Fax to Friant, Krickl, Del Prado, Miyazaki, Mogi: ASM Organization in Korea' (18-1-1993).

131 ASM International, Arthur del Prado, 'Memo to Art Launder: Won Ik' (17-11-1994) ) Archive Arthur del Prado - ASM Korea/ASM Genitech, J.V. Korea; Won Ik Corporation, 'Presentation of Sales Meeting: For ASM International meeting Mar. 10-11 in Holland' (10-5-1994) ) Archive Arthur del Prado - ASM Korea/ASM Genitech, J.V. Korea.

132 ASM Wafer Process Equipment Limited, Steve Reiutz 'Fax to Friant, Krickl, Del Prado, Miyazaki, Mogi: ASM Organization in Korea' (18-1-1993).

133 ASM International, John Benoist, 'Fax to Arthur del Prado: Samsung' (21-3-1995) Archive Arthur del Prado-ASM Korea/ASM Genitech, ASM Korea 1993-1995.

134 Candidates for the joint-venture were Won-Ik, Hyundai, Dong Bu, and Oyang Scientific Inc - ASM International, Arthur del Prado, 'Memo to Ivo Raaijmakers: Dong Bu' (13-11997) Archive Arthur del Prado - ASM Korea/ASM Genitech, J.V. Korea; ASM International, Arthur del Prado, 'Fax to Y.H. Lee, Won Ik Corporation' (30-10-1995) Archive Arthur del Prado - ASM Korea/ASM Genitech, ASM Korea 1993-1995; Won Ik Korea, B.H. Ahn, 'Fax to John Benoist' (27-10-1995) Archive Arthur del Prado - ASM Korea/ASM Genitech, ASM Korea 1993-1995; Oyang, Scientific Incorporated, John Benoist, 'Fax to Arthur del Prado: J-V + Agency Agreement' (24-10-1995) Archive Arthur del Prado - ASM Korea/ASM Genitech, ASM 
March 1996, ASM Korea was established as a joint-venture between ASM International and a local agency called Oyang Scientific, Inc. ${ }^{135}$ Benoist remained general manager of the new South-Korean subsidiary, receiving support from Beijersbergen. ${ }^{136}$ They focused on getting the A400, the A600, and the Epsilon One sold to Samsung, LG, and Hyundai.

\section{Centripetal versus centrifugal forces}

Although Friant succeeded in stimulating communication among the operations, the business units' pursuit of their own interests and opportunities still bore centrifugal effects. ASM remained a diversified company with epitaxy, vertical furnaces, and plasma CVD as its core competencies. The business units continued to be responsible for the development and execution of the various competitive strategies. Consistently, there was strive about whether particular elements could be fully deployed as competitive strategies or had to be subjected to the corporate strategy.

Throughout 1995 and 1996, this dichotomy manifested itself most clearly in a scheme involving central coordination for manufacturing and technological development. Since the early 1990s, management at ASM International in Bilthoven had been aware of the ineffectiveness of maintaining multiple manufacturing locations. As Del Prado stated years earlier:

'Manufacturing of the same products at more than one place at ASM had led to disastrous effects, because R\&D and engineering have been allowed to diverge in all directions. Needless to say that economies of scale also played a factor.' ${ }^{137}$

However, the equity crisis that numbed the company, together with the implosion of ASM Europe and the AMTC, prevented a resolute solution of this issue (cf. Innovation III). In the meantime, Friant struggled to control the cost

Korea 1993-1995. The establishment received input from various governmental agencies, including the Ministry of Science and Technology, and the national Science and Technology Policy Institute (STEPI). - Royal Netherlands Embassy, W.L. Bronkhorst, 'Fax from Chargé d'Affaires W.L. Bronkhorst to Arthur del Prado: Your visit to Seoul' (27-2-1995) ) Archive Arthur del Prado - ASM Korea/ASM Genitech, J.V. Korea.

135 Oyang, the predecessor of OSI, represented ASM and ASML in 1984-1985. Tokyo Electron became supplier as well, and requested the termination of the ASM agency. In 1995, Oyang reorganized and became OSI. It had 7 employees. - ASM International and Oyang Scientific Inc, 'Sales Agency Agreement' (20-3-1996) Archive Arthur del Prado - ASM Korea/ASM Genitech, ASM Korea'96-'02.

136 Jaap Beijersbergen, 'Interview with author'.

137 ASM International, Arthur del Prado, 'Memorandum to Ray Friant: ref:92.070 AdP/tv' (268-1992) Archive Arthur del Prado - Ray Friant file. 
of manufacturing in Nagaoka, Phoenix, and Bilthoven. Moreover, in the spring of 1996, Art Launder resigned as general manager of ASM America, after being a mere year in office. While Friant intervened as interim-manager in addition to his job of $\mathrm{COO}$, the lack of a dedicated general manager allowed further deterioration of manufacturing efficiency.

In 1996, Del Prado distinguished an opportunity to address the matter. He wanted to elaborate on the template used for the production and engineering of the A400. During the rapid ramp-up of production of A400s to meet the Micron order, both ASM Europe and Philips Machinefabrieken collaborated to their mutual satisfaction. Del Prado was eager to elaborate on this successful manufacturing strategy. As he communicated to Friant:

'Considering what they [Philips Machinefabrieken] did for ASM-E in the A400 arena and what they did for ASM-L in the stepper field, throwing in all their technology resources, we can only win.' ${ }^{138}$

The entrepreneur had concocted a scheme that would kill two birds with one stone. He wanted to deploy the engineering skills of Philips Machinefabrieken for the design and manufacturing of a standard wafer handling platform. Such a platform could be used for the new 300-millimeter versions of the Epsilon and the Eagle-10 single wafer reactors, or for the A600 and A400 vertical batch systems. It was an ingenious way of centralizing some part of manufacturing, in this case at Philips Machinefabrieken. Moreover, ever since the late 1980s, the ASM executive board had been trying to create a common platform for all the various products and processes (see Innovation III). While competitors like Applied Materials succeeded, ASM seemed to be incapable of overcoming the divergent interests of the various products groups.

The forthcoming introduction of 300-millimeter wafers constituted another opportunity to establish an ASM-wide wafer handling platform, and achieve much desired economies of scale. ${ }^{139}$ To facilitate the new wafer size, all wafer handling technology of the ASM products had to be redesigned. This formed a clear window of opportunity to harmonize and standardize the wafer handling platforms. As Del Prado explained to Friant, who remained wary of rushing into over-ambitious endeavors again:

138 ASM International, Arthur del Prado, 'Memo: Agenda Front-end Board' (5-9-1996) Archive Arthur del Prado-Ray Friant file.

139 ASM International, Ray Friant, 'Minutes of the Front-End Board Meeting Phoenix, September 9 and 10, 1996' (18-2-1996) Archive Arthur del Prado - ASMI Management 90's; Management Meetings '89-'04. 
'I am still convinced our basic platform approach is excellent but it is a difficult one to manage. ... Besides all the human, political and strategic aspects of the above, we have to enable ourselves to manufacture cost effectively and with a time to market momentum to capture the windows of opportunity the market offers us. Along this line it has been proven how valuable the cooperation and exploitation of an integrated supplier of parts, modules, subassemblies and almost finished systems can be. (A400/PMF/Micron)' ${ }^{140}$

At the head office, Del Prado's assessment was shared by CTO Ernst Granneman, Strategic Marketing Director Chris Werkhoven, and a new scientific executive named Sieb Radelaar. ${ }^{141}$ Each of these technologists propagated the design of a common platform that would even 'surpass a "me too" update of today's technology.' ${ }^{142}$

At the subsidiaries, however, this viewpoint was not automatically shared. Both at ASM America and at ASM Japan, the product groups knew exactly how they wanted to compete. After all, they were responsible for the competitive strategy of their product. Complying with the headquarters' ambitions would distract attention from their own game plans, while also diverting scarce resources.

Most striking was the discussion surrounding the redesign of the standalone single wafer Epsilon reactor into a cluster system. By 1995, Epsilon lost ground to Applied Materials' clustered single wafer epitaxial reactor, the Centura. ${ }^{143}$ The competition with Applied not only intensified in court surrounding mutual infringements of intellectual property but also in productivity, costs, and service of the machine.

To compete with Applied Materials' cluster reactor Centura, Werkhoven tried to amass support for the development of a clustered epitaxy system in Phoenix. Combining multiple Epsilon reactors decreased cost-of-ownership and improved ASM's competitiveness. The rather expensive wafer handling and cleanroom interface modules could be amortized over multiple instead of a single reactor

140 ASM International, Arthur del Prado, 'Memo to Ray Friant' (June 1996) Archive Arthur del Prado - Ray Friant file.

${ }_{141}$ ASM International, Ray Friant, 'Minutes of the Front-End Board Meeting Phoenix, September 9 and 10, 1996' (18-2-1996) Archive Arthur del Prado - ASMI Management 90's; Management Meetings '89-'04.

142 ASM International, Arthur del Prado, 'Memo: Agenda Front-end Board' (5-9-1996) Archive Arthur del Prado - Ray Friant file.

143 ASM America, Art Launder, 'Facsimile Transmission: Epsilon Red Flag' (26-8-1994) Archive Arthur del Prado - Ray Friant file. 
chamber. Through a joint-development program with Siemens Semiconductors, a single wafer handler platform - dubbed A800 - was already integrated with various Epsilon process modules (see Chapter 26). This first wafer handling platform had been designed and manufactured by Philips Machinefabrieken, and was envisaged to be a stepping stone for ASM International's ambition in platform consolidation.

At ASM America a strong product group was in charge. It consisted of Armand Ferro as dedicated product manager, John Krickl in the varying roles of interim general manager and senior sales manager, Gloria Zemla as controller, and a number of engineers including Bob Haro and Richard Crabb. Most of them had been involved with the machine since the 1980s (cf. Innovation II). Their familiarity with the machine's properties and capabilities enabled a deliberate exploration of opportunities. Earlier attempts to diversify the Epsilon to other applications, such as the polysilicon Paragon reactor, proved futile. Furthermore, the success of the Epsilon product group had been critical in the survival of ASM front-end in the early 1990s. They had won their spurs. They stuck to their game plan of innovating and commercializing standalone single wafer epitaxial equipment.

Moreover, with regard to the forthcoming 300-millimeter standard, the product group had already made substantial progress. Manufacturers of epitaxy equipment led the industry - together with silicon wafer manufacturers - in preparations for the new 300-millimeter wafer standard. In this context, ASM America already secured commitment of major wafer manufacturers Komatsu, Wacker, Monsanto, and chip manufacturer Motorola for the 300-millimeter Epsilon in the spring of 1995. ${ }^{144}$ Furthermore, ASM Europe and German wafer manufacturer Wacker, with support from the European Community, started a research project with the acronym LASSIE, meaning Large Area Substrate Silicon Epitaxy. ${ }^{145}$ The customer participation in the Advisory Council and LASSIE endorsed the course of ASM America's development externally - in competition with Applied Materials - but also internally, vis-à-vis ASM's head office.

The attempt to centralize manufacturing and harmonize technological development got bogged down in the fall of 1996. By that time, Friant was ready

144 Representatives of these customers took part in an Advisory Council, which functioned as a soundboard for the Epsilon engineers. - Armand Ferro, 'Interview with author'; ASM International, 'Progress Report June 1995' (June 1995) Archive Arthur del Prado - RvC 19941996 file.

145 LASSIE was part of the fourth European Framework Program (ESPRIT) of the European Commission; ASM International, 'Large-Area Substrate Silicon Epitaxy (LASSIE). Proposal for the ESPRIT 4th Framework Programme for the Development of a $300 \mathrm{~mm}$ Wafer Epitaxy System' (6-6-1995) Archive Arthur del Prado - RvC 1994-1996 file. 
to retire as $\mathrm{COO}$. Having originally been appointed as interim- $\mathrm{COO}$, his tenure was extended several times as he was in the middle of steering ASM away from the abyss. In the fall of 1996, his successor was ready to replace him. ${ }^{146}$ This was Daniel Queyssac, an Americanized French industry veteran who had worked for Italo-French chip manufacturer SGS-Thomson and American equipment manufacturer Novellus.

A worldwide management meeting was the last one presided by Ray Friant. In 1996, from 19 to 22 November, the full front-end board convened in Phoenix. The event constituted Friant's last opportunity to reach agreement and establish common goals. To this end, he organized a team-building day, involving rafting, horseback riding, and a number of games. Tactically Friant had created groups of teams of managers who in his view should know each other better. Even Del Prado participated, while Friant's successor Queyssac - and a few other new staff members - attended as well. Never before had such a day been organized at ASM.

Despite the joyous activities and their contributions to the team spirit, individual differences in corporate and competitive strategies persisted. Although Queyssac followed in the footsteps of Friant, forcing his point of view and management control onto the front-end organizations, the strong-willed and headstrong engineers and managers of the various subsidiaries went their own way.

CTO Ernst Granneman met with this same attitude in the fall of 1996, when he scheduled a 'technology council meeting' on this topic. During these gatherings, R\&D managers and engineers met to discuss technological topics and create an atmosphere of mutual understanding. To stimulate peer-topeer appreciation and creativity among the engineers, Granneman awarded a bottle of scotch whisky to the engineer with the most innovative and creative propositions. ${ }^{147}$ The meetings helped to map and amass support for various roadmaps in the company. For this particular meeting, he had put the issue of a 300-millimeter wafer handler on the agenda, and invited the engineers to discuss probable specifications (figure 64). Granneman explained that the new 300-millimeter manufacturing systems formed a unique opportunity to prune the proliferation of common technology across the subsidiaries. The provisional A800 and the Epsilon standalone tools constituted a good example, but he also referred to the Japanese Eagle-10 plasma CVD reactor:

'Although, the epi module can be used on a $300 \mathrm{~mm}$ cluster system, such a system is not scheduled yet... The future $300 \mathrm{~m}$ PECVD modules

146 In 1993, Queyssac had already been identified as successor for Friant by Del Prado and Friant. - ASMI, Rray Friant, 'Memo: ASM Front-End status' (20-3-1993) Archive Arthur del Prado-RvC 1992-1993.

147 Ernst Granneman, 'Interview with author'. 
will be connected to a $300 \mathrm{~mm}$ cluster platform. ... As the objectives to develop only one platform to be used for Eagle 10 as well as for Epsilon, it is necessary to design a platform which also accommodates the Epsilon specs. ${ }^{.148}$

\section{Figure 64}

Schematic view from above of a potential central wafer handler serving reactor chambers of ASM's subsidiaries

This configuration was proposed by Chief Technology Officer Ernst Granneman during a Technology Council Meeting in the fall of 1996. For the new wafer size - 300 millimeters - a standardized wafer handler might be able to serve all the various reactor types within ASM International, such as ASM Japan's Eagle-12, ASM Japan/Europe's A600-UHV, and ASM America's Epsilon 3000. Such a general-purpose wafer handler might offer economies of scale across the company. Yet the viability of this proposal for several of the applications was not accepted by engineers of the various subsidiaries.

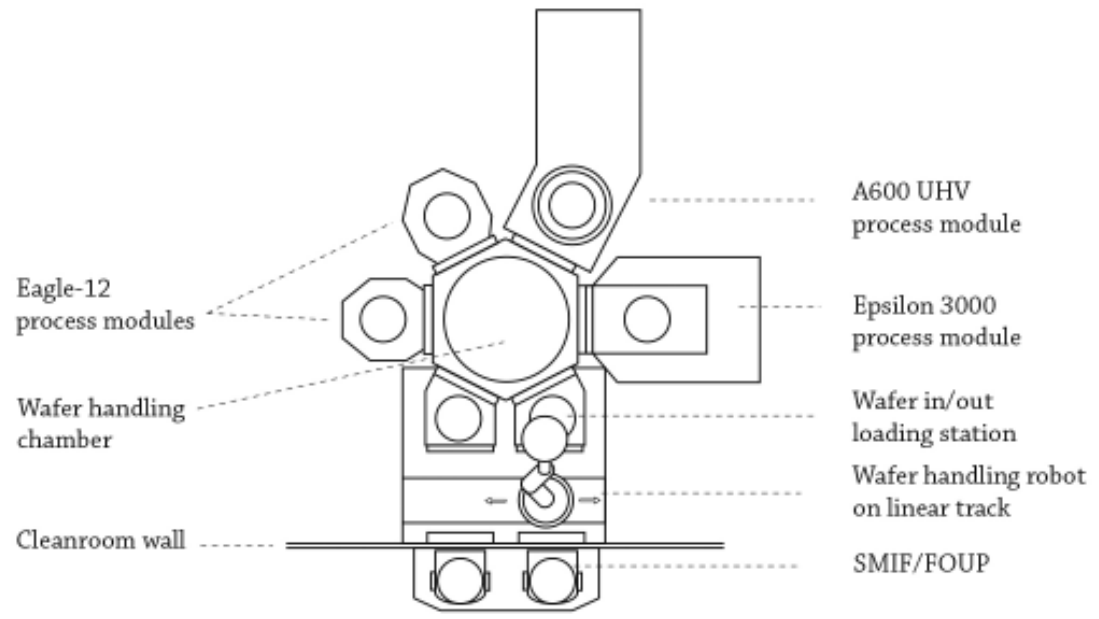

However, during the meeting, the engineers emphasized the differences. The Eagle PECVD single wafer tool required its own platform, as did the Epsilon. This meant that a wafer handler platform could not be defined, which in its turn meant that Del Prado could not proceed with his scheme to further centralize manufacturing at Philips Machinefabrieken. The status quo persevered.

\section{Birth of a visionary}

The increased confidence was not limited to the subsidiaries; it also concerned Del Prado. Since the late 1980s, the entrepreneur had been consistently blamed for the company's inherent weaknesses. The bankers, his Supervisory Board,

148 ASM International, Ernst Granneman, 'Fax: Announcement Technology Council Meeting \#18: ASM 300mm wafer handling/cluster platforms and related corporate technology' (1012-1996) Archive Arthur del Prado - ASMI Management '90s - Technology Council Meeting. 
managers, employees - all heaped criticism on his inability to address failing organizational processes within and among the subsidiaries. Ten years after his celebratory acclamation, the 1983 Dutch Director of the Year seemed to be knocked off his pedestal.

His position of dominant shareholder (he still retained about 35 percent of ASM stock), his achievements in building the company, and his rampant perseverance prevented that the founder got sidelined. Nevertheless, facing the shutdown of his company and also through Ray Friant's personal energetic and imposing personality, Del Prado had conceded major responsibilities. By relying on Friant to take care of the operational management, Del Prado's role within the firm changed. He remained chief executive officer, and fully engaged with his firm. But, now, he could focus more on areas in which he excelled, such as scavenging for new opportunities and charming prospective investors, management candidates, or equipment manufacturers. In other words, he could work on developing ASM's future course, while not being distracted by the daily management affairs.

Throughout the mid-1990s, Del Prado regained confidence in his capability for recognizing, and appropriating, future opportunities. This was stimulated by the significant growth of the semiconductor equipment industry and four specific events: the balancing of the ion implantation investment of the late 1980s, the initial public offering of ASM Lithography and Berliner Electro Semiconductor Industries (BESI), and the improved quotation of ASM International on the stock exchange. These events proved Del Prado's critics wrong, and established the entrepreneur as visionary.

Initial appreciation of Del Prado's visionary instincts followed from a consideration of the investments in ASM Ion Implant. This operation was divested in 1988 to appease the anxious banks. In the fall of 1994, De Leeuw assessed the return on investments. ${ }^{149} \mathrm{He}$ calculated that ASM had invested 10.5 million dollars, for which it obtained 15.4 million dollars during the sale, and 5.4 million dollars in subsequent royalties from 1989 to 1993. In other words, ASM's investment of 10.5 million dollars had resulted in a revenue of 20.8 million dollars.

Secondly, ASM Lithography conducted an initial public offering in March 1995 on the Amsterdam Stock Exchange and Nasdaq, floating 12.6 million shares (38.2 percent) for 28.5 Dutch guilders per share. ${ }^{150}$ This meant that the company was valued at 940.5 million Dutch guilders. Philips already earned 273.6 million

149 ASMI, Willem de Leeuw, 'Memo: ASM Ion Implant' (16-8-1994) Archive Arthur del Prado - RvC 1994-1996.

150 Including some commissions. ASM Lithography, 1995 Annual Report (February 7, 1996). 
Dutch guilders from this transaction, floating 9.6 million shares. ${ }^{151}$ Since ASM International's divestment of the stepper manufacturer in 1988, it had grown from 35 million Dutch guilders in 1988 to 534 million in $1994 .{ }^{152}$ This incredible achievement of the ASM Lithography employees negated all preconceived doubts about the viability of a Dutch stepper manufacturer. Moreover, it proved Del Prado's rather rash decision to save the Philips' stepper technology from oblivion to be quite worthwhile.

The third event contributing to Del Prado's renewed confidence was the initial public offering of BESI. In December 1995, the manufacturer of semiconductor packaging equipment sold 9.6 million shares (37.7 percent) for 13 dollars each on the Nasdaq, the Amsterdam Stock Exchange, and the Frankfurt Stock Exchange. ${ }^{153}$ This concerned the former ASM Fico activities, totaling 88 million dollars in sales in 1994, but also Meco, a manufacturer of plating equipment, plating chemicals, and lead-frames, which was acquired on May 1, 1995, and totaled 98.5 million dollars in 1994 sales. Fico and Meco had been integrated into BESI for 60 million guilders and 115 million guilders, respectively, and together they now enjoyed a market capitalization of 331 million dollars (or 530 million Dutch guilders). This was a harsh contrast to the low valuations attributed by Del Prado's bankers prior to ASM Fico's divestment. Although the disentanglement of Fico from ASM had contributed to this achievement, the public offering of BESI also proved the viability of Del Prado's entrepreneurship.

And finally, Del Prado's tenure consolidated through the radically improved quotation of ASM International on the stock market (figure 65). Elaborating upon its strong sales of 670 million Dutch guilders in 1995, 'reflecting a 92 percent gain in front-end and a 11 percent improvement in back-end,' ASM's stock improved. ${ }^{154}$ Front-end sales increased from 181 million Dutch guilders in 1994 to 342.5 million in 1995 and 361 million in 1996. ${ }^{155}$ Over 1995, the company had an average market capitalization of 548.43 million Dutch guilders, a remarkable improvement after its deplorable average valuation of 28.66 million Dutch guilders (!) over 1993. ${ }^{156}$

151 In successive flotations in 1996 and 1997, it capitalized even more on ASM Lithography's success, diluting its ownership to 23.9 percent.

152 ASM Lithography, 1994 Annual Report (February 73 1995).

153 After withholding commission, 117.9 million dollars in proceedings went to the company. - Morgan Stanley \& Co, BE Semiconductor Industries Prospectus 9,600,000 common shares (412-1995) Archive Arthur del Prado - BESI files; Richard Blickman, 'Interview with author'.

154 ASM International, 1995 Annual Report (15-3-1996).

155 ASM International, 1998 Annual Report (26-2-1999).

156 In 1995, ASM had 10,460,581 outstanding shares with an average price of 32,69 dollars per share, valuing the company at 341.96 million dollars. December 31, 1995, 1 dollar traded for 1.6038 Dutch guilders. However, at the peak of the market in the third quarter of 1995, ASM 


\section{Figure 65}

Graph of high, low, and average annual market capitalization on the Nasdaq stock exchange from 1992 to 1999.

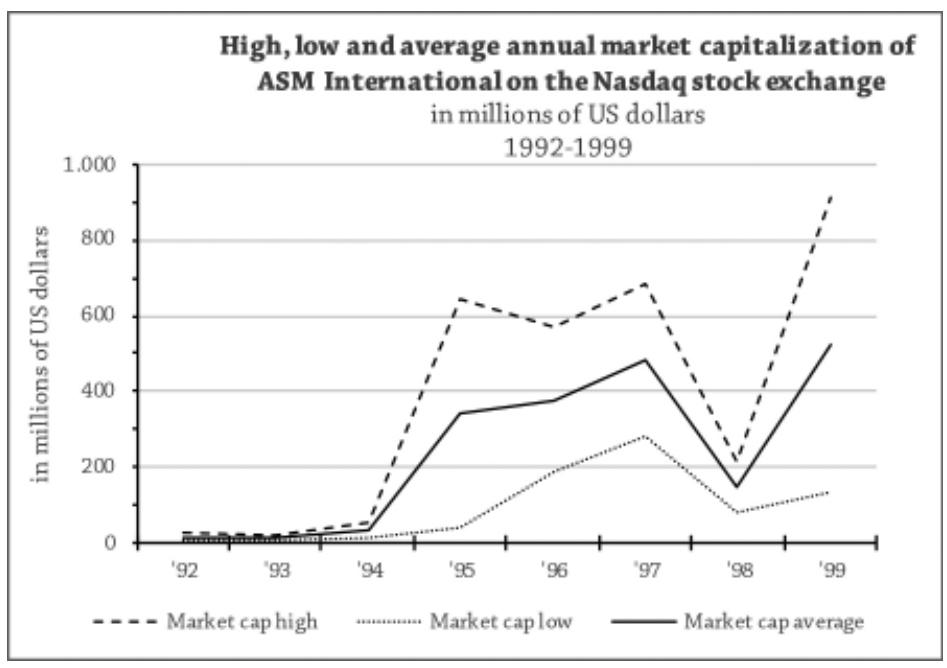

This significant improvement of the company's results allowed Del Prado to renew relations with his bankers. This was done by capitalizing on the renewed investor appreciation. In March 1996, ASM pursued a stock split during which shareholders got three shares for every single share, multiplying the number of outstanding shares threefold to about 31 million. ${ }^{157}$ The rationale behind this move was to increase the liquidity of stock, which might result in improved stock prices. The success of ASM Lithography and BESI also paved the way for a listing of ASM on the Amsterdam Stock Exchange by December 1996. Being a Dutch company, the exposure to investors in its home country might be beneficial. During the offering, ASM sold 1.5 million common shares, whereas Del Prado and the American investment bankers Grantham, May, Van Otterloo \& Co. sold 2.6 million common shares. ${ }^{158}$ After the transaction, Del Prado retained 28.2 percent of the company. On the date of listing, ASM's market capitalization amounted

stock was valued 61,25 dollars per share, valuing the company at 640.71 million dollars, or 1.02 billion Dutch guilders. In 1993, stock price averaged between 2.125 to 0.625 dollar per share, and with 10,742,366 shares outstanding, and one dollar worth 1.94 guilders. - ASM International, 1995 Annual Report (15-3-1996) and ASM International, 1993 Annual Report (26-4-1996).

157 ASM International, Jobs Wagenaar, 'Memorandum to the Supervisory Board: Splitsing van aandelen' (29-9-1995) Archive Arthur del Prado - RvC 94-96 file.

158 Del Prado sold 1.5 M of his 10.803 million shares. Diluting his share from 34.3 to $28.2 \%$. The investment bankers retained 9.9 percent. 
to 594.5 million Dutch guilders. ${ }^{159}$ The company itself retained about 26 million Dutch guilders in proceeds, which constituted a welcome replenishment to its cash flow.

Surrounding the offering, ASM repaid about 13.8 million of bank loans. More importantly, ASM finally relieved itself from the 25 million Dutch guilders convertible loan held by Grantham, Mayo, Van Otterloo \& Co, which had been looming under very unfavorable terms since 1987.160 Furthermore, ASM International completed a renewal of its bank loans at ABN Amro and the National Investment Bank, which involved an expansion of the credit facilities and deferment of installments. While about 176 million Dutch guilders in gross interest bearing debt remained, these actions decreased the financial pressure from the banks. ${ }^{161}$

The staggering results confirmed Del Prado's assessment about his firms, and increased his grudge toward his banks. After all, they had forced him to divest these lucrative and promising operations. If the crisis years since the mid-1980s caused Del Prado to doubt his entrepreneurial instincts, this was negated by the quotations of ASM Lithography, BESI, and ASM International - even though it is fair to add that the valuation of the first two had been the sole achievement of their engineers and managers. Regardless, the events on the stock exchange re-established his role of visionary, as a man capable of recognizing technological opportunities and enabling innovation beyond the common horizon of investors.

159 ING Barings, Merrill Lynch International, and ABN Amro Rothschild, 'ASM International Offer of 4,100,00 Cmmon Shares' (11-12-1996).

160 ASM International, Arthur del Prado, 'Progress Report January 1996' (February 1996) Archive Arthur del Prado - RvC $96=98$ file.

161 All of this debt was secured against all available assets, including property, inventory, ASMPT, etc.- ASM International, Jobs Wagenaar, 'Memorandum to Supervisory Board: Funding opportunities' (January 1997) Archive Arthur del Prado - RvC 96=98 file. 
ASM International management board, 1985

From left to right: Franc

DeWeeger (ASM America),

Patrick Lam (Asian operations)

Willem de Leeuw (Director of

Technology), Herbert Lakens

(Director of Marketing),

Arthur del Prado (sitting),

Jan Heetebrij (European

operations), Paul Krebs

(Treasurer), and Yo Miyazaki

(ASM Japan).

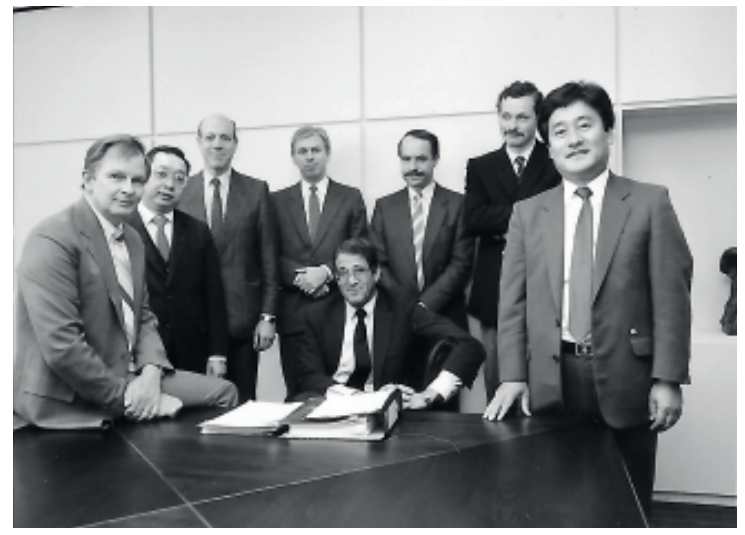

Co-founder and

chief executive

officer of ASM Pacific

Technology Patrick

Lam, the late-1980s

(left)

Arthur del Prado, 1989 (right)
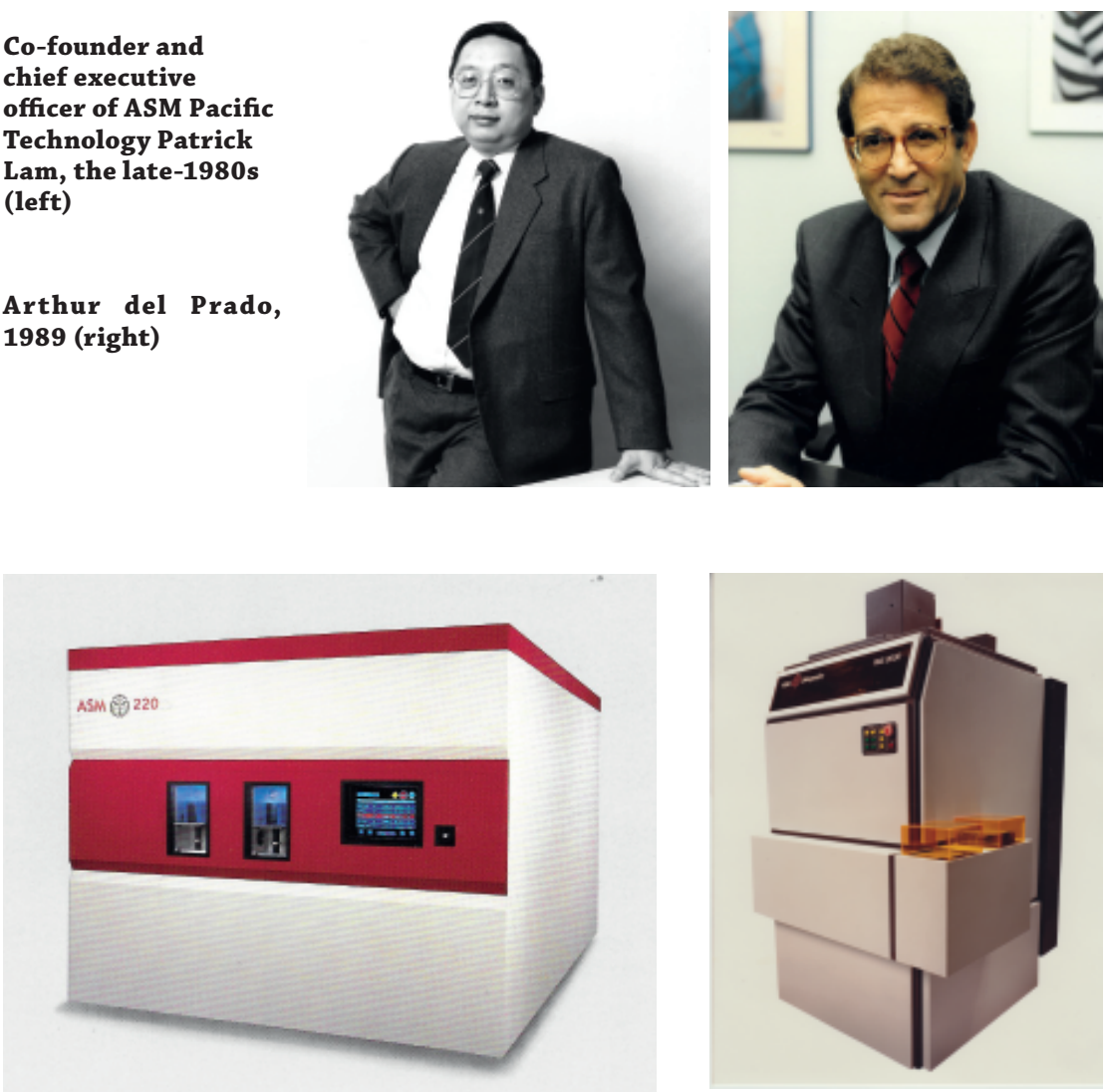

On the left, the ASM Medium Current Ion Implanter ASM 220, of ASM Ion Implant. On the right, the PAS2000 stepper machine of ASM Lithography, late-1980s 


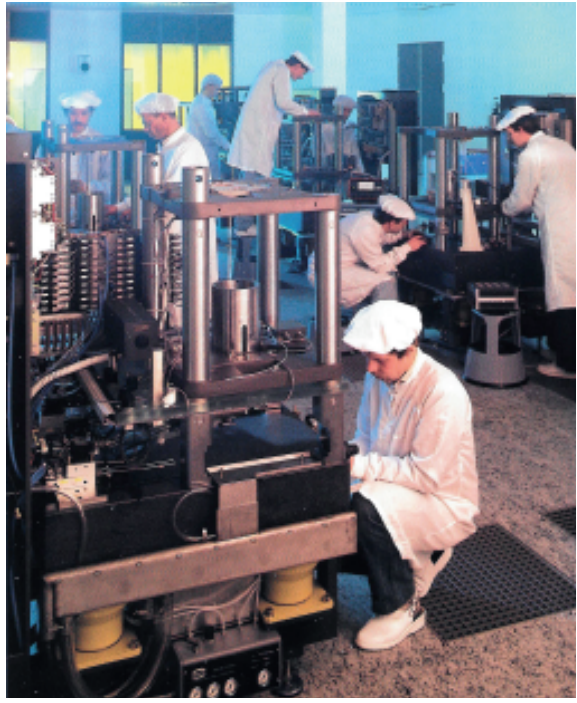

Engineers working on a stepper at ASM Lithography, 1987

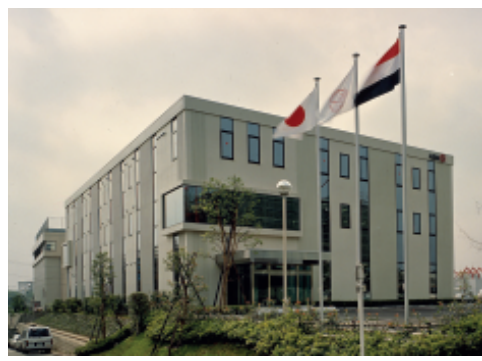

ASM Japan's new head-office in Tama, 1989

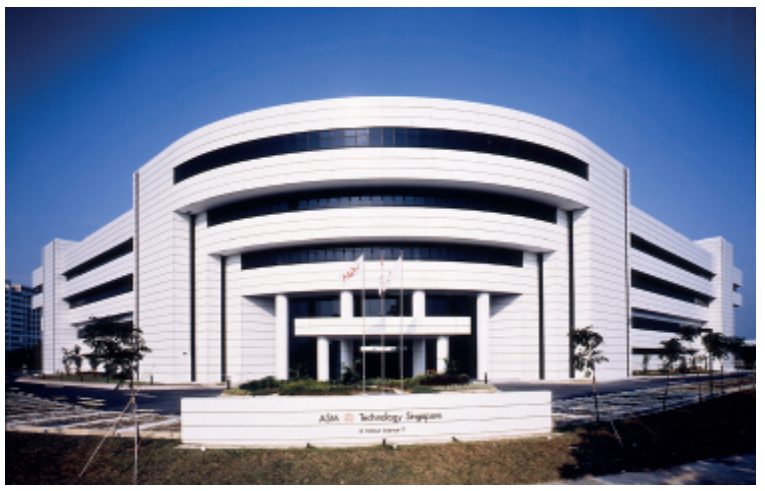

The Singaporean facility of ASM Pacific Technology named ASM Technology Singapore after completion in 1991

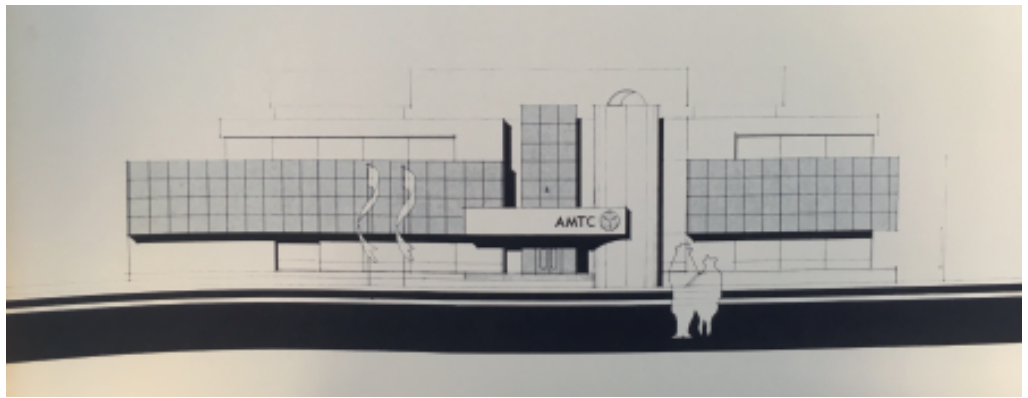

Artist impression ASM Micro-Electronics Technology Center (AMTC) to be built in Bilthoven, 1985 
Cleanroom of the ASM Micro-Electronics Technology Center, 1987

As the construction of a new building was postponed, the AMTC was located at the

Rembrandtlaan in Bilthoven. The tool on the left is a wafer cleaning station. In the middle, an engineer (un)loads a cassette with wafers in a horizontal furnace. On the right, an elipsometer.
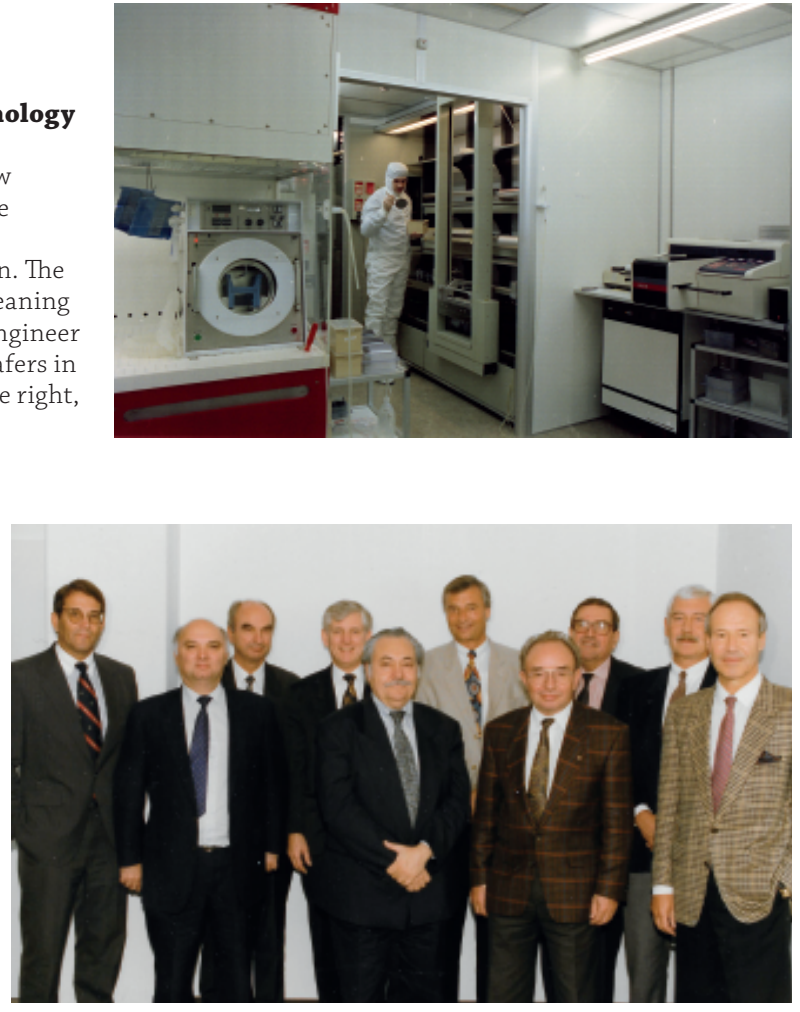

JESSI board, early 1990s

From left to right: Arthur del Prado, Ronald Lawes (Rutherford Appleton Laboratory), Heiner Gutberlet (Robert Bosch), Doug Dunn (Plessey), Pasquale Pistorio (SGS Thomson), Jürgen Knorr (Siemens Semiconductors), and others.
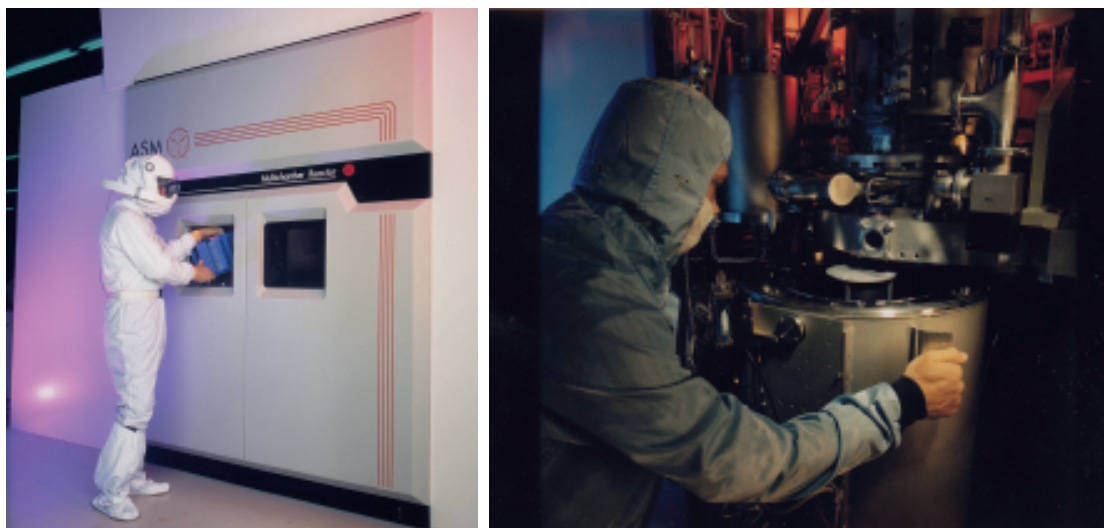

An engineer shows the loading of an A600 during a Semicon Exhibition, 1988

Engineer working on a vertical reactor tube of the A600-2 (low-pressure deposition variation), 1990 


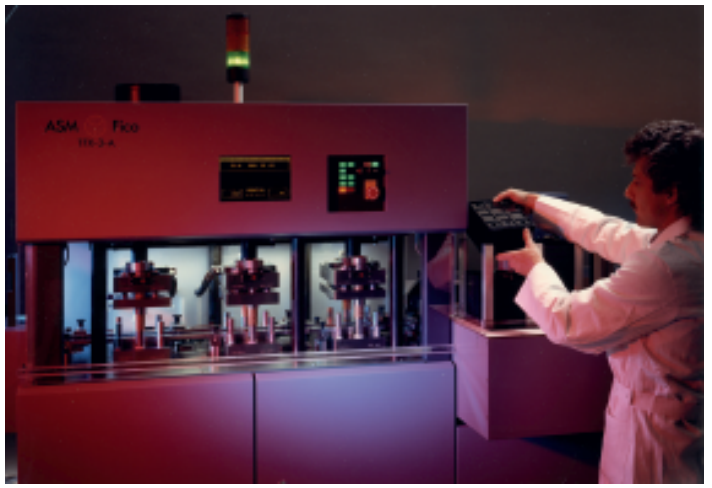

ASM Fico automatic molding machine, 1992

These molding machines

attracted keen interest of leading

American chip manufacturers.

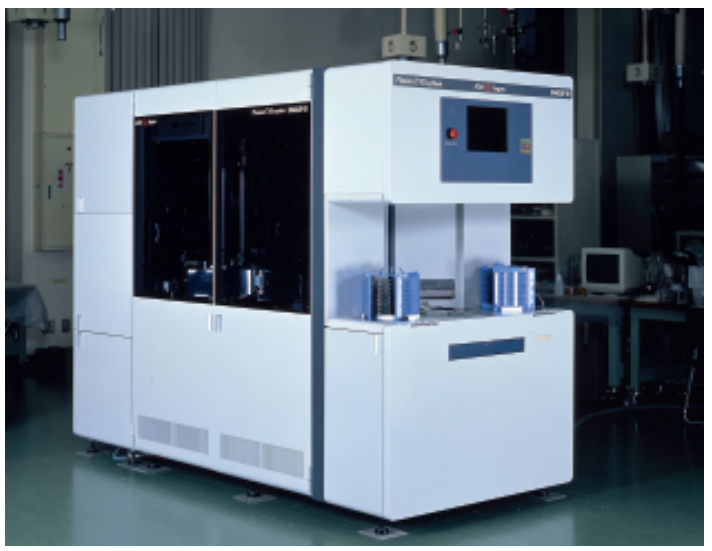

ASM Japan's Eagle-10, 1994

The machine contained two single wafer plasma enhanced chemical vapor deposition reactors. The Eagle-10 helped ASM Japan to overcome the obsolete business of horizontal plasma furnaces.

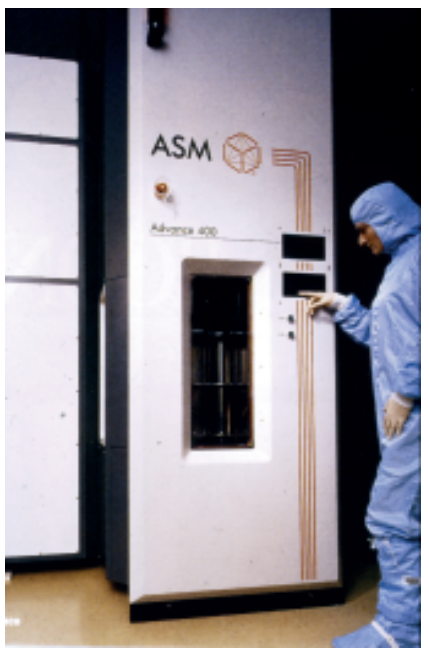

An engineer loads an A400 vertical furnace, 1995 From 1994 onwards, the A400 was developed, built and sold by ASM Europe. The machine overcame a longlasting company-wide dispute about vertical furnace technology. Moreover, the machine ensured the survival of the Dutch operation 


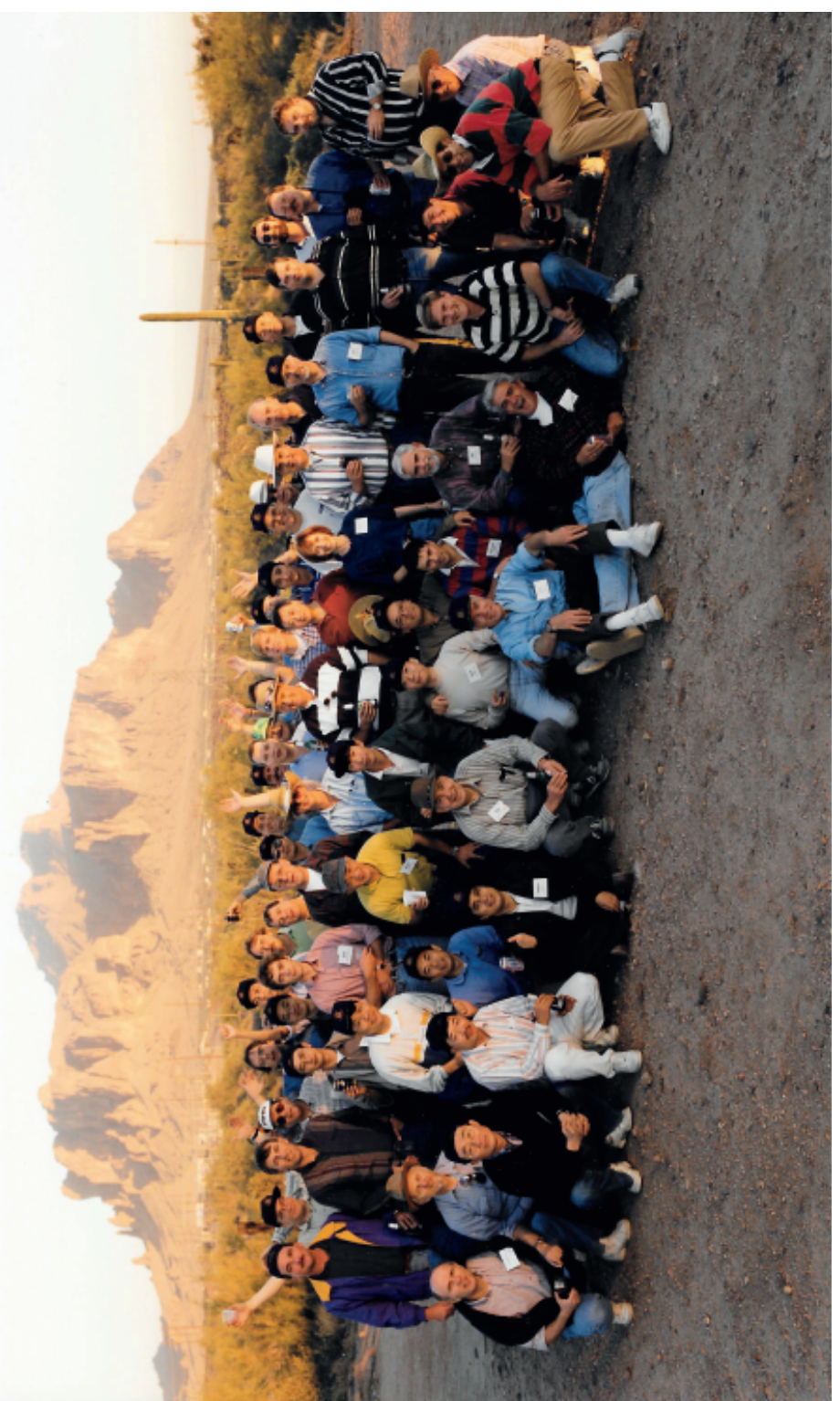

Pictures taken during the 1996 worldwide meeting with ASM's front-end managers in Phoenix, Arizona

Some members on the front row: With thumbs up Fukumi Tomino (general manager ASM Japan), above him in yellow Hitoshi Miura (controller ASM Japan), right to Tomino is Ray Friant (COO). Wearing white socks is John Benoist (general manager ASM Korea). Laying on the floor is Chris Werkhoven, and right from him Bjorn Geel. Arthur del Prado leans on the right-end with a striped sweater. The lady in the middle is Gloria Zemla (controller ASM America). On the right of her with a white head is Armand Ferro (product manager Epitaxy) and without a hat Ernst Granneman (CTO). 


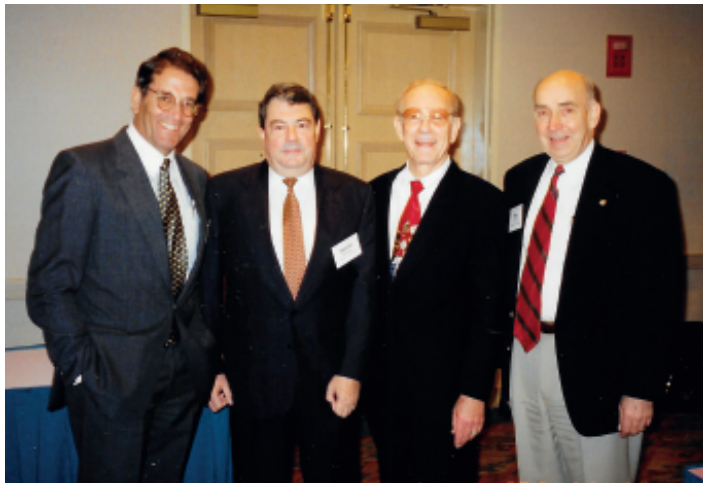

ASM International's operational management during the 1996 Management Meeting in Phoenix, Arizona From left to right: Arthur del Prado, Daniel Queyssac, Ed Foreman (motivational speaker and former US Congressman), and Ray Friant.

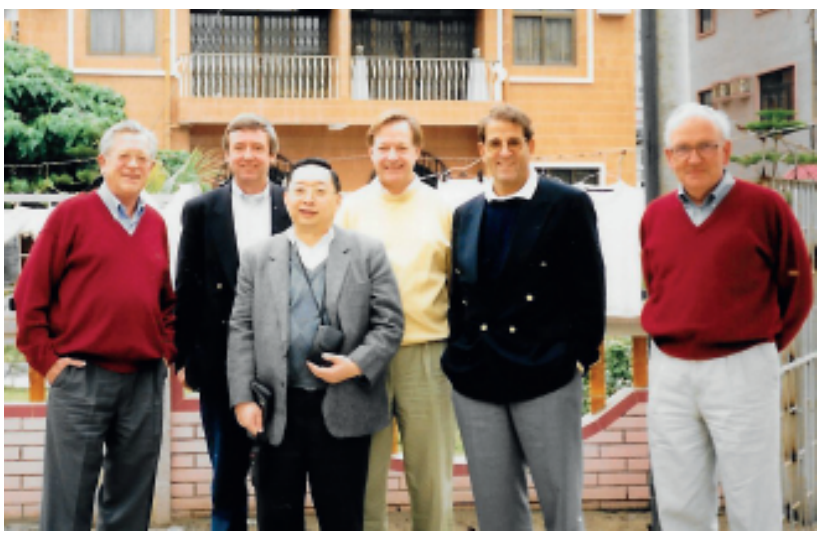

Arthur del Prado, Patrick Lam and the ASM International Supervisory Board during a trip to the company's Asian activities in 1996 From left to right: Lex Helfrich, Frans Saris, Patrick Lam, Paul van den Hoek, Arthur del Prado, and Ferdinand Rauwenhoff.
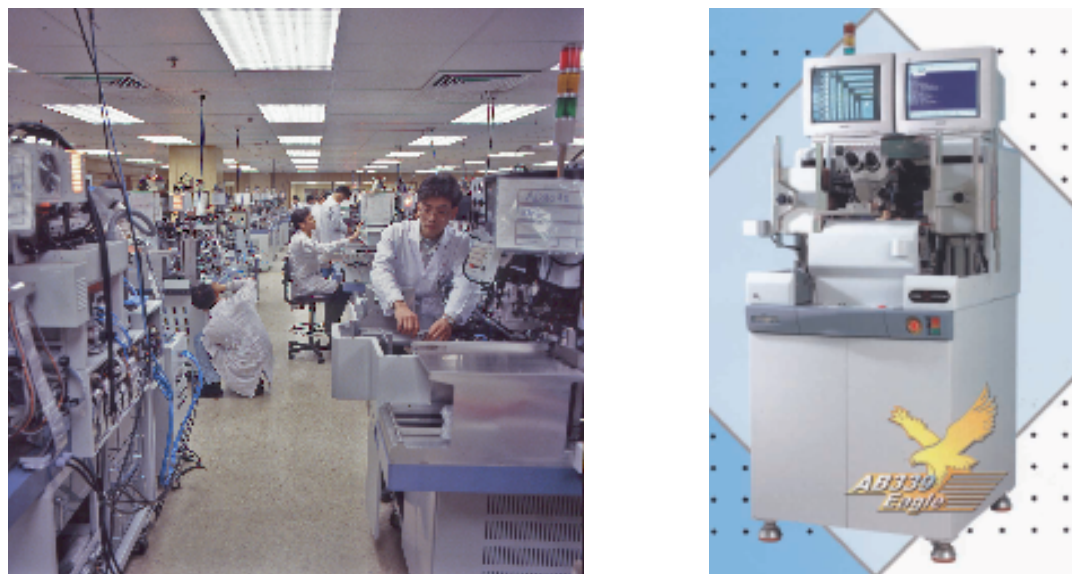

Left, the production of AD809S Die Bonders by ASM Pacific Technology, mid-1990s. On the right, the AB339 gold wire bonder, 1999 
ASM America new facilities at East University Drive, Phoenix Arizona, 1997

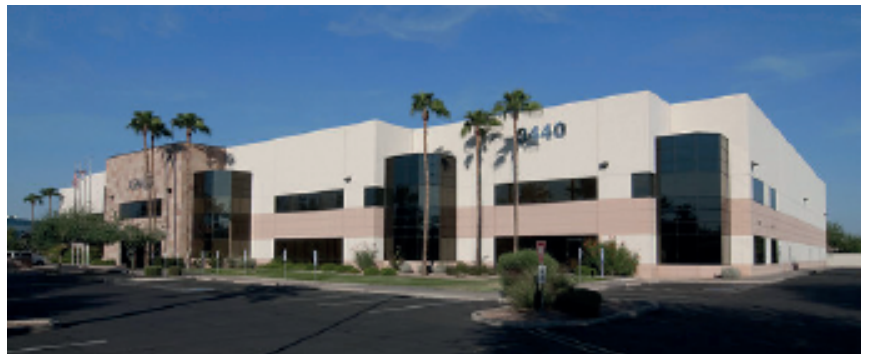

The $\mathbf{A 8 0 0}$ cluster used in the Siemens joint-development program, late 1990s
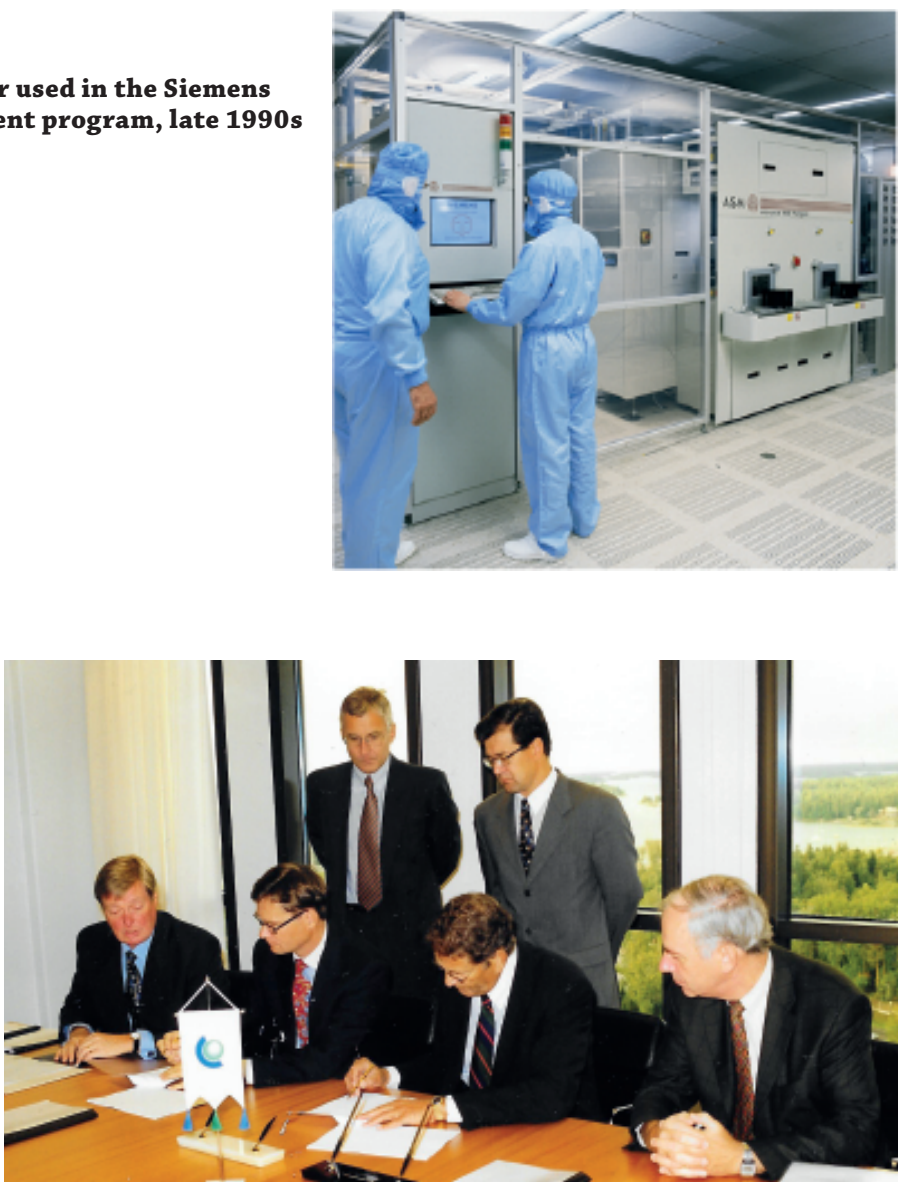

Signing ceremony for the acquisition of ASM Microchemistry, September 1999 From left to right: Kari Lampinen (Merger \& Acquisitions, Fortum Gas \& Oil/Neste), Juha Laaksonen (CFO Fortum Gas \& Oil/Neste), standing person unkown, Arthur del Prado (CEO ASM International), Masse Ervasti (managing director Microchemistry) and Ernst Granneman (CTO ASM International). 


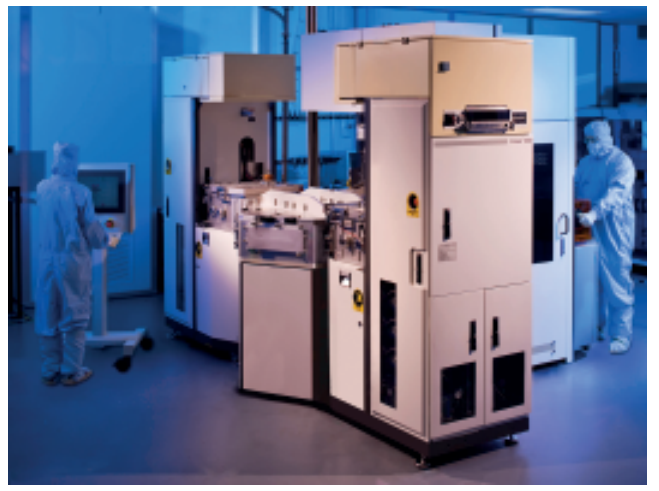

Two Pulsar high-k ALD reactor connected to a Polygon 8300 wafer handler, 2007

The machine is seen from the backside. The picture is taken at IMEC.

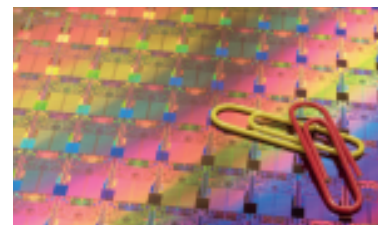

Close up of a wafer with Intel's 45 nanometer chips, 2008 Copyright Intel.

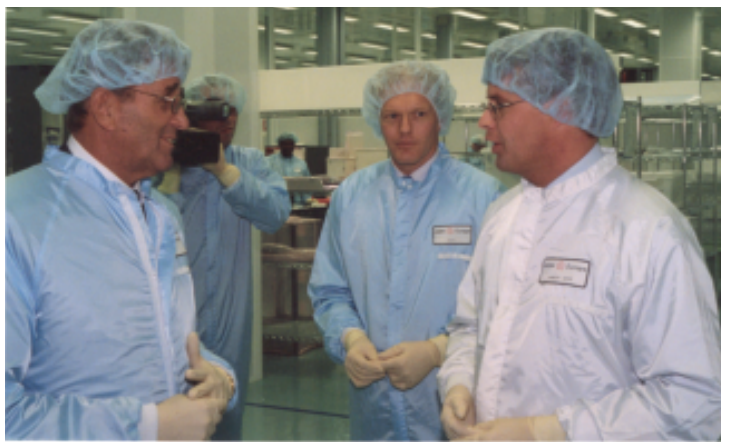

Dutch prime minister Jan Peter Balkenende visits the Almere facility of ASM Europe in November 2003 From left to right: Arthur del Prado, Albert Hasper (general manager ASM Europe), and Dutch prime minister Jan Peter Balkenende.

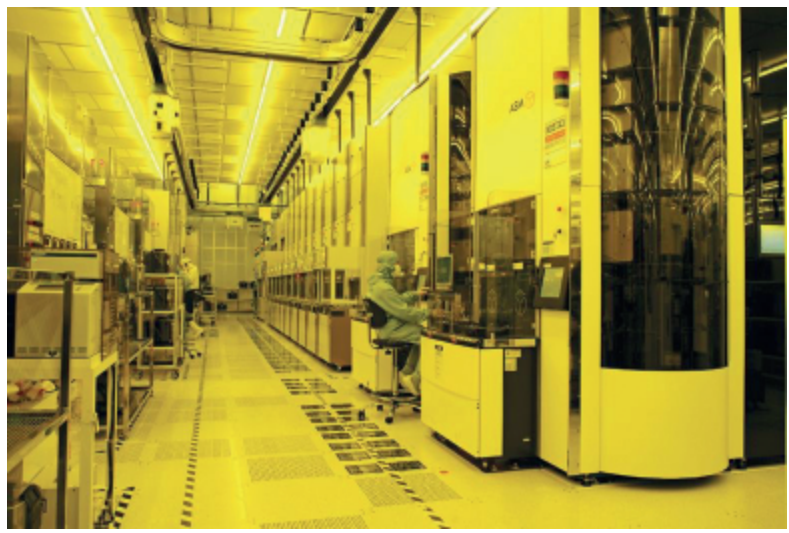

A modern 300-mm wafer cleanroom of TSMC, late-00s

Mind the 'automated material handling system' at the ceiling, through which the FOUPs containing the wafers - are transported from machine to machine. This feature was new for the 300-mm wafer fabs, as the weight of a loaded FOUP became to heavy. On the right side in the picture, an A412 vertical furnace of ASM is visible.

Copyright of TSMC 
Detail of the Levitor reactor chamber, showing a floating wafer, 2000s

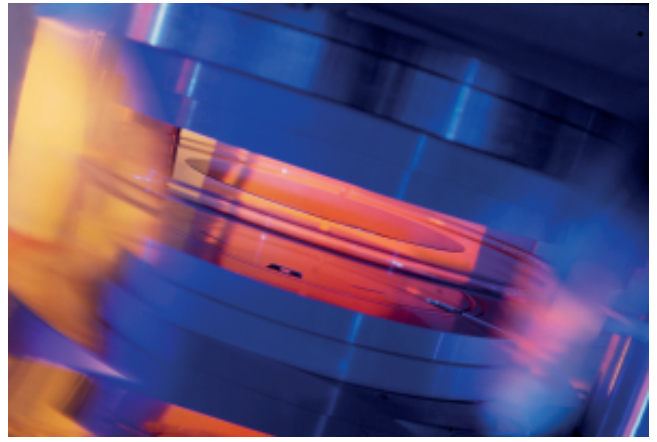

ASM International's management team plants a ceremonial tree in front of the new ASM Genitech office, March 2007

From left to right: $\mathrm{Mr}$.

Saitoh, Fukumi Tomino (general manager ASM Japan), Han Westendorp (chief operational Officer), S.W. Go (general manager ASM Genitech), Hans van Selm (a financial director, ASM), Arthur del Prado (chief executive officer), and Ivo Raaijmakers (chief technology officer).

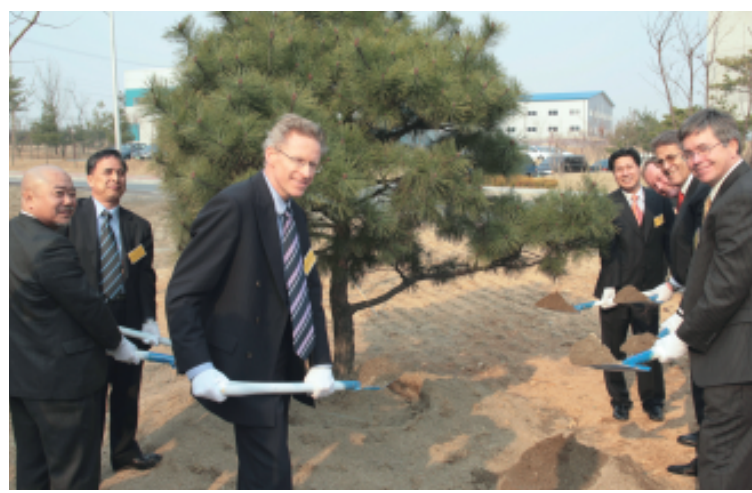

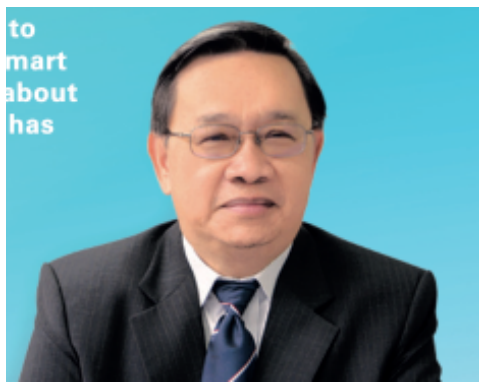

Portrait of W.K. Lee, ASM Pacific Technology's new CEO, late-00s

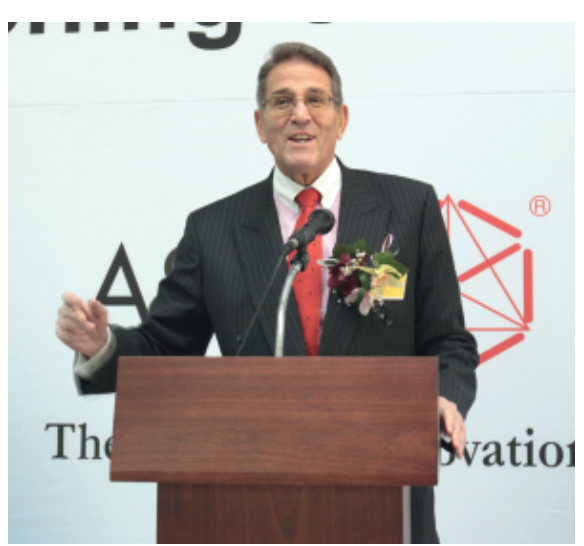

Arthur del Prado delivers a speech during the opening of ASM Genitech Korea facilities, March 2007 


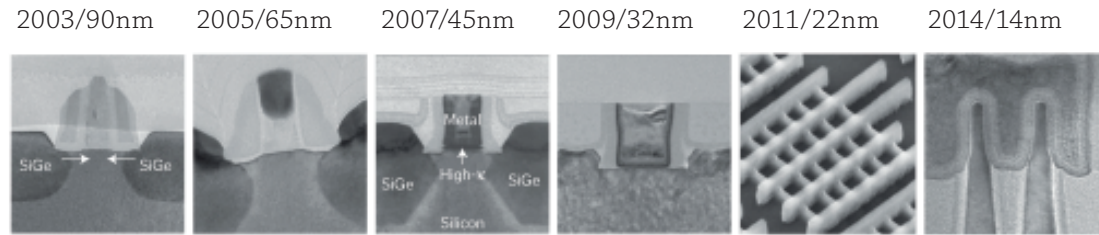

\section{Recent transistors, late-00s}

Microscopic vertical cross-sectional pictures of various transistor generations, showing the incredible innovations in shape, material and production since 2003. The two most left contain strained silicon, the two in the middle are high-k metal gate transistors, and the two on the right, are FinFET transistors.

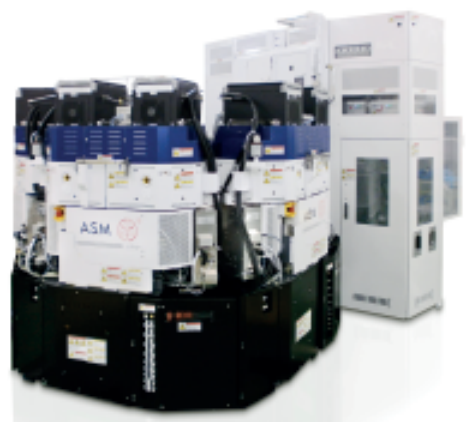

An ASM Eagle XP-8 PEALD reactor, 2013

The cluster machine, seen from the backside, serves 8 single wafer reactor chambers. The white front contains the interface with the rest of the cleanroom.

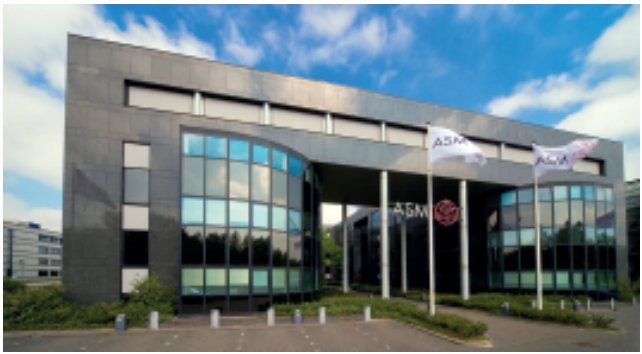

ASM International's head-office in Almere, since 2009

The facilities of ASM Europe are located just around the corner.

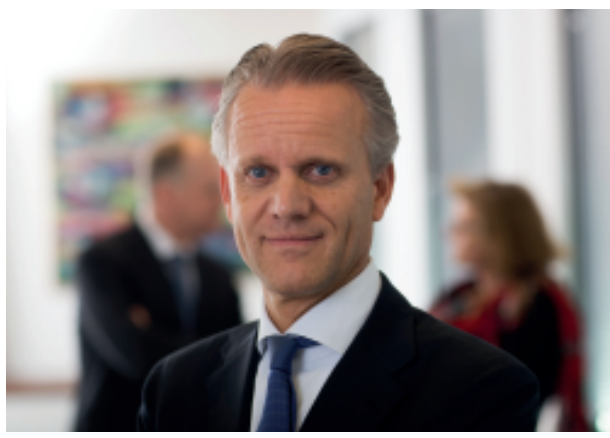

Chuck del Prado, 2015 


\section{Chapter 25 \\ Prospects put into perspective, 1996-1999}

In the final years of the $20^{\text {th }}$ century, ASM's hard-won recovery proved to be very vulnerable. An accumulation of disrupting events shook the company's very foundations. Thrown back into firefight mode, Del Prado and his management harnessed the crisis to break internal opposition to further concentration of activities.

\section{Industrial context:}

\section{Harmonization and destabilization}

The 1995 boom subsided into another period of stagnation (figure 66). ${ }^{162}$ From 1996 until 1998, the semiconductor equipment market contracted. The downturn was aggravated by a financial crisis that numbed Asian economies. As the Asian markets had gained significance, the new crisis affected the global semiconductor industry. The financial anxiety caused withdrawal of investment plans in manufacturing lines. Orders for semiconductor equipment were cancelled or reduced. Investments in 1997 for 0.25-micron technology created overcapacity. Forecasts for 1998 deteriorated time after time, as the recession in the semiconductor industry even deepened. Only by the second half of 1999, there were signs of the market's recovery.

Since most of the DRAM chip manufacturers were located in Asia, this market segment drove the recession. ${ }^{163}$ One of the economies affected by the crisis was South Korea, home to some of the leading DRAM chips manufacturers. Korean companies, accounting for over 14 percent of all capital spending in the chip industry in 1997, cut back their investments by 70 percent over $1998 .{ }^{164}$

162 Dataquest, Clark J Fuhs, Ronald Doornseif, James Hines, Takashi Ogawa, and Klaus Rinnen, 'Conference Call on Capital Spending and Wafer Fab Equipment Midyear Forecast Update: Where's the !@\#?! “Up” Button?', Dataquest Semiconductor Equipment Manufacturing and Materials Worldwide: Event Summary (21-9-1998)

163 ASMI, Arthur del Prado, 'Progress Report May 1998' (May 1998) Archive Arthur del Prado - RvC 1998-2000 file; Dataquest, 'Worldwide Semiconductor Forecast: 6 Percent Decline in 1998 Followed by 12 percent growth in 1999' Dataquest Alert (21-9-1998), derived from: Computerhistory.org.

164 Dataquest, Clark J Fuhs, Ronald Dornseif, James Hines, Takashi Ogawa, and Klaus Rinnen, 
The market for DRAM chips was already quite volatile, caused by regular accumulations of excess capacity. Memory manufacturers competed primarily through accumulating market share, which resulted in overproduction. By the end of 1997, the latest $16 \mathrm{MB}$ chips were hardly profitable, causing a shift in production to $64 \mathrm{MB}$ and reducing memory production at large. The anxiety ruling over Asian stock exchanges, nicknamed the Asian Flu, aggravated this volatility even further. ${ }^{165}$

\section{Figure 66}

Graph of annual growth semiconductor industry, semiconductor equipment industry and ASM International worldwide, 1989-1999

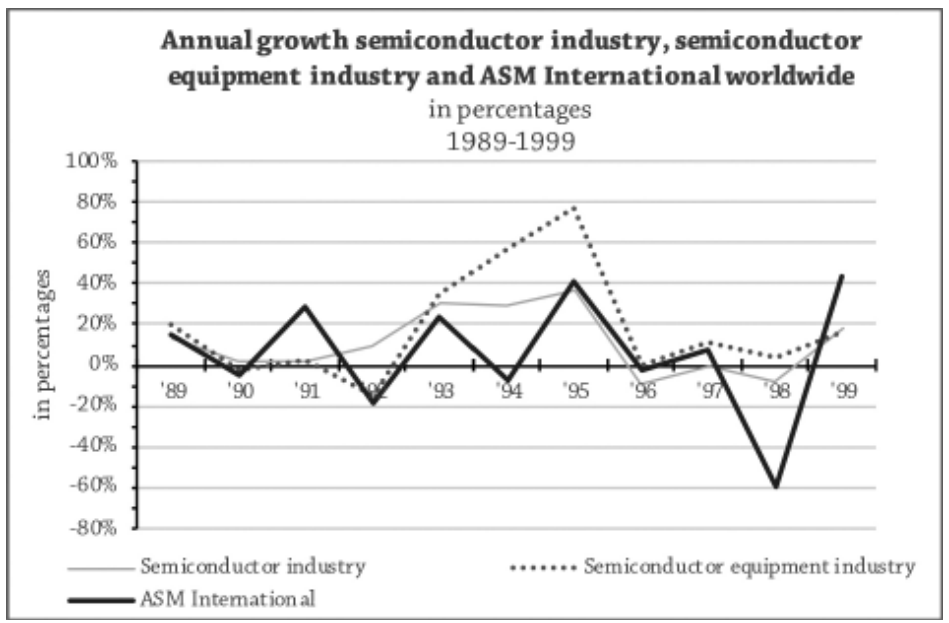

\section{An international harmonization in the United States}

Whereas the Asian market was characterized by extreme volatility, the American semiconductor industry witnessed a blooming harmonization of technological roadmaps in compliance with the regular pace of miniaturization of CMOS chips, as encapsulated in Moore's Law. ${ }^{166}$ Since 1992, through a National Technological

'Conference Call on Capital Spending and Wafer Fab Equipment Midyear Forecast Update: The Second Half of the 'W' Unfolds', Dataquest Semiconductor Equipment Manufacturing and Materials Worldwide: Event Summary (23-2-1998); Dataquest, Clark J Fuhs, Ronald Dornseif, James Hines, Takashi Ogawa, and Klaus Rinnen, 'Conference Call on Capital Spending and Wafer Fab Equipment Midyear Forecast Update', (21-9-1998).

Dataquest, Ron Donseif, 'Is the Industry Putting Moore's Law in a Straitjacket?', Dataquest Semiconductor Equipment, Manufacturing, and Materials Worldwide: Market Analysis (30-111998), derived from: Computerhistory.org. 
Roadmap for Semiconductors (NTRS), the American industry anticipated forthcoming technological challenges. By 1997 the scope was globalized through the International Technology Roadmap for Semiconductors (ITRS). The NTRS and ITRS codified what was known across the industry, and subsequently what was unknown. It was the "industry-wide consensus on the "best current estimate" of the industry's research and development needs out to a 15 -year horizon. ${ }^{167}$ As such, it helped to align and integrate the industry's efforts, including those by chip manufacturers, equipment vendors, material suppliers, research institutes, and governmental agencies. ${ }^{168}$

The regularity of miniaturization enabled rationalization of future technological challenges. These could be seen as 'anticipatory reverse salients.' ${ }^{169}$ Examples were the ability to project smaller lines with lithography at an industrial scale, the integration of copper as an interconnecting material, replacing aluminum, or the shrinkage of the transistor's gate stack. Another topic that prevailed in the technological roadmaps was the advent of 300-millimeter wafers. ${ }^{170}$

The roadmaps indicated probable technological challenges surrounding the new wafer size, as identified by Sematech, the institute responsible for the roadmaps, located in Austin, Texas. At Sematech, the latest 300-millimeter equipment was evaluated by all major American chip manufacturers. Companies like ASM, Varian, and Applied Materials supplied their machines or demo-wafers free of charge to the institute, where these were evaluated and benchmarked extensively. In the case of ASM, this involved the 300-millimeter version of the Epsilon and the vertical furnace. By 1997, the initial results of these evaluations became apparent, after which it was expected that individual chip manufacturers started their own pilot lines for 300-millimeter wafers.

Hopes were up for the equipment suppliers, as this new phase in the introduction of the bigger wafers finally might result in some orders. However, the NTRS and ITRS predictions and forecasts merely concerned technological development, not economic or market dynamics. In 1998, the market recession, driven by the Asian Flu, caused a delay in the introduction of 300-millimeter equipment. ${ }^{171}$

167 SIA, 2007 International Technology Roadmap for Semicondcutors (ITRS), (Washington 21-82007), p. 1.

168 Schaller, Technological Innovation in the Semiconductor Industry, p. 456.

169 'Thomas Hughes, Networks of Power: Electrification in Western Society, 1880-1930 (John Hopkins University Press, Baltimore, 1983) pp. 79 and 90; David Brock and Christophe Lécuyer, 'Digital Foundations: The Making of Silicon-Gate Manufacturing Technology', Technology and Culture 53:2 (2012) pp. 561-597, p. 564.

170 Ham, et.al, 'The Evolving Role of Semiconductor Consortia'.

171 EDN staff, 'Wafer weight gain', edn.com (1-3-2001). 


\section{Corporate course:}

\section{When ASM Pacific Technology sneezes, the rest of ASM International gets a cold}

This third and final chapter, covering the period between 1997 and the first months of 1999, concentrates on the ongoing pursuit of core competencies aimed at improving the company's viability. One example of this effort involved a management buy-out of ASM France. ${ }^{172}$ This small subsidiary of ASM Europe developed and produced mass flow technology, gas valves, and some horizontal diffusion furnaces designated for the French market. Its divestment had been pending since the early 1990s. ${ }^{173}$

Further harmonization of the competitive strategies of the three subsidiaries - ASM Japan, ASM America and ASM Europe - could potentially strengthen the focus on core competencies, but this seemed not possible without jeopardizing the much-needed recovery. With the 300-millimeter versions of their tools, the operations made promising inroads into the different research consortia. The decentralized course - if not the course of actions propagated by ASM International's management - appeared to pay off.

By 1997, however, the fragile situation of ASM International did not yet warrant ambitious reorganization schemes. For one thing, the very costly settlement with Applied Materials significantly reduced ASM International's financial and political clout to bend the subsidiaries to its will. After more than five years of litigation, ASM settled its dispute with Applied Materials on infringement of epitaxial technology patents for a staggering 80 million dollars. This sum evaporated the company's carefully amassed cash reserves and negated basically much of the earnings made with the Epsilon reactor. For ASM, the closing years of the $20^{\text {th }}$ century were dominated by having to cough up that amount of money.

Moreover, by 1998, the company as a whole had to digest the recession that hampered the industry as a whole. Sales projections were revised and staff was laid off. Front-end sales declined from 361.2 million dollars in 1996 to 292.8

172 The management buy-out involved the mass flow technology and was led by ASM France's general manager Claude Jacquemin in October 1997. The service business of the horizontal diffusion product line was sold to a French company called Upsys, for a total of 238,000 Dutch guilders. An (un)fortunate fire preceding the dissolvement of ASM France in April 1997 generated about 7.3 million Dutch guilders in insurance money, making the whole transaction a 3.4 million Dutch guilders positive on a cash flow base. - ASMI, 'Progress report October 1997’ (October 1997) - Archive Arthur del Prado - RvC 1996-1998 file.

Stibbe Simont Monahan Duhot, and Paul van den Hoek, 'Letter to Arthur del Prado, ref: PCH/1h-127597.B05’ (26-4-1995) Archive Arthur del Prado - RvC 1994-1996; ASMI, Willem de Leeuw, 'Memorandum: ASM France Overview' (5-7-1995) Archive Arthur del Prado - Willem de Leeuw; ASMI, Willem de Leeuw, 'Memorandum to RvC: ASM France' (12-3-1996) Archive Arthur del Prado-RvC 1996-1998. 
million in 1998 (figure 67). ${ }^{174}$ After three profitable years, the front-end group saw a loss of 2.9 million guilders in 1998. By that year, tens of A400s were sold for a total of nearly 90 million Dutch guilders, as well tens of Epsilons for a total of approximately 100 million and about two dozen Eagle-10 reactors for a total of about 60 million. ${ }^{175}$ The A600-UHV fell short of expectations. Just four machines were built. The number of employees in front-end activities dropped from 898 in 1996 to 756 in $1998 .{ }^{176}$

\section{Figure 67}

Graph of ASM International earnings and ASM front-end and back-end revenues, 1992-1999

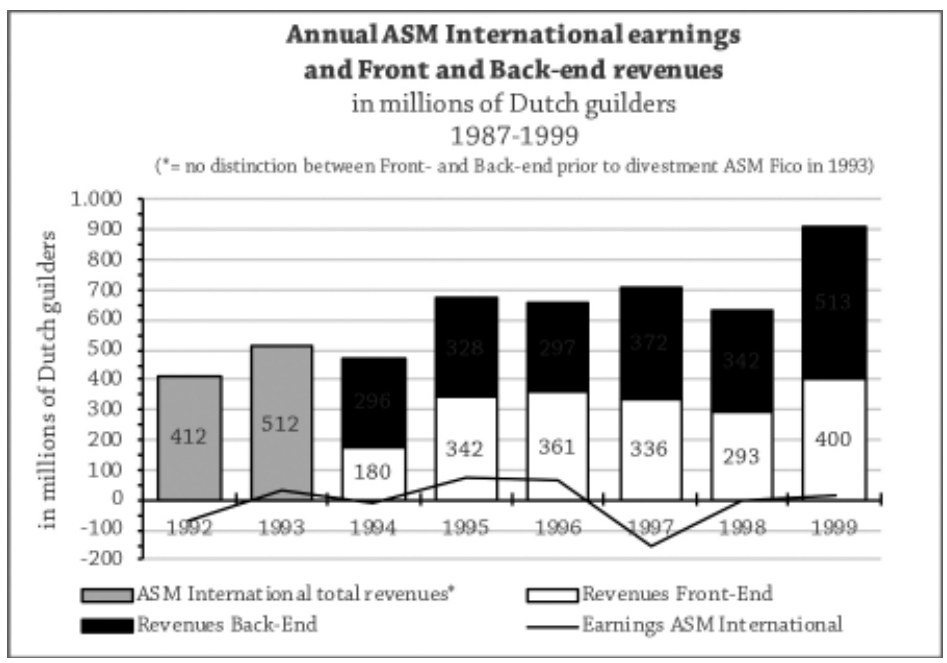

The recession increased the parent company's dependency on ASM Pacific Technology. Del Prado had always been able to fall back on its solid performance. Ever since Del Prado hired Patrick Lam in 1975, the Hong Kong-based operation in assembly and packaging equipment had been profitable. The steady stream of dividends and its gradual growing market capitalization always soothed Del Prado's financial sorrows. Banking loans providing cash for the development of the 300-millimeter tools, among other things, and the deferred payment of the Applied Materials settlement were secured by ASM International's interest in ASM Pacific Technology. This subsidiary's sales grew from 297 million Dutch guilders in 1996 to 342 million Dutch guilders in 1998 (figure 67). Staff steadily

174 ASM International, 1998 Annual Report (26-2-1999).

175 ASMI, Arthur del Prado, 'Progress report February' (26-2-1999) Archive Arthur del Prado - RvC 98-00 file.

176 ASM International, 1998 Annual Report (26-2-1999). 
increased as well, from 3,242 employees in 1996 and 3,680 in 1998. All the while, ASM Pacific Technology remained profitable.

However, the Asian Crisis exposed the risk of relying on ASM Pacific Technology. Disturbances at this subsidiary bore severe implications for the rest of the company. Put differently: if ASM Pacific Technology sneezed, the rest of the company would get a cold. And infected by the Asian Flu, ASM Pacific Technology did sneeze early in 1998. Anxiety numbing the Hong Kong Stock Exchange negatively affected the market capitalization of ASM Pacific Technology. By the fall of 1998, this gave rise to a reoccurrence of the equity crisis, also because of the need to repay Applied Materials.

The sudden crisis was used to further push the focus on core competencies. In a rush to improve the balances of the subsidiaries, European and American manufacturing was centralized and outsourced in the Netherlands. The business model of ASM Europe was extended to ASM America. This bold move strengthened the centralization of the company, and shook up the balance of power between the front-end business units and the head office. Yet the benefits of the restructuring - more focus on the company's core competence of innovating instead of on manufacturing - hardly seemed to outweigh the disadvantage: an inherent depreciation of trust in the American operation to commercialize their Epsilon reactor.

\section{Elaboration of affairs}

\section{Burying the hatchet: settling with Applied Materials}

Hopes that the company might swiftly recuperate were dashed by a costly settlement with Applied Materials surrounding mutual allegations of infringement of intellectual property. The whole affair was characterized by a sense of bewildered resignation. To this day, it is hard to provide definite answers about the motivation for settling, and for the validity of the mutual claims and accusations. Yet the settlement's effect on ASM International was dramatic, as it threatened to annul all efforts to save the company since the late 1980s and deprived it of vital equity.

By the fall of 1996, the litigation between ASM and Applied Materials resembled a wildfire, rapidly spreading beyond the original instigation. Five years earlier, it had started with Applied Materials accusing ASM of infringing its intellectual properties related to epitaxy. While the Epsilon single wafer epitaxial reactor rapidly disrupted Applied Materials' long-lasting market dominance in epitaxy (figure 68), ASM stuck to its argumentation that the presumed violated patents were either invalid or not in jeopardy. Applied Materials countered by claiming ASM's infringement of recent innovations as well. More allegations followed that moved beyond epitaxy, where Applied Materials sued ASM Japan 
for violating its patents relevant for the growth of interlayer dielectrics. Interim judgments by the court failed to de-escalate the legal battle.

\section{Figure 68}

Graph of revenues ASM and Applied Materials in epitaxial equipment worldwide, 1987-1999. Data based upon industry reports of Dataquest, derived from Computer History Museum.

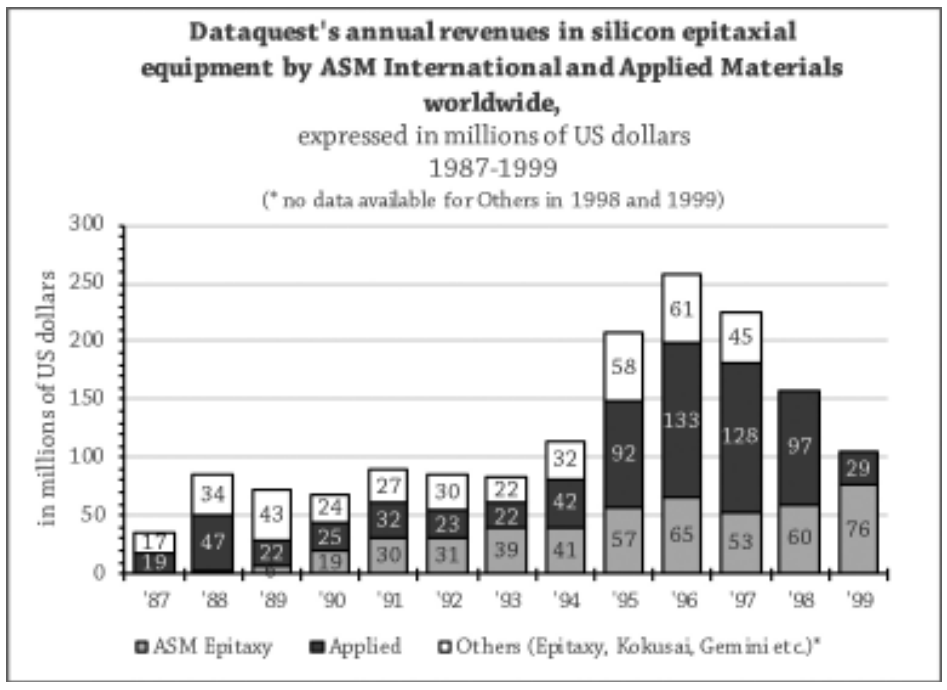

By the mid-1990s it became clear that Applied Materials was resolved to overwhelm its competitor, and that the Dutch equipment manufacturer was fighting a losing battle. Even customers were affected. By using the Epsilon, the matter of complicity in the presumed patent infringement appeared as a potential business risk. Although the most crucial accounts - Motorola, Intel, and Lawrence Semiconductors - still backed ASM through declarations of support, they grew increasingly anxious about the whole affair.

Furthermore, ASM lost ground in the legal battles. Most of them were fought in the Northern District of California, where Applied Materials was located. ASM's lawyers had underestimated the home advantage held by their opponent. A local judge had to consider the charges and defenses concerning advanced and complex technology of a local employer against those of a foreign, Dutch, company. ${ }^{177}$ In November 1995, the District Court ruled that patents were valid and infringed, yet it permitted the sale of Epsilons until June 1996. This was

177 Applied Materials Chief Executive Officer James Morgan was married to Rebecca ('Becky') Quinn Morgan, who was elected to the California State Senate as representative of the 11th District in 1988 and 1992. She was well-connected and well acquainted with judges of the Northern Californian District Court. 
appealed by ASM, but unsuccessfully so. After the appeal's dismissal in the fall of 1996, the court scheduled a trial for determining damages for July 1997. ${ }^{178}$ While ASM tried to reopen cases based on newly discovered evidence, it slowly dawned on its legal team that it was running out of time and that ASM would be better off by settling before a judge determined the value of the damages inflicted upon Applied Materials. Damage control was imperative.

So far, any attempt by ASM to settle the dispute bilaterally had been in vain. Only when the courts ruled against ASM in the fall of 1996 was Applied Materials willing to open negotiations. This puzzled Friant, who anxiously assessed Applied Materials. ${ }^{179}$ Friant realized that, whatever the motivations of Applied Materials, ASM did not have many options left. Settling the matter was crucial. Not in the least to stop the annual legal fees of a few million dollars. As he concluded, it was time to bite the bullet. ${ }^{180}$

But it took another year before an agreement was signed, during which Applied Materials and ASM negotiated at the highest levels. ${ }^{181}$ In November 1996, Arthur del Prado and Applied Materials' chief executive officer James ('Jim') Morgan set out the parameters for further negotiations. Facing a scheduled trial which would determine the damages by July 1997, negotiations were hurried on from January 1997 onward. ${ }^{182}$ Morgan wrote Del Prado in a handwritten note:

'I am glad we had a chance to discuss our unfortunate situation. I hope your representative comes with a creative + suitable proposal.'183

In the following months, Ray Friant's successor Daniel Queyssac and ASM America's legal team negotiated with their counterparts at Applied Materials.

178 United States Court of Appeals, Federal Circuit, '98F3d 1563: Applied Materials Inc v. Advanced Semiconductor Materials America Inc., ASM NV' (24-10-1996) Archive Arthur del Prado - Knobbe files; Thompson \& Knight, Stephen Stein, 'Confidential legal memorandum: status report' (14-4-1997) Archive Arthur del Prado - Knobbe files.

179 Ray Friant, 'Fax to Arthur del Prado: Martens Conversation' (31-10-1996) Archive Arthur del Prado - Ray Friant file.

180 Ibid.

181 ASM, author unknown, 'Settlement terms Applied Materials Draft - internal review' (24-61997) Archive Arthur del Prado - Knobbe files.

182 Applied Materials, James Morgan, 'Letter to Arthur del Prado' (17-1-1997) Archive Arthur del Prado - Applied Materials; ASMI, Arthur del Prado, 'Letter to Applied Materials, James Morgan, ref: B970005.doc' (21-1-1997) Archive Arthur del Prado - Applied Materials.

183 Applied Materials, James Morgan, 'Handwritten letter to Arthur del Prado' (17-11-1996) Archive Arthur del Prado - Applied Materials files. 
This process was carefully monitored by judge Edward Infante, who was to define damages by July 1997. ${ }^{184}$

By June 1997 a decision was made and both parties agreed on the outlines of the settlement. ${ }^{185}$ The terms of the settlement stated that ASM had to reimburse Applied Materials 80 million dollars. As ASM lacked the financial reserves to pay this amount up front, both equipment manufacturers also determined the terms of payment. ASM paid 15 million dollar immediately. The remaining 65 million would be turned into a convertible note, which could be converted after one year against a guaranteed price of 20-21 dollars per share. For the future, until the relevant patents expired, ASM would pay Applied Materials a royalty on its epitaxial sales, and a royalty on each Eagle-10 machine processing a specific interlayer dielectric process. Both companies would cross-license the disputed patents, stop further litigation relating to the patents, and entered a covenant in which they pledged not to sue on future patent issues for the next few years. ${ }^{186}$ To crown it all, Del Prado had to give in a 'right of first refusal,' which entailed that Applied Materials would be offered any deal involving a merger or acquisition of ASM International on equal terms. ${ }^{187}$

Through the settlement, Applied Materials wrung out ASM. The American equipment manufacturer undisputedly intended to hit its Dutch competitor most lethally. As such, Friant's and Del Prado's worst scenario came true. The costs of the settlement evaporated ASM's painstakingly established financial reserves over the course of five years and inflated its liabilities, thus reigniting the company's equity crisis. The funding scheme involving the 65 million dollar convertible note returned ASM into the bosom of its bankers. In the summer of 1997, ASM was back to square one.

184 ASM America, Russ Fairbanks, 'Facsimile Transmission: ASM”s Settlement Conference Statement'(19-6-1997) Archive Arthur del Prado - Knobbe files; ASM America, Daniel Queyssac, 'Letter to Chief Magistrate Judge, Edward Infante' (30-6-1997) Archive Arthur del PradoKnobbe files.

185 ASM International, Daniel Queyssac, 'Letter of Acceptance' (27-6-1997) Archive Arthur del Prado-Knobbe files.

186 Applied Materials and ASM International, 'Memorandum of Understanding' (14-10-1997) p.7; ABN Amro, 'Information Memorandum and prospectus ASM International' (31-3-1999) p. 38.

187 Change of Control includes sales of shares of stock to any single shareholder or group of aligned shareholders (other than Del Prado) of more than 30\% of ASM outstanding and issued stock. - Applied Materials and ASM International, 'Memorandum of Understanding' (14-10-1997) p.7; ABN Amro, 'Information Memorandum and prospectus ASM International' (31-3-1999) p. 38. 


\section{ASM Pacific Technology in the limelight}

Throughout 1997 and 1998, ASM Pacific Technology continued to perform well, technologically and sales-wise. The company neared the ambition formulated by Patrick Lam, its chief executive officer, a few years earlier to become one of the three biggest semiconductor assembly and packaging equipment suppliers in the world. Two products were critical for this achievement. One was the product offering a complete and integrated assembly and packaging line called the IDEALine. The other concerned a state-of-the-art gold wire bonder named the AB339. But the organizational developments that made these developments possible proved to be more important. After more than fifteen years of operating in relative niche segments of the semiconductor market, the company was able to channel the knowledge, skills, and experience obtained in order to realize its ambition.

Most critical had been a reorganization of the research and development groups, located in Hong Kong and Singapore, by Lam and his new chief technology officer (CTO), professor Peter Liu. ${ }^{188}$ Contrary to Lam's principles, Liu had not grown through the ranks of the company. Prior to his appointment as CTO, Liu was a professor at the Polytechnic University in Hong Kong who had held various executive positions at high-tech firms in Taiwan, Silicon Valley, and Canada. ${ }^{189}$ Upon his arrival, Liu encountered a quite typical Chinese company: engineers and management walked around in white lab coats, the walls came with scant decoration, and instead of a penchant for technological contemplation there was a focus on hands-on engineering. Structural R\&D hardly moved beyond servicing and trouble-shooting issues of customers. Having Lam's explicit support, Liu set out to update the R\&D group to modern Western standards. This involved implementing component reliability tests, establishing close ties with technical universities in Hong Kong and mainland China, attracting talented university graduates, and improving knowledge of materials and physics.

Next to the R\&D reorganization, the other executives of the Asian equipment manufacturer set themselves to update the rest of the organization. This involved modernizing the Shenzhen factory, where all the components and parts of ASM Pacific Technology's products were made. At the product groups in Singapore and Hong Kong, investments were done in computer aided engineering (CAE) techniques. Furthermore, an unexpected failure of the AB309A gold wire bonder in the market freed engineering capacity in the product group of the Singapore

188 Patrick Lam, 'Interview with author'; Peter Liu, 'Interview with author'; Patrick Lam and Edmund Lam, Soaring like Eagles: ASM's High-Tech Journey in Asia (John Wiley \& Sons, Singapore, 2006).

189 Peter Liu, 'Interview with author'. 
location. ${ }^{190}$ ASM Technology Singapore had all means available to plunge into the technological development that ought to rebound its position in the market for gold wire bonders.

The AB339 gold wire bonder and the IDEALine were the first results of the new approach. At the 1997 Semicon West Exhibition in San Mateo, California, ASM Pacific Technology introduced both the IDEALine and the AB339. Although other products were introduced as well, such as new die bonders AD889 and AD829A plus packaging techniques for the latest QFN standards, the AB339 and IDEALine managed to attract most attention.

The IDEALine integrated all semiconductor assembly techniques in one production line. By 1997, ASM Pacific Technology had familiarized and developed all techniques, from die bonding, wire bonding, and encapsulation to trim \& form for the latest packages, such as 'Ball Grid Arrays' and 'QFN' packages. Whereas most customers selected the best of each breed in the market place, few customers procured the whole product range of ASM Pacific Technology. SGS-Thomson was an exception, and in particular to benefit these few dedicated customers, the IDEALine had been developed. Although this product merely commanded a niche market, its significance lay foremost in its symbolic value. It showed that ASM Pacific Technology was able to offer the whole range of semiconductor assembly and packaging technologies. The IDEALine removed any doubt about the equipment manufacturer's ambition.

Whereas the significance of the IDEALine was rather symbolic, the AB339 launched ASM Pacific Technology to the forefront of the semiconductor assembly equipment industry, technologically as well as commercially. ${ }^{191}$ The market for gold wire bonders was the biggest and most technologically advanced among the assembly techniques. Just like the wafer processing segment of semiconductor fabrication, the assembly segment was keyed to shrinking dimensions. In the case of the wire bonding technology, this shrinkage entailed the miniaturization of bonding pads on the chip. The stream of electrical signals between computer chip and its device - a printed circuit board principally - increased by every new generation of computer chips. To facilitate these signals, more gold wires had to be bonded between the die - an unpackaged computer chip - and its package. Consequently, the diameter of the wires and the surface of the pads shrank, requiring more precise and faster wire bonders. From 1995 until 1997, the size of this bonding pad decreased from about 100 microns to 70 microns. The machine

190 Patrick Lam, 'Interview with author'; 'W.K. Lee, 'Interview with author'; and Y.M. Wong, 'Interview with author'.

191 Lam and Lam, Soaring like Eagles, p. 78. 
had a better performance, given that bonding gold wires faster and more precise, as well as a higher reliability. Apart from its commercial attraction, innovating gold wire bonder was quite prestigious.

The group of ASM Technology Singapore distinguished itself with the AB339 by pushing the limits on all possible fronts. The result was a wire bonder with a pitch capability of 50 microns, much more precise than the rest of the industry. ${ }^{192}$ Moreover, it offered this technology at its usual attractive price-performance ratio. Had the AB309 carved out some market share for the Asian manufacturer of assembly and packaging equipment, the AB339 was to consolidate and expand this position.

In the fall of 1997, the machine was awarded '1998 Product of the Year Award' by Semiconductor International, the semiconductor equipment industry magazine. ${ }^{193}$ The machine opened the doors to the biggest and technologically advanced customer, AMKOR, based in South Korea. Throughout 1998, over two hundred AB339 wire bonders were manufactured and sold. The machine represented the culmination of Lam's achievements, elaborating on his core principles of maintaining profitable, vertical integration of manufacturing, and harnessing internally fostered talents.

\section{A sneeze in Hong Kong...}

In 1998, the Asian Flu's tight hold on the Asian financial markets infected ASM Pacific Technology, and subsequently confined ASM International as a whole to its sickbed. Ever since the initial public offering on the Hong Kong Stock Exchange in 1989, the modestly traded ASM Pacific Technology shares had steadily increased in value. ${ }^{194}$ So far it had not been necessary to spend too much time on this matter beyond obliging to the minimal requisites related to a listing. This neglect got exposed by the Asian financial crisis, and the consequences were born not so much by Lam's company, but by ASM International.

In the second quarter of 1998, the stocks of ASM Pacific Technology suddenly plumped. Across the Hong Kong Stock Exchange, investors sold their interests. ${ }^{195}$ So far, Patrick Lam and his CFO Alan Fung had hardly spent time on cultivating relations with investors. Consequently, they had no means to stop the collapse of its stock price during the general panic that paralyzed the Hong Kong Stock Exchange. Its share price halved in the third quarter of 1998, from 6.25 Hong

192 This capability came to be known a few months after the introduction. - Y.M. Wong, 'Interview with author', and W.K. Lee, 'Interview with author'. Lam and Lam, Soaring like Eagles. Ibid.

195 Author unknown, 'Tsang: The Worst is Over' Money.CNN.com (8-10-1998). 
Kong dollars per share and even down to 1.80 Hong Kong dollars. ${ }^{196}$ As the market capitalization of ASM Pacific Technology evaporated, so did the assets of its parent company, ASM International. ${ }^{197}$ Del Prado had secured his bank loans - even the Applied Materials settlement - with ASM's interest in ASM Pacific Technology. The value of these securities dropped dramatically from 293.93 million Dutch guilders to 82.67 million. ${ }^{198}$ This amount did no longer cover the money owed to Applied Materials (65 million dollars, or 123 million Dutch guilders) and the 55 million Dutch guilders owed to the banks. This implied that the banks, once again, and Applied Materials had to be reassured of ASM's solvency.

Del Prado, his CFO Rinse de Jong, and his Supervisory Board chairman Paul van den Hoek had to knock together a scheme to deliver the funds. After the initial upfront payment of 15 million dollars to Applied Materials, ASM still had to come up with 65 million dollars by November $1998 .{ }^{199}$ In close consultation with Applied Materials, a new payment scheme was developed. In this arrangement, ASM had to pay 20 million dollars in cash by December 1998. A year later, another 10 million had to be redeemed, and the remaining 35 million dollars were placed in 1.5 million warrants at 5.375 dollars each with a maturity date in 2000. ${ }^{200}$ From the summer until December 1998, Del Prado and De Jong contemplated complex schemes to come up with the initial 20 million dollars. The men called all favors left within the Netherlands, from public officials, bankers, and entrepreneurs to competitors in the Dutch semiconductor equipment industry. ASM Pacific Technology were traded at a maximum price of 6.40 Hong Kong dollars in the second quarter of 1998. In the third quarter, their lowest price was 1.80 Hong Kong dollars. As exchange rate, I used the rate mentioned in ASM International's annual report, that of December 31, 1998, 1 Hong Kong dollar = 0.2436 Dutch guilder. - ASM International, Annual Report 1998 (26-2-1999) p. 35.

199 Stibbe Simont Monahan Duhont, Paul van den Hoek, 'Letter to Arthur del Prado and Rinse de Jong, ref: PCH/nj-B01' (17-3-1998) Archive Arthur del Prado - RvC 1998-2000 file.

Given a share increase of ASM by that time, this solution allowed Applied Materials to recover the settlement at an even higher price. The warrants were secured against stakes in ASM Japan, ASM Europe, and ASM America, whose intrinsic values had been improved due to good evaluations of their forthcoming 300-millimeter equipment (for more on this, see below). - Applied Materials, Nancy Handel, 'Letter to Rinse de Jong' (1-12-1998) Archive Arthur del Prado - Applied Materials settlement; ASMI, Rinse de Jong, 'Letter to Nancy Handel, Vice President Global Finance and Treasurer Applied Materials' (25-11-1998) Archive Arthur del Prado - Applied Materials settlement. 
A combination of Dutch parties was convened to cough up the 20 milliondollar payment. This involved ASM's bankers ABN Amro and the National Investment Bank, public officials from the Ministry of Economic Affairs, but also Dutch equipment manufacturers BESI and ASML. The full weight of the Dutch semiconductor equipment ecosystem put their heads together to save ASM, if in most cases not very enthusiastically. Through sticks and carrots some agreement was achieved. Public officials deployed their leverage at the National Investment Bank and ASML, while BESI and ABN Amro were actuated by holding out interests in ASM Pacific Technology. A chain of events that had started with the sudden downfall of ASM Pacific Technology's stock had made Del Prado and his company dependent again upon the mercy of ruthless and opportunistic money lenders.

This in particular involved the Dutch banker, ABN Amro, which depreciated ASM's solvency and moved on to secure the bank's liabilities. Luckily, personnel changes at ABN Amro helped Del Prado's cause. The entrepreneur's original contact Louis de Bièvre resigned early in 1997 and was succeeded by Jan Peter Schmittman as manager in charge of the bank's Financial Restructuring \& Recovery department. While De Bièvre's patience with Del Prado - having gone through numerous crises - was rather worn out, the new manager had a tender spot for ASM. ${ }^{201}$ Schmittman's clemency prevented an immediate liquidation of ASM's assets. It resulted in tough, but fairly prospective negotiations.

But also the involvement of BESI came at a price. In exchange for rescuing his former parent company - and employer - the chief executive officer of BESI, Richard Blickman, wanted a call option of ten percent of ASM's ownership in ASM Pacific Technology, while he intended to acquire 20 percent of the shares on the open market. ${ }^{202}$ The incredibly low share price of ASM Pacific Technology had caused the whole crisis, but offered BESI also a rather cheap opportunity to force a merger, in particular since the call option on ASM's 10 percent would dilute ASM's ownership of ASM Pacific Technology to under 50 percent. Such a move would enable the smaller BESI to acquire its bigger competitor ASM Pacific Technology by a backdoor method. It would make ASM International just 'an investor' in ASM Pacific Technology, instead of being the 'parent company', bearing consequences for the Dutch company's reliance upon the securitization

201 During the meetings at Blickman's house De Bièvre operated as chairman, however. - Rinse de Jong, 'Interview with author'; ABN Amro, Jan Peter Schmittman, 'Handwritten letter to Arthur del Prado' (13-11-1999) Archive Arthur del Prado - RvC 1998-2000 file; ASMI, Arthur del Prado, 'Fax to Rinse de Jong, ref:ni007499' (14-12-1999) Archive Arthur del Prado - RvC 1998-2000 file.

202 ASMI, Rinse de Jong, 'Letter to ABN Amro, att: Jan Peter Schmittman: Option Structure' (29-10-1998) Archive Arthur del Prado - ABN Amro file. 
and steady stream of dividends, turning it into a mere front-end enterprise. ${ }^{203}$ Moreover, ASM International's diluting would jeopardize morale among ASM Pacific Technology's staff and management. ${ }^{204}$ Support came at a price.

Throughout October and November 1998, Del Prado desperately tried to increase his alternatives. He argued - in vain - that the dependency of ASM's securities on the day-to-day trade in ASM Pacific Technology's stock did not reflect the true value of the asset. ${ }^{205}$ The current low share price was an anomaly and the stampede around it not necessary. Moreover, the Hong Kong Stock Exchange was not really suitable for the trade of technology stock like that of ASM Pacific Technology. The volumes were too low, and investors did not know how to appreciate the company. In order to buy time and to shift the attention of the bankers, he proposed a delisting of ASM Pacific Technology on the Hong Kong Stock Exchange and an immediate relisting on the Nasdaq. Such a move might stabilize ASM Pacific Technology stock, and offer significant allowances to the bankers if they facilitated the de- and re-listing.

Del Prado enunciated his difficult position to Schmittman and pleaded for some leniency:

'In our view, the intended transaction with BESI, the transaction we have planned with ASM Lithography Holding N.V. and the supporting transactions with ABN Amro and the government would largely accommodate our short term financial needs. ... However, we also want to stress our view on the long term positioning of ASM International and the financial structure that is needed. Giving up control of ASMPT means that the character of ASM International will change and that we will be a front-end company.' ${ }^{206}$

Hotheaded and emotional meetings were held not only at Del Prado's private home in Bilthoven, sitting around the round table that had been the stage for all defining moments in the history of the company, but also at the private home of Blickman in Bussum. ${ }^{207}$

203 ASMI, Arthur del Prado, 'Letter to BE Semiconductor Industries, attn: R.W. Blickman' (611-1998) Archive Arthur del Prado - Applied Materials settlement.

204 ASMI, Arthur del Prado, 'Letter to ABN Amro, attn: Jan Peter Schmittman' (30-10-1998) Archive Arthur del Prado-ABN Amro file.

205 ASMI, Arthur del Prado, 'Fax to ABN Amro Bank, attn: P.R. Kalff, ref: F07598' (9-9-1998) Archive Arthur del Prado-ABN Amro file.

206 ASMI, Arthur del Prado, 'Letter to ABN Amro, attn: Jan Peter Schmittman' (30-10-1998) Archive Arthur del Prado-ABN Amro file.

207 Richard Blickman, 'Interview with author'. 
By December 1998, Del Prado succeeded in preventing the splitting up of his company. A deal was concluded through the intervention of another sponsor, a wealthy and rash Dutch entrepreneur named Frank Zweegers. ${ }^{208}$ The participation of Zweegers made partaking of BESI no longer necessary, and as such prevented a dilution of ASM International's stake in ASM Pacific Technology. His 7.5 million loan was backed by stakes in ASM Pacific Technology, and the entrepreneur explicitly ensured his involvement in a delisting of ASM Pacific Technology from the Hong Kong Stock Exchange and a relisting on the Nasdaq, if such event would be considered.

ASML, ABN Amro, and Zweegers each coughed up one third of 22.5 million dollars for ASM in a subordinated convertible note, due to fall in 2003. ${ }^{209}$ Through Jan Peter Schmittman and despite ASM's deplorable credit rating, ABN Amro was also willing to participate, taking up a share of 7.5 million dollars. ASML pledged this amount in exchange for the right and license of using the name ASM and derivatives thereof. ${ }^{210}$ In addition to the 22.5 million required to redeem Applied Materials, the National Investment Bank granted a 7.5 million subordinated loan to replenish ASM's cash reserves. ${ }^{211}$ Applied Materials, in other words, received its 20 million dollars on time.

The company was saved, but it was rather a pyrrhic victory. The whole affair put at risk ASM's interest in ASM Pacific Technology, as well as, subsequently, this subsidiary's future. This was especially cruel, as the Asian manufacturer of assembly and packaging equipment rose to the fore in its industry segment with its AB339 wire bonder. Naturally, Patrick Lam and Alan Fung initiated an investor relation effort to cultivate relations with investors and to prevent another sudden deterioration of share prices. Furthermore, the stock price and thus the valuation of ASM International's securitizations improved strongly in the first quarter of

208 Frank Zweegers participated in a real estate company Breevast, in which Del Prado was member of the Supervisory Board. - ASMI, Arthur del Prado, 'Letter to ZBG Services, attn: Frank P.B.L. Zweegers, ref: b99053’ (14-12-1999) Archive Arthur del Prado-Applied Materials settlement; ZBG Services, Kris van Dorst, 'Letter to Arthur del Prado: Memorandum of Understanding, ref: ZBG/kvd980240’ (5-11-1998) Archive Arthur del Prado - Applied Materials settlement.

209 The 2.5 million dollars left after paying Applied Materials' 20 million dollars constituted a bank fee for facilitating the deal. - ABN Amro, 'Loan Agreement between ASM International NV as Borrower and ABN Amro Effectencompagnie BV, ASM Lithography Holding NV, Bickersville Corporation NV as Lenders, relating to NLG 45,000,000 convertible subordinated loan' (4-12-1998) Archive Arthur del Prado - ABN Amro file.

210 ASML and ASMI, 'Memorandum of Understanding' (5-11-1998) Archive Arthur del Prado Applied Materials settlement.

211 ASMI, Arthur del Prado, 'Letter to Director Financieringen en deelnemingen, Ministerie van Economische Zaken, attn: W.G. Kooijman’ (23-10-1998) Archive Arthur del Prado-Applied Materials settlement. 
1999, proving Del Prado right once again about the unnecessary anxiousness of banks.

It is also true, however, that the significance of a healthy cash flow was reconfirmed, as the company operated in a volatile market and could not rely too much upon conservative money lenders, such as the Dutch bankers. Del Prado and De Jong grasped that for the survival of ASM cash was king. ${ }^{212}$ But in 1998 there was no cash left in the company. Cash had to be obtained through restructuring. All the company's ambitions were deferred, except for the actual commitments into 300-millimeter equipment of the three front-end product groups. Across the company, the belt had to be tightened - again.

\section{Consolidation of operations}

The sudden reoccurring equity crisis of ASM had dramatic consequences for ASM America. A reorganization of the American operation, caused by a depressed American market, concurred with the slumbering plan to expand ASM's collaboration with Philips Machinefabrieken. Outsourcing parts of manufacturing helped the company to concentrate on its core competencies and to reduce cost. Del Prado had been anticipating the expansion of his collaboration with Philips Machinefabrieken. Throughout 1996 and 1997, it was envisaged that the Dutch subcontractor would take up a new cluster wafer handler, named A800, to which the Epsilon reactors would be connected (see Innovation Chapter IV). ${ }^{213}$ Due to the American management changes - the exit of Launder, the interim operation of Friant, and the latter's replacement by Queyssac - not much progress was made on the cluster machine at ASM America.

This changed after the arrival of a new executive in Phoenix. In the summer of 1997, Dr. Meindert Beerlage started as product manager for the single wafer cluster. ${ }^{214}$ He operated alongside the American product group unit for standalone epitaxy processes managed by Armand Ferro. Being rather unexperienced in semiconductor technology and candid in his analysis and management style, Beerlage had a keen vision on how to structure and manage an organization. After a marketing tour visiting major customers and operations of ASM globally, he

212 Rinse de Jong, 'Interview with author'.

213 Philips Machinefabrieken Almelo, H. Thijsen, 'Fax to Arthur del Prado: Verslag bespreking ASMA en Philips Machinefabrieken' (16-9-1996) Archive Arthur del Prado - RvC 19961998 file; ASM Europe, Ronald Luijks, 'Presentation Review Meeting joint world-trip ASM International and Philips Machinefabrieken' (7-6-1996) Archive Arthur del Prado - RvC 19961998 file.

214 Del Prado was member of the supervisory board of Old Delft Instruments. Beerlage had been responsible for one of the subsidiary operations. After six months of familiarizing himself with the operation, Beerlage took over the position of general manager by the fall of 1997. ASM America, Daniel Queyssac, 'Memorandum: Announcement' (14-07-1997) Archive Arthur del Prado-ASM America 90's, ASM America Febr. 1997-April 1998. 
reignited efforts regarding the single wafer cluster and subsequent outsourcing scheme. ${ }^{215}$ By the end of the year, Del Prado got convinced that Beerlage might be the right person to put the American operation back into order. The many management changes in the previous five years - in chronological order: David Sikes, John Krickl, Art Launder, Ray Friant, and Daniel Queyssac - had not done much good. Del Prado desired a firm hand to reestablish control, and Beerlage seemed to be just that. In the fall of 1997, just after the settlement with Applied Materials was concluded, Beerlage was promoted to the position of general manager of ASM America.

The appointment seemed right on time. Just like the American market, ASM America had to shrink accordingly. As analyzed by Beerlage:

'ASMA's major problems may be seen as operational problems. These operational problems might very well be the consequence of ASMA's fundamental or strategic problems ... What to do about it? Strategy is the simple one. ... No matter how much you personally care for all of ASM-I: 99\% of people don't give a damn about Europe or Japan. They are interested primarily in themselves. The further a strategy gets away from their department the less they care. ${ }^{216}$

Therefore, he was in favor of the centralization scheme as pondered by Del Prado. But he also realized that the time was not yet ripe for such a move.

Beerlage communicated the major reorganization to his staff on August 24, 1998. ${ }^{217}$ He reorganized the operations department in numerous shops, such as the quartz shop, sheet metal shop, machining shop, and assembly shop. He redefined responsibilities of the purchasing, quality control, logistics, engineering, and marketing \& sales groups. And he diminished the development department involved in the preparation of the new wafer size. ${ }^{218}$ Approximately 30 employees were laid off.

215 ASM International, Meindert Beerlage, 'Memo: multiprocess clusters, preparation for marketing visits' 29-10-1997) Archive Arthur del Prado - Meindert Beerlage file; and ASM America, Meindert Beerlage and Ivo Raaijmakers, 'Interoffice Memorandum: Intel/Hillsboro Visit Report - Nov. 7, 1997' (24-11-1997) Archive Arthur del Prado - Meindert Beerlage file; ASM International, Meindert Beerlage, 'Memo: Preparation for marketing visits' (29-10-1997) Archive Arthur del Prado - Meindert Beerlage file.

216 ASM International, Meindert Beerlage, 'Memo: ASMA Problems' (15-1-1995) Archive Arthur del Prado - Meindert Beerlage file.

217 ASM America, Meindert Beerlage, 'Memo: ASMA Reorganizations and Cost-Reduction Measures' (24-8-1998) Archive Arthur del Prado - Merio file.

218 Ivo Raaijmakers, 'Interview with author'. 
By November 1998, amidst the consternation surrounding the funding of the 20 million dollars load repayment to Applied Materials, and uncertainty about the start of market's recovery, Del Prado had to conciliate his bankers by displaying his willingness to clean up his house. His cash flow had to be improved. Being at his wit's end, Del Prado had not many options left. One route was to increase outsourcing, thereby reducing the operational costs. Beerlage seized the opportunity and suggested to outsource ASM America's production of the Epsilon to Philips Machinefabrieken in the Netherlands.

Del Prado conceded, as through this plan multiple birds would be killed with a single stone. The multiplicity of manufacturing costs would decrease. ASM would strengthen its position at home and subsequently increase active and passive support from the Dutch government. ASM would be able to benefit from the proven engineering qualities of Philips Machinefabrieken - which had been crucial for ASML's success. And finally, ASM would overcome the problems in controlling its American subsidiary, bringing it back into line with the corporate strategy.

Beerlage lost no time, and initiated the radical overhaul of the American operation through the 'Merger of International Operations,' or simply: Operation Merio. This was done in a rather brusque manner, which antagonized many of the employees working at ASM America for years. As observed by the COO of ASM International and President of ASM America, Daniel Queyssac:

'It is clear that Beerlage is making a power play at a moment he feels can have a lot of leverage. ... The first phase ... is involving an equipment manufacturing transfer that we were planning to do at a slower pace through Philips. ${ }^{219}$

On January 22, 1999, Queyssac announced the restructuring of ASM America, involving the transfer of the Epsilon to Europe. ${ }^{220}$ In addition to improving the cash flow of ASM, this effort was expected to result in compliance to the latest quality control standards (called ISO9000), more flexibility, less inventory, and more competitive costs. The machine shop and assembly shop were to be closed, while product management, development engineering, sales \& marketing, service, spares, training, and software development remained at ASM America. The new facility of ASM America on University Drive had to be vacated, as the remaining departments moved to the old facility on Harbour

219 ASMI, Daniel Queyssac, 'Fax to Del Prado: Organization' (6-11-1998) Archive Arthur del Prado-Merio file.

220 ASMI, Daniel Queyssac, 'Memorandum to FEB: Restructuring of ASM America' (22-1-1999) Archive Arthur del Prado - Merio file; ASMA, Meindert Beerlage, 'Speech prepared for Arthur del Prado' (January 1998) Archive Arthur del Prado - Merio file. 
Drive in Phoenix. This transfer was expected to be completed by July 1999. From that moment, ASM Europe had to build thirty to thirty-five epitaxy machines that year, so approximately one a week.

The transfer of manufacturing drew widespread skepticism within ASM. After all, why move production of epitaxial equipment to the Netherlands, when most of the customers were in the United States? ${ }^{221}$ The staff of ASM America felt undervalued and also feared the transfer of other activities, such as R\&D. The saying 'if you ain't Dutch, you ain't much' circulated among its employees. ${ }^{222}$ Also at the company's headquarters in Bilthoven, however, the move was critically analyzed. CFO Rinse de Jong was wary about the calculations and costs of the reorganization. ${ }^{223}$ Issues such as tax loss carried forward, travel expenses of staff, the vacation of the University Drive building, and transfer pricing between ASM Europe and ASM America might accumulatively negate the gains of outsourcing and centralization of manufacturing. Furthermore, Operation Merio increased ASM Europe's exposure to the dollar. ${ }^{224}$

Operation Merio also required Queyssac to reshuffle management. ${ }^{225}$ Beerlage had indicated his desire to resign by April 1999. Through Operation Merio, he had hoped to become the general manager overseeing both the European and the American operations. After all, the set of tasks of ASM America's general manager was much reduced. However, the creation of a new management position overseeing the European and the American operations did not make sense, with the tenure of Daniel Queyssac as chief operating officer responsible for the whole of front-end. Beerlage could not realize his ambitions within ASM anymore, leaving the position of ASM America's general manager vacant again. Queyssac had Hans Wunderl fill that position. The general manager of ASM Europe had indicated his desire to focus on sales instead of on operational affairs, and the job description of ASM America's general manager was closer to this preference.

221 ASM Europe, Hans Wunderl, 'Vragen \& Antwoorden “Merio"' (January 1999) Archive Arthur del Prado - Merio file.

222 John Krickl, 'Interview with author'; Gloria Zemla, 'Interview with author'; and Armand Ferro, 'Interview with author'.

${ }^{223}$ ASMI, Rinse de Jong, 'Fax to FEB: Merio Costs/proposal' (29-1-1999) Archive Arthur del Prado-Merio file.

224 De Jong estimated that approximately 54 percent of the costs of an Epsilon reactor would be subjected to currency exchange of dollar to euro/guilder. - ASMI, Rinse de Jong, 'Transfer Epitaxy Manufacturing, Impact on currency profile' (26-2-1999) Archive Arthur del Prado - RvC 1998-2000 file.

225 ASM America, Daniel Queyssac, 'Fax to Arthur del Prado: Organization' (8-1-1999) Archive Arthur del Prado - Merio file. 
Within ASM Europe, Albert Hasper - one of the ten engineers who transferred from Tempress to ASM alongside with the CVTR in 1994 - became product manager for vertical furnaces. A new general manager was attracted in the person of the 42-year-old Han Westendorp. After obtaining his PhD, he had joined ASM Ion Implant in the mid-1980s, worked for a while at the AMTC, and continued his career at Tokyo Electron in Beverly, Massachusetts, in metal CVD and liquid crystal display (LCD) technology. At his return to ASM, the soft-spoken and punctual Westendorp was made responsible for the manufacturing of both vertical furnaces and epitaxy products, but also for all operational obligations of running ASM Europe. ${ }^{226}$

By the summer of 1999, with the recovery of demand for semiconductor equipment rapidly setting in and most of the organizational turmoil of Operation Merio resolved, the whole effort might still came back to haunt the company. Operation Merio had disturbed many minds indeed. In particular, Beerlage's hardhanded methods had agonized the American staff members. This did not decrease after he was replaced by Hans Wunderl, who could be equally blunt. This attitude may have helped Wunderl to turnaround the Bilthoven operation, but it raised eyebrows in Phoenix. Del Prado had to concede that his management appointments, set against a general sense of urgency, had not been entirely successful. ${ }^{227}$

Moreover, technological development remained highly decentralized and difficult to harmonize. Dissatisfaction with this reality made Ernst Granneman resign as chief technology officer in the summer of 1999. He had been the key player in the establishment of a coherent innovation strategy within ASM since the start of his employment in the mid-1980s. Initially, he contributed to this objective in his role as Technological Director of the AMTC. In the 1990s, he was appointed by Ray Friant as chief technology officer to cancel non-relevant or non-prospective operations and to strengthen collaboration and coherence among them. Granneman had grown frustrated about the lack of cooperation and progression. As he explained in his resignation letter:

'ASM is organized in a geographically decentralized way with a high degree of local control and independence. The ASM divisions are used to operate primarily in a reactive mode, i.e. to respond to short-term customer demands. At the divisional level there is little or no willingness to contribute resources on developments targeting results which are more than, say, one year out.

227 ASM International, Arthur del Prado, 'Letter to Daniel Queyssac, ref: M00999.doc' (20-71999) Archive Arthur del Prado - Front-End board file. 
The CTO function, being a staff function, makes it virtually impossible to get something done within the divisions which does not lead to short term results. The frustrating situation is that the local management never bluntly refuses to cooperate, but rather, knowingly, or unknowingly, sabotages such initiatives, simply by taking no actions. ... All in all, I feel that, although I have no problem with spending long days on the realization of company objectives, I can no longer accept the frustratingly low return on my investment in time.'228

Granneman stayed on within the company, but he would focus on a new project. His resignation revealed once again the obduracy of particular elements in ASM's business culture. A most defining feature involved the effort to find a balance between the competitive benefits of decentralization and the pursuit of the ostensible cost-efficiencies of centralization. 


\section{Conclusions}

At first sight, ASM International's sales experienced relative stable growth from 1992 until 1998 and into 1999. Its sales increased from 412.5 million Dutch guilders in 1992 to 634.9 million in 1998. The number of employees increased from 2,539 to 4,436 in the same period of time. However, this general and more distant perspective overlooks the various temporal crises that deeply troubled the company. In the summer of 1992, the summer of 1993, and the fall of 1998 assets were insufficient to leverage innovations elsewhere in the company. In this respect, ASM International's average market capitalization on the Nasdaq is more telling, as it encompassed also a valuation by investors of the viability of the company. The market capitalization increased from 5.7 million dollars over 1992 to 537.6 million over 1998. This enormous improvement illustrated the re-establishment of prospects of the enterprise and as such the development of the firm in this chapter. After years of growth through expansion of activities, ASM International learned to sustain its business. Here, in this conclusion, I will delineate the actions underlying this improvement, and reflect on path, fortuna, and virtù as guiding forces in this development.

\section{Path}

From 1992 until 1999, ASM International underwent a phase of reluctant, existential contemplation. Faced with inadequate alignment to the interests of its customers and its bankers, the viability of the company was highly uncertain. In conjunction with the latest insights into business management - C.K. Prahalad \& Gary Hamel's emphasizing of strategy intent and core competences - ASM International's Supervisory Board and Arthur del Prado tried to redefine the company's essence, its core competencies.

Here, I explore this process by fitting the instigation for contemplation in a wider context, followed by a recapitulation of ASM's core products, core competencies in production, and prevailing tyranny of business units. I end with a reflection on ASM's compliance to Prahalad and Hamel's ideas. ${ }^{229}$

To start with the context, business historians Abe de Jong, Keetie Sluyterman, and Gerarda Westerhuis described a wider development in which multi-divisional

229 Prahalad and Hamel, 'Strategic Intent'; Prahalad and Hamel, 'The Core Competence of the Corporation'. 
enterprises reassessed their activities. ${ }^{230}$ The authors explain that across various Dutch firms financial markets pushed for more profitable businesses. Though overwhelming and surprising for ASM, the contingency fitted to wider developments. The authors' hypothetical explanation for this trend among Dutch corporations - involving more strict financial scrutiny, new information and communication technologies and requirements following intensified globalization of industries - seemed to be relevant for ASM as well. ${ }^{231}$

In the case of ASM, bankers stirred the focus on core competences. The seemingly endless sequence of unpleasant financial surprises - whether from disappointing sales or discontent bankers - taught Del Prado that cash was king. Adequate cash flow and reserves were imperative to shelter the company against disposition of market and bankers. However, to that end, organizational processes and procedures had to be redefined and assessments about the future had to be more robust.

These adjustments were contemplated and executed by intervening chief operations officer Ray Friant. He turned the company's attention to cost and cash. Friant instilled new oversight through new communication procedures and technologies. And the changed market circumstances caused a shift from geographical management toward product management at the equipment manufacturer.

In the successive restructuring effort, core products were defined (figure 69). Through the subsequent strict operational control of the front-end operations, and by bankers bringing decisions to a head, a new footing was found. Activities that did not warrant the investments were annulled. The result of this effort centered around a majority stake in ASM Pacific Technology, through which technological development of four products - the American Epsilon epitaxy reactor, the Japanese Eagle-10 plasma deposition reactor, the European A400 vertical furnace, and the American-European-Japanese A600-UHV machine was leveraged.

ASM International's quest for cost minimization, in order to optimize the cash flow, was not limited to its products and markets, but also to how the company enabled those, or in other words, manufacturing machines. Confronted with imminent collapse, the company's true value continued to be its mastery of semiconductor manufacturing technology. In the case of the front-end activities, this involved process knowledge: making the machines deposit semiconductor materials within the ever advancing parameters of the chip industry. All the other activities were reconsidered, from manufacturing sheet metal and wiring 
to the design of common technological components such as wafer handling. Costs could be limited by centralization, harmonization, and outsourcing. To this end, a successful experience involving ASM Europe and subcontractor Philips Machinefabrieken, surrounding the manufacturing of the A400 vertical furnace, was extended to the development of a general single wafer handler and to the manufacturing of ASM America's Epsilon epitaxial reactors.

\section{Figure 69}

Graph of revenue contribution per product group of ASM front-end, 1988-1999.

Data based upon industry reports of Dataquest, derived from Computer History Museum.

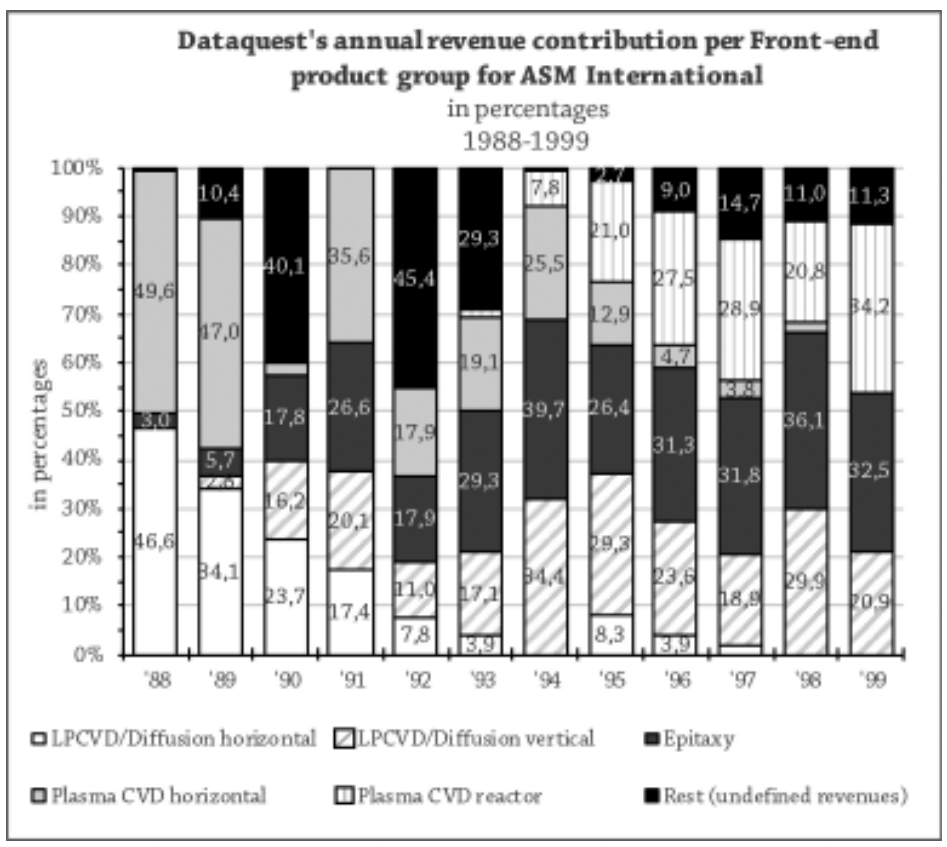

The concerted effort to save costs was met by resistance among the front-end business units. Adjusting the manufacturing operations interfered in the competitive strategies of the subsidiaries. The old dichotomy between the subsidiaries' competitive strategies and the head office's corporate strategy that had numbed ASM International in the late 1980s - or the 'tyranny of strategic business units' in the terms of Prahalad and Hamel - still prevailed. The decentral obstinacy could only be breached by the head office through sheer power-play and by taking advantage of a sudden equity crisis in the fall of 1998 and into 1999. Up to this point, it would remain uncertain whether the pursuit of cost optimization had not been pushed too far. 
In adjusting the company's business strategy, ASM's management partially adhered to the outlines provided by management gurus Prahalad and Hamel. Explicitly and foremost implicitly, the company tried to redefine its strategic intent and core competences. The initial strategic intent was to make front-end sellable. In this effort, the company sifted the wheat from the chaff, selecting the viable products. The Supervisory Board and the Management Board had to balance between cutting too deep or too superficial. Cash-generating products had to be spared to realize the strategic intent of making front-end sellable. The 'tyranny of strategic business units' got partially breached in pursuit of the strategic intent.

However, the effort of the head office to consolidate the core competences in production of machines proved to be a bridge too far. Once again, the business units proved to be unruly. Chief technology officer Ernst Granneman's personal frustration about his effectiveness in streamlining the interests of the business units was telling in this regard. Moreover, the heavy-handed restructuring of American manufacturing, in line with the ambition to focus on critical fabrication activities, seemed to be ineffective as well. It disrupted the American business unit's ability to compete with its epitaxial products.

\section{Fortuna}

It was impossible to predict the outcome of ASM International's contemplation effort. Unforeseen events and developments beyond the influence of the company - or fortuna - were determinative once again. But unlike in Business III, fortuna did not only have a negative effect on ASM. Fortuna manifested itself as the reoccurring whimsical growth and decline in demand for semiconductor equipment and materials. In combination with ongoing internal developments, their impact disturbed the company, for better or worse.

It is possible to identify four specific instances of fortuna. The first manifestation of fortuna involved the depressed European and Japanese markets for semiconductor equipment in 1992 and 1993. In addition to ASM's obsolete horizontal furnaces and not yet ready new products, the downturn deprived ASM International from a viable future. Moreover, it affected ASM's Dutch competitor, Tempress. As both ASM Europe and Tempress shared their fate, their paths crossed, resulting in the successful A400.

A second fortuna pertained to a sudden and dramatic surge in demand in 1995. Combined with ASM's new products, like the A400 and the Eagle-10, the tables got turned: the company was viable again. The revival of the market ended the process of reorganizations and restructuring.

The two other variations of fortuna stand out because they potentially implied lethal consequences, or so-called Machiavellian Moments. As discussed 
in the introduction and elsewhere in this dissertation, the subversive nature of such events tend to instigate radical changes of course. The third fortuna was the threat of bankers to call their loans in 1992 and into 1993. Although in general the viability of the company had been in question, the announcement of the bankers to call their loans by the summer of 1992, and their perseverance after the summer of 1993, forced the Supervisory Board to reconsider ASM International's activities and future. It resulted in the divestment of ASM Fico, the cancellation of numerous products in front-end, and the emergence of new core competencies.

A fourth and final manifestation of fortuna - prompting the second Machiavellian Moment - was the sudden devaluation of ASM Pacific Technology's stock during the Asian crisis despite the steady performance of the company. In this instance, fortuna came on top of the costly settlement with Applied Materials, which had been pending for some time. Although the settlement did not come as a total surprise, its cost proved a great shock. Together, the ill-advised depreciation of ASM Pacific Technology's stock and the settlement with Applied Materials plunged ASM International into yet another crisis. ASM International's bank loans and its large debt to Applied Materials stood under water. To retain its solvency and thus to survive, ASM had to restructure its debt or even divest operations. Unsure about recovery of the market in 1999, the situation prompted a renegotiation of debt by an ad hoc alliance of money lenders and a drastic reorganization of manufacturing at ASM America.

This last Machiavellian Moment differed from the other to the extent that the gravity of the situation was shared across the company. It merely affected the head office, while - following the costly Applied Materials settlement - the consequences were carried by ASM America.

Fortuna exposed the company's main organizational weakness: it lacked reserves to absorb the volatility of the market. The cyclical pattern of downturns and upswings was hardly new, however; this cycle has been a major characteristic of the semiconductor (equipment) industry since the early 1960s. Yet Del Prado leveraged all the company's funds into new and ongoing technological developments, which increased the company's reliance on external funders. The trust and patience of these funders were rooted in the relative short-term assessment of stock exchanges, economic conjectures, balance sheets and so on. Moreover, Del Prado did not command full control of how these funders appreciated his firm. It is hardly surprising, then, that both Machiavellian Moments had financial origins. 


\section{Virtù}

By displaying virtù, ASM International's management regained control over fortuna and, subsequently, the company's fate. Within the organization, the display of virtù alternated between the head office and the business units, resembling a swinging pendulum.

In the face of the first and second Machiavellian Moment, the head office of ASM International ensured the company's survival by showing virtù. The principal body that determined the course of action was the Supervisory Board in concert with Arthur del Prado. The Supervisory Board formulated the objective to make ASM front-end sellable for divestment - as a strategic intent in the sense of Prahalad \& Hamel. The Management Board - consisting of Arthur del Prado, the chief financial officer, the chief technology officer, and the chief operations officer - took action in order to realize that intent. Subsequently, the members of the Supervisory Board actively worked toward this goal by participating in meetings and negotiations with banks and public officials.

As in the previous chapters, Del Prado remained a nucleus of virtù within the company, based on his actions as chief executive officer, and his shareholding in the company. Del Prado was vital in approving technological and commercial strategies, as well as safeguarding his company's assets from skeptical bankers and his Supervisory Board. Through relentless wiggling, the entrepreneur obtained some grace toward installments from his creditors. And time was of the essence in the volatile semiconductor equipment industry. Within a couple of months, downturns could turn into huge upswings, recovering demand for ASM's products and improving the appreciation of the firm by investors.

Yet the reach of Del Prado's virtù grew more limited and was confined to areas in which he excelled, even though he remained responsible for all the tasks related to his position of chief executive officer Del Prado's concentration on his talents - his own core competencies, one might say - was enabled by the entrance of Ray Friant as chief operating officer. Within the simple and concise definition set by the Supervisory Board - make front-end sellable - Friant defined courses of action, and acted. It was a sheer display of virtù. He did not merely set out operational directives, but he personally ensured their implementation, and if this did not happen he intervened.

Friant turned front-end around, and, helped by a surge in demand for equipment, he ensured that the subsidiaries became viable again. Where Del Prado lacked the patience and/or the capability to ensure a sound cash flow, Friant was brought in to correct it. The personal experience and skills of both Del Prado and Friant were critical for the survival of the company, and they supplemented each other adequately. 
Yet in the face of market dynamics - not marked by Machiavellian Moments - virtù resided with the business units. This involved primarily the market boom in 1994 and 1995. Through their concentrated actions in support of their respective products, the subsidiaries as a whole dragged ASM out of its misery. The observation made in Business III that the corporate office did not compete proved to be true again. The business units competed and secured the enterprises revenues and profits.

All in all, throughout the years covered in Business IV, and in the face of ever disrupting fortunas, the pendulum favored the head office's virtù more often. The scale of these events required a corporate response. This contrasted strongly with the previous years, when the business units had enjoyed the initiative predominantly.

Del Prado's confidence in the business units' ability to drag the company out of its mess abated, perhaps because of the severity of the crisis, Yet his trust and willingness to rely on the business units' vigor did not subside entirely. After all, the product groups had been determinative in the recovery of the company. As revealed by Granneman's expounded frustrations in his resignation letter, the virtù of the business units continued to thwart corporate plans.

After Friant's retirement and through his successor Daniel Queyssac as COO, the operational management became more institutionalized within ASM International. Still, management would remain slightly arbitrary due to the company's exposure to the whims of fortuna. Moreover, the company had proven its ability to sustain business - the low pressure CVD, plasma enhanced CVD and epitaxy technologies - and this contributed to its apparent viability. Queyssac lacked the momentum to control or break the tyranny of the strategic business units.

In the next decade, the company succeeded in carving out a market share with the 300-millimeter variations of its products: the Eagle-12, the A412, and the Epsilon 3000. But the company also resumed efforts toward its expansion through acquiring external inventions. A soaring semiconductor equipment industry at the turn of the century opened new perspectives and opportunities. Once again, the business units and the head office executives would be challenged to vie for their virtù. 


\section{Innovation IV}

\section{Enacting high-k gate \\ dielectrics and atomic layer \\ deposition technology, \\ 1996-2007}




\section{An introduction}

In 2007, a process of intense collaboration between a select group of chipmakers, equipment manufacturers, and material suppliers resulted in a revolutionary innovation. That year, one of those chip manufacturers - Intel - began the industrial production of its 45-nanometer computer chips, which deviated from its many predecessors in a profound way. To continue Moore's Law, Intel had changed the transistors' gate for the first time in three decades of semiconductor manufacturing. The transistor gate constituted a stacked dielectric and electrode that defined the transistor's ability to electrically switch on and off. ASM's technology played a vital role in the replacement of the traditional dielectric silicon oxide - for a new one - hafnium oxide (figure 70).

The replacement of a single material may seem a minor issue, but historians David Brock and Christophe Lécuyer explain its relevance in this context:

'By 2007, leading-edge microchips contained over a billion transistors. ... a very particular type of transistor had, since the 1970s, been the switch of choice for microchips: the silicon gate transistor. The concatenation of trillions of these silicon-gate MOS transistor switches, flipping on and then off, generated the inaudible hum of the digital world.'

Intel and ASM, in other words, were fiddling with the 'object most made by humans.'2

Moreover, in this process, the equipment supplier pioneered a completely new manufacturing technique called 'atomic layer deposition' (ALD). This technology enabled chip manufacturers to grow materials one atom at a time, offering unprecedented conformality and uniformity. After the fortunate acquisition of Microchemistry, a Finnish firm founded by the inventor of ALD, ASM and its customers took up the effort to integrate this new technique in the industrial orchestration of innovation, i.e., a semiconductor production line. ${ }^{3}$

1 David Brock and Christophe Lécuyer, 'Digital Foundations: The Making of Silicon-Gate Manufacturing Technology', Technology and Culture 53, 3 (July 2012) pp. 561-597, p. 563. Their article reconstructs the materialization of the polysilicon MOS transistor in the late 1960s - the transistor design that would become the semiconductor industry's standard (cf. Intermezzo in Business I). The chapters of Innovation IV about the innovation of the gate stack forty years later can be seen as the next episode of that technological development.

2 Ibid.

3 The term 'orchestration' has been suggested in contrast to systems of innovation by historian 


\section{Figure 70}

Schematic horizontal cross-section of a polygate (left) and high-k gate (right) MOS-transistor Innovation IV centers around the innovation process involving the change of the dielectric from silicon oxide for a high-k material. Such transistors (n-type and p-type) were combined in one CMOS device, which on their turn are integrated by billions or more in one chip.
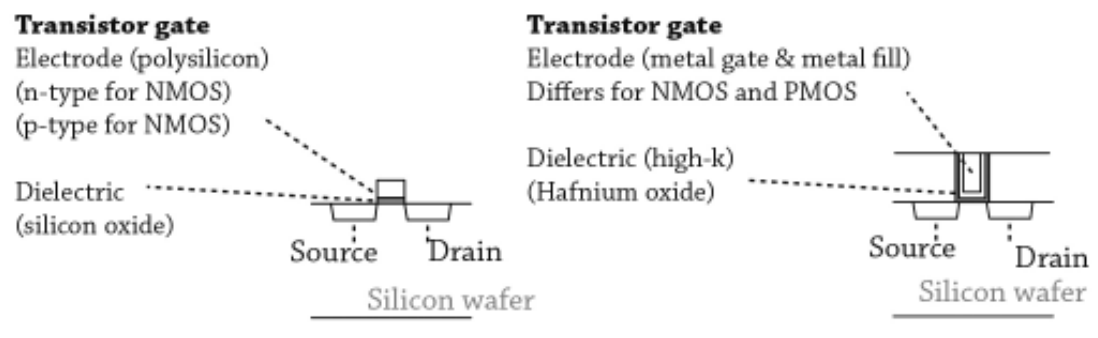

The revolutionary innovation of the transistor gate stack constitutes a premise for studying the dynamics of customer-oriented innovation. In the previous Innovation chapters, ASM's customers - chip manufacturers - were identified as being defining for the company's innovation process. Innovation IV further studies this relationship. What was the influence of equipment supplier ASM and its customers on the innovation of a new semiconductor manufacturing technique?

This question is explored by following the protracted yet disrupting development of the transistor gate stack from 1996 to 2007. Throughout this development, the technological interdependence between equipment manufacturer and chip producer increased: in for a penny meant in for a pound. The effort entailed a collaborative search for new materials, the maturing of new deposition techniques, and the best way of integrating both material and technique in an industrial production line.

The intense collaboration between ASM and its customers resided in, and was driven by, two wider contingencies. The first involved the advent of co-innovation between suppliers and customers. Another was the irrepressible approach of a technological challenge regarding the transistor gate stack. Below I will discuss these developments in further detail.

David Brock: 'In semiconductor manufacturing there exists an ecosystem of technologies. Within this ecology lithography exposure tools and photoresist are highly coupled: the performances and characteristics of each help define the fitness and success of the other.' David C. Brock, 'Patterning the World: The rise of Chemically Amplified Photoresist', Chemical Heritage Foundation, Center for Contemporary History and Policy: Studies in Materials Innovation (2009), p. 17. 


\section{Co-innovation in the semiconductor supply chain}

Throughout the 1990s, confidence in the possible role of the supply chain with regard to innovation increased. Management scholar Eric von Hippel argued that addressing user-needs increased the chance of success. ${ }^{4}$ Other authors noted the benefits of getting suppliers involved in technological development. ${ }^{5}$ This insight elaborated on a specification of 'core competences' - involving make-orbuy decisions (cf. Business IV).

By the mid-1990s the equipment suppliers' contribution extended beyond the mere supply of tools and processes. Equipment suppliers were increasingly seen as potentially contributing to innovation as well. Such new role, however, also required new capabilities, as observed by management scholars Rajan Kamath and Jeffrey Liker in Harvard Business Review in 1994:

'Many suppliers, in both the United States and Japan, make it a goal to "move up the ladder" from a simple parts-supplying role to one that provides more value to the customer. But the move is expensive, and suppliers cannot be partners with all customers. If a supplier wants to move up the ladder, it must broaden its technological base. ... An upwardly mobile supplier must also have a good track record at its current level, build a relationship carefully with its targeted partnercustomer, and develop an ability to innovate. ${ }^{6}$

Across the semiconductor industry supply chain, habitual roles began to shift or fade. This involved the relation between chip designer companies and their contract manufacturers, or 'foundries,' in semiconductor jargon. But new appreciation regarding the supplier's role in technological development also evolved between semiconductor equipment manufacturer and chip producer.

Heeding the advice of Kamath and Liker, if perhaps not deliberately so, ASM selected the customer it wanted to win over, while expanding its technological capabilities. After having worked on a series of failed products in the early 1990s,

4 Eric von Hippel, The Sources of Innovation (Oxford University Press, New York, 1988).

5 Francis Bidault Charles Despres, and Charles Butler, Leveraged Innovation: Unlocking the Innovation Potential of Strategic Supply (Palgrave Macmillan, London, 1998); Janet Hartley, Jack Meredith, David McCutcheon, and Rajan Kamath, 'Suppliers' Contribution to Product Development: An Exploratory Study’, IEEE Transactions on Engineering Management 44:3 (1997) pp. 258-267; Rajan Kamath and Jeffrey Liker, 'A Second Look at Japanese Product Development', Harvard Business Review (November-December 1994) pp. 154-170; Shona Brown and Kathleen Eisenhardt, 'Product Development: Past Research, Present Findings, and Future Directions', The Academy of Management Review 20:2 (1995) pp. 343-378.

$6 \quad$ Kamath and Liker, 'A Second Look at Japanese Product Development', pp. 154-170. 
Del Prado urged his technical team to collaborate more closely with leaders in chip manufacturing. In his view,

'major opportunities are existing at the customer level everywhere in the world. I am convinced both Applied and Lam earned their rise not primarily from internal [sic] originated R\&D, but from customer initiatives and sponsorship in America (Intel, Motorola, TI, IBM and long time ago Bell-Labs/Maydan-Wang).'7

Del Prado realized that an equipment manufacturer's success very much rely on its ability to address specific problems of customers. By the mid-nineties, customer involvement had determined the success of ASM's A400 vertical furnace, the Eagle-10 single wafer plasma CVD, and the Epsilon reactor, and this had in fact secured ASM International's recovery (cf. Chapter 24). To be taken seriously as co-innovator by chip manufacturers, ASM had pursued the role of manufacturing processes integrator since the 1980s. ${ }^{8}$ By offering integrated process technologies, ASM increased its responsibilities toward its customers, added technological prestige and could provide larger financial rewards.

Around 1993, due to deplorable commercial opportunities in Europe and Japan, ASM decided to focus on the United States as the most prospective market. Intel and IBM deployed the highest capital expenditures, including investments in equipment. Moreover, the technology involved tended to disperse from these tech giants toward the rest of the industry. A successful cooperation with either Intel or IBM, or both of them, might thus result in more sales to other customers worldwide.

ASM's involvement in gate stack innovation resulted from a deliberate strategy: closer cooperation with technologically leading customers. This strategy was effectuated by becoming a process integrator, and by targeting leading American chip manufacturers. The gate stack dielectric emerged as a prestigious and perfect showcase for ASM to advance its position and prominence vis-à-vis its customers.

\section{An industrial and technological challenge: the gate stack}

The second contingency that drove the interaction between Intel and ASM formed the technological challenge posed by the gate stack. Moore's Law - or constant miniaturization of computer chips' components - required an overhaul of the crucial element: the basic metal-oxide-silicon (MOS) transistor. This

$7 \quad$ ASMI, Arthur del Prado, 'Memo to Chris Werkhoven, and FEB' (13-1-1997) Archive Arthur del Prado-Chris Werkhoven file.

8 AMTC, Ernst Granneman, 'Proposal for process development on ASM equipment placed at IMEC' (6-8-1992) Archive Arthur del Prado - IMEC file. 
involved in particular the gate stack, which, since the late 1960s, consisted of a polysilicon electrode and a silicon oxide as dielectric, grown in a chemical vapor deposition batch furnace (cf. Intermezzo in Business I). Over time, innovations in production methods facilitated the regular shrinkage of the gate electrodes and dielectrics, enabling further shrinkage in line with Moore's Law and subsequent improvements in computer chips performance.

However, at a certain scale, a smaller transistor does not only increase performance; it also tends to leak more current during the 'off'-mode. Electrons continue to slip away from source to drain. This causes heat-up of the chip as a whole, as well as reduced battery-life for portable electronics. The latest chip generation required forceful cooling, which made them unfit for mobile applications.

Limiting this leakage results in less power consumption. Less energy consumption enabled the application of faster chips in portable electronics, such as the emerging mobile phones and notebooks. ${ }^{9}$ Thus, around the turn of the century, the limitation of current leakage of transistors constituted the Holy Grail in chip manufacturing.

Over the course of forty years, the 'complementary metal oxide silicon transistor' (CMOS) had been the enabler of Moore's Law. This transistor consisted of two types of MOS switches: a positive-channel MOS and a negative-channel MOS. With relevancy to the gate stack, the electrodes of both transistors differed electrically. The dielectric material was the same. Thus, the majority of computer chips consisted of CMOS transistors, which in their turn contained two gate stacks - one for positive-channel MOS and one for negative-channel MOS.

One form of energy leakage was caused by the decreasing effectiveness of the transistor gate dielectric. In order for the gate stack to function properly as a switch, a certain amount of electrical capacity has to be stored. ${ }^{10}$ This electrical charge that can be stored across the gate is proportional with the surface area of the stack and with its dielectric constant. The electrical capacity is inversely proportional to the thickness of the dielectric film. When the dimensions of the transistor shrink, the gate stack surface obviously decreases. To sustain the electrical capacity, the choice is either decrease the thickness of the dielectric

9 At this stage, the advancement of portable electronics depended foremost on more efficient chips rather than better batteries; the progression of Moore's Law was not matched by improvement in battery performance.

10 The following is based on a note from Ernst Granneman to the author. - Ernst Granneman, 'Note to author'. More information about the physics: Jean-Pierre Locquet, Chiara Machiori, Maryline Sousa, Jean Fompeyrine, and Jin Won Seo, 'High-K dielectrics for the gate stack', Journal of Applied Physics 100:5 (2006). 
or increase the dielectric constant. It had always been easiest to decrease the thickness and stick with the same material, i.e. silicon oxide.

However, at some point the film became so thin that the structure could no longer hold off the electric voltage: the transistor either broke down or the leakage current increased. The 'dielectric constant' of a silicon oxide film would not be enough - it would be too low to function as a barrier between the channel and the gate electrode.

The only, and unavoidable, way to keep the leakage current acceptable was to increase the dielectric constant of the gate dielectric. This meant, in other words, that one had to replace silicon oxide for a material with a higher dielectric constant, while keeping the layer sufficiently thick to avoid heating problems. This new material was dubbed a 'high-k dielectric,' the 'k' being an abbreviation of the Greek letter kappa, symbolizing 'dielectric constant.' The pursuit of decreasing current leakage of the gate, then, zoomed in on the search for a new high-k gate dielectric.

Yet with regard to the gate dielectric the uncertainties were paramount. The material of the high-k dielectric was not yet known. What kind of technique could be used to deposit this new material at the smallest dimensions? How could the new material and production technique be integrated in a production line? And when would the silicon dielectric become defunct and the high-k dielectric indispensable for the progression of Moore's Law? Across the industry, scientist and engineers identified several candidates as material and production methods, based on publicly available results and knowledge.

The challenge of finding this high-k gate dielectric could be seen as an 'anticipatory reverse salient. ${ }^{11}$ This notion, put forward by sociologist Thomas Hughes (later adapted by historians David Brock and Christophe Lécuyer), refers to an element expected to threaten the progression of a technological system, or, in the case of the semiconductor industry, preventing the continuation of Moore's Law.

Industry-wide the challenge of the gate stack was recognized and encapsulated in the National Technology Roadmap for Semiconductors from 1994 on, and as of 1997 in the International Technology Roadmap for Semiconductors. The roadmap set out the industrial consensus about technological development for CMOSbased computer chips, and institutionalized the pace of miniaturization captured by Moore's Law. Moreover, it helped to align and attune efforts among the industry's actors - chip manufacturers, equipment vendors, material suppliers, research institutes, and governmental agencies. ${ }^{12}$ From 1994, the numerous

11 Thomas Hughes, Networks of Power: Electrification in Western Society, 1880-1930 (John Hopkins University Press, Baltimore, 1983) pp. 79 and 90; Brock and Lécuyer, 'Digital Foundations', p. 564.

12 Others examples were the ability to project smaller lines with lithography at an industrial 
technological challenges related to the gate stack became apparent through scientific research and engineering, and these were integrated into the roadmap.

Based on this information, many semiconductor manufacturers preferred to dodge the issue. The importance of the high-k gate dielectric as anticipatory reverse salient differed along the industry. Not all chip manufacturers faced the limits of miniaturization simultaneously. At one point in the future, all of them would have to address the physical limits of silicon oxide, but the timing might very much differ. After all, the time path enunciated in the industry's roadmap was a mere aggregate of the individual schedules. As explained by ASM International's future chief technology officer, Ivo Raaijmakers:

'[I]t is about spreading and evaluating risk. Just look at how a company like Intel does it: they have a long list of improvements for their device [chip], and they develop each one of them at its own pace. If they [Intel] have to make a choice [like defining a new chip], they choose some of these technologies that would realize the desired device performance. At such a moment, they opt for technologies that both enable such a device improvement and are sufficiently mature to be integrated in manufacturing. All the other technologies are left alone until the next [technology] node. Those are developed further. Two years later, another choice has to be made, and then they [Intel] decide: we chose this one, that one, and the other one - which, taken together, allows them to realize another performance improvement. ${ }^{13}$

Upon the individual roadmaps of semiconductor manufacturers, the challenge of replacing the high-k dielectric was not always imminent or urgent.

For manufacturers of memory chips, the inclusion of a high-k dielectric surfaced earlier than for the manufacturers of customized chips and microprocessors. In their market segment, performance - and thus the attractiveness of their chips - was primarily related to the shrinkage of capacitors, not of transistors. Producers of memory chips integrated high-k dielectrics first in metal-insulator-metal memory capacitors, and not yet in their transistors. The

scale, or the integration of copper as an interconnecting material, replacing aluminum. Or think about the advent of 300-millimeter wafers, and, most significant for this chapter, the shrinkage of the gate stack. - Robert Schaller, Technological Innovation in the Semiconductor Industry: A Case Study of the International Technology Roadmap for Semiconductors (George Mason University, 2004) p. 456; Rose Marie Ham, Greg Linden, and Melissa M. Appleyard, 'The Evolving Role of Semiconductor Consortia in the United States and Japan', California Management Review 41:1 (1998) pp. 137-163.

13 Original quote in Dutch. - Ivo Raaijmakers, 'Interview with author'. 
high-k dielectric in the capacitor had to comply with specifications that differed from those for the high-k dielectric in a gate stack. ${ }^{14}$

Moreover, not all chips were subjected to the economics of Moore's Law. For some semiconductor manufacturers, their sales depended not on the performance to process a maximum amount of information, but on appropriating unique tasks. Such chips - later known as 'More than Moore' - did not yet need a high-k dielectric. For them, the silicon oxide still complied as gate dielectric.

Only a select group of microprocessor manufacturers required the high-k gate dielectric first. For them, their ability to shrink transistors was key to their competitiveness. These were predominantly American chip manufacturers, such as Intel, IBM, and Motorola, but also Asian contract manufacturers like TSMC from Taiwan or Samsung in South Korea.

And even then, there were work-arounds that enabled a postponement of the tricky challenge posed by the gate stack. One route was to license an alternate chip design named ARM. Performance enhancements could also be achieved by ingeniously designing the integration of transistors and other electrical components on a chip. ARM design required fewer transistors and thus less energy to achieve the same information output.

To put it differently, even though the gate stack formed an industry-wide anticipatory reverse salient, its realization was not. Only a few chip manufacturers carried the whole innovation of the gate stack from its initial identification onward. They blazed the trail, so to speak.

From the turn of the century, Intel became the main protagonist in advancing the new high-k gate dielectric in semiconductor manufacturing. The manufacturer of microprocessor chips enjoyed the highest revenues of all semiconductor producers due to its pivotal role in powering personal computers and servers. Intel's success and viability depended on realizing Moore's Law. Consumers were willing to pay for more computer power, faster computer chips. While memory could be extended by adding multiple memory chips to a computer, the computing power resided in a single chip. The higher the performance of this chip, the more possibilities in processing information were offered to a consumer.

In the semiconductor industry, Intel was renowned for having mastered the art of road mapping technological challenges and probable solutions. Moreover, Intel harnessed the biggest capital expenditures in the industry: it had the largest

14 A capacitor is often a metal-insulator-metal configuration. The insulator - the high-k dielectric in this case - merely has to comply with the metal - most often polysilicon. In the case of the gate stack, the high-k dielectric had to be compatible with the metal electrode and the silicon substrate. Subsequently, aluminum oxide functioned as high-k dielectric for the capacitor, while this material did not work for the gate stack. Its dielectric constant was too low for this function. 
financial and technological resources to invest in new equipment and production lines. To achieve this constant performance improvement, the ability to realize further shrinkage of CMOS transistors at a predictable and constant pace defined Intel's competitiveness. This dynamic accounts for the fact that the gate stack dielectric enjoyed a prominent position on Intel's technology roadmap. The particular logics determining Intel's competitiveness - such as the application and construction of its microprocessors - gave the American chip manufacturer a pivotal role in the development of the novel gate stack, industry-wide as well as at $\mathrm{ASM} \cdot{ }^{15}$

\section{Outline of Innovation IV}

Innovation IV consists of three chapters, each of which details a different phase of the development process of high-k gate dielectrics. Chapter 26, deals with the initial work of ASM on gate stack technology from 1995 until 1998. Chapter 27, covering the years 1999 until 2003, begins with the acquisition of the ALD technology and its application for the gate stack by ASM. This involved collaboration with customers and research institutes. Next, development also focused on the selection of the new gate dielectric material, hafnium oxide. Chapter 28 details the integration of this material into semiconductor manufacturing from 2003 until its introduction in high-volume manufacturing by Intel in 2007. In the Conclusions, I reflect on the above-formulated question by returning to this study's three basic conceptual elements: path, virtù, and fortuna. 


\section{Chapter 26 \\ Pursuing integrated and rapid thermal processes, 1995-1999}

After booming demand around 1995, semiconductor revenues declined due to overcapacity of product lines and an economic crisis in South-East Asia that lasted into 1998 (cf. Business IV). At the start of this period, ASM International's operations active in wafer processing equipment strictly focused on three products: vertical furnaces, epitaxy, and single wafer plasma deposition. This focus had enabled the recovery of ASM International after the volatile early 1990s. Consequently, ideas or suggestions for new diversification of activities tensed up management. The remaining products required plenty of resources, for instance in coping with their own demand and preparing for the new wafer 300-millimeter standard. Amidst these circumstances, the innovation of gate stack technology was not self-evident within ASM International.

Against all odds, the gate stack emerged as a viable application to be pursued because of four concurring narratives. The first was the necessity to collaborate with customers, following several costly technological failures in the previous years. This resulted in a plan to penetrate leading chip manufacturers in the United States. The second narrative involved the consideration whether - and, if so, how - ASM should join a burgeoning market for a complementary technology named 'rapid thermal processing.' Thirdly, the Dutch equipment manufacturer had been trying to increase its capabilities as service to its customers by mastering multiple process steps in one machine, dubbed 'integrated processing.' And finally, Del Prado and his management had been weighing ASM's core competencies, resulting in the focus on the three products mentioned above, but also in the willingness to outsource some development tasks. A Dutch subcontractor, Philips Machinefabrieken, was hired to develop and fabricate a wafer handler (cf. Chapter 24). Only through the interference and championship of the head office - ASM International - and several technical managers, research into gate stack technology survived the company's intense internal competition for resources.

\section{A prelude: ASM, the American market, RTP, and a project named IVPS}

Since the mid-1980s, American semiconductor manufacturers tended to focus their activities on customized chips, known in the industry as 'application specialized integrated circuits,' or ASICs. Memory chips were predominantly 
produced by Japanese and, later on, South-Korean producers. As discussed in Chapter 18, this geographical specialization affected the course of technological development in these regions. Memory chips were produced in high volumes and with little variety. To achieve the high throughput, batch machines were attractive. ${ }^{16}$ The opposite was true in relation to customized chips, which involved relatively lower volumes and higher variety among chips. Customized chips varied greatly in design and thus fabrication process. Single wafer machines enabled flexible and quite economical production.

The American preoccupation with customized chips - and thus single wafer processes - resulted in the advent of a new segment in semiconductor equipment called 'rapid thermal processing' (RTP). Since the early 1990s, there had been much speculation in the semiconductor industry about the direction of single wafer processes. It was widely expected that the continuing miniaturization of transistor dimensions and the success of single wafer machines would pave the way for more integrated single wafer processes. ${ }^{17}$ In order to grow very thin films in high quality and with a high throughput, wafers had to be transferred very rapidly between hot modules, offering a shorter process cycle time. For this reason, these so-called rapid thermal processes enjoyed a healthy demand in the United States. ${ }^{18}$

By the mid-1990s, the market for RTP grew rapidly in size and in applications (figure 71). Worldwide revenues in RTP grew from 45.2 million US dollars in 1993 to 153.3 million in 1995 and 272.9 million in 1997, with the American market constituting approximately 40 percent. $^{19}$

16 This is not to say that the fabrication of memory chips did not rely on single wafer processes. Initially, however, the introduction of single wafer processes started for customized chips, in the United States, after which they were also used in memory.

17 Industry data firm VLSI Research anticipated a future in which the fab consisted of mere single wafer cluster tools comprehending multiple process steps (see VLSI Research Inc. 1.1. pp. 37-42). In particular Texas Instruments was a proponent of this at that time. Texas Instruments participated in a DARPA funded research project called Microelectronics Manufacturing Science and Technology (MMST), a program aimed at studying CMOS integrated circuit fabrication through single wafer RTP-based systems. Philips conducted studies into RTP-based CMOS processes as well. - M. Moshlehi et al., 'Single-Wafer Integrated Semiconductor Device Processing' IEEE Transactions on Electron Devices 39 (1992) pp. 4-32; M. Moshlehi et al., 'Microelectronics manufacturing science and technology (MMST): single-wafer RTP-based 0.35 /spl mu/m CMOS IC fabrication', Technical Digest International Electronic Devices Meeting 1993, (5-12-1993); Fred Roozeboom (ed.), Advances in Rapid Thermal and Integrated Processing (Dordrecht 1993).

18 Bo Lojek, 'Early History of Rapid Thermal Processing', 7th International Conference on Advanced Thermal Processing of Semiconductors (Colorado Springs, 1999), p. 292.

19 In 1993, 1995, and 1997, US revenues for rapid thermal processing accounted for, respectively, 18.7 million, 69.7 million, and 105.8 million US dollars, or 41.2\%, 45.5\%, and $38.8 \%$ of all global sales. - Dataquest, 'Chapter 5: RTP and Oxidation/Diffusion', Dataquest 


\section{Figure 71}

Graph of worldwide revenues in rapid thermal processing equipment per supplier, 1993-1997

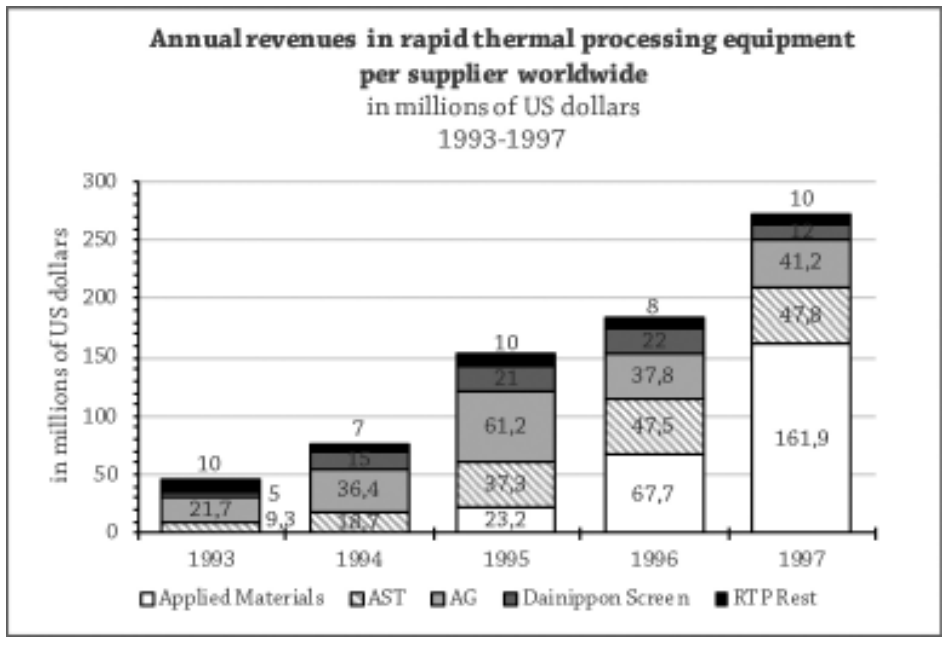

Variations of RTP were rapid thermal annealing (RTA), oxidation (RTO), and chemical vapor deposition (RTCVD). As of the late 1980s, three firms the American AG Associates, the German AST Electronik, and the Japanese Dainippon Screen - pioneered these new market segments. By the mid-1990s, the biggest competitor of ASM, Applied Materials, rapidly obtained a major headstart in most of these segments. It was widely expected, by 1995, that sooner or later more competitors would join this promising market (figure 72).

ASM's involvement in gate stack innovation ensued from its efforts to join the RTP bonanza. The central piece of technology was the Epsilon single wafer reactor. Originally intended for epitaxial processes, it proved to be applicable for various RTP chemical vapor deposition processes as well. The Epsilon became part of ASM's efforts into RTP in two ways. One route was to modify a standalone version of the Epsilon for new RTP processes. The other route involved integrating various Epsilon process chambers into a cluster machine. Because all the Epsilon know-how was in the hands of ASM America in Phoenix, Arizona, this operation became the focal point of ASM's efforts into gate stack technology.

As of 1989, engineers at ASM America began to work on turning the Epsilon into a RTP reactor. The Paragon, the first outcome of this effort, performed a polysilicon RTP deposition process, a material normally grown by means of batch systems - like ASM's horizontal and vertical LPCVD furnaces. Despite

Market Statistics: 1997 Wafer Fab Equipment Market Share Estimates: Deposition and Removal (1-6-1998), pp.58 and 63. 
high expectations and being shepherded through the sweeping reorganizations of the early 1990s at ASM, the Paragon RTP reactor failed to live up to its promise. As customers were not willing to use standalone single wafer processes for the growth of polysilicon, the Paragon would solely find its way into niche applications.

\section{Figure 72}

Graph of forecast rapid thermal processes per application, 1996-2001

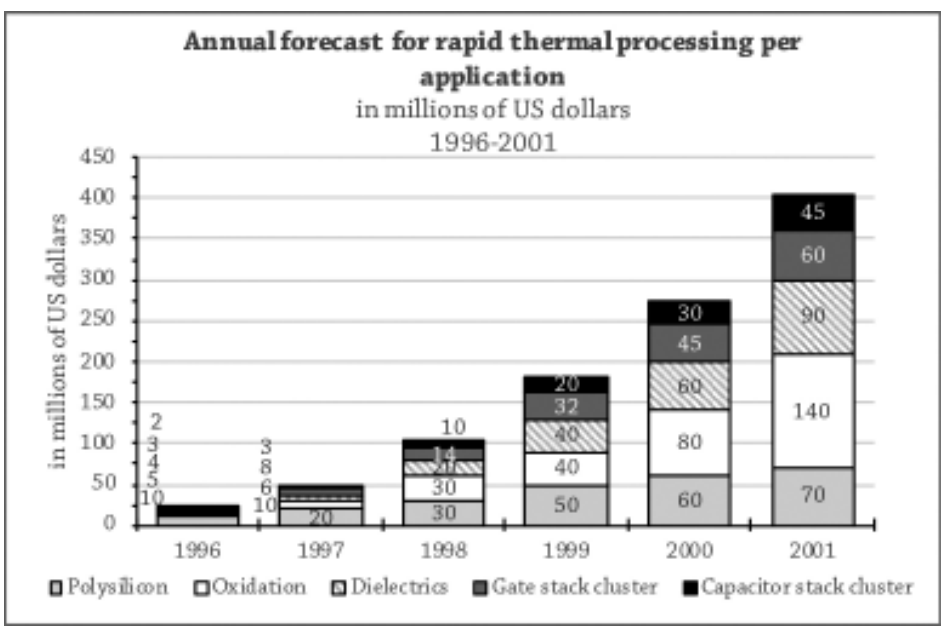

Although ASM's prospects of joining the promising RTP market diminished through the failure of the Paragon, its work through the European research program JESSI into 'integrated vacuum processing systems' (IVPS) represented another opportunity. Starting in the late 1980s, ASM set itself up as a process integrator through its A600-2 cluster machine and the IVPS project (cf. Chapter 22). Originally, the IVPS project was intended to foster ASM as an integrator of external process modules. To this end, it designed a wafer handler in conjunction with its competitor Novellus and subcontractors Brooks and Philips Machinefabrieken.

By the mid-1990s, however, after disappointing market acceptance of the A600-2 and turbulence in the European semiconductor industry, ASM was forced to lower its ambitions. From 1994 on, the IVPS project refocused on integrating and harmonizing software - according to protocols defined by the standardization committee of SEMI - between an ASM-provided central wafer handler, controllers of Epsilon process chambers, and modules supplied by third parties. Because half of the cost was covered by the government, the IVPS project could be continued and, along with it, the appliance of Epsilon reactors for RTP. 
Within ASM International, merely two individuals were involved: software application engineer Timo Bergman and executive scientist Chris Werkhoven, who in the summer of 1996 managed to secure support for the continuation of the IVPS project.

\section{Siemens Semiconductors puts ASM on the track toward a new gate stack}

A rather conventional joint-development program together with Siemens Semiconductors and the German equipment manufacturer AST Elektronik allowed ASM to continue its initial efforts into RTP and integrated processing (which also implied the continued involvement of Philips Machinefabrieken as subcontractor for wafer handling technology). Siemens and AST had been involved in the IVPS project as well. Werkhoven championed the continuation of the cooperation in a new joint-development program. He was personally convinced of the diversification of the Epsilon for RTP and the pursuit of integrated processes. ${ }^{20}$ Through this program, he secured a committed customer and funding for a development machine, offering just enough air to further his ambitions. This Siemens joint-development program would put ASM onto the path of innovating the production techniques for the gate stack.

The Siemens joint-development program foresaw a cluster machine, which would allow Siemens Semiconductors to create an 'electrically erasable programmable read only memory' (EEPROM) cell. Siemens Semiconductors was specialized in memory chips. Therefore it had a keen interest in innovating production technologies for the EEPROM. The structure of this EEPROM cell and how ASM and AST intended to manufacture those in their cluster tool closely aligned with the production of forthcoming metal-oxide-silicon gate stacks.

An EEPROM cell basically consists of two stacked-up MOS gate stacks, a configuration used widely today for flash memory chips as well (figure 73). The EEPROM cell, from bottom to top, consists of a tunnel oxide, a floating gate, a gate dielectric, and a gate electrode. Each of the modules of the ASM-AST cluster designed for the Siemens joint-development program could build one of these elements of the cell. Through this, the whole EEPROM cell could be created in a single system: the ASM-AST cluster.

20 Initially, Werkhoven had looked into integrated processes of tungsten silicides and proposed a collaboration with equipment supplier Genus, which offered single wafer tungsten silicide modules. Metallization in particular seemed a major growth market for RTP, and Werkhoven stipulated how ASM might join this development. This illustrates that the gate dielectric was not a predestined topic of research for ASM. - ASM International, Chris Werkhoven, 'White Paper on Single Wafer Rapid Thermal Processing (RTP)' (early 1995) Archive Arthur del Prado-Chris Werkhoven file. 


\section{Figure 73}

Schematic horizontal cross-section of a typical EEPROM-cell, mid-1990s.

By means of the ASM-AST cluster tool, Siemens Semiconductors wanted to create this type of memory cell, multiplied by thousands across a memory chip.

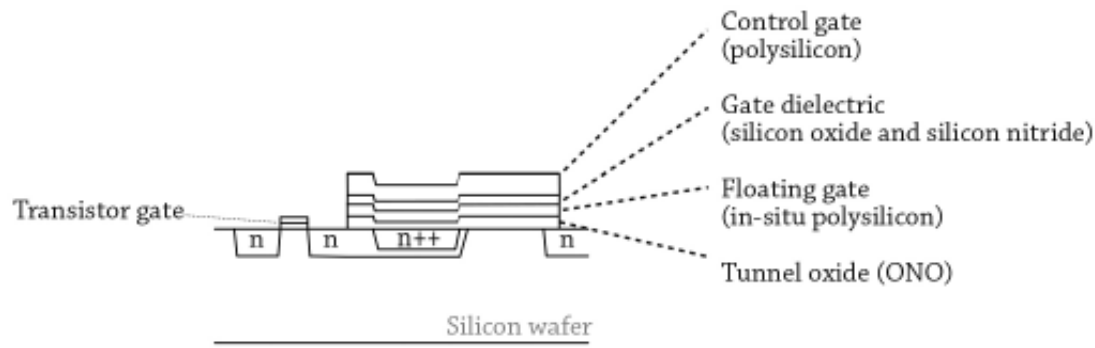

Technologically, four distinctive goals were identified within the jointdevelopment program. The first goal was to prove ASM's capability as system integrator - ensuring that it controlled the sequential construction of the EEPROM cell in the cluster. Secondly, AST had to demonstrate that it could construct a thin oxide-nitride-oxide (ONO) dielectric, which had to function as a tunnel oxide. A third goal was that ASM could deposit a doped film of polysilicon in-situ, as part of the integrated process.

The fourth and final goal of the program requires a little more attention here. Within the program, ASM wanted to develop a silicon-nitride process module. This was an Epsilon-based chamber - just like the polysilicon variation, dubbed Paragon (cf. Chapter 23) - but supplemented with a 'microwave radical generator' (MRG). The MRG had been developed by the Siemens engineer assigned to the joint-development program, Dr. Alexander Gschwandtner, in order to clean the reaction chamber after the nitride process. For this program, Siemens and ASM intended to use the MRG to improve the silicon-nitride deposition process in ASM's module. The MRG was in fact a 'remote plasma source', which meant that a gas discharge was generated outside the reaction chamber (figure 63 in Chapter 24). Nitrogen gas passed through the MRG, got ionized, and was introduced in the reaction chamber. ${ }^{21}$ Switching between the precursors and nitrogen radicals allowed ASM to grow a unique thin film of pure nitride, a few angstroms thick. ${ }^{22}$

21 The lamp-based Epsilon chamber was not suitable to facilitate a direct plasma above the wafer. Hence the need for the remote MRG, which was built underneath the Epsilon chamber. - Chris Werkhoven, 'Interview with author' and Ivo Raaijmakers, 'Interview with author'.

22 Timo Bergman, 'Interview with author'; Chris Werkhoven, 'Interview with author'; Ivo Raaijmakers, 'Interview with author'. Initially ASM was not sure whether it had succeeded in growing a nitride film by means of this remote plasma source. Its metrology equipment was not capable of measuring such thin films. Only with more advanced metrology equipment, available at IMEC, did ASM grasp the capabilities of the remote plasma reactor. 
The fourth objective - developing the silicon-nitride module - was the zenith of customer-supplier collaboration within the joint-development program. Moreover, it involved the technology that would push ASM forward toward innovating CMOS gate stacks.

The cluster supplied to Siemens contained the following (figure 74 ). ${ }^{23}$ The central wafer handler was called A800, and it was built and designed by ASM and Philips Machinefabrieken. The A800 moved the wafers in vacuum from a transfer box to four process chambers and back into the transfer box. For the creation of the EEPROM cell, the wafer moved first into an AST cleaning module. It removed a native oxide in the exposed silicon gate windows. Next, the wafer moved to a Rapid Thermal Oxidation and Nitridation (RTO/N) module of AST, where it was processed at around 1000 degrees Celsius to grow the ONO tunnel dielectric. A few minutes in the third module - a Paragon-based chamber of ASM - were needed to deposit a phosphorus-doped polysilicon electrode film at 600 degrees Celsius. This created the floating gate.

\section{Figure 74}

Schematic vertical cross-section of the integrated rapid thermal machine used in the Siemens joint-development program, mid-1990s.

Elaborating upon the initial JESSI project called IVPS, the collaboration between ASM and STEAG-AST was continued in a Siemens joint-development program. With this machine, EEPROM cells could be created in an integrated manner - the wafer moved from reactor chamber to reactor chamber without leaving the cluster.

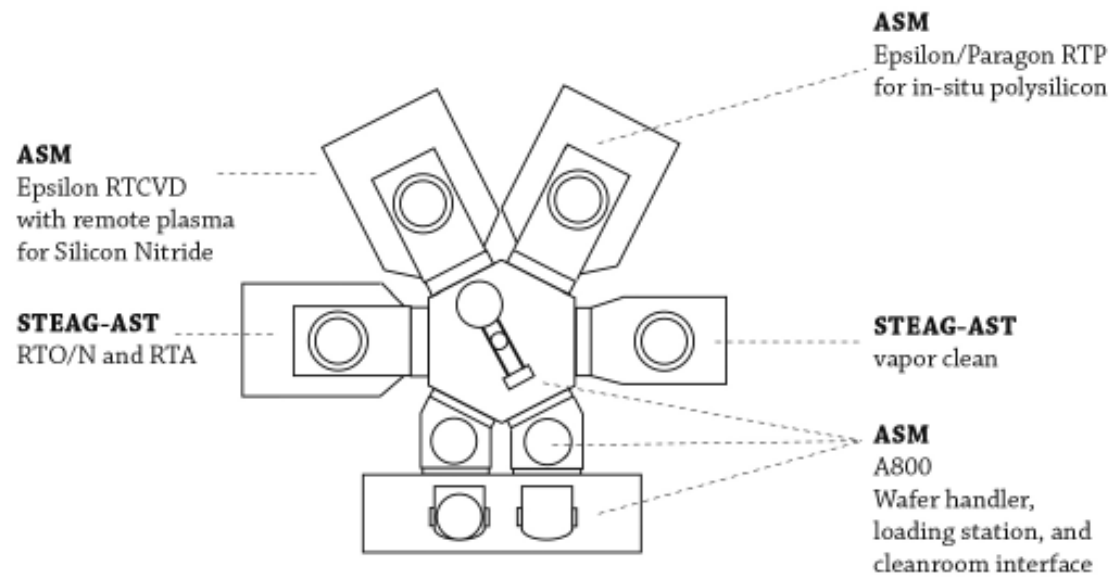

23 ASM International, Chris Werkhoven presentation: single wafer market analysis (TC Meeting 6/96) Archive Arthur del Prado - Chris Werkhoven file. 
For the fourth step, the wafer returned to the AST RTO/N chamber, where three nanometers of silicon oxide were grown at 900 degrees Celsius. The next step involved the deposition of a film of 20 nanometer silicon nitride at 800 degrees Celsius in the - Epsilon based - silicon-nitride module of ASM. At this stage, the tunnel oxide, the floating gate, and the gate dielectric were created within the cluster. This basic outline of the initial process shows why it was called integrated rapid thermal processing. The wafer was processed hot and fast, and all of it was integrated in one system.

For the final step in the construction of the EEPROM cell, the wafer returned to the transfer box and was transported through the cleanroom to another machine, a vertical furnace like ASM's A400. In such a furnace, a final, relatively thicker, layer of doped polysilicon was grown. This final gate electrode completed the EEPROM cell. Due to its relative thickness, it was more effective to grow the gate electrode in a batch furnace rather than in the polysilicon module of the cluster.

From the angle of ASM, the project amounted to a strategic and technologically advanced collaboration with a customer, with Siemens determining the application of ASM's technology. The program also advanced ASM's ambitions in RTP and integrated processes without burdening its scarce resources. Funding from the German chip manufacturer and the European Commission paid for the A800 wafer handler, the polysilicon module, and the silicon-nitride module. The European Commission subsidized half of the costs through an ESPRIT IV project, dubbed CICDIB. ${ }^{24}$ This accounted for half of the total 5.6 million euros. The other half - predominantly man hours for servicing and development, as well as oversight - was paid by the companies involved.

ASM committed a fairly limited number of manhours to the project. ${ }^{25}$ One process engineer, Christophe Pomarede, and one part-time service engineer, Joerg Weidmann, worked on location at the Siemens facilities in Perlach, Germany. ASM engineer Timo Bergman, who had worked on software development in the IVPS project, continued his job within the project, while taking up more coordinative tasks as well. In addition, AST committed two engineers. Gschwandtner, the inventor of the MRG, was the designated project manager on behalf of Siemens who tried to convince his own organization of the results obtained in the program, but he also steered the ASM and AST engineers into the

24 The official ESPRIT program was called 'Hot Cluster for Integrated Vapor Phase Cleaning \& Processing of Dielectric and In-Situ Doped Polysilicon' with program number 20628. European Commission, 'Hot Cluster for Integrated Vapour Phases Cleaning and Processing of Dielectrics and Insitu Doped Polysilicon (CICDIP)' cordis.europa.eu (1-6-1996).

25 ASM International, Meindert Beerlage, 'Memo: Siemens A800 project responsibility \& staffing' (20-8-1997) Archive Arthur del Prado - Meindert Beerlage file. 
direction most useful for Siemens. All in all, the size of the program was fairly small, but its impact potentially big.

The program started after the successful conclusion of IVPS in June 1996, and it would last two years. Its results were evaluated by Siemens, as well as externally by industry research institutes such as Sematech and IMEC. This external evaluation was tied to Siemens' specific commitment to the project. Siemens Semiconductors was interested in the outcomes, but refrained from committing itself to use the cluster in high-volume manufacturing of EEPROM chips. This positioning allowed ASM and AST to hawk with the results, and eventually opened doors to the American, technologically leading chip manufacturers.

\section{Single wafer cluster hangs on a thread}

The Siemens joint-development program was not recognized wholeheartedly as a strategic opportunity across ASM. The consensus about the significance of the RTP efforts prevailing at a corporate level was not shared by the engineers and managers of business units. ASM International continued to see the Siemens A800 development as strategic, while ASM Europe treated it as a mere installation job - as it was not responsible for the Epsilon technology - and ASM America regarded it as someone else's problem. ${ }^{26}$ Still, as of the spring of 1996, plans were drafted and strategies laid out at ASM International in Bilthoven. ${ }^{27}$ In this effort, Werkhoven received support from Ernst Granneman, ASM's chief technology officer, and Sieb Radelaar, an interim adviser and former professor at Delft University. If Arthur del Prado and his chief operating officer Ray Friant were not uncooperative, they pushed for a more cautious approach, as reflected by their insistence on customer-involvement. ${ }^{28}$

One route was to add a new business unit dedicated to cluster and RTP technology through the acquisition of a prospective competitor. Since the early 1990s, Del Prado and his team kept a keen eye for an opportunity to acquire a RTP manufacturer or piece of technology externally, in line with ASM's common growth and innovation strategy. To this end, an acquisition of AST was considered during the summer. ${ }^{29}$ However, another party, a manufacturer named STEAG, was one up on ASM, merging with AST into STEAG-AST in August 1996.

26 Ibid.

27 ASM International, Ray Friant, 'Minutes of Front-End Board Meeting Phoenix April 25/26 1996' (26-2-1996) Archive Arthur del Prado - ASMI Management 90's; Management Meetings '89-'04.

28 ASM International, Ray Friant, 'Minutes of the Front-End Board Meeting Feb. 18 1996' (18-2-1996) Archive Arthur del Prado - ASMI Management 90's; Management Meetings '89-'04.

29 In 1985, AST was founded by Peter Augustin and Günther Kaltenbrunner, who had been Del Prado's sales managers in Germany. The initial products of AST elaborated upon ASM's technologies. In the following years, Augustin and Kaltenbrunner played themselves into the 
While this route did not result in anything substantial, Granneman tried to amass support among the company's key engineers for a general ASM cluster platform for the forthcoming 300-millimeter tools. He invited the engineers to consider the A800 - or a modified version - as a general wafer handler applicable for ASM America's single wafer Epsilon module and ASM Japan's single wafer plasma CVD reactor Eagle-10. ${ }^{30}$ If successful, the proposal would have boosted the development program into clustered RTP and integrated processes. But the engineers could not agree upon a single platform that aligned with particular requirements of their respective products. This implied that the ball - the single wafer cluster processes - would remain in the hands of the existing ASM business units.

ASM America, the organization responsible for the Epsilon reactor and the A800 wafer handler, was not too enthusiastic about RTP technology, in particular after the failure of the Paragon polysilicon machine. The American management team had enough on its plate. ASM America was fully occupied with an escalating litigation against Applied Materials surrounding the Epsilon epitaxy reactor. Moreover, ASM America was in the midst of developing new 300-millimeter epitaxial processes. Moving into new, uncertain territory by retooling the Epsilon for clustered RTP processes depleted the scarce resources required for the epitaxy business.

In Phoenix, the indecisiveness lingered in part due to a series of management successions. Early in 1996, ASM America's general manager Art Launder had resigned after merely one year in office. Chief operation officer Ray Friant,

hands of Siemens through their pioneering RTP products. During the IVPS project and the Siemens joint-development program, AST remained wary of actions and intentions of ASM. In 1995, the entry of Applied Materials into the RTP market, put a stop to AST's prospects for growth because this new competitor commanded much bigger financial, technological, and marketing resources than the small German operation. To survive, it had to team up with other players. -Lojek, 'Early History of Rapid Thermal Processing', p. 292; Stibbe Blaisse De Jong, 'Dagvaardiging ASM NV and ASM Germany Sales versus Guenther Kaltenbrunner' (January 1986) Archive Arthur del Prado - ASM Germany files; interview Bas van Nooten; Dataquest, 'Chapter 5: RTP and Oxidation/Diffusion', Dataquest Market Statistics: 1997 Wafer Fab Equipment Market Share Estimates: Deposition and Removal,(1-6-1998, pp. 58 and 63; ASM International, Jobs W. Wagenaar, 'Annex 4: A.S.T. Elektronik GmbH' (24-5-1996) Archive Arthur del Prado - RvC '90's - RvC feb'96 - feb'98.

30 Granneman had instituted 'technology council meetings' to coordinate technological development across the various subsidiaries. The R\&D managers and the engineers involved would gather to discuss topics like the scale-up to 300 -mm wafer. Sometimes these meetings were meant to challenge the engineers to deliver innovative solutions, the best of which would be awarded a bottle of Scotch. - Ernst Granneman, 'Interview with author'. The proposition resembled the original idea for the A600 in the 1980s. - ASM International, Ernst Granneman, 'Fax: Announcement Technology Council Meeting \#18: ASM 300mm wafer handling/cluster platforms and related corporate technology' (10-12-1996) Archive Arthur del Prado - ASMI Management '90s - Technology Council Meeting. 
and shortly thereafter his successor, Daniel Queyssac, intervened as interim manager. Among all the other things at hand for Queyssac - such as rolling out 300-millimeter development plans, improving the effectiveness of all ASM front-end subsidiaries, and specific operational matters of ASM America - cluster and single wafer RTP technology did not enjoy much urgency. The technology developed within the Siemens joint-development program remained a suppositious child within ASM.

In 1997, things finally changed with the arrival of two new managers at the American operation. Through their interference, research and development department got structured, budgets were proposed and evaluated, and priorities were set. Foremost this involved the bulk of ASM America's activities: selling and innovating epitaxial machines. But it also involved the future of the cluster technology - and, subsequently, ASM's involvement in innovating the gate stack.

The first manager was Dr. Ivo Raaijmakers, who started in July $1996 .{ }^{31} \mathrm{He}$ previously worked at the Philips Research Laboratory, Philips-Signetics, Novellus, and Applied Materials. At ASM America, he started in the capacity of Director of Technical Programs, and later he became Vice-President of Advanced Technology Development. His last two former employers led the industry in integrated processing and RTP. Relying on his intimate experience, Raaijmakers urged his colleagues and the Front-End Board to mature the single wafer cluster aspirations:

'What this boils down to is that we have to develop a good plan to penetrate this market, and to break the AMAT [Applied Materials] monopoly. ... I have not yet seen such a plan ... Resources (including sales and marketing) should be acquired or re-allocated to make this a success, it should not be just a fill-in job as it is now. I would suggest to start it as a reasonably self-contained business, or at least a well-defined program with a visible product P\&L.' ${ }^{32}$

This advice was picked up by the second manager, Dr. Meindert Beerlage. In the fall of 1997, after a marketing tour visiting major customers and operations of ASM globally, Beerlage established a product group consisting of the single wafer cluster (the A800 installed at Siemens) and the RTP program (the modified Epsilon reactors). ${ }^{33}$ Through the support of Beerlage, the commercialization

$31 \quad$ Raaijmakers started in July 1996, and became vice president at ASM America by May 1997. - ASM America, Daniel Queyssac, 'Memorandum: Organization announcement' (29-5-1997) Archive Arthur del Prado-ASM America 90's, ASM America Feb. 1997-April 1998.

32 ASM America, Ivo Raaijmakers, 'Fax: Single Wafer Clusters' (7-4-1997) Archive Arthur del Prado - Ivo Raaijmakers file.

33 ASM International, Meindert Beerlage, 'Memo: multiprocess clusters, preparation for 
of ASM's processes applicable to the production of gate stacks became more substantial. He structured the proliferation of single wafer process development, and coordinated related efforts with regard to Siemens' A800 cluster. ${ }^{34}$ He did not prefer the standalone or integrated RTP processes, as he stated that 'establishing ourselves into clusters only makes sense if we have mastered individual processes first. ${ }^{35}$ He detailed forecasts for the various RTP processes, such as RTP poly and nitride, and applications, such as gate stacks and capacitor stacks (mind figure 72). With regard to the gate stack, he expected that the market would grow from 3 million dollars in 1996 to 60 million in 2001, a substantial growth. ${ }^{36}$

Finally, in the fall of 1997, Granneman saw some movement in the development of the cluster tool:

'In the past, at ASMA, the single-wafer "hot-processing" cluster systems (Siemens system, A800) have consistently been treated as an activity burdening the Epi product line, instead of treating it in its own right (and despite the clear signs from the market that such systems are becoming important). Consequently, the moment the Siemens system was shipped, people did not want to be bothered by it anymore (far away in Europe, has nothing to do with the main (Epi) product line, so why bother?) Now that we have a dedicated Product Manager (Meindert Beerlage) for this product line, the situation has improved dramatically in only two months' time!' 37

The RTP developments, and in particular the cluster project, had found a place of its own within ASM's development ambitions. The upgrade of the RTP activities into a product group pertained primarily to the equipment - the hardware and control software - rather than to its application. Despite the promising work

marketing visits' (29-10-1997) Archive Arthur del Prado - Meindert Beerlage file; and ASM America, Meindert Beerlage and Ivo Raaijmakers, 'Interoffice Memorandum: Intel/Hillsboro Visit Report - Nov. 7, 1997’ (24-11-1997) Archive Arthur del Prado - Meindert Beerlage file; ASM International, Meindert Beerlage, 'Memo: Preparation for marketing visits' (29-10-1997) Archive Arthur del Prado - Meindert Beerlage file.

34 ASM International, Meindert Beerlage, 'Memo: Siemens A800 project responsibility \& staffing' (20-8-1997) Archive Arthur del Prado - Meindert Beerlage file. He also engaged in cluster efforts at IMEC, such as the dry clean program of Hessel Sprey. ASM International, Meindert Beerlage, 'Memo to Daniel Queyssac: Dry Clean Programmes' (8-8-1997) Archive Arthur del Prado-Meindert Beerlage file.

35 ASM International, 'Business Plan RTP/Clusters' (8-12-1997) Archive Arthur del PradoMeindert Beerlage file.

36 Ibid.

37 ASM International, Ernst Granneman, 'Fax to FEB: Matrix Organisation' (13-9-1997) Archive Arthur del Prado - ASMI Management 90's; Management Meetings '89-'04. 
done in the Siemens joint-development program, the EEPROM or the gate stack was just one of various applications of ASM's standalone and clustered RTP technology.

\section{Taking stock of the joint-development program's results}

By the spring of 1998, the Siemens joint-development program drew to a close. It was time to take stock of its results. At the Siemens facilities, the A800 cluster was capable of creating EEPROM cells at a total output of approximately eight 200-mm wafers per hour. If this was hardly sufficient for high-volume manufacturing, it was in line with the specs of the development program. ${ }^{38} \mathrm{ASM}$ and STEAG-AST had proven their ability to create EEPROM stacks with an ONO dielectric. The program was a success technologically.

Through their integration in the cluster, ASM America's engineers had perfected and obtained valuable information about its Epsilon RTP machines for polysilicon and nitride. ${ }^{39}$ In particular, the modified Epsilon reactor capable of growing nitride films looked promising. ASM engineers Timo Bergman and Christophe Pomarede successfully applied the MRG module to improve the nitride film itself. ${ }^{40}$ It resulted in astonishing thin films, initially not measurable with conventional metrology equipment. ${ }^{41}$

Through continuous marketing efforts, the Epsilon nitride RTP reactor with remote plasma attracted attention in the United States. Since Siemens had not committed itself to the cluster after the program, Beerlage and Werkhoven had been peddling with the results. ${ }^{42}$ The American interest opened a pathway for commercialization of ASM's technology developed in the Siemens jointdevelopment program for MOS gate stacks.

38 ASM America, Ivo Raaijmakers, 'Memo: CICDIP Program; June 2, 1998, Perlach meeting minutes' (2-6-1998) Archive Arthur del Prado - Ivo Raaijmakers.

39 ASM America, Ivo Raaijmakers, 'Fax to patent lawyer Russ Fairbanks: Gate stack patent possibility’ (21-1-1998) Archive Arthur del Prado - Ivo Raaijmakers file.

40 Timo Bergman, 'Interview with author'; Chris Werkhoven, 'Interview with author'; Ivo Raaijmakers, 'Interview with author'.

41 Only with more advanced metrology equipment, available at IMEC and Sematech, did ASM grasp the capabilities of the remote plasma reactor. - Chris Werkhoven, 'Interview with author'.

42 ASM International, Meindert Beerlage, 'Memo: Preparation for marketing visits' (29-101997) Archive Arthur del Prado - Meindert Beerlage files; ASM International, Meindert Beerlage, 'Memo: Preparation for marketing visits; part 2' (14-11-1997) Archive Arthur del Prado Meindert Beerlage file; ASM America, Meindert Beerlage and Ivo Raaijmakers, 'Interoffice Memorandum: Intel/Hillsboro Visit Report - Nov. 7, 1997’ (24-11-1997) Archive Arthur del Prado-Meindert Beerlage file. 


\section{Contemplating pursuit of the gate stack, clustered, or standalone processes}

In the summer of 1998, two routes for the future of the technologies developed during the Siemens joint-development program emerged and were explored. For each one of the routes, the MOS gate stack formed a very probable application. One route was elaborating upon the integrated production process developed together with STEAG-AST in the Siemens joint-development program. The other option involved pursuing the vague interest in a standalone Epsilon silicon nitride reactor. In the new capacity of Strategic Marketing Manager and as protagonist of both technologies, Chris Werkhoven explored the interest at various customers.

The formal completion of the joint-development program implied an end to the collaboration between ASM and STEAG-AST. This was most unfortunate, however, as the two equipment vendors had just established the potential of a promising technology. During Semicon West 1998 in May, Werkhoven and managers of STEAG-AST discussed the future of the program. ${ }^{43}$ Could both parties commercialize their technology? Throughout the summer, Queyssac, Raaijmakers, Werkhoven, and A800 engineer Timo Bergman continued discussions with STEAG-AST about probable technological and commercial options. ${ }^{44}$

The deliberations dragged on, chiefly regarding the structure of further cooperation and the envisaged technological roadmap. The commercialization of a cluster process by two distinct equipment manufacturers would be messy. Also, the commercial prospects of the cluster for the production of ONO dielectrics or EEPROM chips were limited. Both firms had a suboptimal penetration with single wafer processes at memory manufacturers in Europe and the United States. Moreover, the industry's roadmap expected the insertion of new high-k dielectrics to be around the corner for both MOS gate stacks and EEPROMs. Exotic materials for the semiconductor industry, like tantalum pentoxide $\left(\mathrm{Ta}_{2} \mathrm{O}_{5}\right)$ or titanium oxide $\left(\mathrm{TiO}_{2}\right)$, were considered as dielectric materials in the gate stack. Both parties had to align their technology roadmaps without revealing too much of their capabilities and plans. ${ }^{45}$

But time was running out. Chief operating officer Daniel Queyssac posed a clear deadline for the A800 cluster variation:

$43 \quad$ ASMI, Chris Werkhoven, 'E-mail to Queyssac and others: AST Information (16-7-1998) Archive Arthur del Prado - Chris Werkhoven file.

${ }^{44}$ ASMI, Chris Werkhoven, 'Steag AST meeting report' (26-8-1998) Archive Arthur del PradoSteag file.

45 AST proposed to develop high-k materials and processes using conventional Metal Organic Chemical Vapor Deposition (MOCVD). At ASM, Werkhoven dismissed this suggestion, since it involved 'multi-valent oxides' and bore the risk of carbon contamination from the MOCVD compounds. - Chris Werkhoven, 'Interview with author'. 
'The A800 program will be funded until the end of this year. From now to year end outside funding has to be found from customer or partner at the level of $\$ 3.0 \mathrm{M} . .$. If no funding is secured before the year's end, the plug will be pulled. ${ }^{46}$

With this deadline of the inconclusive STEAG-AST discussions in mind, Werkhoven kept in touch with Intel. Among other pressing topics regarding ASM's Epsilon, Eagle-10, and A400, he tried to generate interest in the A800 cluster. In successive meetings throughout October 1998, Werkhoven went into more detail with the Intel engineers about Epsilon grown dielectrics, but he remained wary about the chip manufacturer's precise intentions. ${ }^{47}$ Intel was enthusiastic about the nitride Epsilon module, so much was clear.

Through similar positive responses from other customers, Werkhoven became convinced that the Epsilon nitride reactor might soon be applicable for the creation of gate stacks in high-volume manufacturing. In November and December, he visited Motorola and IBM, European customers like Philips Research and Siemens Semiconductors (to be renamed Infineon Technology $y^{48}$ ), as well as the research centers IMEC, CNET, and LETI. ${ }^{49}$ The Epsilon nitride reactor with remote plasma, developed during the Siemens joint-development program, seemed to be a real asset for ASM and was most viable for commercialization in the short term.

\section{The A800 runs out of steam}

From the fall of 1998 until early 1999, Werkhoven tried to amass support within ASM to pursue the gate stack application. He propagated to Del Prado that the A800 cluster and the Epsilon standalone RTP module both enjoyed good prospects at customers, but that some decision had to be made. ${ }^{50}$ As he stated:

46 ASMI, Daniel Queyssac, 'Fax: Meindert proposal Ver. 2 d.d. October 12' (14-10-1998) Archive Arthur del Prado - Merio file.

47 ASM America, Chris Werkhoven, 'Intel Epislon RTP Visit Report' (3-11-1998) Archive Arthur del Prado - Chris Werkhoven file.

48 Siemens Semiconductors became a separate organization of Siemens as of April 1, 1999, under the name of Infineon Technology. Afterward an IPO was prepared by 2000. - P. Tischer, 'Letter to Arthur del Prado' (17-3-1999) Archive Arthur del Prado - Siemens file.

49 With Siemens, Werkhoven discussed a continuation of cooperation into high-k gate dielectrics. At Philips Research, Werkhoven discussed the Epsilon nitride reactor with one of the inventors of the machine, Wiebe de Boer (see Innovation Chapter II). - ASM America, Chris Werkhoven, 'RTP Visit Report European Customers' (14-12-1998) Archive Arthur del Prado - Chris Werkhoven file; ASMI, Chris Werkhoven, 'E-mail to ASMA board: Motorola Epsilon RTP Visit Report (3-11-1998) Archive Arthur del Prado - Chris Werkhoven file.

50 ASM International, Chris Werkhoven, 'Nitride Gate Stack Business' (21-2-1999) Archive Arthur del Prado - Chris Werkhoven file. 
'[W]e are early in the program and have a chance to be designed into the $100 \mathrm{~nm}$ generation from the beginning rather than replace an existing choice ... To not lose it now already, a clear commitment with timelines and resource allocation towards a dielectric program in Phoenix has to be shown within a few weeks. It is not clear whether this can be done on the basis of the current approval status within ASMI.' ${ }^{51}$

It was now or never with regard to ASM's strategy aimed at collaboration with a customer in technological development.

The RTP technologies developed at ASM America very much remained niche products, however. Early in 1999, the American operation was in the midst of a drastic reorganization. Under the label of Operation Merio, Beerlage initiated a transfer of manufacturing from Phoenix to the Netherlands (cf. Chapter 25). Next to the organizational turmoil, the semiconductor industry delayed the introduction of 300-millimeter wafer equipment while adding 200-mm product lines. ${ }^{52}$ In response, equipment manufacturers, one after another, halted their efforts in 300-millimeter technology. This sudden decision - fortuna - negated the justification for technological investments. ASM America's technical director, Ivo Raaijmakers, had to cut his staff in half and, consequently, make choices about the scope of its development activities. ${ }^{53}$

In March 1999, Raaijmakers observed the following about continuation of the A800 cluster program for gate stacks:

'We will focus on stand-alone. .... We will not pursue the cluster as a business now, per FEB [Front-End Board] decision. Productizing, manufacturing, and supporting a cluster cannot be sustained within the current priorities and resource constraints. ... Citing Meindert, we could treat the cluster as an "opportunity business". ${ }^{54}$

Since the Epsilon nitride reactor elaborated upon the existing infrastructure and organization of ASM, and because it enjoyed the particular interest of leading American chip manufacturers, it was less costly and more promising to pursue

51 ASM International, Chris Werkhoven, 'Fax: Intel Epsilon RTP Visit Report' (3-11-1998) Archive Arthur del Prado - Chris Werkhoven file.

52 SIA, The International Technology Roadmap for Semiconductors 1999 (1999) p.7; ASM International, Ernst Granneman, 'Visit report: International Sematech Global Suppliers Meeting, San Francisco - May 14, 1999' (14-5-1999) Archive Arthur del Prado - Ernst Granneman file.

53 Ivo Raaijmakers, 'Interview with author'.

54 ASM America, Ivo Raaijmakers, 'Fax to Daniel Queyssac: A800/TSMC' (23-3-1999) Archive Arthur del Prado - Ivo Raaijmakers file. 
Chapter 26 - Pursuing integrated and rapid thermal processes, 1995-1999

the standalone variation. Although the A800 had put ASM America onto the path of new gate stack fabrication technologies, the curtain seemed to fall for the company's integrated process ambition. 


\section{Chapter 27}

\section{Enacting atomic layer deposition, 1999-2001}

This chapter, covering the years 1999 until 2001, will situate the development of the new gate stack in a complex and rather mature infrastructure of governmentally and industrial collaborative efforts. ASM capitalized on this infrastructure as it tried to enact a newly acquired deposition technique and its lately conceived contribution for gate stack technology. Moreover, a new technology - named atomic layer deposition - and its applicability for high-k gate dielectrics enjoyed the particular interest of leading chip manufacturers across the world. From 1999 onward, the innovation of atomic layer deposition furthered the preceding ambitions into RTP and integrated processes.

This all happened against the backdrop of an unprecedented peak in demand for semiconductor equipment, fostered by the Dotcom Boom (cf. Business V). Worldwide semiconductor sales grew from 149 billion dollars in 1999 to 222 billion in 2000.5 This growth rate was even surpassed by the semiconductor equipment industry, whose worldwide sales increased from 22 billion dollars to 48.4 billion dollars in the same period. ${ }^{56}$

Within this industry boom, Intel stood out from the rest by having the highest capital expenditures - that is, investments in facilities, equipment, and materials. In 2000, Intel outpaced its competition through its capital expenditures of 6.7 billion dollars, compared to TSMC's 3.1 billion dollars, Motorola's 2.4 billion, IBM's 1.7 billion, NEC's 1.7 billion, and Philips' 1.6 billion dollars. ${ }^{57}$ Intel's ambitious investment program foremost involved new 300-millimeter production

55 Author unknown, 'Chip sales slowing', money.cnn.com (2-1-2001). But other sales numbers have been mentioned for 2000 (\$204 billion) as well. See, for instance, McKinsey: Marc de Jong, Hubert Heersche, Freek Kelkensberg, and Hiroaki Ohta, 'Capital Equipment: Will further shrink bring growth?’, McKinsey on Semiconductors 5 (Winter 2015) p. 80.

56 J. Robert Lineback, 'SEMI: Chip Equipment Sales Are Stronger Than Expected', eetimes.com (21-4-1999); Solid State Technology, author unknown, 'Semiconductor equipment sales total in 2000 higher than previous 2 years combined' electroiq.com (1-3-2001).

57 Only semiconductor related capital expenditures included. - Intel, Annual Report 2000: Silicon is in (Santa Clara, 2001), p. 2; Motorola, Annual Report 2000: Something Big is Happening (2001), p. 29; TSMC, 'Security and Exchange Commission Form 20-F' (21-6-2001), p.5; Philips, Annual Report 2000 (2001), p. 62; IBM, Annual Report 2000 (2001), p. 92; NEC, Annual Report 2000: The Right Strengths for the Internet Era (2001), p. 52. 
lines, expected to be operational by 2001. It was leading the industry regarding the new wafer standard.

After years of cultivating its relationship with Intel, ASM profited from this spending urge. ${ }^{58}$ This pertained in particular to the new 300-millimeter Intel factories. For these new fabs, ASM collaborated with new advanced 300-millimeter versions of its three major products: the A412 vertical furnace, the Eagle-12 single wafer plasma CVD reactor for low-k dielectrics, and the Epsilon3000 for epitaxial processes (cf. chapters 30 and 31). Apart from being lucrative and prestigious, the supply of multiple products had a great impact upon the organization of the equipment manufacturer.

The innovation of the gate stack was a mere aside during these expansive years: prestigious, promising, yet hardly relevant for the booming market at the time. Moreover, amidst the efforts to innovate gate stack technology, the development of the high-k dielectric process by means of the newly acquired atomic layer deposition overshadowed the RTP ambition. The other aim of advancing ASM's capabilities as process integrator remained central to the company's strategy.

\section{Enter Microchemistry and atomic layer deposition}

On January 22, 1999, a single visit radically overturned ASM's future. On that date, Ernst Granneman received two visitors from Finland: Kari Lampinen and Matti Ervasti. The former was a manager for mergers and acquisitions at a Finnish energy company called Fortum. The latter was a manager of a small subsidiary called Microchemistry, located in Espoo, Finland. Both men visited Bilthoven in order to find out whether ASM was interested in acquiring Microchemistry and its technology.

Their pitch entailed something like this: the founder of the company had developed a process called 'atomic layer deposition' (ALD). ${ }^{59}$ This entailed the controlled deposition of films in layers of single atoms. The process enabled the formation of the thinnest films with unprecedented conformity and step coverage, while offering low contamination of unwanted impurities. Through the prevalence of Moore's Law, technologies enabling the construction of materials at the smallest dimensions - atoms in this case - enjoyed the particular interest of the chip industry. It was just a matter of time before ALD would become indispensable for further miniaturization

58 John Krickl, 'Interview with author' and Chris Werkhoven, 'Interview with author'.

59 The technology has been referred to as 'atomic layer epitaxy' or, initially at ASM, 'atomic layer chemical vapor deposition.' Suntola dubbed the process 'atomic layer epitaxy' ('epitaxy' meaning 'ordered manner' in ancient Greek). However, Suntola was unaware of the use of this definition for a process in semiconductor manufacturing. Initialy ASM used ALCVD as a brand name. The industry at large would come to use the term 'atomic layer deposition,' as will I do here. 
At first sight, atomic layer deposition has some resemblance with chemical vapor deposition (CVD). In the classical CVD process, two or more reactants form a film of the desired material by introducing them in the reactor at the same time. In the case of an ALD process, the desired reactant gasses are inserted sequentially into a reaction chamber (figure 75). The basis of the ALD process encompassed the principle of self-saturation of the available bonds of the exposed surface with a reactive material.

\section{Figure 75}

Simplified overview of a single atomic layer deposition (ALD) cycle.

A single cycle results in the formation of one molecular layer of of the desired material. As the cycle is repeated the layer increases in thickness. In this case, the process of growing hafnium oxide $\left(\mathrm{HfO}_{2}\right)$ is taken as example, which was the chemical reaction eventually used to grow high-k gate dielectrics on an industrial scale.

Reaction 1: $\mathrm{HfCl}_{4}(\mathrm{~g})+\mathrm{OH}(\mathrm{s}) \mathrm{O}-\mathrm{HfCl}(\mathrm{s})+\mathrm{HCl}(\mathrm{g})$

Reaction 2: $\mathrm{HfCl}(\mathrm{s})+\mathrm{H}_{2} \mathrm{O}(\mathrm{g}) \mathrm{O}-\mathrm{Hf}-\mathrm{OH}(\mathrm{s})+\mathrm{HCl}(\mathrm{g})$

Introduction of first precursor and reaction with activated substrate to form 1st film of molecules
After surface is saturated, remnant precursor molecules and byproducts are removed

by means of a purge gas

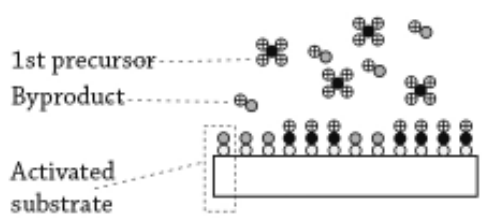

Non-reactant purge gas

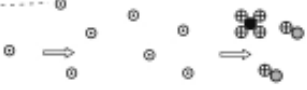

1 st film of molecules

\section{8}

Introduction of second precursor, reaction with surface, and activatino of first film of molecules
After surface is saturated, remnant 2 nd precursor molecules and byproducts are removed by means of a purge gas

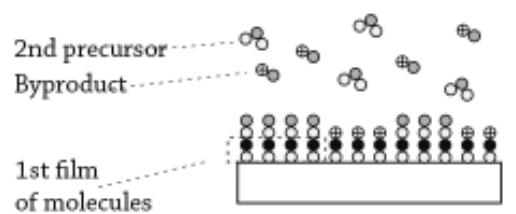

of molecules
Non-reactant purge gas

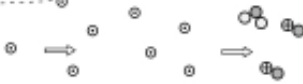

1st film of molecules

- Hafnium

- Oxide

- Hydroger

$\oplus$ Chloride

- Nitrogen
Repeat the above depicted cycle until the desired thickness is achieved

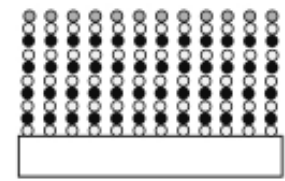


The principle of self-saturation is important and enables the sequential deposition of layers of the same or different composition. The reaction with the exposed surface would automatically stop after all the available sites of the surface have been 'occupied,' causing the substrate surface to be 'saturated.' Adding more reactants would not result in more reactant on the surface. After saturation, a purge of inert gas like nitrogen or hydrogen removes possible reaction products and all the surplus reactant molecules in the chamber. Next, the second reactant is inserted, which reacts with the first reactant until - again - all available sites of the substrate have reacted. Once more, the remaining reaction products and the redundant reactant molecules are purged out of the reactor. This complete process, called a 'cycle,' delivers part of one layer of molecules on the surface. This cycle can be repeated until the desired layer thickness is obtained.

Apart from the ALD process, the small Finnish company triggered the interest of Granneman with its treasure trove of processes. Over the course of many years, it had developed several pieces of equipment and various ALD chemistries. Through its tools, process knowledge, and interactions with some chip manufacturers, Microchemistry singled out various applications in semiconductor production. But the most prospective was the gate stack. Microchemistry knew how to use ALD for the deposition of new exotic materials for the gate stack, for instance for the creation of high-k dielectrics and metal electrodes. It was this application that stirred the interest of a few technologically leading chip manufacturers.

Microchemistry's work on gate stack materials also perfectly aligned with ASM's work done in the Siemens joint-development program (figure 76). Processand material-wise, Microchemistry's techniques formed the missing piece. Moreover, some of its tools were designed according to the MESC standards. In other words, they fitted to the A800 cluster tool developed in IVPS and the Siemens joint-development program. All things fell in place.

One week later, after consulting Del Prado, Werkhoven, and Raaijmakers, Granneman e-mailed Lampinen to confirm ASM's interest in a joint future with Microchemistry. ${ }^{60} \mathrm{He}$ argued that the technology clearly matched ASM's technology roadmap, and that the company would fit in the ASM organization. The organizational structure of ASM as designed by Del Prado allowed the Finnish start-up to grow into an established original equipment manufacturer rather independently. Once again, ASM would serve as a de-facto incubator.

60 ASM International, Ernst Granneman, 'E-mail/Fax to Kari Lampinen: Interest in Microchemistry' (2-2-1999) Archive Arthur del Prado - Ernst Granneman file. 


\section{Figure 76}

Simplified schematic overview of technology contributions of process, software, and hardware innovations within ASM International, 1993-2001

The prominence of boxes is not indicative for their relative significance of the final result of technological development, ASM's high-k process. The development had its roots in the central wafer handler of ASM's Micro-Electronic Technology Center (AMTC) and ASM America's Epsilon process modules, both shown on the left side, and resulted in the Polygon cluster, eventually manufactured by ASM America, shown on the right side, involving various innovations,

collaborations and acquisitions.

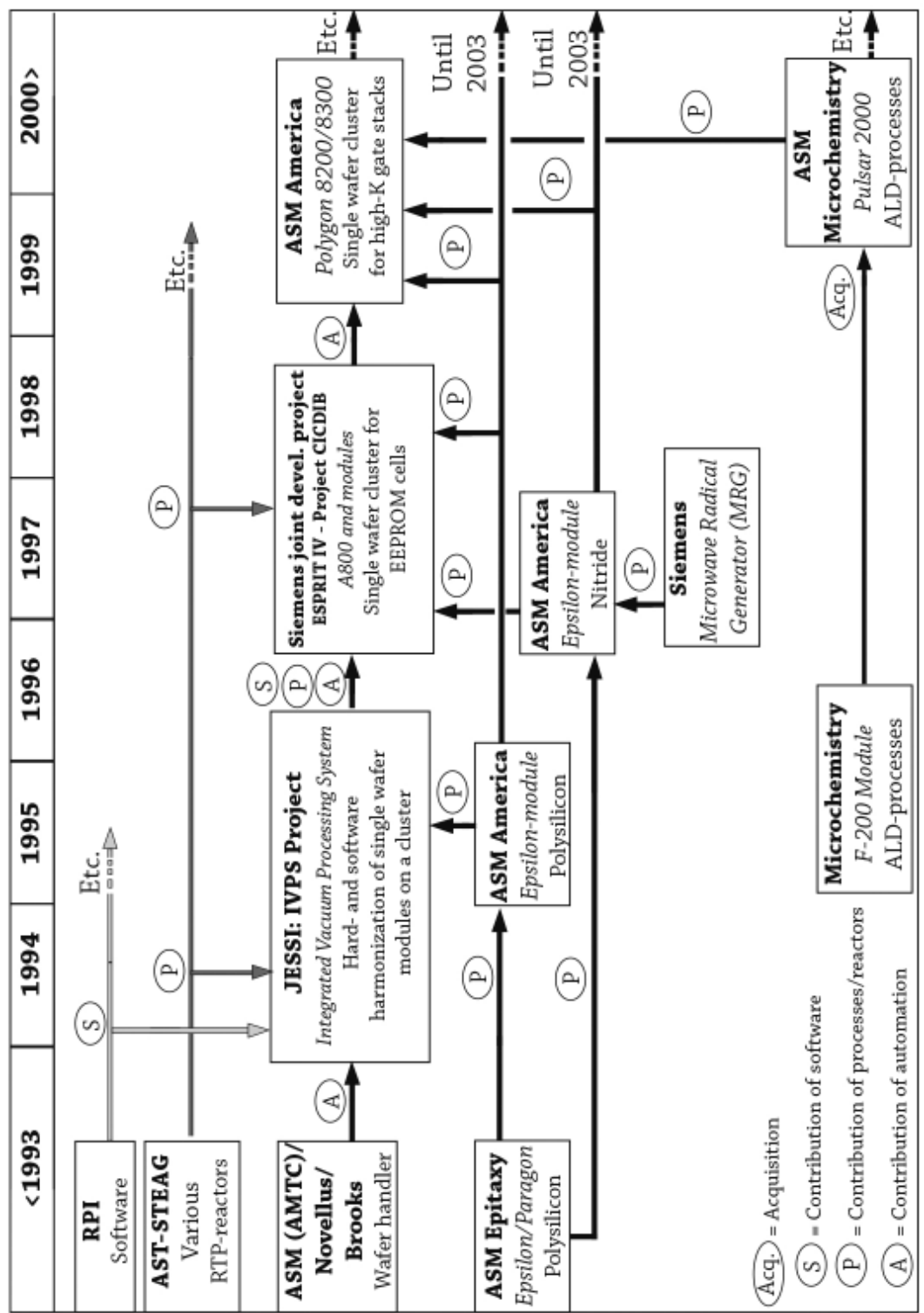


After the initial meeting in January, things moved fast, in particular within ASM. Werkhoven and Granneman visited Microchemistry to learn about the technology. Del Prado, Granneman, and ASM's chief financial officer Rinse de Jong worked out the financial details with Ervasti and Lampinen. By July, Del Prado and De Jong succeeded in finding 'an acceptable creative financial solution' and finalized the acquisition (cf. Chapter 30). ${ }^{61}$ The firm was now called ASM Microchemistry.

By 1999, Microchemistry employed 42 staff, of which 14 in development, 12 in engineering, and 8 in manufacturing. Microchemistry had four types of machines, including the F120 and the F200 for semiconductor production. The F120 was a mere R\&D reactor, only capable of processing very small substrates, and primarily meant for process development. The F200 was designed for semiconductor manufacturing. Technology development agreements were in place or were negotiated with some American chip manufacturers and research institutes like IMEC were considered.

Soon after the acquisition was finalized, positive signals were received. Major chip manufacturers congratulated ASM, after strategic marketing manager Chris Werkhoven contacted prominent customers surrounding ASM's due diligence of Microchemistry. They had anxiously awaited the outcome of the acquisition process, and now Werkhoven could report:

'A few hours after [they] called. Also about MC [Microchemistry], congratulating ASM with what [they] ... called a very good buy, quickly concluded and successful in competition with 12 (!) other contenders [sic]. So, a job well done. ${ }^{62}$

Chip manufacturers had set their hopes on ALD as a new production method for gate stacks. As some Intel engineers involved in the process development of the gate stack later recalled:

'for the first two years, all the dielectrics we tried worked poorly. ... You want a transistor to operate exactly the same way every time it switches, but these gate-stack structures behaved differently each time they were charged up. The results were very discouraging. ... To make the dielectric layer, we were using one or two different semiconductor-manufacturing techniques: reactive sputtering and metal organic chemical vapor

61 ASM International, Supervisory Board, 'Minutes Supervisory Board meeting April 19, 1999' (16-6-1999) Archive Arthur del Prado - RvC feb 1996-feb 1998.

62 ASM International, Chris Werkhoven, 'Fax: Intel ALCVD/MC Interactions.' (2-7-1999) Archive Arthur del Prado - Chris Werkhoven file. 
deposition. Unfortunately, both processes produce surfaces that, though remarkably smooth by most standards, were nevertheless uneven enough to leave some gaps and pockets in which charges could get stuck. We needed something even smoother - as smooth as a single layer of atoms, actually.' 63

Depositing such thin films in a controlled manner was not possible with any other method. Process-wise, ALD had the best papers, even though this had to be reproducible in high-volume manufacturing, naturally.

The acquisition of the rather unknown company and its novel technology set ASM on a trail packed with uncertainties, but with high expectations as well (cf. the international roadmap and its emphasis on new gate stack technology). The positive comments from customers, some of which were the most advanced semiconductor manufacturers at the time, stimulated confidence in the path chosen. As communicated to the worrisome Supervisory Board of ASM:

'The announcement of the intended acquisition has created a lot of positive momentum for ASM from customers like Intel, IBM, Philips, and STMicroelectronics. The combination of Microchemistry's technology with ASM's global infrastructure solves the main issue from these customers that Microchemistry on its own was too small to support the technology and create a production ready solution.

... The introduction of ASM in the process did, however, place the decision making on a different level .... For ASM this is a very positive signal indeed. ${ }^{64}$

Microchemistry was a gift from heaven: unexpected, but most welcome.

\section{A flashback: Microchemistry's long run-up in ALD}

In contrast to ASM's out-of-the-blue acquaintance with atomic layer deposition, Microchemistry had worked on the technology and its applicability for the deposition of dielectric materials for quite a number of years. ${ }^{65}$ Moreover, major

${ }_{63}$ Intel, Mark T. Bohr, Robert S. Chau, Tahir Ghani, and Kaizad Mistry, 'The High-k Solution', Spectum.ieee.org (1-10-2007).

64 ASM International, Supervisory Board, 'Acquisition proposal Microchemistry Ltd' (23-71999) Archive Arthur del Prado - RvC feb 1996-feb 1998.

65 In 1989, however, the technology of ALD had been discussed at ASM's technology center (AMTC) as well. At the time, it was still known as atomic layer epitaxy. In this case, AMTC engineer Boudewijn Sluijk looked into the possibility of indium tin oxide deposition through LPCVD as an alternative to the more common processes of reactive sputtering. In 
chip manufacturers had been imperative in the merger of Microchemistry with ASM. The roots of the company can be traced back to the inventor of ALD, while Microchemistry and ASM's respective interactions with Intel brought both parties together in the end.

The Finnish company was founded in 1987 by the original ALD inventor, Dr. Tuomo Suntola, as a subsidiary of the Finnish national oil company called Neste Oy. ${ }^{66}$ But Suntola had been developing and exploring multiple possibilities of the process already since May $1974 .{ }^{67}$ Originally, he developed the technology for the production of thin film electroluminescent displays (flat panel displays). In 1974, he concluded that the growth of crystalline thin films was required for this application. ${ }^{68}$ At the time, the idea was, as Suntola recalled: "how about

his studies, he stumbled upon the process of 'atomic layer epitaxy,' and he indicated that a Finnish company Lohja - the predecessor of Microchemistry - was capable of growing the films, but that he lacked any further information. Moreover, he concluded that ALD was not competitive, because it took too long to grow a thin film of the desired thickness through ALD. - AMTC, Boudewijn Sluijk, 'Memorandum: ITO Deposition, ref: R\&D8222/bs' (11-2-1988) Archive Arthur del Prado - AMTC files, 1988-1989; Standard Telecommunication Laboratories, C.H.L. Goodman, 'Atomic Layer Epitaxy - An Introduction' (February 1985) Archive Arthur del Prado - AMTC files, 1988-1989.

66 Like many inventions in history, the origins of atomic layer deposition are not singular. The process emerged in two separate locations: Leningrad (Saint Petersburg) and Helsinki. The Russian Valentin Borisovich Aleskovskii and his colleague Stanislav Ivanovich Koltsov published their first article on what was to be known as 'molecular layering' in 1965. In the subsequent decade, both men continued to work on the process of molecular layering in Leningrad. In Helsinki (or, more precisely nearby Espoo) Suntola and his group of engineers developed a process, dubbed 'atomic layer epitaxy' initially. It is the Finnish story that got entangled with the history of the semiconductor industry - and ASM's in particular - a few decades later. In 1990, at a conference in Saint Petersburg, Suntola learned about Aleskovskii's work. - Marcel Junige, Tanja Kallio, Timo Sjavaara, Jonas Sundqvist, and others, 'On the Early History of ALD: Molecular Layering' Conference Paper 14th International Conference on Atomic Layer Deposition (Kyoto, June 15-18, 2014).

67 Fortunately, the history of this company and its atomic layer deposition process attracts keen interest from engineers or scientists involved with the process worldwide. Through the Virtual Project on the History of ALD (VPHA), Professor Riikka Puurunen has guided international efforts that reconstructed - and continue to reconstruct - the origins and early developments of the technology This resulted in multiple overview articles on the history of ALD. The website of the VPHA is: vph-ald.com. Some parts of the following reconstruction derive from these, while also relying on my own interviews. - Esko Hvenniuemi, Riikka Puurunen, and many others, 'Review Article: Recommended reading list of early publications on atomic layer deposition - Outcome of the "Virtual Project on the History of ALD" Journal of Vacuum Science Technology Association 35 (jan/feb 2017) 1-13.

68 In electroluminescent displays, a stack of thin films totals about 1 micron. When charged by 200 Volt, this created an extremely high electrical field. To control the electrical properties, the materials had to be defined and arranged precisely. During an interview, the following metaphor was communicated to the author (by either Suvi Haukka or Professor Leskela): looking at a paper bin, it is noticeable that simply throwing balls of paper in it, does not 
a sequential build-up of the compound?' Because he understood how to 'make a compound in a controlled way,' he knew he had to do it 'stepwise. ${ }^{69}$ After contemplating the premises of the atomic layer deposition process, Suntola and his team designed a tool to materialize his idea during the summer of 1974 , including the design and production of a tool plus the filing of a first patent. ${ }^{70}$

In the following years, Suntola worked on new chemical compounds and precursors, as well as the design of new equipment for the application of ALD in electroluminescent displays. ${ }^{71}$ In close cooperation with the University of Helsinki, research concentrated on developing new ALD chemistries in particular for dielectric materials - meant to create displays in different colors. ${ }^{72}$ From 1987, elaborating on the ALD chemistries for dielectric materials, Suntola and his team at Microchemistry pursued applications beyond the electroluminescent displays. Initially they did so for energy-related technologies (photovoltaics and catalysts), but soon thereafter also for other ones, such as magnetic heads and semiconductor production technology. ${ }^{73}$

As of 1994, Suntola and his small research firm specifically addressed the semiconductor market. Relying upon years of material research and the deep

fill it effectively. Gaps remain and the balls of paper occupy too much space in the bin. To use the bin more effectively, the papers should be piled upon each other unfolded. More paper can be dumped with a higher density as a result. This anecdote is sometimes put forward as the historical event through which Suntola came up with the sequential process. - Tuomo Suntola, 'Interview with author'; Riikka Puurunen, 'A Short History of Atomic Layer Deposition: Tuomo Suntola’s Atomic Layer Epitaxy' Chemical Vapor Deposition 20 (2014) pp. 332-344.

69 Tuomo Suntola, 'Interview with author'.

70 The patent was filed in Finland, the United States, Japan, and the Soviet Union. This patent focused on the self-saturation effect, the use of elemental reactants, and the option of using compound reactants. - Tuomo Suntola and Jorma Antson, 'US 4,058,430: Method for Producing Compound Thin Films' (filed: 25-11-1975; published: 15-11-1977), [foreign application priority data: 29 November 1974, 743473].

71 Puurunen, 'A Short History of Atomic Layer Deposition', p. 335.

72 Markku Leskelä, 'Interview with author'.

$73 \quad$ This involved catalysts and photovoltaic applications. Lohja also got a stake of 20 percent in the new operation, Microchemistry, as it licensed the patents for PV and catalysts to Microchemistry. Having led all the research efforts in ALD for almost fifteen years, Suntola was fully aware of the potential and characteristics of his process. Microchemistry formed the perfect vehicle to pursue these new applications. In 1990, after Lohja was acquired by an American company called Planar, the license for ALE to Microchemistry was extended to cover all ALE technology not covered by Lohja's EL patents. This enabled Microchemistry to pursue new applications of ALD, like for example for the semiconductor industry. -Puurunen, 'A Short History of Atomic Layer Deposition', p. 339. In 1982, Suntola already discussed the use of ALE in semiconductor manufacturing with an American device producer. However, at that time the process did not offer significant benefits to the existing technologies to grow dielectric and passivation films. 
pockets of its parent company, Microchemistry developed a treasure trove of ALD process knowledge. Naturally, the Finnish engineers attracted the interest of the most advanced and ambitious semiconductor manufacturers: Samsung, IBM, and Intel. ${ }^{74}$ Throughout the nineties, it became clear that the ALD process was highly suitable for the deposition of dielectrics in semiconductor manufacturing.

If there was no question about the applicability of the ALD processes in semiconductor production, it was most uncertain whether Microchemistry could commercialize it. So far, their ALD processes were just research tools capable of depositing thin films consisting of various exotic materials, not even close to being qualified for industrial production. The materials and the ALD equipment had yet to be assimilated in semiconductor manufacturing. Moreover, Microchemistry had no experience in commercializing semiconductor equipment. Building and developing equipment within the very strict and challenging parameters of the semiconductor industry required absolute control of manufacturing and automation, but also of physical and chemical processes. Furthermore, one needed to have deep pockets to maintain investments throughout commercialization. ${ }^{75}$ It was an entirely different ballgame.

From the fall of 1997, Suntola prepared Microchemistry for a new role. To this end he hired a new business manager by the name of Matti Ervasti, while he himself moved to the parent company Neste in the capacity of Research Fellow. ${ }^{76}$ Initially, Ervasti could rely upon the financial reserves of Neste. This small company's working capital and balance were rebalanced every year.

However, the commercialization of ALD by the Finnish company got jeopardized by events at its parent company in 1998. That year, Neste and energy company Imatran Voima decided to merge their activities into a new energy company named Fortum. As of January 1999, this merger was to be effective. As a consequence, however, the new company had to divest its non-energy related

74 The first joint-development program was started with Samsung, shortly after the Boston presentation in 1994, for the production of dielectric films in DRAM capacitors. However, Finland was too far away, and Microchemistry was too small to support the big Korean chip manufacturer effectively. The Samsung-Microchemistry cooperation was problematic. - Suntola, 'Interview with author'; ASMI, Ernst Granneman, 'Visit Report: International Sematech Global Supplier Meeting, San Francisco; May 14, 1999’ (14-5-1999) Archive Arthur del Prado - Ernst Granneman file.

75 Suntola recalled that one semiconductor manufacturer expressed interest, but also stated that they refused to do business with companies with an annual turnover below 100 million dollars. - Tuomo Suntola, 'Interview with author'.

76 At Neste Suntola focused on catalysts. So far, the small subsidiary had been working primarily on the development of ALD. The catalyst activities were accommodated at Neste, in order to give Microchemistry more focus. Since Suntola was more a scientist than an entrepreneur, it was up to the new manager Ervasti to commercialize the accumulated knowledge in ALD technology. 
activities, including Microchemistry. For a final time and to increase the appeal of the small operation, Neste invested 10 million dollars in a 3,200 square meter cleanroom and in demo equipment.77 Now, a new owner for Microchemistry had to be found.

At this stage, Intel took a coordinative role from the sidelines.78 It was imperative to secure Microchemistry's unique knowledge of ALD processes and materials for the future. Moreover, the chip manufacturer had been anxious whether the Finnish firm was capable of complying with the industry's - and Intel's particular - stringent demands for quality, safety, and performance in a timely manner. After all, the progression of Moore's Law never halted.

Together with Matti Ervasti, Intel explored viable options to safeguard Microchemistry. First, Intel tried to interest a venture capitalist called Vision Capital, located in Silicon Valley, to take over the small company.79 The other option Intel and Microchemistry contemplated was the acquisition by an established original equipment manufacturer - particular one who was known by Intel. Candidates were all the usual suspects: Novellus, Applied Materials, Veeco, ASM, etc. It was in the interest of Ervasti to keep the Microchemistry operation viable, while Intel pushed for parties whose technological roadmaps aligned with its own.

\section{Enactment of ALD and new gate stack materials}

After the formalization of the acquisition of Microchemistry, it was up to ASM International's management to capitalize on the momentum. A new approach had to be developed to enact the newly obtained ALD technology. The matter was quite urgent indeed. ASM had been propelled to the lead in ALD and gate stack technology. Moreover, the major chip manufacturers were impatient. Moore's Law defined the pace of their technological development and the gate stack constituted a rapid approaching obstacle on their route.

Also for ASM's Front-End Board, the tiresome deliberations and anxiety surrounding customer interest for the single wafer cluster technology evaporated. Chris Werkhoven recognized the significance:

77 ASM International, Ernst Granneman, 'Visit Report: Microchemistry, Finland, March17, 1999’ (18-3-1999) Archive Arthur del Prado - Ernst Granneman file.

78 Matti Ervasti, 'Interview with author'; Tuomo Suntola, 'Interview with author'.

79 Ervasti discussed potential buyers with his contact Sidharta Das at Intel. Matti Ervasti, 'Interview with author'. 
'This may be the first sign of a wave of interest for our gate stack technology. In retrospect, it was right to work on nitride materials as they will play a role to keep the more exotic materials under control.' 80

And Del Prado observed:

'I do agree that we are making progress with high level customer relationships. I guess I am too impatient and have been frustrated about the lack of it for too long. ${ }^{.81}$

ASM International's technology management, consisting of Ernst Granneman, Ivo Raaijmakers, and Chris Werkhoven, designed a comprehensive strategy to enact the ALD technology and speed up development of the gate stack. This was done by developing plans for integration of ASM Microchemistry's organization and technology within ASM, setting up a governmentally supported research effort, collaborating with research institutes, establishing joint-development programs with customers, and safeguarding intellectual property. From the summer until the fall of 1999, things evolved incredibly fast.

Ivo Raaijmakers, who was just appointed as chief technology officer, laid down the most probable routes of development into ALD..$^{82}$ Pivotal was the A800 cluster tool as developed during the IVPS project and the joint-development program with Siemens and AST. The compatibility of the A800 and ASM Microchemistry's reactor with the industry's standard - MESC - eased the introduction of the Finnish ALD tools in the semiconductor industry. During the spring of 1999, work on the A800 was revitalized by Werkhoven and Bergman. Among other things, this involved renaming the A800 into Polygon 8200, and ASM Microchemistry's F200 as Pulsar $2000 .{ }^{83}$ Raaijmakers noted:

'The platform [Polygon 8200] and modules will be commercialized with "gate stacks" (dielectric and electrode) as the "killer application". Our road

80 ASM International, Chris Werkhoven, 'Fax to Ernst Granneman: IBM ALCVD' (1-7-1999) Archive Arthur del Prado - Chris Werkhoven file.

81 ASM International, Arthur del Prado, 'Letter to Daniel Queyssac, ref: M00999.doc' (20-71999) Archive Arthur del Prado - Front-End board file.

82 ASM International, Ivo Raaijmakers, 'Position Statement from the Front-End on the Cluster Product Line' (15-10-1999) Archive Arthur del Prado - Ivo Raaijmakers file.

83 Timo Bergman came up with the name Polygon, named after the numerous modules that could be connected to the wafer handler. Menso Hendriks, a very experienced engineer at ASM Europe, came up with the name Pulsar. This name referred to the pulsing of precursors during an ALD cycle. The F200 module was renamed Pulsar 2000 to indicate the difference to customers between the R\&D tool and the module intended for high-volume manufacturing. 
map for gate stacks is sound, we have a leading position, and we control all steps to supply the full process flow from pre-gate clean (HF vapor) to electrode deposition (poly-Si). This is an excellent opportunity. ... It is thus very important to realize that the acquisition of Microchemistry and [ALD] of high-k gates is a key aspect of the road map and hence commercialization of the cluster. Without that technology we would not be able to supply the customer with the $100 \mathrm{~nm}$ high-k gate technology he is/will be looking for, i.e. a complete road map.' ${ }^{84}$

The following configuration of gate stack technology was offered by ASM to its customer base: a cluster consisting of the Polygon 8200 wafer handler platform, one HF vapor etch module, one Epsilon nitride RTP module, one Pulsar 2000 ALD module, and one Epsilon polysilicon RTP module (figure 76 \& 77). ${ }^{85}$ All the modules came from ASM America and had been used in the Siemens jointdevelopment program, with the exception of the Pulsar 2000 reactor and the HF vapor etch module. In this configuration, ASM and its customers were capable of fabricating the complete gate stack in one system, including an exotic high- $\mathrm{k}$ material.

The envisaged process sequence, then, was as follows. First, the hydrogen fluoride vapor etch module removed the native oxide from the substrate, after which an ultra-thin interfacial silicon oxide buffer layer was grown with the nitride RTP module. With the Pulsar 2000 ALD module, the high-k dielectric was deposited. Next, a very thin silicon nitride dielectric was deposited, again with the Epsilon nitride RTP module, to act as a barrier between the gate electrode and the high-k dielectric. This last part, the electrode consisting of a polysilicon film, was grown using the Epsilon polysilicon RTP module. Needless to say that many of the underlying technologies used in the high-k cluster were based on the experience of ASM with its Epsilon modules, vertical furnaces, and the Siemens joint-development program.

Raaijmakers took charge of listing, renewing, and expanding ASM Microchemistry's intellectual property. Most of the original Suntola patents were about to expire, which is why ASM's position in ALD matters had to be secured. After the disruptive Applied Materials litigation, the equipment vendor was aware of the strategic importance of protecting its innovations. In this effort,

84 ASM International, Ivo Raaijmakers, 'Position Statement from the Front-End on the Cluster Product Line' (15-10-1999) Archive Arthur del Prado - Ivo Raaijmakers file.

85 ASM International, Ernst Granneman, 'Memo: ALCVD Projects' (21-4-2000) Archive Arthur del Prado - Ernst Granneman file. 
Raaijmakers licensed intellectual property that seemed to bridge ALD with the Epsilon remote plasma nitride process. ${ }^{86}$

\section{Figure 77}

Schematic horizontal cross-section of ASM America's Polygon cluster machine meant to fabricate a complete gate stack, 2001

Initially, this cluster was developed by ASM America for the production of gate stacks. During the development project, the Epsilon Rapid Thermal Processing (RTP) and the Hydrogen Fluoride (HF) vapor clean module were deselected, and one Pulsar 3000 was added to increase productivity and decrease cost-of-ownership.

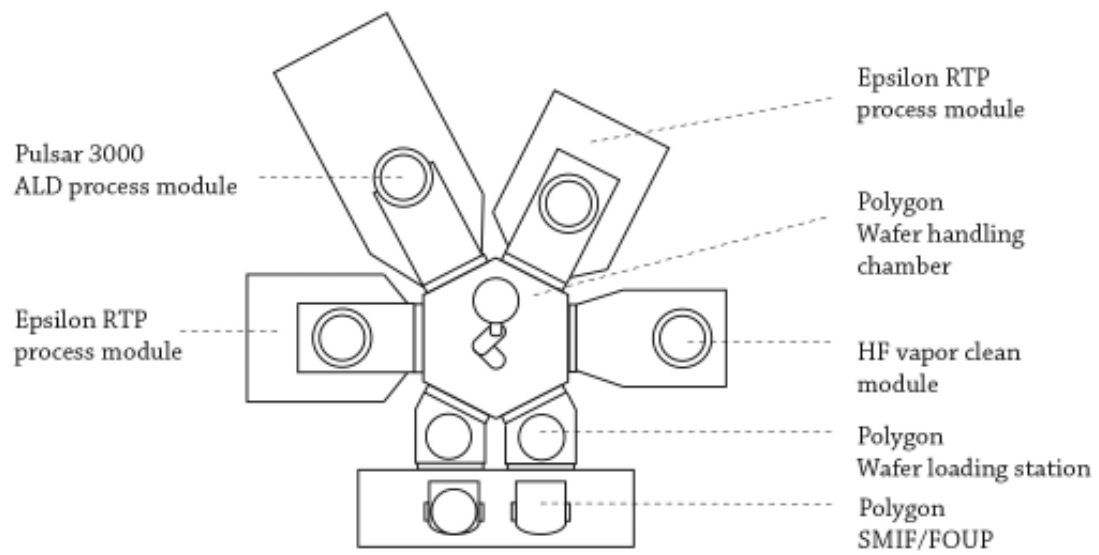

Moreover, together with the manager for governmental affairs, Erik Kamerbeek, he set up a public-private funded research project. ${ }^{87}$ This was done within the framework of the MEDEA program, a European intergovernmental research initiative and the successor to JESSI (cf. Innovation III). Since the 1980s, ASM had positioned itself at the heart of the European microelectronics industry, with regard to chip manufacturers, research institutes, and the government actors involved. ASM exploited this position, also given the sense of urgency and the anxiety surrounding gate stack technology and the promise of ALD. The governmental involvement was motivated by the aims of improving Finnish equipment and process knowledge within the European semiconductor industry,

86 ASM International, Ivo Raaijmakers, 'Memorandum: Arthur Sherman ALCVD Patent' (79-1999) Archive Arthur del Prado - Ivo Raaijmakers files.

87 ASM Microchemistry had already been working on some proposals under the working titles 'Algate' and 'Albase.' These proposals became part of the new ASM initiative. - ASM International, Ivo Raaijmakers and Erik Kamerbeek, 'MEDEA Full Project Proposal: Atomic Layer Chemical Vapor Deposition Equipment and Processes for the Manufacturing of 100nm Integrated Circuits, ALAD1N’ (29-9-1999) Archive Arthur del Prado-MEDEA file. 
strengthening the European semiconductor industry at the smallest technology nodes, and ramping up European intellectual property (in the competition with the Asian and American economies). ${ }^{88}$

In November 1999, the MEDEA board approved the 'Atomic Layer Deposition for 100-nanometer Devices' program, also known by its acronym: ALAD1N. Starting January 1, 2000, and lasting until the summer of 2002, the program aimed at proving the applicability of ALD for gate stacks and dual damascene interconnections by the time chips with a linewidth of 100 nanometers would be introduced in high-volume manufacturing. This was expected to be the case around 2005. Several objectives were recognized, such as, in chronological order, building a complete cluster, proving the feasibility of the clustered process, investigating the right gate stack materials, and developing the clustered production process and integrating it in a CMOS process flow for 100-nanometer chips.

Participants in the project were the research institutes IMEC and LETI, plus chip manufacturers Philips and ST (figure 78). ASM participated through ASM Microchemistry and a newly established subsidiary called ASM Belgium, located on the premises of IMEC and having a staff of about twenty-five. ${ }^{89}$ The project costs were projected to be about 22.7 million euros, of which ASM Microchemistry and ASM Belgium took up approximately 8.4 million euros. Most of the costs involved the construction of the tools and facilities. About fifty percent was covered by the respective national governments, in this case: the Dutch, Belgian, and Finnish authorities.

\section{Figure 78}

Table of development programs with institutes and customers, 1999-2000
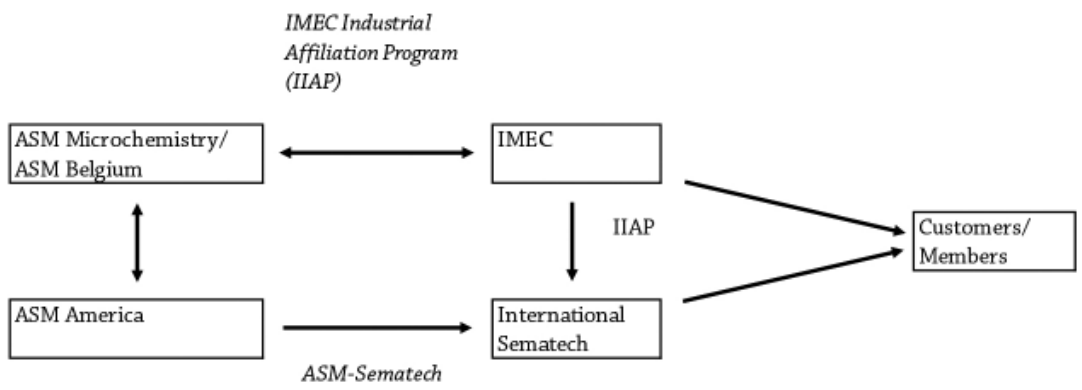

88 ASM International, Ivo Raaijmakers, 'MEDEA Technical Report ALAD1N (T653): Progress Report of First Si Months, January 2000-June 2000' (24-7-2000) Archive Arthur del PradoJESSI/MEDEA: ALAD1N file.

89 ASM Belgium was a legal entity of ASM Europe. 
The available funds made it possible to finance one tool. ${ }^{90}$ This involved a Polygon 8200 for the creation of a gate stack, including all ASM's modules developed during the IVPS and Siemens projects plus ASM Microchemistry's Pulsar 2000 module. With this ASM system, to be installed at IMEC, the films' characteristics could be verified and studied in more detail. ${ }^{91}$ Moreover, since IMEC possessed the whole range of semiconductor production technologies, ASM could study the integration of the new gate stack technologies in a full CMOS production chain. ${ }^{92}$ This secured ASM's information flow and decreased its reliance on the bits of information it received from its customers. Furthermore, IMEC would sell the results of their findings, achieved on ASM's equipment, to affiliated customers and the International Sematech Institute - thereby increasing the exposure of the technology globally (figure 78). ${ }^{93}$ The ALAD1N project was a vital part in ASM's strategy of enacting ALD and high-k technology in the public domain.

Retired from his position of CTO, Granneman dived into the technological and operational integration of ASM Microchemistry, and the commercialization of a new rapid thermal processing system, in Bilthoven, called the Levitor. His role in Finland involved maturing the technology to ASM's and the industry's standards and aligning operational and technological roadmaps. He became responsible for realizing the execution of the integration.

As the dust of the acquisition and the initial acquaintance with the Finnish technology and organization had settled, Werkhoven began to secure the interest of potential customers. This involved aligning the technological roadmap of the

90 ASMI, Ernst Granneman, 'E-mail to FEB: Meeting Gilbert de Clerck' (21-2-2000) Archive Arthur del Prado - IMEC file.

91 In the semiconductor industry, metrology follows the shrinkage of transistor's dimensions. The thinnest film requires the newest metrology equipment. Equipment manufacturers often have basic metrology tools, but cannot afford to invest in the latest technologies. Relying on the tools installed at research institutes - often for the same reasons as the equipment manufacturers but than the other way around - offers the opportunity to access those.

92 IMEC offered the infrastructure of a modern research facility and manufacturing line, while it would get access to ASM's equipment in return. The institute itself went on the road to attract partners for its own high-k gate stack development program. Therefore, initially, IMEC and ASM were fishing in the same pond of customers. During the initial development surrounding high-k dielectric and dual damascene structures, disagreement arose about the question of what kind of knowledge IMEC could sell, and if IMEC was allowed to collaborate with ASM's main competitor on high-k dielectrics as well. - ASMI, Ernst Granneman, 'Memo to Gilbert Declerck, IMEC: Relation IMEC-ASM; ref: imeclgd285str.doc. Appendix B: Summary of Recent Events.' (16-10-2000) Archive Arthur del Prado - IMEC file; ASMI, Ernst Granneman, 'E-mail to FEB: Meeting Gilbert de Clerck' (21-2-2000) Archive Arthur del Prado -IMEC file.

93 ASMI, Ivo Raaijmakers, 'E-mail to Del Prado and Granneman: Happy IMEC' (8-6-2000) Archive Arthur del Prado - IMEC file. 
chip manufacturers with the current and forthcoming process capabilities of ASM. By December, demos for silicon nitride and high-k were requested by all major chip manufacturers in the United States, Europe, Japan, Korea, and Taiwan. Moreover, the installation of the first couple of cluster tools was scheduled. The first would go to ASM America, since most of the modules were already present in Phoenix. ${ }^{94}$ Next was IMEC - for the ALAD1N project. The following would go to one of the leading American chip manufacturers like Intel, IBM, or Motorola, by the fall of 2000 .

At the turn of the century, ASM International's technology management had put the ball in the court of the business units: ASM Microchemistry, ASM America, and ASM Belgium. As throughout ASM's history, the holding company (ASM International) had no role in the execution of technological development (see Innovation III). It defined the corporate strategy. Competing in the market and further developing the technologies was left up to the subsidiaries. They were responsible for the realization of the plans: the commercialization of ALD and the gate stack technology. As Werkhoven summarized the state of affairs and the risks involved:

'The high-k program is now globally one program and we have a lot of eggs in that basket. This cooperation may get a lot of publicity as it is the first between two competing institutes [IMEC and Sematech] on different continents working on one single problem in the industry replacing $\mathrm{SiO}_{2}$ as the gate dielectric. If we do not perform the whole world will be watching us do so.' ${ }^{95}$

ASM had put itself into the spotlight; now it had to realize its potential.

\section{Maturing equipment in Espoo and Phoenix}

The first steps in the realization of the corporate strategy involved the cramming of the machines. This occurred at ASM Microchemistry in Espoo, Finland, and at ASM America in Phoenix. The Finnish operation focused on integrating their ALD tools with ASM's product portfolio. Their American colleagues worked on improving the Polygon 8200 and the various Epsilon modules.

In Espoo, Granneman collaborated with the team of Matti Ervasti. As he warned his colleagues on the Front-End Board of ASM: 'the inertia of changing

94 ASMI, Chris Werkhoven, 'E-mail: IMEC/Siemens' (15-9-1999) Archive Arthur del PradoIMEC file.

95 ASMI, Ivo Raaijmakers, 'E-mail to Del Prado and Granneman: Happy IMEC' (8-6-2000) Archive Arthur del Prado - IMEC file. 
the initial choices is very large. ${ }^{96}$ Th first thing that had to be done was to ensure compliance of ASM Microchemistry's machines with basic European Community's quality and safety standards, dubbed CE. Also, the Finnish operation had to be prepared for higher-volume manufacturing and the stringent quality demands of the chip industry. Granneman distinguished areas which had to be improved for competitive reasons, like throughput and footprint of the Pulsar modules.

To this end, the switching speed of the gas valves - used to get the sequential insertion of gasses in the reactor chamber - had to speed up and become more reliable. ${ }^{97}$ The valves used by ASM Microchemistry switched several times per second already. This had to increase. Furthermore, their mean time before failure was 'just' four million cycles. This had to be increased to at least thirty million cycles.

Another area was the development of a solid source for the precursor. ${ }^{98}$ Several high-k materials - like zirconium oxide, hafnium oxide, etc. - required solid sources, while others - aluminum oxide, for instance - could be utilized using gaseous or liquid precursors. As Raaijmakers explained:

'The solid source was a result of the chosen precursor. ASM had chosen for hafnium [or zirconium] chloride, because it did not contain any carbon. Back then, we were aware that carbon might have disadvantageous effects on the reliability of the material!'99

Solid sources bore unique technological challenges, however. The chloride precursor had to be evaporated in a consistent quality over a sustained period of time. By 2000, ASM Microchemistry had not yet developed such a solid source for the Pulsar 2000. So far only a F950 reactor - not designed for semiconductor applications, and thus not qualified for installation in cleanrooms - had such a solid source. Initially, the Pulsar modules first to be installed would contain this improvised solid source, and were suitable for R\&D primarily. In the meantime, ASM Microchemistry developed a new kind of evaporator in close cooperation with the high-k precursor supplier Air Products. It was called a HIG source (Hot Isothermal Gas source).

96 ASM International, Ernst Granneman, 'Memo: Redesign(s) Pulsar 2000 system' (5-1-1999) Archive Arthur del Prado - Ernst Granneman file, p. 2.

97 ASM International, Ernst Granneman, 'Memo: Conclusions/Action Items First Operations Review ASM Microchemistry, Espoo, Finland, January 12,13, 2000’ (14-1-2000) Archive Arthur del Prado - Ernst Granneman file.

98 ASMI, Ernst Granneman, 'Memo: Strategy and priorities ALCVD program' (8-2-1999) Archive Arthur del Prado - Ernst Granneman file.

99 Original quote in Dutch. - Ivo Raaijmakers, 'Interview with author'. 
Granneman also helped to define specifications for the 300-mm variation of the Pulsar. ${ }^{100}$ So far it processed only 200-millimeter wafers. But by the time the module was expected to be used in mass production, the bigger 300-millimeter wafers would be standard. The engineers of ASM Microchemistry were assigned the task of designing the new Pulsar 3000 module, capable of 300-millimeter wafers, and of addressing shortcomings of the Pulsar 2000.

At ASM America, the Polygon 8200 and its modules had to be prepared. First, this involved integrating the software of the Pulsar 2000. The Dutch engineer Timo Bergman was assigned this task in Phoenix, elaborating upon his earlier work done in the IVPS project. In early 2000, he got support from the engineer responsible for the A600-UHV, Henk de Waard. ASM America's engineer Eric Shero took up a pivotal role in the preparations of the Epsilon modules for the gate stack application.

Furthermore, ASM America had to ensure the supply of the wafer handling module. ${ }^{101}$ The wafer handler had been co-developed with Philips CFT (formerly known as Philips Machinefabrieken). However, due to the Dotcom Boom, this Dutch subcontractor was already flooded with orders from ASM - generic modules of vertical furnaces and Epsilons - and ASML. It could not guarantee the delivery of the cluster tools, let alone a new 300-millimeter version. This forced ASM America to search for a local subcontractor.

In the meantime, ASM America had to fabricate a number of Epsilon nitride and polysilicon RTP modules for the envisaged clusters to be installed at the company itself, IMEC, and the more closely involved customers. So far, the Epsilon nitride with MRG source had been solely constructed for the Siemens joint-development program. New ones had to be built rapidly. This also involved the hydrogen fluoride vapor module. This cleaning module was derived from ASM's batch cluster (A600), designed during the early 1990s.

\section{Selecting the right high- $k$ dielectric}

While the infrastructure, tools, and operations were prepared for ASM's enactment, the most critical part involved process development. ASM stated its intention to innovate gate stack production technology, and now it had to substantiate this ambition. From the processes offered by ASM, the chip manufacturers could select their right material for the envisaged high-k

100 ASM International, Ernst Granneman, 'Memo: ALCVD projects' (21-4-2000) Archive Arthur del Prado - Ernst Granneman file.

101 ASM International,, Ernst Granneman, 'Memo: System and Process Development Strategy Pulsar 2000 module’ (11-10-1999) Archive Arthur del Prado - Ernst Granneman file. 
dielectric. ${ }^{102}$ ASM Microchemistry had a treasure trove of materials available. Depending on the interests of the customers, ASM grew the materials and optimized the process. For the equipment vendor it was critical to prove its capability of depositing the viable materials and to innovate it as much as possible.

The quest for a new high-k gate dielectric material encompassed fiddling at the very foundation of the highly complex structure of an integrated circuit. This concerned not the horizontal shrinkage of components on an integrated circuit, but the vertical compatibility between different, adjacent layers of materials. An integrated circuit can be regarded as a complex labyrinth, on top of which various films are stacked. Each of these films was supposed to have a very specific function, and this determined the material chosen. And to make things even more challenging, the proper functioning of the film depended on the quality of the process through which the material was applied. It was an incredible risk to tinker with the heart of a transistor, taking into consideration that millions of transistors were needed to enable the proper functioning of an integrated circuit. Millions of such circuits had to be fabricated with very high yields to guarantee a return of the interrelated billion-dollar investments. In short, a new material - a high-k dielectric for example - required intensive study with regard to chemistry, compatibility, and process.

Various materials with a high dielectric constant had been deemed probable. As Intel's leading process development engineers recalled:

'We set about studying a veritable alphabet soup of high-k dielectric candidates, including aluminum oxide $\left(\mathrm{Al}_{2} \mathrm{O}_{3}\right)$, titanium dioxide $\left(\mathrm{TiO}_{2}\right)$, tantalum pentoxide $\left(\mathrm{Ta}_{2} \mathrm{O}_{5}\right)$, hafnium dioxide $\left(\mathrm{HfO}_{2}\right)$, hafnium silicate $\left(\mathrm{HfSiO}_{4}\right)$, zirconium oxide $\left(\mathrm{ZrO}_{2}\right)$, zirconium silicate $\left(\mathrm{ZrSiO}_{4}\right)$, and lanthanum oxide $\left(\mathrm{La}_{2} \mathrm{O}_{3}\right)$. We were trying to identify such things as the material's dielectric constant, how electrically stable it was, and its compatibility with silicon. ${ }^{103}$

For years, ASM Microchemistry - and in particular the engineer responsible for process development, the unequaled expert in ALD, Dr. Suvi Haukka - had successfully proven the ability to grow these materials through ALD. Now it was up to ASM to prove that these materials could be deposited within the parameters for chip production.

102 ASM International, Chris Werkhoven, 'Fax to FEB: Intel ALCVD/MC Interactions' (2-7-1999) Archive Arthur del Prado - Chris Werkhoven file.

103 Intel, Bohr, Chau, Ghani, and Mistry, 'The High-k Solution'. 
Through the new interactions via ASM's sales network, the Finnish operation obtained numerous requests for demos of these materials. Since 1998, the most obvious dielectric material had been aluminum oxide, which was already applied for as dielectric in DRAM capacitors. Although some customers - in particular memory manufacturers - still requested this material, it had been rejected already as a dielectric for gate stacks. The dielectric constant was too low. By the summer of 2000, most of the research singled out zirconium oxide as the most probable option, due to its high dielectric constant. Initially, then, most development concentrated upon zirconium oxide. ${ }^{104}$

Until the spring of 2000, due to the limited available resources and capacity, demos were done in various types of equipment available to the engineers of ASM Microchemistry. This involved the module specifically intended for the semiconductor industry, the Pulsar 2000, or F200, but also the reactors meant for the flat panel displays and magnetic head production, the F450 and F950. Since the Pulsar 2000 was being modified to meet the semiconductor industry standards, ASM Microchemistry could only work with two F200 reactors, not yet adapted to ASM's criteria. These processed aluminum oxide. The F450 and F950 were the only ones to process zirconium oxide. At this stage, foremost the characteristics of the various materials had to be defined. Thus, ASM settled for the non-semiconductor machines, while the Pulsar was modified to process zirconium oxide instead of aluminum oxide.

The weight of process development was removed from the Finnish operation as soon as ASM America and IMEC received the new Pulsar 2000 modules, installed them, and got them running. In April 2000, a module capable of processing zirconium oxide was installed and integrated in the Polygon 8200 at ASM America. In June, IMEC and the American customers received various processes and modules during the summer months.

By that time, ASM's partners in the ALAD1N program already obtained and were able to share some results of the zirconium oxide films, supplied by ASM Microchemistry. ${ }^{105}$ ASM America redesigned and studied the other processes - the nitride and polysilicon modules - required for integrated manufacturing of the gate stack. The nitride module served a variety of process needs and its

104 Another option, strontium oxide, was requested by the research director of Motorola in particular. This material was soon dropped, however, after this director resigned and the first results of zirconium oxide and hafnium oxide were obtained. - ASM International, Chris Werkhoven, 'E-mail: IBM/Motorola and Further Gate Stack Developments' (22-9-2000) Archive Arthur del Prado-Chris Werkhoven files.

105 ASM International, Ivo Raaijmakers, 'MEDEA Technical Report ALAD1N (T653): Progress Report of First Si Months, January 2000-June 2000’ (24-7-2000) Archive Arthur del PradoJESSI/MEDEA: ALAD1N file. 
standalone demo and development variant in ASM America's lab was therefore heavily used.

After installation of the whole system, the other customers had to wait a little longer before their evaluation of high-k dielectrics like zirconium oxide could get started. ${ }^{106}$ As explained above, during the redesign of the Pulsar 2000 a solid source delivery system had to be included in order to deposit zirconium oxide and, later on, hafnium oxide. The design and installation of the HIG source took longer than expected. During the year 2000, the solid source proved to be critical not only for gas delivery and process, but also for reactor reliability in terms of scheduled and unscheduled downtime. ${ }^{107}$ The evaporation process was a potential particle generator when not designed or operated correctly.

By September 2000, customers requested demo wafers with a film of hafnium oxide. ${ }^{108}$ The latter material has a slightly lower k-value than zirconium oxide, yet might be more suitable for integration than zirconium oxide. Just installed and running, all the development tools had to be modified to run the hafnium oxide process instead of the zirconium one. As recalled by the Intel engineers:

'With two candidate materials [zirconium oxide and hafnium oxide] identified, we started making NMOS and PMOS transistors out of them. Then came the next snag. These transistors, pretty much identical to our existing transistors except for the different dielectric, had a few problems. For one thing, it took more voltage to turn them on than it should have-what's called Fermi-level pinning. For another, once the transistors were on, the charges moved sluggishly through themslowing the device's switching speed. This problem is known as low charge-carrier mobility.

We weren't the only ones encountering these problems; just about everybody else was struggling with them, too. With the countdown in progress for the next generation predicted by Moore's Law, understanding why the high-k dielectric transistors performed so poorly

106 In the meantime, the installed system would only process inessential aluminum oxide films.

107 After the zirconium HIG source was installed in the summer of 2000, it was first integrated in the F200 tools of ASM Microchemistry used to process demo wafers. Next was ASM America. It was not before the fall of 2000 until the HIG solid source was installed at IMEC. While most research at ASM Microchemistry, ASM America, and IMEC - through demo wafers of ASM Microchemistry - shifted toward the use of zirconium oxide, IMEC had to wait until the HIG source got installed.

108 ASMA, Chris Werkhoven, 'Monthly Report Chris Werkhoven, September 2000' (oct. 2000) Archive Arthur del Prado - Chris Werkhoven file. 
and finding a solution became an urgent task. Using a combination of experimental work and physics-based models, we began to figure out what had gone wrong. The source of the trouble, ultimately, came down to the interaction between the polysilicon gate electrode and the new high-k dielectrics. ${ }^{109}$

It appeared that in particular the zirconium oxide dielectric showed compatibility problems with the polysilicon electrode. The fabrication process of the gate stack was normally followed by anneal steps. During such a step, the wafer would be heated very shortly but intensively, in order to remove material deficiencies. Due to this step, the polysilicon electrode reacted with the zirconium oxide dielectric. The film of zirconium oxide seemed to crystallize. The compatibility of both materials - the exotic high-k dielectric and traditional gate electrode - was far from optimal.

To tackle this issue, some studies were done with various high-k alloys, such as aluminum zirconium oxide by ASM Microchemistry. Another option was to change the electrode from polysilicon for a new metal gate. This was a step envisaged anyway, if a few nodes further down the industries roadmap. Replacing the gate stack dielectric by an exotic material was deemed challenging enough, let alone combining this with the supplementation of the polysilicon electrode by another new material.

In the case of ASM, a viable metal gate process was not yet in place, nor did ASM have the resources - funds, manhours, and operational capacity - to pursue this line of research. As more information turned toward the applicability of hafnium oxide as gate dielectric, the development tools in the field had to be modified accordingly. These adjustments consumed all the available time of the already overburdened Finnish operation. Therefore, it was key to define the appropriate high-k dielectric in combination with a conventional polysilicon electrode. ${ }^{110}$

\section{Deluging demand}

In the hurry to get the first tools in the field for external evaluation and validation, errors due to inadequate procedures crept into the delivered tools. By the fall of 2000, this already started to backfire. ASM America was confronted constantly with technical issues involving its Pulsar module in Phoenix. As Chris Werkhoven reported:

Intel, Bohr, Chau, Ghani, and Mistry, 'The High-k Solution'.

110 ASM International, Chris Werkhoven, 'E-mail: IBM/Motorola and Further Gate Stack Developments' (22-9-2000) Archive Arthur del Prado - Chris Werkhoven files. 
'Concern about the functioning of the Pulsar module is increasing rapidly. Next to failures showing up due to inferior workmanship (mainly weldings that are incomplete or corroding) on critical parts, also the solid source, needed for $\mathrm{Zr}$ and $\mathrm{Hf}$ based oxides, has basic flaws that need to be corrected asap. ${ }^{.11}$

However, by October 2000, ASM Microchemistry was almost drowning under all the internal and external requests. Granneman, who operated as a liaison between the rest of ASM and the teams of Matti Ervasti and Suvi Haukka, put on the brakes. In an e-mail to Chris Werkhoven he voiced his concerns about the situation at the Finnish operation:

'The main reason why ASMM is not responding fast enough, is that Intel/you/Alex [Bush, ASM's Intel Account Manager] bombard them with requests for demo's, JDP's, specific Intel programs, etc. It is more than ASMM can swallow, and, by the way, the same is true for me.

... We CANNOT go on like this. Most processes are not fully developed yet, and most requests from your/Intel's side require a lot of work. Many people within ASMM have reached the point that they are ready not to respond at all any more to any further requests to speed up things, to define yet another program, to do even more demo's, etc. It is too easy to say that we should be prepared to work like this, because this is the way the industry works.

Note that in addition to all the above the same group of people [at Microchemistry] is pushed by Ivo (and he is right) to write patent applications (a lot of work), by Erik [Kamerbeek] and me to submit budgets, to write extensive proposals for European programs, to write progress reports, etc.

All of this in a way such that ASMM is financially break-even in 2000. Further, of course, they have to worry about the [customer] orders (that generate the cash) to pay for everything. In addition to the requests form the US, we obviously also get requests from the Far East and Europe. ${ }^{112}$

111 ASMA, Chris Werkhoven, 'Monthly Report Chris Werkhoven, September 2000' (oct. 2000) Archive Arthur del Prado - Chris Werkhoven files.

112 ASMI, Ernst Granneman, 'E-mail to Chris Werkhoven and FEB: Intel B/S' (2-10-2000) Archive Arthur del Prado - Ernst Granneman file. 
Granneman halted the acquisition of other development programs with customers. The organization was not up to the task of dealing with the industry at such a level. It had not grown in tune with the demand.

ASM Microchemistry was still learning to manufacture equipment according to the semiconductor standards. Despite the support of ASM, mainly through Granneman, problems persisted. ${ }^{113}$ In the spring of 2001, at a prominent customer, doubts had arisen concerning the operational capacity and procedures of ASM Microchemistry. Granneman was aware of the operation's shortcomings, and instigated more drastic measures to strengthen the Finnish subsidiary. ${ }^{114}$

By early 2001, things absolutely had to be changed. Chris Werkhoven, now responsible as Technology Manager for the major American customer accounts, set off the alarm:

'We are in the next phase ... and one clearly communicated that with the current lack of professionalism in Espoo, the outlook to continue with ASM looks very questionable....

Do not forget that gate stack programs at all customers we work with is the most strategic, expensive, and risky of any project done so far. ... It is now more than $1 \frac{1}{2}$ year since ASM is responsible and not even the simplest industry standard production and engineering practices have been implemented. ${ }^{115}$

Clearly, the honeymoon was over.

In concordance with chief operating officer Daniel Queyssac, Granneman decided to transfer an operation manager from ASM America to Finland. This was the lead engineer of the gate stack cluster, Timo Bergman. He would serve as liaison between the American and Finnish operations with regard to the gate stack engineering effort. Furthermore, to enhance the manufacturing operation of ASM Microchemistry rapidly, Granneman agreed to invite ASM America's general manager Hans Wunderl to coordinate this process. Based on his achievements at ASM Europe and ASM America, Wunderl was thought to be the right person to get ASM Microchemistry on track again. On April 4, 2001, Queyssac announced to all front-end employees of ASM:

113 The Intel Pulsar 2000 ALD module, for example, was spuriously contaminated by copper and finger prints. - ASMI, Chris Werkhoven and Timo Bergman, 'High-k Polygon Presentation to Intel' (13-3-2001) Archive Arthur del Prado - Intel file.

114 ASM Europe, Ernst Granneman, 'Fax: ASMM Operations' (2-4-2001) Archive Arthur del Prado-ASM Microchemistry file.

115 ASM America, Chris Werkhoven, 'E-mail to Arthur del Prado: Report and Request' (5-1-2001) Archive Arthur del Prado - Chris Werkhoven file. 
'Many large IC companies ordered a Pulsar module (actually more than the targeted number for the year 2000). Due to this success, it is necessary to rapidly transform ASM Microchemistry into a unit that can produce a large volume of [ALD] modules with a consistent high quality, which the IC industry expects. ... The decision has been made to give Hans Wunderl full supervisory responsibility to guide this process. ${ }^{116}$

To address the immediate manufacturing problems, a 'Quality Improvement Plan' for ASM Microchemistry was started simultaneously. This was managed by Timo Bergman, who temporarily relocated to Finland to coordinate the efforts. Until the summer, he and Wunderl tried to get ASM Microchemistry's manufacturing operation function well by means of sticks and carrots.

For the Finnish subsidiary, teaming up with ASM - including the subsequent intense engagement with the industry - felt like jumping aboard a riding train. By trying to deliver the technology for the prestigious and strategic gate stack technology, the Finnish company was punching above its weight. ASM Microchemistry's operation rambled and shambled, while it still wanted to meet the expectations.

116 ASM America, Daniel Queyssac, 'Memorandum: ASM Microchemistry Announcement' (4-4-2001) Archive Arthur del Prado - ASM Microchemistry file. 


\section{Chapter 28 \\ Integrating high-k into production, 2001-2007}

In the third act of this innovation story, the gate stack development entered a highly competitive phase. The right material for the high-k dielectric was selected, and the production technique and materials were integrated into a complete chip production chain. How chip manufacturers controlled the integration of the new production techniques in their existing manufacturing lines was highly proprietary. This knowledge defined their ability to compete. ASM's chief technology officer Ivo Raaijmakers commented on this phase of development as follows:

'Once the technology has been proven on a chip, everyone knows this is going to work. The rest is straightforward engineering. But then particle densities have to be lowered, throughput has to increase, costs have to decrease. The technology really has to become volume-ready and this happens in the run-up to the introduction. ... This is a time of silence in the press. After the announcement that it works, the engineers retreat in order to tinker and hurry to get it ready for the market. ${ }^{\text {'11 }}$

At this stage, the pace of development at customers began to vary, depending on their respective priorities, resources, and progress. The introduction of high-k dielectrics as anticipated in the International Semiconductor Technology Roadmap was delayed several years to around 2006 or $2007 .{ }^{118}$ The changed prognosis was rooted in the highly diverse competitive field involved. Some customers achieved the performance enhancements of their chips via alternate ways than high-k dielectrics. For others, the high-k dielectric formed a key asset in the regular advancements of their semiconductor products. Intel, clearly part of this latter category, became the leading chip manufacturer, driving the pace and course of the high-k gate dielectric developments.

Original quote in Dutch. - Ivo Raaijmakers, 'Interview with author'.

118 Moreover, after 2001 the roadmap distinguished new specifications and roadmaps per semiconductor product. 
In this final phase before official introduction in high-volume manufacturing, ASM prepared its high-k gate dielectrics technology in accordance with industrial standards. The internal development tools at IMEC and ASM America got tweaked and tuned to meet high-volume manufacturing targets. Simultaneously, customers explored the limits and possibilities of ASM's equipment in their own facility with their own tools. Through so-called 'marathon-runs' - involving continuous processing of several thousand of wafers - the quality of the deposition process and performance of the machine was mapped and communicated to ASM. To get a sense of the performance of the few tools present at customer sites, ASM had to distill its information through the requests it obtained about performance of the experimental tools, reparations, and process improvements. This provided the account teams, dedicated to the interaction with respective customers, with a sense of progress, results, and future timing.

While ASM tried to push the gate stack technology as much as possible on the basis of its own studies, experiments, and understanding, much of advanced research switched to future technology nodes and applications. ${ }^{119}$ In this effort, the company reinterpreted the meaning of its name. Instead of being a mere equipment manufacturer, ASM would focus more on the innovation of 'advanced semiconductor materials' for chip production. It was widely expected that for the progression of Moore's Law, new materials would be defining, such as other high-k materials further down the road (in addition to the traditional predominance of lithography). In May 2001, ASM America’s Strategic Marketing Manager Chris Werkhoven took stock of the developments:

'[U]nderstanding of [ALD] is still in its early phases, with most people struggling with hardware and shortcomings in the area of film analysis. ASM projects are not an exception in that respect. ... It does not require much imagination to conclude that gate stack technology is becoming a technology of overwhelming complexity with expertise needed in materials science, device physics, and wafer manufacturing. ${ }^{120}$

The process knowledge of Microchemistry and the ALD process offered a very beneficial starting-point for ASM. The new processes might be used for high-k dielectrics in memory cells, for the deposition of barrier films in the interconnecting areas, or even as a mask for dual patterning (cf. Business V). To this end, ASM proliferated its portfolio through an acquisition of a South-

119 ASMI, Ivo Raaijmakers, 'Memorandum: Summary of status advanced technology development for BoD meeting and earnings conference call, ref: IR/ive/019.004_2' (12-42002) Archive Arthur del Prado - Ivo Raaijmakers file.

120 ASMI, Chris Werkhoven, 'Monthly report, May 2001' (2-6-2001) Archive Arthur del PradoChris Werkhoven file. 
Korean start-up called Genitech, which offered plasma enhanced ALD. Moreover, the internal innovation process was turned around by repositioning ASM Microchemistry within the organization.

Against the backdrop of these events, the semiconductor industry experienced a severe recession. The Dotcom Boom made way for a Dotcom Bust, aggravated by anxiety surrounding the 9/11 terrorist attacks and, later on, the presumed Iraqi weapons of mass destruction. The heydays surrounding the new millennium were gone. Semiconductor equipment sales declined from 26.6 billion dollars in 2001 to 18.5 billion in $2002 .{ }^{121}$ This was followed by a slow recovery to the preY2K growth rate.

Furthermore, in particular, Intel impacted the equipment manufacturer intensively. The chip manufacturer procured already several products of ASM for high volume manufacturing, and was about to integrate the gate stack technology developed by ASM America and ASM Microchemistry. The equipment supplier's audacious, hands-on, and versatile culture enabled striking innovations. But for high-volume manufacturing of chips in billion-dollar factories, chip manufacturers like Intel and IBM required a trustworthy and reliable equipment supplier. All the business units had to comply with stringent demands on organizational, quality, and safety procedures.

The depressed market circumstances, in combination with rigorous demands on supply chain reliability, urged ASM to alter its innovation and organizational strategy. This primarily involved the establishment of internal procedures with regard to accountability, quality, and safety. But control of the proliferation of activities into ALD was also a factor. Amidst these circumstances, the innovation of the new MOS gate stack finally drew to a close by 2007.

\section{Deteriorating prospects and reputation}

Throughout the summer of 2001, ASM's enactment of ALD and its gate stack technology ran out of steam. The company's operational capabilities affected its ability to sustain its lead in gate stack technology. While research into the gate dielectric progressed, it became apparent that more thickness reduction and performance enhancements of the new gate stack could only be achieved by changing the polysilicon electrode for a metal. This required new research into materials and growth methods, however. In a CMOS-transistor, the n-type MOS (NMOS) and the p-type MOS (PMOS) transistor required different electrodes, and thus different materials (some of the options being ruthenium or platinum for the latter and tantalum nitride for the former). As Werkhoven stated:

121 Gartner Dataquest, '2002 Semiconductor Equipment Market Share Analysis (Executive Summary)', Gartner Dataquest (2-5-2003) p. 2. 
'Taking position in this market is mandatory. Because of the thicker gate (contact) layer, [ALD] is not a prime candidate for this process step while, according to the above remarks about air exposure, cluster tool integration is mandatory. ${ }^{122}$

Competition - with the likes of Tokyo Electron and Applied Materials - was tight and commanded more experience in the deposition of metals and gate electrodes. This pertained in particular to the deposition steps succeeding the construction of the metal gate. With regard to the integration of the new gate stack into chip manufacturing, the question emerged of whether the metal gate was to be integrated in a clustered machine used for the successive metallization steps or in a cluster dedicated to the gate stacks. ${ }^{123}$

ASM did not have the best cards. The company simply lacked the financial and technical resources to pursue anything beyond the high-k dielectric. Due to the high demand for this process in the industry, ASM's technical management had already deprioritized its ALD-based dual damascene line of research within the ALAD1N program. ${ }^{124}$ It was difficult, however, to concentrate fully on metal gates instead, in particular because this involved selecting and developing two types of metal gates for the NMOS and PMOS transistors.

The challenges became paramount. In addition to missing the roadmap for metal gates, difficulties surrounding the installation, servicing, and constant modifications of the Pulsar ALD modules negatively affected the confidence of the customers. By June, some of the American customers grew restless, and some were no longer interested in using the complete Polygon cluster. Werkhoven commented:

'This at least opens the door to competitors, more than was hoped for. But from the status of the program ... it is understandable that at this moment in time such a prominent position could not be given to a company with limited resources. ${ }^{125}$

122 ASMI, Chris Werkhoven, 'Monthly report, May 2001' (2-6-2001) Archive Arthur del PradoChris Werkhoven file.

123 Ivo Raaijmakers, 'Interview with author'.

124 But it was reinstated in a separate research effort into the back-end of line processes, called the Coppermine project (see Business Chapter V). - ASMI, Ivo Raaijmakers, 'ASM Barrier and Seed Business/Project Plan' (29-6-2001) Archive Arthur del Prado - Ivo Raaijmakers file.

125 ASMA, Chris Werkhoven, 'Monthly report Chris Werkhoven, May 2001 (June-2001) Archive Arthur del Prado - Chris Werkhoven file. 
One of the customers intensified its evaluation of ASM International as a whole, and ASM Microchemistry in particular. The subsidiary intended to become a mature and reliable equipment supplier. Yet, during these evaluations, it was found that the Finnish operation still bore a high risk as supplier.

\section{The 'first big-bang'}

In August 2001, the Dotcom bubble burst. The boom of ICT related markets - and, subsequently, stock options - made way for economic recession, a development made irrevocable by the 9/11 terrorist attacks on the United States. Investments in semiconductor technology got delayed and demand for new production lines evaporated as of October. ASM had to cut weight in order to stay afloat. All the business units had to lay off staff to improve the operations' balances.

In the case of ASM Microchemistry, the end of the Dotcom Boom constituted fortuna in its most derailing guise. The stagnation of the market threw a spanner into the Finnish operation's ambitions to become a viable original equipment manufacturer. Amidst the recession, ASM Microchemistry had to clean its balance. Moreover, the changed market conditions justified intervention by its interim supervisor Hans Wunderl in order to address the operational problems. Faced with rising uncertainty about the process and organizational procedures, Wunderl drew the conclusion that the Finnish manufacturing operation had to be closed and transferred to Phoenix. Showing little regard for Finnish business culture, pride, and sensitivities, he dropped a bombshell. Despite his antagonizing style, a cocktail of Dutch bluntness and American arrogance, those on ASM International's Front-End Board realized he was right, if only because of the more experienced and better equipped subsidiary in Phoenix. Chief technology officer Ivo Raaijmakers summed up the motivation for the reorganization of ASM Microchemistry in telegraphic style:

'Major problems in equipment installations and reliability, all negative effects multiplied because of a large installed base. Change to manufacturing organization is going too slow. Organization is showing clear signs of burn-out, R\&D performance is suffering.' ${ }^{126}$

A team consisting of Ivo Raaijmakers, Hans Wunderl, and human resource manager Marike Overhoff executed the reorganization from October 2001 on. ${ }^{127}$ Design, production, marketing, sales, and servicing of the Pulsar 2000 and 3000 were transferred to ASM America. The remaining non-semiconductor activities

ASM International, Ivo Raaijmakers, 'Memorandum to FEB:ASMM Charter 2002+' (2-112001) Archive Arthur del Prado - ASM Microchemistry file.

127 ASM Europe, Marike Overhoff, 'Presentation: Reorganization ASMM' (October 2001) Archive Arthur del Prado-ASM Microchemistry file. 
were sold or stalled. The American subsidiary became the sole contact point with regard to ASM's gate stack technology. Because ASM America was an experienced manufacturing operation, the reorganization was expected to address Intel's and other customers' gravest operational concerns. It entailed a significant lay-off of employees in Finland. In Espoo, this announcement came to be known as the 'first big-bang." ${ }^{128}$

The reorganization repositioned the Finnish operation as the center of ASM's enactment of ALD. Raaijmakers and the Front-End Board decided to turn ASM Microchemistry into an 'ALD Center of Excellence. ${ }^{129}$ With Suvi Haukka as executive scientist and Marko Tuominen as general manager (replacing Matti Ervasti who resigned), it became the focal point of ASM's ALD development, thus developing new chemistries, new prototypes, and cooperating with universities, customers, or alliances on new ALD developments. The other activities designing, developing, and manufacturing ALD machines - took place at ASM America, ASM Europe, or ASM Japan. This new role allowed ASM to maintain the intricate ALD knowledge of its Finnish engineers. ${ }^{130}$ As Raaijmakers explained:

'It is clear that the ASMM organization must be significantly "ahead of the curve" in order to guarantee proper time to market. ... it is identified that ASMM must work on technologies at least 3 years out before the high volume ramp (in 2002, ASMM should work on to $50 \mathrm{~nm}$ technology. ... Peer groups for ASMM are universities, R\&D institutes, large companies R\&D departments, etc.' ${ }^{131}$

ASM's innovation process for gate stack and ALD technology was radically reorganized and adjusted to the realities threatening the whole endeavor. Tough choices had to be made. The new role of ASM America and ASM Microchemistry in the development of gate stack technologies addressed concerns about ASM's

128 Suvi Haukka, 'Interview with author' and Matti Ervasti., 'Interview with author'.

129 In the terminology of Raaijmakers, ASM Microchemistry focused on 'concept \& feasibility' and 'exploration' for new technological development. - ASMI, Ivo Raaijmakers, 'Memorandum: ASMM Charter 2002+' (2-11-2001) Archive Arthur del Prado - ASM Microchemistry file.

130 In January 2002, chief technology officer Ivo Raaijmakers set out a more structured way for R\&D within ASM. He distinguished five different stages in development: exploration (pre-competitive), concept \& feasibility ( $\mathrm{C} \& \mathrm{~F})$, Alpha, Beta and Gamma. The stages ranged from very creative and pre-competitive to highly structured and competitive. Each stage was characterized in detail and came with a clear exit strategy. - ASM International, Ivo Raaijmakers, 'ASMI Front End R\&D Policy' (16-1-2002) Archive Arthur del Prado - Ivo Raaijmakers file.

131 ASM International, Ivo Raaijmakers, 'Memorandum to FEB:ASMM Charter 2002+' (2-112001) Archive Arthur del Prado - ASM Microchemistry file. 
capacity to meet the new technological requirements beyond its propagated cluster tool configuration.

\section{A public running score of development}

Despite the organizational turbulence incommoding ASM, 2001 was the year in which the feasibility of high-k gate dielectrics deposited through ALD was proven. From 2 to 5 December, a major annual conference was organized in Washington DC, called the International Electron Devices Meeting (IEDM). ${ }^{132}$ At this conference, semiconductor manufacturers and research institutes presented their achievements and assessments of the newest chip designs and integration efforts. High-k dielectrics and metal gates were among the hottest topics discussed. ${ }^{133}$ All ASM customers who used its ALD modules presented their results with regard to innovating the gate stack. Since the event was foremost aimed at chip manufacturers, it was striking that ASM, as one of the few equipment manufacturers at the event, was mentioned as co-author of various publications. ${ }^{134}$ As such, ASM benefitted from the marketing and public efforts of the chip manufacturers surrounding the event. The technical experts in chip engineering and manufacturing present at the conference were convinced that ASM offered indispensable technology for the new gate dielectric.

In particular Intel used the event to highlight its technological lead in semiconductor development to the world and its peers. One week before the IEDM Conference, Intel published a press release with the title 'Intel Announces Breakthrough in Chip Transistor Design, ${ }^{135}$ and the company also announced a presentation at the conference. Intel's breakthrough pertained to a new material called 'high-k dielectric.' In the rather extensive press release, Gerald Marcyk, Intel Lab's director of components research, explained that 'smaller and faster just isn't good enough anymore':

'Power and heat are the biggest issues for this decade. What we are doing with our new transistor structure is helping make devices that

132 Electronic Devices Society of IEEE, 'Technical Digest International Electron Devices Meeting 2001' (2-12-2001).

133 Other topics included the similar hot topic of dual damascene structures, i.e., the integration of copper in the interconnecting structures of a computer chip (see Business V).

134 Representing ASM, Chris Werkhoven held two presentations on some of ASM America's breakthroughs (together with, respectively, Agere Systems and Sematech). ASM Microchemistry's Suvi Haukka did a presentation together with STMicroelectronics.

135 Intel, 'Intel Announces Breakthrough in Chip Transistor Design' Intel.com (26-11-2001) Archive Arthur del Prado - RvC 2001. 
are extremely power efficient, concentrating electrical current where it's needed.' ${ }^{136}$

Decreasing power leakage was necessary to extend battery life of the rapidly growing market for handheld products such as mobile phones. This was partially achieved by reducing the current leakage of the transistor 100 times by a thin insulating layer of a high-k material. As the press release further explained:

'Another key element is the development of a new material that replaces silicon dioxide on the wafer. ... At the IEDM Conference, Intel researchers will demonstrate record speed for transistors made with a new type of material called a "high k gate dielectric". This new material reduces gate leakage by more than 10,000 times compared to silicon dioxide. The high $\mathrm{k}$ gate material is grown by a revolutionary technology called "atomic layer deposition" in which the new material can be grown in layers only one molecule thick at a time. The result is higher performance, reduction of heat, and significantly longer battery life for mobile applications.' ${ }^{137}$

Moreover, Intel claimed that the new integrated circuit, and its new transistors, would be able to switch on and off more than one trillion times per second. To make this staggering statistic a bit comprehensible, the press release continued as follows: 'It would take a person more than 15,000 years to turn a light switch on and off a trillion times.' The press release was a beautiful example of Intel highlighting the abilities of their new developments, while not giving away too much information about the actual process, materials, and equipment.

Other institutes and companies did not mince matters that much. Bell Labs for instance - at that time a subsidiary of Agere Systems ${ }^{138}$ - announced the incorporation of hafnium oxide as gate dielectric and explicitly mentioned ASM America as supplier. ${ }^{139}$ Multiple chip manufacturers and research institutes presented their work on high-k dielectrics, such as IBM, Motorola, IMEC, Sematech, and STMicroelectronics. ${ }^{140}$ During the event, it became obvious that hafnium oxide or hafnium alloys had the best papers for replacing silicon oxide

136 Ibid.

137 Ibid.

138 ASM started cooperation with Bell Labs in 1999 when it was still a subsidiary of Lucent.

139 The head of development into ALD and high-k at Bell Labs was Dr. Glen Wilk, who would start to work at ASM three years later. - Agere Systems, 'Agere Systems Researchers Report Semiconductors Industry's Smallest Transistors with a Novel Gate Insulator Material' (312-2001) Archive Arthur del Prado - RvC 2001.

140 Electronic Devices Society of IEEE, 'Technical Digest International Electron Devices Meeting 2001' (2-12-2001) (viewed: 7-4-2017). 
as gate dielectric. The conference proved to be a celebration of the achievements so far.

\section{Integrating hafnium oxide}

Following the public announcements surrounding hafnium oxide, the industry turned to the integration of hafnium oxide in the process flow of CMOS-based computer chips. The governmentally supported ALAD1N program was finalized by a first integration of hafnium oxide in a CMOS production line at IMEC. ${ }^{141}$ In this process, original expectations were adjusted at an industrial level as well as at ASM. The insertion of the new gate stack technology was postponed.

Throughout the years, the International Technology Roadmap for Semiconductors was readjusted with respect to the insertion of gate stack technology. The 1999 roadmap warned for a 'Red Brick Wall' surrounding the 100-nanometer node, projected for 2003. ${ }^{142}$ By 2001, this was deferred, anticipating a 65-nanometer node by 2005, and in the summer of 2002 expectations were lowered again, now projecting a 45-nanometer node in $2007{ }^{143}$

The postponement of the hafnium oxide high-k solution followed from other solutions that enabled further shrinkage and maintenance of performance. Other ASM subsidiaries contributed to these innovations as well. For instance, the vertical furnaces from ASM Europe used for the latest oxidations, ASM America's Epsilon reactor for strained silicon, and ASM Japan's plasma deposition process for low-k inter-film dielectrics. ${ }^{144}$ In a paper presented to the Supervisory Board in August 2002, Werkhoven explained Intel's development of strained silicon and high-k and their decision to spread out the introduction of the various technologies:

'The reason why Intel may want to have the higher mobility that comes with the strained $\mathrm{Si}$ as soon as possible, is to compensate for the loss of mobility when high-k gates are used. Since high-k gates are planned

141 MEDEA+, 'Project Profile. T302: Atomic layer deposition for $100 \mathrm{~nm}$ devices (ALAD1N+)' (January 2001).

142 SIA, ITRS 2002 update, p. 9.

143 ASM International, Ivo Raaijmakers, 'Summary of status advanced technology development for BoD meeting and earnings conference call' (12-4-2002) Archive Arthur del Prado Ivo Raaijmakers file. Moreover, by this time the node correlation became product and manufacturer specific and lost its significance as industry-wide parameter.

144 Strained silicon helped to maintain the flow of current at smaller dimensions. - ASMI, Chris Werkhoven, 'Monthly Report Chris Werkhoven August, 2002' (25-9-2002) Archive Arthur del Prado - RvC 2002; Wouter Tinus, 'Intel bestelt strained silicon reactors waarschijnlijk bij ASMI', Tweakers.net (27-9-2002), and Wouter Tinus, 'Intel onthult zijn 0,09 micron productieprocedé', Tweakers.net (13-8-2002). 
for $65 \mathrm{~nm}$, one will have one generation of experience with strained Si a and the introduction of 2 challenging technologies at the same time, can be avoided. ... Hence, Intel has master minded the different leaps in technology very well and is continuously improving its leading position.' 145

The wheat was separated from the chaff among the American customers involved in the gate stack developments. ${ }^{146}$ It was Intel which continued to relentlessly foster the high-k developments in the industry - and thus at ASM.

The development roadmap of ASM centered on the Polygon 8300, consisting of a 300-millimeter single wafer cluster platform with a Pulsar 3000 ALD and Epsilon thermal process modules. Apart from the bigger wafer scale and the Pulsar module, the configuration of the cluster tool still very much resembled the machine derived from the Siemens joint-development program years earlier. Intel prepared the first high-volume manufacturing of 65-nanometer technology in 2005, and successively 45-nanometer in 2007, at its 'D1D' factory - Intel's 300-mm development fab in Hillsboro, Oregon. ${ }^{147}$ After this fab was running smoothly, the technologies would be transferred to other Intel fabs across the globe.

It had been ASM's intention to supply the gate stack cluster so that each customer could tune processes to their own needs and create differentiation with their competitors. All customers, who considered metal gates instead of the polysilicon, had their specifications and requirements. From 2002, the other modules were evaluated intensively as well. For instance, instead of using the HF-vapor module, some customers preferred another method to clean the substrate.

The polysilicon and nitride RTP modules remained critical for the high-k dielectric developments at most customers. The nitride RTP module remained a valuable tool in the research surrounding high-k dielectric compatibility with the polysilicon electrode. A very thin film of silicon nitride was considered as a barrier between the hafnium oxide dielectric and the polysilicon electrode. ${ }^{148}$

145 ASMI, Chris Werkhoven, 'Monthly Report Chris Werkhoven August, 2002' (25-9-2002) Archive Arthur del Prado - RvC 2002.

146 ASMI, Arthur del Prado, 'Letter to Supervisory Board: Technology Up-date' (13-12-2001) Archive Arthur del Prado-RvC 2001.

147 Tom Krazit, Inside Intel's D1D fab - Through the looking glass', inforworld.com (1-12-2005); Mark LaPedus, 'Intel maps out 300-mm campaign - and another Oregon fab - to cut chip costs', eetimes.com (14-5-2001).

148 ASMA, Chris Werkhoven, 'Monthly Report Chris Werkhoven, September 2002' (1-10-2002) Arhive Arthur del Prado - Chris Werkhoven file. 
In September 2002, Chris Werkhoven reported about progress in this direction made by ASM, and its American customers:

'The nitride cap technology ... also shows at other places results ... the amazing thing is that with a rather crude set-up, good nitridation and good layer thickness control is possible. In fact, we are making only one monolayer or about $0.3 \mathrm{~nm}$ of nitride and that is about good enough to have an $\mathrm{HfO}_{2}$ /Poly stack survive an RTA at 1050C.' ${ }^{149}$

The nitride film increased the chances of maintaining the polysilicon electrode, and thus the inclusion of the polysilicon RTP module in ASM's cluster.

\section{Further operational and organizational adjustments}

By the fall of 2002, the semiconductor industry had not yet recovered from the Dotcom bust. The 9/11 attacks and the successive War on Terror, including anxiety about a forthcoming American military intervention in Iraq, smothered any prospects of economic revival. If the market remained healthy, it did not flourish. This economic situation forced ASM to further adapt its expenses and its operations accordingly.

At the end of 2002, ASM America's general manager Hans Wunderl resigned and while his position remained temporarily vacant, the American operation slowly slipped away in disarray. ${ }^{150}$ The size of responsibilities attributed to ASM America and the lack of management control distorted development works and the rollout of epitaxy. Budgeting, communications, and decision-making within the research and development groups was suboptimal. This involved both epitaxy and ALD. Managerial oversight and intervention were indispensable.

In early 2003, as financial returns on the ALD investments did not yet materialize, the Supervisory Board requested a profit and loss account for each product group. The numbers had to speak for themselves. A new group was established, named 'Transistor and Capacitor Products.' As it appeared in 2003, the Transistor and Capacitor Products group had never been profitable since the acquisition of ASM Microchemistry. ${ }^{151}$ Time was ticking, the recession in the industry lingered on, making the Supervisory Board urge the Front-End Board to improve the balance sheet of the company as a whole. ${ }^{152}$ This meant that

\footnotetext{
149 Ibid.

150 ASM International, Ivo Raaijmakers, 'Memorandum: ASMA' (4-11-2002) Archive Arthur del Prado - Ivo Raaijmakers file.

151 ASMI, Marike Overhoff and Ivo Raaijmakers, 'Operation Sauna' (31-3-2003) Archive Arthur del Prado - ASM Microchemistry file.

152 Most of these decisions fell upon the European operations - ASM Europe and ASM
} 
Han Westendorp, who replaced Queyssac as chief operating officer in the fall of 2002, and chief technology officer Ivo Raaijmakers had to make tough decisions concerning the Transistor and Capacitor Products group.

On March 31, 2003, a restructuring scheme labeled 'Operation Sauna' was initiated. Up to that time, ASM Microchemistry operated from its old premises in Espoo, intended to accommodate a growing equipment manufacturer. At this location, however, the working atmosphere suffered from the 'empty building syndrome. ${ }^{153}$ Moreover, the operating costs of the small facility exceeded what could be justified considering its size. In Finland, the restructuring operation was known as the 'second big-bang,' as the operation was downsized again, this time from a few dozen staff to just half a dozen scientists. By August 2003, in concordance with the University of Helsinki - and, in particular, professor in Inorganic Chemistry, Markku Leskelä - the group was relocated to the university's premises. Since the 1980s, this university had been involved in materials research for ALD, often in collaboration with Tuomo Suntola and the Microchemistry staff. ASM Microchemistry would focus on materials and process development and characterization for advanced technology nodes like 32-nanometer and beyond. ASM Microchemistry became the company's materials R\&D center for the Transistor and Capacitor Products product group.

\section{Selecting gate stack materials and suppliers}

In mid-2003, Intel selected the materials - and, in doing so, also their suppliers - that it wanted to use for high-volume manufacturing. At this stage, ASM won and lost. Its high-k dielectric processes was chosen for the 45-nanometer node. But it became clear that ASM would not supply all the techniques for the creation of a complete gate stack.

ASM would owe its success with the ALD hafnium oxide process to its control over its precursor. ALD offered better temperature control, low surface roughness, and precise thickness. ${ }^{154}$ For the growth of the ALD process, ASM used hafnium chloride - or, more precisely, hafnium tetrachloride $\left(\mathrm{HfCl}_{4}\right)$. This in contrast to competitors like Applied Materials, which propagated the rather unpronounceable material tetrakis-dimethylamino-hafnium, or, in short, TDMAH, $\left(\left(\mathrm{CH}_{3}\right)_{2} \mathrm{~N}\right)_{4} \mathrm{Hf} .{ }^{155}$

Microchemistry - and entailed a readjustment of the general manufacturing strategy of all operations (see Business V). - ASMI, Han Westendorp, 'Progress Report Q3, 2003' (20-102003) Archive Arthur del Prado - RvC 2003 file.

153 ASM International, Marike Overhoff and Ivo Raaijmakers, 'Presentation Operation Sauna' (31-3-2003) Archive Arthur del Prado - ASM Microchemistry file.

154 ASM America, Eric Shero, 'Presentation: Production-Ready ALD toolset using HfCl4 derived HfO2 gate dielectrics for CMOS' (23-6-2008) Archive Author.

155 ASM Microchemistry, Marko Tuominen, 'ASM Microchemistry R\&D Future Plans' (175-2002) Archive Arthur del Prado - ASM Microchemistry file; and ASM America, Eric Shero, 
This metal organic compound, a liquid at room temperature, was alternated with water $\left(\mathrm{H}_{2} \mathrm{O}\right)$ or ozone $\left(\mathrm{O}_{3}\right)$ to form a film of hafnium oxide. The difference between TDMAH and hafnium chloride involved the quality of the hafnium oxide film, as well as the stability and safety of the precursor for high-volume manufacturing. ${ }^{156}$ Several customers urged ASM to test the TDMAH precursor in one of its ALD modules. However, this resulted in too much carbon contamination in the film, preventing its proper functioning as dielectric. And, as discussed, leakage reduction was the primary goal of developing high-k gate dielectrics; lower energy consumption opened new applications for computer chips.

The key obstacle for immediate pursuit of hafnium chloride as the precursor for high-k gate dielectrics was its source. ASM's hafnium chloride was supplied through a solid source. The solid material evaporated at higher temperatures without an intermediate liquid phase. The fact that it was a solid material led to numerous engineering challenges. The precursor had to be evaporated in a consistent, reliable, and clean way, uninterrupted for a significant period time. Earlier, ASM Microchemistry developed a delivery system and was very familiar with chloride-based high-k processes, but that system needed to be completely re-engineered in order to meet high-volume manufacturing requirements. As Ivo Raaijmakers explained:

'The solid source was problematic during scale-up, due to the particles and defects, to put it simply. First, it is very difficult to obtain a reproducible dose from a solid source, because the contact between gas and solid phase is not reliable. It takes a lot of time to equilibrate the evaporation density of a solid source. You don't have that time, because you want to pulse very quickly due to the intended throughput. A lot needs to happen to accelerate the solid source development. ${ }^{157}$

The solid source had to balance surface morphology, source depletion, evaporation rate, and temperature control. ${ }^{158}$ By closely collaborating with subcontractors ATMI and Air Products, ASM America redesigned the solid source carrier rather quickly. Key to its design was the subdivision of the container containing the

'Presentation: Production-Ready ALD toolset using HfCl4 derived HfO2 gate dielectrics for CMOS' (23-6-2008) www.asmtheswitchison.com (website no longer online) PDF file of presentation in author's archive.

156 ASM America and ATMI Inc., Mohith Verghese, Scott Battle, and Jeff Roeder, 'Solid-Source Delivery System Enables Hafnium-Based Gate Dielectrics', Semiconductor International (April 2008).

157 Original quote in Dutch. - Ivo Raaijmakers, 'Interview with author'.

158 ASMA, ATMI Inc, Verghese, Battle, and Roeder, 'Solid-Source Delivery System Enables Hafnium-Based Gate Dielectrics'. 
solid source into multiple trays. ${ }^{159}$ This resulted in a larger evaporation surface, increased gas flow, control of material depletion, and better contact between carrier gas and evaporated precursor surface. Devising the solid source carrier and verifying potential for industrial usage was just the beginning, however. In the following years, ASM's hafnium oxide process had to be prepared for highvolume manufacturing.

While ASM succeeded with its high-k process, its ambition to offer a complete cluster system - covering the whole production process of a gate stack - fell apart by mid-2003. In the last years toward the expected introduction in highvolume manufacturing, only Pulsar 3000 modules would be connected to the Polygon wafer handler for reasons of manufacturing efficiency and cost. The 1996 plan to supply an integrated manufacturing process caught up with the desire of the leading customers to use ASM's ALD high-k in combination with their own respective proprietary metal gate processes.

The disintegration of ASM's integrated process ambition was rooted in the emerging production recipe of the chip manufacturers. To create the new gate stack, two options were available: gate first or gate last. ${ }^{160}$ The 'gate first' option was the common way (figure 79). First, the gate stack was created, after which, by means of ion implantation, the source and drain followed. A successive annealing step, required to repair ion implanted parts, negatively affected the gate electrode. The hafnium oxide crystallized and the metal electrode diffused into the dielectric film.

The 'gate last' approach circumvented the annealing step (figure 80). ${ }^{161}$ This approach basically followed the 'gate first' approach, yet it involved a sacrificial polysilicon electrode instead of the intended metal gate. The polysilicon functioned as a sarcophagus for the vulnerable hafnium oxide during ion implantation and annealing of the source and drain. At the high annealing temperatures, hafnium oxide and polysilicon remained compatible. ${ }^{162}$ After the annealing step, the polysilicon was replaced by a metal electrode. Intel opted for this 'gate last' approach, and the rest of the industry would soon follow as well. ${ }^{163}$

159 Ibid.

160 IMEC, Thomas Y Hoffmann, 'Integrating high-k/metal gates: gate-first or gate-last?' Solid State Technology (1-3-2010); Intel, Bohr, Chau, Ghani, and Mistry, 'The High-k Solution'.

161 Intel, Chris Auth, Mark Buehler, Analisa Cappellani et al., '45 nm High-K+Metal Gate StrainEnhanced Transistors', Intel Technology Journal 12:2 (2008), pp. 77-85, p. 78.

162 Note that zirconium oxide had been rejected as a high-k dielectric, despite its higher dielectric constant, because of its incompatibility with polysilicon at higher temperatures. The polysilicon diffused into the zirconium oxide. Hafnium oxide and polysilicon remained stable.

163 IMEC, Hoffmann, 'Integrating high-k/metal gates: gate-first or gate-last?’; Intel, Kaizad 
Innovation IV - Enacting high-k gate dielectrics and atomic layer deposition technology, 1996-2007

\section{Figure 79}

Gate first manufacturing process for high-k metal gate CMOS transistors, late-00s.

\section{Description of} fabrication process

1. Deposition of high- $\mathrm{k}$ dielectric (ALD)

2. Deposition of cap layer (LPCVD)

3. Deposition of P-metal (PVD or ALD)

4. Patterning of P-metal (lithography and etch process)

5. Deposition of $\mathrm{N}$-metal (PVD or ALD)

\section{Patterning of $\mathrm{N}$-metal}

(lithography and etch process)

7. Deposition of metal gate (PVD)

8. Deposition of polysilicon (LPCVD)

\section{Patterning of layers}

(lithography and various etch processes)

10. Formation of source and drain (ion implantation, lithography and etch processes) 11. Annealing of source and drain (RTA)

12. Deposition of gate spacer (CVD)

13. Patterning of gate spacer (etch)

14. Deposition of inter-layer dielectric (PECVD)

\section{Cross-sectional depiction fabrication process of a single CMOS transistor}
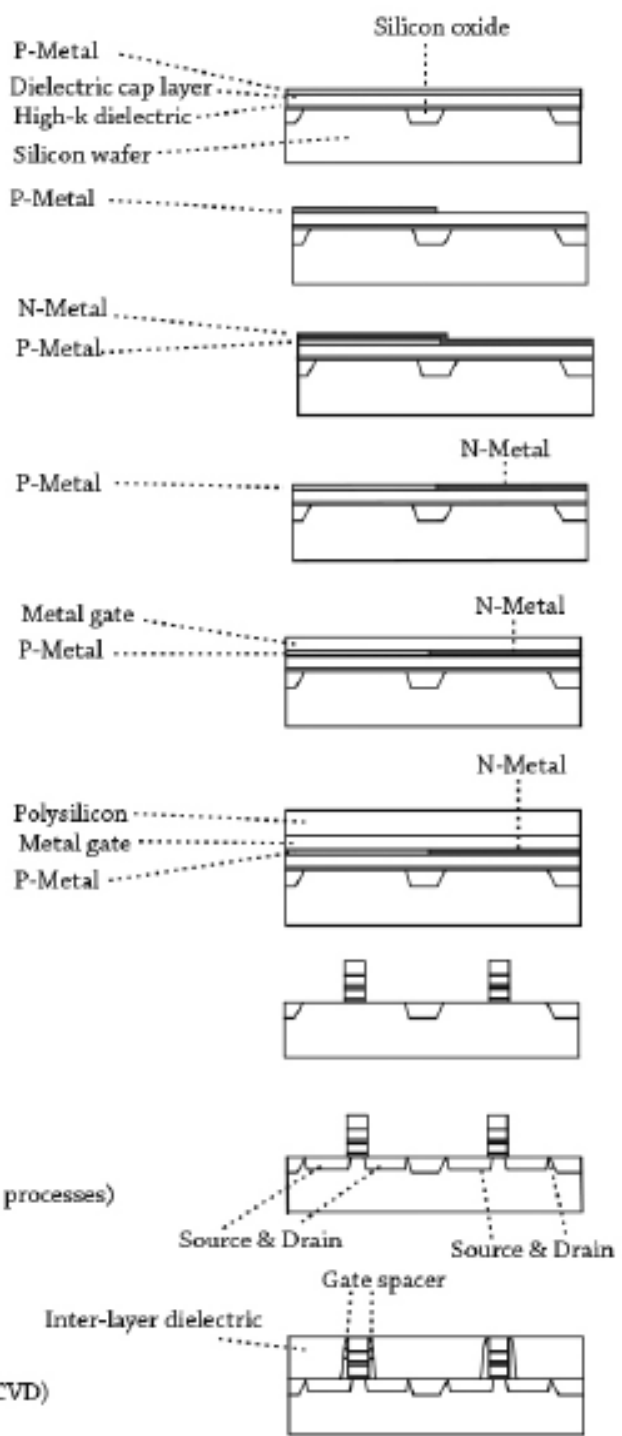

Mistry et al., 'Presentation at 2007 IEDM Conference: A 45nm Logic technology with High0k + Metal Gate Transistors, Strained Silicon, 9 Cu Interconnect Layers, 193 Dry Patterning, and 100 Pb-free Packaging', Intel.com (10-12-2007); and Intel, Bohr, Chau, Ghani, and Mistry, 'The High-k Solution'. 


\section{Figure 80}

Gate last manufacturing process for high-k metal gate CMOS transistors, late-00's

\section{Description of fabrication process}

1. Deposition of high-k dielectric (ALD)

2. Deposition of polysilicon (LPCVD)

3. Patterning of gate stack (lithography and etch process of high-k and polysilicon)

4. Formation of source and drain (ion implantation, lithography and etch processes)

5. Annealing of source and drain (RTA)

6. Deposition of gate spacer (CVD)

7. Patterning of gate spacer (etch)

8. Deposition of interlayer dielectric (PECVD)

9. Removal of polysilicon gate electrode (etch)

10. Deposition of P-metal (PVD or ALD)

11. Patterning of P-metal (lithography and etching)

12. Deposition of N-Metal (PVD or ALD)

\section{Patterning of $\mathrm{N}$-metal} (lithography and etching)

12. Deposition of metal gate (PVD) 13. Metal gate polish (CMP)

P-Metal

\section{Cross-sectional depiction fabrication process of a single CMOS transistor}
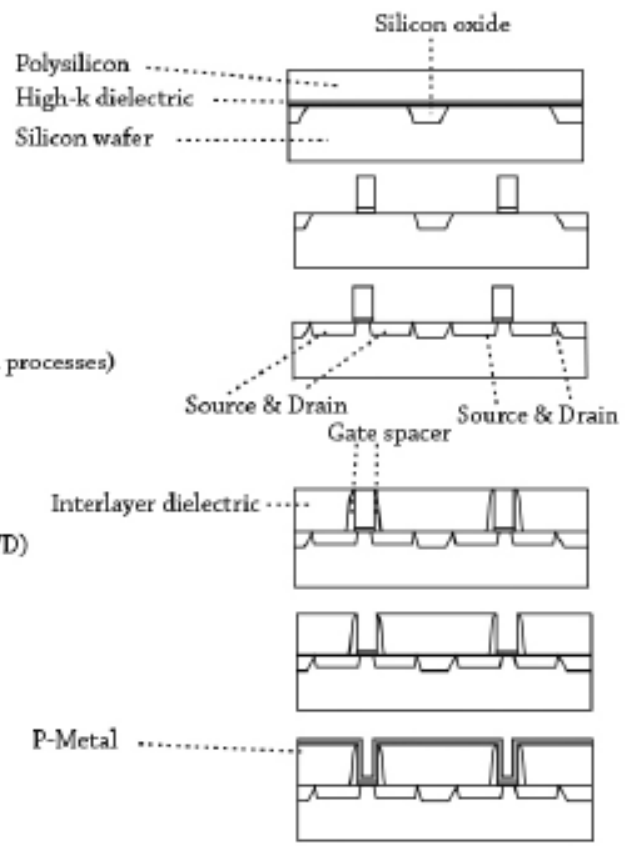

P-Metal

N-Metal

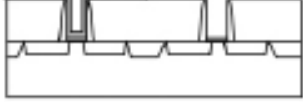

P-Metal

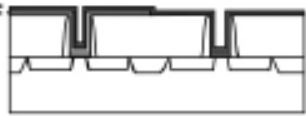

P-Metal

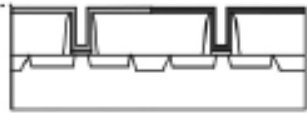

Metal gate

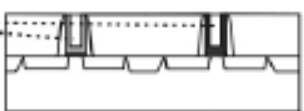


The decision to choose the 'gate last' recipe made that Intel no longer needed the polysilicon and nitride RTP modules (mind the original configuration depicted in figure 77). The polysilicon in the 'gate last' method did not have to be grown in a high quality integrated process. A normal film grown in a common vertical batch furnace was sufficient, as well as more economical. Moreover, ASM did not offer the indispensable annealing step in the Polygon. The switch to metal gate made a nitride barrier film obsolete; the material was not needed between the hafnium oxide and the metal gate. The metal gate processes could be done separately in a metallization machine.

By the end of 2003, the research geared to characterizing the hafnium oxide material came to a conclusion. Intel engineers managed to produce wafers with working transistors containing the new high-k gate dielectric and metal gate, be it at a 130-nanometer scale, however. As the Intel process engineers recalled:

'Having built well-functioning transistors using old technology, in the second half of 2003 it was time to move from research to development of high-k dielectric plus metal gate transistors, as we called them. Engineers began working to determine whether these early transistors could be scaled to the upcoming $45-\mathrm{nm}$ dimensions and still meet the rigorous performance, reliability, and manufacturability requirements of an advanced microprocessor technology. ${ }^{164}$

For the public, this meant that the time of promising announcements was over, as all the competitors - chips and equipment vendors alike - returned to their development labs to ready their gate stack technology for high-volume production. The whole manufacturing process had to be tweaked and tuned to guarantee a robust production flow.

This was also quite visible at the 2003 IEDM conference. ${ }^{165}$ If the new technology was given attention at all, it pertained to hafnium oxide. No presentation was held about zirconium or any other dielectric processes. High-k dielectric ceased to be the 'hottest' topic. More attention was given to other ways of improving the electrical properties of the smallest transistors. After more than three years of research, the semiconductor industry clearly had accepted hafnium oxide as the exotic, high-k dielectric material required for the future gate stack.

164 Intel, Bohr, Chau, Ghani, and Mistry, 'The High-k Solution'.

165 One entire session was called 'Hf-based Gate Dielectric', and was chaired by ASM America's new process engineer Glen Wilk - who previously worked at Bell Labs - and Bich-Yen Nguyen of Motorola. - IEEE, IEEE International Electronic Devices Meeting 2003, Technical Digest (8-122003). 
This new phase in development was also reflected in ASM's gate stack technology staff. The old guard made way for a new group of engineers aiming for productization. In particular ASM International's corporate management distanced itself from the project. With the gate stack program well underway, and after more than ten years of lobbying and support, Chris Werkhoven began to focus on other advanced technology programs that could diversify ASM's addressable markets. Ernst Granneman had already begun to devote all his efforts to the new RTP reactor called Levitor. Chief technology officer Ivo Raaijmakers and chief operations officer Han Westendorp had to concentrate on keeping the proliferation of ALD projects in check beyond the gate stack. Chief executive officer Arthur del Prado grew less involved in operational affairs and focused primarily on strategic developments, such as the acquisition and integration of Genitech and Nutool.

As to the final miles of commercializing ASM's gate stack technology, ASM America was fully in charge. Chuck del Prado, Arthur del Prado's eldest son, who had made a steady career at IBM, ASML, and ASM Europe, filled in the vacancy of General Manager. A former process engineer of Bell Labs, Dr. Glen Wilk took up the role of ALD Technology Manager. The process engineer in charge of Polygon-based developments, Eric Shero, moved into a more prominent position for the gate stack. Ray Ciferno, a former employee of Intel, joined as the new Intel Account Manager, overseeing and streamlining ASM's interactions with this leading account. ASM America's Timo Bergman and Henk de Waard and several others continued to be involved in the project in varying positions. It was now up to Shero, Wilk, and, of course, Suvi Haukka and their engineering teams to walk the last miles of the high-k development for introduction at the 45-nanometer node.

\section{Intel defines the manufacturing process}

At Intel, the main driver of the high-k gate dielectrics, things were prepared for the final push toward ramping up the technology for high-volume manufacturing. The chip manufacturer defined the different metals used for, respectively, NMOS and PMOS transistors, which comprised a CMOS-transistor. The exact composition of these materials has remained secret to this day. All lights turned green, as the Intel engineers recalled:

'During the months that followed, the team cracked one problem after another - making changes to materials, chemical recipes, and manufacturing processes. It wasn't until late 2004 that the team felt it had enough convincing data that the new transistors could be made to work on our 45-nm technology. At that point, there was no turning back. Intel was now committed to making a high-k dielectric plus metal 
gate transistor structure using the gate-last process flow. It was a gutsy call. Our team knew it was committing all of Intel's next generation of microprocessors to the biggest change in transistor technology in 40 years.' ${ }^{166}$

In the meantime, at ASM America, all focus for the development was directed at increasing the reliability and quality of the system. ${ }^{167}$ In cooperation with subcontractors, many efforts concentrated on the sophisticated delivery system and solid source of the hafnium chloride precursors.

The high frequency of reactant injections and purges fundamental to an ALD process required a gas supply system that was very different from a conventional CVD machine. In conventional CVD machines, gasses were supplied through pipes connecting the tool with high pressure tanks or large bubblers outside the clean room. This was not possible for an ALD tool. Reactant delivery needed to be an integral part of the reactor to avoid any chance of precursor condensation during transport into the reactor. Furthermore, the less the precursor vessel had to be exchanged, the better it was. This pertained to safety considerations, as the precursor was rather hazardous, but also to economic concerns, because during exchange of the precursor's vessel the reactor stopped processing wafers in an otherwise 24/7 ongoing production facility. Throughout 2004 and 2005, much effort was put into optimizing change of the solid source. ${ }^{168}$

Another innovation involved the acceleration of the gas injection pulses. Depositing films with a thickness of one molecule layer - alternating between precursors and purge gasses - was relatively slow. Very fast-switching valves were required to speed up this process. To this end ASM developed 'inert gas valving. ${ }^{169}$ A convective gas flow of nitrogen stopped the chemical diffusion of the precursor into the reactor chamber. Through this, switching speeds below 250 milliseconds were possible, and the gas valve itself could be positioned in closer proximity to the reactor chamber.

As an equipment and process supplier, the capability to enable advanced processes on an industrial scale for the high-demanding semiconductor manufacturing constituted ASM's raison d'etre. In the development of the high-k gate dielectric, it was in particular this innovation - using the hafnium

166 Intel, Bohr, Chau, Ghani, and Mistry, 'The High-k Solution'.

167 ASM America, Chuck del Prado, 'Memorandum: Operational Monthly Report, ASMA November' (13-10-2003) Archive Arthur del Prado-ASMA 00’s file.

168 ASM America, Eric Shero, 'Presentation: Production-Ready ALD toolset using HfCl4 derived HfO2 gate dielectrics for CMOS' (23-6-2008) Archive Author. 
chloride solid precursor at an industrial scale - that largely determined ASM's competitiveness.

In the case of the high-k program, developments at ASM progressed independently from those at Intel, even though this firm led the industry on this matter. As Han Westendorp reported to the ASM International Supervisory Board:

'Since mid-2004 our gate metal program has gotten a big boost as a result of the acquisition of Genitech. However, the choice for gate metal, as opposed to gate dielectric, is still open in the industry. ${ }^{170}$

In contrast to the thermal ALD process for high-k dielectrics, the metal gate process was a plasma enhanced ALD (PEALD) process. By the fall of 2004, ASM America had developed a metal gate tool, while elaborating upon ASM Genitech and ASM Japan's plasma-based process knowledge. It offered the EmerALD process module, which could be integrated into the Polygon cluster. ASM continued to foster its capabilities as process integrator through offering both high-k and metal gate modules as part of a Polygon.

In the fall of 2004, ASM shipped additional high-k hafnium development tools to customers in Taiwan, Japan and the United States. In some cases, these tools included even the novel metal gate modules. ${ }^{171}$

\section{Introduction of high-k dielectrics in high-volume manufacturing}

Finally, in December 2005, Intel announced its intention to use high-k at the 45-nanometer node. Two months later, Westendorp reported in anticipation of this decision to the Supervisory Board:

'... If Intel were indeed to select ASM for high-k gate stack, it would be an excellent catalyst for the [Transistor and Capacitor Products] product group to focus on an [high-volume-manufacturing] product. ${ }^{172}$

Was Intel finally going to commit itself to ASM's high-k gate stack technology in the upcoming technology node? Was ASM finally, after all these years, going to deliver the solution for the gate stack challenge envisaged in the 1990s? Westendorp set out his 2006 sales plan modestly just above a ten million euros,

170 ASMI, Supervisory Board, 'ASMI- Full Progress Report Q1 2005' (25-4-2005) Archive Arthur del Prado-RvC 2005.

171 ASMI, Supervisory Board, 'ASMI- Full Progress Report Q1 2005' (25-4-2005) Archive Arthur del Prado-RvC 2005.

172 ASMI, Han Westendorp, 'ASM Front-End Product Portfolio Update - Q1, 2006' (16-4-2006) Archive Arthur del Prado - RvC 2006 files, p. 9. 
with an operating loss of a few millions. Nothing concrete was yet to report. ASM America and ASM Japan were forced to deal with cost reductions in the new ALD applications, such as metal gate and capacitor dielectrics.

By April 2006, the glimmer of hope from months earlier materialized in a real prospect. Intel proceeded with purchase orders For ASM, the ordered tools meant that Intel wanted to integrate ASM's high-k gate dielectric technology in successive fabs all over the world. Things were moving fast now. After the tools got manufactured, installed, and prepared during the course of 2006, the new 45-nanometer factory lines of Intel would ramp up production.

\section{Intel presents its first 45-nanometer microprocessors with high-k dielectrics}

In January 2007, Intel produced its first 45-nanometer computer chips using the new gate stack materials. ${ }^{173}$ Two products were introduced shortly after each other. The first was dubbed the Penryn, which was meant for mobile, desktop, and server applications, or so called high-power applications. Two variants were available, a dual core microprocessor, which consisted of 410 million transistors, and a quad core containing 820 million transistors. Next to the Penryn, the Silverthorne was introduced, having 47 million transistors aiming at low power applications, such as the first smartphones. Each of the millions of transistors in these chips consisted of a gate stack with ASM's high-k dielectric film. The high-k gate dielectric contributed by decreasing energy leakages and thus improving energy efficiencies. ${ }^{174}$ Furthermore, these Penryn and Silverthorne computer chips were manufactured by the hundreds of thousands - imagine the scale! In November 2007, the Penryn was produced in high volume at the different fabs.

The introduction of these 45-nanometer integrated circuits was accompanied by a large marketing campaign of Intel, which highlighted the historic innovation of these chips. The unprecedented development concerned the alteration of the gate stack technology with two new materials: the high-k dielectric and the metal gates. After forty years of semiconductor manufacturing, the CMOS transistor's basic structure was remodified for the first time. Intel announced it as a revolutionary development.

To back up its argument, Gordon Moore - founder of Intel, R\&D manager at the time of the introduction of the polysilicon gate stack forty years earlier, and the man after which the infamous Moore's Law was named - was deployed to emphasize the historic change in semiconductor architecture. Intel also had its leading engineers of the program (Mark Bohr, Robert Chau, Tahir Ghani, and Kaizad Mistry) explain the innovation process, its notable character, and 
its meaning for the industry. ${ }^{175}$ Evidently, Intel wanted to be recognized as the industry technological leader for computer chips. ${ }^{176}$ Through its microprocessors, Intel in particular required high performance chips and thus had driven the high-k metal gate developments. The rest of the industry was able to increase the performance of their chips partially through licensing an alternate chip architecture, named ARM. This smart way of designing a computer chip enabled state-of-the-art performance requiring fewer transistors. And fewer transistors meant less power consumption. Through ARM, the competition was able to address the market for mobile electronics, which did not yet require the costly high-k manufacturing process.

Panasonic's Matsushita was the first chip manufacturer to have a 45-nanometer chip, but one without high-k metal gate materials and thus not capable of harnessing the same performance. ${ }^{177}$ In the introduction of high-k and metal gates into high-volume manufacturing, the competition followed Intel three years later, in 2010. IBM was to be the second to succeed in creating a 45-nanometer chip with the gate technology by 2007, but only at the next technology node it was able to integrate it into a high-volume manufacturing line. ${ }^{178}$ IBM's 32-nanometer technology was licensed by Globalfoundries (a foundry which had acquired the manufacturing operations of AMD and Chartered Semiconductor), Toshiba, Sony, Samsung, Infineon, and others. ${ }^{179}$ The Japanese NEC was the first to announce a working high-k dielectric, to be produced as of mid-2007, yet at a bigger scale of 55 nanometers. ${ }^{180}$ In the following years, all major chip manufacturers presented their solution for new gate stack materials.

Intel had led the herd in applying these new materials into its chips, which was recognized by the industry equipment organization SEMI in 2012 by presenting Intel engineers Bohr, Chau, Ghani, Mistry and some others the 2012 SEMI Award

175 Intel, Bohr, Chau, Ghani, and Mistry, 'The High-k Solution'.

176 Don Scansen, 'Under the Hood: Intel's 45nm high-k metal-gate process', eetimes.com (14-112007).

177 Ibid.

178 Ann Steffora Mutschler, 'Intel, IBM embrace high-k metal gates for 45nm', edn.com (29-12007); IBM, 'IBM Alliances Deliver Easier Path to Next Generation Semiconductor Products', ibm.com (10-12-1007); Mark LaPedus, 'IBM and partners tip high-k, metal gates', eetimes. com (21-1-2007).

179 IBM and AMD also invested heavily into another technique meant to improve chip performance at the smallest scale. This was called 'silicon on insulator', offered by the French firm Soitec.

180 Author unknown, 'NEC offers platform for cell-based ICs', eetimes.com (18-1-2007); Mark LaPedus, 'NEC tips 55-nm process with high-k immersion', eetimes.com (9-6-2006). 
for North America, in recognition of their development work on high-k dielectric and metal gates. ${ }^{181}$

\section{ASM's long development path concluded?}

For ASM, the announcement of the introduction of high-k gate dielectrics marked the conclusion of a unique and distinctive development period. It had started in 1995 with the Siemens and AST joint-development program surrounding the RTP cluster and came to an end with the purchase orders for high-volume manufacturing for Intel's 45-nanometer microprocessors by the fall of 2006. It had taken ASM eleven years of painstaking investments, research, patience, and persistence.

As the other chips manufacturers started to use the high-k dielectrics and metal gates as well, ASM moved forward to cash in on its pioneering role. After all, the introduction of high-k dielectrics was also the first time its ALD technology was used in high-volume manufacturing. Competitors had already supplied less advanced aluminum oxide ALD processes for memory capacitors. But the innovation of a high-k gate dielectric for microprocessors compelled another level of materials research, integration, and process development, as it involved tinkering with the most critical part of the semiconductor technology, the transistor gate. In 2007, ASM started a marketing campaign dubbed 'ASM: The Switch is On.' The company had managed to develop the new gate stack, the switch of the transistor, and everyone should know they had to come to ASM for it. ${ }^{182}$

Unfortunately, the momentous conclusion of the gate stack program was overshadowed by activist hedge funds. In the same period, ASM's long-time chief executive officer and founder Arthur del Prado announced to his shareholders and employees that his son Chuck del Prado, who had been in charge of ASM America since 2002, would succeed him. In the turmoil that followed, ASM received an unsolicited offering from Applied Materials of around 300 million euros for its atomic layer deposition and plasma CVD process. ${ }^{183}$ The rapidly escalating financial crisis of 2007 put a spoke in Applied's wheel and annulled the

181 SEMI, 'Intel Receivers the SEMI Award for A Process and Technology Integration Breakthrough - the High-k Solution', semi.org (5-2-2013).

182 Applied Materials did the same, however, if emphasizing its role for the metal gate. - Applied Materials, 'Press release: Applied Materials Makes the Transistor Cool Again with Integrated High-k/Metal Gate Technology', appliedmaterials.com (17-7-2007).

183 Vidya Ram, 'Applied Materials Makes Move on ASM', forbes.com (8-6-2008); Mark Osborne, 'Applied Materials ends acquisition talks with ASM International' fabtech.org (14-11-2008); ASM International, Erik Kamerbeek and Mary Jo Dieckhaus, 'ASM International announces receipt of unsolicited indicative combined offer for front-end business activities from Applied materials and Francisco Partners' asm.com (17-6-2008). 
negotiations. The takeover was aimed at acquiring ASM's gate stack technology and was a clear token of appreciation of course.

ASM's efforts in innovating the gate stack received an even greater boost, as some customers opted for a metal gate deposited by ALD - ASM's ALD process - in successive technology nodes. ${ }^{184}$ The details of the metal gate process and materials have remained undisclosed, however, even up to this day, and therefore this issue is difficult to assess and study. But it can be concluded that ASM's ALD-based high-k dielectric processes proved to be much more versatile. The process could be applied to the rapidly changing transistor structures after the 32-nanometer node, such as the so-called FinFET's and successive threedimensional structures. For these more complex transistor configurations, the unprecedented conformality (step coverage) of the ALD deposited films was indispensable. The longevity of ASM's hafnium oxide gate dielectric process was critical for its success.

184 [author unknown], 'ASMI New ALD tool offers single-metal gate stack for 32nm HK+MG' electroiq.com (19-5-2008). 


\section{Conclusions}

In 2007, after more than a decade of research and development, ASM succeeded in commercializing and industrializing its high-k gate dielectric and atomic layer deposition (ALD) technology. From 1996 until 2008, ASM's R\&D investments totaled approximately 100 million euros, including all investments in ALD within the Transistor \& Capacitor Group (figure 81). The returns on these investments followed soon after the installation of Polygon cluster machines - combined with at least Pulsar 3000 modules - in 45-nanometer fabs of Intel and other chip manufacturers.

\section{Figure 81}

Graph of ratio of R\&D expenses and revenues in ALD by ASM International, 1999-2007 Due to the introduction of ASM's ALD technology in high-volume manufacturing by Intel 2007, the ratio of R\&D expenses rapidly decreased. The investments in R\&D began to pay off.

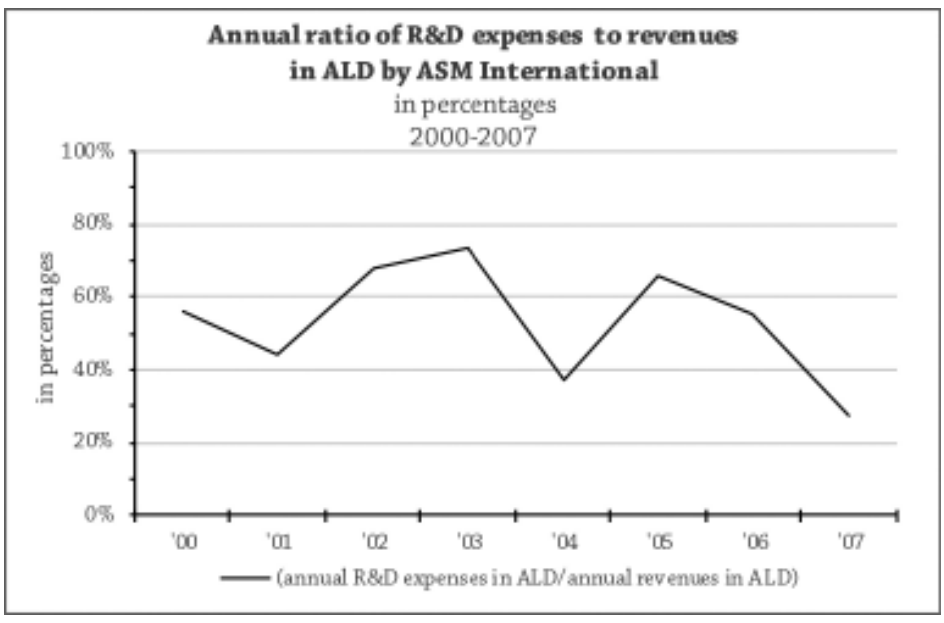

In these conclusions, I assess the influence of ASM on the innovation process resulting in equipment to produce high-k gate dielectrics, as a way to answer the research question posed at the beginning of this part. I will also reflect on the findings in a more sustained fashion by once again considering the role of this study's three key elements in this particular innovation story: fortuna, virtù, and path. 
Mastering the new high-k gate dielectric was not a one-horse race in the semiconductor industry's pursuit of Moore's Law. There were multiple alternatives to the technology, most of them less costly and less complex to master. But innovating the gate stack was relevant for the whole industry, sooner or later. At some point in the near or distant future, chip manufacturers willing to produce CMOS chips at a smaller scale had to deal with the matter. The high-k gate dielectric was unescapable.

But its realization was undefined. The innovation introduced in industrial production by Intel in 2007 could not have been envisaged at the start of the development process. Only through an open-ended process of variation and selection did the hafnium oxide metal gate combination surface as the result. Each action paved the way for the next.

The initial pursuit for integrated rapid thermal processes (RTP) to deposit silicon nitride and polysilicon generated appreciation of the lifespan of fairly more conventional materials and techniques (consider figure 76 in Chapter 27). Embroidering upon the integrated RTP efforts in combination with the novel ALD technique enabled the selection of hafnium oxide as the most viable high-k gate dielectric. Only at that point could the manufacturing process be defined: gate-first or gate-last. Once this was defined, the whole fabrication process had to be matured and scaled to industrial standards, before it could be effectuated in a real manufacturing plant.

This whole process of variation and selection at ASM was very much defined by the chip manufacturers. They defined the application of the technologies in development by ASM, like the RTP cluster for EEPROM and eventually the gate stack in case of the silicon nitride RTP, the A800/Polygon, and ALD technologies. The customers also defined the parameters and specifications to which these techniques had to comply in order to be applicable. Furthermore, customers made material selections in the innovation process. Deselecting silicon oxide, aluminum oxide, and zirconium oxide as candidates.

More significant was Intel's willingness to stimulate mergers and acquisitions within its supply chain - in this case, bringing Microchemistry and ASM together in order to further the development of ALD for the gate stack. A final and striking example of the influence of chip manufacturers on the innovation process in their supply chain involved some of their consultancy into the organizational processes of ASM and its subsidiaries. Chip manufacturers defined the structure and pace of the innovation process at ASM.

Yet their clout did not turn ASM into a mere puppet. The equipment supplier was pivotal in the evolvement and thus outcome of the innovation process. This started with the development of unique technological capabilities, like the silicon nitride RTP process with remote plasma generator or the Microchemistry's 
ALD process. Another contribution was the upgrading of scientifically proven technologies from lab to fab - from a laboratory to an industrial factory. This involved ingenuous engineering in order to comply to MESC standards or specific customer demands. Furthermore, the equipment supplier effectuated the materials and tools to explore further options.

Returning to the research question about the influence of the equipment supplier on the innovation process, I conclude that the supply chain as a whole was challenged to participate. For none of the links in this chain was innovation a mere fill-in job. Equipment suppliers, but also the gas suppliers ATMI and Air Products, constructed new realities for further action. This applied to ASM vis-à-vis its customers, but also to ATMI and Air Products vis-à-vis ASM. In turn, companies like Intel provided room for innovation toward their customers - the manufacturers of PCs predominantly. All participated in a chain of interdependent innovation indeed.

\section{Fortuna}

Unexpected events - fortuna - partially steered the innovation process as well. To be more precise, manifestations of fortuna affected ASM and Intel. Here, I will assess this influence of fortuna for ASM.

Gate stack innovation witnessed four distinct manifestations of fortuna. The first was the unexpected thin film of silicon nitride resulting from ASM's silicon nitride RTP process with remote plasma generator. This fortuna put ASM onto the path of the technologically advanced semiconductor manufacturers in the United States like Intel and IBM.

The second was the sudden availability of Microchemistry. A new technology and operation were added to the company's assets. In the pursuit to capitalize on both, the firm and the technology, the gate stack became definitely consolidated as a viable opportunity. Henceforth, the unexpected acquisition of Microchemistry boosted ASM's slumbering efforts into innovating gate stack technology.

Fortuna manifested itself a third time through the industrial and economic upturn and downturn from 1999 to 2001 . The Dotcom Boom was a dynamic that was unexpected, yet highly defining for the evolvement of the innovation process. In its wake, ASM acquired Microchemistry and initiated a thorough plan for the development of ALD and the gate stack. The following Dotcom Bust forced a radical overhaul of the development program, resulting in the downsizing of ASM Microchemistry and the transfer of the high-k developments to ASM America in Phoenix, Arizona.

The fourth manifestation of fortuna can be said to have been present throughout the years addressed: the intentions of ASM's customers, Intel primarily. What did this company want? What were its intentions with ASM? The role of Intel in bringing Microchemistry and ASM together underlined the chip 
manufacturer's clout. Conversely, uncertainty about ASM's customers' intentions constituted a major concern for the equipment vendor during the entire period covered here. Even close consultancy initiatives taken by the chip manufacturers could not fully remove the anxiety.

Like in the previous Innovation chapters, fortuna manifested itself within the material, economical, and industrial realm during this period. Individual and financial manifestations that affected ASM's innovation process in the previous case-studies were absent. The same is true of the life-threatening Machiavellian Moments. The far-reaching involvement of Intel in ASM's organizational processes might be one explanation. Intel deliberately tried to limit risk, unexpected surprises, i.e. fortuna. In particular with regard to the prestigious innovation of the gate stack for which the stakes were incredibly high at Intel itself.

As for ASM, the wheels that turned within its customers' organization often resembled the wheels of fortune. Customer feedback was to be expected, but what it would be and what impact it would have was hard to anticipate in most cases. Moreover, until Intel actually procured ASM's machines, the whole endeavor remained uncertain to a large degree. Even more than in the previous chapters, ASM was exposed to the whims of its customers.

\section{Virtù}

Three examples of virtù can be distinguished. The first display of virtù paved the way for the acquisition of Microchemistry and set ASM upon the course of innovating the gate stack. It entailed the actions taken by Chris Werkhoven in pursuit of his ideas about integrated RTP and customer-oriented innovation. Initially by securing the interest of Siemens Semiconductors for further development of integrated processes in a joint-development program in 1996. At the end of the Siemens-project, Werkhoven successfully secured the interest of leading American chip manufacturers in the silicon nitride RTP process. Through this actions - persistent hawking, to be accurate - Werkhoven kept ASM's potential as process integrator alive despite internal skepticism within ASM, unintentionally launching the equipment manufacturer on this gate stack trajectory.

Secondly, virtù was shown by the corporate management of ASM International. Not so much individually but rather as a collective, in various configurations, the managers acted upon unexpected events affecting the development. This involved the adequate acquisition and integration of Microchemistry in 1999, and the 2001 reorganization.

The third display of virtù involved Intel. By consistently and opportunistically arranging its supply chain to evolving technological understanding and industrial dynamics, Intel secured the survival of the gate stack development. 
The most striking instance was Intel's involvement in searching a partner for Microchemistry, after the Finnish parent had to divest the startup in 1999. In order to secure the viable ALD chemistries, Intel suggested companies that engaged in research potentially relevant to its own interests - such as ASM.

Remarkable was that the first example of virtù, as demonstrated by Werkhoven, enabled a new manifestation of fortuna: the acquisition of Microchemistry. Yet, without his persistent pursuit of integrated RTP, ASM would not have been in the picture with regard to the gate stack. Most certainly, the opportunity to acquire Microchemistry would not have been arisen. In defiance of internal skepticism, Werkhoven found ways to pursue his goals.

Virtù - the impromptu response to fortuna - foremost moved away from entrepreneurial individuals and toward collective action. Except for this first example, most innovation did not involve marked entrepreneurial display of virtù. No longer did Arthur del Prado himself lead the herd. Apart from the first instance, virtù foremost entailed risk evasion and preservation in relation to the innovation process and vis-à-vis Intel. As in the case of the interactions with the Dutch authorities (cf. Innovation III), this primarily came down to relation management. It was largely reactive, and only to a lesser extent a force of creation and innovation. By contrast, Intel's virtù became even more omnipotent compared to its role in the case-studies discussed in the previous Innovation chapters. In my account in Innovation IV, Intel actually both allowed and curbed ASM's virtù.

\section{Path}

In order to reflect on the innovation process by means of the element of 'path,' I will assess some of the structural aspects in ASM's innovation process, before I return to a few academic concepts previously addressed in this study, involving ASM as enactor, chip manufacturers as selectors, ASM as a specialized supplier, bridging incidents, and anticipatory reverse salients. Moreover, I elaborate on a few other concepts, such as strategizing and Utterback's notion of waves of innovation, in order better to grasp the technological path taken by ASM throughout this story of innovation.

The overhaul of the gate stack enjoyed a prominent presence in the (Inter) National Technological Roadmap for Semiconductors. For any chip manufacturer involved in the miniaturization of CMOS chips, the high-k dielectric and metal gate were unescapable at some point. But, as became apparent over the course of Innovation IV, the urgency was not equally shared across the industry. Chip manufacturers found ways to work around it, delay the issue, or simply lacked the resources to see it through. At the turn of the century, ASM was overwhelmed by customer 
requests for demos. Yet, only a few chip manufacturers - with Intel in the lead continued to further the development process to production unimpededly.

For ASM, the prominence of gate stack in the technological roadmaps was used as a tool for mobilization. By aligning ASM's intentions for ALD with these roadmaps - in particular the looming challenge of gate stack innovation research institutes, governments, suppliers and customers were heralded around ASM's banner. This mobilization enabled ASM to initiate a governmentally supported project bearing the acronym ALAD1N at research institute IMEC. This project allowed the equipment manufacturer to sustain its own research into the gate stack and ALD in addition to more proprietary cooperation with customers. Put differently, the stature of the gate stack in the industry's technology roadmap allowed ASM to harness support for its ambitions.

The prominent role of ASM in gate stack innovation followed from its experience as process integrator and its ownership of the unique and critical ALD technology after 1999. ALD was a solution looking for a problem, as ASM's chief technology officer Ivo Raaijmakers once put it, and the most prospective challenge to be solved was high-k gate dielectric. ${ }^{185}$

Through its own efforts in the Siemens joint-development program and via the pioneering work of Microchemistry, ASM got involved relative early in the gate stack innovation process. At this stage, the outcome and subsequent expectations or demands were not yet known. The chip manufacturers could not do otherwise than to draw in their equipment suppliers. There were too many gaps to be filled in, to be decided upon. The innovation process at ASM was not a mere supply-demand relationship, but entailed nothing less than co-innovation even if strongly guided by the chip manufacturers. ASM would supply a solution for their problems, enabling them to compete.

Throughout the innovation process, priorities changed and so did ASM's innovation strategy. Its strategy to enact its integrated process equipment consisting of RTP modules, and later ALD ones, morphed into a scheme to enact its high-k gate dielectric technology. This change affected appropriated roles of the company's respective business units. In particular, the new role of Microchemistry illustrated the altered strategies: from equipment manufacturer to sole material development. The organizational structure of ASM International - comprising decentralized, rather autonomous operations - offered sufficient versatility to the temporal progression of strategies. In other words, not so much the structure primarily defined the course of innovation, but the very specific properties of ASM's technology and the different demands of its customers.

185 Ivo Raaijmakers, 'Interview with author'. 
When reflecting on these dynamics, various concepts seem relevant again. Yet the case elaborated in Innovation IV also offers the opportunity to dive deeper into the interaction between ASM and its customers, between enactor and selector. The notions of 'competition of enactment' and 'alliance of enactment,' as addressed in, respectively, Innovation II and III, provide a good starting-point.

ASM enacted its ALD technology for the high-k gate application, but was entangled in a competition of enactment with other equipment suppliers. Individual chip manufacturers had to weigh the pros and cons of ASM's ALD solution versus others, like metal organic CVD processes or even alternate chip designs. This selection was determined by experimental results and performance of the enacted technologies.

Yet it was also in the interest of the chip manufacturers to monitor the efforts of the equipment manufacturers closely. A joint-development program offered just that, establishing a kind of 'alliance of enactment.' After all, the chip manufacturers were themselves, in conjunction with their respective customers, also competing with each other. Still, in this case it would be more appropriate to refer to competing 'chains of enactment.'

Demands from Intel's customers - the PC manufacturers - determined the prominence of the gate stack solution at the American chip manufacturer's technological roadmap. For Intel, Moore's Law was an enacted benchmark toward its customers, to measure its performance gains and continuing relevance as chip supplier. The gate stack was an 'anticipatory reverse salient,' an element expected to impede the progression of a technological structure, in this case Moore's Law. ${ }^{186}$ Subsequently, Intel, on its turn, urged its supply base to pick up the challenge of the gate stack. Only after selectors - such as Intel, IBM and Motorola - indicated the probable applicability of the equipment manufacturer's technology for the gate stack did ASM consider enacting the integrated RTP cluster and ALD technology to this 'anticipatory reverse salient.' The chip manufacturer's well-being depended on it, as was true of that of ASM.

The whole innovation process can be seen as a 'bridging incident' (cf. conclusions of Innovation II): the settlement on conditions for which the solution complies with the addressed problem, institutionalized in a joint-development program. On the one side of this proverbial bridge, there was ASM, hoping to foster its own technologies and elevate its competitive chances. Successful collaboration with one company might result in sales to others as well. On the other side there were the semiconductor manufacturers, who - individually or by emergent consent - defined the high-k dielectric material, deposition method, and industrial requirements, based on their own experiments and ASM's results. 
Various moments of 'closure' were defined at the beginning of the jointdevelopment, involving targets or specifications to which technological development had to adhere. Yet the most important moment of closure in the innovation process occurred when Intel selected the ASM Polygon and Pulsar 3000 tools for its 45 -nanometer product lines. For the other chip manufacturers, closure took a bit longer. Through the joint-development programs, to paraphrase business scholars Rajan Kamath and Jeffrey Liker, ASM was able to broaden its technological base and move up the ladder in the semiconductor supply chain, from being a mere equipment supplier to 'one that provides more value to the customer.'187

ASM's innovation process did not deviate from the pattern of a 'specialized supplier,' which I concluded to be relevant in Innovation I. To cite from the definition:

'The main tasks of innovation strategy are keeping up with users' needs, learning from advanced users and matching new technologies users' needs. ${ }^{188}$

Through ASM's strategy to cultivate contacts with semiconductor manufacturers, the equipment manufacturer tried to embed itself in the industry's ecosystem. Such embedment would increase the chances to 'advance technology with user requirements. ${ }^{189}$ It is safe to argue that ASM, throughout its innovation history, grew into its role of 'specialized supplier.'

To conclude, I would like to consider the company's innovation process from the angle of overall industrial development. In this context, the notion of 'waves of innovation' is helpful again (see Intermezzo in Business I). The introduction of metal gates and high-k dielectrics in the transistor marked the end of the MOS-transistor's predominance in the chip industry. It was the first of a series of alterations in the transistor's design that would follow in the next decade. The polygate transistor lost its status of 'dominant design' after forty years. According to Utterback and Abernathy's proposition, this meant that the wave of process innovations - that is, the relative increase and decrease of innovations in production techniques - was about to end for the semiconductor industry.

Obviously, this vanishing wave of process innovation had repercussions for Moore's Law, which was foremost a statement about production technologies.

\footnotetext{
187 Kamath and Liker, 'A Second Look at Japanese Product Development', pp. 154-170. and Organizational Change (2nd edition; Wiley, Chichester, 2001), p. 113. Ibid.
} 
Innovation IV - Enacting high-k gate dielectrics and atomic layer deposition technology, 1996-2007

Commanding knowledge about the current state of the semiconductor industry - anno 2018 - the truth of this assessment seems hardly contestable. Fewer improvements in computer chip performance are primarily originating from the miniaturization of transistors. Moore's Law is slowing down. ${ }^{190}$ From this perspective, the innovation of the high-k gate dielectric constituted the semiconductor's symbolic crossing of the Rubicon. As such it marked the end of an era in the semiconductor industry's development, ushering in an altogether new phase.

190 Rick Meritt, 'GlobalFoundries Halts 7nm Work', eetimes.com (27-8-2018); Dylan McGrath, 'Intel Delays 10-nm Volume Production Until 2019', eetimes.com (27-4-2018); Rick Meritt, 'TSMC Ready for EUV on 7, 5 nm' eetasia.com (3-5-2018). 


\section{Business V}

\section{Finding a balance between sustaining and disrupting technologies, 1999-2008}




\section{An introduction}

For ASM International, the first decade of the new century was characterized by sequences of contraction and expansion, resembling a cardiac cycle. The company relapsed into its old habit of growing by means of leveraging new technologies and business units, while simultaneously pursuing cost reduction and stabilization of the cash flow through further centralization of manufacturing. Successive economic booms and busts drove this seemingly contradictory organizational development.

Business V covers the final years of Arthur del Prado's tenure as chief executive officer (CEO) of ASM International. In his capacity of chief executive officer, majority shareholder, and founder of the company, Del Prado played a pivotal role in how the company progressed into the new millennium. The unprecedented boom in the market around the year 2000 empowered the entrepreneur to acquire new technologies and add new activities. Through the expansions, he and his staff were able to anticipate the revolutionary advent of new materials and subsequent production techniques in semiconductor manufacturing. However, the subsequent downturn and depressed economic situation in the years between 2001 and 2005 prompted a focus on consolidation again.

From 1999, as Del Prado's ownership was diluted through successive issuances of convertible notes, his relation with his Supervisory Board began to change. The eminent entrepreneur assumed the persona of a visionary and - seemingly altruistic - industrialist. His ability to look beyond temporal worries and considerations and appreciate the true potential of technologies had been proven multiple times. Moreover, he had consistently been a major advocate of concerted industrial efforts to further public, technological, and commercial interests of the semiconductor industrial ecosystem as a whole, including government involvement.

Conversely, the Supervisory Board's assessment of the playing field and the available options and business opportunities revolved around their accountability toward investors, shareholders, and stakeholders. But the board also sought to ensure the viability of the company beyond Del Prado's presence as chief executive officer. After all, even the illustrious and seemingly inexhaustible entrepreneur was mortal.

The entrepreneur and his impetuous and hardnosed pursuit of new technological and commercial opportunities no longer fitted the times of strict corporate governance, risk control, and process management - all indispensable 
for running a $21^{\text {st }}$-century, publicly listed multinational enterprise. On March 1,2008 , against the backdrop of a Supervisory Board anxiously contemplating ASM's future and activist shareholders opportunistically challenging the company's strategy and compliance with new corporate governance regulations, Del Prado stepped down as chief executive officer, to be replaced by his son, Chuck del Prado. By that time, however, the new business groups embodying the company's founder's strategy for realizing disruptive technologies and new industrial potential had been fairly established within ASM.

\section{Contemporary appreciation of a multi-divisional enterprise}

The cardiac cycle experienced by ASM International in the period from 1999 until 2008 fitted the times. Prevailing academic debates about management, strategy, and innovation centered on the basic challenge of how to deal with changes in a company's environment while maintaining ongoing activities. ${ }^{1}$ Prominent ideas in this respect were articulated by management scholar Clayton Christensen in his The Innovator's Dilemma (1997). ${ }^{2}$ Christensen distinguishes strategies for success that start from the notion of 'sustaining' technologies versus 'disruptive' ones. Sustaining technologies are 'new technologies [that] foster improved product performance,' which involves listening to demanding customers, investing in customer interests, pursuing higher margins, and focusing on larger markets. ${ }^{3}$ In contrast, disruptive technologies are innovations that address initially lowend or new markets discarded or unknown to the incumbent. The pursuit of either disruptive technologies or sustaining ones require different actions from

1 For instance: James Utterback, Mastering the Dynamics of Innovation (Harvard Business School Press, Boston, 1994); David Teece, Gary Pisano, and Amy Shuen, 'Dynamic Capabilities and Strategic Management', Strategic Management Journal 18:7 (1997) pp. 509-533; McKinsey \& Company, Richard Foster and Sarah Kaplan, Creative Destruction: Why Companies That Are Built to Last Underperform the Market - and How to Successfully Transform Them (Currency Doubleday, New York, 2001); Rita Gunther McGrath and Ian MacMillan, The Entrepreneurial Mindset: Strategies for Continuously Creating Opportunity in an Age of Uncertainty (Harvard Business Review Press, Boston, 2000); Rita Gunther McGrath, 'Exploratory Learning, Innovative Capacity, and Managerial Oversight', Academy of Management Journal 44:1 (2001) pp. 118-131; Richard Leifer, Christopher McDermott, Gina Coarelli O’Connor, Lois Peters, Mark Rice, and Robert Veryzer, Radical Innovation: How Mature Companies Can Outsmart Upstarts (Harvard Business School Press, Boston, 2000); and also: Joseph Bower and Clayton Christensen, 'Disruptive Technologies: Catching the Wave'. Harvard Business Review (February 1995).

2 Clayton Christensen, The Innovator's Dilemma: When New Technologies Cause Great Firms to Fail (Harvard Business Review Press, Boston, 1997); In his second book, Christensen elaborated on the same theme: Clayton Christensen and Michael Raynor, The Innovator's Solution: Creating and Sustaining Successful Growth (Harvard Business Review Press, Boston, 2003); Bower and Christensen, 'Disruptive Technologies'.

3 Clayton Christensen, The Innovator's Dilemma, p. xv. 
a company while also implying other ramifications. As observed by innovation scholars Johan Schot and Edward Steinmueller:

'[T]he character of technological change was recognized as being cumulative and path dependent. A balance existed between major disruptive innovations that alter the trajectories of search and improvement (path-disrupting), and cumulative [sustaining] innovations that reinforce and strengthen existing strengths and centers (path-reinforcing)."4

Christensen outlines strategies aimed at enabling disruptive technological developments within a company preoccupied with nourishing its existing business. To develop disruptive technology, according to Christensen, managers should set up smaller and less costly autonomous organizations geared to pursuing new markets and customer interests at arm's length of the culture and values predominating in the parent company, while allowing ample room for failure.

Christensen's strategies for sustaining and disrupting technologies seemed to shed light on ASM International's cardiac cycle of contraction and expansion in the first decade of the $21^{\text {st c }}$ entury. For its wafer processing products, the equipment manufacturer employed both strategies, one to sustain technologies and the other in support of disruptive innovations.

Christensen's analysis stresses the role of two kinds of narratives: those sustaining specific business activities and those pioneering new business activities. At ASM, the main protagonist in favor of enabling disruptive innovations was Del Prado, while the Supervisory Board advocated a focus on sustaining innovation. Before making this dichotomy appear like a duel, I want to emphasize that both Del Prado and the Supervisory Board were on the same team, pursuing the same goal: sustaining the viability of ASM International. Yet they both relied on different experiences, skills, and values, which is why they had a different appreciation of the playing field and thus of the available options.

\section{Outline of Business $V$}

Del Prado's departure happened in three acts, as addressed in the next three chapters in chronological order. They cover the run-up to Del Prado's retirement, but also how ASM pioneered the revolutionary manufacturing technique called atomic layer deposition after the acquisitions of Microchemistry and Genitech.

Johan Schot and Edward Steinmueller, 'Three frames of innovation policy: R\&D, systems
of innovation and transformative change', Research Policy 47 (2018) pp. 1554-1567, p. 1558. 
Other topics are the unfortunate acquisition of NuTool and the respectable role of three major ASM products - the Epsilon epitaxial reactor, the A412 vertical furnace, and the Eagle-12 machines - in progressing Moore's Law into the new century.

The three chapters are demarcated by changes in the general economic climate between 1999 and 2008. Chapter 30 describes the developments from 1999 until mid-2001, during which the semiconductor equipment industry experienced unprecedented growth. Chapter 31, covering the years 2001 to mid-2004, starts with the sudden collapse of the Dotcom Boom and anxieties surrounding the so-called War on Terror, plunging the semiconductor equipment industry into a downturn. Finally, Chapter 32 addresses the onset of economic recovery, driving along the rise of private equity investors until the sudden collapse in late 2007, also known as the 'credit crunch,' and Del Prado's retirement in 2008.

In the Conclusion, I reflect on the events and the cardiac cycle by returning to a consideration of path, fortuna and virtù and their role in ASM's evolution in the first several years of the new millennium. 


\section{Chapter 30}

\section{Surging ahead, 1999-2001}

During the period of strong economic growth also known as the Dotcom Boom the sky was the limit for companies in internet, electronics and semiconductor related activities. ASM International was finally able to shrug off long-pending creditors. Moreover, it prepared itself for the future through new acquisitions and collaborations.

\section{Industrial context:}

\section{The Dotcom Boom}

Around the turn of the century, leading economists observed an 'irrational exuberance' among investors. ${ }^{5}$ From 1998 to mid-2001, capital markets were enthralled about internet- and technology-related stocks. From the mid-1990s onward, technology stocks outperformed other segments on the stock exchange. New firms exploiting commercial opportunities offered by the internet and the World Wide Web attracted attention in particular. Like a snowball rolling down a mountain, accumulating more snow with every inch, public awareness increased about the possibilities of the internet. Fear of missing out caused investors to put their money into these stocks. It resulted in the 'Dotcom Boom,' named after the staggering investments in companies having '.com' as a prefix in their name.

From the mid-nineties onward, the internet opened for civilian and thus commercial purposes. Well-known brands today, such as Amazon, E-Bay, Google, Netflix, and Yahoo - and a whole range of forgotten companies like Pets.com, World Online, Pixelon, and Webvan - explored new commercial opportunities, rousing eager investors. Capitalizing on the excessive willingness of investors, one dotcom-company after the other conducted staggering initial public offerings. ${ }^{6}$

5 This notion of 'irrational exuberance' originated from a 1996 speech by the long-lasting chairman of the United States Federal Reserve Board, Alan Greenspan, but it has also been attributed to economist, and Nobel Prize laureate, Robert Shiller. The term became a reference for the prevailing sentiments during the Dotcom bubble. For the Greenspan speech, see: Federal Reserve Board, Alan Greenspan, 'Remarks at the Annual Dinner and Francis Boyer lecture of The American Enterprise Institute for Public Policy Research, Washington DC: The Challenge of Central Banking in a Democratic Society' (5-12-1996); and for Shiller's book, see: Robert Shiller, Irrational Exuberance (Princeton University Press, Princeton, 2000).

6 As discussed in Chapter 25, technology-related stock like ASML, BESI, and ASM International also enjoyed excessive interest from investors in the Netherlands. 
Moreover, any sense of restraint regarding equity investments seemed to have vanished in thin air. A general sentiment of euphoria prevailed.

Awareness about the pervasiveness of computer technology was also boosted by the impending 'Year 2000 Problem' (Y2K), also known as the millennium bug. It was widely assumed that computer software, which used to indicate years merely as '98 (1998) or '99 (1999), could cause major confusion on January 1, 2000, by providing ambiguous indications for dates, such as numbers like '00 (1900 or 2000?) and '01 (1901 or 2001?). It became clear quite soon that the problem proved to be marginal at most. ${ }^{7}$ It was largely the sheer number of computer systems in the world, taking care of critical aspects of human life, that turned Y2K into a daunting event. After all, what if the computers of traffic control had been prepared incorrectly? What would happen to nuclear facilities? If Y2K triggered conspiracy theories and apocalyptic scenarios, it for the first time highlighted the omnipresence of computer technology in modern societies.

\section{Orchestrating new techniques and materials}

At first sight, the Dotcom boom and Y2K predominantly affected computer and internet firms, but they also gave a boost to the semiconductor industry and its ecosystem of equipment and material suppliers. Annual sales of personal computers grew rapidly, increasing semiconductor sales as well. Worldwide shipments of personal computers grew from 70.87 billion units in 1996 to 82.1 billion units in $1997 .{ }^{8}$ Worldwide revenues from semiconductors increased from 126 billion dollars in 1998 to 149 billion in 1999 and 204 billion in 2000. ${ }^{9}$ In these same years, global sales of semiconductor equipment grew modestly at first from 22 billion dollars in 1998 to 25.2 billion in 1999, after which they doubled to 47.7 billion in 2000 .

In this same period, technological development progressed at a relentless pace (figure 82). At an international level, new materials and processes were invented and considered for introduction. The International Technology Roadmap for Semiconductors (ITRS) and the Sematech institute were instrumental here, and both were opened to the global industry in 1998. American chip manufacturers IBM and Intel led the industry by pioneering new materials and processes in semiconductor manufacturing. ${ }^{10}$ Intel relied on its strong position with regard

7 In this case, I can rely on my own recollection.

8 Author unknown, 'Worldwide PC Market Posts Nearly 16 Percent Growth in 1997, According to Dataquest', tech-insider (26-1-1998).

9 Compiled from various press releases by industry data analyst Gartner and the industry association for semiconductor equipment manufacturers, SEMI. - Editor, 'Semiconductor equipment sales were \$47.7B last year', eetimes.com (29-3-2001); Robert Lineback, 'SEMI: Chip Equipment Sales Are Stronger Than Expected', eetimes.com (21-4-1999).

10 ASM International, Daniel Queyssac, 'Presentation to Supervisory Board: Front-End 
to microprocessors. Every personal computer controlled by Microsoft software - Windows 95 and 98, for instance - ran typically on an Intel microprocessor. Intel mapped, familiarized, and integrated new technologies critical to sustain its leading position, offering more computer power with every generation. Meanwhile IBM, which was no longer commanding the highest revenues in semiconductor sales, broke ground with some staggering breakthroughs in semiconductor manufacturing technologies, which it licensed to an alliance of other chip manufacturers across the globe. 'Big Blue' formed a striking example of an incumbent enterprise successfully innovating disruptive technologies. ${ }^{11}$

Figure 82

Table of changes in semiconductor manufacturing technology in 1995 and 2005

\begin{tabular}{|l|r|r|}
\hline & $\mathbf{1 9 9 5}$ & $\mathbf{2 0 0 5}$ \\
\hline Cost of a fab & $\$ 500 \mathrm{M}$ & $\$ 2000 \mathrm{M}$ \\
\hline Automation & SMIF & FOUP \\
\hline Wafer size & $200 \mathrm{~mm}$ & $300 \mathrm{~mm}$ \\
\hline Linewidth & $0.5-0.35 \mu$ & $0.09-0.065 \mu$ \\
\hline Clean room class & 10 & 10 \\
\hline Chip Generation & VLSI & ULSI \\
\hline \# components & 4.000 .000 & $125-188 \mathrm{M}$ \\
\hline Workers garment & Bunny Suits & Bunny Suits \\
\hline
\end{tabular}

Through the progression of Moore's Law - the miniaturization of transistor dimensions - a series of material innovations were anticipated by the end of the $20^{\text {th }}$ century. Until that date the ability to print smaller dimensions through lithography had been defining in the pursuit of Moore's Law. But this was about to change. While lithography remained critical for the shrinkage of dimensions, chip manufacturers also had to replace traditional materials by newer ones. At the smallest scales, the common materials in semiconductor manufacturing such as aluminum, silicon, silicon oxide, and silicon nitride no longer functioned (cf. Innovation IV). By alloying one material with another one commonly used in chip production, immediate challenges were overcome during the 1990s. But across the industry - and institutionalized through organizations like SEMI, SIA, Sematech, IMEC, and the ITRS - it was realized that new semiconductor materials and thus new manufacturing processes had to be contemplated. Materials innovation topped the agenda of semiconductor manufacturing once again.

Operations' (28-7-2003) Archive Arthur del Prado - RvC 2003 files.

11 Leifer, et al., Radical Innovation, p. 103. 


\section{Integrating and innovating copper-based manufacturing processes}

The most revolutionary step with regard to material innovations was achieved by the integration of copper as an interconnecting metal in computer chips (mind the myriad of layers depicted in figure 7 in the intermezzo, Business I). Copper replaced aluminum interconnections. At the interconnecting levels the various layers of labyrinths consisting of metals and insulators directing electrical current to and between transistors and other components - aluminum did not conduct sufficient electrical current for computer chips with features below 0.25 micron. Copper, by contrast, did conduct electrical signals even at the tiniest scale. However, copper had been avoided meticulously in semiconductor manufacturing. The tiniest traces of copper were known to disrupt the proper function of materials in the complex structures of computer chips. Integrating this ostensible hazardous metal in a computer chip and in the manufacturing lines would pose immense challenges for the industry.

In the fall of 1998, IBM shook the global semiconductor industry by announcing it had successfully integrated copper interconnections in its latest chips, containing about 150 to 200 million transistors with features of 0.12 micron. ${ }^{12}$ The American chip manufacturer had developed a manufacturing process dubbed 'dual damascene' (figure 83). This process involved the deposition of an interlayer dielectric, a barrier film between the dielectric and the copper, and a complete process to deposit copper at the first few levels of interconnects above the transistor.

By the late 1990s, electrochemical deposition surfaced as the method of choice for depositing copper. ${ }^{13}$ Through this process, a wafer, submerged in a chemical bath, is electroplated with copper. In this bath, copper ions migrate from a copper electrode to the wafer. That this method was picked as the method of preference had two distinct consequences. The first was that it had to be done upon a so-called copper seed-layer, a thin film of copper grown on top of the barrier material to guarantee proper adhesion and electrical current flow. The second was that chemical mechanical polishing was required. The electrochemical deposition process resulted in an uneven copper surface. Through mechanical polishing, the surface was evened, planarized, removing excessive materials. ${ }^{14}$

12 Dataquest, Ron Donseif, 'IBM Transfers First Copper Metalization Process Into Production', Dataquest Semiconductor Equipment, Manufacturing, and Materials Worldwide: Technology Analysis (13-10-1997).

13 Dataquest, Ron Donseif, 'Compacted Change in Interconnect Technology and the Impact on Equipment and Materials Industries, Part II' Dataquest Semiconductor Equipment, Manufacturing, and Materials Worldwide: Market Analysis (26-1-1998).

14 Dataquest, Ron Donseif, '1997 CMP Equipment Market Continues to Outpace All Other Wafer Fab Equipment Segments' Dataquest Semiconductor Equipment, Manufacturing, and Materials Worldwide: Market Analysis (1-6-1998). 


\section{Figure 83}

A simplified vertical cross-sectional depiction of a dual damascene process for the deposition of copper interconnections

\section{Description of} fabrication process

Deposition of low-k dielectric and nitride (PECVD)

Patterning of Low-K dielectric and nitride (lithography \& plasma etch)

Deposition of diffusion barrier (PVD or ALD)

\section{Deposition of copper seed} (PVD or ALD)

\author{
Copper plating \\ (electro-chemical deposition)
}

\section{Cross-sectional depiction fabrication process of copper interconnections}
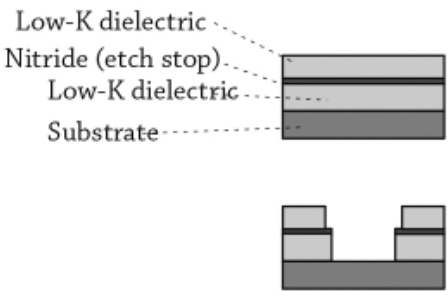

Diffusion barrier (Titanium Nitride)

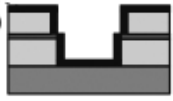

Copper seed

Diffusion barrieŕ

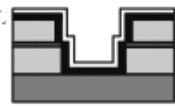

Copper

Diffusion barriér

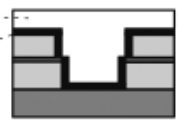

Polishing of copper and diffusion barrier (chemical mechanical polishing)

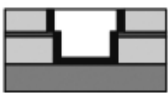

As more and more chip manufacturers turned to copper interconnections, imagined economies increased exponentially. The advent of copper created opportunities for equipment suppliers to develop competitive copper seed, deposition, or polishing processes. The whole dual damascene process resulted in various additional manufacturing steps. The development of an alternate copper deposition process requiring fewer processes formed the equivalent of a Holy 
Grail for equipment manufacturers. Chip manufacturers would pay happily if they could get rid of these additional manufacturing steps.

Companies pursued various alternatives for the deposition of copper through conventional methods, like chemical vapor deposition (CVD) or through entirely new approaches. All of these new production processes required intense research into manufacturing methods, compatibility among materials (the interlayer dielectric, barrier and the copper), and compatibility of methods and materials. Big Blue had a head start of at least three years. The competition scrambled to familiarize and innovate other elements in the dual damascene process, of which many still had to be refined and innovated. Dual damascene, in other words, was the industry's hottest topic.

\section{Familiarizing high- $k$ dielectrics and silicon germanium}

Other material challenges prevailing on the industry's technology roadmap were the changing properties of dielectric materials. The dielectric of a MOS transistor and the inter-dielectric in a MIM-capacitor of a memory chip no longer sufficed: it failed to provide sufficient insulation at the smallest dimensions. The semiconductor had to change the original silicon oxide for another exotic material, which provided better insulation and thus enabled further miniaturization. This material, code-named 'high-k dielectric,' posed severe challenges to the industry with regard to selecting the right material, ensuring compatibility, and integrating it in semiconductor manufacturing (cf. Innovation IV). Also, for the dual damascene process, an interlayer dielectric was required with a relatively lower dielectric constant than the common silicon oxide, deposited through plasma CVD. This material was named 'low-k.' In combination with a barrier film, required to integrate copper, interlayer dielectrics had to ease up a little.

A final example of material innovations concerned the alloying of silicon with germanium, resulting in silicon germanium (often denoted as SiGe). Since the late 1980s, Silicon germanium had been pursued to improve the performance of computer chips. IBM, however, discovered the process and found out that this material enabled higher speed and lower energy consumption. From 1998 onward, IBM propagated silicon germanium in a bipolar CMOS, or BiCMOS, transistor configuration for wireless communication chips. Such chips enabled cellular phones and breaking the ground for Wi-Fi and satellite-communication systems.

Around the turn of the century, and elaborating on IBM's pioneering work in silicon germanium, the market for wireless communication chips grew rapidly. Less subjected to the yoke of miniaturization, this segment of the semiconductor industry began to distinguish itself by the notion of 'More than Moore.' European companies like Philips, Siemens, and Plessey, which earlier stepped out of the race of progressing Moore's Law and had retained expertise in BiCMOS, succeeded 
in these new communication technologies. ${ }^{15}$ But also an American fabless chip designer named Qualcomm joined their ranks. ${ }^{16}$ Throughout the new century, the wireless chip industry would gain traction and foster new opportunities for the semiconductor industry.

\section{Introducing 300-millimeter wafer equipment}

If all these new material developments were not enough, the semiconductor industry was also in the midst of converging to a new wafer size. In the fall of 1998, the introduction of 300-millimeter wafer was deferred. Due to the Dotcom Boom, demand focused on existing chip designs, still manufactured on 200-millimeter wafers. By the fall of 1999, the introduction of 300-millimeter was reignited by Intel, a consortium of Siemens and Motorola, and TSMC. Most of the new machines had already been evaluated at research consortia like Sematech in the United States (I300i) and Selete in Japan. Before they could be integrated in semiconductor manufacturing, the new machines had to be able to process the latest materials and chemistries. This meant, for instance in the case of lithography, handling bigger wafers but also handling them more precisely to enable the printing of even smaller line-widths of 0.18 micron and less. In the case of the deposition segment, this involved handling bigger wafers, growing thinner films more uniformly across the bigger wafer surface, and processing new materials.

In September 1999, Siemens and Motorola finished the first 300-millimeter wafer pilot fab line in Dresden, Germany, followed by volume production in December 2001. ${ }^{17}$ This new fab for producing 256 Megabit DRAM chips costed around 1.1 billion euros. Intel completed its first 300-millimeter wafer in Hillsboro, Oregon by $2001 .^{18}$

In the case of the semiconductor equipment industry, the new material challenges offered new opportunities to distinguish themselves. Old techniques would not suffice (figure 82). For this reason, those capable of offering technologies complying to the new material demands might benefit from firstmover advantages. This also pertained to the new wafer size. Simultaneously, the equipment industry was asked to meet a sudden peak in relatively older

15 European chip manufacturers were fairly late in familiarizing themselves with CMOS chip technology in the 1970s and 1980s, but they excelled in bipolar chips. The advent of bipolar CMOS chips in the early 1990s enabled them to capitalize on their expertise.

16 Dataquest, Dale Ford, 'Wireless Semiconductor Industry Activity Heats Up in February', Dataquest Communications Semiconductors and Applications Worldwide: Product Analysis (13-41998).

17 Infineon, 'Press release Infineon Technologies Dresden' (December 2001); Infineon, 'Press release: Pioneering 300. Less is More in Semiconductor Production' (December 2001).

18 Mark LaPedus, 'Intel maps out 300mm strategy', eetimes.com (14-5-2001). 
techniques. Because more and more money became available to meet all these new requirements, prospects rapidly improved. The start of the new century could not have been better.

\section{Corporate course: Ongoing expansion}

From 1999 to 2001, ASM's outlook and prospects changed radically. The company's core competencies, which had been carefully cultivated throughout the 1990s, were redefined. New products were added and the surge in demand redefined the company's manufacturing strategy. The industry-wide momentum created by the Dotcom Boom and the effective actions of ASM International's management pushed back technological and financial frontiers.

Orders for ASM's products soared in the second half of 1999, as major customers extended their product lines to meet demand. More Epsilons were sold. More Eagle-10 reactors were sold. The A400 did extremely well, and even the A600-UHV regained some traction. Primarily, the new orders involved 200-millimeter equipment. Through a dedicated strategy from all ASM's frontend subsidiaries to penetrate the lucrative American market, the geographical entrapment of ASM Europe's vertical furnaces and ASM Japan's plasma reactors was overcome. With the forthcoming transition to 300-millimeter equipment constituting a major window of opportunity - the stakes could not have been higher.

Yet, in the first half of 1999, ASM International was still bogged down by its financials. The urgency to strengthen the company's cash flow had not subsided. The company was still bogged down by its debt to Applied Materials, and its bankers ABN Amro and National Investment Bank [in Dutch: Nationale Investeringsbank, NIB]. The sudden 1998 financial crisis that numbed ASM International had annulled prospects for new funding schemes, such as a 35 million dollars convertible note that had been considered. As Del Prado explained in a letter to De Jong, such a deal

'will settle the issue with A.M.T. [Applied Materials], and brings us more time to plan for equity transactions tuned to market developments. It also will de-fuse the time bomb with ABN/NIB and hopefully enable us to concentrate on running our business under the umbrella of relative peace.' $^{19}$

19 ASM International, Arthur del Prado, 'Memorandum to Rinse de Jong, ref: M01299.doc' (1-4-1999) Archive Arthur del Prado - RvC'98-'00 files; Patrick Lam and Edmund Lam, Soaring like Eagles: ASM's High-Tech Journey in Asia (John Wiley \& Sons, Singapore, 2006); Rinse de Jong even negated excessive claims about the company on investor fora. He did so not by his own name, but via personal acquaints. - Rinse de Jong, 'Interview with author'. 
According to Del Prado, ASM's financial troubles in 1998 and its inability to refinance its debt in 1999 were rooted in an inadequate appreciation of the company's technology and market position. Having learned from the 1998 crisis, ASM International - and ASM Pacific Technology - actively engaged with their shareholders. ${ }^{20}$ This effort paid off. Refunding debt the issuance of convertible notes or equity became more prospective. ${ }^{21} \mathrm{Up}$ to that point, however, the costs of a convertible note - expressed in dilution of existing stock - outweighed the benefits of such a transaction, which would relieve the company's debt.

ASM swiftly freed itself from restraints. The first area involved three new technologies apart from the main product lines: rapid thermal annealing through a machine called the Levitor, integrated metrology through Nanophotonics, a German company, and atomic layer deposition via Microchemistry, a Finnish operation.

The second area of expansion involved the cash flow. With help of a booming financial market, improved coverage of ASM's stock, new orders, and the company's investment in its future (atomic layer deposition, etc.), ASM's market capitalization rapidly improved. This indication of the company's value opened new routes for refinancing the company's debt.

The third expansion entailed the company's manufacturing operation following unprecedented high demand for incumbent products. As ASM's machines were selling like hot cakes, the pressing urgency to meet demand counteracted concerns about the deterioration of operational costs.

The final expansion entailed two collaborations effectuated in 2001. This involved a South-Korean startup named Genitech, which had developed a plasma enhanced atomic layer deposition process. Another involved a young American enterprise called NuTool, which owned a copper electro chemical mechanical deposition process technology.

20 ABN Amro, Merril Lynch, and CIBC Oppenheimer indicated that they would be interested in covering ASM publicly in their analysis if this might result in the issuance of convertible notes or equity. - ASM International, Rinse de Jong, 'Memorandum to Supervisory Board: Refinancing' (1-7-1999) Archive Arthur del Prado - RvC '98-'00 files;; ASMI, Rinse de Jong, 'Memo Supervisory Board: Refinancing' (23-7-1999) Archive Arthur del Prado - RvC '98-'00 files.

21 ASM International, Rinse de Jong, 'Memorandum to Supervisory Board: Refinancing' (1-71999) Archive Arthur del Prado - RvC'98-'00 files. 


\section{Elaboration of affairs}

Exploring new technologies: the Levitor, Microchemistry, and Nanophotonics

Amidst the never-ending financial troubles, ASM engaged new technological developments in the first half of 1999: rapid thermal annealing, atomic layer deposition, and integrated metrology. These investments in non-core competencies were rationalized by limited acquisition cost, their unique technological application and capabilities, or their huge potential of addressing imagined economies. Despite prevailing doubts among members of the Supervisory Board, Del Prado sided with his engineers and deployed his salesman skills to sell the new innovations to skeptical Supervisory Board members. Myopic procrastination due to the financial shortages impeding the company could not be allowed. By deploying ingenious financial ploys - such as governmental research programs, equity arrangements, or Del Prado's personal wealth - the company's cash flow was hardly burdened.

The first new innovation, the Levitor, had been developed by chief technology officer Ernst Granneman. ${ }^{22}$ The machine oxidized or annealed a thin film by rapidly heating the wafers. The market for rapid thermal processes had matured rapidly since the mid-1990s. ASM had missed that boat, however, despite preliminary efforts involving the A800 cluster platform and modified Epsilon reactors (cf. Chapters 24 and 26). The Levitor should also help ASM to enter the market for these machines. Granneman's design differed from that of the competitors by having the wafer levitating on a cushion of gas while residing in the reaction chamber. This was spectacular.

But the Levitor was also a late entrant in a 331 million-dollar market, and the existing ASM subsidiaries were already overburdened. ${ }^{23}$ To relieve the Bilthoven facility operationally - which, after all, had to devote all its effort to the vertical furnaces - and in line with the Operation Merio scheme, manufacturing and major parts of engineering were outsourced to Philips Machinefabrieken. ${ }^{24}$ From the summer of 1999, Granneman resigned as chief technology officer and fully dedicated himself to the commercialization of the Levitor in Bilthoven. He received support from the Russian engineer Vladimir Kuznetsov. It was envisaged to deploy the project within the framework of EUREKA governmental support

22 This followed in the wake of a brainstorm session he had with engineers MacDonald Robinson and Wiebe de Boer during the Epsilon Technology Program, December 19, 1986.

23 Author's personal archive: Gartner, 'Wafer Fab Equipment by Region, 1998-2017'.

24 ASMI, Ernst Granneman, 'Memorandum: Floating Wafer Meeting Bilthoven, January 19, 20, 1999, ref: tc-mtgsleg022min.doc' (22-1-1999) Archive Arthur del Prado - Ernst Granneman files. 
programs, such as MEDEA..$^{25}$ Introduction to the rest of the industry was planned for May 2000, during the Semicon West Annual Exhibition in California. The Levitor became a distinct product group within ASM Europe.

First, however, another innovation required Granneman's attention: the acquisition of Microchemistry and its revolutionary atomic layer deposition technology (ALD) in the first half of 1999 (see Chapter 27 for more details about this deal and technology). ${ }^{26}$ By injecting the precursors in sequence instead of both simultaneously, one atomic layer at a time could be deposited in a controlled fashion. The technology offered unique uniformity and step coverage at the tiniest structures on a silicon wafer. Moreover, by means of ALD a whole new package of materials could be grown and integrated in semiconductor manufacturing. As Moore's Law continued to progress with ever smaller geometries of transistors, it was a matter of time before ALD might be indispensable.

The small Finnish operation Microchemistry possessed valuable capabilities for this new market and technology. In 1987 it was founded as a subsidiary of a national energy firm, called Neste, by the inventor of the ALD process, Tuomo Suntola. By 1999, Microchemistry employed 42 employees, offered four types of machines, was located in a brand new facility in Espoo, and still relied on the generosity of its parent company. To get the green light for a merger with another energy firm, Neste had to divest non-core activities, Microchemistry being one of them. Microchemistry's general manager Masse Ervasti searched for potential candidates and ended up at ASM.

Microchemistry fitted perfectly into ASM's technological roadmap and could be integrated fairly easily into the company's organization without having to dismantle the Finnish operation. ${ }^{27}$ That ASM was a European organization, and well established within the European microelectronics industry, did not hurt either. All in all, Microchemistry's approach for a merger and acquisition constituted a unique opportunity.

One prestigious application for ALD involved the production of new transistor gate stacks for which Microchemistry and ASM offered critical technology (cf.

25 This happened from 2001 to December 2003 in the MEDEA+ program, the successor of MEDEA. The project was called T303: Contactless anneal and silicides system (CLASS). MEDEA+, 'Rapid Thermal Processing Boosts European Chipmaking', MEDEA+ Project Result (Date unknown).

26 ASM International initially referred to it as atomic layer chemical vapor deposition (ALCVD), and was quick to claim this name. In fact, the aluminum CVD process of the 1980s had the same abbreviation, ALCVD. The original inventor of the technology called it atomic layer epitaxy (ALE). The rest of the industry called it ALD, and so will I here, in particular to avoid confusion with aluminum CVD.

27 An attentive reader might also see the resemblance with ASM's practice of acquiring technologies from disintegrating multi-divisional firms in the early 1980s. 
Innovation IV). That Intel, IBM and other major chip manufacturers had taken strategic interest in the Finnish capabilities for this application removed any doubt about the value of atomic layer deposition. Moreover, the Finnish company had also developed a range of new materials applicable in other parts of the chips production process, such as dual damascene processes (integrating copper).

Just acquainted with ALD, ASM's technological management was determined to advance itself as market leader in the ineluctable technology. The new chief technology officer, Dr. Ivo Raaijmakers drew up an ambitious roadmap for ASM's commercialization of the newly acquired technology. European governmental programs like MEDEA, strategic collaborations with research institutes IMEC (Belgium), Sematech (United States), and LETI (France), in addition to quickly secured joint-development programs with major chip manufacturers, decreased the risk of fostering ALD alone. This effort contributed to ASM's position as leader in ALD industry-wide. However, as argued by Granneman to the Supervisory Board:

'As commercial applications in the IC [integrated circuit] market are still years away, the short term growth of ASM's core business can continue without the new technology. However, given the interest expressed by market leaders as Intel and IBM, the [ALD] technology deserves a lot of attention to protect the Company's future. Getting in early can be done at a relative low price and would provide ASM with a strong patent position. This ensures at the minimum "a place at the table" whenever this new technology is considered. ${ }^{28}$

Moreover, ALD gave 'the Company exposure to large, first-tier customers (Intel, IBM, Texas Instruments, Micron, STMicroelectronics, Philips).'29

To acquire Microchemistry without burdening ASM's finances too much, a demand of the Supervisory Board, the following deal was concocted. ${ }^{30}$ The total acquisition sum was 50 million Finnish marks, or approximately 3.9 million euros. Of this sum, about 23 million Finnish marks was a convertible loan, 12.4

28 ASMI, 'Minutes Supervisory Board Meeting July 23rd, 1999' (26-10-1999) Archive Arthur del Prado-RvC'98-'00 files.

29 ASM international, Supervisory Board, 'Progress Report April 1999' (19-4-1999) Archive Arthur del Prado-RvC feb 1996-feb 1998; ASMI, 'Minutes Supervisory Board Meeting, October 26, 1999' (15-12-1999) Archive Arthur del Prado - RvC'98-'00 files.

30 The acquisition sum was about 18 million Dutch guilders. - ASMI, 'Memo to Supervisory Board: Microchemistry Business Plan and Integration’ (26-10-1999) Arthur del Prado - RvC '98-'00 files; CIBC World Markets, Robert Stephens, Warburg Dillon Read, Prospectus issuance of 5,000,000 Common Shares of ASM International (14-3-2000) p. 25. 
million a government granted development loan, and 15.6 million was paid in cash. On August 27, 1999, the deal was completed.

While the scope and significance of ALD began to dawn upon ASM, the company simultaneously engaged another new technological endeavor: integrated metrology from Nanophotonics. Through integrated metrology, the thickness and electrical properties of a deposited film can be characterized in a module that is an integral part of a deposition machine. So far this was done in dedicated standalone machines, manufactured by companies like KLA Tencor, Veeco, and Nova. ${ }^{31}$

The technology in question was developed by a small German firm called Nanophotonics, located in Mainz. It employed merely seven employees, among whom the president and founder Dr. Michael Abraham and a technological manager, Dr. Dietrich Drews. Through extension of an European research program, ASM had worked on particle and ellipsometry together with Nanophotonics and a Russian firm called Reflex. ${ }^{32}$

Industry-wide, a trend was envisaged in which metrology would cease to be a separate tool, as anticipated, for instance, in the National and International Technology Roadmap for Semiconductors. ${ }^{33}$ At one point, it might turn out to be beneficial to conduct the metrology steps right after one of the fabrication steps. In such a case, the wafer would not leave the machine. This came with the benefit that deposition processes could be immediately adjusted after detection of anomalies by the metrology tool: a short and efficient feedback-loop, which might prevent failures in the fabrication process from affecting too many costly wafers. In particular in the case of bigger wafers of 300 millimeter, and even 450 millimeter in the future, it was crucial to control the cost of failed wafer processes.

For ASM, this was relevant in its A400 and A412 vertical furnaces. In these machines a huge number of wafers, comprising thousands of dollars in potential revenues, were processed simultaneously. A small module of Nanophotonics would be integrated in the vertical furnace, and following the deposition process,

31 Just like the rest of the wafer processing equipment industry, the metrology suppliers had to cope with ever shrinking dimensions. Their machines had to be able to measure the properties at ever smaller geometries.

32 This European project was the IVPS project, discussed in Innovation III (Chapter 22) and Innovation IV (Chapter 26).- ASMI, Ernst Granneman, 'Visit Report Reflex, Selenograd, Moscow on October 27, 28, 1998; ref: visitsleg298rus.doc' (November 1998) Archive Arthur del Prado - Ernst Granneman files.

33 ASMI, Ivo Raaijmakers, 'Technology Council Meeting \#29: In System Metrology, Bilthoven’ (10-1-2000) Archive Arthur del Prado - Nanophotonics file; Sematech International, Alan Diebold, 'Impact of the ITRS Metrology Roadmap', nist.gov (1999). 
wafers would pass through this module and move to the transfer box, batch after batch. The ability to tweak and adjust the process in the case of minor deficiencies in thickness or physical properties could save enormous investments and would contribute to these furnaces' cost-of-ownership.

In the summer of 1999 - simultaneous with the acquisition of Microchemistry - Del Prado presented a plan to acquire Nanophotonics to the Supervisory Board. ASM had a clear opportunity to familiarize itself with this prospective technology. Moreover, the competition - Applied Materials in particular - had already made deliberate steps into the same direction. ${ }^{34}$ It was envisaged that the metrology technology of Nanophotnics could be integrated in all ASM's products. Next to the other two new innovations, this acquisition opened the door to a new market: that of metrology. ${ }^{35}$ However, just like the other new technologies pursued (the Levitor, ALD), Nanophotonics was too immature for immediate commercialization. It would take some significant cash before it was ready for production. To secure the technology for ASM, Del Prado therefore suggested the following deal to his Supervisory Board. Because ASM did not have the cash to foster three new innovations in addition to its other commitments, the company would acquire an interest of 24 percent for a modest 406 thousand dollars, while Del Prado personally would take an additional interest of 44.5 percent. ${ }^{36} \mathrm{He}$ explained the rationale for the scheme as follows:

'Our offer is for a limited participation only because a larger share would trigger the inability of the two banks [of NanoPhotonics] to continue their financing because NanoPhotonics would no longer qualify as a small company. This would make the financing of the development an exclusive ASM affair, which we do not want at this stage. ${ }^{37}$

Over time, ASM would acquire Del Prado's remaining shares.

34 Applied Materials made inroads into metrology, inspection, and integrated metrology through acquiring various companies and technologies, such as OPAL and ORBOT in 1997, Nanometrics in September 1998, and Consolium in December 1998. Moreover, it introduced an integrated metrology technology on its Producer platform.

35 From its establishment until the mid-1980s, ASM America had offered some basic metrology equipment applicable for epitaxy processes. Subsequently, ASM did not pursue metrology anymore.

36 Further ASM would provide Nanophotonics with 800 thousand German marks in a subordinated loan. ASM International, Supervisory Board, 'Nanophotonics' (15-12-1999) Archive Arthur del Prado - RvC 1999 - 2000.

37 Ibid. 
The three new innovations - the Levitor, ALD, and integrated metrology positioned ASM in new markets. The business groups were placed at arm's length from the other subsidiaries, just like Del Prado had always done. This allowed the groups to pursue and realize their opportunities undisturbed. Formally, all three fell under the responsibility of ASM Europe. But since neither of the products was going to be manufactured in Bilthoven, the entanglement remained limited. Those at the head office, at ASM International, were basically in charge of the new activities.

\section{Benefitting from improved investor relations}

Investors did not respond negatively to the new additions to ASM's product portfolio. This was helped by rapid improvements in sales, profits, and backlog over the first three quarters in 1999. Appreciation for ASM was helped by Intel's selection of ASM Europe's A412 a 300-millimeter pilot line in Oregon, bearing the promise of replacing the incumbent Kokusai as supplier of vertical furnaces. Although ASM's Bilthoven operation could not market this breakthrough - it was the first time the equipment manufacturer supplied to the industry's largest chip producer - it could optimistically declare that the A412 found appreciation among 'major chip producers' in the United States. ${ }^{38}$ Furthermore, the euphoric claim of competence towards the investors was a bit premature. Demanding chip producers like Intel required strict procedures to be in place with regard to quality control, safety, and handling of information - areas in which ASM Europe had to make huge steps. ${ }^{39}$

Still, ASM's deliberate strategy to highlight positive notes to investors paid off: one after another, investment bankers improved their recommendations for ASM from 'sell' to 'buy'. Acting on this cautious recovery, the constructive bankers of CIBC World Markets arranged a 15 million dollar zero coupon debenture in October 1999. ${ }^{40}$

Through the arrangement, another tranche of the Applied Materials' loan could be repaid. ASM's financial officer De Jong now moved forward to discuss a convertible note for the refinancing of the remaining Applied Materials debenture and that of the National Investment Bank, totaling some 130 million guilders. ${ }^{41}$

38 Intel forbade its suppliers to market their relationship. By reading between the lines, however, observant analyst were able to know who supplied Intel with what.

39 ASMI, 'Minutes Supervisory Board Meeting, October 26, 1999' (15-12-1999) Archive Arthur del Prado-RvC'98-'00 files.

40 ASMI, Rinse de Jong, 'Letter to Supervisory Board' (8-10-1999) Archive Arthur del Prado - RvC '98-'00 files.

${ }^{41}$ Simultaneously, ASM discussed with Teijin Seiki, a Japanese firm, whether it would like to take an equity position in ASM International in an effort to start collaboration between the Japanese firm and ASM Japan. - ASMI, Rinse de Jong, 'Letter to Supervisory Board, 
The time was ripe, as confirmed by a sudden increase of ASM's share price by 50 percent in one day on November 3, 1999 (figure 84). ${ }^{42}$

\section{Figure 84}

Graph of high, low and average annual market capitalization of ASM International on the Nasdaq stock exchange, 1998-2008

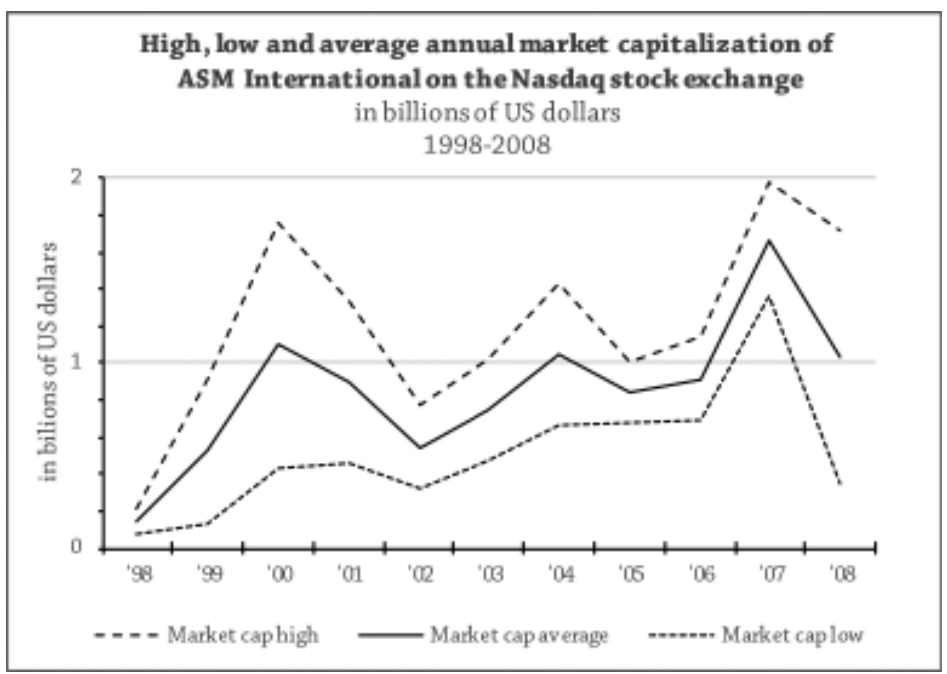

Prevailing doubts about the timing of the new technological endeavors retreated into the background. Even Supervisory Board member, and former Philips executive, Ferdinand Rauwenhoff had to admit to Del Prado:

'Now that the financial market (finally) recognized the true potential of ASMI, I want to admit how much I appreciate your vision and perseverance aimed at making this technologically innovative enterprise of yours a success. In our Supervisory Board meetings I tend to be critical because I perhaps assess the innovation/realization balance a bit differently ... I would love to see that we truly achieve good-sized volumes and sales with the package of products developed in recent years. That way, we secure the financial base for the next forward leap.

Financing' (26-10-1999) Archive Arthur del Prado-RvC'98-'00 files.

42 Del Prado stated that this improvement put all the sorrows of the past five years into perspective: 'If one considers that during these years also a patent battle was overcome at the costs around Dfl 170 million (including legal fees), we can be proud of our team at work and it provides adrenaline to go for "300mm gold" at the next Olympics' - ASMI, Arthur del Prado, 'Memo to Supervisory Board, ref: 01399.AdP/tv' (5-11-1999) Archive Arthur del Prado-RvC'98-'00 files. 
This is why I argued "not now" with regard to the Finnish case, even though I realize that this particular technology might be of importance in the distant future. But now, fortunately, all signs are positive. ${ }^{33}$

All obstacles had been removed. By December, CIBC even proposed a 150 million dollars equity offering, while ABN Amro suggested a 35 million dollars convertible loan as well. ${ }^{44}$ ASM wavered. On the one hand, Del Prado did not want to pass by Peter Jan Schmittman, the ABN Amro banker who had defended ASM within his own organization. On the other hand, CIBC World Markets took a much more favorable and constructive position vis-à-vis ASM. A very optimistic CIBC analyst named Ali Irani argued that the transaction sum indicated the confidence of the banker in ASM. After careful consideration, ASM went for the CIBC offer.

From February until April 2000, the refinancing effort took the name of 'Project Van Gogh. ${ }^{45}$ Through this, ASM would repay Applied Materials, pay off $\mathrm{ABN}$ Amro and redeem the National Investment Bank. ${ }^{46}$ If everything went according to plan, ASM would retain 35 million in cash. It happened from April 6 to April 12, with a purchase price of 29 dollars per share. ${ }^{47} \mathrm{~A}$ total of 5.75 million shares were placed. ASM retained in total 116.8 million dollars after the transaction. Finally, after more than a decade of struggles, ASM was relieved from the yoke of its bankers ABN Amro and National Investment Bank. As the Supervisory Board commented:

'The relationship has had many ups and downs but it was felt that the last two years had demonstrated a fundamental lack of understanding [of our needs] by the bank ... . Neither management nor the Board were impressed with the level of knowledge and support shown by the bank, with [as] a positive exception ... Mr. Schittmann, until recently in charge of our account whilst heading the bank's special credit division. ... The

43 Original quote in Dutch. - Ferdinand Rauwenhoff, 'letter to Arthur del Prado' (14-11-1999) Archive Arthur del Prado - RvC'98-'00 files.

44 ASMI, Rinse de Jong, 'Letter to Gerben Kuyper of ABN Amro Rothschild' (10-12-1999) Archive Arthur del Prado - RvC'98-'00 files; ASMI, Arthur del Prado, 'Fax to Rinse de Jong, ref: ni007499' (14-12-1999) Archive Arthur del Prado - RvC'98-'00 files; ASMI, 'Memorandum to Supervisory Board: Refinancing' (15-12-1999) Archive Arthur del Prado-RvC '98-'00 files.

45 ASMI, 'Memorandum Supervisory Board: Project Van Gogh (Refinancing)' (7-2-2000) Archive Arthur del Prado-RvC'98-'00 files.

46 The National Investment Bank had issued a loan to ASM of 55 million Dutch guilders in 1986, which was 25 million dollars in 2000.

47 ASMI, 'Memorandum Supervisory Board: Project Van Gogh' (28-4-2000) Archive Arthur del Prado-RvC'98-'00 files. 
Board decided that, in the best interest of the Company, a new banking relationship was needed. ${ }^{48}$

Bidding farewell to the bankers was bittersweet. Del Prado's strategy of leveraging innovation had been liable to the demands of the banks. In this, the exciting narrative of ASM and Del Prado about appropriating profits by advancing technological innovations clashed with that of the bankers, who were driven by securing financial returns through risk evasion. Under pressure of the bankers, ASM restructured its balance sheet in the 1990s. Less leverage with fewer assets. This had resulted in the divestment of cash-draining but highly prospective activities - ASM Lithography, ASM Ion Implant, and ASM Fico. But the bankers' resolve had also rushed decisions about the obsolete horizontal furnace lines and urged for effective addressing of the company's geographical organization. The returns of Project Van Gogh ended this banking relation full of old sores, freed the company's interest in ASM Pacific Technology, and opened roads to new, more constructive, financial relations. ${ }^{49}$ ASM's new innovations were to be leveraged through the earnings of the successful business groups.

\section{Proliferation of manufacturing}

By the first half of 2000, demand outpaced production capacity. This was not limited to the front-end activities. Shipments of ASM Pacific Technology's AB339 wire bonders drove its sales (cf. Chapter 25). Output increased from about 50 bonders - both wire- and die bonders - per month in 1999 to about 250 monthly units by April 2000. ${ }^{50}$ Meanwhile a new version of the AB339 gold wire bonder, the Eagle wire bonder (not to be confused with ASM Japan's Eagle-10 plasma deposition reactor) capable of bonding even more precise, at 35 microns, was prepared for introduction. The Shenzhen manufacturing operation, responsible for the production of all parts and generic modules, was expanded by 60 percent, and also a Malaysian production facility, in Pasir Gudang near the border with Singapore, added manufacturing space to meet the demand.

ASM Japan obtained significant orders for the plasma deposition reactor Eagle-10 beyond its Japanese native market into Taiwan. Moreover, six of its 300 millimeter version of the Eagle-12 were ordered by Hitachi. Its Nagaoka factory was fully booked, and required expansion. Sales of ASM America's Epsilon

48 ASM International, Supervisory Board, 'Minutes Supervisory Board meeting April 28, 2000' (30-5-2000) Archive Arthur del Prado - RvC 1999 - 2000.

49 ASMI, Supervisory Board, 'Memorandum: New Banking Relationships' (30-5-2000) Archive Arthur del Prado-RvC eind 2000-juli 2003 file.

50 ASMI, 'Supervisory Board Progress Report' (28-4-2000) Archive Arthur del Prado - RvC'98-'00 files. 
went up because of its appliance of silicon germanium epitaxy. ${ }^{51}$ By means of a reduced-pressure variation, the American operation profited from the advent of wireless communication chips, which was driven by the use of silicon germanium.

ASM Europe's latest A412 vertical furnace obtained new orders across the globe. The Taiwanese foundry TSMC considered the procurement of the A412 for its first 300-millimeter production line. Samsung already evaluated one. More importantly, the A412 was qualified by the 'the three Big I's': Infineon, Intel, and IBM. ${ }^{52}$ The novel vertical furnace was licensed to technology partners of these customers, and in most cases used in the production of memory chips. ASM Europe's manufacturing facility was fully booked. ASM Europe's general manager Han Westendorp explored new facilities for the production of the A412, ending up in Almere (near Amsterdam and to the north of Bilthoven).

In Europe, the shortage in manufacturing capacity undermined and subsequently ended Operation Merio. Just one year earlier, ASM had outsourced the production of generic modules for ASM America's Epsilon and ASM Europe's vertical furnaces to a Dutch subcontractor named Philips Machinefabrieken. This arrangement elaborated on the positive experience of ASM Europe surrounding the A400. Moreover, it intended to engage the subcontractor in more advanced engineering tasks, freeing the equipment manufacturer of non-core activities. The new Levitor, as well as a forthcoming wafer handler named Polygon (cf. Chapter 27), was to a great extent engineered and manufactured by Philips Machinefabrieken. However, the subcontractor failed to deliver in the face of the surging demand. Renamed Centrum for Fabricage Technologieën (CFT) in mid-2000, it served not only ASM Europe and ASM America, but also ASML, the rapidly growing Dutch manufacturer of lithography equipment.

The Epsilon came off worst. ASM America had to quote delivery times of six to seven months, while its major competitor, Applied Materials, offered two to three months. In addition, the relation between ASM and its subcontractor got troubled by missed deadlines and disputes about pricing. To cope with the demand, Philips CFT partially outsourced work to third parties, creating a longer and more expensive supply chain. ASM did not have direct control over that chain and quality issues became more difficult to deal with. This raised eyebrows not only in Bilthoven, but also among customers. ASM had to rethink its collaboration with Philips Machinefabrieken.

51 ASMA, John Krickl, 'Phoenix Manufacturing White Paper' (23-5-2000) Archive Arthur del Prado-RvC $1999-2000$.

52 Ernst Granneman, 'Interview with author', Albert Hasper, 'Interview with author', and Bas van Nooten, 'Interview with author'. 
'It is imperative that we have control over the supplier in terms of quality and price. This is one of the prime conditions to support a customer .... It is felt that Philips Machinefabrieken in Acht [near Eindhoven] that handles the Epsilon does not give us sufficient comfort, although Philips Machinefabrieken in Almelo (handling the Advance and Polygon lines) provides excellent support. For this reason, ASM is pulling part of the Epsilon production away from Philips and is testing US based suppliers to provide generic Epsilon machines. To cope with the much-increased demand, we have re-opened the Phoenix facility and will start final assembly and testing there.' ${ }^{53}$

In April 2000, manufacturing of the Epsilon was moved back to ASM America. Its general manager, Hans Wunderl, would imitate the Philips Machinefabrieken arrangement with a local subcontractor. ${ }^{54}$ In Phoenix, American Sheet Metal was hired to deliver generics against lower rates than those of Philips. Another subcontractor named CoorsTech, located in Denver, would take care of the Epsilon 2500. ASM America's University Drive building reopened for final assembly and testing operations.

The return of manufacturing to the United States - the annulment of Operation Merio - and the expansion of manufacturing in Almere, Nagaoka, Shenzhen, and Pasir Gudang caused a temporal deterioration of operational costs into 2001. This setback was most unpleasant. Operation Van Gogh had freed ASM from its creditors, but only modestly replenished the company's financial reserves. The manufacturing expenses temporarily deteriorated the profit margins of the successful products. Moreover, the new developments - atomic layer deposition, the Levitor, and Nanophotonics - also drained the cash flow. As long as the surge in demand lasted, however, these operational costs could be justified.

\section{Between confidence and fatigue}

By the fall of 2000, some of ASM's leading managers began to feel the fatigue resulting from the ongoing boom and all its challenges and opportunities. Earlier, Ivo Raaijmakers succeeded Ernst Granneman as CTO. Around the same time, in mid-1999, CFO Rinse de Jong indicated his desire to retire. The renegotiations of ASM's debt, nudging by the Supervisory Board and Del Prado, and his sense of duty delayed this decision. But by the fall of 2000, De Jong insisted on his

53 ASM International, Supervisory Board, 'Minutes of Supervisory Board meeting May 30, 2000’ (14-7-2000) Archive Arthur del Prado - RvC 1999 - 2000.

54 Wunderl had arranged ASM's first deal with Philips Machinefabrieken surrounding the A400 in 1994, when he was still general manager of ASM Europe. 
departure. COO Daniel Queyssac also wanted to quit, for he had 'little ambition to carry responsibility during the next down cycle. ${ }^{.55}$

The previous year's rampant growth, in addition to the financial and operational sorrows, had done little to improve the organizational procedures and structures. The top management had to direct and execute plans themselves. For some, this mode of conduct was tiresome. As De Jong recalled:

'Daniel [Queyssac] ... came from a large company with more structure and bureaucracy, and this you could notice. We had a kind of professional level of management, involving Queyssac, me, but also people like Hans Wunderl, etcetera. Well, and there was Arthur, who could be seen wandering all over the place, rather haphazardly, having his own priorities. He also had his own network within the firm, which he consulted all the time, and vice versa, they consulted him. It was quite difficult actually, since we hardly had any management meetings. ${ }^{56}$

Efforts to improve the organizational processes got nowhere. This was due not so much to sheer opposition, but because the list of more urgent matters prevailing at the subsidiaries and the head office never got shorter. If the company - or Del Prado - never ran short of ideas or new initiatives, it was constantly understaffed.

Other executives showed signs of fatigue. Members of the Supervisory Board, who together with De Prado steered the company out of the messy 1990s, retired at the end of their turn. Lex Helfrich was replaced by Jacob den Hoed, former chief financial officer of the Dutch chemical multinational Akzo Nobel. Johan Danneels, former chief executive officer of Alcatel Microelectronics, succeeded Frans Saris as technical conscience on the Supervisory Board. By 2002, Ferdinand Rauwenhoff was expected to be replaced. The changes stirred chairman Paul van den Hoek to contemplate his own future. He had been chairman since ASM International got listed on the Nasdaq in 1981, and his current term would end by 2004 . He, too, indicated his desire to retire.

Del Prado had no intention to follow suit. After all, sales were soaring. Over 2000, revenues doubled compared to the 1999 levels for each of the products. Net sales increased to 935 million euros, approaching the magical level of one billion. ${ }^{57}$ Moreover, the company was on the verge of pioneering the revolutionary atomic layer deposition technology. The entrepreneur was still busy reinforcing

55 Stibbe Simont Monahan Duhot, Paul van den Hoek, 'Letter to Supervisory Board: ASMI (toekomstige) vacatures topmanagement' (19-10-2000) Archive Arthur del Prado - RvC '99 '00 files.

56 Original quote in Dutch. - Rinse de Jong, 'Interview with author'.

57 In dollars, the sales increased to 867 million dollars. 
his reputation as industrialist and visionary. For instance, during a high-profile trade mission commemorating 400 years of Dutch-Japanese relations - an event to which the presence of the Dutch crown-prince Willem-Alexander, various ministers, and a flotilla of Dutch navy vessels added luster - Del Prado took center stage through 'his' ASM Japan, the first fully Dutch-owned subsidiary in Japan he founded and his directorship of Dujat, the Dutch Japanese Trade Association.

In mid-2000, however, Del Prado suffered a severe heart-attack which hospitalized him for weeks in the United States. Friends and colleagues were left in the dark with regard to his whereabouts. The situation offered Van den Hoek a window of opportunity to address the matter weighing on him:

'Arthur will be, I believe, 69 next month, and it seems appropriate to me that he, in particular after his recent hospital experience, presents his vision on his own future. ... I myself am scheduled to resign during the annual general meeting of 2001. If deemed a good cause, I will be available for reappointment. But my availability is linked to how the CEO position will be filled in. After this issue has been settled, I may decide to retire. ${ }^{58}$

Obviously, Van den Hoek encouraged Del Prado to make preparations for his retirement. After all, Del Prado just survived a heart-attack. Moreover, the entrepreneur had managed his company out of the mess, had a 30-meter new sailing yacht built, and a flourishing relationship with his life partner Joan de Vos Steenwijk. Was it not time to sit back and relax and reflect on his marvelous achievements?

The die was cast. Del Prado's retirement had formally become an issue for the Supervisory Board. But preparing for Del Prado's leaving the company, either planned or not, required serious provisions, given his close and rather intricate ties to the firm and its organizational procedures. As it turned out, Del Prado did not dismiss Van den Hoek's argument entirely, nor did he follow up on it. The entrepreneur still had a number of cards up his sleeve, which he eagerly wanted to play.

\section{Addressing the biggest growth market: copper interconnections}

In the first half of 2001, ASM embarked on advanced technological developments linked to the biggest technological development occupying the industry: the integration of copper as interconnecting material. Copper replaced aluminum, a change requiring new manufacturing processes and equipment. By the late 1990s,

58 Original quote in Dutch. - Stibbe Simont Monahan Duhot, Paul van den Hoek, 'Letter to Supervisory Board: ASMI (toekomstige) vacatures topmanagement' (19-10-2000) Archive Arthur del Prado - RvC'99 - '00 files. 
the manufacturing process for such structures was known as 'damascene process', which involved the deposition and planarization of copper.

In 2001, ASM's chief technology officer Ivo Raaijmakers tried to revitalize the company's efforts into damascene processes. This involved innovation of some of the production steps of interlayer dielectrics and copper barrier seeds. Up until 2001, progress in these fields had been slow and the Dutch equipment manufacturer had not yet made any progression in the market. If ASM wanted to join the copper-bonanza, time was of the essence.

After years of development, ASM continued exploring the commercialization of its interlayer dielectrics process on the Eagle reactors. To accelerate performance of computer chips, not only the resistivity of metals but also the permittivity of interlayer dielectrics had to decrease. ${ }^{59}$ This requirement meant that in addition to the replacement of aluminum by copper, silicon oxide had to be changed for a new material. Such a substitute had to insulate less, hence it was known as a 'low-k material,' with 'k' denotating the dielectric constant. Candidates were polyimides and carbon doped silicon oxides. In 1997 ASM Japan's engineer Nobuo Matsuki had come up with a suitable chemical process for the latter, dubbed 'Aurora'. ${ }^{60}$ From 1999, ASM Japan had been tweaking and tuning this chemistry and the Eagle-10/12 plasma enhanced chemical vapor deposition reactor, in close collaboration with Intel and microelectronics research institute IMEC for introduction in high-volume manufacturing. ${ }^{61}$ To interest other customers, and make some proper return on investments, ASM had to show how its Aurora low-k material could be integrated in the damascene process. ${ }^{62}$

59 Dataquest, Ron Donseif, 'Compacted Change in Interconnect Technology and the Impact on Equipment and Materials Industries, Part II' Dataquest Semiconductor Equipment, Manufacturing, and Materials Worldwide: Market Analysis (26-1-1998).

60 Matsuki named the process after the glow in the skies in the polar areas because he felt a special connection to Alaska. - Nobuo Matsuki, 'Interview with author'.

61 ASM Japan, Yoshida Tominor, 'Memo: IMEC Low k/Cu Program' (16-7-1998) Archive Arthur del Prado - IMEC file; Fukumi Tomino, 'Interview with author', Nobuo Matsuki, 'Interview with author'.

62 From 1998 onward, ASM tried to explore an integrated process for copper. To this end, it approached the startup CuTech, and briefly collaborated with Semitool, one of the first suppliers of copper plating technology. - Dataquest, Ron Dornseif, 'Deposition Equipment Family Welcomes Two New Babies: ECD and SOD', Dataquest Semiconductor Equipment, Manufacturing, and Materials Worldwide: Market Analysis (14-9-1998); ASMI, Ernst Granneman, 'Visit Report CuTek, San Jose California, on 11-9-1998' (16-9-1998) Archive Arthur del Prado - Ernst Granneman files; ASMI, Ernst Granneman, 'Visit Report: Semitool, Electrochemical Deposition Division, Kalispell, Montana, USA on March 31, 1999; ref: visits\eg091stl.doc' (2-4-1999) Archive Arthur del Prado - Ernst Granneman file; ASMI, Ernst Granneman, 'Letter to Semitool, attn: Fabio Gualandris: Response to visit Hasper, Yoshida and Granneman to Semitool' (date unknown) Archive Arthur del Prado - Ernst Granneman file; ASMI, Ernst Granneman, 'Memo to Gilbert Declerck, IMEC: Relation IMEC-ASM; ref: 
Progress in this regard was slow. Only by 2001 was Aurora successfully integrated in a fully-fledged damascene fabrication process at IMEC. ${ }^{63}$

In contrast, no progress was made with ASM Microchemistry's barrier and copper seed processes, which complemented the low-k efforts beautifully. Copper easily diffused into low-k dielectrics, distorting the electrical properties of a computer chip. Therefore, it had to be contained by a diffusion barrier. This involved a thin film between the low-k dielectric and the copper. Candidates for this material included titanium nitride (TiN) and tantalum nitride (TaN). The latter enjoyed the highest prospects, since tantalum and copper are immiscible metals; they do not form alloys at any temperature. At the same time the absence of chemical bonds makes the deposition of copper on tantalum difficult. Instead, a copper film had to be grown using a process with less atom mobility and lower temperatures. Such a film was a copper seed. ${ }^{64}$

Through the acquisition of Microchemistry, ASM had obtained valuable process knowledge to address this market. By means of ALD, the barrier and the copper seed could be grown with incredible uniformity and step coverage. Within the comprehensive governmentally supported ALAD1N program - meant to advance the immature ALD technology as a semiconductor manufacturing method - ASM pursued this application. However, throughout the year 2000, the development of ALD copper barrier and seed materials had been relatively overlooked. Within the ALAD1N program all attention had gone to the development of an ALD high-k gate dielectric (cf. Chapter 27). ${ }^{65}$ By December 2000, not a single development tool had been installed at research partner IMEC.

At the start of 2001, Raaijmakers stumbled upon two small starting semiconductors equipment manufacturers with technologies that might boost ASM's aspirations in damascene processes. The first was a South-Korean firm named Genitech offering plasma enhanced ALD and a copper CVD process. The second was an American startup named NuTool that developed an alternate copper deposition technique. The introduction of copper in semiconductor manufacturing had created new markets, like low-k, copper barrier seeds, and the distinct copper deposition methods. So far ASM had tried to innovate in

imeclgd285str.doc. Appendix B: Summary of Recent Events.' (16-10-2000) Archive Arthur del Prado - IMEC file.

63 IMEC, Luc van den Hove and Rudy Catuyvels, 'Letter to Ivo Raaijmakers: ARRM' (5-11-2002) Archive Arthur del Prado - IMEC files.

64 Simon Wong, Changsup Ryu, Haeburn Lee, et al., 'Barrier/Seed Layer Requirements for Copper Interconnects', Proceedings of the IEEE 1998 International Interconnect Technology Conference (June 1999) pp. 107-109.

65 Although it was reinstated in a separate research effort into back-end of line processes, called the Coppermine project cf. Business V). - ASMI, Ivo Raaijmakers, 'ASM Barrier and Seed Business/Project Plan' (29-6-2001) Archive Arthur del Prado - Ivo Raaijmakers file. 
these segments. NuTool and Genitech, in contrast, had tried to overhaul the whole damascene process. If the development of low-k and copper barrier and seed layers had already been disruptive relative to traditional semiconductor manufacturing, the initiatives offered by Genitech and NuTool were so even more.

In the process of due diligence for ALD and related processes, Raaijmakers learned about Genitech, and decided to take stock of this company during Semicon Korea in January 2001.66 Five years earlier, in 1996, Genitech had been established by two men: Dr. Sangwon Kang and Dr. Kevin Kyoungsoo Yi. ${ }^{67}$ Kang had stimulated Yi to commercialize their intimate process knowledge, while capitalizing on readily available venture capital for Korean firms in semiconductor manufacturing technology ${ }^{68}$ Ever since the mid-1980s, the Korean authorities, in close conjunction with the country's major industrial chaebols like Samsung, Huyndai, and LG, drove and coordinated efforts to boost its national semiconductor industry. Yi and Kang located the firm near the Korea Advanced Institute of Science and Technology (KAIST), in Daejon, where Kang was a professor. Yi came up with a name:

'The Genie is from Aladdin's lamp. So, I wanted to make a company that could solve clients' problems, any problem. ... Like a Genie. So, I made the name, Genie plus technology, which makes Genitech. ${ }^{69}$

66 Based on his experience at Applied Materials, Raaijmakers instigated defensive and offensive measures to secure ASM's lead in ALD. This involved upgrading ASM's patent portfolio, licensing related processes from external parties, and suing competitors. In this process, Raaijmakers learned about Genitech. - ASM International, Ivo Raaijmakers, 'Memorandum: Arthur Sherman ALCVD Patent' (7-9-1999) Archive Arthur del Prado - Ivo Raaijmakers files; ASMI, Supervisory Board, 'Memorandum: Asserting patent Position ALCVD' (26-10-2000) Archive Arthur del Prado - RvC 2001.

67 The men knew each other from the Electronics and Telecommunication Research institute (ETRI), near Daejon. At ETRI, the men - and later other engineers of Genitech - worked on the development of South Korea's first 4 MB DRAM chip in the late 1980s. After years of research and a PhD in CVD-processes, Dr. Yi found himself wondering about his future around the mid-nineties. By that time, Dr. Kang had become professor at the Korea Advanced Institute of Science and technology (KAIST), which was also located in Daejon.

68 Genitech was established as the 12th venture company of ETRI. By September 1996, the company was selected as one of the focal high-tech ventures of the Korea Institute of Industrial Technology (KITECH). By March 1998, the company obtained its first venture capital from KTB Network, LG Investments, and a funding vehicle from Hyundai. This accumulated to 1 million dollars. Kevin Kyoungsoo Yi, 'Interview with author'; Genitech, 'Company Overview' (March 2003) Archive Arthur del Prado - Genitech file.

69 Kevin Kyoungsoo Yi, 'Interview with author'. 
A new company was born. Just like the genie of Aladdin's lamp fulfilled three wishes, Genitech addressed prevailing needs of the semiconductor industry with three innovations. The first was 'double orbital chemical mechanical polishing' technology. This technology was meant to accelerate the planarization of copper interconnections after deposition..$^{70}$ The second product was named 'Copper Superfill CVD.' In June 1998, Dr. Wonyong Koh joined Genitech to commercialize this idea. ${ }^{71}$ Based on Copper Superfill CVD, trenches could be filled with copper through a dry process instead of by the common electroplating process. Genitech's third product was plasma enhanced ALD (PEALD). This variation of ALD was expected to be applicable for new dielectrics, metals, and copper seeds - just as Microchemistry was pursuing. Yi and his engineers added a plasma in their ALD reactor to decrease process temperatures from April 2000 onward. $^{72}$

Despite contacts with the industry, the company was running out of money by 2001, and as a consequence it was running out of time as well. Only one piece of equipment had been sold. Yi, in his capacity of chief executive officer, was confronted with the survival of his company. He recalled:

'Genitech's identification was one as an equipment company. So I wanted to sell equipment to semicon companies.... Until I found out that they only wanted our technology, not the equipment. The equipment was not good. So I found out: semiconductor companies are not our customers. Semiconductor equipment companies are our customers!?33

This change of perception was a turning point. During Semicon Korea 2001, Yi specifically tried to get in touch with equipment manufacturers instead of chip producers. ${ }^{74}$ At that moment, a curious Ivo Raaijmakers walked into their booth.

70 After one year, due to disappointing results, Yi and Kang also began to look to other deposition processes. The commercialization of the CMP process was accompanied with numerous difficulties. It involved merely a mechanical process instead of a chemical one, and therefore it was beyond Yi's professional skills. The entrepreneur had enjoyed an extensive career in chemical vapor deposition. The route to CMP was not seen as feasible for the company, and the technology was transferred to a company called Doosan Machinery Co. This license provided the company with some income. - Kevin Kyoungsoo Yi, 'Interview with author'.

71 Copper Superfill CVD was originally invented by professor Jiwha Lee at Seoul National University. Working at chemical supplier UPChem, Koh learnt about the technology. Wonyong Koh, 'Interview with author'.

72 Kevin Kyoungsoo Yi, 'Interview with author'; Wonyong Koh, 'Interview with author'; and Hyungsang Park, 'Interview with author'.

73 Kevin Kyoungsoo Yi, 'Interview with author'.

74 Kevin Kyoungsoo Yi, 'Interview with author'; Wonyong Koh, 'Interview with author'. 
As a follow-up to the initial encounter at Semicon Korea, ASM's chief technology officer visited the South-Korean company on March 15, 2001. ${ }^{75}$ The Dutchman wanted to know whether the PEALD process could be harnessed for the development of high-k gate dielectrics as currently pursued by ASM Microchemistry, whether a license would be possible, or if he could passivate this potential competitor. During the meeting, Raaijmakers learned that Genitech's PEALD process ignited the plasma directly above the wafer (consider figure 63 in Chapter 23). This contrasted with an ASM-owned method, whereby gasses were directed through a remotely generated plasma before being inserted into the reactor chamber. ${ }^{76}$ Quite similar to what happened with CVD, PEALD might very well be a new or even competing market for the 'regular' thermal ALD processes (cf. Chapter 9). If ASM would act determinedly and quickly, it might obtain the technology first. Raaijmakers reported to the ASM front-end board:

'I am very impressed with the level and knowledge of the engineers and managers I talked to. Genitech is on our heels with ALD knowledge and far ahead in PEALD. PEALD is the future of ALD: the choice in chemistries can be larger, film quality can be better controlled and in situ chamber cleaning would be viable. ${ }^{17}$

Genitech indicated that they would like to have a long-term business relation with ASM, but it also mentioned its intention to remain an independent OEM. ${ }^{78}$ The company saw ASM as a steppingstone for its PEALD technology.

Teaming up with Genitech offered even more for ASM. After a presence of half a decade in South Korea, ASM was losing terrain in that country. The South-Korean market constituted the most promising one, with customers like Samsung, Hynix (Hyundai), and an active and ambitious Korean government. So far, the big Korean companies had not been very content with ASM's service. At the same time, ASM had been concentrating on its core operations and halting any geographical expansion during the early nineties. Moreover, the equipment manufacturer had been wary about losing its intellectual property. Korean chip manufacturers and suppliers allowed themselves some slack in this regard in

75 ASM International, Ivo Raaijmakers, 'Genitech Visit Report' (15-3-2001) Archive Arthur del Prado - ASM Korea/ASM Genitech, Genitech.

76 ASM International, Ivo Raaijmakers, 'Memorandum: Arthur Sherman ALCVD Patent' (79-1999) archive Arthur del Prado - Ivo Raaijmakers files.

77 ASM International, Ivo Raaijmakers, 'Genitech Visit Report' (15-3-2001) Archive Arthur del Prado - ASM Korea/ASM Genitech, Genitech.

78 ASM International, Ivo Raaijmakers, 'Genitech Cooperation' (15-3-2001) Archive Arthur del Prado - ASM Korea/ASM Genitech, Genitech. 
order to achieve their ambitions. Teaming up with a local, innovative equipment manufacturer might relieve ASM's local troubles. As Raaijmakers reported:

'We should therefore carefully consider our options to work with Genitech ... We should try to leverage it to our advantage in the Korean market, and not only for ALD. ${ }^{79}$

From April to June 2001, successive meetings followed, resulting in a memorandum of understanding between both firms. ${ }^{80}$ For the period of five years, ASM got the exclusive right to sell and market Genitech's products outside of South Korea. Genitech would manufacture the modules, so they could be fitted on ASM's platform, the Polygon. In exchange, ASM would support Genitech with the platform and their experience in semiconductor manufacturing. In addition, ASM paid for the license and production of the first modules. Genitech was desperately in need of cash. Although ASM was foremost interested in the PEALD technology to grow metals and barriers, Genitech also included the Copper Superfill CVD process into the deal. As such, ASM suddenly had an alternative technique for its ambitions in dual damascene.

ASM's limited enthusiasm about Copper Superfill CVD was tied to its contacts with NuTool. The technology of this ambitious startup promised to be much more disruptive and viable than the Korean copper deposition technique. It was called 'Electro Chemical Mechanical Deposition'. This technique combined the common copper electro chemical deposition with copper chemical mechanical polishing in a single machine (mind figure 83). In theory, it constituted a revolutionary technology, halving the number of production steps.

Moreover, the company enjoyed a good reputation. NuTool had been established in mid-1998 by a well-known engineer of copper deposition processes named Homayoun Talieh. Raaijmakers, who knew Talieh from his time at Applied Materials, succeeded the American as development manager of the physical vapor deposition division. ${ }^{81}$ Afterward, Talieh worked amongst others copper mechanical polishing at Applied Materials, Ontrak (currently LAM Research). Furthermore, several semiconductor manufacturers participated in the company,

79 ASM International, Ivo Raaijmakers, 'Genitech Visit Report' (15-3-2001) Archive Arthur del Prado-ASM Korea/ASM Genitech, Genitech.

80 These meetings took place during Semicon Europe in Munich, April 2001, and during the International Interconnect Technology Conference in San Francisco in June 2001. ASM International, Ivo Raaijmakers, 'Meeting ASM_Genitech, 4/24/01 and Genitech/ASM Comments' (22-5-2001) Archive Arthur del Prado - ASM Korea/ASM Genitech, Genitech.

81 ASMI, Ivo Raaijmakers, 'Memorandum: NuTool opportunity, ref: IR/ive/005.09' (18-9-2001) Archive Arthur del Prado - NuTool file. 
including Intel (10\%), Micron (2.5\%), a supplier of CMP polishing pad's 3M (16\%), and Infineon (2.3\%).

A collaboration with this promising startup might foster ASM's chances in the market for damascene processes. Several times, Raaijmakers, and later also Arthur del Prado, visited NuTool at its location in Milpitas, in California's Silicon Valley. A collaboration with NuTool might positively affect the sales of low-k equipment, increase the potential of ASM Microchemistry and Genitech's copper barrier seed effort, and expand ASM's general status in the market for interconnections. ${ }^{82}$

In September 2001, the collaborations with both Genitech and NuTool were presented to ASM International's Supervisory Board. ${ }^{83}$ Their approval was required in particular for the deal with NuTool. Talieh had demanded that in order to cooperate, ASM took a stake in his firm. For the scope of the collaboration, both parties agreed upon a 15 percent interest, acquired for approximately 18 million dollars. The Supervisory Board was rather skeptical. Not only because the investments bore the promise of further diversification and deterioration of the company's cost base. But also because of the collaboration itself. Fearful of knowledge leakage and eager to reap the maximum benefits of its innovation, NuTool had demanded that it and ASM did not physically cooperate on the integration of their technologies, but through a 'virtual fab. ${ }^{84}$ In particular Supervisory Board Member Ferdinand Rauwenhoff expressed his concern that ASM might not get access to NuTool's know-how. The concerns were dismissed. A sense of urgency prevailed, stimulated by the interest taken in NuTool by the chip manufacturers.

The investment community, embodied by the analyst Ali Irani of CIBC bank that had freed ASM from its bankers, took away the remaining doubts about the collaborations. Irani congratulated Del Prado with the NuTool deal:

'This [interest], in my opinion, finally positions your company to compete most effectively in a market place which is migrating towards process sequence integration, and where mindshare with leading chip makers such as Intel, Micron, Infineon and Taiwan Semiconductor - each both

82 ASMI, Ivo Raaijmakers, 'Memorandum: NuTool acquisition plans' (20-11-2003) Archive Arthur del Prado - NuTool file.

83 ASMI, Arthur del Prado and Robert de Bakker, 'Strategic investments in NuTool Inc and Genitech Co. Ltd.' (19-9-2001) Archive Arhtur del Prado - RvC 2001.

84 This in imitation of Applied Materials, which also offered such a virtual lab to its customers. ASMI, Supervisory Board, 'Minutes Supervisory Board meeting October 15, 2001' (22-102001) Archive Arthur del Prado - RvC 2001; ASMI, Ivo Raaijmakers, 'Memorandum: NuTool acquisition plans' (20-11-2003) Archive Arthur del Prado - NuTool file. 
ASM and NuTool customers - will depend on equipment suppliers' ability to supply all the critical elements ... ASM International's early investment in NuTool, much similar to your early investment in Microchemistry, not only makes your company a partner with Intel, Micron and Infineon which are all investors in NuTool, cementing your ties with these large fab operators; but also strategically eliminates the risk of your competitor purchasing this critical technology. ${ }^{285}$

ASM's new collaborations with NuTool and Genitech did not go unnoticed by its major competitor Applied Materials. The American equipment manufacturer concluded in an inter-company newsletter:

'These partnerships suggest that ASM's strategy is to invest into the $<0.1$ micron nodes. The results of these partnerships are not likely to generate significant revenues in the next upturn, but could position them well two years down the road should everything work as they claim of course. ... All-in-all, this latest move by ASM is an interesting one: it is bold, and risky. ASM must be a believer of the saying "big rewards are usually accompanied by big risk". ${ }^{86}$

ASM's biggest competitor saw it correctly.

The deals involving Genitech and NuTool were right up Del Prado's alley. They fitted perfectly in his range of leveraged innovations, betting on future profits. This was not limited to ASM. Close to the end of running ASM International, he personally invested in a Dutch startup for e-beam lithography, called Mapper Lithography. Two Technical University of Delft students, Bert-Jan Kampherbeek and Marco Wieland, in collaboration with their professor, Pieter Kruit, had designed a lithography machine that beamed electrons in multiple rays. Over the years, Del Prado deliberately and too naively continued to invest in this startup with tens of millions of euros, preventing it from fizzling out. Being too far removed from immediate commercialization or ASM's activities, Mapper Lithography and ASM International would always remain separate activities for Del Prado. His investment in Mapper Lithography well illustrated his thirst for action, however. Instead of backing down, it seemed that his hospitalization reignited his entrepreneurism. There was still so much to be done.

85 CIBC Semiconductor Food Chain Equity Research, Ali Irani, 'Fax to Arthur del Prado: Letter in support of investment in NuTool' (13-10-2001) Archive Arthur del Prado-NuTool file.

86 Applied Materials, Peter Kim et al., 'ASM Partners with NuTool and GeniTech', [Undefined inter-company newsletter] (October 2001) - Archive Arthur del Prado - RvC 2001. 


\section{Chapter 31}

\section{Redefining foundations, 2001-2004}

After an unprecedented economic boom, ASM had to deal with a period of stagnation. Consolidating and controlling expenses was required, while the new additions to ASM International's activities were formally integrated. Moreover, the search for a successor of Del Prado commenced. This time, after the destabilizing downturns in the late 1980s and throughout the 1990s, ASM's management was determined to save its economic bacon.

\section{Industrial context:}

\section{From Boom to Bust}

The terrorist attacks on September 11, 2001, in New York and Washington DC, marked the beginning of an industry-wide recession that depressed the market into 2005. The traumatic experience of the attacks did not only have economic effects in the United States, but also among its allies, including the European Union member states, Japan, and South Korea. Air travel was subjected to much tighter security and the prevailing anxiety undermined economic recovery for years. This was hardly helped by the ill-rationalized American invasion of Iraq in 2003 and the outbreak of 'Severe Acute Respiratory Syndrome' (SARS) in SouthEast Asia. Moreover, a series of terrorist attacks, such as in Mumbai (2003) and Madrid (2004), and great political instability in the Middle East contributed to an escalating 'War on Terror,' involving global military action and far-reaching expansions of intelligence capabilities. Islamophobia surged.

The $9 / 11$ attacks accelerated the deflation of the Dotcom bubble. ${ }^{87}$ By the summer of 2001, capital spending of semiconductor manufacturers was expected to decline by 26 percent, or 47.3 billion dollars, a figure which by the end of the year even dropped to 44.5 billion. ${ }^{88}$ The rush for technology- and internet-related stock had been too exuberant. Many of the ostensibly promising internet firms proved to be over-valued. As fast as the bubble had grown, it deflated again. Investors moved their money to more stable funds, which undermined the investment climate in the fall of 2001.

87 Gartner, Charles Smulders, 'Worldwide Semiconductor Forecast Scenarios: Life After 11 September', gartner.com (19-10-2001).

88 Mardi Scalise, 'Gartner Dataquest forecasts decline in worldwide semiconductor spending', lightwaveonline.com (17-7-2001; and from the author's personal archive: Gartner, 'Semiconductor Capital Spending by Region, 1998-2017'. 


\section{Strengthening of corporate governance}

The busting of the Dotcom Boom also exposed fraudulent business practices at numerous firms, instigating a tightening of corporate governance regulation in the United States. Affairs at companies like WorldCom, Enron, and AOL raised awareness about inadequate self-regulation of companies. Oversight had failed. In the summer of 2002, the American Congress passed the Sarbanes-Oxley Act (SOX). This new regulation emphasized risk control, and stipulated procedures for the annual disclosure of internal and external information. In response, ASM's Supervisory Board set up an 'audit committee,' which would supervise the internal control on procedures and the dispersion of information, in addition to the external oversight performed by accountants.

In the Netherlands, ASM International's home country, a similar tightening of corporate governance regulation occurred, fitting in a general trend of European and global capital markets integration. During this process, according to economic historians Abe de Jong, Gerarda Westerhuis, and Ailsa Röell, the Dutch economy was characterized by the prominence of growing stock markets, the breakdown of corporate take-over defenses, and restriction on 'self-perpetuation' in management boards (the 'old boys' network). ${ }^{89}$ Shareholder value prevailed over the interests of stakeholders, whereby shareholders also included employees, authorities, investors, etc. ${ }^{90}$

Being a small and open economy, the Dutch government often took the lead in the advocacy of liberalizing trade and market integration nationally, as well as within the European Union. This process was stimulated by the introduction of the euro as European currency in 2002 and the expansion of the European Union with ten Eastern-European member states in 2004. ${ }^{91}$

In the Netherlands, the development of market integration was embodied by a corporate governance code on January 1, 2004. This so-called 'Tabaksblat Code' - named after Morris Tabaksblat, the chairman of a commission tasked with the

89 Abe de Jong, Ailsa Röell, and Gerarda Westerhuis, 'Changing National Business Systems: Corporate Governance and Financing in the Netherlands, 1945-2005’, Business History Review 84:4 (2010) pp. 773-798.

90 Abe de Jong, Keetie Sluyterman, and Gerarda Westerhuis, 'Strategic and structural responses to international dynamics in the open Dutch economy, 1963-2003', Business History 53:1 (2011) pp. 63-84; Keetie Sluyterman, 'Introduction: Changing Business Systems in the Netherlands in the Twentieth Century', The Business History Review 84:4 (2010) pp. 737750; De Jong, et.al, 'Changing National Business Systems'; Dirk Akkermans, Hans van Ees, Niels Hermes, Reggy Hooghiemstra, Gerwin van der Laan, Theo Postma, and Arjen van Witteloostuijn, 'Corporate Governance in the Netherlands: an overview of the application of the Tabaksblat Code in 2004' Corporate Governance 15:6 (2007) pp. 1106-1118.

91 De Jong et. al, 'Strategic and structural responses'; Keetie Sluyterman \& Ben Wubs, Over Grenzen. Multinationals en de Nederlandse markteconomie (Boom Uitgevers, Amsterdam, 2009). 
analysis of Dutch corporate governance - stipulated codes of conduct for listed enterprises with regard to transparency in accounting practices, responsibilities of supervisory boards, and the rights of shareholders. ${ }^{92}$ The new code gave rise to more self-reflection and self-assessment by management and in annual reports among all listed companies in the Netherlands, including ASM International. Meanwhile, shareholders and investors were forced to reconsider their investments, as well as observance of their rights as shareholders. The legislation contributed to further management professionalization at listed corporations, and it would gradually redefine the relationship between management and shareholders (as will become apparent in the next chapter).

\section{Adjusting expectations by equipment supplier}

For semiconductor equipment manufacturers, the period from 2001 to mid2004 was far from ideal. In 2001, 2002, and 2003, the semiconductor equipment industry's growth fell short of expectations. ${ }^{93}$ Even worse, over 2001 and 2002, the sector witnessed a steady decline in sales after the Dotcom-boom years of overinvestment. Due to overcapacity of 200-millimeter production lines, fab utilization rates declined from 97 percent in the third quarter of 2000 to 60 percent in the third quarter of $2001 .^{94}$ This in turn delayed the roll out of 300-millimeter fabrication processes. The introduction of the new wafer size foremost pertained to initial pilot lines. It was not feasible anymore to expand these lines into full-fledged fabs rapidly. As a result, 300-millimeter lines were added at a much slower pace than originally anticipated.

Capital spending by chip manufacturers declined from 44.6 billion dollars in 2001 to 27.6 billion in 2002, of which 23.7 billion and 16.2 billion, respectively,

92 In April 2003, fraudulent business practices were revealed at Dutch retailer Ahold, , which confirmed the necessity to stipulate corporate governance rules. - Randall K. Morck and Lloyd Steier, 'The Global History of Corporate Governance', in: Randall Morck (ed.), A History of Corporate Governance around the World: Family Business Groups to professional Managers (University of Chicago Press, Chicago, 2005) pp. 1-64; Abe de Jong and Peter Roosenboom, 'De achilleshiel van Tabaksblat', Economisch Statistische Berichten 88:4411 (22-8-2018) p. 392; Abe de Jong, Ailsa Röell, and Gerarda Westerhuis, 'De rol van aandeelhouders in historisch perspectief', Economisch Statistische Berichten 102: 4751 (13-7-2017) pp. 312-315.

93 The semiconductor industry itself obtained a small 1.4 increase in sales to 155.4 billion dollars in 2002. - Author unknown, 'Semiconductor industry showed light growth in 2002', electroiq.com (13-12-2002).

94 Gartner, Charles Smulders, 'Worldwide Semiconductor Forecast Scenarios: Life After 11 September', gartner.com (19-10-2001).. 
pertained to wafer fab equipment. ${ }^{95}$ By 2003 , recovery set in, if modestly. ${ }^{96}$ This primarily involved assembly and packaging equipment, with 30.5 percent of the total revenues in semiconductor equipment, while wafer fab equipment sales increased by a modest 3.6 percent. Back-end saw more recovery than frontend. Over 2004, semiconductor equipment sales reached 37.6 billion dollars. ${ }^{97}$ In this year, wafer fab equipment suppliers achieved the highest growth. More 300-millimeter than 200-millimeter equipment was sold, with companies like Applied Materials, Tokyo Electron and ASML obtaining 6.3, 4, and 2.7 billion dollars in revenue, respectively, compared to 3.2, 2.1, and 1.4 billion in 2003.

In this period, the chip industry enabled the advent of new portable electronics. The utilization of silicon germanium and a more efficient architecture in computer chips (known as ARM) enabled faster speeds and lower energy consumption. These enhancements gave rise to new products, such as Nokia mobile phones, digital cameras, and digital music players like the iPod.

The advent of digital and portable electronics was accompanied by a major shift in consumption of semiconductors from the West to Asia. For the first time in the history, the semiconductor industry sold more in Asia than in the United States and Europe. This change was propelled in particular by the Taiwanese and South-Korean markets, developing their own national semiconductor infrastructure.

Following this shift in consumption, semiconductor equipment manufacturers expanded their activities in Asia. ${ }^{98}$ Until 2005, however, the United States remained the biggest national market. Although the European support schemes remained in place, like the EUREKA program MEDEA+, the Semiconductor Equipment Assessment (SEA), and the EU's European Framework programs, their public visibility was significantly lower than in the 1980s and early 1990s.

95 Gartner, Klaus Rinnen, Dean Freeman, James F. Hines, and Bob Johnson, 'Semiconductor Industry Equipment Spending Will Recover in 2003', gartner.com (10-7-2002); Author unknown, 'Gartner says worldwide semiconductor capital equipment spending to grow in 2003', vision-systems.com (10-7-2003); and from the author's personal archive: Gartner, 'Wafer Fab Equipment by Region, 1998-2017’.

96 Gartner, 'Press Release: Gartner Says WorldWide Semiconductor Manufacturing Equipment Sales Experienced a 10 Percent Increase in 2003', gartner.com (8-4-2004); and from the author's personal archive: Gartner, 'Wafer Fab Equipment by Region, 1998-2017'.

97 U.S. International Trade Commission, 'Industry \& Trade Summary: Semiconductor Manufacturing Equipment', USITC Publication 3868 (June 2006), p. 5.

98 Ibid., p. 15. 


\section{Corporate course: \\ Biding time}

The end of the Dotcom bubble heralded a period of consolidation for ASM International. After shaking off its long-lasting creditors and having revitalized its technological portfolio, the company had to ensure it continued to be the master of its own fate. A reorganization of the innovation efforts, an optimization of organizational quality and safety procedures, concentration of manufacturing and the incorporation of Genitech and NuTool were the main actions to that purpose. Yet, not all of these managerial interventions by the head-office were instigated by ASM itself. These decisions were prompted in part by stakeholders and external dynamics. Be that as it may, through the mentioned actions, ASM harnessed the intermission in the market's growth to prepare itself for the next upturn. By that time, it would be ready.

From 2001 to 2003, the company adjusted its strategy to ever deteriorating forecasts. In 2001, its front-end operations incurred a loss of 3.7 million euros on sales of 336.6 million euros. ${ }^{99}$ Back-end partially knew to offset the depressed market by laying off staff, with the total number of employees dropping from 6,027 in 2000 to 4,830 in 2001 (figure 85). In 2002, front-end operations made a loss of 42.7 million euros against sales of 266.9 million, while back-end remained profitable with slightly growing sales and increased staff. Cutting costs was nevertheless inevitable.

\section{Figure 85}

Graph of number of employees ASM front- and back-end, 1998-2008

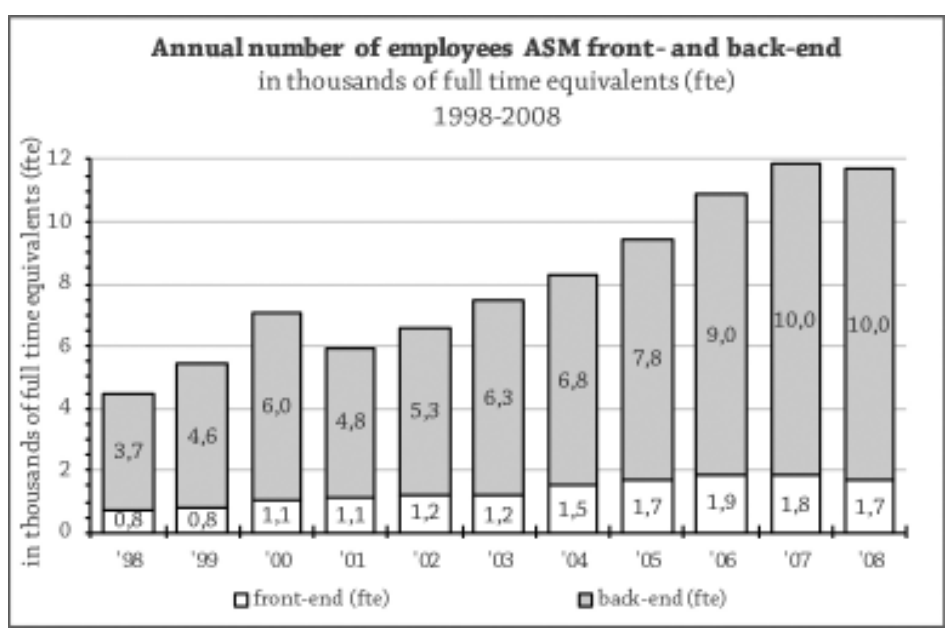

99 ASM International, Annual Report 2001 (11-2-2002). 
The one ASM operation that did very well was ASM Pacific Technology. Despite the depressed market and less revenue, the Hong Kong-based manufacturer of assembly and packaging equipment was capable of sustaining its profitability. Its position in the market for light emitting diodes (LED) and its vertically integrated manufacturing operation helped to offset the dramatic downturn of the chip market. The company led by Patrick Lam was less susceptible to the troubles affecting its competitors, such as Kulicke \& Soffa, ESEC, and Shinkawa. What is more, in 2002, ASM Pacific Technology became the biggest supplier of semiconductor assembly and packaging in the world! It was a position the company would retain throughout the ensuing decade.

Such joyful achievement did not befall ASM's front-end operations. In this regard, the ASM International Supervisory Board stepped up its urgency for proper accountability of profitability, cash flow, and strategic value per product group. Decentral pursuit of new - potentially disruptive - technologies had to be reined in. Emphasis on sustaining existing activities and sticking to core competencies returned. The newly established Audit Committee was meant to ensure oversight.

Within the ASM front-end operations, priorities were set with regard to the new technological developments, such as atomic layer deposition (ALD) and damascene processes. Chief technology officer Ivo Raaijmakers restructured research and development across the company, resulting in a reorganization of ASM Microchemistry. ${ }^{100}$ Meanwhile, ASM's reliance on just a few customers yet being technological leaders in the industry - resulted in a company-wide effort to update and harmonize its procedures with regard to safety, information handling, and quality management. Furthermore, amidst the depressed market circumstances, the cost-inefficiencies of having multiple manufacturing centers was addressed through a central manufacturing operation in Singapore, named Front-End Manufacturing Singapore (FEMS). The plan constituted the first effort to define and address synergies between ASM Pacific Technology and the frontend operations. And finally, despite the deteriorating sales and the increasing scrutiny by customers and the ASM Supervisory Board, Del Prado was able to concoct one of his final entrepreneurial tricks. In January 2004, he got the Supervisory Board to approve a full acquisition of Genitech and NuTool, which secured the disruptive potential of these startups.

At the corporate level, a wariness about further expansions mounted, a sentiment also seeping into the business units. It was imperative to sustain activities in order to keep the company afloat. Throughout the downturn, the Supervisory

100 ASM International, Ivo Raaijmakers, 'ASMI Front End R\&D Policy' (16-1-2002) Archive Arthur del Prado - Ivo Raaijmakers file. 
Board felt empowered to restrain their headstrong and wayward chief executive officer. Del Prado's position was thinning out. The successive issuance and refinancing of convertible notes diluted his ownership of the company. His stake balanced around 23 percent during the period covered in this chapter. ${ }^{101}$ Following Supervisory Board chairman's Paul van den Hoek's urgency, a possible successor of Del Prado had been headhunted: Haijo Pietersma. Additionally, the management of ASM International was revitalized by resignations and new appointments, introducing new perspective and energy.

\section{Elaboration of affairs}

\section{Reorienting innovation}

By the fall of 2001, the rapidly declining orders prompted a reorganization across ASM International. Through an additional 90 million revolving credit facility and a successive placement of a 115 million convertible subordinated note, liquidity was ensured. ${ }^{102}$ The operations had cut costs to prevent overreliance upon these bank loans and credit facilities, however. Spending had to meet earnings, and even with a rapidly deteriorating profit and loss account, the management intended to reach break-even for the fall of 2001, or at least for the first half of 2002. ${ }^{103}$

In December, the outlines of a major reorganization program were defined. ${ }^{104}$ ASM America laid off forty-seven employees, ASM Europe sixty employees, the Taiwanese sales office ten staff members, and ASM Pacific Technology reduced its staff by 14 percent. The A600-UHV was phased out. At the head office,

On March 14, 2000, Del Prado owned 10,704,292 common shares of ASM International of the 47,220,979 outstanding common shares, or 22.67 percent. On February 24, 2005, he owned $11,476,878$ of the $52,618,073$ common shares, or 21.8 percent of ASM International's stock. This was a slight dilution, owing to new issuances of stock and despite an increase in the number of common shares owned by Del Prado. Of Del Prado's shares, about 7,692,039 common shares were held by a trust named 'Stichting Administratiekantoor ASM International,' which was controlled by Arthur del Prado. - CIBC World Markets, Robert Stephens, Warburg Dillon Read, Prospectus issuance of 5,000,000 Common Shares of ASM International (14-3-2000) p. 54; ASM International, Annual Report 2004 (24-2- 2005) p. 80.

Just as in the case of the March 2000 Convertible Note, Ali Irani of CIBC led the transaction. The price per note was about 18.85 dollars. The revolving credit facility could be used to an aggregate of 65 million dollars for up to 10 million dollars in common shares. ASMI, Arthur del Prado and Robert de Bakker, 'Memorandum to Supervisory Board: Various financing transactions' (22-5-2001) Archive Arthur del Prado - RvC 2001 file; ASM International, Annual Report 2001 (11-2-2002); ASM International, 'Progress Report December 2001' (17-12-2001) Archive Arthur del Prado - RvC 2001 file. 
salaries were cut by 15 percent. ASM Japan was unable to make contributions due to a pending order for its low-k process. Despite the setback, Del Prado and his management were determined to sustain the pursued new technological opportunities:

'ASMI's future is determined by our ability to offer breakthrough technology at the right point in time. This means our R\&D activities must be continued at the maximum affordable level. This to not lose the momentum we currently have. ${ }^{105}$

This involved technologies relevant for below 100-nanometer transistor structures in particular. Chief technology officer Ivo Raaijmakers restructured research and development across the company. These changes were accompanied by reorganizations, a realignment of the ALD and the copper strategy (including the newly added collaborations with NuTool and Genitech), and by setting limits to the proliferation of wafer handling technologies. Moreover, Nanophotonics had to pursue sales beyond ASM Europe. The Levitor was put on hold with regard to the development of a 300-millimeter variation.

Proportionally, ASM Microchemistry was hit hardest by the reorganization. In Finland it was even nicknamed 'the big bang', as the restructuring shattered prevailing hopes of maturing the operation into a full-fledged original equipment manufacturer. ${ }^{106}$ ASM had managed to join several joint-development programs with leading chip manufacturers and research efforts at IMEC and Sematech for the development of high-k gate dielectrics. But in meeting this challenge, ASM and ASM Microchemistry missed steps. The learning curve for the Finnish operation proved to be too steep. ${ }^{107}$

Moreover, with rapidly declining sales across the company, the continuation of a new manufacturing location could not be explained, in particular because the American operation was fully qualified and up and running. It was decided, then, that production and development of the ALD reactors - the Pulsar 2000 and 3000 - were moved to Phoenix, which reduced the number of staff at the Finnish operation to thirty. The copper barrier seed efforts of the Finnish operation were put on hold. Competing sputtering processes had been making much more progress, while the Finns hardly had the resources - financial, technological, and foremost human - to address the matter. ASM Microchemistry had to be ahead of the curve,' thus working on technologies at least three years out before the

105 Ibid.

106 Suvi Haukka, 'Interview with author'.

107 ASM International, Ivo Raaijmakers, 'Memorandum to FEB:ASMM Charter 2002+' (2-112001) Archive Arthur del Prado - ASM Microchemistry file. 
high-volume ramp with peer groups, such as universities, R\&D institutes, and large companies' R\&D departments. ${ }^{108}$

In January 2002, Raaijmakers completed the $R \& D$ reorganization by articulating a more structured approach for R\&D within ASM ${ }^{109}$ He distinguished five different stages in research and development, indicated as pre-competitive exploration, concept \& feasibility, Alpha, Beta, and Gamma. ${ }^{110}$ The stages ranged from very creative and precompetitive to highly structured and competitive. Each stage was characterized in detail and had a clear exit strategy. This organization helped to reduce over-commitment of the scarce research and development resources to one customer, something which had hindered ASM Microchemistry.

\section{Aligning operational and technological capabilities}

By August 2002, ASM had become a critical supplier for Intel.111 Sales to Intel increased tenfold from 2000 to 2003 - or, respectively, a couple and more than a third of all front-end revenues. ${ }^{112}$ The company's deliberate strategy to penetrate the industry's leader paid off. For its chips in the 130-nanometer node (2001), Intel used the A412 vertical furnaces of ASM Europe and the ASM America Epsilon reactor. Meanwhile, ASM Japan's low-k process in its Eagle-12 single wafer plasma enhanced CVD reactor was up for the 90-nanometer node (2003) and the 65-nanometer node (2005). And finally, the toolset for the creation of the revolutionary high-k gate dielectric - a Polygon cluster containing Pulsar 3000 ALD modules - was considered for the 65-nanometer or 45-nanometer technology node.

By 2001, the implementation of an Epsilon silicon germanium process in particular caught the industry's attention. Silicon germanium processes had been developed and propelled through their application in wireless communication chips (cf. Chapter 30). But Intel used the machine to fabricate so-called 'strained

108 del Prado - Ivo Raaijmakers file.

110 The first two entailed research, the other three development. At the Alpha stage, requirements, interests, and inquiries of customers with regard to the program are listed and incorporated, preferably with a JDP. During this stage, there should be fewer than three tools in the field. During the Beta stage, customers evaluate the tool and focus on reliability. At this point, two to six systems had been installed in the field, supported by a dedicated team of field service, manufacturing, and marketing. During the last stage, the product would shift from development to operations. It was ready for high-volume manufacturing, while ASM's production operation was ready for the product as well.

111 ASMI, Supervisory Board, 'Attachment to interim progress report Q4 2002: ASM products for Intel' (11-12-2002) Archive Arthur del Prado - RvC 2002.

112 ASMI, 'Appendix Progress Report October 2004' (27-10-2003) Archive Arthur del Prado - RvC 2004 file. 
silicon' (figure 86). ${ }^{113}$ By selectively growing the sources and drains through silicon germanium epitaxy, the crystal structure of the channel got compressive in PMOS transistors as part of the CMOS transistor. ${ }^{114}$ As a consequence of this strain, the flow of current in a transistor's channel - between the source and drain - improved at smaller dimensions. Intel had applied the Epsilon to this end without ASM's full collaboration. ${ }^{115}$

\section{Figure 86}

A simplified vertical cross-sectional depiction of strained silicon
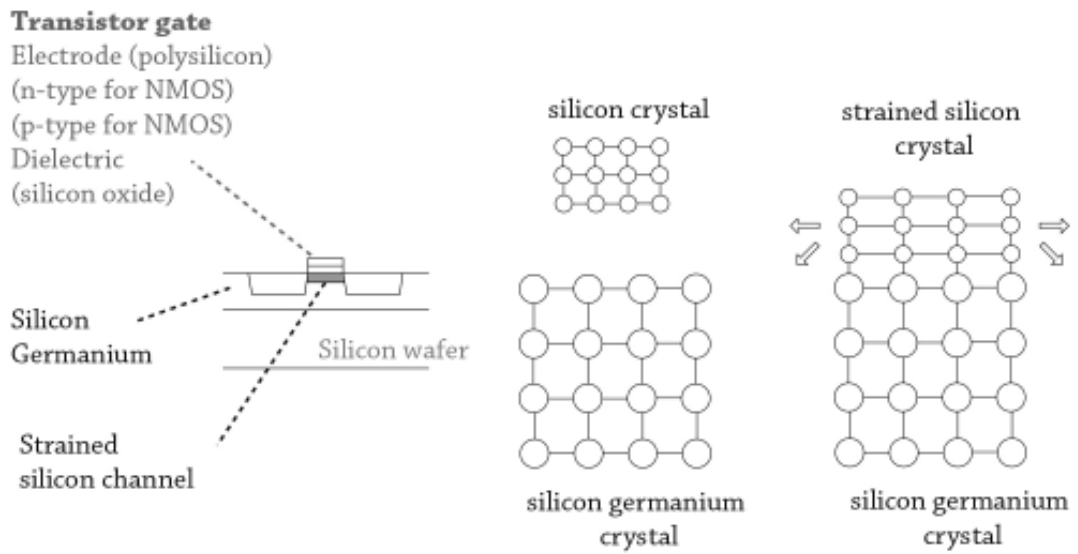

The strained silicon preluded a period in which the polysilicon MOS transistor no longer would be the same. Rather quickly, the rest of the industry traced

113 The process of strained silicon was developed by Judy Hoyt and Eugene Fitzgerald in 1990 and 1992. The process involved the deposition of a thick layer of silicon germanium on a blanket wafer, on selected areas of which - namely where the channel was intended to be, the part between source and drain - a thin monocrystalline film of silicon epitaxy was grown. In the selected areas, the upper film of silicon adopted the crystalline structure of silicon germanium instead of pure silicon. This caused the silicon to stretch out - or strain, so to speak - in biaxial direction. Simultaneously, Intel worked on the solution by exploring selective deposition of silicon germanium films, enabling uniaxial strained silicon. This variation offered better performance for PMOS transistors. Only by 2001 it became possible to prepare uniaxial strained silicon - together with copper and low-k interconnects - for high-volume manufacturing at the 90-nanometer node, expected to commence in 2003. Intel, Mark Bohr, 'The Invention of Uniaxial Strained Silicon Transistors at Intel', Intel.com (January 2007).

114 Through a capping layer of silicon nitride on a NMOS transistor, and not needing silicon germanium source and drains, the channel could be made tensile.

115 ASMI, Chris Werkhoven, 'Monthly Report Chris Werkhoven August, 2002' (25-9-2002) Archive Arthur del Prado - RvC 2002. 
the strained silicon technology of Intel to ASM America's Epsilon. ${ }^{116}$ Chip manufacturers were eager to pick ASM's ears. As Werkhoven proclaimed in another report:

'Do press releases make waves! Obviously, the Strained Silicon (SS) one of Intel did and the debate about why and when to use it has not revealed a clear answer ... Nobody seems to know how the SS is integrated. ... So far, options are numerous and customers expect some expert help from ASM to find their way. Given the real knowledge about SS integration, or even process vs defect knowledge at ASM, it is clear that expectations do not match with reality. ... [Developments] should be directed to alleviate this discrepancy asap, otherwise others may jump into this market before ASM is able to do [so].' ${ }^{117}$

Supplying an industry leader like Intel required ASM to have its house in order. Del Prado and his newly promoted chief operating officer Han Westendorp explained and rationalized the far-reaching influence of the customers:

'Having an involvement with Intel on four product lines is new for us and given the nature of this client, also quite demanding. This is also the case in a similar situation with IBM. The service and maintenance crews in our U.S. locations are given quite a challenge on products that are often new to us. There are offsetting benefits of doing business with these two large customers though. Both indeed take their relationships with key suppliers seriously.' ${ }^{118}$

For ASM International, operating closely with demanding customers allowed the equipment supplier to learn from the best and foster its innovations, while it also provided lucrative opportunities (within the boundaries of proprietary information of course). ASM could absorb technological and commercial spillovers. Other chip manufacturers might license or imitate these state-of-the-art fabrication processes, resulting in more sales for ASM. Supplying to customers like Intel and IBM, however, also implied that ASM, with its impetuous past, had

116 Tweakers, Wouter Tinus, 'Intel bestelt strained silicon reactors waarschijnlijk bij ASMI', Tweakers.net (27-9-2002), and: Tweakers, Wouter Tinus, 'Intel onthult zijn 0,09 micron productieprocedé, Tweakers.net (13-8-2002).

117 ASMI, Chris Werkhoven, 'Monthly Report Chris Werkhoven September, 2002' (23-10-2002) Archive Arthur del Prado-RvC 2002.

118 ASMI, Supervisory Board, 'ASM International N.V. - Progress Report Q3 2002' (21-10-2002) Archive Arthur del Prado - RvC 2002. 
to go all out to secure customer contentment, even if this involved an exercise in humility.

For instance, Intel was renowned for scrutinizing its supply chain. An example was its concept of 'Copy Exactly!'119 Since the 1980s, Copy Exactly! ensured the duplication of manufacturing processes globally, at all of Intel's fabs, as well as over time, by codifying characteristics and limiting alterations to its equipment, materials, and manufacturing infrastructure. In the case of ASM this meant that the equipment manufacturer had to supply exactly the same tool after qualification. Because any impact on the production process had to be excluded, not even minor changes were allowed. Apart from strict quality control, Intel also surveyed and coached its suppliers. Technological leaders in the semiconductor industry, like Intel and IBM, did not want to alter complex and thoroughly researched and developed billion-dollar manufacturing lines due to issues at a supplier. The employed risk management policies stretched from financial stability to the supplier's information procedures, involving in their proprietary fabrication process knowledge.

On a regular basis and involving various paygrades, meetings were organized to review and discuss the relation between supplier and customer. During such particular events, the ASM engineers and sometimes even executives had to remove a range of concerns across the products it supplied. During one of these meetings with customers, Del Prado humbly observed:

'I realize and appreciate the tremendous amount of effort that [you are] putting into helping ASM be successful. At the same time, I also understand from the executive level that we are not performing to your expectations, and that there are serious concerns about ASM's ability to support [you] in High Volume Manufacturing. ${ }^{120}$

The head office had to implement the latest quality and safety procedures company-wide, instead of addressing ad hoc deficiencies in respective interactions between customers and ASM Japan, ASM Europe, ASM America, or ASM Microchemistry. From September 2001 to September 2003, ASM initiated efforts to improve strategic planning, gap analysis, 'Best-known-methods'

119 Intel Sematech, Chris J. McDonald, ‘The Evolution of Intel's Copy EXACTLY Technology Transfer Method', Intel Technology Journal Q4 (1998); Chris J. McDonald, 'Copy EXACTLY: A Paradigm Shift in Technology Transfer Method', IEEE/SEMI Proceedings of Advanced Semiconductor Manufacturing Conference and Workshop (ASMC) from 10-12 september 1997 in Cambridge (1997); Joel Hruska, 'Deliberate excellence: Why Intel leads the world in semiconductor manufacturing' extremetech.com (1-5-2012).

120 ASM International, Arthur del Prado, 'Notes on presentation: ASM Business Update \& Key Messages' (October 2002) Archive Arthur del Prado - Intel file. 
implementation, communication, spare parts and service plans, enterprise resource planning and coaching/advice for HVM \& Development platforms. On top of this, an customer account teams were formed, consisting of dedicated engineers and managers. The major American chip manufacturers consulted in, or even initiated, the transformation of ASM into a $21^{\text {st }}$-century original equipment manufacturer.

\section{New faces and perspectives}

In this same period, ASM strengthened the management at its headquarters. If not related to the demands of the biggest customers, these changes were meant to enhance the operational oversight of the company. In the summer of 2002, Haijo Pietersma was appointed as deputy chief executive officer of ASM International. Pietersma was seen as potential successor of Arthur del Prado. Pietersma, who came from Ericsson Nederland, lacked experience in the semiconductor industry, and therefore he would operate alongside Del Prado. It was expected that Pietersma might succeed Del Prado perhaps by mid-2004. Up to that time, he would acquaint himself with the business, focusing on operational and process management - issues in which the entrepreneurial chief executive officer had shown little interest.

In December 2002, Chuck del Prado was appointed as general manager of ASM America. ${ }^{121}$ Arthur del Prado's eldest son had deliberately and meticulously made his way in the semiconductor industry. After obtaining a Master in Industrial Engineering and Management he worked in marketing \& sales at IBM Nederland, from 1988 until 1996, and in manufacturing management in Taiwan and Veldhoven for ASM Lithography from 1996 onward. In March 2001, Chuck del Prado joined ASM Europe as Director of Marketing, Sales, and Service. Upon his start in Phoenix in December 2002, he immediately faced many thorny issues. The American business unit was in disarray, and the pressure was running high. ${ }^{122}$

After the resignation of Hans Wunderl, ASM America evolved into a heavily compartmentalized operation. Its departments worked on their own, instead of with each other. The whole organization was heavily consumed by its task of serving the leading American chip manufacturers with its epitaxy and Polygon ALD products under Timo Bergman. Meanwhile, those involved in new process developments and engineering largely pursued their own interests. ${ }^{123}$ Instead of objective information, preconceptions and misguided assumptions seemed

121 ASM America, Daniel Queyssac, 'Memorandum: Announcement - Appointment of ASM America General Manager' (11-12-2002) Archive Arthur del Prado - ASMA '00 file.

122 ASM International, Ivo Raaijmakers, 'Memorandum: ASMA' (4-11-2002) Archive Arthur del Prado - Ivo Raaijmakers file.

123 An example is 'New Technology,' developed by engineer Michael Todd. It entailed a new silicon precursor which would enhance the process capabilities of the Epsilon. 
to dominate arguments and discussions about operational and technological priorities. Amidst this turmoil, the 41-year-old Chuck del Prado had to prove his worth. Just like at his previous positions, he had to show that he earned his position on his own merits, not those of his illustrious father. ${ }^{124}$

Finally, almost simultaneous with Chuck del Prado's start, Han Westendorp succeeded Daniel Queyssac as COO. The 62-year-old Frenchman retired. ${ }^{125}$ Albert Hasper, the co-inventor and product manager of the vertical furnaces, succeeded Westendorp as general manager of ASM Europe.

\section{FEMS and pursuing structural cost improvements}

A persisting downturn urged the ASM front-end board to take another round of actions in the spring of 2003. Operational costs had to be lowered. Frenetically, ASM's managers explored options to cut costs. However, after the initial restructurings not many options were left to improve the company's balance sheet in the short term.

One solution involved another downsizing at ASM Microchemistry, which came to be known in Finland as the 'second big bang.' On March 31, 2003 a restructuring scheme dubbed 'Operation Sauna' was initiated. At that point, ASM Microchemistry was still located at its old premises in Espoo, which was projected to accommodate a growing equipment manufacturer. No wonder, the operating costs of the small operation exceeded what could be justified considering its size. Motivation among employees was low as well, due to the 'empty building syndrome. ${ }^{126}$ Operation Sauna entailed a further reduction of ASM Microchemistry's operation, from a few dozen staff to just six scientists, as well as turning it into the company's materials R\&D center for ALD processes. In accordance with the University of Helsinki, and professor in Inorganic Chemistry Markku Leskelä in particular, the group was relocated to the university's premises. ${ }^{127}$ In this way, the group would focus on materials and process development and characterization for advanced technology nodes, such as 32-nm and beyond.

124 To this end, coaching offered by veterans such as John Krickl and the former chief operating officer Ray Friant was appreciated but hardly needed. A few months after Chuck del Prado's appointment, Krickl retired, having worked for fifteen years at ASM America. - ASM Europe, Han Westendorp, 'Memorandum: John Krickl to retire' (5-6-2003) Archive Arthur del Prado - ASMA '00s file.

125 Daniel Queyssac passed away on October 12, 2009. - [Family message], 'Obituary Daniel Queyssac' The Arizona Republic (12-10-2009.

126 ASM International, Marike Overhoff and Ivo Raaijmakers, 'Presentation Operation Sauna' (31-3-2003) Archive Arthur del Prado - ASM Microchemistry file.

127 ASM International, Ivo Raaijmakers, 'Memorandum: Restructuring ASM Microchemistry' (25-8-2002) Archive Arthur del Prado - ASM Microchemistry file. 
A solution for improving ASM International's front-end cost performance in the longer term involved a consolidation of manufacturing. Across the various subsidiaries, the costs of manufacturing had increased by the reopening of the University Drive facility in Phoenix, a new facility in Almere, the Netherlands, and expansions of ASM Japan's facilities in Tama and Nagaoka. The alternate strategy to extend a collaboration with Philips Machinefabrieken, involving ASM Europe and products of ASM America and dubbed Operation Merio, had failed. Moreover, in South Korea, Samsung urged ASM to localize production, and thus to establish a cooperation with a South-Korean subcontractor. ${ }^{128}$ Also, ASM Europe's relation with Philips Machinefabrieken suffered from disagreements about pricing, which instigated a search for another subcontractor. ${ }^{129}$

The most obvious candidate was found close-by: ASM China, the manufacturing operation of ASM Pacific Technology, located in Shenzhen. ${ }^{130}$ During the downturn, ASM Pacific Technology remained profitable and even rose to lead its segment of semiconductor equipment, and in 2003 it recovered much quicker than the ASM front-end operations. This feat was linked in part to a general recovery of assembly and packaging equipment and to the success of new products, such as 200-millimeter and 300-millimeter wafer die bonders and a new product family of LED test handlers. But first and foremost ASM Pacific Technology owed its resilience to its robust manufacturing strategy. Ever since the 1980s, the Hong Kong company had been able to rely on low cost and high availability of labor in mainland China through its local manufacturing facility in Shenzhen.

Over the years, several ASM front-end managers explored whether they could tap into this market as well by collaborating with Patrick Lam's organization. ${ }^{131}$ However, the business proved too different (cf. Chapter 24). Front-end products were produced in low volumes and high varieties. Each customer required their machines to be tweaked and tuned to facilitate their particular processes. This contrasted with the assembly and packaging industry, where volumes of purchased machines were rather high, while their variety was fairly low due to the standardized chip packages.

128 ASMI, Ray Edinger, 'ASM Front-End, GOMEC' (8-2-2001) Archive Arthur del Prado - FEMS file.

129 ASM International, 'Progress Report December 2001' (17-12-2001) Archive Arthur del Prado - RvC 2001 file.

130 ASM Pacific Technology, James Chow, 'Trip Summary - ASME Almere Plant Visit (Feb 4 to 7, 2002)' (7-2-2002) Archive Artur del Prado - FEMS file; ASMI, Ray Edinger, 'Manufacturing in Far East' (26-4-2002) Archive Arthur del Prado - FEMS file; ASMI, Ray Edinger, 'ASM FrontEnd, GOMEC' (8-2-2001) Archive Arthur del Prado-FEMS file.

131 For instance, Franc DeWeeger on behalf of ASM America in the mid-1980s, and Fukumi Tomino on behalf of ASM Japan in the early 1990s. 
This time around, however, ASM Europe and ASM Pacific Technology would find each other. By Spring 2003, the outlines of the collaboration between ASM Europe and ASM Pacific Technology - and its subsidiary ASM China - became more substantial. ${ }^{132} \mathrm{ASM}$ front-end would establish a local manufacturing facility in Singapore, which would elaborate on the experience and knowledge of ASM China and ASM Pacific Technology in vertically integrated manufacturing. Two buildings adjacent to ASM Technology Singapore, the local operation of ASM Pacific Technology, had become available. Moreover, the Economic Board of Singapore offered attractive incentives to establish a local presence, such as a ten-year tax holiday, research and development subsidies, and training grants. ${ }^{133}$ At the Singapore location on Yisun Industrial Park Avenue, one building would be used for tool fabrication - involving CNC machining, laser cutting, welding, and painting of subassemblies - and another for the assembly, involving wiring, integration, and testing. Neighboring ASM Pacific Technology would provide plant management in the initial three years (to get things started with the authorities), facilities, production equipment, and staffing. ${ }^{134}$

As the urgency to improve front-end's profit and loss account increased, things got moving by October 2003. The new operation was named 'Front-End Manufacturing Singapore' (FEMS). ASM Europe's vertical furnaces would lead the way, as they were produced in fairly high volumes compared to the other frontend products, thus making a ramp-up of the new facility more cost-effective. ${ }^{135}$ Initially, the generic subassemblies of the latest $\mathrm{A} 412$ vertical furnaces were to be manufactured by FEMS. Final assembly, testing, and customization remained in the Netherlands. ASM Europe thus profited from the low cost of labor in SouthEast Asia, while also paving the way for the other front-end operations. Since the production of an A412 took almost 7000 manhours, FEMS would decrease the cost of labor by 45 percent plus other operational efficiencies, saving between 230 and 115 thousand euros per machine. ${ }^{136}$ Overall, manufacturing costs were expected to decrease by 30 percent.

132 ASM Europe, Peter Buijze, 'Memorandum: FESEA Project Meeting Minutes' (30-1-2003) Archive Arthur del Prado - FEMS file.

133 ASMI, Arthur del Prado, 'Letter to EDB Singapore, attn: Tan Choon Shian, ref: b200308' (3-10-2003) Archive Arthur del Prado - FEMS file; EDB Singapore, Tan Choon Shian, 'Letter to Arthur del Prado: In principle support for ASM International's proposed wafer fab equipment (vertical furnace, epitaxial, CVD equipment) project in Singapore' (7-8-2003) Archive Arthur del Prado - FEMS file.

134 ASM FEMS, 'Presentation: FEMS Project - Discussion with ASMFE Top Management' (102-2004) Archive Arthur del Prado - FEMS file.

135 Higher volumes enabled the appropriation of economies of scale.

136 ASM FEMS, 'Presentation: FEMS' (15-12-2005) Archive Arthur del Prado - FEMS file. 
The transfer as a whole was expected to take about three years. The facility had to be prepared. Capacity had to be built step by step. The operation had to be certified for ISO 9001 quality standards. The drawings of the vertical furnaces had to be adjusted for the transfer. Other matters involved the training of local staff in the particular art of producing scratch-free flanges, quartz, sheet metals, and slideway elevator assemblies. Gradually, cleanrooms and new production techniques were to be added. Depending on the progress, production would increase from 3 units in 2004 to 84 units by 2006, including other products such as the 200-millimeter versions of the vertical furnace and the epitaxial reactor. As high-volume would commence, expected to be somewhere in 2005, FEMS had to be qualified for producing machines to the industry's highest standards, like Intel's 'Copy Exactly!'137 Moreover, FEMS had to be integrated as a fullfledged ASM operation, and not be disregarded as a mere internal subcontractor like Philips Machinefabrieken. ${ }^{138}$ FEMS was here to stay, and would remain an integral feature of ASM International's front-end manufacturing strategy.

As it took time before FEMS would contribute to ASM Europe's cost base, and to remedy further deterioration of operational costs, ASM Europe consolidated manufacturing at its Almere facility by the fall of 2003 (the company headquarters was the only office to remain in Bilthoven). That on October 15 the Dutch primeminister Jan Peter Balkenende paid a visit to the Almere facility certainly added luster to ASM Europe's regained strength.

\section{Solidifying a lead in ALD through Genitech}

In addition to the reorganization and the consolidation of manufacturing through FEMS, the year 2003 was characterized by ASM's strategy to solidify its lead in ALD. This was accompanied by litigations against Genus surrounding infringement of ASM's intellectual property. ${ }^{139}$ Further, ASM reacted to an infringement letter by Applied Materials relating to Plasma CVD most adequately and decisively, nipping potential escalation in the bud. ${ }^{140}$ Having learned from

137 ASM FEMS, 'Presentation: Intel Qualification framework' (7-9-2005) Archive Arthur del Prado-FEMS file.

138 ASM Pacific Technology, Patrick Lam, 'Memorandum: FEMS, re: IM-337-05/PL' (30-8-2005) Archive Arthur del Prado - FEMS file.

139 In the case of the Genus litigation, which started in 2001, ASM had to back down and settle in the fall of 2003. - ASM America, Todd Westersund, 'Memorandum: Status of ASM v. Applied Materials (Marshall)' (31-10-2003) Archive Arthur del Prado; ASM America, Arthur Sherman, and Genus, 'Settlement Agreement' (November 2003) Archive Arthur del Prado Genus file; United States Court of Appeals, Federal Circuit, '401F3D1340: ASM America Inc., ASM International NV., Arthur Sherman v. Genus Inc; no. 04-1211' (16-3-2005) Archive Arthur del Prado - Genus file.

140 Todd Westersund, 'Interview with author'. - Furthermore, ASM also sued a subcontractor of quartz for violation of intellectual property. -Editor, 'ASMI wint zaak over patenten', NRC 
the traumatic litigations surrounding the Epsilon reactor in the 1990s, ASM was determined to advance its patent position actively and in a well-structured way. But ASM's determinative stance with regard to its lead in ALD also affected its collaboration with Genitech in South Korea.

By 2003, the pros and cons of cooperating with the South-Korean startup had become more distinct. Genitech offered unique and promising capabilities with its plasma enhanced ALD (PEALD) technology. This technique was very much applicable for metallization and dielectric processes. However, the partnership had been hampered by disagreements about remunerations, terms of supply, and the utilization of wafer handling platforms. ${ }^{141}$

In the summer of 2003, Del Prado discussed the issues with Genitech's chief executive officer Inkyu Park by phone and e-mail. ${ }^{142}$ Both men agreed that it was to both parties' best interest to continue the collaboration, yet not on the existing terms. To address the various issues, it was preferable for ASM to acquire the Korean company. ${ }^{143}$

The acquisition would give ASM unhindered access to the PEALD technology, it would expand ASM's intellectual property in ALD extensively, and being a South-Korean firm Genitech would form a bridgehead with Samsung - the chip manufacturer harnessing the largest capital expenditures in the industry and an outspoken supporter of localized equipment suppliers. ${ }^{144}$ Management would be continued under Inkyu Park, while ASM Japan's general manager Fukumi Tomino and controller Hitoshi Miura would oversee integration into ASM. Genitech was acquired for 3.97 million dollars in cash and 5.19 million dollars in shares, or a total of 9.17 million dollars. In addition, the owners of Genitech could accumulate up to 9 million dollars in royalties for sales in PEALD before 2008. Over time, ASM Korea, the sales and service office of ASM International in South Korea, would merge with Genitech.

In January 2004, Del Prado presented the acquisition proposal to his Supervisory Board. ${ }^{145}$ Its response betrayed little enthusiasm:

Handelsblad (11-5-2001) p. 13.

141 ASM International, Ivo Raaijmakers, 'E-mail to Arthur del Prado and Menso Hendriks: Genitech, Attorney Client Privileged' (14-5-2003) Archive Arthur del Prado - ASM Koreal ASM Genitech, Genitech; Stibbe, Hugo van Heemstra, 'Letter to Dr. I.K. Park, Genitech: ASM/ Genitech' (12-6-2003) Archive Arthur del Prado - ASM Korea/ASM Genitech, Genitech.

142 Genitech, Inkyu Park, 'E-mail to Arthur del Prado: Re: M\&A' (23-6-2003) Archive Arthur del Prado - ASM Korea/ASM Genitech, Genitech.

143 ASMI, Board of Management ASM International N.V., 'Memorandum: Genitech Ltd acquisition' (26-1-2004) Archive Arthur del Prado - RvC 2004.

144 ASMI, Ivo Raaijmakers, 'Memorandum: Genitech Acquisition Plans' (27-11-2003) Archive Arthur del Prado-ASM Korea/Genitech file.

145 ASMI, Board of Management ASM International N.V., 'Memorandum: Genitech Ltd 
'The SB [Supervisory Board] would have preferred not to have Genitech on the table as an acquisition proposal at all, but now that [it] was nevertheless on the table, the general feeling was that the transaction is too expensive and that in the proposal structure too much money will be paid up-front.' ${ }^{146}$

Due to the strategic interest of PEALD, however, ASM had to move on and acquire Genitech. Otherwise, it was feared, the competition would seize the opportunity. The acquisition was approved and formalized by February 2004.

\section{Acquiring NuTool}

The reluctant approval of the Supervisory Board followed from another pending acquisition: that of NuTool. After ASM had taken an interest of 18 percent in the Californian startup, both parties had worked on the integration of NuTool's revolutionary ECMD technology through a 'Virtual BEOL Fab,' or merely sharing information rather than integrating equipment and components. ${ }^{147}$ In the fall of 2003, however, NuTool's chief executive officer Humayoun Talieh indicated that he received an offer from another large equipment supplier, presumably Applied Materials. This urged ASM to act swiftly. Chief technology officer Ivo Raaijmakers summarized the urgency:

'As this supplier's CMP product line is very successful, it may benefit more by killing the NuTool technology (which is claimed to eliminate CMP need) then by developing it. The bid gives ASM a chance to use their right of first refusal.' 148

Either ASM acquired a majority share of NuTool, or it allowed a competitor to run off with the technology. ${ }^{149}$ Although there was clearly an opportunity for ASM, three aspects needed to be assessed more carefully: the status of the collaboration, the process of due diligence, and the necessity of the acquisition.

acquisition' (26-1-2004) Archive Arthur del Prado-RvC 2004.

146 ASMI, Supervisory Board, 'Minutes Supervisory Board Meeting December 15, 2003' (20-22004) Archive Arthur del Prado - RvC 2004.

147 ASMI, Ivo Raaijmakers, 'Memorandum: NuTool acquisition plans' (20-11-2003) Archive Arthur del Prado-NuTool file.

148 Ibid.

149 At this stage, TEL terminated its sales representative agreement per January 2004, causing NuTool to attract a larger partner with 'significant financial, marketing, sales and service power to succeed in the market.'ASM hoped to be that partner, instead of Applied Materials. Cf. ibid. 
First, the collaboration between NuTool and ASM did not progress very well. Issues pertained to 'lack of free information flow, lack of NuTool equipment availability, lack of internal NuTool and NuTool/ASM alignment, and limited ASM management bandwidth.' ${ }^{150}$ Raaijmakers felt that 'we do not get enough detail about the true performance of the NuTool equipment.'

Secondly, the state of the offer made by the 'third-party' remained dubious and unclear. ${ }^{151}$ Typically for a Silicon Valley high-tech startup, NuTool boasted its capabilities while carefully guarding its proprietary assets. Was it a verbally enunciated proposal, or was it a written expression of interest? More information was required. This involved substantiation of the offer, the state of bookings, and customer interaction at NuTool; a proposal for integration with ASM; and an analysis of why earlier customers like Texas Instruments, TSMC, and Samsung postponed or even returned their procurements from NuTool.

Thirdly, Raaijmakers voiced doubts about the merits of acquiring NuTool. His only reason to proceed would be to keep access to copperplating and polishing technology. Yet he also stated that ASM did not have to acquire NuTool for that purpose, as it could also collaborate with Ebara. Moreover, ASM would not be able to contribute to the NuTool sales because of ASM's premature network for sales in interconnection fabrication processes.

It was nevertheless against Arthur del Prado's entrepreneurial instincts immediately to dismiss the opportunity. The imagined economies were too big. NuTool's technology constituted ASM's final straw to penetrate the 700 milliondollar market for copper deposition technologies. ${ }^{152}$ Moreover, ASM already invested 20 million dollars in the Californian operation, which was significantly higher than the acquisition sums of Microchemistry and Genitech. Del Prado was not the man to back down; he would see how the cards were played.

Moreover, ASM should at least conduct due diligence. On November 30, 2003, Han Westendorp and Chuck del Prado visited NuTool to this end. ${ }^{153}$ The company employed about sixty staff. It had managed to install a few demo-tools at customers, but these customers indicated not to proceed with any further purchases. ${ }^{154}$ Toshiba and ST remained promising prospects, indicating their

150 Ibid.

151 ASMI, Arthur del Prado, 'Letter to NuTool, Mr. Homayoun Talieh' (11-11-2003) Archive Arthur del Prado - NuTool file.

152 Gartner, 'Equipment segments in millions of dollars, 1998-2017', Personal archive author.

153 ASMI, Chuck del Prado and Han Westendorp, 'Memorandum: Visit to NuTool on November 30 2003, by CdP and HW' (3-12-2003) Archive Arthur del Prado-NuTool file.

154 Moreover, each of the earlier customers demanded a refund for the machine, as it turned out later on. - Deloitte, author unknown, 'Project Walnut: Issue Summary Memo' (23-2-2004) Archive Arthur del Prado - NuTool file. 
enthusiasm about the ECMD technology offered by NuTool. ${ }^{155}$ Moreover, the appropriable market - that of copper plating - was expected to grow from 318 million dollars in 2003 to 713 million in 2010.156 During the following weeks, Arthur del Prado's appetite for the operation was further stirred with more news about the 'third-party' offer, as he reported to his Supervisory Board:

'we have consistently and repeatedly received confirmation from a number of different persons - be it verbal and all from the NuTool "camp" - that [a competitor] indeed made a cash offer of some US\$65 million.' ${ }^{157}$

ASM took the risk.

In January 2004, simultaneously with the acquisition of Genitech, the chief executive officer presented a new narrative to the Supervisory Board, in which ASM had deliberately pursued a position in damascene processes and inherently rationalized the acquisition of NuTool. ${ }^{158}$ This narrative started with ASM Japan's low-k dielectric process, Microchemistry, and its copper barrier seed technology in 1999, etc. As he stated:

'It is therefore the opinion of the ASMI Management Board that we should use this opportunity to decisively put our BEOL [Back-Endof-Line] program much stronger on the competitive map. The full acquisition of NuTool (and Genitech) will allow us to effectively organize the joint development programs, which will push our combined offerings in BEOL over the threshold of the required minimum critical mass. The incorporation into ASMI will remove existing doubts in the mind of potential customers about the future financial viability of NuTool as a stand-alone company and equally strengthen the confidence in the ASM integration capability.' ${ }^{159}$

Despite its reservations, the Supervisory Board let itself again be persuaded (as in the Genitech case). NuTool was acquired by issuing ASM stock. NuTool's chief executive officer Homayoun Talieh, owning 75 percent of the stock, and other

155 ASMI, Chuck del Prado and Han Westendorp, 'Memorandum: Visit to NuTool on November 30 2003, by CdP and HW' (3-12-2003) Archive Arthur del Prado - NuTool file.

156 ASMI, Board of Management ASM International, 'Memorandum to Supervisory Board: NuTool Inc acquisition' (26-1-2004) Archive Arthur del Prado - NuTool file.

157 Ibid.

158 Ibid.

159 Ibid. 
officers received about 23.3 million dollars: 5 million dollars at the closing of the acquisition and, based on meeting sales criteria in the next three years, a maximum of 17 million dollars in stock. ${ }^{160}$ The total acquisition added up to a maximum of 35 million euros. ${ }^{161}$ It was a much more expensive acquisition than Genitech, but NuTool's technology addressed a much bigger market and was deemed much more mature. By June 2004, the merger was finalized.

The NuTool acquisition concluded a period characterized by serious efforts to consolidate and sustain existing businesses, while nurturing new activities. Given financial restraints and the Genitech and NuTool deals, the patience of the Supervisory Board was running thin. The executives on this board grew more aware of their responsibilities following new codes of conduct for corporate governance in the United States and the Netherlands. Del Prado's close ties with some board members began to attract suspicion. This foremost involved Paul van den Hoek, who as a prominent corporate lawyer was expected to comply with the new 2004 Dutch corporate governance code of conduct. He had been serving as ASM's chairman for a long time, while he also combined positions on too many supervisory boards. Operating carefully but purposefully, Van den Hoek began to distance the Board from Del Prado, improving the Board's supervision, while trying not to antagonize the founder, chief executive officer, and long-time business companion. Given these various circumstances, Genitech and NuTool might well have been Del Prado's last trick as ASM's chief executive officer.

160 ASMI, Arthur del Prado, 'Letter to NuTool Inc, Homayoun Talieh: Letter of Intent' (25-112003) Archive Arthur del Prado.

161 ASM International, 2004 Annual Report, p. F-16. 


\section{Chapter 32 \\ A shakeup, 2004-2008}

After enduring the downturn, ASM awaited the improvement of the semiconductor market from 2004 onward. Revenues recovered and grew. New technologies were expected to enter markets. Yet, as the company regained its footing, its Supervisory Board got battered by activist shareholders questioning the company's strategy. The dispute negatively colored the final years of Arthur del Prado's position as chief executive officer and overshadowed the technological achievements.

\section{Industrial context:}

\section{Separating the sheep from the goats}

In the final years of Del Prado's leadership, from 2004 until 2008, the market's recovery was followed by the 2007 financial crisis, which would more structurally distress the world economy. During these years, three developments determined ASM's course: the Dutch corporate governance, the semiconductor industry, and the semiconductor equipment industry.

\section{Investors}

In the Netherlands, the period between 2004 and 2008 was characterized by the advent of institutional investors who explored the limits of their rights as articulated in the new corporate governance regulation, known as the Tabaksblat Code. Private equity and hedge funds pursued higher profitability through rational and calculative evaluation of stock performance and balance sheets and subsequent advocation of organizational change. These investors did not hesitate to break-up companies in pursuit of these profits. Moreover, these institutional investors deployed more resources to ascertain compliance with their rights as shareholder than the conventional shareholders and investors. Some demanded to be heard in the board rooms and tried to influence company policies, while others explored gaps or loopholes in the Dutch corporate governance code.

The advent of institutional investors and the new regulation seemed to reflect a gradual shift of the Dutch market economy toward the Anglo-Saxon tradition. ${ }^{162}$ From 2004, the significance of the Dutch national economy grew stronger for

162 De Jong, et. al, 'Changing National Business Systems'; De Jong, et.al 'Strategic and structural responses'. 
ASM International, in particular with regard to management and corporate governance concerns.

\section{Asian contract manufacturers lead}

In this same period, a major transformation among chip manufacturing enterprises forced the semiconductor equipment industry to follow in their wake. The change in the industry consisted of a shift toward Asia, consolidation of competition, the advent of new materials, and spiraling diversification in technological development beyond Moore's Law. The available money for new equipment of chip manufacturers - their capital expenditures - steadily increased and even peaked in 2007, before the credit crunch caused a deep plunge (figure 87).

\section{Figure 87}

Graph of capital expenditures of semiconductor manufacturers per geographical market, 19982008

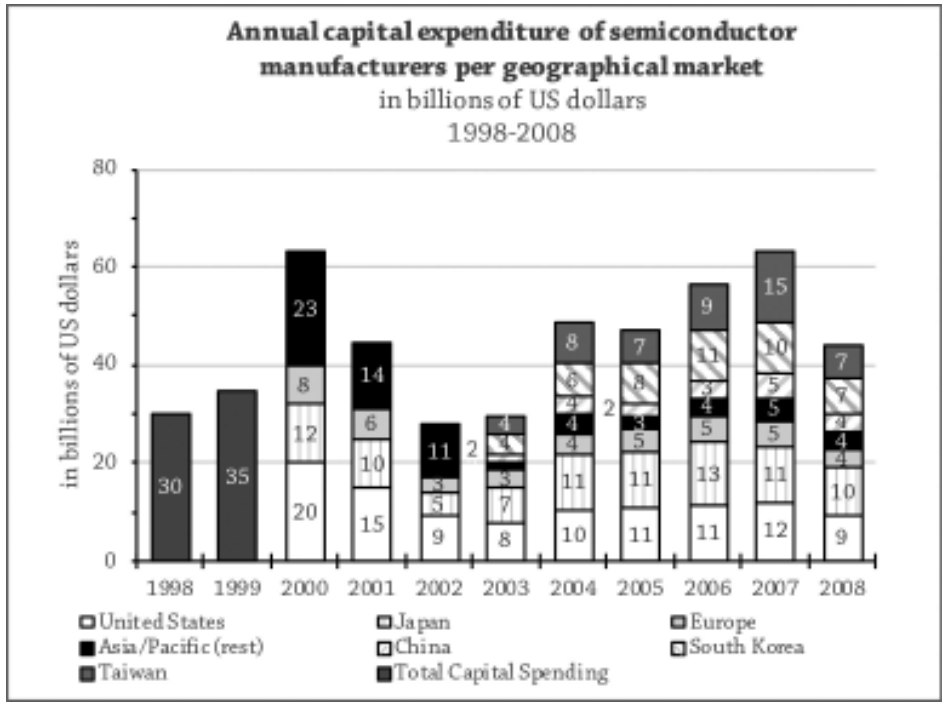

Revenues in semiconductor equipment increased in 2004 to 37.1 billion dollars, declined over 2005 to 32.9 billion, and peaked at 44.9 billion in 2007 (figure 88). ${ }^{163}$ The financial crisis caused another downturn to 16.7 billion dollars in 2009. 


\section{Figure 88}

Graphs of annual growth semiconductor industry, semiconductor equipment industry, and ASM International, 1998-2008

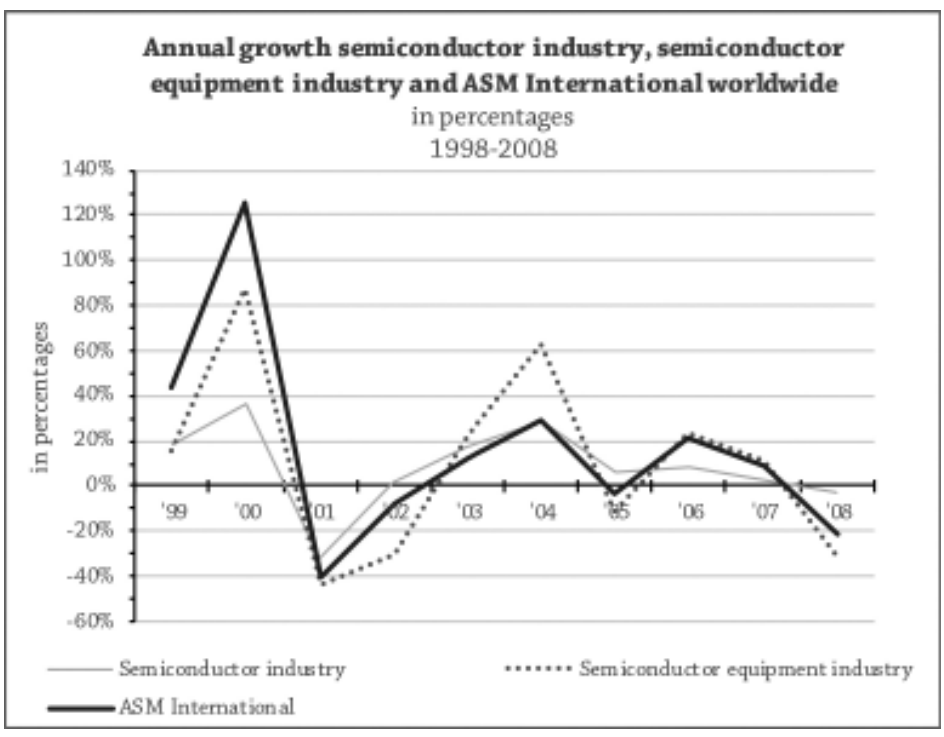

Money was to be made in Asia, in particular. In 2004, after the Asian semiconductor industry had been growing for a decade, Asia became the biggest market for semiconductors and semiconductor equipment. This in particular involved South Korea, Taiwan, Japan (to a lesser degree), and China, if slowly at first. From 2004 on, contract manufacturers, known as foundries, like TSMC (Taiwan), Samsung (South Korea), and UMC (Taiwan) constituted the biggest drivers for wafer fab equipment procurements. ${ }^{164}$ Ambitious governments linked industries, companies, and foreign investment in order to stimulate the national economy and prepare it for the $21^{\text {st }}$ century, in a fashion similar to those endowed by Japan, Europe, and the United States in the 1980s (cf. Innovation III). Asian chip manufacturers did not limit their attention to the bulk production of memory chips; they also pursued contract manufacturing of customized chips, microprocessors, and flash memory.

\section{More than Moore and More Moore}

Amidst the determined and resourceful Asian competitors, Western and Japanese chip manufacturers lost the race to advance Moore's Law. The cost of new production lines grew just as exponential as Moore's Law. Every new technology 
node became more expensive, as the limitations of the dominant design - the polysilicon-gate MOS transistors as part of a computer chip (cf. Intermezzo) came into sight. To advance Moore's Law and achieve better performing computer chips, technological caprioles like strained silicon and high-k gate dielectrics (cf. Chapter 28) became indispensable. The integration of such inventive technological solutions required tremendous efforts in research and development. These investments came on top of the expensive new 300-millimeter wafer fab lines that were rolled out. In the face of these challenges - continuing Moore's Law and utilizing new wafer sizes - competing in the chip industry exceeded the capabilities of many chip manufacturers. Not everyone had pockets deep enough to keep joining the race.

One way of dealing with the increasing costs of chip manufacturing was to divest semiconductor divisions, merge activities, or establish joint-ventures. The Siemens, Hyundai Motorola, and Philips semiconductor divisions were divested and rebranded as, respectively, Infineon (1999), Hynix (2001), Freescale (2003), and NXP (2006). In South Korea, LG Semiconductors merged with Hynix in 1999. A new Japanese memory manufacturer, named Elpida Memory, was created by the merger of the DRAM businesses of NEC and Hitachi (1999), joined by Mitsubishi, in 2003. In that same year, Hitachi and Mitsubishi merged their remaining semiconductor activities into Renesas Technology.

But by 2004, even after joining forces, the race proved to be too costly. Companies turned to chips that competed through their ingenious design, rather than their capability to process (more) information faster. Such chips were customized chips (or in industry-jargon: Application Specific Integrated Circuits, ASICs) and wireless communication chips used in cars, modems, and portable electronic devices like notebooks, MP3-players, and the first smartphones. A new market segment emerged known as 'More-than-Moore.'

Companies like Philips Semiconductors (NXP, STMicroelectronics, Freescale (previously Motorola Semiconductors), and National Semiconductors followed this path. Such chip manufacturers did not have to invest in the latest chip equipment, and if they did require the latest fabrication technologies, they could put an order at one of the contract manufacturers that did master the latest technology nodes.

The dilution of the competitive field in pursuit of Moore's Law, then, did not imply shrinkage of the semiconductor industry. New applications were found and created. The semiconductor market grew from 214 billion dollars in 2004 to 256 billion in 2007, after which, following the financial crisis, sales declined to 226 billion in 2009 (figure 88).

Still, most of the chip manufacturers remained committed to the shrinkage of transistors from the 90-nanometer size in 2003, to 65 nanometers in 2005, and 
45 nanometers in 2007. In particular for the 45-nanometer size, new materials were expected to be required, offering opportunity to equipment manufacturers to distinguish themselves. Moreover, from 2004 onward, for the first time, more 300-millimeter equipment was procured than 200-millimeter equipment. All in all, the bulk of the opportunity for semiconductor equipment manufacturers still resided with the chip manufacturers in pursuit of 'More Moore' - progressing miniaturization according to Moore's Law.

The More Moore segment required the latest equipment and was willing to pay for it, as long as the tempo of Moore's Law could be maintained. In contrast, More-than-Moore did not need these latest innovative machines. The old, predominantly 200-millimeter, techniques sufficed. The competitiveness of More-than-Moore chip producers depended foremost upon productivity, not their advanced capabilities in enabling shrinkage. Furthermore, as the 45-nanometer node proved to be a hurdle too big to take, the More-thanMoore segment increased in size. The renewal and turnover of semiconductor equipment decreased in the More-than-Moore segment. Being a company that drove miniaturization, this obviously affected ASM's appropriable market.

\section{Corporate course: A dynamic finale}

In revenue terms, the final years of Del Prado's tenure as chief executive officer looked glorious. Revenues grew from 754 million euros in 2004 to 955 million in 2007 - almost a billion! In dollars, then, 2004 was already the first year in which the company crossed the magical demarcation of one billion dollars in sales, growing from 1.02 billion dollars in 2004 to 1.4 billion in 2007 (figure 89). Of this portion, revenues for front-end products grew from 481 million dollars in 2004 to 658 million in 2007. Back-end grew from 539.7 million dollars in 2004 to 737 million in 2007, with a slight dip in 2005 (434 million dollars).

The Taiwanese market was the biggest growth market for ASM front-end, with revenues going up from 52 million euros in 2004 to 122 million in 2007. Sales in the United States continued to be largest, hovering between 115 and 130 million euros. In Japan proceeds were achieved of 77.8 million euros in 2004, declining to 50 million in 2005 before recovering to 78 million in 2007 . Sales in Europe grew from 68 million euros in 2004, peaking at 96 million in 2005 before stabilizing at 81 million in 2007.

Over 2004, sales of vertical furnaces, epitaxy, and plasma CVD generated 324 million euros, with profits of 24.2 million euros (figure 90). ${ }^{165}$ The vertical furnaces were the bestselling product, with a revenue of 144 million dollars in

165 ASMI, 'Business Plan 2006, Version II' (October 2005) Archive Arthur del Prado - RvC 2005 file. 
2004, and growing to 297 million by 2007. Sales in plasma CVD and epitaxy hovered between 120 and 150 million dollars during the period covered in this chapter.

The actual performance of ASM International, however, left much to be desired. On paper, in the annual reports, the company remained profitable with profits increasing from 40 million euros in 2004 to 61 million in 2007 (figure 91). These profits were obtained from ASM Pacific Technology. The combined front-end activities generated a loss of 29 million euros in 2004, 91 million in 2005, before 'improving' to a loss of 2.3 million in 2007. These losses were mainly caused by investments in research and development. In 2004, the frontend operations spent about 53 million euros, while back-end activities came at a cost of about 27.3 million euros. By 2007, these spending levels remained roughly the same.

Although the company earned small profits through sales of vertical furnaces, plasma CVD, and epitaxy, its expenses for new products, such as the ALD, the Levitor, Genitech, NuTool, and Nanophotonics, were substantial. These investments accumulated to 29.8 million euros in 2004. In addition, there were corporate costs of about 8.3 million euros, and this contributed to a loss of 16.5 million euros, to which other expenditures had to be added. With a decline in overall sales over 2005 , this imbalance further aggravated to a loss of front-end of 38.4 million euros. The Levitor sold poorly. Costs of the ALD technology were only slightly alleviated by sales to the market of magnetic head producers in the hard disk drive industry. ${ }^{166}$ The other new investments proved to be cash-draining efforts for the time being.

The situation was further aggravated by the suboptimal cost base of ASM's front-end activities. ${ }^{167}$ With FEMS still being started, manufacturing costs tripled at the three business units (ASM Europe, ASM Japan, and ASM America). Even the products that did sell - the vertical furnaces, plasma CVD, and epitaxy - did so at relatively low margins, well below industry standards of 30 to 40 percent, which was considered indispensable to sustain innovation. Moreover, the margins were constantly under pressure of customers seeking lower costof-ownership. Chip manufacturers wanted to pay lower prices, in particular for second-generation equipment.

166 Through serving this application, marginal sales of 20 and 30 million dollars were achieved in, respectively, 2005 and 2006.

167 ASM International, Ivo Raaijmakers, 'Memorandum: ASM FE Product Structure' (8-10-2003) Archive Arthur del Prado - Ivo Raaijmakers file. 


\section{Figure 89}

Graph of revenues of front-end and back-end, 1998-2008

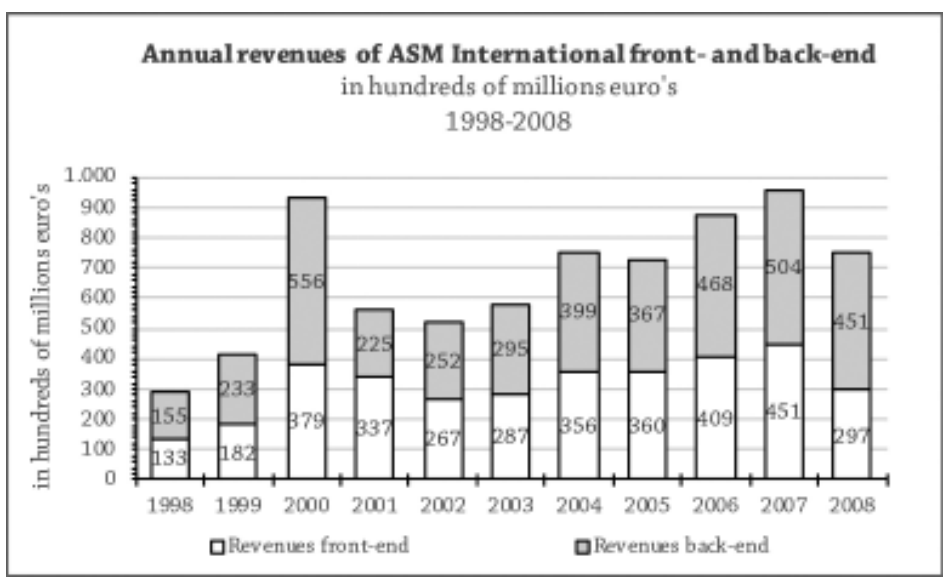

\section{Figure 90}

Graph of relative revenues of ASM International's epitaxy, ALD, vertical furnaces and PECVD product groups, 1998-2008

Absolute revenues per product group are proprietary information of ASM International.

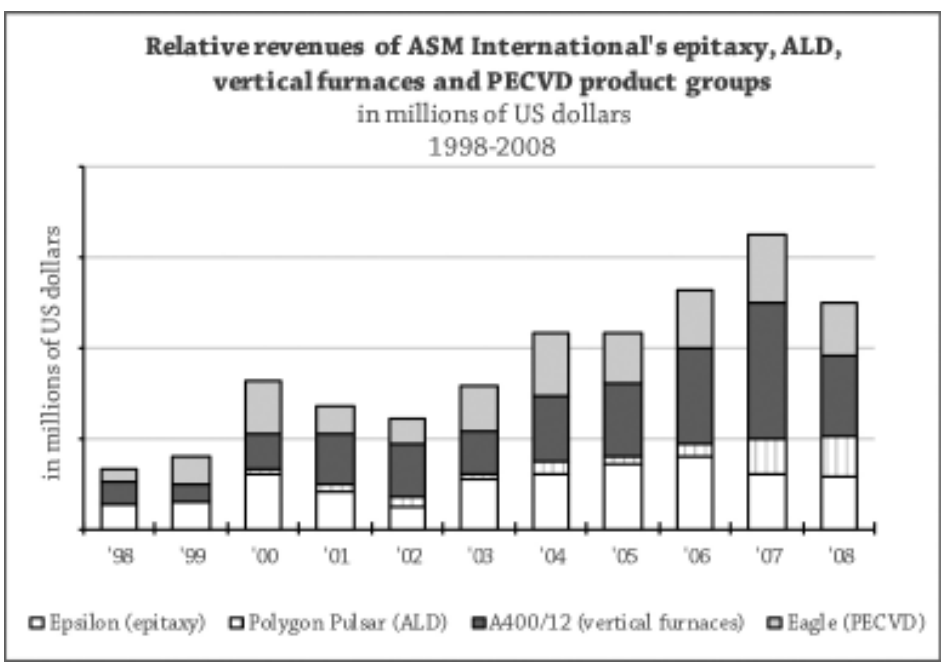




\section{Figure 91}

Graphs of net earnings front-end and back-end, 1998-2008

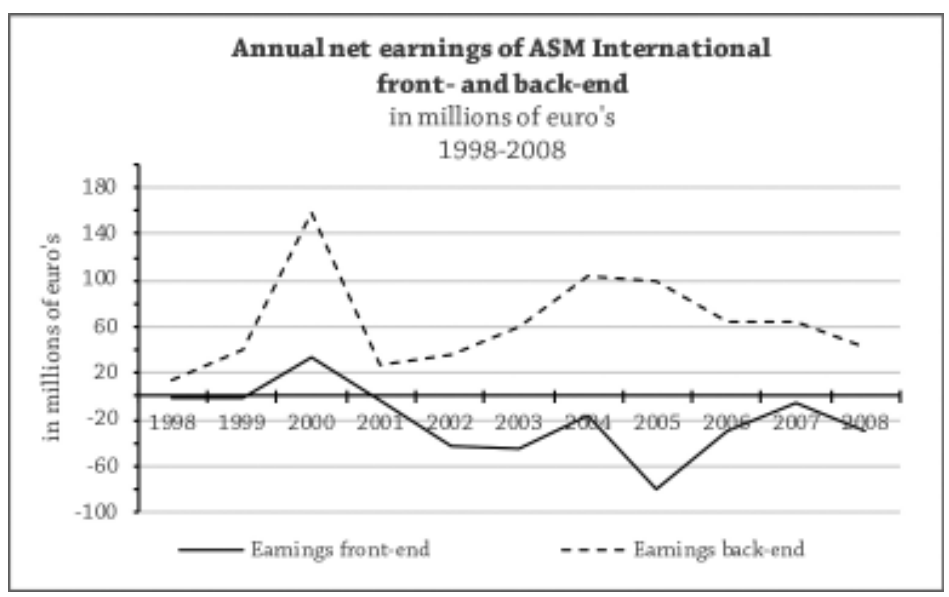

ASM was loaded with potential, but lacked the resources to cash in on it. In 2005, ASM's new account manager Ray Ciferno - coming from Intel - noted the following as he started out and had to deal with all the ASM operations:

'[ASM was] a multinational, a very diverse company. ASM was clearly Arthur won't like this - a 40-year-old teenager. So a lot of spunk, a lot of positive anxiety, a lot of traction, a lot of creativity, a lot technology, which was really, really cool. And it was, but it was a 40 -year-old company, right. It was fragmented in nature, which to me I think was a signature of the founder, rather than a highly integrated, functional multinational organization. ... [H] liked to piece different organizations and different technologies together and let them bloom on their own.' ${ }^{168}$

It was inherent to this dynamic enterprise that all the revenues of existing products were invested in new products. However, by 2005 the imbalance between earnings and expenditures into new technologies was too large. Again, like in the 1980s, Del Prado had over-leveraged innovation. He was betting too much on the come. His innovation strategy was challenged through two events: an internal challenge involving the dissolution of ASM NuTool and an external one entailing the advent of activist shareholders.

The internal challenge involved the NuTool investment. So far, ASM had invested over 80 million dollars in this operation, as it promised to be disruptive

168 Ray Ciferno, 'Interview with author'. 
and revolutionary. ${ }^{169}$ After its integration, however, the Californian operation's true state of affairs was painfully exposed. Realizing that NuTool's copper deposition technology was not yet suitable for high-volume manufacturing in the short term, NuTool got restructured and its intellectual property divested. The founder's long-lasting business principles of decentralization and confidence in self-reliance of subsidiaries seemed anachronistic.

The external event that challenged Del Prado's strategy originated with new ASM shareholders. Empowered by the Dutch Tabaksblat Code and after careful analysis of ASM's financial performance, activist shareholders disputed the innovation strategy and management composition of ASM International from December 2005 onward. A hedge fund and a British pension fund claimed that through the strategy of leveraged innovation, ASM denied its shareholders their legitimate profits. Front-end had been leveraged by the performance of back-end. Yet it was still generating losses. The shareholders argued in favor of a divestment of ASM Pacific Technology to discipline the front-end activities and let front- and back-end have their true appreciation on capital markets.

These external and internal pressures on the company's innovation strategy overshadowed Del Prado's retirement and the start of Chuck del Prado's role as chief executive officer. In this respect it was paradoxical, perhaps, that ASM's advanced high-k gate ALD process finally was integrated into high-volume manufacturing by Intel in 2007, which was a major industrial and technological breakthrough. Moreover, at ASM Genitech Korea another new process was on the verge of being marketed, fostering ASM's sales from 2009 onward: the application of PEALD in double patterning. It proved the viability of Del Prado's strategy of leveraged innovation.

These technological breakthroughs resulting from Del Prado's strategy gained little public attention, however. As the global economy was hit by the financial crisis, ASM had to put all its effort in warding off its own corporate governance crisis. Arthur del Prado's illustrious career in the semiconductor equipment industry seemed destined for a tumultuous ending.

\section{Elaboration of affairs}

\section{Cost pressures on sustaining businesses}

The ASM business units constantly engaged in pursuing even the slightest opportunity indicated by customers, the one potentially more disruptive for the industry than the other. As the technological diversity within the semiconductor

169 This involved the initial 18 million dollars for the 15 percent stake, the acquisition sum of 35 million dollars, and another 19 million dollars in investments in 2004. 
industry increased - considering More Moore, More-than-Moore, forthcoming changes in transistor design, and the diverging demands of contract, memory, and microprocessor manufacturers - technological development proliferated at ASM. This involved not only new products, such as ASM Japan's new compact plasma CVD reactor Dragon and ASM America's plasma ALD modules for metal gates (EmerALD), but also new applications, such as high-k dielectrics for capacitors in memory chips by ASM Genitech, as well as higher variety among wafer handling platforms. ${ }^{170}$ Increasingly, ASM diversified, and its portfolio contained too many products that hardly gained interest beyond the original customer.

Yet, for a supplier of new deposition processes such as ASM International, it became indispensable to secure sizable gross margins on equipment sales. With lower volumes of tools sold, higher investments in research and development had to be recovered. The years 2004 and 2005 were characterized by efforts to improve the performance of already successful product lines.

To equilibrate new activities, the company enhanced corporate oversight on expenses, limit proliferation, and, most importantly, raise the influx of revenues. A profit \& loss (P\&L) account per product group was made, instead of per geographical business unit (figure 92). ${ }^{171}$ In a platform consolidation program, ALD, PEALD, PECVD processes and EmerALD modules were consolidated on the Japan-made EagleXP or Dragon wafer handling platforms. ${ }^{172}$ The American-made Polygon wafer handler was only used for qualified production processes, such as high-k gate dielectrics. Simultaneously, the earnings of the company improved by elaborating on the successes realized in relation to industry leaders like Intel and IBM, by ramping up the central manufacturing operation, and by improving the cost performance of each of the products.

170 By 2004, ASM International offered three wafer handling platforms: the American Polygon, the Japanese Eagle XP, and the Japanese Dragon XP. Moreover, the Epsilon epitaxial reactor and the A400/A412 vertical furnaces had their own integrated wafer platforms.

171 ASMI, Supervisory Board, 'Minutes Supervisory Board meeting 26 April 2004' (5-5-2004) Archive Arthur del Prado - RvC 2005.

172 ASM International, Ivo Raaijmakers, 'Memorandum: ASM FE Product Structure' (8-102003) Archive Arthur del Prado - Ivo Raaijmakers file; ASM International, Ivo Raaijmakers, 'Memorandum: ASM Single Wafer Platform Roadmap' (29-4-2004) Archive Arthur del Prado - Ivo Raaijmakers file. 


\section{Figure 92}

Organigram of ASM International by early 2005

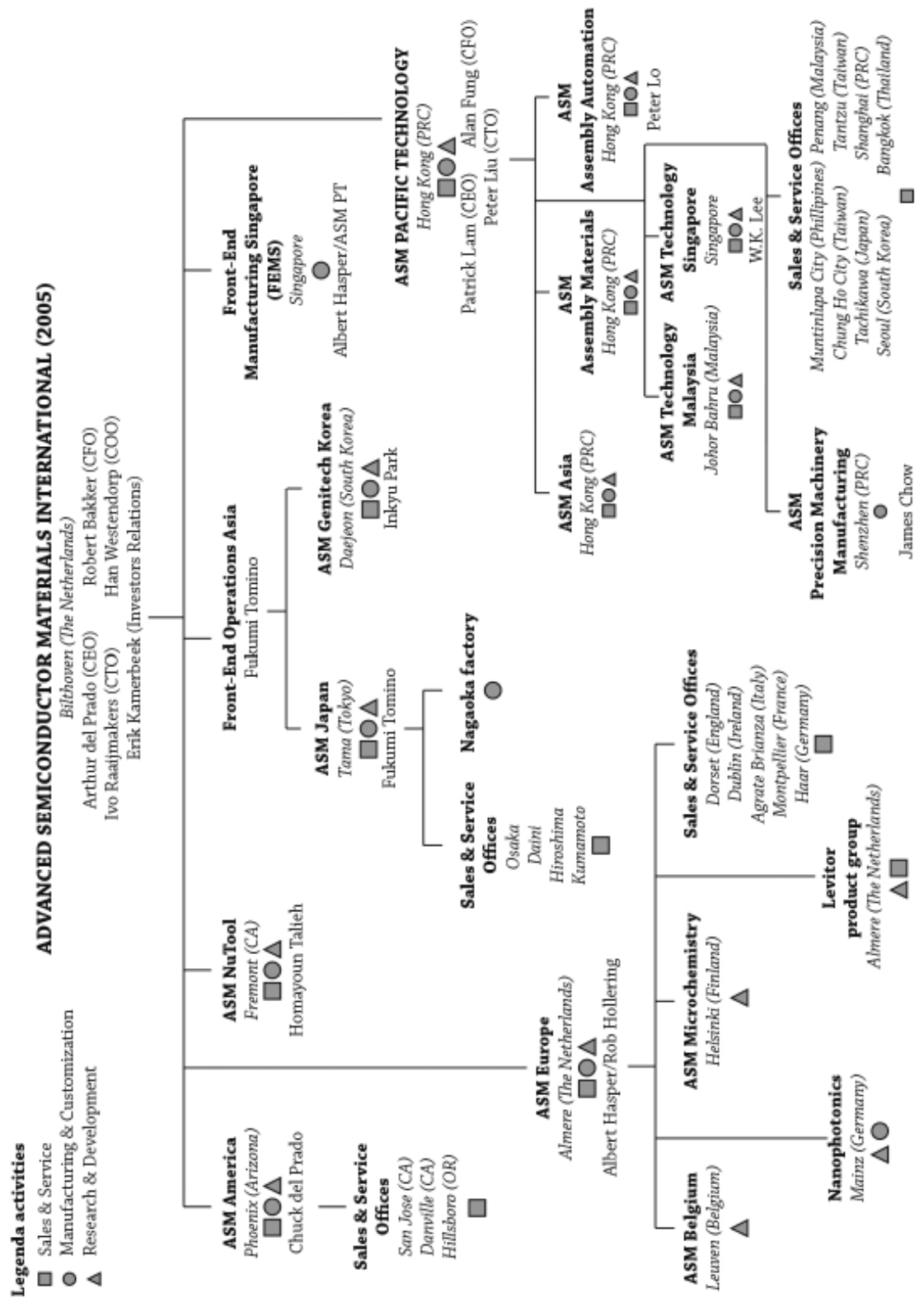




\section{Elaborating on successes}

Several years of more sustained collaboration with industry leaders like Intel and IBM had allowed ASM to leave behind the troublesome early 1990s definitively. In the context of the 65-nanometer node, ramped up to high-volume manufacturing from 2004 until 2006, Intel procured ASM America's epitaxial reactor, ASM Japan's plasma CVD low-k process, and ASM Europe's vertical furnaces. ${ }^{173}$ The equipment vendor once again managed to join the ranks of leading equipment suppliers. ASM was a party to be taken seriously for semiconductor manufacturers trying to advance Moore's Law. From 2004, ASM was determined to cash in on its achievements. As Del Prado and Westendorp articulated the strategy to the Supervisory Board:

'While the market has widely accepted the need for new materials, and while the market has acknowledged ASM's key role in it, ASM must now turn this position into financial success. We pointed out ... that one of the key ingredients of our goals for the years 2004 and 2005 is to bring our $300 \mathrm{~mm}$ tool set to a broader customer base. Many of ASM's $300 \mathrm{~mm}$ tool selections and qualifications in 2001 through 2003 were performed at Intel (with the exception of Vertical Furnace where selections at IBM, Infineon and Promos were won). Design wins at other customers are required to reap the fruits of the investments we made .... ${ }^{174}$

Other chip manufacturers - lagging behind the likes of Intel and IBM in technological development - would turn to ASM to gain access to state-of-the-art process knowledge. Combined with their own integration and process capabilities, chip manufacturers would be able to figure out how to use ASM's equipment themselves.

In line with this effort, ASM America sold its first epitaxy equipment to Texas Instruments, which usually relied on Applied Materials equipment. Other doors opened as well, such as at AMD Dresden, Freescale, and TSMC. Vertical furnaces were sold to Infineon first, and via this supplier also to Promos and others. The supply of the Aurora low-k process to Intel resulted in sales by ASM Japan to Taiwanese chip manufacturers as well.

The elaboration upon earlier investments to raise revenues also involved the license of technologies. The front-end operations had accumulated and familiarized numerous processes for various applications, but these hardly

173 Mark LaPedus, 'Intel procures initial 65-nm chip equipment (Updated)', eetimes.com (28-32004).

174 ASMI, 'Progress Report Q2, 2004 to Supervisory Board' (27-7-2004) Archive Arthur del Prado $-R v C 2004$. 
managed to compete in all those markets. From the summer of 2005 onward, the company tried to improve the range of its technologies by licensing them to competitors and other equipment manufacturers. The earnings thus obtained diminished the burden of these technologies on the company's profit and loss account.

One prime example involved ASM's main competitor, Applied Materials. In the summer of 2005, Arthur del Prado sat down with Applied Materials' chief executive officer Mike Splinter following mutually presumed violations of intellectual property. ${ }^{175}$ Both parties agreed upon institutionalizing further contacts about mutual patent infringements. Moreover, Del Prado and Splinter wanted to explore probable license deals.

This foremost involved licensing ASM's technology to Applied Materials, offering additional earnings. Above all, Del Prado was eager to license products that complemented Applied Materials' portfolio and that were no yet doing well. This pertained to ASM Europe's Levitor, ASM NuTool, and the integrated metrology of Nanophotonics. ${ }^{176}$ Licensing or even selling these technologies to Applied Materials would increase chances of commercialization and decrease the financial burden on ASM. The licensing strategy was expanded beyond Applied Materials. Some ALD-related patents were licensed to Veeco, Hitachi Kokusai and Tokyo Electron. ${ }^{177}$

\section{Ramping up FEMS}

ASM's major effort to improve its front-end profitability, Front End Manufacturing Singapore (FEMS), was nearing completion. By 2005 the first generics of the A412 vertical furnaces were manufactured in Singapore. Moreover, customers qualified the production location, which meant that the modules and equipment manufactured by FEMS were eligible to be used in their factories. Moreover, the production of epitaxy equipment was being prepared.

By the fall of 2005, Patrick Lam, chief executive officer of ASM Pacific Technology, and his management team retired from running FEMS. They managed to set up the operation and to achieve the major target of producing

175 Prior to his position at Applied Materials, Mike Splinter had been involved as Vice-President and general manager of Intel's Technology and Manufacturing Group. In this capacity, he had been deeply involved with the integration of amongst others ASM's technologies in Intel's latest production lines. - ASMI, Board of Directors, 'Memorandum to Supervisory Board: Applied Materials' (26-7-2005) Archive Arthur del Prado-RvC 2005 file. In addition to the ASM products, Del Prado tried to stir Splinter's interest in Mapper, a Dutch startup in e-beam lithography in which Del Prado had personally invested.

177 ANP, 'Licentie ASMI naar Amerikaans Veeco', NRC Handelsblad (23-6-2005) p. 17; ASM International, Erik Kamerbeek and Mary Jo Dieckhaus, 'Press Release: ASM International and Tokyo Electron Sign Licensing Agreement for Atomic Layer Deposition Technology’, asm. com (19-12-2008). 
twenty generic modules. ${ }^{178}$ Some ninety staff engaged in the effort, and in 2005 production amounted to 6 million euros, with capital investments of about 12 million euros. Savings were expected to be about 30 percent, yet this was merely $17 \%$ in the case of the A412.

The exact interpretation of the role of FEMS within ASM's operational infrastructure was not written in stone. Depending on the ups and lows in revenues, its role was adapted, as in July 2005. ${ }^{179}$ Instead of doing the full production of verticals - involving the fabrication of generics, but also testing, final assembly - by 2006 FEMS was designated to manufacture all generics of all products, with assembly and testing remaining at the current locations.

Also within the family of ASM subsidiaries, the position and role of FEMS had to be emancipated (mind figure 92). Merely subcontracting FEMS was not sufficient; the transfer of manufacturing to the Singaporean operation had to be accompanied by sound daily process management and committed managers. Since the foundations of the manufacturing operations were in place, managers from ASM Europe were transferred to coordinate and mature the production of vertical furnaces. ASM Europe's general manager Albert Hasper and operational manager Fokko Leutscher took up this role, and began to travel back and forth between Bilthoven, Almere, and Singapore.

\section{Decreasing cost-of-ownership, too little too late}

Strengthening the margins of ASM's existing product lines was not only required to improve the company's revenues; it was also indispensable for being able to compete. Customers constantly tried to lower their cost-of-ownership for equipment, pursuing higher productivity against lower equipment costs. For the latest piece of equipment, enabling the latest shrinkage according to Moore's Law, chip manufacturers were willing to pay. But for second-generation tools they expected either significantly improved productivity or a lower rate.

As such, pricing was a permanent concern with respect to ASM's ongoing product lines, as exemplified by the epitaxy product line. A chip manufacturer which used the Epsilon 3000 at the 90-nanometer node, expected substantial discounts for the 65-nanometer node, to be ramped up to high-volume manufacturing by $2005{ }^{180}$ Initially, request was dismissed by ASM America, which perhaps regarded

178 ASMI, Johan Danneels, 'X-Ray 2005 Report to ASMI Supervisory Board' (December 2005) Archive Arthur del Prado - RvC 2005 file.

179 ASMI, Board of Directors, 'Memorandum to Supervisory Board: Fast on FEMS' (26-7-2005) Archive Arthur del Prado - RvC 2005 file.

180 The 300-millimeter machine was much more expensive compared to its 200-millimeter predecessors, due to - among other things - a required switch from casting to machining of components - ASMI, Johan Danneels, 'X-Ray 2005 Report to ASMI Supervisory Board' 
it as a bluffing game. Within ASM America's management, it was assumed that customers, like always, merely tried to increase competitive pressures to improve their cost performance. After all, the Epsilon reactor dominated the epitaxial market for chip manufacturers. ${ }^{181}$

However, by April 2005, this customer announced that it would persevere in its pursuit for a better cost performance, and that it would evaluate the Epsilon 3000 next to a machine from a competitor. The competitor's Epi system presumably offered a lower cost-of-ownership than ASM. ${ }^{182}$ ASM America scrambled to offer a 30 percent discount, enabled by FEMS in a few years, discuss a dual chamber configuration of the Epsilon for the 45-nanometer node, and begged for patience. All these gestures were too little too late. The chip manufacturer selected the competitor's clustered epitaxy processes.

This particular situation was a major blow to ASM's American operation. Some of the engineers dismissed the event, referring to the full order book for 2005. After all, ASM America had successfully penetrated Texas Instruments - the Applied Materials stronghold. You win some, you lose some. However, some pointed out to potential snowball effects in the industry. ${ }^{183}$ If you lose this customer, it was just a matter of time, or a few technology nodes, before you would lose other businesses as well. Others rationalized the event by suggesting that the customer wanted ASM America to focus on other forthcoming technologies like the revolutionary high-k gate process. For them, the added value of the latest innovations raised by ASM America outstripped the value offered by second-generation products. In particular, since the American operation had also been struggling to meet demand for some time. ${ }^{184}$ Either way, the lesson was clear: being a trail-blazer at the latest technology nodes was not enough to succeed. The cost of incumbent products had to be decreased constantly as well, to increase ASM's own profit margins and to decrease the cost-of-ownership for its customers.

(December 2005) Archive Arthur del Prado - RvC 2005 file.

181

182

$$
\text { to }
$$

Already in 2002, Chris Werkhoven had warned that the cost-of-ownership for Epsilons had to improve, whether through efficient tools or efficient operations. As he claimed: 'With the anticipated explosion in demand, serious investments will be needed to defend our position and if the prognosis is right, this could mean that ASMA probably has to double in size within five years from now. Loss of focus or commitment will open the door to competitors and lead to loss of market share.' - ASMI, Chris Werkhoven, 'Monthly Report Chris Werkhoven August 2002: Paradigm Shift for ASM Epi and Others' (1-9-2002) Archive Arthur del Prado - Chris Werkhoven file. 


\section{The problem that is front-end}

Despite all these efforts to improve the company's profit and loss account through platform consolidation, FEMS, licenses, improving cost-of-ownership of tools - the results continued to disappoint. ASM International booked a loss of 40.2 million euros over 2005. This poor result was not caused at all by the back-end activities (figure 91). ASM Pacific Technology continued to flourish during 2005 with sales of 366.8 million euros and earnings of 98.7 million euros. The constant viability, profitability, and achievements of the global leader in semiconductor assembly and packaging equipment were celebrated. In the prominent Hong Kong Convention and Exhibition Center, overlooking Victoria Harbor, Patrick Lam, Arthur del Prado, and the staff of ASM Pacific Technology observed the thirtieth anniversary of the Hong Kong operation with speeches, performances, a dinner, and a party. ${ }^{185}$ While back-end hanged up streamers, front-end reported significant operational losses: 80.3 million euros loss over net sales of 359.6 million euros. The disparity was striking.

Del Prado's strategy of leveraged innovation arrived at a precarious stage. After all, front-end had been loss-making for years. And by 2005 ASM frontend's development costs even exceeded the earnings from ongoing activities and the dividends of ASM Pacific Technology. The losses were dragging down ASM International as a whole.

This was bound to be drawing attention from shareholders and other investors. That these losses pertained to advanced innovations addressing new technological and market developments a few years down the road hardly made a difference. Even the pro-active decision to transfer manufacturing to Singapore (the FEMS initiative) did not affect the current losses. After more than ten years, the viability of ASM's front-end operations was seriously questioned once again.

Moreover, Del Prado's relentless pursuit of new opportunities and front-end's never-ending losses alienated several of the executives during the summer of 2005. CFO Robert de Bakker was succeeded by Arnold ('Naud') van der Ven, after De Bakker indicated his desire to retire during the summer. Del Prado's intended successor Haijo Pietersma resigned as deputy chief executive officer, as he never obtained - or was allowed to obtain - a role of any significance. Through Pietersma's resignation the succession of Del Prado was back to square one. As a result, the candidate to succeed Paul van den Hoek as chairman of the Supervisory Board, Adrie Baan, resigned as well and was succeeded by Leon van den Boom, an executive with experience at various Dutch firms. ${ }^{186}$ 
In response to the slippery slope on which ASM International seemed to proceed, a fact-finding mission across the company was initiated. In the fall of 2005 , the Supervisory Board dispatched its most technologically grounded member, Johan Danneels to that purpose. ${ }^{187}$ The Flemish executive visited all ASM frontend operations to find answers to major questions like: is ASM front-end well on track? Does ASM have the right products to achieve revenue growth? Can we achieve enough sales to please shareholders with a sustainable business? Danneels probed the local managers for technological developments, markets, margins, applications, etc. By December he was able to report a positive answer:

'Broadly summarizing, my strong conviction is that ASMI does have a (maybe too rich) portfolio of right products for a growing market in its core business.' 188

Danneels claimed that ASM's success in turning all its potential technologies into revenue would depend on its operational margins. These had to be improved significantly, in his view, a task for which FEMS was indispensable. But he also argued for less differentiation among equipment platforms. The variety among the tools in outline, components, and parts was too high, preventing economies of scale. As he concluded:

'Finally I want to stress that I have been impressed by the high level of professionalism in all parts of ASMI that I visited. I repeat that the nature of the Front End business is enormously complicated both from a semiconductor process technology as from a high technology equipment manufacturing point of view in development stages of various products with low volumes, all at the same time. One could argue if indeed this is not too much. ... In other words: "what is the core business where we absolutely need to gain a minimum worldwide market share" at a reasonable time with acceptable economics.' ${ }^{189}$

Danneels' assessment fitted in the line of thinking advocated by the Supervisory Board: more focus on fewer products in order to achieve higher margins and better results. The pursuit of opportunities had scattered ASM's activities across markets and applications, often with too much effort for too little returns. Realizing that the technological diversity in the industry proliferated rapidly,

187 ASMI, Johan Danneels, 'X-Ray 2005 Report to ASMI Supervisory Board' (December 2005) Archive Arthur del Prado - RvC 2005 file. 
Danneels and the Supervisory Board urged Del Prado and his team to establish core competences. The mainstay of the business had to be consolidated.

The management of ASM front-end reluctantly accepted the losses over 2005, planning to get the operations profitable again. ASM International's management was hopeful that the cash-draining transistor \& capacitor group might achieve break-even levels by 2007. ${ }^{190}$ This confidence, however, did not apply to the copper-plating operation ASM NuTool. Throughout 2005, the Californian operation even became a burden.

\section{ASM NuTool's violation of decentral self-reliance}

Del Prado's trust in ASM NuTool's technology proved to be mistaken. After the first year, by December 2004, the Californian operation had sold not a single piece of technology, earned not a single dollar of revenue. Moreover, the prospective customer accounts did not justify any optimism. This situation was rather peculiar because at the time of the acquisition, NuTool's management budgeted 22.7 million dollars in sales for 2004, 60.4 million in 2005 and as much as 92 million dollars in 2006. The beautiful forecasts and the presumed maturity of the copper deposition technology had convinced Del Prado and his management to acquire NuTool. For 2005, the Electro-Chemical Mechanical Deposition (ECMD) technology was not yet written off. But as expenditures had to match earnings across ASM International, investments in NuTool were brought into line with the prevailing reality.

The ambitious general manager and founder of ASM NuTool, Homayoun Talieh, disputed the decision to attribute less money to his operation. The discussion centered around ASM's contractual obligation to allocate funds 'at some indeterminate level to maximize the earnout.' ${ }^{191}$ This earnout involved up to 17 million dollars in ASM stock, which ASM promised if Talieh and his team achieved the projected sales. He insisted that by reducing the investments in his company, his team's chance of achieving the earnout decreased. ${ }^{192}$ Talieh and his

190 Amidst the doubts about ASM front-end cost performance, ASM's ownership of Nanophotonics was formalized. Because ASM had carried all the investments over the past years, the company had become the de facto owner already. - ASMI, Board of Directors, 'Memorandum to Supervisory Board: Getting to 100\% Shareholding in NP' (19-12-2005) Archive Arthur del Prado - RvC 2005 file.

191 Quarles \& Brady, Steven Emerick, 'E-mail to Robert de Bakker: Amendment' (31-1-2005) Archive Arthur del Prado - NuTool file.

192 Pillsbury Winthrop Shaw Pittman LLP, Albert Boro, 'Letter to ASM International, attn: Arthur del Prado: Notice of Dispute Under Section 11.3 of Merger Agreement regarding Extension of Earnout Milestones' (30-9-2005) Archive Arthur del Prado-NuTool file. 
team demanded full empowerment of their activities and wished to be exempted from the head office's budgetary constraints.

Put differently, NuTool challenged the budgetary power of the parent company and de facto advocated further decentral emancipation. Even within the context of ASM's long-lasting dichotomy between decentralization and centralization, this was a remarkable proposition. ASM NuTool pushed the boundaries of ASM's strategy of granting significant portions of autonomy to the business units in order to foster entrepreneurship, innovation, and vigor. Del Prado had always been susceptible for subsidiaries' plea for more freedom of action. He knew all too well that relinquishing business units from strict corporate control was key to commercial success, even though the 1990s had taught him that some harmonization among operations was indispensable as well. Moreover, he was not the man to pass his hand; he would persevere in what he had started.

As a token of continued support, Del Prado extended the starting-date for measuring the NuTool's performance by one year and a half. ${ }^{193}$ This gesture bought Talieh and his team another year to comply with the targets and earn the substantial royalties. At the same time, however, Del Prado explained to Talieh that:
'ASMI has to make these decision on the basis of all available information, including the competing demands for capital from each element of our business. Occasionally, business unit managers believe that the allocation of capital in the budget to their specific business units is not adequate. This is to be expected, but it cannot unduly influence the overall allocation decisions. In the case of NuTool, I can assure you that the decisions regarding funding have been taken in good faith, and represent what we honestly believe in the best interests of ASMI.' 194

It was up to Talieh and his team to prove their potential by starting to make inroads at customer sites.

However, the company failed to realize its prospects one after the other. Toshiba had been the most promising and enthusiastic customer. By March 2004, the Japanese chip manufacturer visited the Californian operation to witness a marathon-run of the machine. By processing three to five thousand wafers continuously, marathon-runs were used to evaluate the equipment's performance in industrial conditions. After all, once integrated in high-volume manufacturing, the machine ought to be running 24/7. It was during this evaluation that an

193 ASMI, Arthur del Prado, 'E-mail to Homayoun Talieh: amendment' (27-1-2005) Archive Arthur del Prado - NuTool file.

194 ASMI, Arthur del Prado, 'Letter to Homayoun Talieh' (10-2-2005) Archive Arthur del Prado - NuTool file. 
insurmountable deficit of NuTool's ECMD technology surfaced. The polishing pads that evened the copper surface merely lasted 500 wafers before having to be replaced. NuTool failed to complete Toshiba's marathon-runs. Moreover, the supplier of the polishing pads - 3M - indicated that the lifetime of the component could not be extended further. ${ }^{195}$ Marathon-runs were out of the question, as seemed true of the ECMD technology's aptitude for high-volume manufacturing.

Toshiba deprioritized the ECMD technology. Also, the French chip manufacturer ST dismissed it for its 65-nanometer node fab-line. Other prospects, mainly in Taiwan, became uncertain as well. UMC dismissed the ECMD due to unfavorable cost-of-ownership, and its healthy relation with competitor Novellus. TSMC did not want to collaborate after a dispute with Talieh about refunding an initial evaluation tool years earlier.

Perhaps because of the lack of positive results, Han Westendorp and Del Prado were kept at a distance by the Californian operation. Constantly, Talieh claimed to have everything under control, and he also persisted in his dissatisfaction about the reduced investments in his firm. Furthermore, facing the de facto obsolescence of the ECMD technology, Talieh unilaterally pivoted ASM NuTool's activities toward a new technology concept, dubbed 'Electro-Chemical Mechanical Polishing. This new concept, the details of which were sketchy at best, seemed to be even further away from high-volume manufacturing.

In the fall of 2005 ASM International's Supervisory Board called for an intervention. Over the first nine months, ASM NuTool's revenues were a meagre 72 thousand dollars, a negligible sum against the projected 44.6 million dollars. Over the course of 2004 and 2005, ASM invested more than 19 million dollars in the operation without any returns. Efforts to license intellectual property to Applied Materials, Novellus, and Ebara failed. ${ }^{196}$ Clearly, the investments in the Californian operation were not paying off. In just two years, in fact, ASM NuTool had become a significant burden to the company.

ASM decided to transform ASM NuTool into an intellectual property generating operation, reducing staff from 57 to a mere fifteen. However, Talieh was determined not to give in so easily. In December 2005, Westendorp reported to the Supervisory Board that the relation had turned sour:

'[Talieh] now asserts that ASM had breached the merger agreement through various acts and omissions, primarily the alleged failure to

195 Quarles \& Brady, Don Martin, 'Letter to Honary Coleman Fannin: NuTool Dispute with ASMI: Mediation Memorandum' (16-1-2006) Archive Arthur del Prado - NuTool file.

196 ASMI, Board of Directors, 'Memorandum to Supervisory Board: Progress on Solving Issues - ASM NuTool' (19-12-2005) Archive Arthur del Prado - RvC 2005 file. 
provide adequate levels of good faith funding for NuTool operations and provide necessary business support. ${ }^{197}$

ASM International's management rejected Talieh's claims and set out to prove it had supported NuTool in good faith despite the deplorable results. The disagreement was not resolved until January 2006. Immediately afterward, the operation was closed and a few staff members were transferred to Phoenix.

The ASM NuTool acquisition proved a genuine failure. The Dutch equipment manufacturer's - and Del Prado's particular - appetite to join the copper bonanza in the equipment industry drowned out rationality, as evidenced by ASM's urgency to outbid a vague, verbal third-party offer for this assumed treasure trove. Furthermore, since the start of collaboration in 2001, Talieh effectively managed to frustrate intervention by ASM. Initially he did so by safeguarding the proprietary technology and tapping into the romance of disruptive innovation and golden mountains associated with Silicon Valley high-tech startups. Technological alignment with other ASM operations only occurred via a 'Virtual Fab.' Later, ASM was held at arms-length by shielding the parent company from directly contacting customers, exaggerating prospects, and disputing the budgetary power of the head office. Moreover, ASM lacked the technological expertise to critically assess NuTool's copper technology. While dust was thrown into ASM's eyes, the company had been either to eager or too credulous - or both.

Trust in the self-reliance of subsidiaries had of course been a key element in Del Prado's management practices since he began his company in the 1960s (cf. Chapter 3). Del Prado and his managers foremost intervened in strategic matters. Operationally, the business units were always fairly autonomous, even after the tightening of corporate control since the mid-1990s. The operations were allowed to rely on their own technological and commercial experts. In a rather painful manner, the NuTool affair wiped the floor with this basic feature of ASM's innovation strategy - making Del Prado and ASM International's corporate staff look naieve.

The timing of NuTool's downfall could not have been worse. In 2004 and 2005, ASM's front-end operations generated losses due to the investments in new disruptive technologies such as ECMD, ALD, and PEALD. Del Prado leveraged the small profits of the successful front-end products and the ASM Pacific Technology dividends to fund these new innovations. In his firm confidence in these new technologies, Del Prado once again pushed the boundaries. The entrepreneur over-leveraged innovation.

197 ASMI Supervisory Board, 'Overview Legal Issues - ASM NuTool' (19-12-2005) Arthur del Prado-RvC 2005. 
NuTool's contribution to this precarious situation would cost Del Prado dearly. In the late 1980s and early 1990s, a situation of over-leveraged innovation was rebuked by bankers, resulting in - among other things - divestment of ASM Lithography and restricting of the remaining operations. By 2005, however, the illustrious chief executive officer was no longer his own boss; he no longer owned the majority of shares. Other shareholders, mainly institutional investors, objected strongly, demanding ASM to make its front-end profitable, as well as harassing Del Prado in the autumn of his career as ASM International's chief executive officer.

\section{Stirring shareholders}

From the fall of 2005, ASM International found itself in the line of fire, caused by shareholders testing the grounds of their freshly codified rights. The 2004 Dutch corporate governance regulation, the Tabaksblat Code, constituted a code of conduct for listed corporations in the Netherlands, but it was also an idealized image of the mutual expectations and obligations of management and owners. Later revisions, such as in 2008 (Frijns code) and 2016 (Van Manen code), removed obscurities and incorporated new insights.

The empowerment of shareholders through the new corporate governance regulation coincided with the advent of institutional investors in the Netherlands. ${ }^{198}$ Bolstered by low interest rates, private equity groups and hedge funds took a more prominent position in the Dutch investment climate. Unlike the few individual or traditional institutional investors, including pension funds, these stockholders put in much more money and had an activist agenda. Hedge funds were less transparent than other institutional investors, and they tended to take more risk, operated faster, and were more aggressive. They pursued profitability in the relative short term, and were willing to force management to comply with their demands. The new institutional investors had clout.

The Tabaksblat Code merely stimulated the assertive institutional investors. Through annual general meetings and if necessary via court, shareholders ascertained compliance of their rights and let their voices be heard and their demands be met. ${ }^{199}$ On the battlefront of corporate governance in the Netherlands, shareholder value increased in significance at the expense of the traditional valuation of stakeholder interests. Dutch market capitalism moved further away from coordinated enterprise and toward the liberal model, or, in

198 Abe de Jong, Peter Roosenboom, Marno Verbeek, and Patrick Vermijnmeren, Hedgefondsen en Private Equity in Nederland (Erasmus University, Rotterdam, 2007) p. 17.

De Jong et. al, 'De rol van aandeelhouders na “Tabaksblat”'. 
other words, from the Rhineland tradition toward a more Anglo-Saxon, capitalist one. ${ }^{200}$

The assertive institutional investors pursuing short-term profits, new corporate governance regulations, and a cultural shift toward shareholder-value conflicted with ASM's strategy of leveraged innovation. This strategy rather aimed at creating value in the long term. All the revenues were re-invested to appropriate even bigger returns on investment. Moreover, to foster the interests of all its stakeholders (not just shareholders), ASM had consistently situated itself in an elaborate Dutch and European network of government officials, customers, suppliers, and investors. After all, with its chief executive officer still owning a majority portion of the company's stock, the company could permit itself such a strategic and industrial approach, even as Arthur del Prado's stake had been diluted to 18 percent over the years. Other shareholders in ASM International were pacified by Del Prado's majority share ownership and his eloquence with regard to the company's strategy and achievements. Due to new rules of the game encapsulated by the new code, the advent of resourceful institutional investors, and ASM's consistent front-end losses, the company's strategy was increasingly contested.

For the first time in 2005, ASM International actually had to deal with a private equity group, called Francisco \& Partners, which was looking for a stake in the company, in combination with representation on the Supervisory Board. Next, in December 2005, ASM received a letter from a hedge fund named Mellon Alternative Strategies, which owned barely 1 percent of the company's stock. Mellon questioned the company's strategy by indicating that the market capitalization of ASM Pacific Technology on the Hong Kong Stock Exchange exceeded that of ASM International on the Nasdaq and Amsterdam Stock Exchange. According to Mellon, this was remarkable because the market capitalization of ASM International encompassed the activities of both its frontend operations and ASM Pacific Technology. In other words, investors valued ASM International's front-end operations negatively. Moreover, the investors argued that the profits and dividends of ASM Pacific Technology were used to compensate for the (prospective) losses produced by front-end activities in other sections of the parent company, while those profits should be paid to the shareholders. ASM International received 40 million euros in dividends out of ASM Pacific Technology in 2004 and 37 million in 2005. ${ }^{201}$ In the letter, Mellon's attorney, Pieter van der Korst from the Houthoff Buruma law firm, stated:

De Jong et. al, 'Changing National Business Systems'; De Jong et. al 'Strategic and structural responses'.

201 ASMI, Board of Directors, 'Memorandum to Supervisory Board: Use of ASMPT Dividend' (8-3-2007) Archive Arthur del Prado - RvC 2007 file. 
'[It is] clear that ASM PT is a highly profitable stand-alone operation. There are no apparent reasons for ASMI to maintain this participation structure. On the contrary, it is in the interest of the present ASMI shareholders to split the present corporate structure. ${ }^{202}$

The letter was a shot across the bows, stipulating the demands of the hedge fund. ${ }^{203}$ Mellon propagated the divestment of ASM Pacific Technology in order to have ASM International bring the house in order and reflect its true value. Mellon hedged that after such a divestment the stock of both ASM International and ASM Pacific Technology would shoot up, offering the investor a significant and rapid return on its interest. Thus, the hedge fund demanded that the matter of splitting up ASM International would be discussed as a separate item on the agenda of the next annual general meeting.

After ample consultation with legal advisors, ASM complied and announced that a discussion of ASM's strategy would be part of the next annual general meeting, to be held on May 18, 2006. ${ }^{204}$ The company refused to put the issue of splitting the company on the vote during the annual general meeting. ${ }^{205}$ In the run-up to the annual general meeting, both ASM and Mellon instigated a public campaign to harness support for their respective viewpoints. In an avalanche of letters, Mellon increased its demands, while steadily increasing its stake from 1 percent to 6.1 percent. Moreover, the hedge fund got support from another institutional shareholder named Hermes Focus Fund, a British investment manager of the BT Pension Scheme, owning 5.3 percent of ASM's shares. Simultaneously, Del Prado reached out publicly to defend his strategy:

'[Market] volatility is a big headache. Either people are in love with semiconductors or there is a tremendous fear factor. They enjoy the ride up and then bail out ... I try to tell people to think long term and to understand that this is an excellent time to invest. But all we can do is manage through the cycles as we always have. We have made a decision

202 Houthoff Buruma, Pieter van der Korst, 'Letter to ASM International, attn: management board and supervisory board; ref: 43101226/567204.1' (12-12-2005) Archive Arthur del Prado - Mellon file.

203 The disparity in performance and ostensible lack of synergy between ASM front-end and back-end had come to the fore earlier in discussions between ASM International's new chief financial officer Naud van der Ven and Mellon, as well as during quarterly earnings conference calls. Every time, these were dismissed.

204 ASM International, 'Press release: Merits of Business Model on Agenda for General Meeting of Shareholders' (22-12-2005) Archive Arthur del Prado - Mellon file.

205 Pieter Elshout, 'Hedge fund dreigt ASMI met de rechter', Het Financieele Dagblad (8-5-2006) p. 1. 
early on that ASMI would have a presence not only in the front end of the manufacturing chain, but also in the back end.... Because of the way capital investment cycles work, being involved at both ends dampens volatility to some extent. ${ }^{206}$

The founder of the company reaffirmed his confidence in a long-term strategy, because with a short-term strategy it was more difficult to withstand the volatility of the semiconductor market. In support of his argument about the synergy and strategic rationale of combining front- and back-end activities, Del Prado indicated that future technological development would blur the distinction between wafer processing and assembly equipment technologies. This appreciation of the future was shared by the likes of Intel, Samsung, and Sematech, but also by financial institutions such as CIBC World Markets. ${ }^{207}$ To back up his argument, Del Prado pointed to the wide acknowledgment of ASM International's intellectual property portfolio. ${ }^{208}$ And finally, as Del Prado argued, Mellon knew in advance about the kind of company in which it invested, so why complain.

During the eventful 2006 annual general meeting, the two parties were pitted against each other, and the activist shareholders found another stick to achieve their goal. Since the resignation of Haijo Pietersma and Adrie Baan in the summer of 2005, the Supervisory Board had been contemplating Del Prado's and Van den Hoek's succession. In anticipation of Arthur del Prado's retirement and in an effort to strengthen the company's management, the Supervisory Board promoted chief operating officer Han Westendorp and ASM America's general manager Chuck del Prado to the Board of Directors. In addition, the Supervisory Board replaced Baan by Berend Brix, and announced its intention to add a new member. Moreover, Patrick Lam - the co-founder and long-time chief executive officer of ASM Pacific Technology - had announced his retirement. As of January 2007, he was to be succeeded by the 52-year-old Wai Kwong ('W.K.') Lee, the manager of ASM Technology Singapore and employed by the company since 1981.

During the annual general meeting, all these appointments were up for approval by the shareholders, which normally would merely be a formal affair. This time, however, the representatives from Hermes, Mellon, and a Dutch investor association, called 'Vereniging van Effectenbezitters' (VEB), questioned

206 Author unknown, 'Arthur del Prado of ASM International: Full faith in the semi market', Euromoney Magazine (January 2006).

207 Bert van Dijk, 'Grote synergie binnen ASMI: Europa wordt kennisleverancier voor chipsector in Azië', Het Financieele Dagblad (18-5-2006) p. 17.

208 Bert van Dijk, 'Octrooi klein ASMI maakt grote indruk', Het Financieele Dagblad (9-11-2006) p.1. 
the procedures and suitability of the appointees. The activist shareholders felt frustrated about being presented with a fait accompli. ${ }^{209}$

Through a barrage of questions and comments, representatives from Mellon, Hermes, and the VEB disputed all they could in a 'well-orchestrated, intentionally disruptive and well outside the rules of order' manner. ${ }^{210}$ The capability of the Supervisory Board to oversee and interfere in the company's affairs was questioned. To this end, the critics aptly pointed to Van den Hoek's 25-year-long tenure as chairman, the presence of merely one member on the Supervisory Board with demonstrable professional knowledge of the semiconductor industry, and the unconventional procedures surrounding the appointment of new executives. ${ }^{211}$

In particular, the appointment of Chuck del Prado drew attention, as he was the chief executive officer's eldest son. Mellon argued that the way in which ASM was run 'meets the governance standards of a family owned business instead of the good governance standards of a Euronext listed company. ${ }^{.12}$ The activist shareholders dismissed Chuck del Prado's twenty-year career, and they also challenged the vigorousness of the other nominee, Han Westendorp, likewise commanding over twenty years of experience in the industry. Unexpectedly, the annual general meeting turned into a tempered debate.

Precarious to make commitments or to lose his footing in the new corporate governance, Paul van den Hoek dexterously chaired the meeting. In the end, the nominations were approved - Arthur del Prado's stake of 18 percent secured this. But several commitments to the shareholders were made as well, such as an alteration of the company's charters in line with the Tabaksblat Code and an evaluation of the company's strategy by an external consultant. By November 2006, an extraordinary annual general meeting would be organized to discuss these matters.

The May 2006 annual general meeting had shocked the Supervisory Board. ${ }^{213}$ As Van den Hoek noted in an evaluative memorandum:

209 ASM International, 'Verslag Algemene Vergadering van Aandeelhouders ASM International N.V., 18 mei 2006’ (date unknown) Arcchive Arthur del Prado-AVA file.

210 The characterization followed from external consultant for investor relations, Mary-Jo Dieckhaus. - Stibbe, Paul van den Hoek, 'Memorandum to RvC and RvB: ASMI; Hoe nu verder?' (12-6-2006) Archive Arthur del Prado - RvC 2006 file.

211 ASM nominated one candidate versus one dummy candidate, while its statutes only allowed a dismissal of the whole nomination by two-thirds or more of the votes. This conflicted with the Tabaksblat Code, which advocated a policy during which a candidate could be nominated by a simple majority of votes. - ASM International, 'Verslag Algemene Vergadering van Aandeelhouders ASM International N.V., 18 mei 2006' (date unknown) Archive Arthur del Prado - AVA file.

212 ASMI, Erik Kamerbeek, 'Letter to Mellon HBV Alternative Strategies UK, attn: Cor Timmermans' (26-4-2006) Archive Arthur del Prado - Mellon file.

213 Stibbe, Paul van den Hoek, 'Memorandum to RvC and RvB: ASMI; Hoe nu verder?' (12-6- 
'What did surprise me and stick to me most, was the lack of confidence in the management of the company, shown by the attending shareholders. I expected criticism, but also support. Not once did a shareholder take a stand for our position. ... The conclusion thrusts itself upon us that management unrealistically assessed feelings and actions of the shareholders, and, as a result, misinterpreted their viewpoints. Whatever shareholders tell us during an informal meeting over a cup of tea seems to be irrelevant whenever they do not turn out at the annual meeting and support the policies of the management and Supervisory Board. Active mobilization of these shareholders is a priority.'214

In particular, the capabilities and professionalism of the Supervisory Board had been questioned. The meeting left the Supervisory Board divided. ${ }^{215}$ Some tended to agree with some of the criticism of the shareholders, while others propagated a thorough investigation of the actual situation by an external consultant. Arthur del Prado and the Board of Directors, by contrast, remained belligerent. The dispute changed. As CFO Naud van de Ven put it: "The strategy is and remains the responsibility of the management. Shareholders do not divest subsidiaries. ${ }^{216}$

ASM was not going to act on the plea for a revision of the company's strategy. Tasting blood, the activist shareholders, in their turn, became more resolute, steadily increasing their shares. Van den Hoek sought to find a compromise between the interests of the anxious Supervisory Board, the determined Del Prado, and the malcontented shareholders:

'ASM International's outstanding shares are $78 \%$ owned by outsiders, $22 \%$ is owned by the founder/CEO. This means that the Supervisory Board has to focus upon the interests of the enterprise and those involved - including primarily the shareholders - and observing the interests of the outside shareholders. The idea is that the $\mathrm{CEO} /$ majority shareholder can look after himself ... The Supervisory Board gained the trust during the AGM [Annual General Meeting] ... due to the votes of

2006) Archive Arthur del Prado - RvC 2006 file.

214 Original quote in Dutch. - Stibbe, Paul van den Hoek, 'Memorandum to RvC and RvB: ASMI; Hoe nu verder?' (12-6-2006) Archive Arthur del Prado - RvC 2006 file.

215 ASM International, 'Minutes Supervisory Board 23 June 2006' (28-7-2006) Archive Arthur del Prado-RvC 2006 file.

216 Original quote in Dutch. - Bert van Dijk en Pieter Elshout, 'Hedge fund ruikt zege in strijd om opsplitsing ASMI' Het Financieele Dagblad (28-9-2006) p. 1. 
the CEO - on which they are expected to supervise. This does not look pretty from a corporate governance point of view. ${ }^{217}$

In other words, ASM International's management and the Supervisory Board were walking a slippery slope.

For the extraordinary general meeting in November 2006, it was imperative to keep control over the outcomes and process. The Supervisory Board and the Board of Directors were determined to stop the discontent among the shareholders. Throughout the summer and fall, ASM International proceeded in an elaborate process of deliberation among its management and with its legal advisers, stakeholders such as works councils, and the shareholders. The outcome of this process seemed to apply the strategic classic of 'divide and rule' toward the activist shareholders.

By November 2006, ASM successfully gained support of the activist shareholder Hermes. ${ }^{218}$ By that time, Hermes had already obtained 9.9 percent of the shares. As Del Prado observed at a Supervisory Board meeting in that same month:

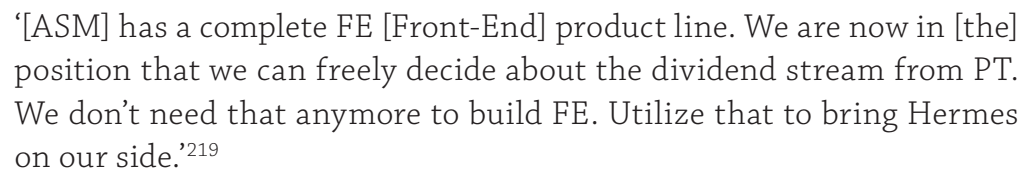

To pacify this shareholder, ASM promised no longer to use the dividends of ASM Pacific Technology to fund front-end. Instead, these profits would be used to the benefit of the shareholders. ${ }^{220}$ Either through buying back shares issued for convertible notes or - possibly in the future, and counter to ASM's prevailing policies - through ASM International dividends. In return, Hermes offered time to make front-end profitable again. Hermes - and Mellon - remained critical,

217 Original quote in Dutch. - Stibbe, Paul van den Hoek, 'Memorandum to RvC and RvB: ASMI; Hoe nu verder?' (12-6-2006) Archive Arthur del Prado - RvC 2006 file.

218 Bert van Dijk, 'ASMI verwerft de steun van grote belegger: Hermes tegen splitsing van bedrijf', Het Financieele Dagblad (25-11-2006) p. 11; ASMI, Board of Directors, 'Memorandum to Supervisory Board: Use of ASMPT Dividend' (8-3-2007) Archive Arthur del Prado - RvC 2007 file.

219 ASM International, 'Minutes of Supervisory Board 14 November 2006', (27-11-2006) Archive Arthur del Prado-RvC 2006 file.

220 Stibbe, Allard Metzelaar, 'Memorandum to ASM International Management Board and Supervisory Board: Distributions to Shareholders' (13-11-2006) Archive Arthur del Prado - AVA files. 
however, about compliance with the Tabaksblat Code regarding the nomination of new executives.

Together, the stakes of Hermes and Del Prado totaled 31 percent of the shares, sufficient to block any motion from Mellon, which owned 7.5 percent of the shares. Furthermore, Jeff Farni, an investor in ASM since the days of the 1982 Epsilon Limited Partnership who took up a firm position of 30 percent during ASM's 1993 equity crisis, flew in from Minnesota to voice his support for ASM International's strategy. ${ }^{221}$

The atmosphere at the extraordinary general meeting of ASM International in Zeist (near Utrecht) was tense, but there were no new surprises. ${ }^{222}$ Although shareholders articulated critical comments and questions, these did not further undermine the company's interests. Paul van den Hoek, and Arthur del Prado were much better prepared, and W.K. Lee presented his plans for ASM Pacific Technology. The Supervisory Board responded to the shareholders' request for more technological and industrially relevant expertise on the board by nominating and appointing several new members.

By the fall of 2006, ASM International seemed to have appeased most of the critics too some extent. The task of making front-end operations profitable again was clear and embraced by the Board of Directors without dissent. Similarly, the adjustments of charters and the new agreements about the usage of ASM Pacific Technology dividends were accepted and implemented. Moreover, in the weeks following the extraordinary meeting, Mellon was acquired by the Bank of New York, renamed Fursa Alternative Strategies, and was put under auspice of American authorities due to in-transparent practices. Anxiously, the Supervisory Board looked on, hoping it might tune down the assertive shareholder. In the meantime, members of the Supervisory Board and the Board of Directors continued to deliberate with representatives of both Hermes and Fursa. For the time being, divestment of ASM Pacific Technology was not an issue anymore.

\section{Finally leveraged innovation pays off}

During 2006, the prospects of ASM's front-end operations improved significantly. This followed from the downsizing of lagging development activities - like NuTool, Nanophotonics, and the Levitor. In particular activities in Asia contributed to

221 Mary Jo Dieckhaus, 'Interview with author'; Barbara Bier and Hajo Kraak, 'Proces Verbaal Buitengewone Algemene Vergadering van Aandeelhouders ASM International N.V held on November 26th, 2006.; ref: BB/6003889/440119.prv' (21-5-2007)Archive Arthur del PradoAVA file; Bert van Dijk, 'ASMI drukt belager in het nauw', Financieele Dagblad (28-11-2006).

222 Barbara Bier and Hajo Kraak, 'Proces Verbaal Buitengewone Algemene Vergadering van Aandeelhouders ASM International N.V held on November 26th, 2006.; ref: BB/6003889/440119.prv' (21-5-2007) Archive Arthur del Prado - AVA file; Bert van Dijk, 'ASMI drukt belager in het nauw', Financieele Dagblad (28-11-2006). 
this positive shift, involving the FEMS manufacturing operation, as well as a significant increase in sales to Taiwanese customers. Moreover, a merger of ASM Korea with ASM Genitech improved the strategic intent of ASM's activities in the lucrative South-Korean market. The first procurements of the Pulsar high-k ALD reactor by Intel provided an even greater boost. Finally, after seven years of investments, the first ALD product was about to be integrated into high-volume manufacturing product lines.

Based on prevailing customer interests and progression, a few tailing development efforts were downsized. Foremost this involved NuTool, whose staff members were nearly all laid off while its facility was closed in the spring. Nanophotonics, the German startup in integrated metrology, was also urged to clean up its act, by regaining control of its expenditures. Partially this was done by divesting several standalone technologies. In the Netherlands, at ASM Europe, the Levitor product group arrived at an either kill or cure stage. If its rapid thermal process reactor offered unique technology through its wafer levitation and unique carbon heating technique, it came quite late in a rather sated market. Efforts to sell the technology to a competitor named Mattson failed, after which the staff was reduced from 75 to 25 individuals. All efforts were directed at becoming at least break-even. Pending sales to Micron for a few evaluation tools and to AMD for high-volume manufacturing might just do that. ${ }^{223}$

It is clear, however, that ASM's Asian activities were crucial in tackling the company's front-end problem. A major boost was given by FEMS' higher productivity. The first A412 generic modules manufactured by FEMS had been accepted by the biggest customers. Throughout the same year, the Singaporean operation produced about sixty-five A412 furnaces, twenty A400 furnaces, twenty-two Epsilon 2000, and the first Epsilon 3200. All machines produced by FEMS were tested and customized by the respective business units, in this case ASM Europe for the furnaces and ASM America for the Epsilon reactors. With its growing output, FEMS contributed to healthier margins. Yet a lot still had to be improved, from maturing manufacturing practices, localizing and optimizing the supply chain, and manufacturing more of ASM products.

Between 2005 and 2007, most growth was achieved by ASM in Taiwan. While the Taiwanese semiconductor industry was known for its foundry business centering around TSMC and UMC - ASM primarily realized sales of its vertical furnaces to local memory manufacturers like Inotera, Nanya, WinBond, and Promos. These deals followed from ASM's A412 qualification at the German memory manufacturer Infineon (its DRAM operation was renamed Qimonda in mid-2006). Through license deals and joint-ventures, Infineon shared its

223 ASMI, Erik Kamerbeek, 'Minutes Supervisory Board 23 June 2006' (28-7-2006) Archive Arthur del Prado-RvC 2006. 
manufacturing technologies for DRAM chips, including ASM Europe's A412 furnace. Supplemented with minor sales of Eagle plasma CVD reactors and Polygon high-k clusters to TSMC, ASM's revenues increased from 53 million euros in 2004 to 85 million in 2006. ${ }^{224}$ By 2007, sales in Taiwan even surpassed those achieved in the United States, grossing 122 million euros.

Apart from the vertical furnaces, ASM International enforced its efforts to penetrate Asian memory manufacturers with its ALD technology. High-k dielectrics deposited through ALD had been used for a while in high-volume manufacturing in the memory industry. These materials were used as insulator in metal-insulator-metal capacitors. Initially, aluminum oxide was used for this purpose. But, according to ASM's leading ALD expert, 'any box can run aluminum oxide. ${ }^{.25}$ By 2005, new materials and better processes were developed for production. ASM wanted to capitalize on its lead in high-k gate dielectrics for logic chips and microprocessors (cf. Innovation IV) and the plasma enhanced ALD processes developed by ASM Genitech. The Korean subsidiary's process technology aimed specifically at developing capacitors in conjunction with the leading memory manufacturers, South Korea's Hynix and Samsung.

So far, ASM Genitech had only collaborated with Samsung in R\&D; no processes or equipment were used in production. ${ }^{226}$ As recalled by ASM Genitech's process engineer Yong Min Yoo:

'Actually, Samsung developed their high-k process with our tool. And, in their R\&D center, all their high-k processes they developed with our tool, and transferred that process to the [competitor's] tool. So, our tool worked for the process application, but the problem was productivity.'227

By April 2006, more effort was put into advancing ASM Genitech as original equipment manufacturer. To this end, the two Korean operations - ASM Korea and ASM Genitech - merged into ASM Genitech Korea. The merger meant that the ASM Korea sales office moved in with ASM Genitech. Now, ASM had a fullfledged Korean subsidiary commanding sales, service, manufacturing, and - most importantly - research and development. Moreover, all plasma enhanced ALD processes and knowledge could now be concentrated within the Korean operation.

In its reliance on a single technology, ASM's Korean operation joined the ranks of the company's operations in Japan, the Netherlands, and the United

224 ASMI, Annual Report 2007 (1-4-2008).

225 Suvi Haukka, 'Interview with author'.

226 ASM America, Glen Wilk, 'Memo:Genitech-Samsung JDP Status Update' (21-2-2005) Archive Arthur del Prado - Genitech file.

Yong Min Yoo, 'Interview with author'. 
States. As such, ASM Korea made it possible for ASM International adequately to address the size and intensity of the Korean market and Samsung in particular. The merger removed any prevailing doubts about ASM's sincerity toward Korean customers. The newly developed MIR3000 was specifically intended to offer a high throughput. ${ }^{22}$ In his unofficial role of ASM Genitech's godfather, Ivo Raaijmakers rejoiced at the progress of the Korean firm:

'We had manufacturing and development. That and the fact that we had just a marvelous team at ASM Genitech. That was one of the best teams within ASM, really! I was so proud. Those guys really progressed, unbelievable! There were simply very creative people, combining creativity with speed and sensitivity... It was incredible what they achieved. That attitude and the fact that they were a Korean knowledge firm, involved in Korean manufacturing, opened many doors at Samsung.'229

This new range of activities also required a new building. Its construction in Cheonan was to be completed by March 2007. After Inkyu Park retired as general manager of ASM Genitech, Sang Woo Go, a former employee of ASM Pacific Technology and Novellus, was appointed general manager of the new combined operation. Throughout 2006 and into 2007, ASM worked on revitalizing its Korean activities, an effort which in a few years' time would be paid back.

The imminent introduction of ASM International's ALD technology for the production of high-k gate dielectrics constituted a most welcome breakthrough. This process - equipment, chemistry, and material - was developed by ASM Microchemistry, ASM America, and ASM Belgium over the course of seven years. The replacement of silicon oxide by hafnium oxide as insulator in the transistor gate had been enjoying the particular interest of the industry for years.

By 2006, Intel led the industry in the integration of hafnium oxide into highvolume manufacturing, having an advance of approximately two years. For its forthcoming 45-nanometer computer chips, Intel procured ASM's Polygon 8300 wafer handler to which some Pulsar 3000 ALD reactors were connected. Between the fall of 2006 and that of 2007, Intel procured these Polygon combinations for its latest fabs.

After investing approximately one hundred million euros in the commercialization and industrialization of ALD, the Intel procurements offered

228 ASM International, Han Westendorp, 'ASM Front-End Product Portfolio Update-Q3, 2006' (27-10-2006) Archive Arthur del Prado - RvC 2006.

229 Original quote in Dutch. - Ivo Raaijmakers, 'Interview with author'. 
some timely financial relief. Up to that point, the interrelated 'Transistor and Capacitor Products' merely costed money. The only revenues were secured through some evaluative tools as well as minor sales of the Pulsar reactors to magnetic head producers in the hard disk drive industry. If these latter sales fell outside of the core business of the company, they were indispensable to limit its losses. The integration of the Polygon clusters at Intel marked the end of plodding. Moreover, the Polygon procurements showed that Del Prado's costly strategy of cultivating potential disruptive technologies paid off. ASM's ALD technology finally was ready for the market.

Another sign that the times were changing was the retirement of Patrick Lam as chief executive officer of ASM Pacific Technology in January 2007. Being deliberate and inquisitive, Lam oversaw and managed the growth of the company into the industry's biggest manufacturer of assembly and packaging equipment with revenues of 468 million euros over 2006. At his departure, Lam reflected on the reasons for his achievements, pointing out the importance of keeping a low profile in the industry and allowing the results to speak for themselves. ${ }^{230}$ Other strengths he recognized were the organic growth strategy, consistent profitability, and trust in the potential of the employees. Lam lauded Del Prado's autonomyoriented approach:

'I'd also like to express my gratitude to Arthur and ASMI, for ... your wise decision to give me a free hand to run ASMPT since the beginning. I would certainly say that the autonomy given to ASMPT's management is one of our success factors. ${ }^{231}$

Moreover, the 57-year-old industry veteran provided the following advice to the remaining managers of ASM Pacific Technology and ASM International:

'No company, no matter how well-managed, is immune to the challenges of its external environment and the changing shareholder demands.... as ASM has powered up its engine and headed towards deep water for the larger catch, we will inevitably be confronted with bigger waves. ${ }^{232}$

A company's ambitions, in other words, should not exceed its means. While ASM Pacific Technology always adhered to this tenet under Lam's management, the

230 ASM Pacific Technology, Patrick Lam, ‘Farewell Dinner Speech’ belzalel.hk [personal website Patrick Lam] (16-12-2006).

Ibid.

232 Ibid. 
same cannot be said of its parent company. In contrast to Lam, Arthur del Prado can hardly be called a humble entrepreneur. He rather enjoyed fishing in deeper, more turbulent waters. Why would ASM not be capable of appropriating the most prestigious and luring opportunities? This endearing confidence almost wrecked ASM in the late 1980s, which for Patrick Lam had always been a welllearned lesson.

Twenty years later, however, ASM International found itself again in a similar, risky situation. By pursuing and realizing disruptive innovations, the company had exposed itself too much to the unruly forces in its environment. Keeping control under such circumstances was rather difficult, as became apparent in the final years of Arthur del Prado's tenure as chief executive officer.

\section{A tumultuous retirement}

During the 2007 annual general meeting, the circumstances were favorable to actuate Arthur de Prado's succession, which had been in the pipeline since 2001. Most importantly, the revenues were very promising. In the first quarter, ASM's front-end operations achieved a net profit of 1.2 million euros, and the second quarter performance was better than predicted in the outlook. ${ }^{233}$ Moreover, ASM heeded its promise to share the dividends from ASM Pacific Technology with the shareholders. ${ }^{234}$ The most intractable activist shareholder Fursa - formerly known as Mellon - did not raise any new concerns, following its acquisition, American governmental oversight, and ASM's good results.

Just prior to the start of the 2007 Annual General Meeting, on May 22 at the Hilton Parc Hotel in Soestduinen, a press release was published announcing Chuck del Prado as chief executive officer as of March 1, 2008. ${ }^{235}$ During the meeting, the announcement was accepted by the attending shareholders. Based on his personal merits as manager, the Supervisory Board unanimously selected Chuck del Prado as successor of Arthur del Prado. Remarkably, Fursa did not attend the annual general meeting, and consequently did not challenge or question the succession. Also Hermes kept a low profile. The meeting proceeded rather smoothly, suggesting an end to the turbulence involving activist shareholders demanding a say in the strategy and the company's future. Aside from the

233 ASMI, Board of Directors, 'ASMI - Financial Progress Report [to Supervisory Board] Q12007' (2-5-2007) Archive Arthur del Prado - RvC 2007 file.

234 In this year, ASM had two convertible notes standing. One of 90 million dollars, due for 2010, and another of 150 million dollars due December 2011. - ASMI, Board of Directors, 'Memorandum to Supervisory Board: Use of ASMPT Dividend' (8-3-2007) Archive Arthur del Prado-RvC 2007 file.

235 Manon Cremers, 'Proces-Verbaal Algemene Vergadering van Aandeelhouders ASM International, ref: DMO/6003889/487004.prv' (27-11-2007) Archive Arthur del Prado - AVA file. 
announced leadership change, the meeting reflected an atmosphere of business as usual again.

Or so it seemed. In reality, the activist shareholders were sharpening their knives. Just a few weeks after the meeting, on June 14, 2007, Fursa reignited its efforts to alter the strategy of ASM International, hoping to enforce higher returns on their investments. The hedge fund, owning 9.1 percent of ASM's stock, sent a letter to ASM's management and Supervisory Board. ${ }^{236}$ Fursa disputed the company's compliance with corporate governance. This entailed in particular the ability of shareholders to influence the succession and composition of the management board. The sudden announcement of Chuck del Prado as new chief executive officer merely was grist to their mill. The shareholder wondered whether family ties had determined the nomination of Arthur del Prado's son as successor, and if so, it would be a grave violation of corporate governance.

Over the course of the year, the doubt about Chuck del Prado's nomination became the pivot of the hedge fund's efforts to influence ASM International's strategy, i.e. enforcing a divestment of ASM Pacific Technology or liquidation of the company's front-end operations. The hedge fund was in for a penny, in for a pound. Fursa would not let go easily. As ASM failed to remove the objections of Fursa, Hermes raised its criticism again as well. The armistice was over, and Arthur del Prado's retirement - or Chuck del Prado's start as chief executive officer - would be marked by the dispute.

In December 2007, Fursa assembled a 'team of experts' and presented them as alternative management for ASM International. ${ }^{237}$ The team of experts consisted of former Applied Materials executives Farhad Moghadam, David Wang, Nick Miller, and Sam Ishii - all respected and reputable managers in the semiconductor equipment industry. ${ }^{238}$ With this move, the hedge fund implicitly dismissed the argument of the Supervisory Board that talented managers in the semiconductor equipment industry were hard to find. Moreover, by presenting the team Fursa posed an alternative strategy: not one of leveraged disruptive innovations but one of sustaining the businesses in place to the benefit of the shareholders.

Publicly, but also during meetings with the ASM Management and Supervisory Board, Moghadam et al. presented their alternative appreciation

${ }^{236}$ Fursa Alternative Strategies, William Harley, 'Letter to the Management Board and Supervisory Board of ASM International' (14-6-2007) Archive Arthur del Prado - RvC 2007 file.

237 Joost van Mierlo, 'Arthur del Prado mag verdienen aan zijn aandeelhouders', Het Financieele Dagblad (19-12-2007) p. 7.

238 For instance, David Wang was one of the engineers who joined Applied Materials from Bell Labs in 1981. He was pivotal in developing Applied Materials' plasma etch technology, based on their experience gained at Bell Labs (cf. Business II). Moghadam worked at Intel and Applied Materials. 
and strategy for ASM International. ${ }^{239}$ Moghadam assessed that ASM's margins were too low, there was too much dependency on one customer (Intel), and big market penetration was too limited. He and his colleagues also summed up all the technological issues with ASM's products based on information from their network at Applied Materials. Having listened to Moghadam, Arthur del Prado responded to the uninvited and even hostile assessment of his company rather sarcastically: '[It] is amazing how much information can be gathered by a group of outside experts. ${ }^{240}$

Naturally, Del Prado was referring to the big elephant in the room: Applied Materials and the unclarified involvement of ASM's major competitor in Fursa's ploy. It was obvious that the operational details in Moghadam's assessment did not originate from Fursa. It was very much possible that Applied Materials tried to gain backdoor access to ASM's technologies and products by collaborating with Fursa.

In the run-up to the 2008 annual general meeting of May 21, the intentions of the activist shareholders became crystal-clear. Fursa demanded a vote during the meeting on the proposal to reject ASM's leadership and replace it with Morghadam et al. This way, Fursa, with support from Hermes, hoped to gain control over the company. ${ }^{241}$ Moreover, another hedge fund by the name of Centaurus joined the party, taking 7.2 percent of the shares. Together, the activist shareholders owned 32.2 percent of the stock, against Arthur del Prado's 21 percent. ${ }^{242}$

On his way to retirement - though he refused to call it that way - Del Prado focused on limiting the impact of Fursa's and Hermes' maneuvers. The 'Stichting Continuïteit ASM International' (Foundation for Continuity of ASM International) was mobilized. ${ }^{243}$ This foundation was a Dutch ring fence to prevent hostile take-overs. Incorporated in 1997, the Foundation could exercise an option on preference shares. It was a remedy of last resort, because such a call option

239 ASM International, Erik Kamerbeek, 'Minutes meeting between industry experts and Management Board and representatives of Supervisory Board, 10 January 2008 in Bilthoven' (1-2-2008) Archive Arthur del Prado - RvC 2008 file.

240 Ibid.

241 A 13-D SEC filing revealed these intentions of Fursa. - Stibbe, A.C. Metzelaar, 'Memorandum: Status Quo and Issues re Fursa (and others?)' (1-2-2008) Archive Arthur del Prado - RvC 2008.

242 Editors, 'Reorganisatie bij geplaagde divisie ASMI', NRC Handelsblad (28-4-2008) p. 13.

243 This involved making the Foundation independent from ASM's management. Del Prado and Van den Hoek retired as board members of the Foundation. Also, the charters of the Foundation were changed. - Stibbe, A.C. Metzelaar, 'Memorandum: Stichting Continuïteit ASM International' (10-1-2008) Archive Arthur del Prado - RvC 2008; Ivo Bökkerink Pieter Couwenbergh, and Joost van Mierlo, 'Stichting frustreert compromisvoorstel van ASM', Financieele Dagblad (20-5-2008) p. 19. 
most probably would result in litigation about the lawfulness of the Foundation's intervention. Foremost, the Foundation would be able to buy time. ${ }^{244}$

After presenting the fourth quarter results of 2007 to the company's investors, Del Prado retired. He remained Chairman of ASM Pacific Technology until 2016, and obviously retained his 21 percent stake in the company. In his final year, ASM achieved a record 955 million euros in revenues and 147 million euros in profits. ${ }^{245}$ By the fall of 2007 , the progress of the front-end operations stagnated, resulting in a slight loss of 500,000 euros. Although disappointing, it constituted a significant improvement compared to the loss of 7.1 million euros in 2006 and the loss of 25.4 million euros in 2005. From March 1, 2008, it was up to Chuck del Prado to continue the positive trend and address the concerns of the shareholders.

\section{Epilogue}

The final years of Arthur del Prado's tenure as chief executive officer were characterized by the strategy of leveraging existing businesses to realize new disruptive know-how and equipment, in order to find a balance between sustaining and disruptive technologies. Del Prado had always explored the limits of what was possible through this strategy, while the Supervisory Board constantly urged for moderation. Driven by their pursuit of short-term returns and empowered by new corporate governance regulations, activist shareholders disputed the effectiveness of the balancing act all together. With Arthur del Prado's retirement, the impasse between Management Board, Supervisory Board, and shareholders had not been resolved yet. Even more, over the course of the next years, the dispute about the strategy was carried to extremes - at great personal cost of those involved, Chuck del Prado in particular.

As of March 1, 2008, the new chief executive officer was in danger of being swallowed up by wider and fast progressing developments - such as the pursuit of a more sustainable strategy, the enactment of corporate governance, and an equilibration of power between ASM's management board, Supervisory Board and shareholders following Arthur del Prado's retirement. In the run-up to the 2008 annual general meeting on May 21, Fursa and Hermes forged an alliance among shareholders to catapult Morghadam et al. as replacement of Chuck del Prado. As the chief executive officer observed:

'As the 'son of', you got to prove yourself three times more than usual. I am just two months Chief Executive Officer, and our shareholders

Stibbe, A.C. Metzelaar, 'Memorandum: Stichting Continuïteit ASM International' (10-12008) Archive Arthur del Prado - RvC 2008. 
already prepared a successor. ... Apparently, the changes are not progressing fast enough. ${ }^{246}$

At the final moment, Fursa and Hermes' coup was prevented by an intervention of the Foundation (Stiching Continuïteit ASM International), thwarting Chuck del Prado's own efforts to gain the shareholders' trust, and resulting in an eighthour court session on the evening before the annual general meeting. Fursa and Hermes' suit to force a vote about purported mismanagement of ASM was deferred by the Dutch Commercial Court. ${ }^{247}$ During the 2008 annual general meeting - with Moghadam anxiously waiting in a side-room to be called in Fursa and Hermes' ploy collapsed. Chuck del Prado remained chief executive officer. All that was left for the shareholders was to not grant Arthur del Prado a discharge over his management in 2007 - a symbolic dig, since the entrepreneur was no longer in charge. ${ }^{248}$ In the following months, the failed coup and efforts to solve the dispute were overshadowed by a formal offer for ASM's front-end activities by Applied Materials. Chuck del Prado was not granted any respite to secure his authority and control.

These events and the ensuing high-stake and Shakespearean affairs happened beyond the reach of this study, which is confined to Arthur del Prado's tenure as chief executive officer at ASM International. Beyond March 1, 2008, I do not have access to primary sources, implying that I can merely rely on new articles and informal conversations with those involved. These sources do not allow me to reconstruct the remaining events in the manner done throughout this study . Moreover, the events surrounding corporate governance in the period between 2006 until 2013 - the power play between shareholders and management -

246 Original quote. - Editor, 'Chuck del Prado wil nog niet opgeven: ASMI Dynastie wankelt', Dagblad de Pers (29-4-2008) p. 3.

247 The Commercial Court forbids the addition of a new item to the agenda of the annual general meeting of the next day involving the composition of boards. Through this item, the activist shareholders had intended to oust Chuck del Prado. Instead, the Judge decided that the parties had to settle their dispute in one month. - Ivo Bökkerink and Pieter Couwenbergh, 'ASMI komt met extreme maatregel tegen activistische aandeelhouders en ziet Ondernemingskamer opdoemen.', Financieele Dagblad (15-5-2008) p. 27; Editors, 'Stichting ASMI trekt beschermingswal op', De Telegraaf (15-5-2008) p. 27; Ivo Bökkerink Pieter Couwenbergh, and Joost van Mierlo, 'Stichting frustreert compromisvoorstel van ASM', Finanieele Dagblad (20-5-2008) p. 19; Gerechtshof Amsterdam, Ondernemingskamer, 'Hermes Focus Assset, Fursa versus ASM International, zaaknummer: 200.005.940/1 OK; ECLI: GHAMS:2008:BD2197’ (21-5-2008).

248 Loyens \& Loeff, Rudolf van Bork, 'Akte houdende proces verbaal van vergadering van ASM International, gehouden op 21 mei 2008 te Hilton Hotel Royal Parc te Soestduinen' (15-102008), Archive Arthur del Prado - AVA file. 
would require in-depth historical research, in order to distinguish, represent, and analyze structural and fortuitous events.

Of course, I cannot leave the reader with an altogether open-ended story. I will therefore limit myself here to three observations about the period following Arthur del Prado's retirement. The first two shed light on the dispute between management and shareholders involving ASM's strategy of leveraged innovation. The final observation reflects on the context in which Chuck del Prado became chief executive officer. This third observation also constitutes a prelude to this study's Epilogue, in which I briefly describe the most recent episode in the history of ASM International, the years between 2008 and 2018.

My first observation pertains to the recognition and appreciation of ASM's front-end activities, as well as, implicitly, all the new activities engaged in by the company in the period since 1999. In June 2008, Applied Materials made an offer for ASM's ALD and plasma CVD activities and, later on, one for all of the company's front-end. ${ }^{249}$ From June until November 2008, Applied Materials and ASM negotiated until a severe economic downturn thwarted the effort, evaporating cash reserves of Applied Materials, neutralizing Fursa as activist shareholder, and reversing ASM front-end's precarious road to profitability. The sum of 800 million dollars, or 475 million euros, proposed by Applied Materials numbed purported doubts about the viability of the new technologies pursued by Arthur del Prado and ASM front-end as a whole. Indisputably, the strategy of leveraged innovation did not center around a few hobby-horses: real commercially valuable technologies were developed. ${ }^{250}$

The second observation relates to an equilibration of the balance of power between the Management Board, the Supervisory Board, and the shareholders and the resulting influence of these actors on the company's strategy. Surrounding Del Prado's retirement and following from new corporate governance regulations,

249 The initial offer was about 256 to 320 million euros, or about 450 million dollars. Chuck del Prado communicated that negotiations could only start if Applied Materials made an offer for the front-end operations as a whole. Cherry-picking would not be tolerated. A month later, Applied Materials, together with private equity firm Francisco Partners, followed through. In the media it was suggested that Del Prado had stimulated an offer by Applied Materials in order to get a true valuation of front-end beyond the daily stock valuation - Pieter Couwenbergh and Joost van Mierlo, 'Del Prado sprak eerder met Applied', Het Financieele Dagblad (19-6-2008) p. 17; Editor, 'Applied roept hulp private equity in bij slag om ASMI', Het Financieele Dagblad (18-6-2008) p. 1; Pieter Couwenbergh and Joost van Mierlo, 'ASMI houdt rechter even buiten de deur', Het Financieele Dagblad (23-6-2008) p. 1; Pieter Couwenbergh and Joost van Mierlo, 'Shakespearedrama by ASM International', Het Financieele Dagblad (16-4-2009) p. 17; Editor, 'Concurrent wil ASMI’s technologie overnemen', NRC Handelsblad (6-6-2008) p. 13.

250 Moreover, by June 2009, Intel took a stake in ASM International in support of its ALD technology. - Pieter Couwenbergh, 'Intel wil zelfstandig ASMI 'zeker stellen' met nemen van belang', Het Financieele Dagblad (12-6-2009) p. 13. 
the Supervisory Board professionalized and obtained a more prominent position in the company's affairs. The dispute between shareholders and ASM's management on the former's say about the company's strategy escalated via the Dutch Commercial Court to the Dutch Supreme Court, where, in 2010, and during successive appeals in 2012, the judges dismissed all claims of the activist shareholders. ${ }^{251}$ The verdict read:

'Therefore, by principle, the strategy to be pursued by ASMI is an affair of the management, and it is up to the management, under supervision of the Supervisory Board, to assess if and to what extent it is desirable to confer with external shareholders. ... [The] statutory responsibility [of the Supervisory Board] does not entail that the Supervisory Board has to act as arbitrator during conflicts between management and shareholders. On that subject, the Supervisory Board is also not accountable. ${ }^{252}$

This verdict clarified unresolved issues in Dutch corporate governance. The question of whether to pursue a strategy of leveraged innovation resided with ASM, not with the shareholders.

Finally a third observation on the tumultuous succession of Arthur del Prado by Chuck del Prado, which indicated the dawn of a new period in the company's history. Chuck del Prado succeeded his father, but did not inherit his father's authority among the Supervisory Board, shareholders, and industry. The new chief executive officer inhabited a totally different playing field. Throughout his twenty-year career path in the semiconductor industry, Chuck del Prado operated in a highly structured and matured industry. By contrast, Arthur del Prado personally contributed to the industry's development from its inception and into the $21^{\text {st }}$ century. The open-ended, unobvious, and sanguine realities that the illustrious entrepreneur encountered at the beginning of his career

251 The Dutch Commercial Court decided that external shareholders lacked influence on the company's strategy and corporate governance. This conclusion was refuted by the Supreme Court on July 9, 2010. Pieter Couwenbergh, 'Hoge Raad ziet geen rol commissaris bij conflict', Het Financieele Dagblad (10-7-2010) p. 1; Gerechtshof Amsterdam, Ondernemingskamer, 'Hermes, Fursa, en VEB versus ASM International, Stichting Continuïteit ASM International, Ondernemingsraad ASM Europe en Arthur del Prado. Zaaknummer: 200.005.940; ECLI:NL:GHAMS:2009:BJ4688' (6-8-2009); Hoge Raad, Eerste Kamer 'Cassatie Stichting Continuïteit ASM International versus Hermes, Fursa, VEB, ASM International, Ondernemingsraad ASM Europe en Arthur del Prado. Zaaknummer: 09/4465 en 09/04512; ECLI:NL:HR:2010:BM0976’ (9-7-2010); Hoge Raad, Eerste Kamer, 'Cassatie van Hermes, Fursa en VEB versus ASM International, Stichting Continuïteit ASM International, Ondernemingsraad ASM Europe en Arthur del Prado. Zaaknummer: 11/03182; ECLI:NL:HR:2012:BV1435' (30-3-2012).

252 Original quote in Dutch. - Hoge Raad, Eerste Kamer 'Cassatie Stichting Continuïteit ASM International versus Hermes, Fursa, VEB, ASM International’ (9-7-2010). 
resonated in his perception and understanding of the industry as well as his company. Chuck del Prado had no option but to match the template of a chief executive officer, complying with 21st-century corporate governance regulations. He entered a leadership position that from the very start and in many respects was a straitjacket of all sorts of regulations, making it much more difficult for him to pursue disruptive innovation - if he wanted to do so at all. 


\section{Conclusions}

Arthur del Prado's final years as chief executive officer at ASM International were marked - more than earlier periods, perhaps - by the cardiac cycle: between contraction and expansion, and between sustaining and disrupting innovations. In these conclusions, I highlight two of such dynamics, before analyzing the developments through the elements of path, fortuna and virtù.

The first cardiac cycle involved, on the one hand, flourishing incumbent product lines, and, on the other hand, cash-draining new investments in front-end. Most operations that contributed to ASM International's surviving the internal equity crisis of the early 1990s continued to excel into the $21^{\text {st }}$ century. Revenues grew from 414.5 million euros in 1999 to 955.2 million in 2007, while slightly dropping to 747.4 million in 2008 (cf. figure 89 in Chapter 32). In particular ASM Pacific Technology soared, becoming the biggest semiconductor assembly and packaging equipment supplier globally in 2002 - and maintaining that position for years. The most successful front-end product was the vertical furnace - the A400 and its 300-millimeter version, the A412 - grossing about 1.25 billion dollars in revenues from 1999 to 2008 (cf. figure 90 in Chapter 32). Epitaxy earned the company some 969 million dollars and ASM Japan's single wafer plasma CVD reactors amounting to 917 million dollars. Furthermore, ASM America's 300-millimeter Epsilon epitaxial reactor obtained more than 80 percent of the worldwide sales in epitaxial equipment in 2005, while encompassing half of the global annual sales in the preceding and successive years ${ }^{253}$

Yet the investments in new technologies in combination with low profit margins of the incumbent products negatively affected the company's balance. Across front-end and back-end, investments in research \& development grew from 47.1 million euros in 1999 to 83.5 million in 2007 - or, cumulatively, a total of 721 million euros (figure 93). Furthermore, ASM International acquired new operations for approximately 70 million euros, including Microchemistry, Genitech, and NuTool. ${ }^{254}$ Apart from the take-over, these activities also required

253 In 2005, ASM sold for 141 million dollars in Epitaxial equipment in a market totaling 172 million dollars. Data based on ASM International archive and Gartner market data in Arthur del Prado's archive.

254 This involved 3.9 million euros for ASM Microchemistry, 407 thousand and another round of 1.1 million euros for Nanophotonics, 7.94 million euros for Genitech, and up to the 35 million in 2003 plus 20.3 million euros in 2001 and another 1.23 million in 2003 for NuTool - the sum total being 69.88 million euros. 
additional investments for product development. In the years covered in Business V, ASM's front-end activities were profitable only in 2000, while 2005 represented the ultimate low with a loss of 91 million euros.

\section{Figure 93}

Graph of ASM International R\&D expenditures and issued patents, 2000-2008

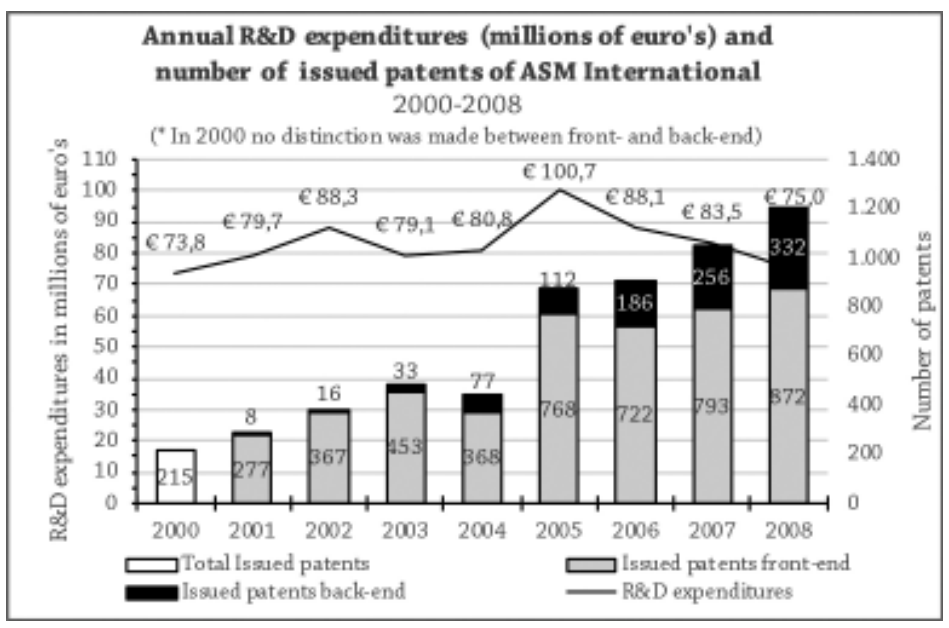

The second cardiac cycle pertained to the cost base of ASM's products and operations. In this cycle, spiraling demand during the Dotcom Boom undid operational consolidation efforts. Operation Merio was annulled, as the manufacturing of epitaxial reactors was transferred back from the Netherlands to Phoenix. This move and the expansions of the manufacturing capacity in Japan and the Netherlands increased operational costs. Contraction followed in the form of the Singaporean manufacturing operation FEMS, aside from regular reorganizations. FEMS was effective as a structural solution to solve the problem of low margins, even though it would take time before its impact was felt.

\section{Path}

Like in the previous chapters, I reflect on regularities in ASM's business history through the element 'path'. The most striking structural aspect of ASM International during the first years of the new millennium formed its handling of opportunities for expansion and need for contraction. Sustaining revenues and profits and limiting the drainage via disruptive technologies became a major concern for the company.

At first sight, the equipment manufacturer's strategy of leveraged innovation seemed to have much ground in common with the contemporary ideas of 
management scholar Clayton Christensen. Dedicated business units could pursuit new or small markets by means of 'disruptive technologies' without burdening - or being exposed to - the ongoing business of the enterprise. Within ASM's strategy, and quite in line with Christensen argument of compartmentalization, revenues and profits on one side were leveraged to enable new business on the other side.

Yet, other than management scholar Christensen's predication, ASM had not balanced sustaining and disruptive technologies. Ultimately, the strategy of leveraging disruptive innovation jeopardized the survival of the company. The level of profits earned could not justify the level of innovation. The accumulative weight of the disruptive innovations dragged down the enterprise as a whole.

After all, ASM was not an incumbent multi-divisional enterprise - like presumed in Christensen's strategy. After the derailing 1990s, ASM was thrown back in the rankings of semiconductor equipment manufacturers. Even its 'old' product groups - epitaxy, vertical furnaces and plasma deposition - were relative newcomers to their respective markets (cf. figure 92 in Chapter 32). Their 'newness' was further aggravated by the new 300-millimeter wafer standard, which constituted a complete new market in its own right.

Thus even ASM's 'sustaining technologies' still inclined toward disruption. In particular this accounted for the products procured by Intel. The epitaxial, vertical and plasma machines entered the industry primarily via industry leaders such as Intel and IBM, enabling new processes like strained silicon and low-k. These new processes were new markets as well. Only after these customers integrated the various products in its high-volume manufacturing lines in the period 2001 to 2003 did the products comply with Christensen's definition of sustaining technology - in particular after other chip manufacturers turned to these ASM products successively.

By the end of Del Prado's tenure as chief executive officer, his innovation strategy that prevailed for decades crumbled under external and internal forces. The external pressure came from the shareholders of ASM International. In contrast to the late 1980s, shareholders, rather than the banks, questioned the strategy of leveraged innovation. ASM structurally under-performed compared to its peers, not technologically but financially. Internally, Del Prado's innovation strategy suffered a major blow by the restructuring of NuTool in 2006. The investments and acquisitions of this Californian operation were misplaced and exposed lack of oversight of and trust in the business units.

The compartmentalization in decentral and segregated business units, as advocated by Christensen and being an integral part of ASM's business strategy for decades, had not prevented a failure of the company's strategy. This time, however, the decentral structure had not thwarted the clout of the management 
office. Instead, the combination of decentral businesses formed the problem. Looking at Christensen's principles for disruptive innovation, ASM's candor had been enabled by its investment in too many small markets at the same time. Moreover, since all these small markets were new, the company could not rely upon adequate market information. Like in the 1980s, ASM had betted on the come too much. At the end of his career, Del Prado's strategy was found wanting.

\section{Fortuna}

Of course, the role of fortuna - the unforeseen - also informed the overall pattern of expansion and contraction in economic opportunity throughout the years covered in Business V. Fortuna manifested itself in six ways, which coincided with an economic, competitive, customer, personal, organizational, and investor level of analysis. A seventh example stood out from the others, as it formed a true Machiavellian Moment.

The economic dynamic involved the inflation and deflation of the Dotcom bubble, as well as the unpredictable pace of recovery in subsequent years. If this development could hardly be influenced by ASM International, it certainly had a strong impact on the company. Finally, the 2007 'credit crunch' set the tone for the finale of Arthur Del Prado's tenure, albeit indirectly: the rapidly escalating financial crisis undermined his clout, in particular regarding critical opposition to his way of running 'his' company.

The second group of fortuna entailed competitive events or opportunities. A prime example was the meeting of Ernst Granneman with the Finnish businessmen, resulting in the acquisition of Microchemistry and the projection of ASM as pioneer in ALD. But also, the third-party offer to acquire NuTool - in the fall of 2003 - accounts for this category of fortuna. In both cases, ASM felt it had to act if it was to outplay the competition. The risk of being sidelined outweighed the technological and business risks involved in acquiring Microchemistry and NuTool. By contrast, ASM's interest in Nanophotonic and Genitech was much more deliberate and in line with the company's developmental trajectory.

Thirdly, ASM's interaction with its leading customer Intel constituted another category of fortuna. Demanding customers like Intel and IBM significantly affected not only ASM's performance, but also its technological development and organizational procedures. Even amidst the well-defined demands and their close collaboration, much was left open for interpretation, such as the timing of orders. ASM was overly exposed to the whims of these industry leaders.

The fourth manifestation of fortuna was personal, involving Del Prado's heart attack in 2000. Although this incident was not disruptive for the company at that moment, it instigated preparations for succession. After all, even Del Prado had to be succeeded at some point. The procedure surrounding the change of 
leadership certainly tested the relationship between the Supervisory Board, Arthur Del Prado, and ASM's shareholders.

The fifth fortuna was organizational. It entailed the technological and subsequently commercial failure of ASM NuTool. Its Electro-Chemical Mechanical Deposition fall short of its promises. Arthur del Prado had been too well-disposed, his judgement clouded.

The sixth category of fortuna confronting ASM involved its investors. This specifically pertained to the upgrading of corporate governance by the authorities of respectively the Netherlands and the United States. These decisions lay beyond ASM's control, yet paved the way for more assertive shareholders. Hedge fund Mellon's purchase of its first 1 percent of stock in the fall of 2005 belongs within this category as well, forming another manifestation of fortuna. A publicly listed company does not have the luxury to select its shareholders. Although one can argue that Mellon merely tried to profit from ASM's sloppiness regarding corporate governance regulations and increased empowerment of shareholders, this would be - I believe - too normative a view. The December 2005 letter of Mellon took the Supervisory Board by surprise, bringing the matter of splitting up ASM International to the fore after years of slumbering. This action deprived Arthur del Prado and the Supervisory Board from their illusion of inviolability and raised the issue of compliance with corporate governance, while also shaking Del Prado's and ASM's long-time business strategy.

And finally, the seventh fortuna in Business $\mathrm{V}$, followed from the sequence of events involving shareholders and later Applied Materials trying to split ASM International. Although these developments were rooted in the company's deliberate strategy of leveraged innovations, the events as such posed an existential threat to ASM. The company's survival was at stake. After divestment of ASM Pacific Technology - as propagated by the activist shareholders - frontend would be a prey for acquisitive competition, if not at all nonviable. Amidst this Machiavellian Moment, the internal organizational structural became fluid: the Supervisory Board gained the initiative over Arthur del Prado, who moved aside.

Overall, fortuna once more constituted a defining force of change in ASM International's history. The levels at which fortuna manifested itself aligned with the events described in the previous Business chapters. This is even true for the Machiavellian Moment. Just like in the late 1980s and early 1990s, the company's stakeholders challenged the strategy of leveraged innovation and forced its management to make choices. But this time these stakeholders were the company's owners and not its bankers.

All in all, one category of fortuna stood out from the others. This involved the failure of ASM NuTool. For the first time in the company's history, fortuna 
manifested itself within the organization. It was something which did not ought to happen, and which could only be explained by Arthur del Prado's trust in ASM NuTool's manager Homayoun Talieh. As such, the event was indicative for a new phase in ASM International's history. Del Prado's old ways of running the business - vindication of decentral autonomy of subsidiaries and overruling alternate views from his corporate executives - had expired. It was the final straw.

\section{Virtù}

These conclusions conclude with an analysis of responses to the unexpected and derailing events described above. In other words, who displayed virtù in the face of fortuna, and how? I will start with the 'who', followed by the 'how' and end with a reflection on the role of virtù.

Initially the executives working at the headquarters of ASM International, meaning the staff of Arthur del Prado, showed virtù. Specifically this pertains to the company's chief technology officer, chief operating officer, chief financial officer, etcetera. In Business $\mathrm{V}$, virtù finally moved away from the business units toward the headquarters. Opportunities were still recognized by the respective subsidiaries, yet decisions were made only after approval from the corporate management.

But the displacement of virtù did not stop there. Also within the headquarters, virtù moved from the executive toward the non-executive directors. The Supervisory Board gained clout throughout the first decade of the new millennium. With the demise of Arthur del Prado's influence as chief executive officer and major shareholder, decisions had to be approved by this organ instead of by Arthur del Prado. The Supervisory Board became the key actor in the company's chain of command.

Turning to the question of how virtù was displayed, it is clear that virtù was shown among the executive directors in the incorporation of new opportunities during the Dotcom Boom. With zest ASM embroidered upon the new technological and commercial opportunities following the acquisition of Microchemistry and the ALD process knowledge. In the same period, the executives' virtù involved the timely restructuring of ASM's cumbersome debt. Clearly, the management team of ASM International did not let the grass grow under their feet.

A similar vigor was apparent during the acquisition of Nutool in the fall of 2003 and the spring of 2004. Just like the Finnish case, the opportunity was unexpected but urgent, as there were plenty of competitors. The industrial potential was enormous, even though NuTool's copper technology fell outside of ASM's area of expertise in CVD and ALD processes. Del Prado's experience in acquiring, integrating, and nurturing such technological startups within ASM 
International, in combination with his personal charisma and authority within the firm, tilted the balance in favor of the acquisition.

The displacement of virtù from executive to non-executive directors followed from the context of economic stagnation, a dominant customer and changes amidst the company's owners. After the Dotcom Boom burst, predictability and process were rewarded, which restrained virtù. Initially this followed from the dominance of Intel as customer. The industry leader - technologically and in sales - could not permit its equipment vendor's virtù to interfere in its costly chip factories. ASM's relationship with such customers was defined by technological development, risk evasion and efforts to prevent surprises. Because of its increasingly structured nature, this had little to do with virtù anymore.

Next to demanding customers, the ASM Supervisory Board became a force to structure the company's actions, limiting virtù. As Del Prado's shareholding decreased, the Supervisory Board saw more ways to impress its pursuit for structure and processes. The activist shareholders' appearance on stage did not leave much room for improvisation either, and reinforced the Supervisory Board's pursuit. Any bluff, improvisation, or display of uncertainty was exposed and disputed by shareholders in the annual general meetings. Operating in such a playing field grated with Del Prado's business skills. Supervisory Board chairman Paul van den Hoek needed all his legal intuition, skills, and talent - also virtù, if much more restrained.

With Del Prado's simultaneous retirement and succession procedure, the ball was in the court of the emboldened shareholders' - and thus, as internal representative of their interests, also in that of the Supervisory Board. The shareholders' rejection of ASM International's strategy over 2007 - Arthur del Prado's final year as chief executive officer - during the 2008 Annual General Meeting was telling. The old ways had been weighed and found wanting. As a much more mature industry, business, and corporate governance took over, the impetuousness of ASM International had to subside.

Arthur del Prado's guiding principles of virtù had become an anachronism. These principles involved a decentralized structure, the commercial and technological self-reliance of the business units, and the trust in the business units' entrepreneurial and technological inventiveness. All of which had been proven stimuli for the incubation of new business opportunities and the growth of ASM international. Unfortunately, as it turned out, these doctrines no longer fitted the times. Under pressure of demanding customers, activist shareholders, and an empowered Supervisory Board impulsive entrepreneurial excesses could no longer be allowed. Virtù, in other words, was reined in. 


\section{Epilogue, \\ 2008-2018}




\section{Epilogue}

The start of Chuck del Prado in March 2008 as new chief executive officer (CEO) of ASM International was all but easy. At the time, activist shareholders caused discord among the company's management and cut the ground underneath the new leader. Adding fuel to the fire, fierce competitor Applied Materials made an offer to acquire ASM's promising atomic layer deposition (ALD) technology three months after the new chief executive officer took office. Even worse, the semiconductor industry had to face a financial crisis spiraling out of control, plunging the subjected equipment sector into one of its most dramatic recessions by 2009. This premise offered little confidence in a prolific outlook of ASM and its management.

But such a flourishing future was exactly what was in store for the company and Chuck del Prado. Despite the odds and after a tumultuous and humbling start, he succeeded in straightening major organizational deficiencies that had hampered ASM International for decades. Furthermore, ASM achieved record revenues, profits, and - unprecedented in its history - it even distributed excessive cash to its shareholders. In many ways, ASM International's conventionalities were turned upside down. By 2018, the equipment manufacturer seemed to have arrived on safer grounds.

In this epilogue, this study moves beyond its final date of 2008 to give the reader a preliminary idea of the story's continuation. For the reconstruction of events from 2008 until 2018, I did not rely on historical documentation or authorized oral histories. Instead, I merely used public reports and articles, while also relying on personal interpretations. For this reason, the chronological depiction of events and observations below should not be seen as on a par with this study's other chapters.

My concern in this epilogue is limited to three structural storylines of this dissertation, disregarding the quite Shakespearean events. The first storyline, which is that of industrial and technological development, zooms in on the consolidation of competition and proliferation of technological development, implying attention for 'Industrial context.' The second storyline, 'Corporate course,' pertains to the resounding internal dynamics of ASM International as a multi-divisional enterprise. The third and final storyline, 'Entrepreneurial perils,' focuses on the life of Arthur del Prado. Specifically I discuss how after his retirement the entrepreneur related to his new life outside of ASM International. This epilogue ends with a brief conclusion. 


\section{Industrial context}

Arthur del Prado's retirement in 2008 coincided with a severe economic crisis, which destabilized the global financial world. Banks were bailed-out or collapsed. Financial anxiety and panic lashed out at all and sundry. Successive economic stabilization efforts, often accompanied by austerity measures, stimulated populist resentment in Western societies. As recovery set in, the awareness of imminent climate change began to grow and the need for sustainability measures increased.

So-called 'Big-Tech' firms like Apple, Amazon, Google, and Facebook proliferated developments, emotions, and debates across geographical and cultural boundaries at an unprecedented pace. Helped by the advent of portable electronics - smart phones, tablets, and smart-watches - and ever faster mobile internet - 3G, 4G and 5G - social media got firmly established in the daily lives of consumers and citizens, connecting peoples all over the world. Yet with this new connectivity, Pandora's box was opened. Privacy was under pressure, democracy became vulnerable to manipulation, and extremism fostered. Playing by its own rules of Communism, Capitalism and Confucianism, the People's Republic of China in particular embraced the new technological opportunities to assert its interests and influence domestically and abroad.

These socio-economic dynamics encouraged Western policymakers to reappreciate national authorities in order to reestablish control over the globalized world for the benefit of their constituents. By 2016 citizens of the United Kingdom indicated their desire to withdraw from the European Union through 'Brexit,' and from 2017 onward, the United States embraced a more inward-oriented and explicit self-seeking stance in foreign policy. In addition to the rise of populism, social-technological climate challenges, unrestrained Big Tech, and assertive China, the impression emerged that the globalized liberal world of the late $20^{\text {th }}$ and early $21^{\text {st }}$ century was crumbling. The imminent period of 'slowbalisation' - as put forward by The Economist - in particular endangered the highly globalized orchestration of innovation that is the chip industry. ${ }^{1}$

\section{Semiconductor industry: from despair to unprecedented heights}

The semiconductor industry - and successively its equipment sector - joined the economic waves. During the financial crisis, semiconductor revenues shrank from 256 billion dollars in 2007 to 226 billion dollars in 2009, before steadily recovering to a record 468 billion dollars by 2018 (figure 94 ). ${ }^{2}$

1 The Economist, 'Briefing Slowbalisation: The global list', The Economist (26-1-2019) pp. 17-20; and The Economist, 'The Chips are Down', The Economist (1-12-2018) pp. 20-22, 21.

2 Author's personal archive: Gartner, 'Wafer Fab Equipment by Region, 1998-2017’. 


\section{Figure 94}

Graph of revenues in semiconductor industry and semiconductor equipment industry worldwide, 1969-2018

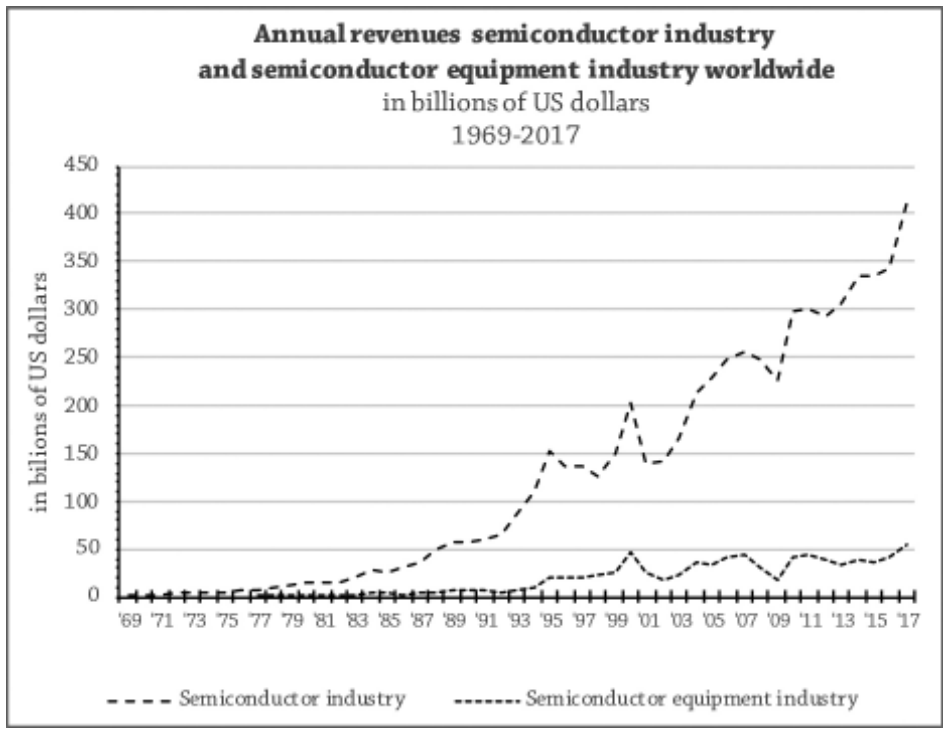

The advent of portable electronics - in particular smartphones - but also electrical cars, the internet of things, and increasingly artificial intelligence drove this exceptional growth. Furthermore, China became the focal point for growth, driven by ambitious governmental programs aimed at fostering the national industry (figure 95). ${ }^{3}$

Amidst the surge, the progression of miniaturization of computer chip components was furthered by fewer companies. It became very difficult to cough up the exponentially increasing costs for each successive generation - from 45 nanometer in 2007 to a mind-blowing 7 nanometer by 2019. The playing field in pursuit of 'More Moore' shrank to merely three players: Samsung, TSMC, and Intel. Others merely followed, like Micron, GlobalFoundries, Toshiba, SK Hynix, and Renesas. ${ }^{4}$ In the meantime, the 'More-than-Moore' segment of the semiconductor industry flourished. Semiconductor manufacturers' ability to produce chips that consumed less energy opened numerous new applications,

3 'Chips on their shoulders', The Economist (23-1-2016).

4 GlobalFoundries was a contract manufacturer based on the former production factories of AMD, IBM, and Chartered Semiconductors. SK Hynix was formerly Hyundai Semiconductors. Renesas involved NEC, Hitachi, Mitsubishi, and Intersil. NXP formerly was Philips Semiconductors, Infineon was Siemens Semiconductors, and the origins of ST can be found in SGS-Thomson. 
from wireless communication, graphic processing chips, to automotive - using sensors, camera communication, and computer chips. Chip manufacturers like NXP, ST, Infineon, and Texas Instruments flourished, as did chip design houses like Qualcomm, Broadcom, ARM, and Nvidia.

\section{Figure 95}

Graph of capital expenditures of semiconductor manufacturers per geographical market, 20072017

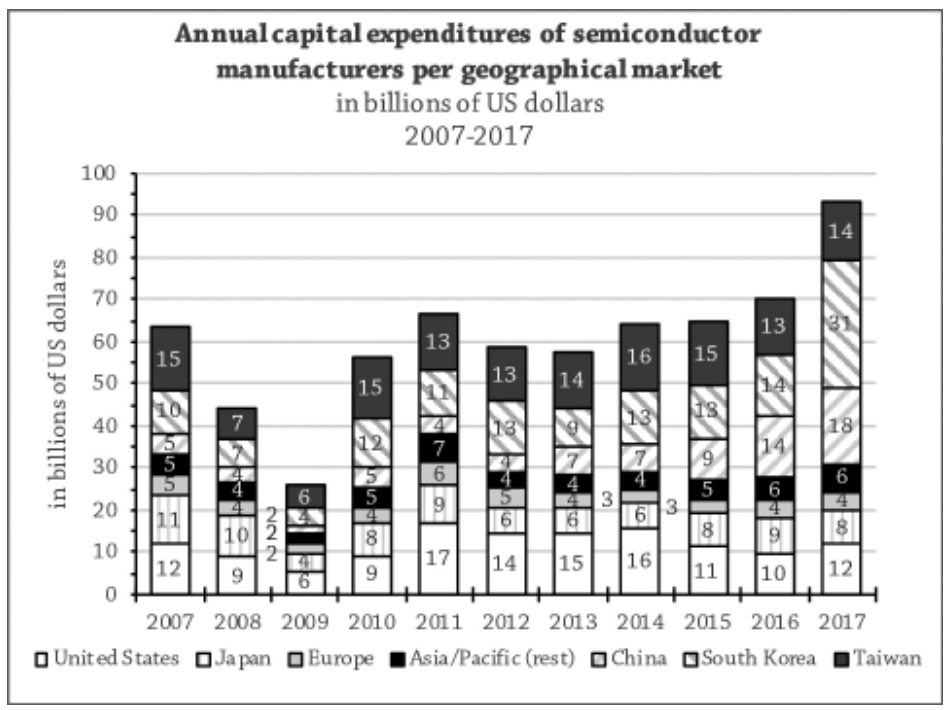

In the decade after the 2008 crisis, the semiconductor equipment industry would follow the growth and decline of the chip industry in even more dramatic swings (figure 96). From 44.9 billion dollars in revenues in 2007, the sector tumbled down to a depressing 16.7 billion in 2009 - the lowest level in fifteen years. Yet one year later, it recovered miraculously to 40.1 billion dollars, after which it grew to an unprecedented 62.1 billion by $2018 .^{5}$

Fewer suppliers could industrialize the latest technologies from 'lab to fab.' Varian Semiconductors was acquired by Applied Materials in 2011. Novellus was acquired by Lam Research in 2012. ASML dominated the market for lithography steppers, as Nikon and Canon lost the competition. By 2018, the biggest equipment suppliers Applied Materials, Lam Research, and ASML achieved revenues between 17 and 11 billion dollars. ${ }^{6}$ There was also diversification within

Author's personal archive: Gartner, ‘Wafer Fab Equipment by Region, 1998-2017’.

$6 \quad$ Fiscal years differ per company. - Applied Materials, 'News Release: Applied Materials Announces Fourth Quarter and Fiscal Year 2018 Results' (15-11-2018); Lam Research, Annual Report 2018 (7-9-2018) p. 28; and ASML, ASML Integrated Report 2018 (5-2-2019) p. 2. (an 
the semiconductor equipment industry. Due to the high entrance barrier for the More Moore segment, smaller and bigger equipment manufacturers sought refuge in related industries. These involved fabrication technologies for solar panels or 'organic light-emitting-diodes' (used, for instance, in smartphone displays). Semiconductor fabrication technology even began to permeate other sectors. Chips were hot, as were their fabrication technologies!

Figure 96

Graph of annual growth semiconductor industry, semiconductor equipment industry and ASM International, 2007-2017

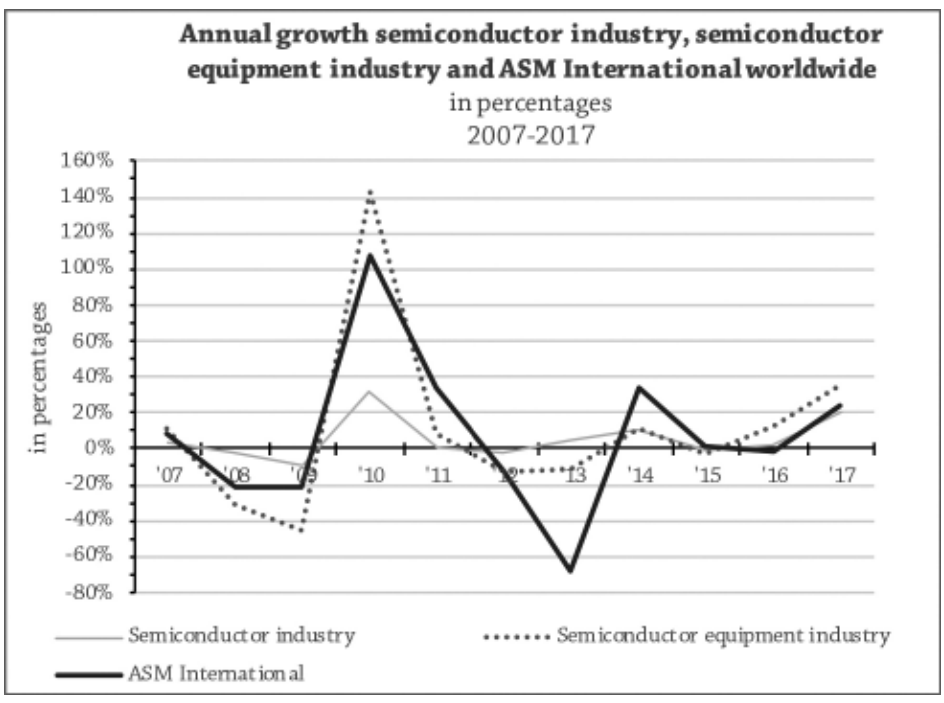

\section{Proliferation of semiconductor technology}

Diversity in technological products and subsequent roadmaps burgeoned, obliviating the International Technological Roadmap for Semiconductors from 2016 onward. Because ASM International primarily addressed the 'More Moore' semiconductor market, I will limit myself to the technological innovations with regard to miniaturization of transistors. From 2008 to 2019, conventional parameters to measure the progression of Moore's Law became inadequate owing to a proliferation of chip component designs. Linewidth made way for electrical specifications. 


\section{Figure 97}

Depictions of novel transistor cell structures, early-2010's.

The upper two images of transistors depict the conventional structure up until 2007 (cf. intermezzo in Business I, and figure 70 in Innovation IV). The second from above depicts a transistor incorporating the silicon-on-insulator technology, introduced in high-volume manufacturing around 2007 onwards. The third images from above depict the fin-FET structure, produced industrially from 2010 onwards. The one at the bottom shows the nanosheet, or 'gateall-around' transistor, expected to be introduced in 2020.

In each of the images, the channel is highlighted, since this part of a field-effect transistor drove the overhaul of structures.

\section{Cross-sectional view of a field-effect transistor}

\section{Transistor gate \\ Electrode (polysilicon) \\ (n-type for NMOS) \\ (p-type for NMOS)}

\section{Dielectric \\ (silicon oxide)}

Channel

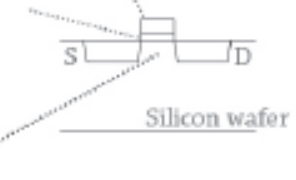

\section{Three-dimensional depiction of a field-effect transistor}

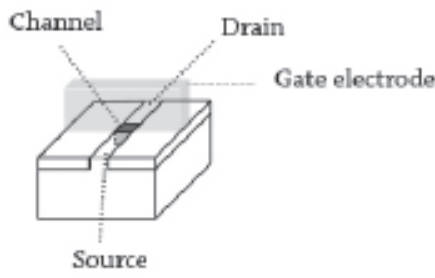

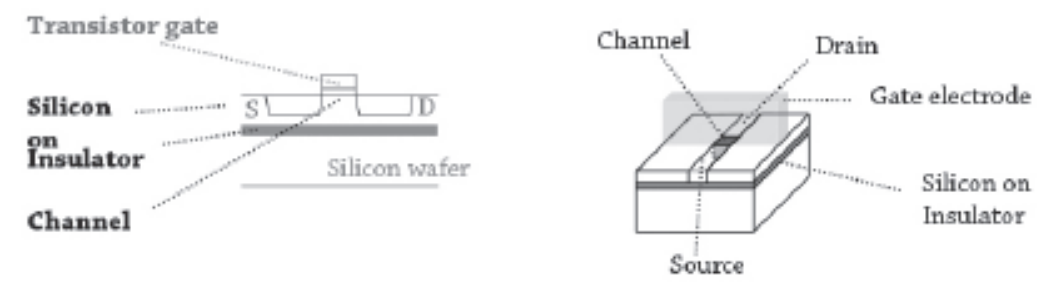

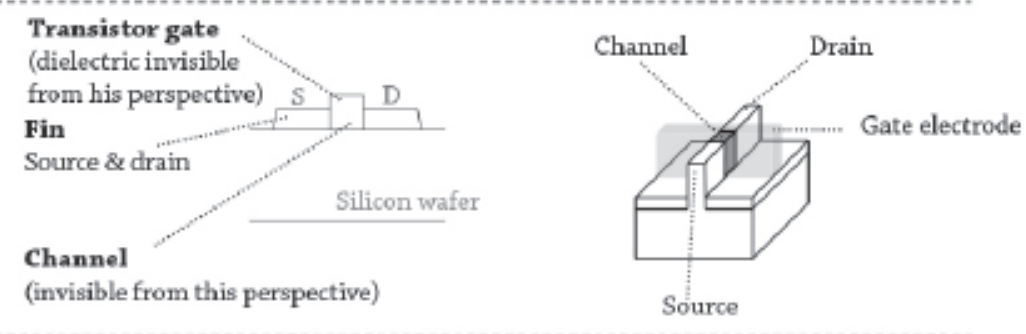

\section{Transistor gate}

(dielectric invisible

from his perspective)

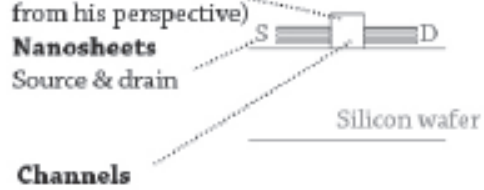

(invisible from this perspective)

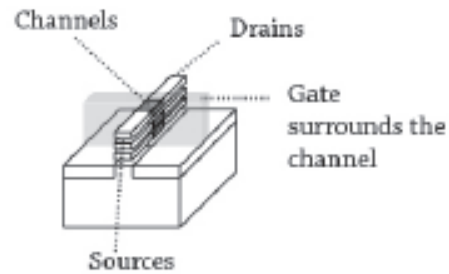


Transistor design increasingly moved away from a sheer planar configuration (figure 97). The introduction of strained silicon in 2004 (cf. Business V), and high-k metal gate transistors in 2007 (cf. Innovation IV) marked the beginning of a new phase in semiconductor technology. The proliferation of design and subsequent production techniques was foremost driven by the need to limit the leakage of the "threshold voltage. ${ }^{8}$ The channel of a typical transistor, or the part between source and drain, leaked the tiniest bits of power into the substrate to other transistors, affecting the performance of a computer chip. The thinner this channel, the smaller the loss and the less power a computer chip used.

One way to decrease leakage was to diminish the thickness of the silicon substrate on which the transistor was constructed. This was done by siliconon-insulator (SOI), a technique developed by a French equipment manufacturer called Soitec. SOI makes the silicon wafer resemble an Oreo-cookie, consisting of a silicon wafer, an insulating film and a very thin film of silicon stacked on each other. With SOI as basis, the transistor barely had to change for further miniaturization. The fabrication process of SOI wafers was rather costly and complex, however.

Another route involved multi-gate 'Fin field-effect-transistors' (FinFET), or sometimes referred to as tri-gate transistors. ${ }^{9}$ In this configuration, the transistor channel was turned 90 degrees; instead of being part of the horizontal silicon wafer, the channel stuck out vertically. This way, the thickness of the channel corresponded with the thickness of the 'fin.' The gate stack - which until that point had been constructed on top of the channel (cf. Innovation IV) - now enveloped the fin on three designated spots. Hence the name tri-gate transistor. In case of the FinFET, shrinkage now pertained to the decrease of fin-thickness and gate density upon the fin.

If these radical overhauls of design were not enough, by 2018, the industry also began to consider 'gate-all-around transistors' or 'nanosheet transistors' for high-volume manufacturing. ${ }^{10}$ Such a development would make transistors no longer planar but three-dimensional. For flash memory chips, this development had been going on for a while already. For so-called NAND or flash memory, cells turned from planar to 3D, enabling bigger density of cells and thus more capacity.

7 Applied Materials, Ahmed and Klaus Schuegraf, 'Transistor Wars', spectrum.ieee.org (2810-2011).

8 Miguel Miranda, 'The Threat of Semiconductor Variability', Spectrum.ieee.org (28-6-2012).

9 Rachel Courtland, 'The Origins of Intel's New Transistor, and Its Future', Spectrum.ieee.org (9-5-2011).

10 Samuel K. Moore, 'Through-Silicon Transistors Could Make Stacking Chips Smarter', Spectrum.ieee.org (1-10-2018). 
New innovative materials and production techniques accompanied this proliferation of transistor technology. As two engineers from Applied Materials explained in an online magazine IEEE Spectrum:

'The single biggest hurdle in making FinFET's is manufacturing the fins so that they're both narrow and uniform. For a $20-\mathrm{nm}$ transistor ... the fin must be about $10 \mathrm{~nm}$ wide and $25 \mathrm{~nm}$ high; it must also deviate by no more than half a nanometer - just a few atomic layers - in any given direction. Over the course of production, manufacturers must control all sources of variation, limiting it to no more than $1 \mathrm{~nm}$ in a 300 millimeterwide wafer. ... This precision is needed not only to manufacture the fin; it must also be maintained for the rest of the manufacturing process, including thermal treatment, doping, and the multiple film deposition and removal steps needed to build the transistor's gate insulator and [electrode]. As an added complication, the gate oxide and the gate must be deposited so that they follow the contours of the fin. Any process that damages the fin could affect how the device performs. ${ }^{11}$

Among the profound technological challenges, the introduction of a new wafer size - 450 millimeter - got postponed and perhaps even annulled. Due to the rapid radical innovations of transistor design, the costs of new fabrication technologies had to be recovered in less time by both the equipment supplier (development costs) and the chip manufacturer (capital expenditures). A new wafer size would only aggravate the economics.

Photolithography continued to be the conventional method to achieve the precision indicated in the quote above. Yet this fabrication technique met with an almost ridiculous challenge in defining the smallest features on a chip, involving investments that could not be mustered by all chip manufacturers anymore. Apart from the rapid innovations of transistor designs, it was the newest photolithography technology that separated the sheep from the goats in the pursuit of Moore's Law.

From the start of the century, consensus emerged across the industry that to define the smallest features extreme ultra violet (EUV) light rays had to be used..$^{12} \mathrm{~A}$ machine the size of a shipping container produced a light ray of extreme ultra violet by ionizing microscopic droplets of tin with an extremely intense

11 Applied Materials, Ahmed and Klaus Schuegraf, 'Transistor Wars', spectrum.ieee.org (28-102011).

12 The International Technological Roadmap for Semiconductor was imperative in reaching this consensus. - Samuel K. Moore, 'EUV Lithography Finally Ready for Chip Manufacturing' Spectrum.ieee.org (5-1-2018). 
laser, and catching and guiding generated light ray through nano-scale-smooth collectors, mirrors, and lenses to a wafer, which in its turn had to be accurately positioned within a few nanometers. Moreover, this incredible process had to be industrialized to be cost-effective at all, i.e., being capable of processing at least 1000 wafers containing numerous chips per day. The resulting bulky machine costed over 100 million dollars.

Only one lithography supplier was capable of realizing this Herculean technological effort: the Dutch ASML and its vast network of research institutes, subcontractors, and other partners. Not to say anything yet about the accompanying fabrication processes developed by other equipment suppliers for the creation of new masks, novel photoresist materials that were susceptible for these volatile EUV rays, and etch processes that worked on these new photoresist materials. All in all, by 2019, when this technology finally was entering highvolume manufacturing, only three chip manufacturers were capable of bearing the acquisition and operational costs of this piece of technology: Intel, TSMC, and Samsung. ${ }^{13}$

Due to the delay and costs of EUV, chip manufacturers turned to alternative lithographic techniques. The industrially available resolution of photolithography was not sufficient to define the smallest transistor features in one single exposure. As a solution, the wafer got exposed multiple times to achieve the desired linewidths. This resulted in 'multiple patterning' (figure 98). As the costs of EUV and the various multiple patterning lithography steps rose, some chip manufacturers considered e-beam lithography as an alternative. No costly (multiple) masks would be needed. But even this technology could not compete with photolithography, despite the fact that multiple exposure rounds were required.

All in all, with the incredible technological challenges in EUV, the unsatisfactory multiple patterning solution, the spiraling proliferation of transistor design and ongoing miniaturization toward sub-nanoscale, the prospects of progressing Moore's Law seemed dim - after more than fifty years. Yet new opportunities emerged in the context of the 'internet of things,' autonomous driving vehicles, and artificial intelligence. Developments that would thrive on - and foster - new semiconductor technologies.

13 In 2018, GlobalFoundries stepped out of the race for Moore's Law through the annulment of its 7-nanometer development efforts. - Samuel K. Moore, 'GlobalFoundries Halts 7-Nanometer Chip Development', Spectrum.ieee.org (28-8-2018); Samuel K. Moore, 'GlobalFoundries CTO on Why the Company Abandoned the "Bleeding Edge", Spectrum.ieee. org (31-8-2018); Steve Blank, 'What the GlobalFoundries' Retreat Really Means', Spectrum. ieee.org (10-9-2018). 


\section{Figure 98}

Simplified cross-sectional depiction of a quadruple patterning process

The double- or multiple patterning process allows to create structures at smaller linewidths with lithography techniques of previous technology nodes. ASM International's plasma enhanced atomic layer deposition (PEALD) process was used to deposit the spacers (depicted in black) for which conformality and thickness uniformity were defining.
A) Pattern photoresist
B) Etch 1st film (lithography)

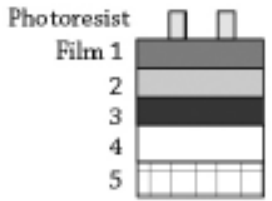

D) Deposit 1st etch spacer (PEALD)

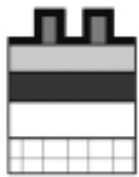

E) Etch 2nd film

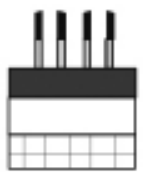

H) Etch top of 2nd spacer

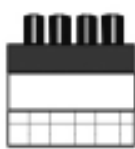

K) Remove remnants
of 2 nd spacer

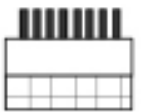

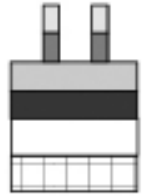

E) Etch top of 1st spacer

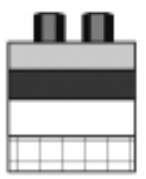

F) Removal renmants of 1st etch spacer

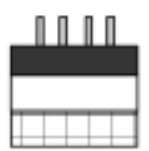

I) Etch remants of 2nd film

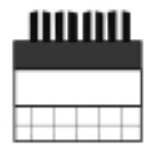

L) Etch 4th film, the target film

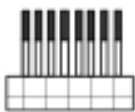

C) Etch remnants of photoresist

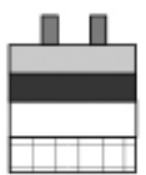

D) Etch remnants 1st film

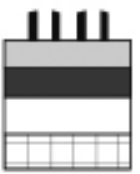

G) Deposit 2nd spacer (PEALD)

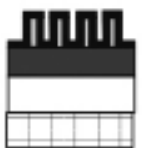

J) Etch 3rd film

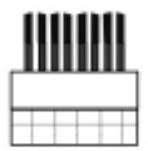

M) Etch 3rd film

Target film

remains

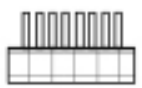




\section{Corporate course}

From 2008 until 2011, the priorities for ASM International and its new chief executive officer became upmost clear. ${ }^{14}$ Activist shareholders demanded a change of management and business strategy (cf. Chapter 32). The company had to divest its interest in ASM Pacific Technology in order to secure a 'true' appreciation for the front-end activities - i.e. wafer processing products. In pursuit of this argument, litigation, defining annual general meetings, and personal attacks were not shunned. Chuck del Prado's position was disputed. Even more, Applied Materials offered about 800 million dollars - or about 475 million euros - for the company's front-end activities. Negotiations on this matter dragged on until the escalating financial crisis thwarted the offer by November 2008, stirring discontent among the Supervisory Board. In the meantime, the overall semiconductor equipment industry was negatively affected by the spiraling financial crisis. Orders for ASM International's products rapidly decreased and profitability of front-end seemed more unlikely than ever. The Dutch equipment manufacturer was cornered.

\section{Realigning the multi-divisional enterprise}

The dramatic recession of 2009 and the failed negotiations with Applied Materials just months earlier forced ASM's management to bring the house in order. The company's executive management in close conjunction with the Supervisory Board set out the lines for a reorganization. The program was called Perform! and would last until the end of 2010.15

Through this effort, structural deficiencies in ASM International were ironed out. The times did not leave room for half-baked actions or accommodation of unwarranted organizational delicacies. All facilities in Bilthoven, including the company's headquarters, were moved to Almere, 30 kilometers northward, to the Versterkerstraat 8, around the corner of ASM Europe's manufacturing operation. Across ASM International front-end, 24 percent of staff was laid off. Structural reductions were made in overhead and research and development. Nanophotonics, the division responsible for integrated metrology equipment, was divested. The Levitor, a rapid thermal annealing machine utilizing floating wafers, was spun off through a management buyout in a new company named Levitech.

The remaining divisions were restructured into a matrix organization scheme. Most profound was an accelerated company-wide centralization of manufacturing in Front-End Manufacturing Singapore (FEMS). Until 2009, only the production of vertical furnaces had been transferred to this facility.

14 Pieter Couwenbergh and Joost van Mierlo, 'Shakespearedrama bij ASM International', Het Financieele Dagblad (16-4-2009) p. 17.

15 ASM International, Annual Reports. 
Now, the manufacturing of all generic elements of ASM's front-end products was concentrated in Singapore. Furthermore, at FEMS a global service center was established. Customization or special products remained at the designated product locations: ASM America for thermal deposition, ASM Europe for vertical furnaces, and ASM Japan for plasma deposition technologies. Finally, after more than fifteen years, ASM seemed to have gotten a handle on the spiraling operational diversification and headstrongness.

The matrix organization also involved the creation of central positions, in the capacity of vice-presidents for Sales \& Service, Marketing, Legal Affairs, and manufacturing (named 'Global Operations'). The position of chief operations officer - held by Han Westendorp - turned into Vice President Front-End Strategy. The names of other positions like chief financial officer (Rob Ruijter), chief technology officer (Ivo Raaijmakers), and chief executive officer (Chuck del Prado) were left the same. From 2010, financial management was consolidated under Peter van Bommel as chief financial officer; he was the first financial manager who did not resign frustrated or worn out within four years. New managers succeeded retiring old-hands or vacant positions. Peo Hansson succeeded Chuck del Prado as general manager of ASM America in 2008. In 2009, after serving of 27 years, ASM Japan's co-founder Fukumi Tomino was succeeded by Tominori Yoshida as general manager of ASM Japan and the business unit manager for plasma products. In 2011, Albert Hasper was succeeded by Fokko Leutscher as Vice President Global operations.

Wafer handling platforms were consolidated and apportioned to the care of ASM Japan. The platform was based upon the EagleXP wafer handling module. Apart from existing commitments this became the standard wafer handler platform. One commitment involved already ongoing utilization of the Polygon wafer handler in combination of the Pulsar high-k reactor chambers. Qualified or legacy products were not changed of course. The persistent proliferation of wafer handling platforms seemed to be curbed after twenty-five years.

These structural changes of the sweeping reorganization program Perform! would be refined further. FEMS would abandon the vertically integrated manufacturing strategy and outsource production of generic modules to VDL-ETG in Singapore by 2014. This operation was a subsidiary of Dutch industrial manufacturing conglomerate VDL and formerly part of Philips Machinefabrieken. Other improvements included the addition of a corporate vice-president for human resource management, and further streamlining and updating of the research and development process involving the product groups ASM Microchemistry and ASM Belgium. From 2014, ASM International reported on social responsibility, such as the wellbeing of employees, social and environmental impact, and waste production. 
Only ASM Genitech Korea was left largely unscathed, which was due to a strategic project running on steam in conjunction with Samsung, the secondbiggest chip manufacturer in the world, and involving a technology that would define ASM International's growth (see below). The Korean division of ASM became a dedicated supplier to Samsung and SK Hynix, with its own Korean manufacturing operation and equipment platform, and this proved a success. As the South Korean semiconductor industry, in particular Samsung, experienced incredible growth in semiconductors, ASM Genitech Korea joined the feast.

Another major structural adaptation to ASM International's structure as multidivisional enterprise involved ASM Pacific Technology. ${ }^{16}$ This operation continued its own growth path with the opening of new research and development facilities in Chengdu (2011) and Taiwan (2018), in addition to its Hong Kong and Singaporean divisions. Its manufacturing operation was expanded with facilities in Huizhou, and for the first time some parts of production were outsourced.

Furthermore, the Hong Kong-based manufacturer of assembly and packaging equipment diversified through the acquisition of the surface mount technology group of Siemens in 2010. It was renamed ASM Assembly Systems. This acquisition was the first in thirty years. Through this move, ASM Pacific Technology appropriated the next step in the electronics supply chain. The division developed technologies for the mounting of chips and other electrical components directly onto the circuit boards. Further diversification involved the acquisition of Dutch laser wafer separation equipment manufacturer ALSI in 2014, an acquisition of a Japanese advanced packaging manufacturer Tokyo Electron NEXX in 2018, simultaneously with the acquisition of a German manufacturer of photonics bonder equipment, AMICRA Microtechnologies.

All these events happened at an increasing distance from ASM International. Following the instigation of shareholders, ASM International studied the effects of its presence in both front-and back-end in relation to its undervalued stock. It was a clear sign that ASM would consider the argument put forward by activist shareholders, but only on its own terms. After the study, ASM International reduced its stake in ASM Pacific Technology with 12 percent in 2013. Another divestment followed in April and November 2017, decreasing ownership to a mere 25 percent. This implied that from then on, ASM International represented front-end operations only.

\section{Recalibrating the balance of power}

The immediate years after Arthur del Prado's retirement were marked by recalibration of relations between management board, supervisory board, and 
shareholders. The balance of power had been altered, and now the players had to establish a new role. Here I will briefly describe three aspects of this recalibration process.

The first aspect entailed the role of the Supervisory Board. Activist shareholders had sparked debates about its role toward management and in particular the diverging interests of its shareholders - Arthur del Prado on one side and hedge funds Hermes and Fursa on the other.

After twenty-eight years as Board chairman, Paul van den Hoek retired at age seventy. ${ }^{17}$ His strong-willed successor, Gert Jan Kramer, rigorously stipulated and observed corporate governance regulations. As the scrupulous activist shareholders trailed the slightest faux pas on corporate governance to enforce their arguments, historical or other sentiments had no place.

This in particular affected Arthur del Prado, the company's founder and the new chief executive officer's father, who had to get accustomed to the fact that he was no longer the shareholder, but merely a shareholder. He was not privileged, receiving the same treatment as other shareholders. Although limits and standards were set, the entrepreneur flexed his muscles in a power play with Kramer - resulting in his retirement after serving merely one term. The new leader of the company Chuck del Prado, commanding a different career, character, and position than his father, successfully conformed. The next Chairman, Jan Lobbezoo - a former Philips Semiconductors financial executive and TSMC Board member - oversaw further compliance and refinement of these boundaries, be it in a less muscular manner.

The second aspect in the calibration process involved the legal stipulation of duties and rights on the matter of corporate governance. By 2009, the escalating financial crisis numbed the hedge funds that circled around ASM. Yet these parties persevered in a legal procedure through which they demanded a say in the company's business strategy. This involved in particular Arthur del Prado's strategy of leveraged innovation, in which assets - most notably the value and profits of ASM Pacific Technology - were used to leverage innovations in front-end. Only by 2012 this dispute was settled through a verdict of the Dutch Supreme Court (cf. epilogue of Chapter 32). ${ }^{18}$ The court ruled that, as matter of principle, strategy was decided by the management, under supervision of the Supervisory Board. The company's management considered on their own whether they wanted to confer with shareholders on this matter. Moreover, the Supervisory Board was no arbitrator between shareholders and ASM.

17 Pieter Couwenbergh, 'Liefhebber van het strategische gevecht', Het Financieele Dagblad (145-2009) p. 2.

18 Hoge Raad, Eerste Kamer 'Cassatie Stichting Continuïteit ASM International versus Hermes, Fursa, VEB, ASM International, Ondernemingsraad ASM Europe en Arthur del Prado. Zaaknummer: 09/4465 en 09/04512; ECLI:NL:HR:2010:BM0976' (9-7-2010). 
The verdict drew a line toward shareholders, but also between management and Supervisory Board. On the matter of strategy, the primacy resided with the management board. In the years afterward, another hedge fund named Eminence Capital tried to foster support for a divestment of ASM Pacific Technology. But this time ASM was tried and tested. Through careful observations of its own interests, while respecting corporate governance conventions, this hedge fund was pacified.

The third aspect of the recalibration process entailed the performance of the company. It achieved record revenues, consistent profitability, and attractive market capitalization. ${ }^{19}$ After the combined net sales of both front- and backend tumbled from 955 million euros in 2007 to 591 million euros in 2009, recovery set in (figure 99). By 2018 ASM International, which by that time consisted of front-end operations only(!), totaled 818 million euros again. The front-end activities - having been a source of concern for years - developed from a loss of 151 million euros in 2009, to turning profitable by 2013, and to a profit of 109 million euros by 2018. Over the same period of time, the front-end revenues increased fivefold.

\section{Figure 99}

Graph of net earnings and revenues of front-end and back-end, 2007-2018

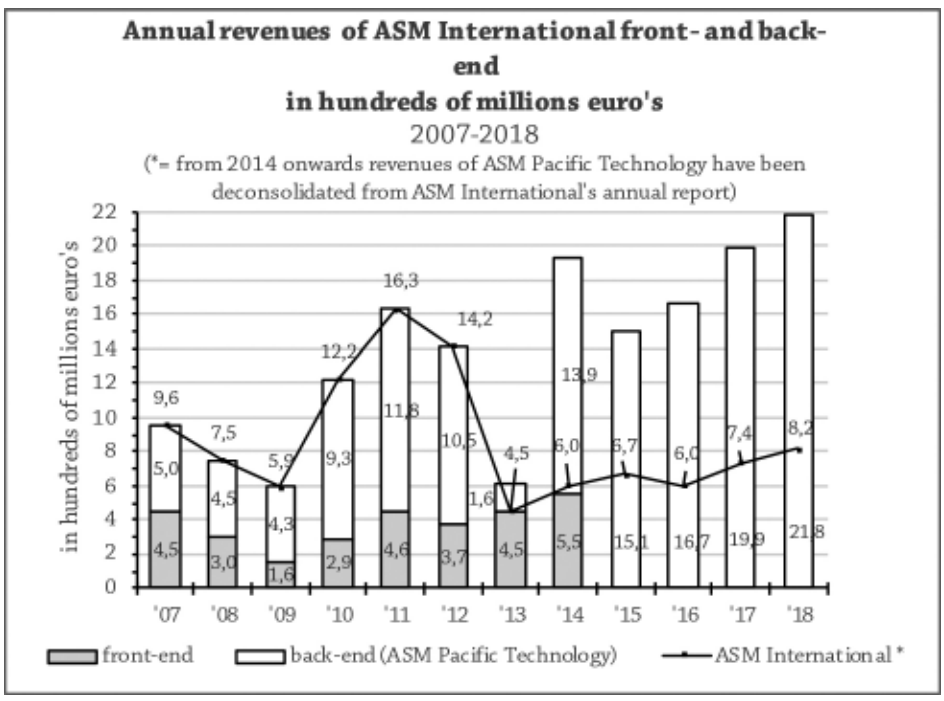

With this upward trend in performance, stability returned among shareholders. Event-driven hedge funds and private equity made way for 
investors pursuing a long-term return on investments. To further remove doubt, the company initiated a consistent dividend policy. Also the proceeds from divesting shares of ASM Pacific Technology were distributed across the shareholders. Furthermore, the company consistently used excess cash reserves for share buy-back schemes - following an industry-wide trend. From 2014 to 2019, these programs totaled 550 million euros. ${ }^{20}$ To stimulate trade, the company voluntarily delisted from the Nasdaq in 2015 due to low trade volumes. Share price peaked at 62.2 euros, resulting in a record market capitalization of 3.65 billion euros in 2017 and 3.28 billion euros in 2018 on the Euronext stock exchange in Amsterdam (figure 100). The implied market capitalization of frontend increased from nearly 500 million euro negative in 2009 to more than a billion euro positive by 2017. It was the world turned upside down compared to the constant cash-scarce days under Arthur del Prado. Successive customer awards - Intel Preferred Quality Supplier Award in 2016 and 2018, plus TSMC Supplier Excellence award 2017, 2018 and 2019 - were the icing on the cake.

\section{Figure 100}

Graph of ASM International's market capitalization on the Euronext stock exchange, 2007-2018

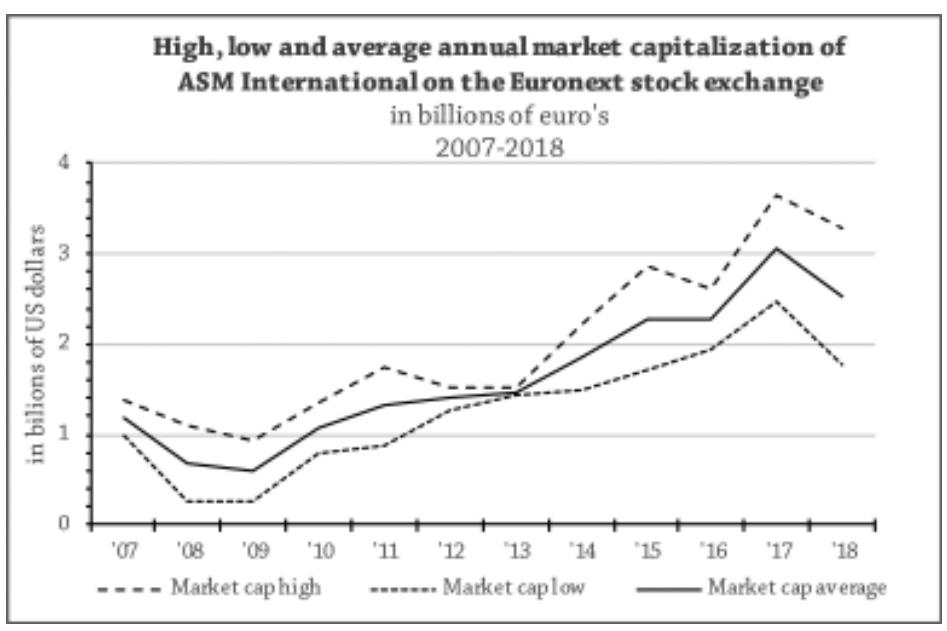

\section{Technological innovations}

The recovery of ASM International front-end was driven by pioneering single wafer ALD processes. ${ }^{21}$ This involved the high-k and later metal gate ALD

$20 \quad$ ASM International, Annual Report 2018 (5-3-2018), p. 168.

21 The account here is based on ASM International's annual reports and personal observations and conversations of the author. 
processes (cf. Innovation IV). The thermal product group established at ASM America fueled these successes after company-wide development efforts. Furthermore, ASM Microchemistry developed into a new ALD materials expertise center, expanding through new facilities over the course of several years. New processes were tested and integrated in state-of-the-art production lines at the Flemish research institute IMEC by ASM Belgium, before they were further commercialized by the product groups and customers. Yet most defining and most unexpected was the breakthrough technology of plasma enhanced ALD (PEALD) for multiple patterning initially (cf. figure 98). Multiple patterning became standard across the industry, pushing ASM's PEALD technology and the rest of the company to new heights.

The pivotal operation in this was ASM Genitech Korea. By 2008, the Korean startup had been developing and working for several years on the applicability of its PEALD technology for various processes in close collaboration with the Korean semiconductor companies Samsung and SK Hynix, the leading memory manufacturers of the world. But up to that point all this effort had been to no avail. One day, however, one of the customer's engineers indicated that they struggled with a low temperature silicon oxide hard mask process for multiple patterning. ASM Genitech Korea did not miss the hint.

The Korean startup had done some preliminary studies into PEALD grown silicon oxide and applicable precursors. They might have a viable solution. In this context, the benefit of proximity - in research \& development, manufacturing and sales - became apparent once again. As a process engineer of ASM Genitech Korea recalled:

'At that time, there was some kind of governmental supported program. If Samsung, [or] Hynix ... would evaluate one certain tool, than that tool would be qualified to all. That kind of program was established to boost the local suppliers. ASM was recognized as a local supplier, so we enrolled that program. ... Samsung also [evaluated] Tokyo Electron's tool for that application. But, TEL is a foreign company, [and]. ... our performance was much better, our support was much better, our uniformity and conformity was much better. ${ }^{22}$

In March 2009, the first development tool got shipped. From that moment, the Korean subsidiary experienced an incredible learning curve. In a matter of months, it had to qualify its technology, manufacturing and sales operations to the highest standards. Since the potential fruits of serving Samsung and

22 Yong Min Yoo, 'Interview with author'. 
SK Hynix were so lucrative, ASM Genitech Korea was exempted from the rigid Perform! reorganization.

And with success. By 2015 over 50 tools had been installed at Samsung facilities alone. For every new fab line and with every increase from double to quadruple to multiple patterning, the number of ASM Genitech PEALD machines increased. The painstaking cultivation of its plasma ALD process over a decade paid off beautifully after all. More and more chip manufacturers turned toward multiple patterning, increasing the appropriable market for ASM.

In order to keep ASM Genitech's focus on Samsung and SK Hynix, ASM Japan - the designated plasma product groups - served other non-Korean customers. The demand for the Japanese-made PEALD technology fueled the platform consolidation effort within ASM as well. The XP-8 (with the 8 denoting the number of single wafer reactor chambers) got established as ASM's standard wafer handler. Even more, by 2018 to increase productivity of the machines and decrease cost-of-ownership for customers - ASM Japan even turned the XP-8 into a XP8-QCM, handling 16 reactor chambers on a single wafer handler. Also ASM Genitech adopted this platform eventually. Clearly, wafer handling diversification among business units seemed to belong to a bygone era.

The company-wide acceptance of cluster platforms even accounted for the epitaxial product line. Ever since the Epsilon single wafer reactor's introduction in 1988, there had been an ongoing discussion as to whether or not this machine ought to be transformed from standalone to a cluster configuration. Disagreement about this issue resulted in significant losses of market share (cf. Chapter 32). By 2018, a new epitaxy cluster named Intrepid finally gained traction among CMOS manufacturers.

The vertical furnace product group changed little since 2008. The Almere operation of ASM Europe took care of the development of new processes. Manufacturing initially occurred at FEMS, in Singapore. However, as demand for vertical furnaces in the More-than-Moore segment increased, it became viable to refurbish older A400 and A412 vertical furnaces and resell them. This task fell to the Dutch engineers in Almere, who were most acquainted with the finesses of the machine. After all, refurbishment was totally different from the highly structured and codified manufacturing process. It required intimate knowledge of all the various components and fabrication procedures, something commanded by the old-hands still present at ASM Europe. The ASM Europe facilities around the corner of the headquarters in Almere even saw a modest revival of activity in recent years. 


\section{Entrepreneurial perils}

After his retirement as chief executive officer, Arthur del Prado did not sit around idly either. ${ }^{23}$ As a wealthy entrepreneur - his value only increased due to the excellent performance of ASM - he had sufficient resources to pursue the joys of life. Together with his partner Joan de Vos Steenwijk he sailed on his 30-meter yacht, the Skipper, the Mediterranean, or they would visit the Far East. He was honored through a 'Legend of the Industry' award, presented at the industry conference Semicon West 2008, and he was also named Officer in the Order of Orange-Nassau, a royal decoration handed to him by the Dutch Minister of Economic Affairs Maria van der Hoeven in 2009. Yet he remained a true entrepreneur and keen on his freedom of action. Everybody who would stand in the way would receive his wrath - whether old chaps, relatives, or business partners. But over the course of his final eight years, some of his tart characteristics softened.

First, Arthur del Prado had to get accustomed to the fact that he no longer was in charge of his ASM International, though he was still the largest shareholder. A wind of change was blowing through the enterprise. The new chairman of the Supervisory Board, Gert Jan Kramer, blocked Arthur's wheeling and dealing. Arthur's new role as Honorary Chairman was only symbolic. In the initial months, Arthur was invited regularly to inform the Supervisory Board, yet as soon as the designated topics had been discussed he was friendly requested to leave again. The Board would proceed without him. The entrepreneur experienced it as an outrageous insult. Furthermore, his eldest son had to blaze his own trail as chief executive officer, was bound by the business, corporate governance, brought in his own interests and personality, and subsequently could not accommodate Arthur either. It would take several years before Arthur del Prado managed to accept his new role.

However, he retained one position of power, as Chairman of ASM Pacific Technology, with W.K. Lee serving as chief executive officer. During this period, he remained closely involved in the various expansions. Shortly after the fortyyear anniversary of ASM Pacific Technology, Del Prado resigned as Chairman. By May 2016, he had become too weak to execute his role, even though he remained closely involved with one of his most successful ventures until the end.

Del Prado also channeled his entrepreneurial spirit through his personal investment vehicle, ADP Industries. This involved Levitech - the spin-off of his trusted former chief technology officer, Ernst Granneman. But also Mapper Lithography, a Dutch startup that had been trying to industrialize its ingenious parallel-ray E-beam lithography machine since 2000. From the start, Arthur invested tens of millions of euros in the venture. Through a footprint, cost, and 
throughput of one-tenth of the forthcoming and widely anticipated ASML EUV stepper machine, Mapper intended to address a market of less resourceful chip manufacturers. Moreover, via E-beam no costly masks were required. Until his death - in fact even thereafter - Del Prado funded and advised this promising startup about which he cared most dearly. Mapper perhaps symbolized an affirmation of his visionary entrepreneurial capabilities, or at least a revanche for his failure in contributing and benefiting from ASML's success.

The stage for all these business actions was Arthur's 'Round Table,' located in the round extension of his home in Bilthoven. He received all his appointments in this room, where he also concocted his new moves. Apart from the ongoing commitments, a steady stream of old-friends, business relations, and former employees visited as a courtesy or to seduce the entrepreneur to participate in another opportunity. These men - foremost they were men - were people to his liking: shrewd, intrepid, determined, and eager for adventure.

Despite the numerous stirring meetings, travels, and opportunities, Arthur del Prado's health gradually deteriorated from 2012 onward. Due to the fierce, loving, and unyielding care of Joan, this process was slow and full of recovery and hope. Until the very end, he continued to travel the world - visiting Hong Kong or going to his yacht, Skipper, in Mallorca. Yet, without losing his decorum and charm, the proud businessman became less mobile. On Friday afternoon, September 9, 2016 Arthur del Prado died peacefully at home, surrounded by his family. His incredible life - from the days as katjong in the Dutch Indies, the Japanese camps in the Second World War, a new start in the Netherlands, the thrilling migration to the United States, and an illustrious career in semiconductor technology - had come to an end.

But his influence did not. In his last will, Arthur del Prado indicated that his inheritance would be liquidated as much as possible and applied to academic research into very rare cancers. In the late 1990s, together with other Dutch captains of industry, he already pledged one million euros for a cancer research fund. ${ }^{24}$ After his passing, this scheme was many times larger. Yet again, as was typical of Arthur, he excelled in indicating the direction of this visionary idea, not its operationalization.

After his death, three close advisors took care of his estate, through the 'ADP Foundation'. They had to list all the assets, apportion parts to relatives, and liquidate whatever was possible. In the meantime, however, Mapper was still not making any money, required additional funding from the foundation, and despite all the implausible efforts eventually it filed for bankruptcy in December

24 Esther Rosenberg and Philip de Witt Wijnen, 'Twee lunches: één kliniek', NRC Handelsblad (20-6-2006). 
2018. ASML took over the intellectual property and pivotal engineers. ${ }^{25}$ Also the $\mathrm{PhD}$ study of yours truly was not yet near completion at the time of his death. Eventually, in the fall of 2018, another fund was established named 'Hanarth Fonds' - after Hanni and Arthur del Prado - in which all liquidated assets would be pledged. From these funds - about 50 to 100 million euros - research would be funded into the use of artificial intelligence and machine learning to improve the diagnosis, treatment, and outcome for patients with cancer. This sum partially originated from the sale of Arthur del Prado's remaining shares in ASM International. After sixty years, via his deputies, the entrepreneur relinquished his stake in the semiconductor industry.

\section{Conclusions}

And so it seems, a marvelous story was brought to a favorable conclusion. Briefly I return to the three narratives introduced at the beginning of this epilogue: industrial development, ASM as a multi-divisional enterprise, and the entrepreneurial spirit of Arthur del Prado.

The proliferation of transistor design and the success of More-than-Moore have been indicative of the profound viability and profusion of innovation. New efforts into research and development were justified by their portrayed relevancy to artificial intelligence, blockchain, or quantum computing. ${ }^{26}$ In particular regarding the latter, expansive, extensive, and expensive projects have been started. ${ }^{27}$ Whether or not quantum computing will become to silicon electronics what the latter has been for vacuum tubes is yet unknown. The physical realities of a quantum chip seem yet to distort the theoretical probabilities. Moreover, in the process of developing quantum computing another more tenable technology might emerge. As has been the basic presumption of this study, achievements of the past do not guarantee the reproduction of opportunities and developments in the future. The waves of innovation very much might continue, and continue, and continue. Or the wave washes ashore.

ASM International became a true $21^{\text {st }}$ century company: firmly embedded in an industrial ecosystem of research institutes, subcontractors, customers, and adhering adequately to corporate governance conventions and its corporate social responsibility, while fostering ever new innovations. The incredible crisis between 2008 and 2010 instigated a fresh, yet turbulent start. In fact, the notion of a Machiavellian Moment once again comes to mind; faced with its imminent

25 This was rather salient, as ASML had refused to acquire the technology earlier. - Casper van der Veen, 'ASML koop technologie van failliete Mapper', nrc.nl (29-1-2019).

26 Nitin, Dahad, 'Seperating AI Hype from Reality', EETimes (22-11-2018); Mikhail Dyakonov, 'The Case Against Quantum Computing', Spectrum.ieee.org (15-11-2018).

27 Mikhail Dyakonov, 'The Case Against Quantum Computing', Spectrum.ieee.org (15-11-2018). 
finality the innovator takes the initiative and the proverbial plunge. In many ways, the company shook off long lasting chains, such as the burden of bolstering multiple manufacturing operations, wafer handling platforms, and competitive strategies per product group.

Most striking was the effect of Arthur del Prado's absence on the company. In a matter of a few years, the corporation rejoined the ranks of its peers with regard to structure, processes, and performance. The unsparing entrepreneur no longer thwarted organizational processes in his pursuit of ever more promising opportunities. These he could now effectuate by himself, unbounded by the limitations of a listed multi-divisional enterprise.

At the same time, the equipment manufacturer itself has remained close to its carefully cultivated competencies. Leveraged innovation, a diversified product portfolio, a decentral organization with a small head office, and applicationoriented research - all these features continue to be at the core of the company's strategy. Only time will tell if an altogether new dynamics will ever present itself within the organization.

\section{Postscript}

Just prior to the publication of this research project, Chuck del Prado announced his retirement at the forthcoming annual general meeting of shareholders in May 2020. Having successfully fulfilled the promise to make the front-end activities profitable and to secure an apt market valuation for the company, the timing seemed perfect. The company even out-performed its peers over 2019. Apart from the state of the company, Del Prado's decision was also personal. As he explained in an inter-company announcement:

'As you can imagine, [the task of steering ASM] leaves little time for a life outside the company and with my family. So, while the many opportunities to further develop ASM continue to drive and inspire me, I have decided that for me personally, it is now time to change the balance. There is never a perfect moment to leave, but [...] I'm convinced that ASM's commercial, financial and technological health means it is well positioned to undergo a change of leadership. ${ }^{.28}$

As mentioned earlier, the younger Del Prado commanded a different character and career than his father and predecessor. Just as Arthur had been a businessman fit to his era, so was Chuck del Prado that to the $21^{\text {st }}$ century. His pursuit of a healthier work-life balance merely exemplified that.

28 ASM International, Chuck del Prado, 'E-mail: Chuck del Prado to retire as CEO, President and Chairman of the Management Board' (30-9-2019) Personal archive author. 
ASM International was ready to move into the next decades of the 21st century. Under the leadership of Chuck del Prado, elaborating upon the company's foundational strategies, ASM became more stable, consistently profitable, and continued to foster high-tech innovations. The retirement of the Del Prado's marked a new phase in ASM International's history. With that, this finale is also a new beginning. 
Conclusion 


\section{Conclusion}

The history of ASM International well reflects the industry's technological dynamism, multinational embedment, and promises of fortune. As this study has revealed, ASM has been involved in all major semiconductor production technologies, from the production of silicon wafers to equipment for all major deposition techniques, ion implantation, lithography, and assembly and packaging. These various activities, which ASM developed in facilities across the globe, allowed the company to join, contribute to, and capitalize on local opportunities in semiconductor manufacturing, giving rise over the years to a billion-dollar enterprise. Moreover, because it entered the business early on, the story of ASM very much coincides with the history of the semiconductor industry.

ASM's history also provides a good illustration of the dynamics of entrepreneurial agency, the effects of volatile markets and cut-throat competition, as well as the challenges involved in amassing and sustaining high capital investments. The multinational equipment manufacturer very much treaded its own path within the wider industrial development. In some respects, this pertness enabled the firm to surpass the competition in entrepreneurism and innovation, but at other moments its assertive style in fact undermined corporate stability and ate into the company's ability to fully effectuate and realize its potential.

In this conclusion, I reflect on ASM's history and the various observations presented in this study. In so doing, I return to the research question explored throughout the book: how to explain and characterize ASM International's innovation processes from 1958 until 2008? In response to this question, I will first characterize ASM's efforts at innovation in general terms, after which I specify them as presented in the Business and Innovation chapters. Next, I will explain the various innovation processes pursued by the equipment manufacturer during the years 1958 to 2008. In reference to this study's three conceptual elements - path, fortuna, and virtù - I relate my observations to specific notions in the academic literature, as developed in the Introduction. I conclude with a reflection on the benefits of studying both innovation and business - a distinct feature of this study.

\section{Characterization of ASM International's innovation processes}

Based on the reconstruction of the history of ASM International presented in this study, it is possible to provide the following succinct characterization: 
Despite attempts and circumstances inducing change, ASM International was a diversified semiconductor equipment manufacturer, which enacted and innovated semiconductor fabrication machines and processes with external conceptual origins in a highly decentralized and applicationdriven manner throughout the period covered in this study.

If this characterization perhaps suggests a steady, unchanging approach to entrepreneurship, it is also obvious that ASM's innovation processes were all but static. The company constantly tried to alter and adapt its innovation practices and strategies to address new opportunities, a changing environment, or varying resources. Diversification, decentralization, innovations with external origins, and application-orientation and semiconductor equipment manufacturing were all subject to modification over the years. Multiple times, the management of the company tried to stick to core competencies, improve central oversight, establish an internal advanced research capability, or explore non-semiconductor markets. Time and again, however, such explorations hardly yielded results. The company's decentral structure, diversification in products, and application-driven development served as pivotal competitive assets.

\section{Characterizing business}

The five Business parts of this study address general developments at ASM International, from its modest beginning as a trading agency for semiconductor materials to becoming a multinational manufacturer of semiconductor fabrication technologies. In these chapters, I detailed how internal and external events, challenges, and opportunities influenced the growth, decline, and consolidation of the enterprise. Special attention was given to the various industrial and technological developments in the semiconductor industry, as well as to the corporate structural effectuation of innovation at and among its divisions.

Business I covers the start of Arthur del Prado's career, the establishment of 'Advanced Semiconductor Materials,' its transformation into an original equipment manufacturer, and its international expansion from 1958 until 1979. Benevolent industrial dynamics like the advent of silicon and the rise of merchant equipment industry defined these formative years.

Five ingredients comprised the company's business strategy and, successively, its innovation process. First, decentralization, which stimulated entrepreneurial and technological intrepidness. Secondly, diversification helped to hedge exposure to markets. Thirdly, the company's start as a sales agency resonated in its innovation practice, involving, for instance, commercializing technologies from its principals and, later, innovating manufacturing techniques invented elsewhere. Fourthly, the company sustained diversification through a strategy 
of leveraged innovations, paying for the first semiconductor equipment through the revenues of its agencies. Fifthly, being in the proximity of the demand, and thus the customers, instigated internationalization.

The chapters in Business II describe the glorious years of ASM International, from 1979 until 1984. The first advent of personal computers in business and households stimulated demand for memory chips and, subsequently, for ASM's deposition machines.

In these years, the company elaborated upon its business strategy as established above. New operations were opened in the vicinity of major markets, as in the case of ASM Japan in 1982. The company continued the industrialization of externally conceptualized manufacturing techniques. This accounted for ASM Assembly Automation and ASM Lithography, for instance. New was that the company no longer leveraged solely its own financial assets to further innovation and growth. For the first time, the company attracted external funds. In this case through listing shares on the Nasdaq stock exchange in New York and through the Epsilon Limited Partnership.

Business III, covering the years from 1984 until 1992, describes how rapidly changing industrial dynamics undermined ASM's business structure and strategy. A divergence emerged among the interests of the corporation as a whole and those of the individual business units, whereby Del Prado's position and conventions complicated adequate intervention.

In the second half of the 1980s, structural elements of ASM's business strategy seriously undermined the company's performance. The decentral and diversified structure had a centrifugal effect, in particular in combination with changing industrial dynamics. Coherence and coordination seemed impossible. As a consequence, too much innovation was leveraged by too few assets. The external stakeholders in the company - most notably the bankers - moved in to secure their assets. Diversification got curbed through the divestment of ASM Lithography and ASM Ion Implant and the establishment of a corporate technology center, the AMTC. ASM International retained its activities in chemical vapor deposition and semiconductor assembly \& packaging technologies.

Business IV details a reluctant but promising recovery in the period from 1992 to 1999. Only in the face of imminent collapse, was the company able to address structural shortcomings in its business strategy. As ASM's remaining products failed to generate revenue, the strategy of leveraged innovation continued to be off-balance. External stakeholders - the bankers - once again tried to secure their assets in ASM International, which would tip the scale and wreck the enterprise. 
Out of sheer necessity, diversification and also decentralization were further restrained. This was done by strengthening corporate oversight, mothballing of products, divestment of subsidiaries, and outsourcing of non-vital activities. But decentralization and diversification were not yet banished completely. The remaining business units were pivoted away from their geographical preoccupation toward that of designated products, each product group commanding its own research and development, engineering, manufacturing, and sales departments.

The chapters in Business V, covering the years 1999 to 2008, deal with the final years of Del Prado's tenure as chief executive officer. Fueled by the Dotcom Boom, ASM expanded geographically, technologically, and operationally. Yet the costs for these auspicious expansions demanded reorganizations, and emancipated the Supervisory Board. The business strategy got adapted.

Although the confidence in decentral organization remained an indispensable component of the company, the relative autonomy was violated by a new expansion. The growing diversification among the product groups technologies ate into the company's margins. Both the volumes of sold products as the variety among these products were high. Again, too few assets leveraged the innovations. This time, however, the shareholders and a few technologically leading customers asserted their interests. To prevent the havocking of the lever underpinning the company, central oversight was strengthened, and further diversification was limited by an increasingly assertive and confident Supervisory Board. The chief executive officer and founder, Arthur del Prado, and with him his seemingly unremitting confidence in his business principles, made way.

What remained at the end of Arthur del Prado's career at ASM International was a company that could best be characterized as a 40-year-old teenager, as one of the company's employees put it. ${ }^{1} \mathrm{ASM}$ remained a multi-divisional company, offering a wide collection of machines and fabrication processes. But it also continued to be managed in a decentralized fashion, with subsidiaries passionately dedicated to a single activity (or a few activities at most). Although ASM had become much more professionalized, its business culture was still defined by dynamic entrepreneurism, autonomy, and a hands-on culture. Despite all the ebbs and flows in the company's history, in other words, its core identity hardly changed.

\section{Characterizing innovation}

In the four parts on innovation, I zoomed in on a few key technological developments in order to gain a better understanding of the innovation practices

\footnotetext{
$1 \quad$ Ray Ciferno, 'Interview with author'.
} 
of ASM International. In succession, ASM's position within the semiconductor industry's ecosystem of innovation came to the fore.

Innovation I explores ASM's transformation from being a representative to becoming an original equipment manufacturer by following four innovations in chemical vapor deposition in the period between 1971 and 1985. Although ASM retained self-willed characteristics from its past as sales agent, the company grew into the subordinated template of an equipment supplier for the chip industry, following an accumulation of opportunities, new experiences, and strategies. ASM's basic approach to innovation got well established in the initial years of the company as semiconductor equipment manufacturer.

ASM's innovation practices consisted of six components, some of which overlap with the elements of its business strategy. First of all, ASM structurally operated close to its customers, the semiconductor manufacturers, rendering accreditation by customers indispensable. Secondly, the company did not have a substantial internal inventive capacity: it did not concentrate on basic research while its innovations were very market-driven. Thirdly, the company had an interest in expanding the applicability of its technologies; claims of competence preceded actual substantiation. Fourthly, diversification enabled continual adaptation to evolving customer demands. Fifthly, innovation took place in the vicinity of the customers - whether this entailed a physical location or a technological market. It was decentralized. A sixth and final characterization is that ASM's innovation elaborated upon externally conceptualized inventions: the equipment manufacturer foremost industrialized immature yet promising semiconductor fabrication technologies.

Next, the three chapters in Innovation II address the development of a complete semiconductor production machine, the Epsilon single wafer epitaxial reactor, in the 1980s, from concept to commercialization. The development phase during which the concept and design of the machine was defined involved the balancing of estimated customer interests with material realities, and included an intense contestation and test of ideas and propositions. Despite this relative uninhibited yet passionate process, the eventual concept and design of the Epsilon reactor very much depended upon its correspondence with semiconductor manufacturers' technological demands and expectations. The case-study did not overhaul the six assessments from the previous Innovation chapters, but enforced those by offering insight into the social interactions and different technological routines.

The willingness of ASM to move beyond application-driven research is also illustrated by the account in Innovation III, covering ASM's interaction with public authorities from 1979 until 1992. These chapters reveal how ASM deployed 
Dutch and European governmental support to alter its innovation strategy and practices. The governmental involvement could not prevent the envisioned new mode of innovation from faltering. In the 1980s, a new ambitious innovation strategy differed too much from the realities and capabilities of the globally and technologically dispersed ASM operations, while subsidies provided an insufficient basis to ward off financial problems.

Innovation III centers around an effort to alter a few of the six components of ASM International's innovation process. A new technological center, named ASM Microelectronic Technology Center (AMTC), and a technology platform, called A600, were both meant to limit decentralization, control diversification, foster advanced technological development, and improve cohesion throughout the company. To gain governmental support for its agenda embodied by the AMTC and the A600, ASM's proposals had to be collaborative and comply with the emergent template of 'precompetitive research.' The deliberately vague notion of 'precompetitive research' pertained to research that was not yet commercially viable.

The alterations to the company's innovation process left their marks. On the one hand, the equipment manufacturer's innovation efforts got firmly embedded within the European microelectronics industry. The relative positioning of ASM toward chip manufacturers got institutionalized through governmental technology programs. Moreover, the perquisite of precompetitive research enforced adaptation of ASM's original application-oriented innovation practices. On the other hand, the events of the early 1990s reconfirmed the company's previous innovation practices of decentral and market-driven innovation, including the industrialization of externally conceptualized innovative techniques.

Innovation IV describes ASM's involvement in the development of the high-k gate dielectric from 1996 until 2007. Industry-wide, the high-k gate dielectric was recognized as an unprecedented technological challenge in semiconductor manufacturing. In pursuit of a strategic and prominent technological challenge like gate stack technology, interdependence between equipment and chip manufacturer increased; in for a penny meant in for a pound.

The impact of ASM's major customers - in particular American chip manufacturers like Intel and IBM - on ASM's innovation process intensified as ASM got involved earlier in the customer's innovation process. Chip manufacturers actively and constructively engaged ASM's particularities, such as its decentral structure, its application-driven research, and its diversification strategy. Yet, interdependence became apparent. Customers depended for their own competitiveness upon ASM's capabilities for innovation. 
Over the course of the Innovation chapters, the structural components of ASM's innovation practice became further institutionalized and professionalized through interaction with authorities and customers. Over time, ASM's engineers and managers embraced their and the company's subordinated or serviceoriented role toward the semiconductor manufacturers at a technological level. Its customers defined the course and applicability of its innovations.

\section{Explanation of ASM International's innovation process}

Here I turn to the second part of the study's research question and will explain ASM International's innovation process. Throughout this study, and following a rich tradition of evolutionary economics, innovation is understood as a process of variation and selection. Such process tends to be determined by deliberate actions of an innovator in combination with a range of external circumstances linked to a dynamic socio-economic context. To unravel this process I introduced the concepts of path, fortuna, and virtù.

'Path' helps us to reconstruct the development of a technology by distinguishing its starting-point, analyzing perceptions of the future, and studying the route traversed. As such, this concept makes it possible to analyze particular variations and selections adopted along the way. The concepts of 'fortuna' and 'virtù,' by contrast, are less conventional. They allow us to distinguish anomalies and their effects in the innovation process. If fortuna emphasizes the volatility of the innovator's selection environment, virtù stresses the degree to which the innovator manages to secure or maintain control amidst constantly changing circumstances. In this, fortuna and virtù serve to counteract any teleological premises implied in the notion of 'path' and evolutionary economics in general.

\section{Explaining with path}

'Path' covers the direction and progression of a technological development, stretching from the past (path dependency) to the future (pursuit of opportunities). Path encompasses that which can be anticipated, such as particular regularities and other known factors.

Below, I discuss and explain path in more detail. First by grasping the rules of the path to which ASM adhered. In other words, its routines. Secondly, I turn to the various roles that defined this path and their interaction. In this I assess who influenced variations and selections in an innovation process. Thirdly, I explain the way ASM International navigated its path, i.e. its strategy. And, finally, I explain what this path was all about by viewing the traversed path amidst a wider context of industrial development. For each of these four components of path, I start with a recapitulation of my observations, followed by a reflection how my findings relate to academic literature. 


\section{The rules of path: Routines and patterns}

ASM's accumulation of knowledge about the semiconductor industry's advanced technologies was, in the first place, driven by demands from its customers, the chip producers. Elaborating on its origins as a sales agent, the equipment supplier basically supplied whatever the chip manufacturers wanted. Already in its very first years (cf. Innovation I), the ever growing accumulation of capabilities and knowledge of semiconductor fabrication processes very much relied on ASM's experience in dealing with semiconductor manufacturers (Motorola, IBM, and Philips), principals (US Dynamics, Applied Materials, and Tylan), and acquired technology from disintegrating electronics conglomerates (Standard Telecommunication Laboratories, and Philips Research). Moreover, from the mid-1990s on, ASM's operations flourished through the close collaboration with technologically leading chips manufacturers, including Intel and IBM. Through such intimate cooperation, the equipment manufacturer familiarized itself with increasingly advanced semiconductor fabrication processes and technologies.

The 'clash of routines' observed in Innovation II illustrated a difference in innovative practices. In this case study engineers brought in their own routines. The clash was rooted in different expectations and perceptions of technological development among the engineers involved. Making technology work sufficed. How and why technology worked only mattered if the engineering process stagnated due to unknown causes. The available resources of the company hardly allowed open-minded and inquisitive explorations into physics and chemistries relevant for semiconductor fabrication. Yet, over time, such ad-hoc explorations in combination with ASM's absorptive capacity caused an accumulation of expert knowledge in semiconductor fabrication processes.

Running ahead in technological development increased the chance of commercial failure. ASM tried to foster a more advanced research capability in order to effectively anticipate technological developments across its operations and markets (see Innovation III). The incarnations of this ambition - the AMTC and the A600 - did result in valuable innovations and knowledge, but failed to win the allegiance of the respective subsidiaries and their appropriable markets. Amidst volatile market circumstances, limited financial resources, and severe competition, explicit demands from customers defined ASM's course of innovation.

To further articulate this practice of the equipment manufacturer, I use Keith Pavitt's taxonomy of innovation patterns (cf. the conclusions of Innovation I). ${ }^{2}$ ASM clearly fits the description of a 'specialized supplier':

\footnotetext{
2 Keith Pavitt, 'Sectoral patterns of technical change: Towards a taxonomy and a theory', Research Policy 13:6 (1984) pp. 343-373.
} 
'Specialized supplier firms are small and high-performing inputs into a complex system of production and product development in the form of machinery, components, instruments and software. Specialized supplier firms benefit from the operating experience of advanced users, in the form of information, skills and the identification of possible modifications and improvements. Specialized supplier firms accumulate the skills to match advances in technology with user requirements, which given the costs, complexity and interdependence of production processes - put a premium on reliability and performance, rather than on price. The main tasks of innovation strategy are keeping up with users' needs, learning from advanced users and matching new technologies users' needs. ${ }^{3}$

Characterizing ASM's innovation process as one of a 'specialized supplier' indicates the stakes and rules of the game played by the equipment manufacturer. The notion of 'specialized supplier' makes us see why ASM could rely on a supply of external inventions, "benefiting from the operating experience of advanced users.' The concept also stresses why ASM operated in such an application-driven manner, while the definition helps us to grasp the relationship between ASM and its customers.

If Pavitt's template is rather static, the history of ASM shows that the company might have been merely intuitively aware of its role as 'specialized supplier.' The development of ASM's innovation pattern, then, can be qualified as emergent, not deliberate - to use terminology from management scholars Henry Mintzberg and James Waters. ${ }^{5}$ Only after ASM's management realized that it could not escape its innovation practice (cf. Innovation III) did it deliberately embed itself in the semiconductor supply chain (cf. Innovation IV).

\section{The roles on a path: Enactors and selectors}

As equipment supplier, ASM had a persistent incentive to extend the applicability of its technologies. Wider pertinence meant a bigger appropriable market. For instance, extending the use of atomic layer deposition beyond the deposition of gate dielectrics might yield more sales. Moreover, even for a similar applications, ASM's products varied. It made a difference whether IBM or Motorola ordered an ASM plasma deposition furnace applied for the growth of a passivation film

3 Joe Tidd, John Bessant, and Keith Pavitt, Managing Innovation: Integrating Technological, Market, and Organizational Change (2nd edition; Wiley, Chichester, 2001), p. 113.

4 Ibid.

$5 \quad$ Henry Mintzberg and James Waters, 'Of Strategies, Deliberate and Emergent', Strategic Management Journal 6:3 (1985) pp. 257-272, p. 257. 
of silicon nitride. Each chip manufacturer had its own peculiarities with regard to the integration of materials, processes, and machines. The technologies of the equipment supplier had to be versatile. Variation was imperative.

In competition with other semiconductor equipment suppliers, ASM bloated the applicability and versatility of its technologies and capabilities. Such 'competition of enactment' was not limited to equipment suppliers, but also applied to ASM's engineers and business units. For instance, engineers would champion their own versions of an epitaxial reactor, be it for simple confidence in the viability of their proposal or in pursuit of peer recognition, if not both (cf. Innovation II). ${ }^{6}$

Likewise, governments had an interest in stimulating early cooperation and alignment between chip and equipment manufacturers in order to foster economies, knowledge infrastructure, and employment within a national context. Collaboration with customers, or an 'alliance of enactment,' increased the probability of success (cf. Innovation III).

Chip manufacturers defined the suitability of a process or machine for a particular application by procuring a piece of technology and applying it for high-volume manufacturing of computer chips. Such procurement secured a technology's final commercialization, marking the end of an innovation process. Ironically, perhaps, equipment suppliers, governments, academic research facilities, and even the most brilliant employees of ASM were never in a position to exercise this ultimate authority over the innovation process.

Yet, on some occasions, even chip manufacturers themselves contributed to the competition of enactment by ASM and its engineers. Both the equipment and chip manufacturer benefitted from early engagement as this limited uncertainty. Having access to innovative fabrication techniques contributed to the competitiveness of chip producers as well. Initiatives like the (Inter) National Roadmap for Semiconductor Technologies (ITRS) helped equipment manufacturers to bring their products and technologies into line with the needs of customers.

While Pavitt's notion of 'specialized supplier' helps us to understand the playing field, the notions of 'enactor' and 'selector,' suggested by innovation scholars Raghu Garud, David Ahlstrom, and Arie Rip, are useful for grasping the participants and their role in the game (cf. conclusions Innovation I). ${ }^{7}$ The

6 Edward Constant II, 'The Social Locus of Technological Practice: Community, System or Organization?', in: Wiebe Bijker and Thomas Hughes (ed.), The Social Construction of Technological Systems: New Directions in the Sociology and History of Technology (MIT Press, Cambridge, 1989) pp. 223-242.

7 . Raghu Garud and David Ahlstrom, 'Technology assessment: a socio-cognitive perspective', Journal of Engineering and Technology Management 14:1 (1997) pp. 25-48; and Arie Rip, 'Folk 
equipment manufacturer was an 'enactor,' which entailed that ASM offered its technology as a solution to multiple problems. By contrast, ASM's customers, the chip manufacturers (the 'selectors'), would carefully choose a technology to solve their singular problem from a variety of solutions offered by competing equipment suppliers.

The eventual selection of a technology by a customer constituted a moment of 'closure." If a technology is not commercialized - i.e. procured by a customer - no closure occurs. The competition of enactment remains unsettled, and most probably loses its momentum entirely after the exhaustion of money and resources. Or the technology is redefined to be applicable for other purposes, complying to other means, etc. ${ }^{9}$ Materiality, time, resources and estimation of customer-interests functioned as 'pre-selectors' in the competition of enactment (cf. Innovation II). In experiments, physical realities of materials could thwart propositions of enactors. Also, time and the depletion of resources forged consensus or resignation within the competition of enactment. In this context, Garud and Ahlstom articulated the useful notion of 'bridging incident,' during which the enactor and selector interact, comparing qualification parameters, so to speak. In the case of ASM, the equipment manufacturer constantly tried to force such a bridging incident rather sooner than later.

The concepts of enactor and selector in fact make us realize that ASM's role and behavior can only be understood by viewing ASM within the wider semiconductor industry - and not just the semiconductor equipment sector. Furthermore, both concepts help us to detail the logic behind variations and selections throughout an innovation process. Enactors stimulate variations in technological development, by propagating their solution for multiple applications. Selectors limit the variation by selecting one of the solutions for their desired purpose.

Obviously, perspective is the crux here. The label of enactors is applicable to engineers within a development project, but also to ASM in its relation to its competitors and customers, or even ASM's customers in relation to other chip companies and electronics manufacturers. As such, both the alliance and the competition of enactment can be projected on various links in the semiconductor or micro-electronics supply chain. It is safe to argue, then, that technological development across the micro-electronics industry - from gas and material suppliers to computer producers - actually constituted a 'chain of enactment.'

Theories of Nanotechnologists', Science as Culture 15:4 (2006) pp. 349-365, pp. 360 and 361.

8 Trevor Pinch and Wiebe Bijker, 'The Social Construction of Facts and Artefacts: Or How the Sociology of Science and the Sociology of Technology Might Benefit Each Other' Social Studies of Science 14:3 (1984) pp. 339-441.

9 Ibid. 


\section{Navigating path: Innovation and business strategy}

During an innovation process, the enactor does not hurtle forward into the future haphazardly. Based on previous experience, as an organization or individually, the enactor anticipates a stream of decisions resulting in the realization of its intention. In other words, the enactor contemplates an innovation strategy. For an enactor like ASM, such an innovation strategy was made at the corporate level and with regard to the technological development involved.

At a corporate level structure defined the innovation strategy. Structure stipulates who innovates where and how. ASM's structure was that of a multi-divisional enterprise, encompassing a head-office and numerous division engaged in various activities. As described above, initially ASM's corporate strategy was highly decentralized, gradually becoming more centralized over time. This decentral structure followed from Del Prado's awareness that ASM had to be in the vicinity of its customers. It reflected the geographically and technologically dispersed markets.

At the corporate level of ASM International, innovation strategy involved outlining the organizational structure and allocation of financial, technological, and human resources to facilitate innovation. At the head office, innovation strategy was subordinate to that of the specific technological endeavors pursued. ASM's first technological directors, Willem de Leeuw and Ernst Granneman, tried to alter the company's overall innovation strategy for good reasons, but to no avail (cf. Innovation III and Business IV). Based on this experience, their successor Ivo Raaijmakers rather sought to work with the existing structure and various innovation strategies (cf. Innovation IV and Business V).

A successful corporate innovation strategy reinforced and enabled the approaches selected for specific projects and by distinct business units. The constant adjustments of ASM's corporate innovation strategy were largely in response to changing economic conditions.

ASM's corporate innovation strategy was very much a product of its time. Experiences from the past blended with continuously advancing appreciations of the innovator's playing field. By voraciously reading magazines like Harvard Business Review, Del Prado obtained inspiration to reinterpret and reevaluate his assets, earlier decisions, and potential actions. Based on such reassessment, the company's corporate innovation strategy was adapted. Particular reassessments did not always entail radical overhauls of the corporate innovation strategy, however, as structural elements prevailed.

The strategies formulated by ASM's management indeed aligned with contemporary insights of management scholars with regard to multi-divisional enterprises. In the 1960s and 1970s, Del Prado's personal experiences as a 
business man corresponded with the advocacy of prominent management scholars Peter Drucker and Ivar Ansoff for decentralization and diversification.10 In the first half of the 1980s, ASM's structure and strategy perfectly adhered to the ingredients for a successful enterprise propagated by Thomas Peters and Robert Waterman in In Search of Excellence. 11 This included the significance of minimal central guidance, hands-on culture, nurturing of autonomy and entrepreneurship, and a 'bias for action'.

However, in the late 1980s renowned management scholar Michael Porter recognized a structural dynamic that hindered decentralized multi-divisional enterprises, which in the same period of time dragged ASM down. ${ }^{12}$ It involved the misalignment of the corporate strategy of the enterprise as a whole and competitive strategies of its subsidiaries. Elaborating upon this assessment, management scholars P.R. Prahalad \& Gary Hamel articulated the notions of 'strategic intent' and 'core competencies' in the late 1980s and early 1990s. ${ }^{13}$ Armed with these concepts, multi-divisional corporations - among which ASM - put a brake on further diversification and decentralization, and defined its core competencies, in products as well as operationally.

After this turn in the academic debate about multi-divisional enterprises' business strategies, in his prolific book The Innovator's Dilemma, management scholar Clayton Christensen advocated segmentation of a company into small business units dedicated to the pursuit of 'disruptive technologies' and subsidiaries taking care of 'sustaining technologies. ${ }^{14} \mathrm{~A}$ buoyant reading of The Innovators Dilemma seemed to have underpinned Del Prado's reignited confidence in decentralization and diversification at the turn of the century.

Yet, the corporate innovation strategies - whether concocted by ASM or presented by management scholars - were foremost embedded in the wider

10 Peter Drucker, 'The Effective Decision', Harvard Business Review 45:1 (1967); Igor Ansoff, Corporate Strategy: An Analytical Approach to Business Policy for Growth and Expansion (McGrawHill, 1965); Peter Drucker, 'New Templates for Today's Organizations', Harvard Business Review 52:1 (1974) pp. 45-53; Igor Ansoff, 'Strategies for Diversification', Harvard Business Review 35:5 (1957) pp. 113-124.

11 Thomas Peters and Robert Waterman, In Search of Excellence: Lessons from America's Best-Run Companies (Warner Books, New York, 1982).

12 Michael Porter, 'From Competitive Advantage to Corporate Strategy', Harvard Business Review (May 1987) pp. 43-59.

13 C.K. Prahalad and Gary Hamel, 'Strategic Intent', Harvard Business Review (May 1989) pp. 65-76; and C.K. Prahalad and Gary Hamel, 'The Core Competence of the Corporation' Harvard Business Review (May 1990) pp. 79-91.

14 Clayton Christensen, The Innovator's Dilemma: When New Technologies Cause Great Firms to Fail (Harvard Business Review Press, Boston, 1997). In his second book, Christensen elaborated on the same theme; see Clayton Christensen and Michael Raynor, The Innovator's Solution: Creating and Sustaining Successful Growth (Harvard Business Review Press, Boston, 2003). 
economic developments. ${ }^{15}$ Both the theories as ASM's own strategy were rooted in the same times. The relevance of context becomes apparent when looking at ASM's corporate strategy in relation with that of other large Dutch corporations after the Second World War.

Business historians Abe de Jong, Keetie Sluyterman, and Gerarda Westerhuis explain that the strategy of Dutch firms was characterized by early internationalization, a multi-divisional structure, and awareness of American studies into management strategies. ${ }^{16}$ These historians further describe a development in which Dutch multi-divisional firm adopted a more functional structure from the late 1980s onward. They also describe the wider protracted emancipation of shareholders and corporate governance. Throughout its history, ASM had to deal with such widespread occurring troubles in managing and strategizing a multi-divisional firm.

At the level of technological development within a project or a business unit, the innovation strategy - the pattern of decisions - differed per case. Within a project, program, or business unit, strategy was determined by a unique combination of forces. The distinction between user logic, competitive logic, and material logic as proposed by historians David Brock and Christophe Lécuyer helps us to specify the different variables in play. Making the product work means having it address the problem of the selector (user logic), dealing with the material realities (material logic), while also accounting for the other enactors (competitive logic). ${ }^{17}$

The order in which these logics came about differed per case. In the case of the early chemical vapor deposition techniques, ASM, or an external supplier of a technique like Rudolph Heinecke, overcame a material reality first. Secondly, ASM aligned this capability with the interest of its customers. Thirdly, in the pursuit of delivering the capability to the users, it accounted for the competition, the other enactors. By contrast, the innovation process set forth in Innovation IV started with the competitive logic (joining the market for rapid thermal processes), followed by the material logic (the unique silicon nitride process with remote plasma generator) and, finally, the user logic (learning about potential applicability for the gate stack at Intel).

Throughout this study, ASM realized that early involvement of customers the user logic - contributed to successful commercialization of inventions. Being

15 Keetie Sluyterman, Dutch Enterprise in the Twentieth Century: Business strategies in a small open economy (Routledge, Abingdon 2005).

16 Abe de Jong, Keetie Sluyterman, and Gerarda Westerhuis, 'Strategic and structural responses to international dynamics in the open Dutch economy, 1963-2003', Business History 53:1 (2011) pp. 63-84.

17 David Brock and Christophe Lécuyer, 'Digital Foundations: The Making of Silicon-Gate Manufacturing Technology', Technology and Culture 53:2 (2012) pp. 561-597. 
a specialized supplier implied that the equipment manufacturer, or its employees, had to offer a technology that worked according to the interests of its customer. The task at hand was ostensibly simple: making the machine or process work for the customer. It was an appreciation that ASM's engineers and management learned by trial and error.

\section{The path traversed: ASM International and industrial development.}

To conclude this discussion of 'path,' I assess the evolvement of ASM's innovation process in relation to the wider industrial development. Elaborating on ASM's innovation pattern of 'specialized supplier' and its role as enactor toward semiconductor manufacturers, it is hard to escape the notion that equipment manufacturers were closely connected to the semiconductor industry. In fact, ASM's innovation was primarily geared at increasing productivity in this sector.

Such productivity was achieved through decreasing the 'cost-of-ownership' for the customer of using an ASM tool. Lowering this cost was achieved by having the revenues attained through the machines (in working chips) outpace the tool's procurement, maintenance, and operational costs. A maximum throughput (wafers processed per hour), yield (number of wafers or chips within specs), bigger wafer sizes (facilitating more chips per wafer), and a small footprint (requiring less precious space in the cleanroom) constituted the parameters for achieving higher productivity.

Unique, however, was that miniaturization of transistors and other electrical components integrated in a computer chip also defined productivity in the semiconductor industry. Smaller and thus cheaper transistors resulted in more power and better performance of computer chips. Over the course of the years covered by this study, the transistor did shrink very much indeed. From 1970 until 2008, the size of a transistor decreased from approximately 10 micron to just 45 nanometer. By 2008, gate oxides had a thickness of about 1 nanometer - two-hundredths of a human hair's diameter. The number of transistors on an Intel computer chip increased from 2300 in 1971 to 731 million by 2008, and even 8 billion by $2017 .{ }^{18}$

Throughout the period covered in this study, the most basic element of the computer chip remained the same. By the late 1960s, the polysilicon-gate metaloxide-silicon field-effect (polygate-MOS) transistor emerged as the common denominator in chip technology (cf. Intermezzo in Business I). Most computer chips contained these polygate-MOS transistors instead of bipolar ones. And through miniaturization of these transistors, their absolute volume produced

18 Data are based on Intel's 4004 chip (1971), its Core i7 Quad (2008), and its 28-core Xeon Platinum 8180 (2017). 
annually increased exponentially, becoming the most produced item by human beings. ${ }^{19}$ All the production innovations in the semiconductor industry involved shrinking the polygate-MOS transistor and creating new interconnecting structures above it to direct electrical signal to these ever smaller constructions.

Only recently did the design of the polysilicon CMOS transistor change. As of 2007, after almost forty years, Intel's computer chips were no longer powered by polygate-MOS but via high-k metal gate MOS transistors (cf. Innovation IV). Ever since, the diversity in transistor design and chip configurations proliferated in the semiconductor industry. More complex structures were fabricated, like FinFET's, 3D structures, and gate-all-around transistors, each requiring more fabrication control and ingenuity on the part of both the manufacturer and the equipment supplier.

Semiconductor equipment manufacturers had a pivotal role in enabling the construction of the tiniest transistors, lowering cost per transistor and subsequently progressing Moore's Law. This was done by improving the accuracy of lithography and by integrating new materials and innovating fabrication techniques. Enabling chip manufacturers to produce the smallest transistors first offered big commercial rewards for companies like ASM. For every new generation of computer chips, with ever smaller features, semiconductor equipment manufacturers might win the allegiance of their respective markets. It was this promise of 'the winner takes all' that fostered innovation in semiconductor fabrication technologies.

Miniaturization and productivity propelled diversity and growth in the semiconductor equipment business. This involved progression in lithography techniques, single wafer processes, and vertical furnaces. Some intended to facilitate bigger wafer sizes. Others to integrate new materials, which introduction was accompanied with new production techniques, like copper mechanical polishing or atomic layer deposition. Each new wafer size, new equipment configuration, new material, and new fabrication technique formed a new market, appropriable by ASM.

For wafer equipment suppliers the variety of production processes and the variety of similar processes among its customers constantly increased. Such high variety and low volumes in products jeopardized economies of scale. Furthermore, dedicated pieces of fabrication technology for each customer was simply unattainable. As a consequence, ASM - and other equipment suppliers standardized common modules and wafer handling platforms. Primarily, reaction chambers and gas supply systems remained adaptable to customer or process specifications.

19 Brock and Lécuyer, 'Digital Foundations'. 
In the semiconductor assembly and packaging industry - handling not wafers but single dies (unpackaged computer chips) - the business was characterized by low variety and high volume of products. Initially, computer chip packages were highly standardized, requiring a standard procedure for each die. Moreover, customers required not a few or a dozen machines as in the wafer equipment segment, but a few dozen or even hundreds similar bonders and molding machines to process all the dies. The low variety among products allowed ASM Pacific Technology to pursue a vertically integrated manufacturing strategy through its Shenzhen operation. This strategy was versatile enough to withstand the proliferation of chip packages standards and the volatility of the market. The required volumes of production machines defined standardization and innovation in manufacturing semiconductor equipment.

Innovation scholars James Utterback and William Abernathy have extensively published about dynamics of innovation and industrial development, and their analysis seems to be particularly relevant for ASM's path. ${ }^{20}$ They conceptualized 'waves of product and process innovation' and the emergence of a 'dominant design.'

Indeed, by the late 1960s and early 1970s, the semiconductor industry seemed to settle upon a 'dominant design.' Arguably, in the case of the semiconductor industry, this dominant design was a computer chip containing polygate-MOS transistors. From the moment that this configuration emerged, competition in the industry shifted from developing new products - 'product innovations' - to innovating fabrication techniques, or 'process innovations.'

After the emergence of the dominant design, the number of process innovations increasingly exceeded the number of product innovations. Competitiveness in the semiconductor industry depended foremost upon productivity, enabling smaller and better production of the dominant design. This was true up until recently, when new products like FinFET undid the prevalence of the industry's dominant design, heralding the end of an era.

Moore's Law also fits in the wave of process innovations in the chip industry. It is no surprise, perhaps, that the 1965 publication of what was to become known as Moore's Law coincided with the emerging dominant design, and that originally it was an economic statement about cost reduction of electrical components on a chip. Thus, the innovations in semiconductor manufacturing technologies nicely fit with Utterback and Abernathy's model.

20 James M. Utterback and William J. Abernathy, 'A Dynamic Model of Product and Process Innovation', Omega 3:6 (1975), pp. 639-656; James Utterback, Mastering the Dynamics of Innovation (Harvard Business School Press, Boston, 1994). 
It is important to emphasize that the emergence of a 'dominant design' does not preclude the presence of other designs. After all, throughout ASM's history much of its products were used for other types of chips as well, like the application of the Epsilon for bipolar chips or BiCMOS. The dominant design, the polygateMOS transistor on a chip, constitutes the general line to which more specific and alternate developments can be related.

For ASM, or the semiconductor equipment industry, the dominant design did not coincide with a specific piece of equipment. The diversity among modules or types of machines was simply too large. A lithographic system differed too much from a deposition or etch machine. Although the equipment industry's etch and deposition cluster tools appeared to be similar on the outside, their functioning and internal make-up differed from one supplier to the next (such as ASM, Applied Materials, Novellus, and LAM Research). In the 1990s, a standardization effort of modules and cluster machines under the SEMI Modular Equipment Standardization Committee harmonized interfaces between wafer platforms and reactor chambers. But contrary to expectations, such harmonization did not herald standardization of equipment. ${ }^{21}$ In the $21^{\text {st }}$ century, each equipment supplier primarily wielded their own internal standards. There was no dominant design in semiconductor equipment.

The development of the semiconductor equipment industry was an inherent part of the development of the semiconductor industry: the equipment industry and chip manufacturers were interdependent. The wave of process innovation thus followed from innovations among both equipment and chip manufacturers.

The model put forward by Utterback and Abernathy also involves claims about the nature of opportunities. According to the model, the technological opportunities emerging for ASM, and the company's capability in providing those, resulted from the growing demand for process innovations. As long as the wave rolled on, ASM - and Arthur del Prado - could be quite sure about the commercial viability of their innovations and entrepreneurial caprices, as long as these products offered chip manufacturers high productivity and miniaturization. The wave of process innovation and the subsequent growth of the semiconductor equipment industry was almost a given, feeding Del Prado's confidence in the feasibility of ASM's numerous costly development projects. The entrepreneur's attributed visionary capabilities were very much rooted in an intuitive appreciation of ASM's being part of the wave of process innovation.

21 As suggested by Richard Langlois, 'Competition through institutional form: the case of cluster tool standards', in: Shane Greenstein and Victor Stango (eds.) Standards and Public Policy (Cambridge University Press 2006) pp. 60-86. 


\section{Explaining with fortuna}

Throughout its history, ASM has been facing the risk of its own demise. At the industrial, technological, and organizational levels, the company was constantly subject to threats and uncertainties that might seal its fate. To the extent that these were hard to predict or anticipate, I have invoked the notion of 'fortuna' in this study.

Fortuna is the unforeseen, a crisis or contingency that will undermine any presumed certainty or logic involved in some planned or predictable 'path'. Fortuna thwarts teleological or progressive imaginaries about businesses and innovation processes. As such it aligns with stochastic genetic mutation in variation and selection processes in biological evolution. Examples of the role of fortuna in this study are economic downturns, an unexpected encounter, or a miraculous technological breakthrough accompanied by an exuberant exclamation of 'Eureka!'. Here I will first reflect upon the manifestations of fortuna and their effects, followed by an appreciation of fortuna's role in ASM's innovation process.

\section{Manifestations of fortuna}

In this study I identified various manifestations of fortuna that would all affect the course of ASM and its innovation process. The unexpected happened at an individual, industrial, economical, organizational, financial, governmental, competitive, and material level.

Instances of fortuna at an individual level entailed Arthur del Prado's encounter with Dean Knapic in 1958, instigating an illustrious career in semiconductor technology, and the availability of Ray Friant as chief operating officer in the 1990s. Or think about the heart failures of Del Prado in 1985 and 2000. At the industrial level, ASM had to deal with sudden upturns or downturns in the market, such as the abrupt downturn in the market of memory chips in 1984 and the successive transformation of geographical semiconductor markets. Economically, fortuna manifested itself in broader prevailing developments, like the Dotcom Boom (and the burst of this bubble) or the 2007 financial crisis.

Other instances of fortuna were rather linked to the organizational level. A case in point is the failure of ASM NuTool in 2005. Financially, fortuna involved the availability of the Limited Partnership funding scheme in 1982, which provided the foundation for the Epsilon single wafer reactor. Or the sudden depreciation of ASM Pacific Technology's stock amidst the Asian financial crisis of 1997. A clear governmental example of fortuna involved the RSV affair, which finalized the turn from defensive economic policies toward innovation policy in the Netherlands. A competitive manifestation of fortuna formed ASM Microchemistry's availability in 1999, or the intentions of one of ASM's leading customers in the $21^{\text {st }}$ century, Intel. 
Material manifestations of fortuna specifically pertained to the confrontation with the physical or chemical conditions during experimental projects or engineering. Innovation, after all, inherently involves clearing a path into the unknown. During such an endeavor, material interference may appear most unexpectedly. One example was the constant breakage of quartz in the Model $2 \mathrm{C}$ variation during the development of the Epsilon reactor (cf. Innovation II). Another example was the ability of the Epsilon reactor, when complemented with a remote plasma generator, to grow unprecedented thin film of silicon nitride, putting ASM in the limelight for gate dielectrics (Innovation IV). None of these results could have been reasonably preconceived.

Yet, the phenomenon of fortuna is always relative, since it involves a contingency in the eyes of the beholder. A striking example was the opportunity to acquire Microchemistry in 1999, which put ASM in the lead of the revolutionary atomic layer deposition technique (Innovation IV). For ASM this opportunity came out of the blue, while Microchemistry and Intel had in fact been concocting the deal for a while already. Another one involved the Machiavellian Moment experienced by Philips in 1990, urging a drastic overhaul of its business strategy in the socalled Operation Centurion, and subsequently its ambitions in semiconductor manufacturing (cf. Innovation III). This event affected ASM through the evaporation of demand for its machines in Europe.

Furthermore, there were numerous, often long-term economic developments that influenced ASM's business and subsequently its innovation process in unexpected ways. Think about the economic stagnation of the late 1970s, which forced large integrated electronics manufacturers to divest activities. Such assets were happily acquired by Arthur del Prado and further developed into innovative pieces of semiconductor equipment. Or consider the Machiavellian Moment involving activist shareholders asserting their rights as investors in the 21st century, which fitted in a longer development of strengthening corporate governance. These manifestations of fortuna might have been anticipated. However, in their timing, their impact, and their shape they still took ASM off guard.

\section{Fortuna's role in ASM's innovation process}

Fortuna confronted the deliberated schemes and shapes of the company for good and bad, creating circumstances in which innovative actions were necessary. In this, the manifestation of fortuna was closely related to the innovation process itself.

A few occasions proved to be truly disruptive, threatening the survival of ASM as a company and negating all presumed certainties. Such events, which historian John Pocock characterized as Machiavellian Moments, call for immediate action 
while at the same time no proven remedy or intervention is available. ${ }^{22}$ Examples of such moments were Del Prado's looming involuntary departure from the market for chemical vapor deposition in 1971, or the imminent call of loans by ASM's bankers in 1988 and 1992.

At these moments the company's survival was under threat, and the actual response also had drastic ramifications for the company's innovation process. Examples are ASM's transformation into an equipment manufacturer, or the curbing of diversification through the divestment of subsidiaries like ASM Lithography. Only Machiavellian Moments disrupted the structural innovation practices of the entrepreneur.

At the level of the technological developments itself, materiality jumps to the fore as defining for the course of the variation and selection process. The material results of experiments stirred the contemplation of new varieties or enforced selections. Enabling such an experimental process of trial and error in a project or business unit was indispensable. Materiality aligned with anthropologistsociologist Bruno Latour's observation that material has agency. ${ }^{23}$ It truly affects the outcome of the innovation process.

Over time, the industrial and technological opportunities became less benevolent or unexpected. After being a force that defined and incorporated the ASM's structure, strategy, and growth, fortuna urged changes to these same aspects of the company. For its investors, managers, customers and employees, semiconductor equipment manufacturers had to be prepared for the severe cyclical nature of their market. Fortuna forged a process of organizational maturation amidst a maturing industry.

In the particular case of ASM International, Del Prado had shown to be a master in appropriating benevolent manifestations of fortuna. Yet he proved to be ill-equipped in dealing with unsettling manifestations of fortuna. In each of the cases, he tended to persist in his old habits which were applicable when fortuna foremost was a force of opportunity. This was shown through his consistent investment of all cash reserves into new innovations, while a buffer of cash was indispensable to withstand fortuna. This realization that cash was king was consistently taken up to Del Prado by his staff members. Only through

22 John Pocock, The Machiavellian Moment: Florentine Political Thought and the Atlantic Republican Tradition (Princeton University Press, Princeton, 1975).

23 Bruno Latour, 'How to write “The Prince” for machines as well as for machinations', in: Brian Elliott (ed.), Technology and Social Change (Edinburgh University Press, Edinburgh 1988), pp. 20-43; and Michel Callon, 'Some elements of a sociology of translation: domestication of the scallops and the fishermen of St Brieuc Bay', in: John Law (ed.), Power, action and belief: a new sociology of knowledge? (London, Routledge, 1986), pp. 196-223. 
crises seized the rest of the company back control, making ASM less susceptible for the impact of fortuna.

Evidently, 'fortuna' can be seen as a constructive element encouraging if not training the innovator to keep an eye out for contingencies and the unforeseen. Any understanding of the development of ASM's innovation process will need to start from the realization of the future's indefiniteness. Even a visionary innovator, after all, has no full control over the future.

\section{Explaining with virtù}

As a third conceptual element in this study, 'virtù' bridges the dichotomy of 'path' and 'fortuna.' It constitutes the ability to act or the activity of acting in the face of derailing events, during which presumed certainties turn obsolete. In the face of fortuna, virtù 'is about taking action, taking initiative, anticipation, and playing along with a given situation.' ${ }^{24}$ Moreover, it involves a 'combination of intelligence, courage, and perseverance, stripped of any moral and theological connotations. ${ }^{25}$ As such it is very much impromptu, temporally embedded, and accompanied by fortitude. Through virtù the new order is encapsulated. It is innovation in its most dramatic appearance.

\section{Demonstrations of virtù}

Quite often throughout this study, virtù seemed to be related primarily to entrepreneurism and technological development. Entrepreneurism evolved around harnessing unexpected opportunities to the benefit of the entrepreneur and enterprise. At a technological level, virtù was demonstrated by engineers facing unexpected material realities. By trial and error, an open-ended process, the engineers overcame fortuna and innovated.

Within ASM International, taking initiative was very much stimulated. All employees, engineers and managers in particular, were expected to bring their own resourcefulness to the fore. Being a fairly small company with suboptimal financial reserves as a matter of course, its competitiveness depended on the inventiveness of staff. An absence of rigid procedures enabled entrepreneurial agility, but also offered little consolation to the employees. Staff saw immediate effect of their actions. The urgency to live up to this expectation was high, and after a while drained most of them.

\section{Virtù and bounded rationality}

More than once in the history of ASM, the capabilities of an individual engaged in an innovation process determined his or her subsequent actions. In the case

24 Original quote in Dutch - Van Middelaar, De nieuwe politiek van Europa, p. 29.

25 Ibid. 
of Del Prado, virtù was also embodied in his steady confidence in industrial growth, the ingenuity of engineers, and his own business principles. The longer he managed to survive in the volatile semiconductor industry, despite having to face antagonistic bankers and major industrial downturns, the more his confidence increased. Age and experience, in other words, consolidated his intuition and skills.

When Del Prado did not know how to proceed after being confronted with fortuna, advisors and consultants would contribute with their skills and knowledge, with varying degrees of success. The interference of one of them, Ray Friant, who served as chief operating officer from 1992 until 1997, would avert immediate bankruptcy. During these years, the survival of the firm depended on skills Del Prado lacked, such as process and human resource management. The example of Friant shows that venturing into the unknown successfully requires intuition and skills, which in his case were based on his experience in operational management.

At the level of engineering, thus beyond the corporate management, the role of conventions was rather remarkable for the innovative environment of chip manufacturing. Most actors were highly rational in their considerations and operations, and as a consequence many practices in the industry relied on solid empirical foundations. But conventions and routines also helped to connect the dots, bridging unknowns.

Conventions constituted temporal explanations for the workings of technology. An example of this attitude is exemplified by Intel's Copy Exactly! policy, to which ASM was subjected as of the late 1990s (cf. Innovation IV and Business V). Under this policy, ASM was not allowed to change components without verifying its neutral effect on the performance of the machine and process.

Conventions also helped to assess the direction of the market and technological development. Examples include the question of whether the industry would again turn from single wafer toward batch processes, the pace of wafer scaling, and the imminent end of Moore's Law or the wave of process innovation as such. Either way, the robustness of conventions was proven most solidly by innovation. The act of innovating constituted the ultimate litmus test.

Thus, virtù involved bounded rationality. This bounded rationality pertained to the innovator's particular conscious or unconscious skills. Whereas the views of Machiavelli are often associated with a notion of amoral resoluteness, political or business leaders cannot escape the conditions of which they are themselves a product. In a situation of absolute bewilderment, innovators have to rely on the skills and experience they accumulated in their life. Yet the innovator himself 
defines which bounds are more determinative. Thus only through his actions do the structural and relevant boundaries become apparent.

\section{Virtù's role throughout ASM's history}

Virtù was a force of path adaptation and creation. By acting in a situation where earlier conventions, perceptions, or rules no longer sufficed, the innovator embarked into terra incognita. Such endeavor was characterized by impetuousness but also serendipity. Trying to break new ground without being afraid of what might be encountered. Consequently, virtù initiated ASM's future as 'creator and repository of product-related embedded organizational knowledge'26 Virtù shaped ASM's path as innovator.

At ASM, the ability to alter the course of the company through virtù - and thus implicitly exposing oneself to fortuna in new destructive and constructive variations - decreased. As the company grew from a one-man business in the 1960s to one with thousands of employees, its responsibilities increased accordingly. To facilitate the company's growth, relations with external parties were established: authorities, investors, suppliers, and customers. To all these stakeholders, the company had to give account, one way or another. Investments had to be safeguarded, risks had to be anticipated, controlled, and consistent performance had to be assured. The difference between Del Prado's impetuous maneuvers of the 1960s and the rigid insistence on corporate governance compliance in 2008 illuminates this trend. The need for accountability eroded virtù's impact on the company's path.

According to innovation scholar James Utterback, an ongoing increase of the structuralizing and rigidity of a company's agility are part and parcel of an industry's maturation. Once the wave of product innovation and process innovation ebbed out, an 'entrepreneurial organic firm' would transform into a 'hierarchical mechanistic firm with defined tasks and procedures and few rewards for radical innovation. ${ }^{27}$ This development coincided with further consolidation of the market and the competition. Utterback's assessment is in line with that of historian of technology Thomas Hughes, who recognized that over time the velocity of technological systems stagnates. ${ }^{28}$ While consolidation of a company and industry enables indisputable advantages like predictability and stability, the

26 Alfred Chandler, Shaping the Industrial Century: The Remarkable Story of the Evolution of the Modern Chemical and Pharmaceutical Industries (Harvard University Press, Cambridge, 2005), p. 6.

27 James Utterback, Mastering the Dynamics of Innovation (Harvard Business School Press, Boston, 1994).

28 'Thomas Hughes, Networks of Power: Electrification in Western Society, 1880-1930 (John Hopkins University Press, Baltimore, 1983);. 
limited virtù in the longer term threatens a company's ability to anticipate new developments, a new wave of product innovation for instance. ${ }^{29}$

Despite compelling general developments and regardless of insisting stakeholders, ASM remarkably evaded the fate of a forty-year-old firm operating in a consolidation industry. In this respect, the characterization of ASM as a '40-year-old teenager' was right on. ${ }^{30}$ Just like a teenager, ASM descried the structuralizing nature of the $21^{\text {st }}$-century semiconductor industry, but constantly tried to pursue its own way nevertheless. In fact, the company's ostensible reckless confidence on leveraging innovation, or the inexorable investment of all assets into new tentative developments, was at the heart of the escalating dispute between activist shareholders and the company's management from 2005 into 2013. Even as ASM matured, it retained impetuous characteristics. These features very much originated from its long-lasting chief executive officer, founder, and majority shareholder: Arthur del Prado.

\section{Virtù and Arthur del Prado}

Arthur del Prado's virtù was defining for the history and development of ASM International. In this, he relied on his intuitive confidence in the viability of his company, his business principles, as well as the industrial dynamics. Through his virtù, he proceeded into the unknown. Here I will single out the role of his character and experiences, position within the firm, and management in relation to his displays of virtù.

Del Prado's virtù very much rooted in his character and personal experiences. A key ingredient, as argued throughout this study, is his Machiavellian inclination to keep firm control over his own fate, not allowing deliberate external interferences affect his opportunities. Part of this trait was the consistent discordant ending of relationships with individuals who questioned his path throughout his career, from Topsøe in the late 1960s to most of his chief financial officers. Another aspect was his frenetic clinging to a majority share in ASM up until the early 1990s. He insisted on instigating matters on his terms. Only in the aftermath of Del Prado's heart failures in 1985 and 2000 - fortuna - was Supervisory Board chairman Paul van den Hoek able to professionalize the company's management and subsequently curbing the entrepreneur's autonomy.

Other major elements of Del Prado's character were his cosmopolitism, encompassing his view of the world as big and with plenty of opportunities. Or

29 For more on solutions to the rigidity of incumbent firms, see: James Utterback, Mastering the Dynamics of Innovation (Harvard Business School Press, Boston, 1994); Clayton Christensen, The Innovator's Dilemma: When New Technologies Cause Great Firms to Fail (Harvard Business Review Press, Boston, 1997).

30 Ray Ciferno, 'Interview with author'. 
his visionary skills, which were rooted in his assertiveness and confidence to foster innovations and technological capabilities beyond the boundaries of time and place. And, finally, his entrepreneurial drive. Throughout his life, he created something out of nothing. He was always aware that nothing about ASM was self-evident, and that therefore no opportunity should be ruled out in advance. As much as Del Prado shaped ASM, so he was shaped by the entrepreneurial activities in semiconductor technology. The present chief executive officer of ASM International Chuck del Prado said about the company's founder and his father:

'The man was not in business, the business was in the man. ${ }^{31}$

Through his dominant position within the firm, Del Prado was fully in charge of strategizing within the company, in both ordinary times (if such existed at all) and times of crisis. Even the Supervisory Board faced the fact that the chief executive officer was also the founder and majority shareholder. Del Prado's word was de facto the law.

The entrepreneur was the spider in the web. There were hardly any strategic memorandums, reports, or correspondence that did not end up on his desk. Moreover, his long-lasting career and his position as chief executive officer ensured an extensive network throughout the industry, and within the Netherlands in particular.

Based on this input advice from all corners, and his own experience, he designed the company's strategy and ensured that the management would implement it. Being a voracious reader of magazines like Harvard Business Review, Business Week, and Electronics Weekly, Del Prado ensured that he always kept track of the contemporary insights into management and the industry.

In the face of whichever manifestation of fortuna, ASM International's the subsequent decision-making process was defined by Arthur del Prado, solely. He tended to evade debates. Most often, he tried to take the sting out of disagreements by bilaterally and prematurely persuading actors to moderate or change their stance. Most often, managers or stakeholders would yield under such a charm or power offensive, empowered by his personal reputation. After all, it was Arthur del Prado himself who engaged you. If conflict was unavoidable, he pursued his will through his position as majority shareholder, by buying time to await benevolent interventions of fortuna or through deliberately exploring alternative routes. Strategy or stipulation of a course of action was hardly defined by open debate.

31 Chuck del Prado, 'Conversation with author'. 
Even the Supervisory Board, though often an institution for discussion and debate, rarely intervened when it came to defining or changing the company's path. Now and again, the Supervisory Board served him as a sounding board or a source of inspiration, given its well-connected and prominent members. Only when Del Prado's ownership share grew smaller and the role of the Supervisory Board formalized due to enhanced corporate governance, room emerged for debating strategies. But, oddly, this more or less coincided with Del Prado's retirement. The company no longer served as his vehicle to appropriate entrepreneurial opportunities.

Del Prado did not manage on a daily basis, personally instigating and overseeing procedures all the time. He hired executives to take care of that, such as chief financial Officers, a chief technology officer, and eventually chief operations officers. These managers executed and operationalized strategies and courses of action. Throughout the history of ASM, Del Prado increasingly served as catalyst of change within the company, enabling and stimulating innovation, fostering virtù.

\section{Grasping innovation through business and technology}

This study deliberately analyzed innovation by considering both business and technological developments over time. Ostensibly unrelated developments within the multi-divisional enterprise like ASM International affected the work of engineers working on a distinct piece of technology, and vice versa. Consider the impact of the money-draining ASM Lithography on the new innovation strategy (cf. Innovation III). Or the effect of the Microchemistry acquisition on ASM's ambitions with regard to rapid thermal processes (cf. Innovation IV). Considering both business and technology - each embedded in an industrial context - illuminates the interaction between these levels of analysis. For the variation and selection process defining contingencies become apparent.

With this, the study amply demonstrated the contextual nature of the developments discussed: to a smaller or larger degree, they all fitted in wider trends. ASM International was very much a child of its time. The various waves of innovation, for instance, also shed light upon Del Prado's seemingly impalpable visionary capabilities. Conversely, however, vigor and entrepreneurship are also extrinsic to industrial development. That someone seizes an opportunity is doubtful already, and then it matters who this venturer is. As we have seen, technological development was very much path-dependent in the case of ASM, yet, someone had to blaze a trail in the first place. To quote Del Prado: 
'Innovation alone too much suggests technological innovation, while foremost a new way of entrepreneurship is necessary.' ${ }^{32}$

Study of the wider technological, corporate, and industrial developments is imperative to grasp the innovation process of a high-tech enterprise like ASM international. Not so much to nuance either the significance of vigor or the validity of wider deterministic trends. But foremost in order to appreciate the dynamic playing field of high-tech innovation. To that end, including regularity, disruption and improvisation, i.e. path, fortuna and virtù, within both the domain of business and technological development complements the analysis. Just as an engineer of ASM International observed, when I asked him to reflect on his career and achievements:

'The big success is of course due to your efforts, but it should also be a bit of luck. But luck is given to you if you are prepared. If you're not, then it will be passing by. It is only going to the people who are ready to receive. ${ }^{33}$

Innovation processes are about preparation, contingencies, and impromptu action.

32 Original quote in Dutch- Arthur del Prado, (date unknown, references indicate 1980s) Archive Arthur del Prado - Del Prado's notebooks.

33 Yong Min Yoo 'Interview with author'. It is a variation of a Latin proverb 'Fortis fortuna aduivat' (numerous variations on this theme exist) and also from a quote of the French scientist Louis Pasteur: 'Dans le champs de l'observation, le hasard ne favorise que les esprits prepares' [In the field of observation, chance favors only the prepared mind]. Lecture, University of Lille, 7-12-1854. 
Afterword 


\section{Afterword}

Researching and writing this study was in itself a process of variation and selection. Amidst unexpected events and through laborious research a clear picture emerged of ASM International within the context of the semiconductor industry. The result and the course of my study were everything but obvious from the outset.

My endeavor was colored by initially undefined research materials, a multifaceted web of stakeholders, and the intellectual challenge of appreciating unfamiliar and complex technological and industrial dynamics. Moreover, this process was regularly disrupted and stimulated by numerous organizational, personal, and scholarly contingencies. These characteristics very much affected the outline of the research, and as such require clarification. Hence it seems fitting at the end of this trajectory to elaborate how 'path', 'virtù,' and encounters with 'fortuna' embodied my personal process of variation and selection resulting in this book.

\section{The prologue}

It all started with a retired professor in dentistry who convinced his friend Arthur del Prado to initiate a PhD study into ASM. At the end of his academic career, emeritus professor Michiel Eijkman supervised a historical PhD study on a topic directly associated with the beginnings of his career in the 1960 s. ${ }^{1}$ During a visit on board of Del Prado's sailing yacht in 2010, and having the time to contemplate, Eijkman enthusiastically probed his friend to initiate a similar effort linked to his life in semiconductor technology. After all, Del Prado had just retired as chief executive officer of ASM International and could look back upon an illustrious career, having witnessed and enabled the advent of microelectronics into our daily lives. During the following three years, Eijkman would raise the matter to Del Prado every time the two encountered each other.

Unknown to Eijkman, Del Prado was considering to write his autobiography after his retirement. Doing so had not been expedient at that point, however, due to the managerial turmoil at ASM International and the subsequent critical media coverage surrounding the businessman's retirement in 2008. Moreover,

\footnotetext{
1 Dennis Edeler, De drinkwaterfluoridering: Tandartsen, staat en volksgezondheid in Nederland, 1946-1976 (Amsterdam University Press, Amsterdam, 2009); Dennis Edeler en Michiel Eijkman, 'De drinkwaterfluoridering in Nederland, 1946-1976: Een maatschappelijk debat zonder winnaars of verliezers', Studium 5:2 (2012) pp. 80-42.
} 
Del Prado was not one to rake up his entrepreneurial tricks and actions. He was a very private person, keeping his cards close to his chest.

By 2011, the idea of a PhD study gained traction. For his own particular reasons, the entrepreneur reconsidered Eijkman's proposal. For over a decade, Del Prado invested tens of millions of euros, if not a few hundred million, in a startup named Mapper Lithography, located in Delft, the Netherlands. The engineers of Mapper developed an inventive e-beam lithography technology, and were trying to commercialize it. Being eighty years old, Del Prado realized he would not be around forever to supplement the startup's financial resources. In this context, he began to toy with the idea that a PhD study into ASM's long history might well result in relevant lessons for Mapper. Moreover, he was pleasantly surprised by the relatively low costs of a $\mathrm{PhD}$ study. It was peanuts compared to the development of a piece of semiconductor equipment! In the fall of 2011, Del Prado conceded to Eijkman's attempts.

Via Eijkman, the project landed with Dirk van Delft, extraordinary professor of Material Heritage of the Natural Sciences, and Harro van Lente, professor of Innovation Studies at Utrecht University. Van Delft combined this professorship with a directorship of Museum Boerhaave, the Dutch national museum for the history of science \& medicine. ${ }^{2}$ In 2012 , the museum would formally become in charge of the project and Del Prado's funding. ${ }^{3}$ The PhD candidate to be appointed would be employed as a member of the Innovation Studies department of the Faculty of Geosciences at Utrecht, where Van Lente held his chair. The project was named Skipper-Boerhaave, after Del Prado's yacht and the museum.

An advisory board was assembled. Its role was to supervise the project's quality. Its members represented the various areas of expertise involved in the study, such as innovation policies and the history of technology, but a personal representative of Arthur del Prado was on the board as well. It the framework and objective of the PhD study: drawing lessons from ASM and ASML's history about the fate of high-tech in the Netherlands. How and why did the Dutch microelectronics industry come around? In particular, the governmental sphere had to be taken into account. The project was supposed to result in a publicfriendly dissertation, several academic articles, and an exhibition at the museum.

Renamed 'Rijksmuseum Boerhaave' in 2018.

3 By billeting the project at the museum's account, vital governmental support for the museum was secured. Amidst the policies of cultural erosion and cutbacks in the first cabinet of Primeminister Mark Rutte (2010-2012) in the Netherlands, the museum had to attract a certain amount of external support. The generous funding by Arthur del Prado for the PhD project constituted a welcome contribution. Through this construction, Van Delft was capable of killing multiple birds with one stone: saving his museum, taking up the role of administrator of the project funds, and filling his position as professor. 
On January 1, 2013 the project was off to a false start. After six months, the initial PhD candidate got bogged down by the difficult commute between his home and Utrecht, and numerous ill-defined aspects of the project. It turned out that not much was known about ASM and its technologies. Although the project was conceived to have a historical perspective, it proved hard to identify historical resources or, for that matter, any other ones. Only snippets of information on the internet about recent years, and some secondary literature offered some consolation. But the two companies involved, ASM and ASML, did not feature in these few sources at all.

Del Prado himself could not help with regard to the historical resources either, as he insisted he saved nothing from the past. He had also distanced himself from the management board of ASM International in 2008, as well as that of ASML back in 1988. Moreover, the entrepreneur did not want to be too closely involved in the project. Just as he tended to do with new ventures at ASM, he left matters to designated individuals as long as they would inform him about the state and progress on a regular basis.

To add to the ambiguity, the project, having a decidedly historical focus, was the odd duck within the Innovation Studies department at Utrecht. In this academic group, innovation was basically studied only in order to formulate alternatives or solutions to current practices. After six months, the PhD candidate withdrew himself from the project. Would this $\mathrm{PhD}$ study be a stillborn? It was a project with great potential according to many, but it was owned by no one.

\section{Fortuna}

Five major manifestations of fortuna defined the course of this study. The first pertained to the fact that I was to be the $\mathrm{PhD}$-candidate subsequently selected to do the project. The second was the sudden availability of an archive two years after my start. The third disruptive and unexpected event was Arthur del Prado's death. The fourth comprised the annulment of a separate public-friendly business history. And the fifth pertained to the sequence of deadlocks and breakthroughs in the final phase. All of these fortuna's would obviously affect and color my personal experience throughout my engagement with the project.

It all started for me in September 2013. One day, much to my surprise, Harro van Lente contacted me, through an acquainted group of historians, and asked me whether I was interested in a privately funded $\mathrm{PhD}$ study about a multinational high-tech enterprise, with the objective of a public-friendly monograph. As a historian, the project would offer me an income, a unique chance to familiarize myself with complex technology and to study a particular business history, and perhaps even an opportunity to travel a little bit and see more of the world. Evidently, it was an offer I could not refuse, even though at that point I was 
not pursuing or considering an academic career at all. For me, personally, the opportunity that came my way out of the blue was a case of fortuna in its purest form: pivotal, impactful, and startling.

As it fell into my lap, I soon had to deal with the project's particularities as well, as they were arranged up to that point - or not arranged, I should say. I encountered a project with funding and a vague conceptualization of its purpose, but there were no historical resources or data upon which to base the study. Even more, a clear appreciation of ASM International's - and ASML's - activities and innovation was not apparent among the members of the advisory board either. Furthermore, Del Prado's commitment to the project - beyond his funding remained doubtful. All in all, apart from the funding, the endeavor that crossed my path was not practicable yet.

The second manifestation of fortuna was the sudden availability of Arthur del Prado's extensive personal archive, almost two years after I started. By that time, I had already interviewed fifty-five individuals all over the world, which provided me a better understanding of the most critical technologies and organizational themes. At the same time, however, it was evident that having primary sources in addition to these oral histories would greatly strengthen the historical and scholarly value of my project.

In the summer of 2015 a modest request to Arthur del Prado as to whether he might have at least a few photographs - since he still insisted on not having an archive - opened the floodgates. By this time, Arthur was struggling with his health and age. He and Joan - his partner - began to clean up all sorts of paperwork and documentation that were lying around the house. On June 29, shortly after one of my regular visits to Arthur, I was informed by Joan that they compiled a box with some information. Shortly afterward, after several explicit queries on my part for additional documentation, an aid informed me that there was another box. This box contained the company's annual reports covering the period 1965-1980, the years prior to ASM's initial public offering. Moreover, the same e-mail casually mentioned the existence of another 179 boxes (!) with information in Almere, at ASM International. This news struck me like a bolt from the blue.

After Arthur del Prado's retirement as chief executive officer of ASM International, his personal archive was stored by the company in its archive. Even more, the entrepreneur proved to have been an ardent collector of corporate information. By the summer of 2015, his aid was instructed to select relevant files and destroy the rest. After consultation with Arthur, Joan, and Chuck del Prado's management assistant, Petra, I found myself in the room with about 180 boxes of information, covering everything from ASM's past - from merger \& acquisition negotiations, minutes of the Supervisory Board, to sales calls and even letters 
from applicants dating from the company's early days. It was a treasure trove indeed! Instead of having to cope with an insatiable appetite for primary sources like I had done so far, I was now inundated by all sorts of historical material. The archive overturned the course of my PhD study as I pursued it up to that point.

A third fortuna involved Arthur del Prado's passing in the late afternoon of Friday September 9, 2016. His death was startling, if not altogether unexpected. Three days earlier I had spoken with him on the phone - he sounded weak and said he was looking forward to seeing my dissertation soon. For me, his death was surreal. During the last several years, Arthur had been omnipresent in my life, as the major actor in my study and as my de facto Maecenas.

In the aftermath of Arthur's death, the project's playing field changed. After almost three years of studying ASM, I appeared to be one of the few with a basic overview of the career of the illustrious yet private entrepreneur and his company. In appreciation of his role toward me and his achievements, I was glad to be able to contribute to the obituary on behalf of the family and ASM International. Moreover, and paradoxically perhaps, in the immediate aftermath of Arthur's passing, I became closer involved with his personal life. For the project itself, things changed as well. A foundation dedicated to research in cancer inherited his assets, including my project. And more significant for this Afterword, I was gradually able to single out the crucial role of Arthur in ASM's innovation processes - something which he had urged me not to do.

The fourth fortuna was the gradual understanding that the project was not going to result in a separate public-friendly business history by the spring of 2018. Up until that point, we assumed that the project, in addition to the dissertation, would also result in a non-academic book about the history of ASM International. Such a publication would simultaneously offer context to the technological histories expounded and analyzed in the dissertation (the current Innovation chapters). As for the timing, a perfect opportunity presented itself in ASM's 50year anniversary in 2018.

However, given the state of my manuscript and the indistinctness at ASM and publishers, the public-friendly publication seemed unfeasible. Consequently, I had to figure out a way to include the business and industrial developments of ASM International into the study. Without this context, the finesses of high-tech innovation would be lost in ill-substantiated narratives about the company and semiconductor manufacturing. After all, there were almost no academic or public historical studies about the semiconductor equipment industry available. The abandoning of the idea of publishing a public business history was critical for my decision to integrate that particular analysis into the dissertation. 
The fifth and final fortuna related to the sequential yet unpredictable conceptual stranding or breakthroughs as my project was evolving. From Autumn 2017, in running anticipation of an imminent conclusion of the study, I increasingly had doubts about the imperfect conceptualization of my academic framework. It just did not fit, was incoherent, and therefore I began to change concepts, develop new insights, and tried to improve the overall framework's coherence. ${ }^{4}$ In this process of conceptual refinement, the successive frustrations and solutions (Eureka!) could not be anticipated. Yet they were all inextricably bound up with the process of designing and writing this study.

\section{Virtù}

The specific manifestations of fortuna I encountered on my path also prompted particular kinds of virtù on my part. The first fortuna resulted in three lines of action in the fall of 2013. One involved a focus on empiricism, i.e., gathering information about ASM International. If you do not know what you are supposed to talk about, how would it be possible to say anything academic about it at all? This line of action resembled snowballing, from watching YouTube-clips explaining semiconductor technology to collecting the company's annual reports, listing data from them, and mapping pivotal managers for interviews. Another line of action was directed at getting critical stakeholders involved. Foremost, this involved enthusing Arthur del Prado, securing cooperation from ASM International, and mapping the story of ASML via author René Raaijmakers. ${ }^{5} \mathrm{~A}$ final line of action at the start of the project was the decision to rely upon oral histories, even though I initially had little experience in interviewing and hardly knew in what kind of materials it might result.

The second display of virtù surrounded the sudden availability of the archive in the summer of 2015. The contents and my mandate were not clear. By playing along with the situation as it evolved, I was able to save almost the complete archive. After years of pushing buttons and doors in pursuit of historical material,

\footnotetext{
4 In numerous cases, unrelated literature offered defining insights or inspiration. Such as Robert Pirsig, Zen and the Art of Motorcycle Maintenance (1974); Luuk van Middelaar, De nieuwe politiek van Europa (2017) [In English: Europe's New Politics]; Yuval Noah Harari, 21st Lessons for the 21st Century (2018), Nassim Nicholas Taleb, The Black Swan (2008); Max Dendermonde, De wereld gaat aan vlijt ten onder (1956) [in English: Diligence havocs the world]; Rosemary Sullivan, Stalin's Daughter: The Extraordinary and Tumultuous Life Of Svetlana Alliluyeva (2016), or the works of contemporary (in time and age) comedian-philosopher Tim Fransen

5 Note that Arthur del Prado had no ties anymore with ASML after ASM International divested its interest in ASML in 1988. Reaching out to ASML proved to be quite difficult. Moreover, René Raaijmakers, an acquaintance of my supervisor Dirk van Delft, had been working on ASML's history for years already. Raaijmakers shared information with me and offered support in uncovering the history of this industry.
} 
doors suddenly flung open. Yet, I operated within unarticulated boundaries with regard to the definition of proprietary information, the handling of such material, and my trustworthiness toward ASM and Arthur. The new rules were not defined right away. ASM nor Arthur had experience in disclosing such information for proprietary information. Only through my actions and rationalization, I was able to integrate the archive into my study. But how, exactly, I would use it did not become clear until after a while only.

The third display of virtù involved my response to the changed circumstances following Arthur del Prado's death in September 2016. On the one hand, the group of stakeholders changed. The family gained in prominence and the ADP Foundation took over the role of Arthur in the project. By rendering immediate assistance in formulating his obituary, I showed a positive attitude to these new parties of interest and their yet undefined stances. In my dealing with these new circumstances I had to act and proceed most prudently. On the other hand, in my study more room became available to reflect on the particular role of Arthur throughout ASM's history. So far, he personally insisted on limiting his profile in the study. Following public and corporate remembrance of his achievements in the aftermath of Arthur's death, it became easier to interpret his directive in various ways. In other words, the sentiment to give account of Arthur's role - for good and for bad - became more difficult to ignore.

Virtù in the face of the fourth and fifth manifestations of fortuna primarily involved my personal willingness to adjust my expectations. Frequently, the challenge was either killing your darlings or sticking up for your darlings. With every new obstacle, I choose the solution that I could defend best. As the project was drawing to an end, thoughtless rummaging through the study or pursuing new lines would be risky. As I alone oversaw the state of my writings, the dynamics of ASM's history, the sense of the academic framework, and my working pace to effectuate all my intentions, I presented the most viable routes to the supervisors as they appeared to me. Naturally, my rationality was bounded. Even with my rich and sometimes caviling imagination, I could not apprehend or anticipate all future conceptual obstacles or insights.

In my dealings with fortuna, I was rather independent. To summarize my personal experience, I would like to quote political historian Luuk van Middelaar:

'To be a good human being ... you have to get embedded in time, accept the contingency of developments, and take up the responsibility for the 
open-ended future. This requires anticipation, preparation, action - and the realization that you will always be surprised.'

This statement not only applies to the European politicians about which Van Middelaar writes, but also - as we have seen in this study - to business executives and enterprises. Even more, the quote applied to me throughout my study. Through my actions, I secured the confidence of these stakeholders and I elaborated upon their expertise and network. In this, I established and destroyed normative boundaries about declassifying proprietary information, prevailing conventions with regard to a $\mathrm{PhD}$ study - or stakeholder's suppositions.

\section{Path}

\section{Roles in my path}

During the study, the expectations and interests of all the stakeholders involved in the project - the supervisors, the advisory board, Arthur del Prado, ASM, the interviewees, and last but not least myself - were defining. Obviously it was both a stimulating and complicating factor that each one of them had strong opinions about the project and its direction. To reuse two concepts from the study, the different stakeholders were either 'enactors' or 'selectors' - i.e. participants that would contribute to increasing or decreasing the various possibilities, narratives, and perspectives.

The first stakeholders were my supervisors Harro van Lente and Dirk van Delft. Throughout the project, they showed alternative concepts and possibilities, stirring my inventiveness, but they also indicated boundaries and requirements. They guided my PhD study toward the moment of 'closure' in the capacity of both 'enactor' and 'selector.' This supervision involved conceptualization, methods, writing, the PhD process at large, as well as personal development. Moreover, in the case of Van Delft until his retirement as Director of Museum Boerhaave in May 2018, this also involved performing as employer. Their approach was characterized by laissez-fair and trust in my self-sufficiency.

The second group of stakeholders were the advisory board members, who oversaw the quality and progress on behalf of the stakeholders, and who represented the variously relevant audiences of the study. Six months after I started, the board was extended to include René Raaijmakers and Han Westendorp. Raaijmakers, an experienced Dutch publicist on high-tech, contributed with his knowledge of oral history, compiling historical information, and his extensive knowledge of the semiconductor equipment industry, in

6 Luuk van Middelaar, De nieuwe politiek van Europa (Historische Uitgeverij, n.p., 2017), p. 32. 
particular ASML. Westendorp joined on behalf of ASM International - in particular in consideration of the issue of handling proprietary information. Arthur del Prado was never part of the board, nor did he join the meetings. After his passing, two of the board members became the de facto Maecenas, through their role in the ADP Foundation.

As a collective, the board functioned as a selector in the biannual meetings. Through consent during the gatherings, the advisory board formally approved or reflected upon decisions with regard to structure, conceptualization, and themes of the study. Individually, the board members operated as enactors, through their structural comments and perspectives, but I also met each of them bilaterally, initially for discussion of main themes and later on as designated adopters of respective chapters.

The third stakeholder in the project was Arthur del Prado. Until I was given access to his archive, the progression of my study largely depended on his relationships and endorsement. His role in my project was determined by his own particular considerations. For instance, his reputation was critical in opening doors to companies and individuals. After his passing, I learned that his status also resulted in some self-censorship among interviewees. Moreover, Del Prado's relationships with many (former) employees had been tainted. Even with his support - or precisely because of it - I could not reach out to every actor directly.

Moreover, throughout the project, Arthur's reticence often impeded my work. Of course, he was all but waiting to hear a young historian's judgment on things pertaining to his life and career. His privacy was very dear to him, and his memory gradually decreased along with his faltering health. For me, his taciturnity made him a 'selector,' defining the outlines of my study. For instance, I could not interview him on the record, something which would have made my work a whole lot easier in the early phases. Instead, we merely discussed how 'things' were or worked, albeit sometimes in extensive meetings. This personal reservation will have been a factor in denying me access to the archive in the first two years of my study.

Conversely, the good part of his reserve was that he did not interfere in my writings or actions. He appreciated self-reliance and result-oriented behavior. Apart from two meetings together with Eijkman and Van Delft, I interacted with Arthur by myself. Regular contact - a visit every quarter and a call at least every month - was mutually appreciated and instigated. Over time, Arthur gradually became more interested, involved, and eager for results even as the particularities of an academic $\mathrm{PhD}$ study continued to be rather unfamiliar to him.

The fourth stakeholder in the project, ASM International, became one only some six months after I started. This was critical in granting access to facilities, 
Arthur's archive, and (former) employees, as well as regarding the non-disclosure agreements they all signed. During the final phase, on behalf of the company, Chuck del Prado even contributed to the publication of this study. Through these examples, ASM helped me apprehending the whole complexity and dynamics of the enterprise. Moreover, ASM International did not interfere in my explorations, as long as I informed them regularly and I handled information prudently. As such they followed the lead of Arthur del Prado in the disclosing of documentation, which is why the existence of an archive remained concealed for me in the first two years.

The fifth group of stakeholders consists of my eighty-five interviewees. The many interviews were meant to help me reconstruct ASM's history and understand the particularities of technological development. In this process, each interviewee advocated his or her respective version of the events. Each had lived their own dramatic career at ASM and beyond - from perhaps peaking early in their career and being full of personal pride to having a strong sense of professional frustration or a feeling of marginality. Some were still pursuing new technological opportunities at an advanced age, out of necessity or intrinsic motivation. Others had peacefully retired. The interviewees wanted to share their experiences, but also expected to be taking into account as well. I was merely recording their history. Or, as understood within the conceptual framework of this dissertation, they enacted their story.

The conclusion is unescapable that ASM's innovations evolved from the accumulation of these narratives. Therefore my interactions with them have been crucial for this study. After initial and successive interviews, the interviewees were given the opportunity to comment on my evolving writings. Even in the final phase, I invited the interviewees to comment on my reconstructions and verify technological and historical details. After all, they constituted my most critical readers with regard to the historical facts.

And finally, of course, I was myself a stakeholder in this endeavor. My role as historian was to explore the unfamiliar grounds of innovation studies and absorb the organizational and historical dynamics of a multi-divisional multinational corporation. Aware of all the complex and particular interest gathered in the project, I tried to give everybody his or her due. In this process, I learned and obtained competencies that stretched beyond the mere academic, ranging from project and relation management to personal development.

Predominantly, I worked from my home, while regularly visiting ASM International, my supervisors in Maastricht and Leiden, interviewees, sometimes participating in graduate school activities, and in the end deliberately joining other $\mathrm{PhD}$ candidates. This meant that I was hardly embedded in an academic 
environment on a daily basis. I pretty much was on my own. Whereas all the other stakeholders played both roles, I solely operated as a hesitant selector. Throughout the project I had to find a voice of my own.

\section{Rules of my path}

Relying on my background in business history, I advocated the inclusion of the corporate developments into the analysis. After all, each technological development occurred within an organization. Furthermore, this organization was again subjected to larger industrial, socio-economic, and technological dynamics.

In the first six months, I made three decisions affecting the scope of the study. The first two were meant to secure the cooperation of Arthur del Prado and ASM International. The first was to concentrate on technological development in generic terms. The study would not be about individual contributions, as many relations between Del Prado and ASM and/or former colleagues appeared to be delicate. The second decision was to limit my study to the period until 2008, the year in which Arthur del Prado retired as chief executive officer. Through this action, I offered the current management of ASM International the ability to dissociate themselves from my findings. Moreover, this way I was not going to cover current proprietary technological and business information. The third decision was to deselect ASML from the study. In my view, there was little organizational, technological, and even industrial overlap between ASML and ASM after 1988 (cf. Chapter 19). Moreover, the respective positions in the Netherlands were incomparable. And the business cultures and strategies were totally unalike. Besides, after the first few months, I still had no clue about how to establish contact with ASML. Arthur del Prado could not offer much help in that regard either. ${ }^{7}$

Based on these selections, and in close consultancy with my supervisors, I identified four central domains for my study: innovation policy, business strategy, technological dynamics, and markets (suppliers, competitors, customers). ${ }^{8}$ I was going to study these domains and their variable interrelationships by means of just a few case-studies. Based on the new insights, I adapted the outline of

$7 \quad$ Also, René Raaijmakers had a major head-start in writing such a business history. If the focus of my study was to be on the Dutch semiconductor equipment industry, I would also have to include another former Dutch subsidiary of ASM, named BESI, posing new challenges with regard to establishing contact and securing historical sources.

8 Very shortly I considered to focus on the themes 'Technological Dynamics,' 'Organization,' 'Geography,' and 'Supply Chain.' For each of the themes, I would study the international trend, the role of innovation policies, the position of ASM International, and the position of ASML. 
the project - meaning the case-studies and their themes - continuously. ${ }^{9}$ Each case-study was to be preceded by a short discussion of the general industrial and corporate dynamics. Over time, these 'intermezzos' grew into full business histories.

\section{Navigating path}

Along the above-depicted stakeholders and rules, I set my course. This involved collecting, processing, and analyzing information (in that order, primarily, and sometimes overlapping).

The first course involved the gathering of historical sources. From day one, I probed for the minutes and appendixes of the ASM International (and ASML) Supervisory Board meetings. Up until the sudden availability of Arthur del Prado's archive, primary sources remained a problem. I merely obtained some minor files, like brochures, public presentations, and some pictures. Thus instead, I conducted interviews in the Netherlands and abroad during several trips in the first two years.

The second course of action involved writing the various case-studies. After all, through the act of writing, information is ordered and gaps in knowledge exposed. Per case, I considered writing it for a conference - offering a clear deadline and feedback from academic peers - or submitting it for an academic journal. My writing process was characterized by the primary structuring of historical and technological facts and a secondary round of conceptualization by means of the innovation literature. It was indispensable to immerse myself into the details. For a layman, something obvious often proved to be more nuanced: the American context depicted in literature did not apply for the Dutch situation, technological simplifications were plainly wrong, and so on. The devil was in the details

The third course involved analysis of my observations. In this process, I singled out larger narratives and dynamics per case-study. During extensive discussions with primarily my supervisor Van Lente and, secondarily, the other advisory board members, I reflected upon these findings through existing bodies of literature. During the first three years, as the historical resources and subsequently the addressable domains expanded, this resulted in a proliferation of academic frameworks. In the run-up to anticipated final deadlines of the project from the summer of 2017, the concepts were fine-tuned. A process during

9 The initial case-studies involved ASM Ion Implant, governmental support program JESSI \& MEDEA, epitaxial technology, atomic layer deposition technology, and the internationalization of ASM. Eventually, the case-study about ASM Ion Implant was replaced by one about plasma CVD, the internationalization case was limited to a specific timeframe, and after a while the internationalization case was replaced by one about wire bonding. The latter was deselected in the summer of 2017 due to a lack of time and coherency among the case-studies. 
which the deadline got delayed several times, from the fall of 2017, to May 2018, to the fall of 2018, and to April 2019. Chapter by chapter, the analysis evolved. Once I had a complete first draft of the study, each chapter had to be readjusted, making the study more coherent.

\section{Path dependency}

My path clearly shows path dependency. To that end, I distinguish three phases in my research. The first phase stretched from the start of the project in November 2013 to the summer of 2015, during which the outlines of research were defined and I gained a first, more comprehensive image of the company through extensive interviews. The second phase lasted from the summer of 2015 to the fall of 2017. This phase was characterized by the familiarization of the historical material from the archive. The final phase, covering the years from the fall of 2017 to the end of the project in the spring of 2019, centered around the jerkily process of conceptual and textual refinement.

Most of the decisions of the first phase were based on the limited resources available and the pursuit of more data. This involved reliance on interviews, with their inherent features, but also a thematic approach and selection of cases. These decisions were indispensable to get the project going, and more prominently to gain the trust of Arthur del Prado and ASM International.

Yet with the availability of the archive, all was open once again. The archive provided tons data, enough to support multiple dissertations - from technological development and innovation policy to corporate governance and business strategy. New viewpoints were possible and the study might obtain much greater depth. But all of this was true in theory. In reality, I had committed myself to the outlines of the study, and the stakeholders ensured explicitly and implicitly my compliance to those. After all, money was limited and the project was already halfway.

At the same time, the archive did restart the program. Obediently, I continued according to the initial plan. But I also utilized the archive to analyze the casestudies in more depth. In the following years - from the summer of 2015 - all presumptions about the storyline were altered. Emphasis changed per case, new information improved the chronological order of events, and eventually Arthur del Prado gained a more prominent role. All the pieces of the proverbial jigsaw puzzle were once again reordered, before I began solving the entire puzzle in the third phase for the final time.

\section{Inventing an author}

So what, in the end, are the effects of my choices, my setting and my history; what did fortuna, virtù, and path achieve? Fortuna proved to be pivotal throughout this $\mathrm{PhD}$ study. In close conjunction with the stakeholders - in particular my 
supervisors - I managed to deal with the different instances of fortuna one by one. Virtù was a force in path-creation. A path resulted from elaborating and executing plans drafted in the aftermath. This included a return to a sequential order of affairs in a conventional $\mathrm{PhD}$ study. An example of the latter was that the conclusions of the various Innovation chapters could only be harmonized after having written all of them. Throughout the study, it proved difficult to skip or bundle steps. Defying dreams and plans, path involves doing things step by step.

Having arrived at the end of this intricate and long-winding process, I clearly see how the whole endeavor shaped me, as much as I shaped it. My findings were derived from the historical documentation, from an accumulation of the interviewees' narratives, and from my personal entanglement with Arthur del Prado and ASM International. In a notable academic handbook about the historiography of history, author John Tosh posed the postmodernist and for this study appropriate appreciation:

'There being no shape to history, historians cannot reconstruct and delineate it from outside. The stories they tell and the human subjects they write about, are merely subjective preferences, drawn from an infinity of possible strategies. Historians are embedded in the messy reality they seek to represent, and hence always bear its ideological imprint ... Historians, it is said, do not uncover the past; they invent it. ${ }^{10}$

Indeed, this trajectory, this study of ASM International's history of technological ingenuity is a piece of innovation in its own right - and it produced a book and author alike.

10 John Tosh and Seán Lang, The Pursuit of History: Aims, methods and new directions in the study of modern history (Pearson Longman, Harlow, fourth edition; 2006), p. 198. 


\section{Historical resources}

\section{Location visits}

\section{Japan}

(November 8-14, 2014 and July 1-7, 2016)

ASM Japan Tama facility

ASM Japan Nagaoka facility

\section{Singapore}

(November 27-December 2, 2014; April 21-24, 2016 and June 20- 26, 2016)

FEMS

ASM Technology Singapore

VDL-ETG Singapore

\section{Hong Kong}

(November 2-7, 2014 and April 16-21, 2016)

ASM Pacific Technology

\section{China}

(April 24-30, 2016)

ASM Technology Chengdu

\section{Finland}

(October 12,-14 2016)

ASM Microchemistry

\section{Belgium}

(July 6, 2016)

ASM Belgium

IMEC

\section{South Korea}

(June 26 -July 12016 )

ASM Genitech Korea 
Historical resources

United States

(April 28 -May 29, 2015 and April 30 - May 19, 2017)

ASM America, Phoenix

Computer History Museum, Mountain View, California

Netherlands

ASML, Veldhoven

ASM Europe Refurbishment, Almere

ASM International, Almere 


\section{Interviews}

苞

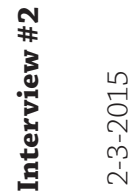

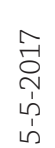

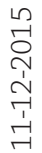

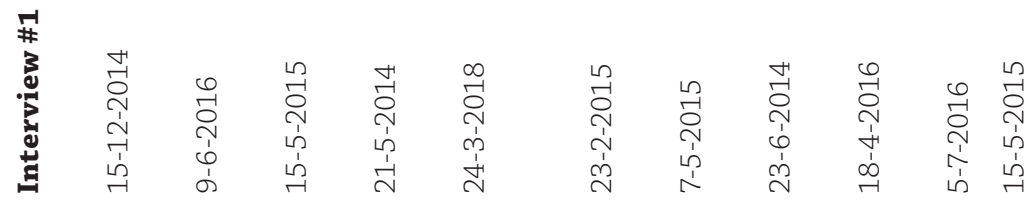

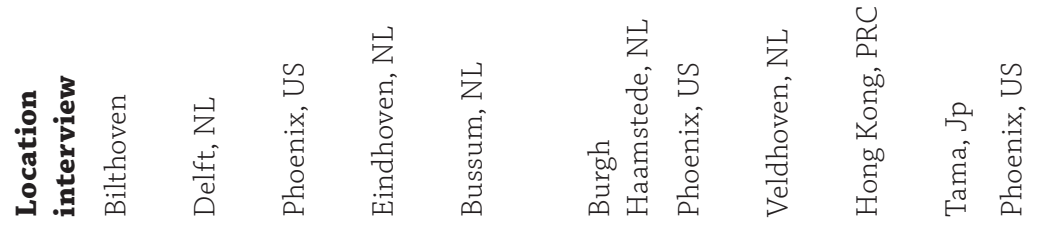

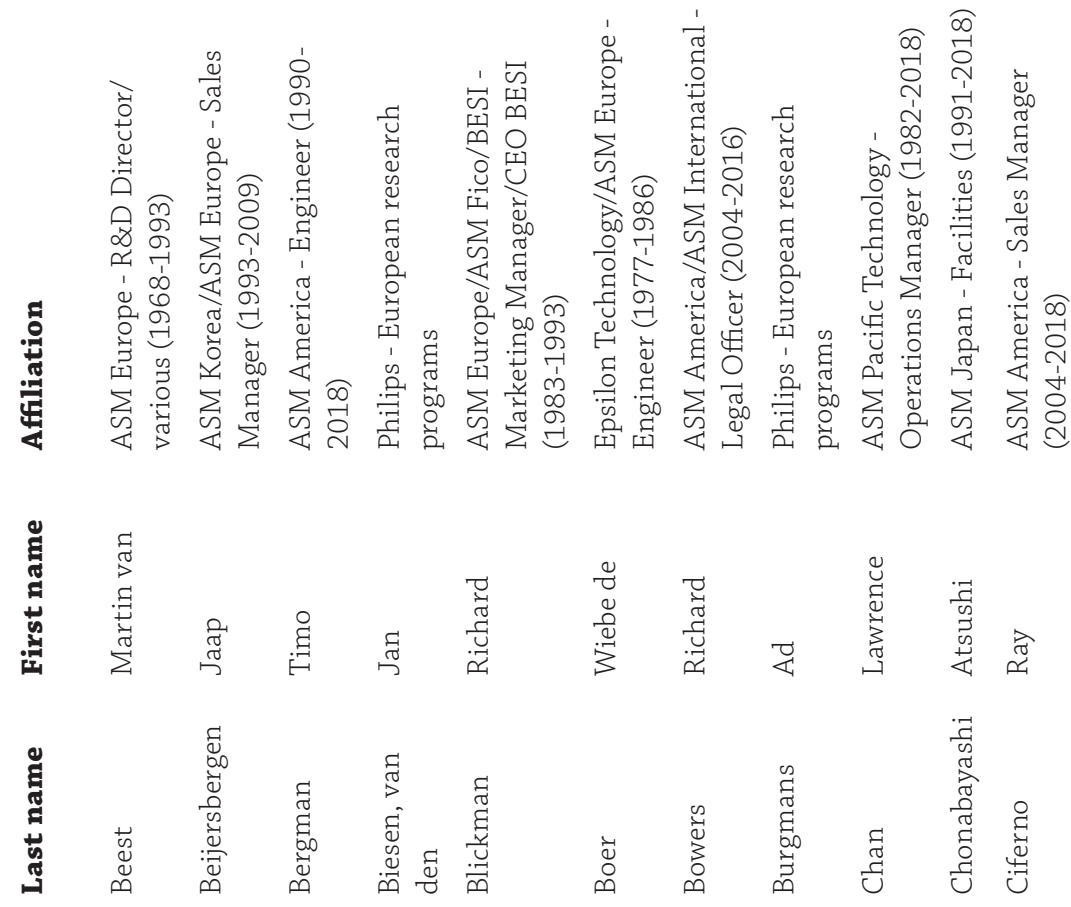



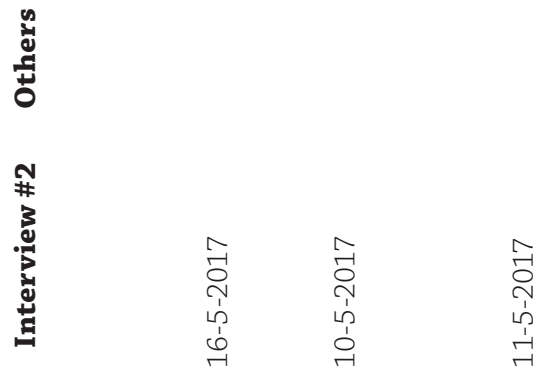

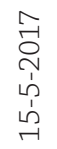

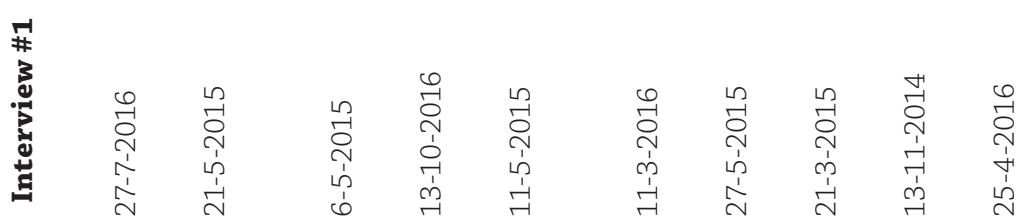

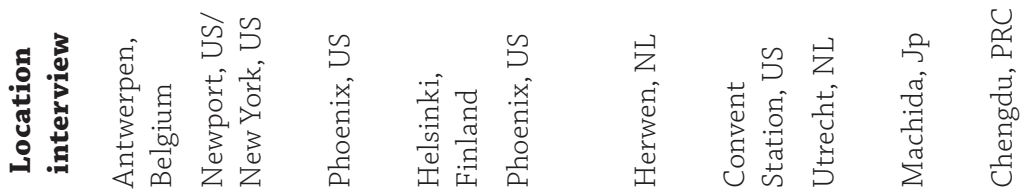

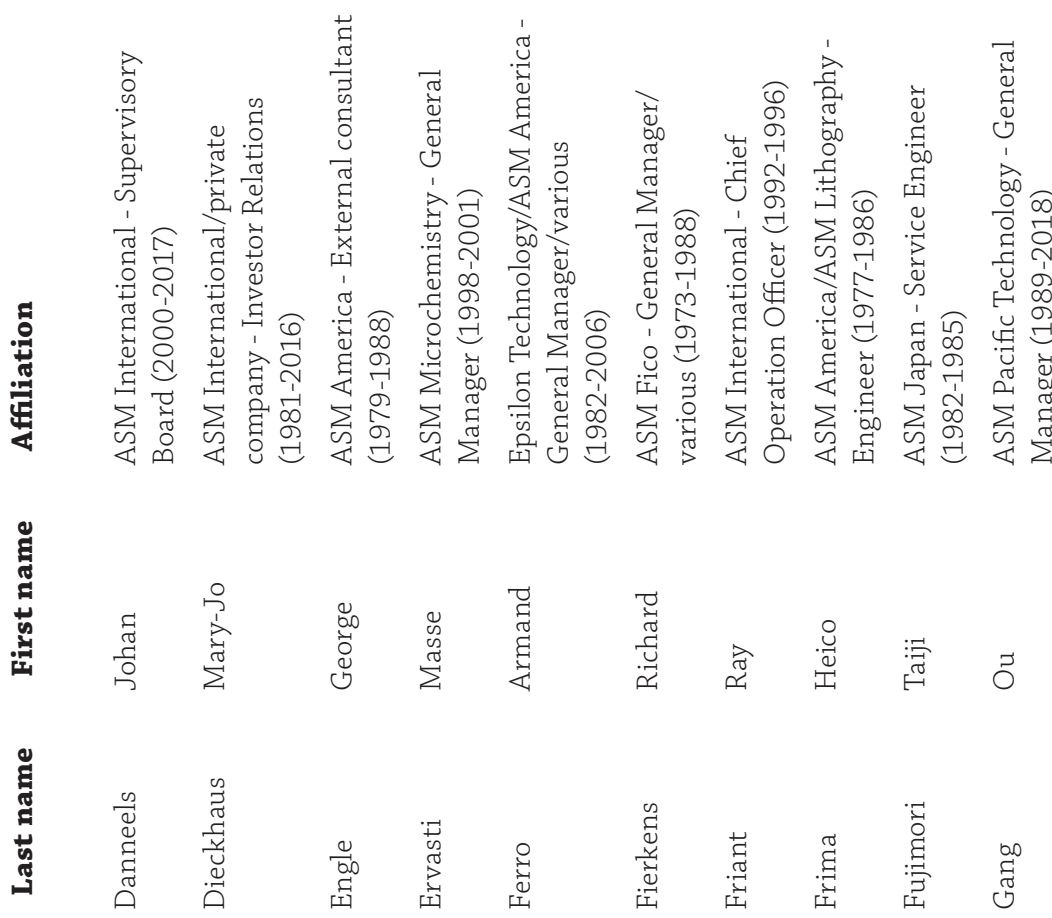




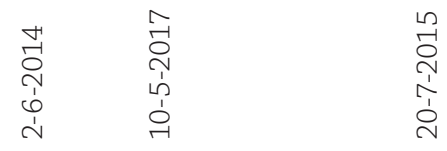

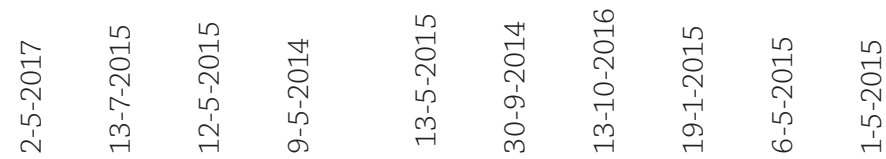

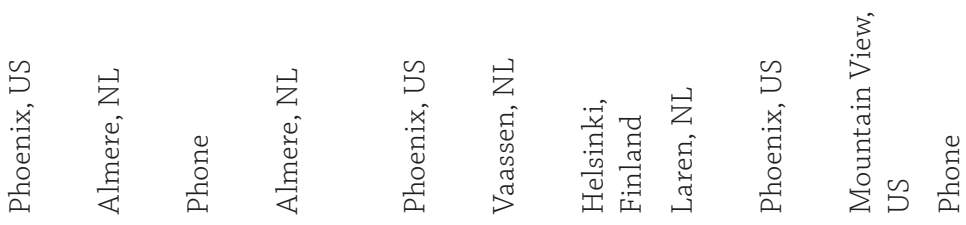

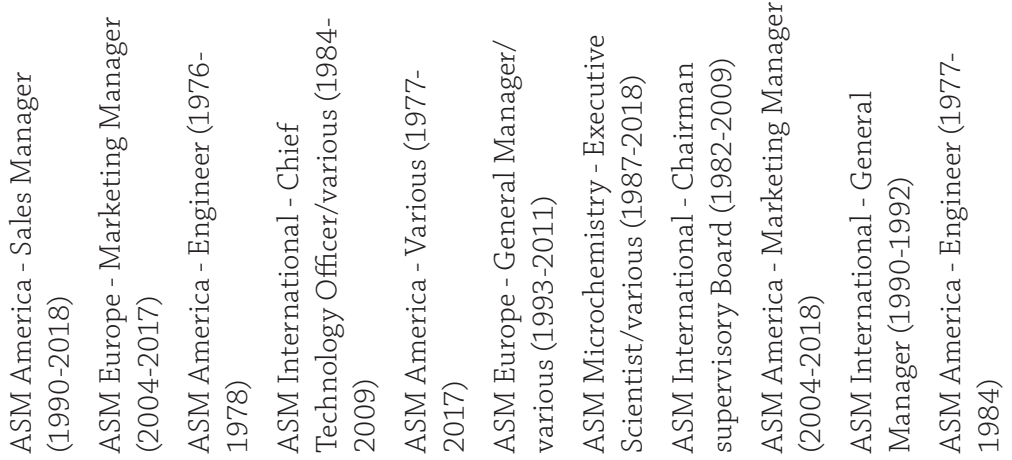

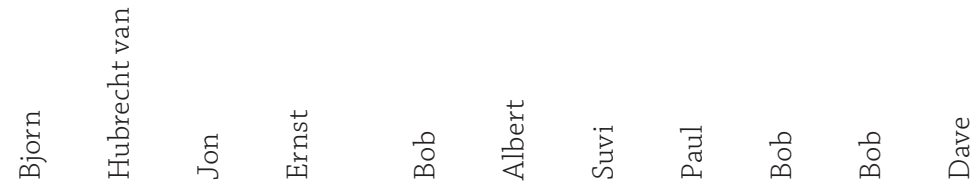

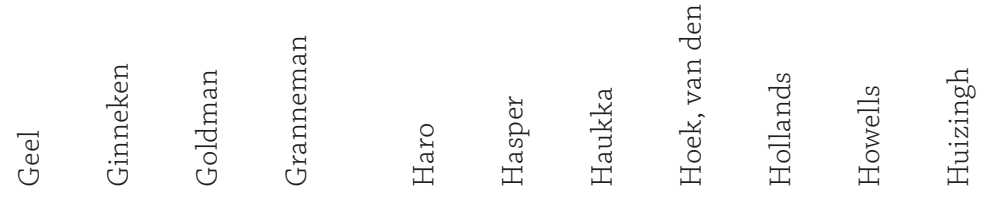


Historical resources

!

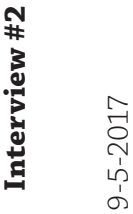

$\hat{0}$
तิ
เ่
ô

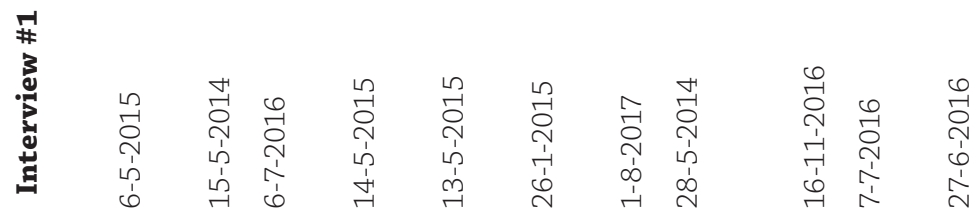

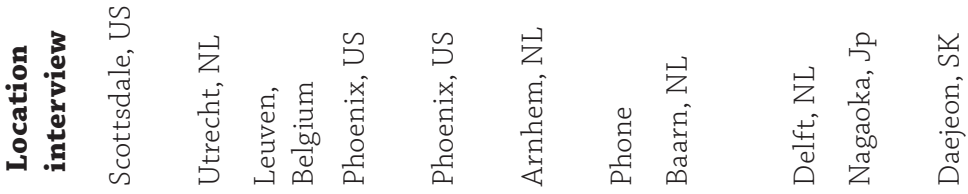

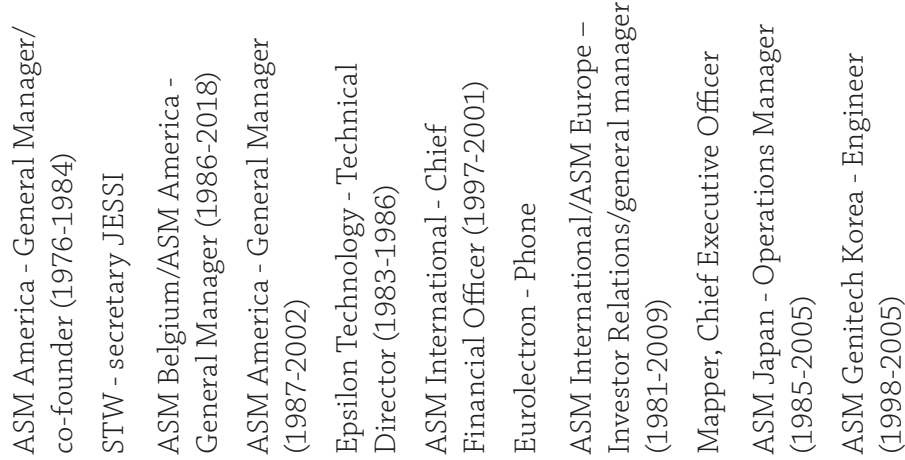

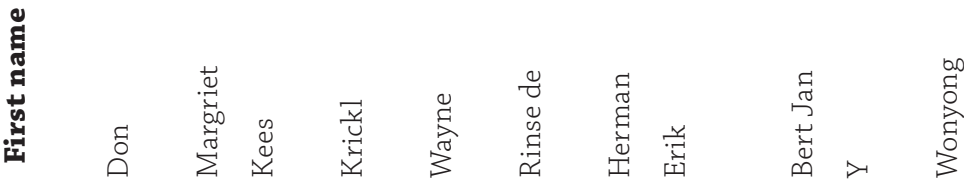

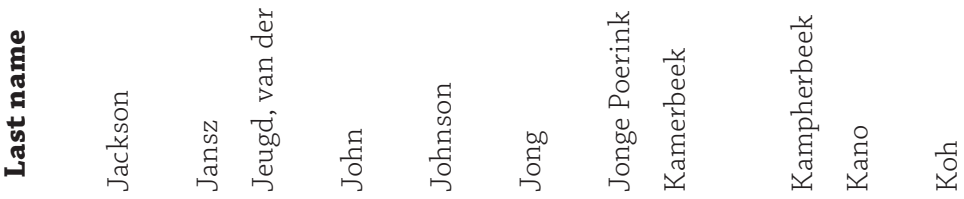




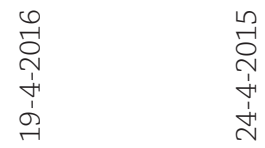

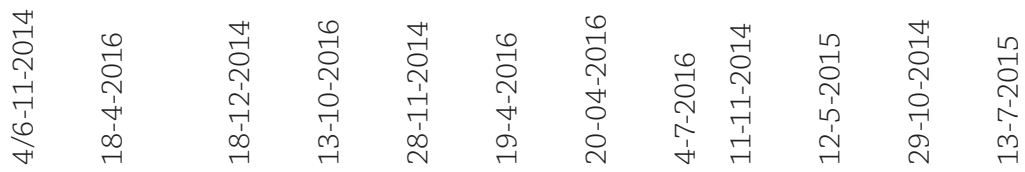

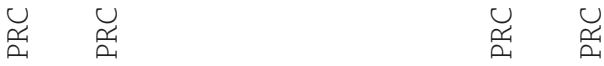

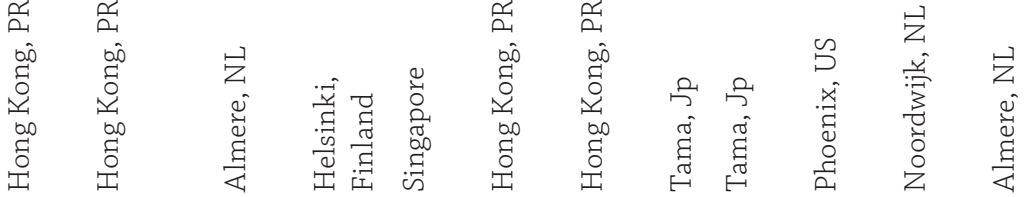

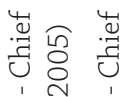

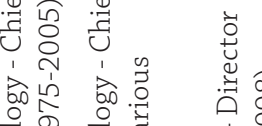

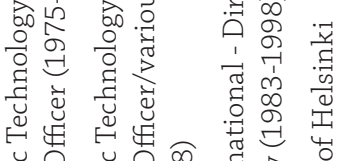

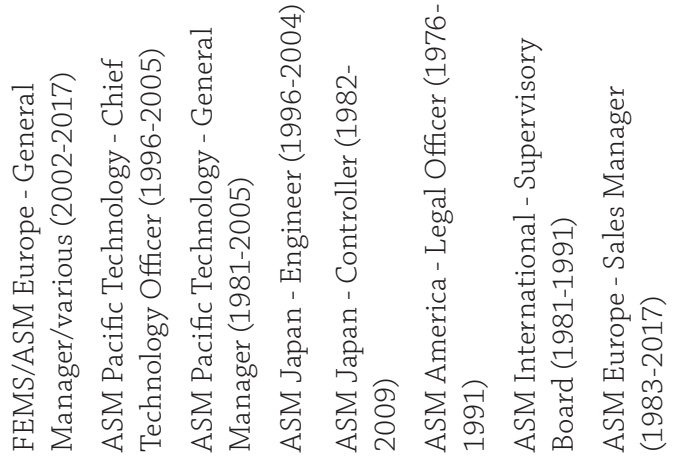

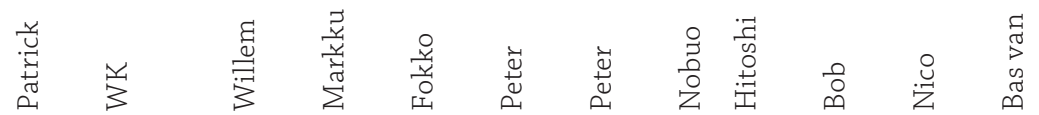

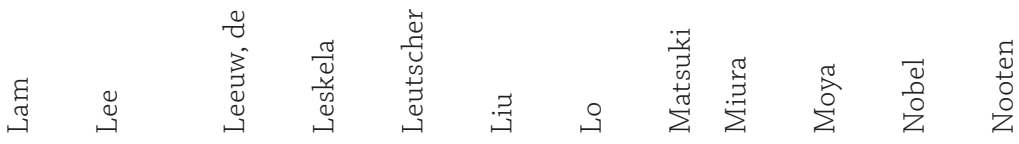


Historical resources

!ิ

部

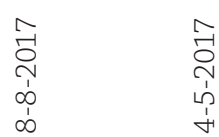

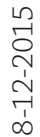

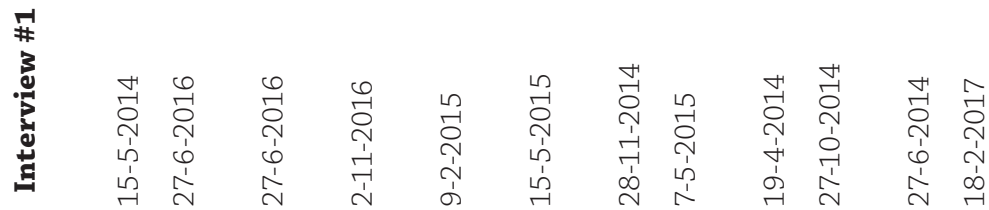

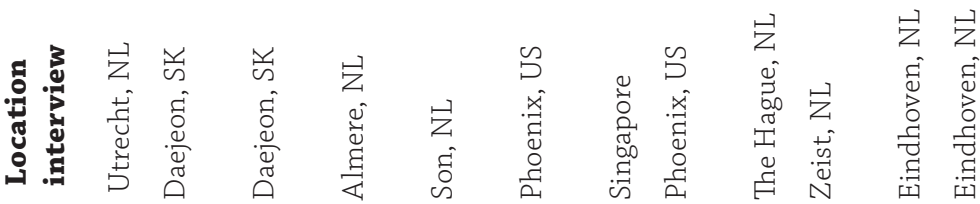

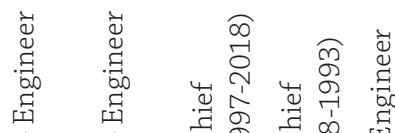

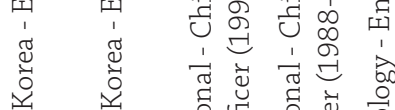

苟芯

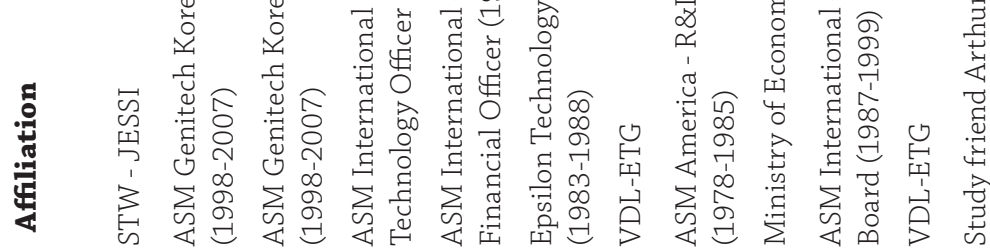

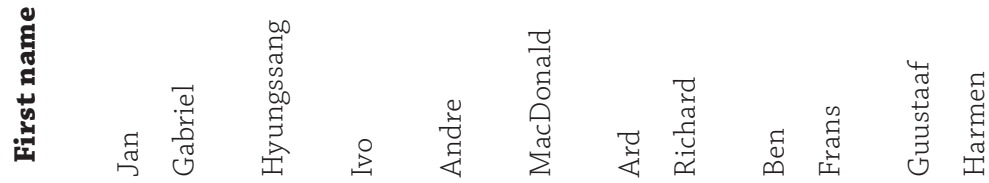

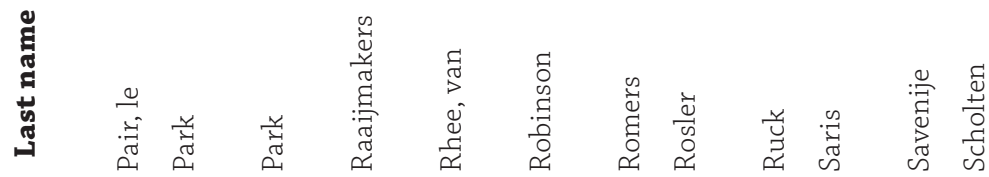




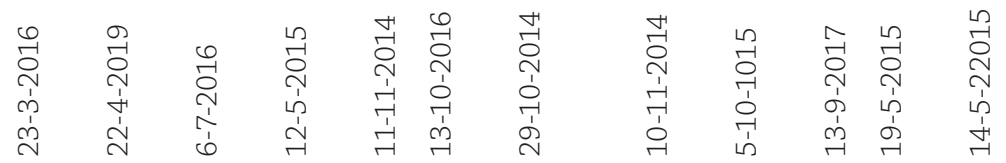

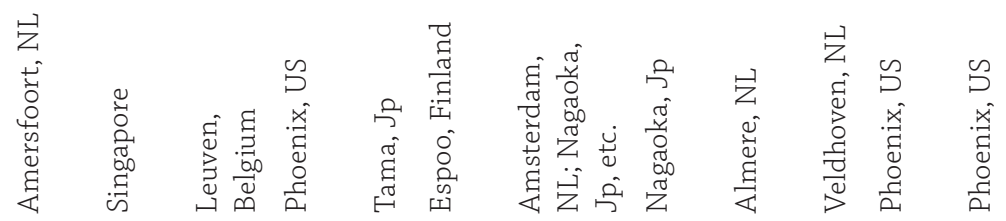

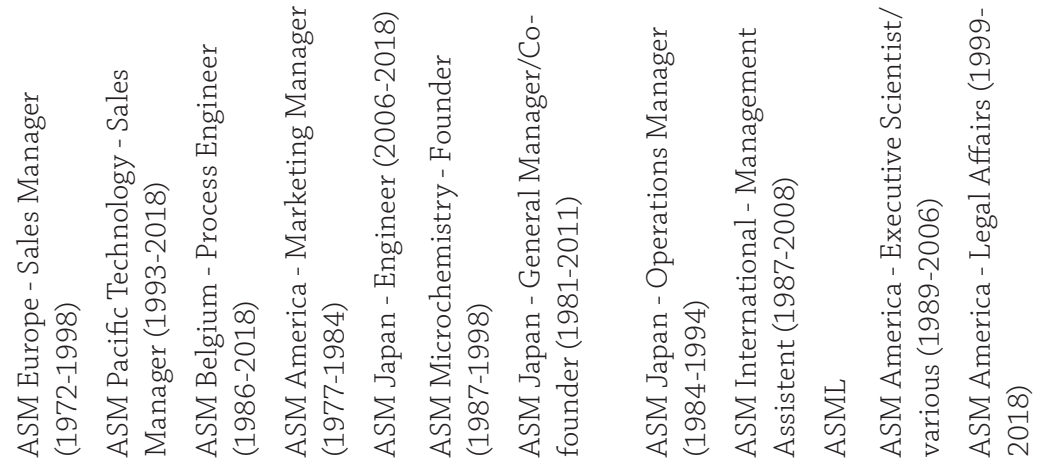

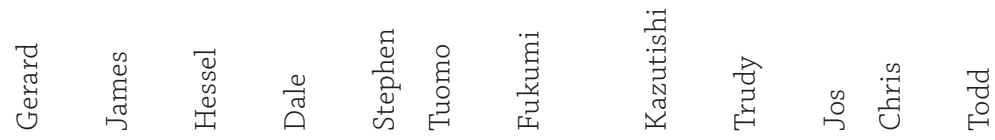

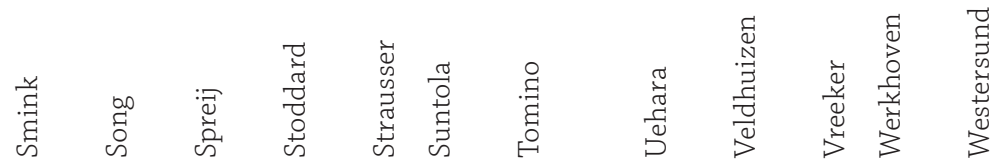


Historical resources

章

\#

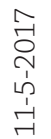

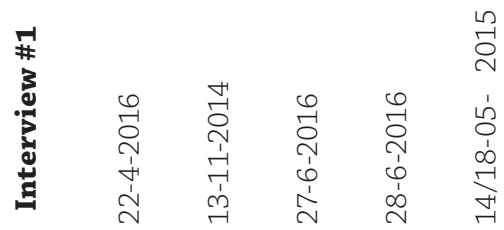

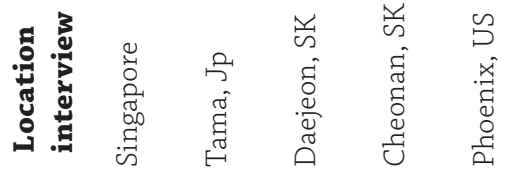

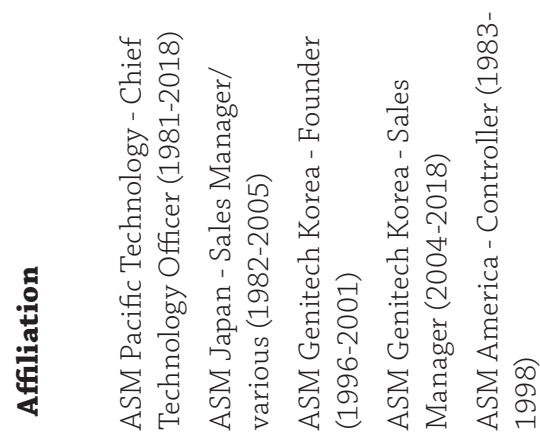

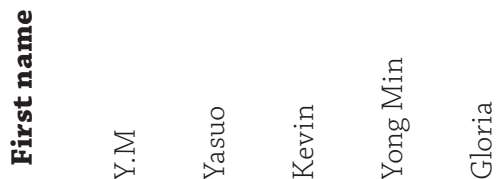

苟 


\section{Archives and collections}

Archive Arthur de Prado - held by ASM International

Collection of Arthur del Prado's Knapic Electro-Physics corporate files (1958-1964

Collection of Arthur del Prado's corporate files covering 1964 until 2008.

\section{Author's personal archive}

ASM America, Ken Davidson, 'ASM Epitaxy Receives Semiconductor International's 1994 Editor's Choice Best Product Award', ASM News (February/ March 1995).

ASM International, Annual Reports (1981-2018).

ASML, Annual Reports (1993-2018).

ASM Pacific Technology, Annual Reports (1999-2018).

BESI, Annual Reports (2001-2018).

Boer, Wiebe de, 'Thin Layers in Semiconductor Industry'.

Boer, Wiebe de, 'Note to author: De ontwikkelingen van de Epsilon reactor vanuit mijn perspectief' (18-1-2019).

Ferro, Armand, 'Notes and Documentation' (1984-1985).

Gartner, 'Wafer Fab Equipment and Capital Expenditures by Region, 1998-2017'. Robinson, McDonald ‘Documentation' (1984-1985).

Personal collections interviewees

Raaijmakers, René, 'ASML Clippings' (1982-1995).

Smink, Gerard, 'Quotations Book ASM' (1971).

Rhee, André van 'Personal archive' (1987-1991) [included to archive Arthur del Prado].

\section{National Archive (The Hague, Netherlands)}

Nationaal Archief, Ministerie van Economische Zaken Directoraat Generaal Industrie en Handel (1939) 1965-1973 (1975) Archiefbloknr E10. Inv.Nr. 254.

Dutch parliament (tweedekamer.nl) [database on-line]

Tweede Kamer der Staten-Generaal, Minister van Economische Zaken G.M.V. van Aardenne, 'Brief van de Minister van Economische Zaken, ref: 18600, nr.15.' Vergaderjaar 1984-1985: Rijksbegroting voor het jaar 1985 (11-10-1984). 


\section{Computer History Museum (Mountain View, California) [database on-line]}

Computer History Museum, '1960 - Epitaxial Deposition Process Enhances Transistor Performance', http://www.computerhistory.org/semiconductor/ timeline/1960-Epitaxial.html (viewed 11-2-2016).

Computer History Museum, '1954 - Diffusion Process Developed for Transistors' http://www.computerhistory.org/semiconductor/timeline/1954-Diffusion.html (viewed: February 8, 2016).

Dataquest market trends reports, covering 1979-1999 (catalog number: 102736033), accessible via computerhistory.org.

United States Air Force, Air Force Systems Command, Integrated Circuits Come of Age (Washington D.C. 1966), p.5. Derived from: Computer History Museum (Catalog Nr. 102740473): http://www.computerhistory.org/collections/ catalog/102740473 (viewed: 6-12-2018).

\section{Chemical Heritage Foundation (renamed Science History Institute) [database on-line]}

R Victor Jones, 'Interview by David Brock via Telephone' Chemical Heritage Foundation Oral History Transcript \#0336 (18-4-2006).

\section{The Chip History Center - The Virtual Museum of Semiconductors (chiphistory. org) [database on-line]}

VLSI Research History of the Semiconductor Equipment Industry (1990) https://www.chiphistory.org/144-vlsiresearch-s-history-of-the-semiconductorequipment-industry (viewed: 10-4-2019)

VLSI Research, Dan Hutchison, 'Hall of Fame: Applied Materials AME-8100 Batch Etcher'. Chipshistory.org (Date unknown) https://www.chiphistory.org/137applied-materials-ame-8100-batch-etcher (viewed: 23-2-2018).

\section{Oral histories of semiconductor equipment industry association SEMI [database on-line]}

Due to changes on the website, most oral histories no longer available in 2019.

SEMI, Craig Addison, 'SEMI Oral History Interview: Karl Lang', semi.org (17-82006) http://www.semi.org/en/About/P040677 (viewed: 3-10-2018).

SEMI, Craig Addison, 'SEMI Oral History Interview: Michael A. McNeilly' (20-72004) www.semi.org/en/about/P035091 (viewed 17-3-2016).

SEMI, Craig Addison, 'SEMI Oral History Interview: Peter Wolken', semi.org (166-2007) http://www.semi.org/en/oral-history-interview-peter-wolken-0 (viewed: 19-2-2018).

SEMI, Craig Addison, 'Oral History Interview: Dan Worsham', semi.org (date unknown) http://www.semi.org/en/oral-history-interview-dan-worsham (viewed: 7-8-2017). 
Harvard Business School Baker Library - Lehman Brothers collection (18502008) [database on-line]

Author unknown, 'Sola Basic industries, Inc: List of Deals', Harvard Business School Baker Library, Historical Collections: Lehman Brothers Collection Contemporary Business Archive, http://www.library.hbs.edu/hc/lehman/company. html?company=sola_basic_industries_inc (viewed: 3-10-2018).

Ancestry.com [database on-line]

New York, Passenger Lists, 1820-1957.

Harvard Business School, 'Yearbook 1957' (1957) U.S. School Yearbooks, 18802012.

\section{CBG Centrum voor Familiegeschiedenis [database on-line]}

'Familieadvertenties Jonge Poerink [periode tot 1970]', Gescande Familieadvertenties tot 1970, p. 3.

\section{Noord-Hollands Archief [database on-line]}

Amsterdam Huwelijksbijlagen 1927, Watergraafsmeer Reg.W2 fol 22v (24-111927), derived from: https://www.openarch.nl/show.php?archive=nha\&identif ier=e0df60b9-9cfc-43d7-bd30-b93614a6db8a\&lang=en\&six=2 (viewed: 20-32019).

\section{Indische Genealogische Vereniging [database on-line]}

'De schepen van de Stoomvaart Maatschappij Nederland, Oranje', Passagierslijsten repatriering (1946-1968) (June 2014) https://igv.nl/wp-content/uploads/2018/03/ Oranje_1945-1962.pdf (viewed: 20-3-2019).

Kluwer Navigator - legal portal about Dutch legislation, commentaries, case law and legal journals [database on-line]

Hoge Raad, 'ECLI:NL:HR:AB3926, Uitspraak m.nt HE. Bröring, Hoge Raad inzake Topsoe-Del Prado' (6-4-1973).

Gerechtshof Amsterdam, Ondernemingskamer, 'Hermes Focus Assset, Fursa versus ASM International, zaaknummer: 200.005.940/1 OK; ECLI: GHAMS:2008:BD2197' (21-5-2008).

Gerechtshof Amsterdam, Ondernemingskamer, 'Hermes, Fursa, en VEB versus ASM International, Stichting Continuïteit ASM International, Ondernemingsraad ASM Europe en Arthur del Prado. Zaaknummer: 200.005.940; ECLI:NL:GHAMS:2009:BJ4688’ (6-8-2009).

Hoge Raad, Eerste Kamer 'Cassatie Stichting Continuiteit ASM International versus Hermes, Fursa, VEB, ASM International, Ondernemingsraad ASM Europe en Arthur del Prado. Zaaknummer: 09/4465 en 09/04512; ECLI:NL:HR:2010:BM0976' (9-7-2010). 
Hoge Raad, Eerste Kamer, 'Cassatie van Hermes, Fursa en VEB versus ASM International, Stichting Continuiteit ASM International, Ondernemingsraad ASM Europe en Arthur del Prado. Zaaknummer: 11/03182; ECLI:NL:HR:2012:BV1435’ (30-3-2012).

\section{Smithsonian - The Chip Collection Smithsonianchips.si.edu [database on-line]}

Author unknown, 'A Series of 1976 reviews of Don Hoefler's Microelectornics News', Integrated Circuit Engineering Collection - Project File 10085 (2-4-1976) http://smithsonianchips.si.edu/schreiner/1976/icer7634.htm (viewed: 3-102018).

\section{Various collections concerning the Japanese occupation of the Dutch Indies [database on-line]}

Author unknown, 'Tjideng Register: Register of Families in Tjideng in April 1944' http://members.iinet.net.au/ vanderkp/Register\%20UK.htm (viewed 22-112016).

Author unknown, 'Soorten kampen', indischekamparchieven.nl (19-5-2010) https:// www.indischekamparchieven.nl/nl/bezetting-en-bersiap/over-de-kampen/ soorten-kampen (viewed 11-9-2018).

Author unknown, 'Tjimahi kampen West-Java: Naamlijst (Augustus 1945)', japanseburgerkampen.nl (26-11-1945) http://www.japanseburgerkampen.nl/ Tjimahi-kampen\%20aug\%201945\%20P.htm (viewed 11-9-2018).

\section{Google Patents [database on-line]}

Alberti, Robert Stanley; Jon Charles Goldman, 'US Patent 4,098,923: Pyrolytic Deposition of Silicon Dioxide on Semiconductors Using a Shrouded Boat' (Filed: 7-6-1976, Accepted 4-7-1978).

Alberti, Robert Stanley; Jon Charles Goldman, 'US Patent 4,098,923: Pyrolytic Deposition of Silicon Dioxide on Semiconductors Using a Shrouded Boat' (Filed: 7-6-1976, Accepted 4-7-1978).

Alberti, Robert Stanley; Jon Charles Goldman, 'US Patent 4,098,923: Pyrolytic Deposition of Silicon Dioxide on Semiconductors Using a Shrouded Boat' (Filed: 7-6-1976, Accepted 4-7-1978).

Baerg, W. 'US385443: Reactor for Depositing Thin Films' (filed 19-12-1973; publication: 17-12-1974).

Benzing, Walter, 'US 3484311: Silicon Deposition Process' (filed: 21-6-1966; published: 16-12-1969).

Biard, James, 'US 3463975: Unitary semiconductor high speed switching device utilizing a barrier diode’ (filed: 31-12-1964; published: 26-8-1969). 
Boer, Wiebe de; Albert Ozias, 'United States Patent 4,821,674: Rotatable Substrate Supporting Mechanism with Temperature Sensing Device for Use in Chemical Vapor Deposition Equipment' (filed: 31-3-1987; published: 18-4-1989).

Boland, Bernard; Don Jackson, and James Williams, 'US: Deposition of Silicon Nitride' (priority: 30-10-1967; published: 23-2-1971).

Burt, Dan; Richard Taraci, and John Zavion, 'US 3934060: Method for forming a deposited silicon dioxide layer on top of a semiconductor wafer' (filed: 19-121973; published: 20-1-1976).

Chruma, Jerry L.; and Paul G. Hilton, 'US 3900597A: System and process for deposition of polycrystalline silicon with silane in vacuum' (filed: 19-12-1973; published: 19-8-1975) also as DE2460211 and CA1047850.

Ellis, Ray; and Walter Leverton, 'US2916359: Preparation of substantially pure silicon' (filed: 14-12-1956; published: 8-12-1959).

Engle Jr., George M.; 'US4223048A: Plasma Enhanced Chemical Vapor Processing of Semiconductor Wafers' (file: 7-8-1978; publication: 16-9-1980).

Engle, George M.; and Richard S. Rosler, 'US4610748A: Apparatus for processing semiconductor wafers or the like’ (filed: 10-12-1984; published: 9-6-1986).

Everstijn, F.; and H. Peek, 'US 3750620: Vapor Deposition Reactor' (priority: 113-1970; published: 7-8-1973).

Goldman, Jon; Larry McMillan, and James Price, 'US 4279947: Deposition of silicon nitride’ (Priority: 25-11-1975; published: 21-7-1981).

Heinecke, Rudolf A.H.; Ronald C. Stern, 'US4328261A: Metallizing semiconductor devices' (priority date: 9-11-1978; published: 4-5-1982).

Heinecke, Rudolf A.H.; Ronald C. Stern, 'US4460618A: Aluminum deposition on semiconductor bodies' (priority date: 25-5-1978; published 17-7-1984).

Heinecke, Rudolf A.H.; Ronald C. Stern, 'US4433012A: Process for the pyrolytic deposition of aluminum from TIBA' (Priority date: 10-7-1980; published 21-21984).

Heinecke, Rudolf A.H.; Ronald C. Stern, and Michael Joseph Cooke 'EP0068738A1: Metalllisation Plant' (priority date: 17-6-1982; published: 5-11983).

Jackson, Don; and James Norling, 'US 3496037: Semiconductor growth on dielectric substrates' (filed: 17-2-1970; published: 29-3-1976).

Mayer, Alfred; and Jospeph Lesky, 'US3177100: Depositing epitaxial layer of silicon from a vapor mixture of $\mathrm{SiH} 4$ and H3' (filed: 9-9-1963; published: 6-41965).

McMullen, James; and James Vokac, 'US patent, US 4203387A: Cage for low pressure silicon dioxide deposition reactors' (filing: 28-12-1978; publication: 205-1980). 
Reinberg, Alan; 'US 3757733: Radial flow reactor' (filed: 27-10-1971; published: 11-9-1973).

Robinson, McDonald; and Albert Ozias, 'United States Patent 4,836,138: Heating System for Reaction Chamber of Chemical Vapor Deposition Equipment' (filed: 18-6-1987; published: 6-6-1989).

Rosler, Richard; and Robert East, 'US 4232063: Chemical vapor deposition reactor and process' (filed: 14-11-1978; published 4-11-1980).

Rosler, Richard S.; and George M. Engle, 'US4401687A: Plasma deposition of silicon' (filed: 12-11-1981; publication:30-8-1983).

Suntola, Tuomo; and Jorma Antson, 'US 4,058,430: Method for Producing Compound Thin Films' (filed: 25-11-1975; published: 15-11-1977), [foreign application priority data: 29 November 1974, 743473].

\section{Media}

Hannah Dogger and Merlijn Schneiders, 'Mazelen op de Nieuw Amsterdam', anderetijden.nl (29-9-2013) http://anderetijden.nl/aflevering/81/Mazelen-opde-Nieuw-Amsterdam (viewed: 23-11-2016). 


\section{Literature}

\section{A}

Akkermans, Dirk; Hans van Ees, Niels Hermes, Reggy Hooghiemstra, Gerwin van der Laan, Theo Postma, and Arjen van Witteloostuijn, 'Corporate Governance in the Netherlands: an overview of the application of the Tabaksblat Code in 2004' Corporate Governance 15:6 (2007) pp. 1106-1118.

Ansoff, Igor; Corporate Strategy: An Analytical Approach to Business Policy for Growth and Expansion (McGraw-Hill, 1965).

ANP, "Visie PvdA op economie komt 13 jaar te laat", Nederlands Dagblad (2-121983), p. 9.

ANP, 'Licentie ASMI naar Amerikaans Veeco', NRC Handelsblad (23-6-2005) p. 17.

Applied Materials, Ahmed and Klaus Schuegraf, 'Transistor Wars', spectrum.ieee. org (28-10-2011) https://spectrum.ieee.org/semiconductors/devices/transistorwars (viewed: 14-11-2018).

Applied Materials, 'News Release: Applied Materials Announces Fourth Quarter and Fiscal Year 2018 Results' (15-11-2018) http://www.appliedmaterials.com/ company/news/press-releases/2018/11/applied-materials-announces-fourthquarter-and-fiscal-year-2018-results (viewed: 10-4-2019).

Applied Materials, 'Press release: Applied Materials Makes the Transistor Cool Again with Integrated High-k/Metal Gate Technology', appliedmaterials.com (17-72007) http://www.appliedmaterials.com/company/news/press-releases/2007/07/ applied-materials-makes-the-transistor-cool-again-with-integrated-high-kmetalgate-technology (1-7-2007).

ASM America, Eric Shero, 'Presentation: Production-Ready ALD toolset using $\mathrm{HfCl}_{4}$ derived $\mathrm{HfO} 2$ gate dielectrics for CMOS' (23-6-2008) www. asmtheswitchison.com (website no longer online) PDF file of presentation in author's archive.

ASM America and ATMI Inc, Mohith Verghese, Scott Battle, and Jeff Roeder, 'Solid-Source Delivery System Enables Hafnium-Based Gate Dielectrics', Semiconductor International (April 2008).

ASM International, Erik Kamerbeek and Mary Jo Dieckhaus, 'Press Release: ASM International and Tokyo Electron Sign Licensing Agreement for Atomic Layer Deposition Technology' (19-12-2008) http://www.asm.com/Pages/Press-releases/ ASM-International-and-Tokyo-Electron-Sign-Licensing-Agreement-for-AtomicLayer-Deposition-Technology.aspx (viewed: 26-11-2018).

ASM International, Erik Kamerbeek and Mary Jo Dieckhaus, 'ASM International announces receipt of unsolicited indicative combined offer for front-end business activities from Applied materials and Francisco Partners' asm.com (17-6-2008) http://www.asm.com/Pages/Press-releases/ASM-International-Announces- 
Receipt-of-Unsolicited-Indicative-Combined-Offer-for-Front-End-BusinessActivities-from-Applied.aspx (viewed: 13-7-2018).

ASM International, 'Press release: ASM International N.V. and Balzers AG investigate merger of metallization activities', PR Newswire (8-5-1991).

ASM International, 'Press release: ASM International sells 10 percent interest in ASM Pacific technology', PR Newswire (4-4-1991).

ASM Pacific Technology, Patrick Lam, ‘Farewell Dinner Speech’ belzalel.hk [personal website Patrick Lam] (16-12-2006).

Author unknown, 'Arthur del Prado of ASM International: Full faith in the semi market', Euromoney Magazine (January 2006).

Author unknown, 'ASM verdrievoudigt verlies tot $\mathrm{f} 61,7 \mathrm{mln}$, omzet dealt met 7pct', NRC Handelsblad (31-3-1987) p. 13.

Author unknown, 'ASMI New ALD tool offers single-metal gate stack for 32nm $\mathrm{HK}+\mathrm{MG}$ ' electroiq.com (19-5-2008) https://electroiq.com/2008/05/asmi-new-aldtool-offers-single-metal-gate-stack-for-32nm-hkmg/ (viewed 31-7-2018).

Author unknown, 'Chipproject JESSI gaat EZ extra geld kosten' NRC Handelsblad (1-6-1990) p. 9.

Author unknown, 'Chip sales slowing', money.cnn.com (2-1-2001) https://money. cnn.com/2001/01/02/technology/semi/ (viewed: 24-8-2001).

Author unknown, 'Europese samenwerking geen liefde op eerste gezicht' Leeuwarder Courant (1-9-1990) p. 21.

Author unknown, 'NEC offers platform for cell-based ICs', eetimes.com (18-1-2007) https://www.eetimes.com/document.asp?doc_id=1164985 (viewed: 31-7-2018).

Unknown author, 'Philips to sell its $16.2 \%$ stake in Taiwan's TSMC', The New York Times (9-3-2007) https://www.nytimes.com/2007/03/09/business/ worldbusiness/09iht-philips.4854503.html (viewed 24-5-2018).

Author unknown, 'Semiconductor equipment sales total in 2000 higher than previous 2 years combined' electroiq.com (1-3-2001), https://electroiq. com/2001/03/semiconductor-equipment-sales-total-in-2000-higher-thanprevious-2-years-combined/ (viewed 24-8-2018).

Author unknown, 'Semiconductor industry showed light growth in 2002', electroiq.com (13-12-2002) https://electroiq.com/2002/12/semiconductorindustry-showed-slight-growth-in-2002/ (viewed: 22-11-2018).

Author unknown, 'Gartner says worldwide semiconductor capital equipment spending to grow in 2003', vision-systems.com (10-7-2003) https://www.visionsystems.com/articles/2003/07/gartner-says-worldwide-semiconductor-capitalequipment-spending-to-grow-in-2003.html (viewed: 22-11-2018).

Author unknown, 'Tsang: The Worst is Over' Money.CNN.com (8-10-1998) https:// money.cnn.com/1998/10/08/markets/moneyline_intv/ (viewed 25-9-2018). 
Author unknown, 'Worldwide PC Market Posts Nearly 16 Percent Growth in 1997, According to Dataquest', tech-insider (26-1-1998) https://tech-insider.org/ statistics/research/1998/0126.html (viewed: 5-10-2018).

\section{$\boldsymbol{B}$}

Bakker, Sjoerd, Competing Expectations: The case of the hydrogen car (BOXPRess, Oisterwijk, 2011).

Baldwin, Richard, 'The Impact of the 1986 US-Japan Semiconductor Agreement' Japan and the World Economy 6 (1994) pp. 129-152.

Banning, Cees; and Ben van der Velden, 'Andriessen wijst verwijten over subsidie aan Philips af; "Chip-project normaal risico", NRC Handelsblad (5-9-1990) p. 11.

Barsuhn, Horst E.; and Karl Ganzhorn, The IBM Laboratories Böblingen: Semiconductor and Chip Development: Research and Development in IBM Germany (Sindelfingen 2000).

Benzing, David; David Wang, Dan Maydan, 'Ion-Assisted Plasma Etching of Silicon-Oxides in a Multifacet System', Solid State Technology (December 1981), pp. 71-75.

Berlin, Lesli, The Man Behind the Microchip: Robert Noyce and the Invention of Silicon (Oxford University Press, Oxford, 2006).

Bidault, Francis; Charles Despres, and Charles Butler, Leveraged Innovation: Unlocking the Innovation Potential of Strategic Supply (Palgrave Macmillan, London, 1998).

Blank, Steve, 'What the GlobalFoundries' Retreat Really Means', Spectrum.ieee. org (10-9-2018) https://spectrum.ieee.org/nanoclast/semiconductors/devices/ what-globalfoundries-retreat-really-means (viewed: 9-4-2018).

Blyth, Mark, 'Coping with the Black Swan: The Unsettling World of Nassim Taleb', Critical Review 21:4 (2009) pp. 447-465.

Bodewitz, Henk; Gerard de Vries, and Pieter Weeder, 'Towards a cognitive model for technology-oriented R\&D processes', Research Policy 17 (1988) pp. 213-224.

Boersma, Kees; and Marc de Vries, 'Transitions in industrial research: the case of the Philips Natuurkundig Laboratorium (1914-1994)', Business History 50:4 (2008) pp. 509-529.

Bökkerink, Ivo; and Pieter Couwenbergh, 'ASMI komt met extreme maatregel tegen activistische aandeelhouders en ziet Ondernemingskamer opdoemen.', Financieele Dagblad (15-5-2008) p. 27.

Bökkerink, Ivo; Pieter Couwenbergh, and Joost van Mierlo, 'Stichting frustreert compromisvoorstel van ASM', Finanieele Dagblad (20-5-2008) p. 19.

Bower, Joseph; and Clayton Christensen, 'Disruptive Technologies: Catching the Wave'. Harvard Business Review (February 1995). 
Breschi, Stefano; and Franco Malerba, 'Sectoral Innovation Systems: Technological Regimes, Schumpeterian Dynamics, and Spatial Boundaries', in: Charles Edquist (ed.), Systems of Innovation: Technologies, Institutions and Organisations (London 1997) pp. 130-151.

Brock, David, Understanding Moore's Law: Four Decades of Innovation. (Philadelphia: Chemical Heritage Press, 2006).

Brock, David; and David Laws, 'The Early History of Microcircuitry: An Overview', IEEE Annals of the History of Computing (2012) pp 7-19.

Brock, David, 'From automation to Silicon Valley: the automation movement of the 1950s, Arnold Beckman, and William Shockley', History and Technology 28:4 (2012) pp. 375-401.

Brock, David, 'A Clear Voice: The Origins of Gordon Moore's 1965 Paper', in: David Brock (ed.), Understanding Moore's Law (Chemical Heritage Press, Philadelphia, 2006) pp. 25-36.

Brock, David; and Christophe Lécuyer, 'Digital Foundations: The Making of Silicon-Gate Manufacturing Technology', Technology and Culture 53:2 (2012) pp. 561-597.

Brock, David, 'Patterning the World: The rise of Chemically Amplified Photoresist', Chemical Heritage Foundation, Center for Contemprorary History and Policy: Studies in Materials Innovation (2009), pp. 17.

Brock, David; 'Chapter 8: Reflections on Moore's Law', in: David Brock (ed.), Understanding Moore's Law: Four Decades of Innovation (Chemical Heritage Foundation, Philadelphia, 2006), pp. 87-108.

Browing, Larry; Janice Beyer, and Judy Shetler, 'Building Cooperation in a Competitive Industry: SEMATECH and the Semiconductor Industry', The Academy of Management Journal 38:1 (1995) pp. 113-151.

Brown, Shona; and Kathleen Eisenhardt, 'Product Development: Past Research, Present Findings, and Future Directions', The Academy of Management Review 20:2 (1995) pp. 343-378.

Brown, Clair; and Greg Linden, Chips and Change: How Crisis Reshapes the Semiconductor Industry (MIT Press Paperback Edition, Cambridge, 2011).

\section{C}

Callon, Michel, 'Some elements of a sociology of translation: domestication of the scallops and the fishermen of St Brieuc Bay', in: John Law (ed.), Power, action and belief: a new sociology of knowledge? (London, Routledge, 1986), pp. 196-223.

Casson, Mark, Entrepreneurship: Theory, Networks, History (Cheltenham, 2010).

Chandler, Alfred, Strategy and Structure: Chapters in the History of the American Industrial Enterprise (MIT Press, Cambridge, 1962). 
Chandler, Alfred, 'Management Decentralization: An Historical Analysis', The Business History Review 30:2 (1956) pp. 111-174.

Chandler, Alfred, Inventing the Electronic Century: The Epic Story of the Consumer Electronics and Computer Industries (Harvard University Press, Cambridge, paperback version 2005) p. 5.

Chandler, Alfred, Shaping the Industrial Century: The Remarkable Story of the Evolution of the Modern Chemical and Pharmaceutical Industries (Harvard University Press, Cambridge, 2005), p. 6.

Christensen, Clayton, The Innovator's Dilemma: When New Technologies Cause Great Firms to Fall, (Harvard Business Review Press, Cambridge, 1997).

Christensen, Clayton; and Michael Raynor, The Innovator's Solution: Creating and Sustaining Successful Growth (Harvard Business Review Press, Boston, 2003).

Cohen, Wesley; and Daniel Levinthal, 'Absorptive Capacity: A New Perspective on Learning and Innovation', Administrative Science Quarterly 35:1 (1990) pp. 128-152.

Constant II, Edward; 'The Social Locus of Technological Practice: Community, System or Organization?', in: Wiebe Bijker and Thomas Hughes (ed.), The Social Construction of Technological Systems: New Directions in the Sociology and History of Technology (MIT Press, Cambridge, 1989) pp. 223-242.

Commission of the European Communities, 'Community Actions in the Field of MicroElectronics' Technology Council Regulation (EEC) No 3744/81' (23-10-1984) http://aei.pitt.edu/3667/1/3667.pdf (viewed 14-7-2017).

Commission of the European Communities, 'Community Actions in the Field of Microelectronic Technology Council Regulation EEC No.3744/81' (2-2-1987) http:// aei.pitt.edu/10405/1/10405.pdf (viewed 13-7-2017).

Commission of the European Communities, ESPRIT European Strategic Programme for Research and Development in Information Technology 1989 Annual Report (Luxemburg, 1990).

Cooke, M. J., and R. Heinecke. "LPCVD of Aluminum and Al-Si Alloys for Semiconductor Metallization.” Solid State Technology 25.12 (1982), pp. 62-65.

Cooke, H.J.; R.A. Heinecke, R.C. Stern, and J. W.C. Maes, Solid State Technol. 25 (1982).

Coombs, Rod, 'Technological opportunities and industrial organization', in: Giovanni Dosi, Christopher Freeman, Richard Nelson, Gerald Silverberg, and Luc Soete, Technical Change and Economic Theory (Pinter Publishers, London, 1988) pp. 295-308.

Courtland, Rachel, 'The Origins of Intel's New Transistor, and Its Future', Spectrum.ieee.org (9-5-2011) https://spectrum.ieee.org/tech-talk/semiconductors/ design/throughsilicon-transistors-could-make-stacking-chips-smarter (viewed: 5-4-2019). 
Couwenbergh, Pieter, 'Hoge Raad ziet geen rol commissaris bij conflict', Het Financieele Dagblad (10-7-2010) p. 1.

Couwenbergh, Pieter, 'Intel wil zelfstandig ASMI 'zeker stellen' met nemen van belang', Het Financieele Dagblad (12-6-2009) p. 13.

Couwenbergh, Pieter, 'Liefhebber van het strategische gevecht', Het Financieele Dagblad (14-5-2009) p. 2.

Couwenbergh, Pieter; and Joost van Mierlo, 'Del Prado sprak eerder met Applied', Het Financieele Dagblad (19-6-2008) p. 17.

Couwenbergh, Pieter; and Joost van Mierlo, 'ASMI houdt rechter even buiten de deur', Het Financieele Dagblad (23-6-2008) p. 1.

Couwenbergh, Pieter; and Joost van Mierlo, 'Shakespearedrama by ASM International’, Het Financieele Dagblad (16-4-2009) p. 17.

Creswell, Julie, 'So Small a Town, So Many Patent Suits' nytimes.com (24-9-2006) https://www.nytimes.com/2006/09/24/business/24ward.html (viewed: 1-112018).

\section{D}

Dahad, Nitin, 'Seperating AI Hype from Reality', EETimes (22-11-2018) https:// www.eetimes.com/author.asp?section_id=240\&doc_id=1334002 (viewed: 5-42019).

Dankers, Joost; Keetie Sluyterman, and Jan Luiten van Zanden, on 'Business in the Netherlands during the Twentieth Century' (Bedrijfsleven in Nederland in the Twintigste Eeuw).

Davids, Mila; Harry Lintsen, Arjen van Rooij, Innovatie en kennisinfrastructuur: vele wegen naar vernieuwing. Bedrijfsleven in Nederland in de Twintigste Eeuw (Boom Amsterdam, 2013).

Davids, Mila; and Geert Verbong, 'Absorptive Capacity in Solid-State Technology and International Knowledge Transfer: The Case of Philips', Comparative Technology Transfer and Society 5:1 (2007) pp. 1-31.

Dijk, Bert van, 'Grote synergie binnen ASMI: Europa wordt kennisleverancier voor chipsector in Azië, Het Financieele Dagblad (18-5-2006) p. 17.

Dijk, Bert van 'Octrooi klein ASMI maakt grote indruk', Het Financieele Dagblad (9-11-2006) p. 1.

Dijk Bert van; en Pieter Elshout, 'Hedge fund ruikt zege in strijd om opsplitsing ASMI' Het Financieele Dagblad (28-9-2006) p. 1.

Dijk, Bert van, 'ASMI drukt belager in het nauw', Financieele Dagblad (28-11-2006).

Dimov, Dimo, 'Grappling with the Unbearable Elusiveness of Entrepreneurial Opportunities', Entrepreneurship: Theory and Practice (January 2011) pp. 57-81. 
Dosi, Giovanni, Technical Change and Industrial Transformation (St. Martin's Press, New York, 1984);

Dosi, Giovanni, Technical Change and Survival: Europe's Semiconductor Industry (Sussex European Research Center, Sussex, 1981);

Dosi, Giovanni, 'Technological Paradigms and technological trajectories. A suggested interpretation of the determination and directions of technical change', Research Policy 11 (1982) pp. 147-162.

Dosi, Giovanni; and Richard Nelson, 'An Introduction to evolutionary theories in economics' Journal of Evolutionary Economics 4:3 (1994) pp. 153-172.

Drucker, Peter, 'The Effective Decision', Harvard Business Review 45:1 (1967), derived from: https://hbr.org/1967/01/the-effective-decision (viewed: 9-102018);

Drucker, Peter, 'New Templates for Today's Organizations', Harvard Business Review 52:1 (1974) pp. 45-53, derived from https://hbr.org/1974/01/newtemplates-for-todays-organizations (viewed: 9-10-2018).

Dunning, John, 'Toward an Eclectic Theory of International Production: Some Empirical Tests', Journal of International Business Studies 11 (1979) pp. 9-31.

Dyakonov, Mikhail, 'The Case Against Quantum Computing', Spectrum.ieee.org (15-11-2018) https://spectrum.ieee.org/computing/hardware/the-case-againstquantum-computing (viewed: 5-4-2019).

\section{$\boldsymbol{E}$}

The Economist, 'Briefing Slowbalisation: The global list', The Economist (26-1-2019) pp. 17-20.

The Economist, 'Technology Quarterly: After Moore’s Law' (12-3-2016) www. economist.com/technology-quarterly/2016-03-12/after-moores-law (viewed: 13-7-2018).

The Economist, 'The Chips are Down', The Economist (1-12-2018) pp. 20-22.

Editor, 'Applied roept hulp private equity in bij slag om ASMI', Het Financieele Dagblad (18-6-2008) p. 1.

Editor, 'ASMI wint zaak over patenten', NRC Handelsblad (11-5-2001) p. 13.

Editor, 'Chuck del Prado wil nog niet opgeven: ASMI Dynastie wankelt', Dagblad de Pers (29-4-2008) p. 3.

Editor, 'Concurrent wil ASMI's technologie overnemen', NRC Handelsblad (6-62008) p. 13.

Editor, 'Oktrooi-conflict bedreigt export van Nederlands bedrijf in chips-branche', Financieel Dagblad (24-11-1980) p. 1.

Editors, 'Reorganisatie bij geplaagde divisie ASMI', NRC Handelsblad (28-4-2008) p. 13. 
Editor, 'Semiconductor equipment sales were \$47.7B last year', eetimes.com (293-2001) https://www.eetimes.com/document.asp?doc_id=1128641 (viewed: 9-4-2019).

Editors, 'Stichting ASMI trekt beschermingswal op', De Telegraaf (15-5-2008) p. 27.

EDN staff, 'Wafer weight gain', edn.com (1-3-2001) https://www.edn.com/ electronics-news/4354350/Wafer-weight-gain (viewed: 5-10-2018).

Edquist, Charles, 'Systems of Innovation Approaches - Their Emergence and Characteristics', in: Charles Edquist (ed.), Systems of Innovation: Technologies, Institutions and Organisations (London 1997) pp. 1-34.

Electronic Devices Society of IEEE, 'Technical Digest International Electron Devices Meeting 2001' (2-12-2001) http://ieeexplore.ieee.org/stamp/stamp. jsp?arnumber=979359 (viewed: 7-4-2017).

Electronic Devices Society of IEEE, IEEE International Electronic Devices Meeting 2003, Technical Digest (8-12-2003) http://ieeexplore.ieee.org/stamp/stamp. jsp?tp=\&arnumber=1269151 (viewed 30-6-2017).

Elshout, Pieter, 'Hedge fund dreigt ASMI met de rechter', Het Financieele Dagblad (8-5-2006) p. 1.

Ende, Jan van den; Nachoem Wijnberg, and Albert Meijer, 'Public Policy and Innovative Capabilities: The Case of Philips' IT Activities', Technology Analysis \& Strategic Management 13:3 (2001), pp. 389-405.

Endt, Friso; 'Silicon Valley in de Jan Steenstraat', NRC Handelsblad (3-10-1981) p. 13.

European Commission, Cordis, "Project MR-11-ASM: Development of a refractory metal deposition process and related equipment' http://cordis.europa.eu/project/ rcn/17362_en.html (viewed 21-7-2017).

European Commission, Cordis, 'PRE-MELREG C - Community Actions (EEC) in the field of microelectronic technology, 1982-1985’ cordis.europa.eu (viewed 19-7-2017).

European Commission, Cordis, 'Hot Cluster for Integrated Vapour Phases Cleaning and Processing of Dielectrics and Insitu Doped Polysilicon (CICDIP)' cordis.europa.eu (1-6-1996) https://www.cordis.europa.eu/project/rcn/32376_ en.html (viewed: 9-4-2019).

\section{$\mathbf{F}$}

[Family message], 'Franc R.J. deWeeger obituary' (11-7-2010) Arizona Republic Derived from: https://www.legacy.com/obituaries/azcentral/obituary. aspx?pid=143995531 (viewed 1-3-2018).

[family message], 'Obituary Arthur Eugene del Prado' NRC Handelsblad (23-121986) p. 16. 
[Family message], 'Obituary Daniel Queyssac' The Arizona Republic (1210-2009) https://www.legacy.com/obituaries/name/daniel-queyssacobituary?pid=134541008 (viewed: 1-11-2018).

Federal Reserve Board, Alan Greenspan, 'Remarks at the Annual Dinner and Francis Boyer lecture of The American Enterprise Institute for Public Policy Research, Washington DC: The Challenge of Central Banking in a Democratic Society' (5-12-1996) https://www.federalreserve.gov/boarddocs/ speeches/1996/19961205.htm (viewed: 15-10-2018).

Feder, Elisabeth, 'The JESSI Program Adopts a Japanese-Style Strategy' Electronique International Hebdo (9-4-1992), published in JPRS Report Science \& Technology: Eureka, p. 2.

Fierkens, Richard, Hightech in een boerendorp. De biografie van Fico-ondernemer Richard Fierkens (Herwen 2014).

Fontana, Roberto; Franco Malerba, and Astrid Marinoni, 'Knowledge intensive entrepreneurship in different sectoral systems', in: Franco Malerba, Yannis Caloghirou, Marueen McKelvey, and Slavo Radosevic (Ed.), Dynamics of Knowledge Intensive Entrepreneurship: Business strategy and public policy. Part of series: Routledge Studies in Innovation, Organization and technology (Routledge 2015) pp. unknown. [viewed at Google Books].

Fransman, Martin, The Market and Beyond: Information Technology in Japan (Cambridge University Press, 1990).

Friant, Ray, Beyond Buzzwords: The New Agenda for Directors, CEOs \& Executives (Advanced Management Press, Convent Station, 2006).

\section{$\boldsymbol{G}$}

Gartner Dataquest, '2002 Semiconductor Equipment Market Share Analysis (Executive Summary)', Gartner Dataquest (2-5-2003) p. 2; obtained from: https://www.bus.umich.edu/kresgepublic/journals/gartner/ research/114400/114433/114433.pdf (viewed: 24-8-2018).

Gartner, Charles Smulders, 'Worldwide Semiconductor Forecast Scenarios: Life After 11 September', gartner.com (19-10-2001) https://www.gartner.com/ doc/345134/worldwide-semiconductor-forecast-scenarios-life (viewed: 22-112018).

Gartner, Klaus Rinnen, Dean Freeman, James F. Hines, and Bob Johnson, 'Semiconductor Industry Equipment Spending Will Recover in 2003', gartner. com (10-7-2002) https://www.gartner.com/doc/363276/semiconductor-industryequipment-spending-recover (viewed: 22-11-2018).

Gartner, 'Press Release: Gartner Says WorldWide Semiconductor Manufacturing Equipment Sales Experienced a 10 Percent Increase in 2003', gartner.com (8-42004) https://www.gartner.com/newsroom/id/492020 (viewed: 22-11-2018). 
Garud, Raghu; and David Ahlstrom, 'Technology assessment: a socio-cognitive perspective', Journal of Engineering and Technology Management 14:1 (1997) pp. 25-48.

Geerken, John; 'Machiavelli Studies since 1969', Journal of the History of Ideas 37:2 (1976) pp. 351-368.

Gerven, Paul van; 'Halfgeleiderverkoop doorbreekt grens van een biljoen', bitschips.nl (30-1-2018) https://bits-chips.nl/artikel/halfgeleiderverkoop-doorbreektgrens-van-een-biljoen-51170.html (viewed: 13-7-2018).

Ghemawat, Pankaj; 'Competition and Business Strategy in Historical Perspective', Business History Review 76 (2002) pp. 37-74.

Gieske, R.J. 'Low Pressure Chemical Vapor Deposition of Polysilicon', Proceedings of 6th International Conference on Chemical Vapor Deposition, October 10-13, 1977, obtained from: http://escholarship.org/uc/item/3mc2f1sx (viewed 3-8-2017).

Goodall, Randal K, 'The Impact of the 300 mm Scale-Up on IC Fab Process, Metrology, and Automation Equipment', Silicon Materials Science and Technology: Proceedings of the Eight International Symposium on Silicon Materials Science and Technology (1998) pp. 1302-1324.

Grindley, Peter; David Mowery, and Brian Silverman, 'SEMATECH and Collaborative Research: Lessons in the Design of High-Technology Consortia', Journal of Policy Analysis and Management 13:4 (1994) pp. 723-758

Gunther McGrath, Rita; and Ian MacMillan, The Entrepreneurial Mindset: Strategies for Continuously Creating Opportunity in an Age of Uncertainty (Harvard Business Review Press, Boston, 2000);

Gunther McGrath, Rita, 'Exploratory Learning, Innovative Capacity, and Managerial Oversight', Academy of Management Journal 44:1 (2001) pp. 118-131;

Guzzetti, Luca, 'A Brief History of European Union Research Policy', European Commission Science Research Development Studies 5 (October 1995) http://www. netaffair.org/documents/1995-a-brief-history-of-european-research.pdf (viewed 4-5-2018) p. 78.

\section{H}

Hall, Bronwyn; and Rosemarie Ham Ziedonis, 'The patent paradox revisited: an empiral study of patenting in the U.S. semiconductor industry, 1979-1995', The RAND Journal of Economics 32:1 (2001) pp. 101-128.

Ham, Rose Marie; Greg Linden, and Melissa Appleyard, 'The Evolving Role of Semiconductor Consortia in the United States and Japan', California Management Review 41:1 (1998) pp. 137-163.

Hart, Jeffrey A., Rival Capitalists: International Competitiveness in the United States, Japan and Europe (Cornell University Press, 1992) p. 216. 
Hartley, Janet; Jack Meredith, David McCutcheon, and Rajan Kamath, 'Suppliers' Contribution to Product Development: An Exploratory Study', IEEE Transactions on Engineering Management 44:3 (1997) pp. 258-267.

Hayes, R.H.; and W.J. Abernathy, 'Managing our way to economic decline', Harvard Business Review (1980) pp. 67-77.

Heijmans, M. (ed.), Kamp Tjimahi 4 - De Japanse bezetting in dagboeken (Bakker 2002)

Heinecke, Rudolph; et al., "Low-pressure Aluminum CVD”, Proceedings of the Fourth European Conference on Chemical Vapor Deposition, (1983) pp. 119-121

Hippel, Eric von, The Sources of Innovation (Oxford University Press, New York, 1988).

Hobday, Michael, 'Corporate strategies in the international semiconductor industry’, Research Policy 18 (1989) pp. 225-238.

Holbrook, David, 'Diversity, Complementarity and Cooperation: Materials Innovation in The Semiconductor Industry', in: Andrew Goldstein and William Aspray (ed.), Facets: New Perspectives on the History of Semiconductors (1997), pp. 75-131.

Holbrook, Daniel, 'Government Support of the Semiconductor Industry: Diverse Approaches and Information Flows', Business and Economic History 24:2 (1995) pp. 133-165

Hughes, Thomas, Networks of Power: Electrification in Western Society, 1880-1930 (John Hopkins University Press, Baltimore, 1983).

Hughes, Thomas, 'The evolution of large technological systems', in: Wiebe Beijker, Thomas Hughes and Trevor Pinch (ed.), The Social Construction of Technological Systems (MIT Press, Massachusets, 1987), pp. 51-82.

Hugle, William B., SEMI - The Early Years (Date unknown) http://www.3dincites. com/wp-content/uploads/SEMITheEarlyYears.pdf (viewed: 3-8-2017).

Hvenniuemi, Esko; Riikka Puurunen, et.al, 'Review Article: Recommended reading list of early publications on atomic layer deposition - Outcome of the "Virtual Project on the History of ALD" Journal of Vacuum Science Technology Association 35 (jan/feb 2017) pp. 1-13.

\section{I}

IBM, 'IBM Deutschland Forschung und Entwicklung, IBM Geschichte im Jahr 1970’ http://www-05.ibm.com/de/entwicklung/1970.html (viewed 3-8-2017).

IBM, Annual Report 2000 (2001) https://www.ibm.com/annualreport/2017/ assets/past-reports/2000-ibm-annual-report.pdf (viewed 24-8-2018) p. 92.

IBM, 'IBM Alliances Deliver Easier Path to Next Generation Semiconductor Products', ibm.com (10-12-1007) https://www.edn.com/electronics- 
news/4315068/Intel-IBM-embrace-high-k-metal-gates-for-45nm (viewed 31-72018).

IMEC, Thomas Y Hoffmann, 'Integrating high-k/metal gates: gate-first or gatelast?' Solid State Technology (1-3-2010) http://electroiq.com/blog/2010/03/ integrating-high-k/ (viewed 1-7-2017).

Infineon, 'Press release Infineon Technologies Dresden' (December 2001) https://www.infineon.com/dgdl/Dresden_Backgrounder_e. pdf?fileId=db3a304412b91b910112baacb86d215d (viewed: 22-11-2018).

Infineon, 'Press release: Pioneering 300. Less is More in Semiconductor Production' (December 2001) https://www.infineon.com/dgdl/300mm Backgrounder_e.pdf?fileId=db3a304412b91b910112baacbc8b2163 (viewed: 22-11-2018).

Intel, Mark Bohr, 'The Invention of Uniaxial Strained Silicon Transistors at Intel', Intel.com (January 2007) http://download.intel.com/pressroom/kits/ advancedtech/pdfs/Mark_Bohr_story_on_strained_silicon.pdf (viewed: 1-112018).

Intel, Annual Report 2000: Silicon is in (Santa Clara, 2001) https://www.intel.fr/ content/dam/doc/report/history-2000-annual-report.pdf (viewed: 24-8-2018) p. 2.

Intel, Mark T. Bohr, Robert S. Chau, Tahir Ghani, and Kaizad Mistry, 'The High-k Solution', Spectum.ieee.org (1-10-2007) http://spectrum.ieee.org/semiconductors/ design/the-highk-solution (viewed 26-6-2017).

Intel, 'Intel Announces Breakthrough in Chip Transistor Design' Intel.com (2611-2001) Archive Arthur del Prado - RvC 2001.

Intel, Chris Auth, Mark Buehler, Analisa Cappellani et al., '45 nm High-K+Metal Gate Strain-Enhanced Transistors', Intel Technology Journal 12:2 (2008) derived from: https://www.intel.com/content/dam/www/public/us/en/documents/ research/2008-vol12-iss-2-intel-technology-journal.pdf (viewed: 20-11-2018), pp. 77-85.

Intel, Kaizad Mistry et al., 'Presentation at 2007 IEDM Conference: A 45nm Logic technology with High0k + Metal Gate Transistors, Strained Silicon, $9 \mathrm{Cu}$ Interconnect Layers, 193 Dry Patterning, and 100 Pb-free Packaging', Intel.com (10-12-2007) http://download.intel.com/pressroom/kits/advancedtech/pdfs/ Mistry_IEDM_2007_HiK-MG_foils.pdf (viewed 1-7-2017).

Irwin, Douglas, 'Trade Politics and the Semiconductor Industry', in: Anne Krueger (ed.), The Political Economy of American Trade Politics (University of Chicago Press, Chicago, 1996) pp. 11-72, pp. 30-35.

\section{$\boldsymbol{J}$}

De Jong, Abe; Keetie Sluyterman, and Gerarda Westerhuis, 'Strategic and structural responses to international dynamics in the open Dutch economy, 1963-2003', Business History 53:1 (2011) pp. 63-84. 
De Jong, Abe; Ailsa Roëll, and Gerarda Westerhuis, 'Changing National Business Systems: Corporate Governance and Financing in the Netherlands, 1945-2005’, Business History Review 84:4 (2010) pp. 773-798.

De Jong, Abe; and Peter Roosenboom, 'De achilleshiel van Tabaksblat', Economisch Statistische Berichten 88:4411 (22-8-2018) p. 392

De Jong, Abe; Ailsa Röell, and Gerarda Westerhuis, 'De rol van aandeelhouders in historisch perspectief', Economisch Statistische Berichten 102: 4751 (13-7-2017) pp. 312-315.

De Jong, Abe; Peter Roosenboom, Marno Verbeek, and Patrick Vermijnmeren, Hedgefondsen en Private Equity in Nederland (Erasmus University, Rotterdam, 2007) p. 17.

Junige, Marcel; Tanja Kallio, Timo Sjavaara, Jonas Sundqvist, and others, 'On the Early History of ALD: Molecular Layering' Conference Paper 14th International Conference on Atomic Layer Deposition (Kyoto, June 15-18, 2014).

\section{$\boldsymbol{K}$}

Kamath, Rajan; and Jeffrey Liker, 'A Second Look at Japanese Product Development', Harvard Business Review (November-December 1994) pp. 154-170.

Käseberg, Thorsten; and Arthe van Laer, 'Competition Law and Industrial Policy: Conflict, Adaptation and Complementarity', in: Kiran Klaus Patel and Heike Schweitzer (ed.), The Historical Foundations of EU Competition Law (Oxford University Press, Oxford, 2013) pp. 162-191.

Kemperman, Jeroen (ed.), Tjideng: De Japanse bezetting in dagboeken (Bakker 2002).

Kerres, Michel, 'Alleen fusie kan Europese chips redden' NRC Handelsblad (155-1991) p. 25.

Kesler, Mark; Diana Kolstad and W.E. Clarke, 'Third Generation R\&D: The Key to Leveraging Core Competencies', The Columbia Journal of World Business 28:3 (1993) pp. 34-44.

Koh, Tijmen, 'Terug naar waar je niet vandaan kwam - Repatriering met MS Oranje', Historiek.net (datum onbekend) https://historiek.net/ms-oranjerepatriering-nederlands-indie/84393/ (viewed: 10-4-2019).

Knox Bassett, Ross, To the Digital Age: Research Labs, Start-Up Companies, and the Rise of MOS Technology (Baltimore 2007) p. 244.

\section{$\boldsymbol{L}$}

Ladas \& Parry, 'A Brief History of the Patent Law of the United States', Ladas \& Parry Education Center, http://ladas.com/a-brief-history-of-the-patent-law-of-theunited-states-2/ (viewed 24-3-2018).

Lam Research, Annual Report 2018 (7-9-2018). 
Lam Research, Martin L. Hammond, 'Poly-Si: A Most Important Material', in: Theordore Kamins, Brhua Raicy, and Carl Thomspon, MRS Symposium Proceedings 182 (November 1990) http://assets.cambridge.org/97811074/10169/ excerpt/9781107410169_excerpt.pdf (viewed: 8-3-2017).

Lam, Patrick; and Edmund Lam, Soaring like Eagles: ASM's High-Tech Journey in Asia (John Wiley \& Sons, Singapore, 2006).

Lammers, David, 'Moore's Law Milestones', ieeespectrum.com (30-4-2015) https:// spectrum.ieee.org/tech-history/silicon-revolution/moores-law-milestones (viewed 6-9-2017).

Langlois, Richard, 'Competition through institutional form: the case of cluster tool standards', in: Shane Greenstein and Victor Stango (eds.) Standards and Public Policy (Cambridge University Press 2006) pp. 60-86.

Langlois, Richard; and Edward Steinmueller, 'Strategy and Circumstance: The Response of American Firms to Japanese Competition in Semiconductors, 19801995’, Strategic Management Journal 21:10 (2000) pp. 1163-1173.

Langlois, Richard, 'Competition through Institutional Form: the Case of Cluster Tool Standards', Economics Working Papers, University of Connecticut (2004).

Latour, Bruno, "How to write "The Prince" for machines as well as for machinations', in: Brian Elliott (ed.), Technology and Social Change (Edinburgh University Press, Edinburgh 1988), pp. 20-43. Downloaded from: http://www. bruno-latour.fr/sites/default/files/36-THE-PRINCE-GB.pdf (viewed: 7-2-2018).

LaPedus, Mark, 'Intel maps out 300mm strategy', eetimes.com (14-5-2001) https:// www.eetimes.com/document.asp?doc_id=1134675 (viewed: 22-11-2018).

LaPedus, Mark, 'Intel procures initial 65-nm chip equipment (Updated)', eetimes. com (28-3-2004) https://www.eetimes.com/document.asp?doc_id=1192532 (viewed: 26-11-2018).

LaPedus, Mark, 'IBM and partners tip high-k, metal gates', eetimes.com (21-12007) https://www.eetimes.com/document.asp?doc_id=1165072 (viewed: 317-2018).

LaPedus, Mark, 'NEC tips 55-nm process with high-k immersion', eetimes.com (9-6-2006) https://www.eetimes.com/document.asp?doc_id=1161892\&utm_ source=eetimes\&utm_medium=relatedcontent (viewed: 31-7-2018).

Lawton, Thomas C., Technology and the New Diplomacy: The creation and control of EC industrial policy for semiconductors (Ashgate Publishing, 1997).

Lengkeek, Elise, De hel van Tjideng (Mitral 2010).

Lente, Harro van, 'Navigating foresight in a sea of expectations: lessons from the sociology of expectations', Technology Analysis \& Strategic Management 24:8 (2012) pp. 769-782.

Lécuyer, Christophe, Making Silicon Valley: Innovation and the Growth of High Tech, 1930-1970 (MIT Press, Cambridge, 2005). 
Lécuyer, Christophe, 'Silicon for Industry: Component Design, Mass Production, and the Move to Commercial Markets at Fairchild Semiconductor, 1960-1967', History and Technology 16:2 (1999) pp. 179-216.

Lécuyer, Christophe, 'What do Universities Really owe Industry? The Case of Solid State Electronics at Stanford', Minerva 43:1 (2005) pp. 51-71.

Lécuyer, Christophe; and David Brock, "From Nuclear Physics to Semiconductor Manufacturing: The Making of Ion Implantation," History and Technology 25:3 (2009) pp. 193-217.

Lécuyer, Christophe; and David Brock, "High Tech Manufacturing," History and Technology 25:3 (2009) pp. 165-171.

Lécuyer, Christophe; and David Brock, Makers of the Microchip: A Documentary History of Fairchild Semiconductor (MIT Press, Cambridge, 2010) pp. 2-3.

Lécuyer, Christophe; and David Brock, "The Materiality of Microelectronics," History and Technology 22:3 (2006) pp. 301-325;

Lécuyer, Christophe; and Takahiro Ueyama, "The logics of Materials Innovation: The Case of Gallium Nitride and Blue Light Emitting Diodes', Historical Studies in the Natural Sciences 43:3 (2013) pp. 243-280.

Leifer, Richard; Christopher McDermott, Gina Coarelli O'Connor, Lois Peters, Mark Rice, and Robert Veryzer, Radical Innovation: How Mature Companies Can Outsmart Upstarts (Harvard Business School Press, Boston, 2000).

Leslie, Stuart W., 'How the West Was Won: The Military and the Making of Silicon Valley', in: William Aspray (ed.), Technological Competitiveness: Contemporary and Historical Perspectives on Electrical, Electronics, and Computer Industries (1993) pp. 75-89.

Liempt, Ad van, 'ASM, Industriële vernieuwing in Bilthoven: "Deze tak bruist van dynamiek, je staat continu in de vechthouding"', Utrechts Nieuwsblad/NZC (24-12-1981).

Lineback, Robert, 'SEMI: Chip Equipment Sales Are Stronger Than Expected', eetimes.com (21-4-1999) https://www.eetimes.com/document.asp?doc_ id $=1187870$ (viewed: 9-4-2019).

Lojek, Bo, History of Semiconductor Engineering (Springer 2007).

Lojek, Bo, 'Early History of Rapid Thermal Processing', $7^{\text {th }}$ International Conference on Advanced Thermal Processing of Semiconductors (Colorado Springs, 1999).

Locquet, Jean-Pierre; Chiara Machiori, Maryline Sousa, Jean Fompeyrine, and Jin Won Seo, 'High-K dielectrics for the gate stack', Journal of Applied Physics 100:5 (2006).

Loon, H.F. van, 'Wie gaat de meeste en dus de beste chips maken?' Telegraaf (311-1981) p. 18. 


\section{M}

Mack, Chris, 'The Multiple Lives of Moore's Law', spectrum.ieee.org (30-3-2015) https://spectrum.ieee.org/semiconductors/processors/the-multiple-lives-ofmoores-law (viewed: 13-7-2018).

Malerba, Franco, The Semiconductor Business: The Economics of Rapid Growth and Decline (University of Wisconsin Press, Madison, 1985).

Malone, Michael S., The Intel Trinity: How Robert Noyce, Gordon Moore, and Andy Grove Built the World's Most Important Company (2014 Harper Collins).

Martin, Stephen, 'Protection, Promotion and Cooperation in the European Semiconductor Industry', Review of Industrial Organization 11 (1996) pp. 721-735.

Mason, Colin; and Charles Harvery, 'Entrepreneurship: Contexts, opportunities and processes', Business History 55:1 (2013) pp.1-8.

Maydan, Dan; David Wang, 'Reactive Sputter Etching and its Applications', Solid State Technology (May 1981) pp. 121-125.

McGrath, Dylan, 'Gartner sees tough year for litho stepper sales', EETimes.com (22-6-2009) https://www.eetimes.com/document.asp?doc_id=1171222 (viewed: 13-7-2018).

McGrath, Dylan, 'Intel Delays 10-nm Volume Production Until 2019', eetimes.com (27-4-2018) https://www.eetimes.com/document.asp?doc_id=1333230 (viewed 30-8-2018).

McKinsey \& Company, Richard Foster and Sarah Kaplan, Creative Destruction: Why Companies That Are Built to Last Underperform the Market - and How to Successfully Transform Them (Currency Doubleday, New York, 2001);

McKinsey \& Company, Marc de Jong, Hubert Heersche, Freek Kelkensberg, and Hiroaki Ohta, 'Capital Equipment: Will further shrink bring growth?', McKinsey on Semiconductors 5 (Winter 2015).

MEDEA+, 'Rapid Thermal Processing Boosts European Chipmaking', MEDEA+ Project Result (Date unknown) http://www.catrene.org/web/downloads/results_ medea/Project_result_T303.pdf (viewed: 23-10-2018).

MEDEA+, 'Project Profile. T302: Atomic layer deposition for $100 \mathrm{~nm}$ devices (ALAD1N+)' (January 2001) http://www.catrene.org/web/downloads/profiles_ medea/T302_profile.pdf (viewed: 27-1-2018).

Meritt, Rick, 'GlobalFoundries Halts 7nm Work', eetimes.com (27-8-2018) https:// www.eetimes.com/document.asp?doc_id=1333637 (viewed: 30-8-2018).

Meritt, Rick, 'TSMC Ready for EUV on 7, 5 nm' eetasia.com (3-5-2018) https:// www.eetasia.com/news/article/18050304-tsmc-ready-for-euv-on-7-5nm (viewed 30-8-2018).

Middelaar, Luuk van, De nieuwe politiek van Europa (Historische Uitgeverij, n.p., 2017). 
Mierlo, Joost van, 'Arthur del Prado mag verdienen aan zijn aandeelhouders', Het Financieele Dagblad (19-12-2007) p. 7.

Miller, William; and Lagndon Morris, Fourth Generation R\&D: Managing Knowledge, Technology and Innovaiton (John Wiley \& Sons, New York 1999).

Mingelen, Ferry, 'Informatica brengt vreugde binnen EG', Nieuwsblad van het Noorden (29-2-1984) p. 21.

Mintzberg, Henry; and James Waters, 'Of Strategies, Deliberate and Emergent', Strategic Management Journal 6:3 (1985) pp. 257-272.

Miranda, Miguel, 'The Threat of Semiconductor Variability', Spectrum.ieee.org (28-6-2012) https://spectrum.ieee.org/semiconductors/design/the-threat-ofsemiconductor-variability (viewed: 5-4-2019).

Mody, Cyrus, The Long Arm of Moore's Law: Microelectronics and American Science (MIT Press, Cambridge, 2017).

Mollick, E., 'Establishing Moore's Law', IEEE Annals of the History of Computing 28:3 (2006) pp. 62-75.

Moore, Gordon, 'Cramming More Components onto Integrated Circuits', in: David Brock (ed.), Understanding Moore's Law (Chemical Heritage Press, Philadelphia, 2006) pp. 55-61.

Moore, Gordon, 'Chapter 7: Moore's Law at 40', in: David Brock (ed.), Understanding Moore's Law: Four Decades of Innovation (Chemical Heritage Foundation, Philadelphia, 2006), pp. 67-84.

Moore, Samuel K., 'Through-Silicon Transistors Could Make Stacking Chips Smarter', Spectrum.ieee.org (1-10-2018) https:/spectrum.ieee.org/tech-talk/ semiconductors/design/throughsilicon-transistors-could-make-stacking-chipssmarter (viewed: 5-4-2019).

Moore, Samuel K., 'EUV Lithography Finally Ready for Chip Manufacturing', Spectrum.ieee.org (5-1-2018) https://spectrum.ieee.org/semiconductors/ nanotechnology/euv-lithography-finally-ready-for-chip-manufacturing (viewed: 5-4-2019).

Moore, Samuel K., 'GlobalFoundries Halts 7-Nanometer Chip Development', Spectrum.ieee.org (28-8-2018) https://spectrum.ieee.org/nanoclast/ semiconductors/devices/globalfoundries-halts-7nm-chip-development (viewed: 5-4-2019).

Moore, Samuel K., 'GlobalFoundries CTO on Why the Company Abandoned the "Bleeding Edge", Spectrum.ieee.org (31-8-2018) https://spectrum.ieee.org/ nanoclast/semiconductors/nanotechnology/globalfoundries-cto-on-why-thecompany-abandoned-the-bleeding-edge (viewed: 5-4-2019).

Morck, Randall K.; and Lloyd Steier, 'The Global History of Corporate Governance', in: Randall Morck (ed.), A History of Corporate Governance around the World: Family Business Groups to professional Managers (University of Chicago Press, Chicago, 2005) pp. 1-64. 
Morgan, James; and Joan Hamilton, Applied Wisdom: Bad News is Good News And Other Insights That Can Help Anyone Be a Better Manager (Chandler Jordan Publishing, Los Altos, 2016).

Moshlehi, M.; et al., 'Single-Wafer Integrated Semiconductor Device Processing' IEEE Transactions on Electron Devices 39 (1992) pp. 4-32 (http://www.academia. edu/4735611/Single-wafer_integrated_semiconductor_device_processing (viewed 4-7-2017).

Moshlehi, M.; et al., 'Microelectronics manufacturing science and technology (MMST): single-wafer RTP-based 0.35 /spl mu/m CMOS IC fabrication', Technical Digest International Electronic Devices Meeting 1993, (5-12-1993).

Mothe, Caroline; Bertrand Quélin, 'Creating Competencies Through Collaboration: The Case of Eureka R\&D Consortia', European Management Journal 18:6 (2000) pp. 590-604.

Motorola, Annual Report 2000: Something Big is Happening (2001) http://www. motorola.com/General/Financial/Annual_Report/2000/pdf/full_report.pdf (viewed: 24-8-2018).

Mowery, David C., 'Plus ca change: Industrial R\&D in the "third industrial revolution”, Industrial and Corporate Change 18:1 (2009) pp. 1-50.

\section{$\boldsymbol{N}$}

NEC, Annual Report 2000: The Right Strengths for the Internet Era (2001) https:// www.nec.com/en/global/ir/pdf/annual/2000/ar00.pdf (viewed: 24-8-2018).

Nee, Eric, Information for Everyone: The Applied Materials Story, 1967-2002 (Applied Materials, Santa Clara, 2003).

Nelson, Richard; and Sidney Winter, An Evolutionary Theory of Economic Change (Harvard University Press, Cambridge, 1982) p. 97.

Nelson, Richard, 'National Innovation Systems: A Retrospective on a Study', Industrial and Corporate Change 1:2 (1992) pp. 347-374.

Niosia, Jorge, 'Fourth-Generation R\&D: From Linear Models to Flexible Innovation', Journal of Business Research 45:2 (1999) pp. 111-117.

Nobelius, Dennis, 'Towards the Sixth Generation of R\&D Management', International Journal of Project Management 22:5 (2004) pp. 369-375.

Nocera, Joe, 'The Town That Trolls Built', Bloomberg.com (25-5-2017) https://www. bloomberg.com/opinion/articles/2017-05-25/the-texas-town-that-patent-trollsbuilt-j34rlmjc (viewed: 1-11-2018).

Noll, Michael, 'Bell system R\&D activities: The impact of divesture' Telecommunications Policy 11:2 (1987) pp. 161-178. 
o

Osborne, Mark, 'Applied Materials ends acquisition talks with ASM International' fabtech.org (14-11-2008) http://www.fabtech.org/news/_a/applied_materials_ ends_acquisition_talks_with_asm_international/(viewed 31-7-2018).

\section{P}

Parrillo, L.C., 'VLSI Process Integration', in: Bell Laboratories, S.M. Sze (ed.), VLSI Technology (McGraw-Hill Book Company, New York, 1983), pp. 478-490.

Park, John, 'Opportunity recognition and product innovation in entrepreneurial hi-tech start-ups: a new perspective and supporting case study', Technovation 25 (2005) pp. 739-752.

Pavitt, Keith, 'Sectoral patterns of technical change: Towards a taxonomy and a theory’, Research Policy 13:6 (1984) pp.343-373.

Peet, Jan; and Erik Nijhoff, Een voortdurend experiment: overheidsbeleid en het Nederlandse bedrijfsleven (Boom, Amsterdam, 2015).

Peters, Tom; and Robert Waterman, In Search of Excellence: Lessons from America's Best-Run Companies (Harpers \& Row, New York, 1982).

Philips, Annual Report 2000 (2001) https://www.philips.com/c-dam/corporate/ about-philips/investors/financial-results/annual-reports/ManagementReport_ AR00(4)-12929.pdf (viewed: 24-8-2018).

Phipps, Charles, 'The Early History of ICs at Texas Instruments: A Personal View', IEEE Annals of the History of Computing 34:1 (2012) pp. 37-47.

Pinch, Trevor; and Wiebe E. Bijker, 'The Social Construction of Facts and Artefacts: Or How the Sociology of Science and the Sociology of Technology Might Benefit Each Other,'Social Studies of Science 14 (August 1984) pp. 399-441.

Pirtle III, Caleb, Engineering the World: Stories from the first 75 Years of Texas Instruments (Southern Methodist University Press, Dallas, 2005).

Pocock, John, The Machiavellian Moment: Florentine Political Thought and the Atlantic Republican Tradition (Princeton University Press, Princeton, 1975).

Porter, Michael, Competitive Advantage: Creating and Sustaining Superior Performance (Free Press, New York).

Porter, Michael, 'From Competitive Advantage to Corporate Strategy', Harvard Business Review (May 1987) pp. 43-59, derived from: https://hbr.org/1987/05/ from-competitive-advantage-to-corporate-strategy (viewed: 26-5-2018).

Popp, Andrew; and Robin Holt, 'The presence of entrepreneurial opportunity', Business History 55:1 (2013) pp. 9-28.

Prahalad, C.K.; and Gary Hamel, 'The Core Competence of the Corporation' Harvard Business Review (May 1990) pp. 79-91. 
Prahalad, C.K.; and Gary Hamel, 'Strategic Intent', Harvard Business Review (May 1989) pp. 65-76;

Puurunen, Riikka, 'A Short History of Atomic Layer Deposition: Tuomo Suntola's Atomic Layer Epitaxy' Chemical Vapor Deposition 20 (2014) pp. 332-344.

\section{Q}

\section{$\boldsymbol{R}$}

Raaijmakers, René; and Paul van Gerven, Natlab: Kraamkamer van ASML, NXP en de CD (Techwatch, Nijmegen 2016).

Raaijmakers, René, De architecten van ASML (Techwatch, Nijmegen, 2017).

Raaijmakers, René, ASML's Architects (Techwatch, Nijmegen, 2018).

Ram, Vidya, 'Applied Materials Makes Move on ASM', forbes.com (8-6-2008) https://www.forbes.com/2008/06/08/asm-applied-closer-markets-equitiescx_vr_ra_0606markets46.html\#79bf483b10d2 (viewed: 10-4-2019).

Rip, Arie, 'Folk Theories of Nanotechnologists', Science as Culture 15:4 (2006) pp. 349-365.

Robinson, McDonald; and Lamonte Lawrence, 'Characterization of High Growth Rate Epitaxial Silicon From a New Single Wafer Reactor', American Society for Testing and Materials, Dinesh C. Gupta (ed) Semiconductor Fabrication: Technology and Metrology (Philadelphia 1989) pp. 30-42.

Rodengen, Jeffrey, 50 Years of Innovation: Kulicke \& Soffa, 1951-2001 (Write Stuff Enterprises, Fort Lauderdale, 2002).

Roobeek, Annemieke, Een race zonder finish: de rol van de overheid in de technologiewedloop (VU Uitgeverij, Amsterdam, 1988).

Roozeboom, Fred (ed.), Advances in Rapid Thermal and Integrated Processing (Dordrecht 1993).

Rosenberg, Esther; and Philip de Witt Wijnen, 'Twee lunches: één kliniek', NRC Handelsblad (20-6-2006).

Rosenberg, Nathan; and W. Edward Steinmueller, 'The Economic Implications of the VLSI Revolution', Futures 12:5 (October 1980) pp. 358-369.

Rosler, Richard; S, Benzing W C, Baldo J, Applied Materials Inc., 'A Production Reactor for Low Temperature Plasma-Enhanced Silicon Nitride Deposition', Solid State Technology (June 1976).

Rothwell, Roy, 'Towards the Fifth-Generation Innovation Process', International Marketing Review 11:1 (1994) pp. 7-31.

Roussel, Philip; Kamal Saad, and Tamara Erickson, Third Generation R\&D (Harvard Business School Press, Cambridge, 1991). 
Roussel, Philip; Kamal Saadn, and Tamara Erickson, 'The Evolution of Third Generation R\&D', Planning Review 19:2 (1991) pp. 18-26

\section{$\boldsymbol{S}$}

Sah, Chih-Tang, 'Evolution of the MOS Transistor - From Conception to VLSI', Proceedings of the IEEE 76-10 (1988) pp. 1280-1326.

Sakakibara, Kiyonori, 'From imitation to innovation: The Very Large Scale Integrated (VLSI) Semiconductor Project in Japan', MIT Alfred P. Sloan School of Management Workingpaper, WP \#1490-83 (1983).

Sakakibara, Kiyonori, 'R\&D cooperation among competitors: A case study of the VLSI Semiconductor Research Project in Japan', Journal of Engineering and Technology Management 10 (1993) pp. 393-407.

Samson, Gerard, 'Pinda's en Poepchinezen' and 'Verwonderd over een wrede wereld', javapost.nl (4-12-2011). https://javapost.nl/2011/12/04/verwonderdover-een-wrede-wereld/ (viewed 22-11-2016).

Sandholtz, Wayne, High-Tech Europe: The Politics of International Cooperation (University of California Press, 1992) http://ark.cdlib.org/ark:/13030/ft609nb394/ (viewed 19-7-2017).

Saras D. Sarasvathy, 'Causation and Effectuation: Toward a Theorethical Shift from Economic Inevitability to Entrepreneurial Contingency', The Academy of Management Review 26:2 (2001) pp. 243-263.

Sato, Yoichiro, 'The Industrial Policy Debate Minus Public Relations: Depoliticizing the History of Semiconductor Industry Development in Japan', Japan Studies Review 5 (2001), pp. 61-80.

Scalise, Mardi, 'Gartner Dataquest forecasts decline in worldwide semiconductor spending', lightwaveonline.com (17-7-2001) https://www.lightwaveonline. com/articles/2001/07/gartner-dataquest-forecasts-decline-in-worldwidesemiconductor-spending-53472317.html (viewed: 22-11-2018).

Scannel, Ed, 'Soviets Seek Ventures with PC Firms: U.S.S.R. Signs Deal with Dataease International' InfoWorld (8-8-1988).

Scansen, Don, 'Under the Hood: Intel's 45nm high-k metal-gate process', eetimes. com (14-11-2007) http://www.eetimes.com/document.asp?doc_id=1281197 (viewed 1-7-2017).

Scholten, Jaap, Horizon City (2014 Samenwerkende Uitgevers VOF).

Schot, Johan; and Edward Steinmueller, 'Three frames of innovation policy: R\&D, systems of innovation and transformative change', Research Policy 47 (2018) pp. 1554-1567.

Schot, Johan; Harry Lintsen, and Arie Rip (ed.), Technology in the Netherlands in the Twentieth Century (Walburg Press, Zutphen, 1998). 
Seidenberg, Philip, 'From Germanium to Silicon: A History of Change in the Technology of Semiconductors', in: Andrew Goldstein and William Aspray (ed.), Facets: New Perspectives on the History of Semiconductors (1997) pp. 35-74.

Sematech International, Alan Diebold, 'Impact of the ITRS Metrology Roadmap', nist.gov (1999) https://www.nist.gov/sites/default/files/documents/pml/div683/ conference/Diebold_2000.pdf (viewed: 23-10-2018).

SEMI, 'SEMI Reports 2008 Global Semiconductor Equipment Sales', semi.org (25-3-2009) http://www.semi.org/en/semi-reports-2008-global-semiconductorequipment-sales (viewed: 13-7-2018).

SEMI, '2018 Global Semiconductor Equipment Sales Jump to Record \$64.5 Billion', semi.org (10-4-2019) http://www1.semi.org/en/2018-global-semiconductorequipment-sales-jump-record-645-billion (viewed: 7-5-2019).

SEMI, 'Intel Receivers the SEMI Award for A Process and Technology Integration Breakthrough - the High-k Solution', semi.org (5-2-2013) http://www.semi.org/ en/node/44791 (viewed 1-7-2017).

Schaller, Robert, 'Moore's Law: Past, Present and Future', IEEE Spectrum 34:6 (1997) pp. 522-59.

Schaller, Robert, Technological Innovation in the Semiconductor Industry: A Case Study of the International Technology Roadmap for Semiconductors (George Mason University, 2004).

Shane, Scott; and Sankaran Venkataraman, 'The Promise of Entrepreneurship as a Field of Research', The Academy of Management Review 25:1 (2000) pp. 217-226.

Shiller, Robert, Irrational Exuberance (Princeton University Press, Princeton, 2000).

Shockley, William, 'The Invention of the Transistor - "An Example of CreativeFailure Methodology", Proceedings of Conference on the Public Need and the Role of the Inventor, June 11-14, 1973, Monterey California, (May 1974) pp. 47-89.

Shurkin, Joel N., Broken Genius: The Rise and Fall of William Shockley: Creator of the Electronic Age (Palgrave Macmillan 2006).

SIA, The International Technology Roadmap for Semiconductors 1999 (Washington 1999).

SIA, The International Technology Roadmap for Semiconductors 2002 update (Washington 2002).

SIA, 2007 International Technology Roadmap for Semiconductors (ITRS), (Washington 2007).

SIA, 'Global Semiconductor Sales Fell by 2.8 Percent in 2008', semiconductors.org (2-2-2009) https://www.semiconductors.org/news/2009/02/02/global_sales_ reports_2008/global_semiconductor_sales_fell_by_2.8_percent_in_2008/ (viewed 13-7-2018). 
SIA, 'Global Semiconductor Sales Increase 13.7 Percent to $\$ 468.8$ Billion', semiconductors.org (4-2-2019) https://www.semiconductors.org\%2Fglobalsemiconductor-sales-increase-13-7-percent-to-468-8-billion-in-2018\%2F\&usg =AOvVaw06y85idHEOBOr6faRC7kd1 (viewed: 7-5-2019).

Sluyterman, Keetie, Dutch Enterprise in the Twentieth Century: Business strategies in a small open economy (Routledge, Abingdon 2005), part of: Geoffrey Jones and Mary Rose (ed.), Routledge International Studies in Business History.

Sluyterman, Keetie, 'Introduction: Changing Business Systems in the Netherlands in the Twentieth Century', The Business History Review 84:4 (2010) pp. 737-750.

Sluyterman, Keetie; and Ben Wubs, Over grenzen: Multinationals en de Nederlandse markteconomie (Boom Uitgevers, Amsterdam 2009).

Sluyterman, Keetie, Kerende Kansen. Het Nederlandse bedrijfsleven in de twintigste eeuw (Boom 2003).

Steffora Mutschler, Ann, 'Intel, IBM embrace high-k metal gates for 45nm', edn. com (29-1-2007) https://www.edn.com/electronics-news/4315068/Intel-IBMembrace-high-k-metal-gates-for-45nm (viewed: 27-8-2018).

Stichting Toekomstbeeld der Techniek, Etienne Davignon, 'Micro-Elektronica voor onze toekomst. Een kritische beschouwing: opening' Toekomstbeeld der Techniek 32 (1982) pp. 1-8.

Stone, Alan, Wrong Number: The Break-Up of AT\&T (Basic Books, New York, 1989).

Swann, Richard, 'First-Hand: The Birth of Glow Discharge Chemistry (aka PECVD)', ethw.org (Date unknown, perhaps 2014) http://ethw.org/FirstHand:The_Birth_of_Glow_Discharge_Chemistry_(aka_PECVD) (viewed: 7-82017).

\section{$\mathbf{T}$}

Taleb, Nassim Nicholas, The Black Roman: The Impact of the Highly Improbable (Penguin Books, $2^{\text {nd }}$ edition, London, 2010).

Teece, David; and Gary Pisano, 'The dynamic capabilities of firms: an introduction', Industrial and Corporate Change 3 (1994) pp. 537-556, pp. 541, 546.

Teece, David; Gary Pisano, and Amy Shuen, 'Dynamic Capabilities and Strategic Management', Strategic Management Journal 18:7 (1997) pp. 509-533.

Thrackray, Arnold; David C. Brock, and Rachel Jones, Moore's Law: The life of Gordon Moore, Silicon Valley's Quiet Revolutionary (2015 Basic Books).

Tidd, Joe; John Bessant, Keith Pavitt, Managing Innovation: Integrating Technological, Market, and Organizational Change ( ${ }^{\text {nd }}$ edition; Wiley, Chichester, 2001).

Tilton, John; International Diffusion of Technology: The Case of Semiconductors (Brookings Institution, Washington 1971). 
Thornberry, Jon B.; 'Competition and Cooperation: A Comparative Analysis of SEMATECH and the VLSI Research Project', Enterprise \& Society 3 (2002) pp. 657-686.

Tosh, John; and Seán Lang, The Pursuit of History: Aims, methods and new directions in the study of modern history (Pearson Longman, Harlow, fourth edition; 2006), pp. 220-221.

TSMC, 'Security and Exchange Commission Form 20-F' (21-6-2001) http://www. tsmc.com/download/ir/secFillings/20F-2000.pdf (viewed: 24-8-2018).

Tweakers, Wouter Tinus, 'Intel bestelt strained silicon reactors waarschijnlijk bij ASMI', Tweakers.net (27-9-2002) https://tweakers.net/nieuws/23567/intelbestelt-strained-silicon-reactors-waarschijnlijk-bij-asmi.html (viewed: 30-62017).

Tweakers, Wouter Tinus, 'Intel onthult zijn 0,09 micron productieprocedé', Tweakers.net (13-8-2002) https://tweakers.net/nieuws/22903/intel-onthult-zijn0-komma-09-micron-productieprocede.html (viewed: 30-6-2017).

\section{$\boldsymbol{U}$}

U.S. International Trade Commission, 'Industry \& Trade Summary: Semiconductor Manufacturing Equipment', USITC Publication 3868 (June 2006) https://www. usitc.gov/publications/332/pub3868.pdf (viewed: 24-10-2018).

Utterback, James; and William Abernathy, 'A Dynamic Model of Product and Process Innovation', Omega 3:6 (1975), pp. 639-656.

Utterback, James; Mastering the Dynamics of Innovation (Harvard Business School Press, Boston, 1994).

\section{V}

Veen, Casper van der, 'ASML koop technologie van failliete Mapper', nrc.nl (291-2019) https://www.nrc.nl/nieuws/2019/01/29/asml-koopt-technologie-vanfailliete-mapper-a3652064 (viewed 5-4-2019).

Velzing, Evert-Jan, Innovatiepolitiek: Een reconstructie van het innovatiebeleid van het ministerie van Economische Zaken van 1976 tot en met 2010 (Eburon, Delft, 2013).

Vries, Marc J. de, 80 Years of Research at the Philips Natuurkundig Laboratorium, 1914-1994 (Pallas Publications, Amsterdam, 2005).

\section{W}

Wadhwani, Daniel; and Christina Lubinski, 'Reinventing Entrepreneurial History’, Business History Review 91:4 (2017) pp. 767-799.

Wang, David; Dan Maydan, H.J. Levinstein, 'Reactive Sputtering Etching and Its Applications', Solid State Technology (August 1980). 
Wittenberg, Dick, 'Debacle Philips zet Europa verder op achterstand; Chips cruciaal in strijd om industriele wereldhegemonie' NRC Handelsblad (5-9-1990) p. 1.

Wittenberg, Dick, 'Mega-project commerciele flop voor Philips' NRC Handelsblad (31-8-1990) p. 11.

Whittington, Richard; and Michael Mayer, The European Corporation: Strategy, Structure and Social Science (Oxford University Press, Oxford, 2002).

Williams, Sam, 'A Haven for Patent Pirates', MITtechnologyreview.com (3-2-3006) https://www.technologyreview.com/s/405259/a-haven-for-patent-pirates/ (viewed: 1-11-2018).

Wong, Simon; Changsup Ryu, Haeburn Lee, et al., 'Barrier/Seed Layer Requirements for Copper Interconnects', Proceedings of the IEEE 1998 International Interconnect Technology Conference (June 1999) pp. 107-109.

\section{$X Y Z$}




\section{Timeline}

1958 Arthur del Prado returns to Europe; European Marketing Manager Knapic Electro-Physics, Naarden

1961 Birth of Charles Dean del Prado

1964 Arthur del Prado starts agency Advanced Semiconductor Materials at Laurillardlaan in Bilthoven

1965 First employees hired.

New office at Soestdijkseweg

1968 Legal founding as limited company Advanced Semiconductor Materials BV

Start lawsuit with Haldur Topsøe

1969 Establishment joint-venture Sola Basic Netherlands (now Tempress)

1971 First deposition reactor built - start front-end portfolio

1972 Agency of Fico Toolings - start back-end portfolio

1973 Acquisition Fico Toolings (renamed ASM Fico)

1975 Establishment ASM Asia in Hong Kong (after 1988 known as ASM Pacific Technology)

1976 Establishment ASM America in Phoenix, Arizona

1977 ASM America starts agency with Marubeni Electronics in Japan Introduction of LTO reactor in cooperation with Jon Goldman

1979 ASM Asia acquires Computervision of Cobilt (renamed ASM Assembly Automation)

Publication of Innovation Note in the Netherlands 
1980 New building at Jan Steenlaan in Bilthoven Introduction horizontal PECVD process in cooperation with George Engle.

1981 IPO at Nasdaq

ASM America acquires Elmont International (automated diebonding)

Introduction aluminum CVD by ASM Europe in cooperation with Rudolf Heinecke.

EEC approves Microelectronic Program (40 million ECU)

1982 Establishment of ASM JapanEstablishment Epsilon Limited Partnership to fund epitaxy reactor Del Prado becomes member of Foundation for Centers of Microelectronics in the Netherlands (until 1985).

1983 Start of development program Epsilon Technology. RSV Affair in the Netherlands

1984 Start joint-venture with Philips in order to develop and market lithography wafer stepper (Veldhoven) Establisment ASM Microelectronic Technology Centre (AMTC) in Bilthoven -a central research laboratory.

EEC starts ESPRIT program Start of Mega-project of Philips, Siemens with support of Dutch and German authorities

1986 Establishment of ASM Ion Implant in Massachusetts.

1987 Hiving off ASM Fico fails due to Black Monday ASM Japan introduces vertical furnaces VMP-100

1988 Equity crisis at ASM Divestments of ASML and ASM Ion Implant IPO ASM PT at Hong Kong Stock Exchange Introduction of Epsilon One.

1989 Establishment operations of ASM PT in Shenzhen Introduction A600 JESSI and ESPRIT II programs start (ASM starts MCBRIDE) Industry-wide negotiations for interface standards MESC start 
1990 Establishment operation ASM PT in Singapore

ASM America acquires EVTR vertical furnace from General Signal and renames it $\mathrm{A} 300$

1991 First lawsuit Applied Materials for violation of epitaxial IP ASM Fico sell equipment in Soviet Union for 115 million guilders Introduction single wafer PECVD reactor Eagle-10 by ASM Japan ASM America acquires vertical furnaces of General Signals (renamed A300 VT)

ASM tries to start IVPS project (until 1995)

1992 Equity crisis at ASM

ASM Japan introduces single wafer plasma CVD reactor Eagle-10. Ray Friant starts as Chief Operational Officer (until 1997)

1993 Official start of collaboration ASM and IMEC; AMTC neutralized Divestment of ASM Fico to Berliner Elektro Holding ASM Europe acquires vertical furnace from Tempress BV (renamed A400)

1994 Change from geographical to product management frontend activities

1995 IPO's of ASML and BESI Establishment ASM Korea ASM America begins preparations for $300 \mathrm{~mm}$ wafers for epitaxy

1996 Listing of ASM International on Amsterdam Stock Exchange A412, Eagle-10, and Epsilon is shipped to test programs for new $300 \mathrm{~mm}$ wafer equipment SELETE and I300i

1997 Settlement with Applied Materials. Introduction of AB339 - gold wire bonder by ASM Pacific Technology

1998 Asian financial crisis affects ASM Pacific Technology stock 
1999 Beginning Dotcom-Bubble

Operation Merio meant to consolidate manufacturing of

ASM Europe and ASM America in the Netherlands

Acquisition Microchemistry (ALD-processes) and investment

in Nanophotonics (integrated metrology equipment)

Introduction Polygon cluster tool by ASM America

Introduction Levitor RTA reactor by ASM Europe

ASM PT in top 5 backend market

2000 Return of American manufacturing to Phoenix due to high demand market

2001 Investments in American company Nutool (CMD-processes) and Korean company Genitech (plasma processes)

Reorganizations - among which ASM Microchemistry

2002 ASM PT largest manufacturer of backend equipment

2004 Acquisition Nutool (CMD-processes), Nanophotonics and Genitech (plasma ALD)

Establishment of FEMS in Singapore to integrate

front-end manufacturing

2005 Divestment ASM Nutool IP

First licensing of ALD IP

2006 Start turbulence with activist shareholders

2007 Nomination of Chuck del Prado as successor of Arthur del Prado Introduction of ASM's high-k ALD process in HVM by Intel

2008 Arthur del Prado steps down as CEO. 


\section{Abbrevations}

ACAMS

ALAD1N

ALD

AMAT

AMT

AMTC

APCVD

ASIC

ASM

ASMA

ASMB

ASMJ

ASMM

AST

BESI

BiCMOS

BMFT

CAD

CAE

CAM

CEO

$\mathrm{CFO}$

CFT

CIBC

CICDIP

CMD
ASM Computer Automated Manufacturing System

Atomic Layer Deposition at the 100 Nanometer node

atomic layer deposition

Applied Materials

Applied Materials

ASM Microelectronics Technology Center

Atmospheric Pressure Chemical Vapor Deposition

Application Specific Integrated Circuit

Advanced Semiconductor Materials

ASM America

ASM Belgium

ASM Japan

ASM Microchemistry

ASM Singapore Technology

Berliner Elektro Semiconductor Industries

Bi-polar Complemtary Metal Oxide Silicon

(field effect transistor)

BundesMinisterium für Forschung und Technologie

Computer Aided Design

Computer Aided Engineering

Computer Aided Manufacturing

Chief Executive Officer

Chief Financial Officer

(Philips) Centrum voor Fabricage technologieen

Canadian Imperial Bank of Commerce

Hot Cluster for Integrated Vapor Phase Cleaning \& Processing of Dielectric and In-Situ Doped Polysilicon

Copper Mechanical Deposition 


\begin{tabular}{ll} 
CMOS & Complementary Metal Oxide Silicon (field effect transistor) \\
CMP & Chemical Mechanical Polishing \\
COB & Chip on Board \\
COO & Chief Operating Officer \\
CP & Capacitor Products (ASM) \\
CTO & Chief Technology Officer \\
CVD & Chemical Vapor Deposition \\
CVTR & Clustered Vertical Thermal Reactor \\
DRAM & Dynamic Random Access Memory \\
Dujat & Dutch Japanese Trade Association \\
ECD & Economische Controle Dienst \\
ECD & Electrochemical Deposition \\
ECMD & Electro-Chemical Mechanical Deposition \\
ECU & European Currency Unit \\
EEC & European Economic Community \\
EEPROM & Electrically Erasable Programmable Eead-Only-Memory \\
Epi & Epitaxy \\
EPROM & Erasable Programmable Read-Only-Memory \\
ESPRIT & European Strategic Program for Research and Development \\
Eureka & in Information Technology \\
EVTR & European Research Coordination Agency \\
FCED & Enhanced Vertical Thermal Reactor \\
FEMS & Fab Capital Equipment Development \\
FOUP & Front-End Manufacturing Singapore \\
GB & Front-Opening Unified Pod \\
Hf & Gigabit \\
HIG & Hafnium \\
High-K & High Temperature Insert Gas Valve \\
HSG & High dielectric constant \\
IC & Hemi-Spherical grained Silicon \\
ICT & Integrated Circuit \\
\hline
\end{tabular}




\begin{tabular}{|c|c|}
\hline IEDM & International Electronic Devices Meeting \\
\hline IMEC & Inter-universitair Micro-Elektronisch Centrum \\
\hline IPO & Initial Public Offering \\
\hline ITRS & International Technology Roadmap for Semicondcutors \\
\hline IVPS & Integrated Vacuum Processing System \\
\hline JESSI & Joint European Submicron Silicon Initiative \\
\hline KAIST & Korean Advanced Institute of Science and Technology \\
\hline $\mathrm{KB}$ & Kilobit \\
\hline KEP & Knapic Electro-Physics \\
\hline LCD & Liquid Crystal Display \\
\hline LED & Light Emitting Diode \\
\hline Low-k & Low dielectric constant \\
\hline LPCVD & Low Pressure Chemical Vapor Deposition \\
\hline LSI & Large Silicon Integration \\
\hline LTO & Low Temperature Oxide \\
\hline $\mathrm{MB}$ & Megabit \\
\hline $\mathrm{MC}$ & Microchemistry \\
\hline MCBRIDE & Multi-Chamber Batch Reactor for Interpoly Dielectrics \\
\hline MEDEA & Micro-Electronics Development for European Applications \\
\hline Merio & (Operation) Merger of International Operations (ASM) \\
\hline MESC & Modular Equipment Standards Committee \\
\hline MFC & Mass Flow Controller \\
\hline MIM & Metal-Insulator-Metal (capacitor) \\
\hline MIP & Maatschappij voor Industriele Projecten \\
\hline MITI & Ministry of International Trade and Industry (Japan) \\
\hline MOCVD & Metal-Organic Chemical Vapor Deposition \\
\hline MOSFET & Metal-Oxide-Silicon Field Effect Transistor \\
\hline MRG & Microwave Radical Generator \\
\hline Nat.Lab & Natuurkundig Laboratorium (Philips Research) \\
\hline $\mathrm{Ni}$ & Nitride \\
\hline $\mathrm{NI}$ & Nationale Investeringsbank \\
\hline
\end{tabular}




\begin{tabular}{|c|c|}
\hline NMB & Nationale Middenstandsbank \\
\hline NMOS & Negative Metal Oxide Silicon (field effect transistor) \\
\hline NOM & Noordelijke Ontwikkelingsmaatschappij \\
\hline NTRS & $\begin{array}{l}\text { National Technology Roadmap for Semiconductors } \\
\text { (United States) }\end{array}$ \\
\hline $\mathrm{ONO}$ & Oxide-Nitride-Oxide \\
\hline P\&L & Profit and Loss \\
\hline $\mathrm{PC}$ & Personal Computer \\
\hline PEALD & Plasma Enhanced Atomic Layer Deposition \\
\hline PECVD & Plasma Enhanced Chemical Vapor Deposition \\
\hline PMOS & Positive Metal Oxide Silicon (field effect transistor) \\
\hline PVD & Physical Vapor Deposition \\
\hline $\mathrm{R} \& \mathrm{D}$ & Research and Development \\
\hline RSV & Rijn-Schelde-Verolme \\
\hline RTA & Rapid Thermal Annealing \\
\hline RTCVD & Rapid Thermal Chemical Vapor Deposition \\
\hline $\mathrm{RTN}$ & Rapid Thermal Nitridation \\
\hline $\mathrm{RTO}$ & Rapid Thermal Oxidation \\
\hline RTP & Rapid Thermal Processing \\
\hline SARS & Severe Acute Respiratory Syndrome' \\
\hline SATC & Stand-Alone Tube Controller \\
\hline SCME & Stichting Centra voor Micro-Elektronica \\
\hline SCRA & Supply Chain Risk Analysis \\
\hline SEA & Semiconductor Equipment Assesment (European Union) \\
\hline SELETE & Semiconductor Leading Edge Technologies \\
\hline Sematech & Semiconductor Manufacturing Technology \\
\hline SEMI & Semiconductor Equipment and Materials Institute \\
\hline Si & Silicon \\
\hline SIA & Semiconductor Industry Association (United States) \\
\hline $\mathrm{SiGe}$ & Silicon Germanium \\
\hline SMIF & Standard Mechanical Interface \\
\hline & Sarbanes-Oxley Act \\
\hline
\end{tabular}




$\begin{array}{ll}\text { SRAM } & \text { Static Random Access Memory } \\ \text { TCP } & \text { Transistor and Capacitor Products (ASM) } \\ \text { TDMAH } & \text { tetrakis-dimethylamino-hafnium } \\ \text { TEOS } & \text { tetraethyl orthosilicate } \\ \text { TIBA } & \text { tri-isobutyl aluminum } \\ \text { TOK } & \text { Technologisch Ontwikkelingskrediet } \\ \text { TP } & \text { Transistor Products (ASM) } \\ \text { TSMC } & \text { Taiwan Semiconductor Manufacturing Company } \\ \text { UHV } & \text { Ultra High Vacuum } \\ \text { ULSI } & \text { Ultra Large Silicon Integration } \\ \text { VEB } & \text { Vereniging van Effectenbezitters } \\ \text { VLSI } & \text { Very Large Silicon Integration } \\ \text { Y2K } & \text { Year 2000 Problem } \\ \text { Zr } & \text { Zirconium }\end{array}$




\section{Glossary}

The following glossary defines some conventional terms in the semiconductor technology. These definitions have been based or cited from public sources like: Renesas, 'Glossary', renesas.com (date unknown) https://www.renesas.com/us/ en/support/glossary.html (viewed: 2-9-2019); and Dataquest, 'Semiconductor Equipment Product Category Hierarchy and Definitions' (1-6-1998) pp. 103-111, derived from Computerhistory.org.

\section{Atomic layer deposition}

Deposition process in which the reactant gasses are introduced sequentially. After saturation of the surface is the next reactant introduced. This enables the controlled growth of film atom layer per layer.

Atmospheric pressure chemical vapor deposition

This process occurs at atmospheric pressure.

\section{Annealing}

A process by which a wafer is heated shortly to alter dopants, change film to film interfaces, densify films or repair damage from implants. See also Rapid Thermal Processing.

\section{Back-end}

The package, assembly and test stages of production in semiconductor manufacturing. Predominantly single dies are processed.

\section{Bipolar transistor}

A semiconductor device formed by two p-n junctions whose function is amplification of an electrical current. Bipolar transistors have three sections: emitter, base, and collector. Operation of a bipolar transistor depends on the migration of both electrons and holes, in contrast to field-effect transistors, where only one polarity carrier predominates. 


\section{Channel}

The region separating the source and drain of a field-effect transistor.

\section{Chemical Mechanical Polishing}

A process in which unwanted dielectric or metal material is removed from a wafer's surface by mans of a corrosive liquid or solid slurry. This material mixture is applied to wafers inside equipment designed to apply pressure to a wafer's active surface. Unwanted material is then removed from the wafer's surface by polishing.

\section{Chemical Vapor Deposition}

A process for depositing a variety of thin films on wafers that function as dielectrics, conductors or semiconductors. A chemical containing atoms on the material to be deposited reacts with another chemical, either at an elevated temperature or in a plasma, producing the desired deposition material. This material is then deposited on wafer surfaces while by-products of the reaction are removed from the process chamber.

\section{Clean room}

A confined area in which humidity, temperature and particulate matter are precisely controlled within specified units.

\section{Conductor}

Any material that offers little resistance to the flow of electrical current. Examples are aluminum, copper or gold.

\section{Czochralski}

A method to produce large single crystals of silicon, germanium or galliumarsenide. In the method, a cylindrical single crystal is pulled vertically, upwards and rotating from silicon melt in a heated crucible.

\section{Die}

A rectangular piece of semiconductor material into which a specific electrical circuit has been fabricated. It is a chip without its package. 


\section{Die bonding}

The process of bonding a die to its package or leadframe.

\section{Diffusion}

A high temperature process in which chemical impurities (dopants) enter and move through the crystal structure of a semiconductor material in order to change its electrical characteristics.

\section{Discrete}

A single electronic component. In contrast to integrated circuits not contained in a chip.

\section{Drain}

One of the regions that form a field-effect transistor. Carriers originate at the source, traverse the channel and are collected at the drain. The flow between source and drain is controlled by the voltage applied to the gate.

\section{Dual Damascene}

A method to create copper metal interconnections by over-filling trenches using Electrochemical Deposition and Chemical Mechanical Polishing.

\section{E-beam lithography}

A lithographic process in which circuit patterns are transferred by means of electron beams.

\section{Electrochemical Deposition}

A process for depositing metallic thin films on wafer surfaces through the use of electric fields and liquids that serve as a transport medium for the metallic ions deposited on the wafers. Includes also electroplating.

\section{Encapsulation}

The process in which a die and leadframe are encapsulated in a ceramic package. 


\section{Epitaxy}

A process for depositing single-crystal silicon on wafer substrates by decomposing silicon precursor gasses such as silane on the substrate. Dopant precursors gasses such as phosphine are frequently mixed with the silicon precursor gas used in the epitaxy process to produce single-crystal silicon with specific electrical properties.

\section{Etch}

The process of removing material form a wafer by chemical, electrolytic or plasma means.

\section{$F a b$}

A factory in which wafer production and processes take place.

\section{Field-effect transistor}

A solid state device in which current is controlled between source and rain by voltage applied to non-conducting gate terminal. See also channel, drain, gate stack and source.

\section{Float-zone}

Alternative method to Czochralski for producing high-purity silicon crystalline material. A rod of polysilicon and a monocrystalline seed are partially seeded by means of radio frequency. The molted polysilicon at the seed freezes. This technique is predominantly used for wafer sizes less than 200 millimeter.

\section{Foundry}

A wafer production and processing factory available on contract basis to companies that do not have such capability of their own, or that wish to complement their own capabilities.

\section{Front-end}

The fabrication processes of an integrated circuit taking place on a wafer. 


\section{Gate stack}

The control electrode in a field-effect transistor. A voltage applied to the gate regulates the conducting properties of the channel region, located directly beneath the gate. A gate consists of a dielectric film and an conducting material.

\section{High-k}

A dielectric material with a higher dielectric constant than the conventional silicon oxide. This is expressed with the Greek letter kappa (k), hence the name high-k.

\section{Integrated circuit}

A combination of electrical or electronic components - such as transistors, capacitors, etc. - interconnected to perform one or more specific functions, and integrated in one single piece of silicon.

\section{Interconnection}

The conductive path required to achieve connection from one circuit element - a transistor, capacitor, etc. - to others in a circuit.

\section{Insulator}

A material that is a poor conductor of electricity or heat. Examples are silicon dioxide (glass), silicon nitride or hafnium oxide.

\section{Ion Implantation}

A process in which impurities are introduced into wafer substrates by means of ion bombardment to achieve desired electrical properties in defined areas of a wafer. Ion implantation tools are differentiated by the ion energies they are capable of generating and the ion doses they are capable of delivering. For example high current or medium current implanters.

\section{Large Silicon Integration}

Meaning computer chips containing 100 to 100,000 transistors. 


\section{Leadframe}

A stamped or etched metal frame, usually connected to the bonding pads of a bonding, that provides external electrical connection for a packaged electrical device.

\section{Linewidth}

The width of the spectrum of a light beam. Ultra-Violet light has a larger width than extreme ultra-violet light. Linewidth defines the dimensions that can be printed by means of lithography. Miniaturization of transistors according to Moore's Law is expressed in linewidth, since this is the most defining parameter for shrinkage.

\section{Lithography}

The transfer of a pattern from one medium to another, as from mask to a wafer. See also E-beam lithography, X-ray lithography, optical lithography, and stepper.

\section{Low Pressure Chemical Vapor Deposition}

This deposition process occurs at low pressure.

\section{Mask}

A transparent glass or quarts plate covered with an array of patterns used in making chips. Each pattern consists of opaque and transparent areas that define the size and shape of all circuit and device elements. The mask is used to expose selected areas of photoresists.

\section{Metal Organic Chemical Vapor Deposition}

A CVD method for the growth of metallic or compound semiconductor films using organic precursors or reactants. Predominantly used for the fabrication of light-emitting diodes (LED).

\section{Metrology}

Refers to a group of tools used to accurately determine the value or tolerance of wafer process parameters: layer-to-layer overlay, critical dimension, and thin film characteristics. 


\section{Moore's Law}

The regular miniaturization of electrical components integrated on a chip. This self-fulfilling prophecy and rule-of-thumb in the semiconductor industry, stipulates that every 18 months the number of transistors on a chip should double. Named after Gordon Moore, who in 1969 extrapolated a development visible since the invention of the integrated circuit. Being exponential and facing increasingly costly solutions to overcome the material challenges of miniaturization, Moore's Law has been proclaimed unviable on a regular basis since the early 1990s, yet still holds.

\section{More Moore}

Further miniaturization of electrical components on a chip according to Moore's Law.

\section{More-than-Moore}

Semiconductor technological and product development independent of the miniaturization of electrical components on a chip as stipulated by Moore's Law.

\section{Multiple patterning}

A class of patterning techniques meant to increase miniaturization of circuit features on a wafer beyond the linewidth enabled by lithography.

\section{Optical lithography}

A light source is used to effect the transfer between mask (reticle) to a wafer. The wave length of the light and the precision of lenses define the ability to miniaturize images.

\section{Oxidation}

A method to produce a thin layer of oxide (silicon dioxide) on a wafer. The process can be done in, and is often combined with, a diffusion furnace.

\section{Passivation}

A final layer covering a semiconductor device that seals the underlying circuit elements. Silicon nitride and silicon oxide are most often used for this purpose. 


\section{Patterning}

The process of creating circuit outlines on a wafer by means of lithography, photoresist spinning and etching.

\section{Photoresist processing}

A light-sensitive liquid that is spread as a uniform thin film on a wafer or substrate. The tools coat, bake and develop photoresist material on wafer surfaces.

\section{Physical Vapor Deposition}

See sputtering

\section{Plasma Enhanced CVD}

Reactant gasses are ionized by means of a plasma in this CVD process. This allows a lower temperature of the reaction.

\section{Plasma Etch}

Etching gasses are ionized through a plasma before they react with the surface of the wafer. This allows selective etching. By-products of the etch process are pumped away using a vacuum-type pump. Also known as 'dry-etch'.

\section{Polysilicon}

A material consisting of multiple silicon crystals. This property makes it applicable as conductor in gate stacks.

\section{Rapid Thermal Processing}

A variety of processes - deposition, oxidation or annealing - can be performed that modify wafer substrates and thin films by exposing them to hightemperature environments. RTP systems generally process single wafers or small batches of wafers at a time.

\section{Reticle}

See Mask. 


\section{Semiconductor}

A material - such as silicon and germanium - that through slight alterations can become a conductor or an insulator. Impurities affect the conductivity.

\section{Silicon}

A solid element that is abundantly available in the form of silicon dioxide (glass, or sand). The material is a semiconductor, and the prime material in the chip manufacturing.

\section{Source}

One of the components of a field-effect transistor. The source is the point where current enters the channel, towards the drain.

\section{Sputtering}

A method of depositing a thin film of material o wafer surfaces. A given material (target) is bombarded with ions generated in a plasma. The ions dislodge atoms from the target material, which in turn, deposit themselves on the wafer surface.

\section{Stepper}

An optical exposure system that projects reticle images onto the wafer, stepping to cover the wafer with the reticle image.

\section{Substrate}

The underlying material on which a microelectronic device is built.

\section{Transistor}

A semiconductor device that amplifies and switches electrical signals.

\section{Ultra Large Silicon Integration}

Meaning computer chips containing 1 million transistors or more. This notion never got widely accepted. 


\section{Very Large Silicon Integration}

Meaning computer chips containing 100,000 transistors or more. Definition regained prominence in the late 1970s and again by the late 1980s.

\section{Wafer}

A thin slice of silicon - about 10 to 30 millimeter thick - on which integrated circuits are fabricated. Over time the diameter of the silicon wafer increased from 25 millimeter (1960) to 300 millimeter (2001), enabling greater output of integrated circuits.

\section{Wafer inspection}

A group of tools used to detect, observe and classify process defects in wafers over the fabrication process.

\section{Wire bonding}

A process used to make connection between a semiconductor and a package. Wires can be made of aluminum, gold or copper.

\section{Work-in-Progress station}

Systems that are automated interfaced stations that store work in process wafers or cassettes containing wafers.

\section{X-ray lithography}

Wafer imaging systems that use X-rays as the exposure source.

\section{Yield}

The percent of wafers, dice or package units conforming to the specification. 


\section{Business index}

$\begin{array}{ll}3 \mathrm{M} & 736,779 \\ \mathrm{~A} 300 & 427,493,499,506,528 \\ & 546,557,566 \\ \text { A400 } & 499,500,506,510,540 \\ & 547,557,560-563,567- \\ & 569,591,610-612,621 \\ & 634,641,715,720,727 \\ & 769,789,801,827 .\end{array}$

A412 615, 645, 707, 720, 722, $726,746,753,769,772-$ 773, 789-790, 801, 827.

A600 220, 370, 393, 425-431, 435, 446, 451, 488-516, 528, 533, 537, 540, 557-568, 572, 591, 610, 630, 636, 662, 715, $744,839,841,922,940$

A800 570-571, 603, 633-647, 655, 695, 717.

AB309 565, 596, 598, 940

AB339 596-598, 602, 725

ABN Amro $\quad 407,408,410$, 431, 529, 542, 576, 595, 600-602, 715-716, 724

ACAMS 391-395, 411, 472

ADP Foundation 829, 870, 872

Adtec Engineering 276

AEG 76, 92, 168-169

Agere Systems 676-677

Air Liquide $\quad 479$

Air Products $\quad 661,682,696$

ALAD1N 657-660, 664, 673, 678, 699, 731

Alcatel 382, 541, 728

ALSI 822
Amazon 708, 811

AMD 378, 405, 412, 525, 552, 691, 771, 789, 812

American Sheet Metal 727

AMI 426

AMICRA Microtechnologies 822 AMKOR 598 AMOLF 385, 471, 530

AMTC 216, 220, 382-396, 410, 421-431, 440, 442, 446, 451, 466-516, 537-538, $546,567,607,621,648-$ $651,839,841$

Anelva 541

Anicon 186, 310, 356

Apple 183, 204, 236, 524, 561, 624, 811

Applied Materials passim ARM 25, 625, 691, 741, 813 ASM-220 410

ASM passim

ASM International passim

ASM America passim

ASM Asia 123, 131-132, 137, 176-177, 240-247, 250, 254, 399-404, 409, 418, 428, 442, 566, 587, 596,627 ,

ASM Assembly Automation 243-244, 247-250, 254255, 272-273, 379, 418

ASM Assembly Materials 254, 399, 418

ASM Assembly Systems 812 ASM Belgium $\quad 658,660,791$, $821,826,879,884,887$ 
ASM Die Bonding

249-250, 254, 379

ASM Epitaxy $\quad 335,350-363$,

370, 396, 410-411, 435,

$440,528-531,540-$

$542,545,557-558$

ASM Fico $\quad 125,131,136-$

$137,154,240,245$,

254, 269, 275, 373,380, 399-405, 409-410, 413-

417, 427-430, 441-442, 468, 474, 59, 542-544,

547-553, 565, 574, 613, 725

ASM France $\quad 124,183,382$,

432, 434-435, 534, 536, 590

ASM Genitech 559, 566-567, 672, 687, 689, 706, 716, 731-737, 742-745, 754759, 765, 768-769, 789$801,804,822$

ASM Ion Implant 354, 374, 383385, 390, 396-399, 407, 10-411, 416, 440-442, 573, 607, 725, 836, 875

ASM Japan passim

ASM Korea 566-567, 734-

735, 755-756, 789, 790

ASM Lithography passim

ASM Pacific Technology passim ASM Qualiflow 142

ASM Technology Singapore 597598, 753, 784

AST Electronik $\quad 491,504,629$, 631-636, 639-641, 655, 692

AST-STEAG $\quad 633,635,639-$ 641

AT\&T $\quad 58,60,204,220,252$, 295, 351, 357-358, 431,
449, 486, 491, 496

ATMI 682, 696

Aurora 730-731, 770

Balzers 433-434, 490491, 495

Banque Paribas 407-410, 431, 542 ,

Bell Labs $\quad 58,60,78,91$, 101, 214, 220, 250-253, 288, 316-319, 325, 367, 460, 677, 686-687, 794

Berliner Elektro Holding 548, 573

BESI 548, 550, 573576, 600-602, 708

BMFT 541

Bosch 57, 123

Broadcom

813

Brooks 630

BT Pension Scheme 873

Canaan Partners 541

Canon 139, 272, 276, 278, 397, 405, 813

CEA-LETI 487-488, 504, 658, 719

Centaurus $\quad 795$

Centura 569

Cerco 277

Chartered Semiconductor 691, 812

CIBC World Markets 716, 719, 722, 724, 736737, 744, 874

CICDIB 634

Cobilt 242, 272

ComputerVision 242, 243, 248

Coorstech $\quad 727$

CVTR 493, 499-503, 506, 539541, 545-547, 560, 607

Cybernetix $\quad 504$

Daimler 541 
Dragon 769

Drexel Burnham Lambert

$\begin{array}{ll} & 141,405-406,409 \\ \text { Drytek } & 426,484 \\ \text { Dujat } & 729 \\ \text { Eagle-10 } & \quad 504,528,537, \\ & 557-564,568,571,591, \\ & 595,610,612,621,641, \\ & 715,725,730\end{array}$

$\begin{array}{ll}\text { Eagle-12 } & 572,615,645, \\ & 707,725,746\end{array}$

Eagle-XP $\quad 769$

Ebara 757, 779

Eclipse 383-385, 396-397

Elcoma 460-462

Electro-Tech 479-504

Elmont International 248-250, 254, 288

Elpida 763

EmerALD 689,769

Eminence Capital 824

Epsilon passim

Epsilon Limited Partnership 262-263, 288, 298, 305$310,326,330,333,349$, 353-354, 358, 360, 364, 367-368, 381, 788, 836

Epsilon Technology passim ESEC 548, 743

ESPRIT 219, 456, 460, 464, 474481, 486-489, 495, 497, 501, 507, 509-510, 512, 514-516, 570, 634

EUREKA 450, 476-479, 497, 717, 741, 852, 869

European Economic Community 253, 446, 452-456, 460, 463-465, 474-477, 486, 488, 508-509

European Framework Program 475-476, 570
EVTR 426-427, 433, 493, 501, 528, 537, 539-540, 557

Facebook 811

Fairchild 35, 47, 58-61, $85,111-112,118,128-$ 129, 158-160, 189, 243

Francisco \& Partners 692, 798

Frank \& Schulte 72-74, 97, 151

Fraunhofer Gesellschaft 478, 504, 506, 560

Freescale 763, 771

Fujitsu 139, 395, 423, 552

Fursa Alternative Strategies 788, 793-799, 823, 981892

GCA 278, 397-398, 426, 433 General Electric 57, 160, 302, 308, 367, 519, 541

General Signal 174, 179, 389, 426, 484, 493, 498, 528, 539

Genus 219, 463, 484, 631, 754 Globalfoundries $691,702,812$, 818

Google 708, 811, 892, 903, 941 Grantham, Mayo Van Otterloo \&Co 432-433, 540, 543, 553, 575-576

GSI $\quad 426$

Gulf\&Western 532

Hanarth Fonds 830

Harvard Business Review 55, 620, 859

Hermes Focus Fund 739, 783-788, 793-797, 823

Hewlett Packard 199, 219, 236, 463

Hitachi 57, 139, 214-217, 226, 272, 423, 525, 552, 560, 725,812 , 
Houthoff Buruma 782-783

HVEC 383

Hynix $734,763,790,812,822$, 826-827

IBM passim

IDEALine 596-597

IEEE Spectrum 817

Imatran Voima 653

Infineon

641, 691, 714, 726, 736-737, 763, 771, $789,812-813$

Inotera 789

Institut National des Sciences

Appliquées de Lyon $\quad 463$

Intel passim

International Electron Devices

Meeting

676-677, 686

International Technology

Roadmap for Semiconductors

589, 623, 670, 678, 699, 709, 710, 713, 720, 843

IPC 252

ITT 58, 92, 168, 188, 204205, 218, 235, 247, 278

IVPS $483,489-491,495,503-$ 504, 507, 515, 562, 627, 630-636. 647, 655, 659, 662, 720

JESSI $219,434,450,460,464$, 475-481, 486-491, 497, 501-516, 630, 633, 657$658,664,875$

K-1 425, 528

KAIST 723

Kempen \& Co $\quad 405-406,417$, 432

Knapic Electro-Physics

$$
\begin{aligned}
& \text { 46, 60-62, 67-89, 92, } \\
& 95-97,120-121,124, \\
& 132,140,143,147-148, \\
& 150,164,177,300
\end{aligned}
$$

Kokusai (Hitachi) 139, 426, 432, 722, 772

Komatsu $\quad 570$

Kulicke \& Soffa $\quad 48,90,132$, 242, 547-548, 553, 565, 743

LAM Research 171, 484, 735, 813,851

LASSIE 570

Lawrence Livermore Laboratories 316

Lawrence Semiconductor

Laboratories 352-353, 359

LETI 487-488, 504, 658, 719

Levitech 820, 828

Levitor 320, 659, 687, 716-718, 721-722, 726-727, 745, 765, 772, 788-789, 820

Lewis \& Rocca 305

Leybold 176, 490, 504

LG 552, 567, 732-763

Lindberg 90-92, 99, 389

Mapper Lithography 272, 737, 772, 828-830, 865

Marubeni Hytech 144-145, 201-202, 215, 259-262, 276

Matra GCA 398

Matris Harris Semiconductors 463

MCBRIDE 487-489

Meco 574

MEDEA 657-658, 664, 678, 718719, 741, 875

Mellon Alternative Strategies 782-788, 793, 805

Merck 79, 158, 160, 301

Micon 136, 182-183, 196, 210

Micro Automation

426

Micron 560-561, 568-569, 719, 
736, 789, 812

Microelectronic Program 455

Ministry of Economic Affairs

268-269, 381-382, 412-

413, 430, 453, 459-468, 471, 478-479, 485, 497-

506, 508-513, 538-540, 545, 547, 555, 561, 600, 828

MIP 278, 413, 417, 427-428, 471,474

MIR3000 791

Mitsubishi 57, 139, 357,

423, 552, 560, 763, 812

Mitsui \& Co $\quad 405,541$

Monsanto $\quad 78,82,351$, 570

Morton 131-133

Motorola passim

Nanophotonics 716-717, 720, 727, 745, 765, 777, 788$789,801,820$

Nanya 789

NASDAQ $\quad 125,143,211$, 245, 268, 273, 431, 458, 550, 573-575, 601-602, $723,728,782,825,836$

NEC $\quad 139,144,185-186,236$, 259, 423, 426, 503, 506, 523, 525, 541, 552, 560, 562, 644, 691, 763, 812

Nederlandse Middenstandsbank $413,413-416,427$

Neste $\quad 651,653-654,718$

Nikon 139, 276, 278, 397, 405, 813

Nokia 741

NOM 498, 501, 506, 540, 547, 560-561

Norsworthy Industry 61 Novellus 356, 424-425,
483-484, 496, 526, 528, 541, 571, 630, 637, 654, $779,791,813,851$

NuTool 687, 707, 716, 731-732, 735-737, 742-745, 756759, 765, 767-768, 772, 777-781, 788-806, 852

Nvidia 813

NXP 505, 763, 812-813

OKI 259, 276, 552, 560

Oldelft 409

Ontrak 735

Oppenheimer 409-410, 413, 427

Osaka Titanium Corporation 351, 357

Oyang Scientific 566-567

Panasonic Matsushita 185,691

Paragon 370, 545-546, 557, 562, 570, 629-630, 632-633, 636

PAS2000/2400/2500 $279,381,397,410$

Perkin Elmer 272

Philips passim

Philips Centrum voor Fabricage

Technologieen 726

Philips Machinefabrieken 277, 561, 568, 570, 572, $603,605,611,627,630$ 631, 633, 662, 726-727, 752, 821

Philips Research Laboratory 70, 270, 273, 456, 460, $465,489,545,637,641$, 841

Philips Science \& Industry 461

Plasmatherm 252

Plasmos $\quad 504$ 
Plessey 76, 92, 463-464, 713

Polygon 648, 655-660, 662, 664, $668,673,679,683$, 686-689, 694-695, 701, 726-727, 735, 746, 750, 769, 790-792, 821

Promos 771, 789

Pulsar 655-662, 664-669, 679, 683, 694, 701, 745-746, 689, 791-792, 821

PXJ-200 423

Qimonda 789

Qualcomm 714,813

RCA 57, 76, 86, 129, 160

Reflex 720

Renesas 763, 812

Rensselaer Polytechnic Institute 318

Rijn-Schelde-Verolme (RSV) 453, 498, 505, 510, 512, 852

Round Table 455-456, 475, 488

Royal Dutch Shell Netherlands 191, 407, 530, 542

RPI 504

Samsung 506, 525, 552, 566-567, 625, 653, 691, 726, 732, 734, 752, 755, 757, 762, 784, 790-791, $812,822,826-827$

Sanyo Electric $\quad 243,432,552$

SCME 459-460, 466, 468-470 SEA 741

Sematech 138, 267, 449$450,487,504,534,552$, $589,635349,642,653$, 659-660, 676-677, 709-710, 814, 719-720, $745,749,784$

SEMI 133, 160, 163, 484, 524,
$550,552,630,691,710$, 851

Semicon $133,143-144$, $150,162,184,198$, 211-215, 245, 249-250, 252, 286, 319, 327, 349, 358, 421, 504, 597, 640, $718,732-735,828$

Semiconductor International 249, 297-298, 310, 359, 558,598

SEMY 382

SGS-Thomson 76, 476-578, 488, 490, 504, 523, 552, $560,571,597,812$

Shin-Etsu Handotai (SEH) 351, 357

Shinkawa 242, 565, 743

Shockley Laboratory 57-61 SIA 267, 377, 487, 589, 710, Siemens passim

Siltec 302-306, 312, 337, 357, 363-364, 367, 369

Singapore Economic

Development Board 419-420

Société Française du Diamant 76, 89, 98-99

Sola Basic 81, 90-92, 98-99, 118-122, 124125, 132, 140-141, 147, 163-165, 174, 228, 498, 539

Solid State Technology 175, 183, 211

ST $\quad 478,658,758,779,812-$ 813

Standard Microelectronics 243 
Standard Telephone

(Telecommunication) Laboraties 205, 208-210, 212, 214216, 247,

Stanford University 353, 357, 449, 470

Stibbe $97-98,141,260,405$, 410, 540, 553, 590, 599, 636, 728-729, 755, 785787, 795-796

Stichting Continuitteit ASM International 795-797, 799, 823

Stipt $\quad 498,539-540$

Sumitomo Bank 405, 541

SVG 426

Telefunken $\quad 76,92,168-169$ Tempress 132, 174, 389, 426, 498-503, 506, 511, 513, 539-541, 546-547, 560-561, 566, 607, 612

Texas Instruments

$58,71,85,92,123$, 160, 189, 193, 199, 236, 312, 314, 412, 428, 523, $552,628,719,774,813$

The Economist $\quad 25,811$ Thermco 124, 174, 182, $185,204,407,433,484$ Tokyo Electron 139, 426, 526, 541, 567, 607, 673, 741, $772,822,826$

Tokyo Electron NEXX 822 Tokyo Hitec 395-396, 424 Toshiba 57, 139, 144, 423, 493,
$525,552,691,758,778-$ 779,812

TSMC 505, 552, 625, 642, 644, 702, 714, 726, 757, 762, 771, 779-790, 812, 818, 823,825

Tylan $\quad 140-143,151,168,174$, $247,257,841$

Ultratech 278, 426

UMC $762,779,789$

Union Carbide Electronics 160, 301

University of Helsinki 652, 681, 751

US Dynamic 119-120

Van der Heem N.V. 75

Varian 385, 416, 541, 589, 813

VDF $396,410,425,427,493$, 557,560

VDL-ETG 821

Vereniging van Effectenbezitters 784

Vertex $\quad 393,425,485-488$

Vision Capital 654

VMP 396, 410, 425-427, 482, 493, 499-501, 506, 540, 557, 560, 655

Wacker Silitronics 78, 358, 362, 479, 489, 570

Western Electric 57, 60, 235, 250-252, 460

WinBond 789

XP-8 827 


\section{Name index}

Aardenne, Gijs van 564, 471

Abernathy, William 40-41, 101, 113-114, 117, 701, 850,851

Abraham, Michael

720

Agt, Dries van 453

Ahlstrom, David 36, 843

Ansoff, Igor 55-56, 87, 148, 150,846

Appleton, Steve 561

Awerman, Jacky 330, 332

Baan, Adrie $\quad 775,784$

Bakker, Robert de $\quad 775$

Baldo, James 189

Balkenende, Jan Peter 754

Baud, Jan Willem 429430, 543, 547-548

Beerlage, Meindert $603-$ 607, 634, 637-639, 642

Beest, Martin van 15,89 ,

91, 94-96, 99, 119-122, $125,148,157,163,165-$ 169, 175-175, 178-185, 209, 212, 216, 223, 227228, 245, 269, 300, 471

Behee, Ron 318

Beijersbergen, Jaap 566-567

Benoist, John 539, 566-567

Benzing, Walter 79, 158, 160, 162, 189, 191, 195, 253, 301

Bergman, Timo 15, 504, 631632, 634, 639-640, 655. 662, 668-669, 687, 750

Bernau, Manfred 548

Berrian, Donald 383
Bes, Jan de 333, 390, 406, 412

Bièvre, Louis de 600

Blank, Julius 60

Blickman, Richard 386, 405, 415, 423, 429, 430, 543, 547-548, $574,600-601$

Bloem, Jan 308, 322, 326, 333

Boer, Ab de 461

Boer, Wiebe de passim

Bohr, Mark 690

Bommel, Peter van 821

Boom, Leon van den $\quad 775$

Bowers, Richard (Dick) 245, 263, 305, 308, 333

Brink, Martin van den 278

Brix, Berend 787

Brock, David 25, 27, 35-36, 47, 60-62, 101, 171, 238, $377,618,623,847$

Brousinne, Marc 95

Cassaro, Bob 350-351

Chan, L.K. 254

Chandler, Alfred 52, 55, 224, 857

Christensen, Clayton 28, 37, 50, 705-706, 803-804, 846

Chruma, Jerry $\quad 172,178$

Ciferno, Ray $\quad 687,767,837$, 858

Colvin, Ron 135, 177178 , 192-193, 196, 257

Corlett, Steve $\quad 338,349-350$, 


\begin{tabular}{|c|c|}
\hline \multicolumn{2}{|c|}{ 354-357, 359} \\
\hline Corsius, Huub & $209,211-212$ \\
\hline Crabb, Richard & 570 \\
\hline Danneels, Johan & $\begin{array}{l}728,773,776- \\
777\end{array}$ \\
\hline $\begin{array}{r}\text { Davignon, Étienn } \\
456,513\end{array}$ & $454-$ \\
\hline $\begin{array}{c}\text { Delft, Dirk van } \\
871\end{array}$ & $17,865,869$ \\
\hline Dennard, Robert & 112 \\
\hline $\begin{array}{c}\text { eWeeger, Frank } \\
354,383 \\
752\end{array}$ & $\begin{array}{l}275,333,351 \\
3-384,393,407\end{array}$ \\
\hline Drews, Dietrich & 720 \\
\hline Drexel, Charles & 141 \\
\hline Drücker, Peter & $\begin{array}{l}37,50,55,87, \\
150,846\end{array}$ \\
\hline enbur & des 190-191 \\
\hline
\end{tabular}

Engle, George $\quad 190-201,224$, 227, 229, 239, 257, 393

Ervasti, Matti $\quad 645,649,653-$ $654,660,667,675,718$

Farni, Jeff 788

Ferro, Armand $\quad 16,302,308-$ 338, 350-367, 537, 558, 570, 603, 606

Fierkens, Richard 48 , 122-125, 131, 133-134, 240, 245, 269, 399-400, Fleck, Earl 311-312, 316$404,428-429,468,548$

$\begin{array}{cl} & 317 \\ \text { Foley, Ed } & 133-135,143, \\ & 177,180 \\ \text { Friant, Ray } \quad 15,48,64,496, \\ 503-506,528,532-537, \\ 541-547,555-573,594- \\ 595,603-604,607,610 \\ \text { 614-615, 635-636, 751, } \\ \text { 852, } 856\end{array}$

Frima, Heico

182, 254, 272, 277-278

Fung, Alan 598, 602

Garud, Raghu 36,843

Geesink, Anton 422

Ghandhi, Sorab 318

Ghani, Tahir 690

Giesen, Ben 459, 466, 468

Go, Sang Woo 791

Goldman, Jon 179-186, 195, 224, 227, 229, 239, 272

Graham, Bob 191, 251

Granneman, Ernst passim

Greveling, Pieter 214-216

Gschwandtner, Alexander

$$
\text { 632, } 634
$$

Hamel, Gary 37, 519-520, 609, 611-612, 614, 846

Hansson, Peo 821

Haro, Bob 195-198, 336338, 359, 370, 570

Harst, Mich van der 474, 478-479

Hartemink, Gerard 141-142

Hasper, Albert $\quad 607,726,730$, $751,773,821$

Haukka, Suvi $\quad 15,651,663$, 667, 675-676, 687, 745, 790

Haussman, Peter 95

Heetebrij, Jan 398, 407

Heikes, Gerard 405, 408, 433

Heinecke, Rudolph 205210, 212, 216-219, 227, 229, 847

Helfrich, Alexander (Lex) 407, 530-531, 542-544, 728

Helmer, Ing-Marie 192-193

Hillige, Jan 461-462

Hilton, Paul 172, 178

Hoek, Paul van den 88, 
97-100, 147, 244-246, $260,386,405-406,409-$ 410, 412-415, 433, 439, 441, 530, 540, 544, 590, 599, 728-729, 744, 759, 775, 784-788, 795, 807, 823,858

Hoeven, Maria van der 828 Hout, Frits van 278 Howells, Bob 433, 435-437, 528

Hukshorn, Hans 503, 529-547 Hurley, Sean 163

Irani, Ali 724, 736-737, 744

Ishii, Sam 794

Jackson, Don passim

Jensen, Klavs 320

Johnson, Wayne 316-337, 365367

Jones, Greg 499, 537, 540

Jones, Rachel 377

Jong, Abe de 23, 518, 609, 739,847

Jong, Rinse de 599-603, 606, 649, 715-716, 722, 724, 727-728

Jonge Poerink, Johanna (Hanni, Joan) 54, 66-67, 73, 77, 830

Kamath, Rajan $\quad 620,701$

Kamerbeek, Erik 212, 216, 269, 391, 460, 466, 471, 474479, 485, 488, 490, 501, 503, 512, 538-540, 555, 657, 667, 692, 772, 785, 789, 795

Kampherbeek, Bert-Jan 737

Kang, Sangwon 732-733

Keynes, John 235, 447

Kiam, Robert 383

Kleiner, Eugene 60

Klem, Dave 311, 317, 326
Knapic, Dinko (Dean) 57, 59-63, 67-68, 72-75, 77, 80, 131, 146

Koh, Wongyong 733

Korst, Pieter van der 782-783

Kramer, Gert Jan 823, 828

Krebs, Paul 407

Krickl, John 15, 302, 337, 353-355, 357, 360, 407, 534, 537, 541, 556, 566, 570, 604, 606, 645, 726, 751

Kruit, Pieter 737

Kuznetsov, Vladimir 717

Lakens, Herbert 351, 357, 378379, 386, 390, 392, 399, 410-411, 483, 488

Lam, See Pong (Patrick) passim Lampinen, Kari $\quad 645,647,649$ Launder, Art 506,556,558, 561-562, 566, 568-569, 603-604, 636

Lawrence, Monte 351-353

Lécuyer, Christophe 25, 43, 47, 58-60, 85, 101, 118, 128, 158-159, 171, 383, 449, 491, 589, 618, 623, 634, 639, 705, 847

Lee, Wai Kwong (W.K.) 16, 242-243, 565-566, 597598, 731-733, 784, 788, 828

Leeuw, Willem de passim

Lente, Harro van 17, 27, 30-31, 865-866, 871, 875

Leskelä, Markku 651

Leutscher, Fokko 773, 821

Liker, Jeffrey $\quad 620,701$

Liu, Peter 596

Lo, Peter 243, 495-496, 
565

Lobbezoo, Jan 823

Lorenzini, Robert 304

Lubbers, Ruud 235, 274, 453

MacDonald, Robinson 16, 295, 316-338, 350, 353, 359, 366-369, 717

Maes, Johan 209, 211-212, 218

Malerba, Franco 39-41, 47, 57-58, 69-70, 75, 78, 84, 86-87, 127-128, 136, 138, 157, 184, 187, 238, 448

Marcyk, Gerald 676

Matsuki, Nobuo 730

Maydan, Dan ～251, 253, 621

McNeilly, Michael

120 ,

122, 158, 160, 162-163, 191

Miller, Nick 38, 310, 794

Mistry, Kaizad 691

Miura, Hitoshi $\quad$ 261-262, 276, $432,564,755$

Miyazaki, Yo 215, 260-262, 276-277, 282-283, 334, 350, 395-396, 409, 411, 422-426, 534, 536, 556, 563,566

Moghadam, Farhad

794795, 797

Moore, Gordon $\quad 27,59,61,111$, 376-377, 690

Morgan, James (Jim) 202, 261, 302, 574, 593-594

Morris, Peter Robin 208

Mowery, David 228, 449-450, 524

Moya, Bob 245, 263, 305, 308, 333

Nijhof, Erik 452
Nobel, Nico 59, 100, 147, 245-246, 272, 304, 406, 435, 708, 728

Noyce, Robert $\quad 59,112,376$ -

377

Onkenhout, Hein 495, 537

Oranje-Nassau, Willem

Alexander van 729

Overhoff, Marike 674,680-681, 751

Pannenborg, Eduard 456-458

Park, Inkyu 755, 791

Pavitt, Keith 40, 226-227, $701,841-843$

Peet, Jan 447, 449, 452453

Perez, Max 120-164

Peters, Tom 233, 291, 651, 705,846

Petterson, Wim 123, 125, 132134

Pietersma, Haijo 744, 750, 775, 784

Plummer, James 312, 353-354

Pocock, John 31-32, 41-45, $165,224,228,518,853$ 854

Polkamp, Kees 181

Pomarede, Christophe 634, 639

Porter, Michael 19, 37, 50, 235, 372-374, 442, 519, 555, 755,846

Prado - van den Berg, Hedwig

(Hetty) del 63

Prado, Arthur del passim

Prado, Arthur Eugene del 63

Prado, Chuck del 16, 77, 687-688, 692, 705, 750-751, 757-758, 768, 784-785, 793-800, 810, 820-823, 831-832, 859, 
867, 873

Prahalad, C.K. 37, 519-523, 609, 611-614, 846

Queyssac, Daniel

571,

594-595, 603-607, 615, 637-642, 655, 668-669, 681, 709, 728, 750-751

Raaijmakers, Ivo 16, 604, 624, 632, 637-642, 647, 655-661, 664, 670-682, 687, 699, 719-720, 727, 730-736, 743, 745-746, 750-751, 755-757, 765, 769, 791, 821, 845, 869, 871,874

Raaijmakers, René

17,86 270, 272, 277, 279, 397, 405, 407, 416, 449, 462, 505

Radelaar, Sieb 635

Rauwenhoff, Ferdinand 530, 723-724, 728, 736

Reagan, Ronald 235, 403, 476

Reinberg, Alan 189

Rhee, André van 358, 386, 409, 413-417, 426-428, 431435,441

Rip, Arie $36,48,226$, 368,843

Röell, Ailsa 439

Roobeek, Annemieke 266, 447-448

Rose, Peter 383

Rosler, Richard (Dick) 179, 189, 191-192, 195-196, 199-201, 204, 251-252, 257, 308, 312, 317, 323, 333, 337, 392, 394, 473

Rowlands, Vernon 71, 76, $79-80,89$

Ruijter, Rob
Saris, Frans

308,326, 385, 407, 472, 530

Schmittman, Peter Jan $\quad 600-$ 602, 724

Schot, Johan $\quad 48,514,706$

Shero, Eric $\quad 662,681,687-$ 688

Shockley, William 57-61 Sikes, David 359, 528, 604 Sluyterman, Keetie 17, 23, 37-38, 43, 47, 55-56, 222, 229, 233, 235, 265, 274, 283, 291, 368, 447, 518-519, 609, 739, 847

Smink, Gerard 128,163

Smit, Gjalt 278-279, 284287, 291, 372, 397, 399, 407, 434, 466

Steinmueller, Edward 706

Sterling, Henley 188-189

Stoddard, Dale 143-144, 184, 192-193, 195, 204, 211, 213, 224, 256-259, 323

Suntola, Tuomo 15, 645, 651$656,681,718$

Tabaksblat, Morris $\quad 739$

Takahashi, Nobuyoshi 537

Talieh, Homayoun 735736, 756-759, 777-780, 806

Terry, Dean 135, 178, 257

Thackray, Arnold 62, 377

Thatcher, Margaret 205, 235

Tomino, Fukumi 16, 144, 185, 202, 217, 261-262, 276, 424, 426, 536, 556, 560, 564, 730, 752, 755, 821

Tong, Jerry 21

Topsøe, Haldor $\quad 67,76,80-82$, 88-89, 97-98, 119-122, $125,147,151,246,858$ 
Troost, Wim 407

Tuominen, Marko 675,681

Turner, Norman 385, 406-407

Ueno, Yukikazu 202, 262, 537

Utterback, James

39-41,

101, 113-114, 117, 236, 698, 701, 705, 850-851, 857-858

Vanderpot, Jack 383, 385, 396397, 407, 411-412, 416

Varnier, Claude 76, 89, 98-99, 124

Ven, Naud van der 775, 783

Verdonschot, Gerard 404-405

Vos Steenwijk, Joan de 18,65, 729, 828-829

Waard, Henk de 662, 687

Wagenaar, Jobs 556,575-576, 636

Wallenburg, Joop 407, 430

Wang, David 251, 253, 621, 794

Waterman, Robert 233, 291, 846

Weidmann, Joerg

Welch, Jack 519

Wengert, Jack 327, 336, 338

Werkhoven, Chris passim

Westendorp, Han 16-17,

607, 681,687, 689, 726, 748, 751, 757-758, 771, 784-785, 791, 821, 871872

Westerhuis, Gerarda 17, 23, 518, 609, 739, 847

Wieland, Marco 737

Wieringa, Max 257-258,302, 304, 317, 325

Wilk, Glen 677, 686-687

Wittkower, Andrew 383, 396-397, 407

Wubs, Ben 55
Wunderl, Hans 556, 560, 606607, 668-669, 674, 680, 727-728, 750

Yamada, Yasuo 202, 262, 537

Yi, Kevin Kyoungsoo 732-733

Yoo, Yong Min 16, 790, 826, 861

Yoshida, Tominor 730, 821

Yoshimi, Takeo 215

Young, Eli 383-385

Zemla, Gloria $\quad 15,302,317$, 333, 337-338, 570, 606

Zweegers, Frank 602 
High-tech innovations have been propelling the Digital Revolution since the end of the Second World War. These advances were not self-evident, but actively pursued by many. A global playing field of entrepreneurs, engineers, scientists, investors, public officials, and consumers stimulated inventiveness for commercial, intellectual, social, and political reasons.

This book explores this dynamic of high-tech innovation by looking at the machinations behind the Digital Revolution. Literally. Technologies developed by the Dutch semiconductor equipment manufacturer ASM International culminated in the linchpin of the Digital Revolution - the computer chip.

Chaired by its illustrious founder and long-time chief executive officer Arthur del Prado, ASM International has been innovating and anticipating technologies across the globe since the early beginnings of the semiconductor industry in 1958. The story of ASM International is a history full of achievements, disappointments, defining innovations, strategic lessons, and strong personalities. It shows the fortunes of high-tech innovation.
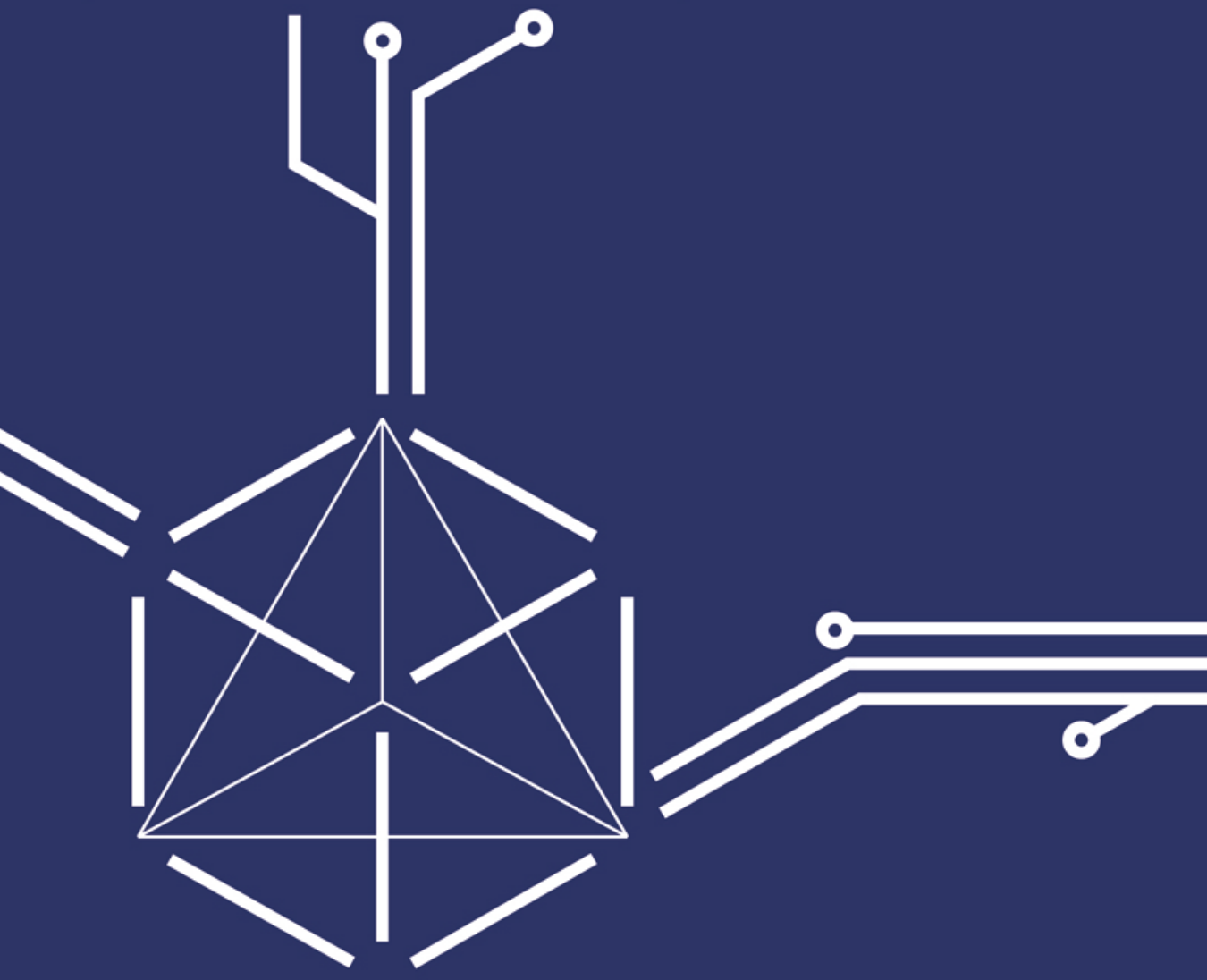